\title{
Soil structure interaction (SSI) analysis of shear wall buildings with a below-ground parkade
}

by

Nanthinee Porchelvam

A thesis submitted to the Faculty of Graduate and Postdoctoral Affairs in partial fulfillment of the requirements for the degree of

\author{
Master of Applied Science \\ in \\ Civil Engineering
}

Ottawa-Carleton Institute of Civil Engineering

Department of Civil and Environmental Engineering

Carleton University

Ottawa, Ontario

(C) 2020, Nanthinee Porchelvam 


\section{Abstract}

The response of buildings to earthquake is affected by the soil surrounding the below grade portion of the structure, or supporting the foundation. A common seismic design approach is to neglect the soil and analyze the entire free-standing structure for its response to earthquake ground motion applied at the foundation. Soil-structure interaction (SSI) effects are not considered in routine design as it is often presumed that SSI is beneficial and ignoring SSI would lead to a conservative design.

Concerns have been expressed whether the foregoing approach is acceptable. The analytical research undertaken in this thesis evaluates the response of shear wall buildings with towers of variable heights, but with a five-level below-grade parkade in Vancouver, and subjected to earthquake loads prescribed by the National Building Code of Canada (NBCC 2015). The analysis is formulated to provide insights into the effects of the inertial and kinematic components of SSI, and the results are compared with the traditional approach.

Two cases are analyzed, (1) the tower and the parkade with the soil surrounding the parkade resting on bed-rock, and (2) the tower and the parkade supported on a rigid mat foundation and resting on a soil deposit overlying the bed-rock. The former case ignores kinematic interaction. The response of each building configuration was assessed for a range of subsoil conditions. The results illustrated that there is magnification in seismic response when SSI is considered, and the effect of SSI depends on various parameters. The kinematic interaction effects led to progressively beneficial outcomes as the soil surrounding the parkade became softer. Therefore, ignoring SSI stating that it is beneficial may lead to unsafe design. 


\section{Acknowledgements}

First and foremost, I praise the Lord, the almighty for providing me this opportunity and granting me the capability to proceed successfully.

I am forever grateful to my research supervisors, Professor Siva Sivathayalan and Professor Jagmohan L. Humar without whose support, guidance and financial aid, this study would not have been accomplished. I am so blessed and grateful to have supervisors like them. I would also like to thank the members of the examination board for taking the time to review my thesis and for their useful suggestions.

I would like to extend my profound gratitude to Mr. Cuckoo Kochar for providing Kochar family scholarship, which made life easier throughout the development of this thesis. Special thanks are owed to Pedram, who tirelessly helped me during the progress of the study. I would like to thank my colleagues Prasanna and Lambo for their motivation and warm company. I am deeply indebted to my friends, who are like a family here in Canada, Sandeep, Tharika, Mathura, and Naveena. I am very grateful for my best friends back home Nikki, Mohan and Gokul for their love and support.

Last but not the least, I would like to thank my family, particularly my father Porchelvam, my mother Eswari, and my sisters Priya and Ranchana for their financial help and for believing in me and encouraging me through all stages of life. I am also grateful for my nieces and nephew, Renee, Andrea, and Ryan for their unconditional love. Without my family's help and moral support this study would not have been possible. 


\section{Table of Contents}

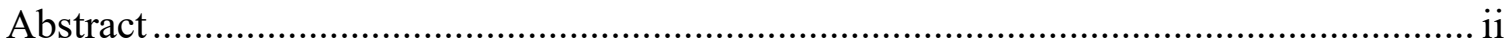

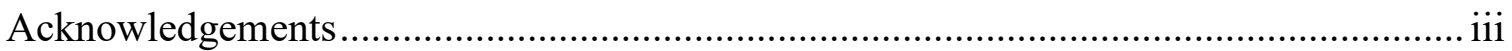

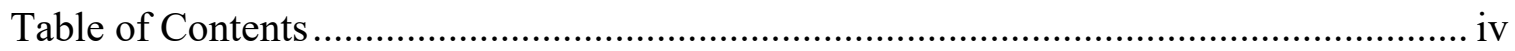

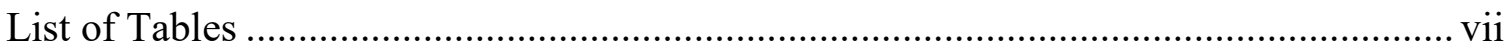

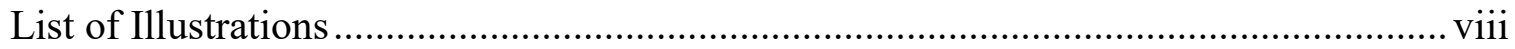

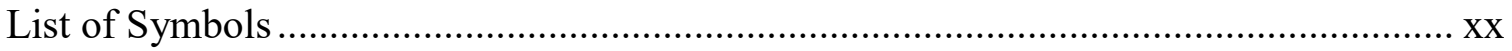

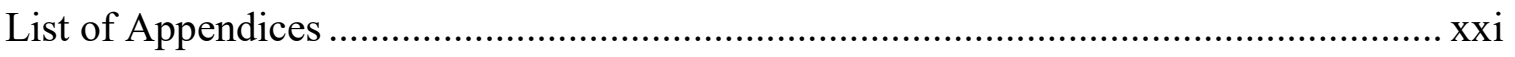

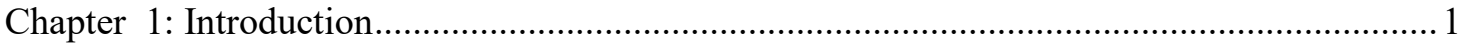

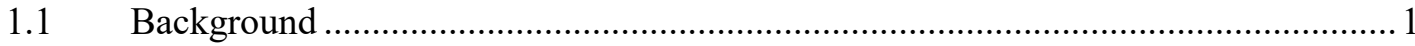

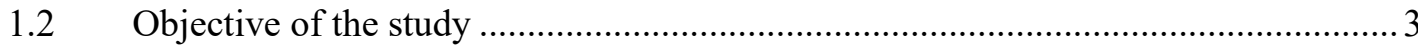

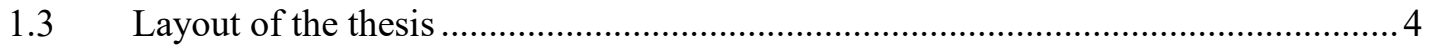

Chapter 2: Soil structure interaction (SSI): Principles \& Background .................................... 6

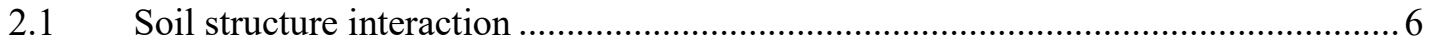

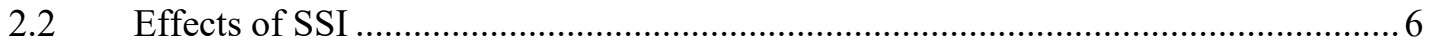

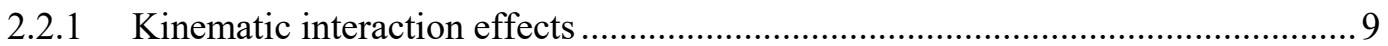

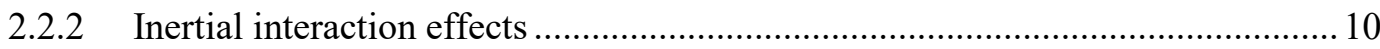

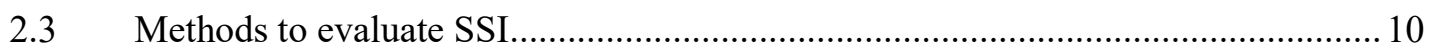

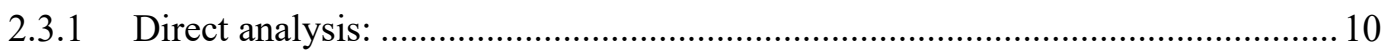

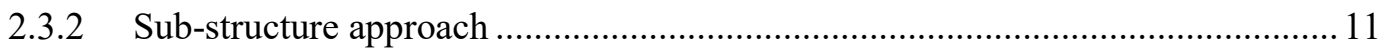

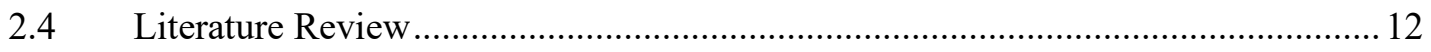

2.4.1 Previous research on soil-structure interaction with buildings .......................... 12

2.4.2 Previous research on soil-structure interaction for buildings with underground

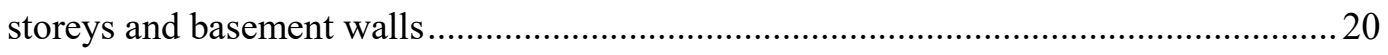




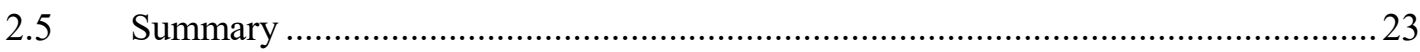

Chapter 3: Soil-Structure Interaction in a Building founded on Rock .................................26

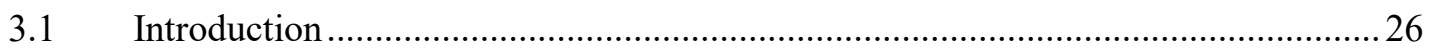

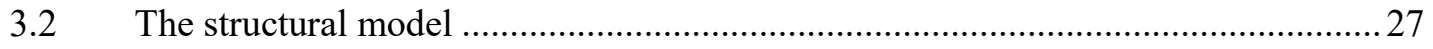

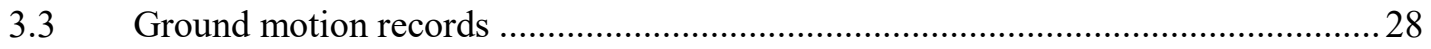

3.4 Assumptions made in generating the analytical mode .........................................29

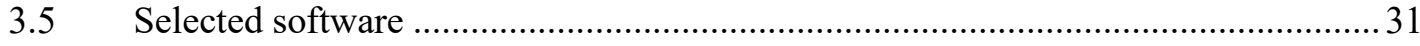

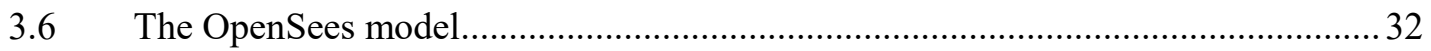

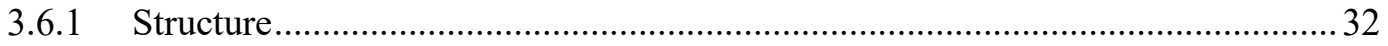

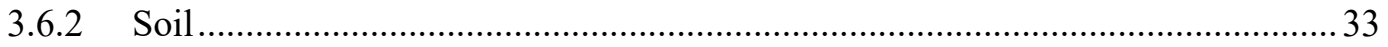

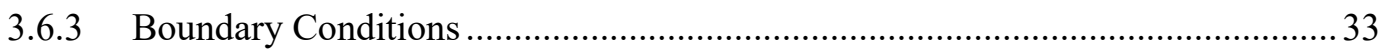

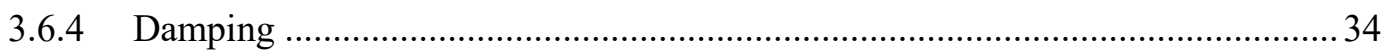

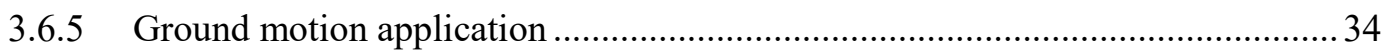

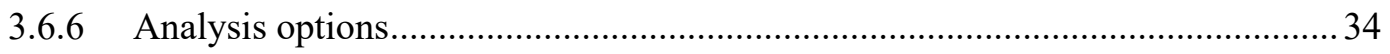

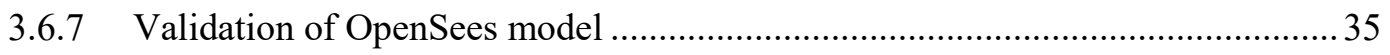

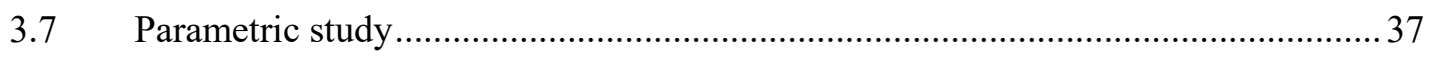

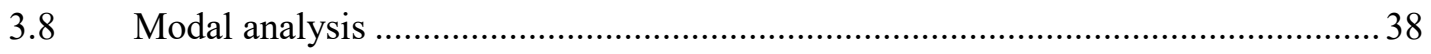

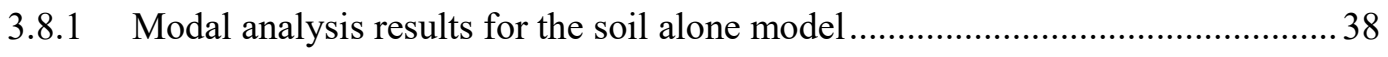

3.8.2 Results of the Modal analysis of 9-storey building model.................................. 41

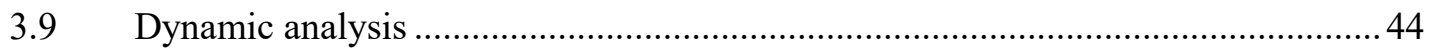

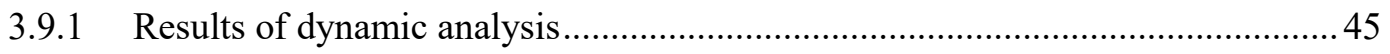

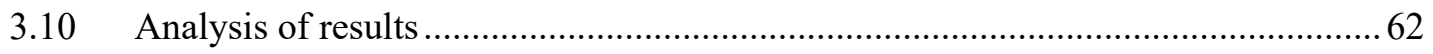

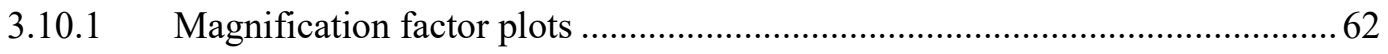

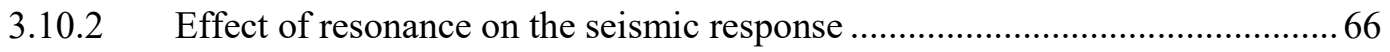

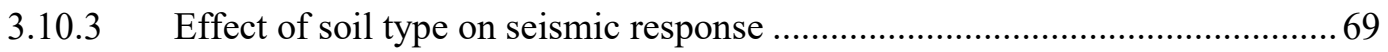

3.10.4 Effect of number of above ground stories on the seismic response ................71 
3.10.5 Effect of earthquake characteristics on the seismic response.

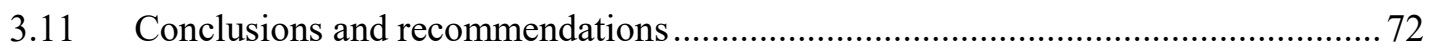

Chapter 4: Soil-Structure Interaction in a Building founded on Soil overlying Rock............. 74

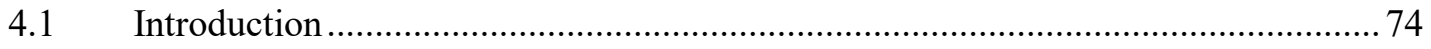

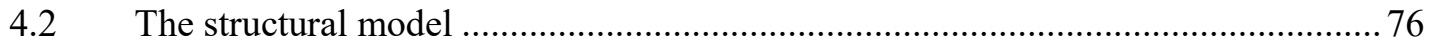

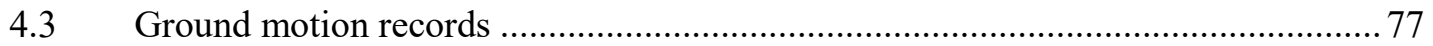

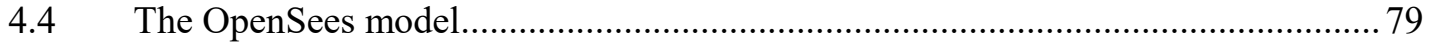

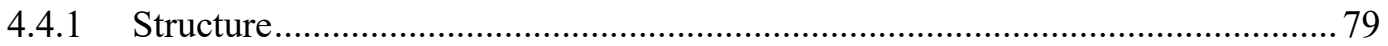

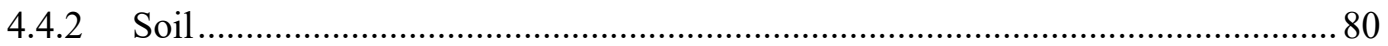

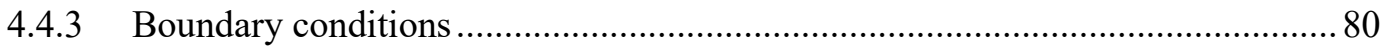

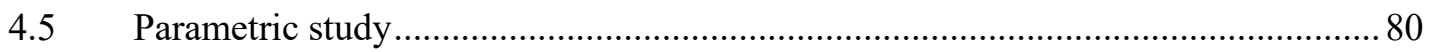

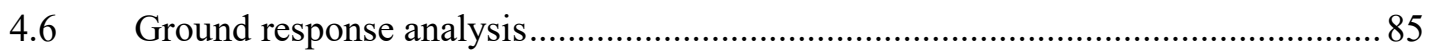

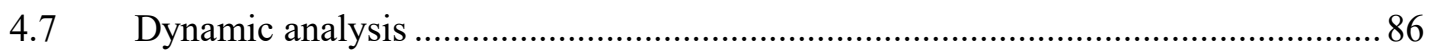

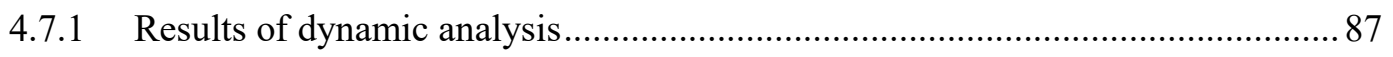

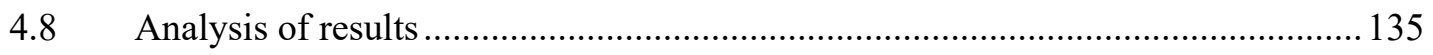

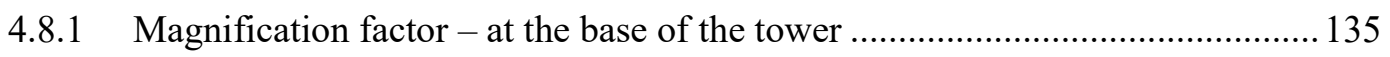

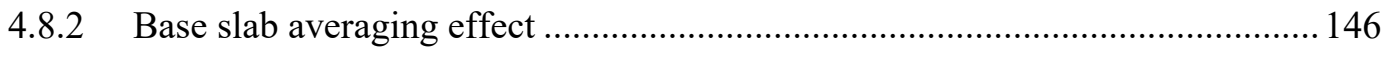

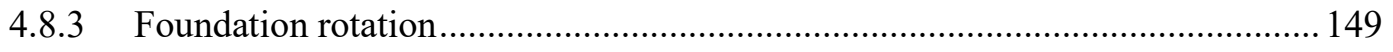

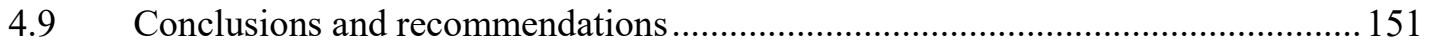

Chapter 5: Summary, conclusion and recommendations ............................................... 153

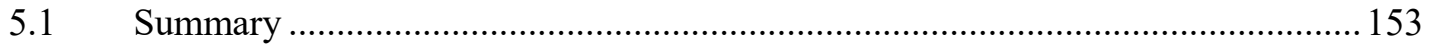

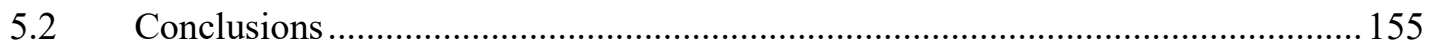

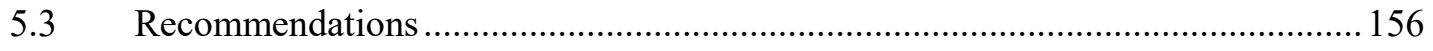

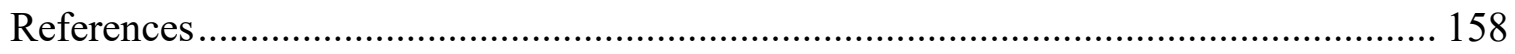




\section{List of Tables}

Table 3-1 Model dimensions used in OpenSees and SAP2000 .................................. 35

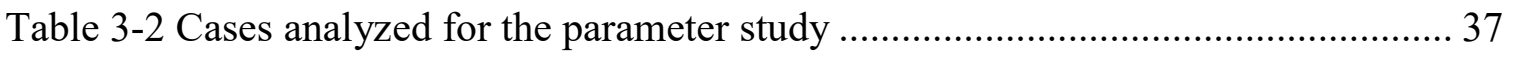

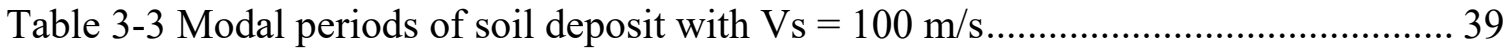

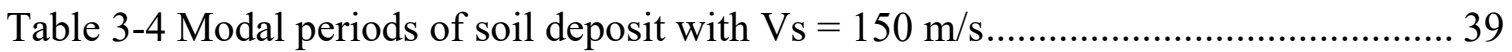

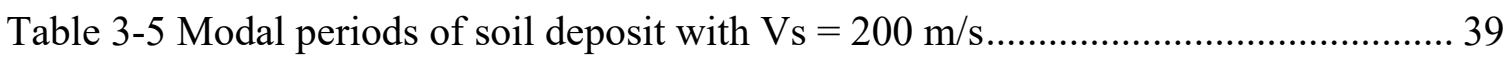

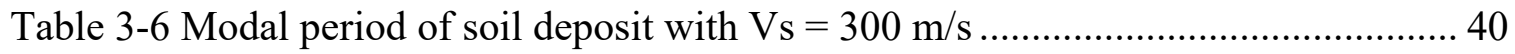

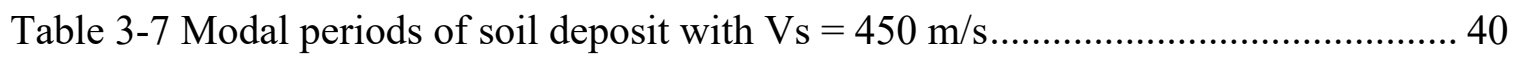

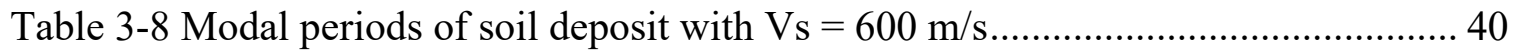

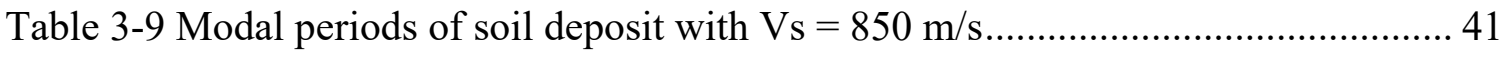

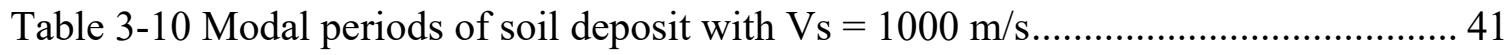

Table 3-11 Modal periods of the 9 storey building without soil................................. 42

Table 3-12 Modal periods of the 9 storey building with soil $\mathrm{Vs}=100 \mathrm{~m} / \mathrm{s} \ldots \ldots \ldots \ldots \ldots \ldots . . . . . . . .42$

Table 3-13 Modal periods of the 9 storey building with soil $\mathrm{Vs}=150 \mathrm{~m} / \mathrm{s} \ldots \ldots \ldots \ldots \ldots \ldots . . . . . . .42$

Table 3-14 Modal periods of the 9 storey building with soil Vs $=200 \mathrm{~m} / \mathrm{s} \ldots \ldots \ldots \ldots \ldots \ldots . . . . . . .42$

Table 3-15 Modal periods of the 9 storey building with soil $\mathrm{Vs}=300 \mathrm{~m} / \mathrm{s} \ldots \ldots \ldots \ldots \ldots \ldots . . . . . . .43$

Table 3-16 Modal periods of the 9 storey building with soil Vs $=450 \mathrm{~m} / \mathrm{s}$.................. 43

Table 3-17 Modal periods of the 9 storey building with soil $\mathrm{Vs}=600 \mathrm{~m} / \mathrm{s} \ldots \ldots \ldots \ldots \ldots \ldots . . \ldots 3$

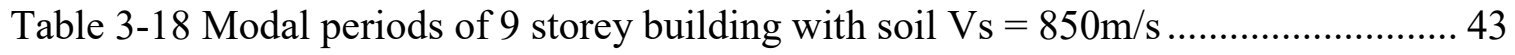

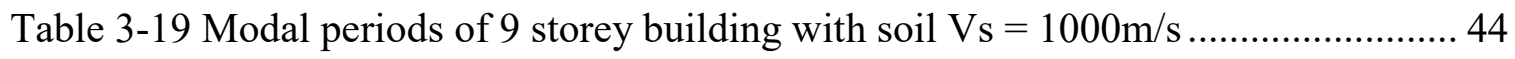

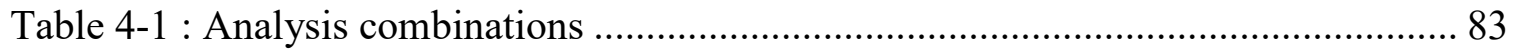

Table 4-2: Subsidiary cases used in the presentation of magnification factors ............. 135 


\section{List of Illustrations}

Figure 2-1 Seismic response of structure founded on rock and on soil (a) Sites; (b) Outcropping rock; (c) Free-field; (d) Kinematic interaction; (e) Inertial interaction (Wolf, 1985) 7

Figure 2-2 Kinematic interaction effects (a) base slab averaging; (b) embedment effect; (c) wave scattering (https://www.slideserve.com/nira/steve-kramer-university-of-washington)

Figure 2-3 Schematic illustration of direct approach (NIST GCR 12-917-21) ……........ 10

Figure 2-4 Schematic illustration of sub-structure approach (NIST GCR 12-917-21) .... 11

Figure 3-1 (a) Elevation, (b) Plan of the 9 storey building (not to scale) ........................ 27

Figure 3-2 Vancouver site B UHS and selected records spectra ................................... 28

Figure 3-3 Analytical model of 9 storey building in OpenSees....................................... 32

Figure 3-4 Comparison of base shear variation obtained from SAP2000 and OpenSees 36

Figure 3-5 Storey shear, mean values for the 9 storey building ..................................... 46

Figure 3-6 Mean moment at the bottom of a storey for 9 storey building........................ 46

Figure 3-7 Storey drift, mean values for the 9 storey building ....................................... 47

Figure 3-8 Displacement at the top of a storey, mean values for 9 storey building ......... 47

Figure 3-9 Acceleration at the top of a storey, mean values for the 9 storey building ..... 48

Figure 3-10 Storey shear, mean values for the 13 storey building ................................. 49

Figure 3-11 Mean moment at the bottom of a storey for 13 storey building .................... 50

Figure 3-12 Storey drift, mean values for the 13 storey building .................................... 50

Figure 3-13 Displacement at the top of a storey, mean values for 13 storey building ..... 51

Figure 3-14 Acceleration at the top of a storey, mean values for the 13 storey building. 51 
Figure 3-15 Storey shear, mean values for the 17 storey building .... 52

Figure 3-16 Mean moment at the bottom of a storey for 17 storey building ................... 53

Figure 3-17 Storey drift, mean values for the 17 storey building ............................... 54

Figure 3-18 Displacement at the top of a storey, mean values for 17 storey building ..... 54

Figure 3-19 Acceleration at the top of a storey, mean values for the 17 storey building . 55

Figure 3-20 Storey shear, mean values for the 21 storey building .............................. 56

Figure 3-21 Mean moment at the bottom of a storey for 21 storey building ................. 57

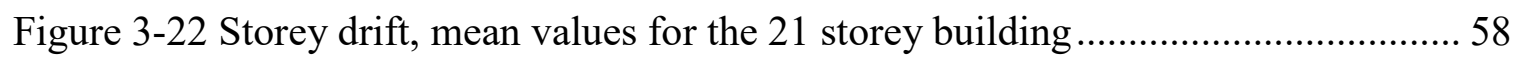

Figure 3-23 Displacement at the top of a storey, mean values for 21 storey building ..... 58

Figure 3-24 Acceleration at the top of a storey, mean values for the 21 storey building . 59

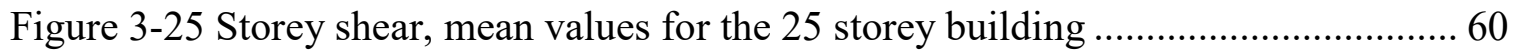

Figure 3-26 Mean moment at the bottom of a storey for 25 storey building .................. 60

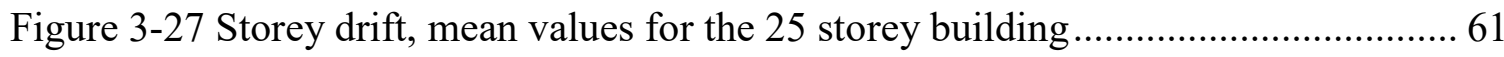

Figure 3-28 Displacement at the top of a storey, mean values for 25 storey building .... 61

Figure 3-29 Acceleration at the top of a storey, mean values for the 25 storey building . 62

Figure 3-30 Magnification factors for 9 storey building with varying soil properties ..... 63

Figure 3-31 Magnification factors for 13 storey building with varying soil properties ... 63

Figure 3-32 Magnification factors for 17 storey building with varying soil properties ... 64

Figure 3-33 Magnification factors for 21 storey building with varying soil properties ... 64

Figure 3-34 Magnification factors for 25 storey building with varying soil properties ... 65

Figure 3-35 Details of shear magnification factors, first mode of the soil, and the first and

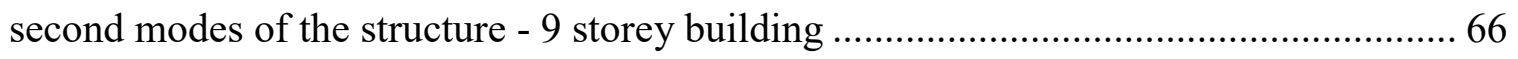


Figure 3-36 Details of shear magnification factors, first mode of the soil, and the first and second modes of the structure - 13 storey building 67

Figure 3-37 Details of shear magnification factors, first mode of the soil, and the first and second modes of the structure - 17 storey building 67

Figure 3-38 Details of shear magnification factors, first mode of the soil, and the first and second modes of the structure - 21 storey building 68 Figure 3-39 Details of shear magnification factors, first mode of the soil, and the first and second modes of the structure -25 storey building 68 Figure 3-40 Shear magnification factors for different tower heights and varying soil properties 70

Figure 3-41 Shear magnification factors for different tower heights with a $100 \mathrm{~m} / \mathrm{s}$ shear wave velocity soil 71

Figure 3-42 Storey shears in 9 storey building with soil shear wave velocity, Vs $=100 \mathrm{~m} / \mathrm{s}$ for 11 different earthquake inputs 72

Figure 4-1: (a) Elevation of 9 storey building (b) Plan of 9 storey building (not to scale) 76

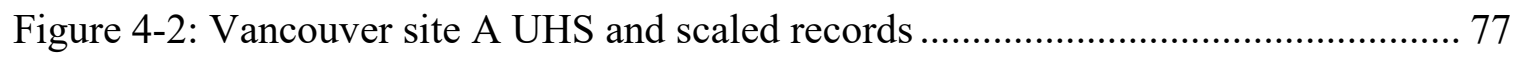

Figure 4-3: Vancouver Site A UHS with the selected record ...................................... 78

Figure 4-4: Analytical model of 9 storey tower in OpenSees ................................... 79

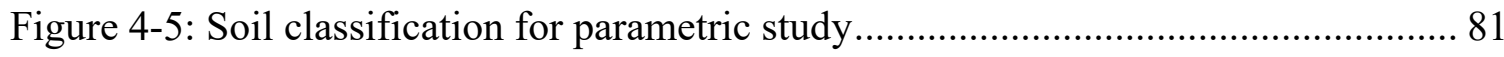

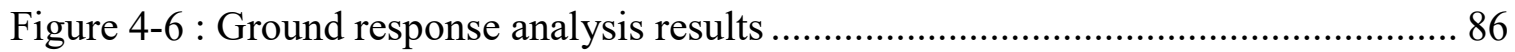

Figure 4-7: Storey shear values for a 9 storey building, shear wave velocity of the soil underlying foundation $=450 \mathrm{~m} / \mathrm{s}$ 90 
Figure 4-8: Moment at the bottom of the storey for a 9 storey building, shear wave velocity of the soil underlying foundation $=450 \mathrm{~m} / \mathrm{s}$ 90

Figure 4-9: Storey drift for the 9 storey building, shear wave velocity of the soil underlying foundation $=450 \mathrm{~m} / \mathrm{s}$ 91

Figure 4-10: Displacement at the top of a storey for 9 storey building, shear wave velocity of the soil underlying foundation $=450 \mathrm{~m} / \mathrm{s}$. 91

Figure 4-11: Accelerations at the top of a storey for 9 storey building, shear wave velocity of the soil underlying foundation $=450 \mathrm{~m} / \mathrm{s}$. 92 Figure 4-12: Storey shear values for a 9 storey building, shear wave velocity of the soil underlying foundation $=750 \mathrm{~m} / \mathrm{s}$

Figure 4-13: Moment at the bottom of the storey for a 9 storey building, shear wave velocity of the soil underlying foundation $=750 \mathrm{~m} / \mathrm{s}$ 93

Figure 4-14: Storey drift for the 9 storey building, shear wave velocity of the soil underlying foundation $=750 \mathrm{~m} / \mathrm{s}$ 94

Figure 4-15: Displacement at the top of a storey for 9 storey building, shear wave velocity of the soil underlying foundation $=750 \mathrm{~m} / \mathrm{s}$. 94

Figure 4-16: Accelerations at the top of a storey for 9 storey building, shear wave velocity of the soil underlying foundation $=750 \mathrm{~m} / \mathrm{s}$. 95 Figure 4-17: Storey shear values for a 9 storey building, shear wave velocity of the soil underlying foundation $=1000 \mathrm{~m} / \mathrm{s}$ 96 Figure 4-18: Moment at the bottom of the storey for a 9 storey building, shear wave velocity of the soil underlying foundation $=1000 \mathrm{~m} / \mathrm{s}$. 96 
Figure 4-19: Storey drift for the 9 storey building, shear wave velocity of the soil

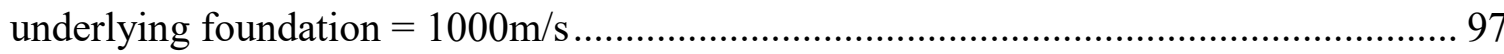

Figure 4-20: Displacement at the top of a storey for 9 storey building, shear wave velocity of the soil underlying foundation $=1000 \mathrm{~m} / \mathrm{s}$. 97

Figure 4-21: Acceleration at the top of a storey for 9 storey building, shear wave velocity of the soil underlying foundation $=1000 \mathrm{~m} / \mathrm{s}$. 98 Figure 4-22: Storey shear values for a 13 storey building, shear wave velocity of the soil underlying foundation $=450 \mathrm{~m} / \mathrm{s}$ 99

Figure 4-23: Moment at the bottom of the storey for a 13 storey building, shear wave velocity of the soil underlying foundation $=450 \mathrm{~m} / \mathrm{s}$

Figure 4-24: Storey drift for the 13 storey building, shear wave velocity of the soil underlying foundation $=450 \mathrm{~m} / \mathrm{s}$ 100

Figure 4-25: Displacement at the top of a storey for 13 storey building, shear wave velocity of the soil underlying foundation $=450 \mathrm{~m} / \mathrm{s}$ 100

Figure 4-26: Acceleration at the top of a storey for 13 storey building, shear wave velocity of the soil underlying foundation $=450 \mathrm{~m} / \mathrm{s}$ 101 Figure 4-27: Storey shear values for a 13 storey building, shear wave velocity of the soil underlying foundation $=750 \mathrm{~m} / \mathrm{s}$ 102 Figure 4-28: Moment at the bottom of the storey for a 13 storey building, shear wave velocity of the soil underlying foundation $=750 \mathrm{~m} / \mathrm{s}$ 102 Figure 4-29: Storey drift for the 13 storey building, shear wave velocity of the soil underlying foundation $=750 \mathrm{~m} / \mathrm{s}$ 103 
Figure 4-30: Displacement at the top of a storey for 13 storey building, shear wave velocity of the soil underlying foundation $=750 \mathrm{~m} / \mathrm{s}$ 103

Figure 4-31: Acceleration at the top of a storey for 13 storey building, shear wave velocity of the soil underlying foundation $=750 \mathrm{~m} / \mathrm{s}$. 104

Figure 4-32: Storey shear values for a 13 storey building, shear wave velocity of the soil underlying foundation $=1000 \mathrm{~m} / \mathrm{s}$ 105

Figure 4-33: Moment at the bottom of the storey for a 13 storey building, shear wave velocity of the soil underlying foundation $=1000 \mathrm{~m} / \mathrm{s}$ 105

Figure 4-34: Storey drift for the 13 storey building, shear wave velocity of the soil underlying foundation $=1000 \mathrm{~m} / \mathrm{s}$ 106

Figure 4-35: Displacement at the top of a storey for 13 storey building, shear wave velocity of the soil underlying foundation $=1000 \mathrm{~m} / \mathrm{s}$ 106

Figure 4-36: Acceleration at the top of a storey for 13 storey building, shear wave velocity of the soil underlying foundation $=1000 \mathrm{~m} / \mathrm{s}$ 107

Figure 4-37: Storey shear values for a 17 storey building, shear wave velocity of the soil underlying foundation $=450 \mathrm{~m} / \mathrm{s}$ 108

Figure 4-38: Moment at the bottom of the storey for a 17 storey building, shear wave velocity of the soil underlying foundation $=450 \mathrm{~m} / \mathrm{s}$ 108 Figure 4-39: Storey drift for the 17 storey building, shear wave velocity of the soil underlying foundation $=450 \mathrm{~m} / \mathrm{s}$ 109 Figure 4-40 : Displacement at the top of a storey for 17 storey building, shear wave velocity of the soil underlying foundation $=450 \mathrm{~m} / \mathrm{s}$. 109 
Figure 4-41: Acceleration at the top of a storey for 17 storey building, shear wave velocity of the soil underlying foundation $=450 \mathrm{~m} / \mathrm{s}$ 110

Figure 4-42: Storey shear values for a 17 storey building, shear wave velocity of the soil underlying foundation $=750 \mathrm{~m} / \mathrm{s}$

Figure 4-43: Moment at the bottom of the storey for a 17 storey building, shear wave velocity of the soil underlying foundation $=750 \mathrm{~m} / \mathrm{s}$

Figure 4-44: Storey drift for the 17 storey building, shear wave velocity of the soil underlying foundation $=750 \mathrm{~m} / \mathrm{s}$ 112 Figure 4-45: Displacement at the top of a storey for 17 storey building, shear wave velocity of the soil underlying foundation $=750 \mathrm{~m} / \mathrm{s}$. 112 Figure 4-46: Acceleration at the top of a storey for 17 storey building, shear wave velocity of the soil underlying foundation $=750 \mathrm{~m} / \mathrm{s}$ 113

Figure 4-47: Storey shear values for a 17 storey building, shear wave velocity of the soil underlying foundation $=1000 \mathrm{~m} / \mathrm{s}$ 114 Figure 4-48: Moment at the bottom of the storey for a 17 storey building, shear wave velocity of the soil underlying foundation $=1000 \mathrm{~m} / \mathrm{s}$ 114 Figure 4-49: Storey drift for the 17 storey building, shear wave velocity of the soil underlying foundation $=1000 \mathrm{~m} / \mathrm{s}$ 115 Figure 4-50: Displacement at the top of a storey for 17 storey building, shear wave velocity of the soil underlying foundation $=1000 \mathrm{~m} / \mathrm{s}$. 115 Figure 4-51: Acceleration at the top of a storey for 17 storey building, shear wave velocity of the soil underlying foundation $=1000 \mathrm{~m} / \mathrm{s}$. 116 
Figure 4-52: Storey shear values for a 21 storey building, shear wave velocity of the soil underlying foundation $=450 \mathrm{~m} / \mathrm{s}$

Figure 4-53: Moment at the bottom of the storey for a 21 storey building, shear wave velocity of the soil underlying foundation $=450 \mathrm{~m} / \mathrm{s}$ 117

Figure 4-54: Storey drift for the 21 storey building, shear wave velocity of the soil underlying foundation $=450 \mathrm{~m} / \mathrm{s}$. 118

Figure 4-55 : Displacement at the top of a storey for 21 storey building, shear wave velocity of the soil underlying foundation $=450 \mathrm{~m} / \mathrm{s}$. 118 Figure 4-56 : Acceleration at the top of a storey for 21 storey building, shear wave velocity of the soil underlying foundation $=450 \mathrm{~m} / \mathrm{s}$.

Figure 4-57: Storey shear values for a 21 storey building, shear wave velocity of the soil underlying foundation $=750 \mathrm{~m} / \mathrm{s}$

Figure 4-58: Moment at the bottom of the storey for a 21 storey building, shear wave velocity of the soil underlying foundation $=750 \mathrm{~m} / \mathrm{s}$ 120

Figure 4-59: Storey drift for the 21 storey building, shear wave velocity of the soil underlying foundation $=750 \mathrm{~m} / \mathrm{s}$ 121

Figure 4-60: Displacement at the top of a storey for 21 storey building, shear wave velocity of the soil underlying foundation $=750 \mathrm{~m} / \mathrm{s}$.

Figure 4-61: Acceleration at the top of a storey for 21 storey building, shear wave velocity of the soil underlying foundation $=750 \mathrm{~m} / \mathrm{s}$. 122 Figure 4-62: Storey shear values for a 21 storey building, shear wave velocity of the soil underlying foundation $=1000 \mathrm{~m} / \mathrm{s}$ 123 
Figure 4-63: Moment at the bottom of the storey for a 21 storey building, shear wave velocity of the soil underlying foundation $=1000 \mathrm{~m} / \mathrm{s}$ 123

Figure 4-64: Storey drift for the 21 storey building, shear wave velocity of the soil underlying foundation $=1000 \mathrm{~m} / \mathrm{s}$ 124

Figure 4-65: Displacement at the top of a storey for 21 storey building, shear wave velocity of the soil underlying foundation $=1000 \mathrm{~m} / \mathrm{s}$. 125

Figure 4-66: Acceleration at the top of a storey for 21 storey building, shear wave velocity of the soil underlying foundation $=1000 \mathrm{~m} / \mathrm{s}$. 125 Figure 4-67: Storey shear values for a 25 storey building, middle of site class C $(450 \mathrm{~m} / \mathrm{s})$ case 126

Figure 4-68: Moment at the bottom of the storey for a 25 storey building, middle of site class $\mathrm{C}(450 \mathrm{~m} / \mathrm{s})$ case 127

Figure 4-69: Storey drift for the 25 storey building, middle of site class C (450m/s) case 127

Figure 4-70: Displacement at the top of a storey for 25 storey building, middle of site class $\mathrm{C}(450 \mathrm{~m} / \mathrm{s})$ case. 128

Figure 4-71: Acceleration at the top of a storey for 25 storey building, middle of site class $\mathrm{C}(450 \mathrm{~m} / \mathrm{s})$ case. 128 Figure 4-72: Storey shear values for a 25 storey building, borderline of site class B and site class $\mathrm{C}(750 \mathrm{~m} / \mathrm{s})$ case 129 Figure 4-73: Moment at the bottom of the storey for a 25 storey building, borderline of site class B and site class $\mathrm{C}(750 \mathrm{~m} / \mathrm{s})$ case 130 
Figure 4-74: Storey drift for the 25 storey building, borderline of site class B and site class C $(750 \mathrm{~m} / \mathrm{s})$ case 130

Figure 4-75: Displacement at the top of a storey for 25 storey building, borderline of site class B and site class $\mathrm{C}(750 \mathrm{~m} / \mathrm{s})$ case 131 Figure 4-76: Acceleration at the top of a storey for 25 storey building, borderline of site class B and site class $\mathrm{C}(750 \mathrm{~m} / \mathrm{s})$ case 131 Figure 4-77: Storey shear values for a 25 storey building, middle of site class B $(1000 \mathrm{~m} / \mathrm{s})$ case 132

Figure 4-78: Moment at the bottom of the storey for a 25 storey building, middle of site class B $(1000 \mathrm{~m} / \mathrm{s})$ case 133

Figure 4-79: Storey drift for the 25 storey building, middle of site class B $(1000 \mathrm{~m} / \mathrm{s})$ case

Figure 4-80: Displacement at the top of a storey for 25 storey building, middle of site class B $(1000 \mathrm{~m} / \mathrm{s})$ case 134

Figure 4-81: Acceleration at the top of a storey for 25 storey building, middle of site class $\mathrm{B}(1000 \mathrm{~m} / \mathrm{s})$ case. 134

Figure 4-82: Magnification factors for 9 storey building, Shear wave velocity of underlying soil $450 \mathrm{~m} / \mathrm{s}$ 136 Figure 4-83: Magnification factors for 9 storey building, Shear wave velocity of underlying soil $750 \mathrm{~m} / \mathrm{s}$ 136 Figure 4-84: Magnification factors for 9 storey building, Shear wave velocity of underlying soil $1000 \mathrm{~m} / \mathrm{s}$ 137 
Figure 4-85: Magnification factors for 13 storey building, Shear wave velocity of underlying soil $450 \mathrm{~m} / \mathrm{s}$ 138

Figure 4-86: Magnification factors for 13 storey building, Shear wave velocity of underlying soil $750 \mathrm{~m} / \mathrm{s}$ 138

Figure 4-87: Magnification factors for 13 storey building, Shear wave velocity of underlying soil $1000 \mathrm{~m} / \mathrm{s}$

Figure 4-88: Magnification factors for 17 storey tower, Shear wave velocity of underlying soil $450 \mathrm{~m} / \mathrm{s}$ 140

Figure 4-89: Magnification factors for 17 storey building, Shear wave velocity of underlying soil $750 \mathrm{~m} / \mathrm{s}$

Figure 4-90: Magnification factors for the 17 storey building, Shear wave velocity of underlying soil $1000 \mathrm{~m} / \mathrm{s}$ 141

Figure 4-91: Magnification factors for the 21 storey building, Shear wave velocity of underlying soil $450 \mathrm{~m} / \mathrm{s}$. 142

Figure 4-92: Magnification factors for the 21 storey building, Shear wave velocity of underlying soil $750 \mathrm{~m} / \mathrm{s}$ 142

Figure 4-93: Magnification factors for the 21 storey building, Shear wave velocity of underlying soil $1000 \mathrm{~m} / \mathrm{s}$. 143

Figure 4-94: Magnification factors for the 25 storey building, Shear wave velocity of underlying soil $450 \mathrm{~m} / \mathrm{s}$ 144 Figure 4-95: Magnification factors for the 25 storey building, Shear wave velocity of underlying soil $750 \mathrm{~m} / \mathrm{s}$ 144 
Figure 4-96: Magnification factors for the 25 storey building, Shear wave velocity of underlying soil $1000 \mathrm{~m} / \mathrm{s}$ 145

Figure 4-97: Spectra plots for 9 storey building, middle of site class C (450m/s) case . 147 Figure 4-98: Spectra plots for 13 storey building, middle of site class C (450m/s) case 147 Figure 4-99: Spectra plots for 17 storey building, middle of site class C (450m/s) case 148 Figure 4-100: Spectra plots for 21 storey building, middle of site class C $(450 \mathrm{~m} / \mathrm{s})$ case 148

Figure 4-101: Spectra plots for 25 storey building, middle of site class C $(450 \mathrm{~m} / \mathrm{s})$ case 149

Figure 4-102: Notations for foundation rotation....................................................... 150

Figure 4-103: Vertical displacement at the end points of the foundation for 9 storey building, middle of site class C $(450 \mathrm{~m} / \mathrm{s})$ case with $200 \mathrm{~m} / \mathrm{s}$ side soil 151 


\section{List of Symbols}

$\begin{array}{ll}\text { G } & \text { Shear modulus } \\ V_{s} & \text { Density } \\ V_{p} & \text { Shear wave velocity } \\ \mathrm{E} & \text { Primary wave velocity } \\ \mu & \text { Poisson ratio } \\ C_{s} & \text { Co-efficient of horizontal dashpot } \\ C_{p} & \text { Co-efficient of vertical dashpot } \\ \mathrm{A} & \text { Tributary area of the node } \\ T_{n} & \text { Theoretical modal periods of the soil } \\ \mathrm{H} & \text { Height of the soil deposit } \\ \mathrm{n} & \text { Number of the mode }\end{array}$




\section{List of Appendices}

Appendix A - Modal analysis results....................................... 164

Appendix B- Response plots for building on rock ........................... 179

Appendix $\mathrm{C}$ - Magnification factor values observed at the base of the tower for building

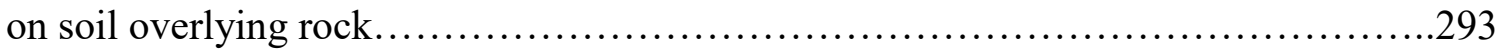

Appendix D - Spectra plots.............................................299

Appendix E - Plots for vertical displacement of the foundation slab................305 


\section{Chapter 1: Introduction}

\subsection{Background}

Earthquakes are one of the worst natural disasters, which have a catastrophic effect on the environment, and cause major loss of life, and property. Prevention, or mitigation, of stated losses requires that the structures be designed to resist earthquakes. This necessitates an analysis of the dynamic response of structures subjected to the ground motions induced by the earthquake. The seismic waves from earthquake source travel through the crust of the earth, reach the foundation of the structure, and cause the dynamic loading. The strength and duration of shaking at a particular site depend on the size and location of the earthquake and the characteristics of the site.

The influence of local site conditions on structural damage has been well recognized since the 1985 Mexico City earthquake. Many buildings in Greater Mexico City, which is about $350 \mathrm{~km}$ away from the epi-centre of the earthquake collapsed, resulting in the death of at least 5000 people. Significant and widespread damage was observed in many 5 to 20 storey buildings, but buildings smaller than 5 storeys or taller than 30 storeys were generally undamaged. Another example of the devastating nature of earthquakes is the 2001 Gujarat earthquake, also known as the Bhuj earthquake $\left(M_{w}=7.7\right)$, which caused a heavy loss of life and injury with about 20,000 dead and more than 60,000 injured.

Narayan and Sharma (2004) studied the effect of local geology on the severity of the damage caused to structures during the Bhuj earthquake. They found that structures located on thicker alluvium deposit and weathered hill had higher intensity of damage, whereas lesser damage was observed in the hard rock areas. Humar et al. (2001) studied the performance of buildings in the Kachchh region which experienced the greatest damage 
during Bhuj earthquake. The authors observed that structures that had masonry infill in reinforced concrete frames performed better during the earthquake. These observations are corroborated by many research studies that have made it evident that damage during an earthquake depends on both the type of structures and the local site characteristics.

Another factor that influences the response to earthquake motion is the presence of soil around the structure. When the structure is embedded in soil the structure and soil are in contact with each other and hence a structure excited by dynamic load interacts with the surrounding soil (Wolf 1985).

The term "Soil Structure Interaction" (SSI) has been coined to represent the process in which the response of the soil influences the motion of the structure and the motion of the structure influences the response of the soil. Observations during previous earthquakes as well as research studies have shown that the interaction between the soil and structure does influence the response of the structure and the damage caused to it (Mylonakis et al. 2006). Often buildings have large below grade structures in which case SSI may have a major influence on their response to earthquakes. The SSI effect on the seismic response of a structure depends on both, the interaction between the soil and foundation, and that between the soil and sidewalls. It requires careful evaluation to determine whether SSI has a significant effect on the forces produced in the structure. There are not many recommendations in the building codes concerning the seismic response of buildings that have several underground storeys. Engineers usually crop the building at the ground level and analyze it assuming that it has a fixed base at that level. The lateral earth pressure on the basements is later accounted for by using the Mononobe-Okabe formulation (Okabe, 1926; Mononobe and Matsuo, 1929). Many earlier studies have focused on the effect of 
soil structure interaction on buildings at the soil/foundation interface (Han, 2002; Bhattacharya and Dutta, 2003; Dutta et al. 2004; Tabatabaiefar and Massumi, 2010; Matinmanesh and Ashegabhadi 2011; Zafarkhah and Dehkordi, 2017). Limited studies exist on the effect of interaction between the foundation of the structure and the soil, along with the interaction between the soil and the basement walls (El-Ganainy and El-Naggar, 2009; Kim et al. 2014; Saad et al, 2016; Prakoso et al. 2017).

The provisions in the newer generation design codes (NBCC 2005 and later) imply higher earthquake loads on foundations and structures. While significant attention has been paid to the effects of this increased demand within the context of structural design, there has been little research of the effects of this on soil structure interaction. Further, the Mononobe-Okabe (MO) method relies on the values of the pseudo-static coefficients $\left(k_{h} \& k_{v}\right)$ which are deemed to be functions of the peak ground acceleration, and are estimated based on past experience. It is unknown whether the formulations to estimate $k_{h} \& k_{v}$ values are applicable under the current regime of shaking intensity. These concerns highlight the need to conduct further studies to assess the response of structures under earthquake loads prescribed by the current building codes, and the implications of using $\mathrm{MO}$ as in current practice. The present research focuses on the development of a finite element model to assess the effect of SSI on the response of shear wall buildings with underground storeys. The study also aims to analyze the effect of various parameters that affect the response.

\subsection{Objective of the study}

The primary objective of this research is to better understand whether the seismic demands considered in the design of structures with a relatively deep underground parkade, within 
the Canadian context, are appropriate. The focus is limited to the seismicity in the Vancouver region given its high seismic risk compared to other Canadian locales, and to structural configurations that are typical in Vancouver. A comprehensive analytical study is carried out to determine the seismic response of a shear wall building using a model that incorporates the structure, soil, and underground storeys, and considers the interaction between both the side-walls and foundation of the structure and the soil. The research focuses on providing an indication of when a designer should take SSI into account. The response of the structure including SSI effect is compared to that of a model of tower and parkade alone analyzed with a fixed base. The following two cases are considered,

\section{1) Building founded on rock}

\section{2) Building founded on soil overlying rock}

For the cases mentioned, a parametric study has been carried out considering buildings with different heights $(4,8,12,16$ and 20 storeys) above the ground with a five level below grade parkade and various site properties (based on the classifications defined in NBCC 2015). For each scenario, the storey shear, the storey moment, the drifts, the displacements, and the accelerations are evaluated to quantify the effects of SSI.

\subsection{Layout of the thesis}

Following this introductory chapter, Chapter 2 presents a critical review of the related literature and highlights the significance of the present research. Previous research on the interaction between the soil and foundation and also between soil and underground storeys or basement walls interaction is discussed briefly. Furthermore, a summary of various factors that affect SSI is discussed to emphasize the need for the study. 
Chapter 3 presents the results of an analytical study of the seismic response of multi-storey buildings with below grade parkade resting on a rock and the impact of SSI on such response. The building is assumed to be fixed at its base, hence the model used in this part of the study ignores kinematic interaction effects between the soil and the structure.

In chapter 4, an analytical study is carried out to study the seismic response of multi-storey buildings with a below grade parkade resting on a rigid mat foundation. The structure is surrounded by soil on the sides and has a soil deposit (of similar or different properties compared to the surrounding soil) beneath the foundation. The soil below the foundation overlies rock, which is subjected to earthquake motion, hence the model used in this part of the study considers both the inertial interaction and the kinematic interaction between the soil and the structure.

Finally, Chapter 5 provides a summary of the research undertaken, its objectives and discusses the implications of the outcomes. Conclusions along with the recommendations for future studies are presented. 


\section{Chapter 2: Soil structure interaction (SSI): Principles \& Background}

\subsection{Soil structure interaction}

The response of a structure to earthquake shaking is affected by interactions between three linked systems: the structure, the foundation, and the soil underlying and surrounding the foundation (FEMA, 2009). A seismic SSI analysis evaluates the collective response of the structure, the foundation, and the geologic media underlying and surrounding the foundation to a specified free-field ground motion (NIST GCR 12-917-21). SSI effects are ignored for a structure analyzed on a rigid base. Therefore, SSI aims to account for the difference in the response of the rigid base structure and the response of the actual structure. It is shown that the evaluation of the effects of SSI is very vital for the design of earthquakeresistant structures.

\subsection{Effects of SSI}

Wolf (1985) compares the dynamic response of structure founded on a rock to that of the same structure embedded in soil to illustrate the effects of SSI. Consider the case of two identical structures with a rigid base (with basement and sidewalls) as shown in Figure 1. One of the structures is founded on rock, the other on a layer of soil that overlies bedrock. The two substructures are located at proximity. Since the distance between the two structures in small, it can be assumed that the seismic waves from the earthquake source propagating through rock are the same at both structures. To make comparison simple, the author selected a horizontal motion propagating vertically and he chose the control point at the free surface of the rock (Point A) as shown in Figure 2-1. For the structure on a rock 
the motion can be directly applied at its base. During an earthquake event overturning moment and transverse shear will develop at the base of the structure.
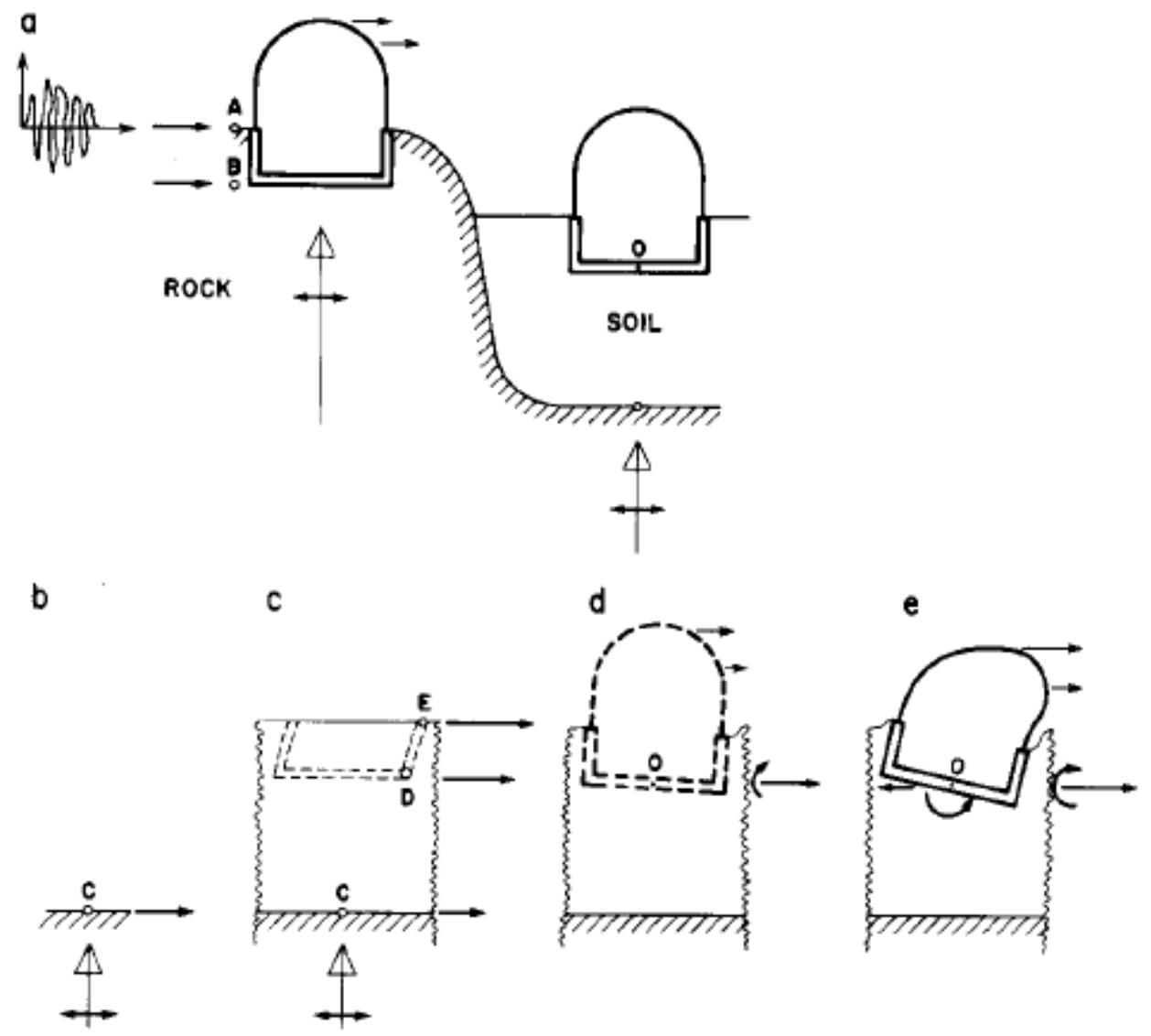

Figure 2-1 Seismic response of structure founded on rock and on soil (a) Sites; (b) Outcropping rock; (c) Free-field; (d) Kinematic interaction; (e) Inertial interaction (Wolf, 1985)

Since the rock is very stiff these effects will not lead to any additional deformation to account for at the base of the structure. Therefore, for structures on rock for a given control motion, the seismic response depends only on the properties of the structure. The second structure is embedded in soil so the soil and structure are coupled; the motion at base of the structure (Point $\mathrm{O}$ ) is now different from the control motion. The author compares the 
following detailed effects to gain insight into how soil affects the dynamic response of the structure.

First, the free-field motion (i.e.) motion at the site in the absence of the structure and any excavation is modified. As in Figure 1-b when there is no soil on top of the rock the motion at point $\mathrm{C}$ hardly differs from the control motion. If there is soil above the rock the motion the motions at point $\mathrm{D}$ and $\mathrm{E}$ will differ from that in $\mathrm{C}$. When the structure will be built, points D and E will lie on the interface between the soil and the structure. The author states that the motion is generally amplified, as it propagates from C to D and E but not always (depending on the frequency content), thus resulting in increased horizontal displacement. Second, the rigid base (Figure 1-d) experiences some average horizontal displacement as well as a rocking motion. This effect is referred to as kinematic interaction. Third, (Figure 1-e) structural inertial loads lead to an overturning moment and a transverse shear which causes deformations in soils and this in-turn modifies the motions at the base; this effect is referred to as inertial interaction.

Referring to Figure 2-1, Wolf (1985) details the main effects of taking soil-structure into consideration as follows,

(1) For an embedded structure, the input motion acting on the structure soil system is amplified in many cases from the free-field motion and a rocking component will arise. This amplification justifies the fact the structures founded on a deep soft soil site are damaged more severely during earthquake events than the neighboring structures on rock.

(2) The presence of soil makes the system more flexible thus decreasing the fundamental frequency significantly below the case of fixed base structure. 
(3) The radiation of energy through waves propagating away from the structure results in an increase in the damping of the system.

\subsubsection{Kinematic interaction effects}

According to (NIST GCR 12-917-21), when stiff foundation elements rest on flexible soil it causes the motion at the foundation to deviate from free-field motions owing to three common reasons,

- Base-slab averaging - stiffness of foundation prevents the motion at the foundation from matching the free-field deformations

- Embedment effects - due to the variation of ground motion with depth. Generally, amplitude of motion decreases with depth

- Wave scattering - scattering off from corners and edges

As a result of these interactions, even though the free field motion is purely translational when caused by vertically propagating S-waves, the foundation is subjected to translational and rocking motion. The degree and nature of the rocking is dependent on the wavelength and the dimensions of the foundation.

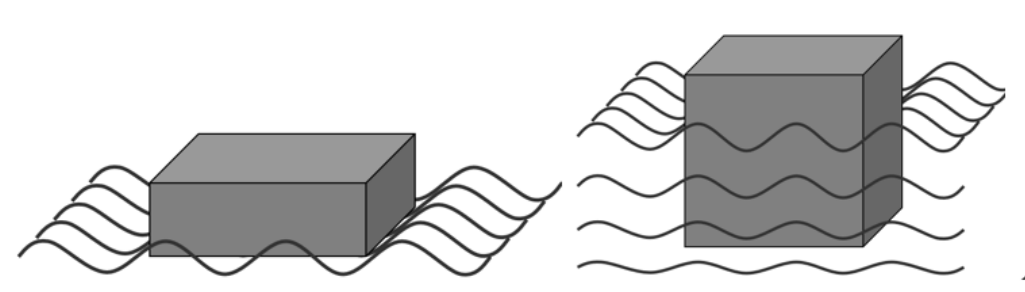

(a) (b)

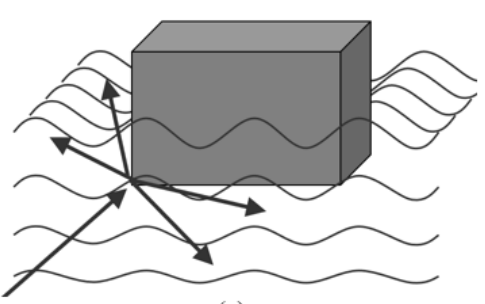

(c)

Figure 2-2 Kinematic interaction effects (a) base slab averaging; (b) embedment effect; (c) wave scattering (https://www.slideserve.com/nira/steve-kramer-university-of-washington) 


\subsubsection{Inertial interaction effects}

The effects that are rooted in the inertia of the structure are referred to as inertial interaction effects. When a structure vibrates inertia forces develop, which give rise to base shear, moment, and torsion. These forces cause displacements and rotation at the interface between the soil and the structure. These displacements and rotation introduce additional flexibility in the soil structure system thereby increasing the period of the structure. They also increase the damping on account of the dissipation of energy by radiation and hysteretic soil damping.

\subsection{Methods to evaluate SSI}

The SSI effects listed in the previous paragraphs can be evaluated using two different approaches: direct approach and sub-structure approach.

\subsubsection{Direct analysis:}

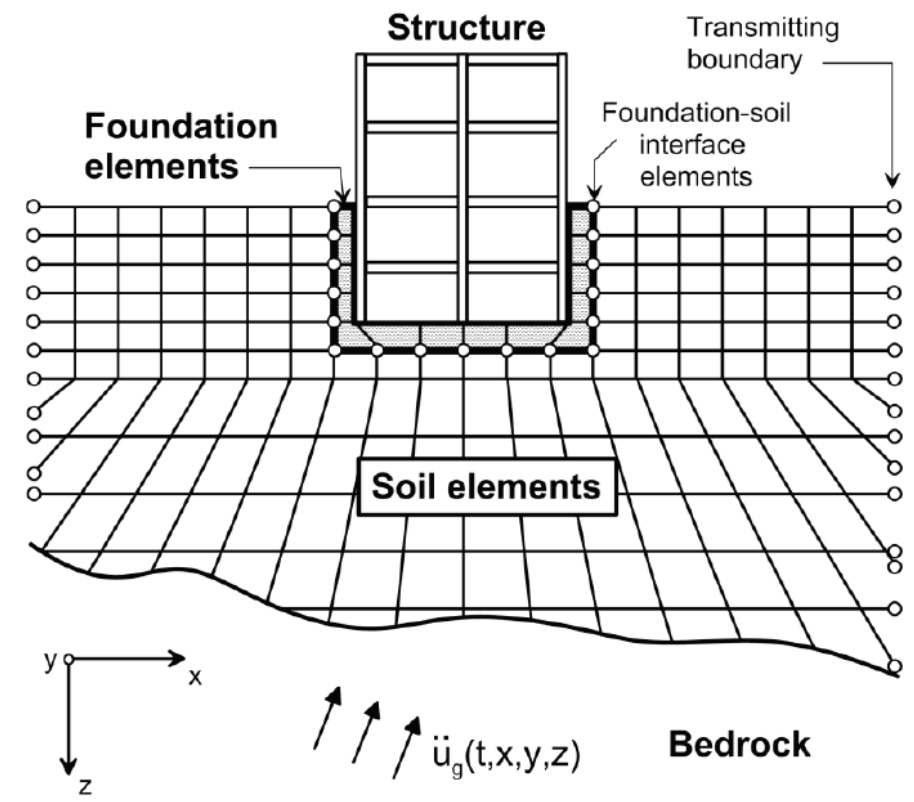

Figure 2-3 Schematic illustration of direct approach (NIST GCR 12-917-21) 
This method requires detailed modelling of both the soil and the structure in the analysis.

Soil is usually modelled as a continuum with suitable boundary conditions at the ends of the mesh and interface elements to replicate the connection between structure and soil. The method requires large computer storage and significant running time since the number of dynamic degrees of freedom in the soil region is large.

\subsubsection{Sub-structure approach}

In the sub-structure approach, soil and structure are modelled separately and then combined. According to NIST GCR 12-917-21, proper consideration of the sub-structure approach requires,

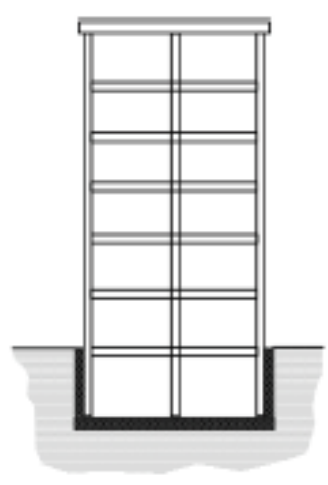

(a) Complete System

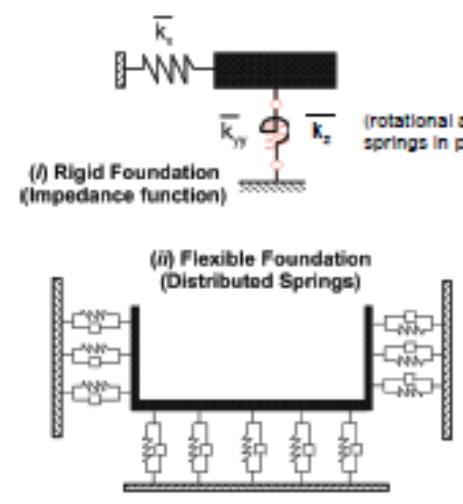

(c) Foundation-Soil Flexibility and Damping

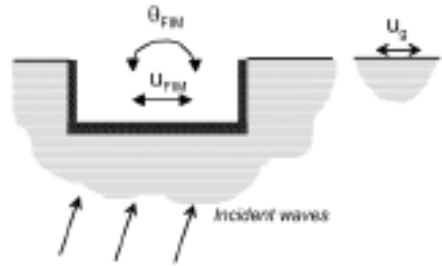

(b) Kinematic Interaction
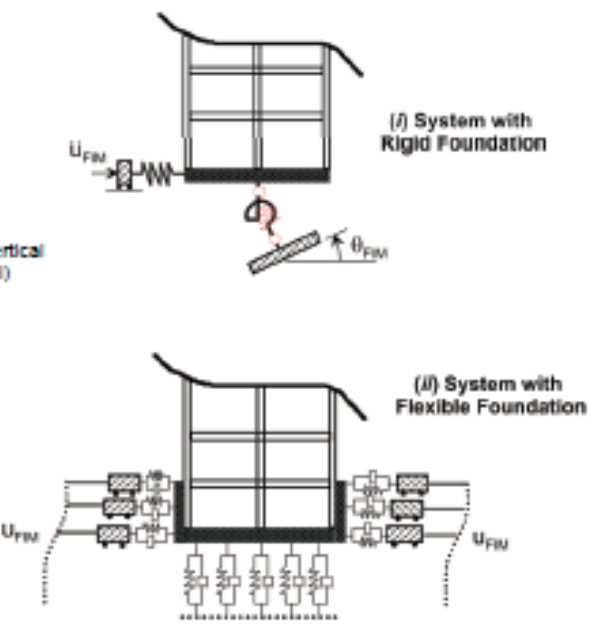

(d) Excitation with FIM of Structure with Foundation Flexibility/Damping 
- $\quad$ an evaluation of free-field soil motions and corresponding soil material properties

- $\quad$ an evaluation of transfer functions to convert free-field motions to foundation input motions

- incorporation of springs and dashpots (or more complex nonlinear elements) to represent the stiffness and damping at the soil-foundation interface

- $\quad$ response analysis of the combined structure spring/ dashpot system with the foundation input motion applied.

In this approach, impedance function models, distributed springs and dashpots are used to describe the stiffness and damping characteristics of soil-foundation interaction. Thus, this method involves many uncertainties in determining the required properties for springs and dashpots. Hence, the direct approach will be used in the study.

\subsection{Literature Review}

SSI and its effects on the response of the structures have been the subject of many studies. A selected number of previous research papers, particularly those in which SSI effects on buildings and buildings with underground storeys and basement walls were assessed are briefly reviewed in the following sections. Finally, based on the reviewed research, a summary of various factors that cause variation in the effect of SSI are discussed.

\subsubsection{Previous research on soil-structure interaction with buildings}

Veletsos and Meek (1974) carried out a study on the dynamic behavior of building foundation systems with the assumptions that foundation is supported at the surface of an elastic half-space and the response of the superstructure lies within the elastic range. The 
authors also suggested a simple and practical procedure for considering the effects of SSI in a response analysis. They concluded that SSI significantly alters the dynamic response of structures and must, in general, be considered in the design. They also stated that the principal effect of SSI is to reduce the resonant frequency of the structure and to modify its effective damping, and that the net result may be an increase or a decrease in the maximum deformation of the structure.

In general, when structures are analyzed for their dynamic response it is assumed that the motion at the base of the structure is the same as the free-field motion. In their study, Veletsos and Boaz (1979) stated that this assumption was valid only for structures supported on a rigid ground. For structures founded on soft soil, the foundation motion was different from the free-field motion and could include a rocking component which may be significant for tall structures. Based on their study the authors stated two reasons for the difference between the response of a rigidly supported structure and an elastically supported identical structure,

(1) The number of degrees of freedom for an elastically supported structure is larger compared to the rigidly supported structure and hence the two have different natural frequencies and modes of vibration.

(2) Owing to the radiation of waves and hysteretic action in the soil, a significant part of the vibrational energy may be dissipated into the supporting medium when the structure is supported on soft soils.

The authors also concluded that the differences in the response would depend on the characteristics of the free-field ground motion, and properties of the structure and the supporting soil. 
Luco et al. (1988) carried out a study to analyze in detail the effects of SSI during forced vibration tests. The authors selected the Millikan Library building as the experimental site for the study. From the results obtained from forced vibration tests, they observed that the responses were affected by the interaction between structures and the soil. The reason was the rigid body motion of the superstructure owing to the translation and rotation of the foundation, which added significantly to the total response. They also found that when the system vibrated at its resonant frequency, a major portion of deformation of the superstructure originated from the inertia forces associated with the mentioned rigid body motion.

Celebi and Safak (1992) performed preliminary analyses on a set of acceleration response records obtained during the Loma Prieta earthquake from a 60-storey vertically tapered, pyramid-shaped Transamerica building. From the Fourier analysis of the accelerograms obtained at the Transamerica, the authors observed that at approximately $2 \mathrm{~Hz}$ there was some rocking. The authors stated that, although the rocking amplitude was very small, it significantly changed the motions at the basement and the ground level, which would affect the development of the design response spectrum. Since the design response spectrum usually assumes free-field motions at the foundation level, it may include site effect but does not take SSI effects into account. Hence, it can be concluded that the motions at the basement levels are affected by SSI effects.

Mylonakis and Gazetas (2000) performed a study to observe whether the seismic SSI was beneficial or detrimental. The main objective of the authors was to evaluate the approach proposed by regulations to determine the effects of SSI and to evaluate the SSI effects on elastoplastic pier bridges. From their study they concluded that the prevailing practice of 
ignoring the effects of SSI represented an oversimplified approach which could lead to unsafe design. The authors pointed out that without proper normalization of periods while averaging the response spectra obtained from motions recorded on soft soil, the conclusions reached could be erroneous. They observed increasing trends in ductility demands at periods other than the predominant periods while analyzing for motions recorded on soft soils which contrasted with the traditional design procedures. They also concluded that depending on the characteristics of motion SSI could cause a significant increase in the ductility demand on the piers located on deformable soils.

Han (2002) carried out a study on a 20 -storey building supported on pile foundation for three different conditions: (1) Rigid base; (2) Linear soil-pile system; (3) Non-linear soilpile system. He also investigated the effects of pile foundation displacements on the behavior of tall buildings. From the study, the author concluded that when non-linearity of the piles was considered in the analysis there was a decrease in natural frequency and an increase in the displacements compared to the linear case. He further stated that the seismic behavior of tall buildings supported on pile foundation was different from that for the one supported on a shallow foundation on a rigid base. The author also found that in the case of a shallow foundation the natural frequencies were lower, and the displacements were larger in both the superstructure and the foundation. The author also concluded that the seismic response of tall buildings depended on non-linearity of the pile group and the group effect.

In their study, Bhattacharya and Dutta (2003) tried to observe the effect of SSI on the lateral natural periods of the building frames resting on isolated and grid foundation. When the lateral natural periods of the buildings change, the seismic response alters considerably. 
The analysis of buildings founded on soil shows an increase in the natural periods of the system as the soil medium below adds to the flexibility, decreasing the overall stiffness. In their paper, the authors presented various curves for dynamic characteristics which may be used with simple linear interpolation to access the effects of SSI for any building frames. The authors concluded that in tall buildings the effects of SSI were less pronounced due to increase in flexibility with increase in number of storeys.

Muria-Vila et al. (2004) selected two best instrumented buildings in Mexico, founded on soft soil (average $V_{S}=68 \mathrm{~m} / \mathrm{s} \& 148 \mathrm{~m} / \mathrm{s}$ respectively) to estimate SSI effects. To simulate the stiffness and frequencies associated with SSI, the authors used both system identification and analytical methods. They concluded that the dynamic responses were very sensitive to the amplitude of the imposed ground motion, even for small levels of excitation. They also observed that the rocking movements were associated with several different frequencies which may possibly be due to uncertain contact pressures at the soilfoundation interface caused by the averaging of incident waves and the forces and moments induced in the structure by new sources of vibration. Finally, they mentioned that the loss of contact at the basement side walls and the pile group effect must be considered to evaluate foundation stiffness and hence SSI could not be ignored.

Dutta et al. (2004) carried out a study on low rise building frames resting on shallow foundations. They modelled the structures with lumped masses using two nodded frame elements and used impedance functions to incorporate the effects of SSI. In their study, the authors stated that flexibility of the soil medium allowed some movement of the foundation, which decreased the overall stiffness of the building frames resulting in a significant increase in the natural periods of the system and the overall response was 
therefore altered. The following conclusions were reached in the study, (1) SSI played a significant role in increasing the base shear in low rise buildings and the influence of SSI generally decreased for medium to high rise buildings and, (2) the effect strongly depended on the frequency content of the input earthquake motion. They also concluded that the increase in base shear was less for stiff soil and larger number of storeys.

Tabatabaiefar and Massumi (2010) carried out a study on the seismic response of reinforced concrete moment resisting building frames. For their research they considered 3,5, 7 and 10 storey models resting on three different types of soil (II, III and IV) defined in Iranian standards. The soil was modelled using finite elements extending up to the bedrock in vertical direction. Appropriate boundary conditions were implemented at other boundaries of the soil medium. The analysis was performed using direct method. Four different earthquake records were used in the analysis. In the case when soil and structure were modelled together, the authors applied the earthquake input directly at the base of the model. From their results, the authors observed that between the two cases (flexible base and fixed base) there was no change in storey shears but the displacements and drifts for 5,7 and 10 storey structures on soil having low shear velocity $(<175 \mathrm{~m} / \mathrm{s})$ were significantly increased. They also stated that SSI effects were negligible for rigid ground but should be considered for less rigid soil, since the decrease in rigidity resulted in an increase in the period.

Matinmanesh and Ashegabhadi (2011) carried out a two-dimensional finite element simulation of a 5 -storey and a 20 -storey building founded on two different type of soils (loose and dense sands). The authors selected three actual ground motion records representing low, intermediate, and high frequency contents for the SSI analysis. Based on 
their study they concluded that all soil profiles amplified ground motions but to different degree and that the amount of amplification depended on the soil type and properties, earthquake frequency content and the properties of the buildings. The authors stated that amplification was higher for the system comprising of soil, structure and seismic excitation which had lower effective damping.

Hokmabadi et al. (2013) in their study stated that the role of seismic soil pile structure interaction (SSPI) was usually considered beneficial as it lengthened the lateral fundamental period and led to higher damping in comparison to the fixed base structures but during recent earthquake events it had been observed that the fixed base assumption could be misleading and neglecting of SSPI could lead to unsafe design. To analyze this effect, the authors carried out a study on 15 storey moment resisting reinforced concrete building using shake table tests and performed numerical analysis employing fully nonlinear three-dimensional model. From the experimental and numerical study, they found that SSI amplified the lateral deflections and inter-storey drifts when compared with the fixed base structure. However, there was a reduction in the lateral displacement with floating pile foundation in comparison to shallow foundation owing to reduced rocking in the former.

Zafarkhah and Dehkordi (2017) carried out a study to determine the effects of soil type and structure height on soil-structure system responses. For their study, they considered frames having 3 bays and 3, 6, 9, 12 and 15 storeys with seven types of soils, namely loose, medium, medium dense, dense sand as well as soft, medium, and stiff clay. From their results, they observed that the effect of SSI on drifts was highest for 6-storey frame and in general, for low rise structures. The amplification in drift due to SSI increased with 
structure height. For medium-rise structures SSI effects were independent of frame height. For tall structures, the effect of SSI on drift became less pronounced as the height increased. The authors also observed that the foundation displacement due to earthquake input depended greatly on the subsoil type and to a lesser extent on the structure height. For all frames, large roof displacement occurred with loose sandy soils. However, low and medium rise structures on soft clay soils had lower roof displacements compared to the rigid base case.

In dense urban environments, underground structures are often built near tall structures. Hashash et al. (2018) did a study to evaluate the impact of an adjacent mid-rise or highrise building on the seismic response of a cut-and-cover tunnel structure and a braced excavation in centrifuge experiment and a corresponding numerical simulation. They considered two cases, an underground structure without any adjacent structure and another with both a 13-storey mid-rise and a 42- storey high-rise structure, common in many seismically active areas of California. From the experimental and numerical investigations, they observed significantly higher dynamic earth pressures on the underground structure wall if it was adjacent to the building site compared to that with no adjacent structure. This was attributed to the base shear in the tall building. The authors also reported that the distribution of lateral pressure was non-linear with depth. Such effects would not be captured by the current design procedures. The authors performed several analyses in which they considered tunnel and excavation configurations and impact of the presence of an adjacent building with a deep basement. They noted that the building created a constraint for the lateral movement of the building sidewalls compared to the case with no adjacent building. 


\subsubsection{Previous research on soil-structure interaction for buildings with underground storeys and basement walls}

The seismic response of buildings with underground storeys depend on the effect of SSI between the side soil and the basement walls, and that between the foundation and the bearing soil. Saad et al. (2016) stated that there were three common methods available to evaluate the effects of side SSI namely, the simple lateral pressure methods, the beamcolumn methods, and the finite element methods. The simple and the traditional lateral pressure method is a pseudo-static method that uses seismic earth pressure distribution based on the formula developed by Mononobe-Okabe (Okabe 1926, Mononobe and Matsuo 1929). However, Ostadan (20005) in his research stated that based on recent field observations and experimental data it appeared that the Mononobe-Okabe method was not suitable for building walls and suggested a simplified method to predict maximum seismic soil pressures for buildings resting on firm foundations which may not be suitable for all foundation types.

El-Ganainy and El-Naggar (2009) investigated the seismic performance of steel buildings having moment-resisting frames and multiple underground storeys resting on shallow foundations. For their study, the authors considered non-linear seismic response of 5, 10 and 15-storey buildings resting on a flexible ground surface and having one, three and five underground storeys. In their analysis, they considered two different soil conditions, soil class C and soil class E defined in NBCC 2005 corresponding to firm and soft soil deposits. The authors modelled the elastic stiffness and non-linear behavior of the side soil but neglected the oscillating mass of the side soil and the radiation damping. They used nonlinear inelastic horizontal and vertical bar elements distributed over the surface area of the 
basement walls to model the side soil. The analysis was non-linear direct integration time history to calculate the seismic response of buildings.

From their analysis, the authors concluded that the SSI effects increased the force and deformation demand in some cases contrary to the postulation in most building codes that SSI leads to a decrease in such demand. They also observed that the SSI effect was dependent on the stiffness of the foundation and the number of underground storeys and was significant for soft soil conditions but negligible for stiff soil conditions. Finally, the authors concluded that the effects of SSI were most significant for buildings resting on flexible ground surfaces, but such effects gradually decreased with increasing number of underground storeys.

Kim et al. (2014) carried out centrifuge tests using an in-flight earthquake simulator on a single degree of freedom structure model, a substructure model (basement), and soil deposit located in a centrifuge container to investigate the effect of soil-basement interaction on the seismic response of structures. For their experiment, they considered two cases, SDOF system with a fixed basement and SDOF system with a half-embedded basement. They concluded that seismic loads on the structures with half-embedded basement were greater over the whole period range when compared with fixed base structures.

Saad et al. (2016) conducted a study to analyze the combined effects of side and foundation soil structure interaction effects for reinforced concrete shear wall buildings under seismic loading. Their study considered two sub-surface conditions, very dense and medium dense sands, and three different levels of ground shaking. The analysis was non-linear direct integration time history analysis using SAP2000 and considered the effect of various 
parameters, such as, the number of above-ground storeys, the number of underground storeys and sub-surface site conditions. For each case considered, they observed the base shear and inter-storey drifts to quantify SSI effects. The authors considered five, ten and fifteen storey buildings with underground storeys ranging from none to three basement floors. The soil next to the basement walls was modelled using non-linear springs (multilinear kinematic link property of SAP2000). From their analysis, they concluded that the common design practice of cropping the structure at the ground surface led to a conservative estimation of base shear for taller and less rigid structures, while resulting in unpredictable or non-conservative trends for shorter and stiffer structures.

Tehranizadeh and Barkhodari (2018) analyzed the influence of peripheral wall openings in the basement and the number of basement floors on the response to near-field earthquakes when considering soil-structure interaction effects. Two-dimensional non-linear models were used for the study and clay site soils with average shear velocity of $400 \mathrm{~m} / \mathrm{s}$ for the first 15-meter depth of soil were assumed. The soils were modelled using quad elements and viscous dashpot elements were used to model absorbing boundaries. From their study, the authors concluded that when the openings were greater than 50\% disregarding them in the analysis for high-rise structures could lead to unsafe design.

Piro et al. (2019) investigated the effectiveness of the existing closed-form solutions, which had been derived from SDOF structural models having shallow rigid foundations placed on a homogeneous, linear elastic half-space. The authors used a single load-bearing wall in an unreinforced masonry building having a shallow foundation or an underground storey embedded in layered soil. They also carried out a series of parametric studies by varying the geotechnical and structural properties, the type and depth of building basement 
(embedded foundation or underground storey), soil layering (homogeneous or layered soil with different combination of material properties), and number of storeys above (2, 3 and 4 storeys). They compared the results from a replacement oscillator approach and twodimensional finite difference analysis and proposed regression models and a relative soilstructure stiffness parameter to predict the frequency reduction induced by soil foundation structure interaction taking into account into account various parameters, such as the presence of an embedded foundation, an underground storey, and a layered soil. The authors stated that the results of their study could be extended to geometric layouts having similar structural configurations in the Italian and European built heritage.

Piro et al. (2019) concluded that SSI influences the dynamic response of a structure and the effect was more pronounced in the presence of an underground storey as well with increasing height of the structure above ground. In addition, they observed that the analyses performed on structures founded on layered soil configurations showed the fundamental period of the system was mostly affected by the upper soil layer compared to the stiffer foundation layer.

\subsection{Summary}

Based on the design codes, which allow for a reduction in the overall seismic co-efficient on account of SSI or suggest that SSI be ignored, one can conclude that SSI has beneficial effects on the seismic response of structures. The reasoning behind this statement is that SSI makes a structure more flexible thereby increasing its natural period and enhances the effective damping. However, from the research cited in previous sections, it can be observed that this is not always the case and SSI effect changes the structural response in various manners depending on the factors detailed below, 
- The earthquake motion on structure and soil system is amplified and rocking is induced in the embedded structures (Wolf 1985, Veletsos and Boaz 1979, Luco et al. 1988, Celebi and Safak 1992).

- There is a significant decrease in frequency when the soil is incorporated into the system (Wolf 1985, Veletsos and Meek 1974, Veletsos and Boaz 1979).

- For buildings with sub-structures the effect of SSI varies at the basement walls (Muria-Villa 2004) and with the number of underground storeys (El-Ganainy and El-Naggar 2009, Kim et al. 2014, Saad et al. 2016, Tehranizadeh and Barkhodari 2018, Piro et al. 2019).

- The effect of SSI depends on the characteristics of ground motion (Veletsos and Boaz 1979, Mylonakis and Gazetas 2000, Muria-villa 2004, Dutta et al. 2004, Matinmanesh and Ashegabhadi 2011), properties of the structure, such as, type and number of storeys (Veletsos and Boaz 1979, Battacharya and Dutta 2003, Dutta et al. 2004, Tabatabaiefar and Massumi 2010, Matinmanesh and Ashegabhadi 2011, Zafarkhah and Dehkordi 2017), properties of soil (Veletsos and Boaz 1979, Tabatabaiefar and Massumi 2010, Matinmanesh and Ashegabhadi 2011, Zafarkhah and Dehkordi 2017, El-Ganainy and El-Naggar 2009, Piro et al. 2019), and type of foundation (Han 2002, Hokmabadi et al. 2013, El-Ganainy and El-Naggar 2009).

Apart from the above listed factors, there are many which would cause variation in SSI effects. For example, Hashash et al. 2018 observed that the presence of tall structure near an underground structure would affect the SSI effects observed on the wall of the underground structure located on the side of the building. The results of the numerous studies highlight the fact that the common assumption that SSI can be ignored could lead 
to unsafe design. Hence, SSI should be incorporated in the analysis and design of structures and its effect determined by proper analysis. In particular, for a building with underground storeys, the common design approach of cropping the structure at the ground level and analyzing it as having a fixed base at that level is not appropriate. It is important to incorporate the structure, the underground storeys, as well as the soil underlying and surrounding the foundation in the model to analyze the effect of SSI on the seismic performance of a building structure.

In addition, it is clear that the influence of SSI is site specific. It depends on the structural configuration and soil properties. In Canada, the Lower Mainland and the city of Vancouver are among the locales with the greatest seismic risk. Hence, it is of interest to understand the effects of SSI in current design practice in that region. 


\section{Chapter 3: Soil-Structure Interaction in a Building founded on Rock}

\subsection{Introduction}

The focus of the current research is the seismic response of multi-storey buildings with below grade parkade and the impact of soil-structure interaction on such buildings. The determination of the response of the structure considering soil structure interaction can be quite complicated. As explained earlier, the standard practice is either to crop the building at the ground level and determine its response for the earthquake ground motion applied at that level. An alternative often used is to consider the entire building height from foundation upward and to study the response of the building to the design ground motion applied at the foundation level. In either case, the earthquake induced lateral earthquake forces on the basement walls below ground are determined using empirical methods and applied statically, ignoring the dynamic nature of the interaction between the soil and the structure. These procedures are used with the assumption that soil structure interaction will usually result in a reduction in the earthquake forces

As previous studies have found, there is not much code specified guidelines for estimating the seismic response of structures having underground stories. The present research investigates the seismic demand on buildings with a deep below-ground structure. The buildings studied have a five-level below grade parkade with an above ground tower of variable heights. In the present chapter response of buildings founded on rock but surrounded by soil with variable shear strength are studied with a view to observe trends that would be useful in design. The model and the ground motions used in the study are first described. The assumptions made in developing the model are then explained. Following that, the components used to create the model in OpenSees are detailed. Finally, 
the results, conclusions, and recommendations observed from the parametric study are presented.

\subsection{The structural model}

The models analyzed consist of five different building configurations differentiated by the height of their tower above the ground, namely 4, 8, 12, 16, and 20 storeys. The tower sits on a deep below grade structure surrounded by a large block of soil. The tower has plan dimensions of $30 \mathrm{~m}$ by $30 \mathrm{~m}$ with $3 \mathrm{~m}$ high storeys, and is supported by a structure that runs through the parkade, as shown in Figure 3-1. Each building has five level below-ground parkade, with storey height of $3 \mathrm{~m}$ and plan dimension of $40 \mathrm{~m}$ by $70 \mathrm{~m}$. The soil acts on the $70 \mathrm{~m}$ face of the parkade. The dimensions of the soil block is $70 \mathrm{~m}$ by $70 \mathrm{~m}$ on either side of the parkade for $15 \mathrm{~m}$ height of the parkade.

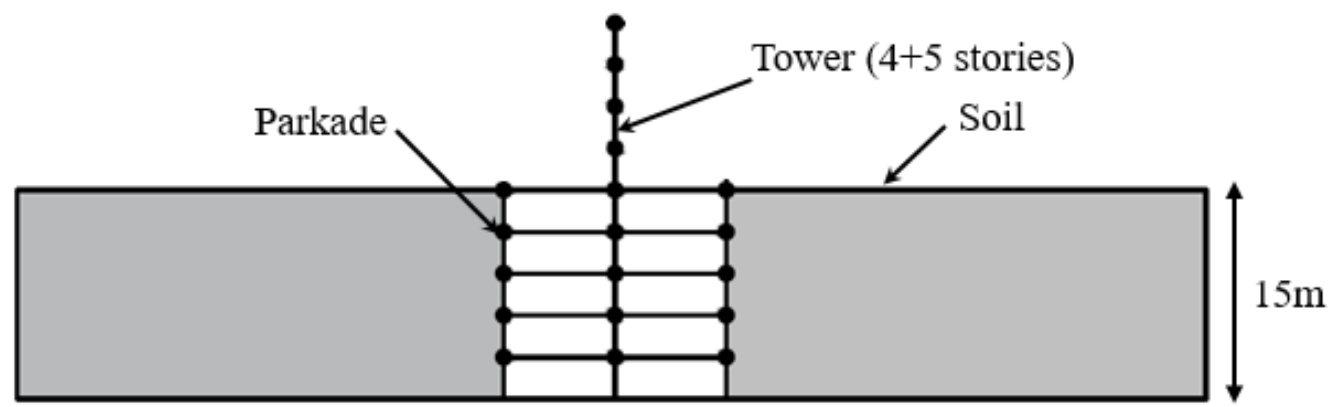

(a)

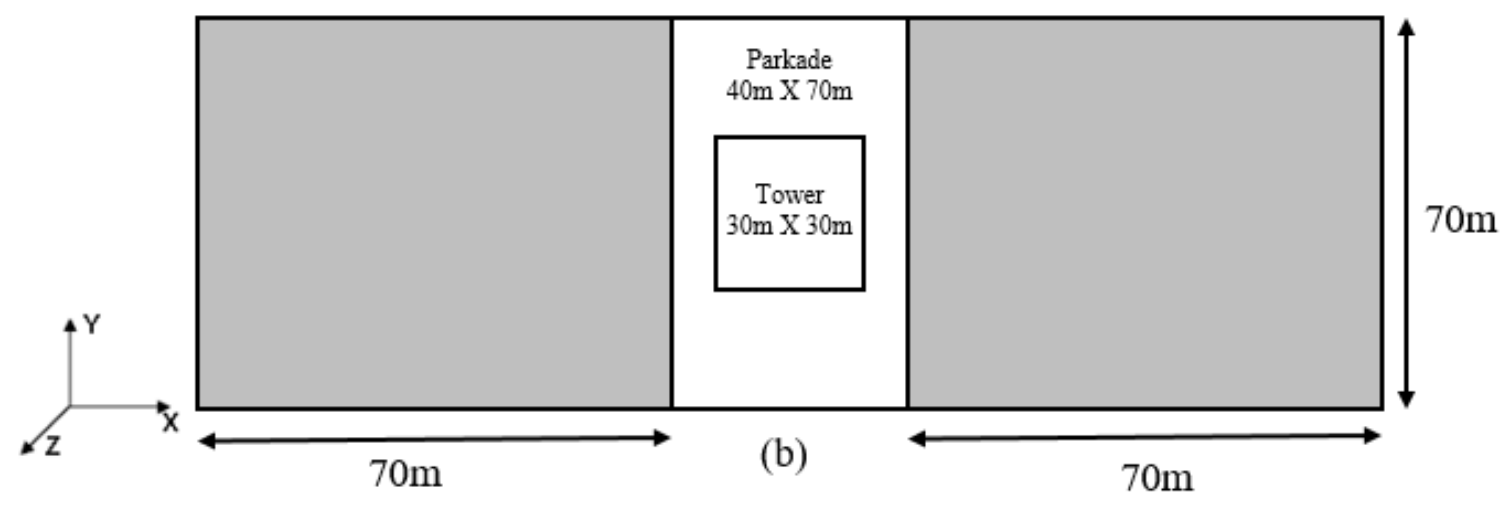

Figure 3-1 (a) Elevation, (b) Plan of the 9 storey building (not to scale) 
The buildings are referred to by the total number of storeys inclusive of the parkade. For example, a building having a tower of height 4 storeys above ground will be referred to as 9 storey building ( 4 above ground storey +5 level parkade). Thus, the buildings referred to as 9 storey, 13 storey, 17 storey, 21 storey, and 25 storey will be used in the analysis. The plan (similar for all buildings) and the elevation of the 9 storey building are as shown in Figure 3-1.

\subsection{Ground motion records}

A set of ground motion records are required to carry out the dynamic time history analyses in the present study. The buildings under study are assumed to be resting on a rock site in Vancouver. The site conforms to site class B as defined in NBCC 2015. A total of 11 sets of earthquake ground motions were selected and scaled to match the Vancouver site B spectrum according to NBCC 2015 ( Commentary J), as shown in Figure 3-2.

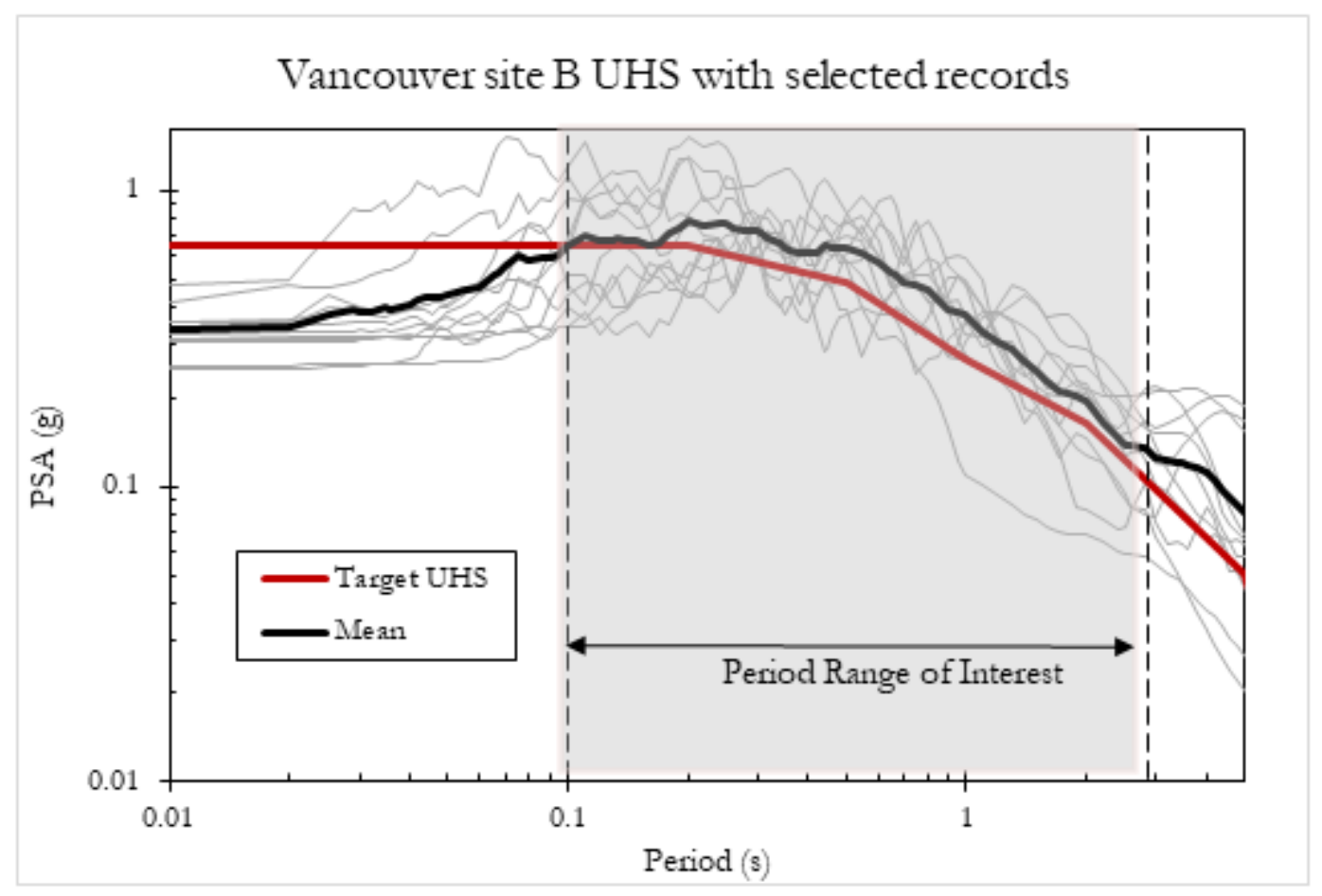

Figure 3-2 Vancouver site B UHS and selected records spectra 
The focus of the study was to assess SSI, and it was considered that using appropriately scaled real earthquakes following the NBCC guidelines, which is common practice in the industry, was more suitable than using artificially simulated earthquakes to match the design spectra. The earthquake ground motions were downloaded from the PEER website and scaled to provide a good match to the UHS over a selected period range, $T_{R}$, which covers the periods of the vibration modes that significantly contribute to the building's dynamic response. In order to avoid scaling for each building heights, the periods were selected such that, $T_{R}$ ranged from $0.1 \mathrm{~s}$ to $2.85 \mathrm{~s}$; the minimum of the range being considerably lower than the period of the shortest structure (9 storey building) and the maximum of the range higher than the period of the tallest structure (25 storey building) considered in this study. The mean of the spectra of the selected earthquake motions were scaled to have a good match over the selected period range. In addition, the earthquake motions were selected such that the spectra of the selected earthquakes matched the UHS spectra with no spikes in low frequency range to prevent any outliers. First, each selected motion was scaled individually such that its response spectrum was equal to or exceeded the target spectrum over the period range, $\mathrm{T}_{\mathrm{R}}$. Next, each ground motion was scaled by a second factor such that the mean response spectrum did not fall more than $10 \%$ below the target spectrum.

\subsection{Assumptions made in generating the analytical mode}

In the current study, the following assumptions are made to formulate the analytical model. A 2-D analysis is used throughout in which the earthquake motion is assumed to be in the $\mathrm{X}$ direction. Thus, the building structure lying in the $\mathrm{X}-\mathrm{Y}$ plane is analyzed for its response to the ground motion in the $\mathrm{X}$ direction. Walls lying in the $\mathrm{X}-\mathrm{Y}$ plane constitute the Seismic 
Force Resisting System (SFRS), Walls that are in the Y-Z plane are assumed to provide negligible resistance, but deliver to the SFRS the forces imposed by interaction with the surrounding soil. It is assumed that the walls deform within their elastic limit, but recognized that in practice one can expect the shear wall to crack at a drift of $0.5 \%$ and to start yielding when the drift reaches $2.5 \%$.

For multi-storey building structures it is reasonable to assume that, all building mass is concentrated at floor levels (Chopra, 2012). Hence, it is an appropriate assumption to model the tower and parkade as stick elements with masses lumped at their storey levels. The weight of the tower is taken as $7200 \mathrm{kN}$ per floor, and the parkade weight is assumed to be $22,400 \mathrm{kN}$ per floor based in a floor slab weight of $8 \mathrm{kPa}$. The material of the tower and parkade is concrete, having a compressive strength of $30 \mathrm{MPa}$. The tower and parkade floors are formed by concrete slabs and may be considered as a rigid diaphragm (Mortazavi and Humar, 2016). The tower, parkade, and soil are rigidly connected so that they move together. To incorporate the effect of cracking in tower and parkade, the cracked shear stiffness is taken as $10 \%$ of the un-cracked shear stiffness, which is accommodated by applying a modifier to the shear area of the tower and parkade. The elements are fixed at the base. Thus, the analytical model considered in this chapter ignores kinematic interaction effect between the soil and the structure.

Rayleigh damping is used in the model. Such damping is a combination of mass proportional damping and stiffness proportional damping. Thus, damping ratios can be assigned to two modes. The selected modes are the first mode, usually being the fundamental mode, and a second mode which is the highest mode with significant mass contribution (Humar, 2012). Based on this consideration, the first and the third modes are 
selected to calculate the Rayleigh damping matrices. The damping ratios specified for the two modes are selected to be equal to each other (Humar, 2012). Here, a damping of 5\% is allocated for the two modes of the structure and the soil.

In real life structures, the wave energy that propagates away is generally lost and never returns into the soil domain. Therefore, absorbing boundary conditions must be employed to ensure the transmission of incident waves without any reflection from the boundary. Two commonly used boundary conditions, tied degrees of freedom (TDOF) and standard viscous boundary (SVB) of Lysmer and Kuhlemeyer (1969), were studied by evaluating their efficiency under free-field response. The results of the free-field analysis (i.e. the response at the top surface of the soil deposit) should almost be the same at all nodes. On the basis of this many trial analysis were carried out to determine the extent of soil deposit (70m) on either side of the building such that with boundary conditions employed, the response of the free-field analysis seems reasonable. Although both proved useful, SVB boundary condition was adopted in the model since TDOF is best suited only for onedimensional soil response (Kontoe et al. 2007).

\subsection{Selected software}

OpenSees, the Open System for Earthquake Engineering Simulation, is an open-source code developed at the Pacific Earthquake Engineering Research Center. The software is capable of simulating the response of structural and geotechnical systems subjected to earthquakes. It is an object-oriented platform that has a vast source of modelling and analysis commands for numerical simulation of static and dynamic systems. OpenSees provides for easy modelling of both structure and soil; it is also convenient for applying earthquake records and for post-processing the data. 


\subsection{The OpenSees model}

\subsubsection{Structure}

The parkade and the tower are modelled using elastic Timoshenko beam-column elements that take shear deformation into account.

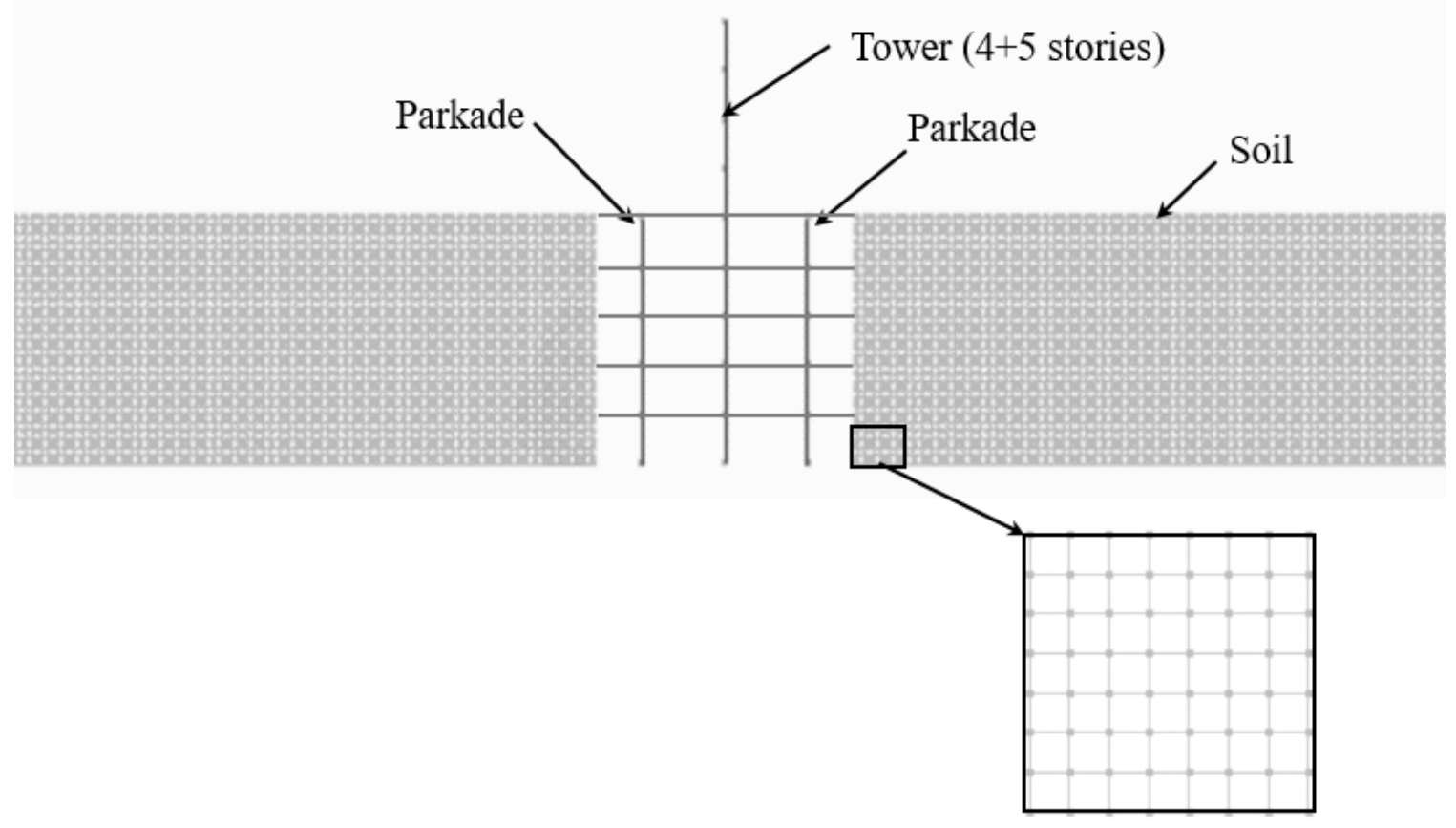

Figure 3-3 Analytical model of 9 storey building in OpenSees

For analysis, only the in-plane walls of the tower and parkade are modelled. The tower walls are $14 \mathrm{~m}$ by $0.3 \mathrm{~m}$ in size, and the parkade walls are $40 \mathrm{~m}$ by $0.2 \mathrm{~m}$ in size. As mentioned earlier, the tower is supported by a structure runs through the parkade. The parkade walls are modelled on either side of the tower, as shown in Figure 3-3. Both the tower and the parkade are fixed against rotation at the bottom. The parkade is shown at a distance from the soil for visibility, however both the soil and the parkade are rigidly connected using equalDOF command in OpenSees. 


\subsubsection{Soil}

As shown in Figure 3-3, soil elements are modelled as four-node quadrilateral elements with plane strain material behavior. The soil elements modelled are of size $0.5 \mathrm{~m} \mathrm{X} 0.5 \mathrm{~m}$ and are $70 \mathrm{~m}$ in thickness. To represent the stress-strain relationship of the soil elements, an NDmaterial object of type elastic isotropic in OpenSees is used, it requires the specification of the modulus of elasticity, the density, and the Poisson ratio as input. The shear modulus $(\mathrm{G})$ of the soil is formulated from the following equation,

$G=\rho V_{s}^{2}$

where $\rho$ is the density of the soil $\left(\mathrm{kg} / \mathrm{m}^{3}\right)$, and $V_{\mathrm{s}}$ is the shear wave velocity of the soil $(\mathrm{m} / \mathrm{s})$. For various soil shear velocities, the modulus of elasticity is calculated from the modulus of rigidity (shear modulus) and the Poisson ratio using the relationship,

$E=2 G(1+\mu)$

where $\mu$ is the Poisson ratio. Poisson ratio of 0.2 and the density of soil equal to 1920 $\mathrm{kg} / \mathrm{m}^{3}$ are used in the present study.

\subsubsection{Boundary Conditions}

The bottom boundary of the analytical model is fixed, assuming that the entire soil structure system rests on a rigid rock. The lateral boundaries are SVB of Lysmer - Kuhlemeyer (1969), as mentioned under section 3.4. At both lateral boundaries, dashpots are attached along horizontal and vertical directions to absorb shear and compression waves, respectively. The dashpots are assigned coefficients as detailed below and are modelled in OpenSees using a uniaxial viscous material command.

Coefficient of horizontal dashpot, $C_{s}=V_{s} A \rho$

Coefficient of vertical dashpot, $C_{p}=V_{p} A \rho$ 
where $V_{s}$ and $V_{p}$ are the velocities of primary and secondary waves, respectively, $A$ is the tributary area of the node and $\rho$ is the density of the soil domain.

Velocity of primary wave, $V_{p}=V_{s} \sqrt{\frac{(2-2 \mu)}{(1-2 \mu)}}$

where $\mu$ is the Poisson ratio and $V_{s}$ is the velocity of the secondary wave as defined in $\operatorname{NBCC}(2015)$.

At each boundary nodal point, two nodes each having 2 DOF's are created, one node is fixed in both $\mathrm{X}$ and $\mathrm{Y}$ direction while the other node has displacement constraints along both axes. The two nodes are then connected using zeroLength elements in OpenSees to simulate viscous dashpots. The node with the displacement constraint is connected to the soil nodes using equalDOF constraint.

\subsubsection{Damping}

As mentioned earlier, Rayleigh damping of $5 \%$ is used for the structure and the soil. To assign damping, all the structural elements and the soil elements are first grouped separately using the region command, following which damping is assigned using Rayleigh command in OpenSees.

\subsubsection{Ground motion application}

The multi support excitation command is used to apply an earthquake time history input to the model along the global X-direction.

\subsubsection{Analysis options}

An Eigen value analysis is carried out using Eigen command in OpenSees to find the first ten modes of the system. The time period of the modes found is then stored in a designated file. Direct integration time history analysis that provides response at discrete intervals of 
time is carried out using the following algorithms defined in OpenSees. A constraints handler is used to determine how the equations are enforced in the analysis, and a transformation constraint handler, that is best suited, is used to carry out the dynamic analysis. The numberer used is RCM, which defines how nodes are numbered. Numbering scheme impacts the solution efficiency. A general solution solver, Umfpack is used. The solution algorithm is Newton, which determines the sequence of steps to be taken for solving the equations. Finally, to perform the integration, Newmark integrator with a gamma value 0.5 and a beta value 0.25 is employed. Once all the above-mentioned algorithms are set, transient analysis is performed.

\subsubsection{Validation of OpenSees model}

To validate the numerical model in OpenSees, a similar model in SAP2000 is created. Both models are analyzed for Elcentro earthquake input, and the results obtained from the two are compared. SAP2000 is a structural analysis and design software that has an intuitive interface, which makes it easier for researchers to model simple 2D to complex 3D problems. A simple model of 9storey building is modelled in both OpenSees and SAP2000 with the parameters as detailed in Table 3-1.

Table 3-1 Model dimensions used in OpenSees and SAP2000

\begin{tabular}{|c|l|l|}
\hline \multirow{4}{*}{ Tower } & Dimensions & $14 \mathrm{~m} \mathrm{X} \mathrm{0.6m}$ \\
\cline { 2 - 3 } & Modulus of Elasticity $(\mathrm{E})$ & $24.9 \mathrm{GPa}$ \\
\cline { 2 - 3 } & Poisson's ratio $(\mu)$ & 0.2 \\
\hline \multirow{3}{*}{ Parkade } & Dimensions & $40 \mathrm{~m} \mathrm{X} \mathrm{0.4m}$ \\
\cline { 2 - 3 } & Modulus of Elasticity $(\mathrm{E})$ & $24.9 \mathrm{GPa}$ \\
\cline { 2 - 3 } & Poisson's ratio $(\mu)$ & 0.2 \\
\hline \multirow{4}{*}{ Soil } & Dimensions & $70 \mathrm{~m} \mathrm{X} \mathrm{70m}$ \\
\cline { 2 - 3 } & Shear wave velocity $\left(\mathrm{V}_{\mathrm{s}}\right)$ & $200 \mathrm{~m} / \mathrm{s}$ \\
\hline & Poisson's ratio $(\mu)$ & 0.2 \\
\cline { 2 - 3 } & Density $(\rho)$ & $1920 \mathrm{~kg} / \mathrm{m}^{3}$ \\
\hline
\end{tabular}


In SAP2000, the tower and the parkade are modelled as frame elements, and the soil region is modelled using shell elements. Dimensions of the tower, the parkade, and the soil elements used in the SAP model are similar to those used in OpenSees as detailed in the earlier sections of this chapter. The masses are lumped at floor levels in both the tower and the parkade. Rayleigh damping of $5 \%$ is assumed for the entire soil structure system in each software analysis. To simplify the analysis employed in this comparison study, the lateral soil boundaries are modelled as free boundaries. The analysis is direct integration time history analysis with a Newmark integrator having a gamma value of 0.5 and a beta value of 0.25 . The base shears obtained from the SAP2000 and OpenSees are both plotted against time and compared, as shown in Figure 3-4.

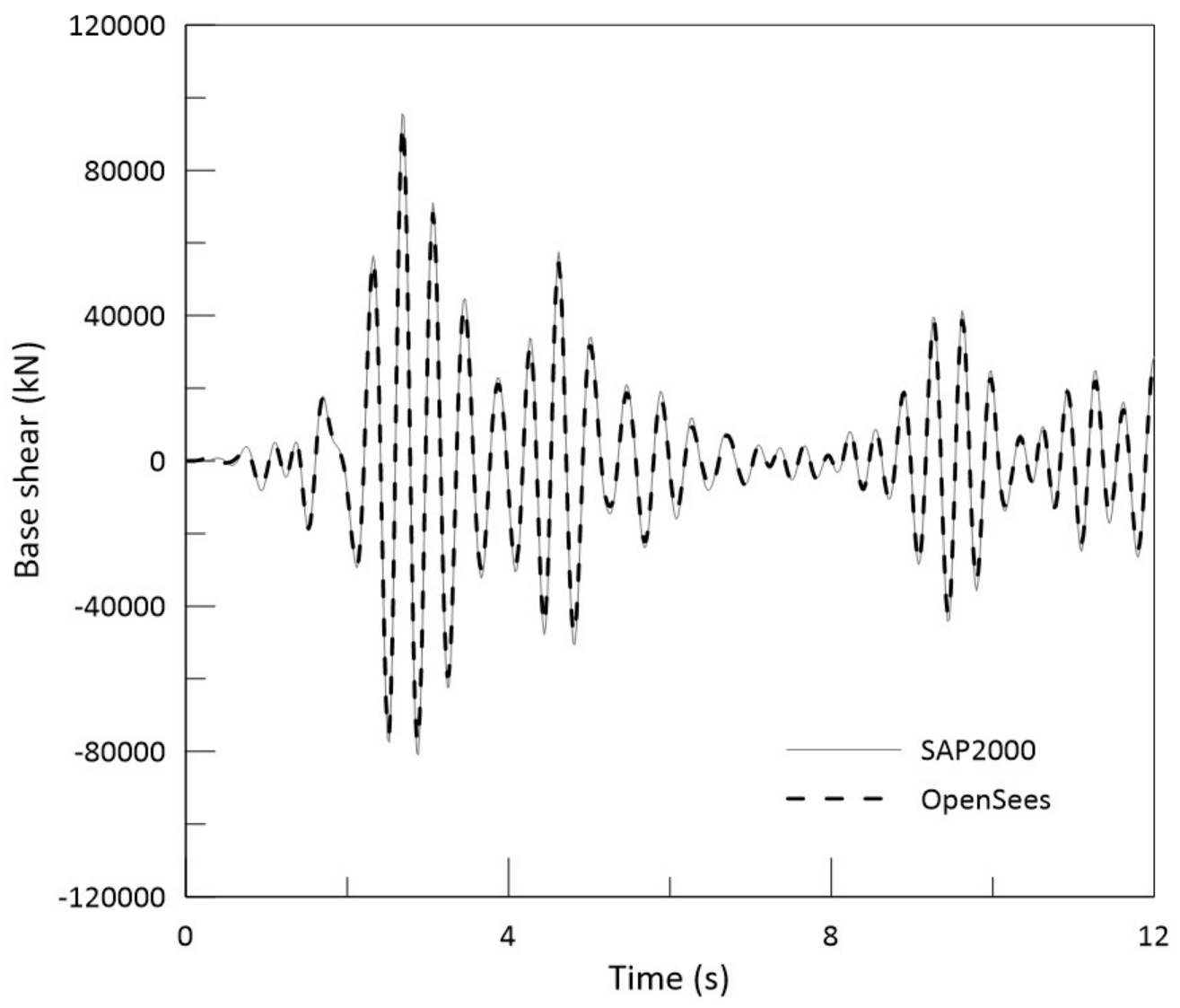

Figure 3-4 Comparison of base shear variation obtained from SAP2000 and OpenSees 
It is evident that both models predict similar time histories for base shear at tower base. The maximum base shear observed from OpenSees is $92.4 \mathrm{MN}$, while that from SAP2000 is $95.6 \mathrm{MN}$. The percentage error between the two is approximately $3.3 \%$ that could be attributed to the difference in the formulation of soil elements since the elements are shell elements in SAP2000 and quad elements in OpenSees. However, the close match between the results obtained from two different finite element software using similar modelling properties serves as a validation for both.

\subsection{Parametric study}

As stated earlier, the purpose of the study is to evaluate the seismic response of multistorey buildings with a deep underground structure. To make the research valid over a wide range of buildings and properties of the surrounding soil, five different buildings with 4,8 , 12,16 , and 20 storey towers situated above an underground parkade of 5 storeys and several different soil properties are analyzed. Details are shown in Table 3-2.

Table 3-2 Cases analyzed for the parameter study

\begin{tabular}{|c|c|c|}
\hline Case No: & Buildings height & $\begin{array}{l}\text { Soil shear wave velocities } \\
(\mathrm{m} / \mathrm{s})\end{array}$ \\
\hline $\mathrm{I}$ & $\begin{array}{l}9 \text { Storey building (4 storey } \\
\text { tower }+5 \text { storey parkade) }\end{array}$ & $\begin{array}{l}\mathrm{Vs}=100,150,200,300,450 \\
600,850, \text { and } 1000\end{array}$ \\
\hline II & $\begin{array}{l}13 \text { Storey building ( } 8 \text { storey } \\
\text { tower }+5 \text { storey parkade) }\end{array}$ & $\begin{array}{l}\mathrm{Vs}=100,150,200,300,450 \\
600,850, \text { and } 1000\end{array}$ \\
\hline III & $\begin{array}{l}17 \text { Storey building (12 storey } \\
\text { tower }+5 \text { storey parkade) }\end{array}$ & $\begin{array}{l}\mathrm{Vs}=100,150,200,300,450 \\
600,850, \text { and } 1000\end{array}$ \\
\hline IV & $\begin{array}{l}21 \text { Storey building (16 storey } \\
\text { tower }+5 \text { storey parkade) }\end{array}$ & $\begin{array}{l}\mathrm{Vs}=100,150,200,300,450 \\
600,850, \text { and } 1000\end{array}$ \\
\hline $\mathrm{V}$ & $\begin{array}{l}25 \text { Storey building (20 storey } \\
\text { tower }+5 \text { storey parkade) }\end{array}$ & $\begin{array}{l}V_{s}=100,150,200,300,450, \\
600,850, \text { and } 1000\end{array}$ \\
\hline
\end{tabular}


After modelling the buildings as detailed in the previous sections, the buildings are subjected to 11 earthquake input motions that are scaled to match Vancouver site B spectrum (refer to Section 3.3) acting in a direction parallel to the X-axis.

\subsection{Modal analysis}

An eigenvalue analysis is carried out in both SAP and OpenSees to determine the vibration periods of the building. Three different cases are considered, model of the structure by itself, model of a soil block extending from rock to the ground, and a model of the structure and the soil. The modal analysis in SAP2000 also provides the modal participation factors. Determination of these factors by OpenSees is more complicated and is not attempted. The results obtained from modal analysis of the building models and soil properties considered are detailed in the following sections. For all cases, vibration periods of the first five modes are listed. In the few instances, when higher modes contribute more to the response, vibration periods are recorded until the modes having the highest modal participation are reached.

\subsubsection{Modal analysis results for the soil alone model}

In the modal analyses soil elements are modelled as quad elements in OpenSees and shell elements in SAP2000. Soil properties are varied as shown in Table 3-2 The vibration periods, and modal participation factors obtained from the analyses are given in Table 3-3 to Table 3-10. For comparison, the theoretical modal periods of the soil as calculated from the following formula (Kramer, 1996) are also shown in these tables,

$$
T_{n}=\frac{4 H}{(2 n-1) V_{s}}
$$


where $\mathrm{H}$ is the height of the soil deposit $(\mathrm{m}), \mathrm{V}_{\mathrm{s}}$ is the shear wave velocity of the soil $(\mathrm{m} / \mathrm{s})$, and $\mathrm{n}$ is the number of the mode under consideration. From the Table 3-4 to Table 3-10, it is observed that for the first mode the theoretical and analytical periods are approximately the same. Higher modes do not compare well

Table 3-3 Modal periods of soil deposit with $\mathrm{Vs}=100 \mathrm{~m} / \mathrm{s}$

\begin{tabular}{|c|c|c|c|c|}
\hline \multirow{2}{*}{ Mode } & \multicolumn{3}{|c|}{ Modal period (s) } & \multirow{2}{*}{$\begin{array}{c}\text { Modal } \\
\text { participation } \\
\text { factor, Ux }\end{array}$} \\
\cline { 2 - 4 } & Theoretical & OpenSees & SAP & 0.750 \\
\hline 1 & 0.600 & 0.651 & 0.654 & 0.047 \\
\hline 2 & 0.200 & 0.559 & 0.400 & 0.014 \\
\hline 3 & 0.120 & 0.392 & 0.377 & 0.009 \\
\hline 4 & 0.086 & 0.369 & 0.333 & 0.014 \\
\hline 5 & 0.067 & 0.367 & 0.293 & \\
\hline
\end{tabular}

Table 3-4 Modal periods of soil deposit with $\mathrm{Vs}=150 \mathrm{~m} / \mathrm{s}$

\begin{tabular}{|c|c|c|c|c|}
\hline \multirow{2}{*}{ Mode } & \multicolumn{3}{|c|}{ Modal period (s) } & \multirow{2}{*}{$\begin{array}{c}\text { Modal } \\
\text { participation } \\
\text { factor, Ux }\end{array}$} \\
\cline { 2 - 4 } & Theoretical & OpenSees & SAP & 0.750 \\
\hline 1 & 0.400 & 0.434 & 0.435 & 0.047 \\
\hline 2 & 0.133 & 0.372 & 0.267 & 0.014 \\
\hline 3 & 0.080 & 0.262 & 0.252 & 0.009 \\
\hline 4 & 0.057 & 0.246 & 0.222 & 0.014 \\
\hline 5 & 0.044 & 0.244 & 0.195 & \\
\hline
\end{tabular}

Table 3-5 Modal periods of soil deposit with $\mathrm{Vs}=200 \mathrm{~m} / \mathrm{s}$

\begin{tabular}{|c|c|c|c|c|}
\hline \multirow{2}{*}{ Mode } & \multicolumn{3}{|c|}{ Modal period (s) } & \multirow{2}{*}{$\begin{array}{c}\text { Modal } \\
\text { participation } \\
\text { factor, Ux }\end{array}$} \\
\cline { 2 - 5 } & Theoretical & OpenSees & SAP & 0.750 \\
\hline 1 & 0.300 & 0.326 & 0.327 & 0.047 \\
\hline 2 & 0.100 & 0.280 & 0.200 & 0.014 \\
\hline 3 & 0.060 & 0.196 & 0.189 & 0.009 \\
\hline 4 & 0.043 & 0.185 & 0.166 & 0.014 \\
\hline 5 & 0.033 & 0.183 & 0.146 & \\
\hline
\end{tabular}


Table 3-6 Modal period of soil deposit with Vs $=300 \mathrm{~m} / \mathrm{s}$

\begin{tabular}{|c|c|c|c|c|}
\hline \multirow{2}{*}{ Mode } & \multicolumn{3}{|c|}{ Modal period (s) } & $\begin{array}{c}\text { Modal } \\
\text { participation } \\
\text { factor, Ux }\end{array}$ \\
\cline { 2 - 4 } & Theoretical & OpenSees & SAP & 0.750 \\
\hline 1 & 0.200 & 0.217 & 0.218 & 0.047 \\
\hline 2 & 0.067 & 0.186 & 0.133 & 0.014 \\
\hline 3 & 0.040 & 0.131 & 0.126 & 0.009 \\
\hline 4 & 0.029 & 0.123 & 0.111 & 0.014 \\
\hline 5 & 0.022 & 0.122 & 0.098 & \\
\hline
\end{tabular}

Table 3-7 Modal periods of soil deposit with $\mathrm{Vs}=450 \mathrm{~m} / \mathrm{s}$

\begin{tabular}{|c|c|c|c|c|}
\hline \multirow{2}{*}{ Mode } & \multicolumn{3}{|c|}{ Modal period (s) } & $\begin{array}{c}\text { Modal } \\
\text { participation } \\
\text { factor, Ux }\end{array}$ \\
\cline { 2 - 4 } & Theoretical & OpenSees & SAP & 0.750 \\
\hline 1 & 0.133 & 0.145 & 0.145 & 0.047 \\
\hline 2 & 0.044 & 0.124 & 0.089 & 0.014 \\
\hline 3 & 0.027 & 0.087 & 0.084 & 0.009 \\
\hline 4 & 0.019 & 0.082 & 0.074 & 0.014 \\
\hline 5 & 0.015 & 0.081 & 0.065 & \\
\hline
\end{tabular}

Table 3-8 Modal periods of soil deposit with $\mathrm{Vs}=600 \mathrm{~m} / \mathrm{s}$

\begin{tabular}{|c|c|c|c|c|}
\hline \multirow{2}{*}{ Mode } & \multicolumn{3}{|c|}{ Modal period (s) } & $\begin{array}{c}\text { Modal } \\
\text { participation } \\
\text { factor, Ux }\end{array}$ \\
\cline { 2 - 4 } & Theoretical & OpenSees & SAP & 0.750 \\
\hline 1 & 0.100 & 0.109 & 0.109 & 0.047 \\
\hline 2 & 0.033 & 0.093 & 0.067 & 0.014 \\
\hline 3 & 0.020 & 0.065 & 0.063 & 0.009 \\
\hline 4 & 0.014 & 0.061 & 0.055 & 0.014 \\
\hline 5 & 0.011 & 0.061 & 0.049 & \\
\hline
\end{tabular}


Table 3-9 Modal periods of soil deposit with $\mathrm{Vs}=850 \mathrm{~m} / \mathrm{s}$

\begin{tabular}{|c|c|c|c|c|}
\hline \multirow{2}{*}{ Mode } & \multicolumn{3}{|c|}{ Modal period (s) } & \multirow{2}{*}{$\begin{array}{c}\text { Modal } \\
\text { participation } \\
\text { factor, Ux }\end{array}$} \\
\cline { 2 - 4 } & Theoretical & OpenSees & SAP & 0.750 \\
\hline 1 & 0.071 & 0.077 & 0.077 & 0.047 \\
\hline 2 & 0.024 & 0.066 & 0.047 & 0.014 \\
\hline 3 & 0.014 & 0.046 & 0.044 & 0.009 \\
\hline 4 & 0.010 & 0.043 & 0.039 & 0.014 \\
\hline 5 & 0.008 & 0.043 & 0.034 & \\
\hline
\end{tabular}

Table 3-10 Modal periods of soil deposit with $\mathrm{Vs}=1000 \mathrm{~m} / \mathrm{s}$

\begin{tabular}{|c|c|c|c|c|}
\hline \multirow{2}{*}{ Mode } & \multicolumn{3}{|c|}{ Modal period (s) } & $\begin{array}{c}\text { Modal } \\
\text { participation } \\
\text { factor, Ux }\end{array}$ \\
\cline { 2 - 5 } & Theoretical & OpenSees & SAP & 0.750 \\
\hline 1 & 0.060 & 0.065 & 0.065 & 0.047 \\
\hline 2 & 0.020 & 0.056 & 0.040 & 0.014 \\
\hline 3 & 0.012 & 0.039 & 0.038 & 0.009 \\
\hline 4 & 0.009 & 0.037 & 0.033 & 0.014 \\
\hline 5 & 0.007 & 0.037 & 0.039 & \\
\hline
\end{tabular}

\subsubsection{Results of the Modal analysis of 9-storey building model}

The vibration periods of the 9 storey building analyzed both with and without the surrounding soil are reported in this section. The soil is modelled by quad/shell elements. Several different shear velocities such as 100, 150, 200, 300, 450, 600, 850 and $1000 \mathrm{~m} / \mathrm{s}$ are considered for the soil. The corresponding modulus of rigidity $G$ and modulus of elasticity E are obtained from Equations, 3.1 and 3.2, respectively. 
Table 3-11 Modal periods of the 9 storey building without soil

\begin{tabular}{|c|c|c|c|}
\hline \multirow{2}{*}{ Mode } & \multicolumn{2}{|c|}{ Modal period (s) } & Modal participation \\
& OpenSees & SAP & 0.582 \\
\hline 1 & 0.449 & 0.449 & 0.318 \\
\hline 2 & 0.236 & 0.236 & 0.036 \\
\hline 3 & 0.109 & 0.109 & 0.038 \\
\hline 4 & 0.090 & 0.090 & 0.005 \\
\hline 5 & 0.066 & 0.066 & \\
\hline
\end{tabular}

Table 3-12 Modal periods of the 9 storey building with soil Vs $=100 \mathrm{~m} / \mathrm{s}$

\begin{tabular}{|c|c|c|c|}
\hline \multirow{2}{*}{ Mode } & \multicolumn{2}{|c|}{ Modal period (s) } & \multirow{2}{*}{$\begin{array}{c}\text { Modal participation } \\
\text { factor, Ux }\end{array}$} \\
\cline { 2 - 3 } & OpenSees & SAP & 0.660 \\
\hline 1 & 0.627 & 0.630 & 0.100 \\
\hline 2 & 0.618 & 0.528 & 0.017 \\
\hline 3 & 0.521 & 0.413 & 0.021 \\
\hline 4 & 0.455 & 0.378 & 0.001 \\
\hline 5 & 0.408 & 0.368 & \\
\hline
\end{tabular}

Table 3-13 Modal periods of the 9 storey building with soil $\mathrm{Vs}=150 \mathrm{~m} / \mathrm{s}$

\begin{tabular}{|c|c|c|c|}
\hline \multirow{2}{*}{ Mode } & \multicolumn{2}{|c|}{ Modal period (s) } & \multirow{2}{*}{$\begin{array}{c}\text { Modal participation } \\
\text { factor, Ux }\end{array}$} \\
\cline { 2 - 3 } & OpenSees & SAP & 0.610 \\
\hline 1 & 0.438 & 0.439 & 0.093 \\
\hline 2 & 0.412 & 0.402 & 0.067 \\
\hline 3 & 0.398 & 0.333 & 0.023 \\
\hline 4 & 0.330 & 0.263 & 0.0002 \\
\hline 5 & 0.304 & 0.254 & \\
\hline
\end{tabular}

Table 3-14 Modal periods of the 9 storey building with soil Vs $=200 \mathrm{~m} / \mathrm{s}$

\begin{tabular}{|c|c|c|c|}
\hline \multirow{2}{*}{ Mode } & \multicolumn{2}{|c|}{ Modal period (s) } & \multirow{2}{*}{$\begin{array}{c}\text { Modal participation } \\
\text { factor, Ux }\end{array}$} \\
\cline { 2 - 3 } & OpenSees & SAP & 0.140 \\
\hline 1 & 0.389 & 0.390 & 0.590 \\
\hline 2 & 0.315 & 0.317 & 0.030 \\
\hline 3 & 0.309 & 0.274 & 0.034 \\
\hline 4 & 0.271 & 0.202 & 0.0001 \\
\hline 5 & 0.228 & 0.190 & \\
\hline
\end{tabular}


Table 3-15 Modal periods of the 9 storey building with soil $\mathrm{Vs}=300 \mathrm{~m} / \mathrm{s}$

\begin{tabular}{|c|c|c|c|}
\hline \multirow{2}{*}{ Mode } & \multicolumn{2}{|c|}{ Modal period (s) } & Modal participation \\
& OpenSees & SAP & factor, Ux \\
\hline & 0.367 & 0.367 & 0.035 \\
\hline 2 & 0.218 & 0.219 & 0.710 \\
\hline 3 & 0.206 & 0.193 & 0.005 \\
\hline 4 & 0.190 & 0.137 & 0.046 \\
\hline 5 & 0.152 & 0.126 & 0.015 \\
\hline
\end{tabular}

Table 3-16 Modal periods of the 9 storey building with soil Vs $=450 \mathrm{~m} / \mathrm{s}$

\begin{tabular}{|c|c|c|c|}
\hline \multirow{2}{*}{ Mode } & \multicolumn{2}{|c|}{ Modal period (s) } & \multirow{2}{*}{$\begin{array}{c}\text { Modal participation } \\
\text { factor, Ux }\end{array}$} \\
\cline { 2 - 3 } & OpenSees & SAP & 0.017 \\
\hline 1 & 0.356 & 0.357 & 0.670 \\
\hline 2 & 0.150 & 0.151 & 0.056 \\
\hline 3 & 0.137 & 0.131 & 0.013 \\
\hline 4 & 0.130 & 0.106 & 0.045 \\
\hline 5 & 0.105 & 0.091 & \\
\hline
\end{tabular}

Table 3-17 Modal periods of the 9 storey building with soil Vs $=600 \mathrm{~m} / \mathrm{s}$

\begin{tabular}{|c|c|c|c|}
\hline \multirow{2}{*}{ Mode } & \multicolumn{2}{|c|}{ Modal period (s) } & Modal participation \\
& OpenSees & SAP & factor, Ux \\
\cline { 2 - 3 } & 0.352 & 0.352 & 0.013 \\
\hline 1 & 0.116 & 0.116 & 0.500 \\
\hline 2 & 0.104 & 0.105 & 0.220 \\
\hline 3 & 0.103 & 0.097 & 0.013 \\
\hline 4 & 0.096 & 0.069 & 0.049 \\
\hline
\end{tabular}

Table 3-18 Modal periods of 9 storey building with soil Vs $=850 \mathrm{~m} / \mathrm{s}$

\begin{tabular}{|c|c|c|c|}
\hline \multirow{2}{*}{ Mode } & \multicolumn{2}{|c|}{ Modal period (s) } & Modal participation \\
& OpenSees & SAP & 0.011 \\
\cline { 2 - 3 } & 0.349 & 0.349 & 0.014 \\
\hline 1 & 0.105 & 0.106 & 0.080 \\
\hline 2 & 0.080 & 0.070 & 0.001 \\
\hline 4 & 0.073 & 0.066 & 0.001 \\
\hline 5 & 0.069 & 0.053 & \\
\hline
\end{tabular}


Table 3-19 Modal periods of 9 storey building with soil Vs $=1000 \mathrm{~m} / \mathrm{s}$

\begin{tabular}{|c|c|c|c|}
\hline \multirow{2}{*}{ Mode } & \multicolumn{2}{|c|}{ Modal period (s) } & Modal participation \\
& OpenSees & SAP & 0.010 \\
\hline & 0.348 & 0.348 & 0.006 \\
\hline 2 & 0.105 & 0.105 & 0.520 \\
\hline 3 & 0.069 & 0.069 & 0.140 \\
\hline 4 & 0.065 & 0.065 & 0.066 \\
\hline 5 & 0.062 & 0.059 & \\
\hline
\end{tabular}

The vibration periods of the other building configurations were also analyzed with and the surrounding soil. Different soil properties are considered as in the case of the 9-storey building. The results of those analysis are presented in Appendix A.

The results presented here show that analyses of the structure by itself using SAP and OpenSees give essentially identical values for all periods. The analyses for structure along with the soil using the two programs also give very close values for most of the lower modes. In some cases, the periods obtained from the two programs show some divergence for the higher modes. This could be attributed to the use of different finite element models used for soil by the two program, shell elements in SAP and quad elements in OpenSees.

\subsection{Dynamic analysis}

To study the seismic response of multi-storey buildings with below grade structures a series of dynamic time history analyses are carried out. The building models are described in Sections 3.2 and 3.4 , and the ground motions used as input to the time history analyses are presented in Section 3.3. The storey shears, storey moments, displacements, drifts, and the accelerations are recorded for each building height and for varying soil properties for all 11 earthquake inputs. An objective of the study is to evaluate the traditional approach in which the structure is analyzed with a fixed base ignoring the effect of soil structure 
interaction. To study this, the mean of the response of the structure and the soil is compared to the mean of the response of the structure alone. Since, in most cases the response in the storey just above the junction of the tower and the parkade, referred to as the base storey, is critical, the effect of the interaction on such response is presented in the form of magnification of the response of the structure and soil when compared with the response of the structure alone. The magnification factors observed for in the base storey of the tower are plotted to quantify the effect of soil structure interaction on the seismic response of the structures. Detailed outputs of storey shear, storey moment, displacement, drift, and acceleration observed for each earthquake input considered in the analysis are shown in Appendix B. The mean values of the results for each tower height considered are presented in the following section.

\subsubsection{Results of dynamic analysis}

The means of the responses from 11 earthquakes are presented in this section. In the following discussion, shear refers to the shear over a storey (for example, shear against storey 6 is the shear throughout the entire storey including its lower end which is the base of the tower, below this shear from the tower gets transferred to the parkade walls through rigid diaphragm), moment is the moment at the bottom of a storey, and accelerations and displacements are measured at the top of the storey. All values are mean of the peaks recorded in the time history of response. For each building the values reported are for the tower and its supporting structure. The response in the parkade has not been reported except for the storey shear response. Figure 3-5 is a plot of storey shears for different shear wave velocities in the soil for a building with 4 storey tower and its supporting structure (i.e., the 9-storey building). Figure 3-6 is a similar plot for the moment at the bottom of each storeys. 
It is evident from these plots that softer soils such as those having shear velocities of $100 \mathrm{~m} / \mathrm{s}, 150 \mathrm{~m} / \mathrm{s}, 200 \mathrm{~m} / \mathrm{s}$ and $300 \mathrm{~m} / \mathrm{s}$ lead to higher values of storey shears and storey moments as compared to those for building alone.

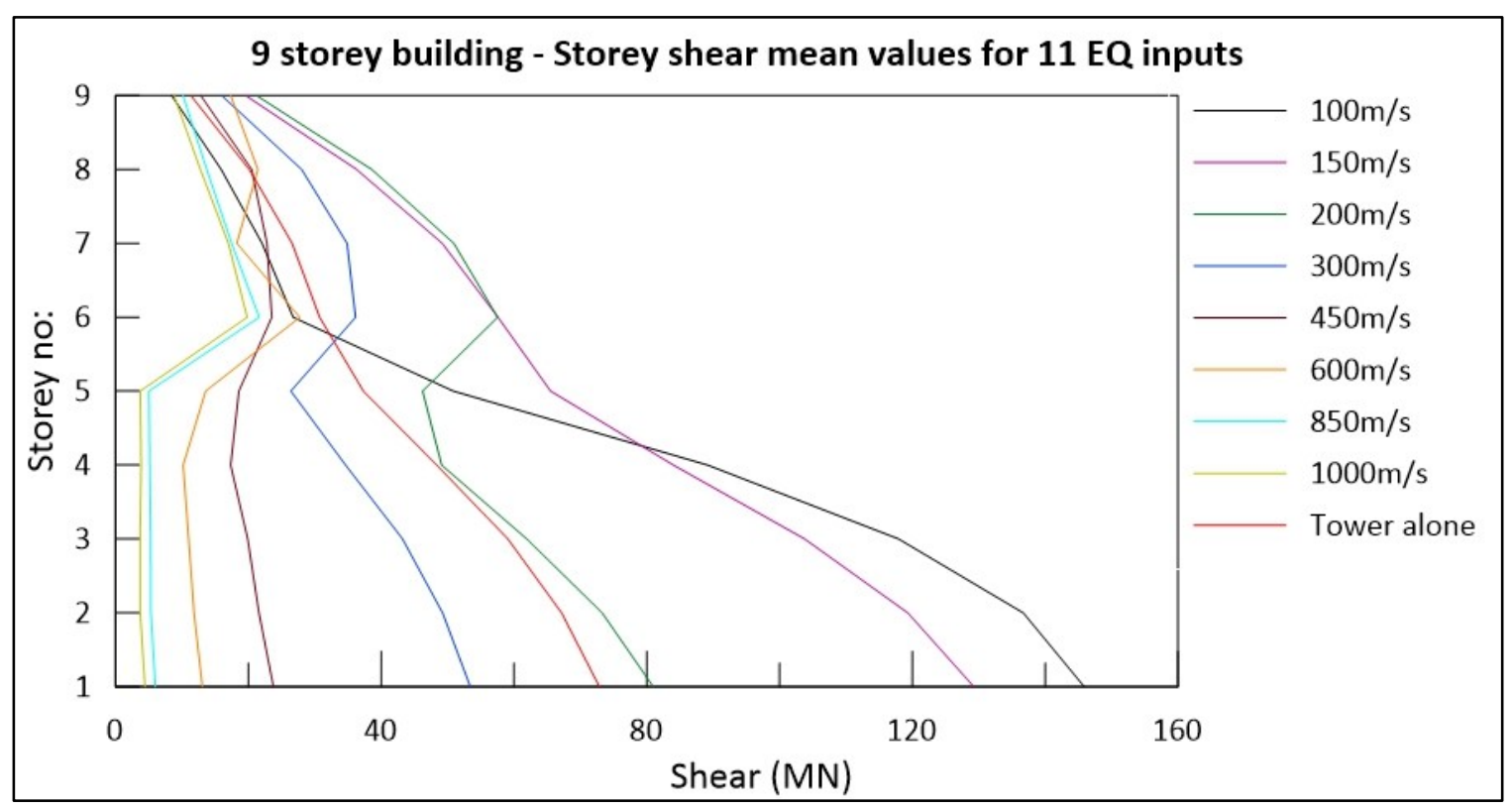

Figure 3-5 Storey shear, mean values for the 9 storey building

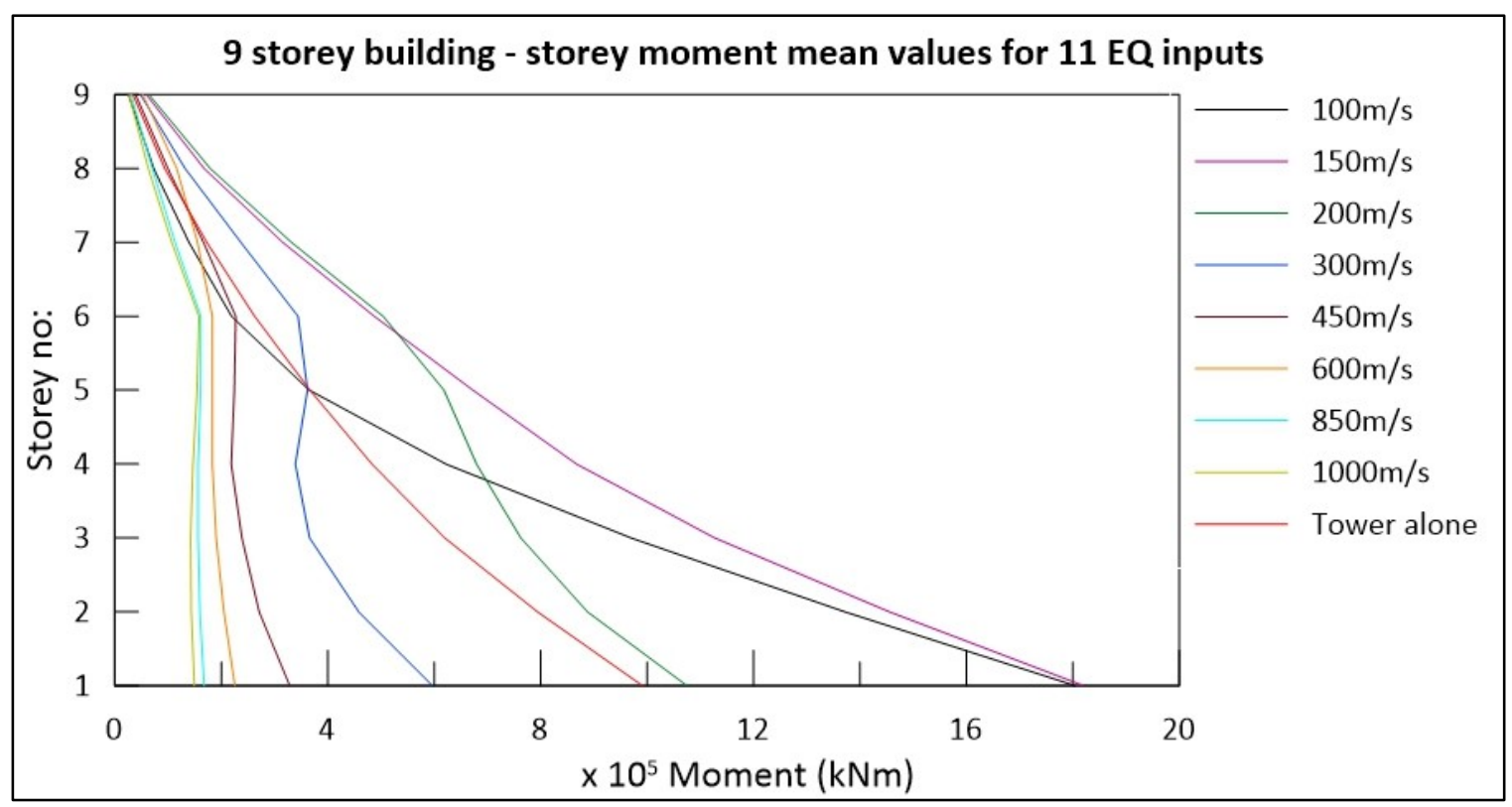

Figure 3-6 Mean moment at the bottom of a storey for 9 storey building 


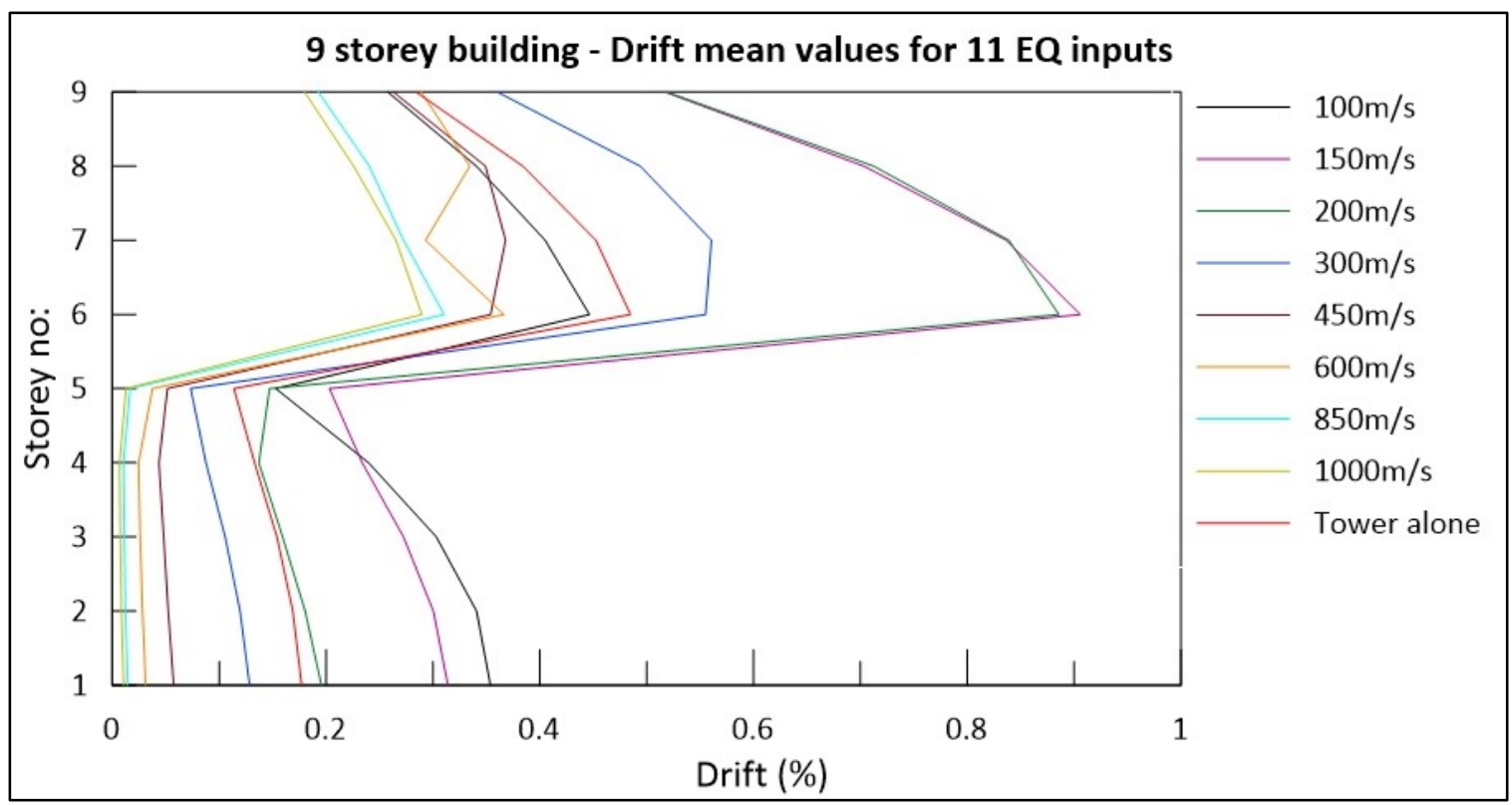

Figure 3-7 Storey drift, mean values for the 9 storey building

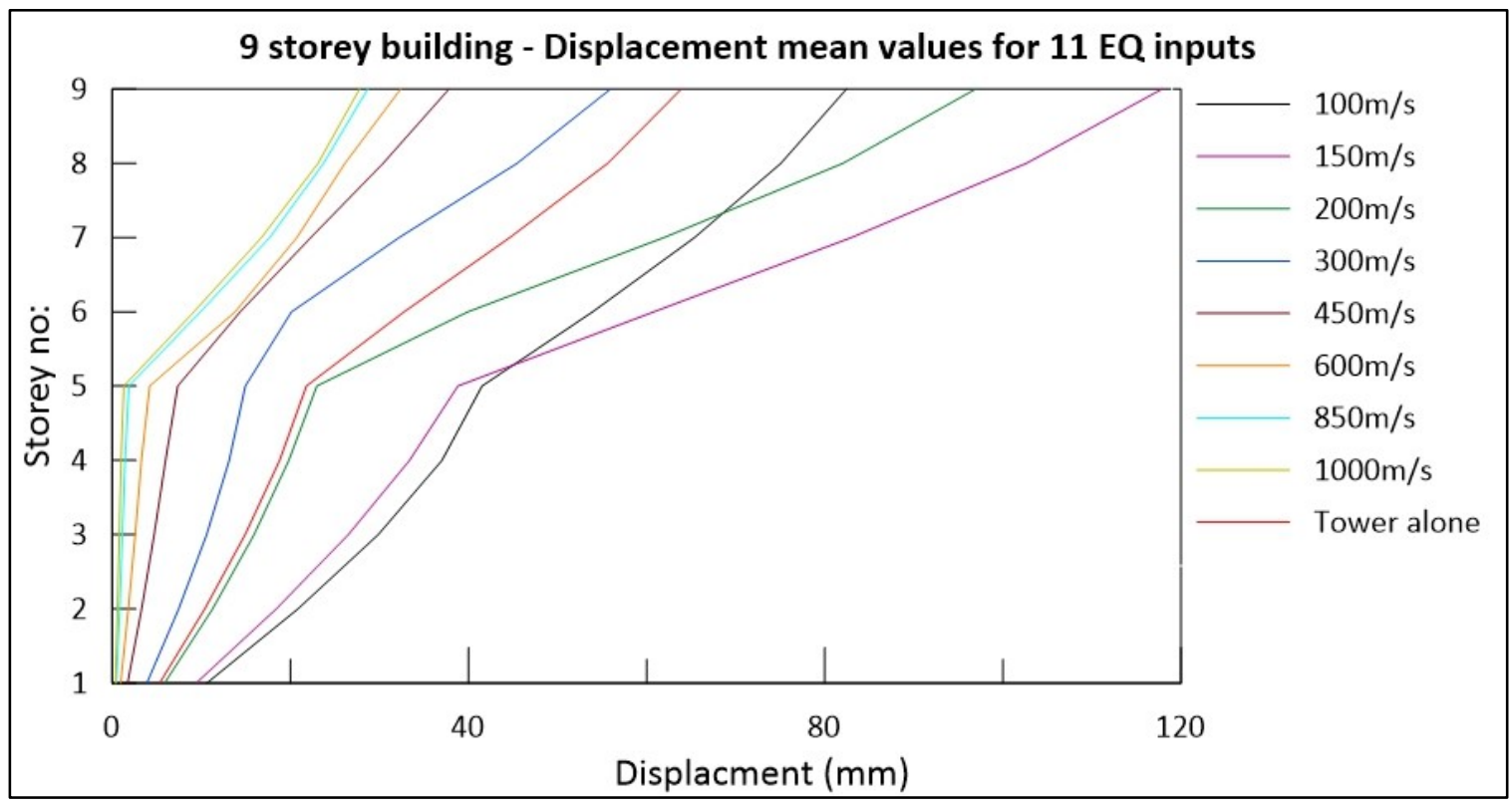

Figure 3-8 Displacement at the top of a storey, mean values for 9 storey building

For 4 storey tower (Figure 3-5 and Figure 3-6), maximum magnification in base shear and base moment is observed for the case when the structure is analyzed with soil having shear wave velocity of $150 \mathrm{~m} / \mathrm{s}$ (site class $\mathrm{E}$ as per NBCC 2015). The second highest 
magnification is observed for soil shear wave velocity of $200 \mathrm{~m} / \mathrm{s}$ (near lower borderline of site class D as per NBCC 2015).

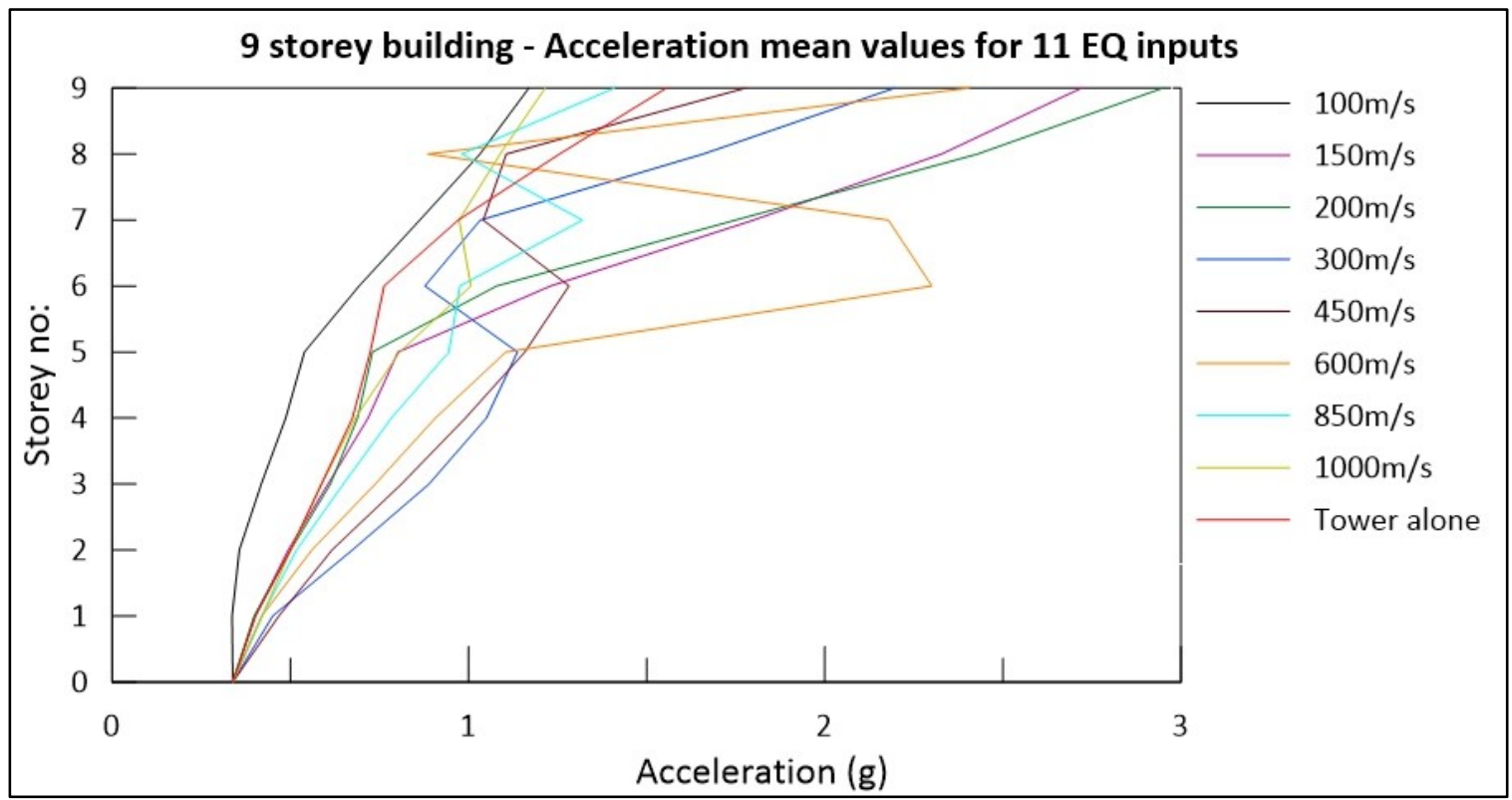

Figure 3-9 Acceleration at the top of a storey, mean values for the 9 storey building

A similar trend, as in the case of storey shear magnification is observed for storey drifts. It is seen from the data presented in Figure 3-7 that the structure surrounded by soil having a shear wave velocity of $150 \mathrm{~m} / \mathrm{s}$ has the highest magnification followed by the structure with soil having shear wave velocity of $200 \mathrm{~m} / \mathrm{s}$. For storey displacement, maximum magnification is observed for the case with a soil shear wave velocity of $150 \mathrm{~m} / \mathrm{s}$ (Figure 3-8). However, for the below-ground structure, maximum magnification is observed when the shear wave velocity in the soil is $100 \mathrm{~m} / \mathrm{s}$. As seen from Figure 3-9, structure analyzed with $600 \mathrm{~m} / \mathrm{s}$ shear wave velocity soil has the highest acceleration at the tower base followed by the structure with soil having $100 \mathrm{~m} / \mathrm{s}$ shear wave velocity.

Figure 3-10 to Figure 3-14 display the response of 8 storey tower and its supporting structure. It is evident from Figure 3-10 and Figure 3-11 that soils having shear wave 
velocities of $100 \mathrm{~m} / \mathrm{s}, 150 \mathrm{~m} / \mathrm{s}, 200 \mathrm{~m} / \mathrm{s}, 300 \mathrm{~m} / \mathrm{s}$, and $450 \mathrm{~m} / \mathrm{s}$ lead to higher values of shears and moments at the bottom of the tower as compared to those for building alone.

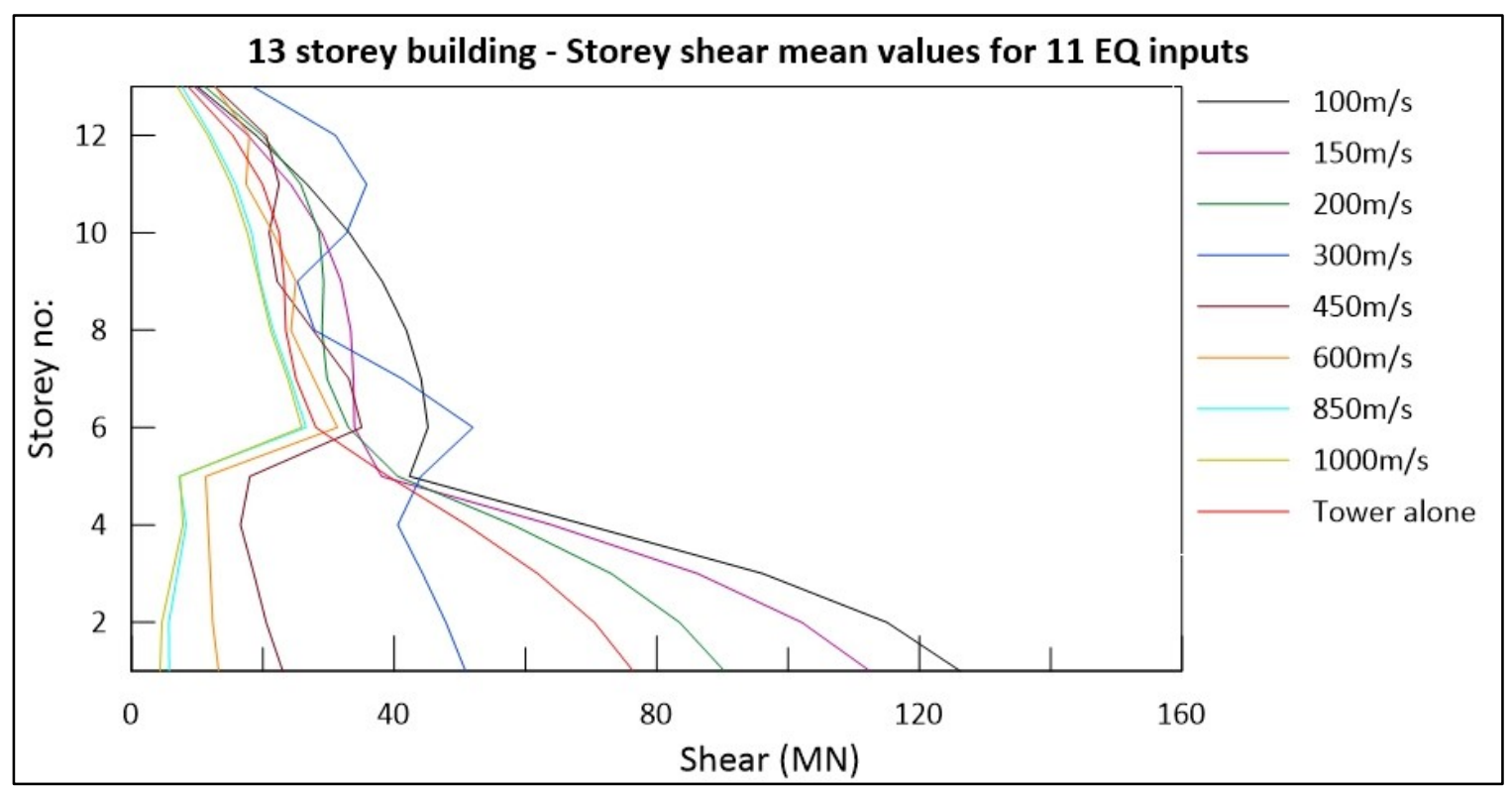

Figure 3-10 Storey shear, mean values for the 13 storey building

From the above figure, it is evident that for 13 storey building with soil having shear velocities such as $100 \mathrm{~m} / \mathrm{s}$ (site class E), $150 \mathrm{~m} / \mathrm{s}$ (site class E), $200 \mathrm{~m} / \mathrm{s}$ (near the lower borderline of site class D), $300 \mathrm{~m} / \mathrm{s}$ (near the upper borderline of site class D), and $450 \mathrm{~m} / \mathrm{s}$ (middle of site class C) have higher values of storey shear and storey moment when compared with that in the building alone. Structure with soil having shear wave velocity of $300 \mathrm{~m} / \mathrm{s}$ has the highest magnification in base shear, followed by the structure with 100 $\mathrm{m} / \mathrm{s}$ shear wave velocity soil. The maximum magnifications of storey shears in the parkade are observed with $100 \mathrm{~m} / \mathrm{s}$ shear wave velocity soil. For moments at the base of the tower, the trend is similar to that for shear, soils described above lead to higher base moments (Figure 3-11). The highest magnification in the base moment is observed for the structure with $100 \mathrm{~m} / \mathrm{s}$ shear wave velocity soil followed by the structure with $150 \mathrm{~m} / \mathrm{s}$ shear wave velocity soil. 


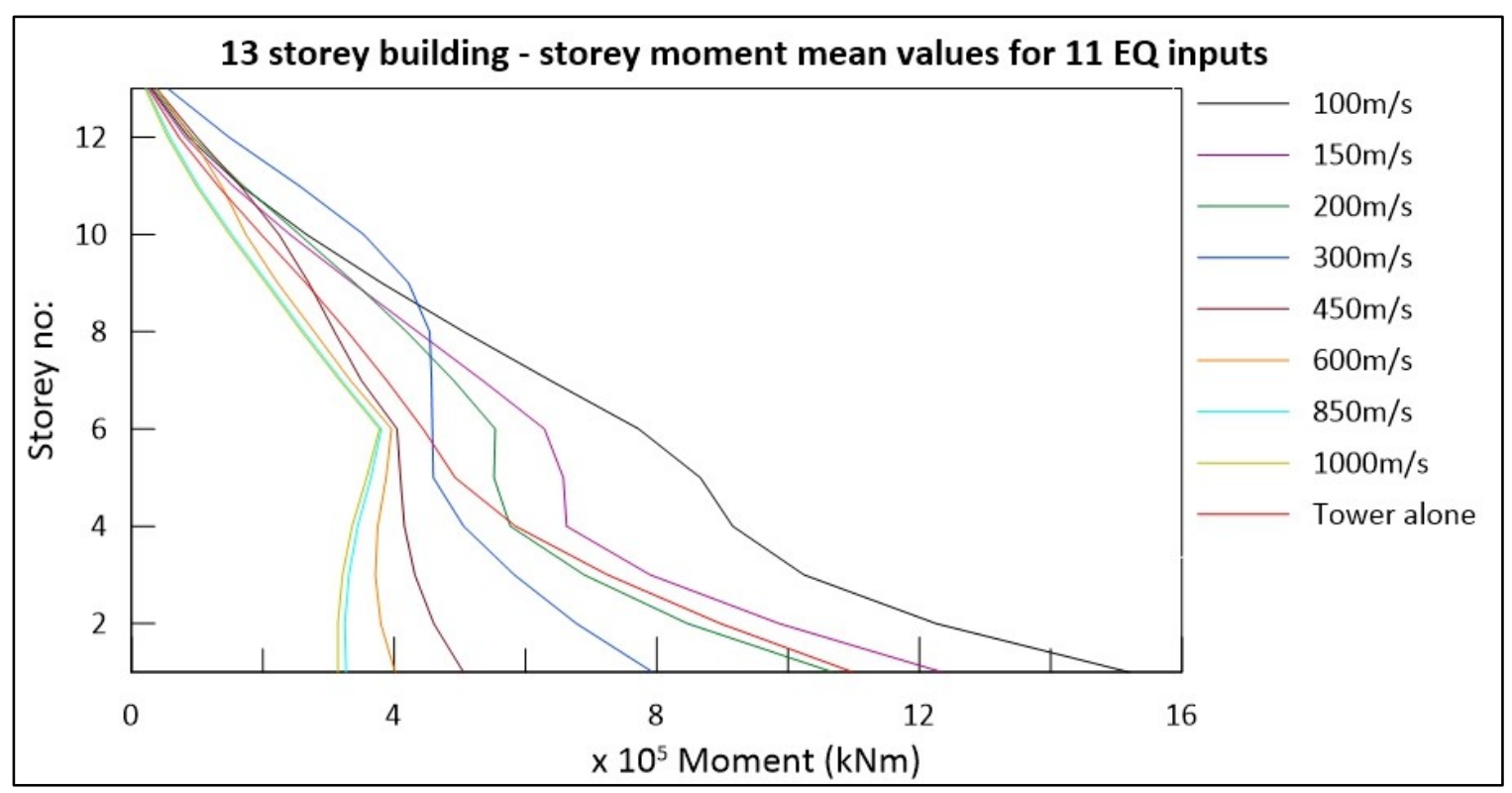

Figure 3-11 Mean moment at the bottom of a storey for 13 storey building

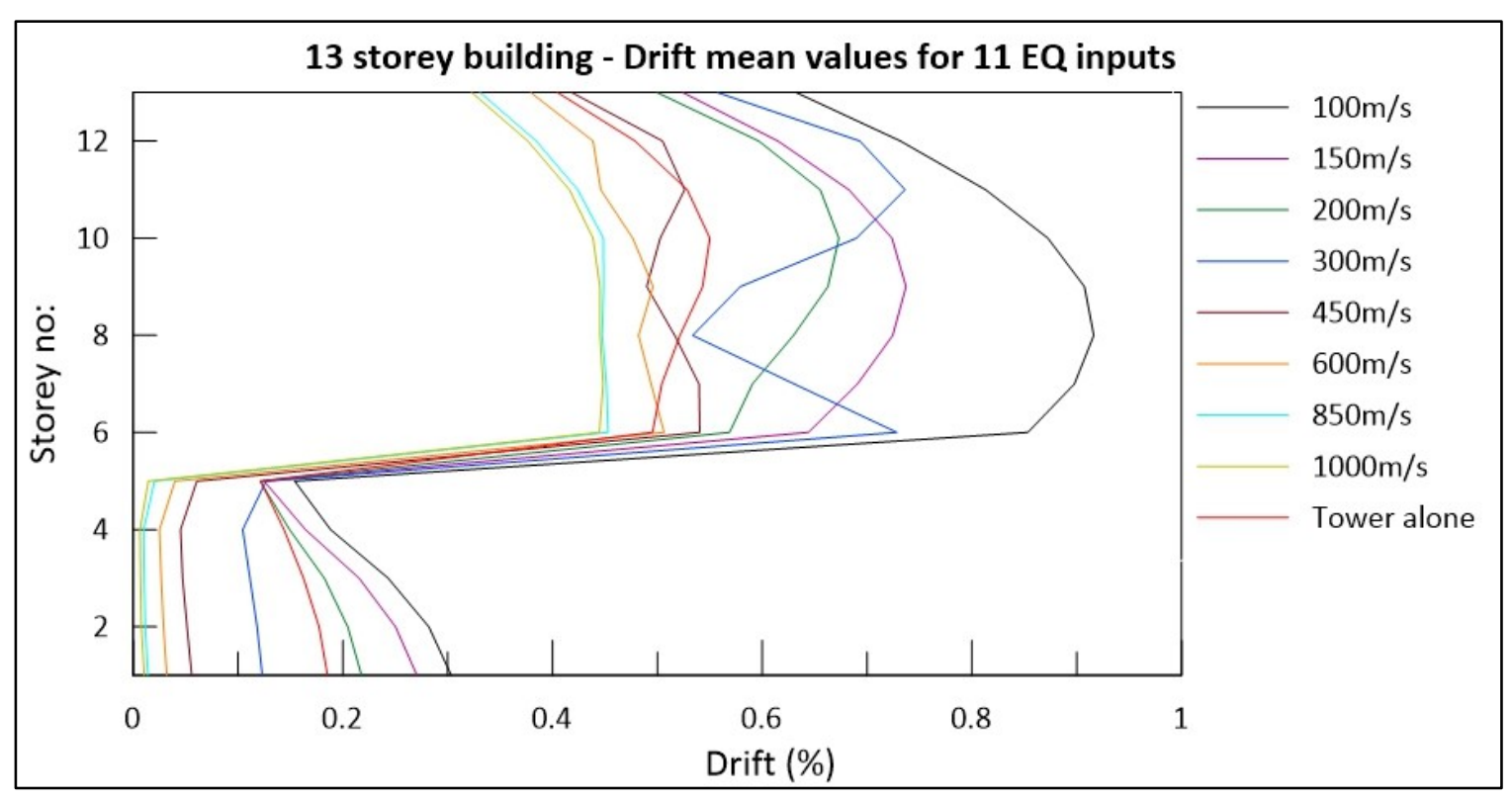

Figure 3-12 Storey drift, mean values for the 13 storey building 


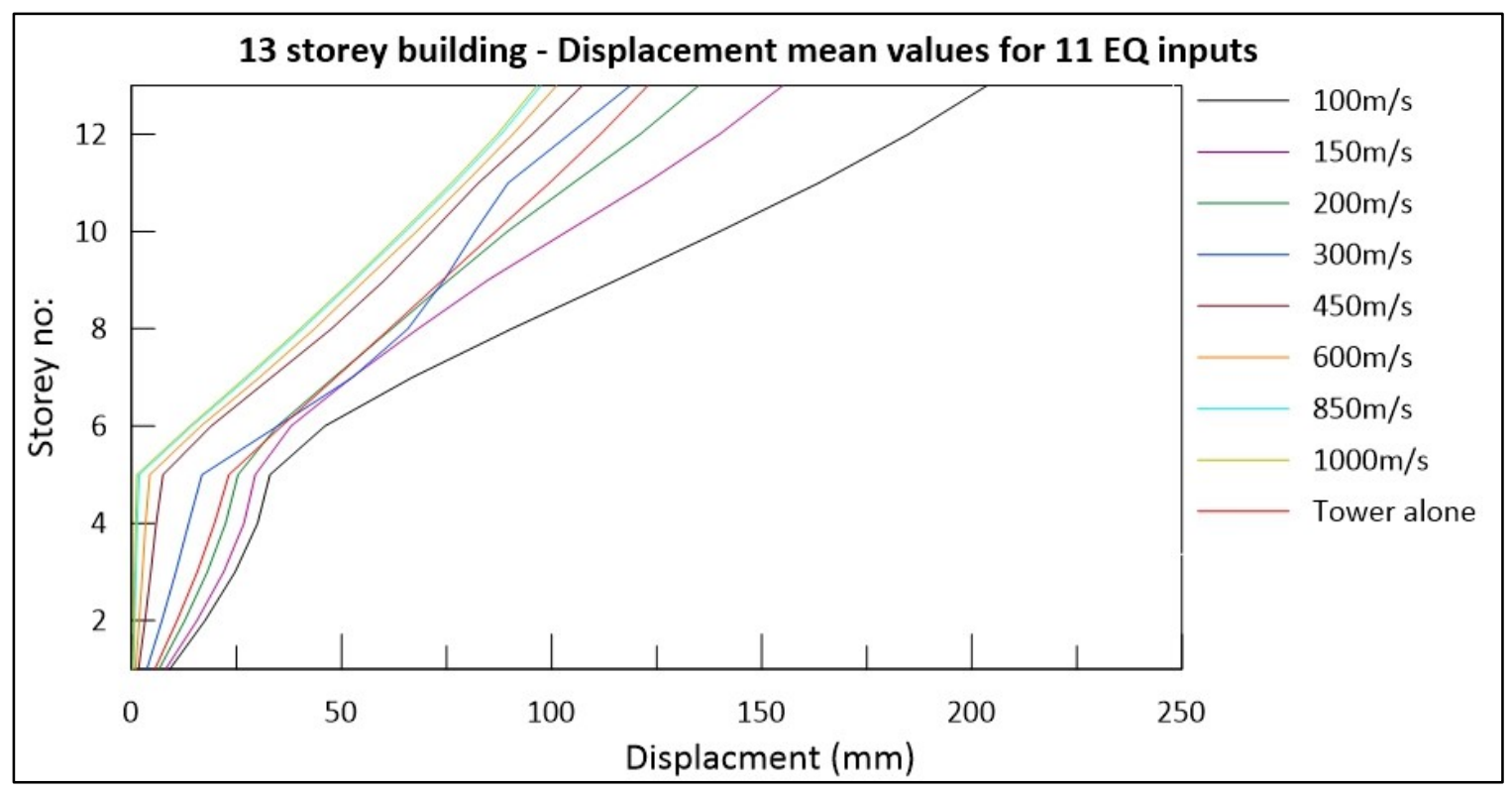

Figure 3-13 Displacement at the top of a storey, mean values for 13 storey building

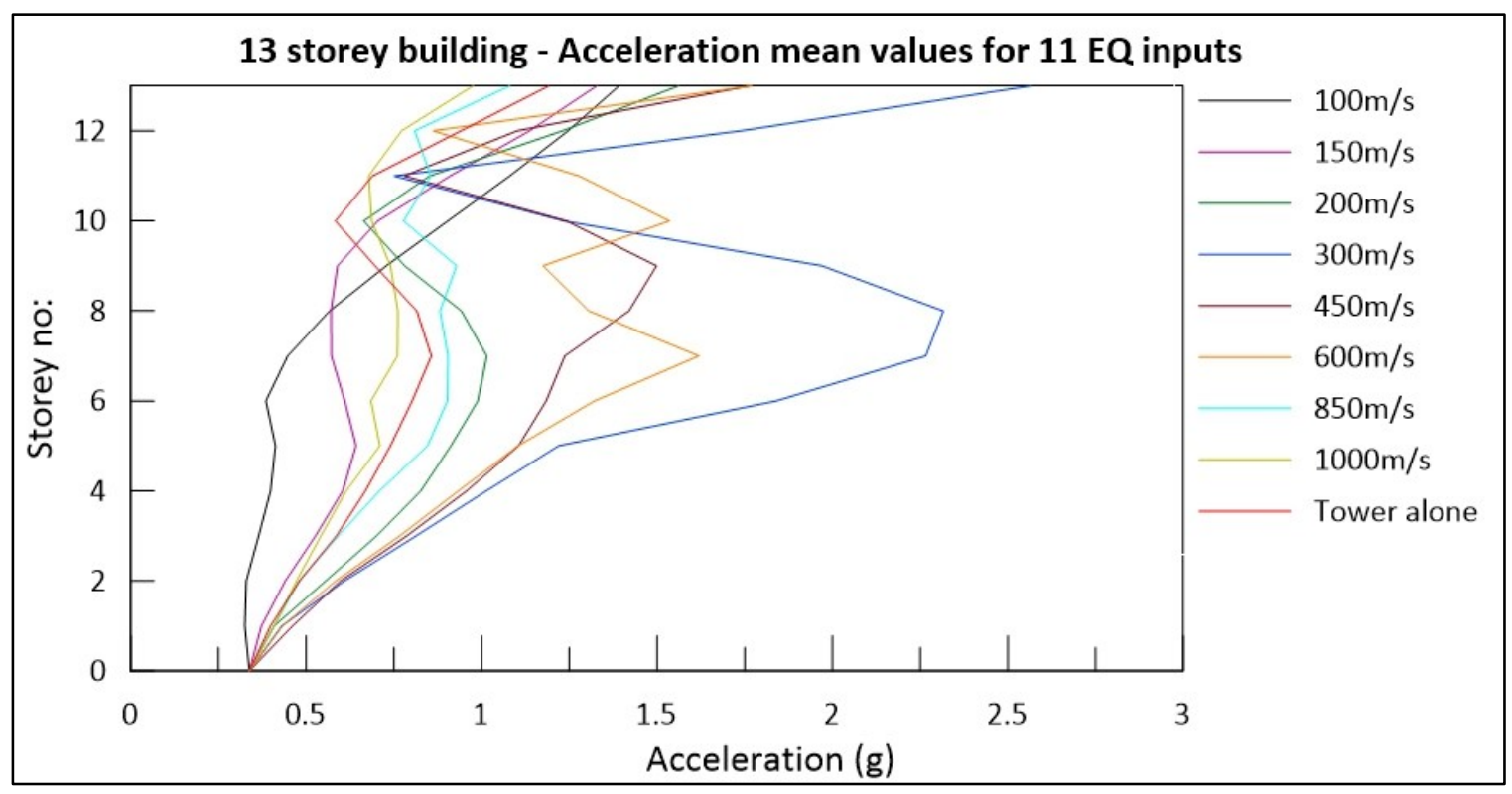

Figure 3-14 Acceleration at the top of a storey, mean values for the 13 storey building

A trend similar to that for shear and moment at the base of the tower is observed in drift and displacement, as shown in Figure 3-12 and Figure 3-13. Highest magnification is seen for the case when the structure is surrounded by $100 \mathrm{~m} / \mathrm{s}$ shear wave velocity soil. The second highest magnification is observed for structure with $300 \mathrm{~m} / \mathrm{s}$ shear wave velocity 
soil. For acceleration response, structure with soil having a shear wave velocity of $300 \mathrm{~m} / \mathrm{s}$ has very high acceleration at the tower base, as shown in Figure 3-14.

Figure 3-15 to Figure 3-19 show the mean seismic response of 12 storey tower and its supporting structure analyzed for 11 earthquake inputs. Magnification in storey shears and storey moments is observed for the 17 storey building with soil having shear wave velocities of $150 \mathrm{~m} / \mathrm{s}$ (site class E), $200 \mathrm{~m} / \mathrm{s}$ (near the lower borderline of site class D), and $300 \mathrm{~m} / \mathrm{s}$ (near the upper borderline of site class D.

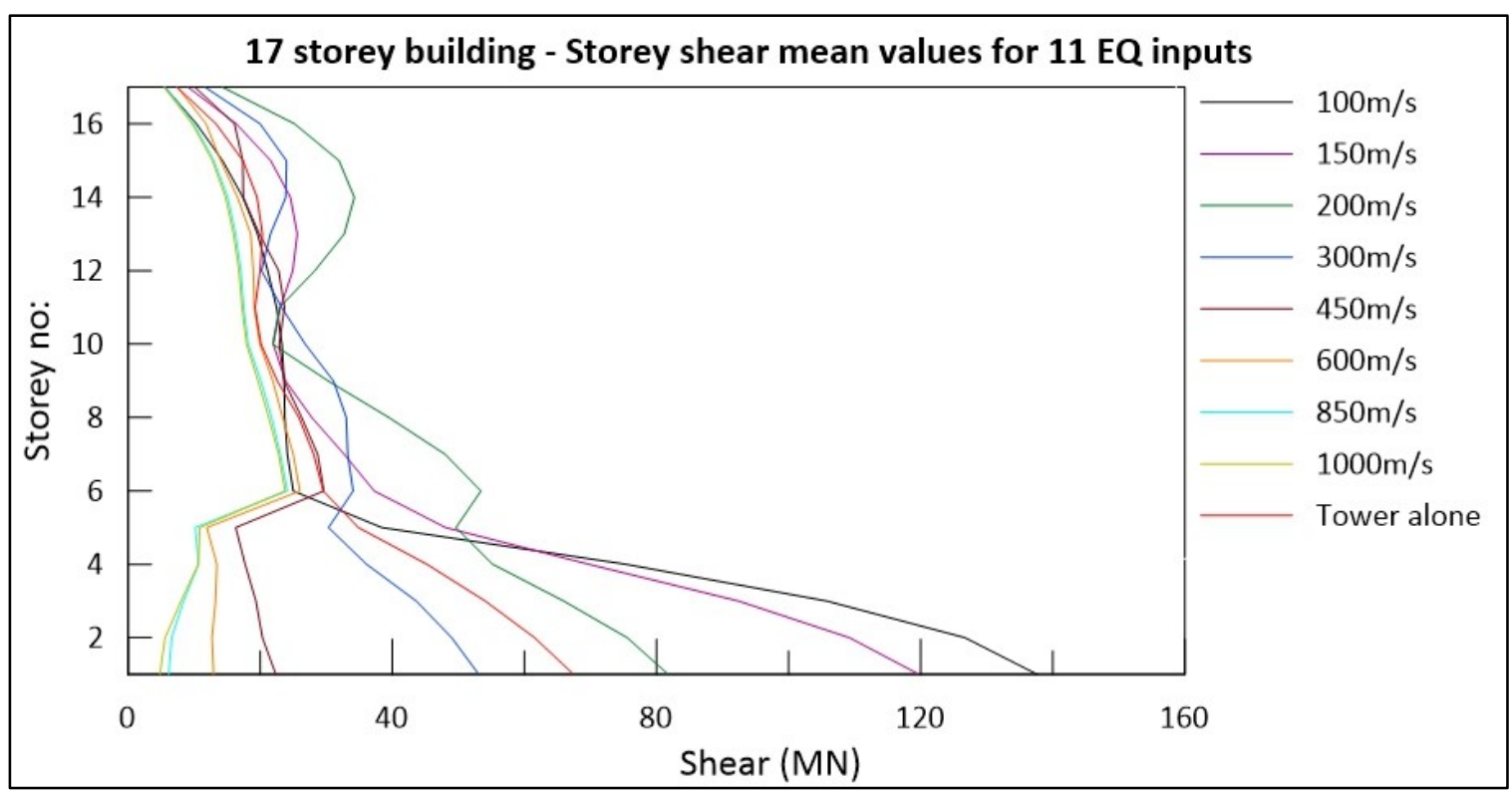

Figure 3-15 Storey shear, mean values for the 17 storey building 


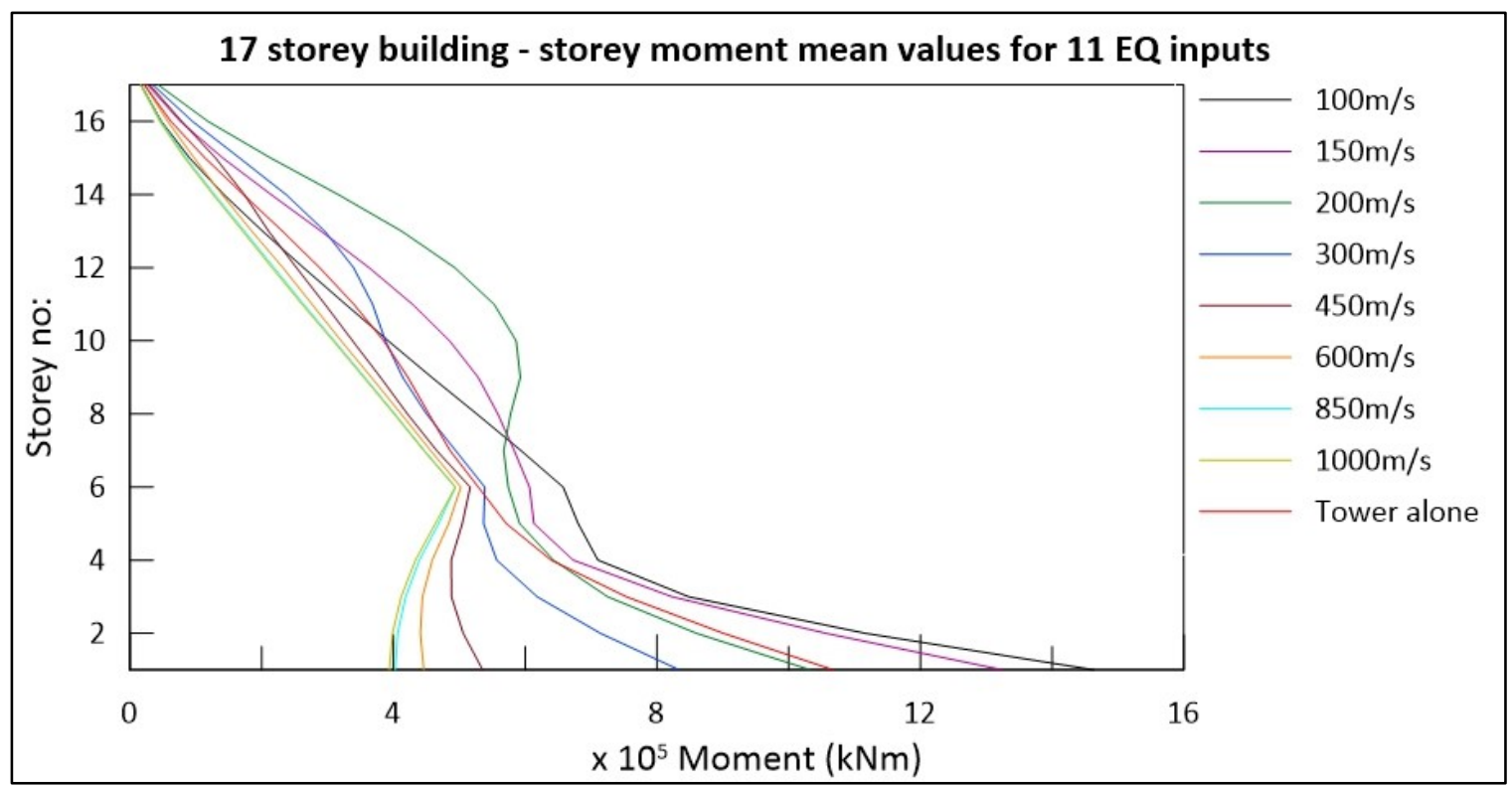

Figure 3-16 Mean moment at the bottom of a storey for 17 storey building

However, as shown in Figure 3-15, the largest magnification in base shear is when the structure is surrounded by soil having a shear wave velocity of $200 \mathrm{~m} / \mathrm{s}$. Figure $3-16$ shows that the maximum magnification in the moment at the tower base is observed when the structure is with soil having a shear wave velocity of $100 \mathrm{~m} / \mathrm{s}$, which is then closely followed by the structure with soil of $150 \mathrm{~m} / \mathrm{s}$ shear wave velocity. 


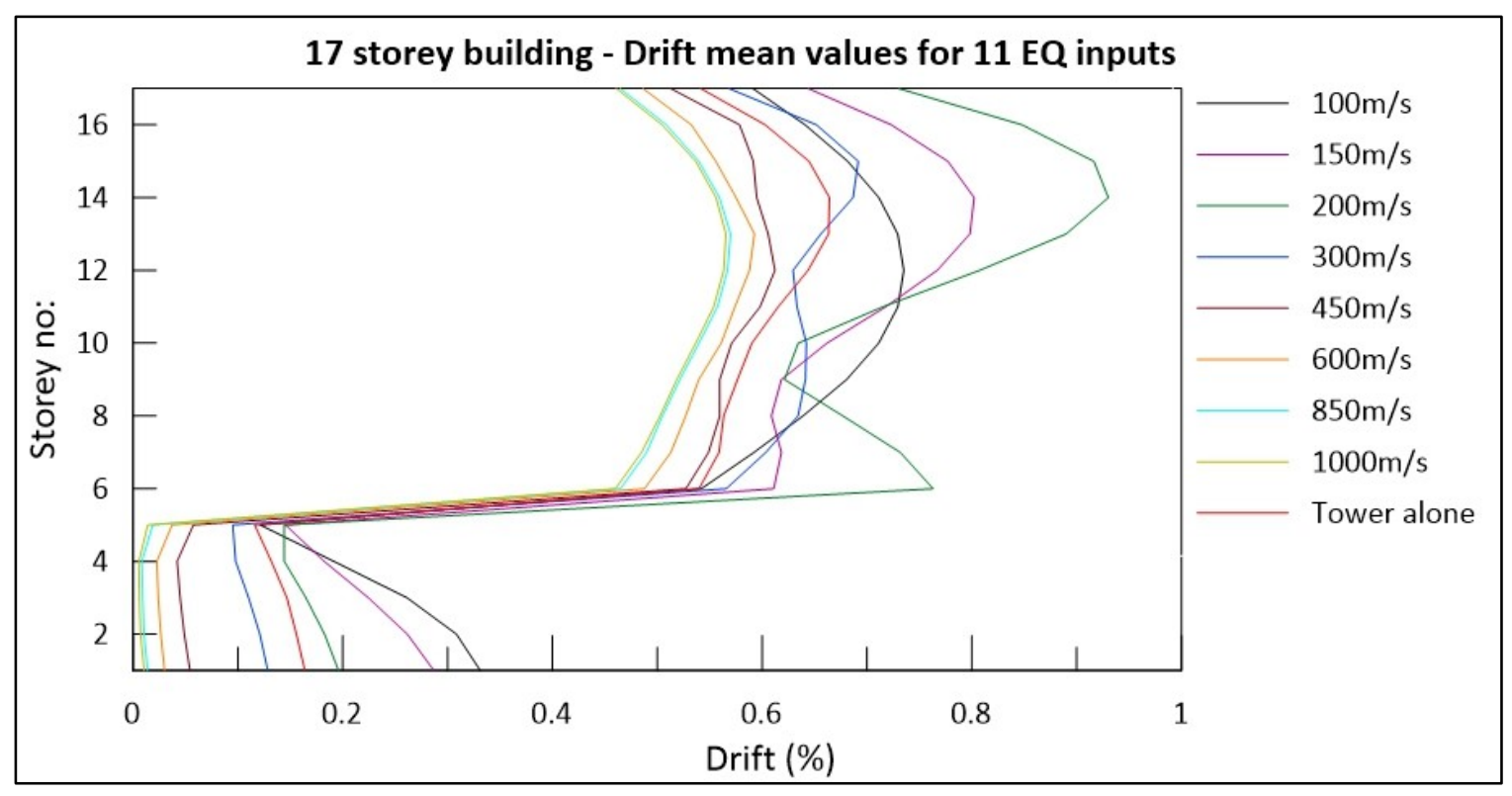

Figure 3-17 Storey drift, mean values for the 17 storey building

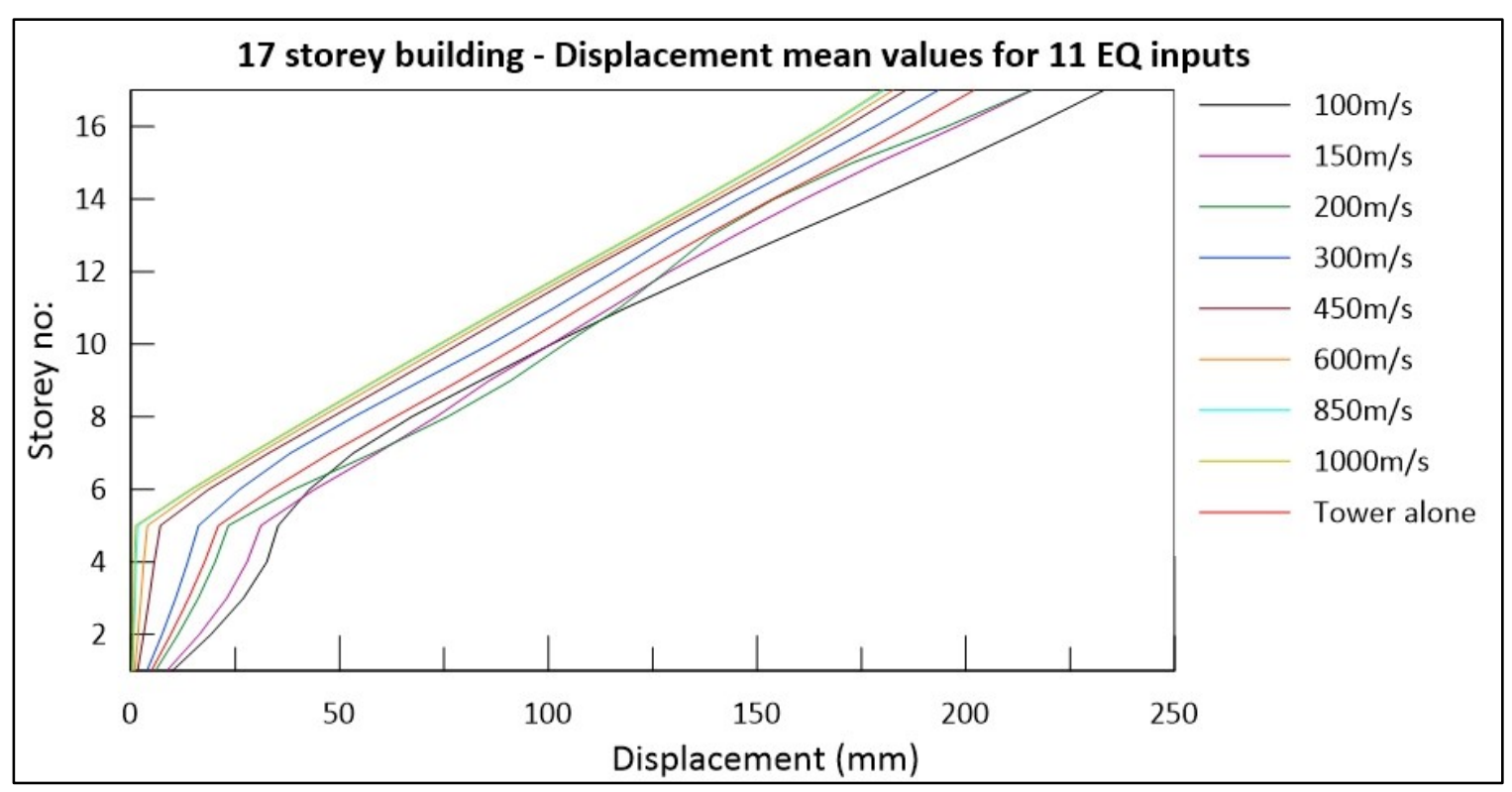

Figure 3-18 Displacement at the top of a storey, mean values for 17 storey building 


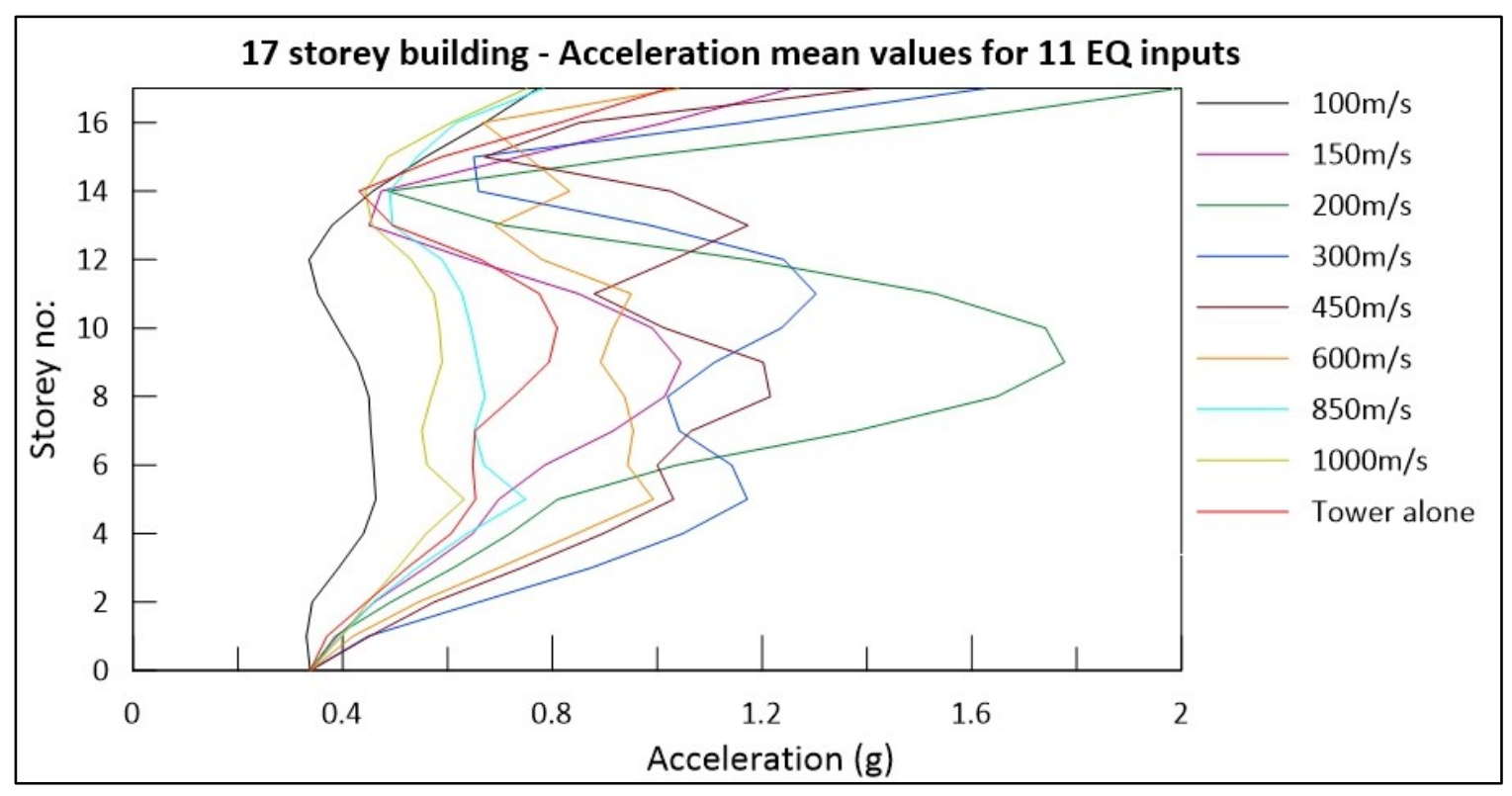

Figure 3-19 Acceleration at the top of a storey, mean values for the 17 storey building

Figure 3-17 shows that maximum magnification in the drift in the base storey of the tower follows the same trend as the magnification in the base shear for structures with soil having shear velocities of $200 \mathrm{~m} / \mathrm{s}, 150 \mathrm{~m} / \mathrm{s}$ and $300 \mathrm{~m} / \mathrm{s}$, in descending order of magnification. For displacement response, the highest magnification at the tower base is observed for the case when the structure is with soil having a shear wave velocity of $150 \mathrm{~m} / \mathrm{s}$. However, a $100 \mathrm{~m} / \mathrm{s}$ shear wave velocity soil produces higher magnification in displacement on the belowground part of the building. Maximum magnification in acceleration (Figure 3-19) is observed for two cases of 17 storey building and soil having shear wave velocities of $600 \mathrm{~m} / \mathrm{s}$ and $200 \mathrm{~m} / \mathrm{s}$.

Figure 3-20 to Figure 3-24 display the mean values of the response for storey shear, storey moment, drift, displacement, and acceleration, respectively for the case of the 21-storey building. 


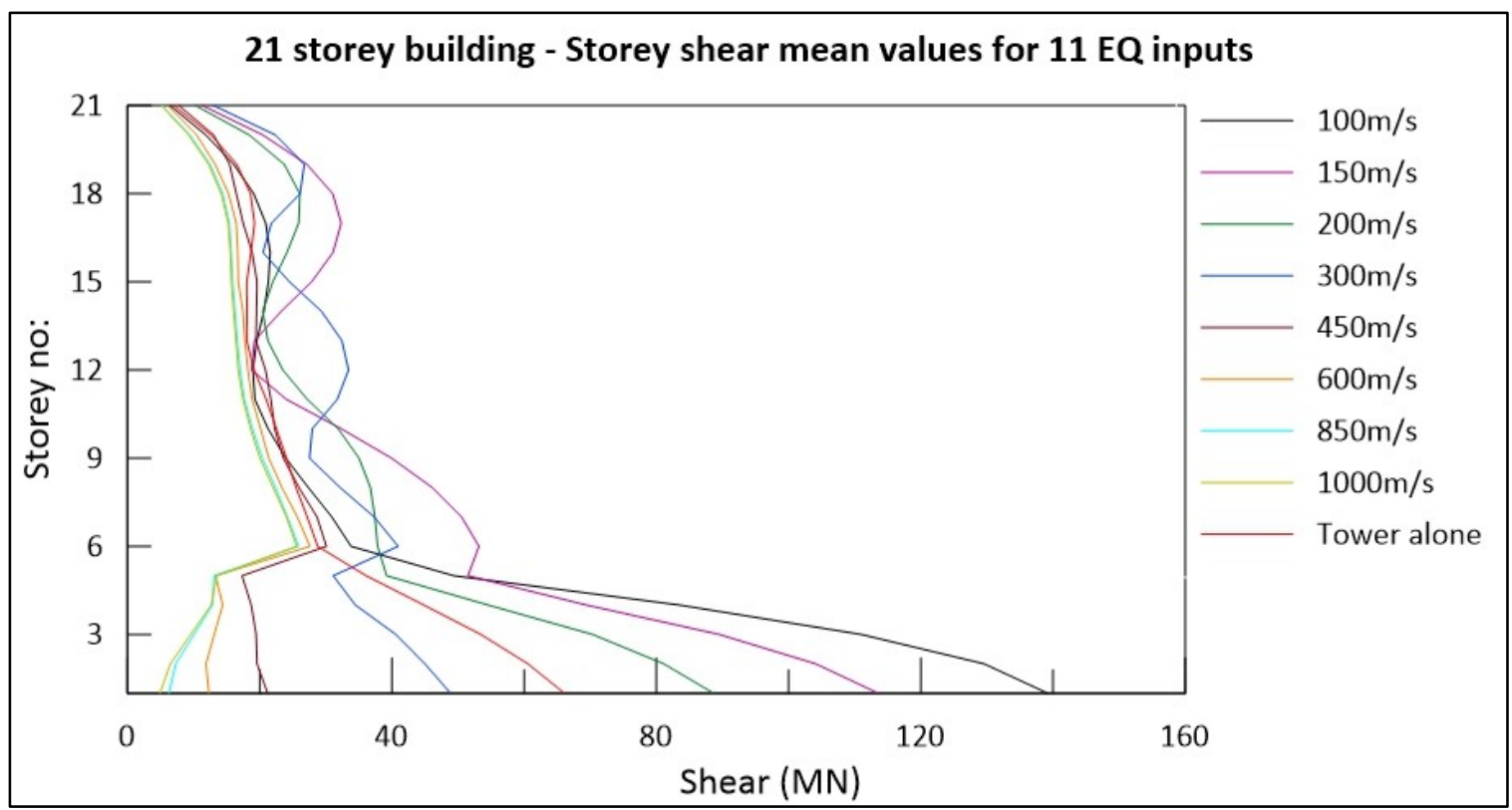

Figure 3-20 Storey shear, mean values for the 21 storey building

Magnification in storey shear and storey moment occurs when the soil has shear velocities of $100 \mathrm{~m} / \mathrm{s}$ (site class E), $150 \mathrm{~m} / \mathrm{s}$ (site class E), $200 \mathrm{~m} / \mathrm{s}$ (near lower borderline of site class D), and $300 \mathrm{~m} / \mathrm{s}$ (near upper borderline of site class D). The maximum magnification in the shear at the base of the tower is in the case of soil having a shear wave velocity of $150 \mathrm{~m} / \mathrm{s}$. However, as seen from Figure 3-20, soil having a shear wave velocity $100 \mathrm{~m} / \mathrm{s}$ causes the highest magnification in storey shears in below-grade structure. 


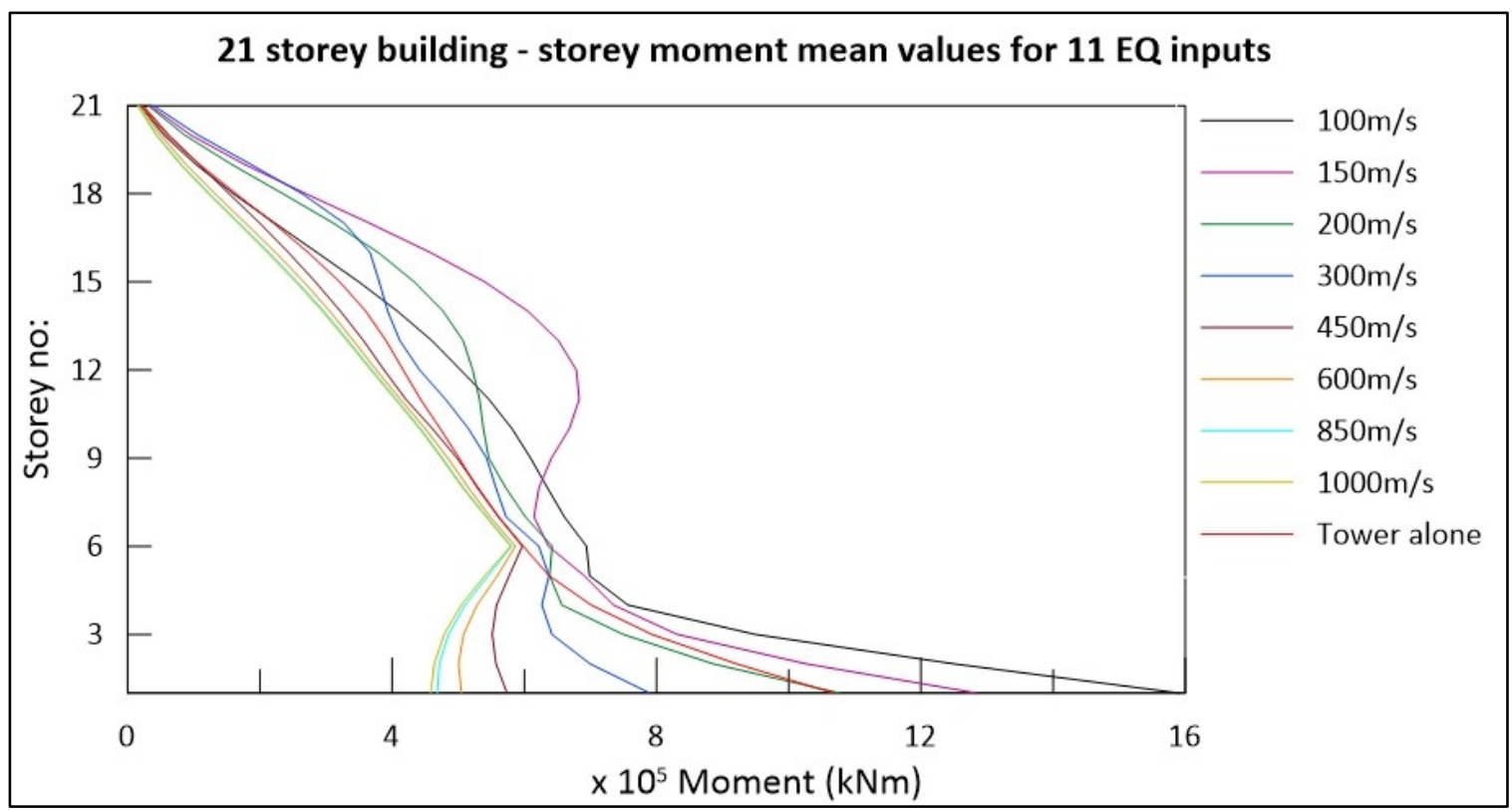

Figure 3-21 Mean moment at the bottom of a storey for 21 storey building

The maximum magnification in the moment at the tower base in the 21 storey building is observed for the case when the building is with soil having a shear wave velocity of $100 \mathrm{~m} / \mathrm{s}$ (Figure 3-21). The magnification in drift over the base storey of the tower follows a trend that is similar to that for shear (Figure 3-22) the highest being for the building with soil having a shear wave velocity of $150 \mathrm{~m} / \mathrm{s}$, followed by that for the building with soil having a shear wave velocity of $300 \mathrm{~m} / \mathrm{s}$. 


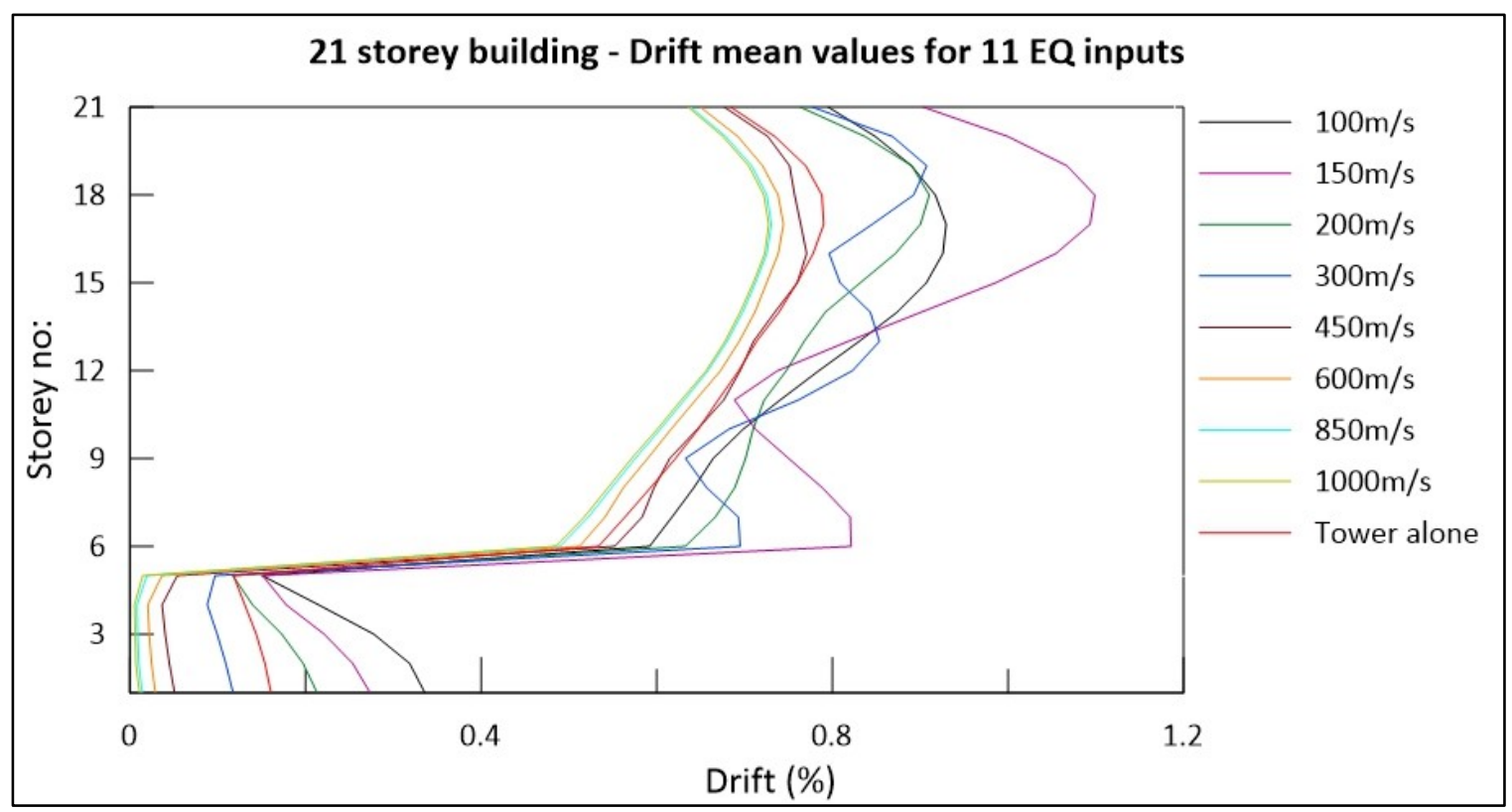

Figure 3-22 Storey drift, mean values for the 21 storey building

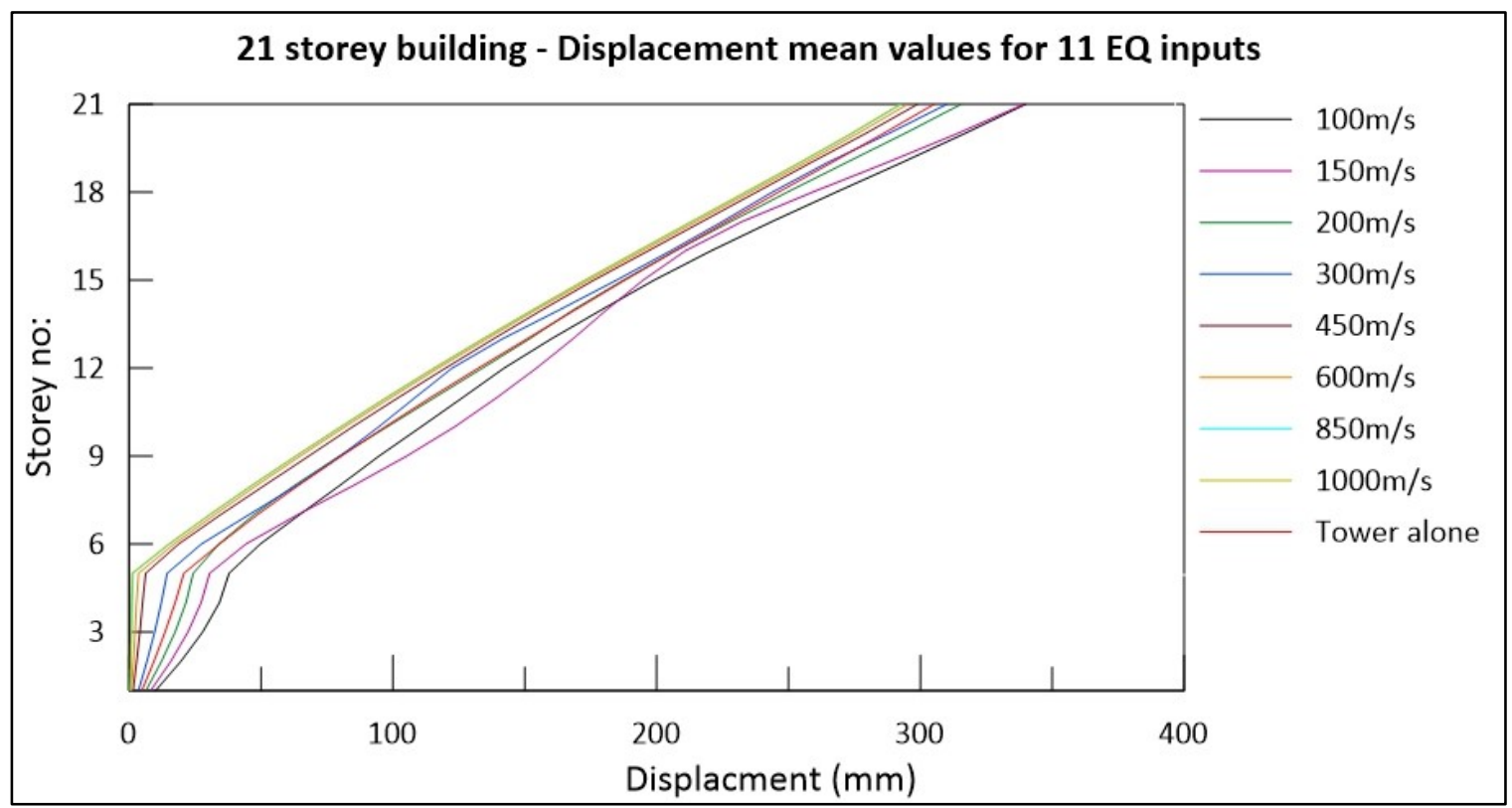

Figure 3-23 Displacement at the top of a storey, mean values for 21 storey building

From Figure 3-23, it is observed that magnification in displacement at the base of the tower is highest for building with soil having a shear wave velocity of $100 \mathrm{~m} / \mathrm{s}$, closely followed by the building with a soil having shear wave velocity of $150 \mathrm{~m} / \mathrm{s}$. Figure $3-24$ shows that the building with soil having a shear wave velocity of $300 \mathrm{~m} / \mathrm{s}$ has the maximum 
magnification in acceleration at the base of the tower when compared with the building alone case, which is then followed by the building with soil having a shear wave velocity of $450 \mathrm{~m} / \mathrm{s}$.

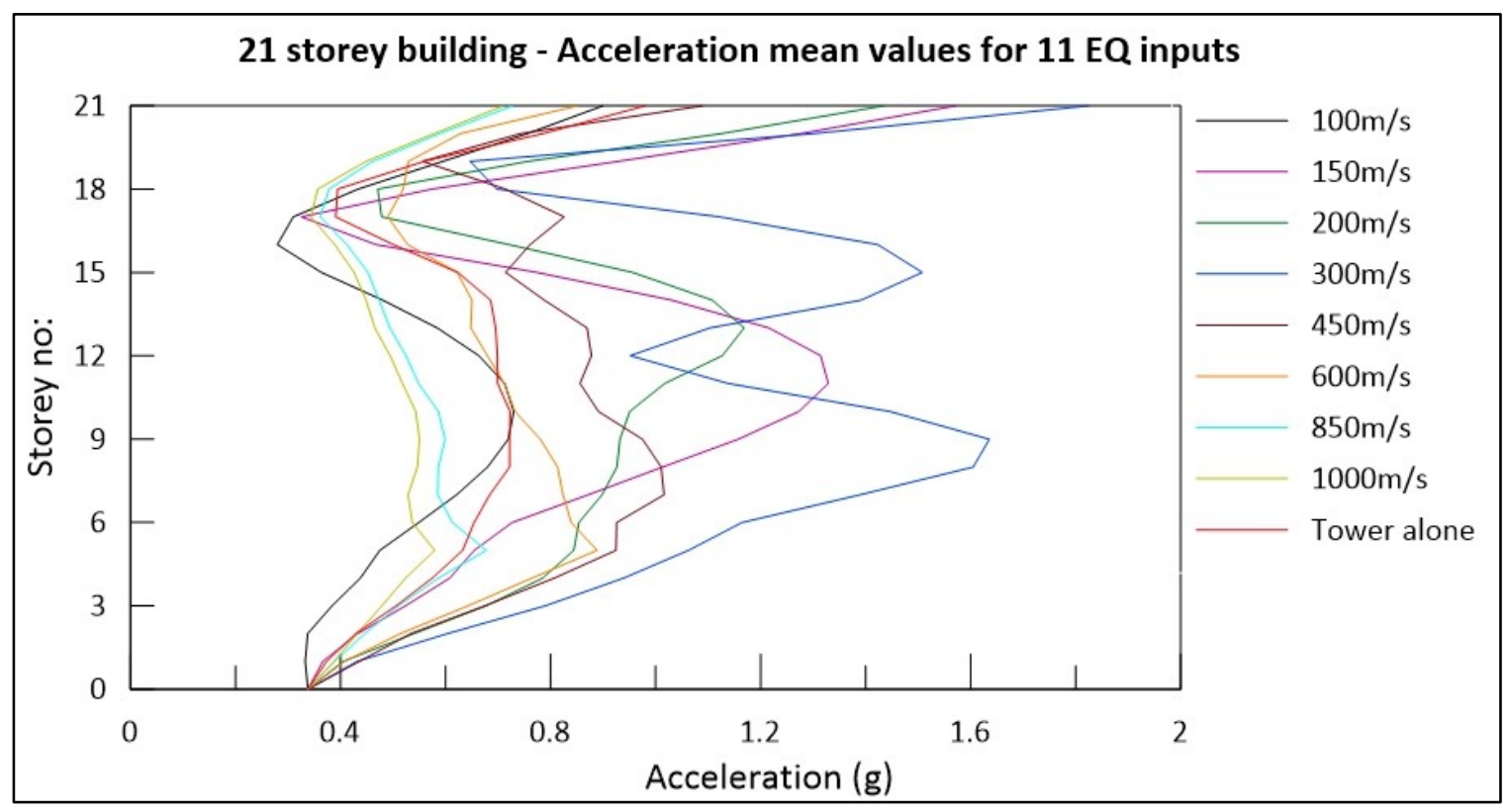

Figure 3-24 Acceleration at the top of a storey, mean values for the 21 storey building

Figure 3-25 to Figure 3-29 show magnifications in the response of 20 storey tower and its supporting structure with soils having several different shear velocities in comparison to those for the building alone. From Figure 3-25 and Figure 3-26, it is observed that, there is magnification in storey shear and storey moment when the soil has shear velocities of $100 \mathrm{~m} / \mathrm{s}$ (site class E), $150 \mathrm{~m} / \mathrm{s}$ (site class E), 200m/s (near lower borderline of site class D), and $300 \mathrm{~m} / \mathrm{s}$ (near upper borderline of site class D). The magnification is highest when the structure is analyzed with soil having a shear wave velocity of $100 \mathrm{~m} / \mathrm{s}$, followed by the case when the structure is with the soil having shear wave velocity of $200 \mathrm{~m} / \mathrm{s}$. 


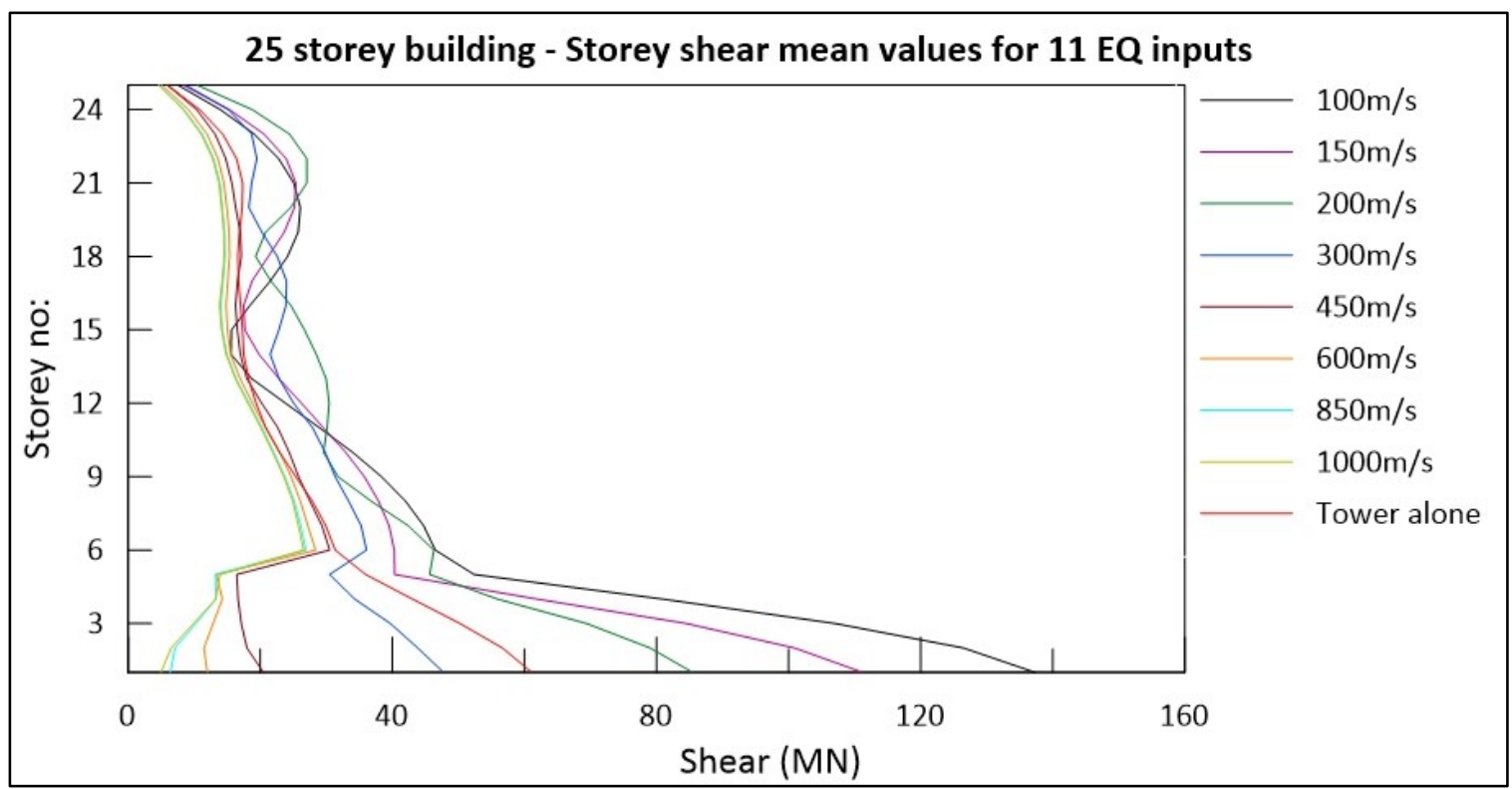

Figure 3-25 Storey shear, mean values for the 25 storey building

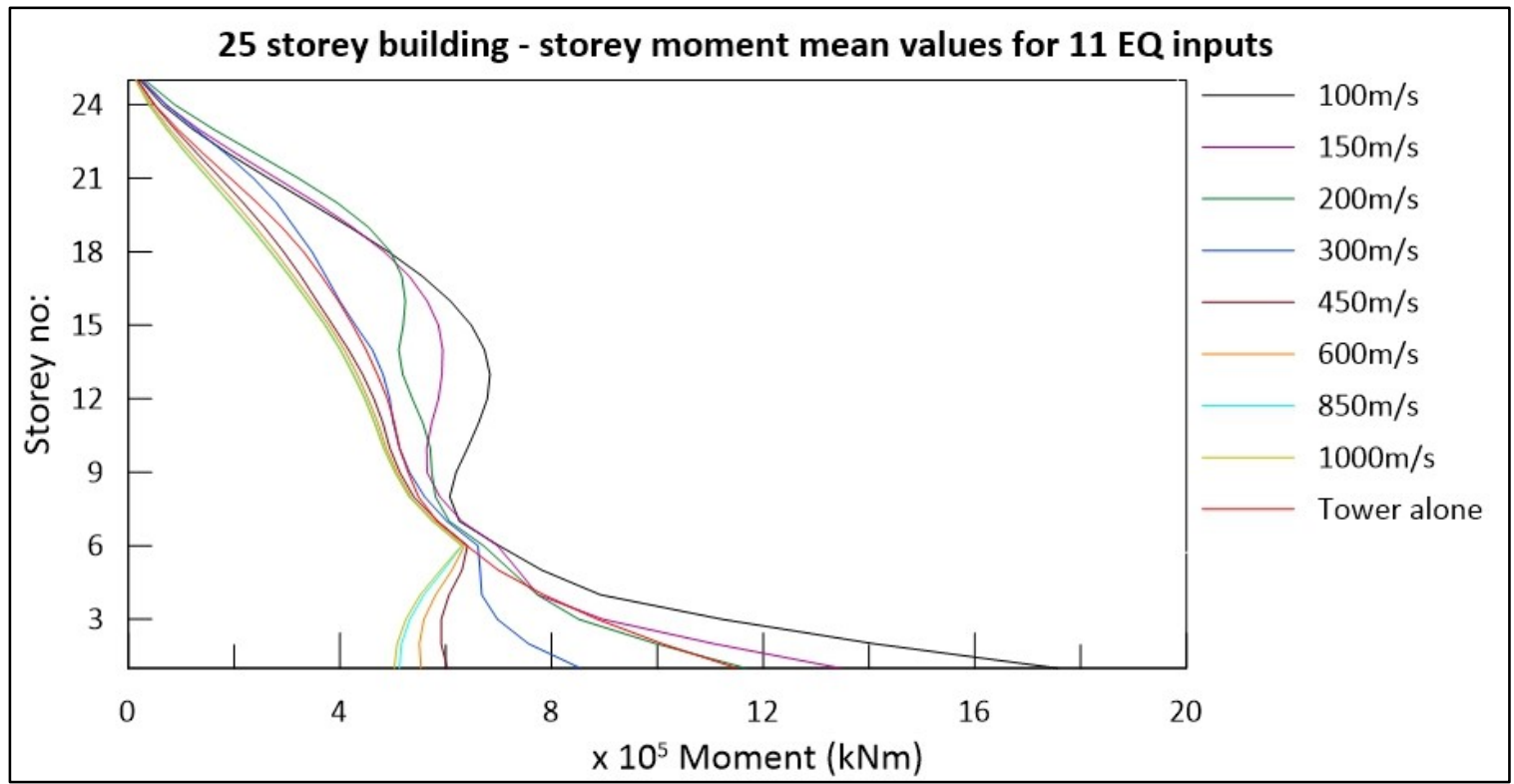

Figure 3-26 Mean moment at the bottom of a storey for 25 storey building

Figure 3-26 shows the mean of the storey moments in 25 storey building. It is observed that there is limited magnification in moments at the base of the tower, maximum magnification is observed when the structure is with a soil having shear wave velocity of $100 \mathrm{~m} / \mathrm{s}$. 


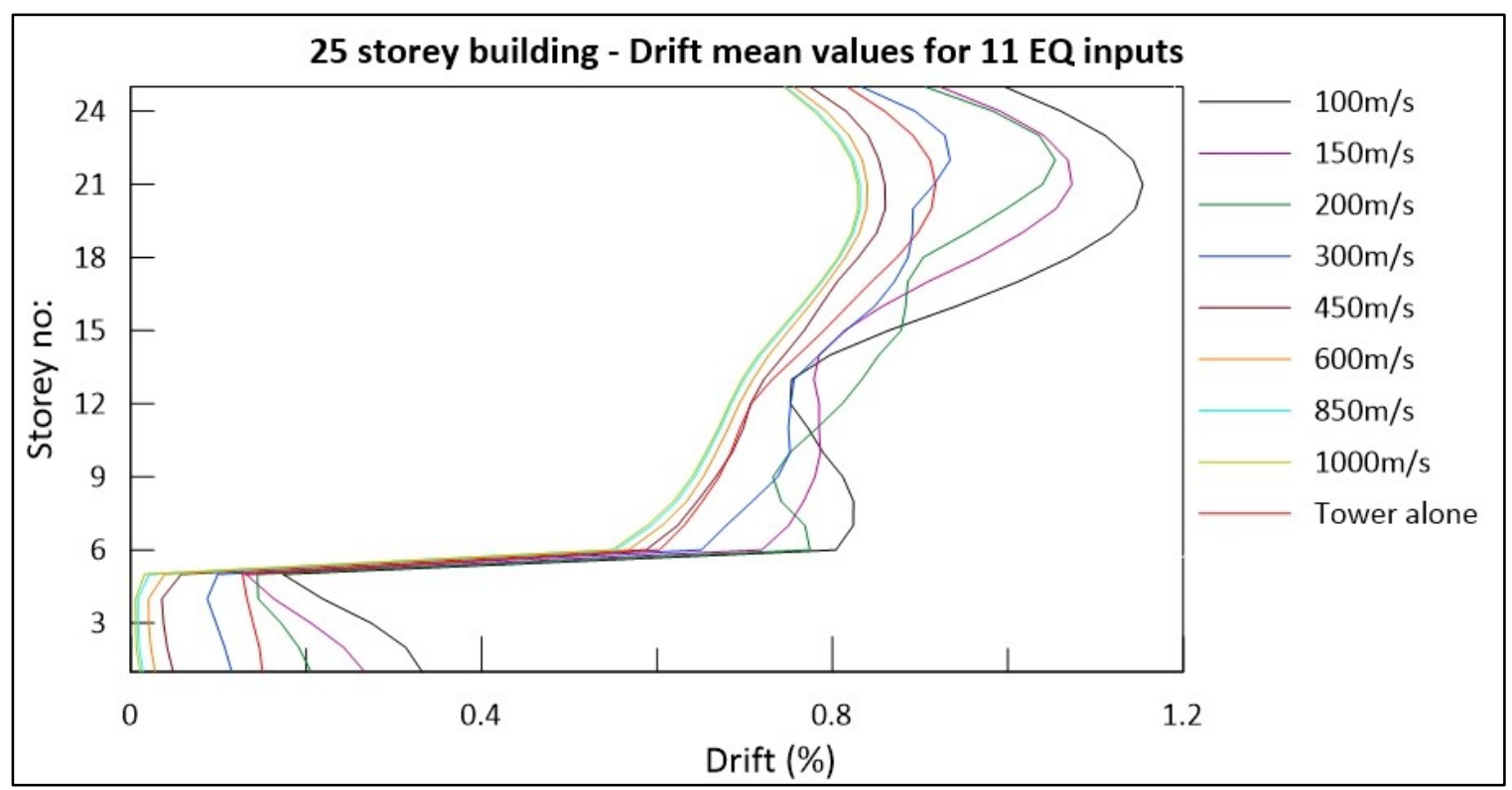

Figure 3-27 Storey drift, mean values for the 25 storey building

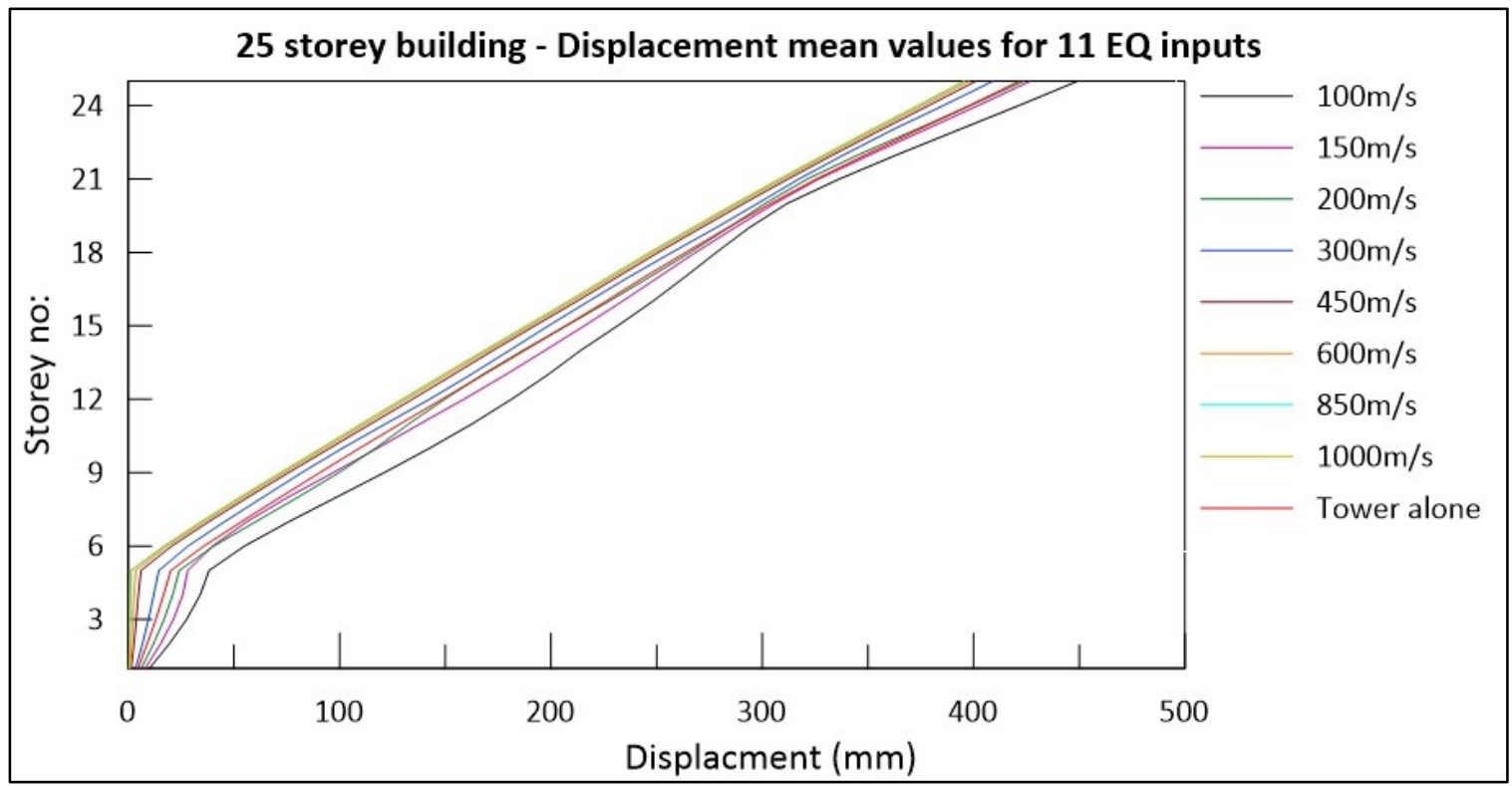

Figure 3-28 Displacement at the top of a storey, mean values for 25 storey building 


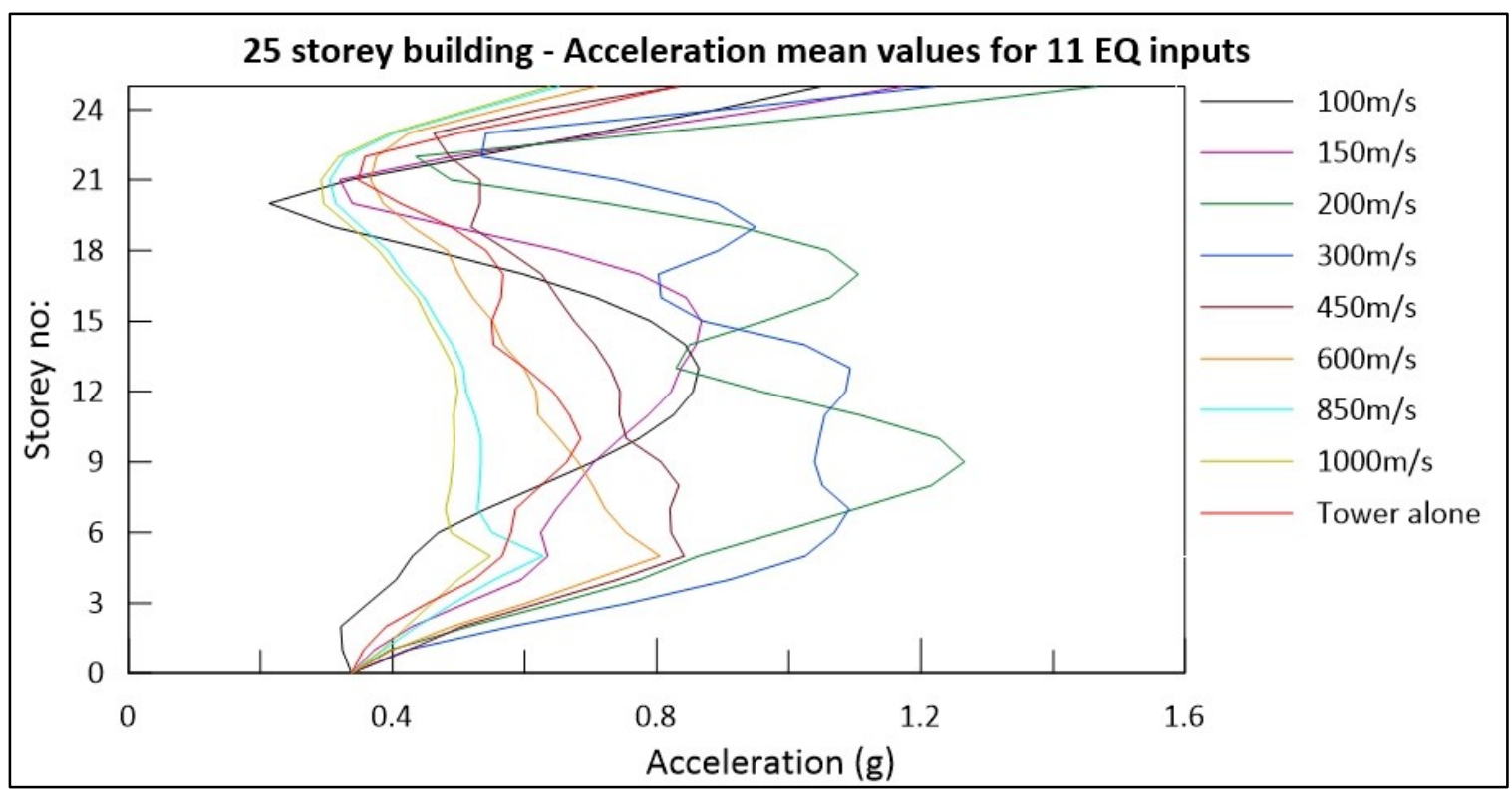

Figure 3-29 Acceleration at the top of a storey, mean values for the 25 storey building

The 25 storey building, with soil having a shear wave velocity of $100 \mathrm{~m} / \mathrm{s}$, has very high magnification in displacement when compared to the displacement in the building by itself. However, as observed from Figure 3-29, the maximum response in acceleration is for the building with soil having a shear wave velocity of $300 \mathrm{~m} / \mathrm{s}$; closely followed by that for the structure with soil having $600 \mathrm{~m} / \mathrm{s}$ shear wave velocity.

\subsection{Analysis of results}

\subsubsection{Magnification factor plots}

For discussions in the following paragraphs a magnification factor is defined as the ratio of the mean of the peak response of the building with soil to that of the building alone. Magnification factors are presented here for shear, moment, drift, displacement, and acceleration in the base storey for $4,8,12,16$, and 20 storey towers with varying soil properties. The data presented in Figure 3-30 to 3.34 demonstrate that the presence of surrounding soil places a heavier demand in many instances (evidenced from a 
magnification factor greater than one). In a few cases, the magnification factor is quite large.

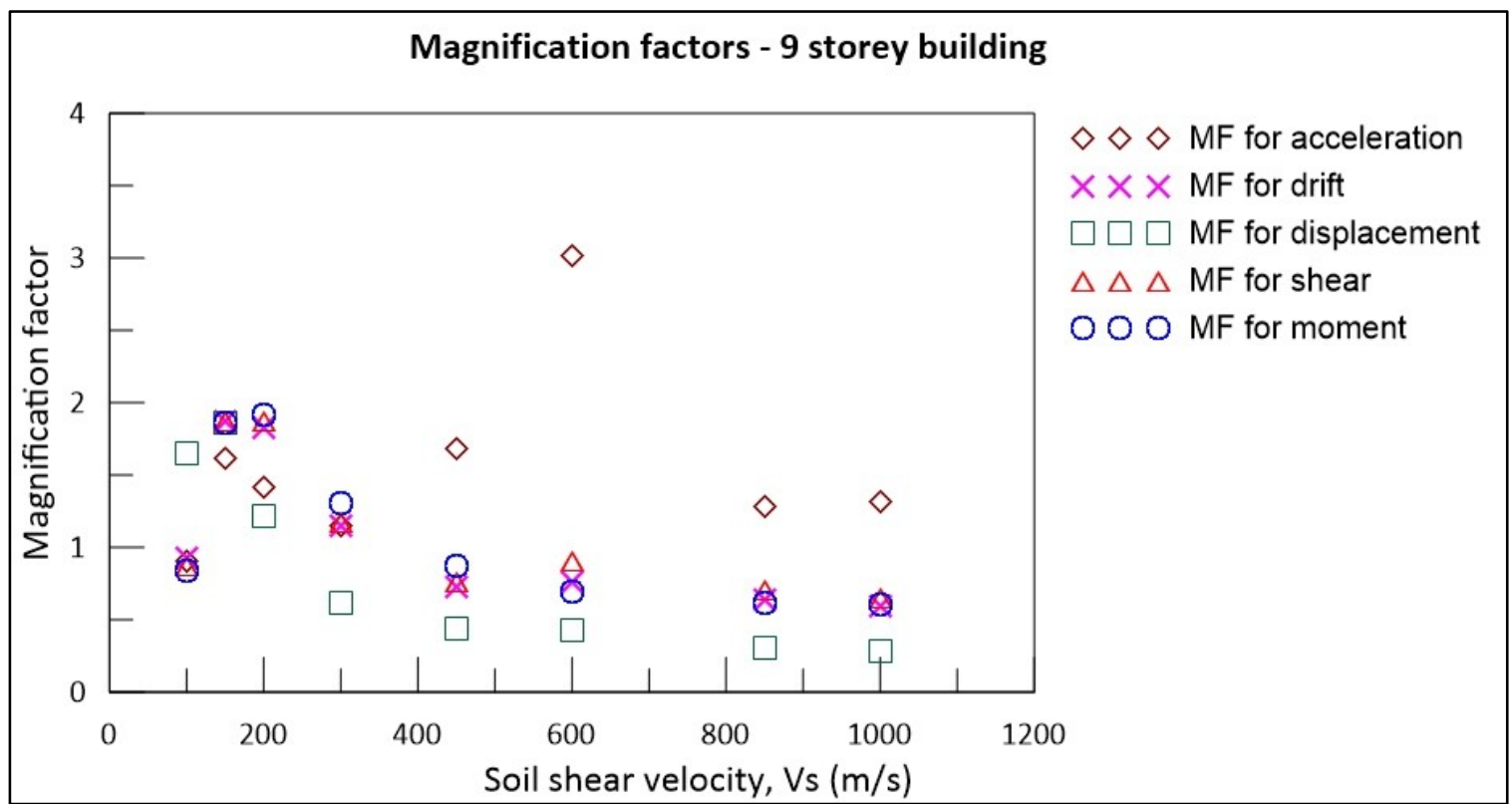

Figure 3-30 Magnification factors for 9 storey building with varying soil properties

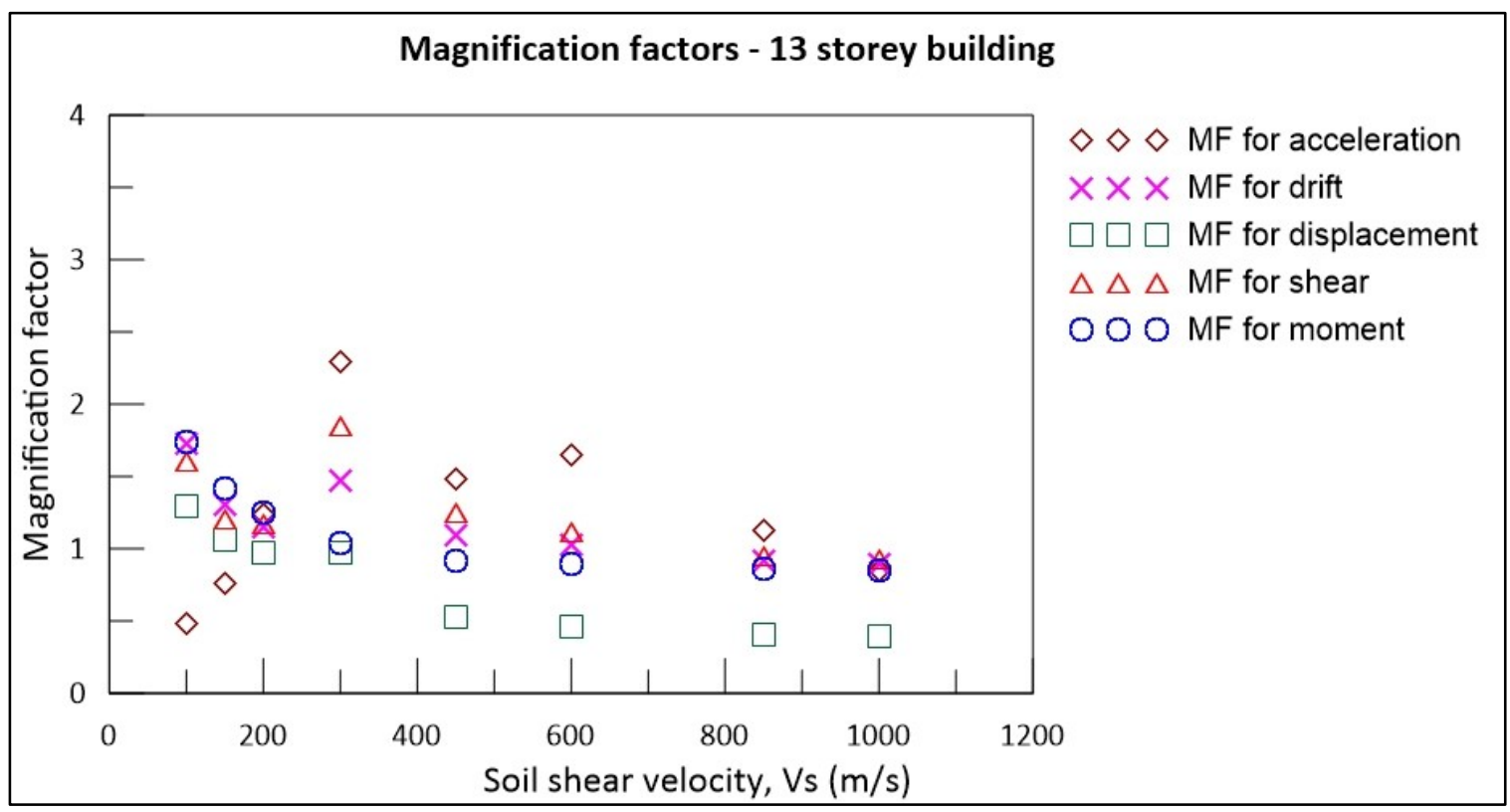

Figure 3-31 Magnification factors for 13 storey building with varying soil properties 


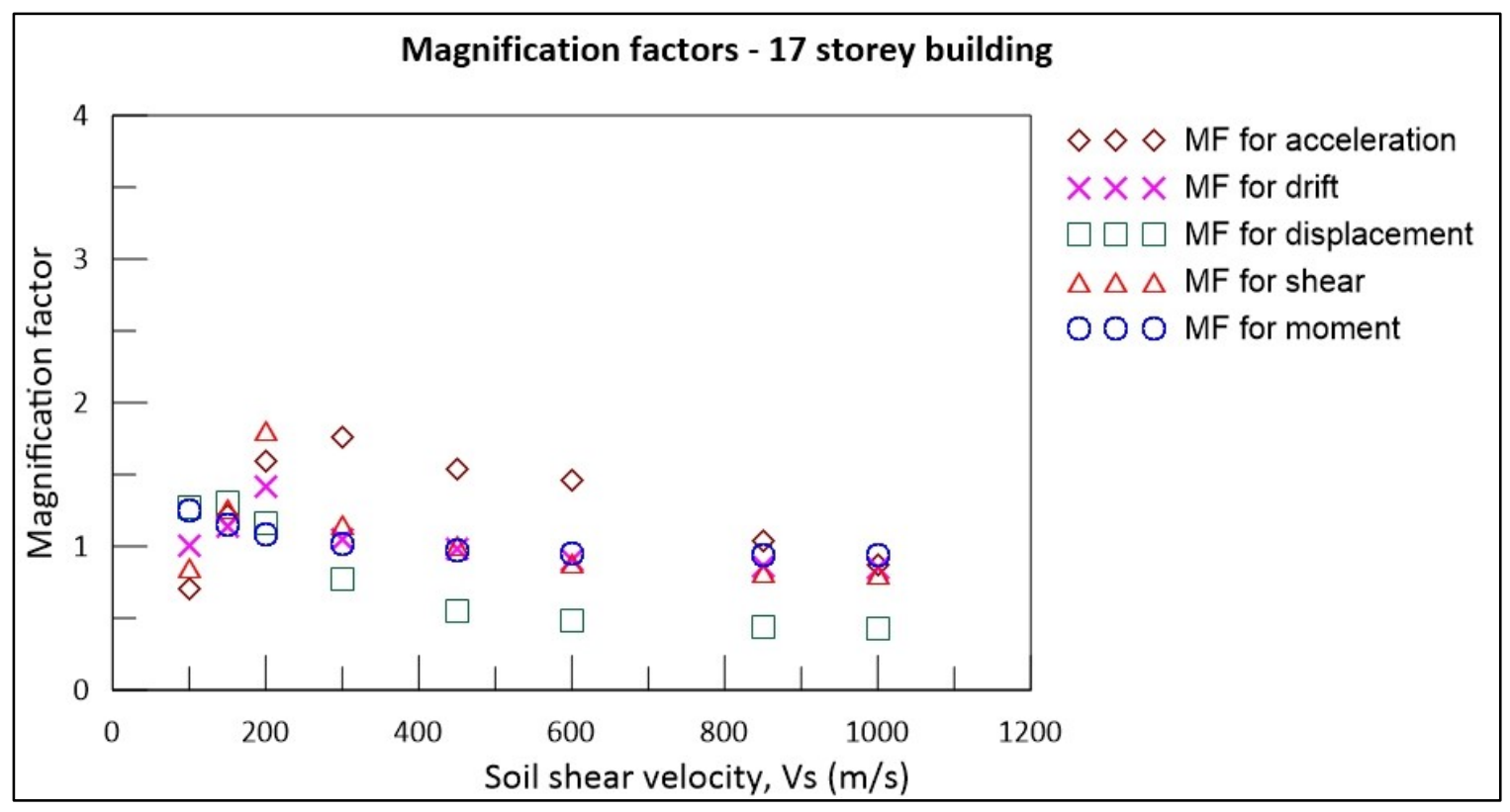

Figure 3-32 Magnification factors for 17 storey building with varying soil properties

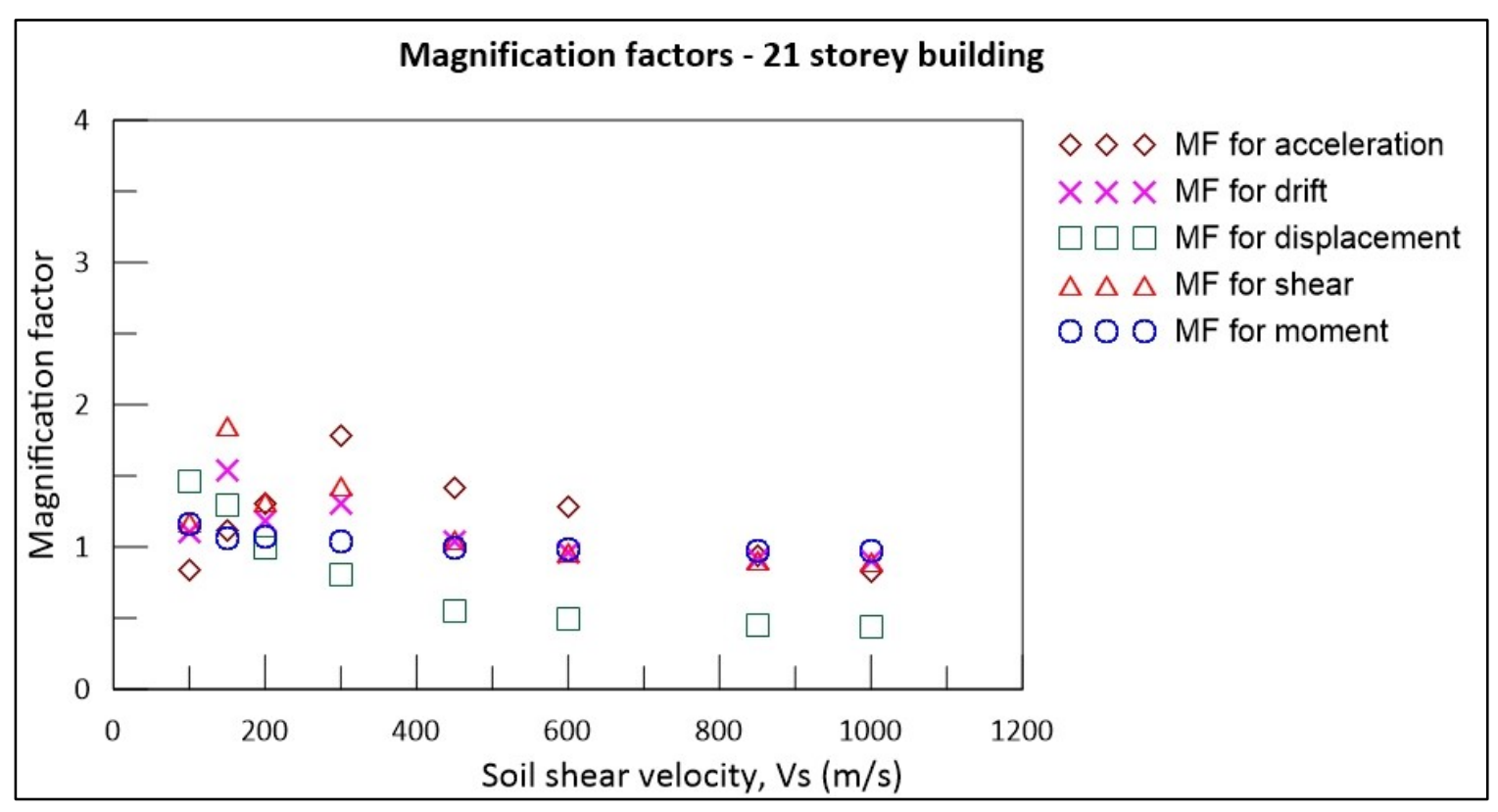

Figure 3-33 Magnification factors for 21 storey building with varying soil properties 


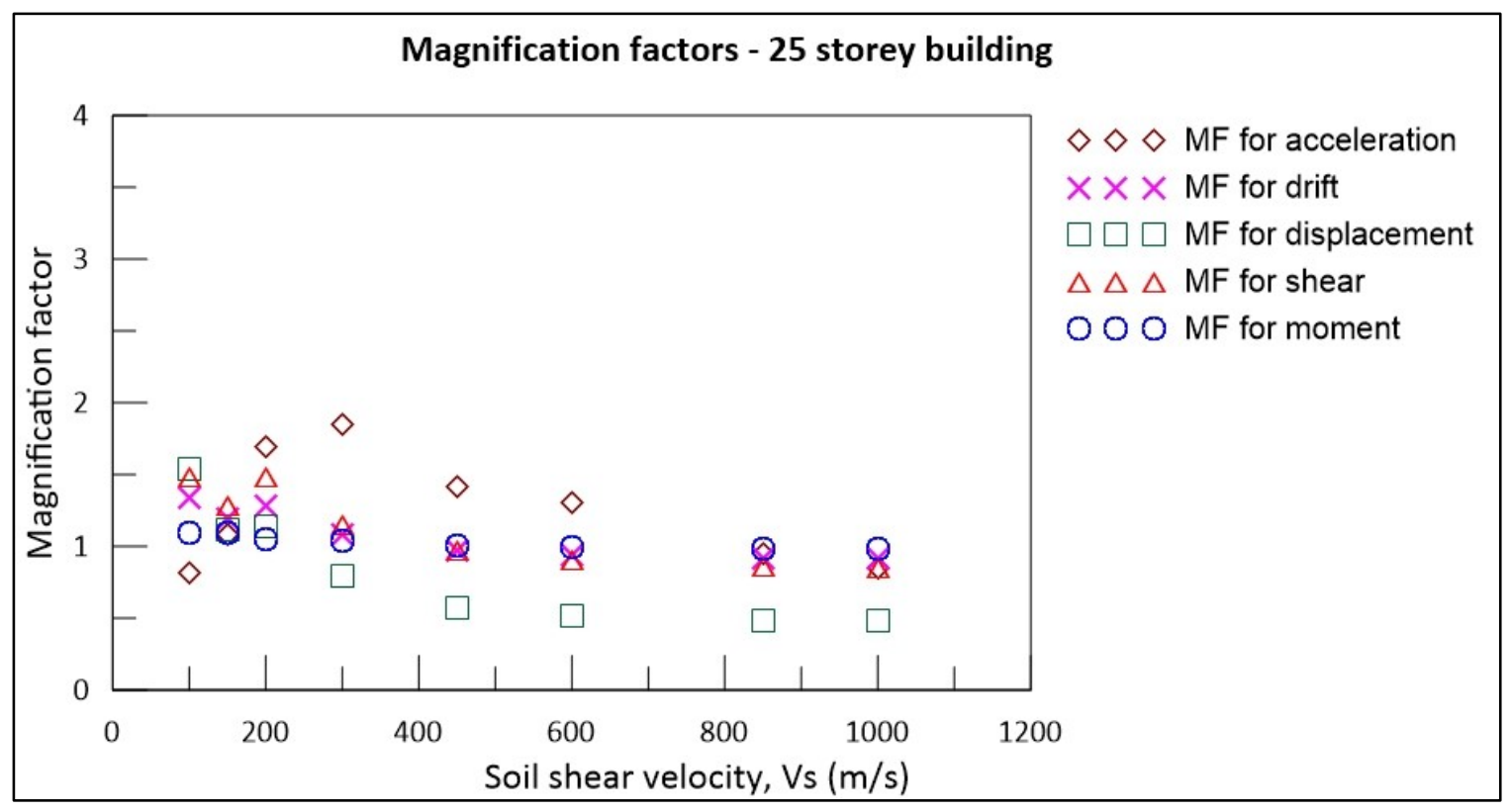

Figure 3-34 Magnification factors for 25 storey building with varying soil properties

From the results presented here, it is observed that the magnification factor is, in general, higher than 1 when the soil has shear wave velocities of $100 \mathrm{~m} / \mathrm{s}$ (site class E), $150 \mathrm{~m} / \mathrm{s}$ (site class E), $200 \mathrm{~m} / \mathrm{s}$ (near the lower borderline of site class D), $300 \mathrm{~m} / \mathrm{s}$ (near the upper borderline of site class D) or $450 \mathrm{~m} / \mathrm{s}$ (middle of site class C). The magnification plots also show that in a few cases, stiff soils having shear wave velocity higher than $450 \mathrm{~m} / \mathrm{s}$ cause significant magnification in acceleration response. It is also observed that the magnification factors for drifts and for shear at the base of the tower, are almost identical, and follow the same trend (i.e.) when there is an increase in drift, there is an increase in base shear.

From the foregoing discussion it is apparent there is magnification in structural response when soil structure interaction is taken into account. Hence, the assumption that soil structure interaction is beneficial and can be ignored in the design of structures is not a valid assumption. 


\subsubsection{Effect of resonance on the seismic response}

An issue that has been discussed by some is whether the magnification in response occurs when there is resonance between the predominant periods of the structure and the soil. To examine this issue, the shear magnification factors for the base storey of the tower, the period of the soil for its first mode, which has a modal participation factor of $75 \%$ (Section 3.8.1), and the periods for the first and second modes of the structure, which dominate the response are plotted for $9,13,17,21$ and 25 storey buildings.

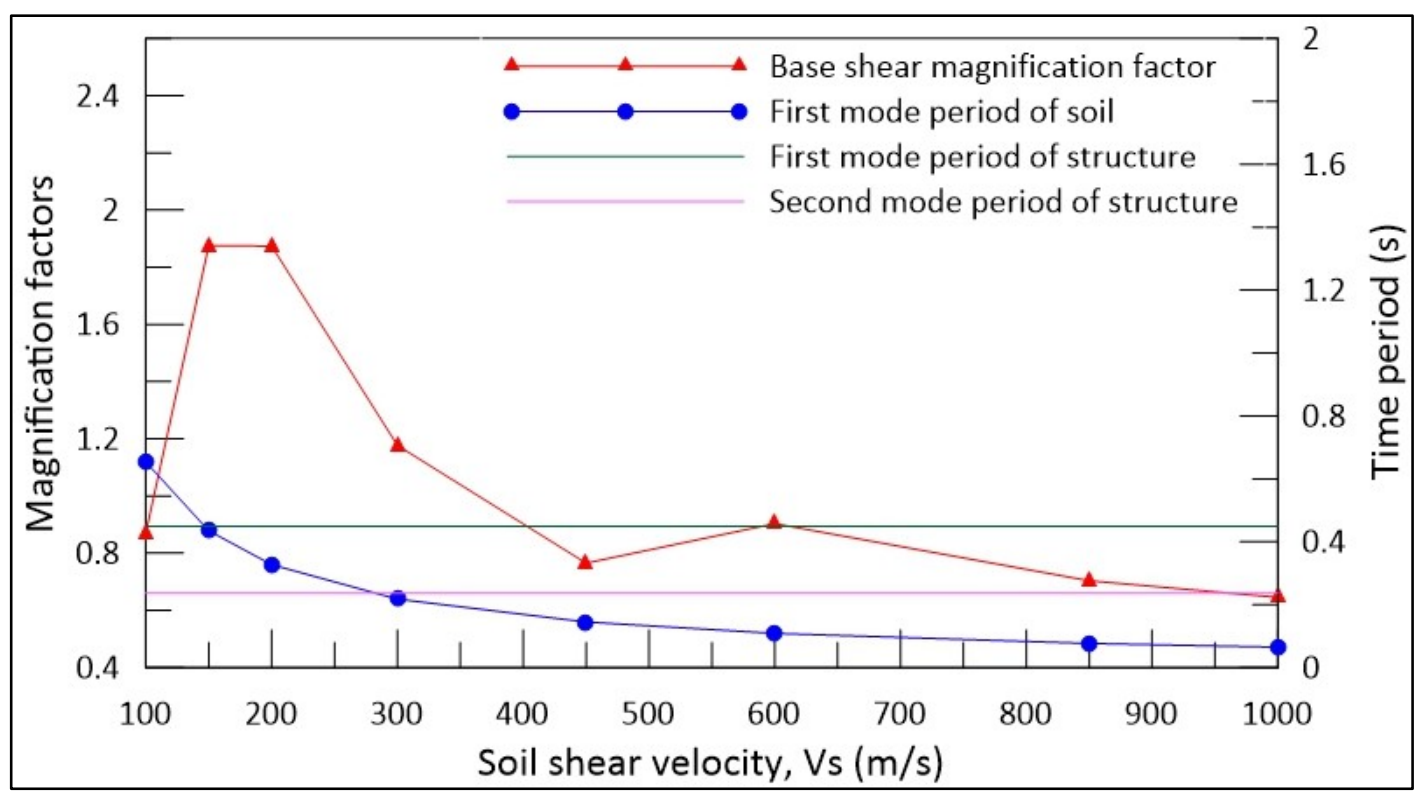

Figure 3-35 Details of shear magnification factors, first mode of the soil, and the first and second modes of the structure -9 storey building 


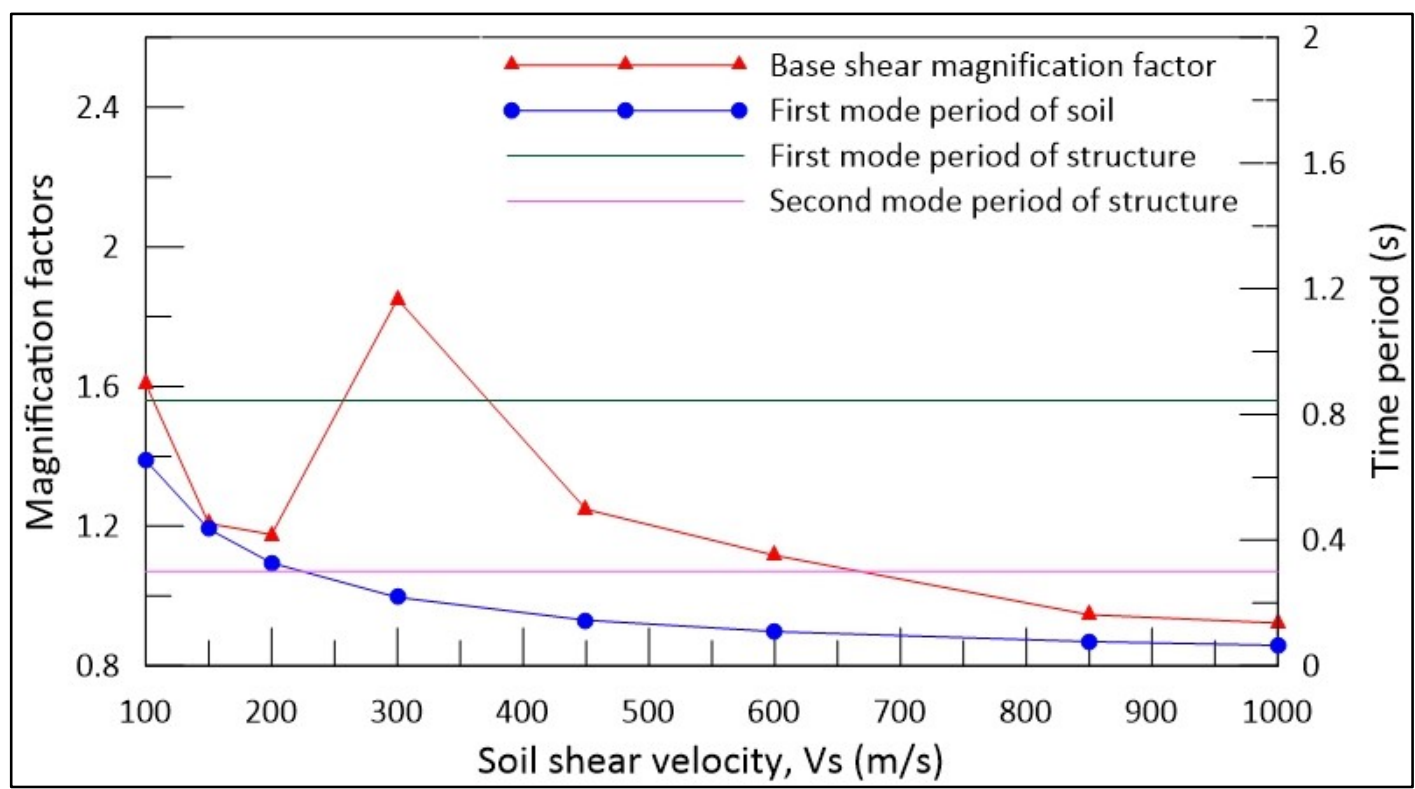

Figure 3-36 Details of shear magnification factors, first mode of the soil, and the first and second modes of the structure - 13 storey building

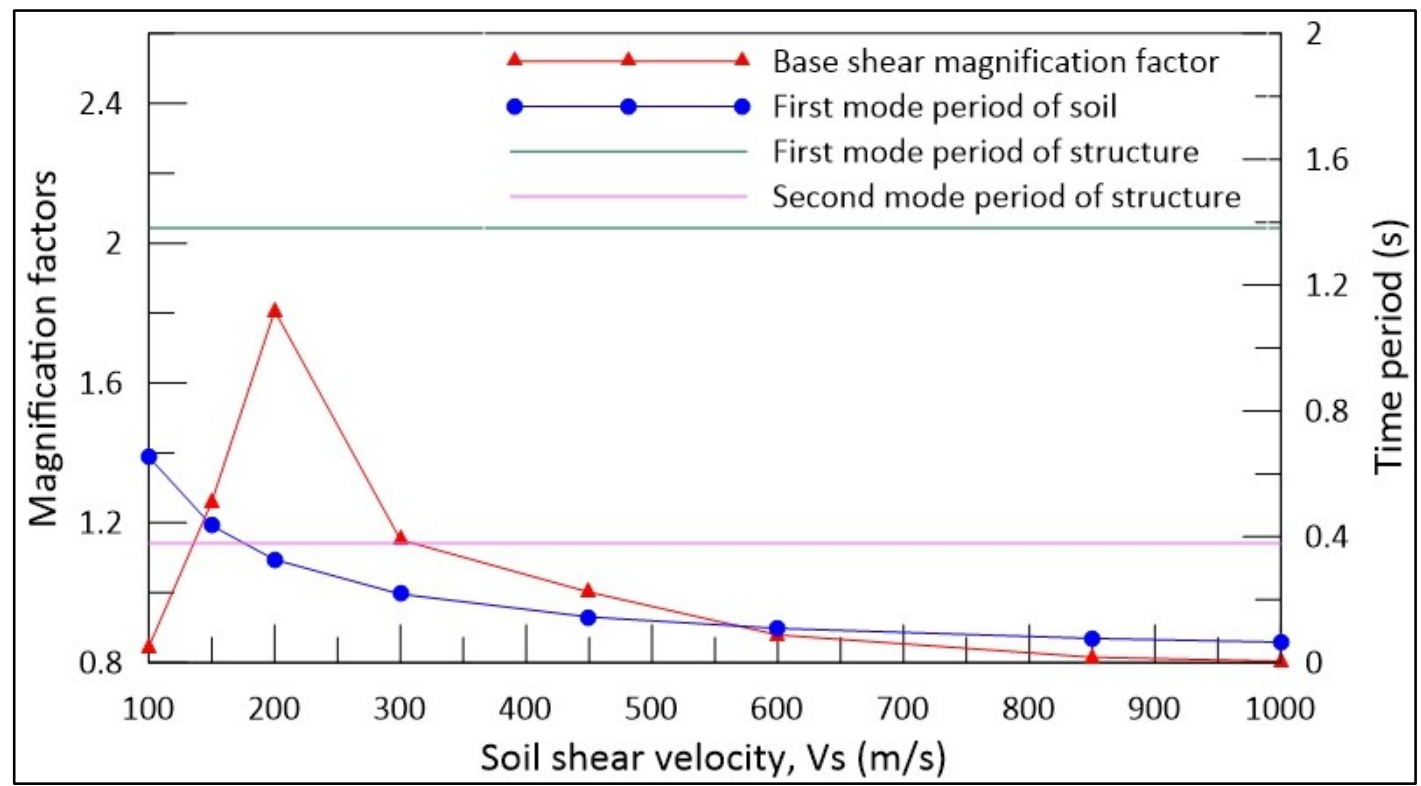

Figure 3-37 Details of shear magnification factors, first mode of the soil, and the first and second modes of the structure - 17 storey building 


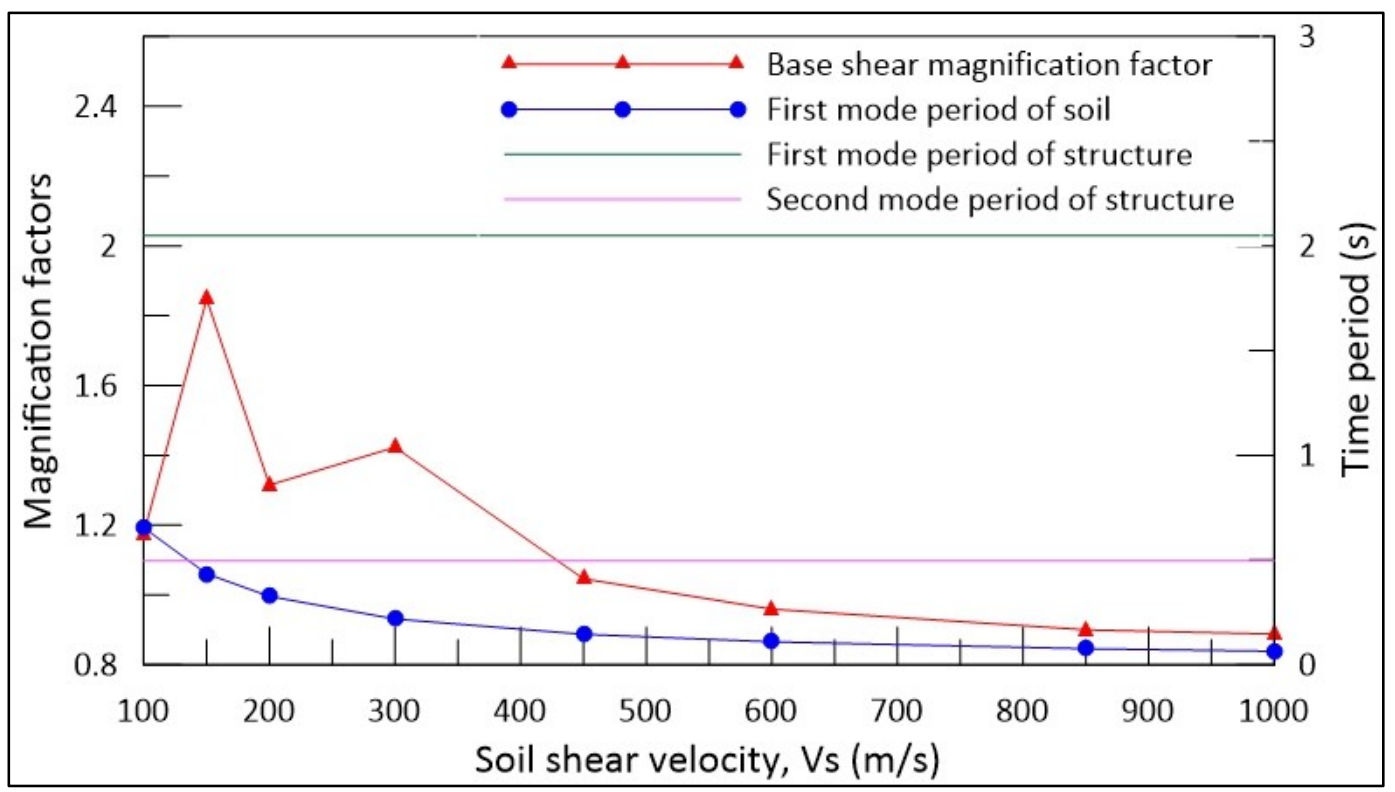

Figure 3-38 Details of shear magnification factors, first mode of the soil, and the first and second modes of the structure - 21 storey building

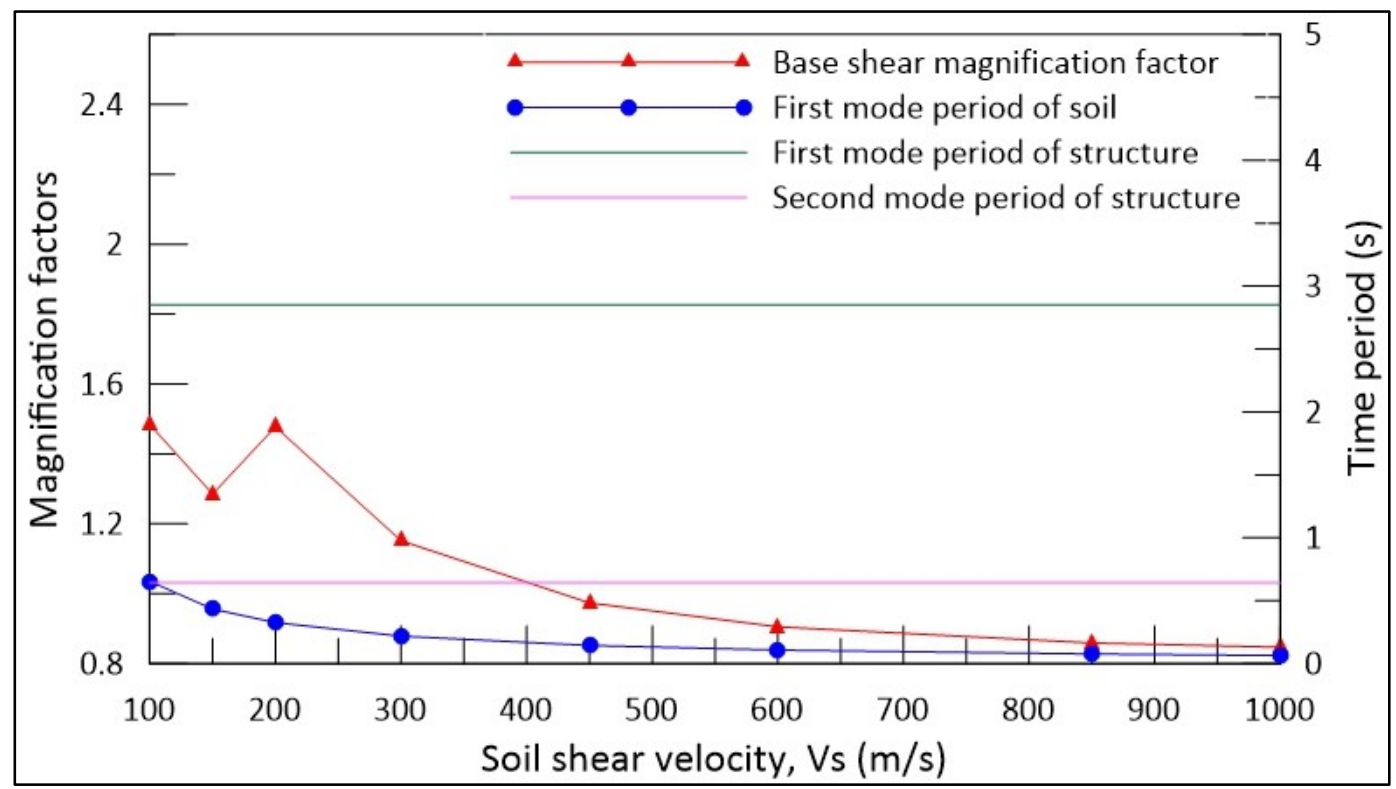

Figure 3-39 Details of shear magnification factors, first mode of the soil, and the first and second modes of the structure - 25 storey building 
Figure 3-35 shows that the magnification factor is 1.88 when the $1^{\text {st }}$ mode period of the structure and the $1^{\text {st }}$ mode period for $150 \mathrm{~m} / \mathrm{s}$ shear wave velocity soil are close to each other. However, for $200 \mathrm{~m} / \mathrm{s}$ shear wave velocity soil, the magnification factor for base shear is 1.87 even though the periods of the structure and soil do not coincide. For the 13 storey building, there is no match between the periods of the structure and the soil. Yet, as seen from Figure 3-36, when the structure is surrounded soil having shear wave velocity of $300 \mathrm{~m} / \mathrm{s}$, a large magnification in the shear at the base of the tower is observed. Similarly, for 17 storey, 21 storey, and 25 storey buildings, where the structure and soil periods are not close shear at the base of the tower is significantly amplified. In conclusion, no definitive correlation between resonance and the magnification factors is found.

\subsubsection{Effect of soil type on seismic response}

To observe the effect of soil type on the seismic response of the buildings, the magnification in shear at the base of the tower for different heights of tower are analyzed with varying conditions of soil as detailed in section 3.7 are plotted in Figure 3-40. From the figure, it is seen that for 9 storey building maximum magnification is observed when the soil has a shear wave velocity of $150 \mathrm{~m} / \mathrm{s}$ or $200 \mathrm{~m} / \mathrm{s}$. For 13 storey building, the maximum magnification occurs when the shear wave velocity of the soil is $300 \mathrm{~m} / \mathrm{s}$, for 17 storey building it is in the case of soil having a shear wave velocity of $200 \mathrm{~m} / \mathrm{s}$, for 21 storey building soil with shear wave velocity of $150 \mathrm{~m} / \mathrm{s}$ produces maximum magnification, and for 25 storey building the maximum magnification is when the soil shear wave velocity is $100 \mathrm{~m} / \mathrm{s}$ Therefore, it is clear that for different tower heights soils having different shear wave velocities ranging from $100 \mathrm{~m} / \mathrm{s}$ (site class E), to $300 \mathrm{~m} / \mathrm{s}$ (near the upper borderline of site class D) cause significant magnification. 


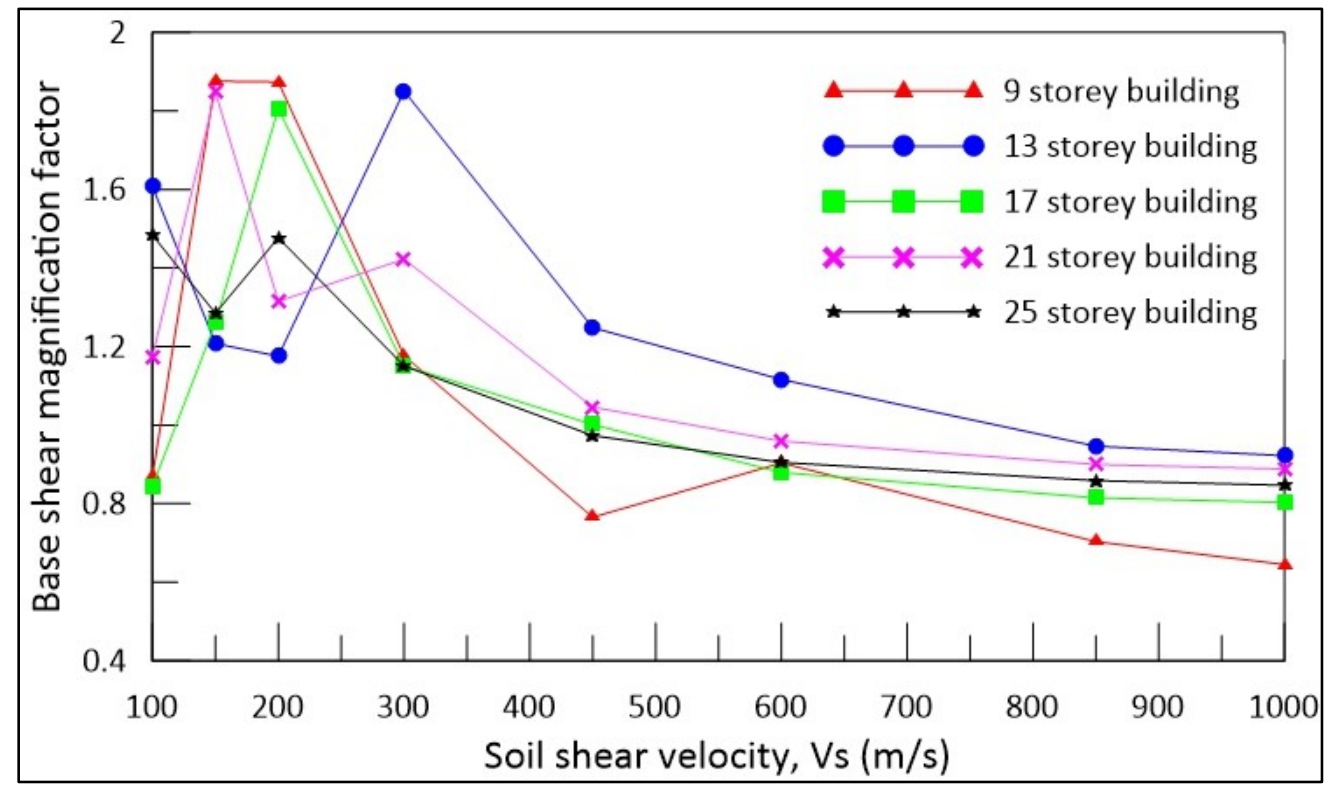

Figure 3-40 Shear magnification factors for different tower heights and varying soil properties

For sites with class C soil $(450 \mathrm{~m} / \mathrm{s}$ and $600 \mathrm{~m} / \mathrm{s})$, there is magnification in shear at the tower base, its value being different for different heights of the building. Effect of SSI with soils belonging to site class $\mathrm{B}(850 \mathrm{~m} / \mathrm{s}$ and $1000 \mathrm{~m} / \mathrm{s})$ is reduction in base shear. The reduced SSI effect for site class B is attributed to the high stiffness of the soil. In general, a reduction in soil stiffness leads to magnification in the base shear.

It is sometime reasoned that nonlinearity in the soil response would reduce the effect of soil-structure interaction. In the present study, it is assumed that the soil remains elastic during its response to an earthquake and hence the effect of nonlinearity is not directly considered. However, the effect of nonlinearity would lead to a reduction in the shear wave velocity and hence in the modulus of rigidity for the soil. Thus, the assumption that with nonlinearity the SSI effect will reduce were to be true a softer soil should reduce the magnification in response. The results show that this is not true. In fact, the softer soils tend to increase the impact of SSI. 


\subsubsection{Effect of number of above ground stories on the seismic response}

For the same local site conditions, the height of the towers above ground influences the seismic response. To understand this effect, consider a site with class E soil $(100 \mathrm{~m} / \mathrm{s})$ and varying tower heights. From the base shear variation for this condition shown in Figure $3-41$, it is apparent that the height of the structure above ground influences the seismic response.

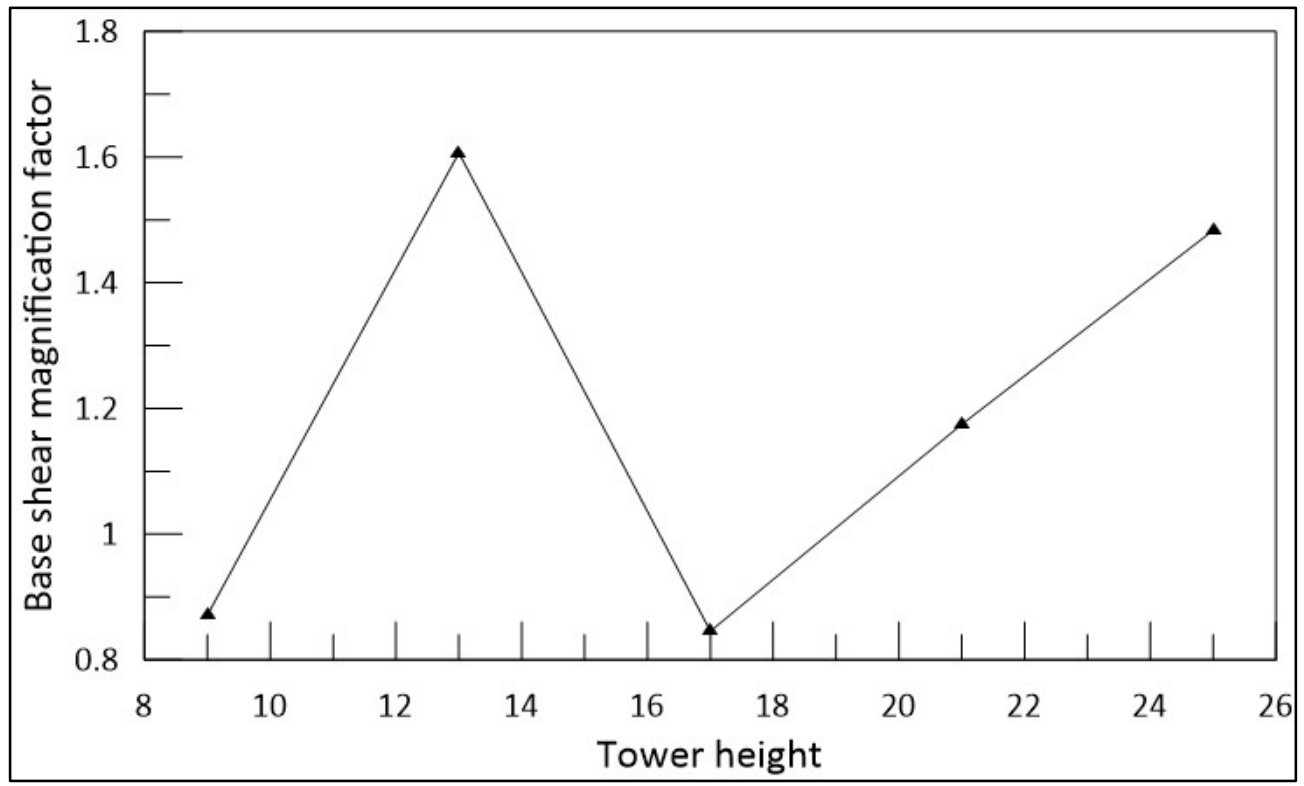

Figure 3-41 Shear magnification factors for different tower heights with a $100 \mathrm{~m} / \mathrm{s}$ shear wave velocity soil

From Figure 3-41, we observe that the site class E soil with $100 \mathrm{~m} / \mathrm{s}$ shear wave velocity causes high magnification in seismic response for the buildings with 8 and 20 storey towers. There does not appear to be a distinctive relationship between magnification factor and tower heights.

\subsubsection{Effect of earthquake characteristics on the seismic response}

To analyze the effect of earthquake characteristics on the seismic response of the structures, storey shears in the soil structure system for a 9 storey building with soil having shear wave 
velocity of $100 \mathrm{~m} / \mathrm{s}$ is plotted for 11 earthquake inputs scaled to match the Vancouver site B spectrum as detailed in Figure 3-42. Similar plots for all buildings with varying properties of the soil are given in Appendix B.

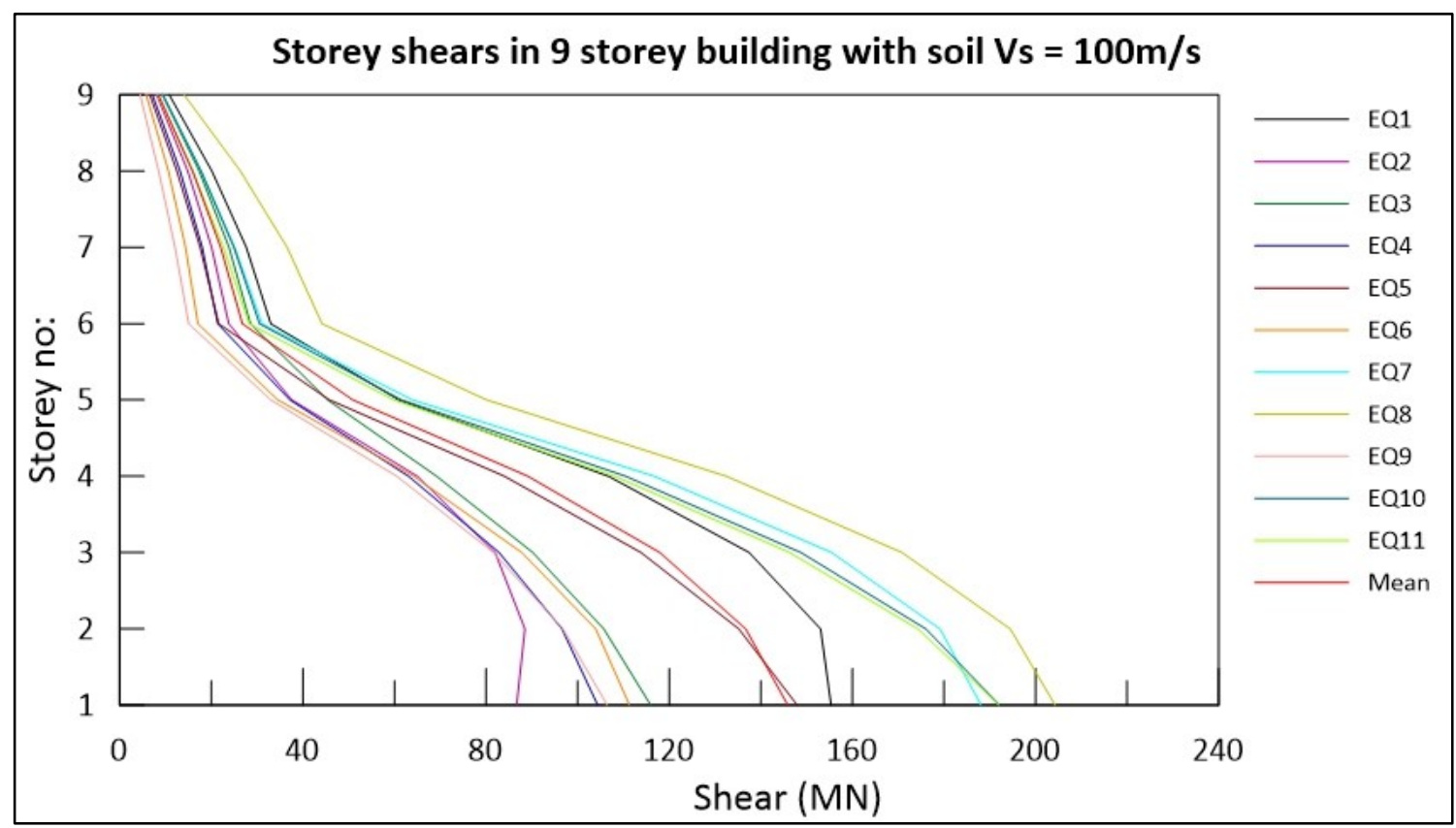

Figure 3-42 Storey shears in 9 storey building with soil shear wave velocity, Vs $=100 \mathrm{~m} / \mathrm{s}$ for 11 different earthquake inputs

As discussed in Section 3.8.2, the first mode period of the 9storey building varies with the property of the accompanying soil. As the soil gets stiffer the period of the soil structure system decreases as the stiffness of the system increases. From Figure 3-42, it is seen that the storey shears are affected by the characteristics of the earthquake input; for the 9 storey building EQ8 input produce the highest shears followed by EQ7 input.

\subsection{Conclusions and recommendations}

1. It is observed that there is magnification in the seismic response of the structure when the effect of soil-structure interaction is considered in the analysis. Hence, the traditional approach of cropping the structure at the foundation level and 
analying it with fixed base, which ignores SSI, assuming that it is beneficial and can thus be ignored in the design is not valid.

2. To examine the effect of resonance on magnification oberved, the modal periods of the structure and the soil are compared. The results show that there is no correlation between resonance and the magnification.

3. The effect of SSI depends on the property of the soil at the site. It is seen from the results that softer soils have greater impact.

4. Based on the results from the analysis of buildings with different tower heights it is apparent that there is no distinctive relationship between the magnification factors observed and the building height.

5. The results of the study also shows that the characteristics of the earthquake input influences the seismic reponse of the SSI system.

The results of this study show that SSI depends on many different parameters, including shear wave velocity in the soil, characteristics of the earthquake and of the structure. Soilstructure interaction can significantly increase the seismic forces in the structure and needs to be considered. Present study assumes that the structure and the soil remain elastic during their response to earthquake excitation. It has sometime been suggested that nonlinearity in the soil may reduce the effect of SSI. The effect of nonlinearity would be to reduce the shear wave velocity in the soil. In this study, analyses have been carried out for several shear wave velocities, including a value as low as $100 \mathrm{~m} / \mathrm{s}$. There is no indication that a reduction in the shear wave velocity would reduce the magnification in forces. 


\section{Chapter 4: Soil-Structure Interaction in a Building founded on Soil overlying Rock}

\subsection{Introduction}

The results of an analytical study carried out to investigate the effect of soil-structure interaction on the seismic response of multi storey buildings with a below-grade structure founded on rock were presented in Chapter 3. The below grade structure was surrounded by soil on each side. The magnification factors of bending moment, shear force, displacement, drift, and acceleration, representing the ratio of the values of a parameter when the building with the surrounding soil to its value when the surrounding soil was absent, were computed to quantify the effects of soil-structure interaction. In practice the foundations are not always placed on bedrock, and often in soil above the bedrock. Analytical studies on the response of such structures under prescribed input bedrock motions is considered when a soil deposit exists between the foundation of the building and rock are presented in this chapter.

When the earthquake waves that travel through the soil deposit below the structure strike the foundation they are scattered and averaged, and the wave motion is altered due to the rigidity of the foundation (commonly referred to as base slab averaging). Further, increasing depth of foundation/basement wall will imply a variation in ground motion along the depth. These factors contribute to the kinematic soil-structure interaction. Also, there is energy loss due to radiation damping in the soil. In addition, the foundation undergoes both displacements and rotations. All these phenomena influence the soilfoundation interaction effects which are the subject of the study reported here. For this 
study, the building is assumed to be supported by a rigid mat foundation resting on a soil deposit overlying rock.

As stated earlier, the focus of the research is to investigate the seismic demand on buildings with a deep below-ground structure. The buildings studied are thus similar to the buildings considered in the previous chapter, and have a five below-grade level parkade with an above-ground tower of variable height. The response of the buildings is analysed for a series of shear strength properties for the soil surrounding and underlying the building. Different combinations of soil shear wave velocities that are compatible with the various site classes defined in NBCC 2015 are adopted The sites considered include site classes B \& C. The buildings studied in Chapter 3 were subjected to Class B motion. To relate the study in this Chapter as closely as possible to the study in Chapter 3 an attempt is made to make the ground response at the foundation level to be similar to Class B motion. This is achieved by applying a Class A motion at the bedrock so that when this motion propagates through the soil overlying the rock at resembles a Class B motion when it arrives at the foundation level. The propagated ground motion at the level of the foundation in the absence of the building and the surrounding soil is first determined. The building alone is next analysed for this propagated motion. In a second set of analysis the system consisting of the building and surrounding soil is analysed for the propagated motion. Finally, the entire system consisting of the building, the surrounding soil, and the soil between the rock and foundation is analysed for the ground motion delivered at the level of rock. The results of the three sets of analyses are compared to find the effect of soil structure interaction. The buildings and the ground motion used in the study are first described. The assumptions made in the analysis are then outlined. The components in OpenSees utilized for building 
the model, and the analysis are then explained, followed by the details of the parametric study. Finally, the results, conclusions, and recommendations derived from the parametric study are presented.

\subsection{The structural model}

As detailed in Section 3.2, the building models analyzed consist of five different building configurations differentiated by the height of their tower above the ground, namely 4,8 , 12, 16, and 20 storeys. The tower sits on a deep below-grade structure surrounded and underlain by a large block of soil. The plan dimensions of the tower and the parkade are $30 \mathrm{~m}$ by $30 \mathrm{~m}$ and $40 \mathrm{~m}$ by $70 \mathrm{~m}$, respectively. In each case, the building under study has five below-grade parkade, and the structure supporting the tower runs through the parkade. Both the tower and parkade storeys are $3 \mathrm{~m}$ in height. The parkade is surrounded by a large block of soil, having a plan dimension of $70 \mathrm{~m}$ by $70 \mathrm{~m}$. The soil deposit under the tower is $180 \mathrm{~m}$ by $70 \mathrm{~m}$ in size and $30 \mathrm{~m}$ in depth, as shown in Figure 4-1.

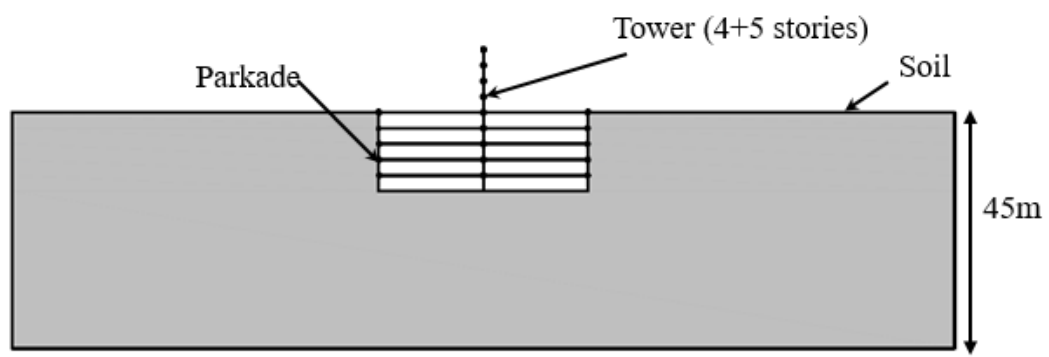

(a)

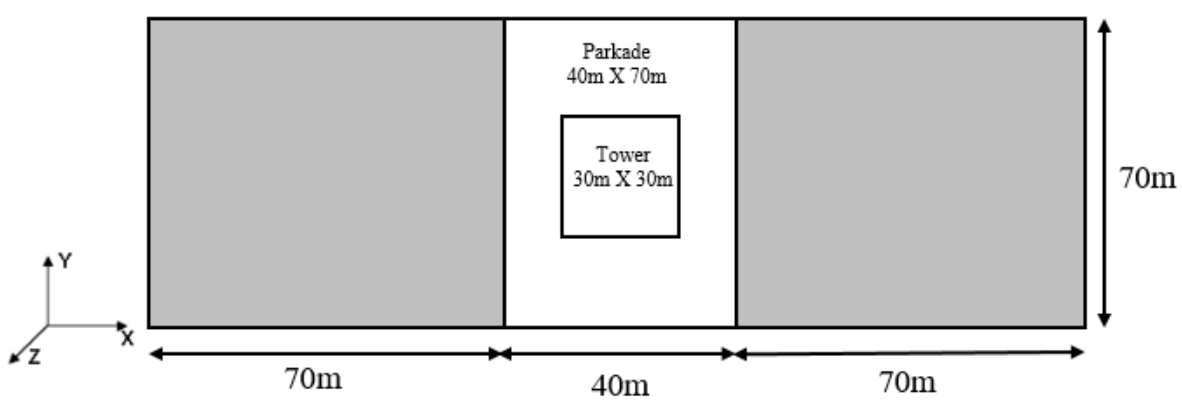

(b) 
The building is assumed to be supported on a thick mat foundation that moves as a rigid body. As explained in the previous chapter, the buildings are identified by the total number of storeys inclusive of the parkade. For example, a building having a tower of height 4 storeys above ground will be referred to as 9 storey building ( 4 above ground storeys +5 below level parkade). Thus, the buildings are referred to as 9 storey, 13 storey, 17 storey, 21 storey, and 25 storey in the analysis as well. The plan view, which is similar for all the buildings under in this study, and the elevation view of the 9 storey building are shown in Figure 4-1.

\subsection{Ground motion records}

The analysis in the study is a time history analysis that requires an earthquake ground motion record as its input. The buildings are assumed to be located on a rock site at Vancouver, conforming to site class A, as defined in NBCC 2015, so the selected ground motion should be compatible with the corresponding uniform hazard spectrum.

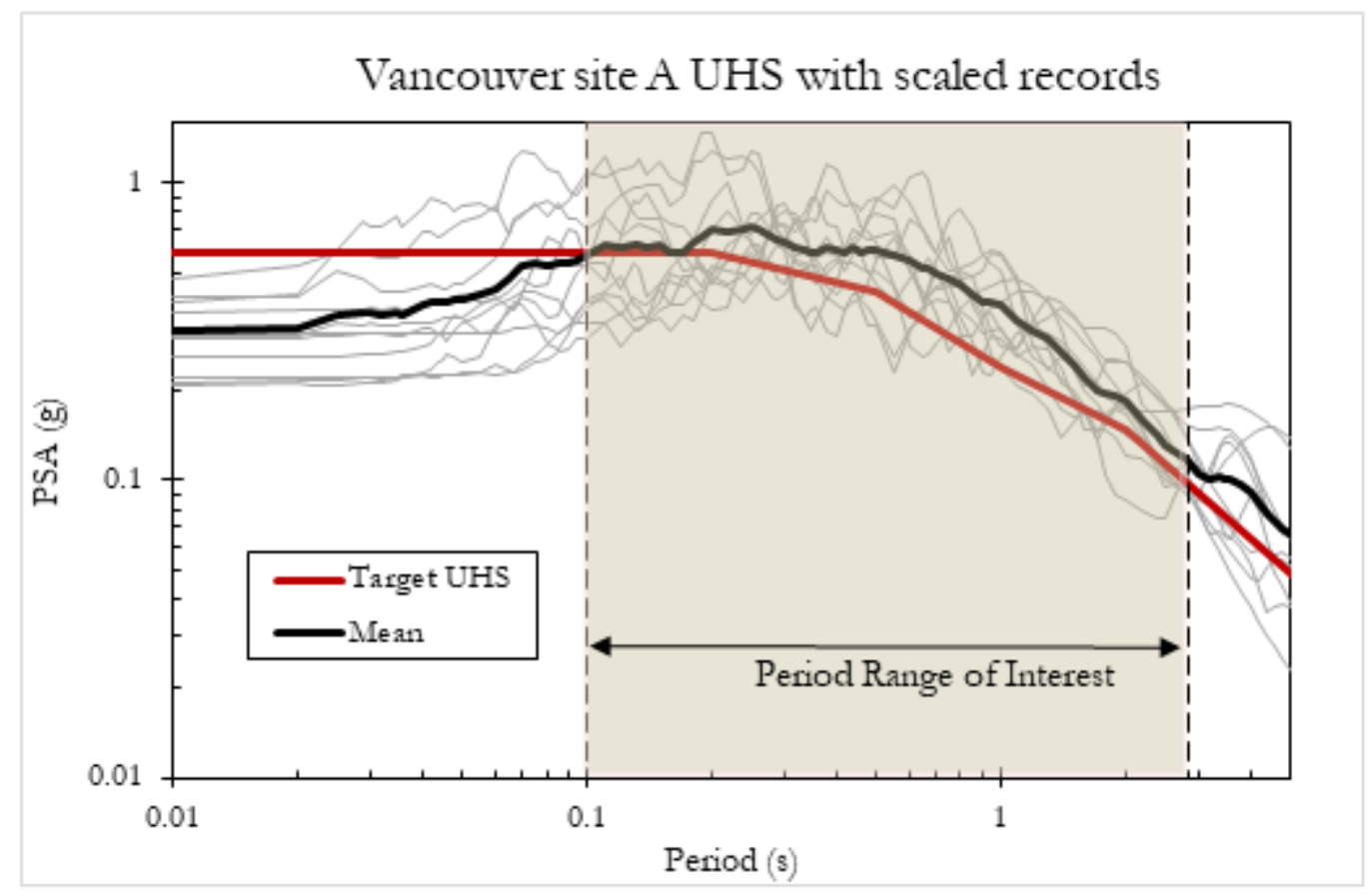

Figure 4-2: Vancouver site A UHS and scaled records 
As explained in Section 3.3, a total of 11 earthquake recorded were downloaded from the PEER website and scaled to match the Vancouver site A UHS over the selected period range (Figure 4-2). From the 11 scaled earthquake records, one earthquake record whose spectrum is closest to the spectrum of class A sites in Vancouver is selected as the input motion for the analysis (Figure 4-3). As seen in Figure 4-3, the scaled spectrum matches the target very closely in the period range of interest (typically about $0.3 \mathrm{~Hz}$ to $10 \mathrm{~Hz}$ ), and deviates at higher frequencies. This characteristic is typical when using scaled natural earthquakes for analysis. Unlike in Chapter 3, the analysis in this chapter considers one earthquake record that is closest to the target. The OpenSees model is developed using assumptions similar to those noted in the previous chapter (Section 3.4).

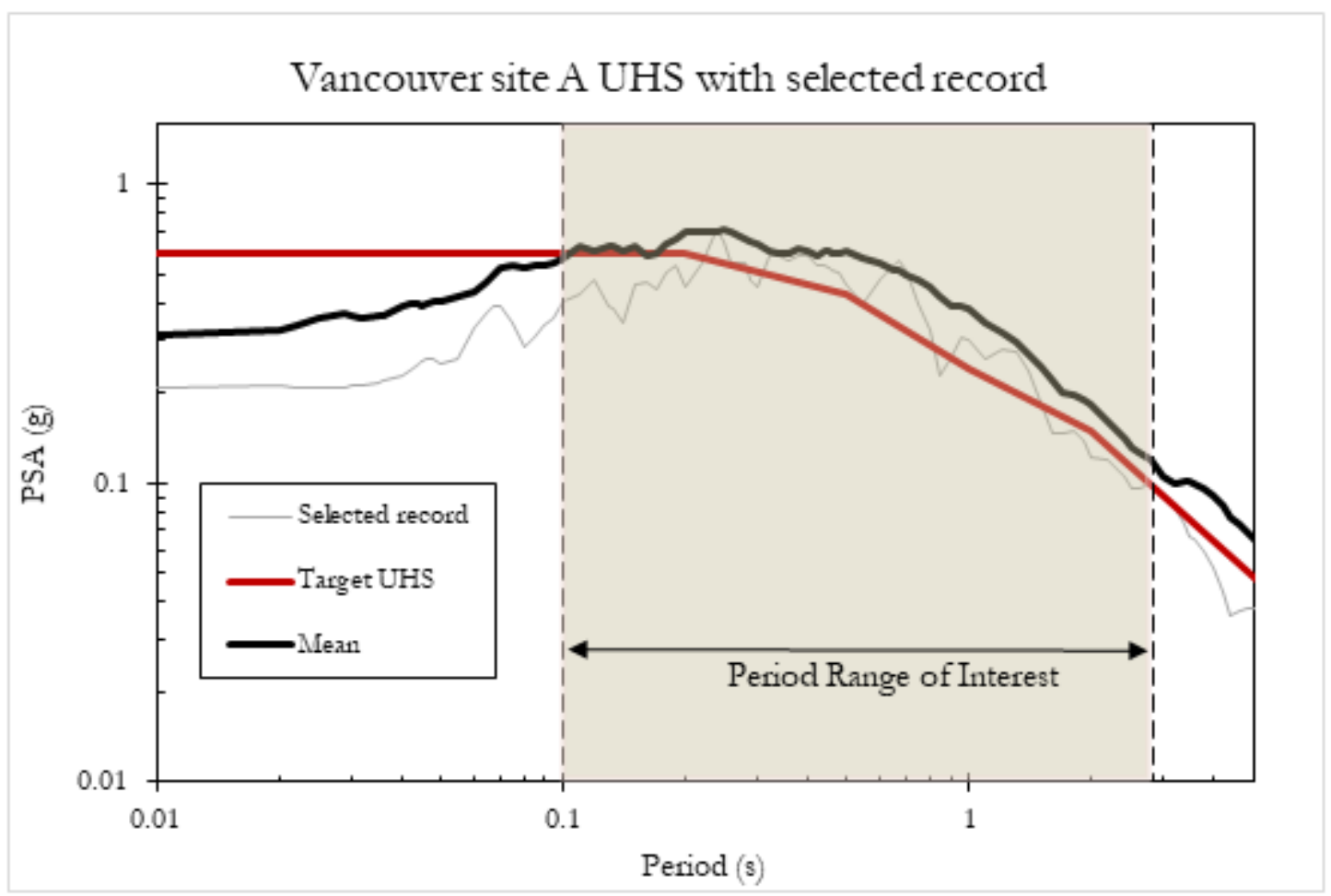

Figure 4-3: Vancouver Site A UHS with the selected record 


\subsection{The OpenSees model}

\subsubsection{Structure}

The analytical model used in the study is as shown in Figure 4-4. The details of the tower structure, including the supporting structure below the ground level, and parkade model are previously presented in Section 3.6.1. The mat foundation is modelled using a series of elastic beam-column elements of $0.5 \mathrm{~m}$ length (selected to be equal to the dimension of the soil element). Very large values are specified for the modulus of elasticity E so that both the flexural rigidity EI and axial rigidity EA are large and the foundation is essentially rigid. The mat covers the footprint of the parkade, and thus the width of the mat foundation is $40 \mathrm{~m}$ (i.e. the distance between the tower, and the parkade wall on either side is $20 \mathrm{~m}$ ). The foundation nodes are connected to the soil nodes using equalDOF command in OpenSees in both $\mathrm{X}$ and $\mathrm{Y}$ directions.

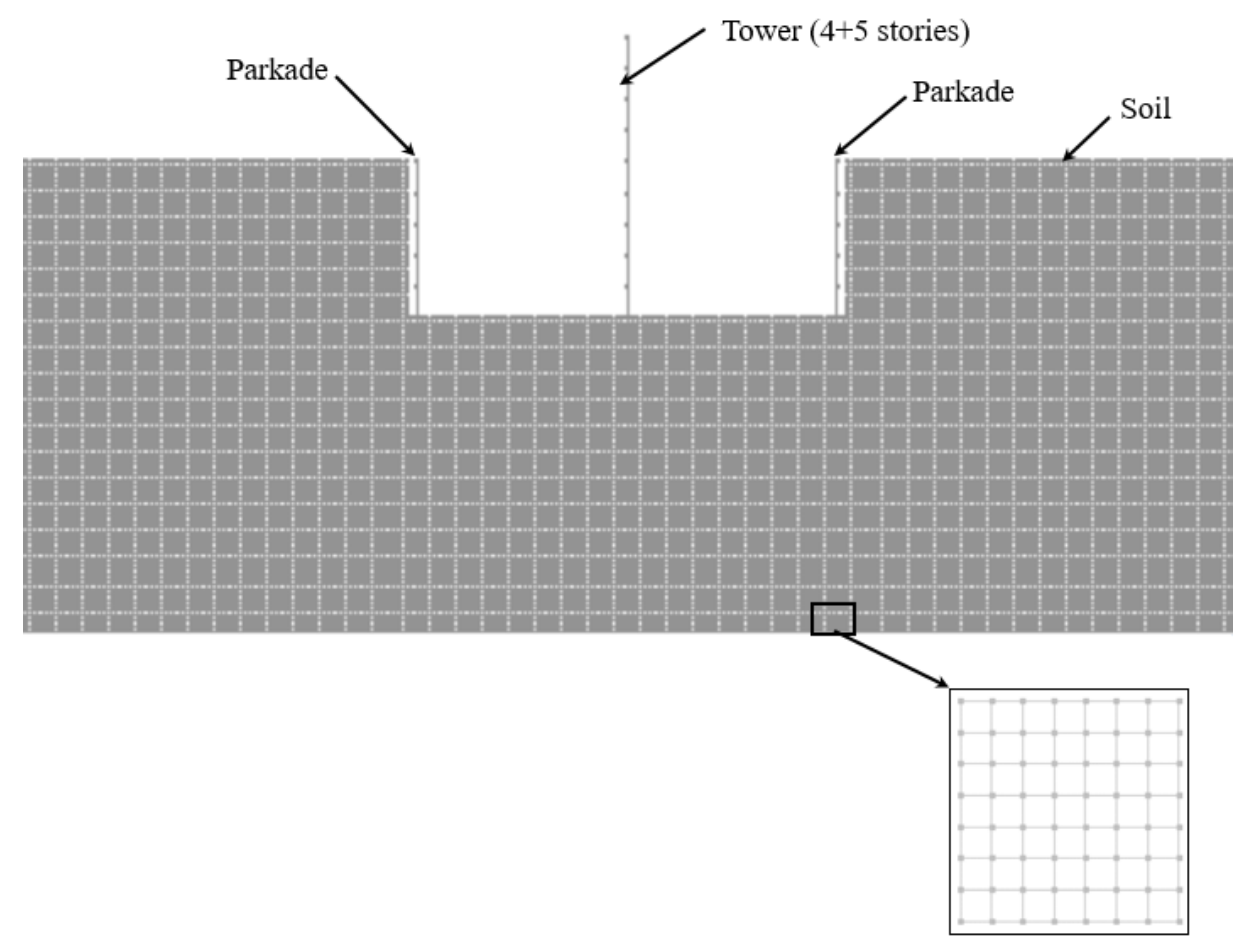

Figure 4-4: Analytical model of 9 storey tower in OpenSees 


\subsubsection{Soil}

The soil elements are modelled as four-node quadrilateral elements of size $0.5 \mathrm{~m}$ by $0.5 \mathrm{~m}$ and thickness 70m using NDmaterial object of type elastic isotopic in OpenSees. The use of an elastic isotropic material model is considered sufficient to yield insights into the effects of SSI for design purposes. Details of the properties used to model the soil elements are presented in Section 3.6.2.

\subsubsection{Boundary conditions}

The soil-structure system consisting of the building, the surrounding soil and the soil underlying the foundation rests on a rigid rock, and the bottom boundary of the system is assumed to be fixed. The lateral boundaries are SVB of Lysmer - Kuhlemeyer (1969), as mentioned in the previous chapter. The dashpots to simulate SVB are modelled using zerolength elements and uniaxial viscous materials in OpenSees. For information on the procedure and the properties used to model dashpots, refer to Section 3.6.3.

\subsection{Parametric study}

The objective of the study is to observe the seismic response of multi-storey buildings with a deep underground structure considering both the inertial interaction, and the kinematic interaction into account. To ensure that the study covers a broad range of building types and soil properties, five different buildings with $4,8,12,16$, and 20 storey towers situated above an underground parkade of 5 storeys and several different combinations of soil properties are analyzed. For each tower height, the following cases are studied, as defined by the shear wave velocity of the soil deposit underneath the building (Figure 4-5). The selected shear wave velocities conform to the soil site classes listed in NBCC 2015,

1) Soil shear wave velocity in the middle of site class B: $1000 \mathrm{~m} / \mathrm{s}$ 
2) Soil shear wave velocity on the border between site class B and site class C: $750 \mathrm{~m} / \mathrm{s}$

3) Soil shear wave velocity in the middle of site class C: $450 \mathrm{~m} / \mathrm{s}$

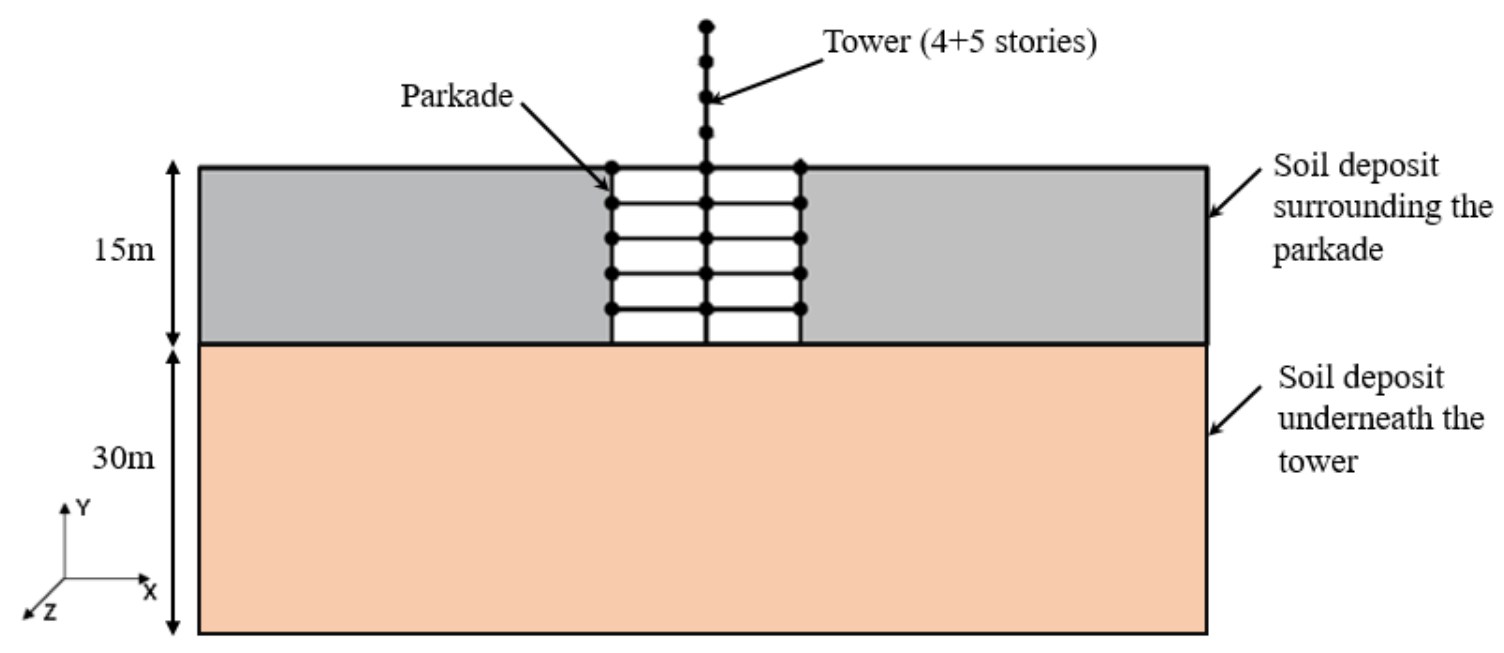

Figure 4-5: Soil classification for parametric study

Consideration was limited to site classes B \& C only since the structure is supported by a mat foundation placed in the soil. Site classes D \& E are not expected to have sufficient capacity to support the taller structures on mat foundations. For the above-listed cases, the following variations are considered. For the purpose of representation, a backslash (/) is used to separate the shear wave velocity of the soil deposit surrounding the parkade and the shear wave velocity of the soil deposit underneath the tower.

\section{Middle of site class B:}

Case 1: $1000 \mathrm{~m} / \mathrm{s} / 1000 \mathrm{~m} / \mathrm{s}$ (same side soil as the soil below the foundation)

Case 2: $750 \mathrm{~m} / \mathrm{s} / 1000 \mathrm{~m} / \mathrm{s}$ (side soil softer than the soil below the foundation)

Case $3: 200 \mathrm{~m} / \mathrm{s} / 1000 \mathrm{~m} / \mathrm{s}$ (very soft side soil as compared to the soil below the foundation)

Borderline of site class B and site class C:

Case 1: $750 \mathrm{~m} / \mathrm{s} / 750 \mathrm{~m} / \mathrm{s}$ (same side soil as the soil below the foundation)

Case 2: $550 \mathrm{~m} / \mathrm{s} / 750 \mathrm{~m} / \mathrm{s}$ (side soil softer than the soil below the foundation) 
Case $3: 200 \mathrm{~m} / \mathrm{s} / 750 \mathrm{~m} / \mathrm{s}$ (very soft side soil as compared to the soil below the foundation)

\section{Middle of site class C:}

Case 1: $450 \mathrm{~m} / \mathrm{s} / 450 \mathrm{~m} / \mathrm{s}$ (same side soil as the soil below the foundation)

Case 2: $300 \mathrm{~m} / \mathrm{s} / 450 \mathrm{~m} / \mathrm{s}$ (side soil softer than the soil below the foundation)

Case 3: $200 \mathrm{~m} / \mathrm{s} / 450 \mathrm{~m} / \mathrm{s}$ (very soft side soil as compared to the soil below the foundation) As stated earlier, a model comprising just the soil block below the foundation without the building and surrounding soil is analysed for its response to the excitation produced by the application of the selected ground motion at the rock below the foundation block. The time history of the horizontal motion at the top surface of the block is determined. This motion is referred to as the propagated motion or free field motion.

To observe the structural demand when the soil structure interaction is ignored, the building consisting of the tower and parkade but without the surrounding soil is analysed for its response to the propagated motion applied at the foundation level. The storey shears, moments, deflections, and accelerations are determined. Next a model comprising the tower, the parkade and the surrounding soil is analysed for its response to the propagated motion. Table 4-1 provides the details of the analysis conducted.

Finally the complete system comprising the building the surrounding soil and the soil below the foundation is analysed for the same ground motion (Vancouver site Class A motion) applied at the rock level. Thus, for each building height, the cases shown in Table 4-1 are analyzed. These are in addition to the analysis of building alone with different tower heights for its response to the propagated motion 


\begin{tabular}{|c|c|}
\hline Tower height & Soil shear wave velocities $(\mathrm{m} / \mathrm{s})$ \\
\hline \multirow{3}{*}{$\begin{array}{l}9 \text { Storey building with the soil on each side } \\
\text { of the parkade as well as under the } \\
\text { foundation analysed for the ground motion } \\
\text { at rock }\end{array}$} & $\begin{array}{l}\text { Middle of site class B: } \\
1000 / 1000,750 / 1000,200 / 1000\end{array}$ \\
\hline & $\begin{array}{l}\text { Borderline of site class B and site class C: } \\
750 / 750,550 / 750,200 / 750\end{array}$ \\
\hline & $\begin{array}{l}\text { Middle of site class C: } \\
450 / 450,300 / 450,200 / 450\end{array}$ \\
\hline \multirow{3}{*}{$\begin{array}{l}9 \text { Storey building with the soil on each side } \\
\text { of the parkade analysed for the propagated } \\
\text { motion }\end{array}$} & $1000 / 1000,750 / 1000,200 / 1000^{(1)}$ \\
\hline & $750 / 750,550 / 750,200 / 750^{(2)}$ \\
\hline & $450 / 450,300 / 450,200 / 450^{(3)}$ \\
\hline \multirow{3}{*}{$\begin{array}{l}13 \text { Storey building with the soil on each } \\
\text { side of the parkade as well as and under the } \\
\text { foundation analysed for the ground motion } \\
\text { at rock }\end{array}$} & $\begin{array}{l}\text { Middle of site class B: } \\
1000 / 1000,750 / 1000,200 / 1000\end{array}$ \\
\hline & $\begin{array}{l}\text { Borderline of site class B and site class C: } \\
750 / 750,550 / 750,200 / 750\end{array}$ \\
\hline & $\begin{array}{l}\text { Middle of site class C: } \\
450 / 450,300 / 450,200 / 450\end{array}$ \\
\hline \multirow{3}{*}{$\begin{array}{l}13 \text { Storey building with the soil on each } \\
\text { side of the parkade analysed for the } \\
\text { propagated motion }\end{array}$} & $1000 / 1000,750 / 1000,200 / 1000^{(1)}$ \\
\hline & $750 / 750,550 / 750,200 / 750^{(2)}$ \\
\hline & $450 / 450,300 / 450,200 / 450^{(3)}$ \\
\hline \multirow{3}{*}{$\begin{array}{l}17 \text { Storey building with the soil on each } \\
\text { side of the parkade as well as and under the } \\
\text { foundation analysed for the ground motion } \\
\text { at rock }\end{array}$} & $\begin{array}{l}\text { Middle of site class B: } \\
1000 / 1000,750 / 1000,200 / 1000\end{array}$ \\
\hline & $\begin{array}{l}\text { Borderline of site class B and site class C: } \\
750 / 750,550 / 750,200 / 750\end{array}$ \\
\hline & $\begin{array}{l}\text { Middle of site class C: } \\
450 / 450,300 / 450,200 / 450\end{array}$ \\
\hline
\end{tabular}


Table 4.1 (Contd)

\begin{tabular}{|c|c|}
\hline Tower height & Soil shear wave velocities $(\mathrm{m} / \mathrm{s})$ \\
\hline \multirow{3}{*}{$\begin{array}{l}17 \text { Storeybuilding with the soil on each side } \\
\text { of the parkade analysed for the propagated } \\
\text { motion }\end{array}$} & $1000 / 1000,750 / 1000,200 / 1000^{(1)}$ \\
\hline & $750 / 750,550 / 750,200 / 750^{(2)}$ \\
\hline & $450 / 450,300 / 450,200 / 450^{(3)}$ \\
\hline \multirow{3}{*}{$\begin{array}{l}21 \text { Storey building with the soil on each } \\
\text { side of the parkade as well as under the } \\
\text { foundation analysed for the ground motion } \\
\text { at rock }\end{array}$} & $\begin{array}{l}\text { Middle of site class B: } \\
1000 / 1000,750 / 1000,200 / 1000\end{array}$ \\
\hline & $\begin{array}{l}\text { Borderline of site class B and site class C: } \\
750 / 750,550 / 750,200 / 750\end{array}$ \\
\hline & $\begin{array}{l}\text { Middle of site class C: } \\
450 / 450,300 / 450,200 / 450\end{array}$ \\
\hline \multirow{3}{*}{$\begin{array}{l}21 \text { Storey building with the soil on each } \\
\text { side of the parkade analysed for the } \\
\text { propagated motion }\end{array}$} & $1000 / 1000,750 / 1000,200 / 1000^{(1)}$ \\
\hline & $750 / 750,550 / 750,200 / 750^{(2)}$ \\
\hline & $450 / 450,300 / 450,200 / 450^{(3)}$ \\
\hline \multirow{3}{*}{$\begin{array}{l}25 \text { Storey building with the soil on each } \\
\text { side of the parkade as well as and under the } \\
\text { foundation analysed for the ground motion } \\
\text { at rock }\end{array}$} & $\begin{array}{l}\text { Middle of site class B: } \\
1000 / 1000,750 / 1000,200 / 1000\end{array}$ \\
\hline & $\begin{array}{l}\text { Borderline of site class B and site class C: } \\
750 / 750,550 / 750,200 / 750\end{array}$ \\
\hline & $\begin{array}{l}\text { Middle of site class C: } \\
450 / 450,300 / 450,200 / 450\end{array}$ \\
\hline \multirow{3}{*}{$\begin{array}{l}25 \text { Storey building with the soil on each } \\
\text { side of the parkade analysed for the } \\
\text { propagated motion }\end{array}$} & $1000 / 1000,750 / 1000,200 / 1000^{(1)}$ \\
\hline & $750 / 750,550 / 750,200 / 750^{(2)}$ \\
\hline & $450 / 450,300 / 450,200 / 450^{(3)}$ \\
\hline
\end{tabular}

(1) Analyzed for the free field motion obtained by ground response analysis of $30 \mathrm{~m}$ soil deposit with $1000 \mathrm{~m} / \mathrm{s}$ shear wave velocity.

(2) Analyzed for the free field motion obtained by ground response analysis of $30 \mathrm{~m}$ soil deposit with $750 \mathrm{~m} / \mathrm{s}$ shear wave velocity. 
(3) Analyzed for the free field motion obtained by ground response analysis of $30 \mathrm{~m}$ soil deposit with $450 \mathrm{~m} / \mathrm{s}$ shear wave velocity.

\subsection{Ground response analysis}

The influence of local soil conditions on the nature of earthquake damage has been recognized for many years (Mendoza \& Auvinet, 1988; Rathje et al. 2000). The properties of the soil play a critical role in determining the characteristics of the ground surface motion for a given bedrock motion. The soil deposit overlying the bedrock acts as a filter and modifies the ground motion characteristics when earthquake waves propagate from the bedrock to the surface. Due to this filtering effect of the soil, the earthquake waves are amplified at some frequencies and damped at some others. The nature of the amplification (or attenuation) at different frequencies will depend on the intensity of the input bedrock motion and the natural frequencies of the soil deposit. A ground response analysis is required to determine this modification in seismic shaking. Two of the cases mentioned in the parametric study, (1) the building alone, and (2) the building with surrounding soil, require input free-field motion. This is determined by using a simple model (only the soil deposit beneath the foundation) analyzed with SVB lateral boundaries and fixed bottom boundary. The damping in the soil is assumed to be $5 \%$. As detailed in the parametric study, three different foundation soil profiles are considered. An earthquake input motion described previously is applied at the bottom of the deposit, and the response on the top of the soil deposit is recorded for all three shear wave velocity profiles. The spectra with $5 \%$ damping ratio are computed for the ground motions and are plotted in Figure 4-6. 


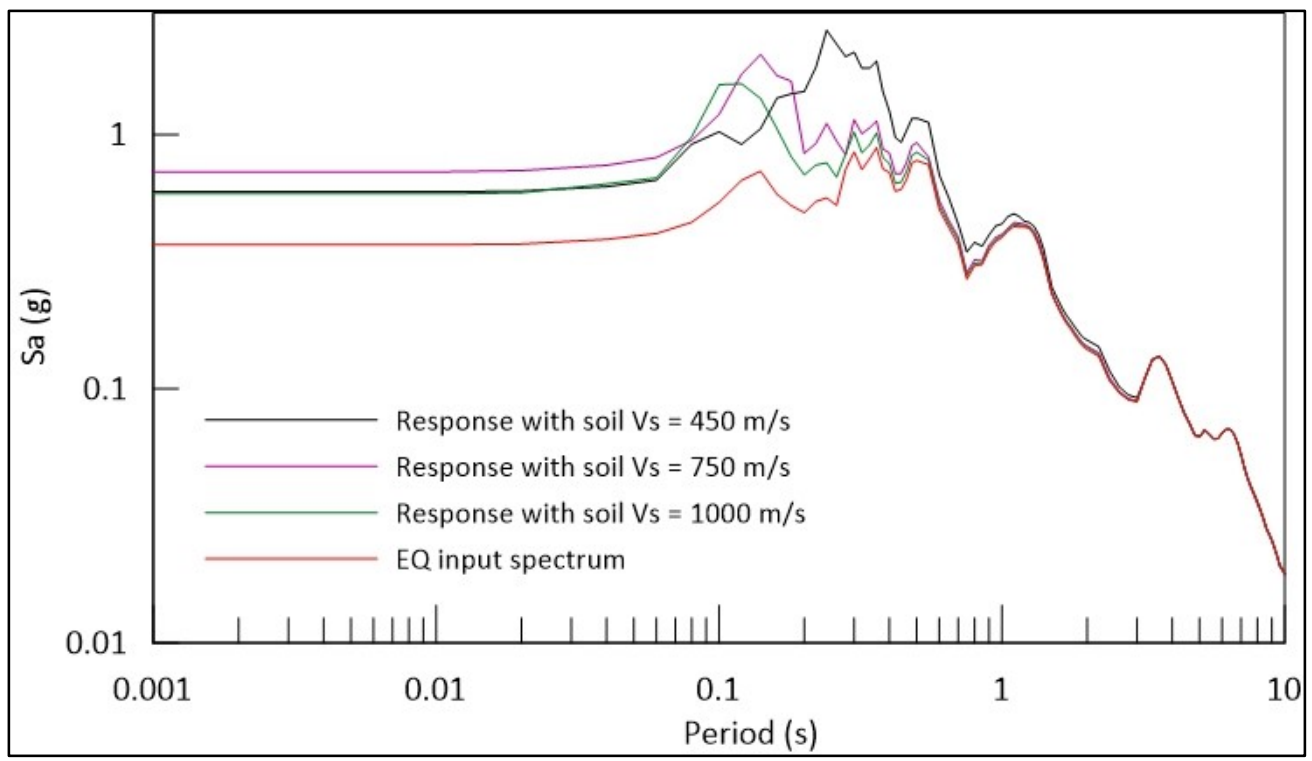

Figure 4-6 : Ground response analysis results

It is observed from Fig. 4-6 that softer soils cause greater amplification in response when compared with the stiffer soils. Also, the peak in response is observed at the periods close to the theoretical first mode periods of the soil deposit (which are $0.27,0.16$ and $0.12 \mathrm{~s}$ respectively for $V_{s}=450,750 \& 1000 \mathrm{~m} / \mathrm{s}$ ).

\subsection{Dynamic analysis}

Following the initial analysis to determine the free-field input motions, the next series of analysis explore the response of the structure subjected to the prescribed bedrock motion without consideration of the soil-structure interaction effects. The earthquake input motion scaled to match the Vancouver site A spectrum is applied at the base of the soil-structure system. The storey shears, storey moments, accelerations, displacements, and drifts are recorded for each building height. As stated earlier, one objective of the present study is to evaluate the traditional approach in which the structure is analyzed with a fixed base ignoring the effect of soil-structure interaction. To examine this, the response obtained by analyzing the complete soil-structure system for site class A compatible earthquake input 
is compared with the response obtained from an analysis of the structure alone to the freefield motion obtained by ground response analysis.

To observe the variation in response when the kinematic interaction and foundation flexibility are ignored, and when both the inertial and kinematic interaction are taken into account, the response obtained by cropping the structure at the foundation level, including the surrounding soil in the model and analyzing the system for free-field motion is compared with the response obtained by analyzing the structure alone for the free-field motion. The magnification factors observed at the base storey of the tower are plotted to understand the effect of soil-structure interaction on the seismic response of the structure. These analyses considered the following cases, and the responses observed for all three cases are presented in the following sections,

(1) the building, the soil surrounding the parkade and the soil under the base of the building analyzed for Site class A compatible earthquake input motion,

(2) the building and the soil surrounding the parkade analyzed for free-field motion, and

(3) the building alone analyzed for free-field motion

\subsubsection{Results of dynamic analysis}

The responses recorded at various tower heights for each of the dynamic analyses are presented in the following sections. As detailed in the previous chapter, shear refers to the shear in a storey, moment is the moment at the bottom of a storey, and accelerations and displacements are measured at the top of the storey. All values are measured at the peaks in the time history of response. For each building the values reported are for the tower and its supporting structure. The response in the parkade has not been reported except the shear 
in the parkade, which has been taken into account for storey shears. In addition, the following two abbreviations are used to identify the type of model used for in the analysis,

- Building on soil overlying rock (BOSR) - the parkade is surrounded by soil and the structure is supported on a rigid mat foundation that rests on a soil deposit overlying rock. This model is analyzed for site A compatible motion applied at the rock level.

- Building on rock (BOR) - the parkade is surrounded by soil and the structure rests on firm ground. This model is analyzed for free-field motion.

The shear wave velocities of soils used in the BOSR are denoted by two numbers separated by a backslash (/) as detailed in section 4.7. For example, BOSR 200/1000 refers to the case when the side soil has a shear wave velocity of $200 \mathrm{~m} / \mathrm{s}$ and the underlying soil has a shear wave velocity of $1000 \mathrm{~m} / \mathrm{s}$.

The BOR model also identifies the same two velocities, the first velocity being of the side soil while the second is that of underlying soil. However in this case Class A motion propagates through the underlying soil without the presence of the building and side soil. The system consisting of the building and the side soil are assumed to rest on firm ground and are analysed for the propagated motion. For example BOR 200/1000 means that Class A motion propagates through the layer of underlying soil having a shear wave velocity of $1000 \mathrm{~m} / \mathrm{s}$ (without the structure in place) and the propagated motion at the top of the soil is then used in the analysis of the building along with side soil having a shear wave velocity of $200 \mathrm{~m} / \mathrm{s}$. The response of the structure under different cases is compared to the typical analysis conducted by most practicing engineers (i.e., the response of the building alone subjected to the input bedrock motions) to determine the level of magnification in the given configuration. 


\section{9 storey building}

Figure 4-7 and Figure 4-8 shows the plots of storey shear, and moment at the bottom of each storey in the 4 storey tower and its supporting structure when the underlying soil has a shear wave velocity of $450 \mathrm{~m} / \mathrm{s}$ while the surrounding soil has one of three different values of the shear wave velocity as detailed in Section 4.7. For comparison the response for the case of building alone are also shown. It is observed that BOR response is generally higher than the response of the building alone (except in the case of BOR 450/450 for the bottom five storeys). The BOSR response is generally lower than the case of building alone, except for the case of BOSR 200/450 which yields somewhat higher moments in the bottom five storeys. Thus, in many cases, the soil and the structure analyzed together resulted in increase in demand.

In general the BOR amplifications are larger than the corresponding BOSR magnifications. Figure 4-9 to Figure 4-11 shows the plots of storey drifts, displacements, and accelerations, respectively, in the 4 storey tower and its supporting structure. The maximum magnification in shear and moment at the base of the 4 storey tower is observed for BOR 200/450. The second highest magnification is observed for BOR 300/450, followed by the case BOSR 200/450. A trend, similar to that in the case of storey shear magnification, is observed for storey drifts. As shown in Figure 4-9, the highest magnification is observed for BOR 200/450 followed by the case BOR 300/450. 


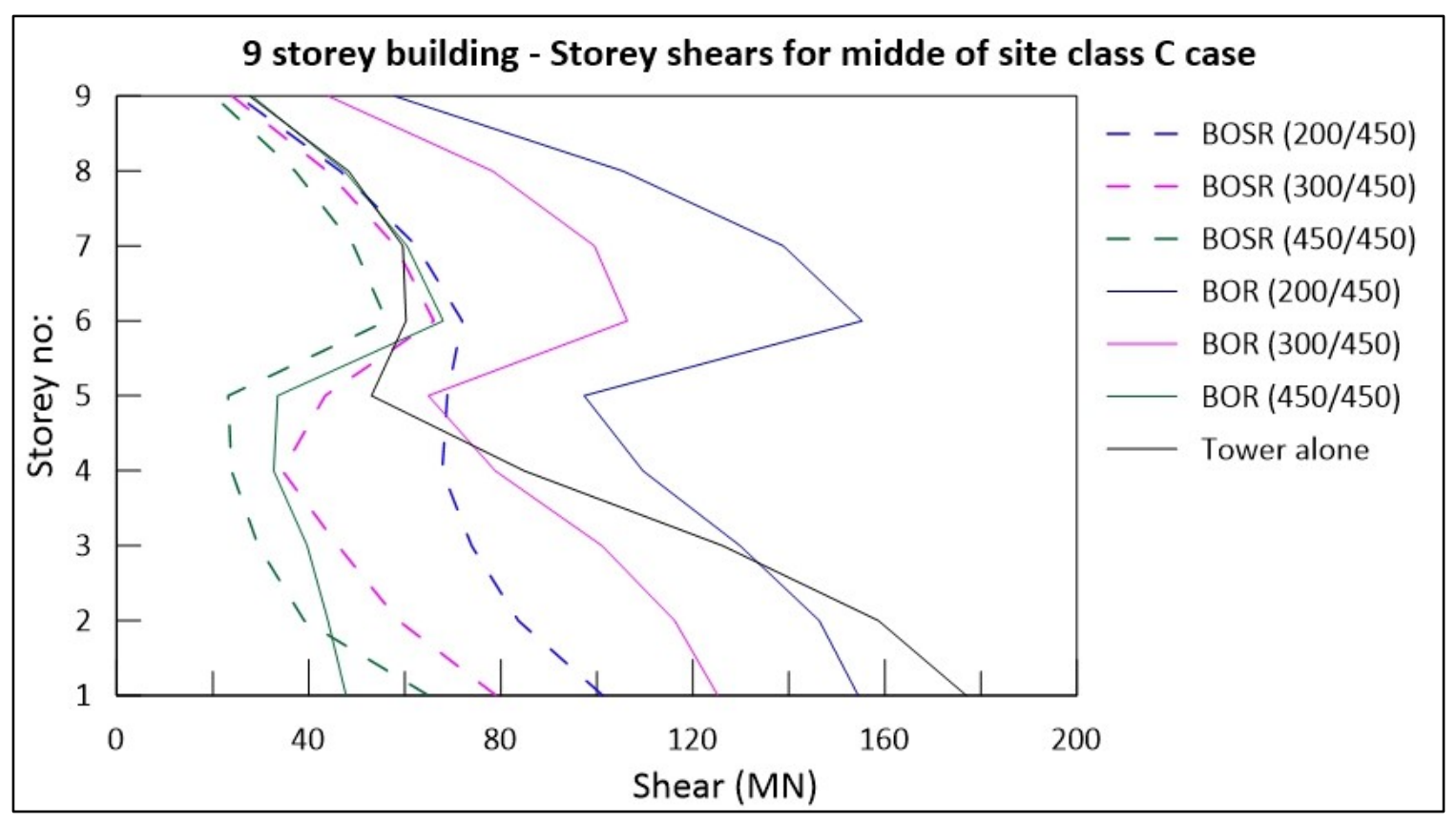

Figure 4-7: Storey shear values for a 9 storey building, shear wave velocity of the soil underlying foundation $=450 \mathrm{~m} / \mathrm{s}$

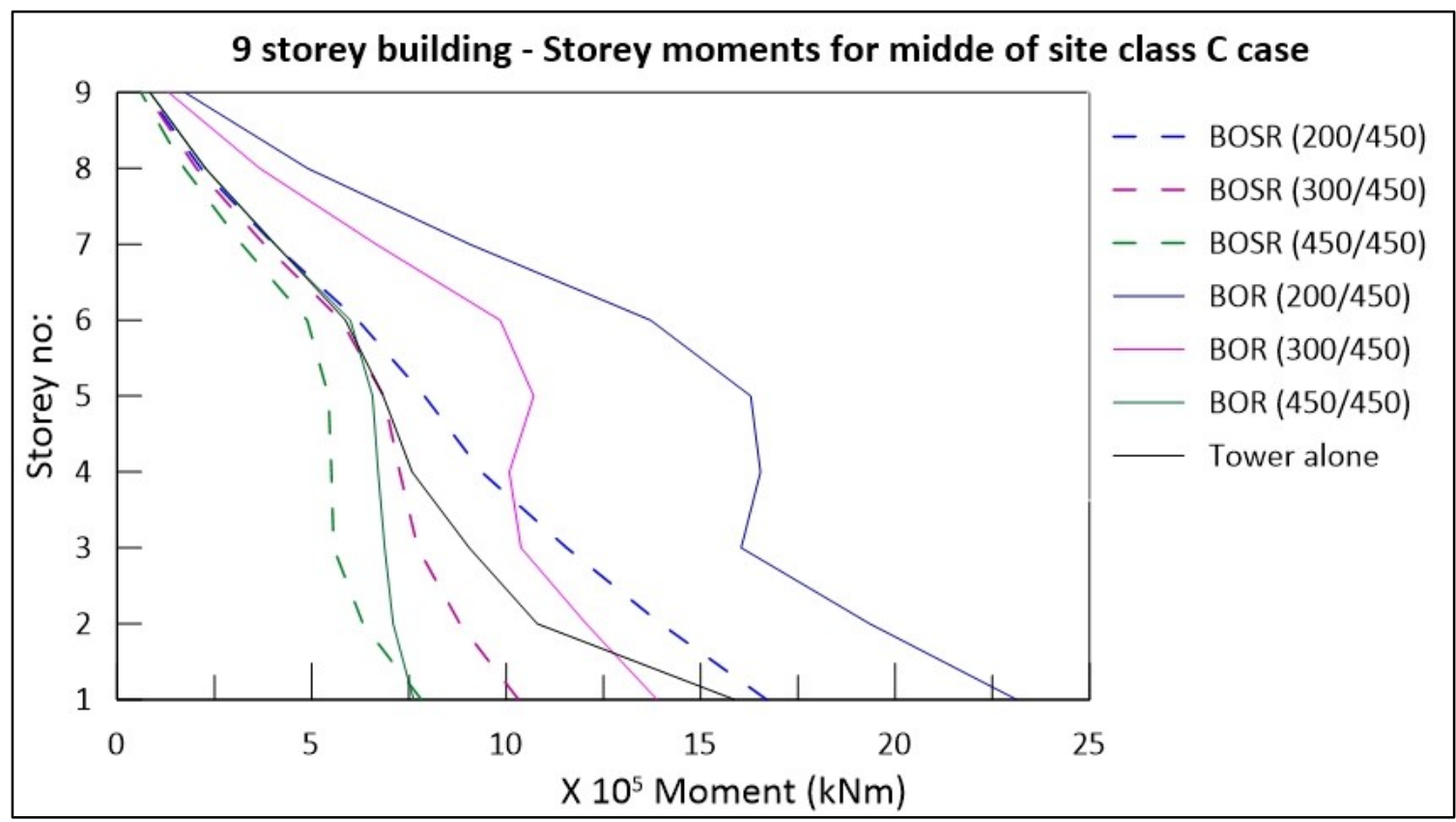

Figure 4-8: Moment at the bottom of the storey for a 9 storey building, shear wave velocity of the soil underlying foundation $=450 \mathrm{~m} / \mathrm{s}$ 


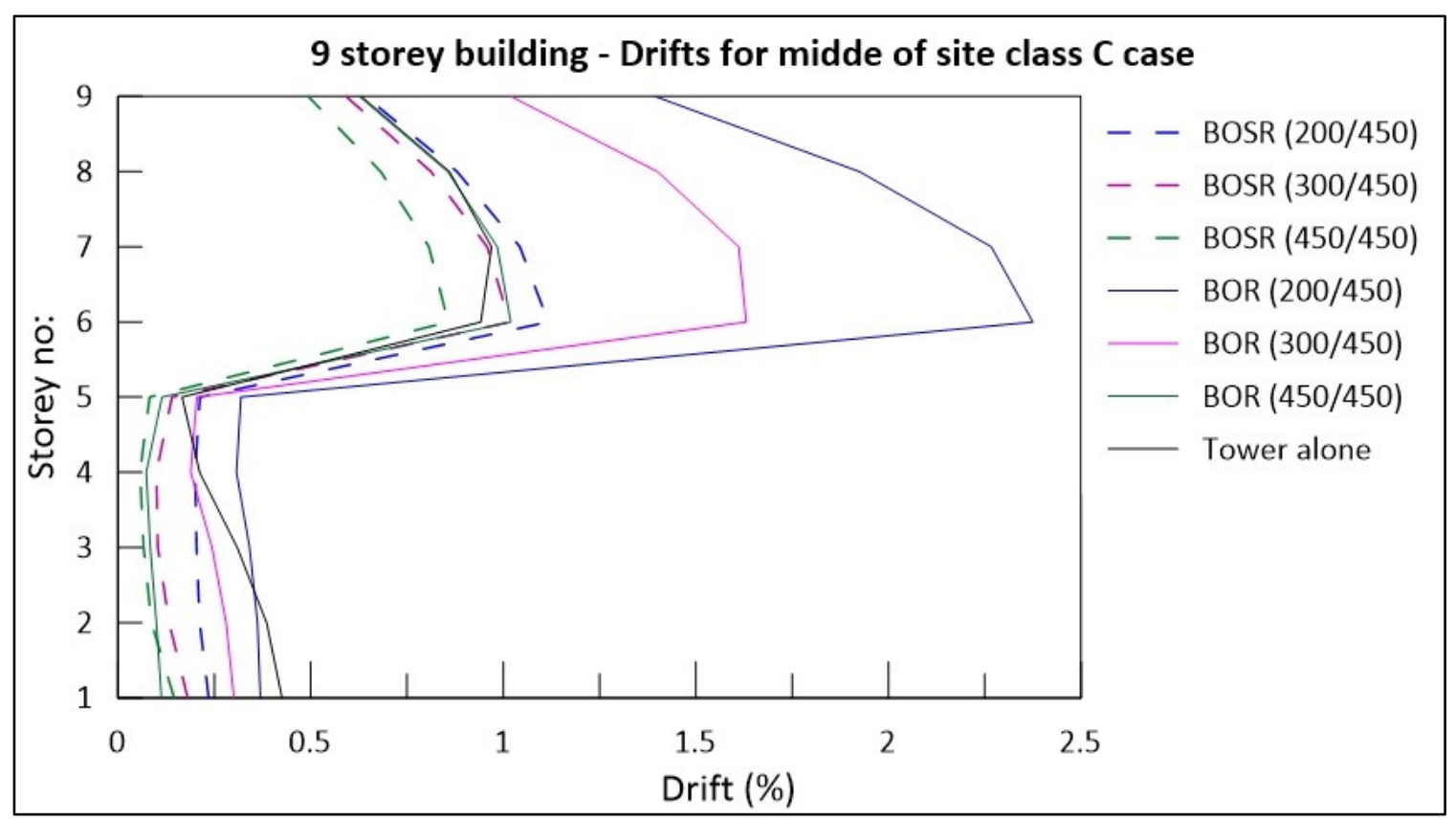

Figure 4-9: Storey drift for the 9 storey building, shear wave velocity of the soil underlying foundation $=$ $450 \mathrm{~m} / \mathrm{s}$

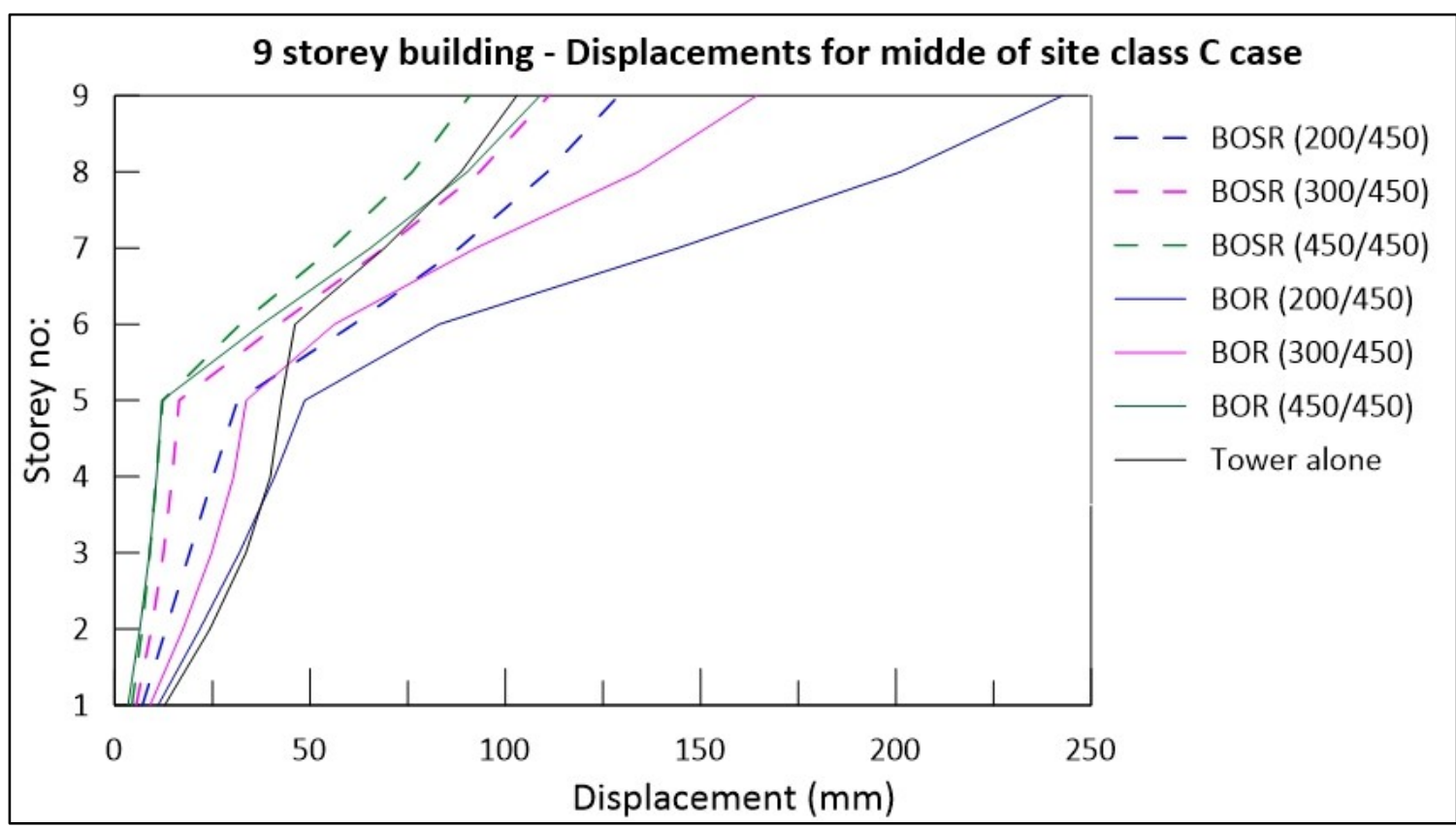

Figure 4-10: Displacement at the top of a storey for 9 storey building, shear wave velocity of the soil underlying foundation $=450 \mathrm{~m} / \mathrm{s}$ 


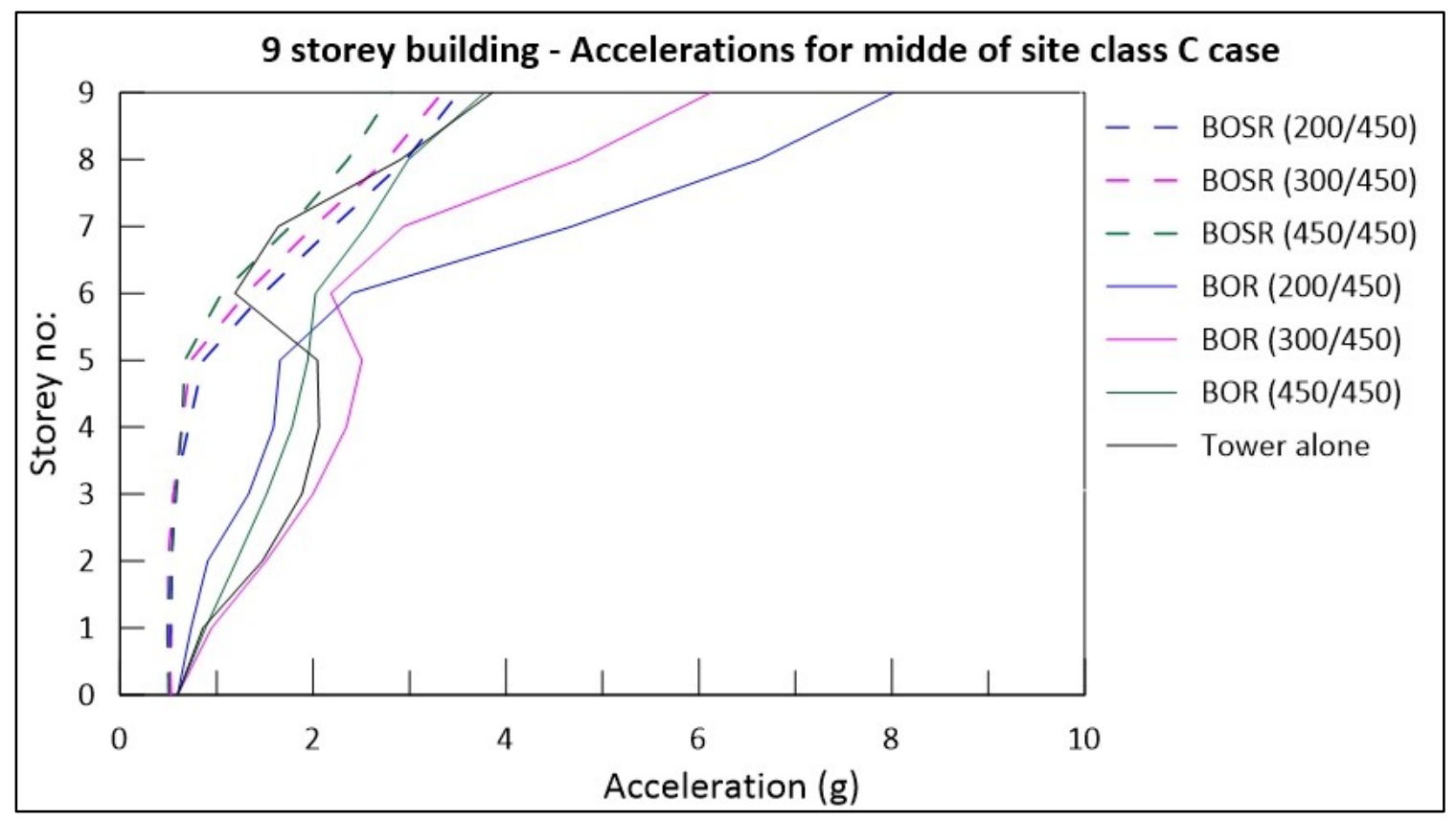

Figure 4-11: Accelerations at the top of a storey for 9 storey building, shear wave velocity of the soil underlying foundation $=450 \mathrm{~m} / \mathrm{s}$

The maximum displacement is observed for BOR 200/450 (Figure 4-10). The highest magnification in acceleration at the base of the tower also occurs for BOR 200/450 as shown in Figure 4-11.

Figure 4-12 and Figure 4-13 presents the results for the 9 storey building when the soil under the base of the building has a shear wave velocity of $750 \mathrm{~m} / \mathrm{s}$. From these figures, it is observed that the highest magnification in storey shear and moments is for the case BOR 200/750. The second highest magnification is observed for the case BOSR 200/750. Again, in general, the magnification in the BOR cases are higher than those in the BOSR cases. The magnification in storey drifts follow the same trend as that for the storey shears (Figure 4-14). 


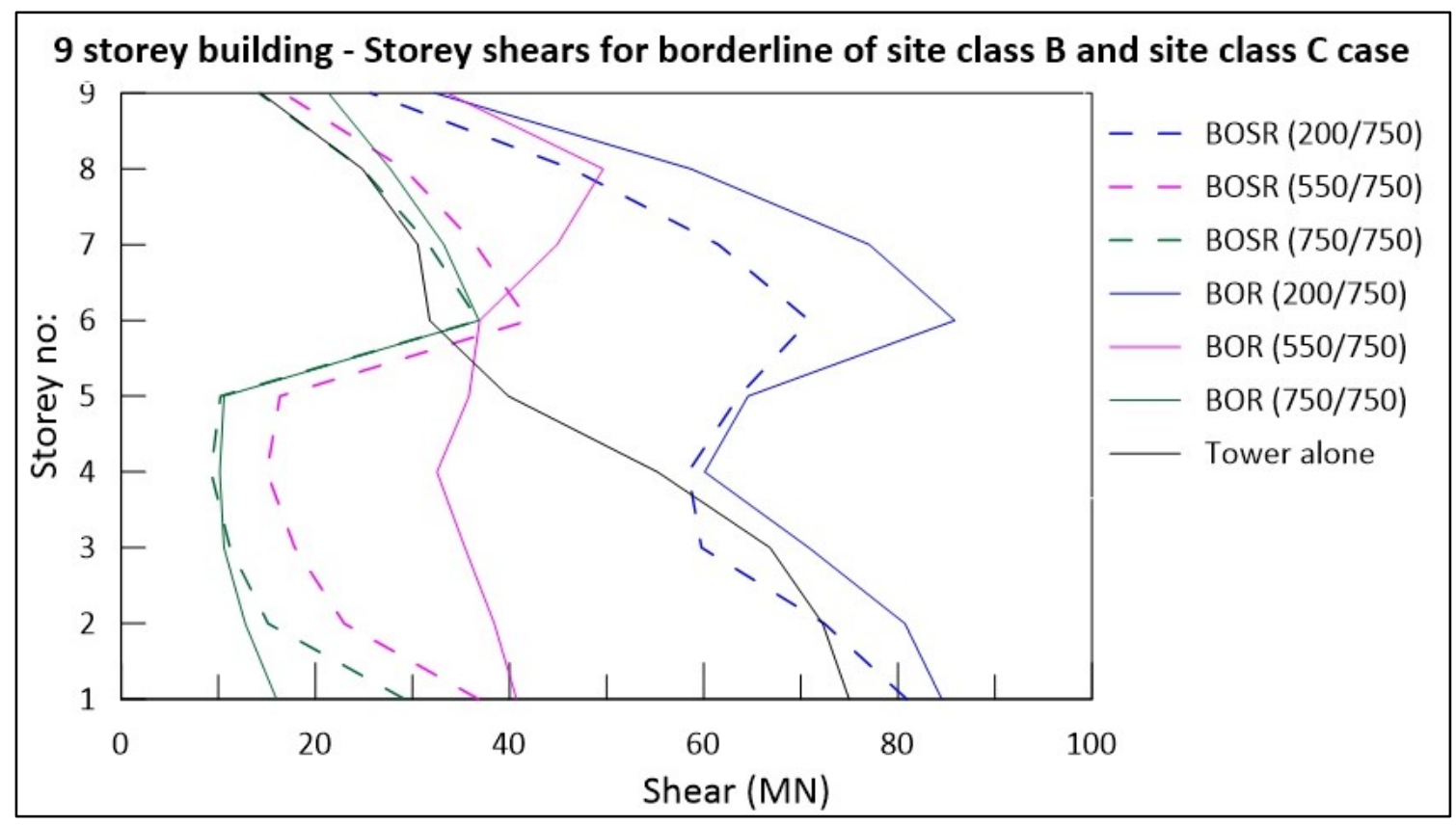

Figure 4-12: Storey shear values for a 9 storey building, shear wave velocity of the soil underlying foundation $=750 \mathrm{~m} / \mathrm{s}$

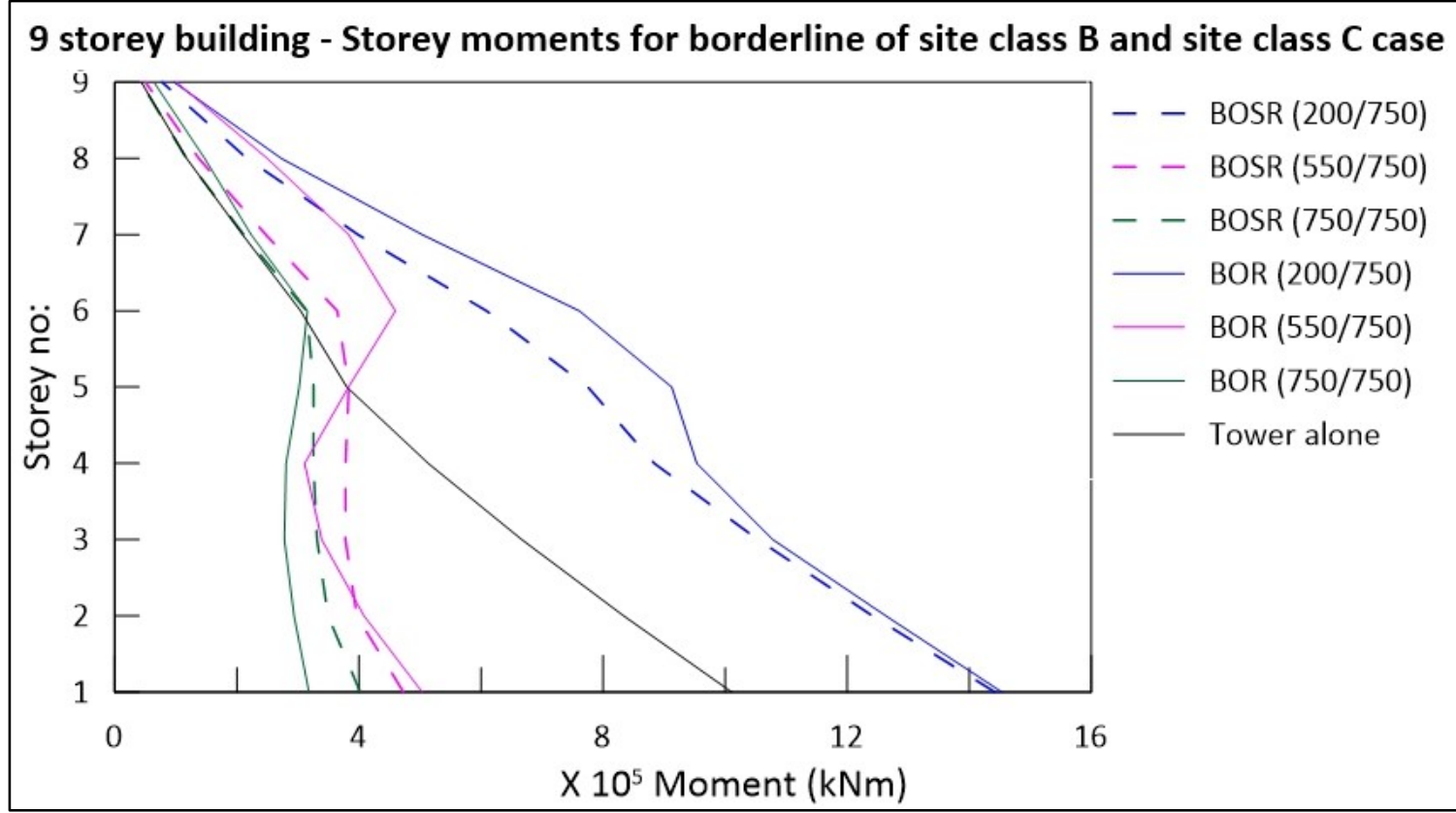

Figure 4-13: Moment at the bottom of the storey for a 9 storey building, shear wave velocity of the soil underlying foundation $=750 \mathrm{~m} / \mathrm{s}$ 


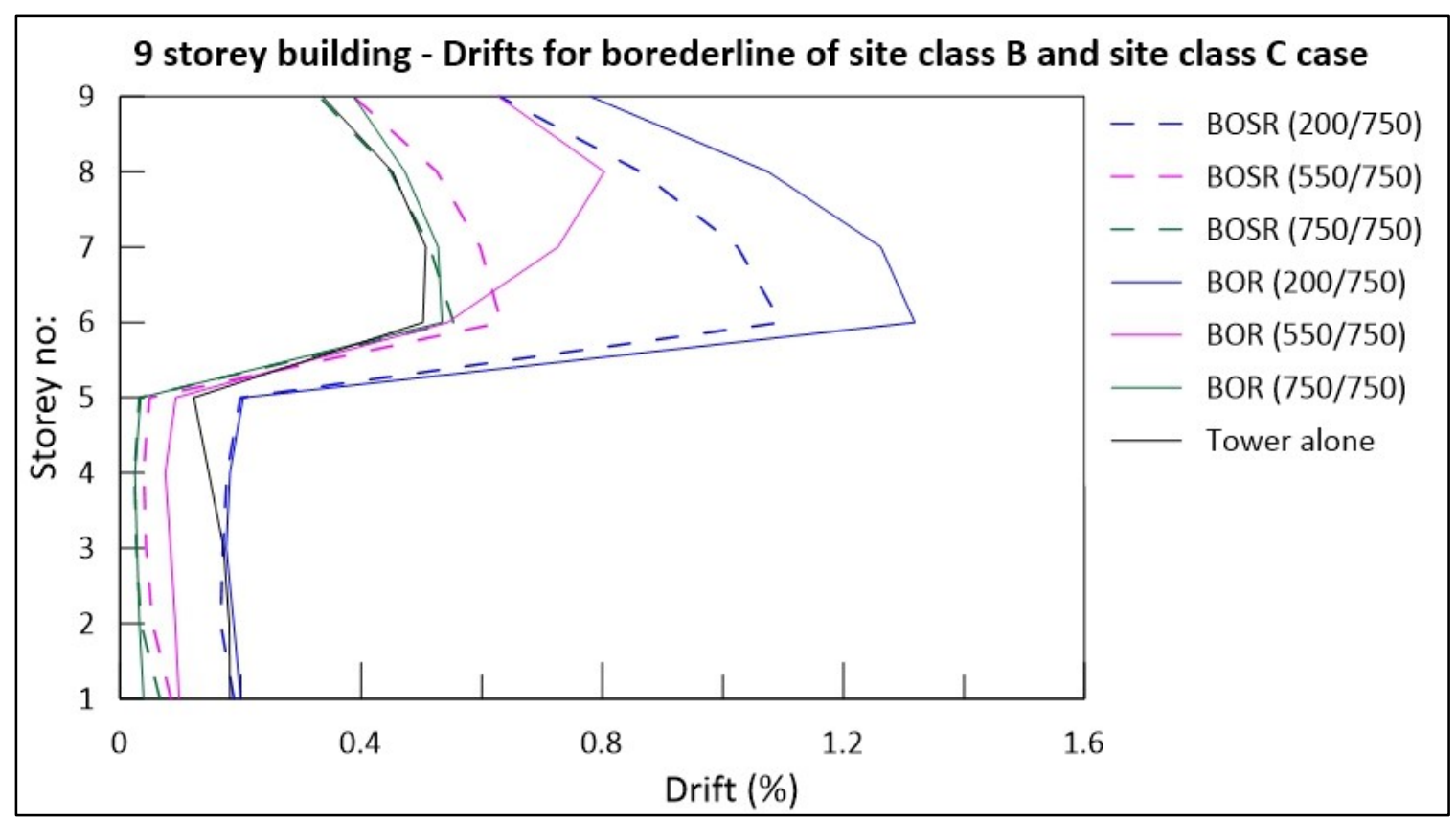

Figure 4-14: Storey drift for the 9 storey building, shear wave velocity of the soil underlying foundation $=$ $750 \mathrm{~m} / \mathrm{s}$

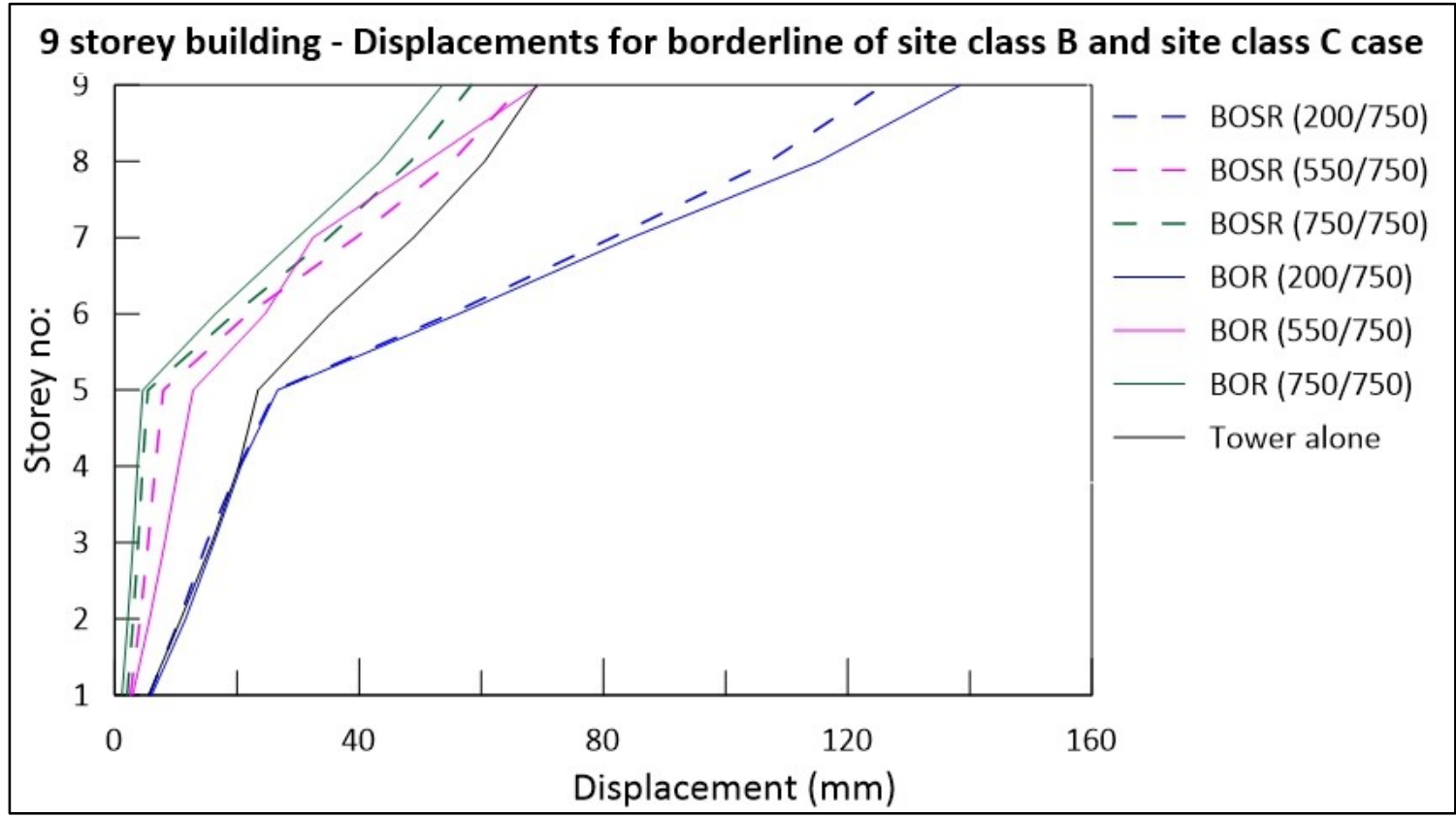

Figure 4-15: Displacement at the top of a storey for 9 storey building, shear wave velocity of the soil underlying foundation $=750 \mathrm{~m} / \mathrm{s}$ 


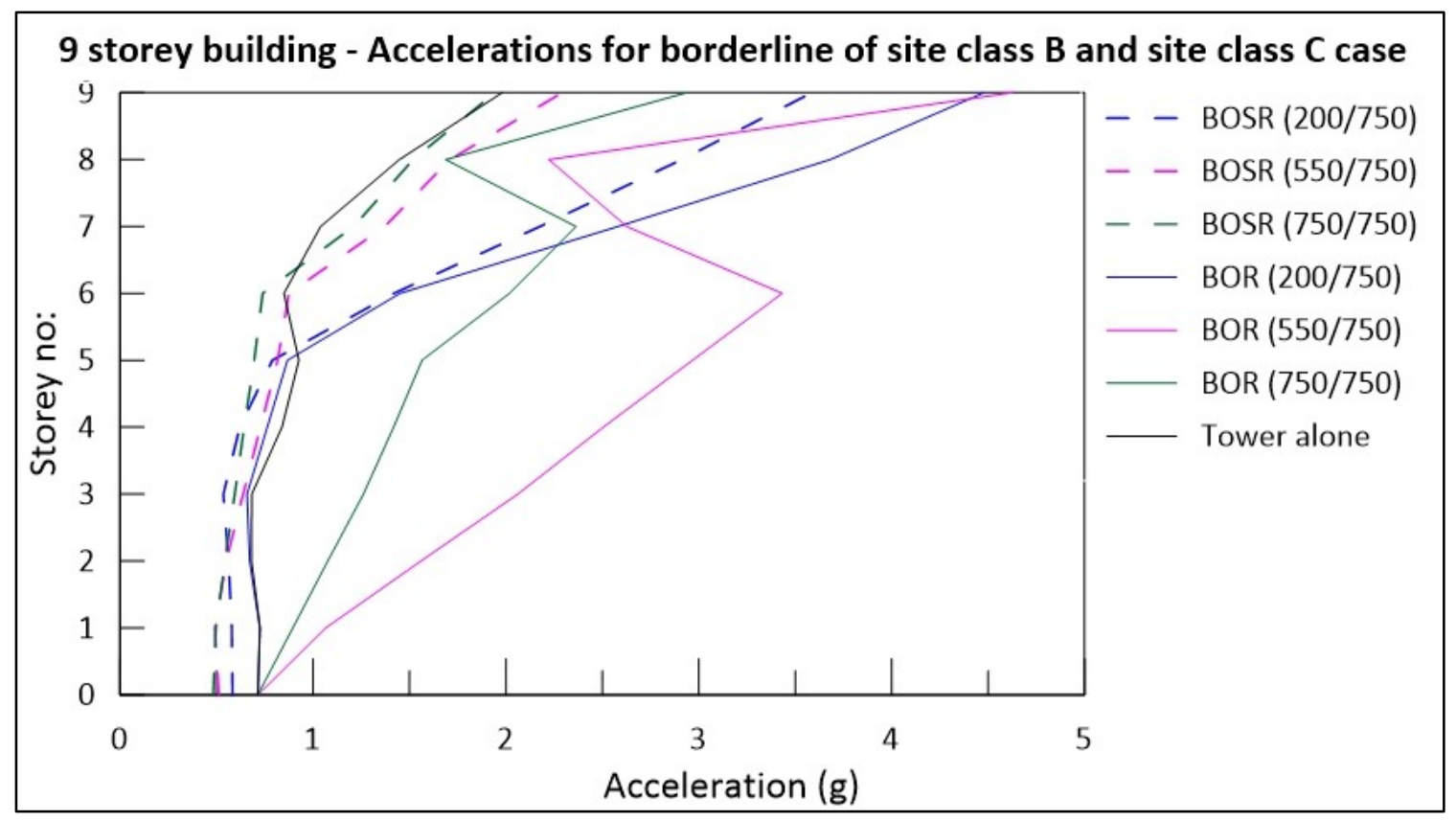

Figure 4-16: Accelerations at the top of a storey for 9 storey building, shear wave velocity of the soil underlying foundation $=750 \mathrm{~m} / \mathrm{s}$

Figure 4-15 shows that maximum displacement is observed for the case BOR 200/750. This is closely followed by the case BOSR 200/750. The highest magnification in acceleration at the base is observed for the case BOR 550/750.

Figure 4-17 to Figure 4-21 shows the results for 9 storey building when the soil underlying the foundation has a shear wave velocity of $1000 \mathrm{~m} / \mathrm{s}$. It is seen that the highest magnification in base shear and the base moment is observed for the case BOR 200/1000. The second highest magnification is observed for the case BOSR 200/1000. 


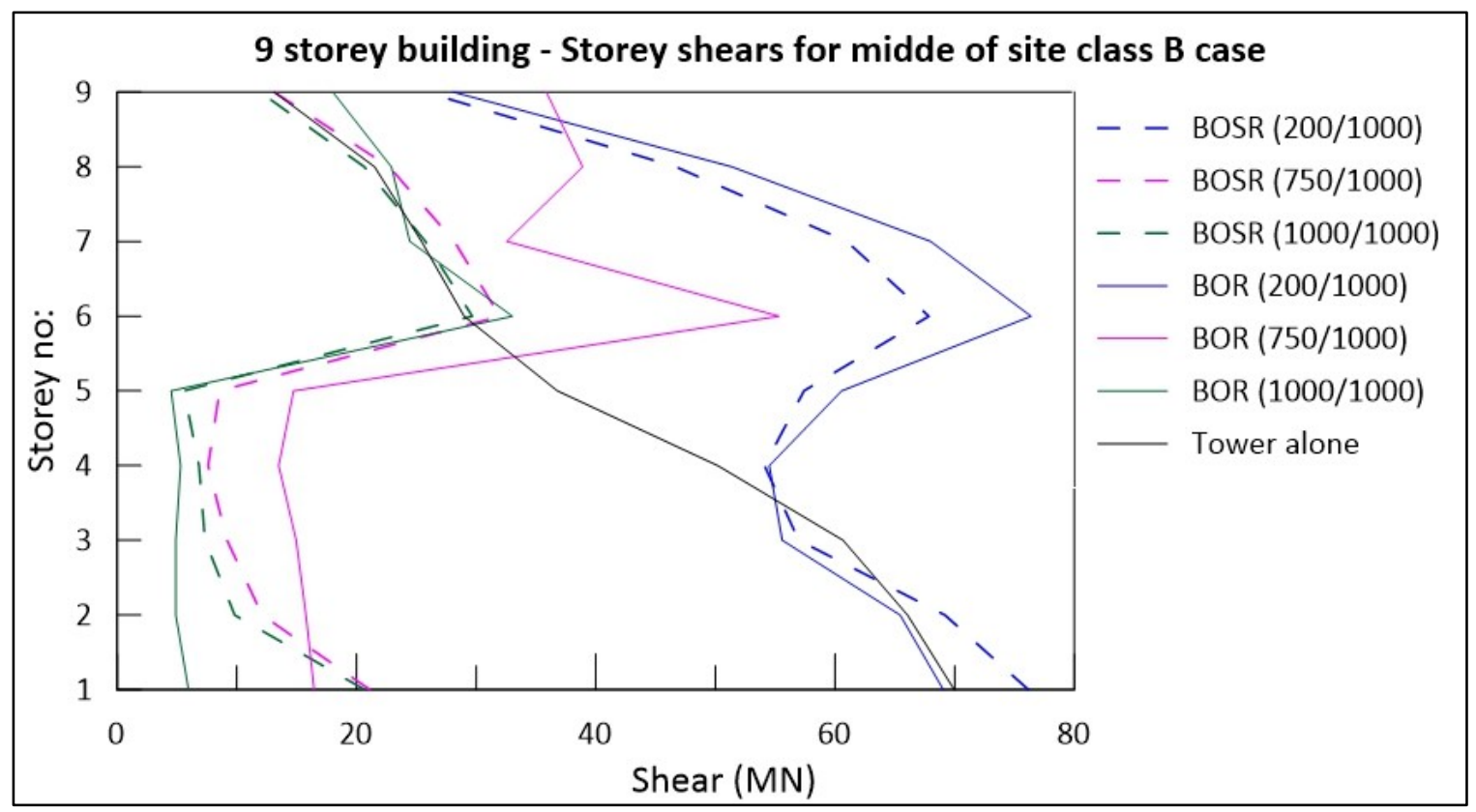

Figure 4-17: Storey shear values for a 9 storey building, shear wave velocity of the soil underlying foundation $=1000 \mathrm{~m} / \mathrm{s}$

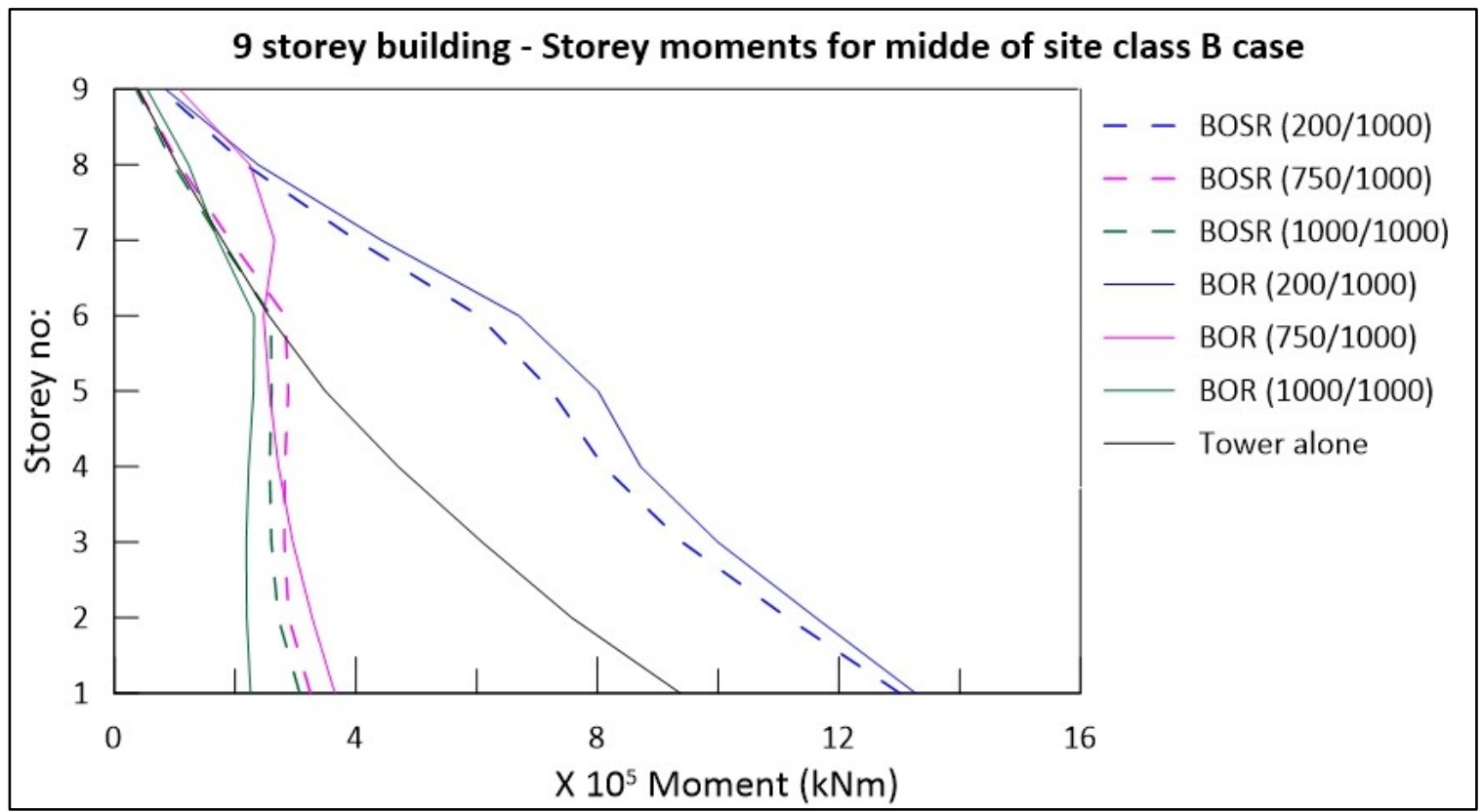

Figure 4-18: Moment at the bottom of the storey for a 9 storey building, shear wave velocity of the soil underlying foundation $=1000 \mathrm{~m} / \mathrm{s}$

From Figure 4-19, it is evident that the magnification in storey drift follows the same trend as that of the storey shears. 


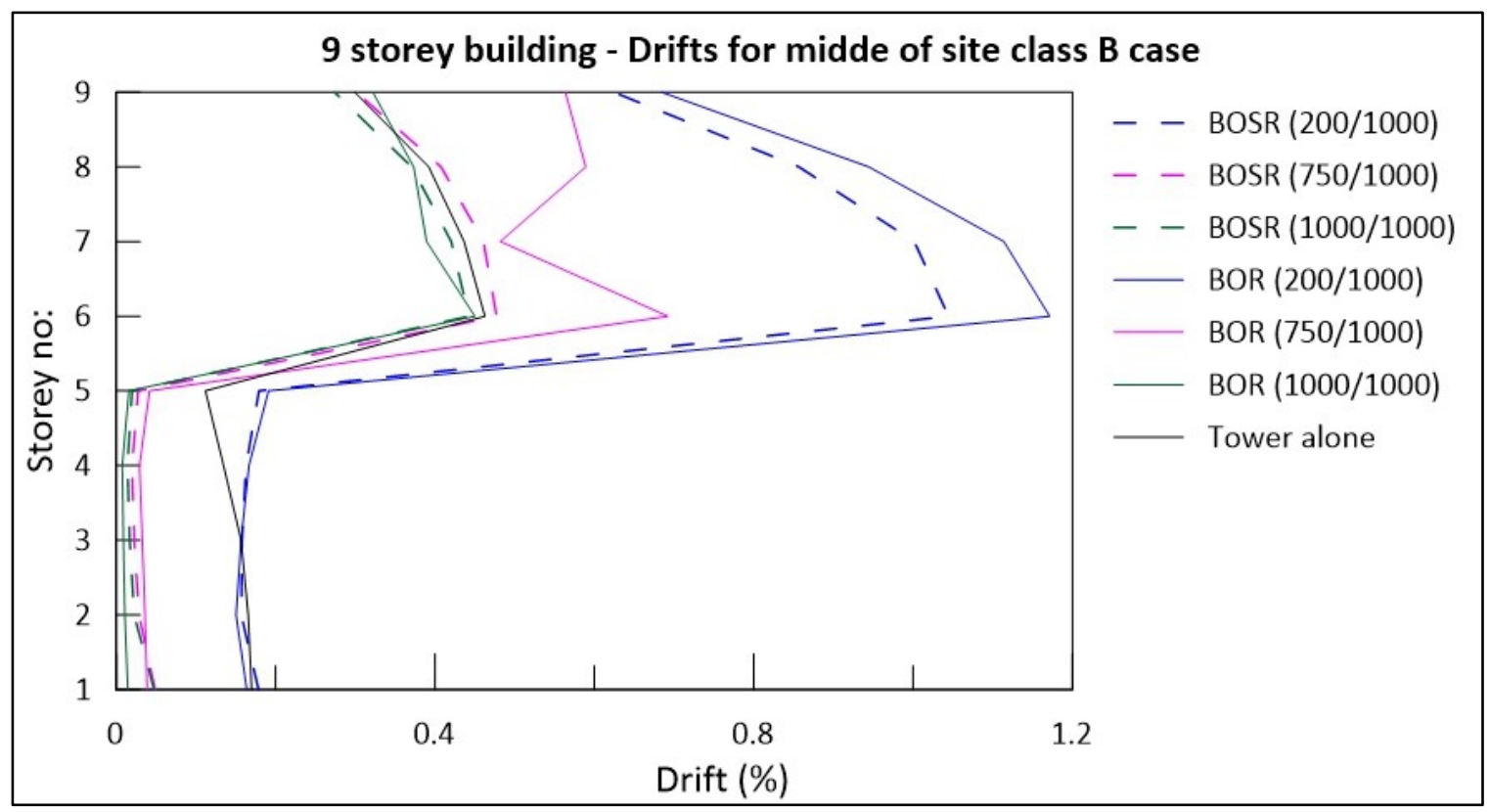

Figure 4-19: Storey drift for the 9 storey building, shear wave velocity of the soil underlying foundation = $1000 \mathrm{~m} / \mathrm{s}$

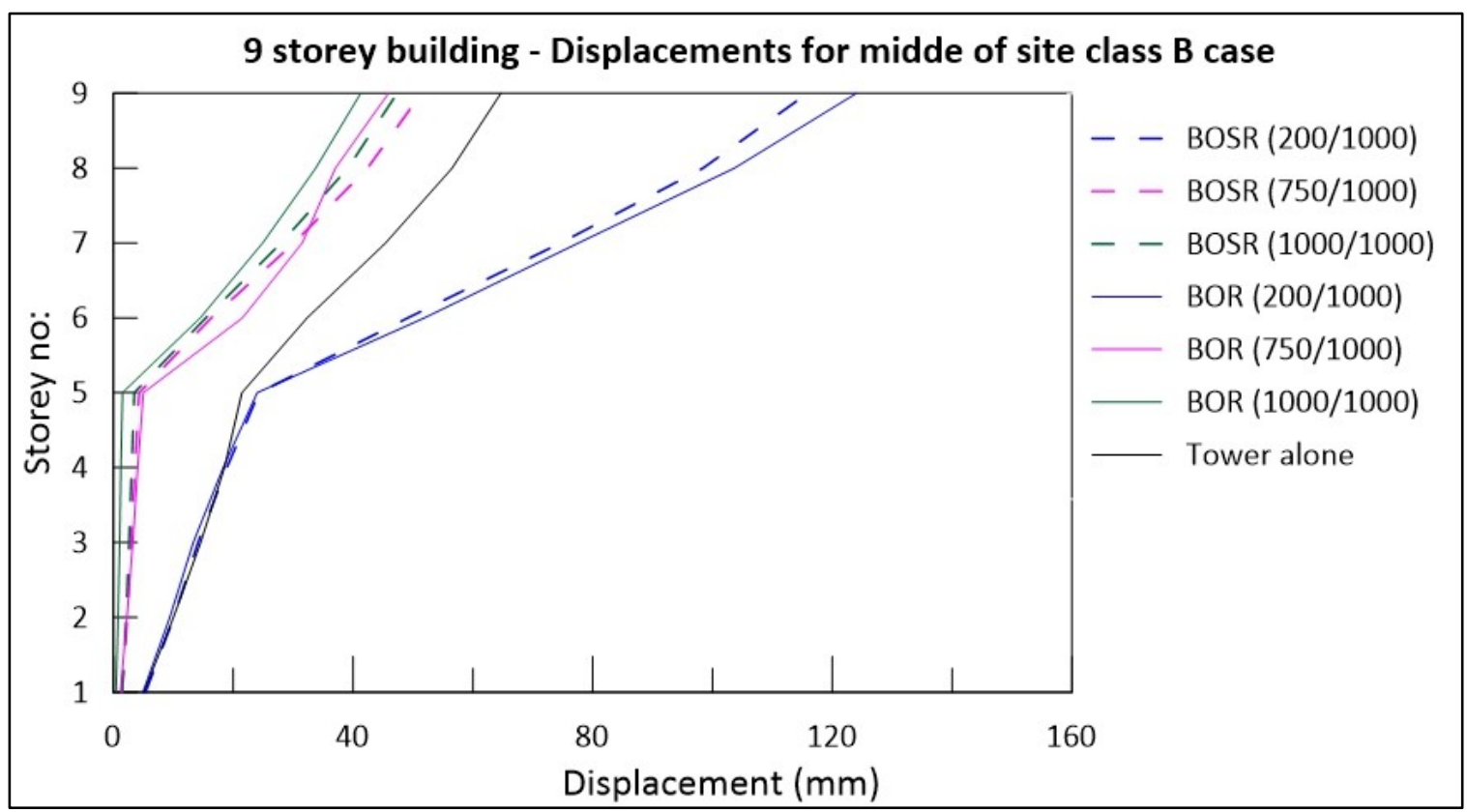

Figure 4-20: Displacement at the top of a storey for 9 storey building, shear wave velocity of the soil underlying foundation $=1000 \mathrm{~m} / \mathrm{s}$ 


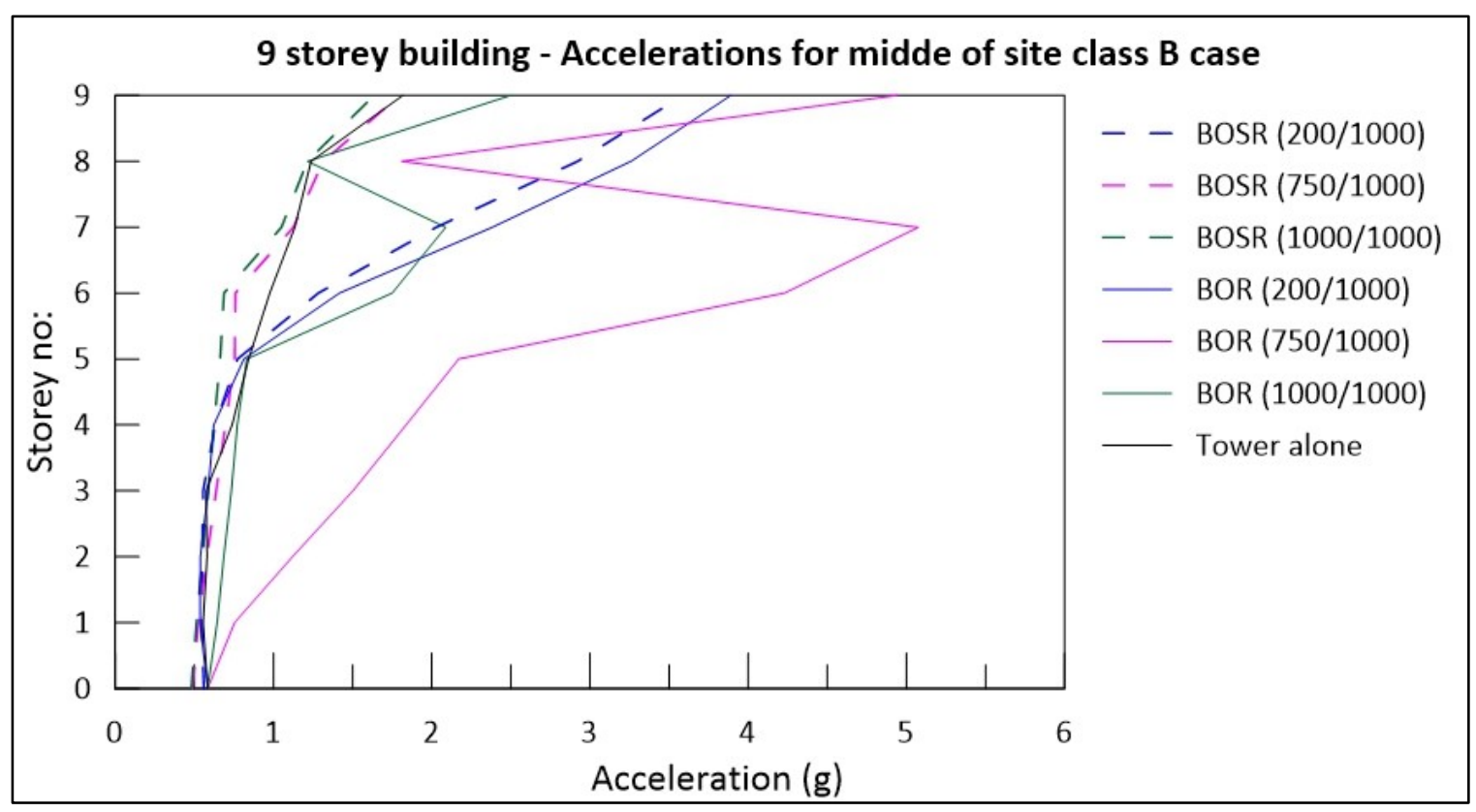

Figure 4-21: Acceleration at the top of a storey for 9 storey building, shear wave velocity of the soil underlying foundation $=1000 \mathrm{~m} / \mathrm{s}$

Figure 4-20 shows that maximum displacement occurs for the case BOR 200/1000. The second highest magnification in the displacement is for the case BOSR 200/1000. The highest magnification in acceleration is observed for the case BOR 750/1000.

\section{3 storey building}

Figure 4-22 to Figure 4-26 displays the results for the 8 storey tower and its supporting structure with $450 \mathrm{~m} / \mathrm{s}$ soil under the base of the building. Figures 4-22 and 4-23 show that the highest magnification in storey shears and storey moments are recorded for the case BOR 300/450. However, maximum magnification in moment at the base of the tower is for the case BOR 200/450 (Figure 4-23). 


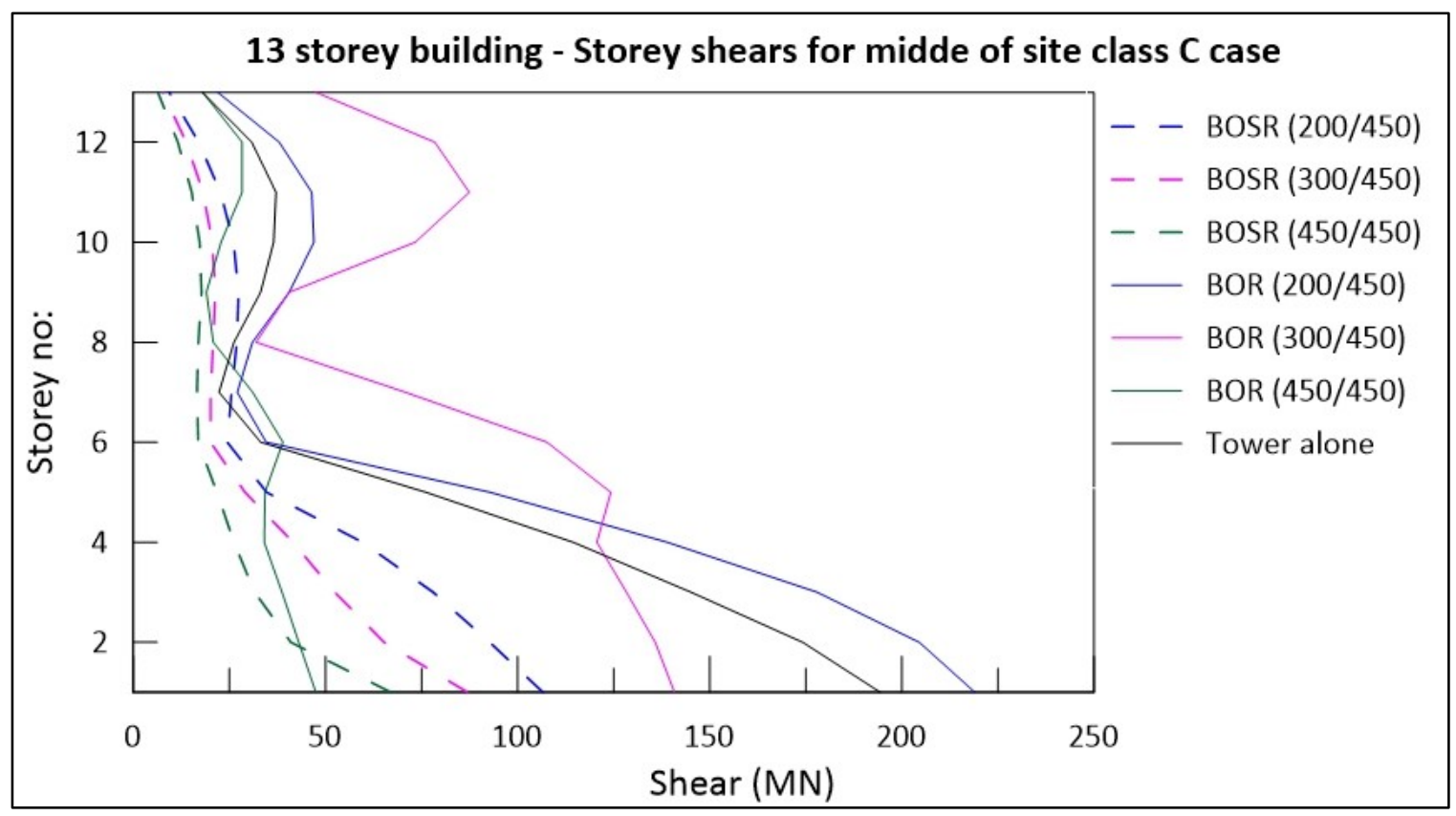

Figure 4-22: Storey shear values for a 13 storey building, shear wave velocity of the soil underlying foundation $=450 \mathrm{~m} / \mathrm{s}$

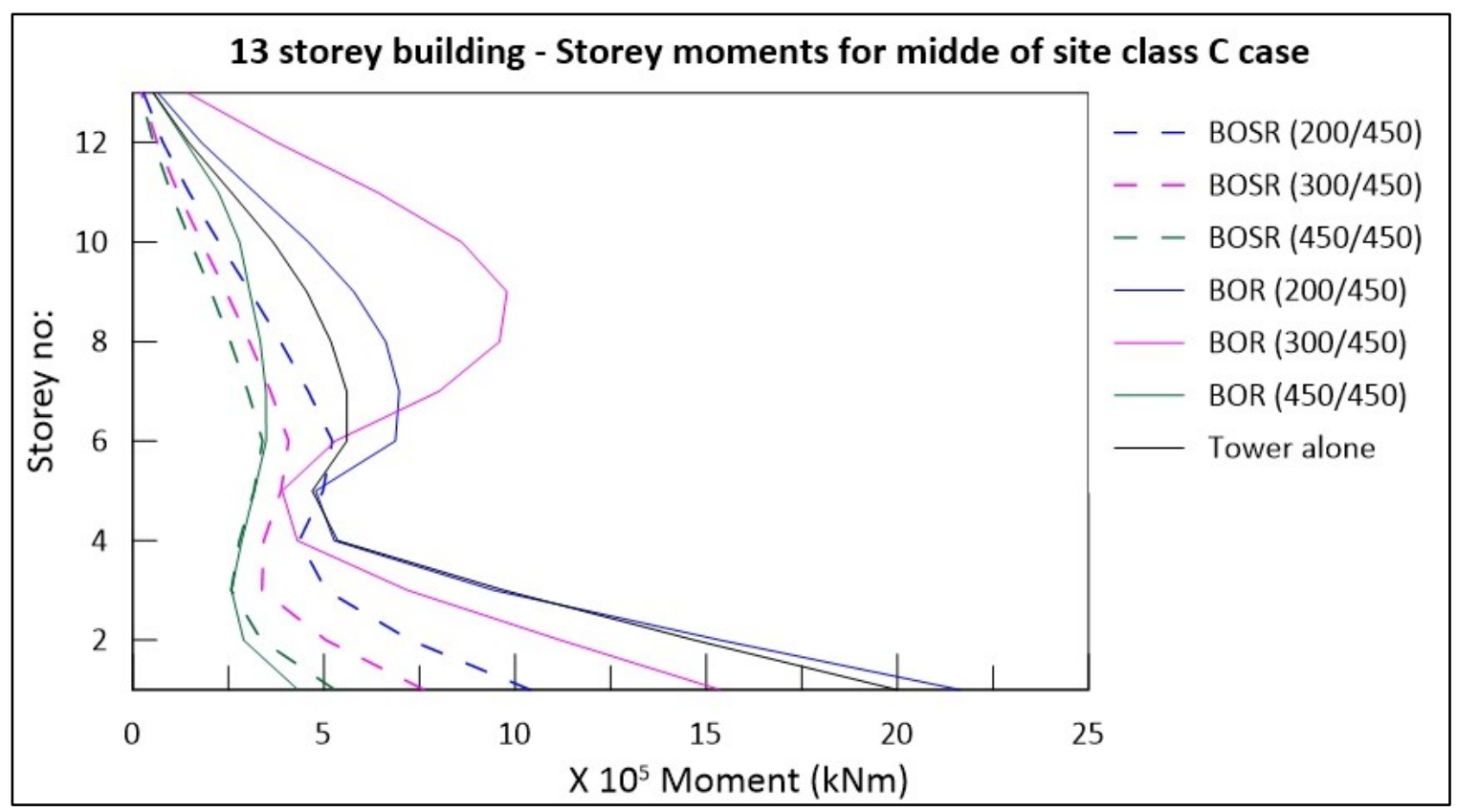

Figure 4-23: Moment at the bottom of the storey for a 13 storey building, shear wave velocity of the soil underlying foundation $=450 \mathrm{~m} / \mathrm{s}$ 


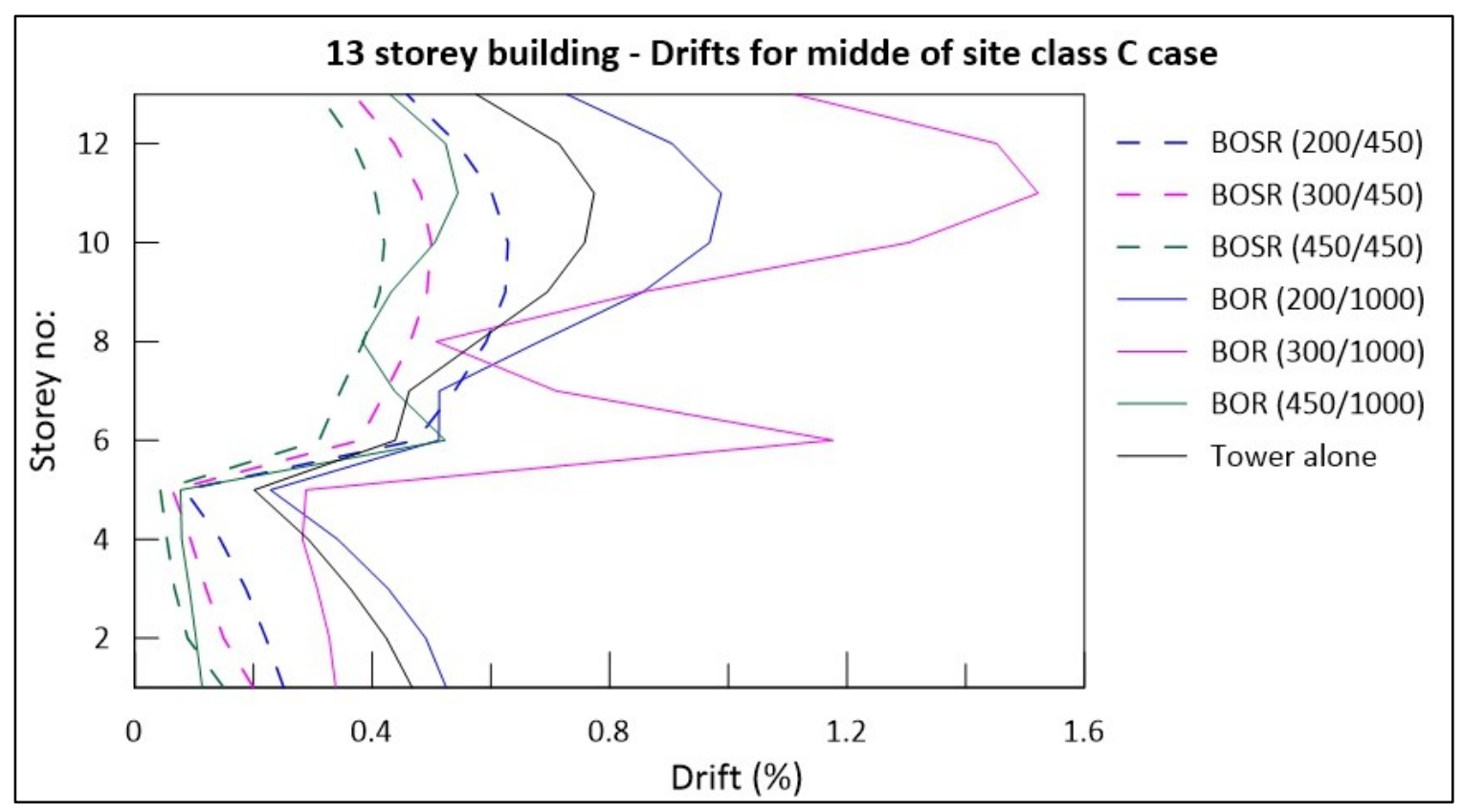

Figure 4-24: Storey drift for the 13 storey building, shear wave velocity of the soil underlying foundation = $450 \mathrm{~m} / \mathrm{s}$

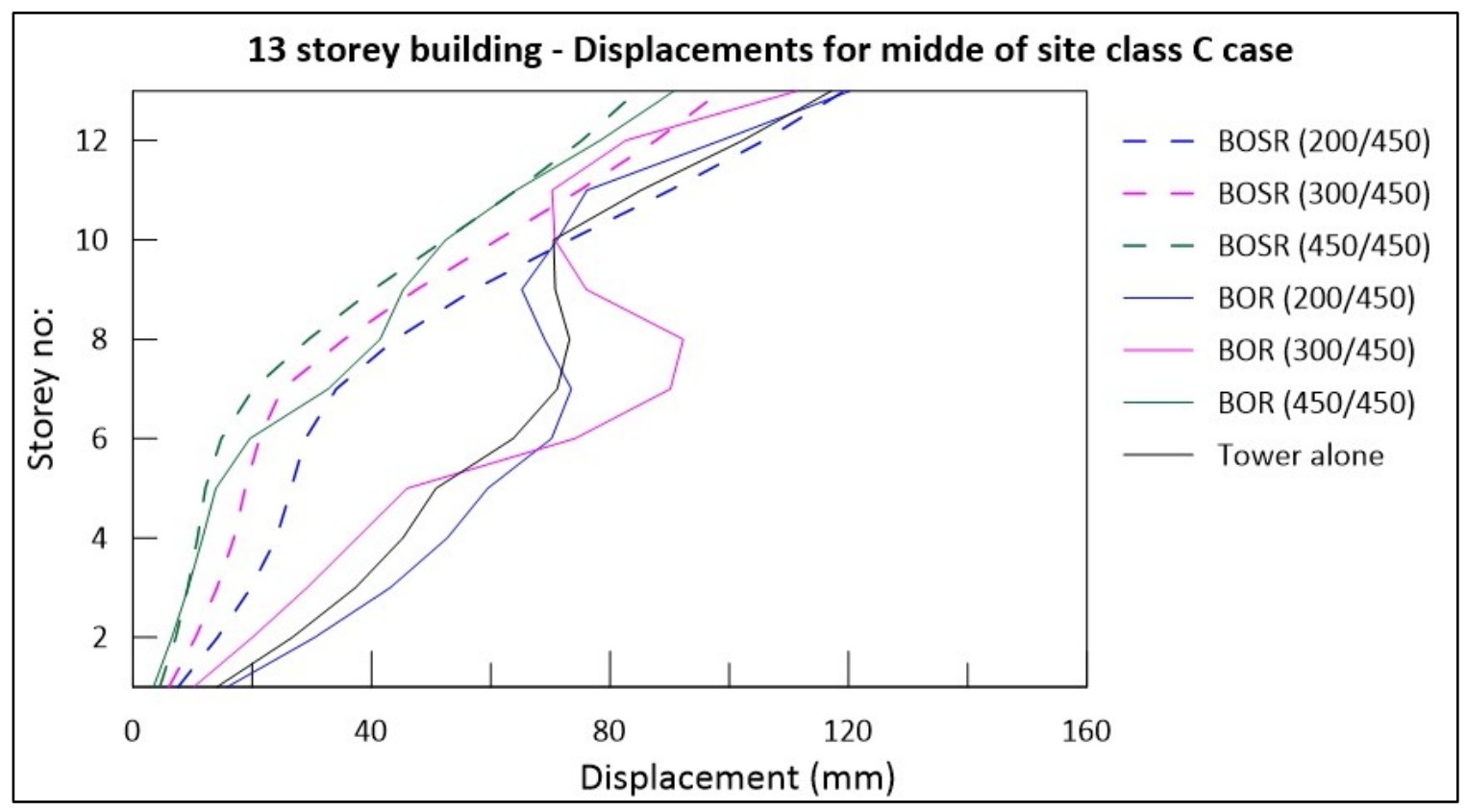

Figure 4-25: Displacement at the top of a storey for 13 storey building, shear wave velocity of the soil underlying foundation $=450 \mathrm{~m} / \mathrm{s}$ 


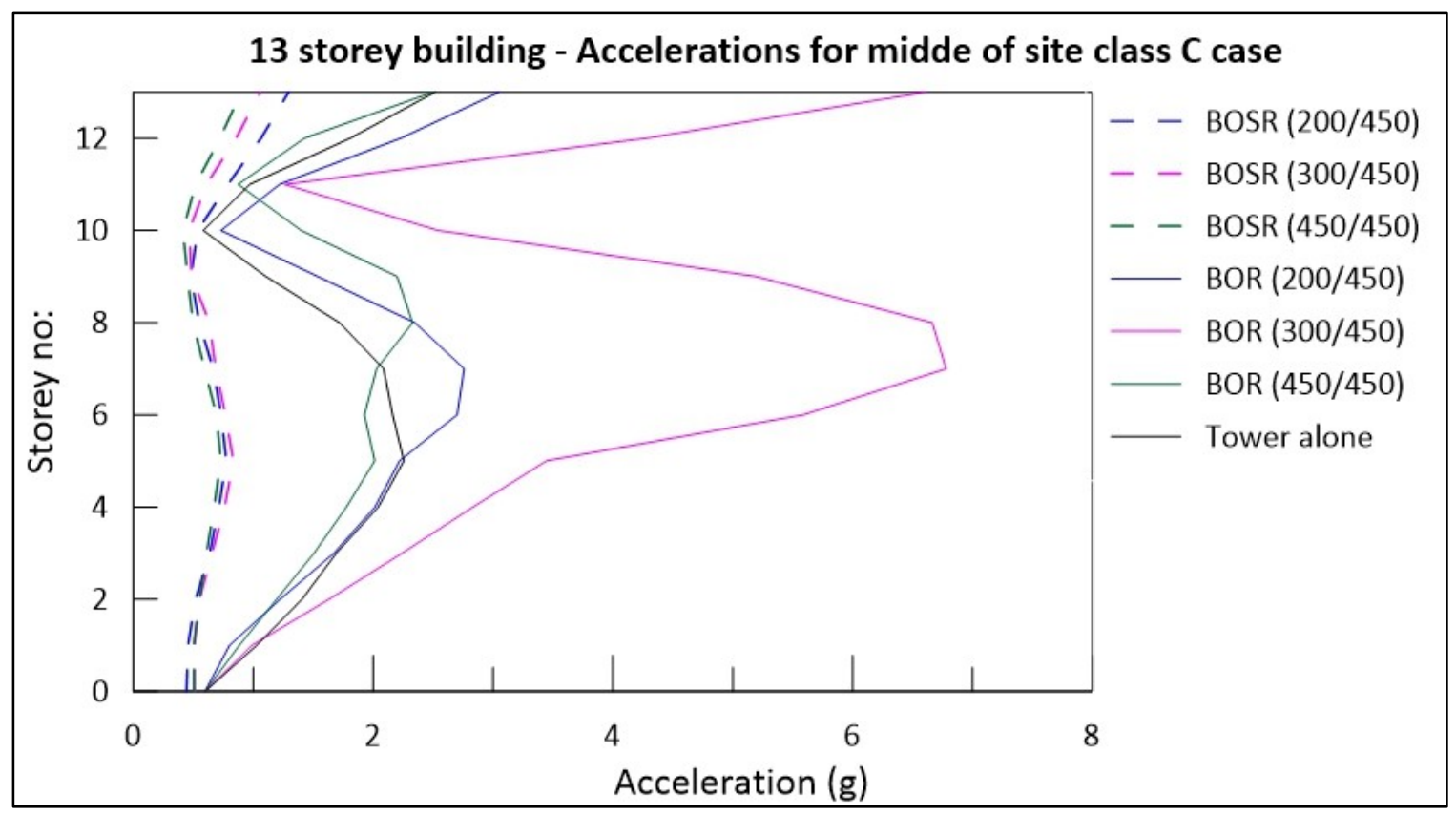

Figure 4-26: Acceleration at the top of a storey for 13 storey building, shear wave velocity of the soil underlying foundation $=450 \mathrm{~m} / \mathrm{s}$

The magnification in storey drifts follows the same trend as that for the storey shears, as shown in Figure 4-24 and Figure 4-25. The highest magnification is seen for the case BOR 300/450. For displacement and acceleration response, BOR 300/450 has very high magnification at the base of the tower, as shown in Figure 4-25 and Figure 4-26.

Figures 4-27 to 4-31 present the results for the 8 storey tower and its supporting structure when the soil under the base of the building has a shear wave velocity of $750 \mathrm{~m} / \mathrm{s}$. It is evident from Figure 4-27 that there is not much magnification in shear at the base of the tower, with the highest recorded for BOR 550/750 being $16 \%$ greater than the building alone. A fairly significant reduction in shear at the base of the tower was noted in most cases compared to the building alone analysis. The moment at the base of the tower (Figure 4-28), is observed to be the highest for BOR 200/750, which is about $10 \%$ greater than the building alone case. 


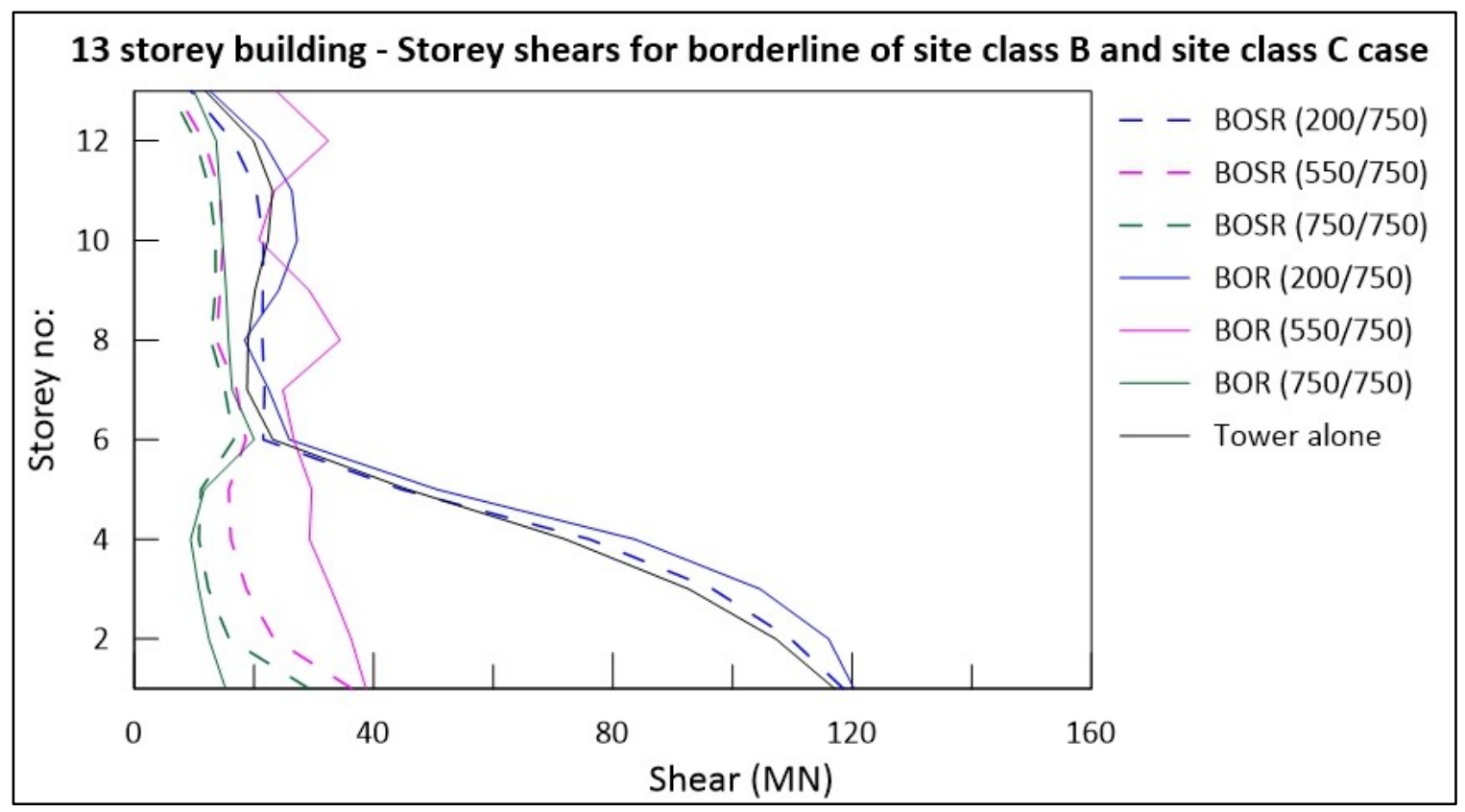

Figure 4-27: Storey shear values for a 13 storey building, shear wave velocity of the soil underlying foundation $=750 \mathrm{~m} / \mathrm{s}$

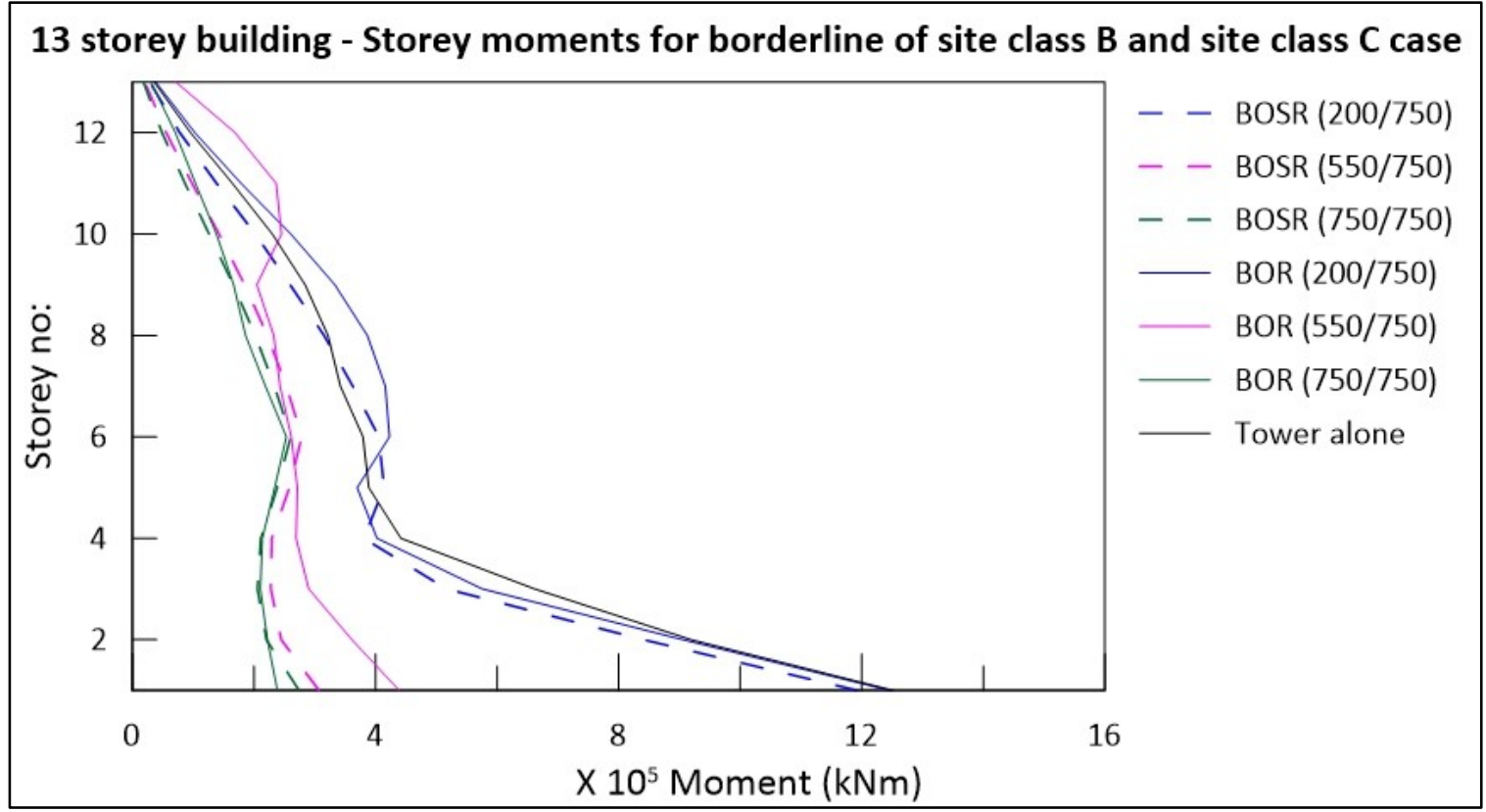

Figure 4-28: Moment at the bottom of the storey for a 13 storey building, shear wave velocity of the soil underlying foundation $=750 \mathrm{~m} / \mathrm{s}$ 


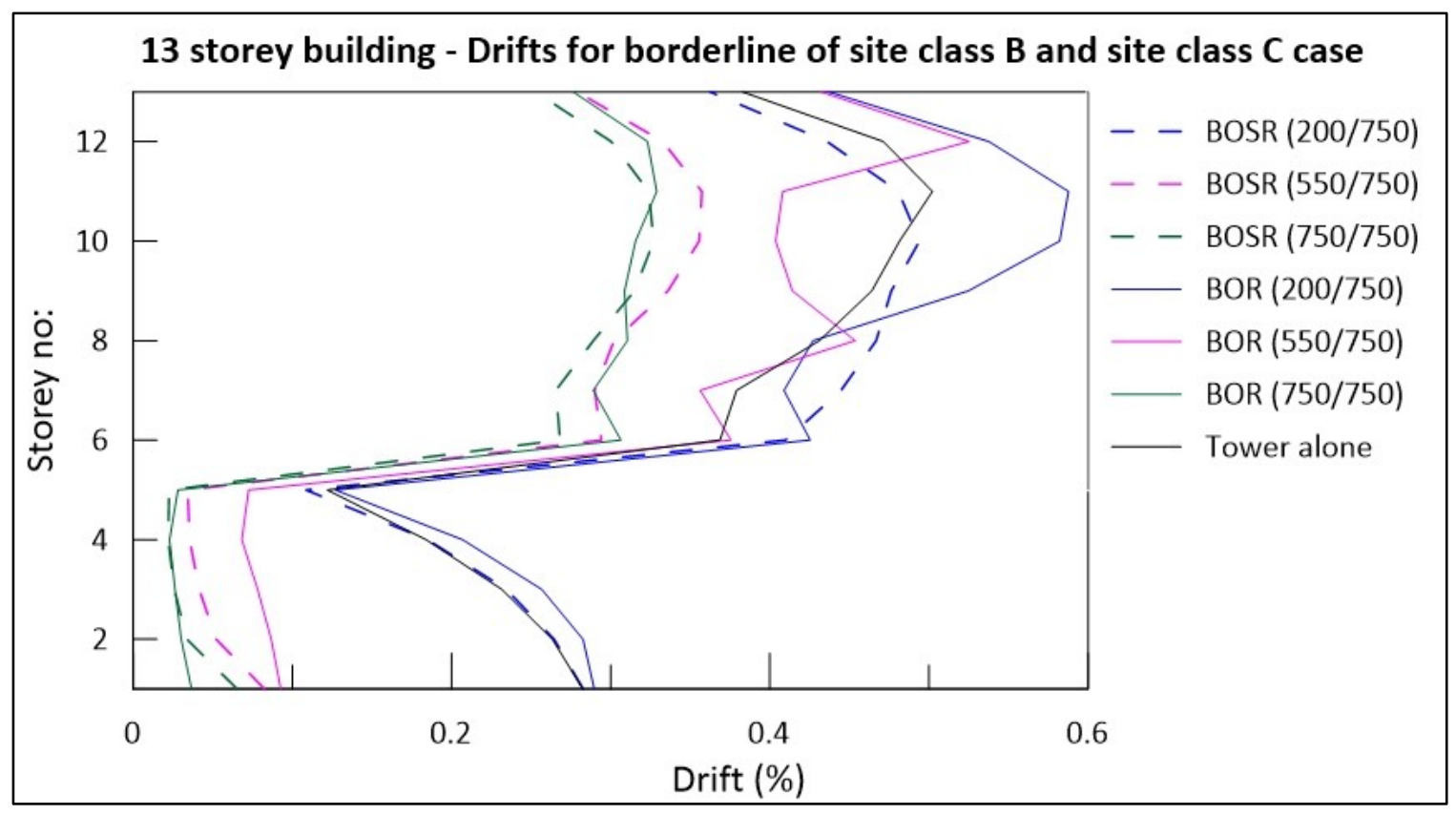

Figure 4-29: Storey drift for the 13 storey building, shear wave velocity of the soil underlying foundation = $750 \mathrm{~m} / \mathrm{s}$

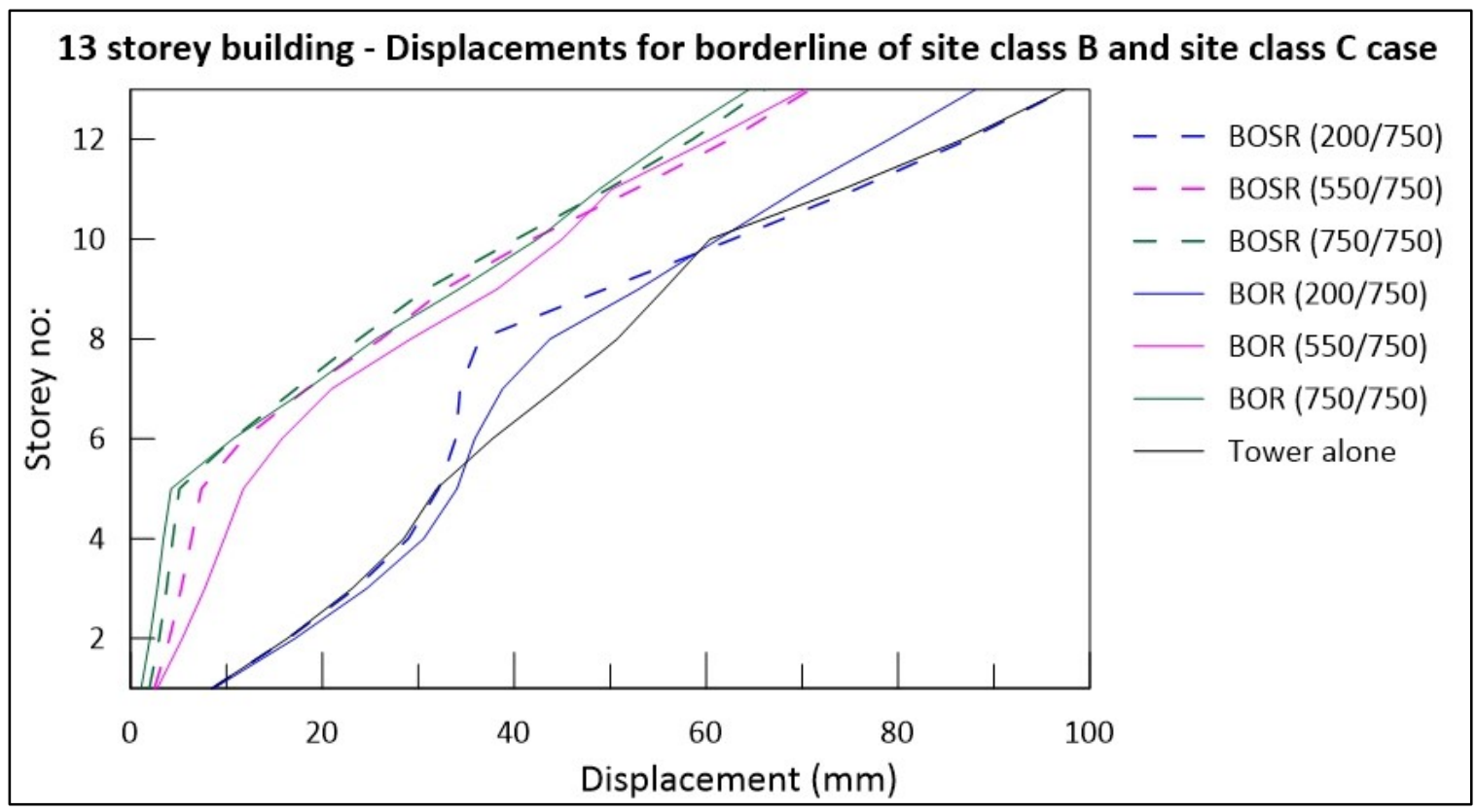

Figure 4-30: Displacement at the top of a storey for 13 storey building, shear wave velocity of the soil underlying foundation $=750 \mathrm{~m} / \mathrm{s}$ 


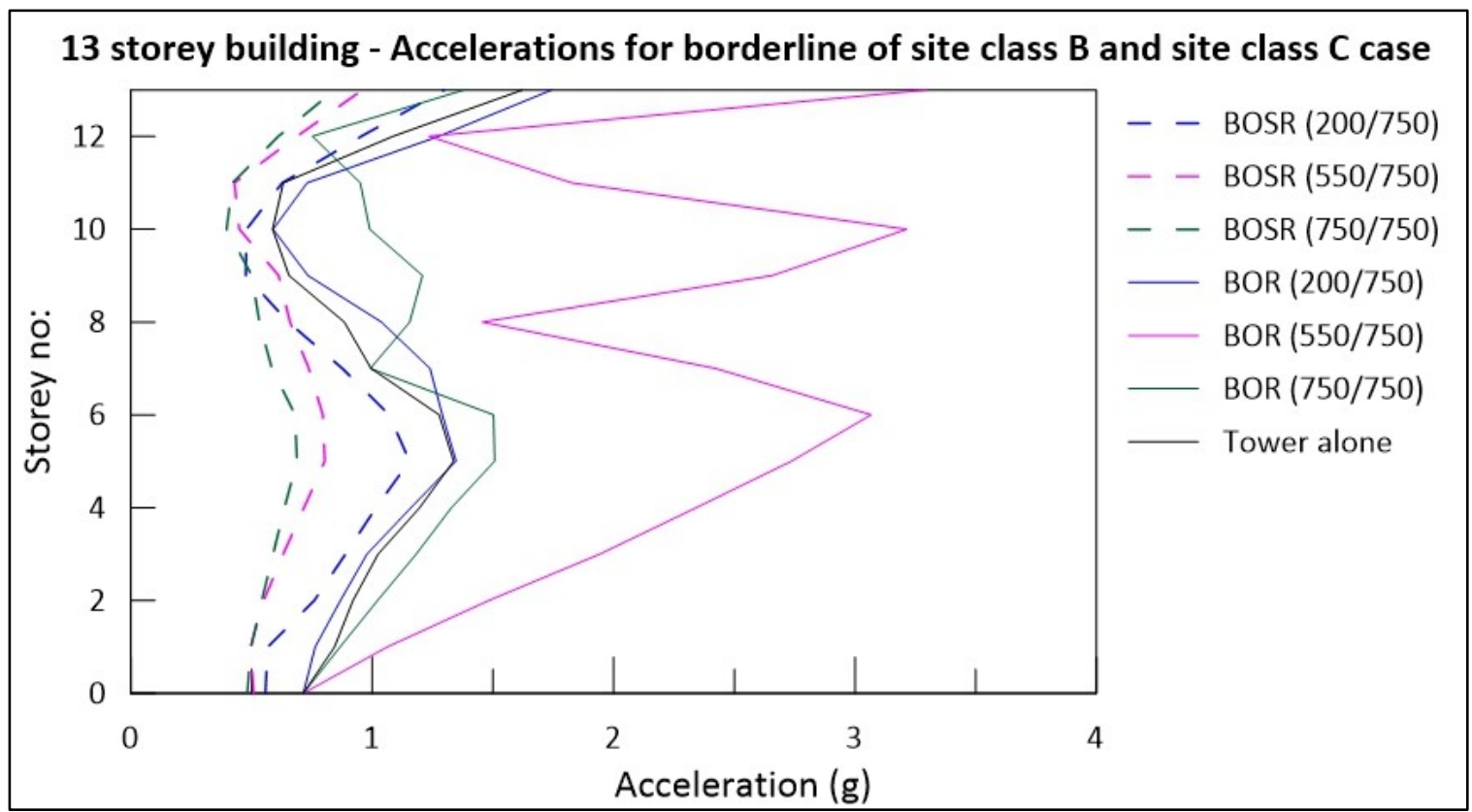

Figure 4-31: Acceleration at the top of a storey for 13 storey building, shear wave velocity of the soil underlying foundation $=750 \mathrm{~m} / \mathrm{s}$

For storey drift, maximum magnification is observed for BOR 200/750, closely followed by BOSR 200/750. From Figure 4-30, it is evident that there is no magnification in displacement at the base of the 8 storey tower. For acceleration response, BOR 550/750 has very high acceleration at the base of the tower, as shown in Figure 4-31.

Figures 4-32 to 4-36 shows the results for the 13 storey building with $1000 \mathrm{~m} / \mathrm{s}$ soil under the base of the building. The maximum magnification in shear at the base of the tower is $12 \%$ higher for BOR 750/1000 when compared with the building alone case. Also, from Figure $4-33$, it is evident that there is no significant magnification in the moment at the base of the tower. 


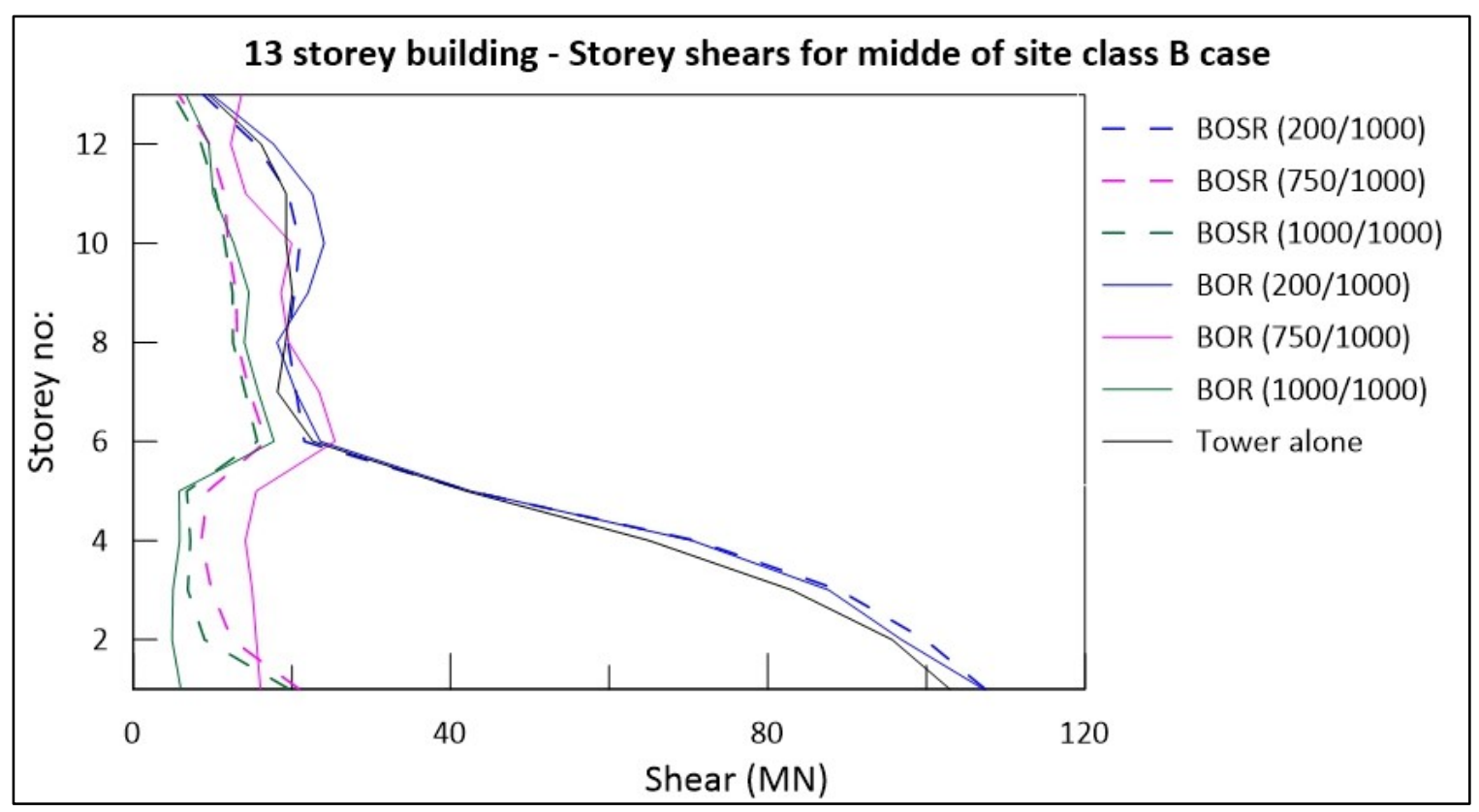

Figure 4-32: Storey shear values for a 13 storey building, shear wave velocity of the soil underlying foundation $=1000 \mathrm{~m} / \mathrm{s}$

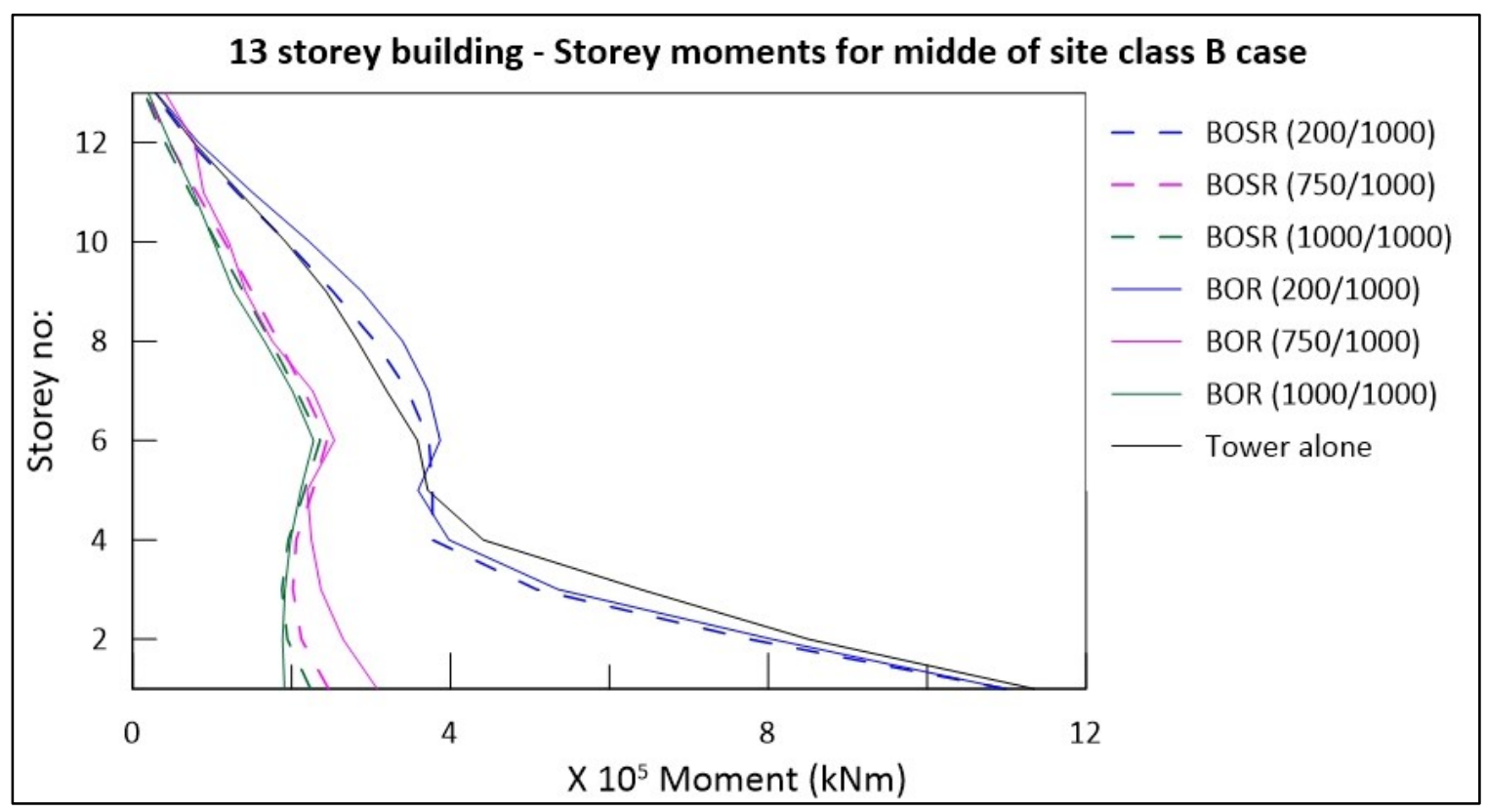

Figure 4-33: Moment at the bottom of the storey for a 13 storey building, shear wave velocity of the soil underlying foundation $=1000 \mathrm{~m} / \mathrm{s}$ 


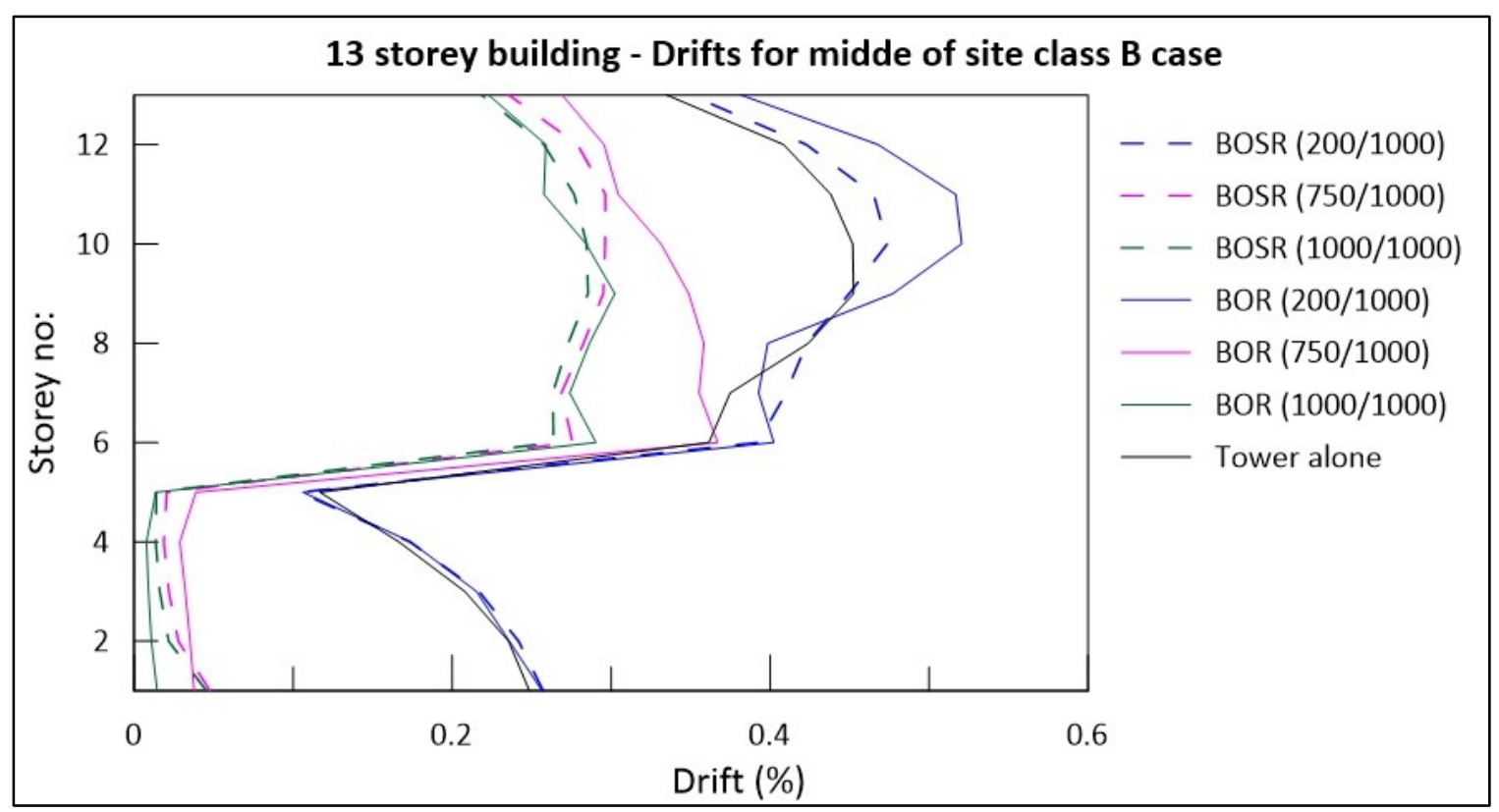

Figure 4-34: Storey drift for the 13 storey building, shear wave velocity of the soil underlying foundation = $1000 \mathrm{~m} / \mathrm{s}$

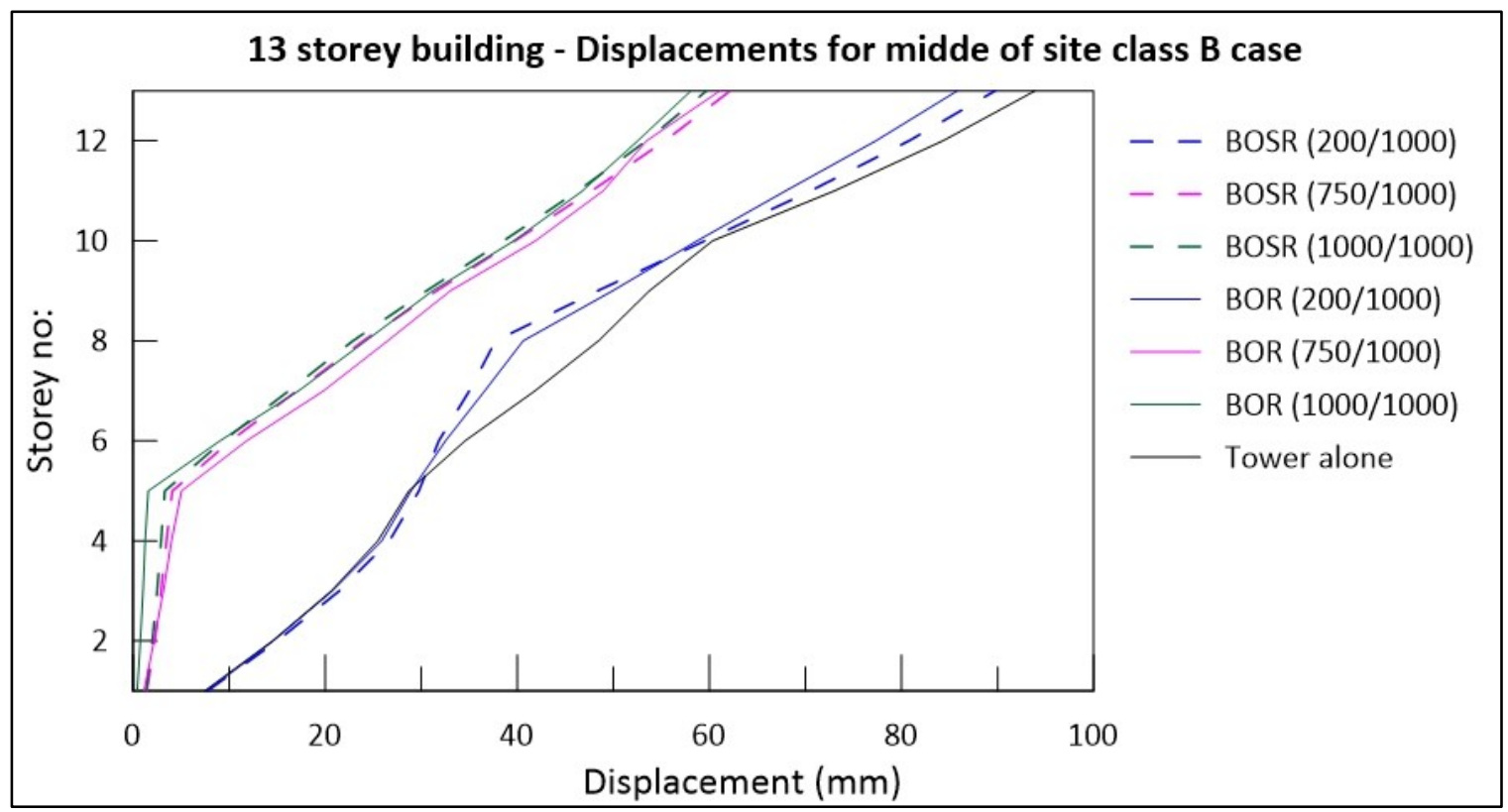

Figure 4-35: Displacement at the top of a storey for 13 storey building, shear wave velocity of the soil underlying foundation $=1000 \mathrm{~m} / \mathrm{s}$

For storey drift (Figure 4-34), maximum magnification is observed for BOR 200/1000, closely followed by the case BOSR 200/1000. 


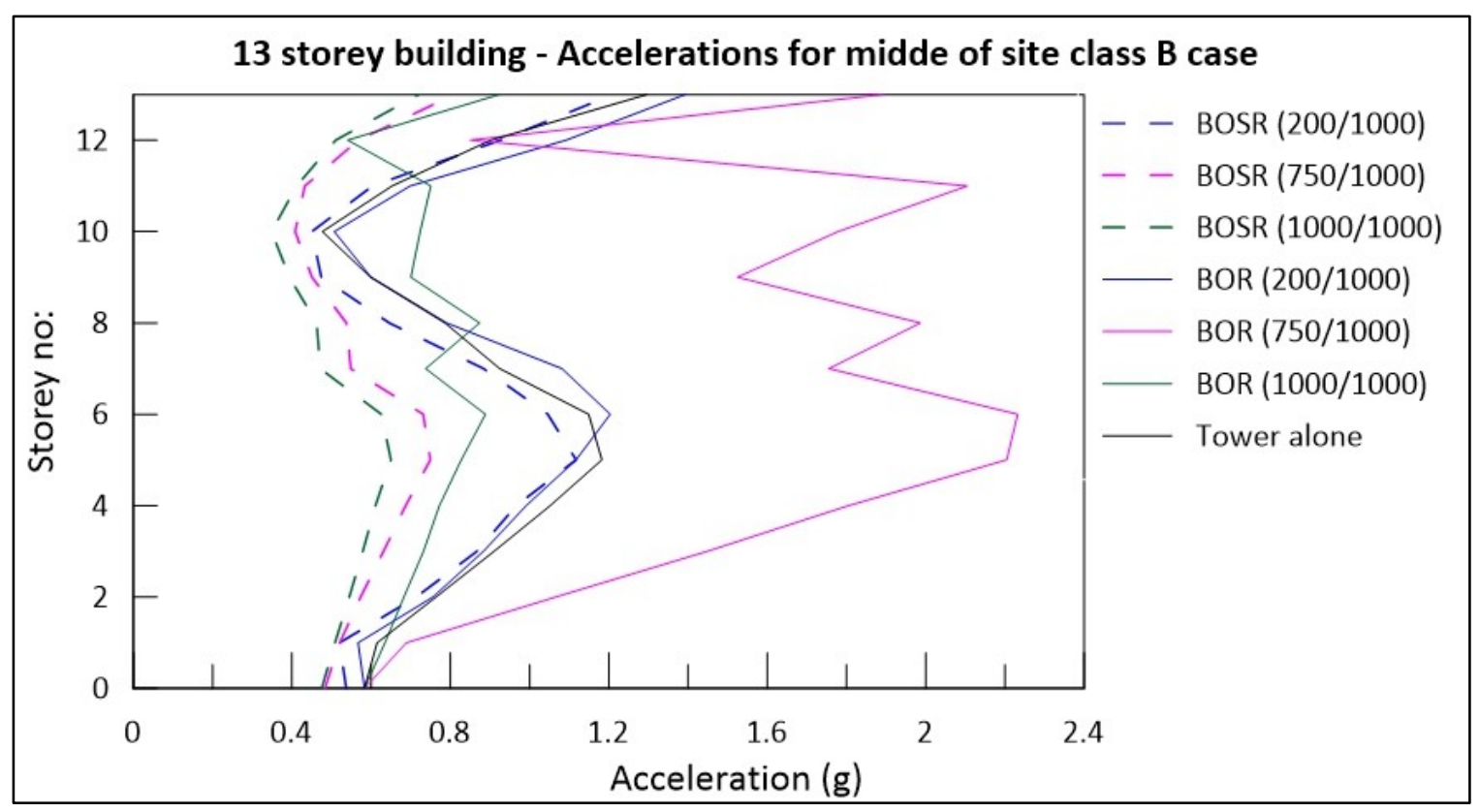

Figure 4-36: Acceleration at the top of a storey for 13 storey building, shear wave velocity of the soil underlying foundation $=1000 \mathrm{~m} / \mathrm{s}$

As seen in Figure 4-35, it is observed that there is no magnification in displacement at the base of the tower. For acceleration response, BOR 750/1000 has very high acceleration at the base of the tower, as shown in Figure 4-36.

\section{7 storey building}

Figure 4-37 to Figure 4-41 shows the seismic response of the 12 storey tower and its supporting structure analyzed with $450 \mathrm{~m} / \mathrm{s}$ shear wave velocity soil overlying the rock. From Figure 4-37 and Figure 4-38, it is seen that maximum magnification in shear and moment at the base of the tower is observed for BOR 200/450. The second highest magnification is observed for the case BOR 300/450. 


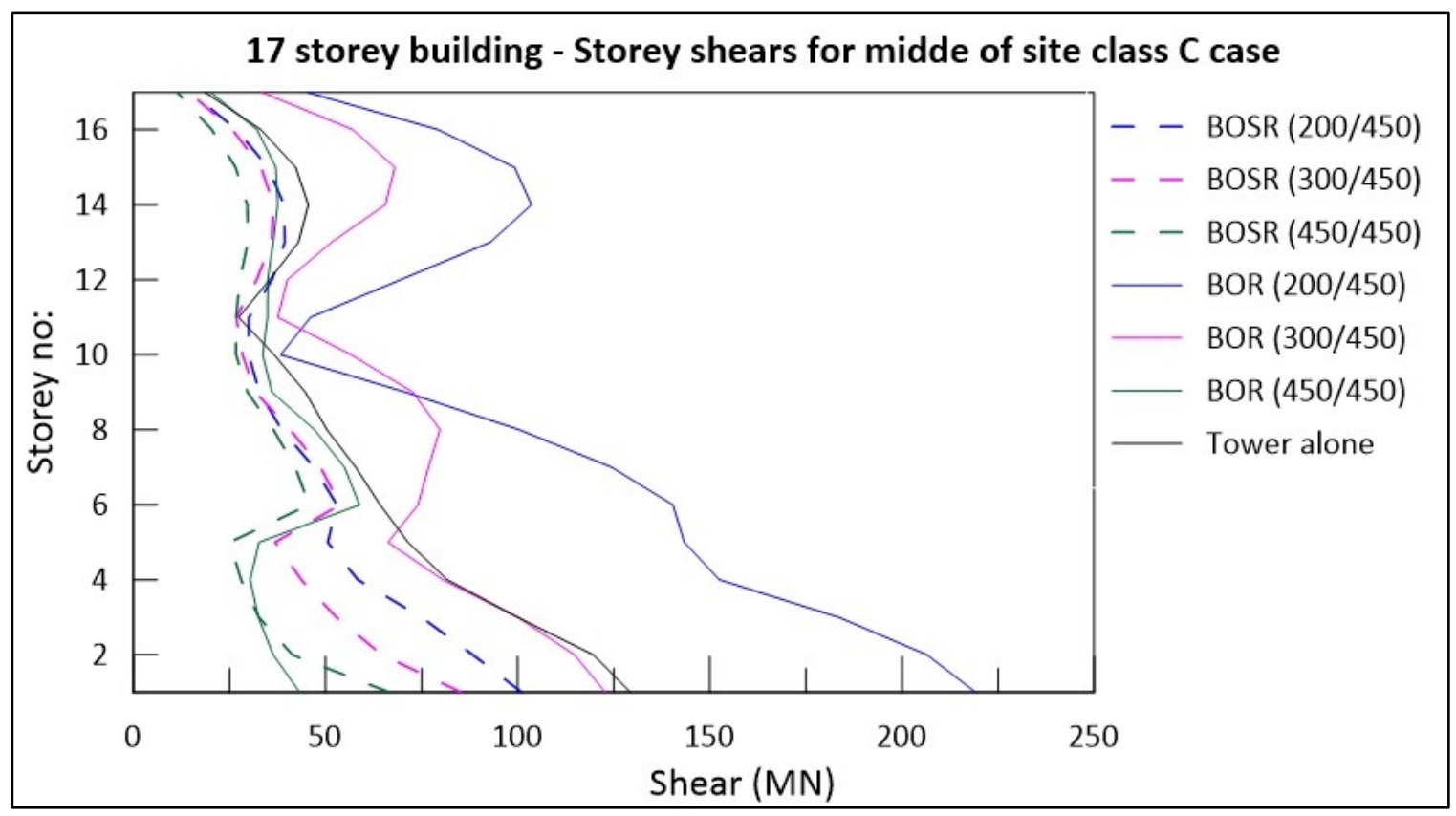

Figure 4-37: Storey shear values for a 17 storey building, shear wave velocity of the soil underlying foundation $=450 \mathrm{~m} / \mathrm{s}$

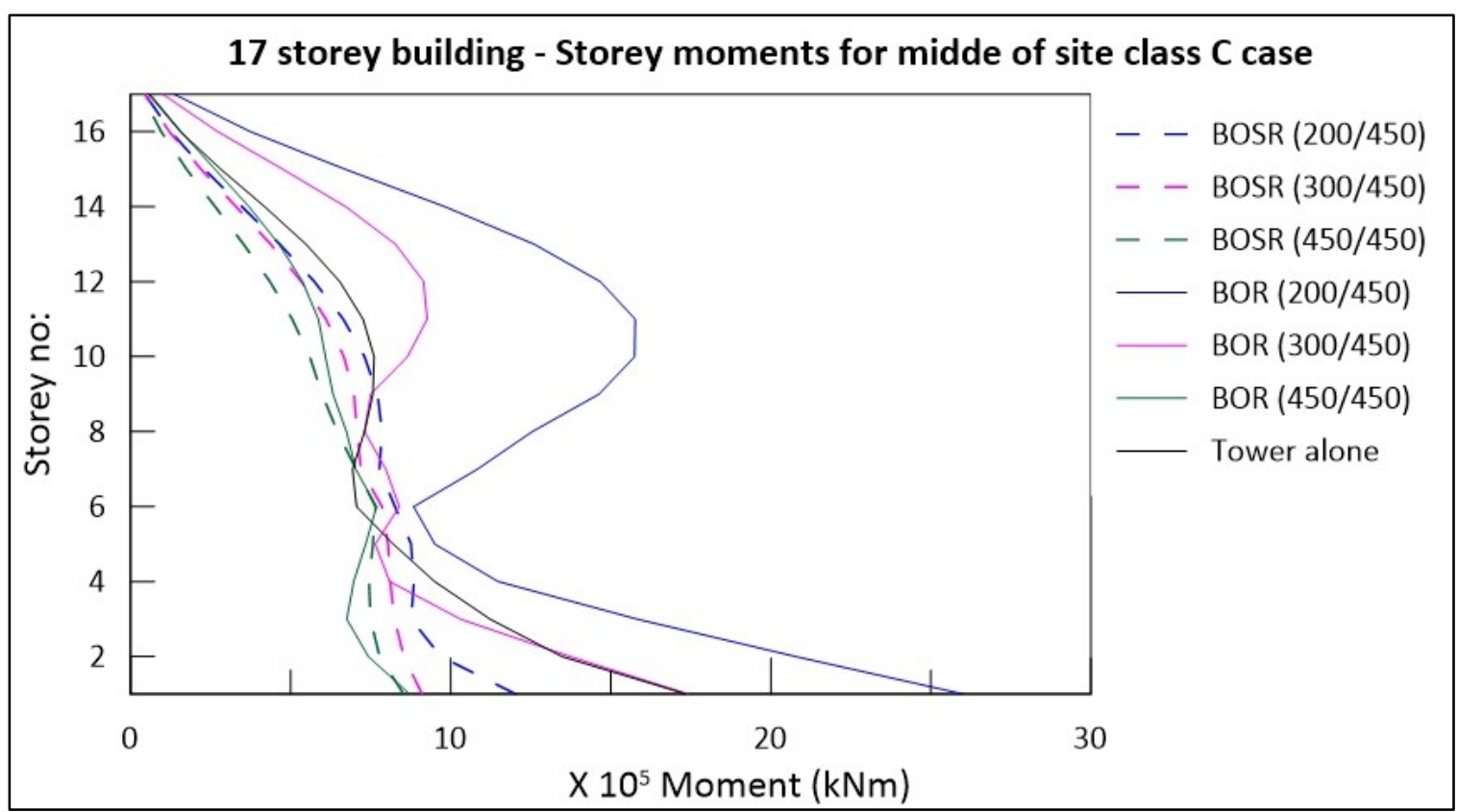

Figure 4-38: Moment at the bottom of the storey for a 17 storey building, shear wave velocity of the soil underlying foundation $=450 \mathrm{~m} / \mathrm{s}$ 


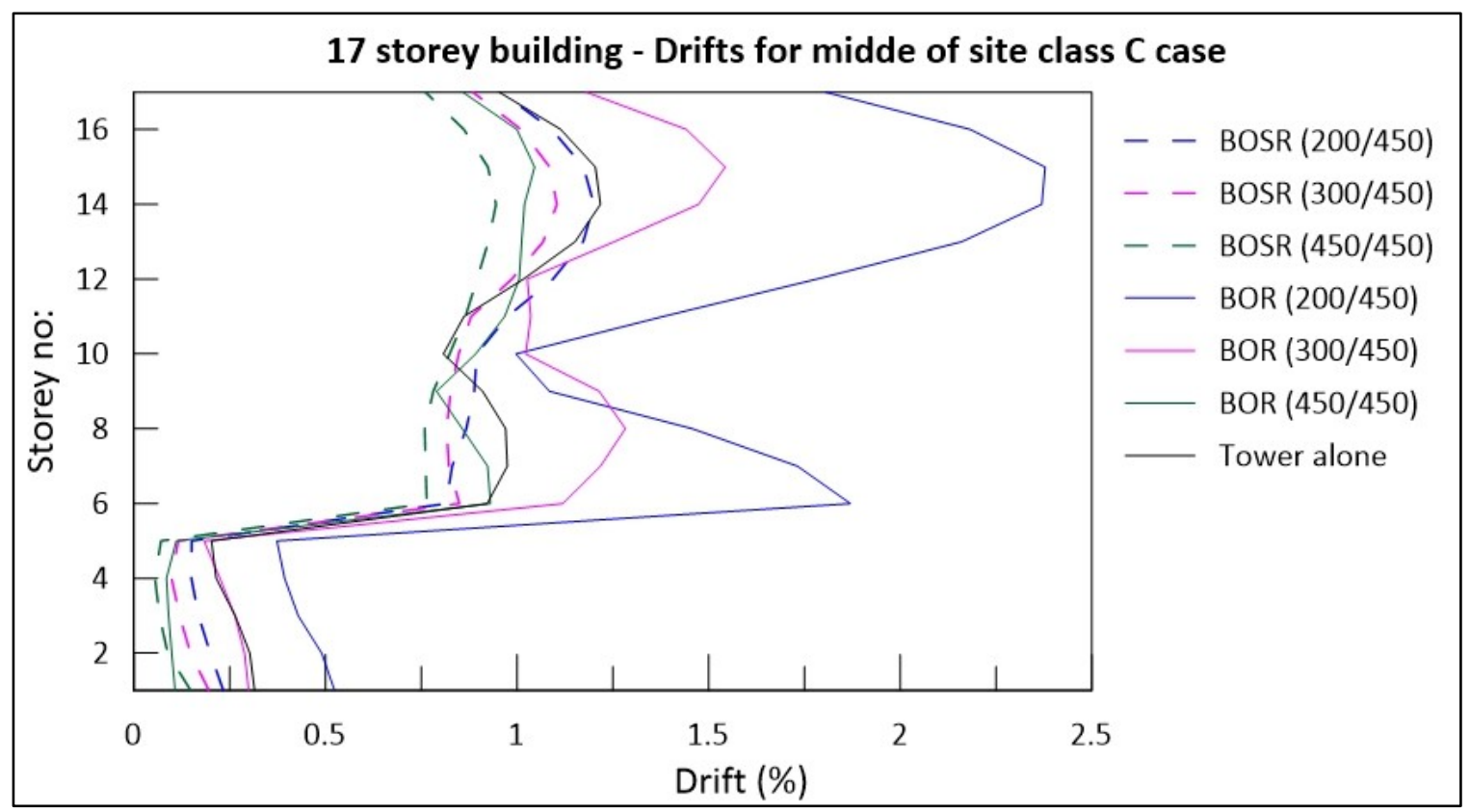

Figure 4-39: Storey drift for the 17 storey building, shear wave velocity of the soil underlying foundation = $450 \mathrm{~m} / \mathrm{s}$

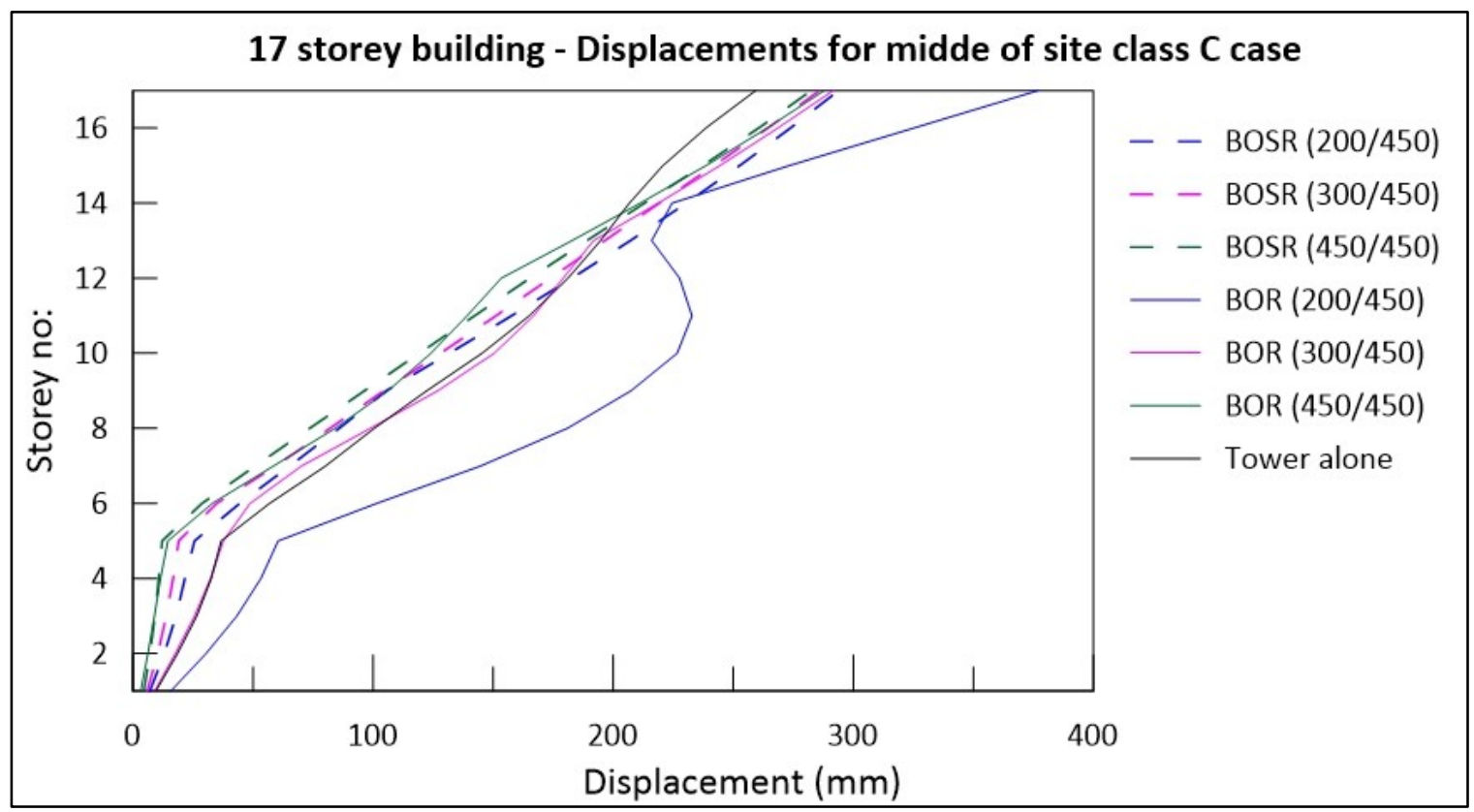

Figure 4-40 : Displacement at the top of a storey for 17 storey building, shear wave velocity of the soil underlying foundation $=450 \mathrm{~m} / \mathrm{s}$ 


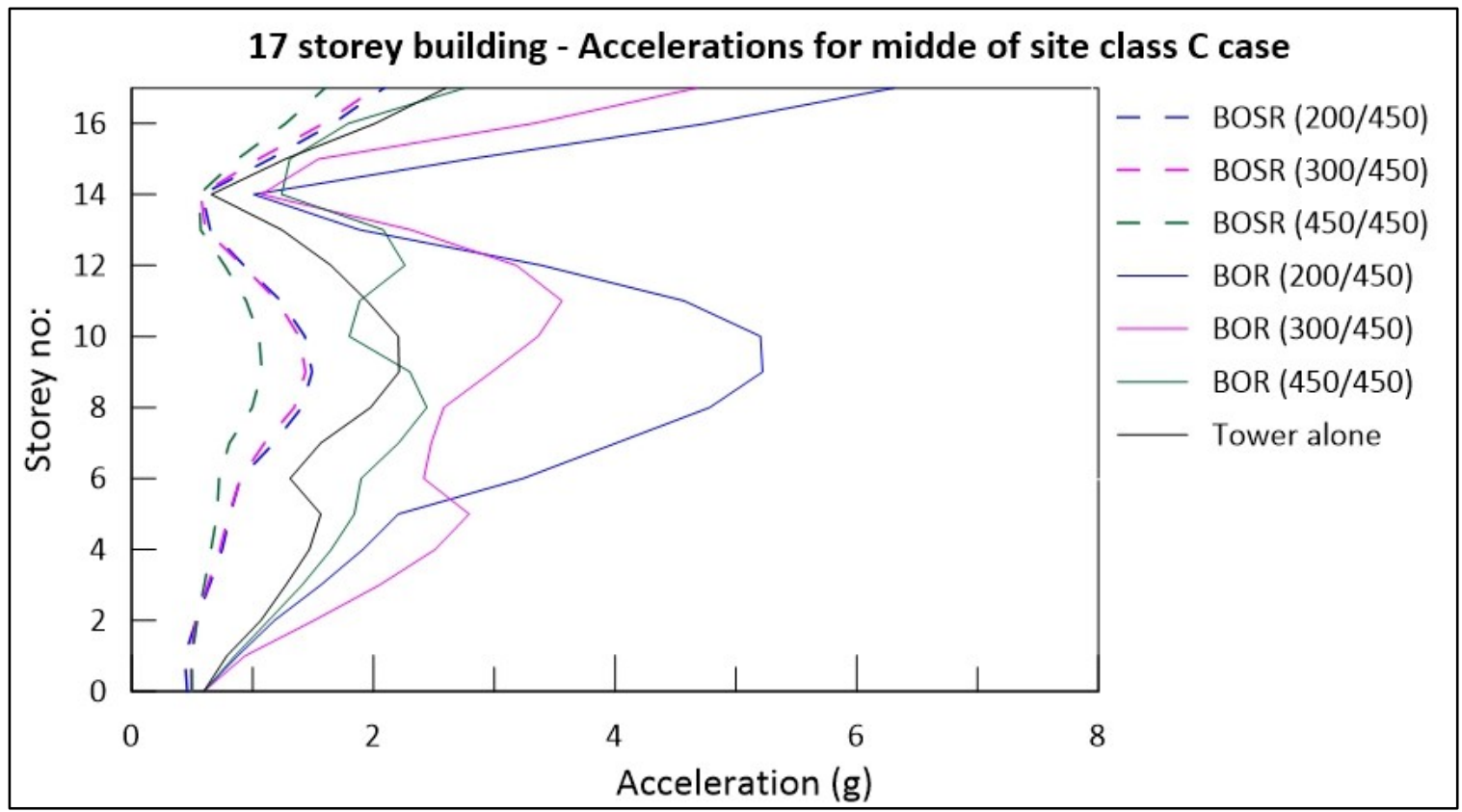

Figure 4-41: Acceleration at the top of a storey for 17 storey building, shear wave velocity of the soil underlying foundation $=450 \mathrm{~m} / \mathrm{s}$

Figure 4-39 shows a similar trend for storey drift as in the case of the shear at the base of the tower with the maximum magnification observed for BOR 200/450, followed by BOR 300/450. For displacement response (Figure 4-40) and acceleration response (Figure 4-41), maximum magnification is observed for the case BOR 200/450.

Figure 4-42 to Figure 4-46 present the results of the 17 storey building with $750 \mathrm{~m} / \mathrm{s}$ soil under the base of the tower. It can be seen from Figure 4-42 that maximum magnification in shear and moment at the base of the tower is observed for BOR 200/750. The second highest magnification is observed for the case BOSR 200/750. Also, from Figure 4-44, it is seen that maximum magnification in the drift in the base storey of the tower follows the same trend as that of the magnification in the base shear and the base moment. 


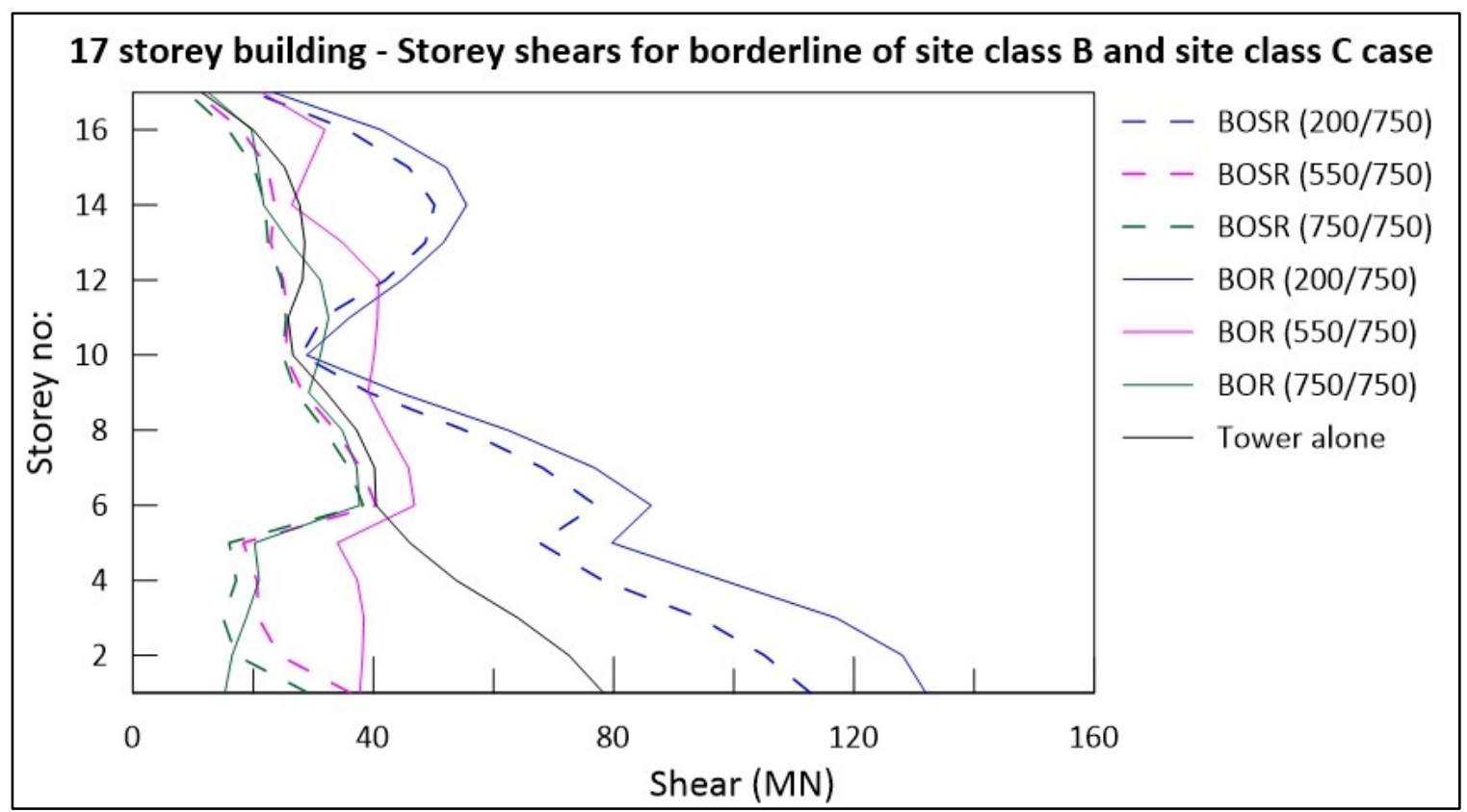

Figure 4-42: Storey shear values for a 17 storey building, shear wave velocity of the soil underlying foundation $=750 \mathrm{~m} / \mathrm{s}$

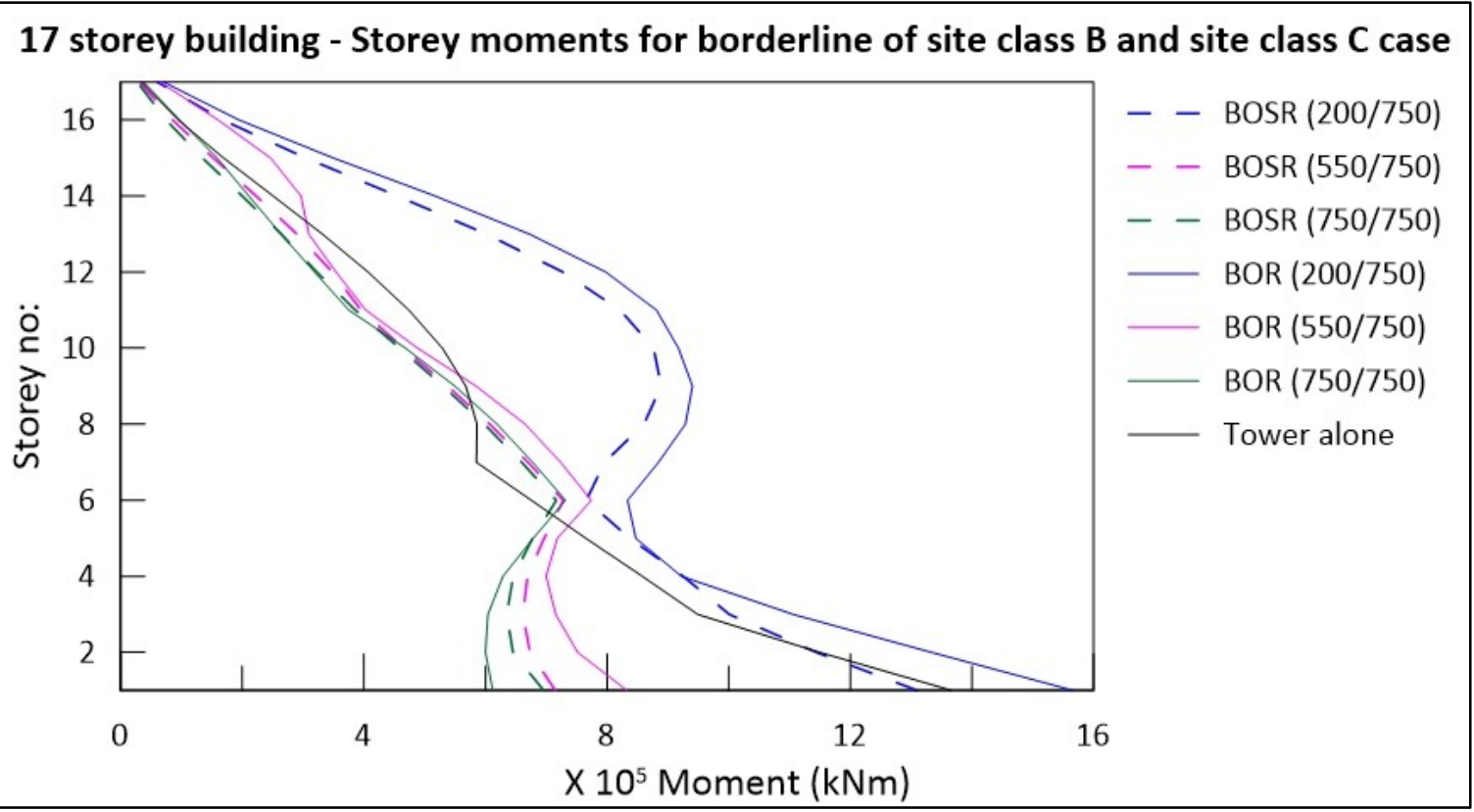

Figure 4-43: Moment at the bottom of the storey for a 17 storey building, shear wave velocity of the soil underlying foundation $=750 \mathrm{~m} / \mathrm{s}$ 


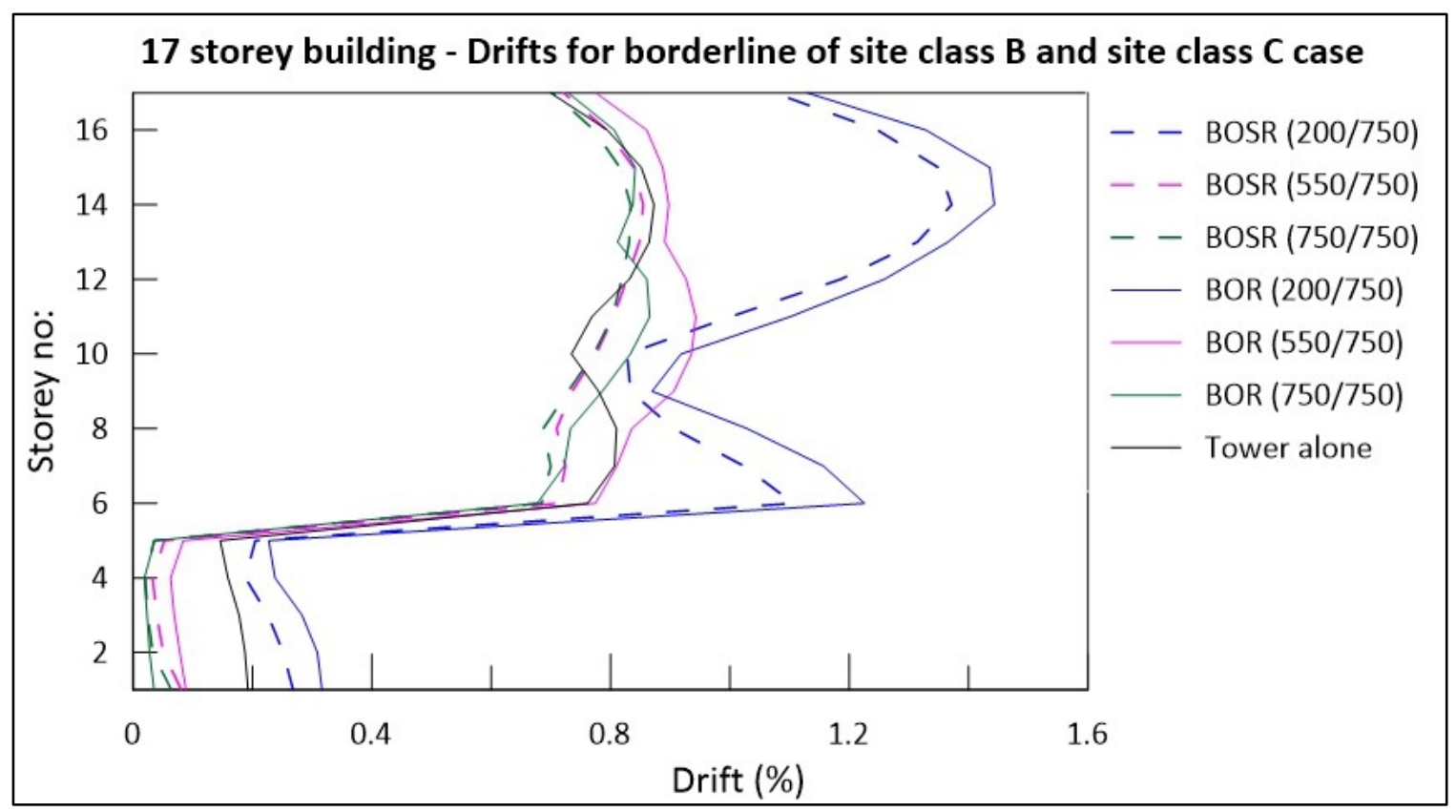

Figure 4-44: Storey drift for the 17 storey building, shear wave velocity of the soil underlying foundation = $750 \mathrm{~m} / \mathrm{s}$

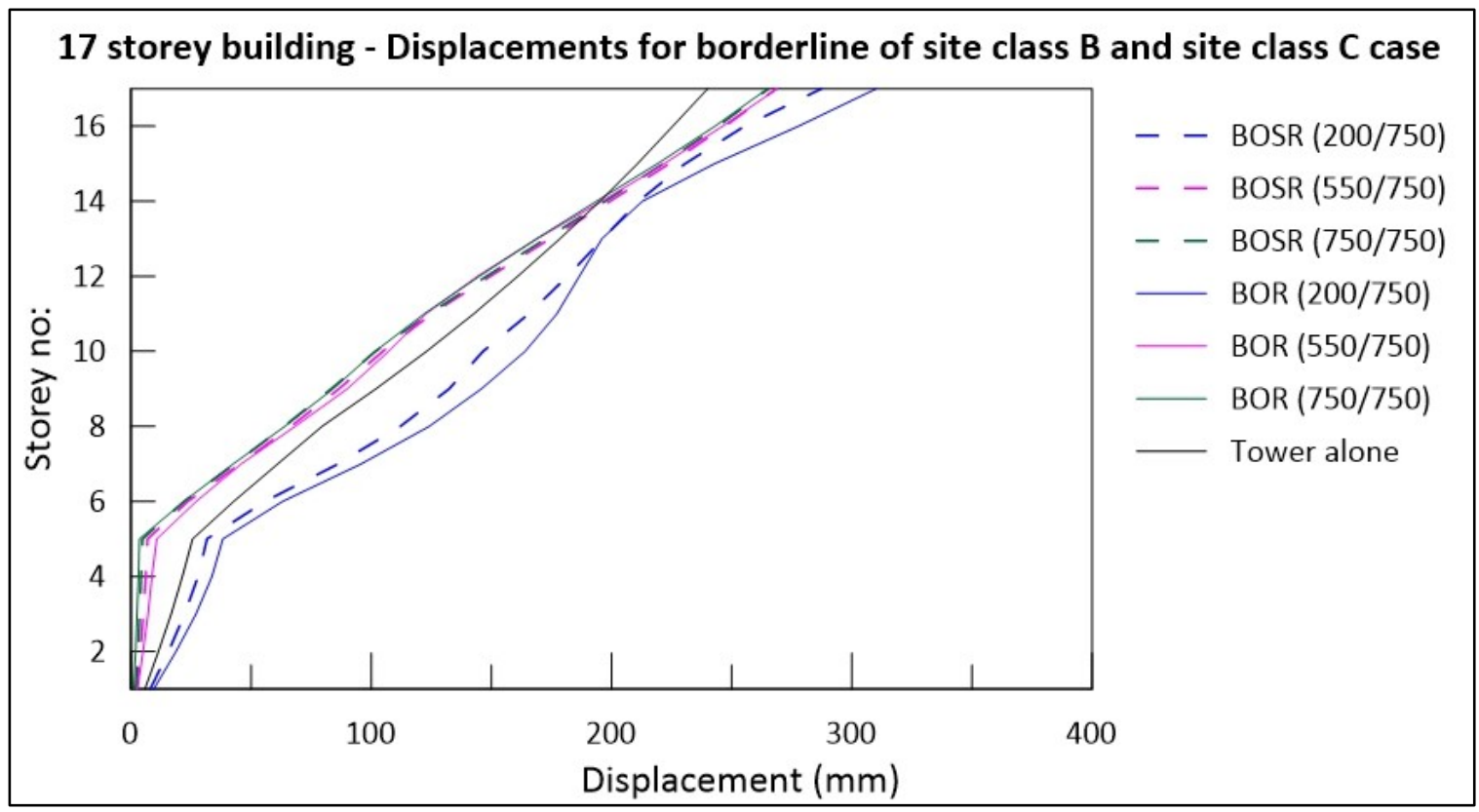

Figure 4-45: Displacement at the top of a storey for 17 storey building, shear wave velocity of the soil underlying foundation $=750 \mathrm{~m} / \mathrm{s}$ 


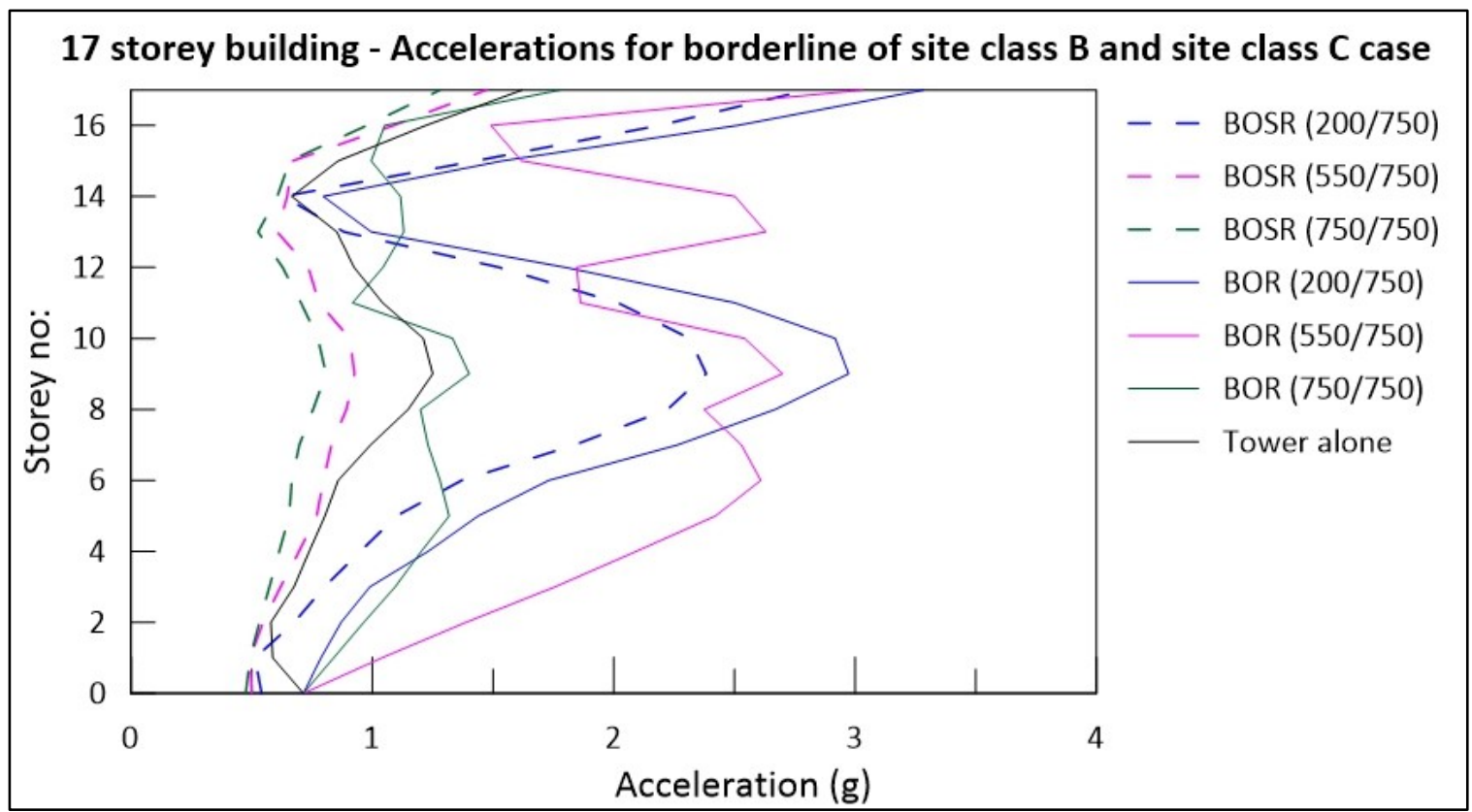

Figure 4-46: Acceleration at the top of a storey for 17 storey building, shear wave velocity of the soil underlying foundation $=750 \mathrm{~m} / \mathrm{s}$

For displacement response, the maximum magnification at the base of the tower is observed for BOR 200/750 and closely followed by the case BOSR 200/750. For acceleration response, the maximum magnification is observed for the case BOR 550/750. Figures 4-47 to 4-51 presents the seismic response of the 12 storey tower and its supporting structure when analyzed with soil under the base of the building having a shear wave velocity of $1000 \mathrm{~m} / \mathrm{s}$. The highest magnification in shear and moment at the base of the tower is observed for BOR 200/1000. The second highest magnification is observed for the case BOSR 200/1000. A similar trend is observed for storey drifts as detailed in Figure 4-49. 


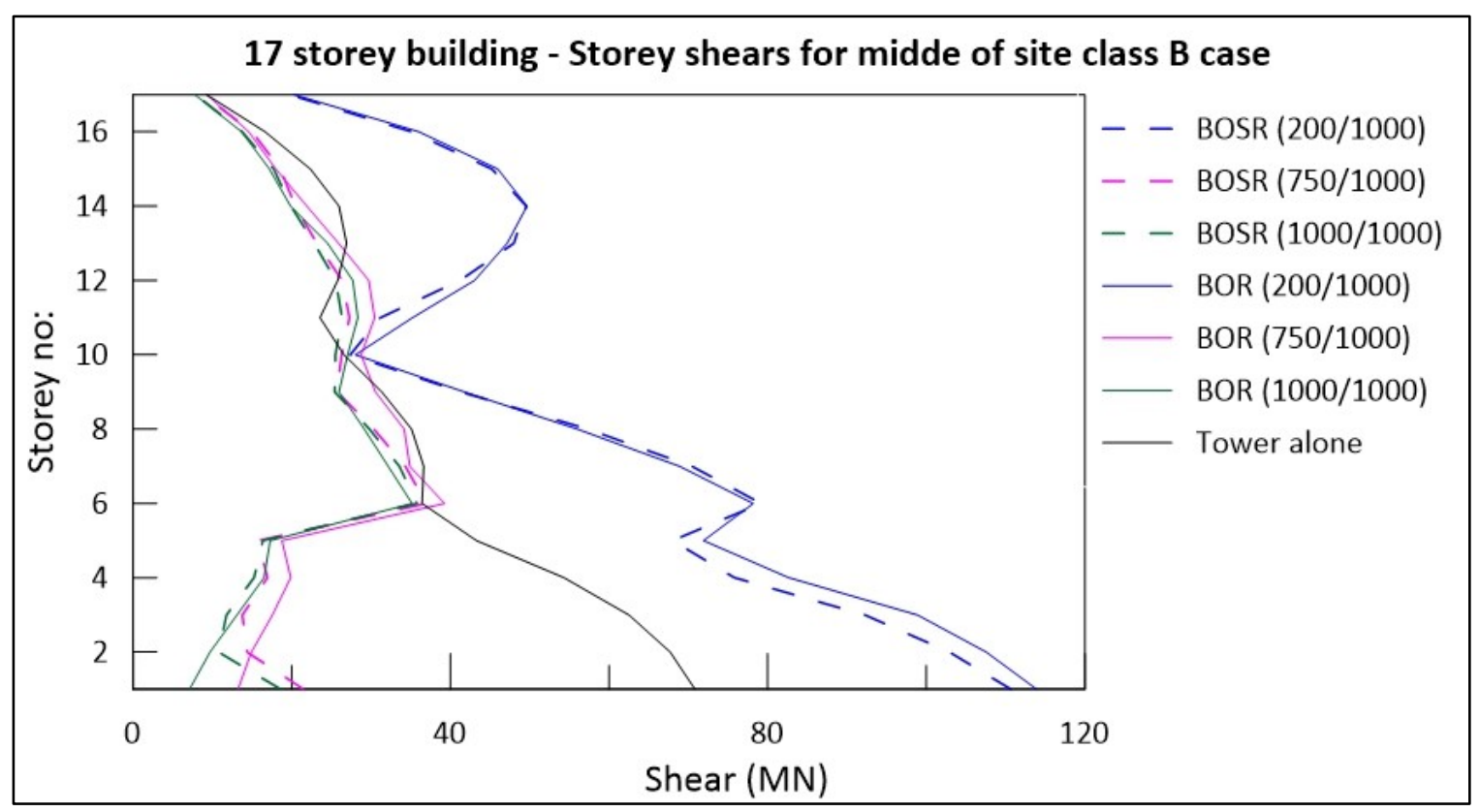

Figure 4-47: Storey shear values for a 17 storey building, shear wave velocity of the soil underlying foundation $=1000 \mathrm{~m} / \mathrm{s}$

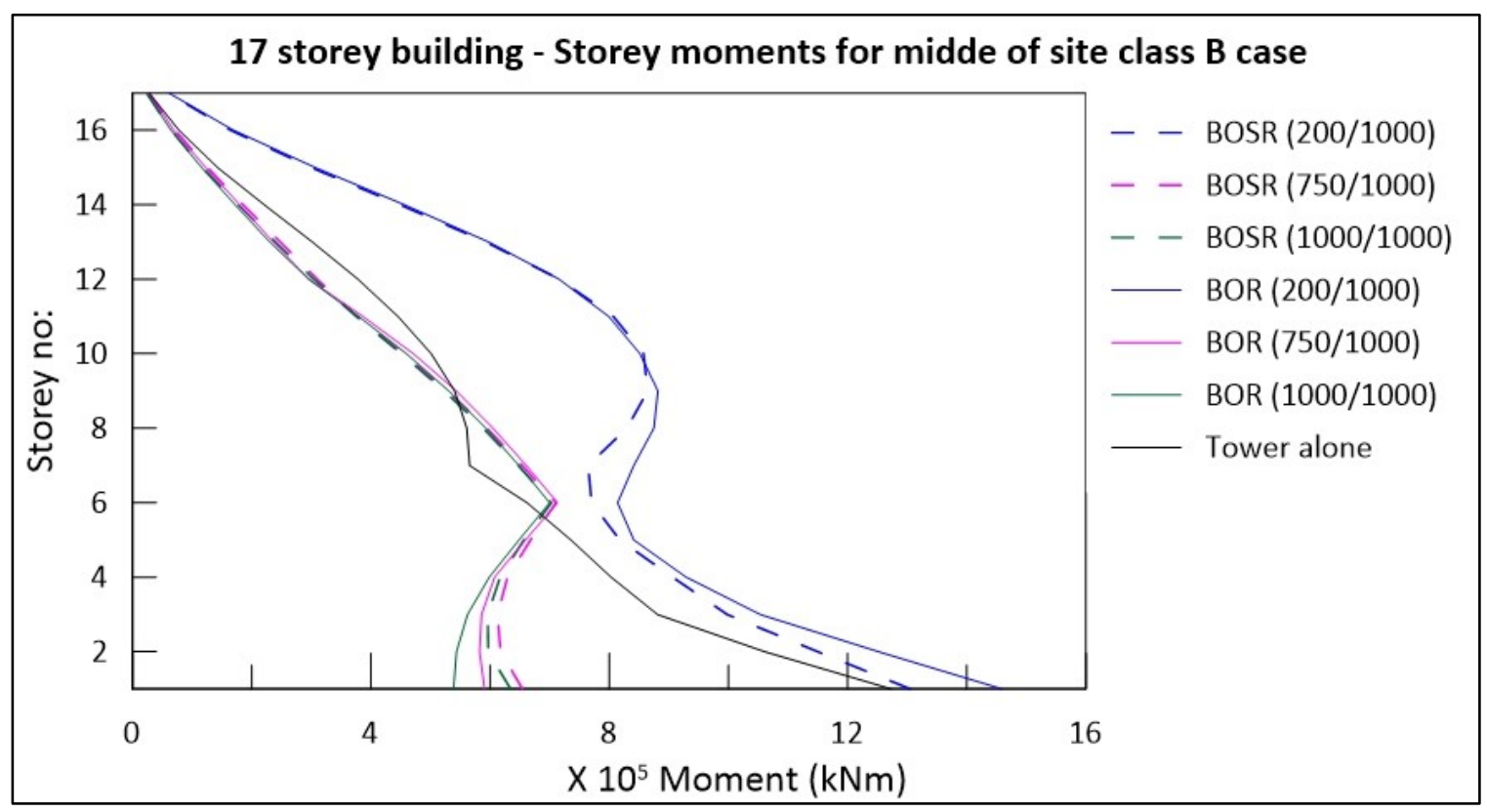

Figure 4-48: Moment at the bottom of the storey for a 17 storey building, shear wave velocity of the soil underlying foundation $=1000 \mathrm{~m} / \mathrm{s}$ 


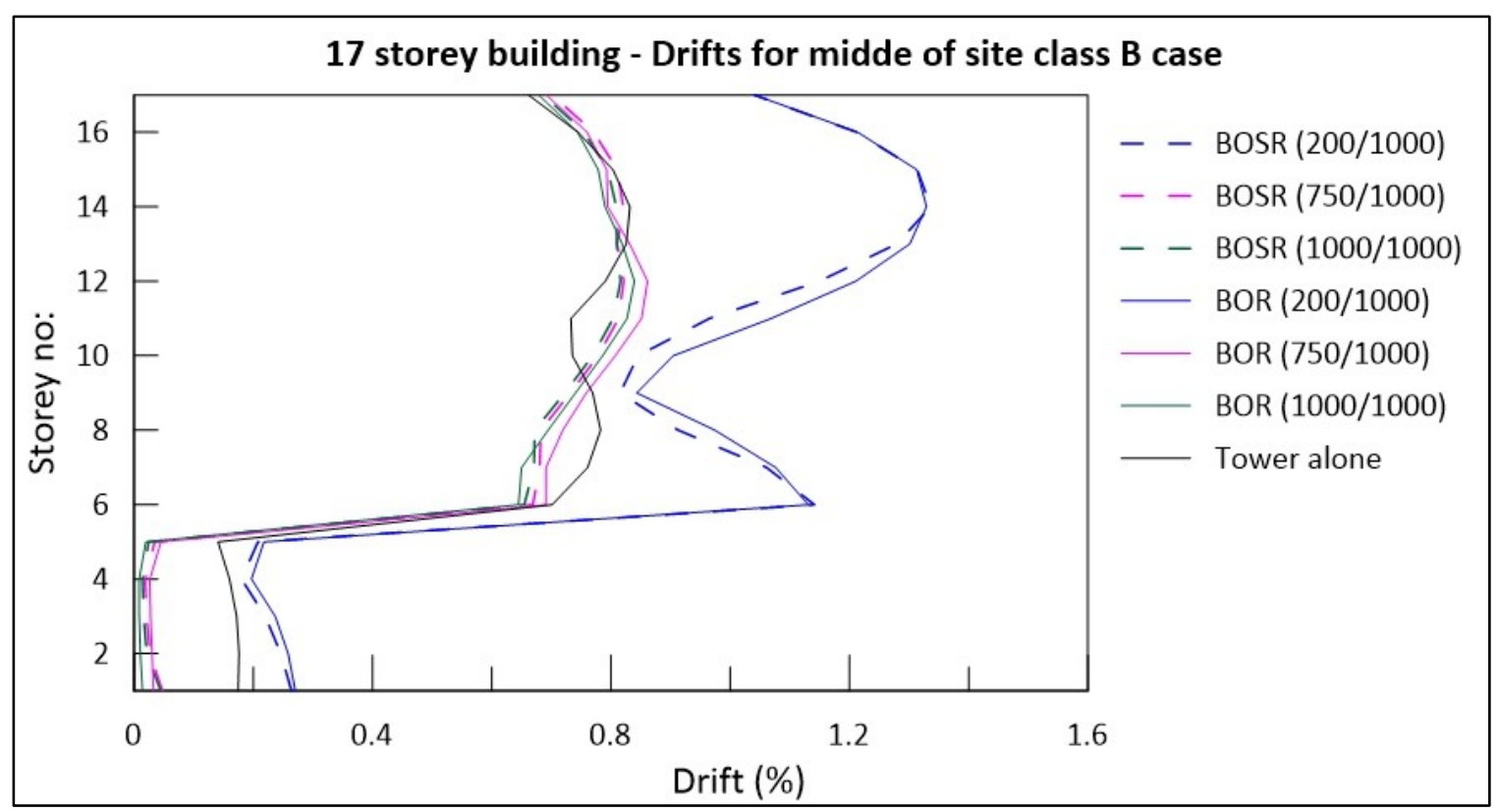

Figure 4-49: Storey drift for the 17 storey building, shear wave velocity of the soil underlying foundation = $1000 \mathrm{~m} / \mathrm{s}$

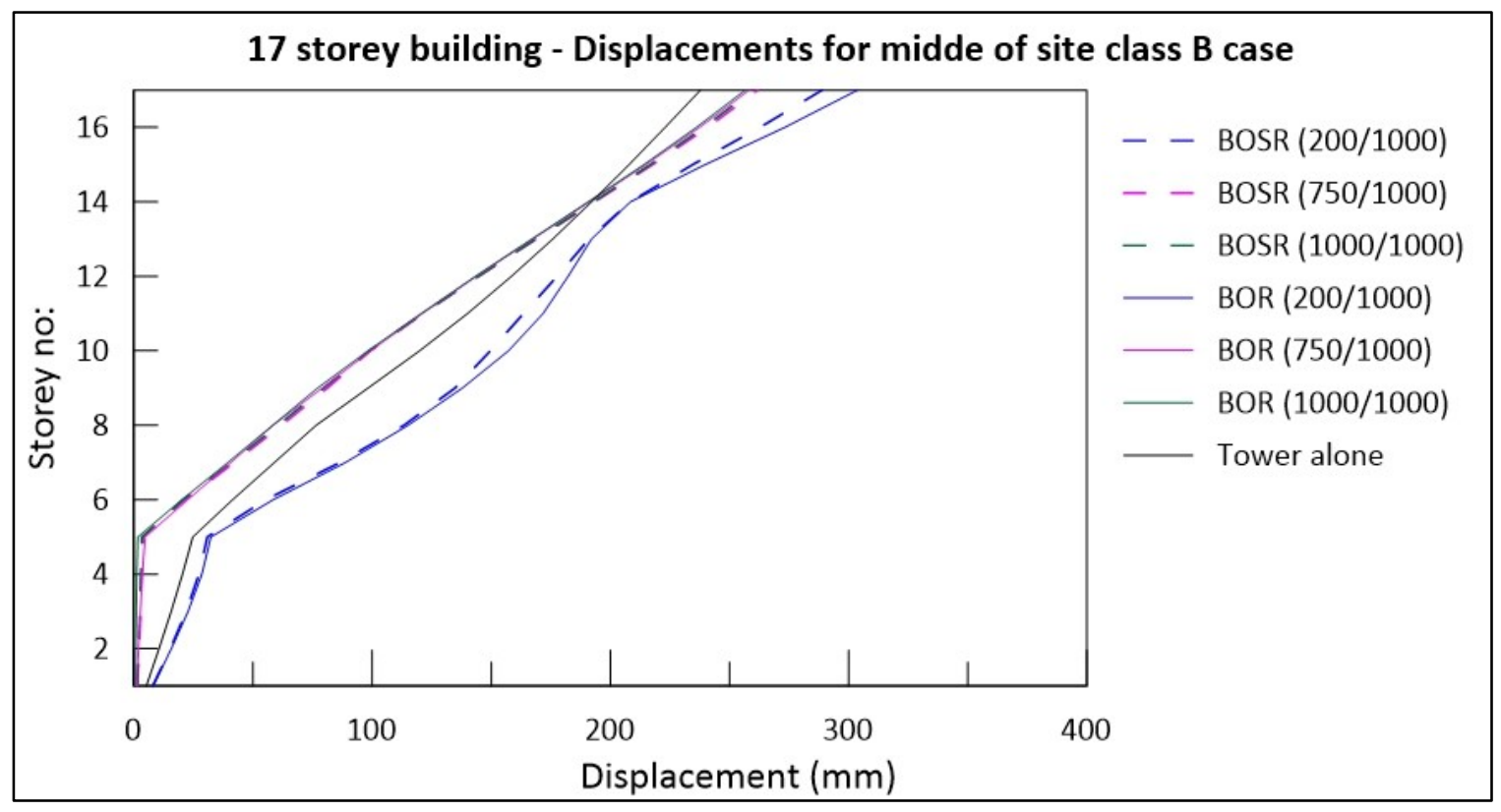

Figure 4-50: Displacement at the top of a storey for 17 storey building, shear wave velocity of the soil underlying foundation $=1000 \mathrm{~m} / \mathrm{s}$ 


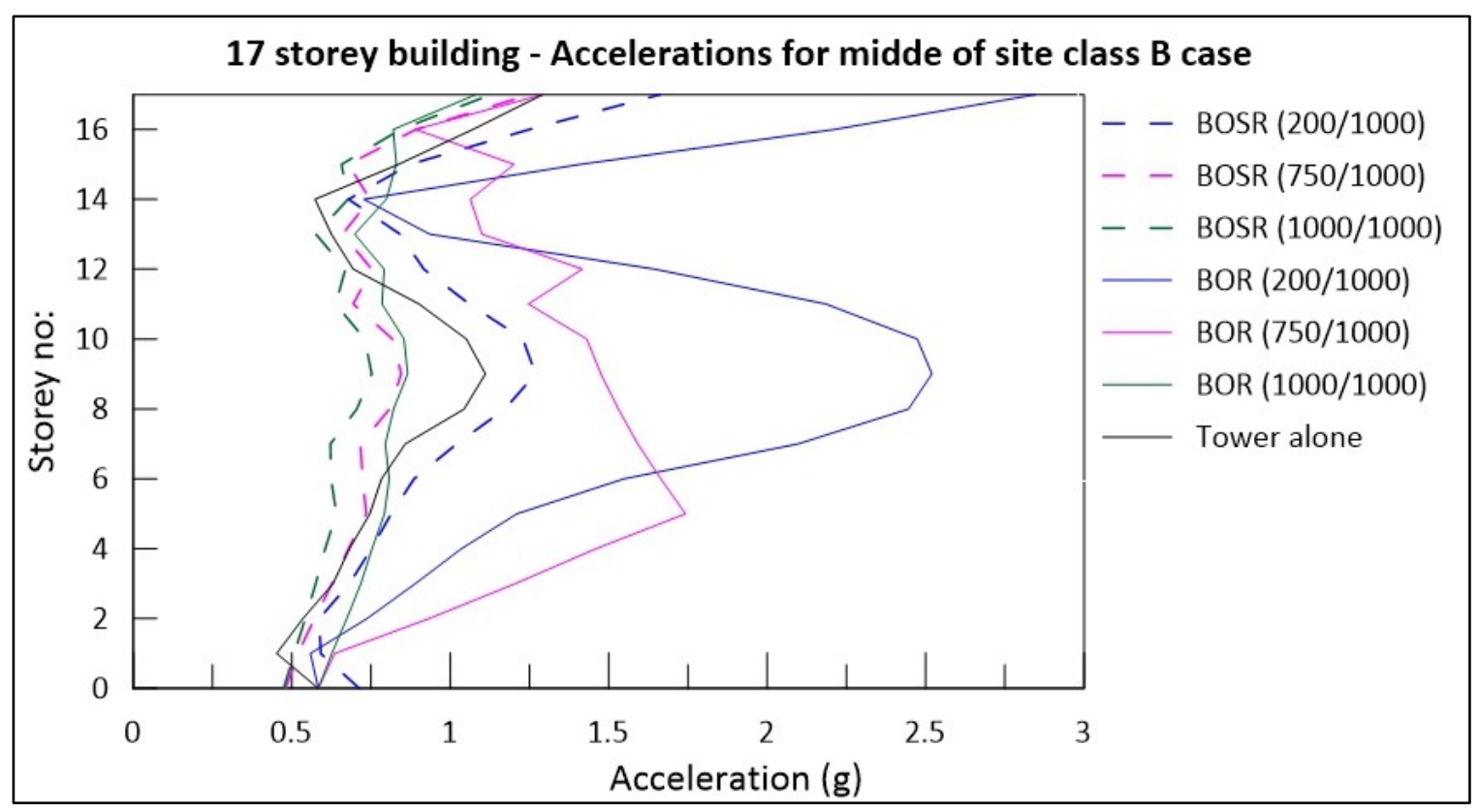

Figure 4-51: Acceleration at the top of a storey for 17 storey building, shear wave velocity of the soil underlying foundation $=1000 \mathrm{~m} / \mathrm{s}$

Considering the displacement (Figure 4-50) and acceleration (Figure 4-51) response, the maximum magnification at the base of the tower is observed for BOR 200/1000. The second highest magnification in displacement at the tower base is observed for the case BOSR 200/1000.

\section{1 storey building}

Figure 4-52 to Figure 4-56 display the storey shear, storey moment, drift, displacement, and acceleration, respectively for the case of the 16 storey tower and its supporting structure that is founded on a $450 \mathrm{~m} / \mathrm{s}$ soil.

Magnification in storey shear and storey moment is observed for BOR 200/450 and BOR 300/450. Among these, the highest magnification in shear at the base of the tower is observed for BOR 300/450. However, no significant magnification in the moment at the tower base is observed when compared with the building alone case, as shown in Figure 4-53. 


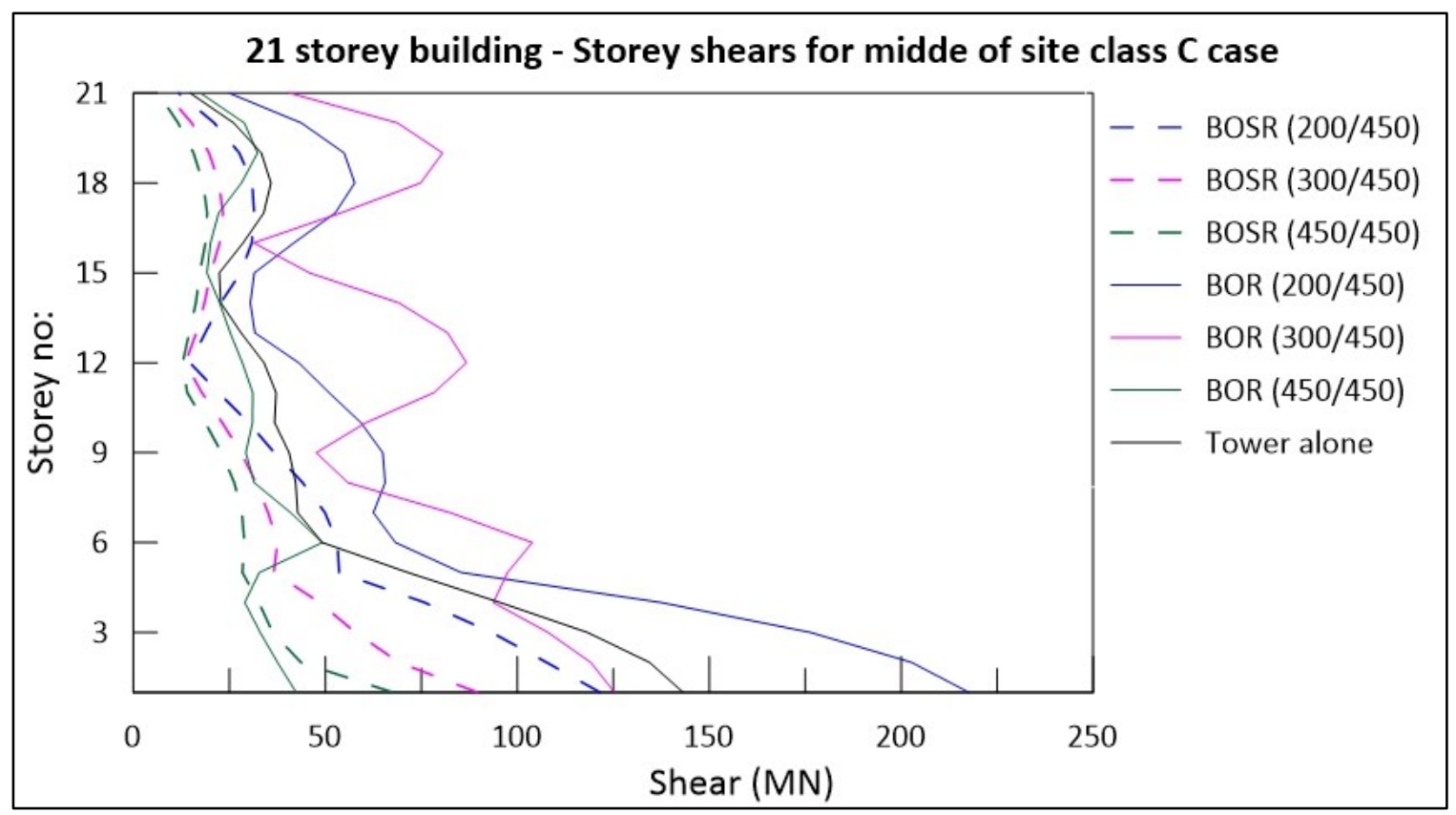

Figure 4-52: Storey shear values for a 21 storey building, shear wave velocity of the soil underlying foundation $=450 \mathrm{~m} / \mathrm{s}$

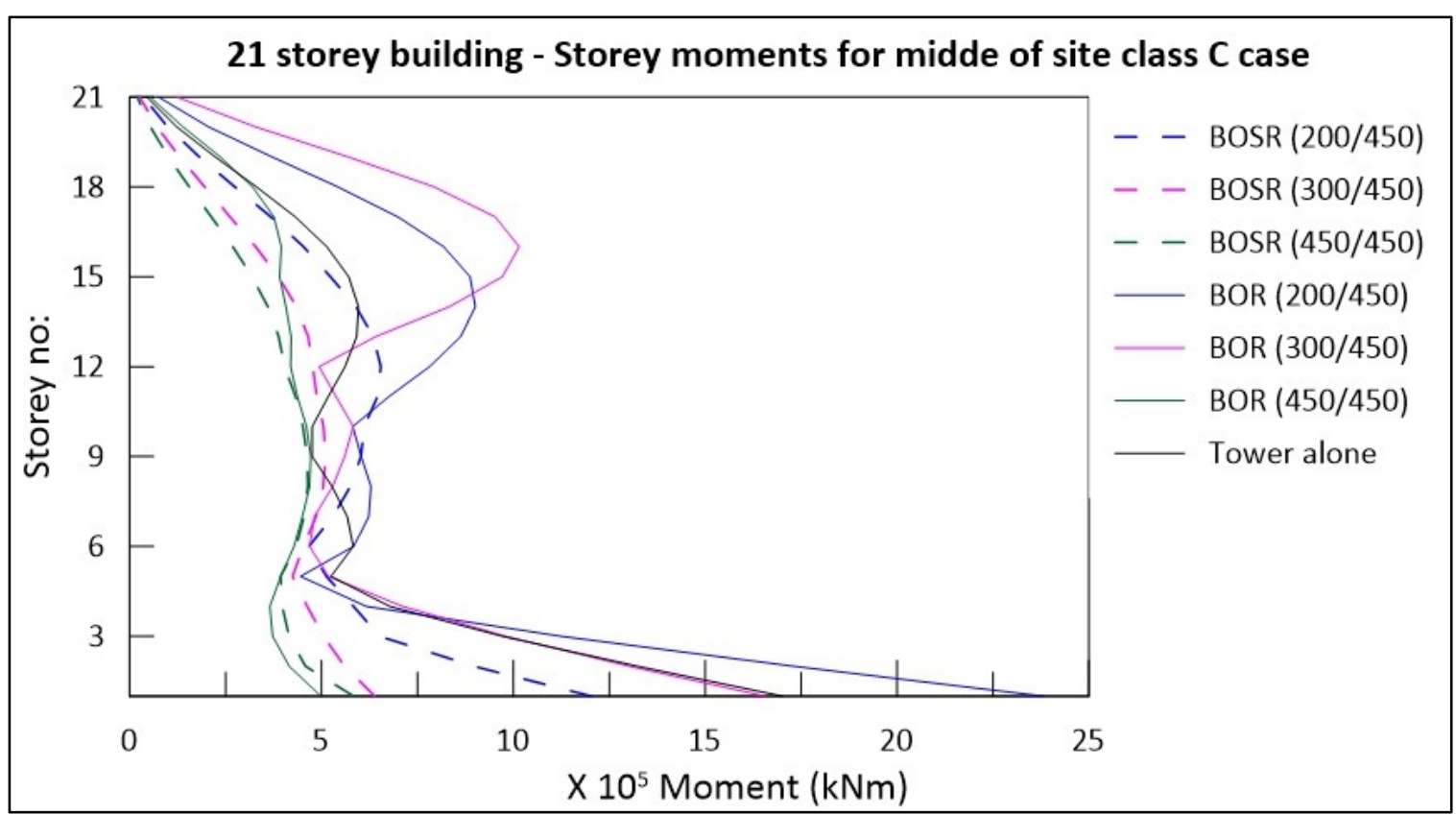

Figure 4-53: Moment at the bottom of the storey for a 21 storey building, shear wave velocity of the soil underlying foundation $=450 \mathrm{~m} / \mathrm{s}$ 


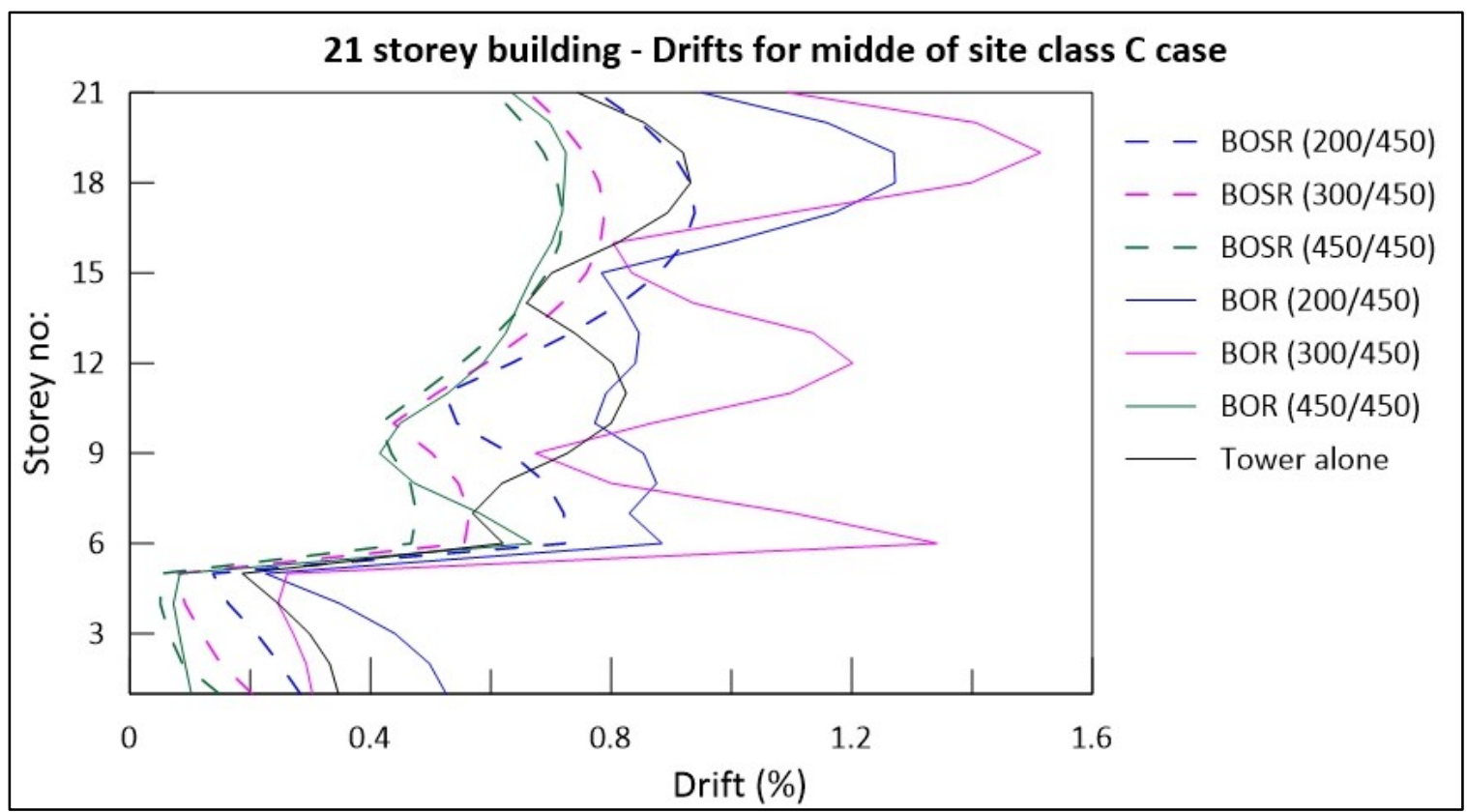

Figure 4-54: Storey drift for the 21 storey building, shear wave velocity of the soil underlying foundation = $450 \mathrm{~m} / \mathrm{s}$

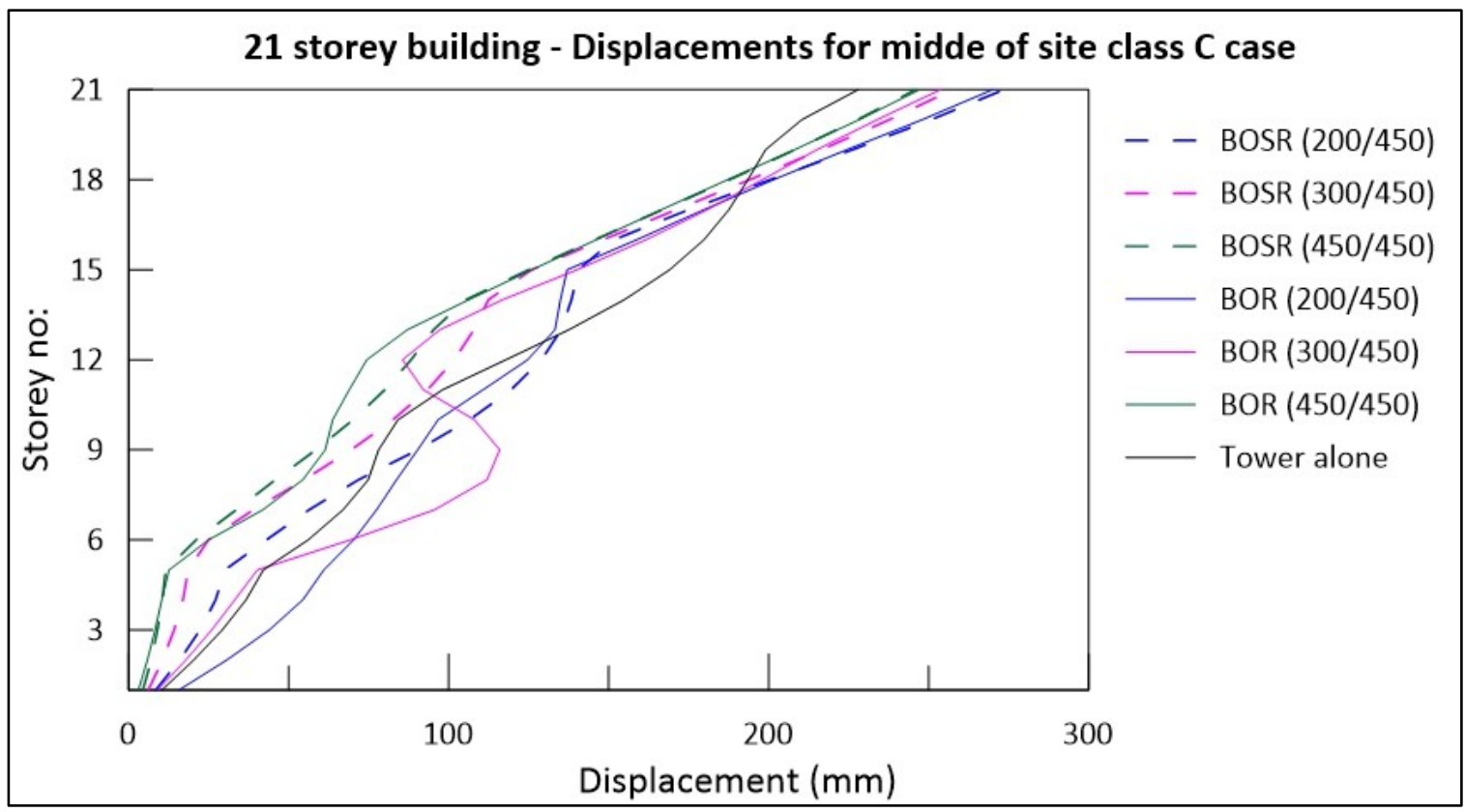

Figure 4-55 : Displacement at the top of a storey for 21 storey building, shear wave velocity of the soil underlying foundation $=450 \mathrm{~m} / \mathrm{s}$ 


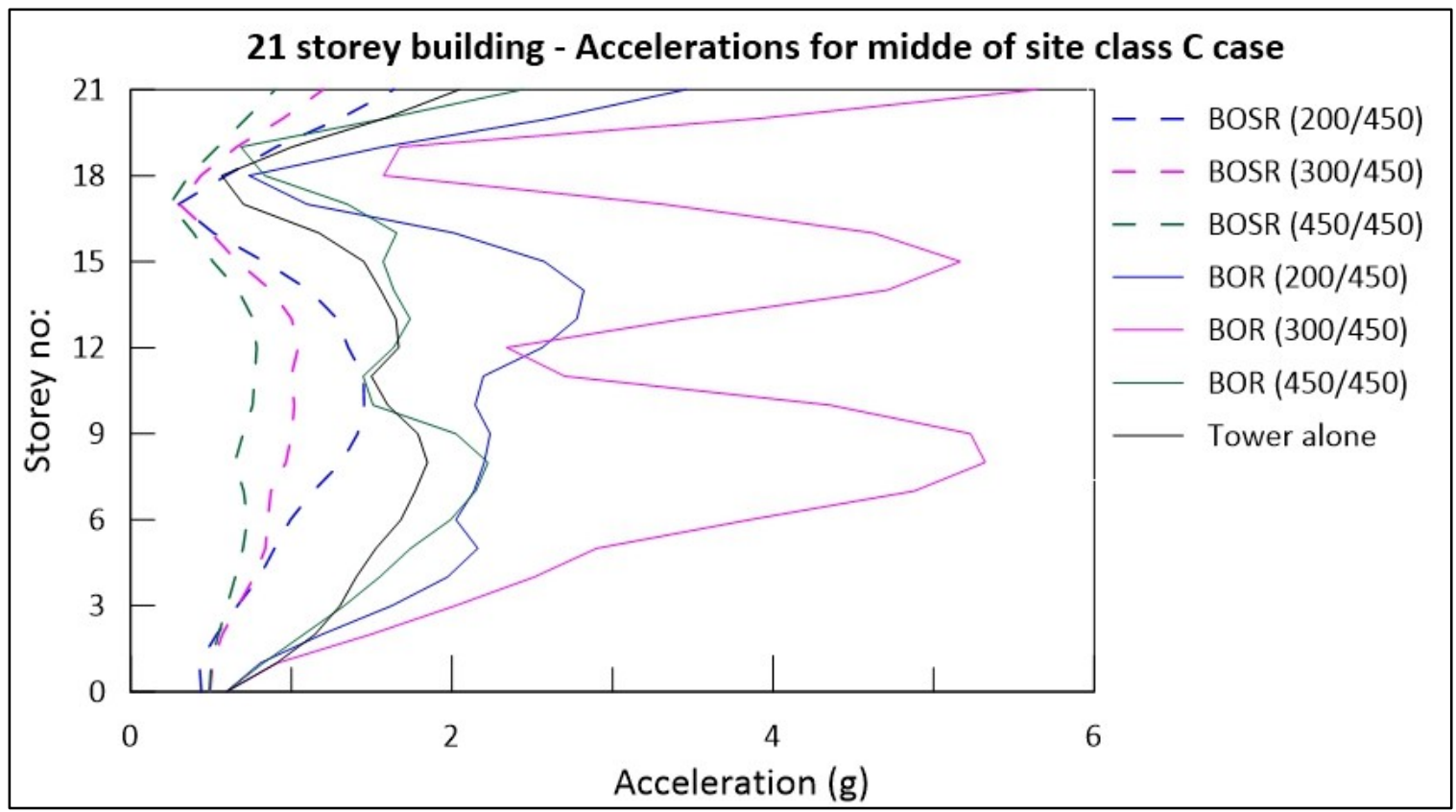

Figure 4-56 : Acceleration at the top of a storey for 21 storey building, shear wave velocity of the soil underlying foundation $=450 \mathrm{~m} / \mathrm{s}$

The magnification in drift over the base storey of the tower follows a trend that is similar to that for the shear at the base storey of the tower (Figure 4-54) the highest being for the case BOR 300/450, followed by BOR 200/450. Similarly, from Figure 4-55, it is observed that magnification in displacement at the base of the tower is highest for the case BOR 300/450 closely followed by the case BOR 200/450. Figure 4-56 shows that BOR 300/450 has the maximum magnification in acceleration at the base of the tower when compared with the building alone. The second highest magnification is observed for the case BOSR $200 / 450$.

Figure 4-57 to Figure 4-61 present the results for the 16 storey tower and its supporting structure when analyzed with soil under the base of the building having a shear wave velocity of $750 \mathrm{~m} / \mathrm{s}$. From Figure $4-57$ and Figure $4-58$ it is obvious that maximum magnification in shear and moment at the base of the tower is observed for the BOR 200/750, closely followed by the case BOSR 200/750. 


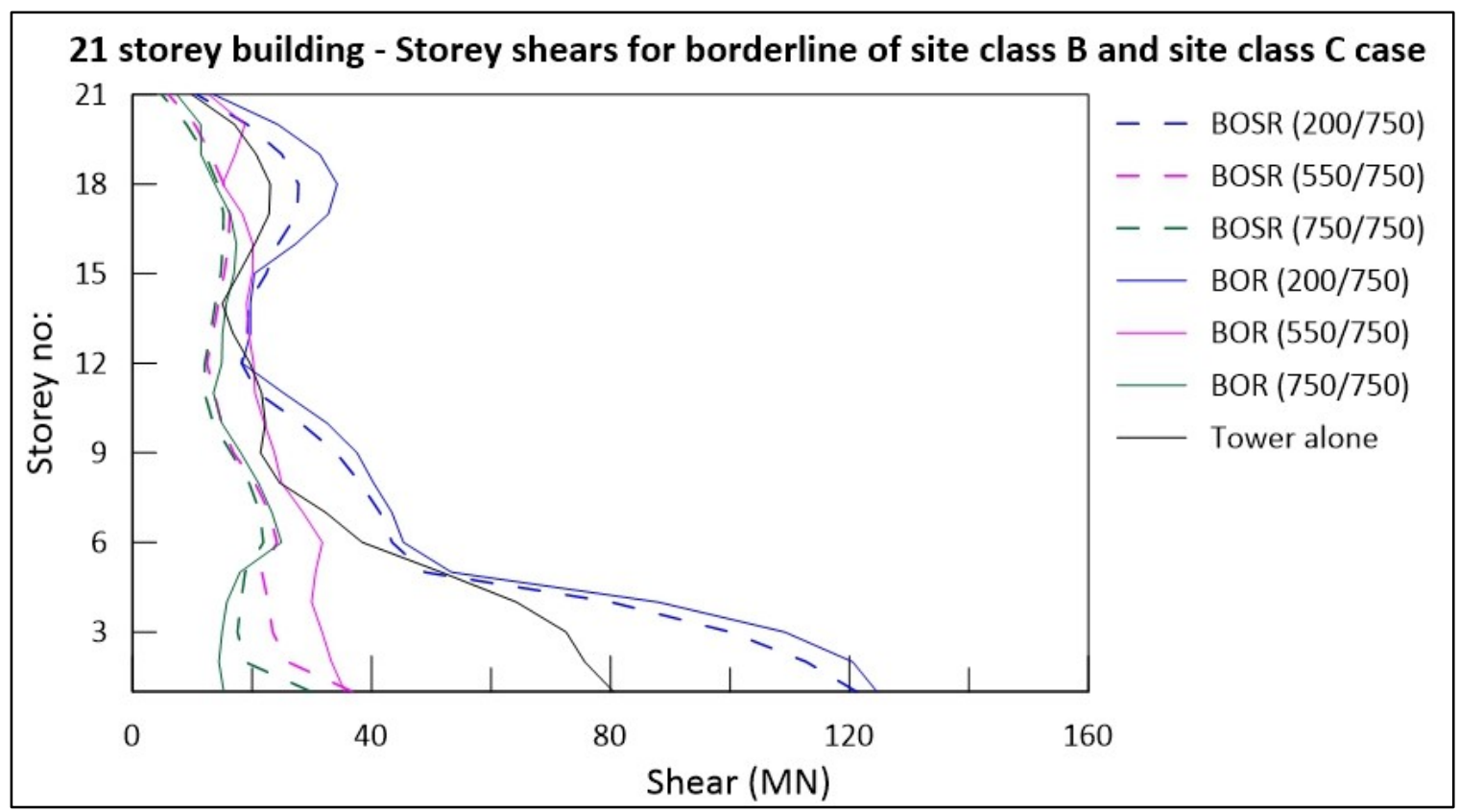

Figure 4-57: Storey shear values for a 21 storey building, shear wave velocity of the soil underlying foundation $=750 \mathrm{~m} / \mathrm{s}$

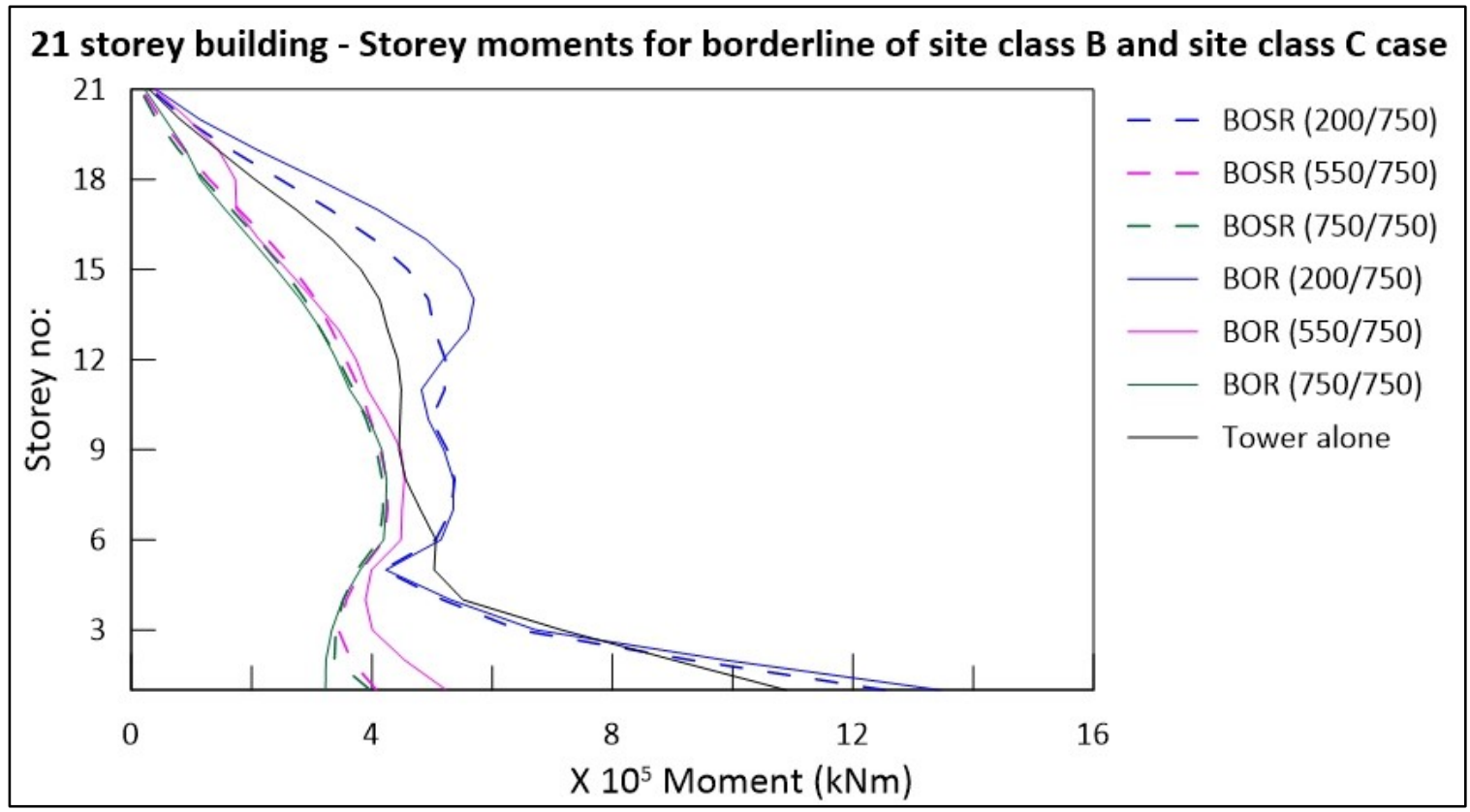

Figure 4-58: Moment at the bottom of the storey for a 21 storey building, shear wave velocity of the soil underlying foundation $=750 \mathrm{~m} / \mathrm{s}$

A similar trend as in the case of shear and moment at the base of the tower is observed for storey drift, with the highest observed for BOR 200/750, followed by BOSR 200/750. 
From Figure 4-60 it is evident that there is no significant magnification in displacement at the base of the tower. For acceleration response (Figure 4-61), BOR 550/750 has the maximum magnification in acceleration at the base of the tower when compared with the building alone. The second highest magnification is observed for BOR 200/750 and closely followed by BOR 750/750.

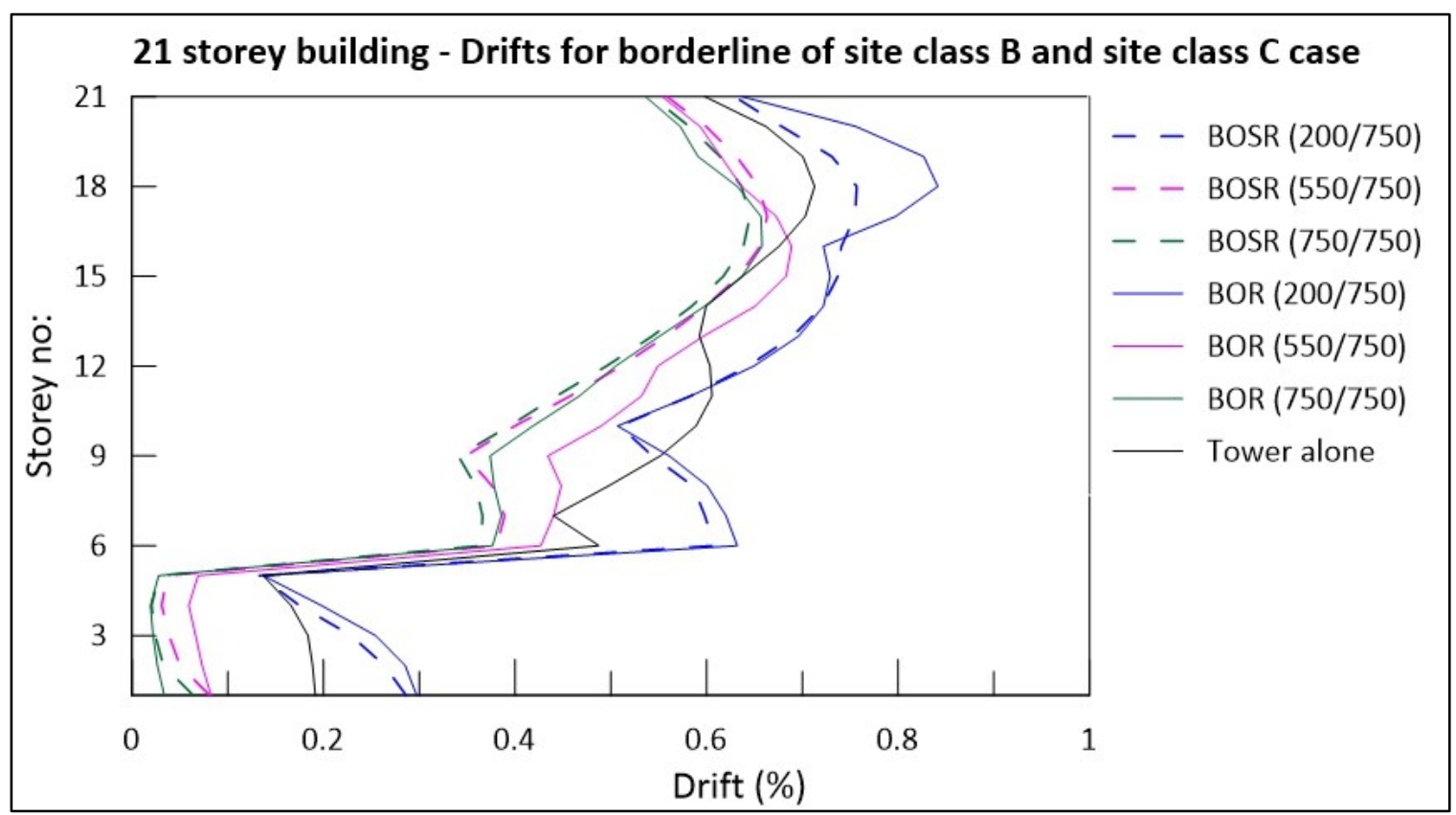

Figure 4-59: Storey drift for the 21 storey building, shear wave velocity of the soil underlying foundation = $750 \mathrm{~m} / \mathrm{s}$ 


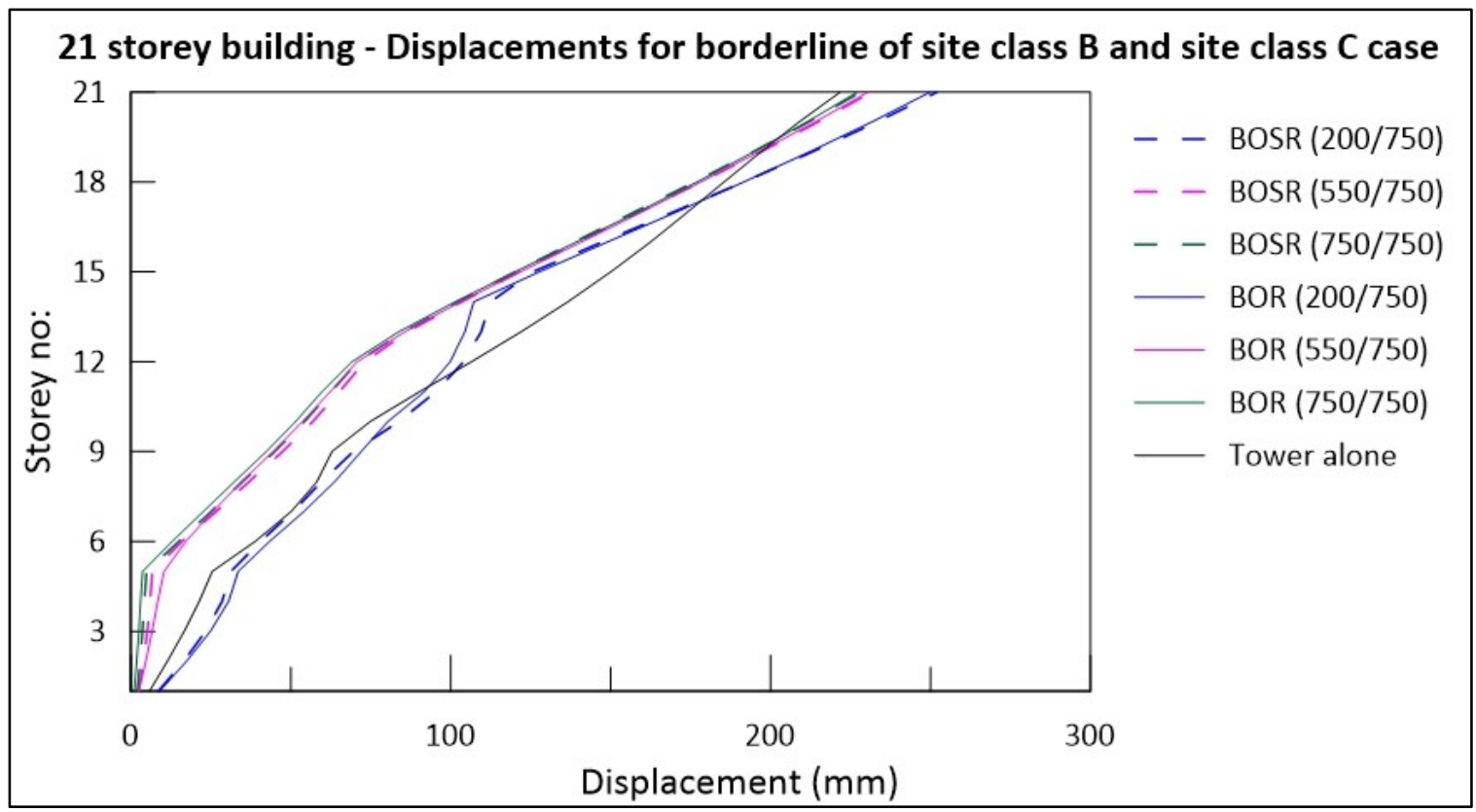

Figure 4-60: Displacement at the top of a storey for 21 storey building, shear wave velocity of the soil underlying foundation $=750 \mathrm{~m} / \mathrm{s}$

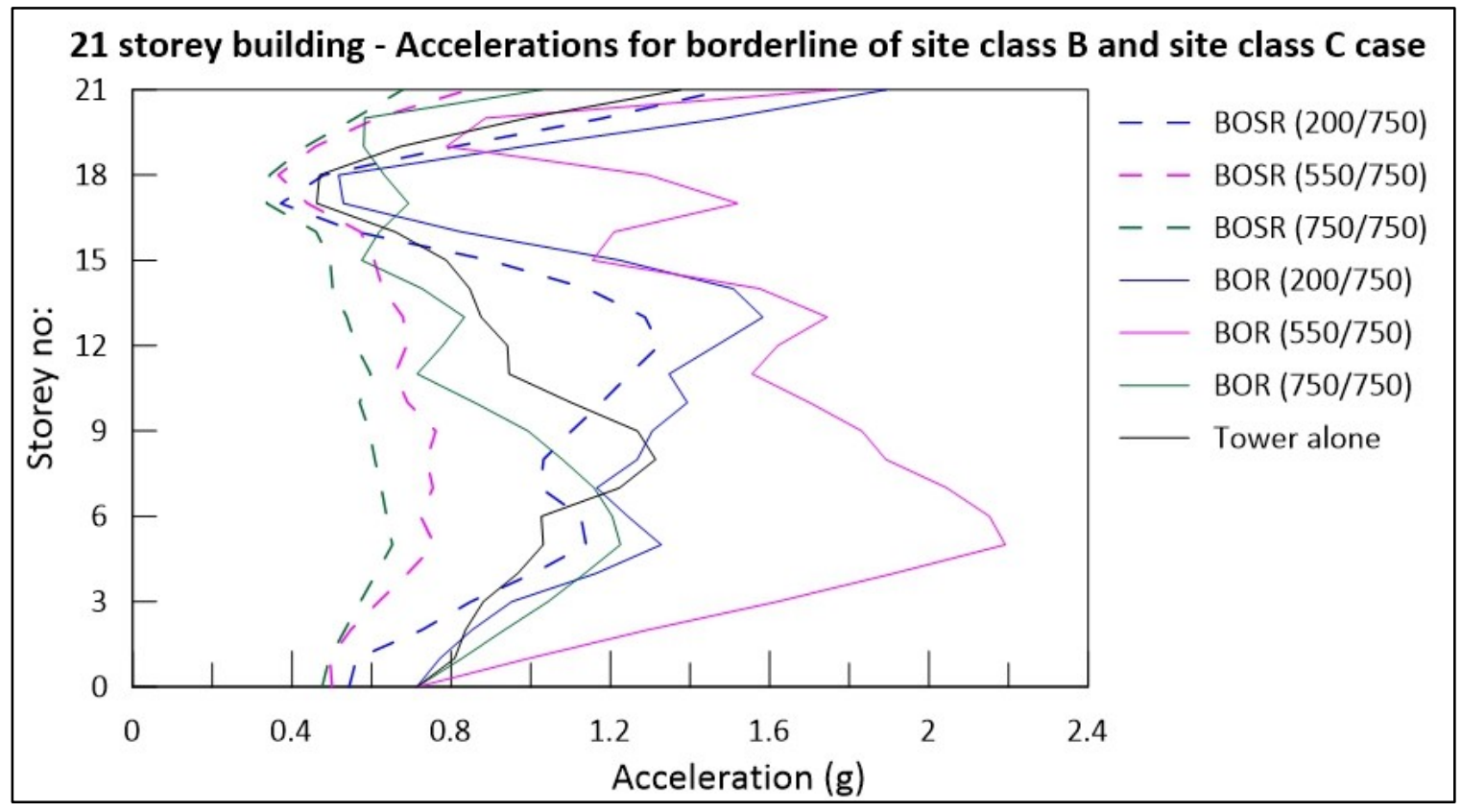

Figure 4-61: Acceleration at the top of a storey for 21 storey building, shear wave velocity of the soil underlying foundation $=750 \mathrm{~m} / \mathrm{s}$ 


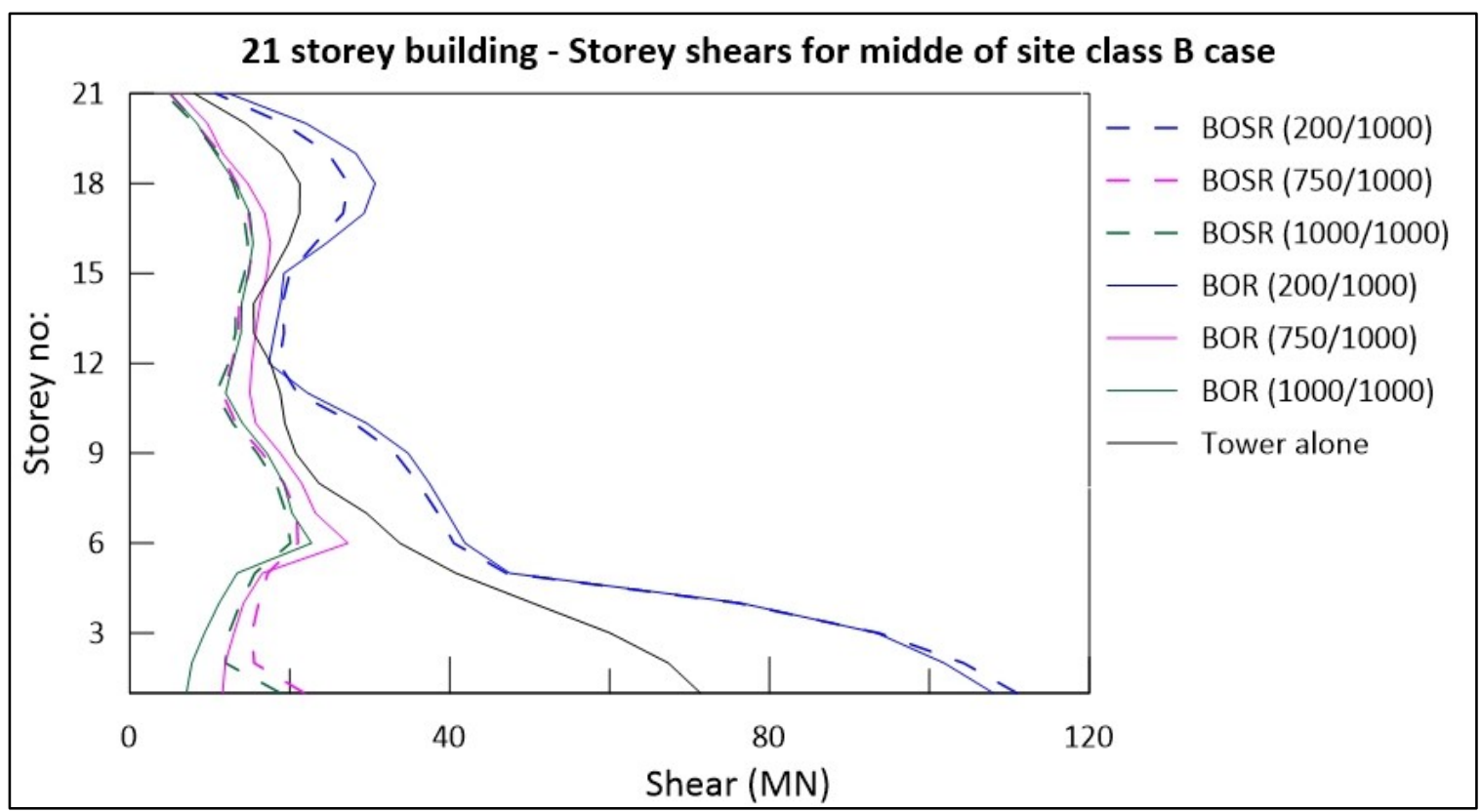

Figure 4-62: Storey shear values for a 21 storey building, shear wave velocity of the soil underlying foundation $=1000 \mathrm{~m} / \mathrm{s}$

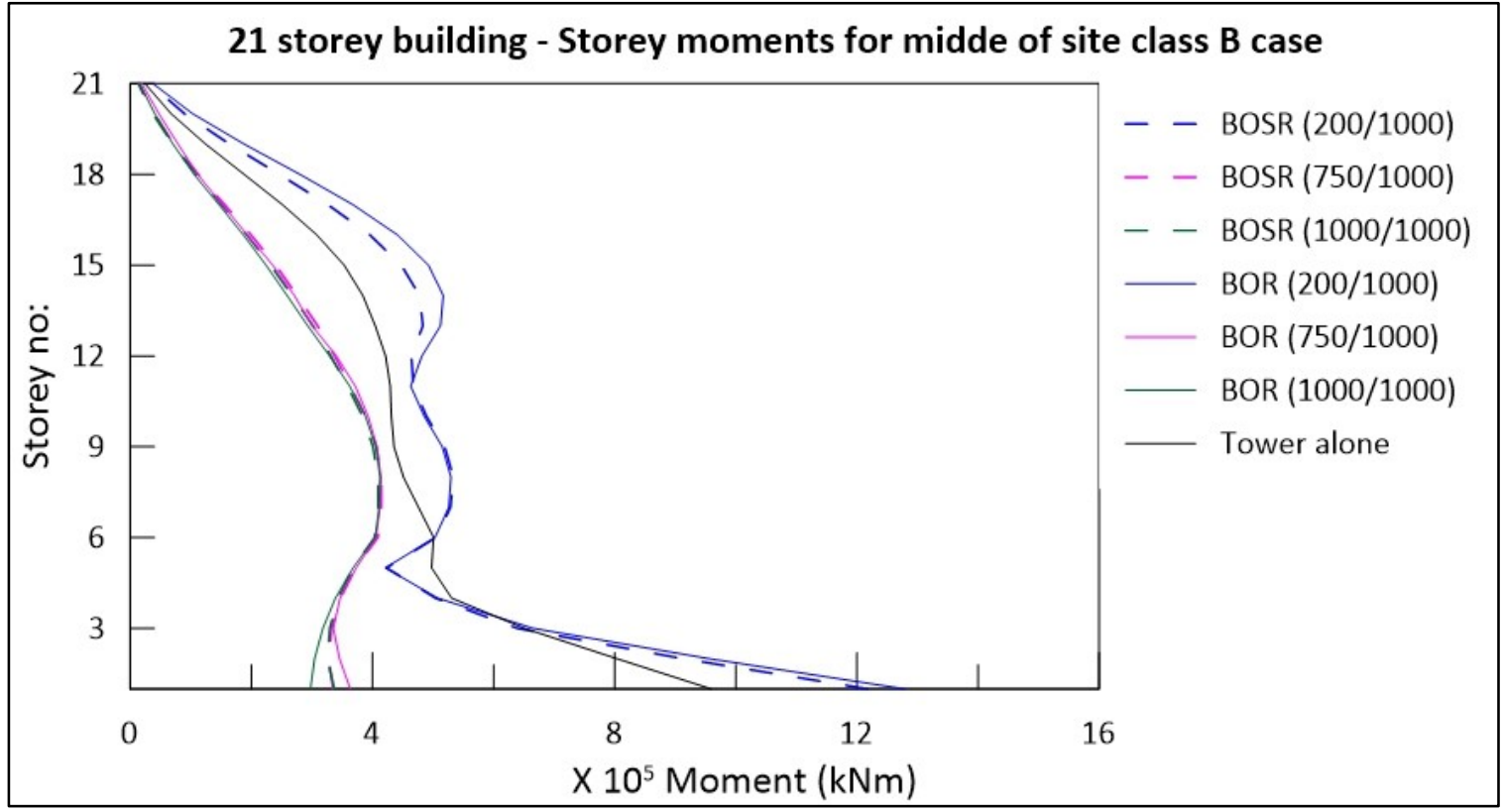

Figure 4-63: Moment at the bottom of the storey for a 21 storey building, shear wave velocity of the soil underlying foundation $=1000 \mathrm{~m} / \mathrm{s}$

Figure 4-62 to Figure 4-66 shows the seismic response of the 21 storey building when analyzed with soil under the base of the tower having a shear wave velocity of $1000 \mathrm{~m} / \mathrm{s}$. From Figure 4-62 and Figure 4-63 it is evident that maximum magnification in shear and 
moment at the bottom storey of the tower is observed for BOR 200/1000, closely followed by BOSR 200/1000. Magnification in drift follows the same trend as that of the base shear and base moment discussed above, with highest recorded for BOR 200/1000, followed by BOSR 200/1000. From Figure 4-65, when compared to the building alone case, no significant magnification in displacement at the base of the tower is recorded. Figure 4-66 shows that the very high magnification in acceleration is observed for the case BOR $750 / 750$.

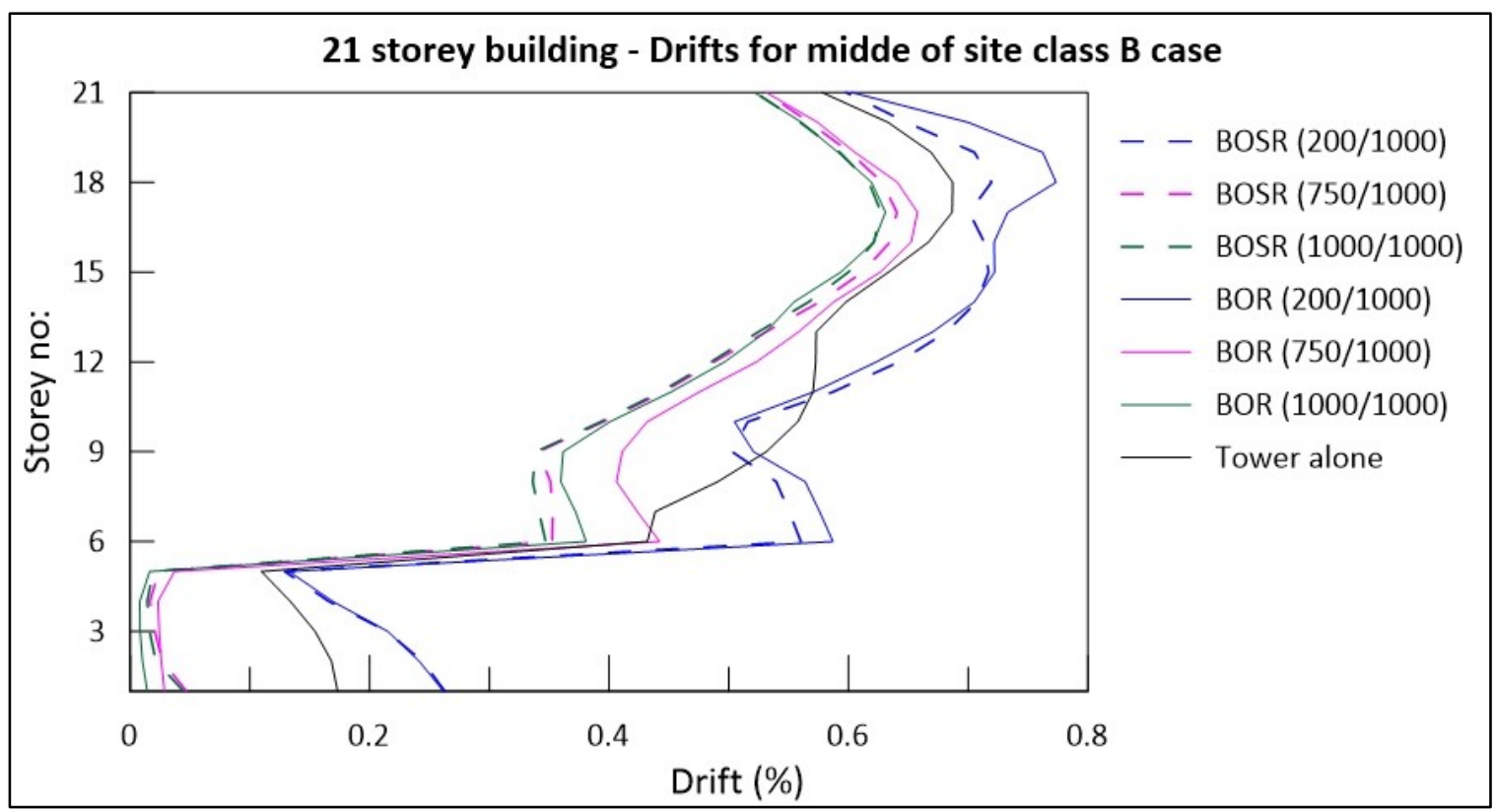

Figure 4-64: Storey drift for the 21 storey building, shear wave velocity of the soil underlying foundation = $1000 \mathrm{~m} / \mathrm{s}$ 


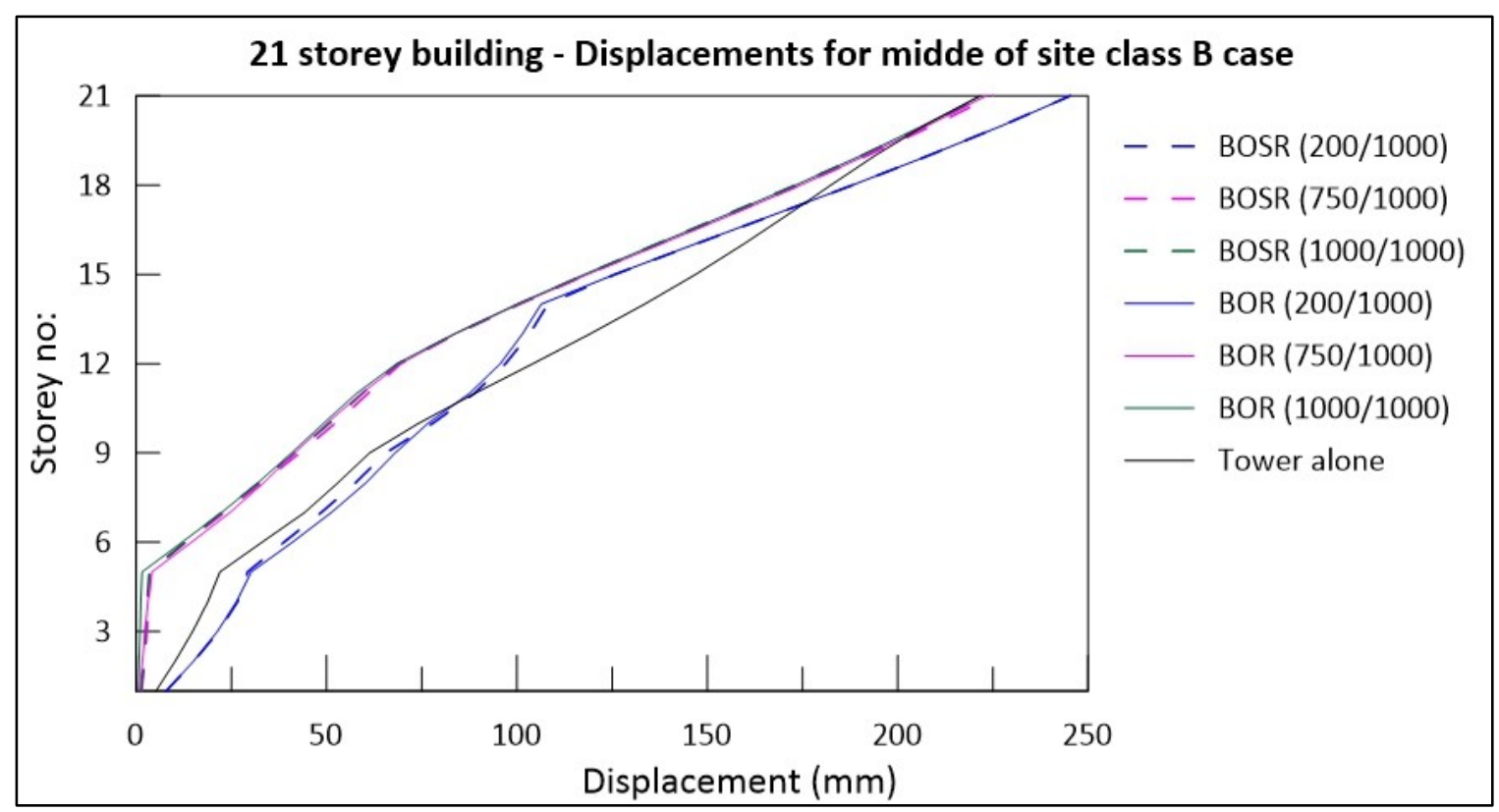

Figure 4-65: Displacement at the top of a storey for 21 storey building, shear wave velocity of the soil underlying foundation $=1000 \mathrm{~m} / \mathrm{s}$

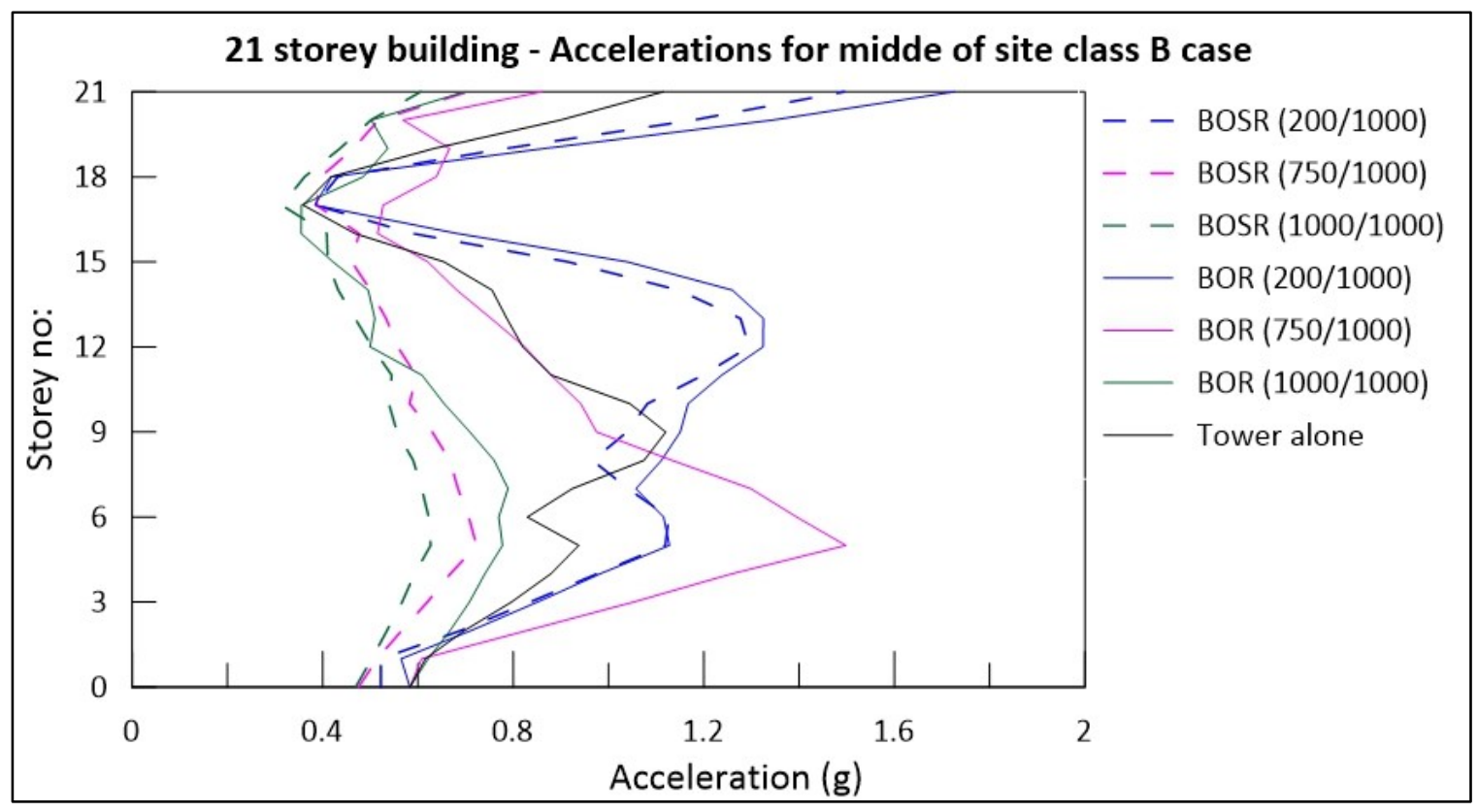

Figure 4-66: Acceleration at the top of a storey for 21 storey building, shear wave velocity of the soil underlying foundation $=1000 \mathrm{~m} / \mathrm{s}$ 


\section{5 storey building:}

For 20 storey tower and its supporting structure, Figure 4-67 to Figure 4-72 displays the values of the response for storey shear, storey moment, drift, displacement, and acceleration, respectively, when it is analyzed with soil under the base of the building having a shear wave velocity of $450 \mathrm{~m} / \mathrm{s}$.

From Figure 4-67 and Figure 4-68, it is evident that magnification in storey shear and storey moment is observed for the following stated cases, BOR 200/450 and BOR 300/450. However, highest magnification in shear at the base of the tower is observed for BOR 200/450 and highest magnification in moment at the base is observed for BOR 300/450.

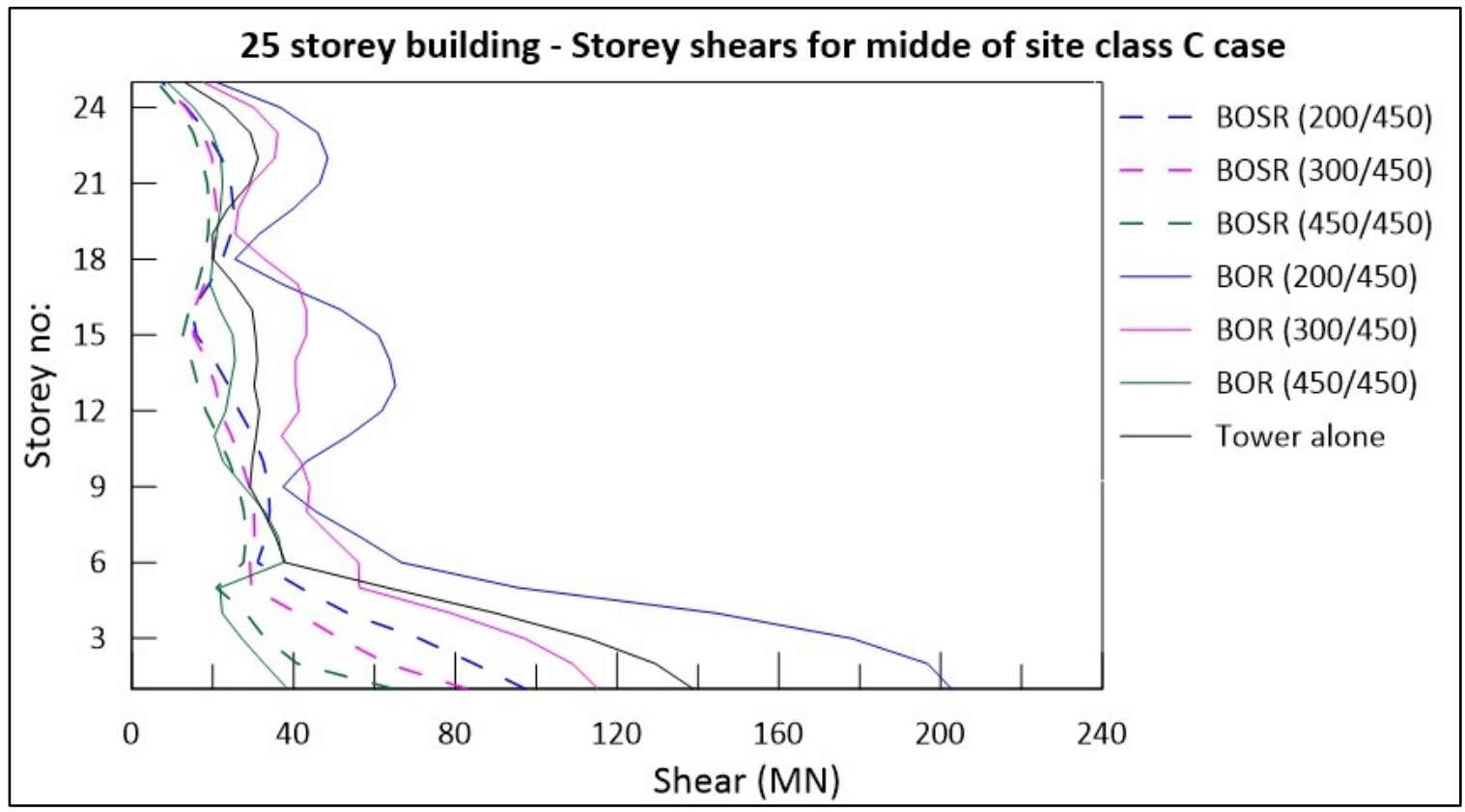

Figure 4-67: Storey shear values for a 25 storey building, middle of site class C $(450 \mathrm{~m} / \mathrm{s})$ case 


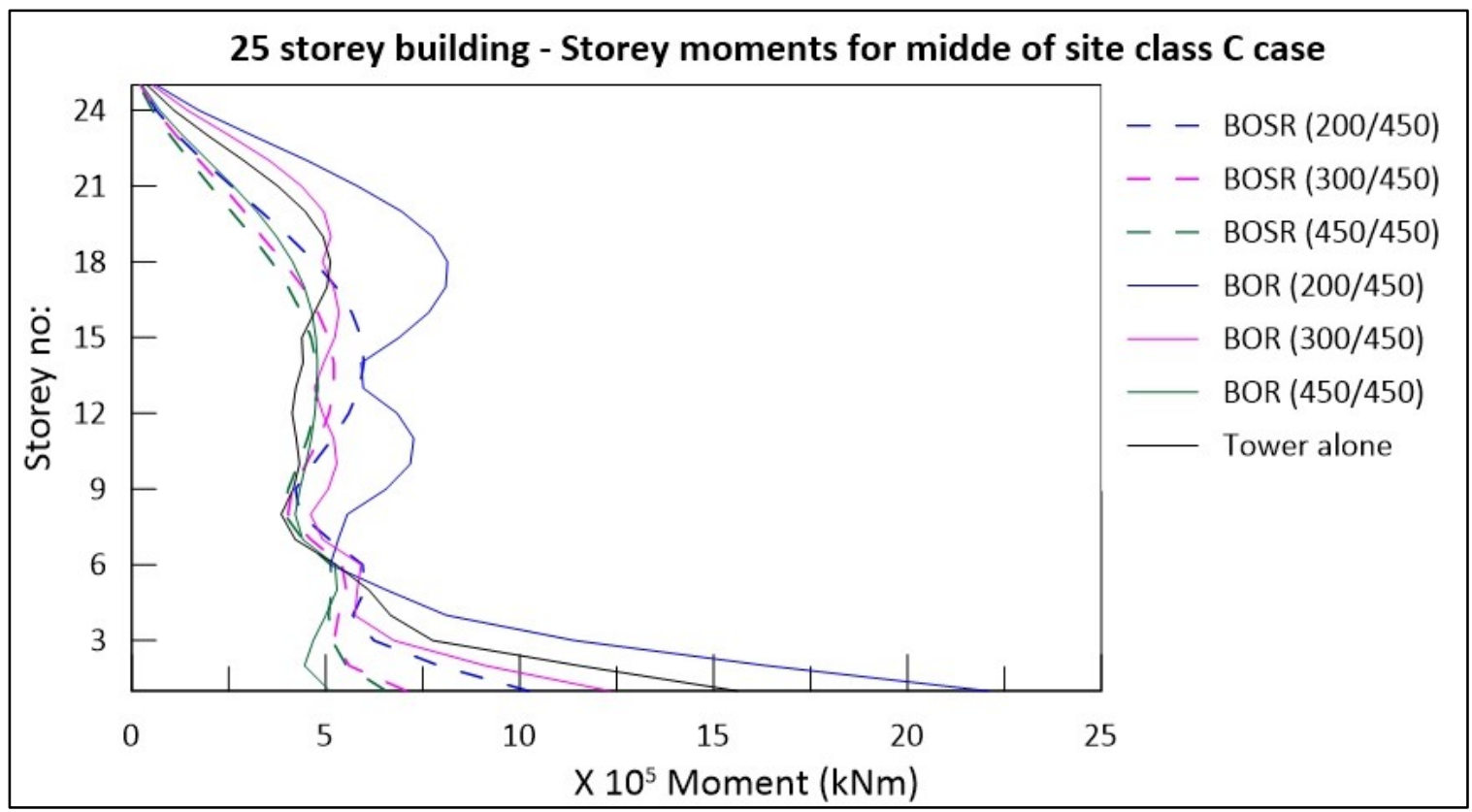

Figure 4-68: Moment at the bottom of the storey for a 25 storey building, middle of site class C (450m/s) case

As seen in Figure 4-69, magnification in drift follows the same trend as that of the shear, with the highest magnification recorded for BOR 200/450 followed by BOR 300/450.

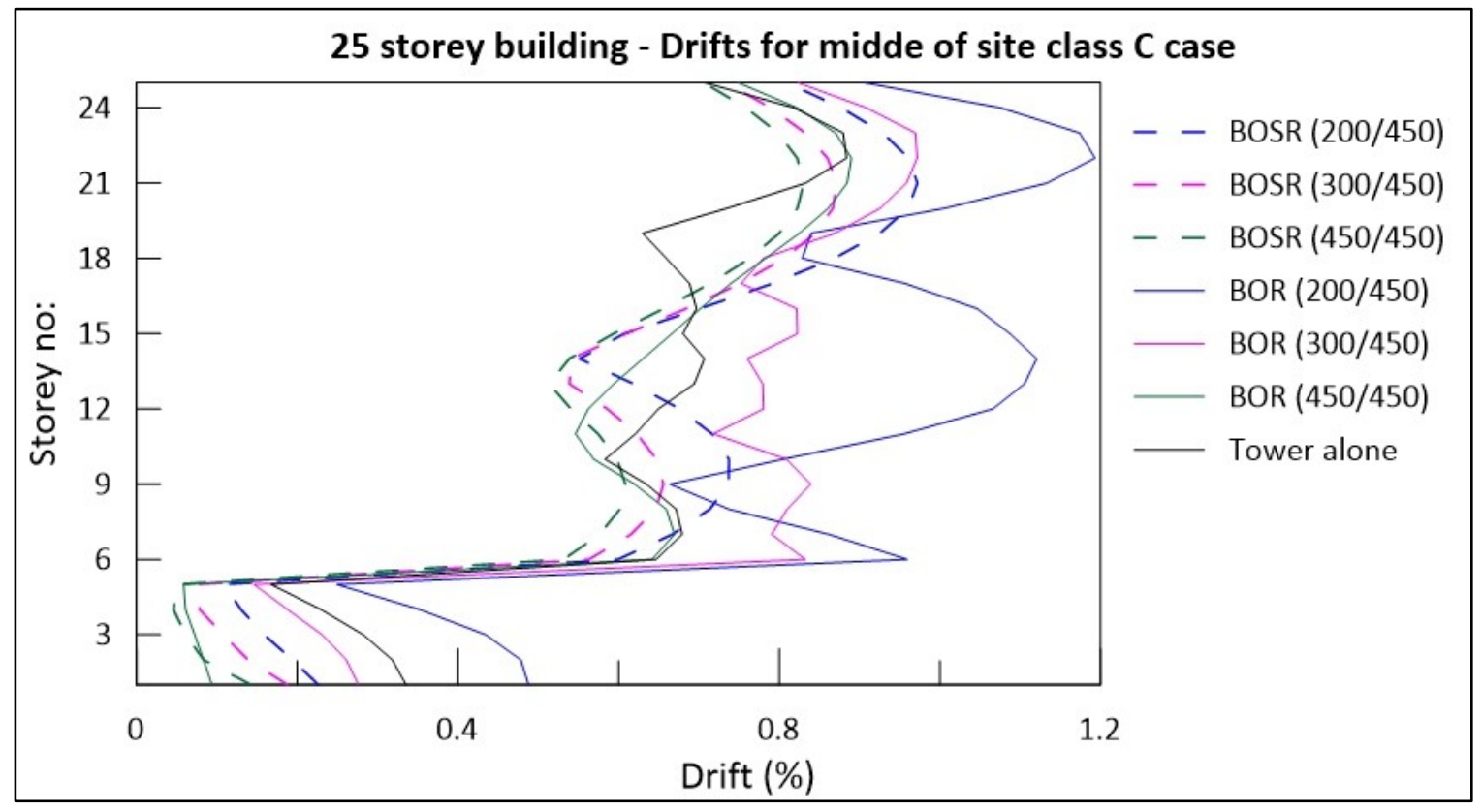

Figure 4-69: Storey drift for the 25 storey building, middle of site class C $(450 \mathrm{~m} / \mathrm{s})$ case 


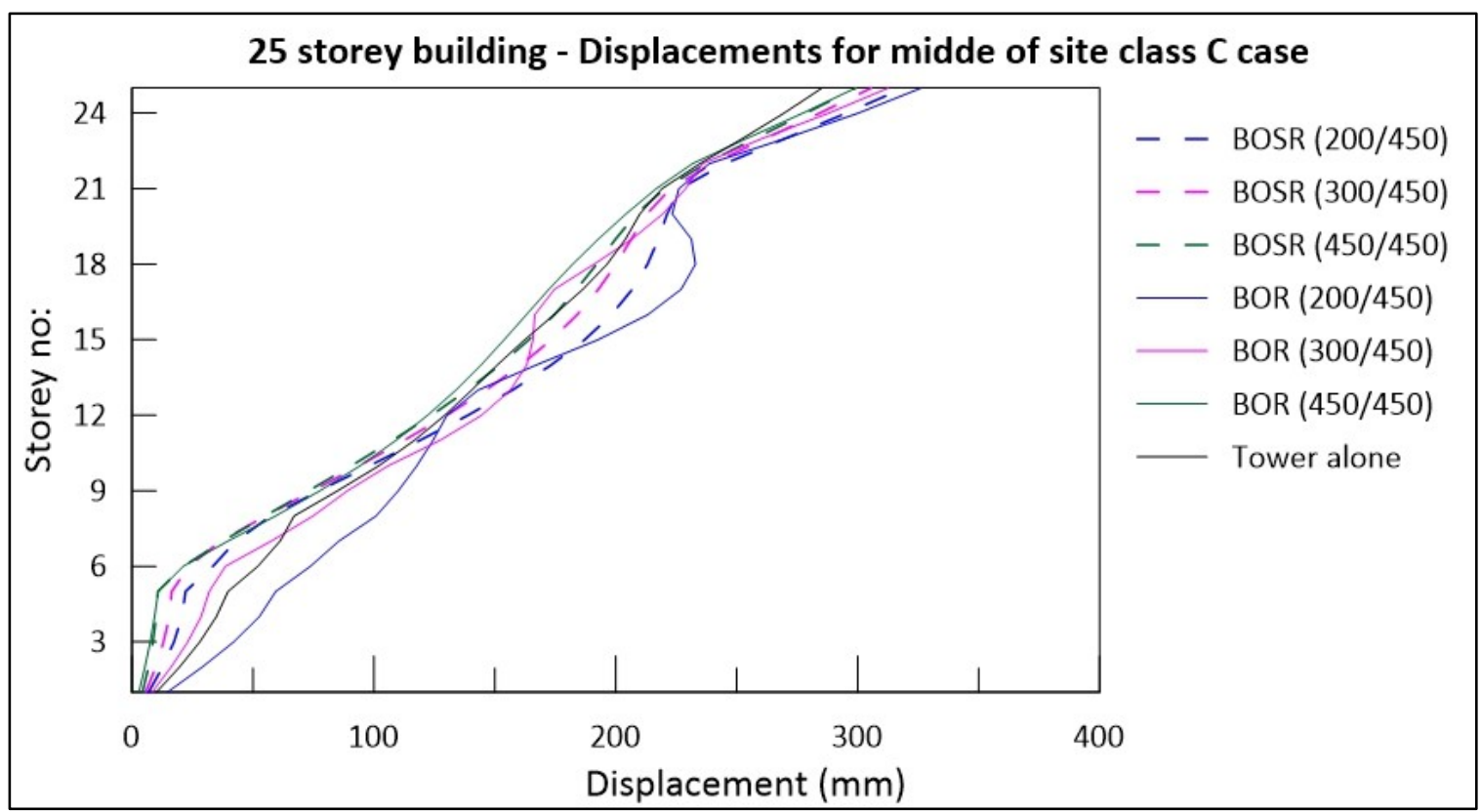

Figure 4-70: Displacement at the top of a storey for 25 storey building, middle of site class C (450m/s) case

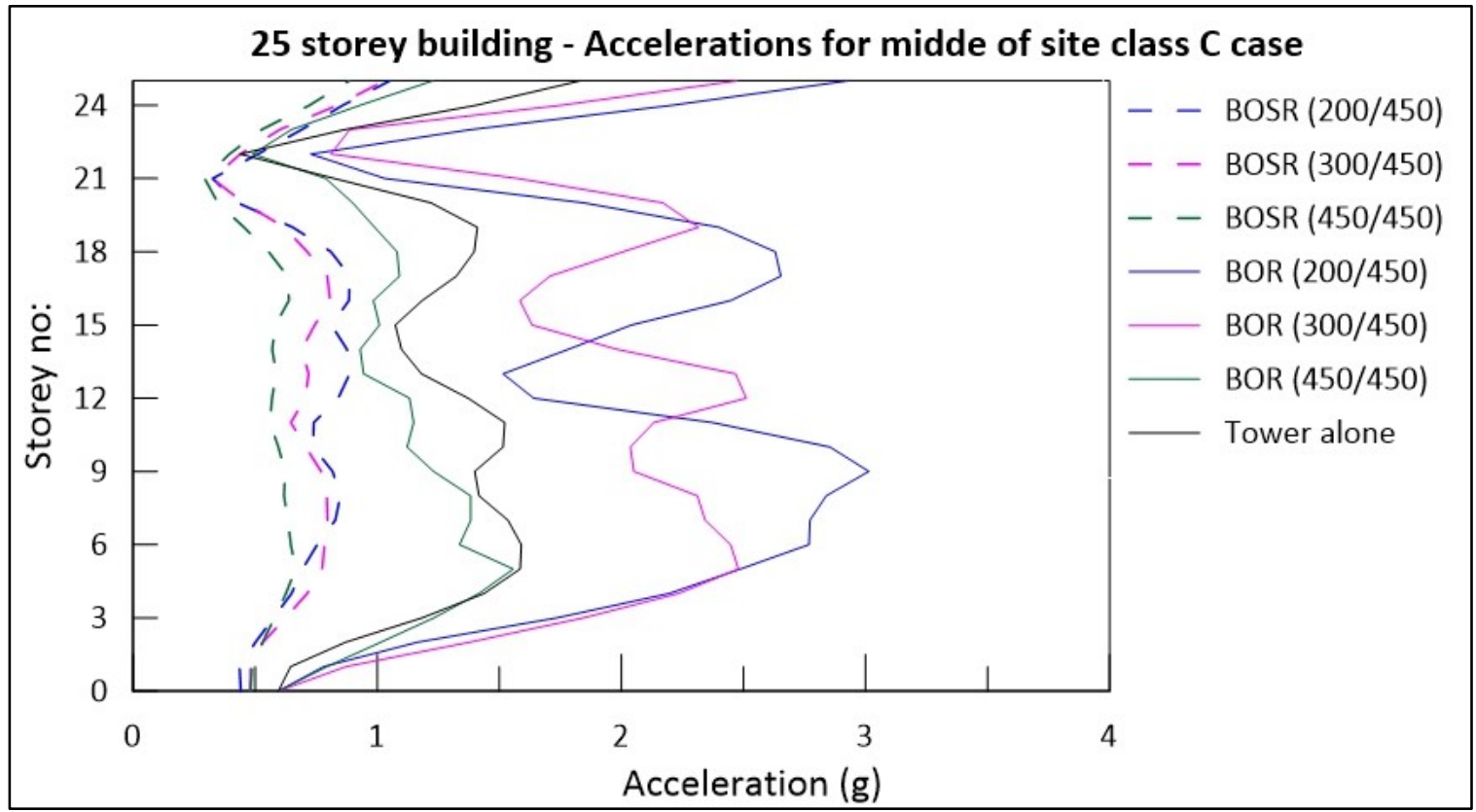

Figure 4-71: Acceleration at the top of a storey for 25 storey building, middle of site class C (450m/s) case

For displacement response and acceleration response, maximum magnification is observed for the case BOR 200/450. The second highest magnification in acceleration response is recorded for BOR 300/450. 
Figure 4-72 to Figure 4-76 shows the response of 25 storey building when analyzed with soil under the base of the building having a shear wave velocity of $750 \mathrm{~m} / \mathrm{s}$. From Figure 4-72 and Figure 4-73, it is observed that there is magnification in storey shears and storey moments for BOR 200/750 and BOSR 200/750. It is evident from Figure 4-74, a similar trend as detailed above for storey shears and storey moments is observed in storey drifts.

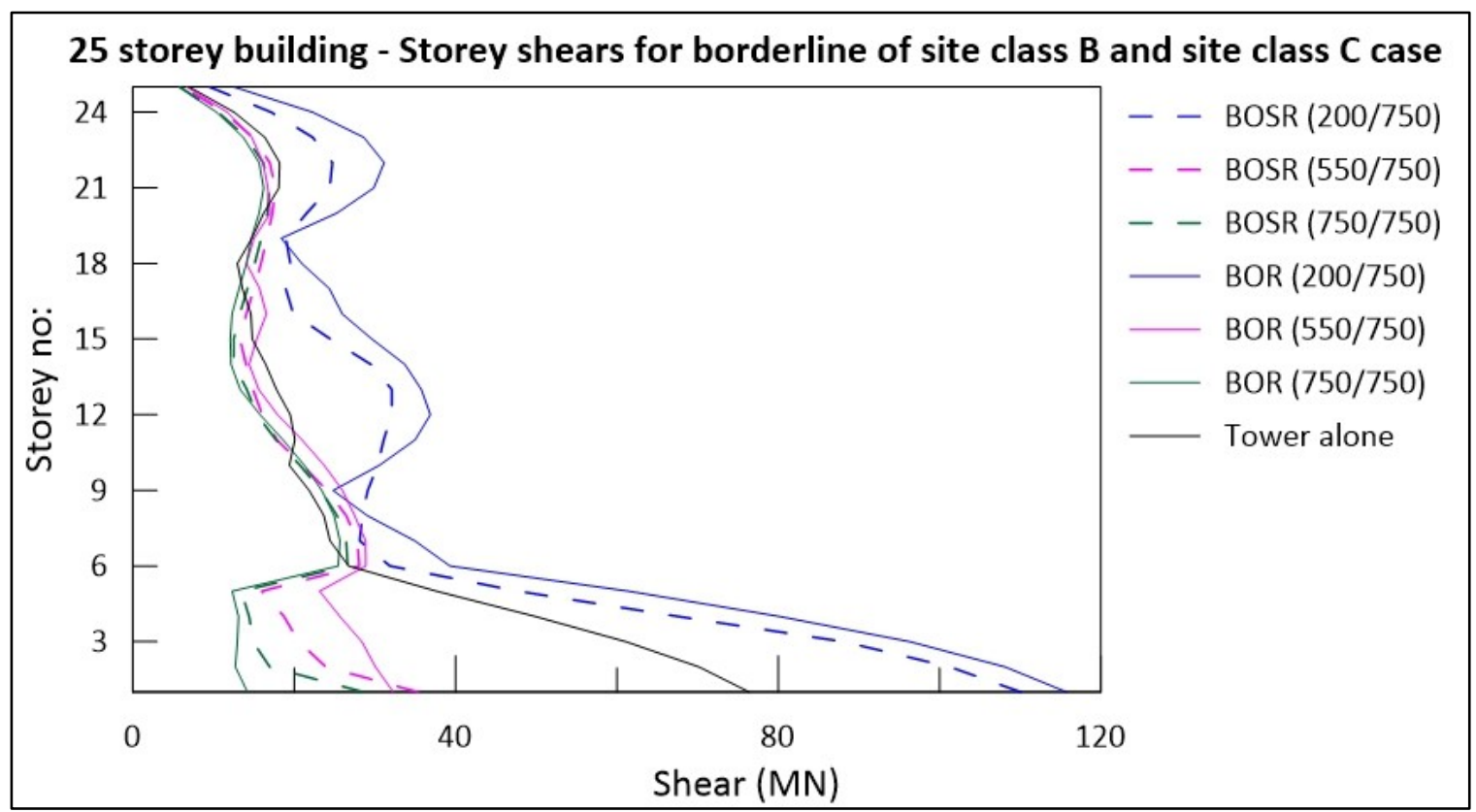

Figure 4-72: Storey shear values for a 25 storey building, borderline of site class B and site class C $(750 \mathrm{~m} / \mathrm{s})$ case 


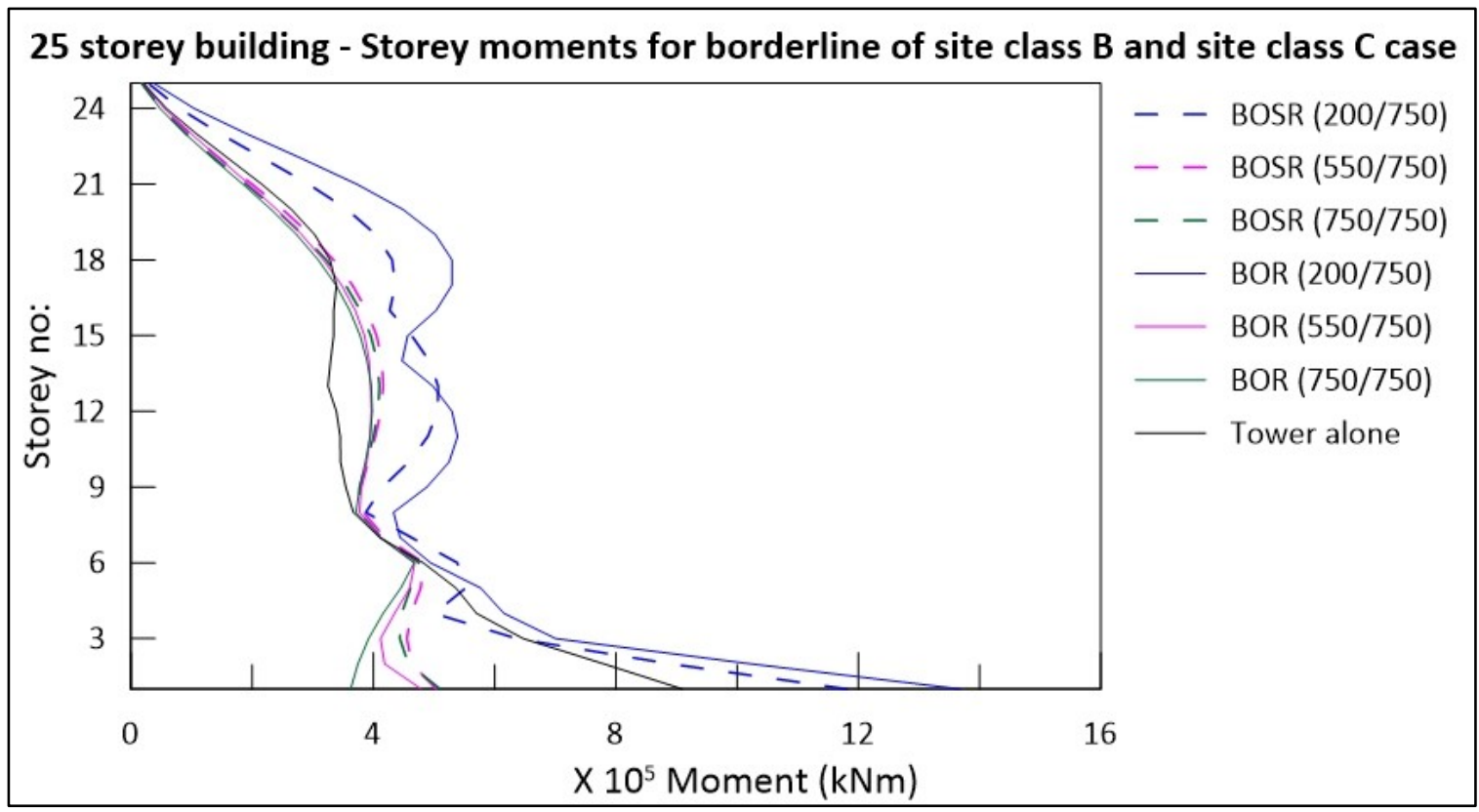

Figure 4-73: Moment at the bottom of the storey for a 25 storey building, borderline of site class B and site class C $(750 \mathrm{~m} / \mathrm{s})$ case

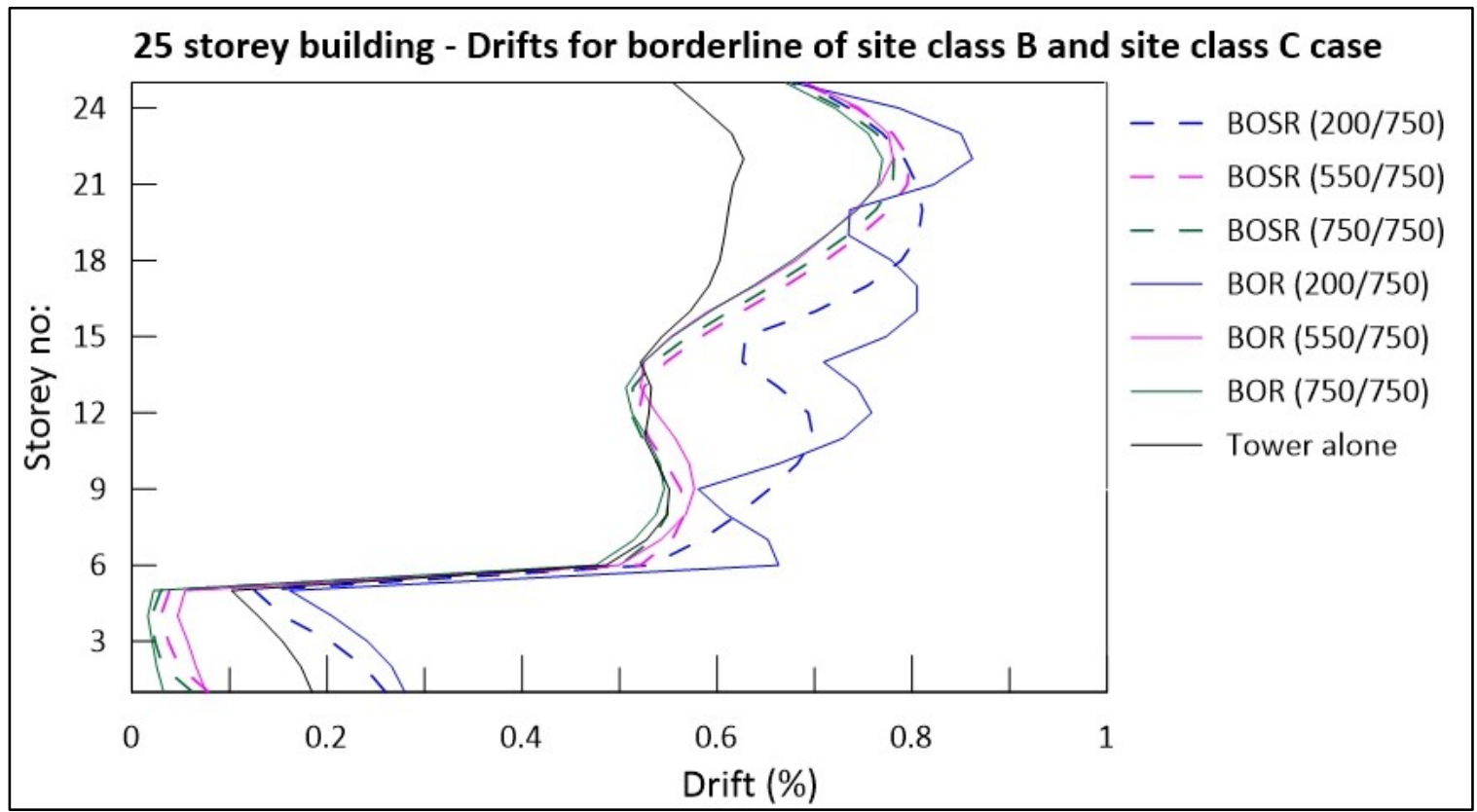

Figure 4-74: Storey drift for the 25 storey building, borderline of site class B and site class C (750m/s) case 


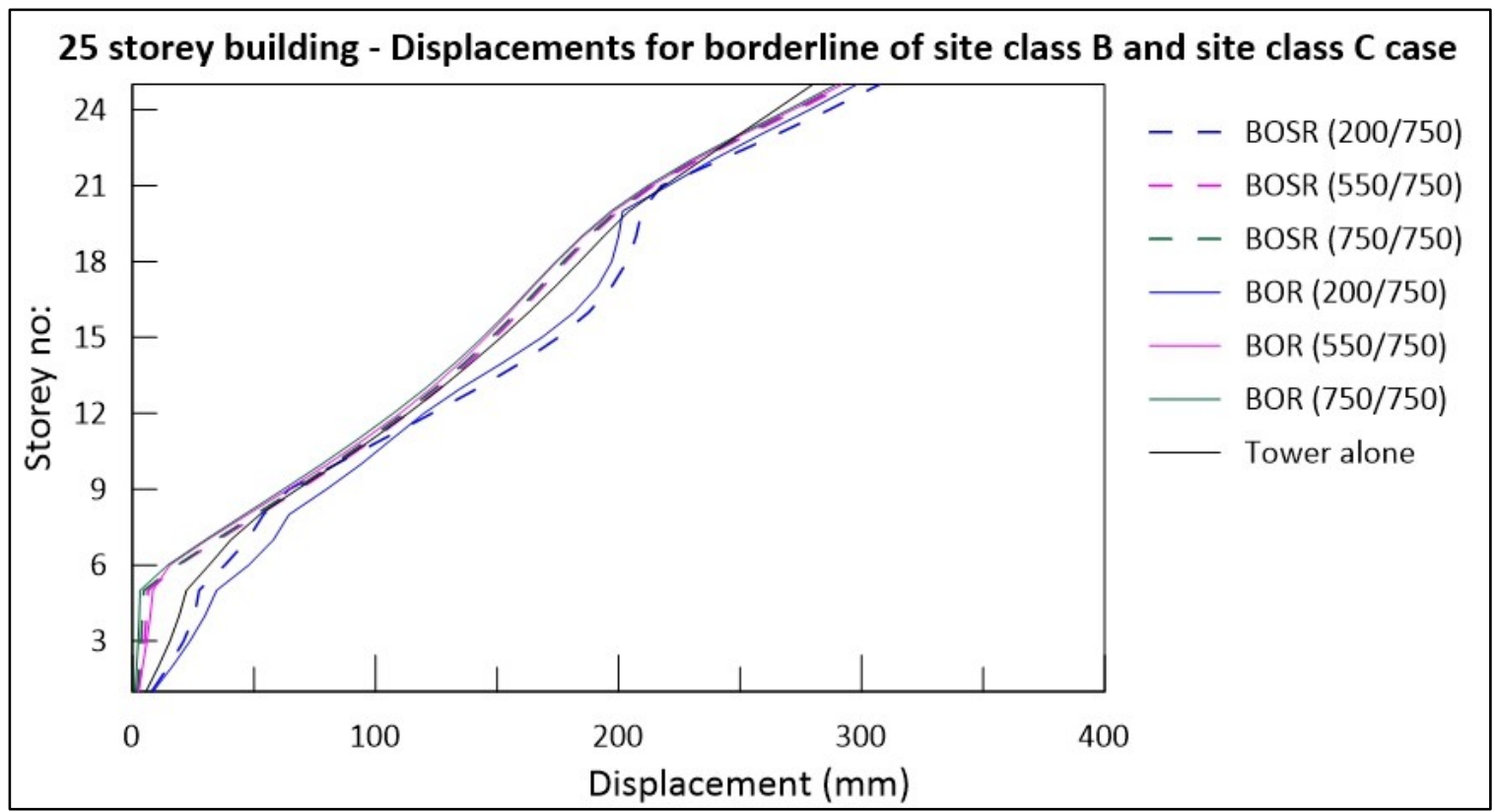

Figure 4-75: Displacement at the top of a storey for 25 storey building, borderline of site class B and site class C $(750 \mathrm{~m} / \mathrm{s})$ case

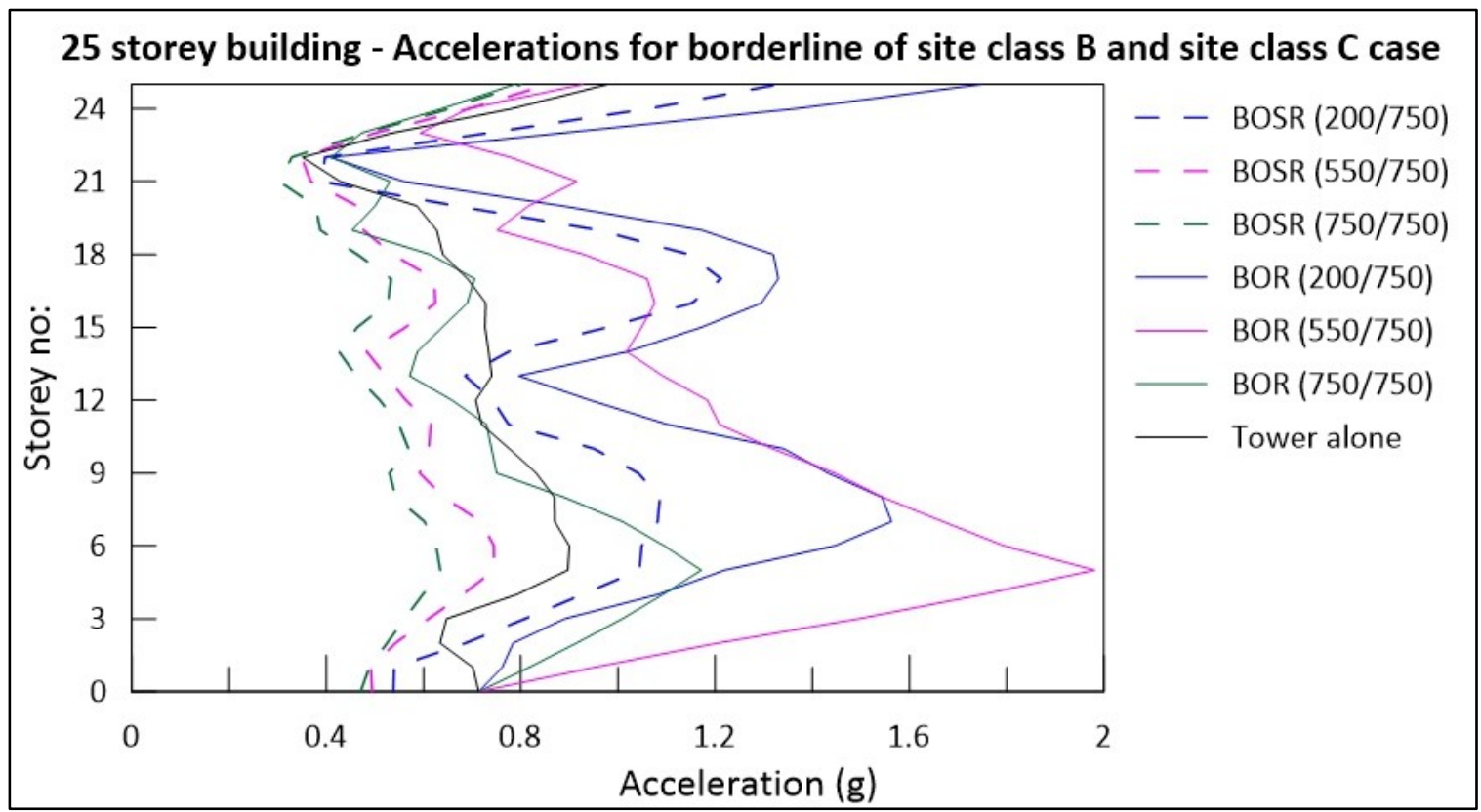

Figure 4-76: Acceleration at the top of a storey for 25 storey building, borderline of site class B and site class $\mathrm{C}(750 \mathrm{~m} / \mathrm{s})$ case

For displacement response, maximum magnification is observed for the case BOR 200/750. From Figure 4-76, it is noted that maximum magnification almost twice as much 
when compared to the acceleration in the building by itself is recorded for the case BOR 550/750, followed by BOR 200/750.

Figure 4-77 to Figure 4-81 shows the response of 20 storey tower and its supporting structure when analyzed with soil under the base of the building having a shear wave velocity of $1000 \mathrm{~m} / \mathrm{s}$.

From Figure 4-77 and Figure 4-78, it is observed that there is the highest magnification in storey shears and storey moments for BOR 200/1000, closely followed by BOSR 200/1000. It is evident from Figure 4-79 and Figure 4-80, storey drift and displacement response follow the same trend as that is observed in storey shears and storey moments.

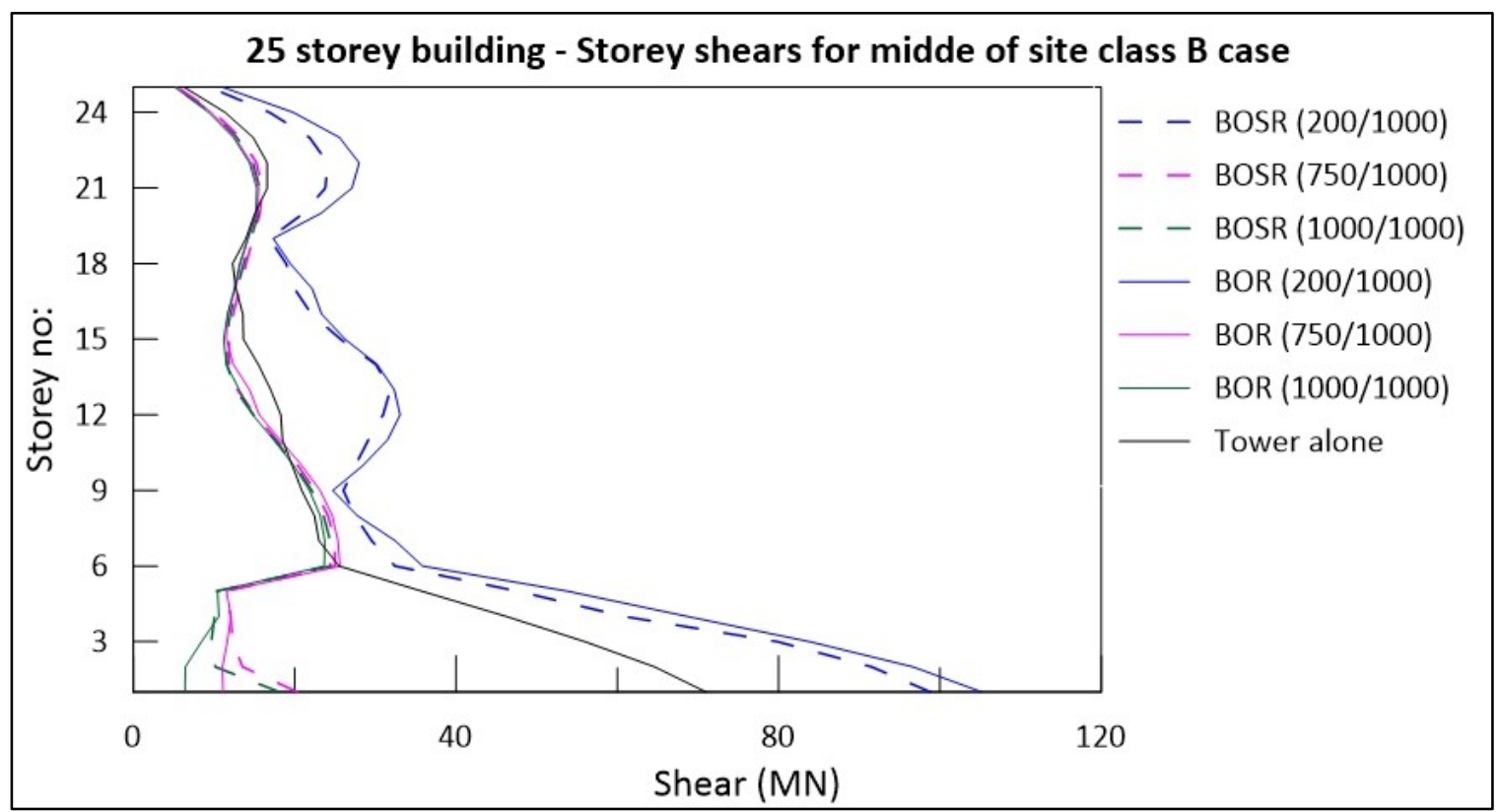

Figure 4-77: Storey shear values for a 25 storey building, middle of site class B $(1000 \mathrm{~m} / \mathrm{s})$ case 


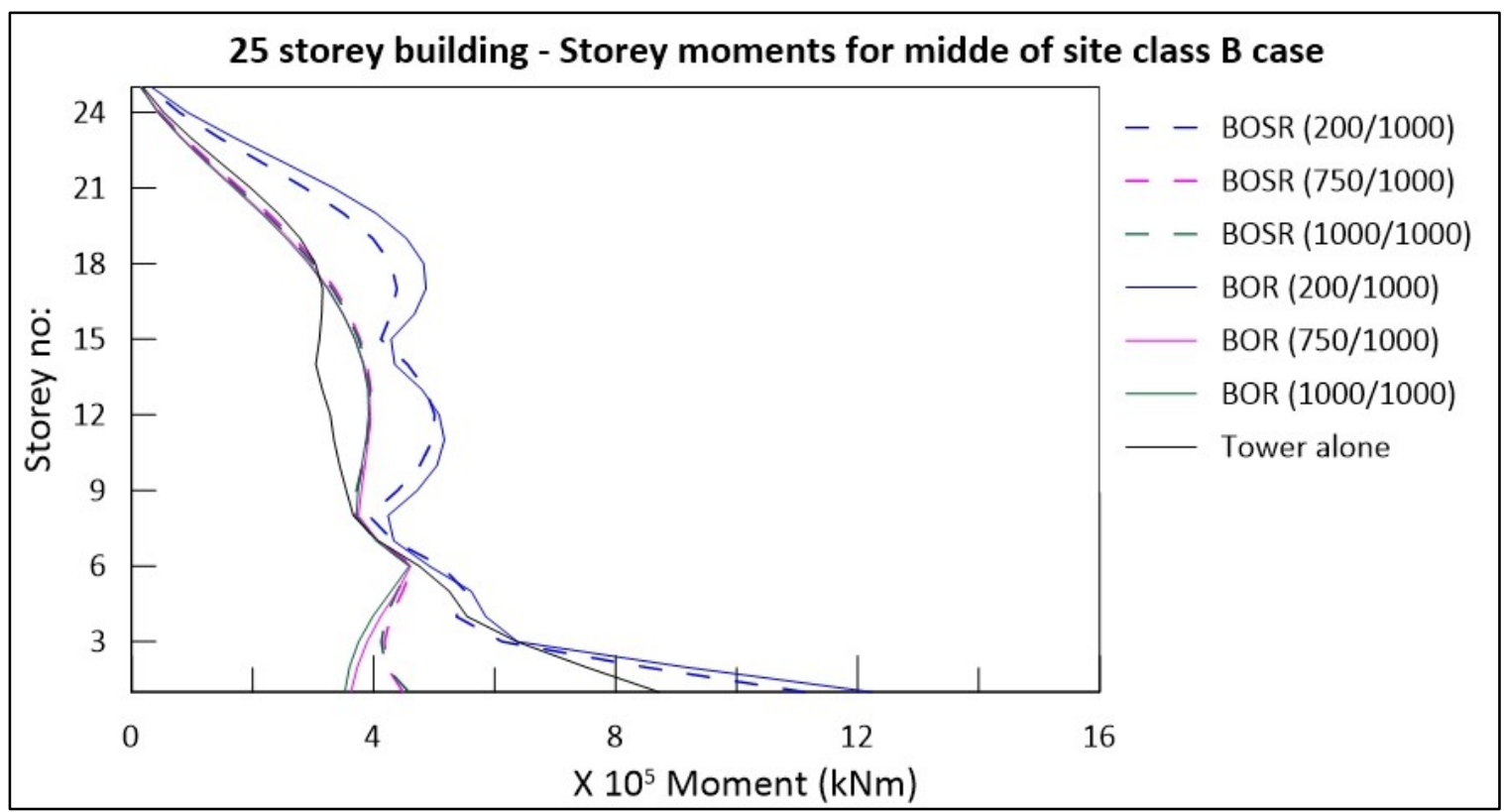

Figure 4-78: Moment at the bottom of the storey for a 25 storey building, middle of site class B $(1000 \mathrm{~m} / \mathrm{s})$ case

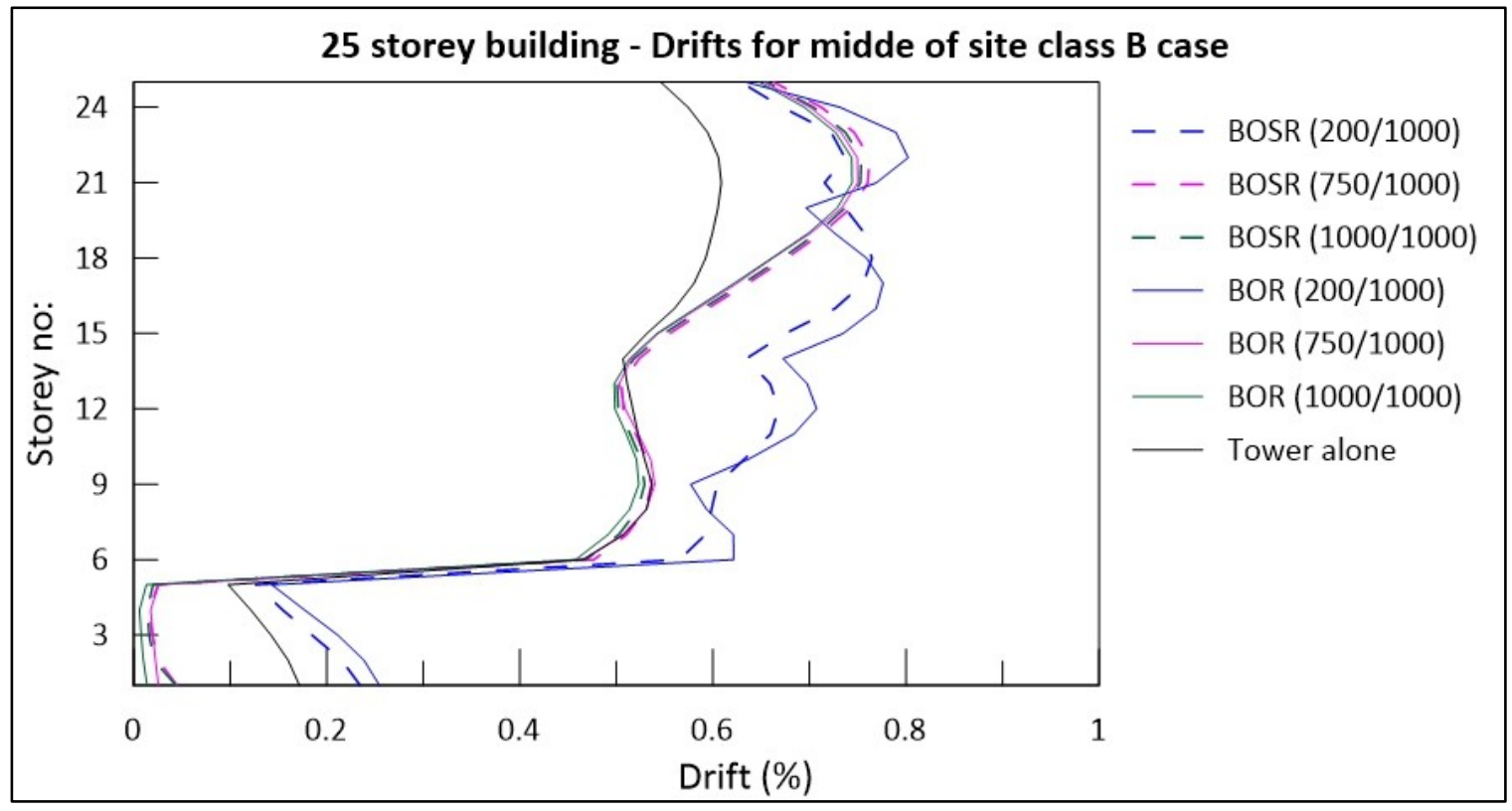

Figure 4-79: Storey drift for the 25 storey building, middle of site class B $(1000 \mathrm{~m} / \mathrm{s})$ case 


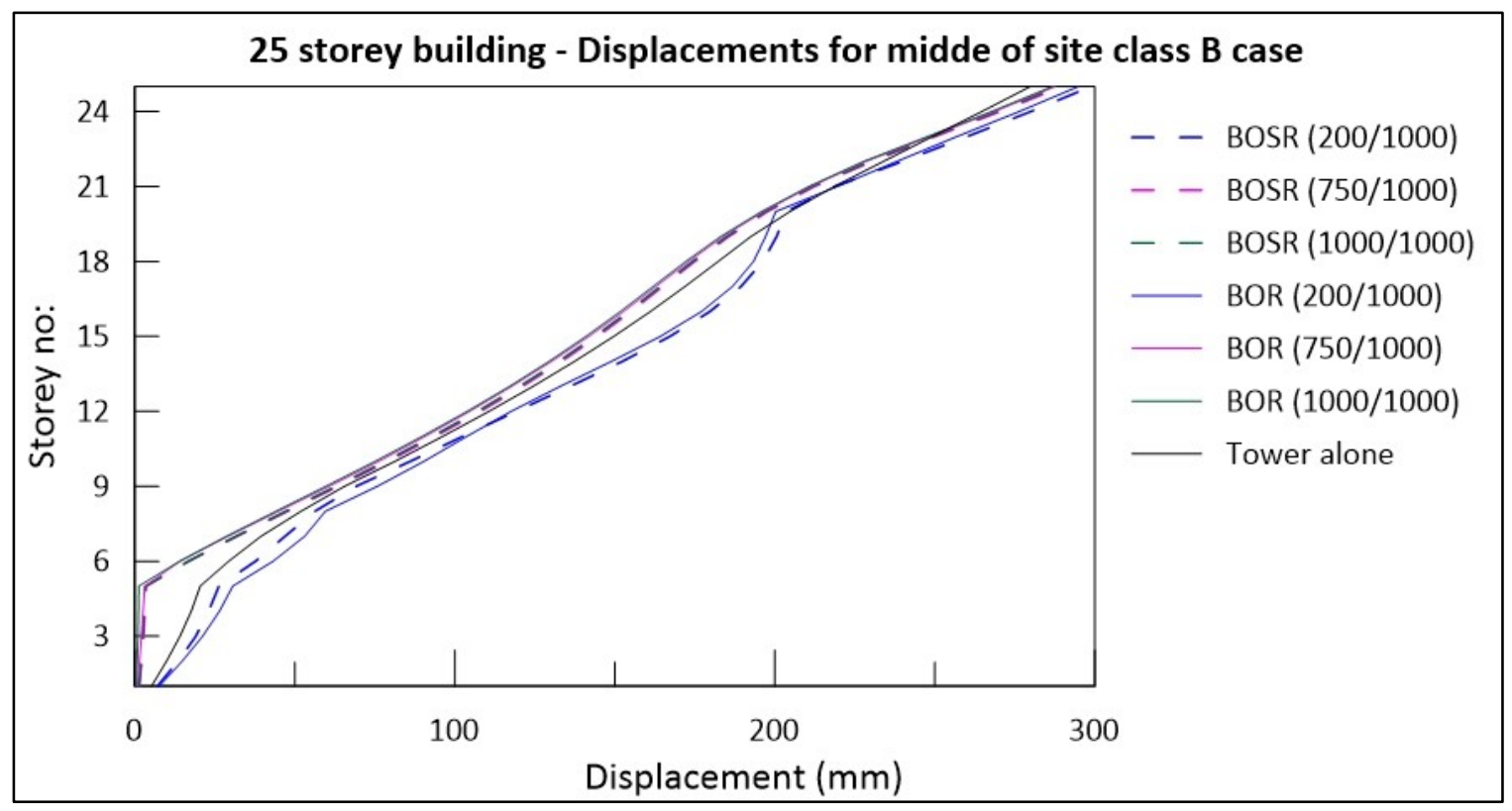

Figure 4-80: Displacement at the top of a storey for 25 storey building, middle of site class B (1000m/s) case

For acceleration response at the base of the tower, maximum magnification is observed for the case BOR 200/1000, closely followed by the case BOR 750/1000 as shown in Figure 4-81.

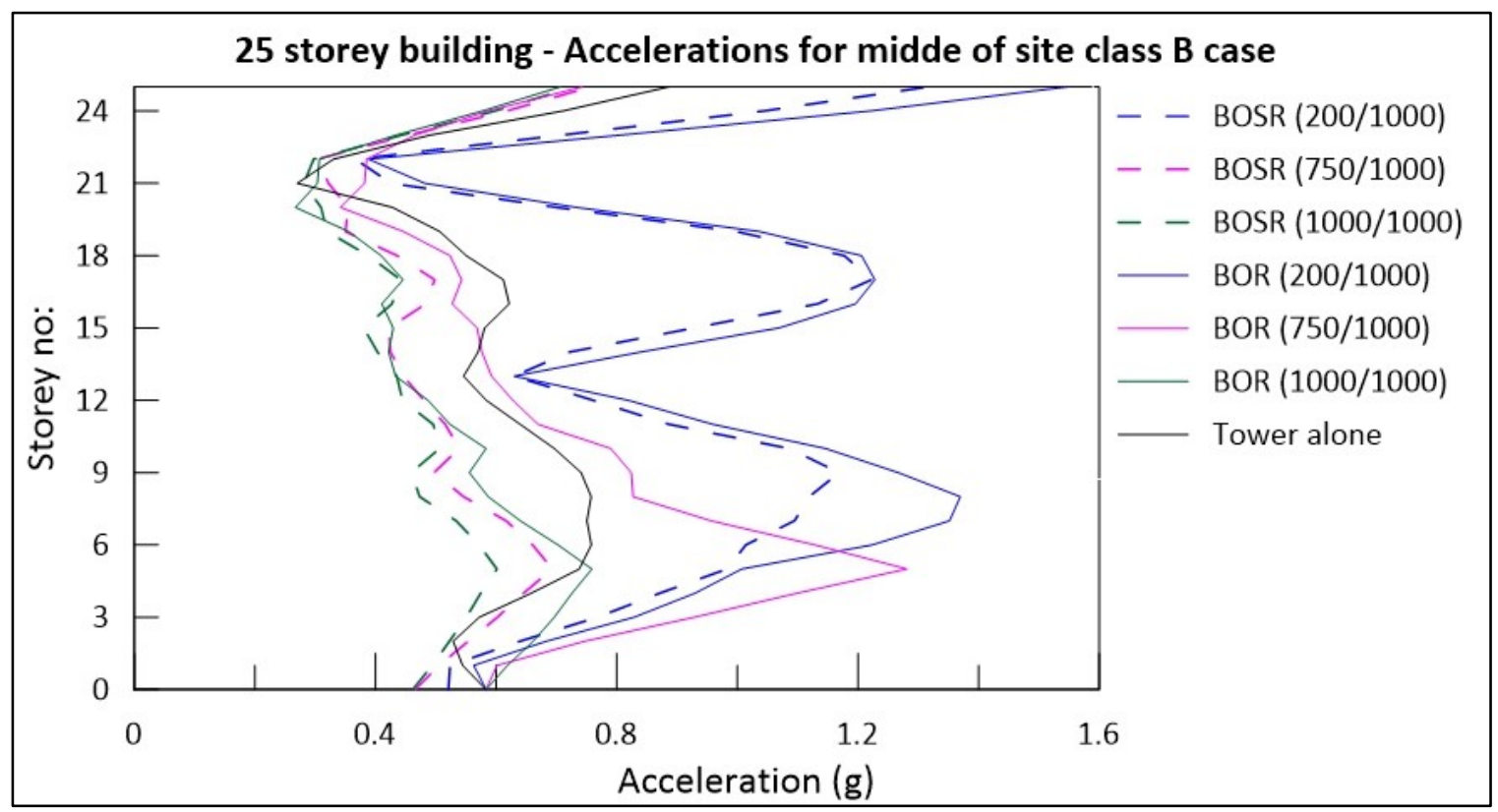

Figure 4-81: Acceleration at the top of a storey for 25 storey building, middle of site class B $(1000 \mathrm{~m} / \mathrm{s})$ case 


\subsection{Analysis of results}

\subsubsection{Magnification factor - at the base of the tower}

The effect of soil-structure interaction on the structural response is presented in terms of the magnification factor in this section; magnification factor is defined as the ratio of the response of the building in presence of the soil to that of the building alone. The intent of the analysis is to delineate the cases where the typical practice would lead to unsafe designs, and identify which combinations of soil properties lead to the highest structural demand.. For all cases detailed in the previous section on parametric study, magnification factors are presented for shear, moment, drift, displacement, and acceleration at the base storey of the tower. Magnification factors are calculated for three primary cases defined by the shear wave velocity of the soil between the rock and the foundation of the building. As described earlier, the selected shear wave velocities correspond to different material based on the classification in NBCC 2015 . Within each primary case there are six subsidiary cases, as outlined in Table 4-2. The magnification factor values for each case analyzed are listed in Appendix C.

Table 4-2: Subsidiary cases used in the presentation of magnification factors

\begin{tabular}{|c|l|l|l|}
\hline Case No: & $\begin{array}{c}\text { Middle of site class } \\
\text { C }\end{array}$ & $\begin{array}{c}\text { Borderline of site } \\
\text { class B and site class } \\
\text { C }\end{array}$ & $\begin{array}{c}\text { Middle of site class } \\
\text { B }\end{array}$ \\
\hline 1 & BOSR (200/450) & BOSR (200/750) & BOSR (200/1000) \\
\hline 2 & BOSR (300/450) & BOSR (550/750) & BOSR (750/1000) \\
\hline 3 & BOSR (450/450) & BOSR (750/750) & BOSR (1000/1000) \\
\hline 4 & BOR (200/450) & BOR (200/750) & BOR (200/1000) \\
\hline 5 & BOR (300/450) & BOR (550/750) & BOR (750/1000) \\
\hline 6 & BOR (450/450) & BOR (750/750) & BOR (1000/1000) \\
\hline
\end{tabular}


Figure 4-82 to Figure 4-84 present the magnification factor plots for the 9 storey building.

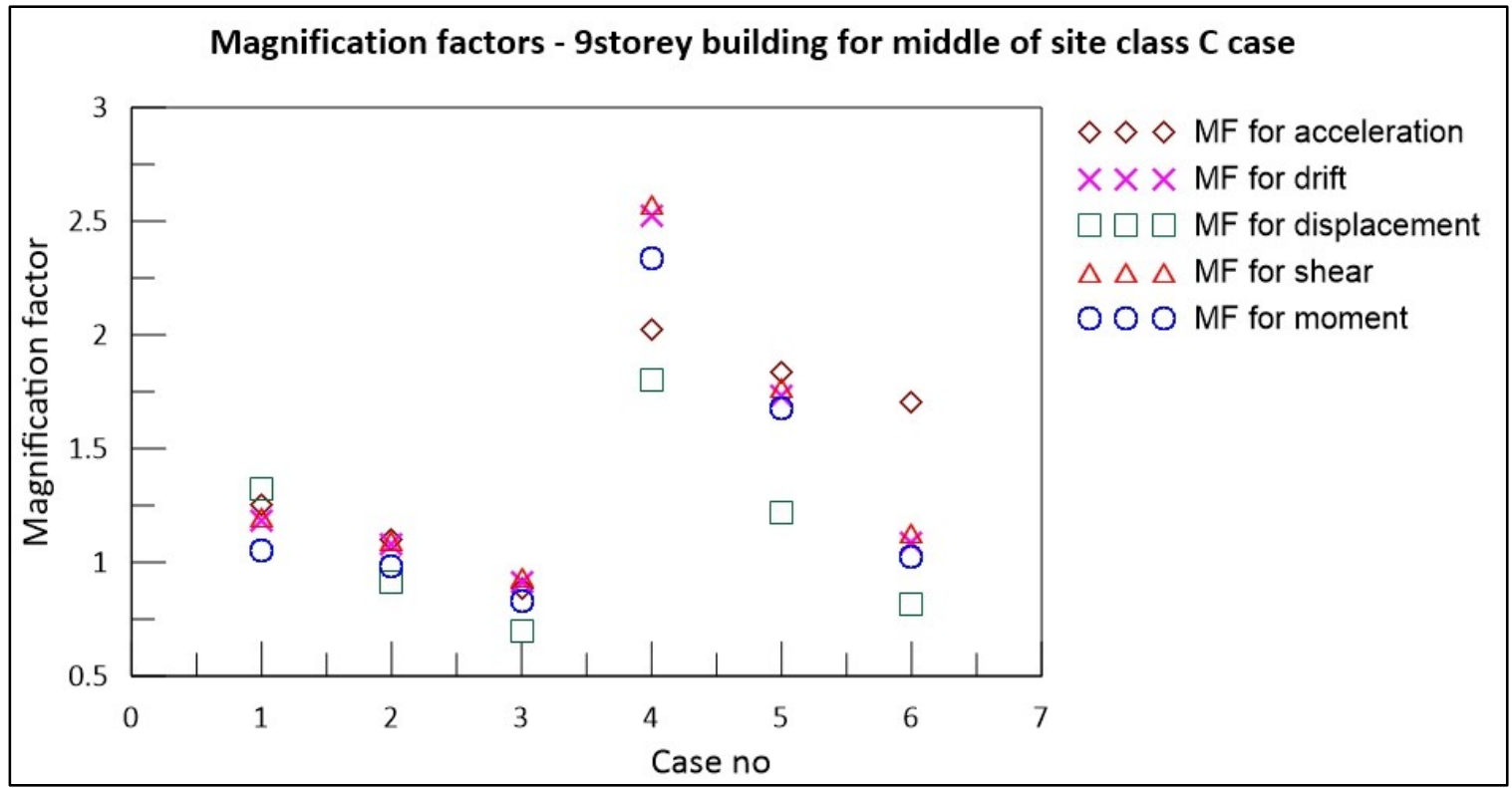

Figure 4-82: Magnification factors for 9 storey building, Shear wave velocity of underlying soil $450 \mathrm{~m} / \mathrm{s}$

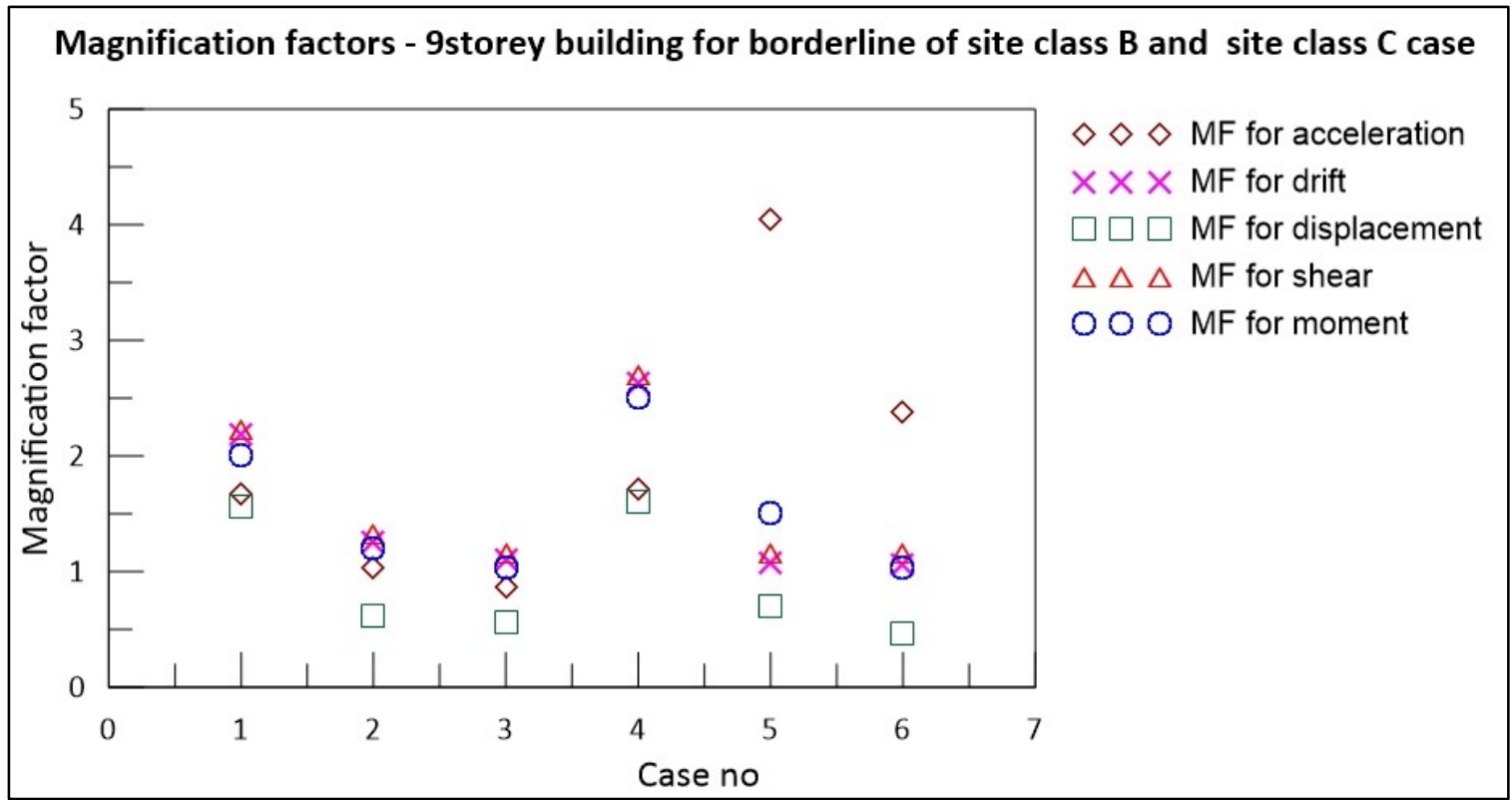

Figure 4-83: Magnification factors for 9 storey building, Shear wave velocity of underlying soil $750 \mathrm{~m} / \mathrm{s}$ 


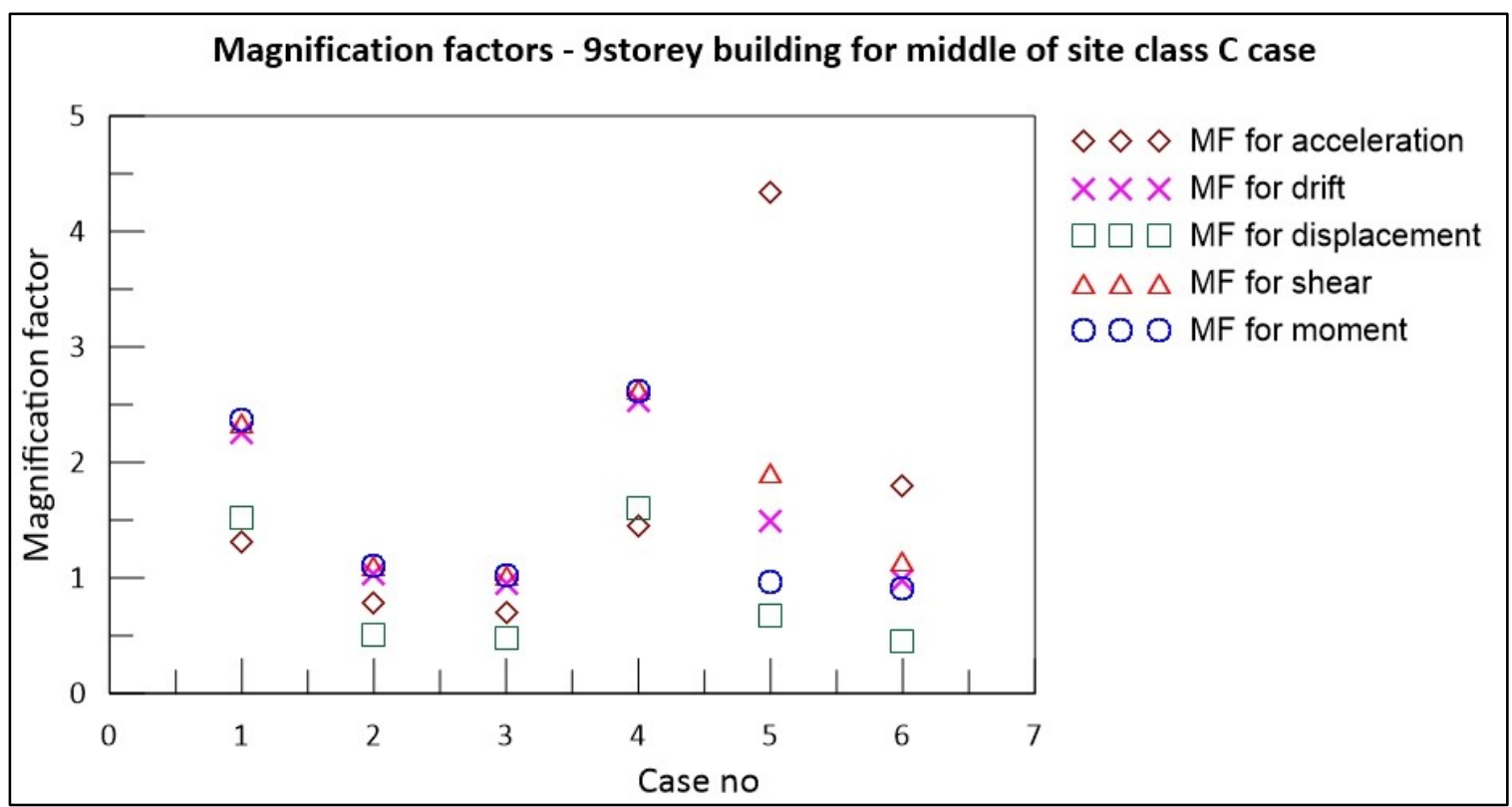

Figure 4-84: Magnification factors for 9 storey building, Shear wave velocity of underlying soil $1000 \mathrm{~m} / \mathrm{s}$

As noted in Table 4-2, case number 1 to 3 correspond to the BOSR analysis, and 4 to 6 the BOR analysis. Generally, the magnification is lower for the BOSR cases (at times less than one, indicating a reduction), but higher for the BOR. In both types of analyses, the larger magnifications correspond to softer soil surrounding the parkade. It is noted that the magnification is similar to the BOR case in BOSR analysis when there is high contrast between the soil surrounding the parkade and the soil underlying the tower. For example, BOSR (200/1000), as shown in Figure 4-84, has a magnification almost close to BOR $(200 / 1000)$. , i.e. when the soil surrounding the structure has a shear wave velocity of 200 $\mathrm{m} / \mathrm{s}$.

Figure 4-85 to Figure 4-87 represent the magnification factor plots recorded for the 13 storey building. The magnification in shear and moment at the base of the 8 storey tower are insignificant in general except for the case when the structure is with $300 \mathrm{~m} / \mathrm{s}$ shear wave velocity soil surrounding the parkade. However, similar to 9 storey building, magnification for the BOSR case are lower than those observed for the BOR case. 


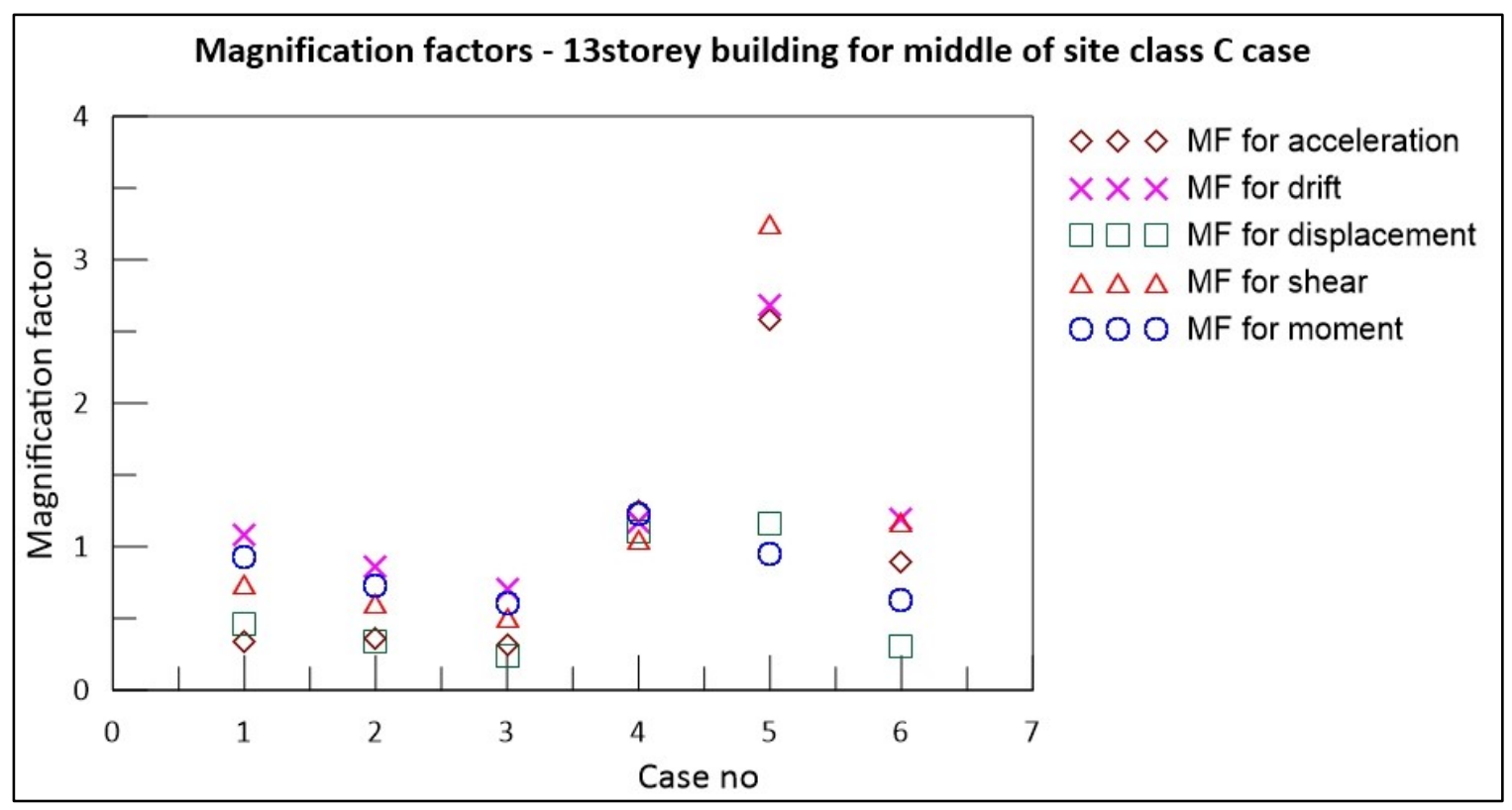

Figure 4-85: Magnification factors for 13 storey building, Shear wave velocity of underlying soil $450 \mathrm{~m} / \mathrm{s}$

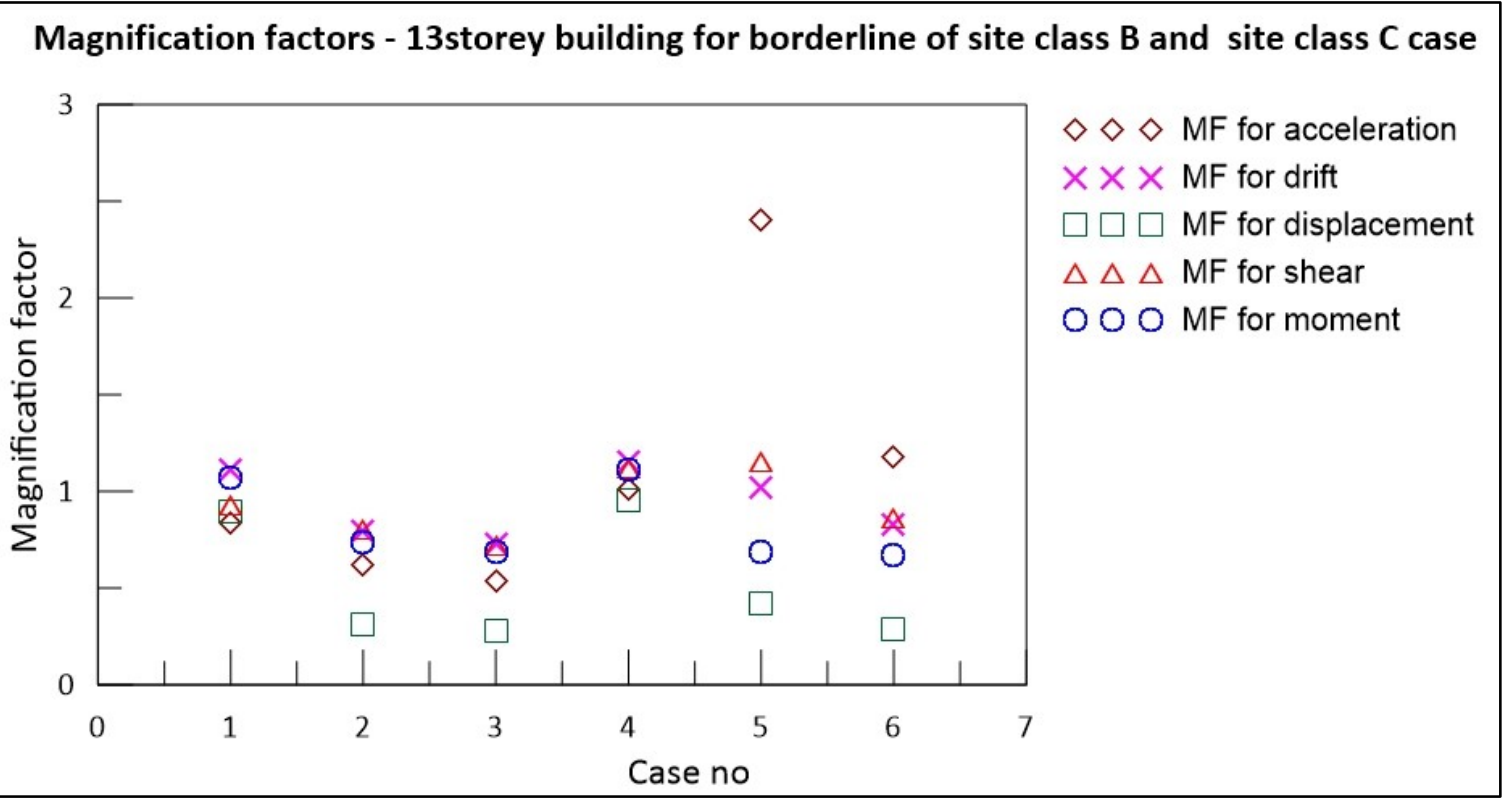

Figure 4-86: Magnification factors for 13 storey building, Shear wave velocity of underlying soil 750 m/s 


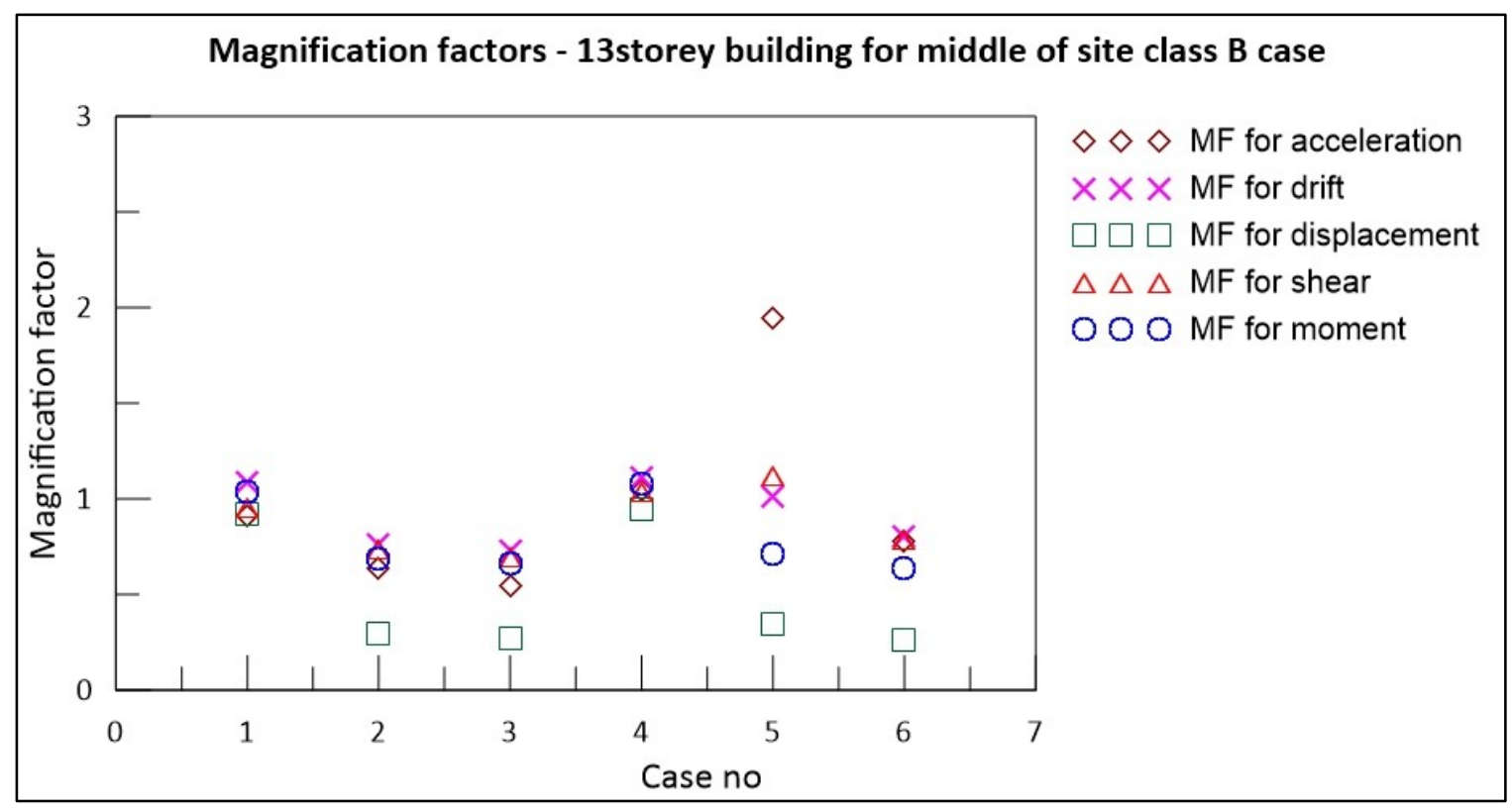

Figure 4-87: Magnification factors for 13 storey building, Shear wave velocity of underlying soil $1000 \mathrm{~m} / \mathrm{s}$

The following figures display the magnification factor plots for 17 storey building. Similar to the 9 storey building, magnification values greater than two are observed for the BOR case. For the BOSR case, magnification similar to BOR is seen when there is a significant difference between the shear wave velocities of soil surrounding the parkade and the soil under the base of the tower, as shown in Figure 4-90. 


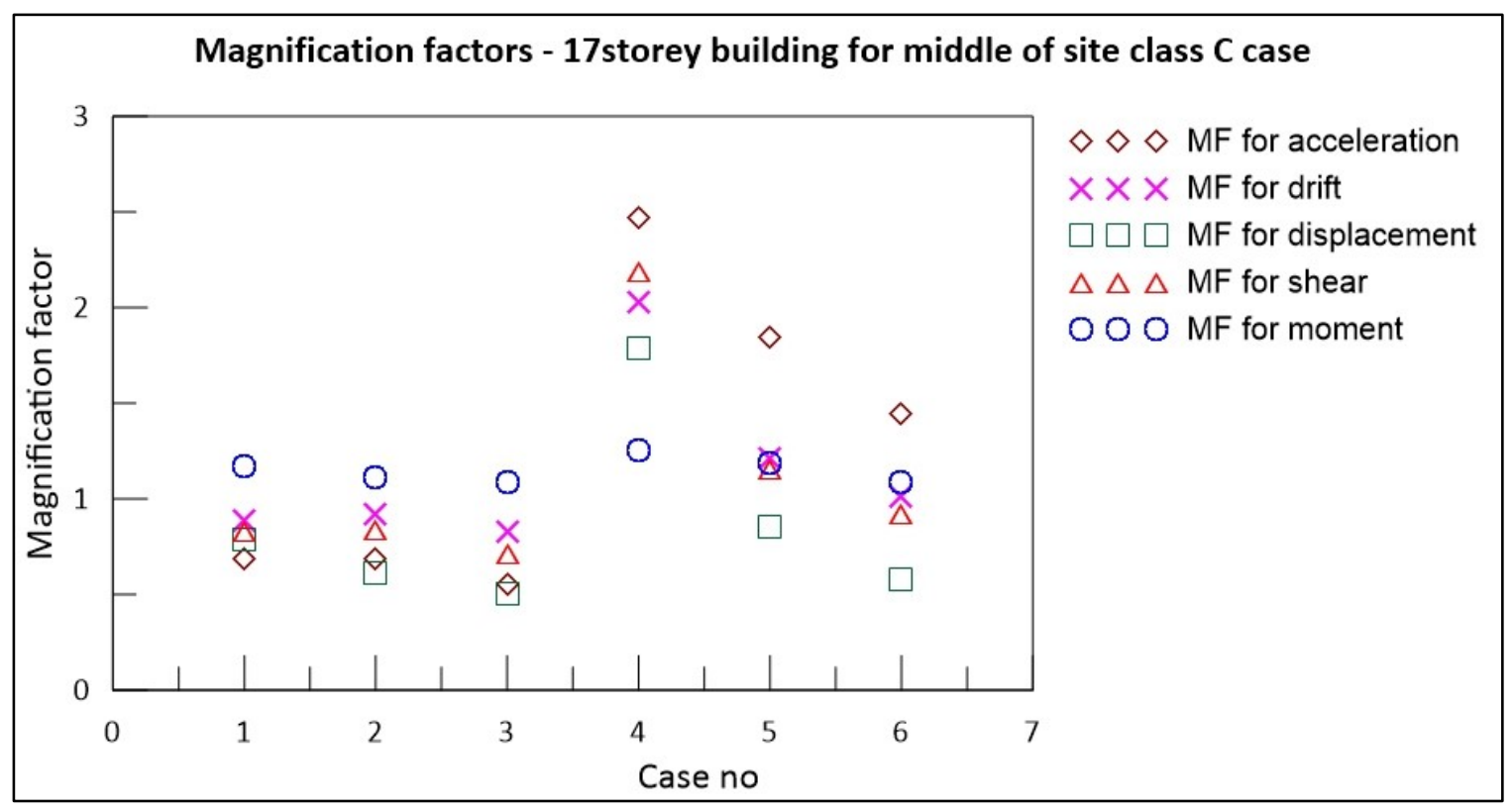

Figure 4-88: Magnification factors for 17 storey tower, Shear wave velocity of underlying soil $450 \mathrm{~m} / \mathrm{s}$

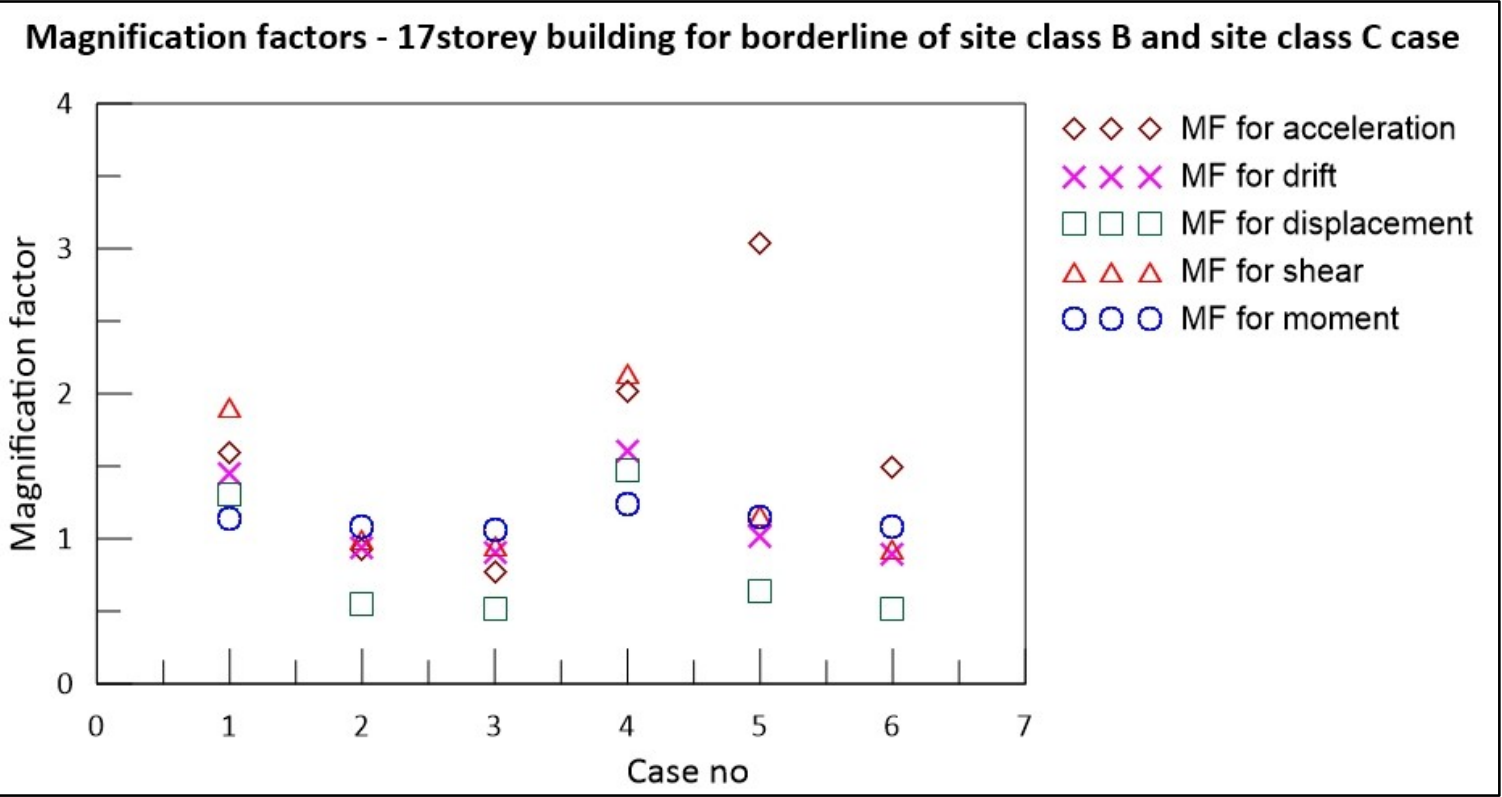

Figure 4-89: Magnification factors for 17 storey building, Shear wave velocity of underlying soil $750 \mathrm{~m} / \mathrm{s}$ 


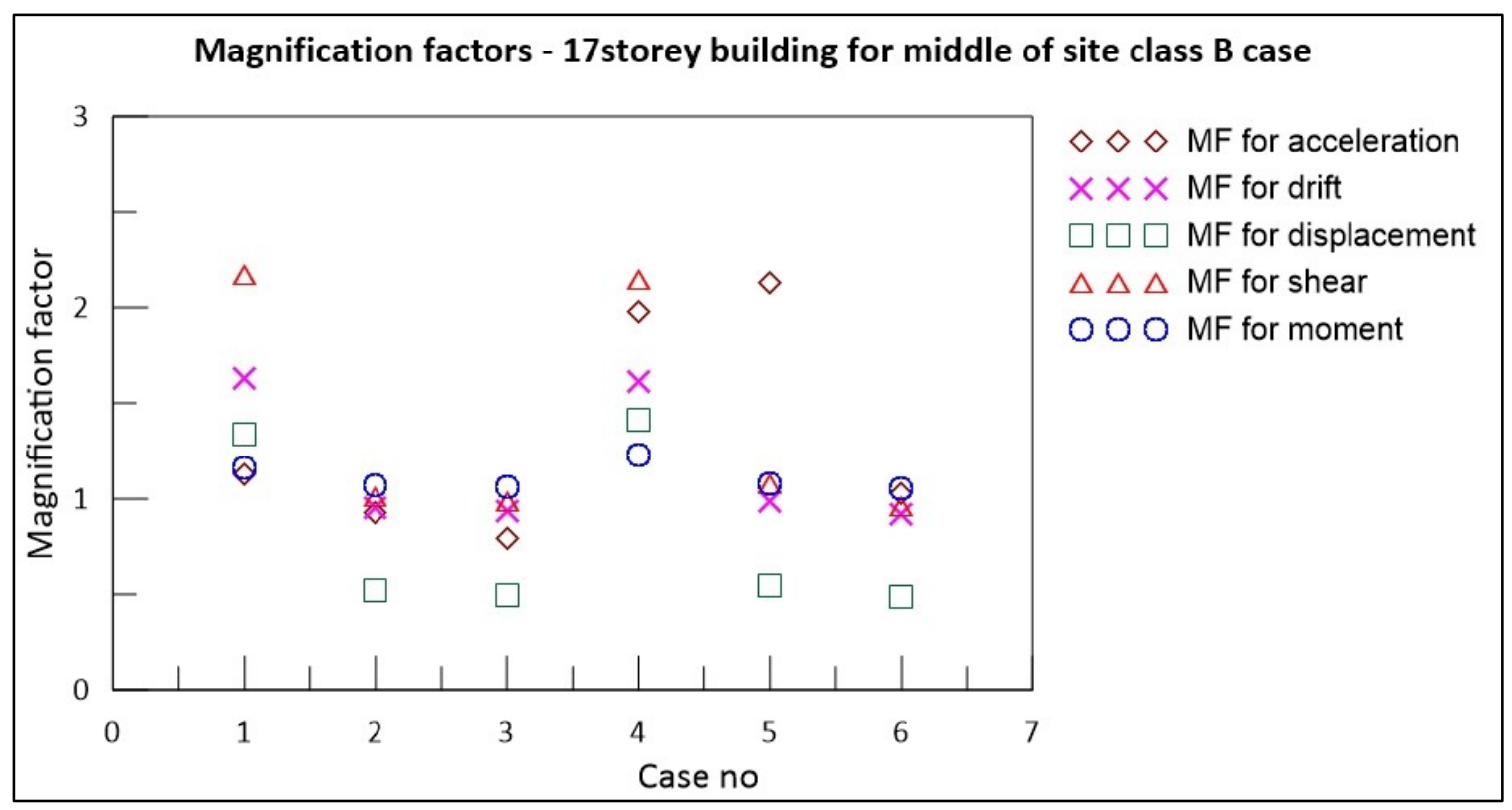

Figure 4-90: Magnification factors for the 17 storey building, Shear wave velocity of underlying soil 1000 $\mathrm{m} / \mathrm{s}$

Figure 4-91 to Figure 4-93 shows the magnification factor results observed for the 21 storey building. Magnification factor greater than two is observed for BOR 300/450. For other cases, no significant magnification in response is observed. However, the magnification values for the BOSR cases are lower than that observed for the corresponding BOR case. 


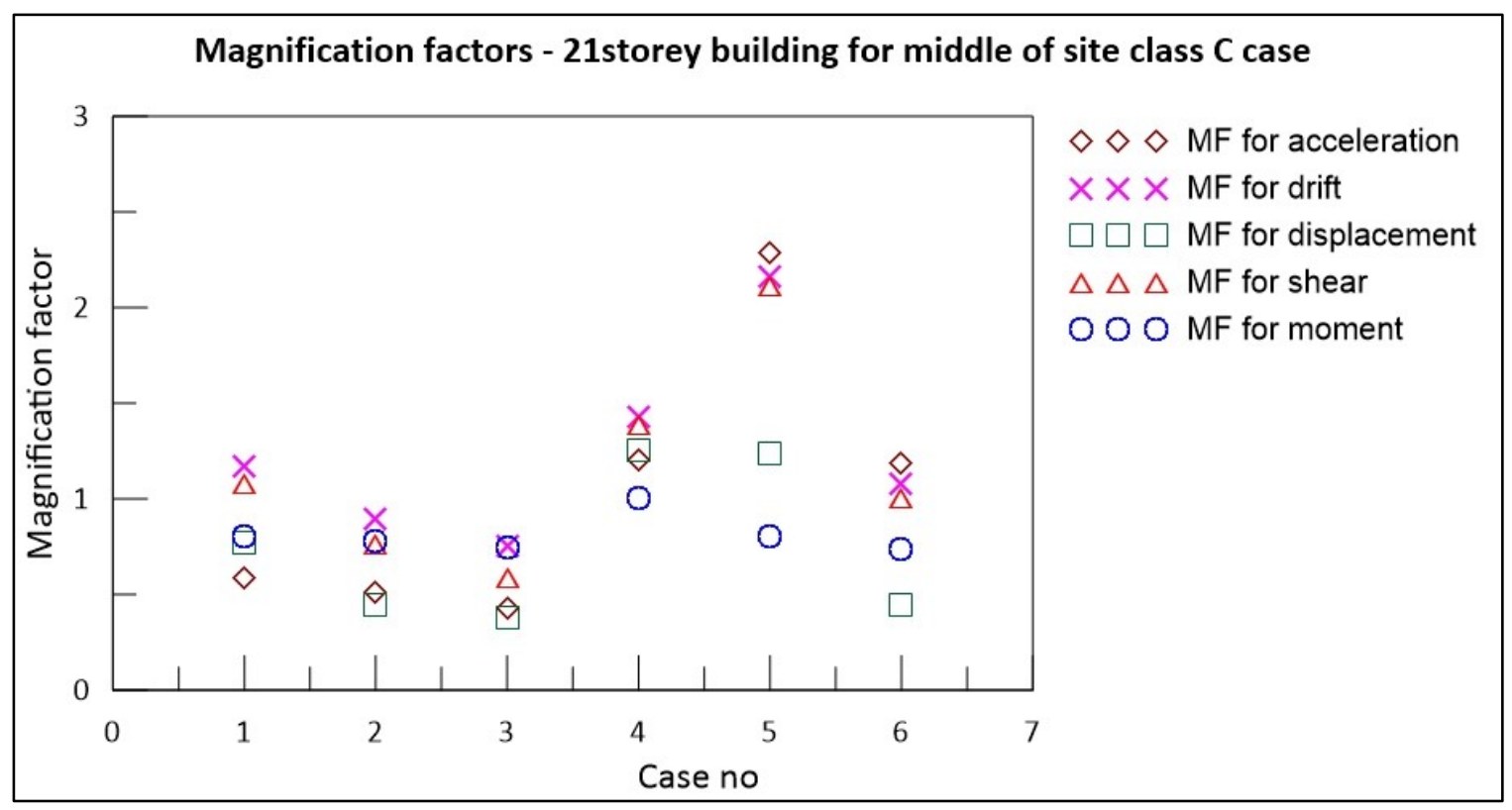

Figure 4-91: Magnification factors for the 21 storey building, Shear wave velocity of underlying soil 450 $\mathrm{m} / \mathrm{s}$

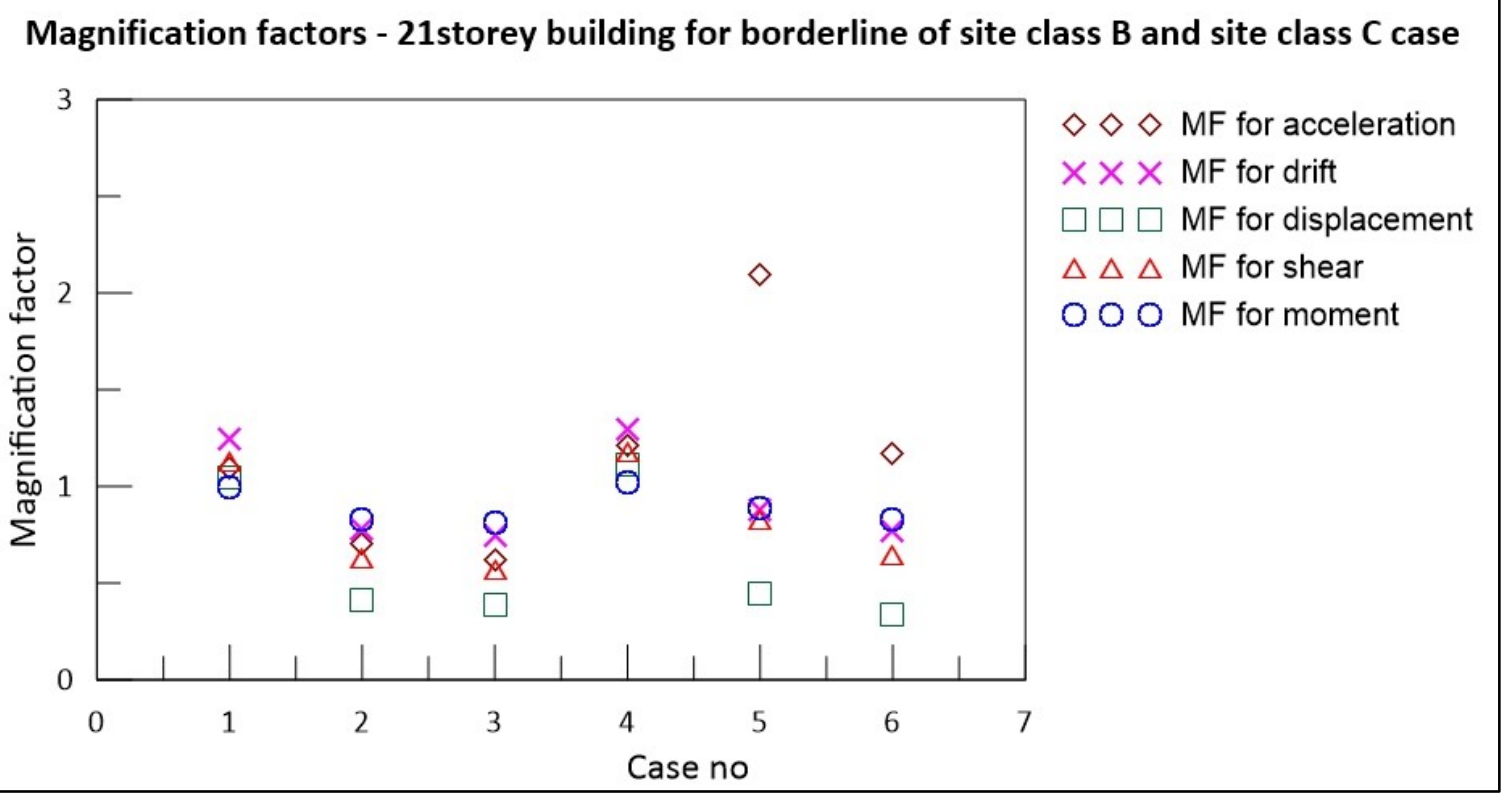

Figure 4-92: Magnification factors for the 21 storey building, Shear wave velocity of underlying soil 750 $\mathrm{m} / \mathrm{s}$ 


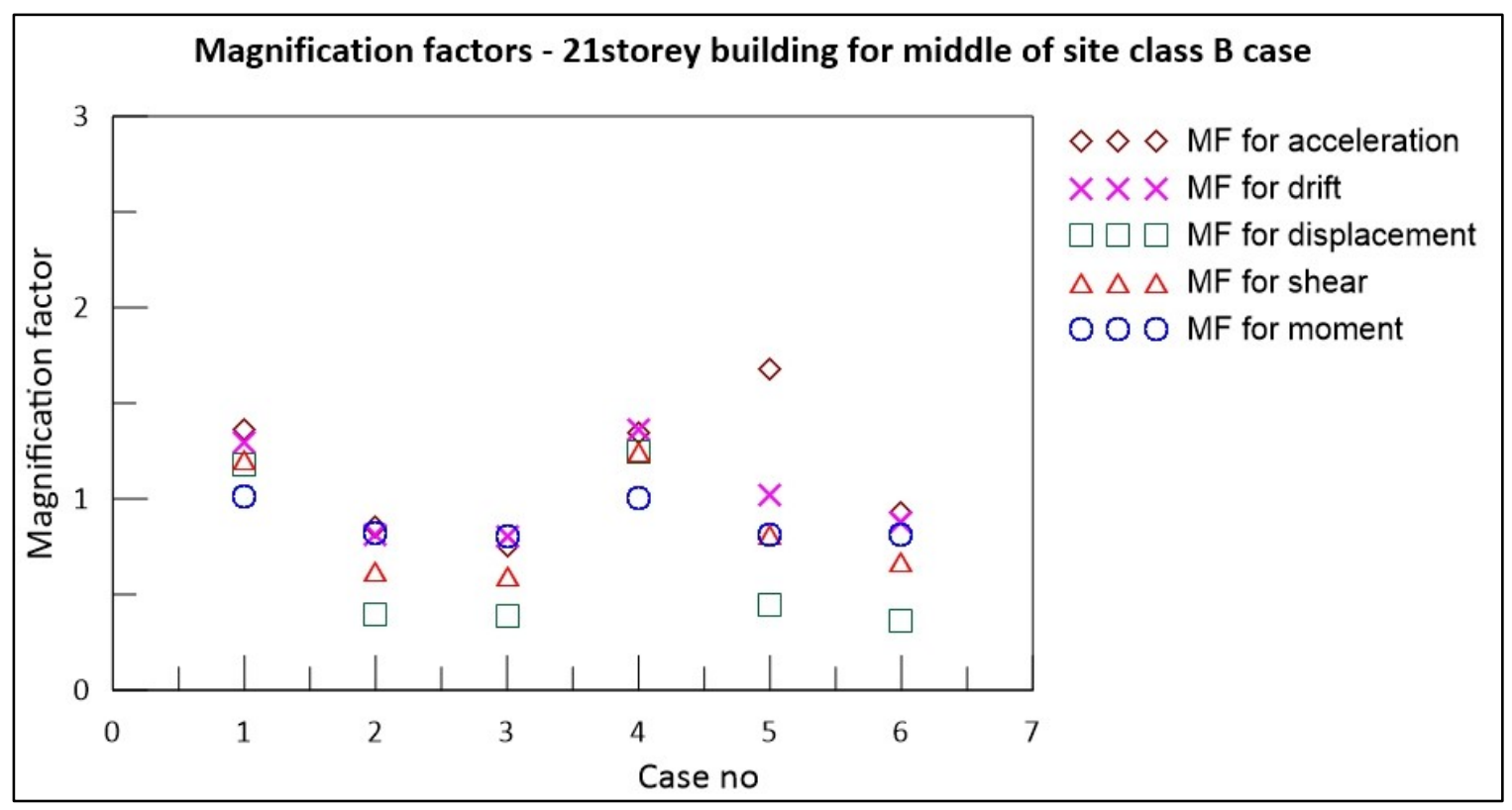

Figure 4-93: Magnification factors for the 21 storey building, Shear wave velocity of underlying soil 1000 $\mathrm{m} / \mathrm{s}$

Figure 4-94 to Figure 4-96 shows the magnification factor results observed for the 25 storey building. Similar to the previous cases BOSR magnification is smaller than the corresponding BOR magnification, and increasing stiffness of the soil surrounding the parkade leads to a reduction in magnification. 


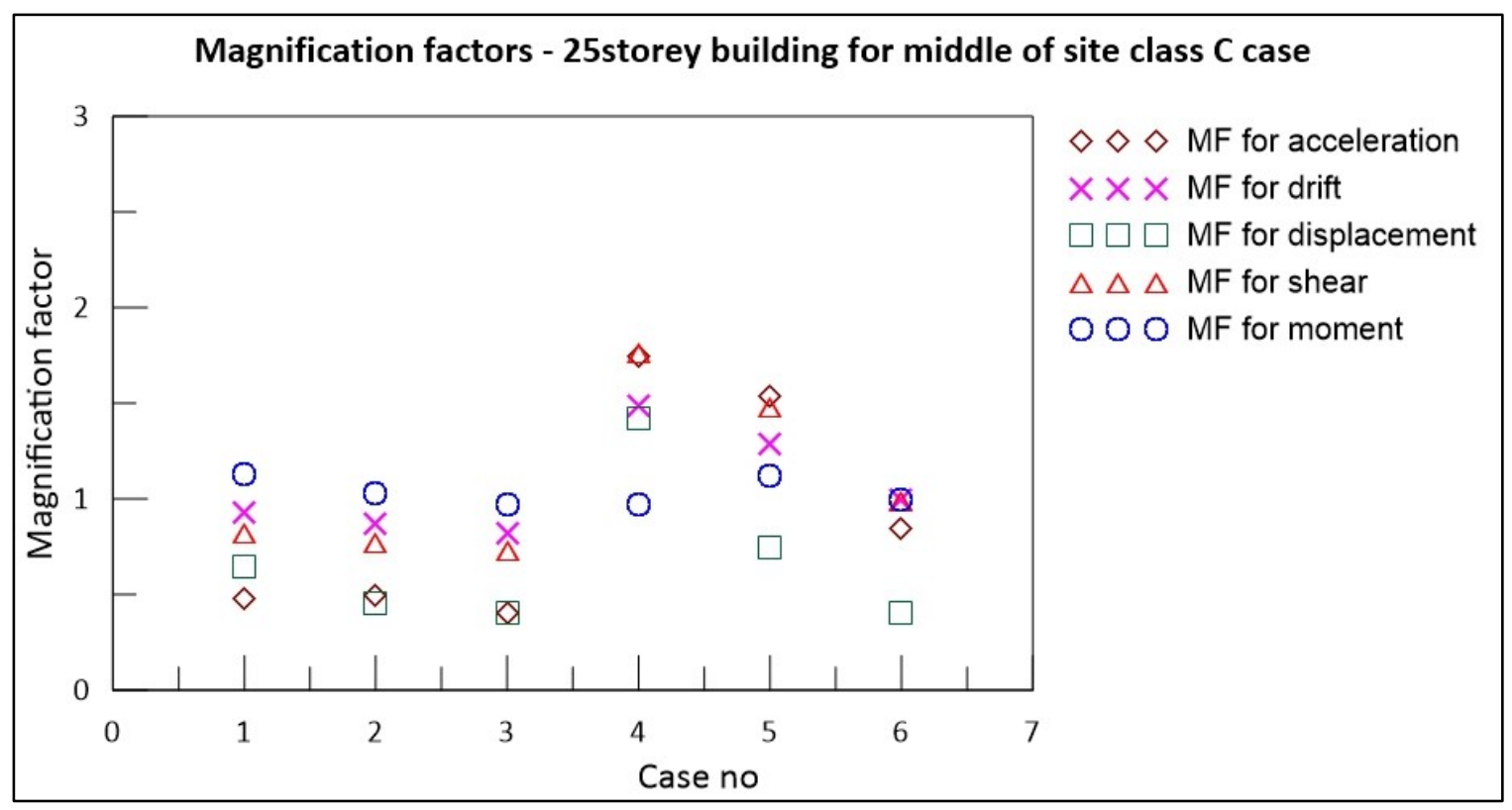

Figure 4-94: Magnification factors for the 25 storey building, Shear wave velocity of underlying soil 450 $\mathrm{m} / \mathrm{s}$

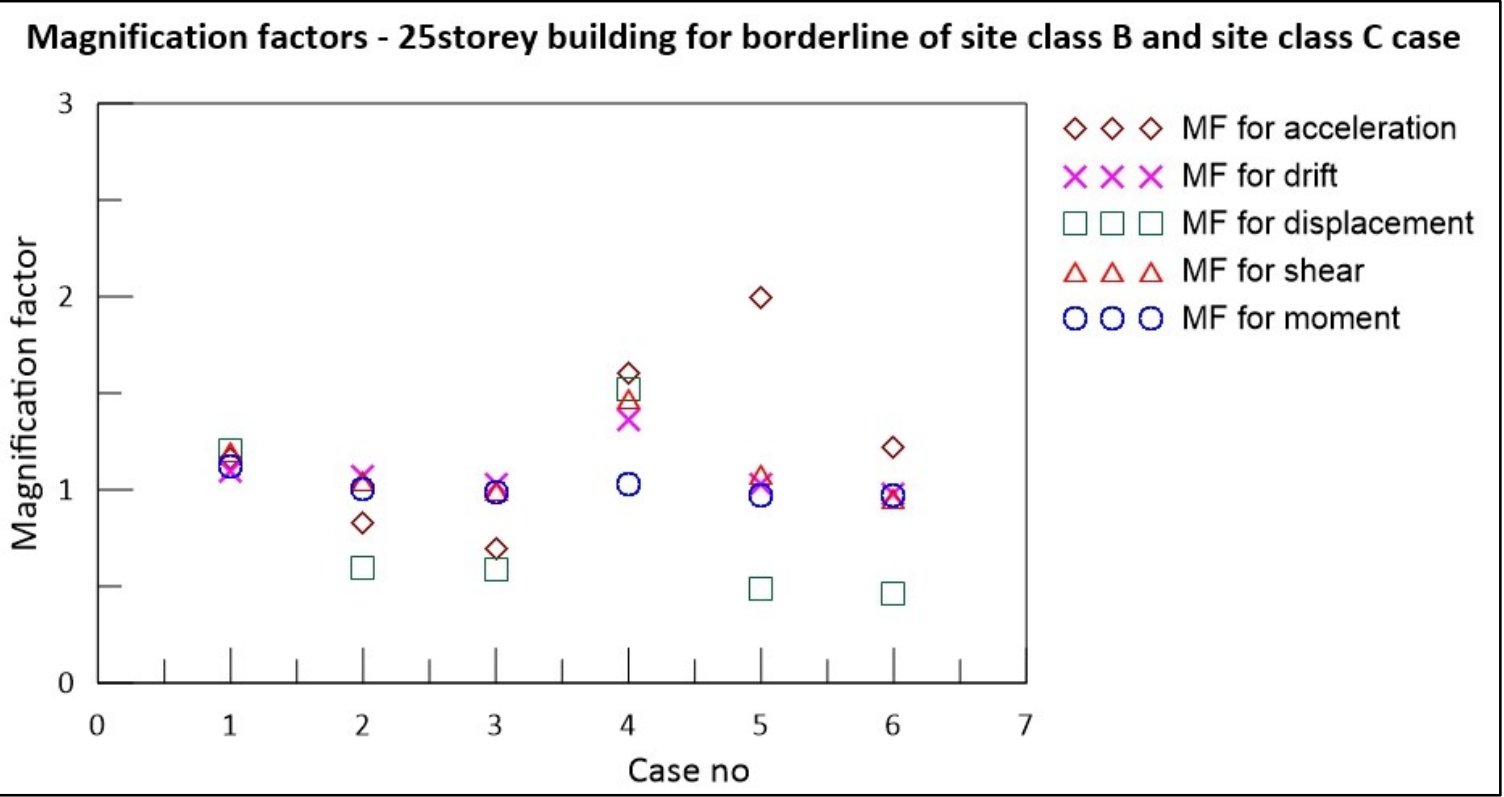

Figure 4-95: Magnification factors for the 25 storey building, Shear wave velocity of underlying soil 750 $\mathrm{m} / \mathrm{s}$ 


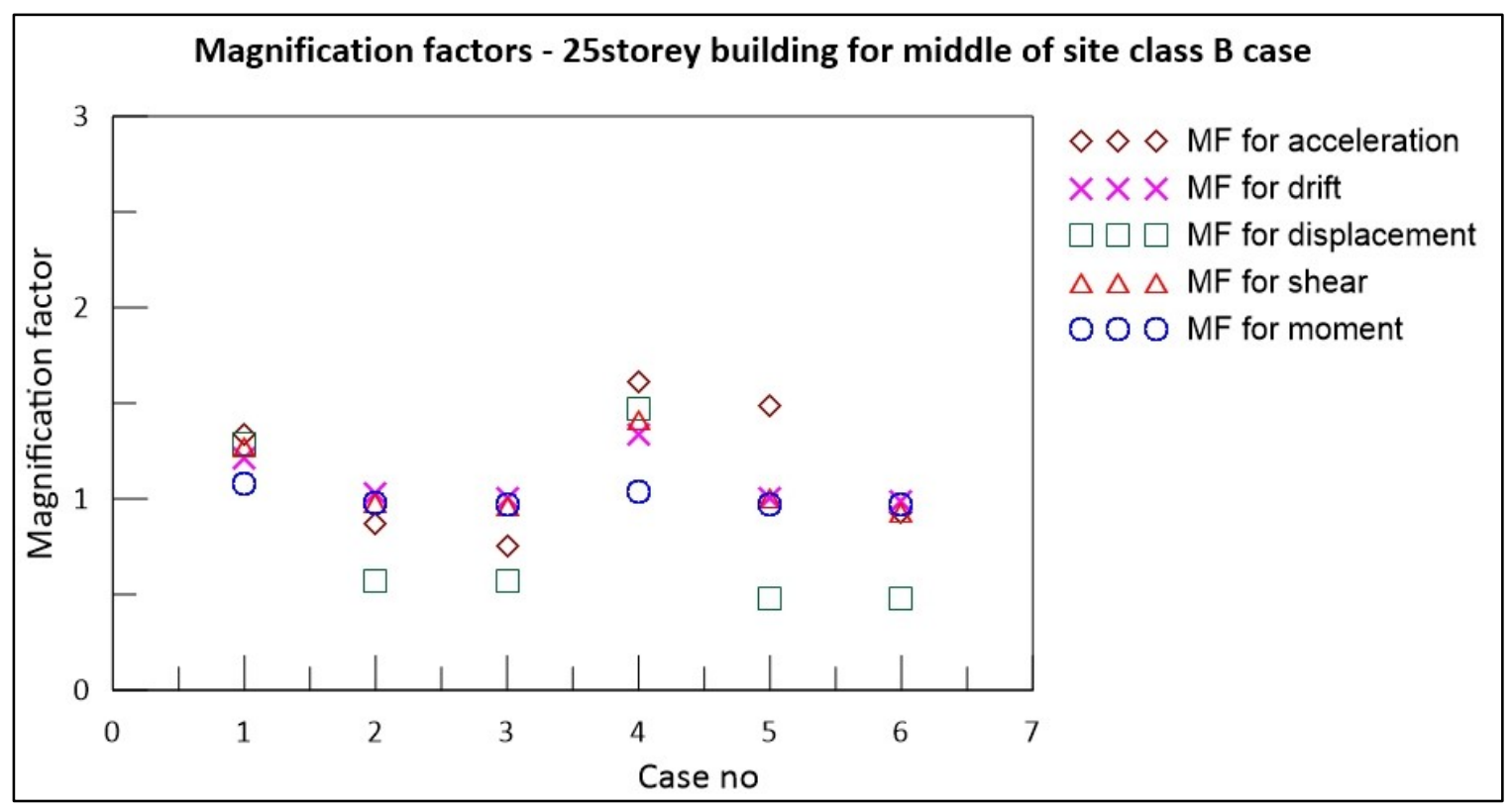

Figure 4-96: Magnification factors for the 25 storey building, Shear wave velocity of underlying soil 1000 $\mathrm{m} / \mathrm{s}$

The magnification factor data presented above indicates that the highest magnification is recorded for the case BOR 200/450. In all cases, the magnification observed in the BOSR case is always lower than the corresponding BOR case.

The analysis presented covered typical cases anticipated in the Vancouver region, and the results indicate that the $\mathrm{BOR}$ analysis, which ignores the kinematic interaction computes the highest base shear, moment, drift etc., or higher magnification factor compared to the baseline analysis (case of the building alone subjected to the propagated motion). The soil surrounding the parkade is considered in this analysis, but the effects of the stiffer foundation sitting on a relatively softer soil are not considered in BOR. On the other hand, the BOSR case consistently yielded lower demand compared to BOR, and in many cases lower demand than the baseline analysis. In BOSR, the structure is modelled with the soil surrounding the parkade and the rigid foundation resting on a soil deposit with overlying rock. This configuration thus considers both inertial interaction and kinematic interactions, 
and demonstrates that simplified models which ignore kinematic interaction may lead to conservative estimates of the structural demand. It is also noted that higher contrast between the soil surrounding the parkade and the soil underneath the base of the tower leads to an increase in magnification.

\subsubsection{Base slab averaging effect}

For the evaluation of seismic demand in structures, slab motion is commonly assumed to be equal to the free field motion. However, soil-structure interaction causes a difference between the two because of the base slab averaging effect. The presence of stiff foundation elements causes the motion to deviate from the free field motion. The impact of this effect is a function of the relative values of the wave length and foundation width. From the results presented in the preceding section, it is evident that there is a reduction in seismic demand when the structure is analyzed with a rigid foundation resting on a soil deposit overlying rock (BOSR) compared to the structure sitting on rock (BOR) case. The following plots illustrate the effect of base slab averaging. The plots are created for varying tower heights for various BOSR cases, as detailed in Section 3.7. The horizontal ground accelerations are recorded at the base of the structure for each BOSR case, and spectra for these motions are created using CUspectra software. For comparison, the free field spectra of the horizontal acceleration recorded at the top of the soil deposit when the structure and side soil are absent, as detailed in section 4.6 included in the plots. The spectrum of the earthquake input motion for Site Class A applied at the base of the underlying soil is also plotted.

Figure 4-97 to Figure 4-101 show the spectra plots for various tower heights for the middle of site class C case. All spectra plots are for 5\% damping. Similar plots for borderline of 
site class B and site class C, and middle of site class B case are presented in Appendix D. As stated in the literature (Lin et al. 2008 \& Hossein et al. 2013), the main effect of kinematic interaction is to filter the high-frequency components of the free field motion, and the same is observed as detailed in the following figures,

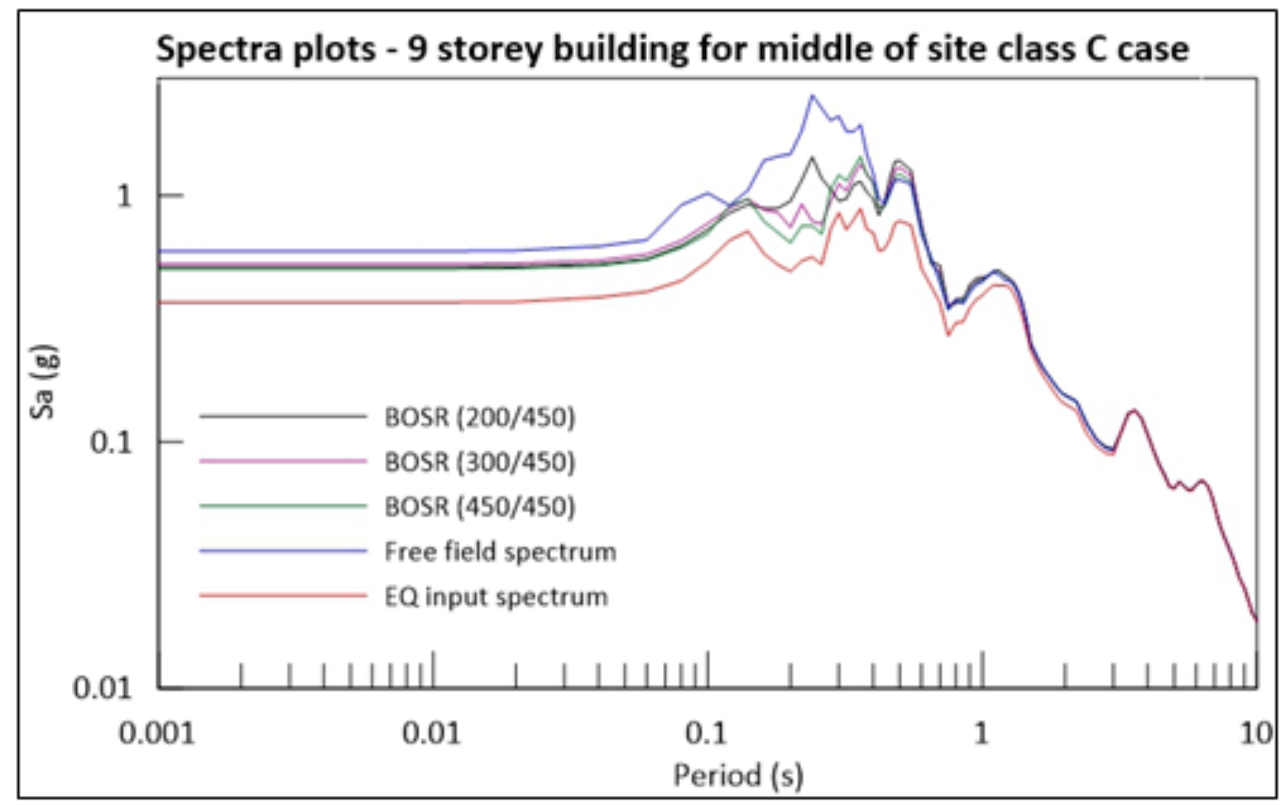

Figure 4-97: Spectra plots for 9 storey building, middle of site class C (450m/s) case

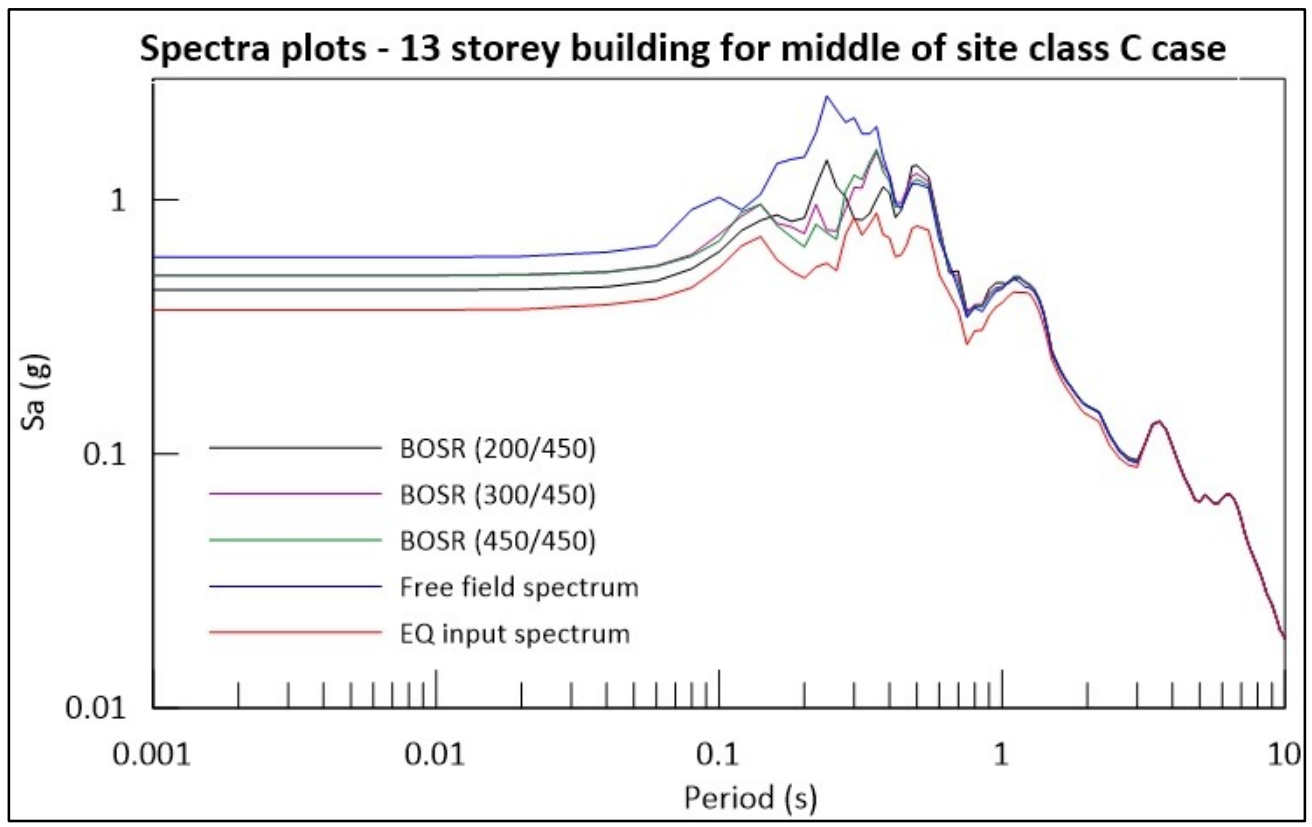

Figure 4-98: Spectra plots for 13 storey building, middle of site class C (450m/s) case 


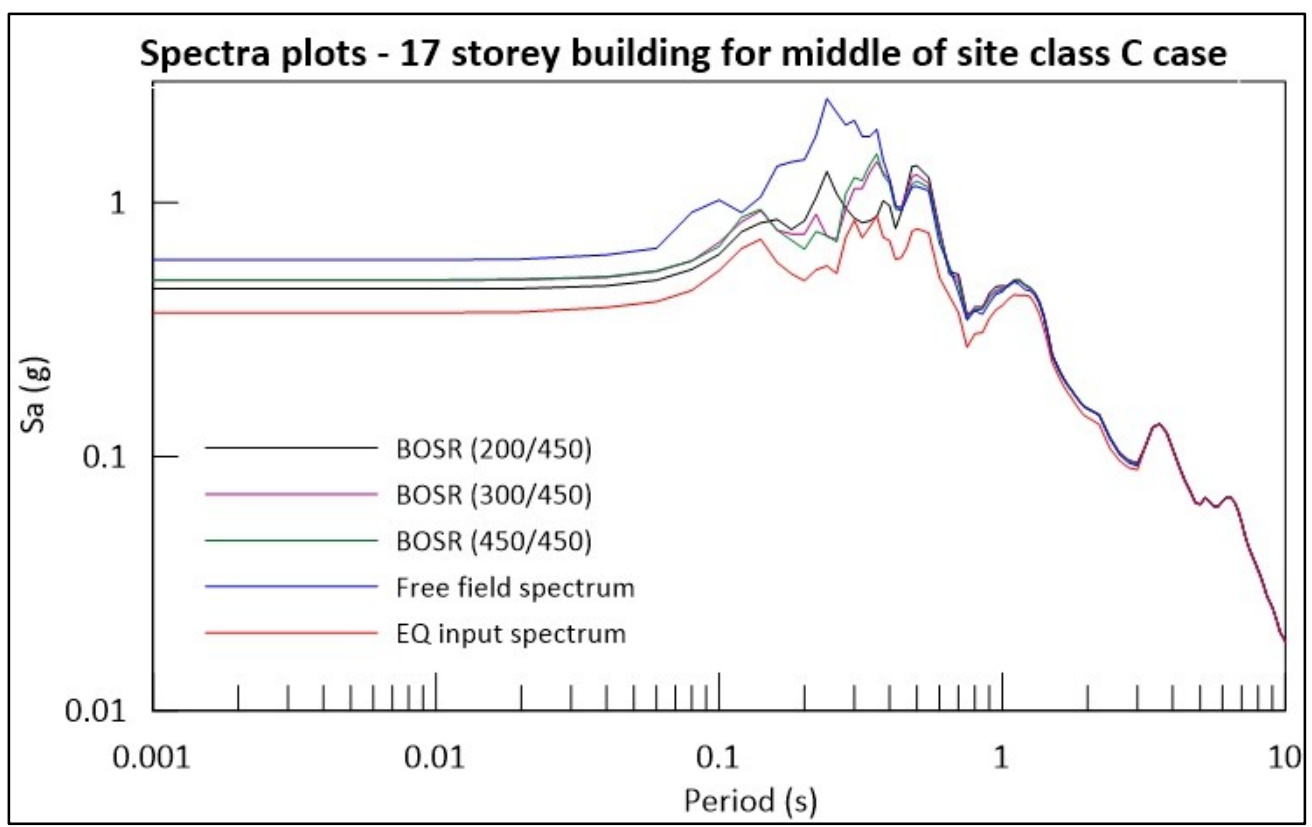

Figure 4-99: Spectra plots for 17 storey building, middle of site class C $(450 \mathrm{~m} / \mathrm{s})$ case

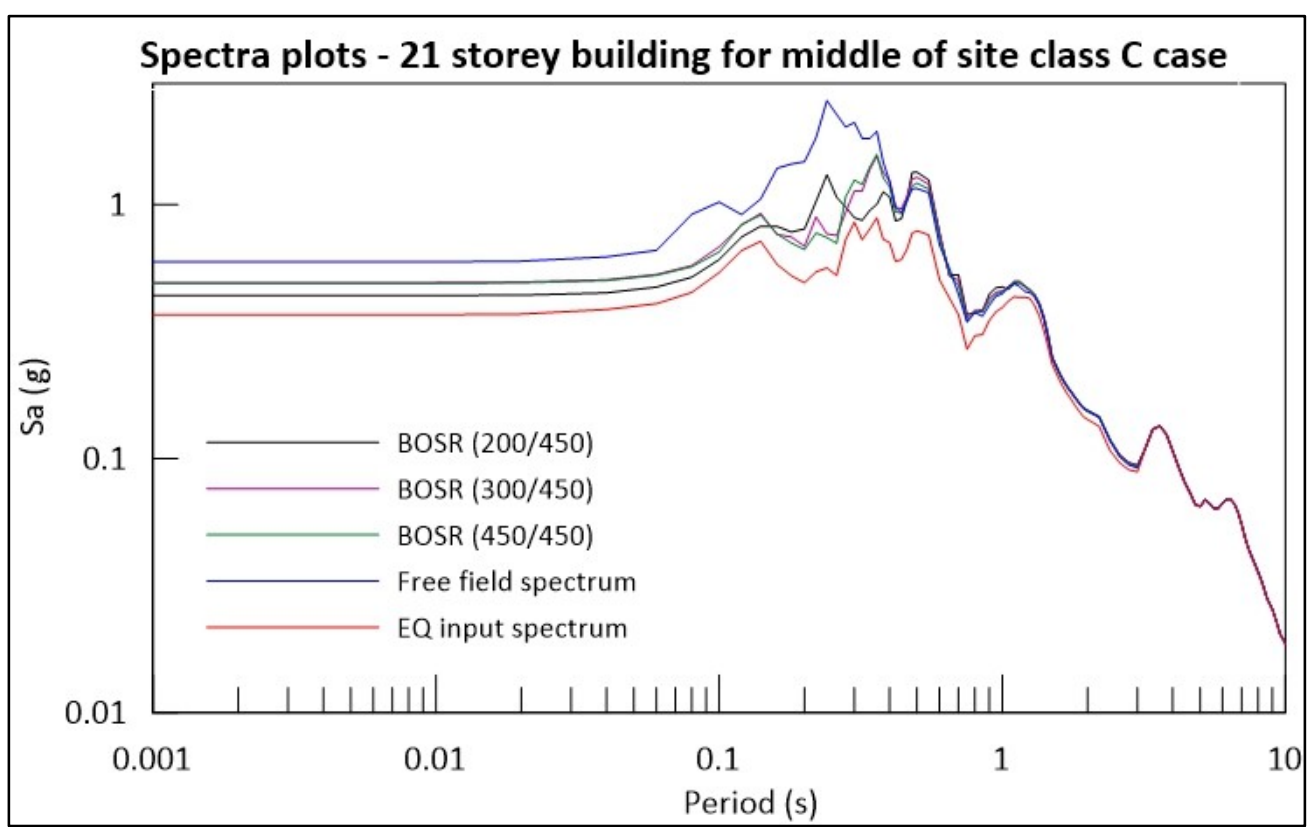

Figure 4-100: Spectra plots for 21 storey building, middle of site class C $(450 \mathrm{~m} / \mathrm{s})$ case 


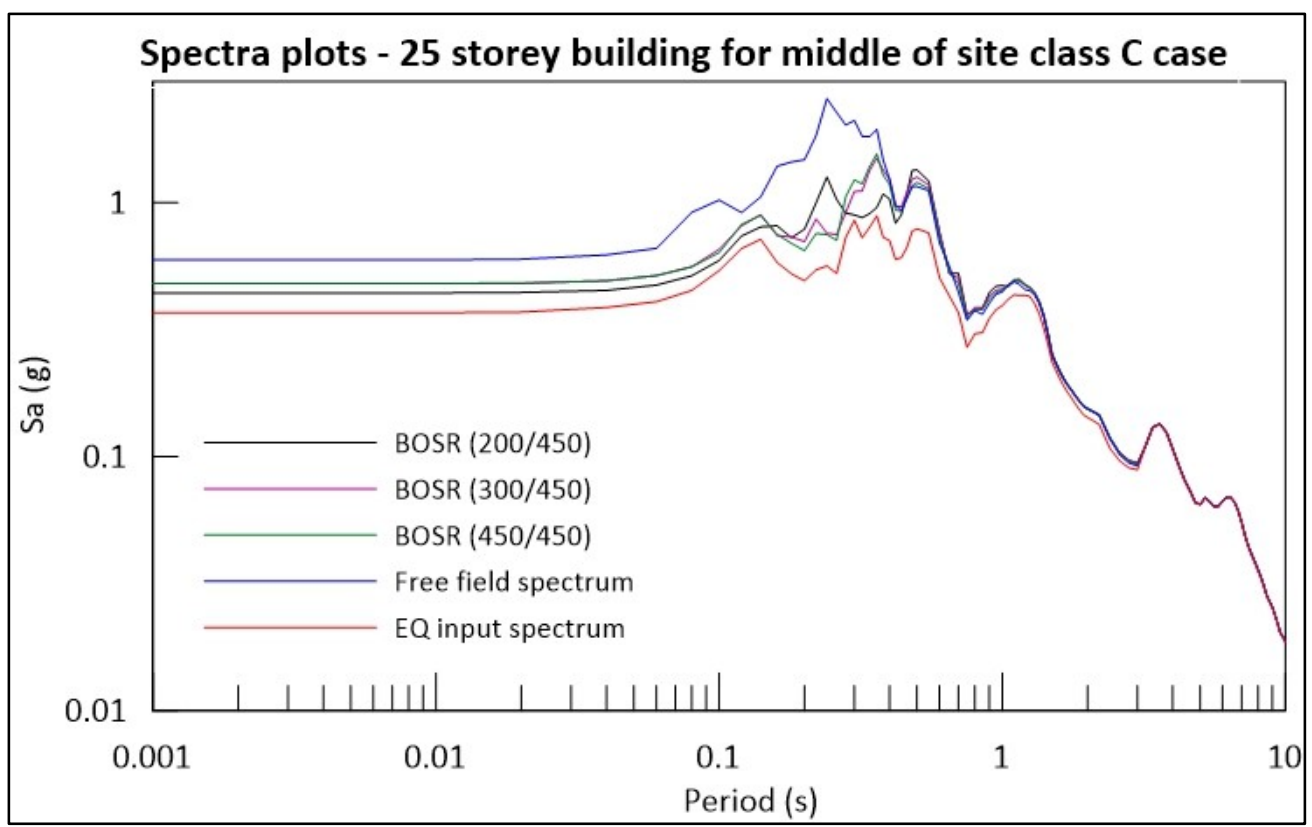

Figure 4-101: Spectra plots for 25 storey building, middle of site class C $(450 \mathrm{~m} / \mathrm{s})$ case

From the above plots, it is observed that the spectra of accelerations recorded at the base of the structure are de-amplified for all the cases when compared with the free field spectra for the same site condition. Hence, there is a reduction in seismic demand on the structures owing to the base slab averaging effect.

\subsubsection{Foundation rotation}

The foundation rigidity combined with flexibility of the soil under the foundation causes the base slab to rotate in addition to being displaced in the horizontal direction. Such rotation causes an increase in the displacements of the upper storeys and a lengthening of the period. Because the spectral accelerations generally decrease with increasing period, lengthening of the period results in a reduction in the seismic demand on the structure. To illustrate the extent of base slab rotation, the vertical displacements and the rotations at the two end and at the mid-point of the base slab are recorded. The notations used to present the displacements are as given in Figure 4-102. From the results, it is observed that foundation rotation exists. The base slab is rigidly connected to the tower and the parkade. 
The base slab is modelled to have a rigid body behavior, hence, the horizontal displacement $\mathrm{X} 1, \mathrm{X} 2$, and $\mathrm{X} 3$ will be the same. The structure being symmetric the center of mass is precisely at the middle, hence the moment generated causes the foundation to rotate about an axis passing through the middle, and leads to alternative compression and tension on either side. In Figure 4-102, the solid lines represent the original position of the foundation, and the dashed lines represent the displaced position. Figure 4-103 displays the vertical displacement recorded at the endpoints of the mat foundation for the 9 storey building with $200 \mathrm{~m} / \mathrm{s}$ shear wave velocity soil surrounding the parkade and $450 \mathrm{~m} / \mathrm{s}$ shear wave velocity underneath the base of the tower. For showing a clearer view of the displacements recorded, only the values between $7.5 \mathrm{sec}$ to $12.5 \mathrm{sec}$ are plotted.

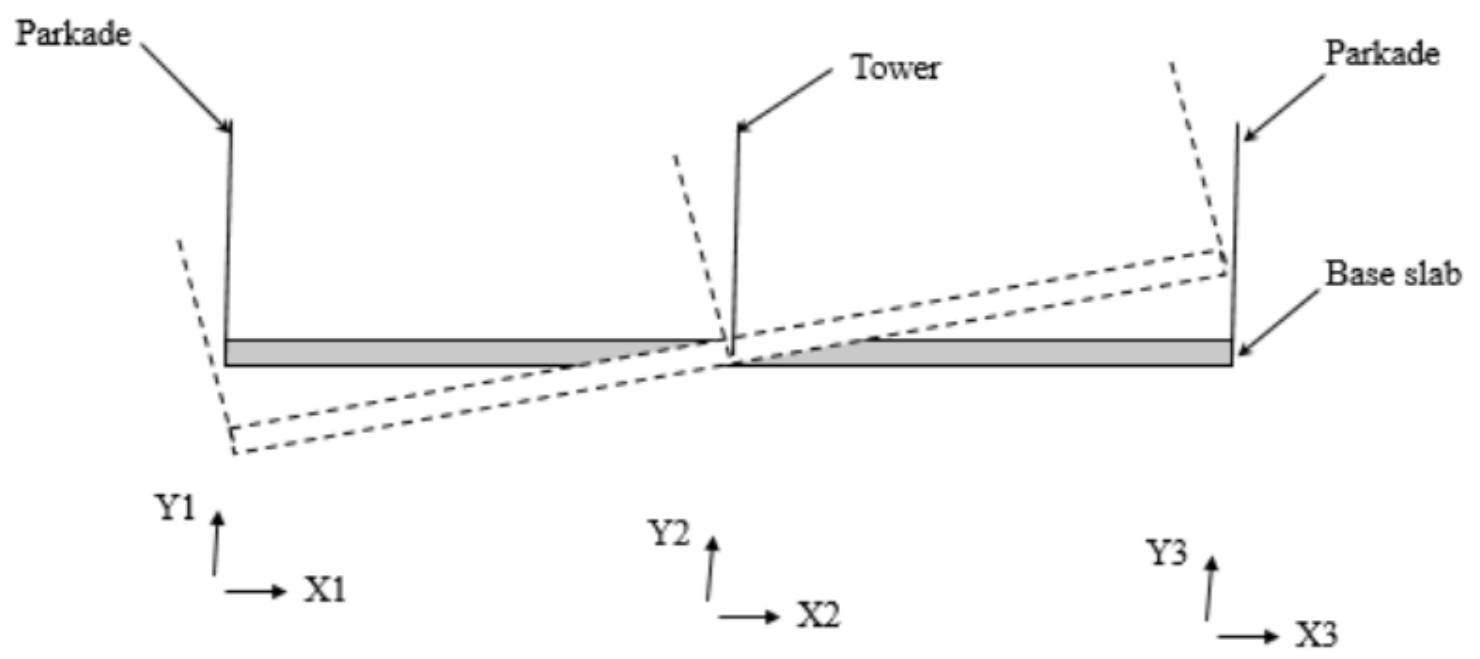

Figure 4-102: Notations for foundation rotation 


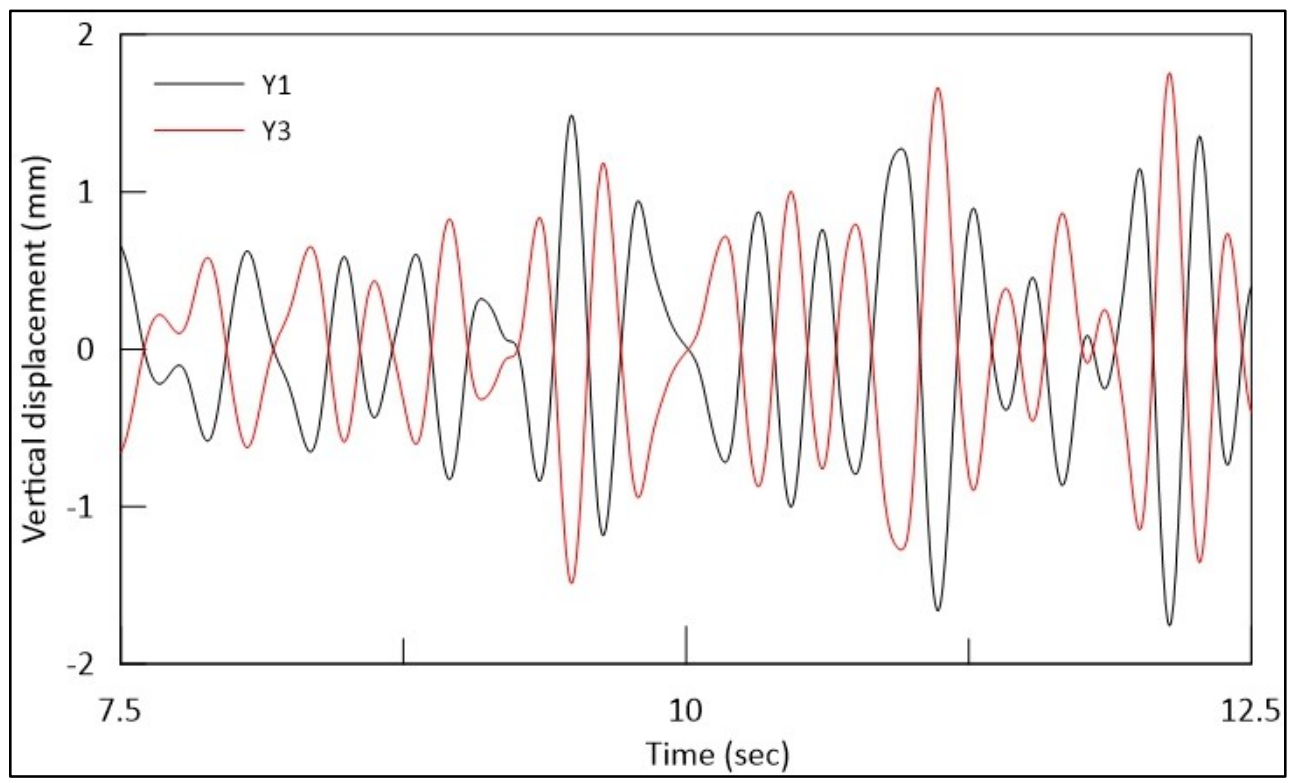

Figure 4-103: Vertical displacement at the end points of the foundation for 9 storey building, middle of site class C $(450 \mathrm{~m} / \mathrm{s})$ case with $200 \mathrm{~m} / \mathrm{s}$ side soil

Similar plots for the remaining BOSR cases listed under the parametric study are presented in Appendix E. Owing to the symmetry of the model, Y1 and Y3 are always equal and opposite with approximately zero vertical displacement (Y2) at the center of the foundation. As stated earlier, foundation rotation causes an elongation in the period of the model and reduction in the seismic demand on the structures, which is further evident from the magnification factor plots presented in Section 3.10.1. The demand for structures with mat foundation resting on a soil deposit is found to be lower than in the case when the structure is assumed to be resting on a rock (when no rotation in foundation is allowed) due to the combined effect of base slab averaging and foundation flexibility.

\subsection{Conclusions and recommendations}

The following conclusions can be drawn from the analysis presented in this chapter.

1. The seismic response in the BOR cases are higher than that in the corresponding BOSR cases. 
2. A magnification in response closer to the BOR case is observed for the BOSR case when the structure is surrounded by very soft soil and is underlain by a very stiff soil, i.e., when there is a significant difference in shear wave velocities of the soil surrounding the parkade and the soil under the base of the tower.

3. The motion at the foundation is filtered out due to base slab averaging, resulting in a reduction in the structure's seismic response.

4. Rotation is observed at the base of the foundation, which results in further reduction in the demand.

When the building parkade is surrounded by soil and rests on rock, the soil structure interaction can lead to high magnification in the seismic response and should not be neglected. The magnitude of the magnification caused by SSI depends on many factors, as discussed previously in Chapter 3. When the structure is analysed with soil surrounding the parkade but is founded on a soil layer under the base of the tower, there is a reduction in demand due to base slab averaging and foundation rotation. However, among many BOSR cases analyzed, there are a few that exhibit significant magnification in response. As stated earlier, no single parameter can be identified as the cause for magnification. It would thus be prudent to consider SSI in the seismic response analysis of structures. 


\section{Chapter 5: Summary, conclusion and recommendations}

\subsection{Summary}

The seismic response analysis of structures considering SSI is quite complicated and is usually ignored assuming that SSI is beneficial. However, this is a common misconception and the effect of SSI on the seismic demand of the structures can be adverse. Often multistorey buildings have a large below-ground structure. SSI in these buildings is affected by the interaction between the foundation of the structure and the bearing soil, and between the basement walls and the surrounding soil. This study focused on analyzing the seismic response of multi-storey towers with a five level below-grade parkade. The main objective of the study is to quantify the effects of SSI by comparing the response of the structure with SSI to the response of the tower and the parkade alone.

The buildings are assumed to be located in Vancouver, a region with higher seismic risk in Canada. Hence, the ground motion records are selected such that they match the design uniform hazard spectra of Vancouver. Each building under study has five below-ground parkade levels and a tower of variable heights running through the parkade. The tower and the parkade are modelled in OpenSees using Timoshenko beam elements and the soil elements are modelled using quad elements. The bottom boundary of the model is fixed and for the lateral ends SVB boundaries are employed. The dynamic time history analysis in OpenSees software was used to assess the response.

In the first part of the study, to evaluate the traditional approach in which the structures are analyzed with fixed base ignoring SSI, the tower, and the parkade along with the side soil are analyzed for $11 \mathrm{EQ}$ inputs. The mean of the response obtained is then compared with the mean of the response of the structure alone analyzed for 11 EQ inputs. Various 
parametric studies are carried out by considering different combinations of soil properties for the surrounding and bearing soil based on the site classes defined in NBCC 2015. In this part of the study, the buildings are assumed to be resting on a rock, hence only the inertial interaction part of the SSI is considered.

To consider and analyze the effect of both the inertial and kinematic interaction of the SSI, the buildings in the second part of the study are supported with a rigid mat foundation and seated on a soil deposit overlying rock. Hence, the model in this part of the study has the structure supported on a mat foundation with soil surrounding the parkade, and between the foundation and the rock.

First, an equivalent free field motion is established by conducting an analysis of the nearing soil layer (without the structure and the surrounding soil). This "propagated motion" is calculated by applying the earthquake input motion matching Vancouver site spectrum at the bedrock and propagated through the soil deposit for three soil types. The response at the top of the deposit is recorded, and used as input to evaluate the effect of SSI. In the first set, a model of the tower and the parkade alone is analyzed for the propagated motion. Secondly, the model of tower and the parkade along with the soil surrounding the parkade is analyzed for the propagated motion (BOR case) without any consideration of the underlying soil. Finally, the entire soil structure system is analyzed for the Vancouver site compatible motion applied at the level of the rock (BOSR case). The response of the structure alone is then compared with the response of BOR and BOSR cases to determine the magnifications observed. 


\subsection{Conclusions}

The following conclusions are drawn from the study presented in the thesis.

1) In common practice, the structures are cropped at the foundation level and analyzed with fixed base ignoring SSI. The results presented in this thesis indicate that this could lead to unsafe designs since the actual demand may be higher than that determined by the simple analysis. A magnification factor defined as ratio of the actual response to that determined by simpler analysis was calculated and presented for base shear, moment, drift etc. A magnification in the response is observed when the structure is analyzed along with soil compared to the case of tower and parkade alone.

2) The modal period of the structure and the soil are compared to examine the effect of resonance on magnification. It is observed that there is no correlation between resonance and the magnification.

3) The results from the analysis of buildings with tower heights shows that there is no distinctive relationship between the building heights and the response magnification.

4) The softer soil had greater impact on the response and hence it is obvious that effect of SSI depends on the property of the soil at the site.

5) The response observed depends on the characteristics of the earthquake inputs.

6) The seismic response in the BOR cases are higher than that in the corresponding BOSR cases. This highlights the effects of kinematic interaction.

7) For BOSR cases, a high magnification in response is observed when the structure is surrounded by very soft soil and is underlain by a very stiff soil, i.e., when there 
is a significant difference in shear wave velocities of the soil surrounding the parkade and the soil under the base of the tower.

8) In BOSR cases, the motion at the foundation is filtered out due to base slab averaging, resulting in a reduction in the structure's seismic response.

9) In addition to base slab averaging, rotation is observed at the base of the foundation, which results in further reduction in the demand.

From the study, it can be concluded that effects of SSI depend on many parameters. Hence, it is recommended that SSI be evaluated for the design of any structure under consideration, especially if the surrounding soils are relatively soft with the possible exception of structures founded on soil that overlies rock and are surrounded by comparatively stiff soil (BOSR) where kinematic interaction and foundation flexibility leads to lower demand on the structure. Inclusion of SSI in numerical modelling and performance assessments may be more feasible and efficient given the recent developments in advanced simulation methods (Huang and Kwon 2018, Mortazavi et. al 2017).

\subsection{Recommendations}

Based on the findings and the conclusions reached in the current study, the following are the few suggested recommendations for future studies,

1) This study was limited to one parkade configuration and select building types. Additional studies on different types of buildings using different earthquake input motions will be helpful for confirming the validity of the conclusions arrived.

2) The effect of non-linearity is not directly considered in this study. Further studies employing a non-linear model is recommended. It may, however, be noted that soils with a range of shear wave velocities, and correspondingly a range of shear 
stiffnesses were considered. Since the effect of nonlinearity in soil is to reduce its shear stiffness, such effect has been indirectly considered.

3) It will be useful to consider a soil model in detail with validated data from site tests having appropriate layering and properties. 


\section{References}

[1]. Amirzehni, E., Taiebat, M., Finn, W. D. L., \& Devall, R. H. (2013). Effect of nearfault ground motions on seismic response of deep basement walls. In ECCOMAS Thematic Conference - COMPDYN 2013: 4th International Conference on Computational Methods in Structural Dynamics and Earthquake Engineering, Proceedings - An IACM Special Interest Conference (pp. 801-811). National Technical University of Athens.

[2]. Bhattacharya, K., \& Dutta, S. C. (2004). Assessing lateral period of building frames incorporating soil-flexibility. Journal of Sound and Vibration, 269(3-5), 795-821.

[3]. Çelebi, M., \& Şafak, E. (1991). Seismic response of transamerica building. I: Data and preliminary analysis. Journal of Structural Engineering (United States), 117(8), 2389-2404.

[4]. CSI Analysis Reference Manual. (2019).

[5]. Dutta, Sekhar \& Bhattacharya, Koushik \& Roy, Rana. (2004). Response of low-rise buildings under seismic ground excitation incorporating soil-structure interaction. Soil Dynamics and Earthquake Engineering. 24. 893-914.

[6]. Chopra, A. K. (1995). Dynamics of structures: Theory and applications to earthquake engineering. Englewood Cliffs, N.J: Prentice Hall.

[7]. El Ganainy, H., \& El Naggar, M. H. (2009). Seismic performance of threedimensional frame structures with underground stories. Soil Dynamics and Earthquake Engineering, 29(9), 1249-1261. 
[8]. Far, Harry \& Massumi, Ali. (2010). A simplified method to determine seismic responses of reinforced concrete moment resisting building frames under influence of soil-structure interaction. Soil Dynamics and Earthquake Engineering. 30. 12591267.

[9]. FEMA P-750, NEHRP Recommended Seismic Provisions for New Buildings and Other Structures (FEMA, 2009).

[10]. Han, Y. (2002). Seismic response of tall building considering soil-pile-structure interaction. Earthquake Engineering and Engineering Vibration, 1(1), 57-64.

[11]. Hashash, F. Y. M. A., Dashti, M. S., Michael Musgrove, S. M., Gillis, K., Martin Walker, M., Kirk Ellison, M., \& Basarah, S. M. Y. I. (2018). Influence of tall buildings on seismic response of shallow underground structures. Journal of Geotechnical and Geoenvironmental Engineering, 144(12).

[12]. Hokmabadi, A. S., Fatahi, B., \& Samali, B. (2014). Assessment of soil-pile-structure interaction influencing seismic response of mid-rise buildings sitting on floating pile foundations. Computers and Geotechnics, 55, 172-186.

[13]. Huang, X., Kwon, O. (2018). A generalized numerical/experimental distributed simulation framework, Journal of Earthquake Engineering, Vol 24, 682-703.

[14]. Humar, J.L., David Lau, and Jean-Robert Pierre. (2001). "Performance of Buildings during the 2001 Bhuj Earthquake.” Canadian Journal of Civil Engineering, 28.6, 979-991.

[15]. Humar, J.L. (2012). Dynamic of Structures. Taylor \& Francis Group. A Balkema Book. 
[16]. Hussien, M. N., Tobita, T., Iai, S., \& Karray, M. (2016). Soil-pile-structure kinematic and inertial interaction observed in geotechnical centrifuge experiments. Soil Dynamics and Earthquake Engineering, 89, 75-84.

[17]. Jarernprasert, S., Bazan-Zurita, E., \& Bielak, J. (2013). Seismic soil-structure interaction response of inelastic structures. Soil Dynamics and Earthquake Engineering, 47, 132-143.

[18]. John P. Wolf. (1985). Dynamic Soil Structure Interaction. Englewood Cliffs, N.J: Prentice Hall.

[19]. Kim, D. K., \& Ha, H. G. (2014). Effect of soil-basement interaction on seismic responses of structures. In Geotechnical Aspects of Underground Construction in Soft Ground - Proceedings of the 8th Int. Symposium on Geotechnical Aspects of Underground Construction in Soft Ground, TC204 ISSMGE - IS-SEOUL 2014, 457464.

[20]. Kontoe, S., Zdravkovic, L., Potts, D., \& Salany, L. (2007). The use of absorbing boundaries in dynamic analyses of soil-structure interaction problems. 4th International Conference on Earthquake Engineering, Thessaloniki, Greece, (1231), $1-10$.

[21]. Lin, Y. Y., \& Miranda, E. (2008). Kinematic soil-structure interaction effects on maximum inelastic displacement demands of SDOF systems. Bulletin of Earthquake Engineering, 6(2), 241-259.

[22]. Luco, J. E., Trifunac, M. D., \& Wong, H. L. (1988). Isolation of soil-structure interaction effects by full-scale forced vibration tests. Earthquake Engineering \& Structural Dynamics, 16(1), 1-21. 
[23]. Lysmer, J. and Kuhlemeyer, R. L. (1969) Finite Dynamic Model for Infinite Media. Journal of Engineering Mechanics Division, 95, 859-878.

[24]. Matinmanesh, H., \& Asheghabadi, M. S. (2011). Seismic analysis on soil-structure interaction of buildings over sandy soil. In Procedia Engineering (Vol. 14, pp. 17371743).

[25]. Mendoza, M. J. \& Auvinet, G, (1988), “The Mexico earthquake of September 19, 1985-behavior of building foundations in Mexico City", Earthquake spectra, $4(4): 835-853$

[26]. Mononobe, N. and Matsuo M. (1929). "On the Determination of Earth Pressures during Earthquakes," Proceedings, World Engineering Congress, Vol. 9, 179-187.

[27]. Mortazavi, P., Huang, X., Kwon, O., Christopoulos, C. (2017). Example manual for the university of Toronto simulation (UT-SIM) framework. An Open-source framework for integrated multi-platform simulation for structural resilience (second edition), International workshop on hybrid simulation, Department of Civil and Mineral Engineering, University of Toronto, Toronto, Canada.

[28]. Mortazavi, P., Huang, X., Kwon, O., Christopoulos, C. (2017). An overview of the university of Toronto simulation (UT-SIM) framework and its application to the performance assessment of structures, 7th International Conference on Advances in Experimental Structural Engineering, Pavia, Italy.

[29]. Mortazavi, P., Humar, J. (2016). Consideration of diaphragm flexibility in the seismic design of one-story buildings, Engineering Structures, Vol 127, 748-758.

[30]. Mylonakis, G., \& Gazetas, G. (2000). Seismic soil-structure interaction: Beneficial or detrimental? Journal of Earthquake Engineering, 4(3), 277-301. 
[31]. Mylonakis, G., Syngros, C., Gazetas, G., \& Tazoh, T. (2006). The role of soil in the collapse of 18 piers of Hanshin Expressway in the Kobe earthquake. Earthquake Engineering \& Structural Dynamics, 35(5), 547-575.

[32]. Narayan, J. P. \& Sharma, Mukat. (2004). Effects of Local Geology On Damage Severity During Bhuj, India Earthquake. 13th World Conference on Earthquake Engineering. Vancouver, B.C., Canada.

[33]. NRCC. 2015. National Building Code of Canada 2015 (NBCC 2015). Canadian Commission on Building and Fire Code, National Research Council of Canada, Ottawa, Ont.

[34]. NIST GCR 12-917-21. 2012. Soil Structure Interaction for Building Structures.

[35]. Okabe, S. (1926) General Theory of Earth Pressure. Journal of Japan Society of Civil Engineers.

[36]. OpenSees. (2014). Open system for earthquake engineering simulation. Pacific Earthquake Engineering Research Center (PEER), (http://opensees.berkeley.edu).

[37]. Piro, Annachiara \& de Silva, Filomena \& Parisi, Fulvio \& Scotto di Santolo, Anna \& Silvestri, Francesco. (2019). Effects of soil-foundation-structure interaction on fundamental frequency and radiation damping ratio of historical masonry building sub-structures. Bulletin of Earthquake Engineering.

[38]. Rahmani, A., Taiebat, M., Liam Finn, W. D., \& Ventura, C. E. (2016). Evaluation of substructuring method for seismic soil-structure interaction analysis of bridges. Soil Dynamics and Earthquake Engineering, 90, 112-127. 
[39]. Rathje, E, Idriss, I.M., Somerville, P., Ansal, A., Bachhuber, J., Baturay, M., Erdik, M., Frost, D., Lettis, W., Sozer, B., Stewart, J., \& Ugras, T., (2000), “Strong ground motions and site effects", Earthquake spectra, 16(A), 65-96.

[40]. Saad, G., Najjara, S., \& Saddik, F. (2016). Seismic performance of reinforced concrete shear wall buildings with underground stories. Earthquake and Structures, 10(4), 965-988.

[41]. Sharma, N., Dasgupta, K., \& Dey, A. (2018, December 1). A state-of-the-art review on seismic SSI studies on building structures. Innovative Infrastructure Solutions.

[42]. Tehranizadeh, M., \& Barkhordari, M. S. (2018). Effect of Peripheral Wall Openings in Basement and Number of Basement Floors on the Base level of Braced Framed Tube System. International Journal of Civil Engineering, 16(9), 1157-1173.

[43]. Veletsos, A. S., \& Meek, J. W. (1974). Dynamic behaviour of building-foundation systems. Earthquake Engineering \& Structural Dynamics, 3(2), 121-138.

[44]. Veletsos, A. S., \& Boaz, I. B. (1979). Effects of soil-structure interaction on seismic response of a steel gravity platform. Journal of Energy Resources Technology, Transactions of the ASME, 101(3), 171-181

[45]. Vila, David \& Taborda, Ricardo \& Zapata, Arabella. (2004). Soil-structure interaction effects in two instrumented tall buildings. 13th World Conference on Earthquake Engineering. Vancouver, B.C., Canada.

[46]. Zafarkhah, E., \& Dehkordi, M. R. (2017). Evaluation and numerical simulation of soil type effects on seismic soil-structure interaction response of RC structures. Journal of Vibroengineering, 19(7), 5208-5230. 


\section{Appendix A - Modal analysis results}

The tables presented here represents the results of the modal analysis of the buildings with $8,12,16$, and 20 storey towers situated above an underground parkade of 5 storeys, when analyzed alone without the surrounding soil and with the surrounding soil. 
$\underline{\text { Modal analysis results for } 13 \text {-storey building model }}$

Table A-1 Modal periods of 13 storey tower without soil

\begin{tabular}{|c|c|c|c|}
\hline \multirow{2}{*}{ Mode } & \multicolumn{2}{|c|}{ Modal period (s) } & Modal participation \\
& OpenSees & SAP & factor, Ux \\
\cline { 2 - 3 } & 0.844 & 0.844 & 0.4066 \\
\hline 1 & 0.300 & 0.300 & 0.4562 \\
\hline 2 & 0.187 & 0.187 & 0.0551 \\
\hline 3 & 0.117 & 0.117 & 0.0150 \\
\hline 4 & 0.096 & 0.096 & 0.0397 \\
\hline 5 & &
\end{tabular}

Table A-2 Modal periods of 13 storey tower with soil Vs $=100 \mathrm{~m} / \mathrm{s}$

\begin{tabular}{|c|c|c|c|}
\hline \multirow{2}{*}{ Mode } & \multicolumn{2}{|c|}{ Modal period (s) } & $\begin{array}{c}\text { Modal participation } \\
\text { factor, Ux }\end{array}$ \\
\cline { 2 - 3 } & OpenSees & SAP & 0.0636 \\
\hline 1 & 0.825 & 0.825 & 0.5900 \\
\hline 2 & 0.623 & 0.627 & 0.1200 \\
\hline 3 & 0.618 & 0.505 & 0.0157 \\
\hline 4 & 0.500 & 0.389 & 0.0003 \\
\hline 5 & 0.455 & 0.380 & \\
\hline
\end{tabular}

Table A-3 Modal periods of 13 storey tower with soil Vs $=150 \mathrm{~m} / \mathrm{s}$

\begin{tabular}{|c|c|c|c|}
\hline \multirow[t]{2}{*}{ Mode } & \multicolumn{2}{|c|}{ Modal period (s) } & \multirow{2}{*}{$\begin{array}{l}\text { Modal participation } \\
\text { factor, } \mathrm{Ux}\end{array}$} \\
\hline & OpenSees & SAP & \\
\hline 1 & 0.807 & 0.807 & 0.0358 \\
\hline 2 & 0.422 & 0.424 & 0.6800 \\
\hline 3 & 0.412 & 0.361 & 0.0524 \\
\hline 4 & 0.359 & 0.267 & 0.0273 \\
\hline 5 & 0.304 & 0.254 & 0.0002 \\
\hline
\end{tabular}


Table A-4 Modal periods of 13 storey tower with soil Vs $=200 \mathrm{~m} / \mathrm{s}$

\begin{tabular}{|c|c|c|c|}
\hline \multirow{2}{*}{ Mode } & \multicolumn{2}{|c|}{ Modal period (s) } & \multirow{2}{*}{$\begin{array}{c}\text { Modal participation } \\
\text { factor, Ux }\end{array}$} \\
\cline { 2 - 3 } & OpenSees & SAP & 0.0278 \\
\hline 1 & 0.796 & 0.797 & 0.7200 \\
\hline 2 & 0.323 & 0.323 & 0.0037 \\
\hline 3 & 0.309 & 0.283 & 0.0263 \\
\hline 4 & 0.282 & 0.214 & 0.0193 \\
\hline 5 & 0.228 & 0.195 & \\
\hline
\end{tabular}

Table A-5 Modal periods of 13 storey tower with soil Vs $=300 \mathrm{~m} / \mathrm{s}$

\begin{tabular}{|c|c|c|c|}
\hline \multirow[t]{2}{*}{ Mode } & \multicolumn{2}{|c|}{ Modal period (s) } & \multirow{2}{*}{$\begin{array}{l}\text { Modal participation } \\
\text { factor, } \mathrm{Ux}\end{array}$} \\
\hline & OpenSees & SAP & \\
\hline 1 & 0.784 & 0.785 & 0.0218 \\
\hline 2 & 0.229 & 0.228 & 0.4600 \\
\hline 3 & 0.206 & 0.207 & 0.2600 \\
\hline 4 & 0.206 & 0.186 & 0.0064 \\
\hline 5 & 0.186 & 0.136 & 0.0426 \\
\hline
\end{tabular}

Table A-6 Modal periods of 13 storey tower with soil Vs $=450 \mathrm{~m} / \mathrm{s}$

\begin{tabular}{|c|c|c|c|}
\hline \multirow{2}{*}{ Mode } & \multicolumn{2}{|c|}{ Modal period (s) } & $\begin{array}{c}\text { Modal participation } \\
\text { factor, Ux }\end{array}$ \\
\cline { 2 - 3 } & OpenSees & SAP & 0.0188 \\
\hline 1 & 0.775 & 0.776 & 0.0206 \\
\hline 2 & 0.208 & 0.208 & 0.6700 \\
\hline 3 & 0.150 & 0.148 & 0.0318 \\
\hline 4 & 0.137 & 0.130 & 0.0068 \\
\hline 5 & 0.130 & 0.116 & \\
\hline
\end{tabular}


Table A-7 Modal periods of 13 storey tower with soil Vs $=600 \mathrm{~m} / \mathrm{s}$

\begin{tabular}{|c|c|c|c|}
\hline \multirow{2}{*}{ Mode } & \multicolumn{2}{|c|}{ Modal period (s) } & \multirow{2}{*}{$\begin{array}{c}\text { Modal participation } \\
\text { factor, Ux }\end{array}$} \\
\cline { 2 - 3 } & OpenSees & SAP & 0.0177 \\
\hline 1 & 0.771 & 0.771 & 0.0081 \\
\hline 2 & 0.205 & 0.206 & 0.1500 \\
\hline 3 & 0.119 & 0.119 & 0.5400 \\
\hline 4 & 0.111 & 0.110 & 0.0297 \\
\hline 5 & 0.103 & 0.098 & \\
\hline
\end{tabular}

Table A-8 Modal periods of 13 storey tower with soil Vs $=850 \mathrm{~m} / \mathrm{s}$

\begin{tabular}{|c|c|c|c|}
\hline \multirow{2}{*}{ Mode } & \multicolumn{2}{|c|}{ Modal period (s) } & \multirow{2}{*}{$\begin{array}{c}\text { Modal participation } \\
\text { factor, Ux }\end{array}$} \\
\cline { 2 - 3 } & OpenSees & SAP & 0.0170 \\
\hline 1 & 0.767 & 0.768 & 0.0047 \\
\hline 2 & 0.204 & 0.204 & 0.0042 \\
\hline 3 & 0.116 & 0.116 & 0.0604 \\
\hline 4 & 0.085 & 0.085 & 0.6100 \\
\hline 5 & 0.080 & 0.079 & \\
\hline
\end{tabular}

Table A-9 Modal periods of 13 storey tower with soil Vs $=1000 \mathrm{~m} / \mathrm{s}$

\begin{tabular}{|c|c|c|c|}
\hline \multirow{2}{*}{ Mode } & \multicolumn{2}{|c|}{ Modal period (s) } & \multirow{2}{*}{$\begin{array}{c}\text { Modal participation } \\
\text { factor, Ux }\end{array}$} \\
\cline { 2 - 3 } & OpenSees & SAP & 0.0168 \\
\hline 1 & 0.766 & 0.767 & 0.0041 \\
\hline 2 & 0.204 & 0.204 & 0.0055 \\
\hline 3 & 0.085 & 0.085 & 0.2400 \\
\hline 4 & 0.069 & 0.069 & 0.4200 \\
\hline 5 & 0.067 & 0.067 & \\
\hline
\end{tabular}


$\underline{\text { Modal analysis results for } 17 \text {-storey building model }}$

Table A-10 Modal periods of 17 storey tower without soil

\begin{tabular}{|c|c|c|c|}
\hline \multirow{2}{*}{ Mode } & \multicolumn{2}{|c|}{ Modal period (s) } & \multirow{2}{*}{$\begin{array}{c}\text { Modal participation } \\
\text { factor, Ux }\end{array}$} \\
\cline { 2 - 3 } & OpenSees & SAP & 0.4018 \\
\hline 1 & 1.381 & 1.381 & 0.3159 \\
\hline 2 & 0.378 & 0.379 & 0.1950 \\
\hline 3 & 0.249 & 0.249 & 0.0176 \\
\hline 4 & 0.167 & 0.167 & 0.0084 \\
\hline 5 & 0.122 & 0.122 & \\
\hline
\end{tabular}

Table A-11 Modal periods of 17 storey tower with soil Vs $=100 \mathrm{~m} / \mathrm{s}$

\begin{tabular}{|c|c|c|c|}
\hline \multirow{2}{*}{ Mode } & \multicolumn{2}{|c|}{ Modal period (s) } & \multirow{2}{*}{$\begin{array}{c}\text { Modal participation } \\
\text { factor, Ux }\end{array}$} \\
\cline { 2 - 3 } & OpenSees & SAP & 0.0360 \\
\hline 1 & 1.360 & 1.360 & 0.6200 \\
\hline 2 & 0.625 & 0.629 & 0.1200 \\
\hline 3 & 0.618 & 0.513 & 0.0140 \\
\hline 4 & 0.508 & 0.394 & 0.0002 \\
\hline 5 & 0.455 & 0.380 & \\
\hline
\end{tabular}

Table A-12 Modal periods of 17 storey tower with soil Vs $=150 \mathrm{~m} / \mathrm{s}$

\begin{tabular}{|c|c|c|c|}
\hline \multirow{2}{*}{ Mode } & \multicolumn{2}{|c|}{ Modal period (s) } & \multirow{2}{*}{$\begin{array}{c}\text { Modal participation } \\
\text { factor, Ux }\end{array}$} \\
\cline { 2 - 3 } & OpenSees & SAP & 0.0309 \\
\hline 1 & 1.346 & 1.347 & 0.7000 \\
\hline 2 & 0.426 & 0.426 & 0.0108 \\
\hline 3 & 0.412 & 0.375 & 0.0336 \\
\hline 4 & 0.374 & 0.319 & 0.0234 \\
\hline 5 & 0.317 & 0.263 & \\
\hline
\end{tabular}


Table A-13 Modal periods of 17 storey tower with soil Vs $=200 \mathrm{~m} / \mathrm{s}$

\begin{tabular}{|c|c|c|c|}
\hline \multirow{2}{*}{ Mode } & \multicolumn{2}{|c|}{ Modal period (s) } & \multirow{2}{*}{$\begin{array}{c}\text { Modal participation } \\
\text { factor, Ux }\end{array}$} \\
\cline { 2 - 3 } & OpenSees & SAP & 0.0282 \\
\hline 1 & 1.336 & 1.337 & 0.2700 \\
\hline 2 & 0.347 & 0.346 & 0.4400 \\
\hline 3 & 0.313 & 0.314 & 0.0275 \\
\hline 4 & 0.309 & 0.274 & 0.0340 \\
\hline 5 & 0.272 & 0.202 & \\
\hline
\end{tabular}

Table A-14 Modal periods of 17 storey tower with soil Vs $=300 \mathrm{~m} / \mathrm{s}$

\begin{tabular}{|c|c|c|c|}
\hline \multirow{2}{*}{ Mode } & \multicolumn{2}{|c|}{ Modal period (s) } & \multirow{2}{*}{$\begin{array}{c}\text { Modal participation } \\
\text { factor, Ux }\end{array}$} \\
\cline { 2 - 3 } & OpenSees & SAP & 0.0258 \\
\hline 1 & 1.325 & 1.326 & 0.0232 \\
\hline 2 & 0.328 & 0.328 & 0.6900 \\
\hline 3 & 0.220 & 0.219 & 0.0115 \\
\hline 4 & 0.206 & 0.194 & 0.0110 \\
\hline 5 & 0.193 & 0.171 & \\
\hline
\end{tabular}

Table A-15 Modal periods of 17 storey tower with soil Vs $=450 \mathrm{~m} / \mathrm{s}$

\begin{tabular}{|c|c|c|c|}
\hline \multirow[t]{2}{*}{ Mode } & \multicolumn{2}{|c|}{ Modal period (s) } & \multirow{2}{*}{$\begin{array}{l}\text { Modal participation } \\
\text { factor, } \mathrm{Ux}\end{array}$} \\
\hline & OpenSees & SAP & \\
\hline 1 & 1.316 & 1.317 & 0.0244 \\
\hline 2 & 0.323 & 0.323 & 0.0097 \\
\hline 3 & 0.174 & 0.174 & 0.0334 \\
\hline 4 & 0.149 & 0.148 & 0.6500 \\
\hline 5 & 0.137 & 0.131 & 0.0337 \\
\hline
\end{tabular}


Table A-16 Modal periods of 17 storey tower with soil Vs $=600 \mathrm{~m} / \mathrm{s}$

\begin{tabular}{|c|c|c|c|}
\hline \multirow{2}{*}{ Mode } & \multicolumn{2}{|c|}{ Modal period (s) } & Modal participation \\
& OpenSees & SAP & factor, Ux \\
\hline 1 & 1.311 & 1.312 & 0.0238 \\
\hline 2 & 0.321 & 0.321 & 0.0071 \\
\hline 3 & 0.172 & 0.172 & 0.0054 \\
\hline 4 & 0.123 & 0.123 & 0.0544 \\
\hline 5 & 0.112 & 0.111 & 0.6100 \\
\hline
\end{tabular}

Table A-17 Modal periods of 17 storey tower with soil Vs $=850 \mathrm{~m} / \mathrm{s}$

\begin{tabular}{|c|c|c|c|}
\hline \multirow[t]{2}{*}{ Mode } & \multicolumn{2}{|c|}{ Modal period (s) } & Modal participation \\
\hline & OpenSees & SAP & factor, Ux \\
\hline 1 & 1.307 & 1.308 & 0.0234 \\
\hline 2 & 0.319 & 0.320 & 0.0058 \\
\hline 3 & 0.171 & 0.171 & 0.0022 \\
\hline 4 & 0.121 & 0.121 & 0.0028 \\
\hline 5 & 0.095 & 0.095 & 0.0076 \\
\hline 6 & 0.081 & 0.081 & 0.3300 \\
\hline 7 & 0.078 & 0.078 & 0.3300 \\
\hline
\end{tabular}

Table A-18 Modal periods of 17 storey tower with soil Vs $=1000 \mathrm{~m} / \mathrm{s}$

\begin{tabular}{|c|c|c|c|}
\hline \multirow{2}{*}{ Mode } & \multicolumn{2}{|c|}{ Modal period (s) } & Modal participation \\
& OpenSees & SAP & factor, Ux \\
\hline 1 & 1.306 & 1.306 & 0.0233 \\
\hline 2 & 0.319 & 0.319 & 0.0055 \\
\hline 3 & 0.171 & 0.171 & 0.0018 \\
\hline 4 & 0.121 & 0.121 & 0.0016 \\
\hline 5 & 0.095 & 0.095 & 0.0021 \\
\hline 6 & 0.079 & 0.070 & 0.1200 \\
\hline 7 & 0.069 & 0.067 & 0.5200 \\
\hline
\end{tabular}


$\underline{\text { Modal analysis results for } 21 \text {-storey building model }}$

Table A-19 Modal periods of 21 storey tower without soil

\begin{tabular}{|c|c|c|c|}
\hline \multirow{2}{*}{ Mode } & \multicolumn{2}{|c|}{ Modal period (s) } & Modal participation \\
& OpenSees & SAP & factor, Ux \\
\cline { 2 - 3 } & 2.050 & 2.050 & 0.4181 \\
\hline 1 & 0.497 & 0.497 & 0.2136 \\
\hline 2 & 0.289 & 0.289 & 0.2440 \\
\hline 3 & 0.216 & 0.216 & 0.0543 \\
\hline 4 & 0.158 & 0.158 & 0.0094 \\
\hline 5 & &
\end{tabular}

Table A-20 Modal periods of 21 storey tower with soil Vs $=100 \mathrm{~m} / \mathrm{s}$

\begin{tabular}{|c|c|c|c|}
\hline \multirow{2}{*}{ Mode } & \multicolumn{2}{|c|}{ Modal period (s) } & $\begin{array}{c}\text { Modal participation } \\
\text { factor, Ux }\end{array}$ \\
\cline { 2 - 3 } & OpenSees & SAP & 0.0364 \\
\hline 1 & 2.028 & 2.029 & 0.6300 \\
\hline 2 & 0.626 & 0.630 & 0.0843 \\
\hline 3 & 0.618 & 0.529 & 0.0295 \\
\hline 4 & 0.526 & 0.459 & 0.0165 \\
\hline 5 & 0.456 & 0.386 & \\
\hline
\end{tabular}

Table A-21 Modal periods of 21 storey tower with soil Vs $=150 \mathrm{~m} / \mathrm{s}$

\begin{tabular}{|c|c|c|c|}
\hline \multirow[t]{2}{*}{ Mode } & \multicolumn{2}{|c|}{ Modal period (s) } & \multirow{2}{*}{$\begin{array}{l}\text { Modal participation } \\
\text { factor, } \mathrm{Ux}\end{array}$} \\
\hline & OpenSees & SAP & \\
\hline 1 & 2.015 & 2.016 & 0.0340 \\
\hline 2 & 0.479 & 0.479 & 0.1200 \\
\hline 3 & 0.418 & 0.420 & 0.5600 \\
\hline 4 & 0.412 & 0.356 & 0.0590 \\
\hline 5 & 0.354 & 0.267 & 0.0257 \\
\hline
\end{tabular}


Table A-22 Modal periods of 21 storey tower with soil Vs $=200 \mathrm{~m} / \mathrm{s}$

\begin{tabular}{|c|c|c|c|}
\hline \multirow{2}{*}{ Mode } & \multicolumn{2}{|c|}{ Modal period (s) } & \multirow{2}{*}{$\begin{array}{c}\text { Modal participation } \\
\text { factor, Ux }\end{array}$} \\
\cline { 2 - 3 } & OpenSees & SAP & 0.0326 \\
\hline 1 & 2.006 & 2.007 & 0.0315 \\
\hline 2 & 0.467 & 0.467 & 0.6900 \\
\hline 3 & 0.322 & 0.322 & 0.0058 \\
\hline 4 & 0.309 & 0.282 & 0.0131 \\
\hline 5 & 0.281 & 0.233 & \\
\hline
\end{tabular}

Table A-23 Modal periods of 21 storey tower with soil Vs $=300 \mathrm{~m} / \mathrm{s}$

\begin{tabular}{|c|c|c|c|}
\hline \multirow{2}{*}{ Mode } & \multicolumn{2}{|c|}{ Modal period (s) } & \multirow{2}{*}{$\begin{array}{c}\text { Modal participation } \\
\text { factor, Ux }\end{array}$} \\
\cline { 2 - 3 } & OpenSees & SAP & 0.0312 \\
\hline 1 & 1.994 & 1.995 & 0.0142 \\
\hline 2 & 0.459 & 0.459 & 0.1200 \\
\hline 3 & 0.240 & 0.239 & 0.5900 \\
\hline 4 & 0.216 & 0.219 & 0.0016 \\
\hline 5 & 0.206 & 0.192 & \\
\hline
\end{tabular}

Table A-24 Modal periods of 21 storey tower with soil Vs $=450 \mathrm{~m} / \mathrm{s}$

\begin{tabular}{|c|c|c|c|}
\hline \multirow[t]{2}{*}{ Mode } & \multicolumn{2}{|c|}{ Modal period (s) } & \multirow{2}{*}{$\begin{array}{l}\text { Modal participation } \\
\text { factor, } \mathrm{Ux}\end{array}$} \\
\hline & OpenSees & SAP & \\
\hline 1 & 1.984 & 1.985 & 0.0303 \\
\hline 2 & 0.455 & 0.455 & 0.0096 \\
\hline 3 & 0.233 & 0.233 & 0.0069 \\
\hline 4 & 0.163 & 0.163 & 0.0639 \\
\hline 5 & 0.148 & 0.147 & 0.6100 \\
\hline
\end{tabular}


Table A-25 Modal periods of 21 storey tower with soil Vs $=600 \mathrm{~m} / \mathrm{s}$

\begin{tabular}{|c|c|c|c|}
\hline \multirow[t]{2}{*}{ Mode } & \multicolumn{2}{|c|}{ Modal period (s) } & \multirow{2}{*}{$\begin{array}{l}\text { Modal participation } \\
\text { factor, Ux }\end{array}$} \\
\hline & OpenSees & SAP & \\
\hline 1 & 1.980 & 1.980 & 0.0299 \\
\hline 2 & 0.453 & 0.453 & 0.0083 \\
\hline 3 & 0.232 & 0.232 & 0.0035 \\
\hline 4 & 0.161 & 0.161 & 0.0051 \\
\hline 5 & 0.125 & 0.125 & 0.3019 \\
\hline 6 & 0.113 & 0.112 & 0.6000 \\
\hline
\end{tabular}

Table A-26 Modal periods of 21 storey tower with soil Vs $=850 \mathrm{~m} / \mathrm{s}$

\begin{tabular}{|c|c|c|c|}
\hline \multirow{2}{*}{ Mode } & \multicolumn{2}{|c|}{ Modal period (s) } & $\begin{array}{c}\text { Modal participation } \\
\text { factor, Ux }\end{array}$ \\
\cline { 2 - 3 } & OpenSees & SAP & 0.0297 \\
\hline 1 & 1.975 & 1.976 & 0.0075 \\
\hline 2 & 0.451 & 0.452 & 0.0023 \\
\hline 3 & 0.231 & 0.231 & 0.0018 \\
\hline 4 & 0.160 & 0.160 & 0.0019 \\
\hline 5 & 0.124 & 0.124 & 0.0037 \\
\hline 6 & 0.102 & 0.102 & 0.0167 \\
\hline 7 & 0.088 & 0.088 & 0.5400 \\
\hline 8 & 0.080 & 0.080 & \\
\hline
\end{tabular}


Table A-27 Modal periods of 21 storey tower with soil Vs $=1000 \mathrm{~m} / \mathrm{s}$

\begin{tabular}{|c|c|c|c|}
\hline \multirow[t]{2}{*}{ Mode } & \multicolumn{2}{|c|}{ Modal period (s) } & \multirow{2}{*}{$\begin{array}{l}\text { Modal participation } \\
\text { factor, } \mathrm{Ux}\end{array}$} \\
\hline & OpenSees & SAP & \\
\hline 1 & 1.974 & 1.974 & 0.0296 \\
\hline 2 & 0.451 & 0.451 & 0.0073 \\
\hline 3 & 0.231 & 0.231 & 0.0020 \\
\hline 4 & 0.160 & 0.160 & 0.0014 \\
\hline 5 & 0.124 & 0.124 & 0.0012 \\
\hline 6 & 0.102 & 0.102 & 0.0014 \\
\hline 7 & 0.087 & 0.087 & 0.0022 \\
\hline 8 & 0.077 & 0.077 & 0.0062 \\
\hline 9 & 0.070 & 0.070 & 0.0769 \\
\hline 10 & 0.068 & 0.068 & 0.5500 \\
\hline
\end{tabular}


$\underline{\text { Modal analysis results for } 25 \text {-storey building model }}$

Table A-28 Modal periods of 25 storey tower without soil

\begin{tabular}{|c|c|c|c|}
\hline \multirow{2}{*}{ Mode } & \multicolumn{2}{|c|}{ Modal period (s) } & Modal participation \\
& OpenSees & SAP & factor, Ux \\
\cline { 2 - 3 } & 2.852 & 2.852 & 0.4359 \\
\hline 1 & 0.643 & 0.643 & 0.1777 \\
\hline 2 & 0.335 & 0.335 & 0.1798 \\
\hline 3 & 0.255 & 0.255 & 0.1267 \\
\hline 4 & 0.194 & 0.194 & 0.0205 \\
\hline 5 & &
\end{tabular}

Table A-29 Modal periods of 25 storey tower with soil Vs $=100 \mathrm{~m} / \mathrm{s}$

\begin{tabular}{|c|c|c|c|}
\hline \multirow{2}{*}{ Mode } & \multicolumn{2}{|c|}{ Modal period (s) } & $\begin{array}{c}\text { Modal participation } \\
\text { factor, Ux }\end{array}$ \\
\cline { 2 - 3 } & OpenSees & SAP & 0.0401 \\
\hline 1 & 2.829 & 2.830 & 0.3900 \\
\hline 2 & 0.645 & 0.645 & 0.2400 \\
\hline 3 & 0.618 & 0.618 & 0.1100 \\
\hline 4 & 0.615 & 0.503 & 0.0150 \\
\hline 5 & 0.497 & 0.390 & \\
\hline
\end{tabular}

Table A-30 Modal periods of 25 storey tower with soil Vs $=150 \mathrm{~m} / \mathrm{s}$

\begin{tabular}{|c|c|c|c|}
\hline \multirow[t]{2}{*}{ Mode } & \multicolumn{2}{|c|}{ Modal period (s) } & \multirow{2}{*}{$\begin{array}{l}\text { Modal participation } \\
\text { factor, } \mathrm{Ux}\end{array}$} \\
\hline & OpenSees & SAP & \\
\hline 1 & 2.816 & 2.818 & 0.0386 \\
\hline 2 & 0.622 & 0.622 & 0.0321 \\
\hline 3 & 0.422 & 0.424 & 0.6600 \\
\hline 4 & 0.412 & 0.364 & 0.0402 \\
\hline 5 & 0.362 & 0.300 & 0.0137 \\
\hline
\end{tabular}


Table A-31 Modal periods of 25 storey tower with soil Vs $=200 \mathrm{~m} / \mathrm{s}$

\begin{tabular}{|c|c|c|c|}
\hline \multirow{2}{*}{ Mode } & \multicolumn{2}{|c|}{ Modal period (s) } & Modal participation \\
& OpenSees & SAP & factor, Ux \\
\hline & 2.807 & 2.808 & 0.0377 \\
\hline 1 & 0.615 & 0.615 & 0.0199 \\
\hline 3 & 0.328 & 0.327 & 0.6000 \\
\hline 4 & 0.309 & 0.304 & 0.0905 \\
\hline 5 & 0.303 & 0.273 & 0.0241 \\
\hline
\end{tabular}

Table A-32 Modal periods of 25 storey tower with soil Vs $=300 \mathrm{~m} / \mathrm{s}$

\begin{tabular}{|c|c|c|c|}
\hline \multirow{2}{*}{ Mode } & \multicolumn{2}{|c|}{ Modal period (s) } & \multirow{2}{*}{$\begin{array}{c}\text { Modal participation } \\
\text { factor, Ux }\end{array}$} \\
\cline { 2 - 3 } & OpenSees & SAP & 0.0367 \\
\hline 1 & 2.794 & 2.796 & 0.0135 \\
\hline 2 & 0.608 & 0.609 & 0.0155 \\
\hline 3 & 0.301 & 0.301 & 0.5900 \\
\hline 4 & 0.222 & 0.221 & 0.1000 \\
\hline 5 & 0.206 & 0.204 & \\
\hline
\end{tabular}

Table A-33 Modal periods of 25 storey tower with soil Vs $=450 \mathrm{~m} / \mathrm{s}$

\begin{tabular}{|c|c|c|c|}
\hline \multirow{2}{*}{ Mode } & \multicolumn{2}{|c|}{ Modal period (s) } & Modal participation \\
& OpenSees & SAP & \\
\cline { 2 - 3 } & 2.784 & 2.786 & 0.0361 \\
\hline 1 & 0.604 & 0.605 & 0.0108 \\
\hline 2 & 0.298 & 0.298 & 0.0048 \\
\hline 3 & 0.203 & 0.203 & 0.0082 \\
\hline 4 & 0.157 & 0.157 & 0.1200 \\
\hline 5 & 0.147 & 0.147 & 0.5400 \\
\hline 6 & & & \\
\hline
\end{tabular}


Table A-34 Modal periods of 25 storey tower with soil Vs $=600 \mathrm{~m} / \mathrm{s}$

\begin{tabular}{|c|c|c|c|}
\hline \multirow[t]{2}{*}{ Mode } & \multicolumn{2}{|c|}{ Modal period (s) } & Modal participation \\
\hline & OpenSees & SAP & factor, Ux \\
\hline 1 & 2.779 & 2.780 & 0.0358 \\
\hline 2 & 0.602 & 0.603 & 0.0099 \\
\hline 3 & 0.297 & 0.297 & 0.0033 \\
\hline 4 & 0.202 & 0.202 & 0.0029 \\
\hline 5 & 0.154 & 0.154 & 0.0045 \\
\hline 6 & 0.126 & 0.126 & 0.0205 \\
\hline 7 & 0.113 & 0.113 & 0.5500 \\
\hline
\end{tabular}

Table A-35 Modal periods of 25 storey tower with soil Vs $=850 \mathrm{~m} / \mathrm{s}$

\begin{tabular}{|c|c|c|c|}
\hline \multirow[t]{2}{*}{ Mode } & \multicolumn{2}{|c|}{ Modal period (s) } & \multirow{2}{*}{$\begin{array}{c}\text { Modal participation } \\
\text { factor, } U \mathrm{x}\end{array}$} \\
\hline & OpenSees & SAP & \\
\hline 1 & 2.774 & 2.775 & 0.0357 \\
\hline 2 & 0.601 & 0.601 & 0.0093 \\
\hline 3 & 0.296 & 0.296 & 0.0026 \\
\hline 4 & 0.201 & 0.201 & 0.0016 \\
\hline 5 & 0.152 & 0.152 & 0.0013 \\
\hline 6 & 0.126 & 0.126 & 0.0015 \\
\hline 7 & 0.107 & 0.107 & 0.0023 \\
\hline 8 & 0.093 & 0.093 & 0.0056 \\
\hline 9 & 0.084 & 0.084 & 0.0427 \\
\hline 10 & 0.080 & 0.080 & 0.5600 \\
\hline
\end{tabular}


Table A-36 Modal periods of 25 storey tower with soil Vs $=1000 \mathrm{~m} / \mathrm{s}$

\begin{tabular}{|c|c|c|c|}
\hline \multirow{2}{*}{ Mode } & \multicolumn{2}{|c|}{ Modal period (s) } & Modal participation \\
& OpenSees & SAP & \\
\cline { 2 - 3 } & 2.773 & 2.774 & 0.0356 \\
\hline 1 & 0.600 & 0.600 & 0.0092 \\
\hline 2 & 0.296 & 0.296 & 0.0024 \\
\hline 3 & 0.201 & 0.201 & 0.0014 \\
\hline 4 & 0.154 & 0.154 & 0.0010 \\
\hline 5 & 0.125 & 0.125 & 0.0010 \\
\hline 6 & 0.107 & 0.107 & 0.0010 \\
\hline 7 & 0.093 & 0.093 & 0.0014 \\
\hline 8 & 0.083 & 0.083 & 0.0024 \\
\hline 9 & 0.076 & 0.076 & 0.0063 \\
\hline 10 & 0.070 & 0.070 & 0.0542 \\
\hline 11 & 0.068 & 0.068 & 0.5500 \\
\hline 12 & & & \\
\hline
\end{tabular}




\section{Appendix B - Response plots for building on rock}

The structure response such as storey shear, storey moment, drift, displacement and acceleration from the soil structure interaction analysis for the building founded on rock

detailed in chapter 3 for 9 storey, 13 storey, 17 storey, 21 storey and 25 storey buildings

under 11 earthquake inputs compatible with Vancouver site B spectrum are detailed in Figure B.1 to Figure B.225. 
$\underline{9 \text { storey building }}$

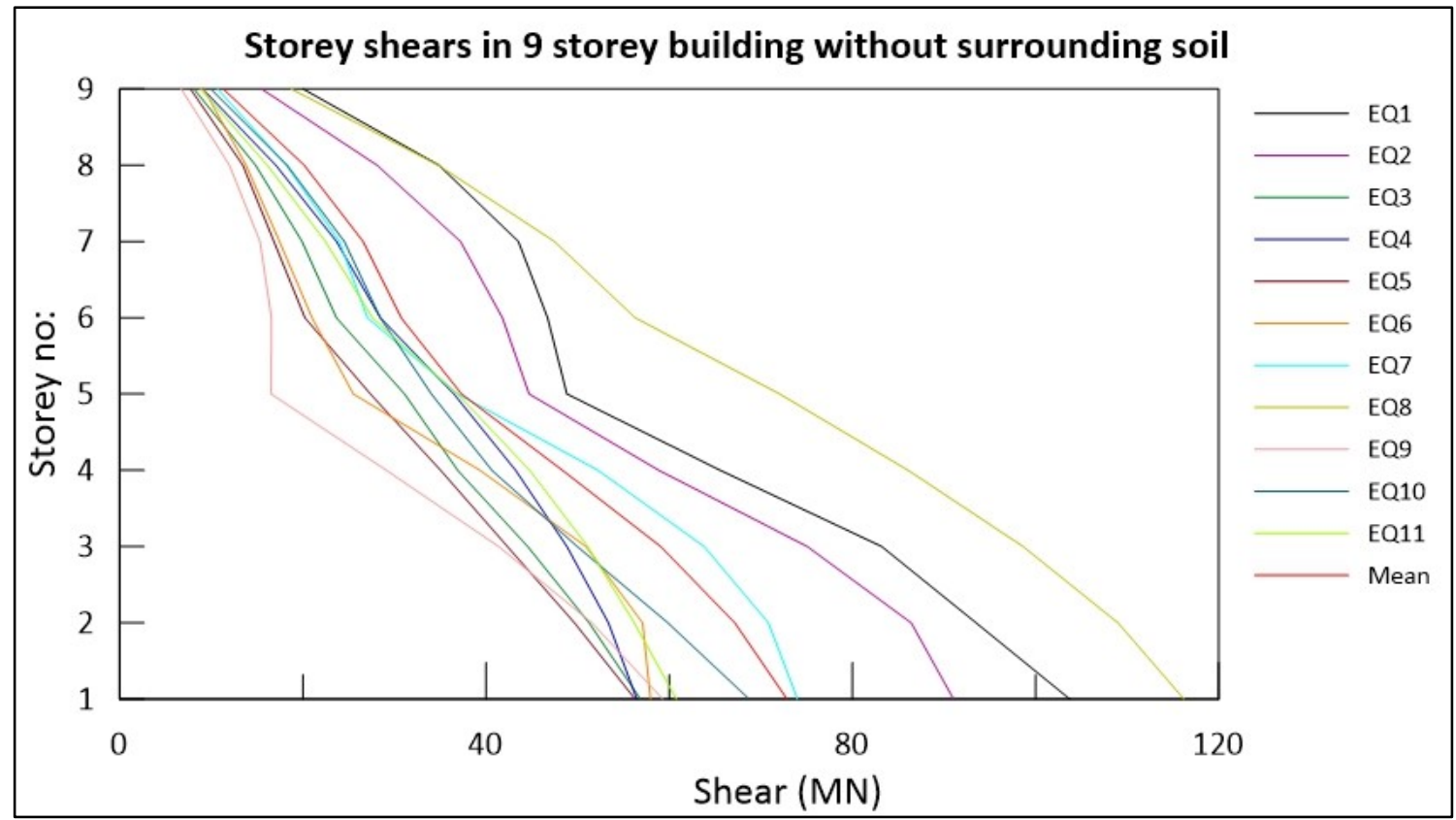

Figure B-1 Storey shears in 9storey building without any surrounding soil analyzed for 11 earthquake inputs compatible with Vancouver site B spectrum

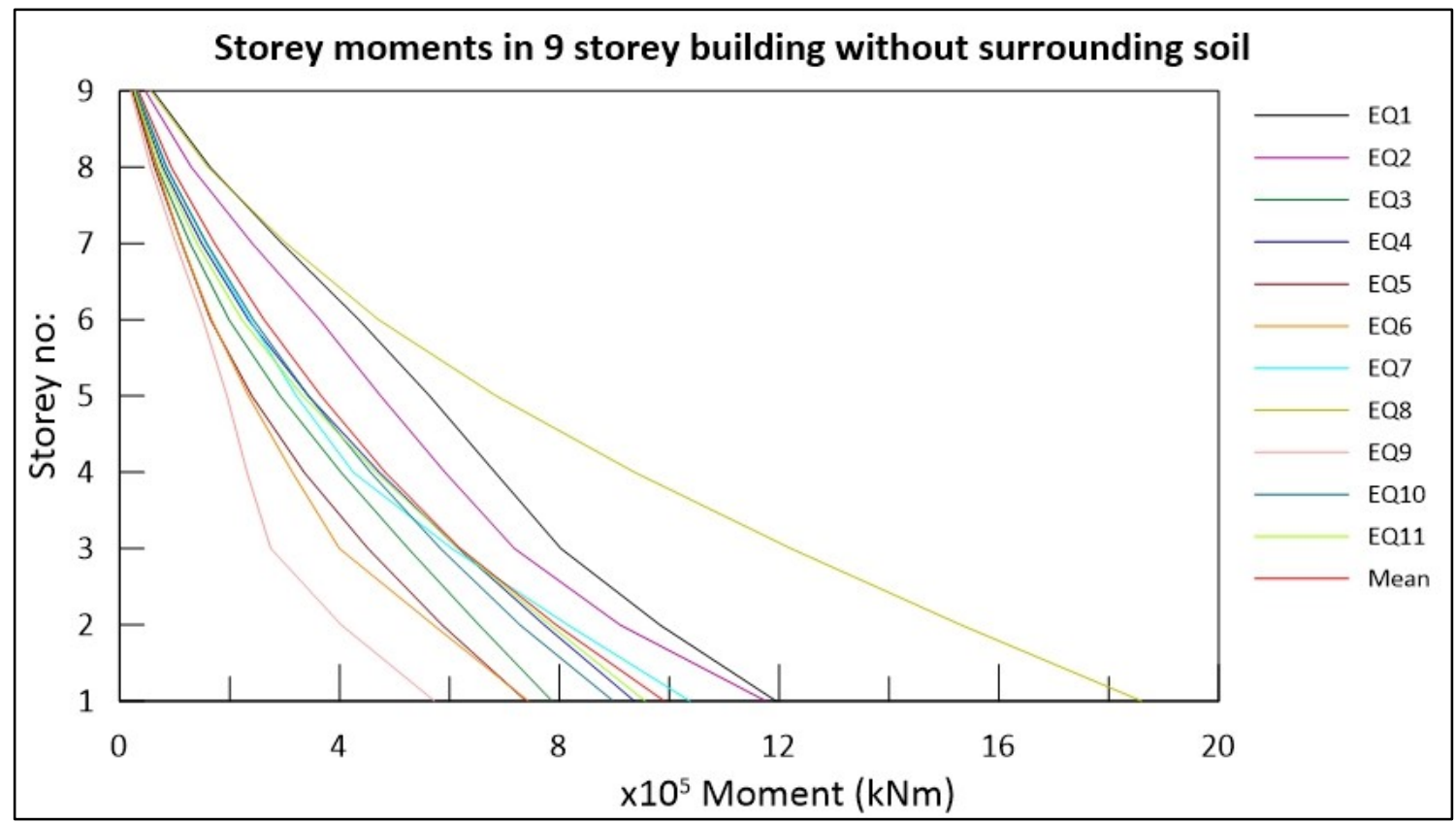

Figure B-2 Storey moments in 9storey building without any surrounding soil analyzed for 11 earthquake inputs compatible with Vancouver site B spectrum 


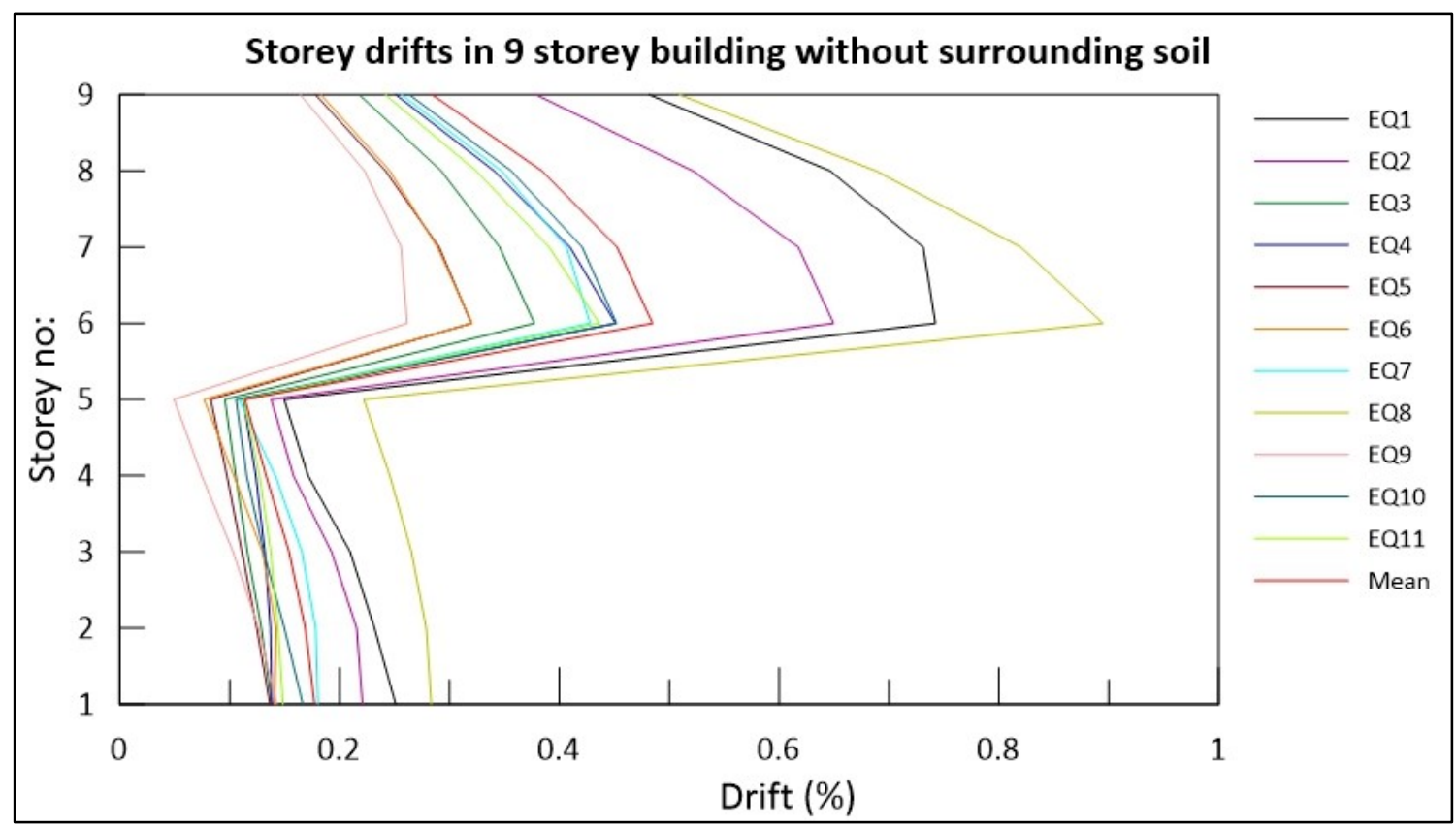

Figure B-3 Storey drifts in 9storey building without any surrounding soil analyzed for 11 earthquake inputs compatible with Vancouver site B spectrum

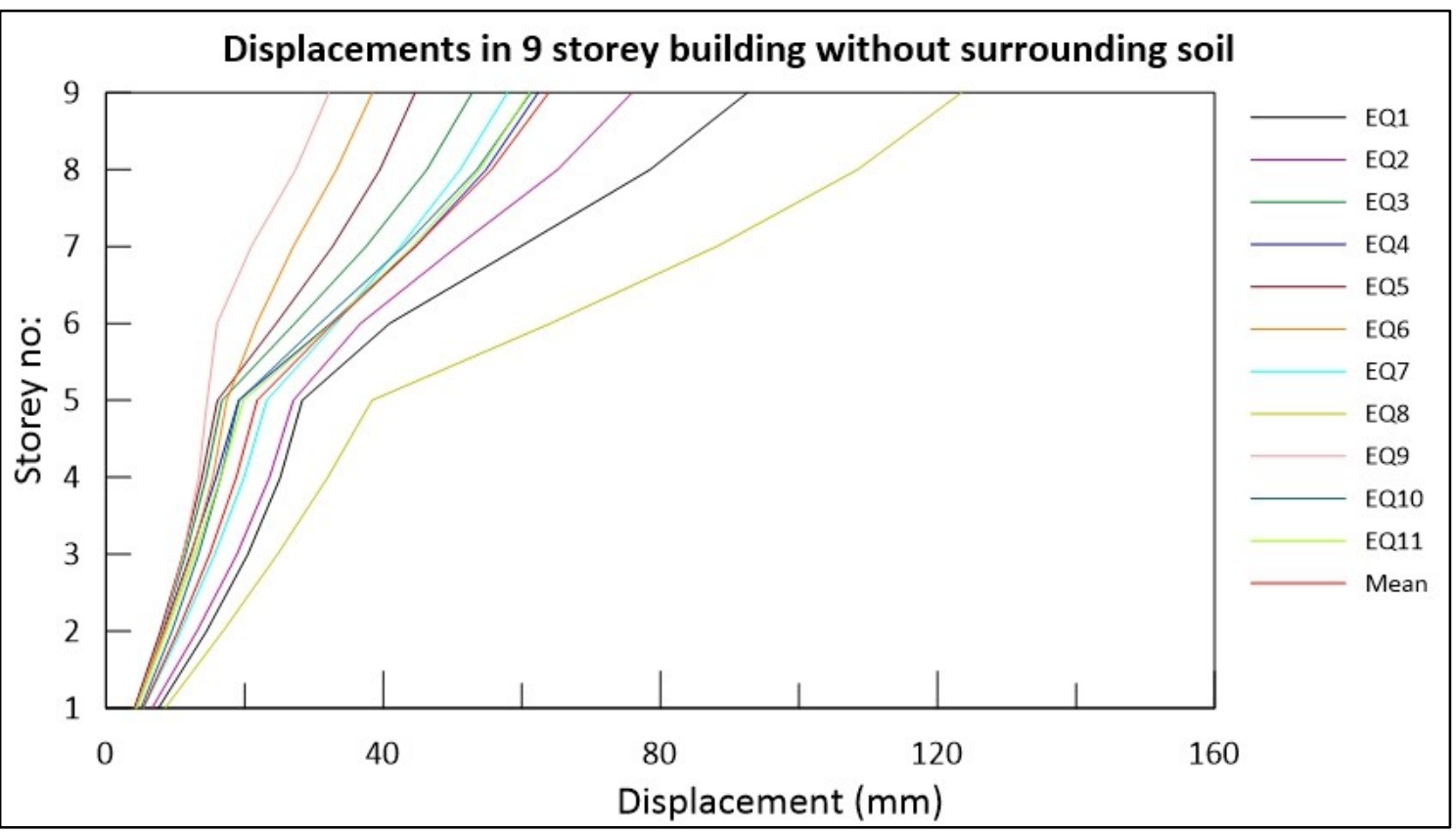

Figure B-4 Displacements in 9storey building without any surrounding soil analyzed for 11 earthquake inputs compatible with Vancouver site B spectrum 


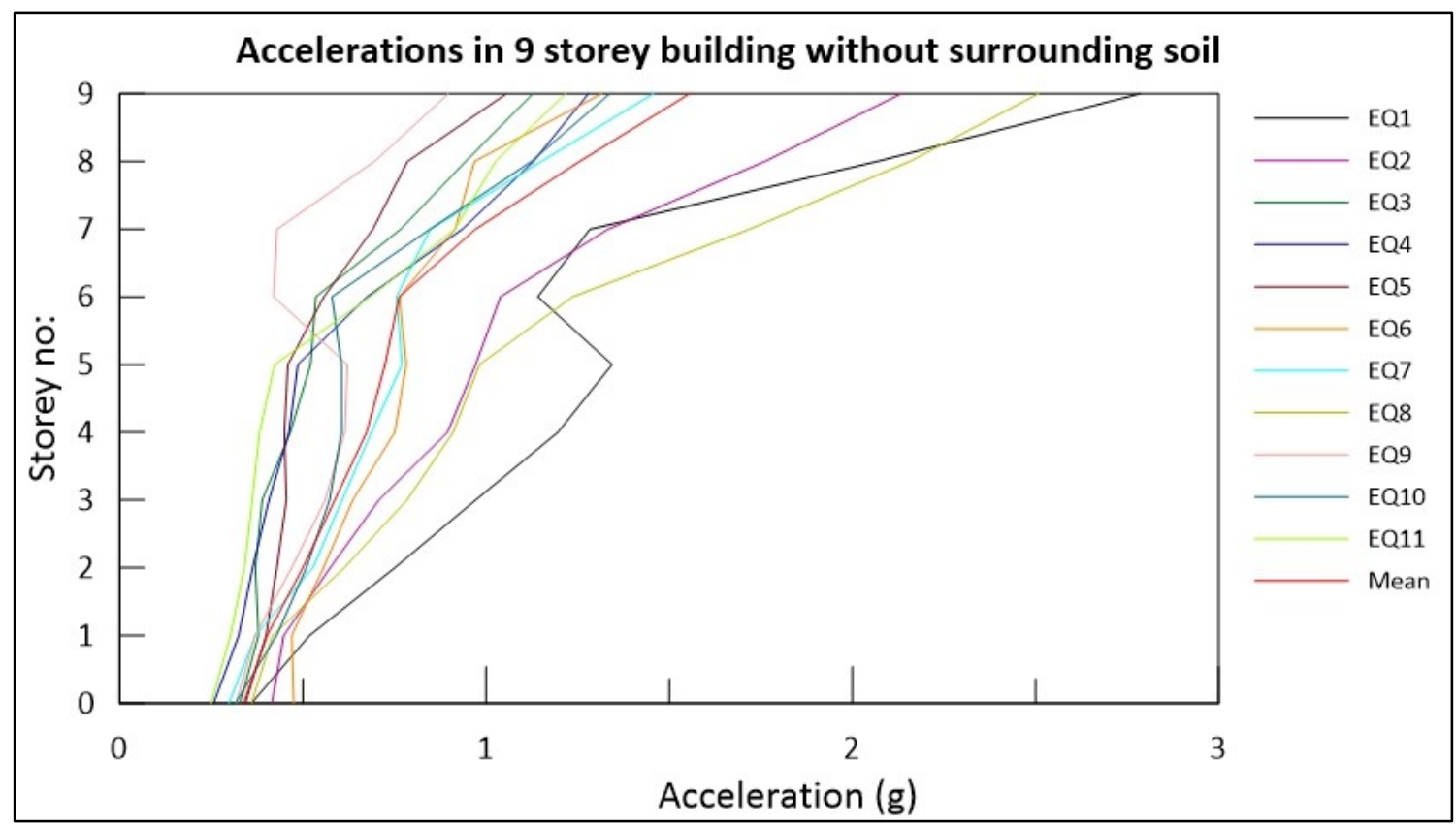

Figure B-5 Accelerations in 9storey building without any surrounding soil analyzed for 11 earthquake inputs

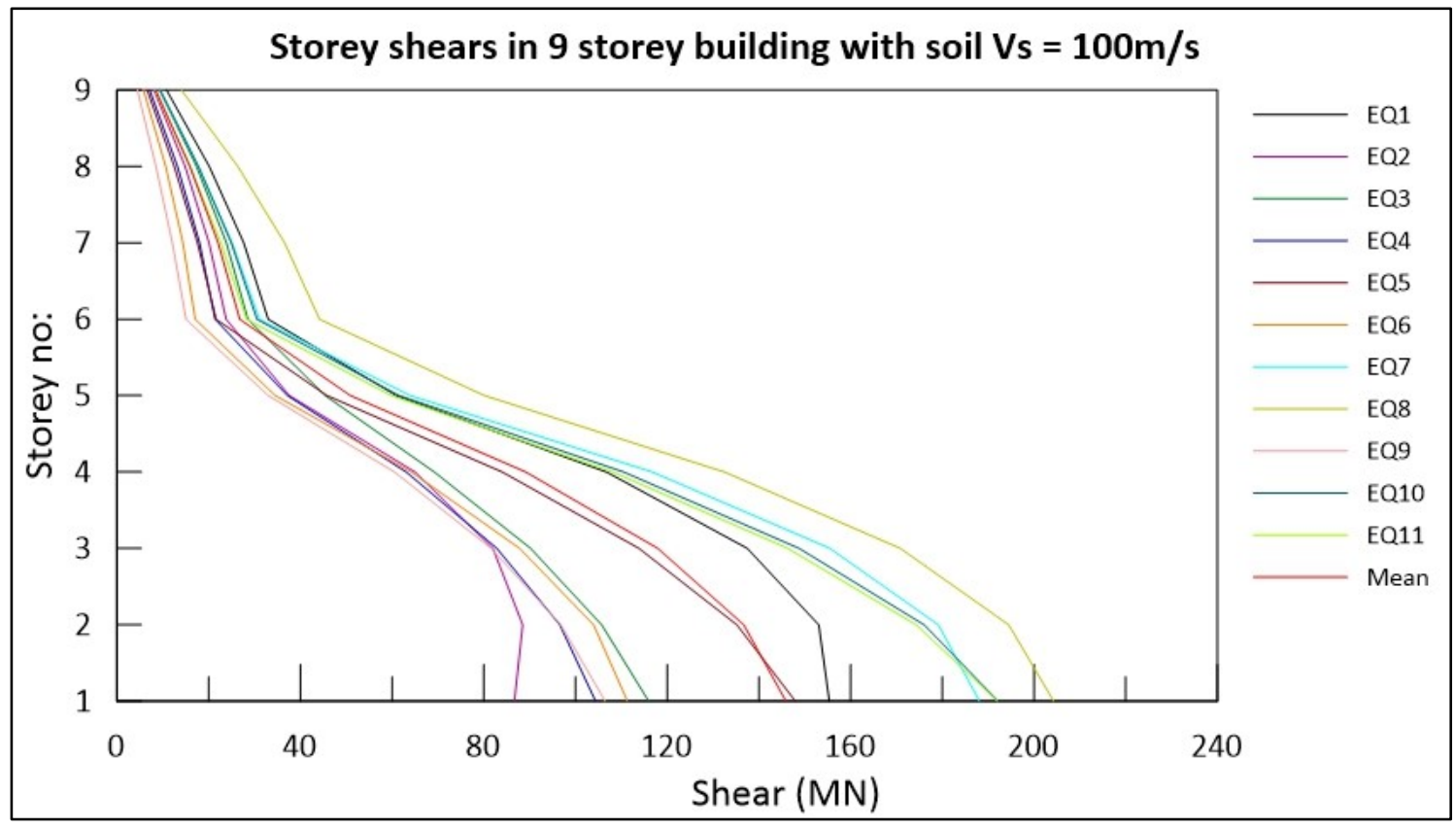

Figure B-6 Storey shears in 9storey building with soil shear wave velocity, Vs $=100 \mathrm{~m} / \mathrm{s}$ analyzed for 11 earthquake inputs compatible with Vancouver site B spectrum 


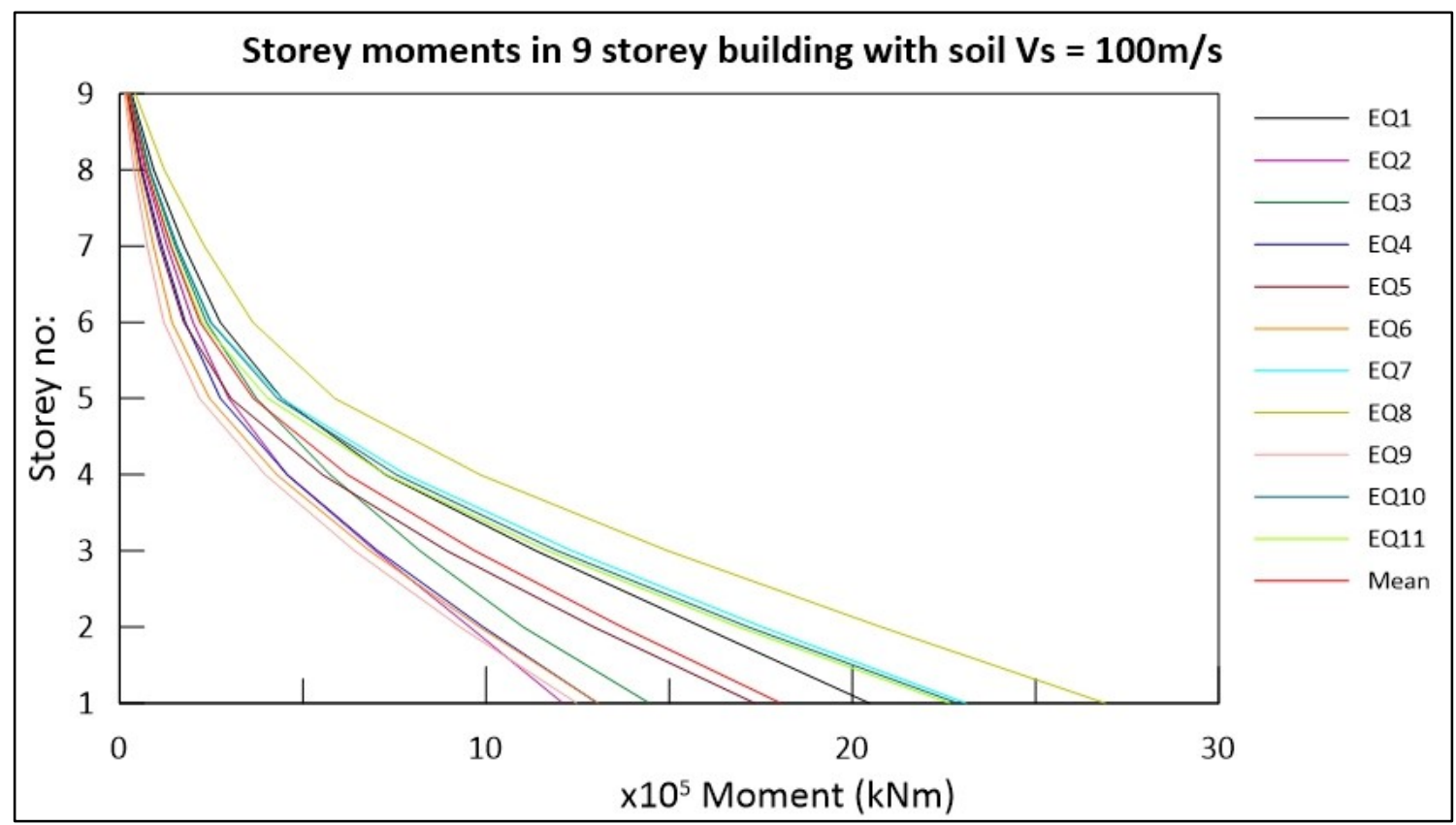

Figure B-7 Storey moments in 9storey building with soil shear wave velocity, Vs =100m/s analyzed for 11 earthquake inputs compatible with Vancouver site B spectrum

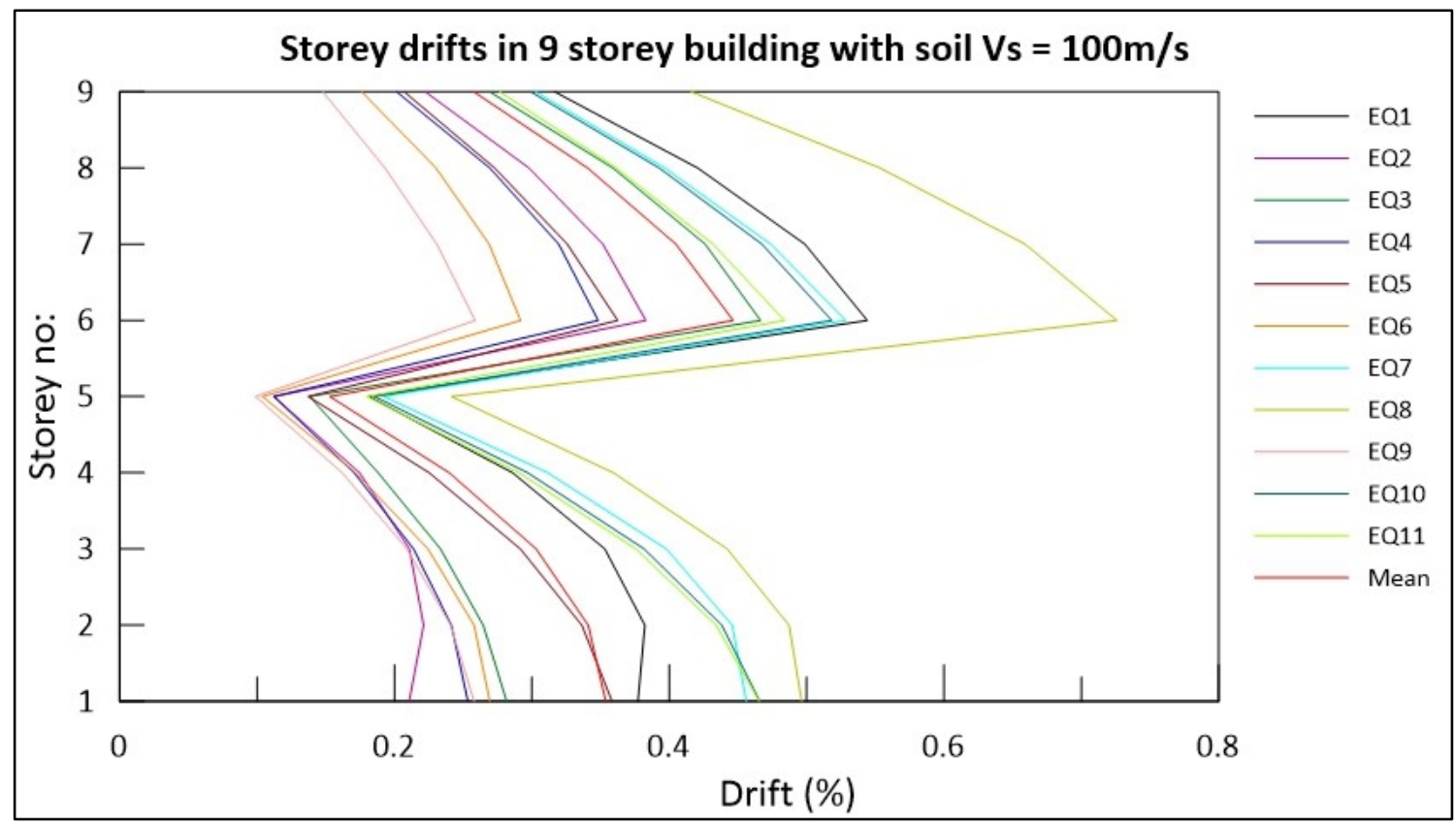

Figure B-8 Storey drifts in 9storey building with soil shear wave velocity, Vs $=100 \mathrm{~m} / \mathrm{s}$ analyzed for 11 earthquake inputs compatible with Vancouver site B spectrum 


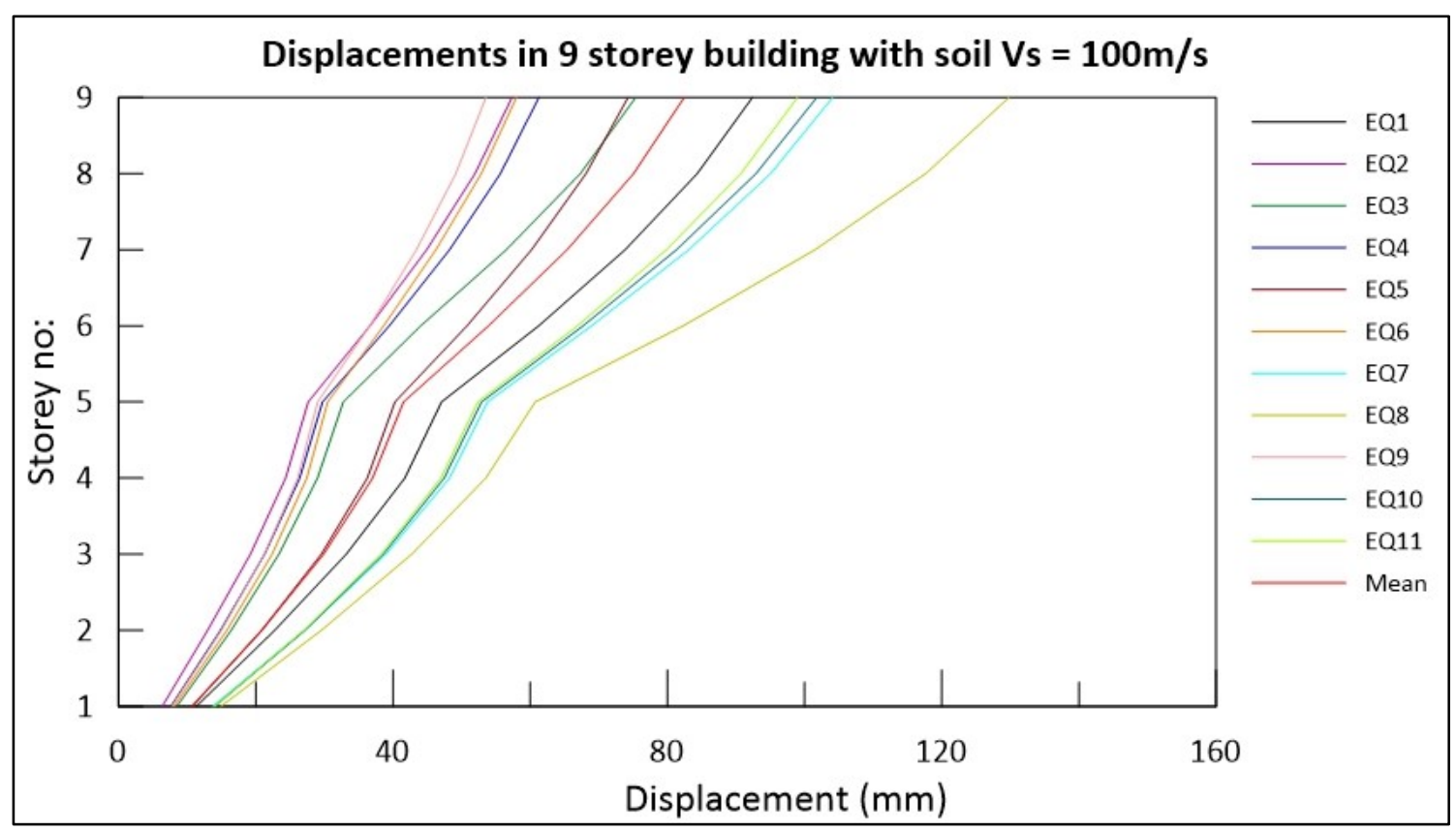

Figure B-9 Displacements in 9storey building with soil shear wave velocity, Vs =100m/s analyzed for 11 earthquake inputs compatible with Vancouver site B spectrum

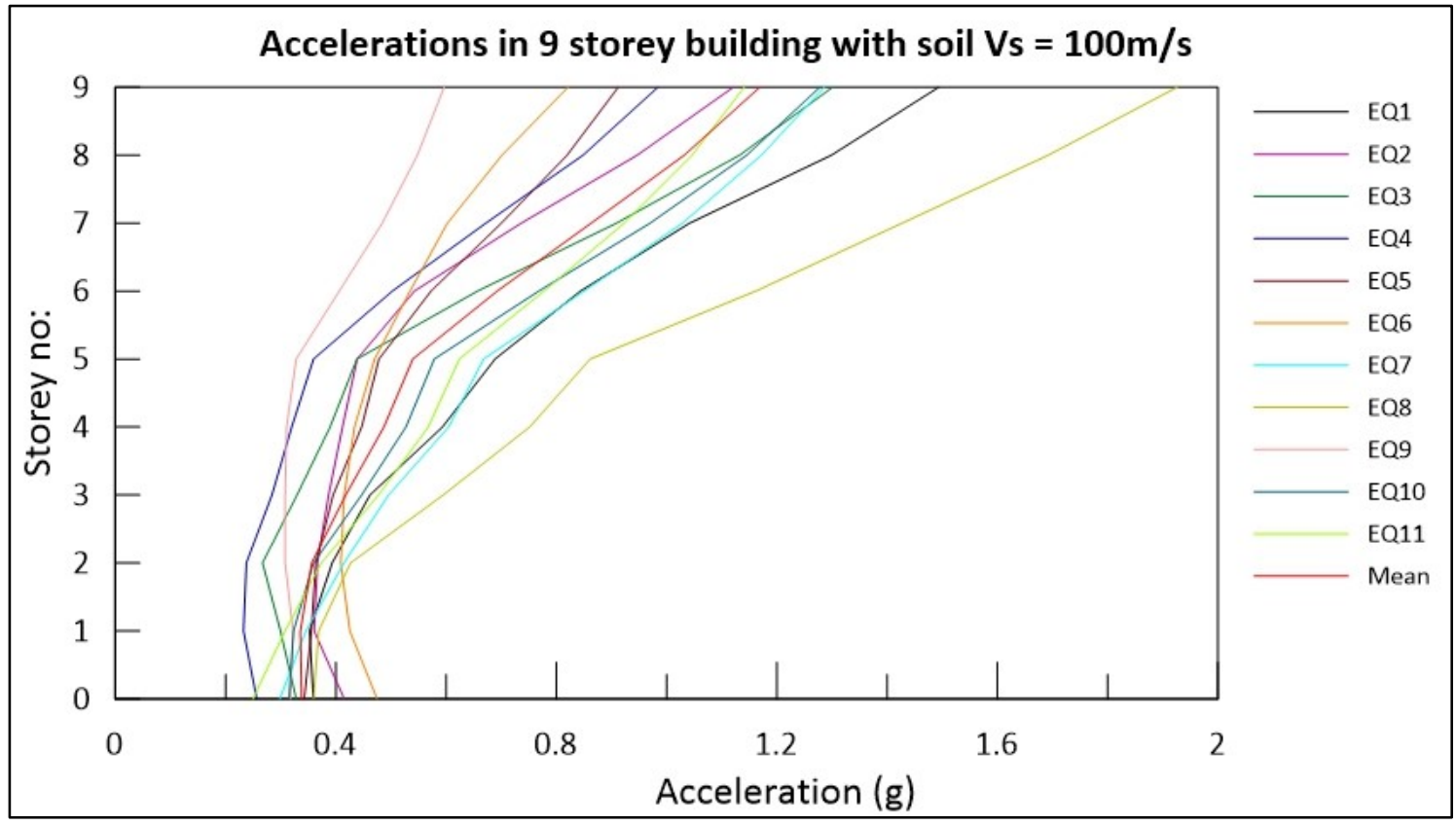

Figure B-10 Accelerations in 9storey building with soil shear wave velocity, Vs $=100 \mathrm{~m} / \mathrm{s}$ analyzed for 11 earthquake inputs compatible with Vancouver site B spectrum 


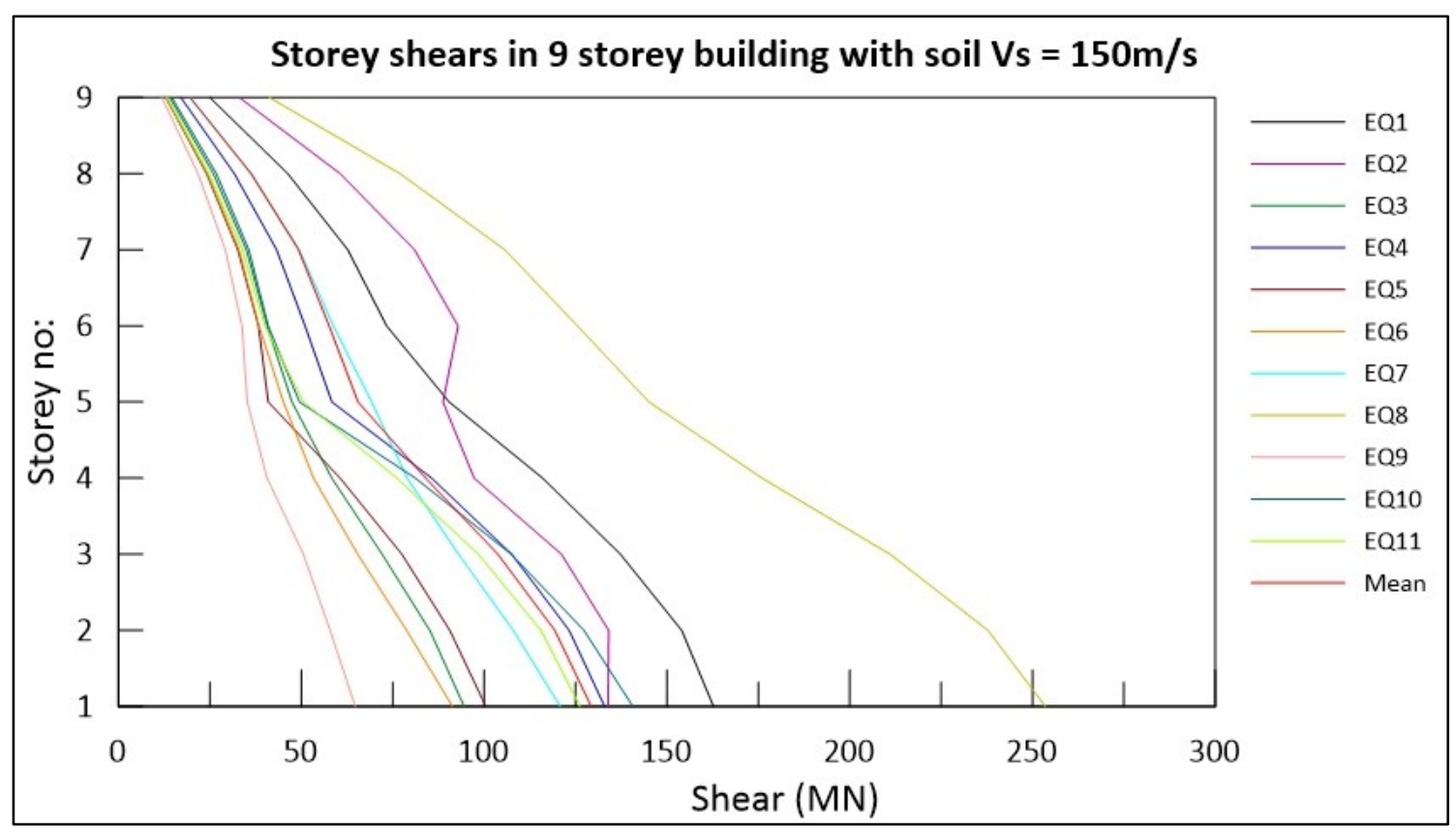

Figure B-11 Storey shears in 9storey building with soil shear wave velocity, Vs $=150 \mathrm{~m} / \mathrm{s}$ analyzed for 11 earthquake inputs compatible with Vancouver site B spectrum

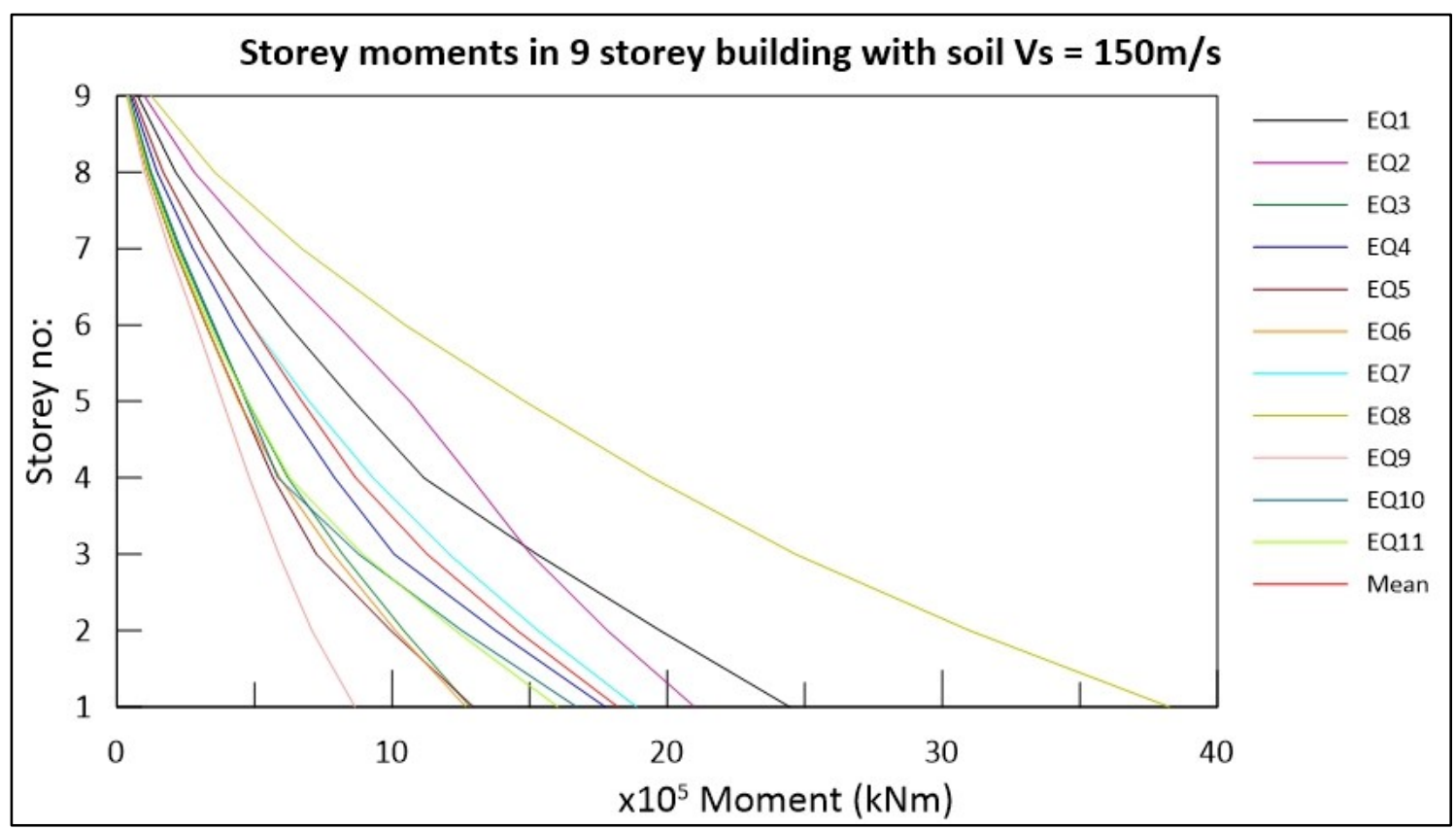

Figure B-12 Storey moments in 9storey building with soil shear wave velocity, Vs $=150 \mathrm{~m} / \mathrm{s}$ analyzed for 11 earthquake inputs compatible with Vancouver site B spectrum 


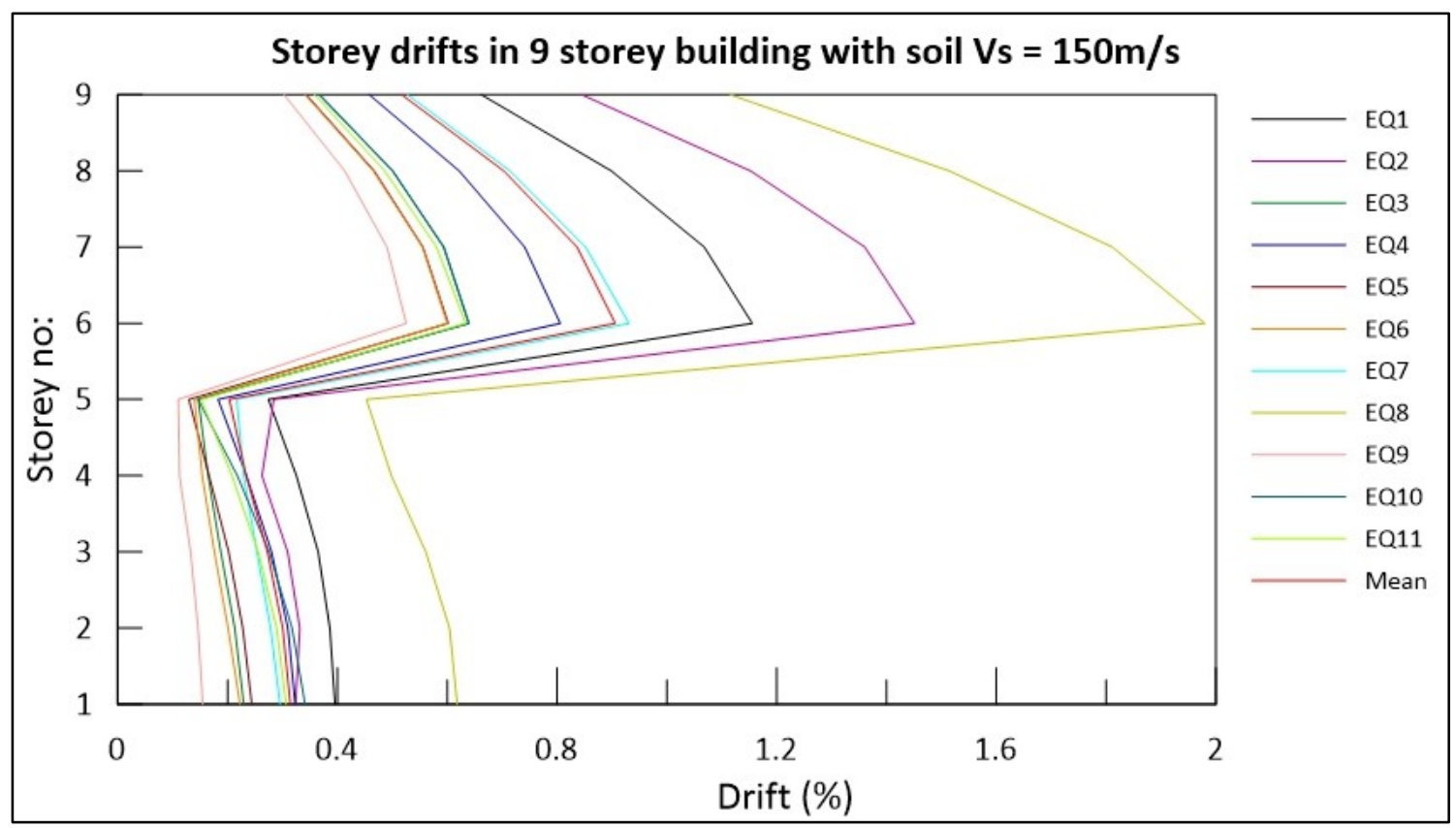

Figure B-13 Storey drifts in 9storey building with soil shear wave velocity, Vs $=150 \mathrm{~m} / \mathrm{s}$ analyzed for 11 earthquake inputs compatible with Vancouver site B spectrum

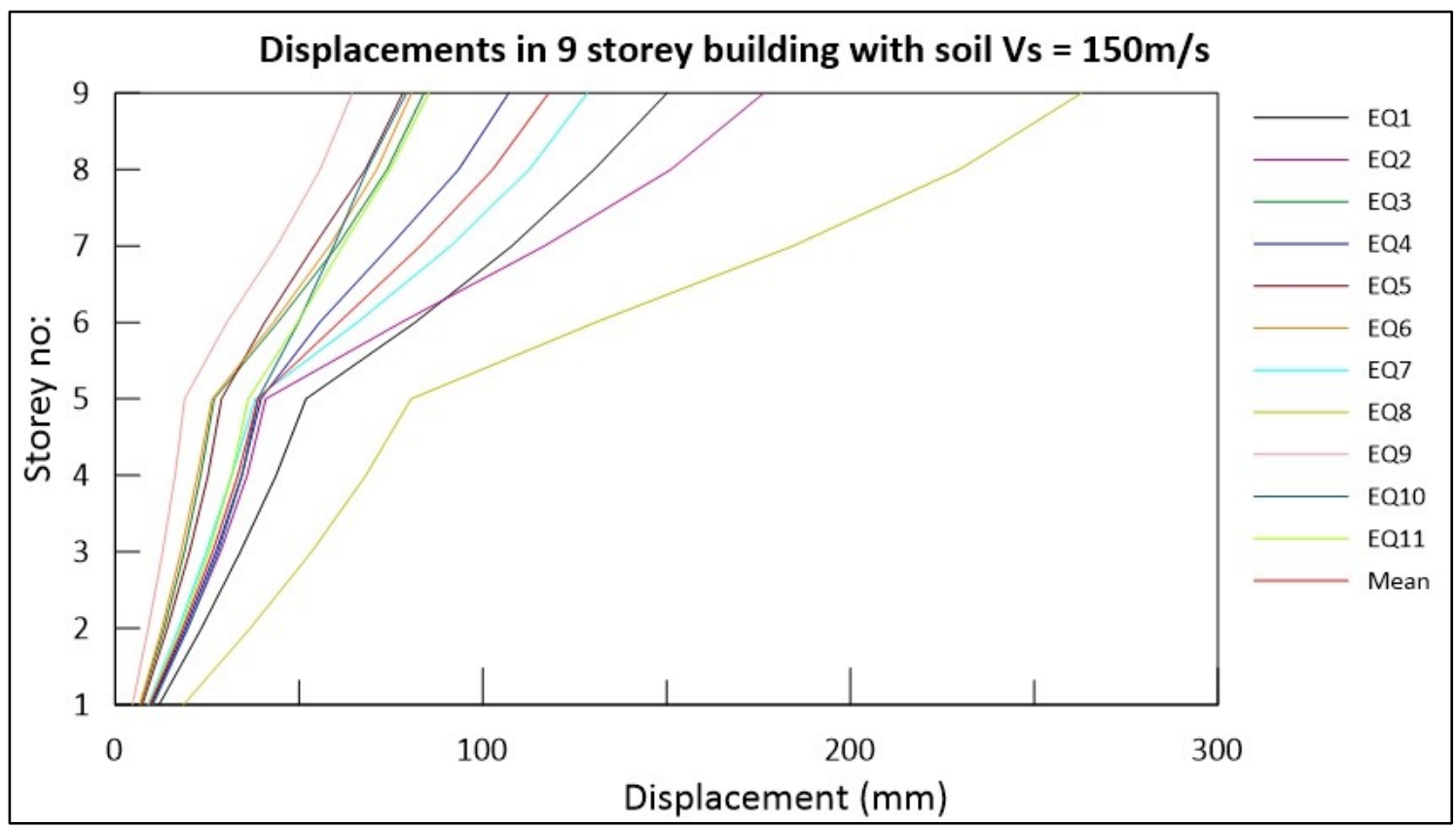

Figure B-14 Displacements in 9storey building with soil shear wave velocity, $\mathrm{Vs}=150 \mathrm{~m} / \mathrm{s}$ analyzed for 11 earthquake inputs compatible with Vancouver site B spectrum 


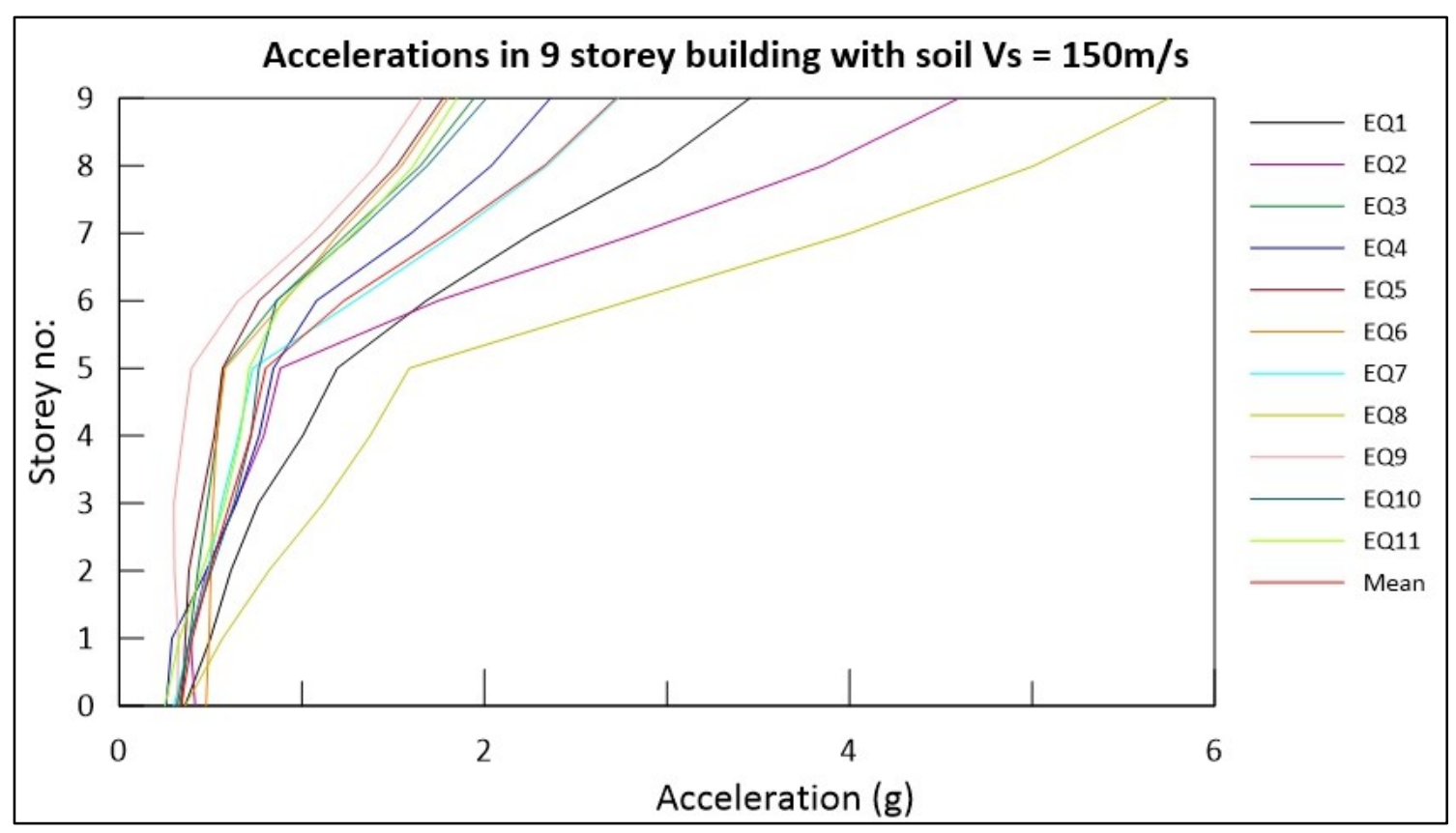

Figure B-15 Accelerations in 9storey building with soil shear wave velocity, $\mathrm{Vs}=150 \mathrm{~m} / \mathrm{s}$ analyzed for 11 earthquake inputs compatible with Vancouver site B spectrum

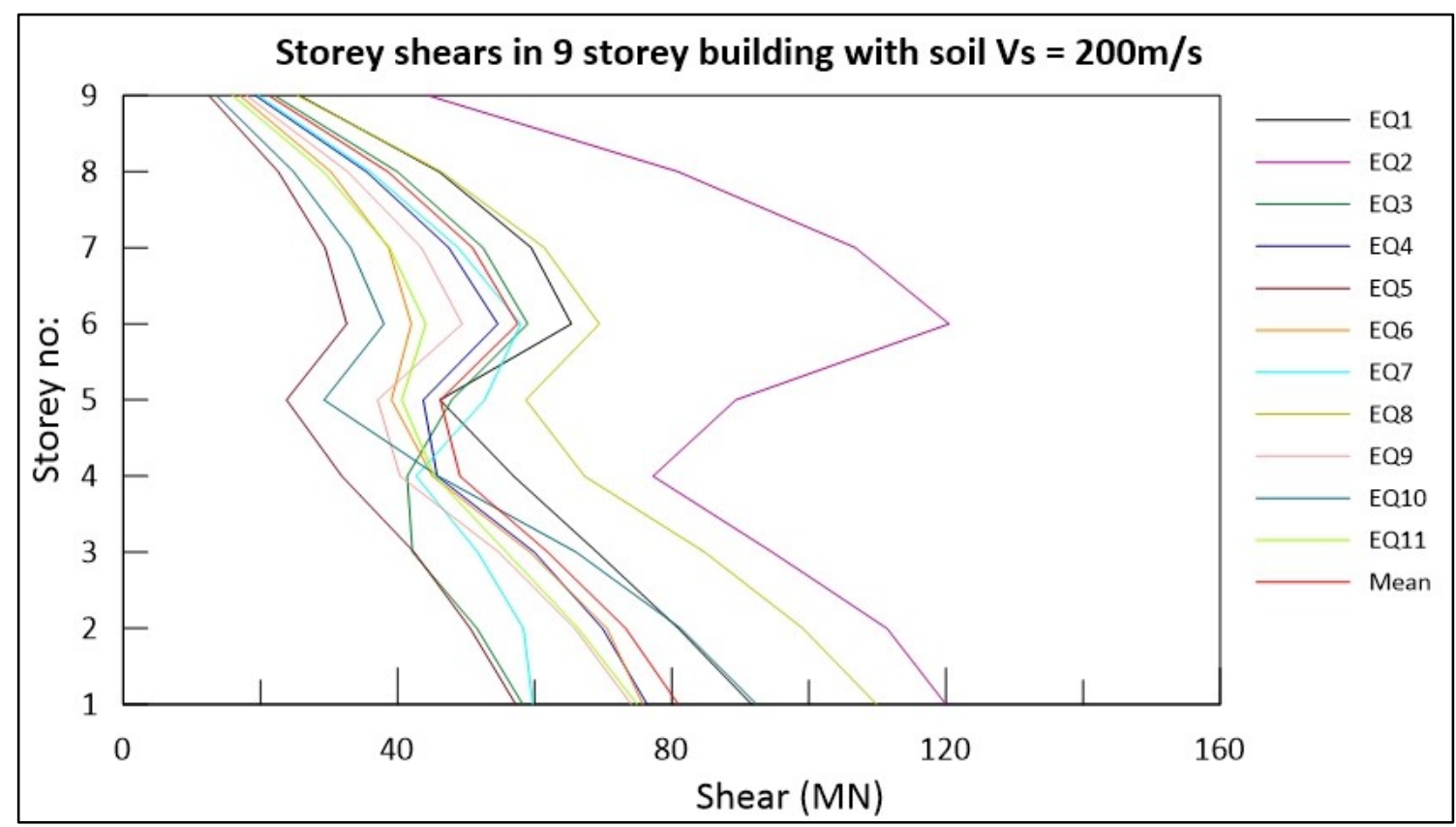

Figure B-16 Storey shears in 9storey building with soil shear wave velocity, Vs $=200 \mathrm{~m} / \mathrm{s}$ analyzed for 11 earthquake inputs compatible with Vancouver site B spectrum 


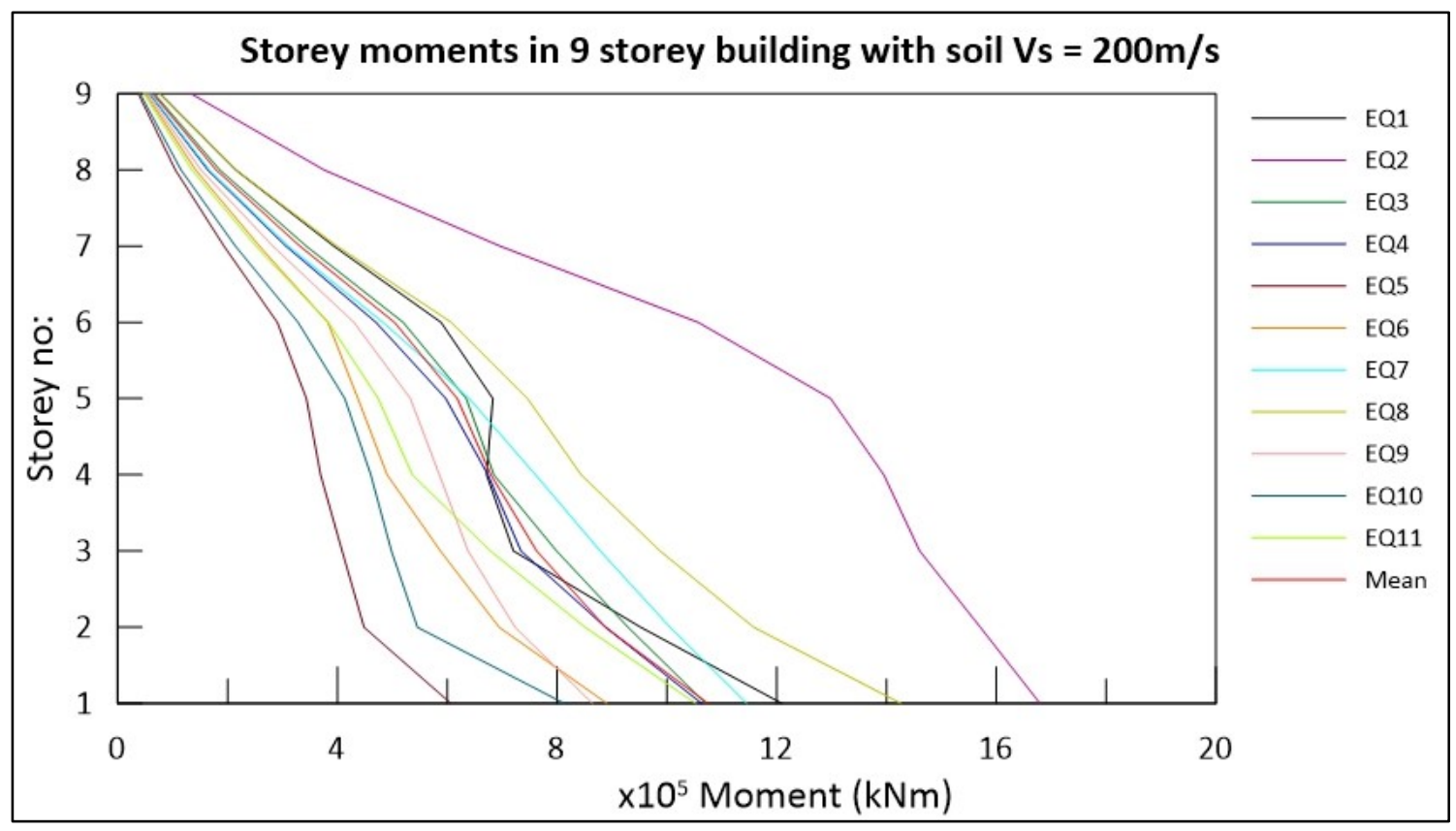

Figure B-17 Storey moments in 9storey building with soil shear wave velocity, Vs $=200 \mathrm{~m} / \mathrm{s}$ analyzed for 11 earthquake inputs compatible with Vancouver site B spectrum

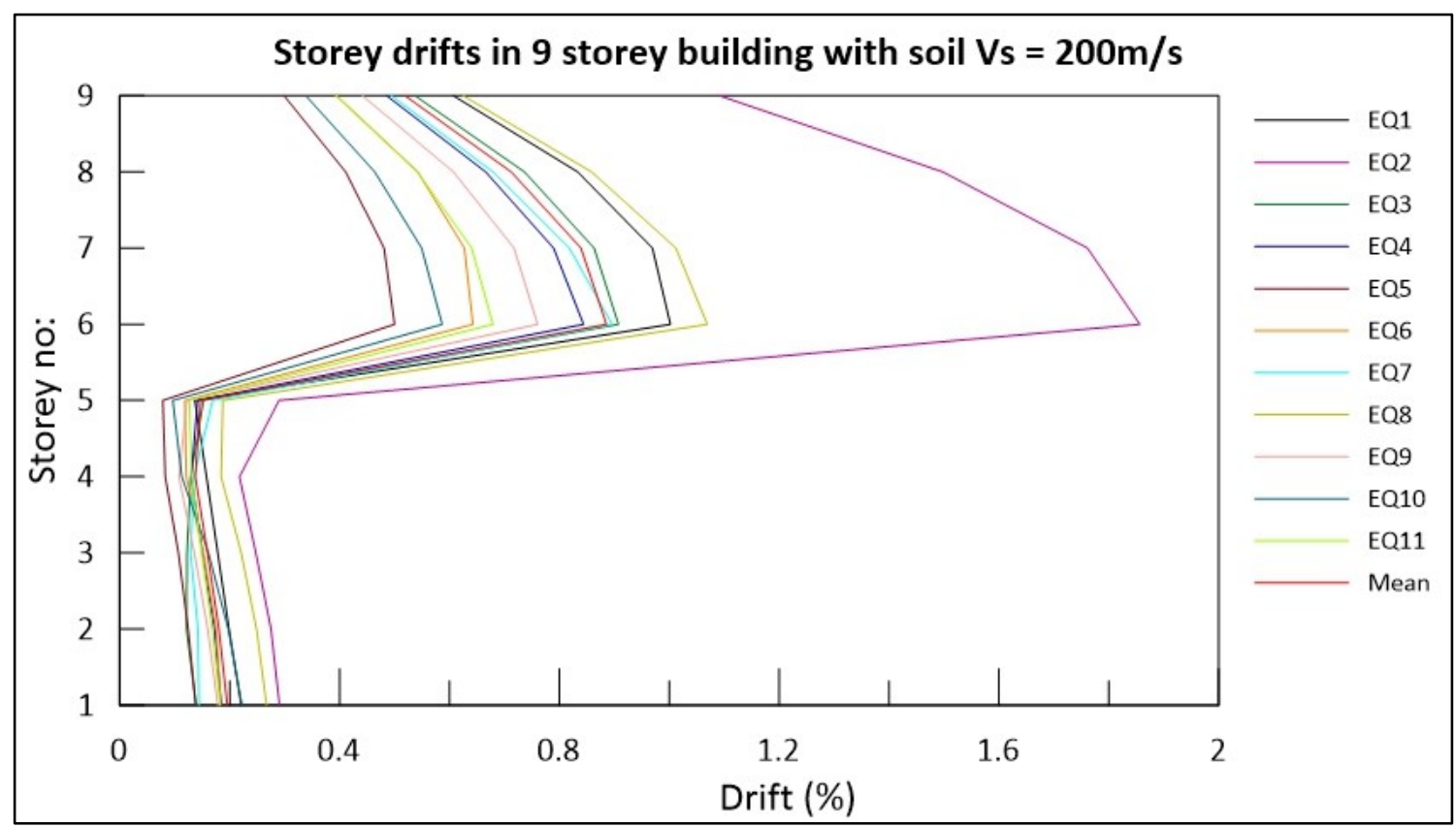

Figure B-18 Storey drifts in 9storey building with soil shear wave velocity, Vs =200m/s analyzed for 11 earthquake inputs compatible with Vancouver site B spectrum 


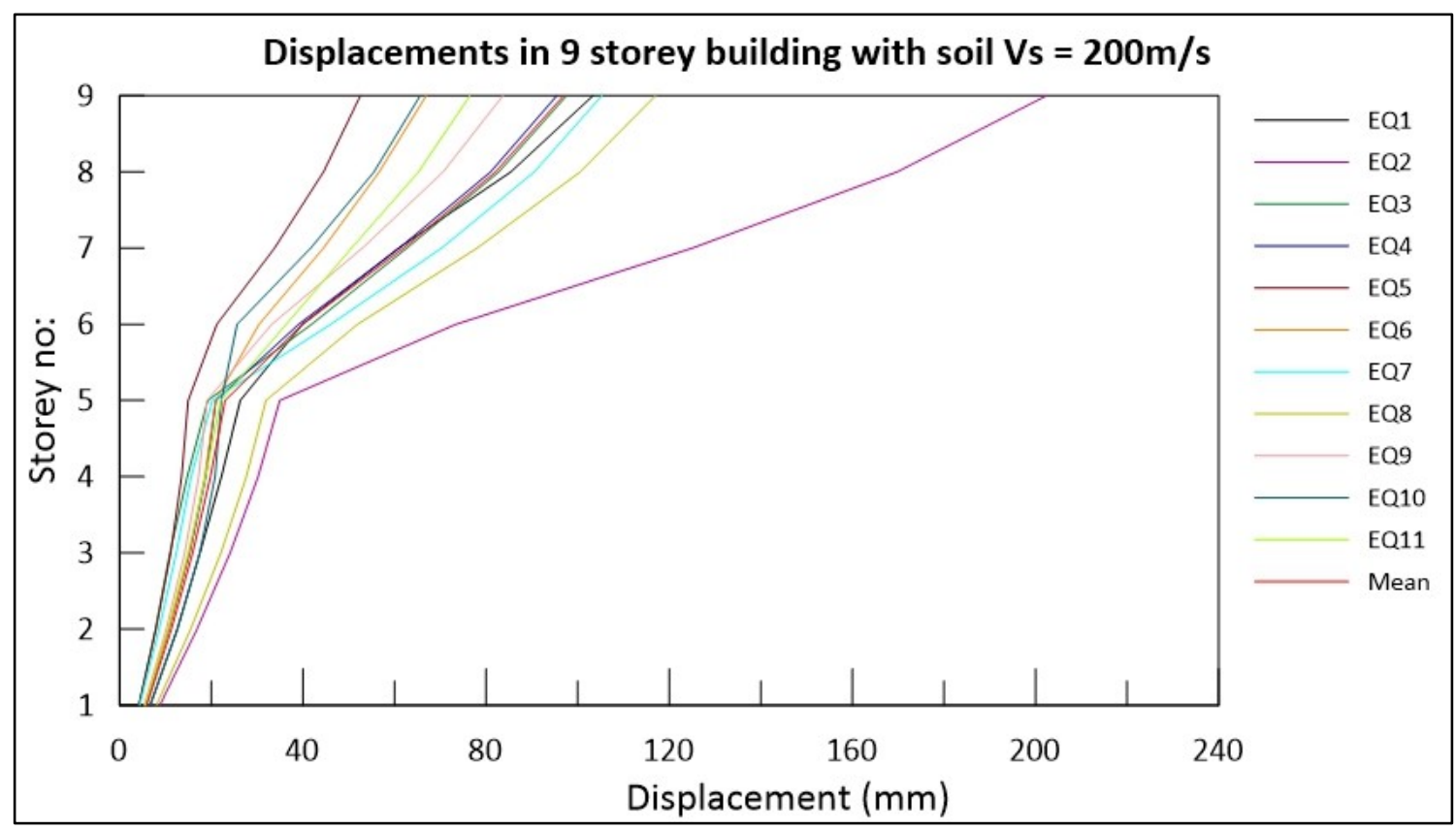

Figure B-19 Displacements in 9storey building with soil shear wave velocity, Vs = 200m/s analyzed for 11 earthquake inputs compatible with Vancouver site B spectrum

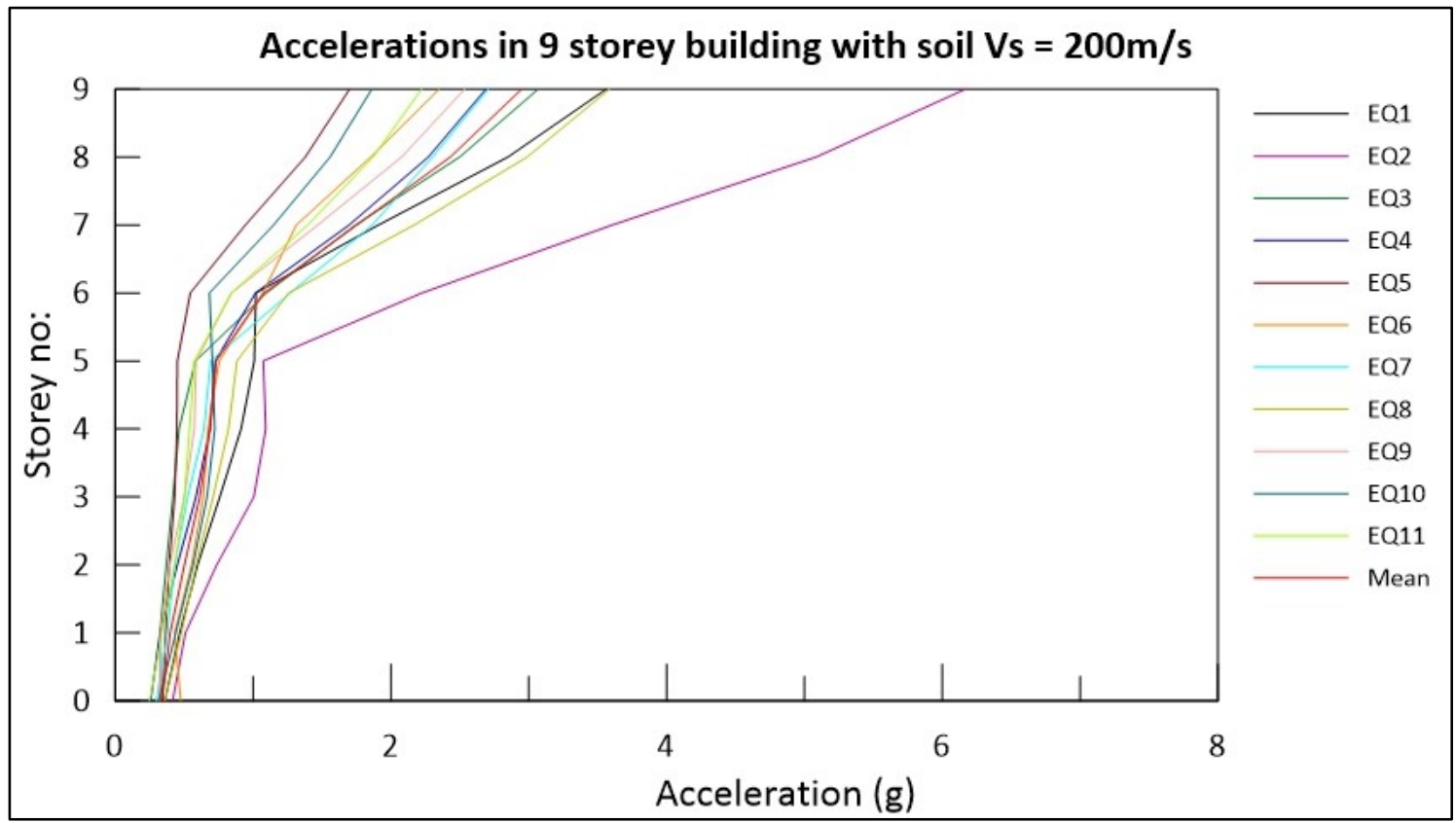

Figure B-20 Accelerations in 9storey building with soil shear wave velocity, Vs $=200 \mathrm{~m} / \mathrm{s}$ analyzed for 11 earthquake inputs compatible with Vancouver site B spectrum 


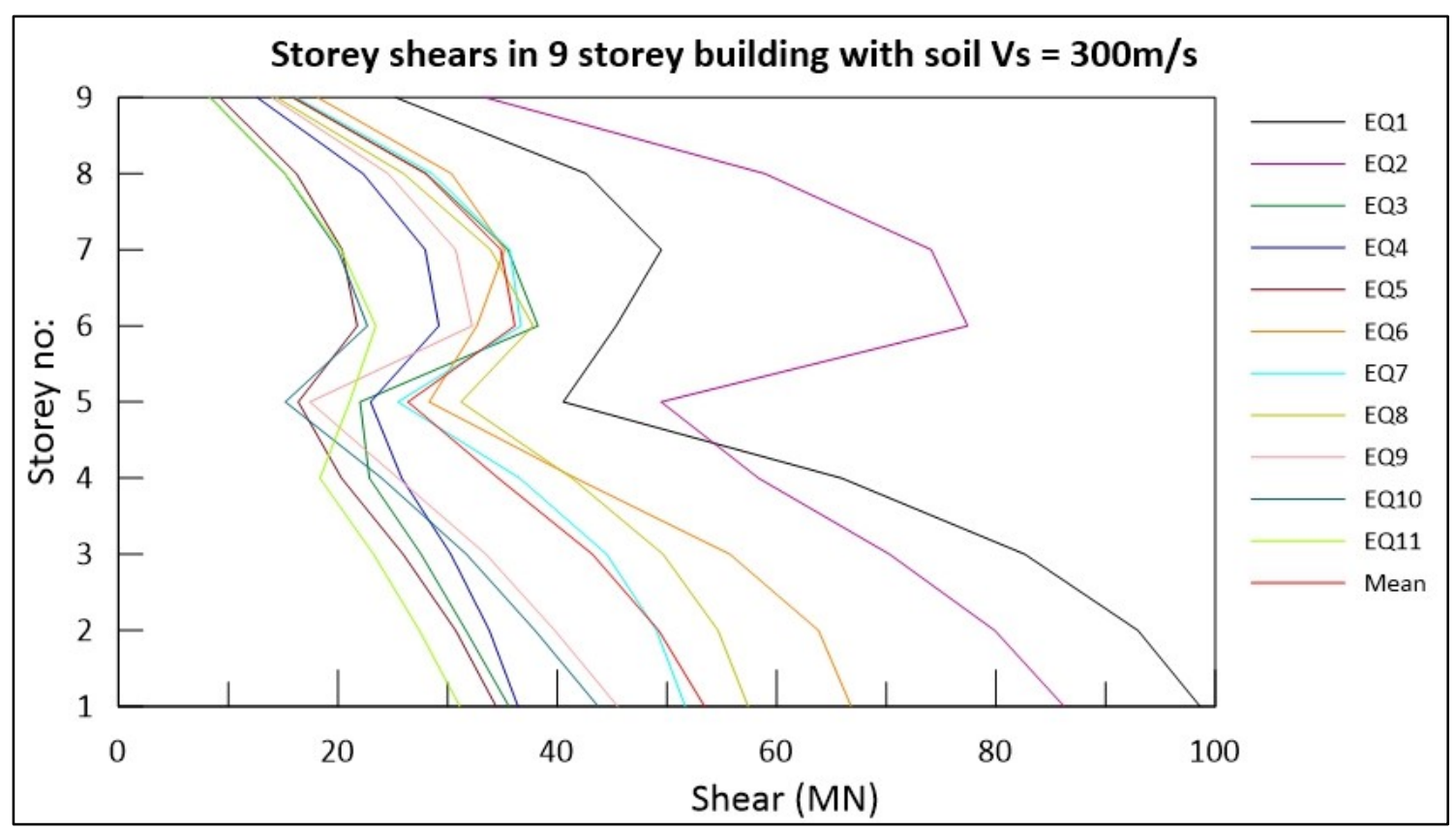

Figure B-21 Storey shears in 9storey building with soil shear wave velocity, Vs $=300 \mathrm{~m} / \mathrm{s}$ analyzed for 11 earthquake inputs compatible with Vancouver site B spectrum

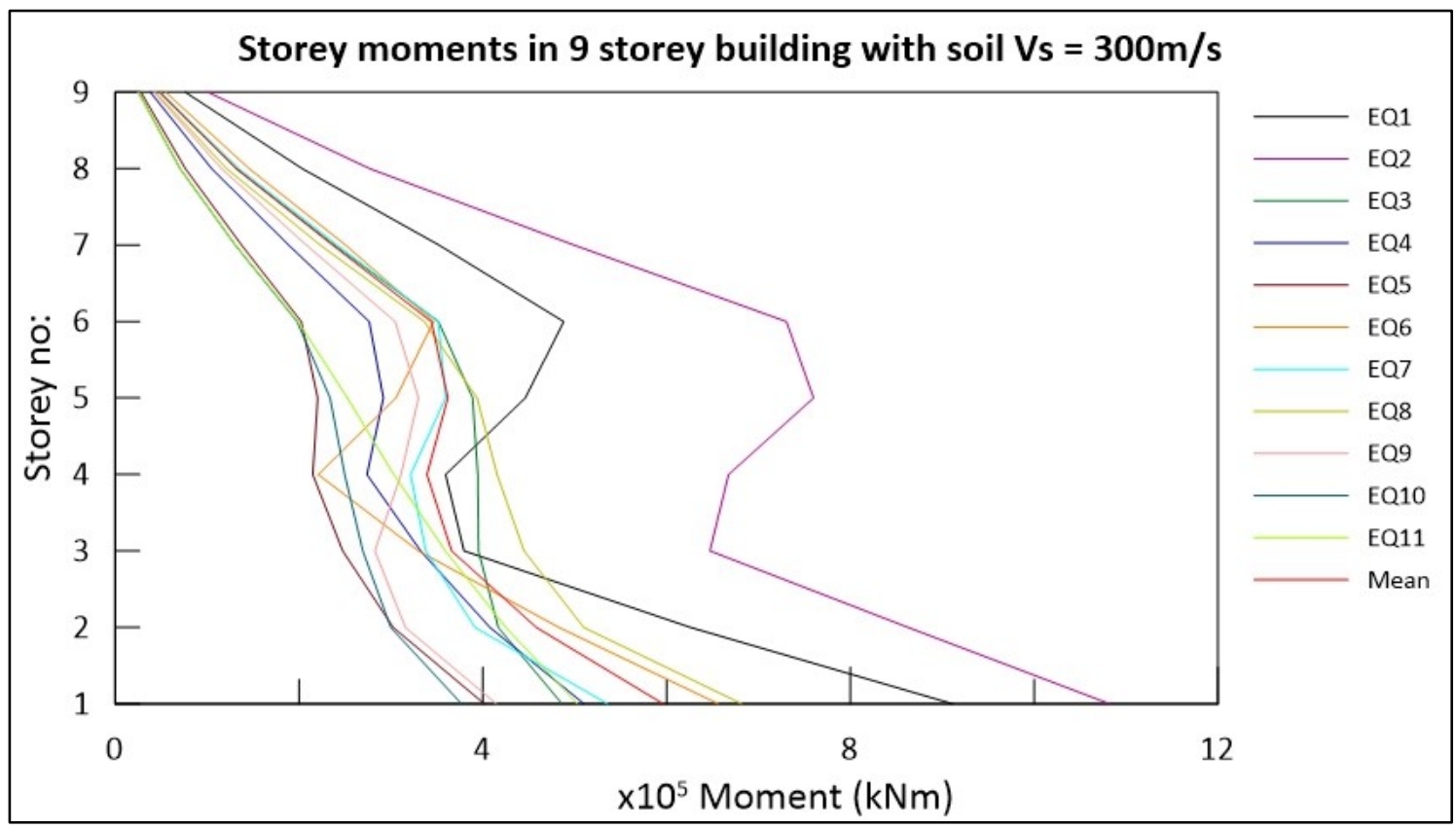

Figure B-22 Storey moments in 9storey building with soil shear wave velocity, Vs $=300 \mathrm{~m} / \mathrm{s}$ analyzed for 11 earthquake inputs compatible with Vancouver site B spectrum 


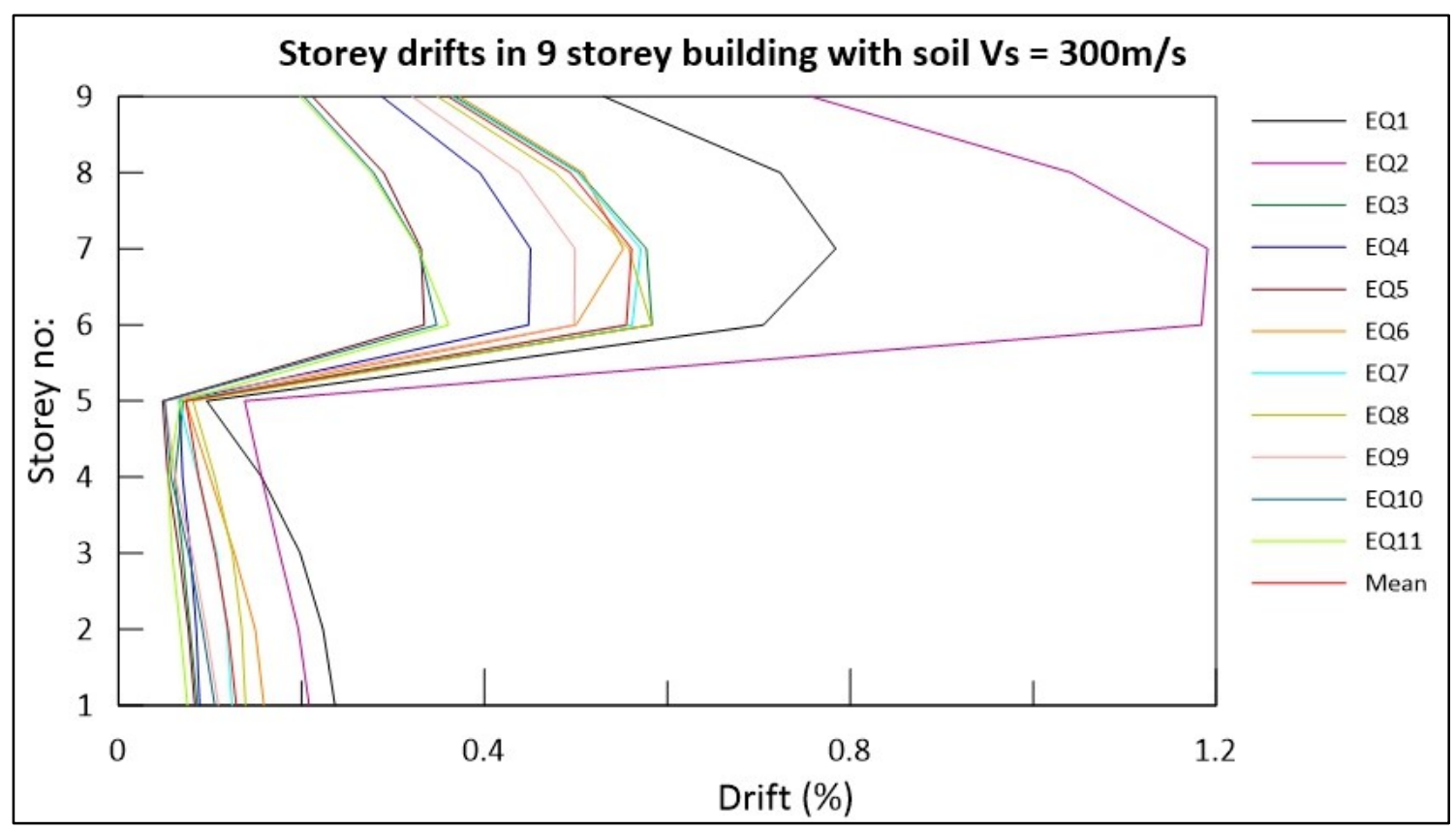

Figure B-23 Storey drifts in 9storey building with soil shear wave velocity, Vs = 300m/s analyzed for 11 earthquake inputs compatible with Vancouver site B spectrum

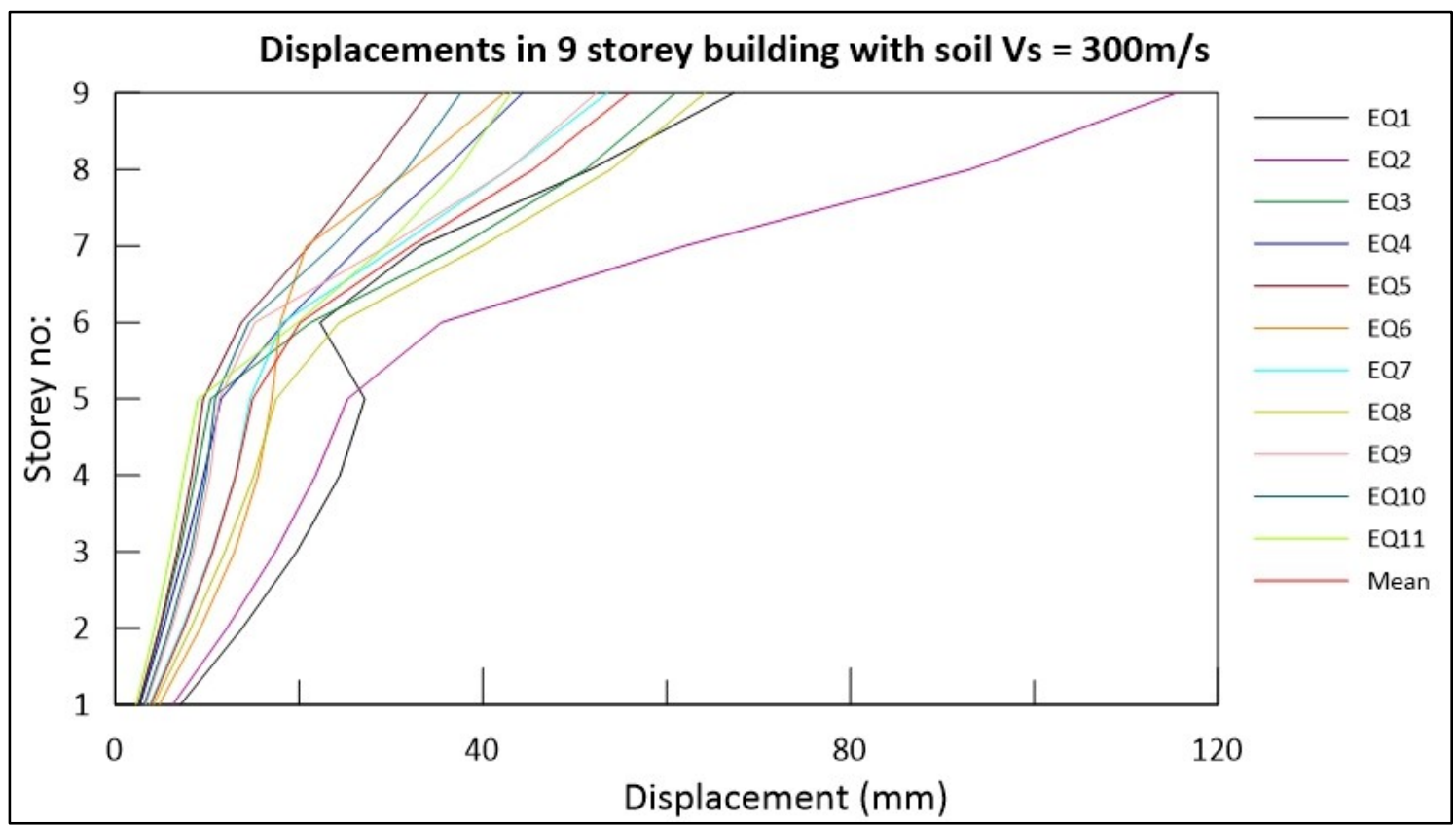

Figure B-24 Displacements in 9storey building with soil shear wave velocity, $\mathrm{Vs}=300 \mathrm{~m} / \mathrm{s}$ analyzed for 11 earthquake inputs compatible with Vancouver site B spectrum 


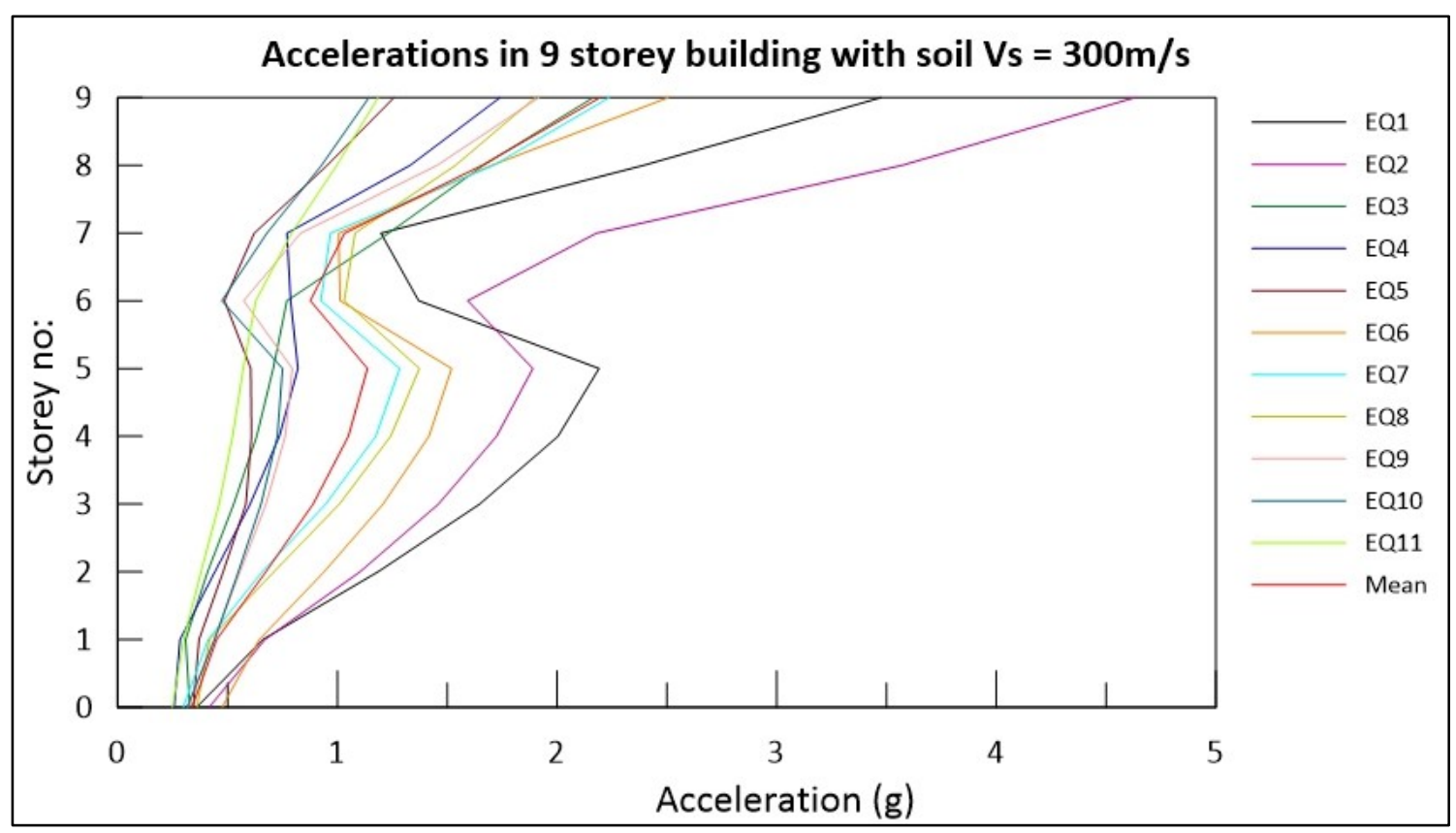

Figure B-25 Accelerations in 9storey building with soil shear wave velocity, Vs =300m/s analyzed for 11 earthquake inputs compatible with Vancouver site B spectrum

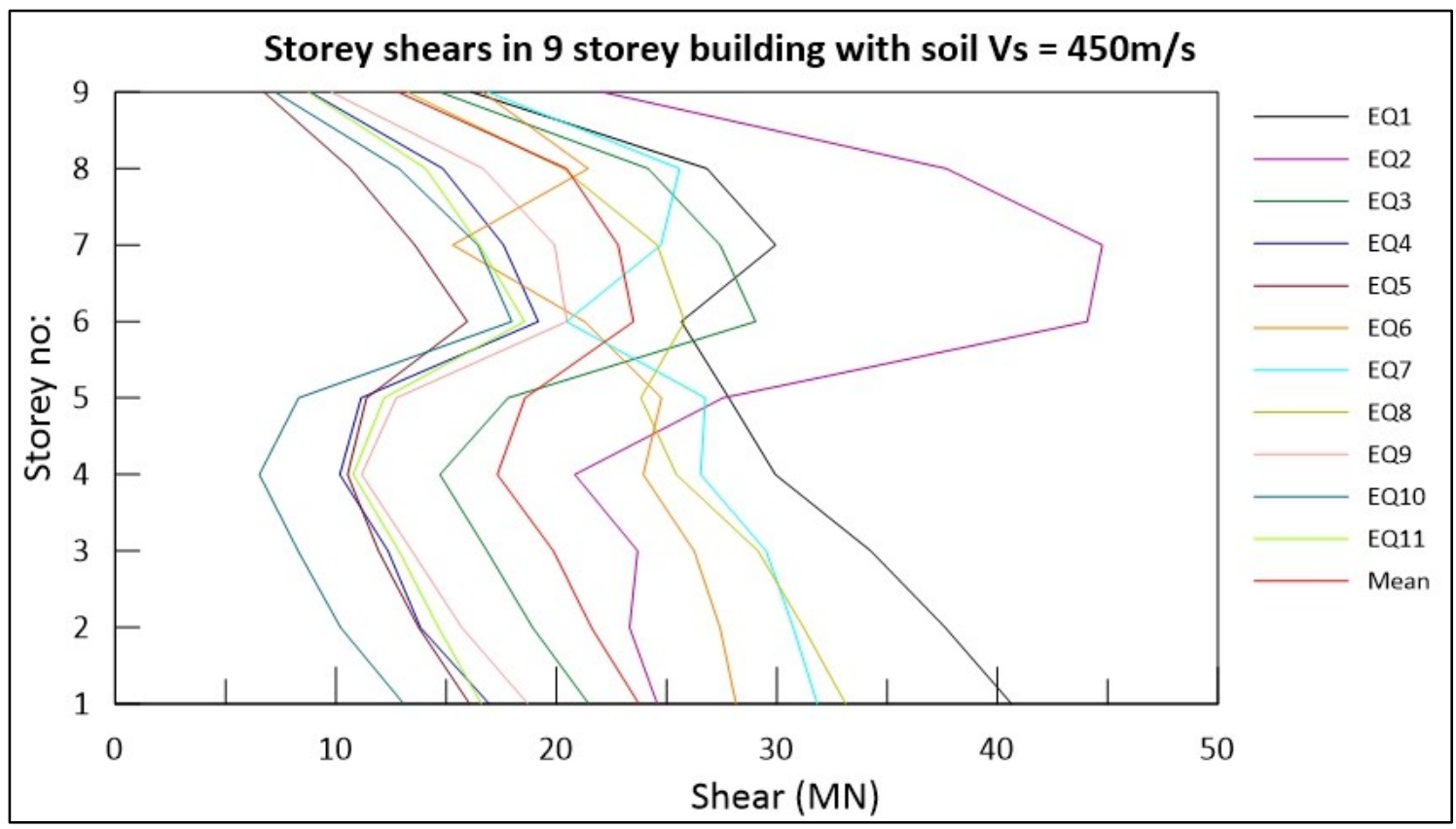

Figure B-26 Storey shears in 9storey building with soil shear wave velocity, Vs $=450 \mathrm{~m} / \mathrm{s}$ analyzed for 11 earthquake inputs compatible with Vancouver site B spectrum 


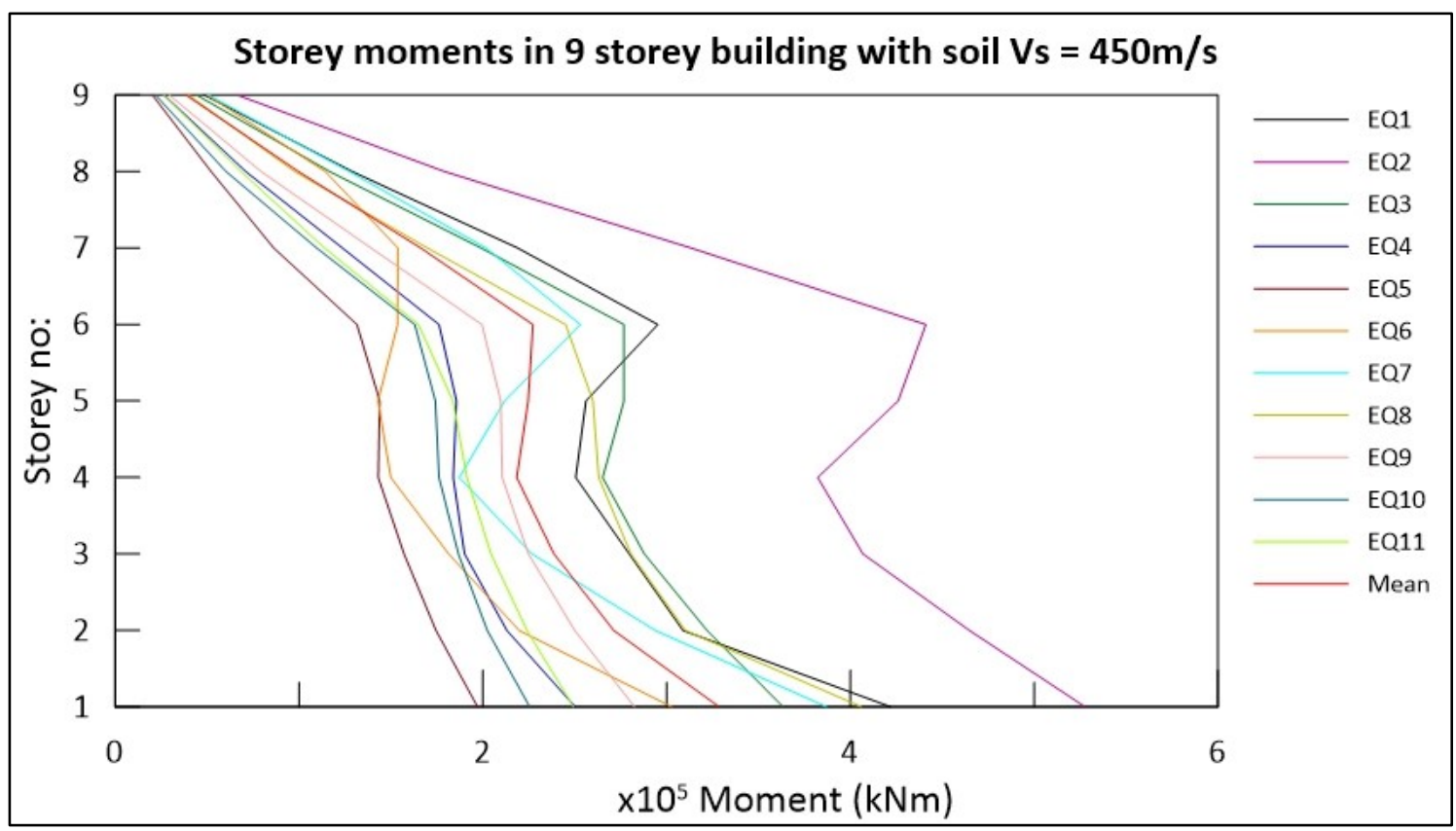

Figure B-27 Storey moments in 9storey building with soil shear wave velocity, Vs $=450 \mathrm{~m} / \mathrm{s}$ analyzed for 11 earthquake inputs compatible with Vancouver site B spectrum

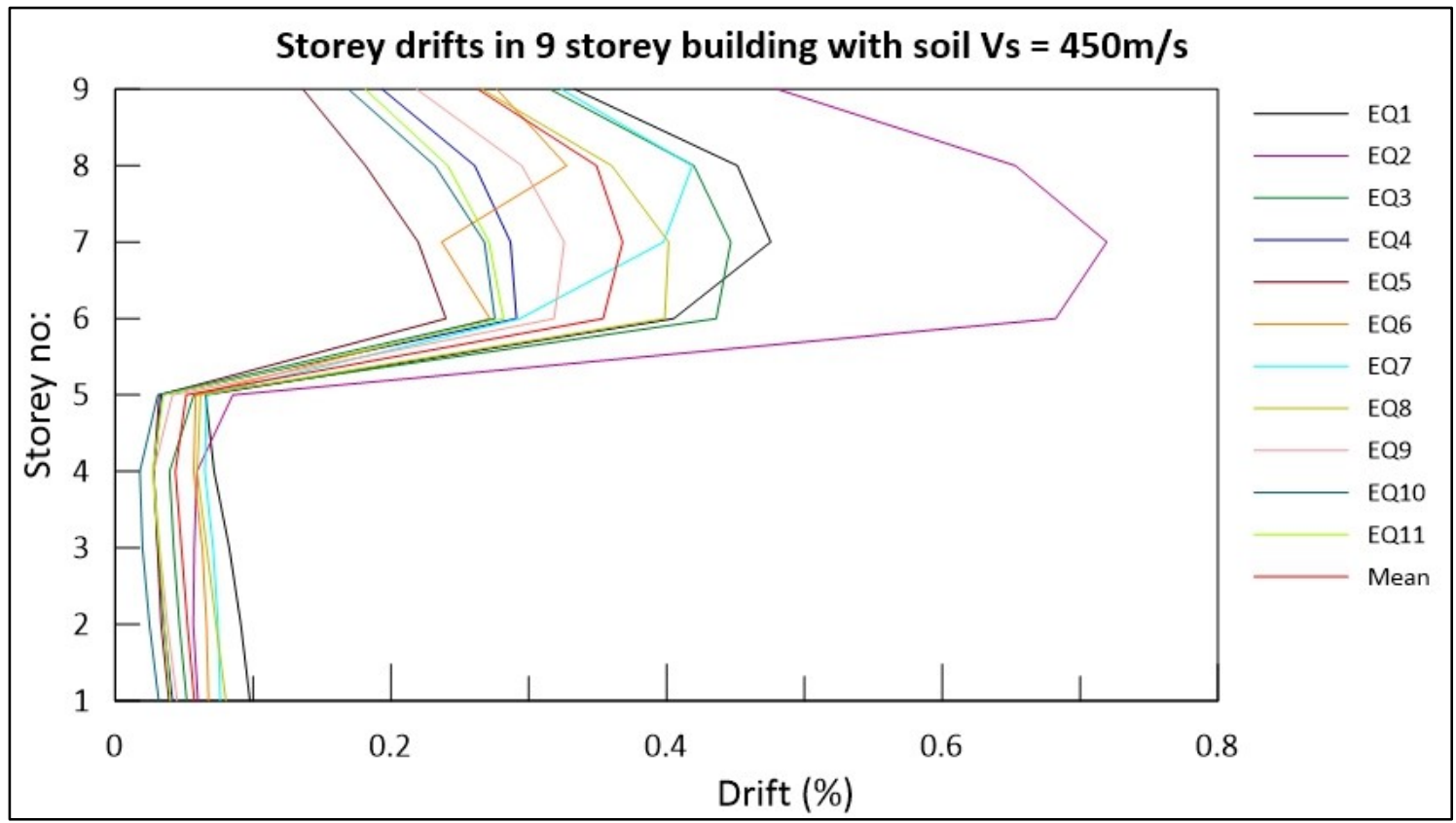

Figure B-28 Storey drifts in 9storey building with soil shear wave velocity, Vs $=450 \mathrm{~m} / \mathrm{s}$ analyzed for 11 earthquake inputs compatible with Vancouver site B spectrum 


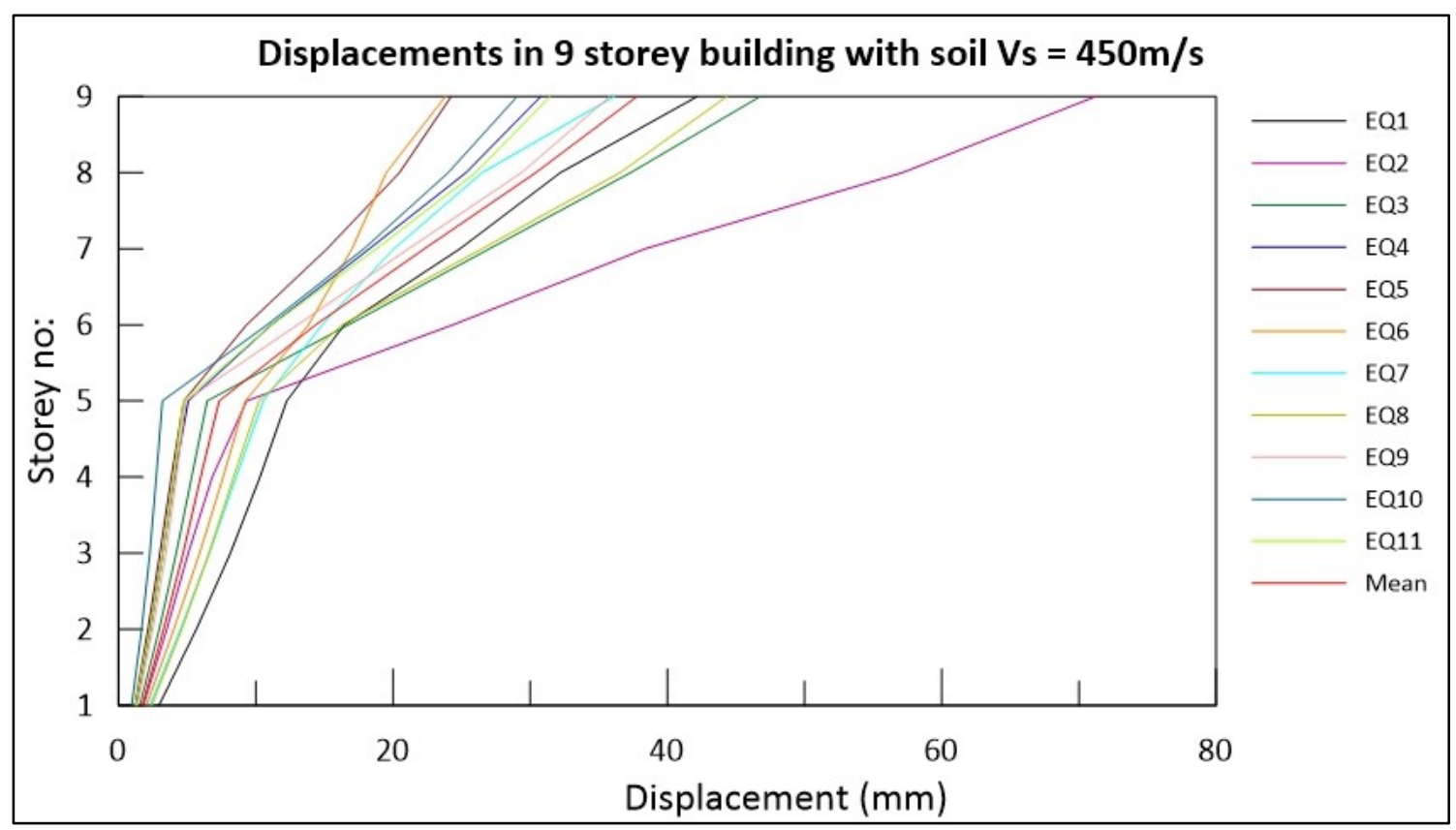

Figure B-29 Displacements in 9storey building with soil shear wave velocity, Vs $=450 \mathrm{~m} / \mathrm{s}$ analyzed for 11 earthquake inputs compatible with Vancouver site B spectrum

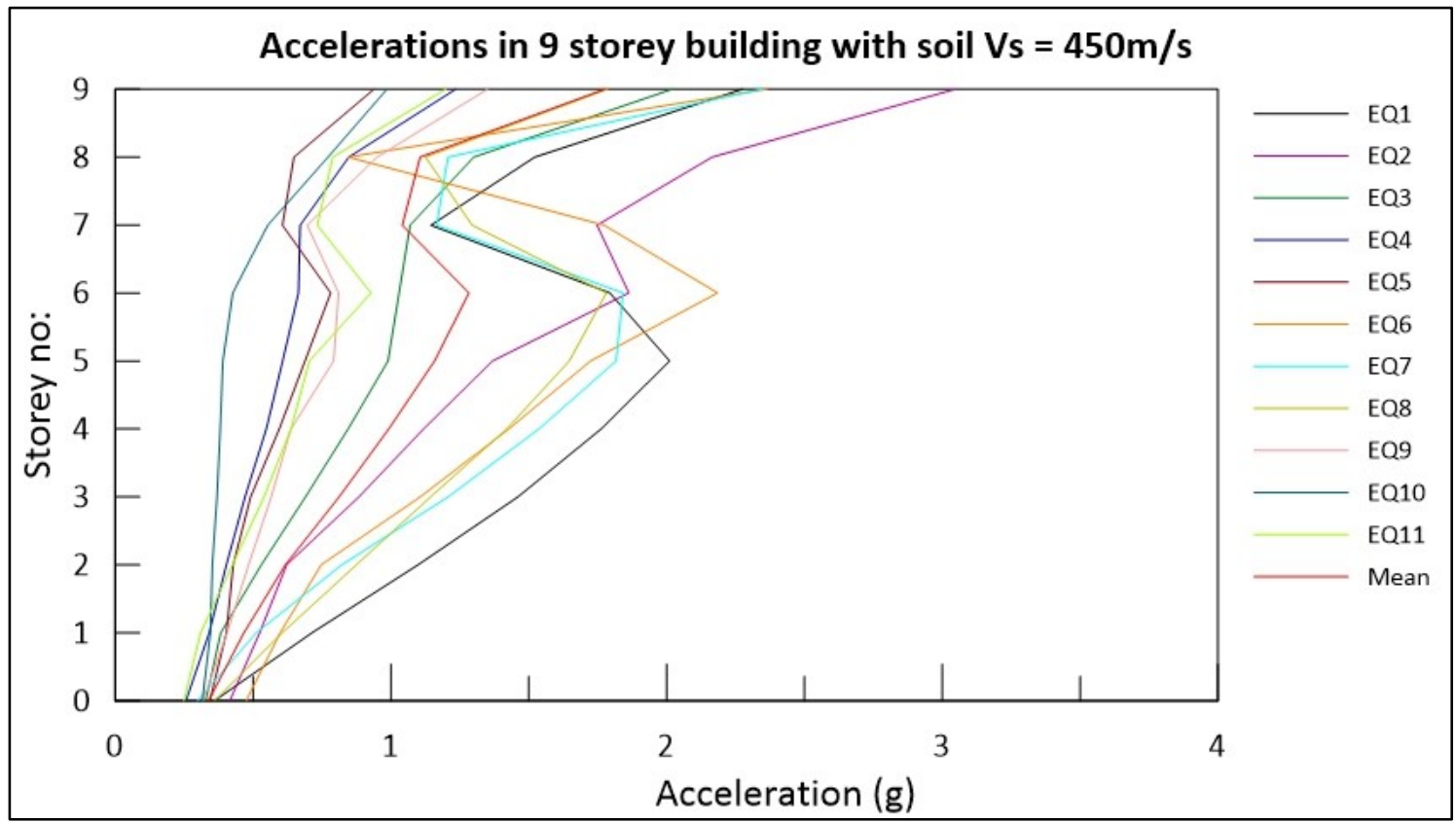

Figure B-30 Accelerations in 9storey building with soil shear wave velocity, $\mathrm{Vs}=450 \mathrm{~m} / \mathrm{s}$ analyzed for 11 earthquake inputs compatible with Vancouver site B spectrum 


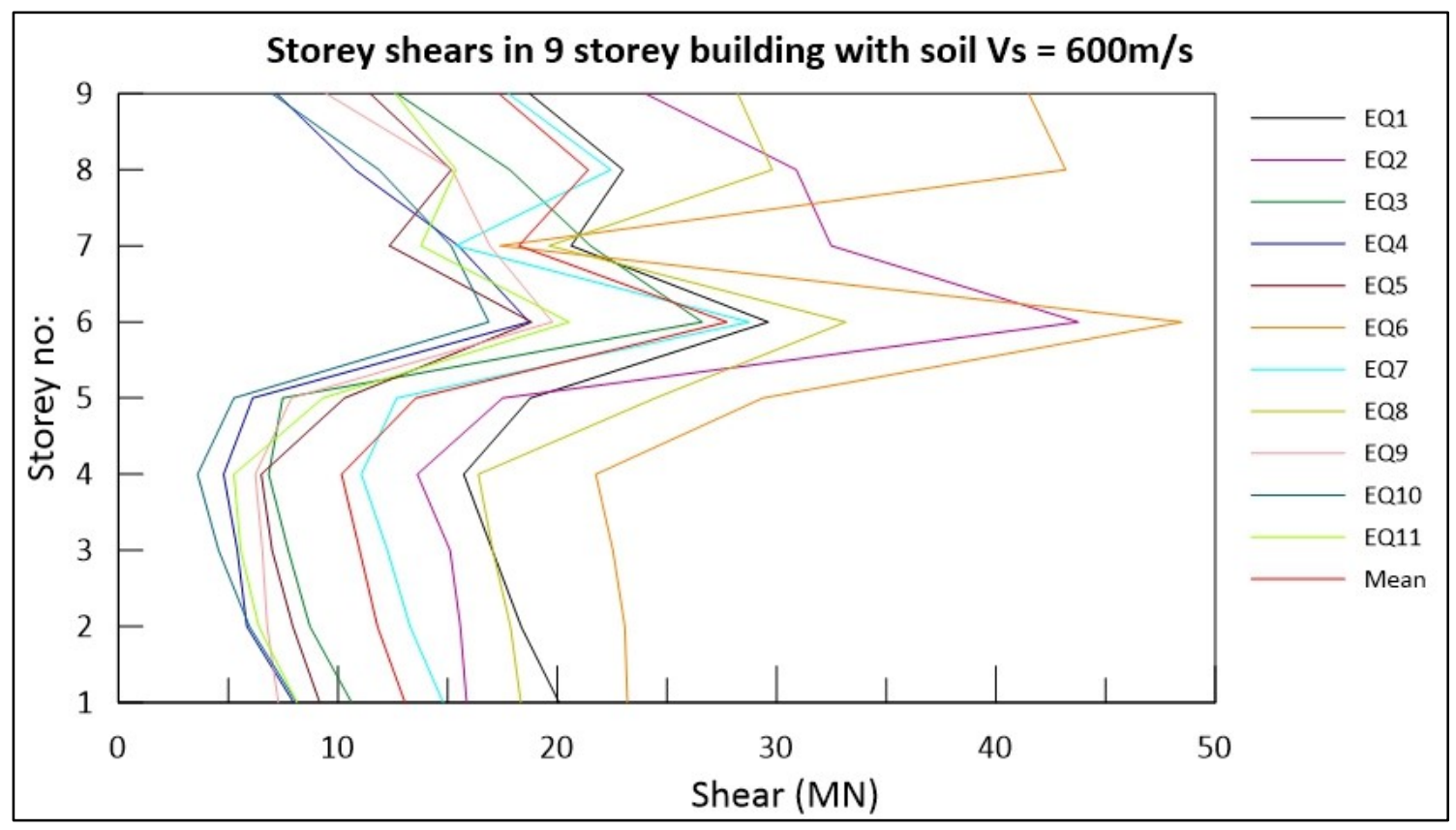

Figure B-31 Storey shears in 9storey building with soil shear wave velocity, Vs $=600 \mathrm{~m} / \mathrm{s}$ analyzed for 11 earthquake inputs compatible with Vancouver site B spectrum

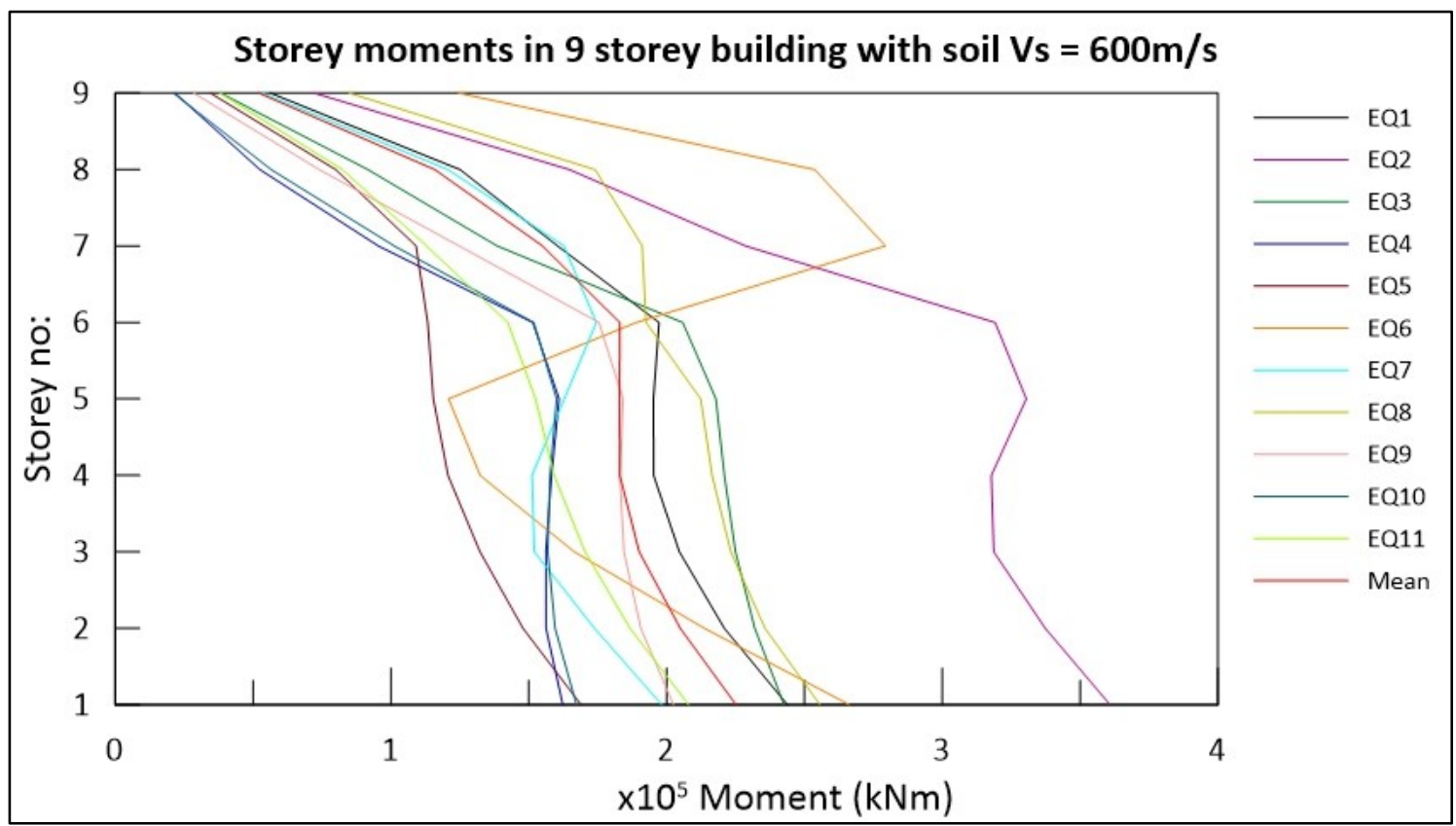

Figure B-32 Storey moments in 9storey building with soil shear wave velocity, Vs $=600 \mathrm{~m} / \mathrm{s}$ analyzed for 11 earthquake inputs compatible with Vancouver site B spectrum 


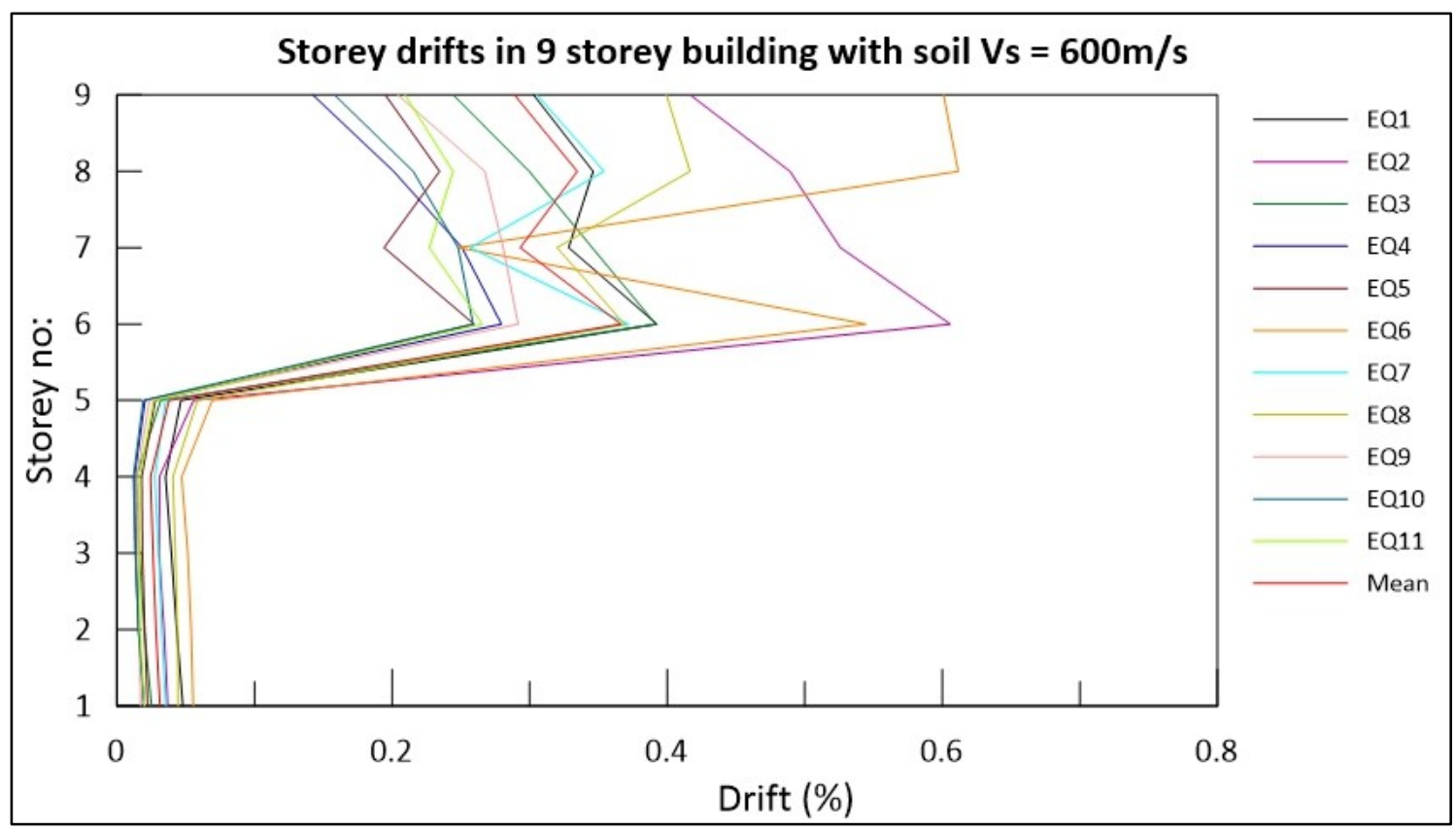

Figure B-33 Storey drifts in 9storey building with soil shear wave velocity, Vs $=600 \mathrm{~m} / \mathrm{s}$ analyzed for 11 earthquake inputs compatible with Vancouver site B spectrum

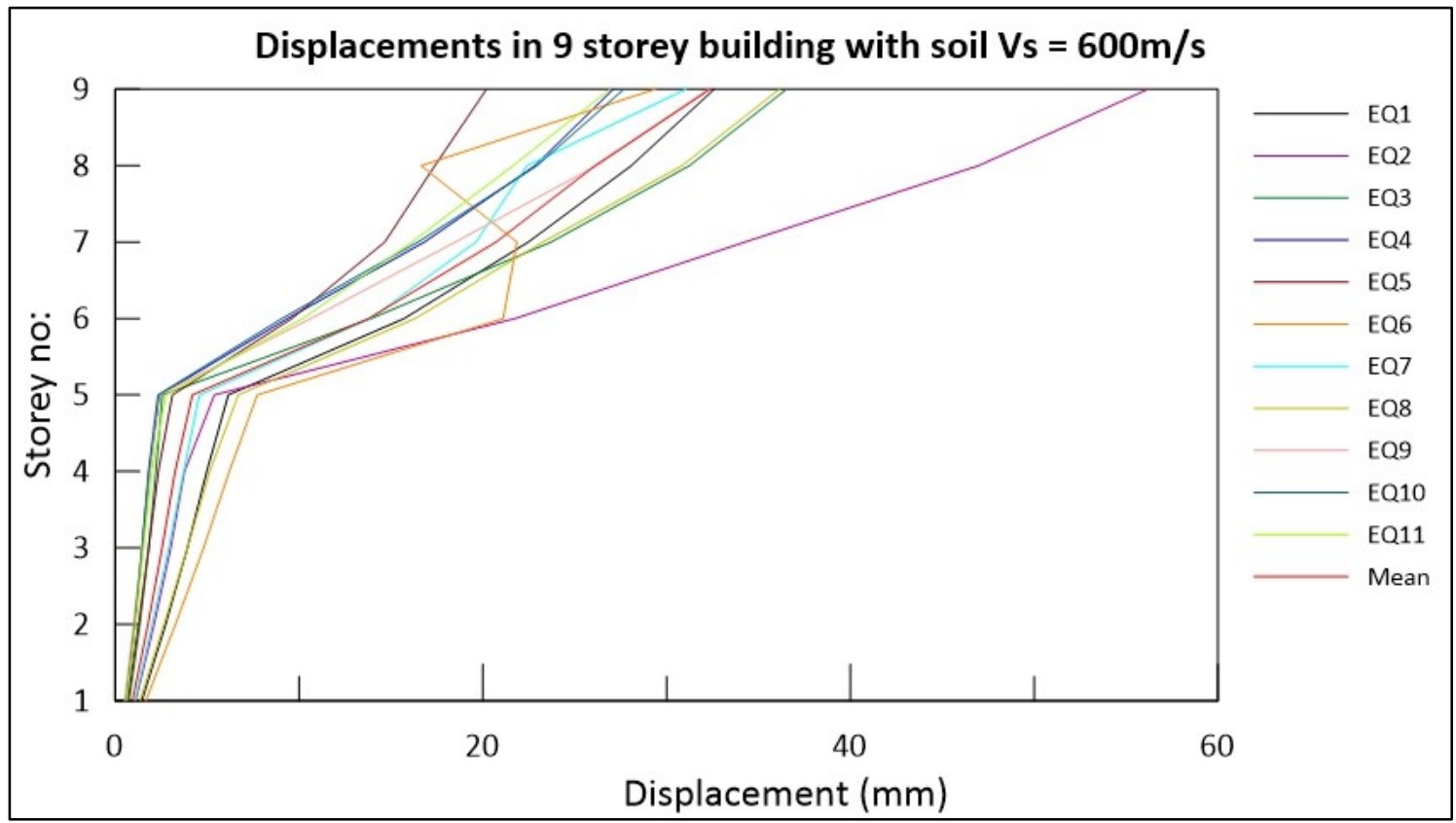

Figure B-34 Displacements in 9storey building with soil shear wave velocity, $\mathrm{Vs}=600 \mathrm{~m} / \mathrm{s}$ analyzed for 11 earthquake inputs compatible with Vancouver site B spectrum 


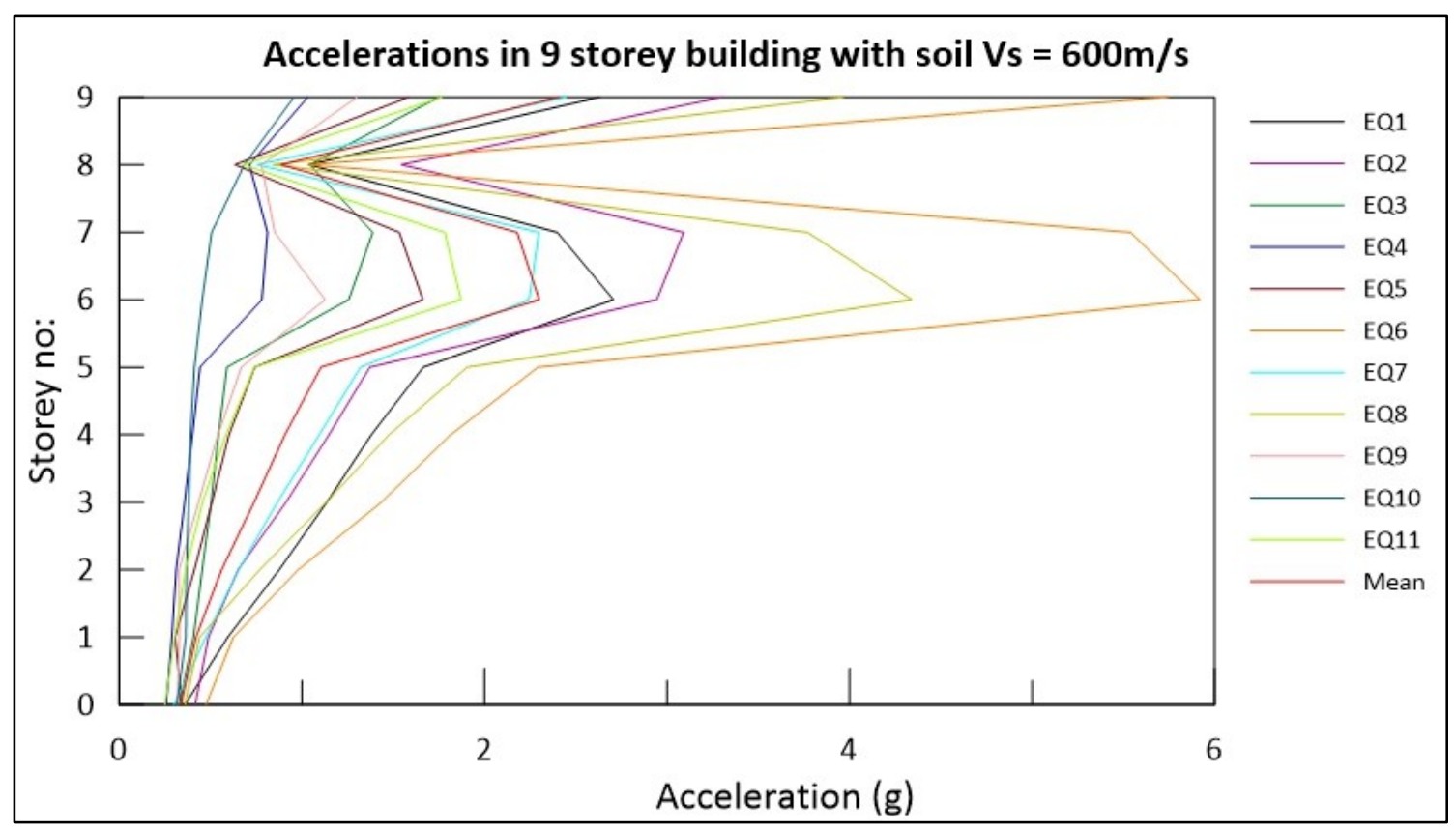

Figure B-35 Accelerations in 9storey building with soil shear wave velocity, Vs =600m/s analyzed for 11 earthquake inputs compatible with Vancouver site B spectrum

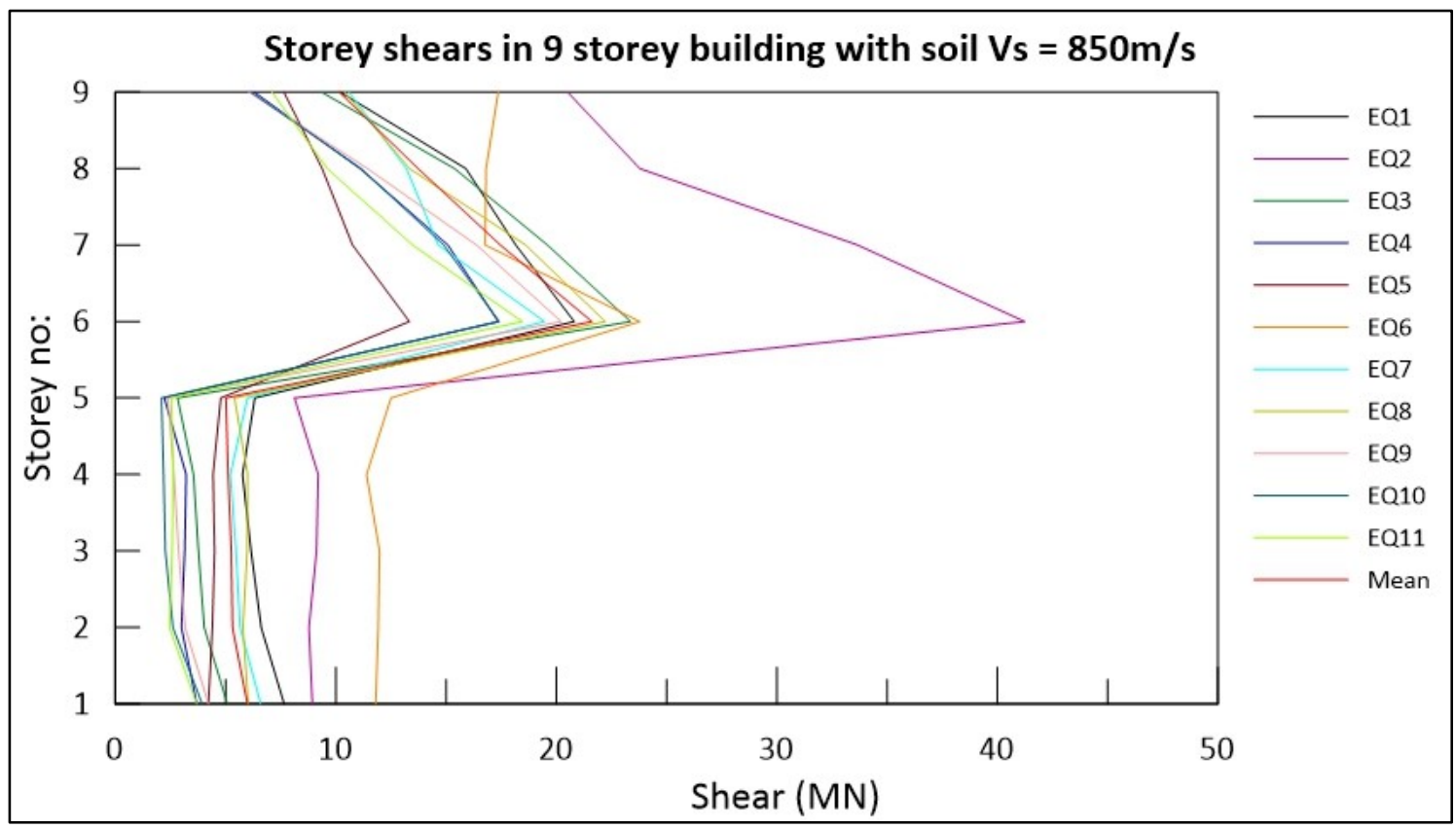

Figure B-36 Storey shears in 9storey building with soil shear wave velocity, Vs $=850 \mathrm{~m} / \mathrm{s}$ analyzed for 11 earthquake inputs compatible with Vancouver site B spectrum 


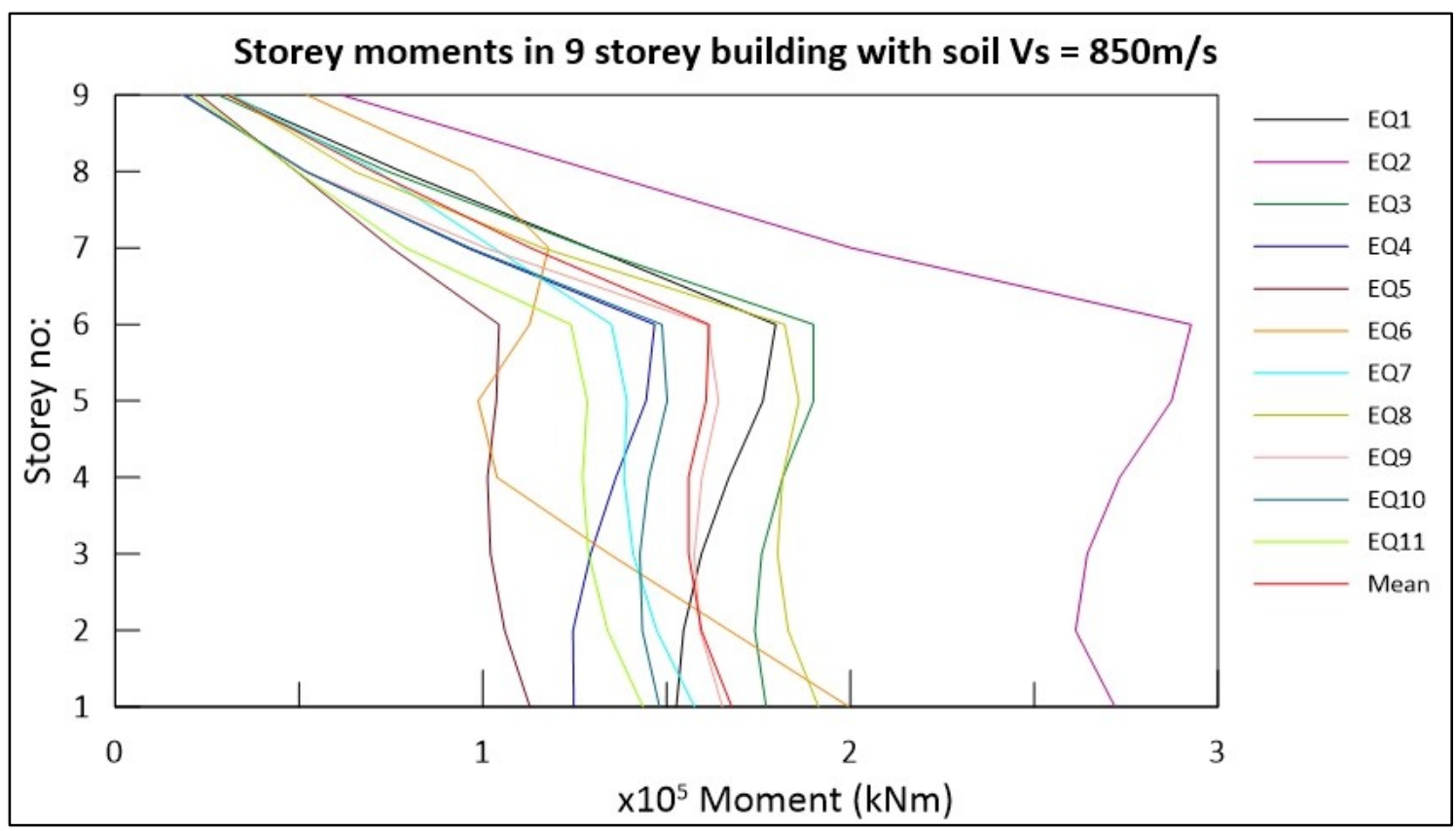

Figure B-37 Storey moments in 9storey building with soil shear wave velocity, Vs $=850 \mathrm{~m} / \mathrm{s}$ analyzed for 11 earthquake inputs compatible with Vancouver site B spectrum

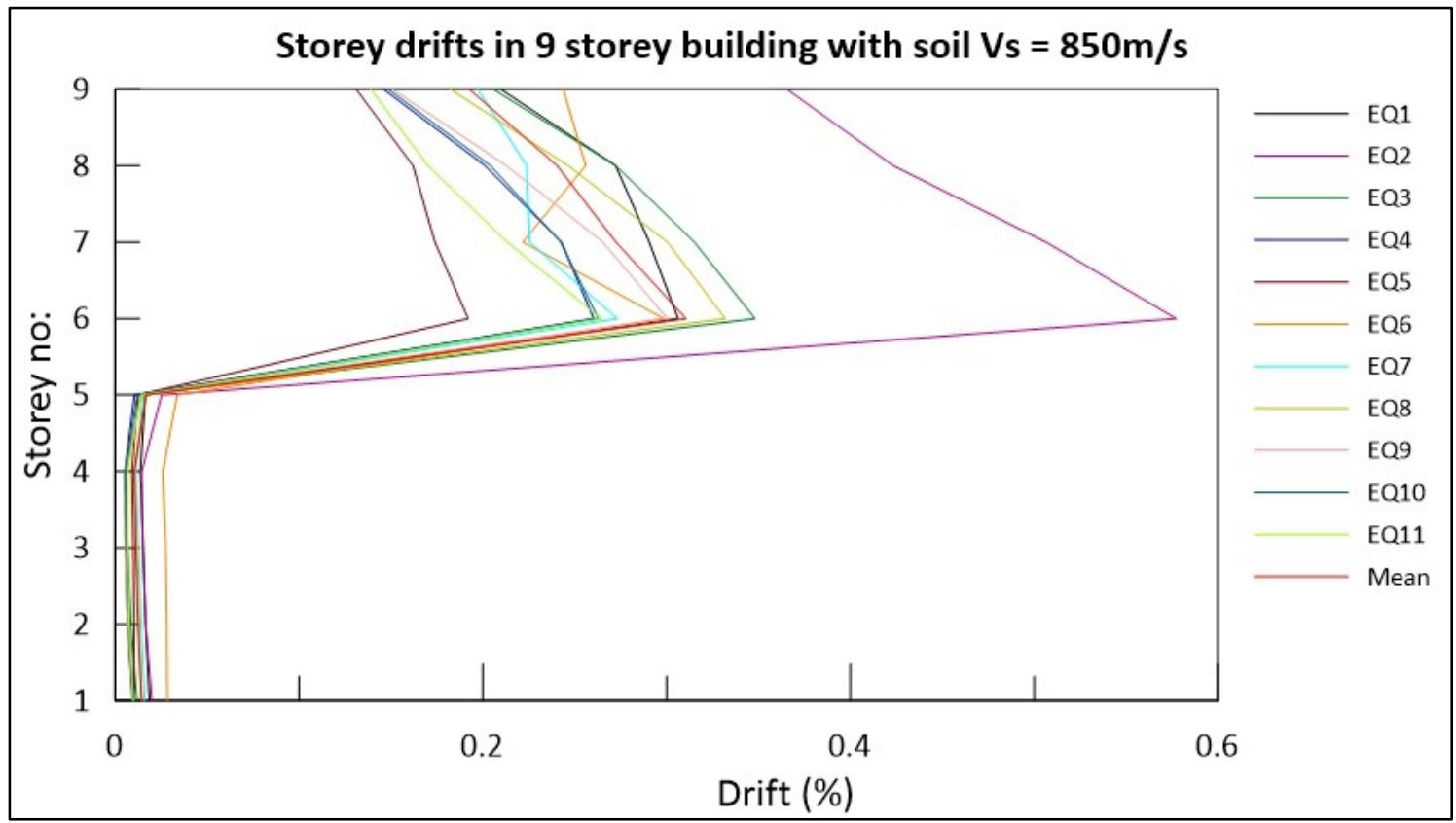

Figure B-38 Storey drifts in 9storey building with soil shear wave velocity, Vs $=850 \mathrm{~m} / \mathrm{s}$ analyzed for 11 earthquake inputs compatible with Vancouver site B spectrum 


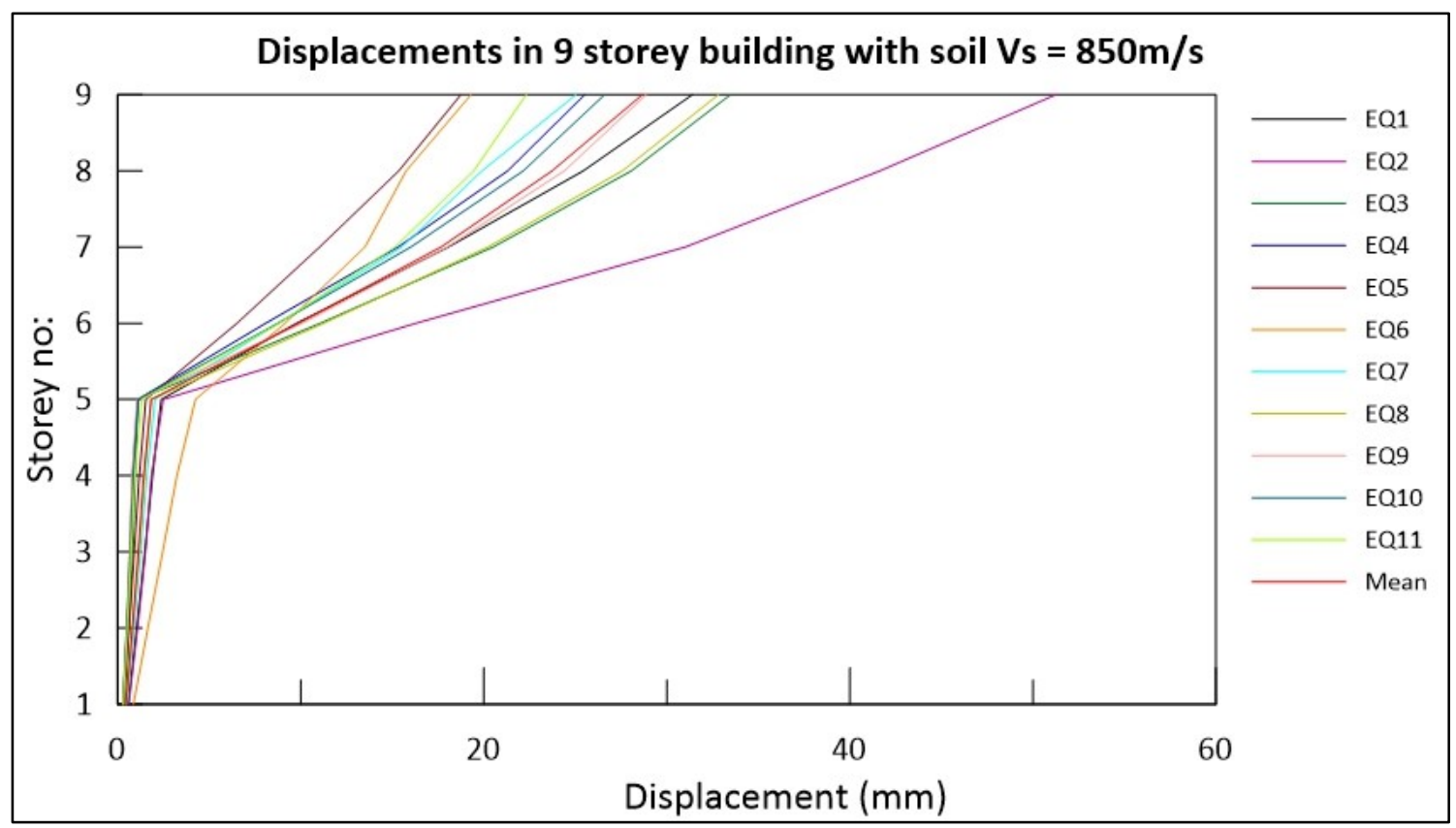

Figure B-39 Displacements in 9storey building with soil shear wave velocity, $\mathrm{Vs}=850 \mathrm{~m} / \mathrm{s}$ analyzed for 11 earthquake inputs compatible with Vancouver site B spectrum

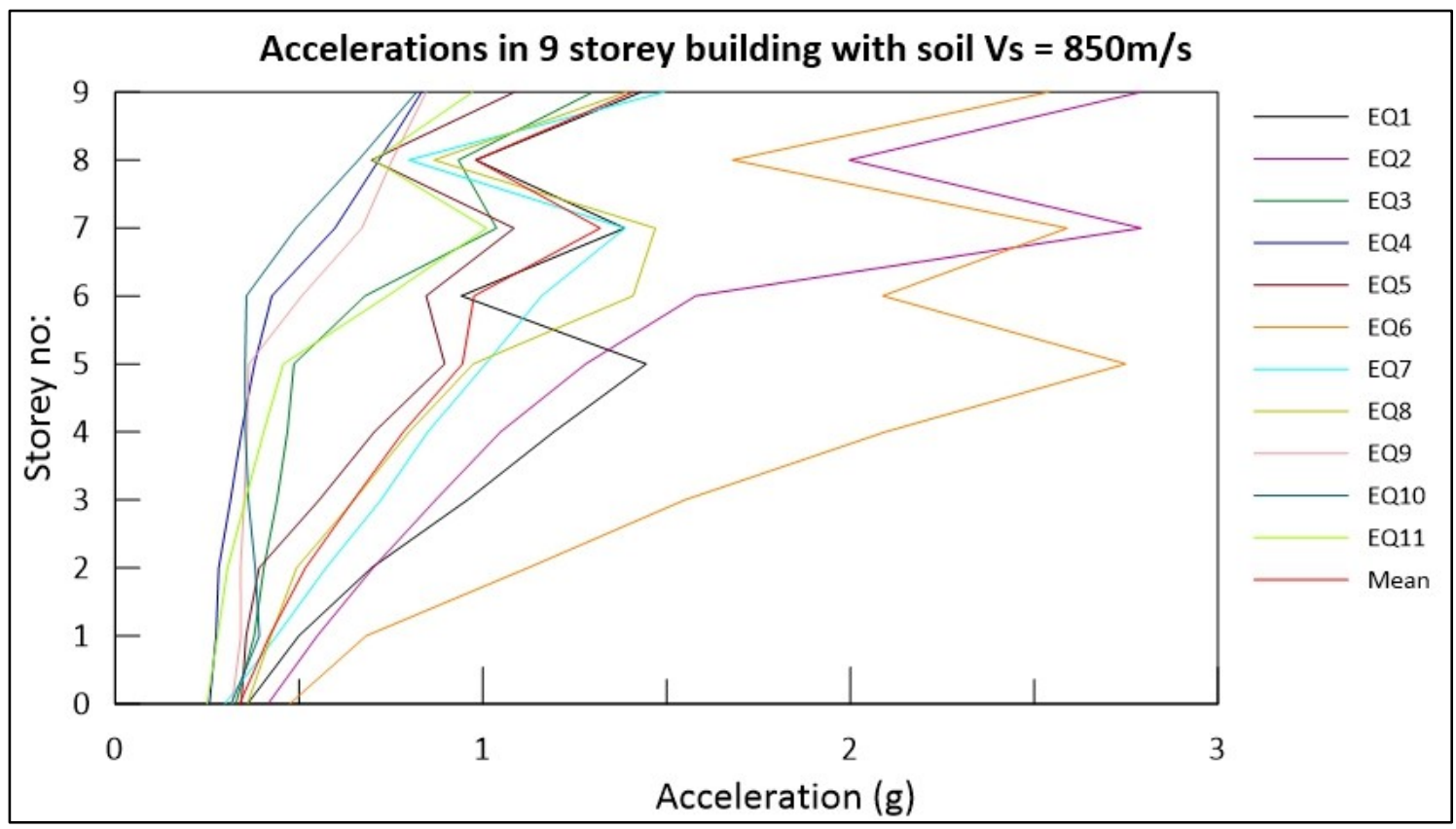

Figure B-40 Accelerations in 9storey building with soil shear wave velocity, $\mathrm{Vs}=850 \mathrm{~m} / \mathrm{s}$ analyzed for 11 earthquake inputs compatible with Vancouver site B spectrum 


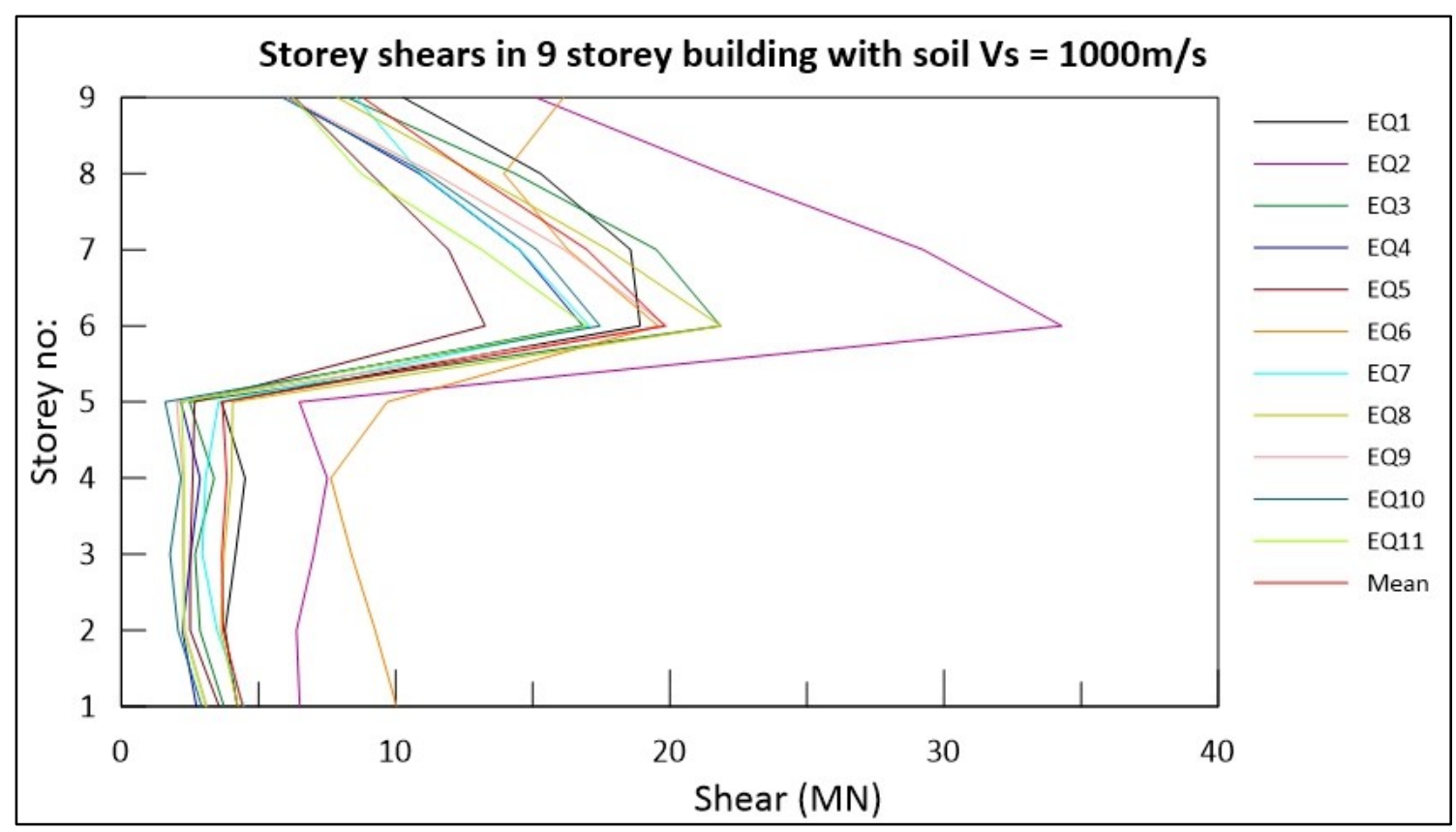

Figure B-41 Storey shears in 9storey building with soil shear wave velocity, Vs $=1000 \mathrm{~m} / \mathrm{s}$ analyzed for 11 earthquake inputs compatible with Vancouver site B spectrum

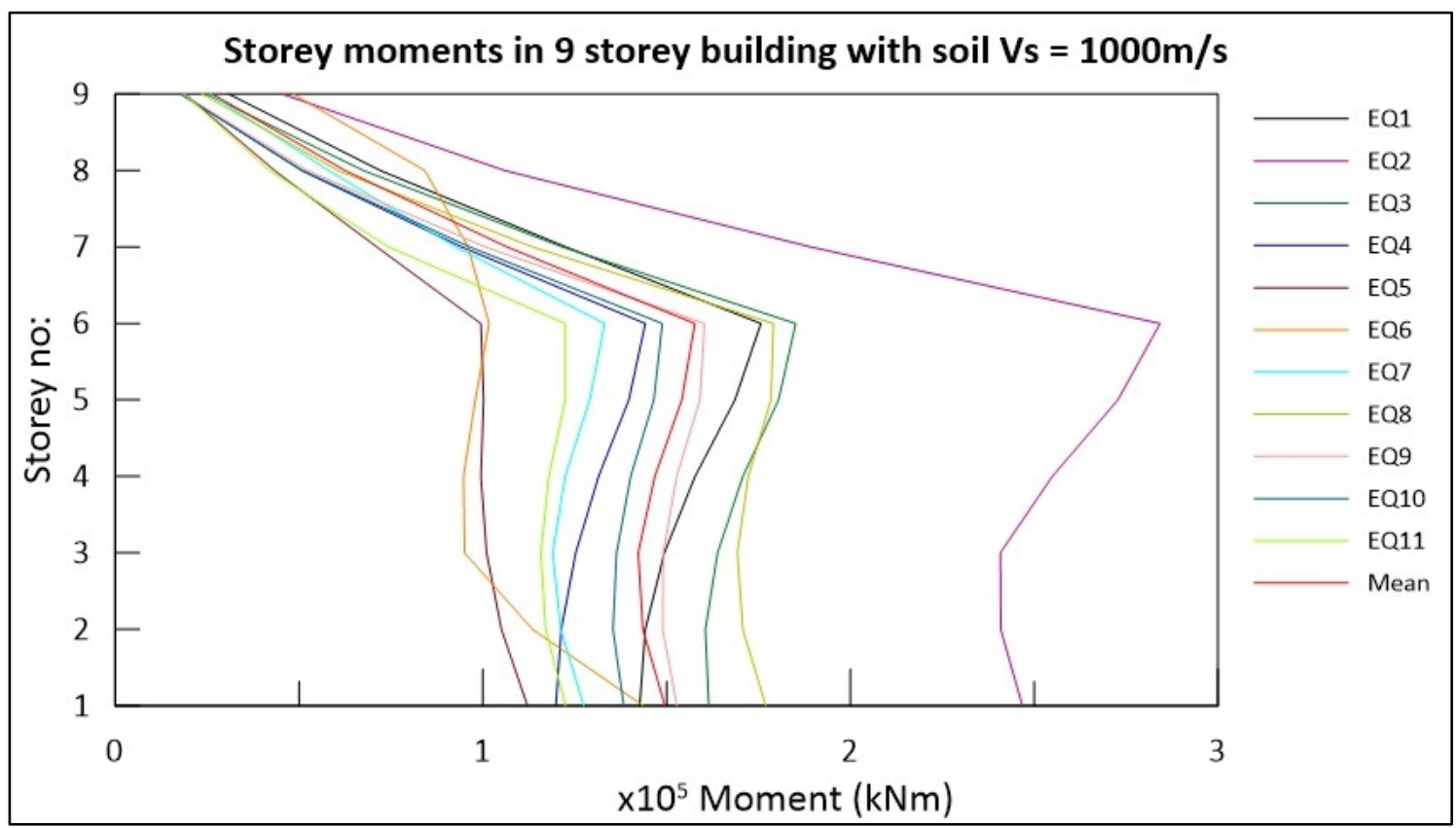

Figure B-42 Storey moments in 9storey building with soil shear wave velocity, Vs $=1000 \mathrm{~m} / \mathrm{s}$ analyzed for 11 earthquake inputs compatible with Vancouver site B spectrum 


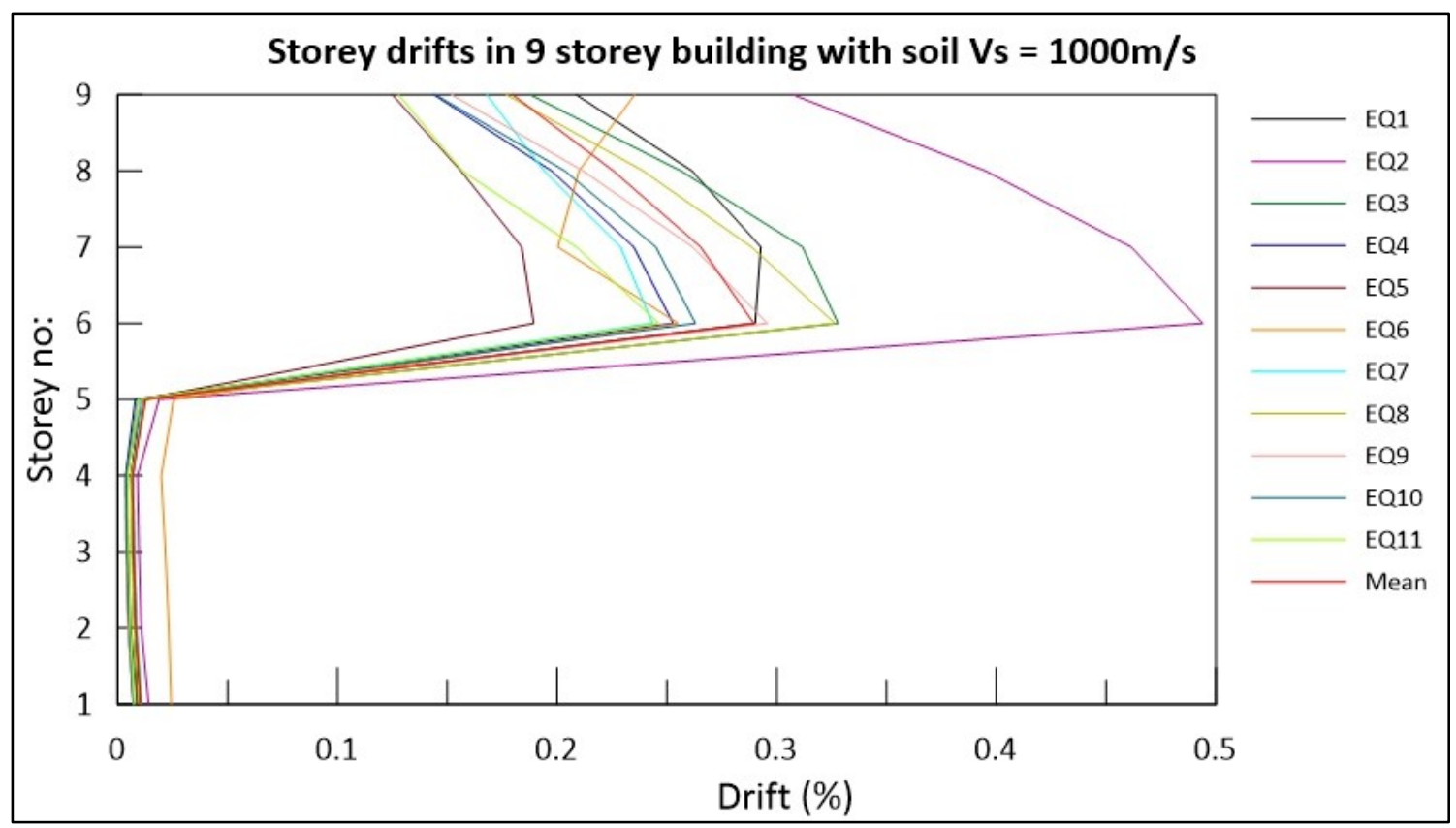

Figure B-43 Storey drifts in 9storey building with soil shear wave velocity, Vs $=1000 \mathrm{~m} / \mathrm{s}$ analyzed for 11 earthquake inputs compatible with Vancouver site B spectrum

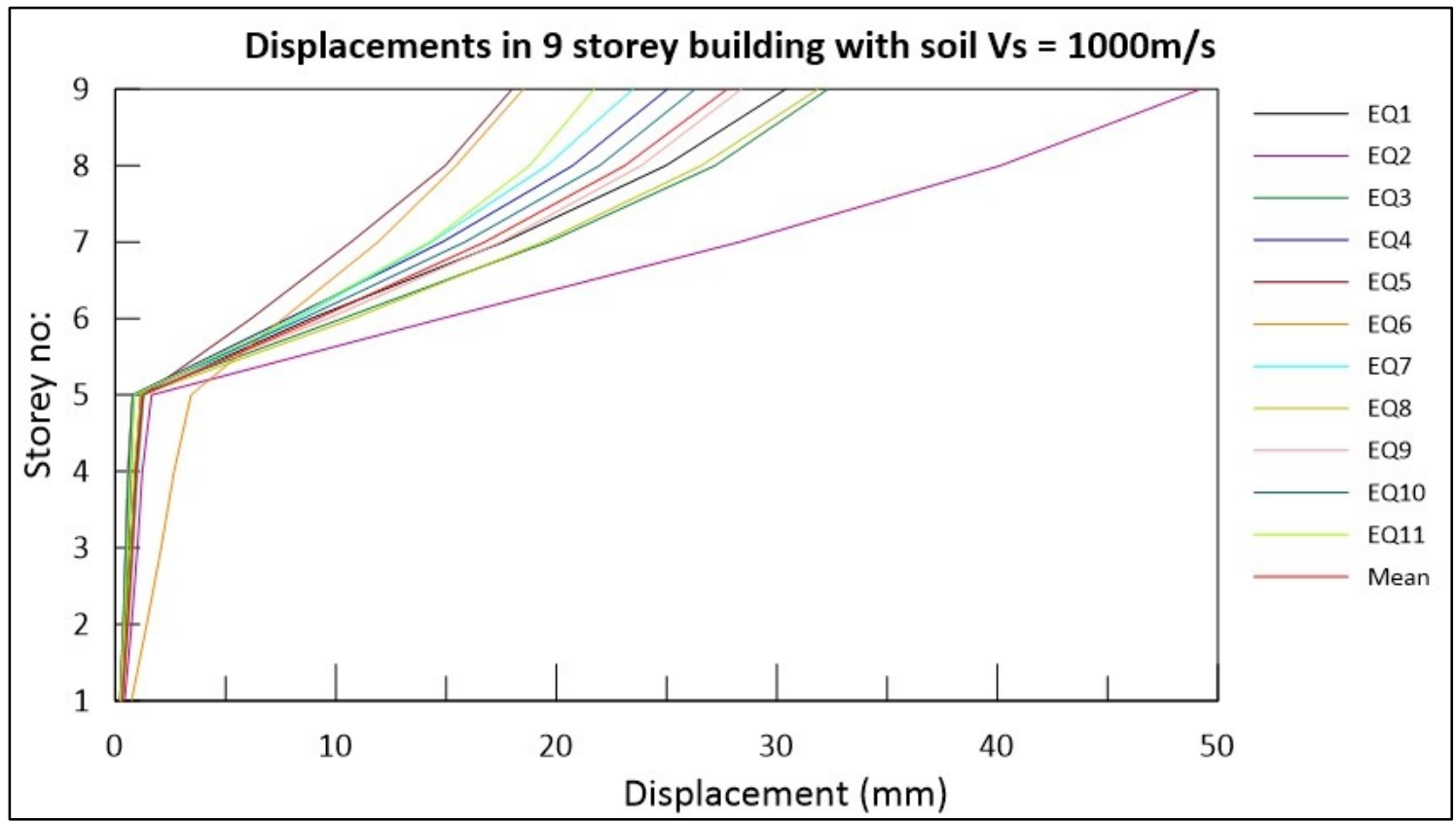

Figure B-44 Displacements in 9storey building with soil shear wave velocity, Vs $=1000 \mathrm{~m} / \mathrm{s}$ analyzed for 11 earthquake inputs compatible with Vancouver site B spectrum 


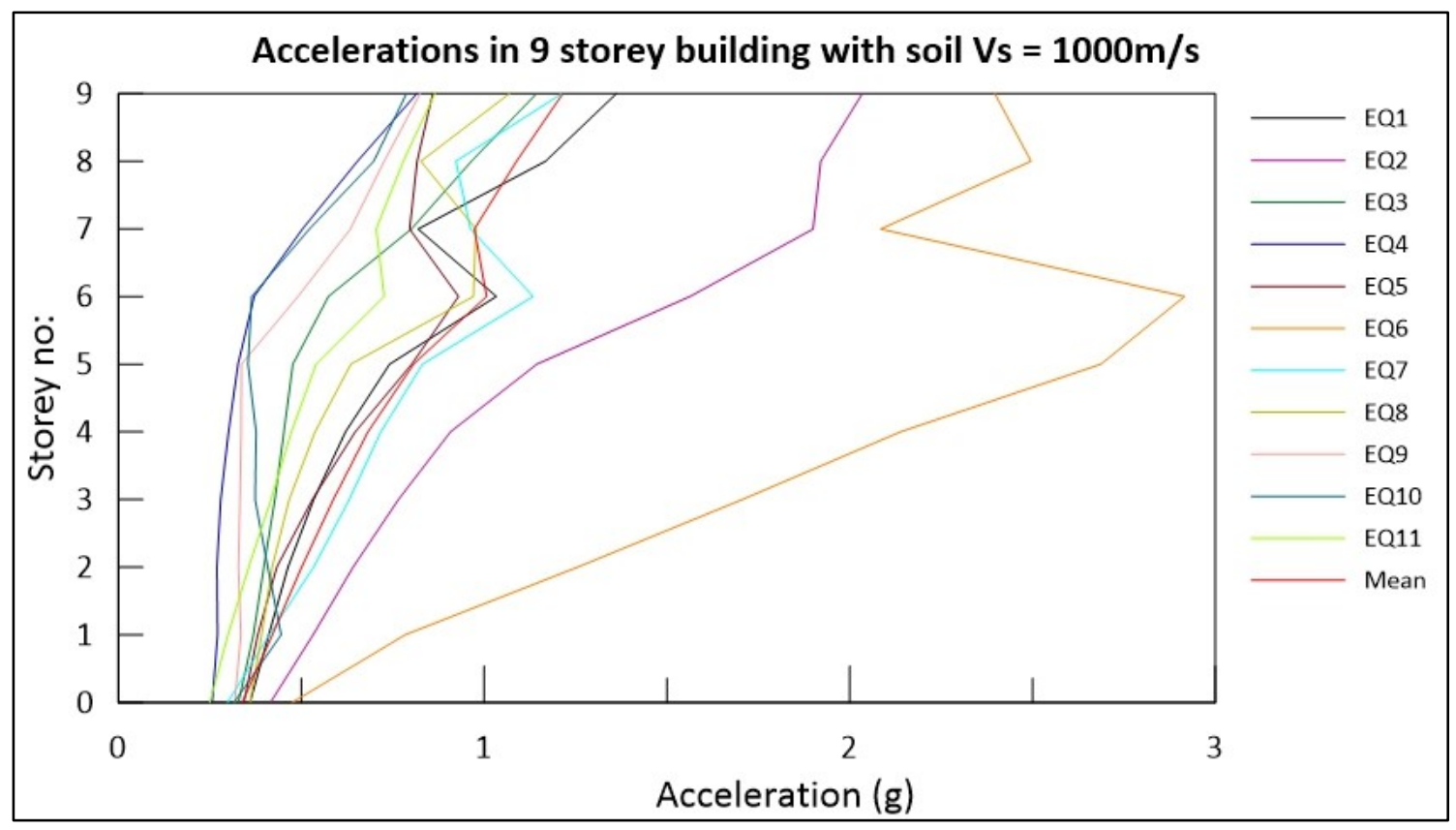

Figure B-45 Accelerations in 9storey building with soil shear wave velocity, Vs $=1000 \mathrm{~m} / \mathrm{s}$ analyzed for 11 earthquake inputs compatible with Vancouver site B spectrum

$\underline{13 \text { storey building }}$

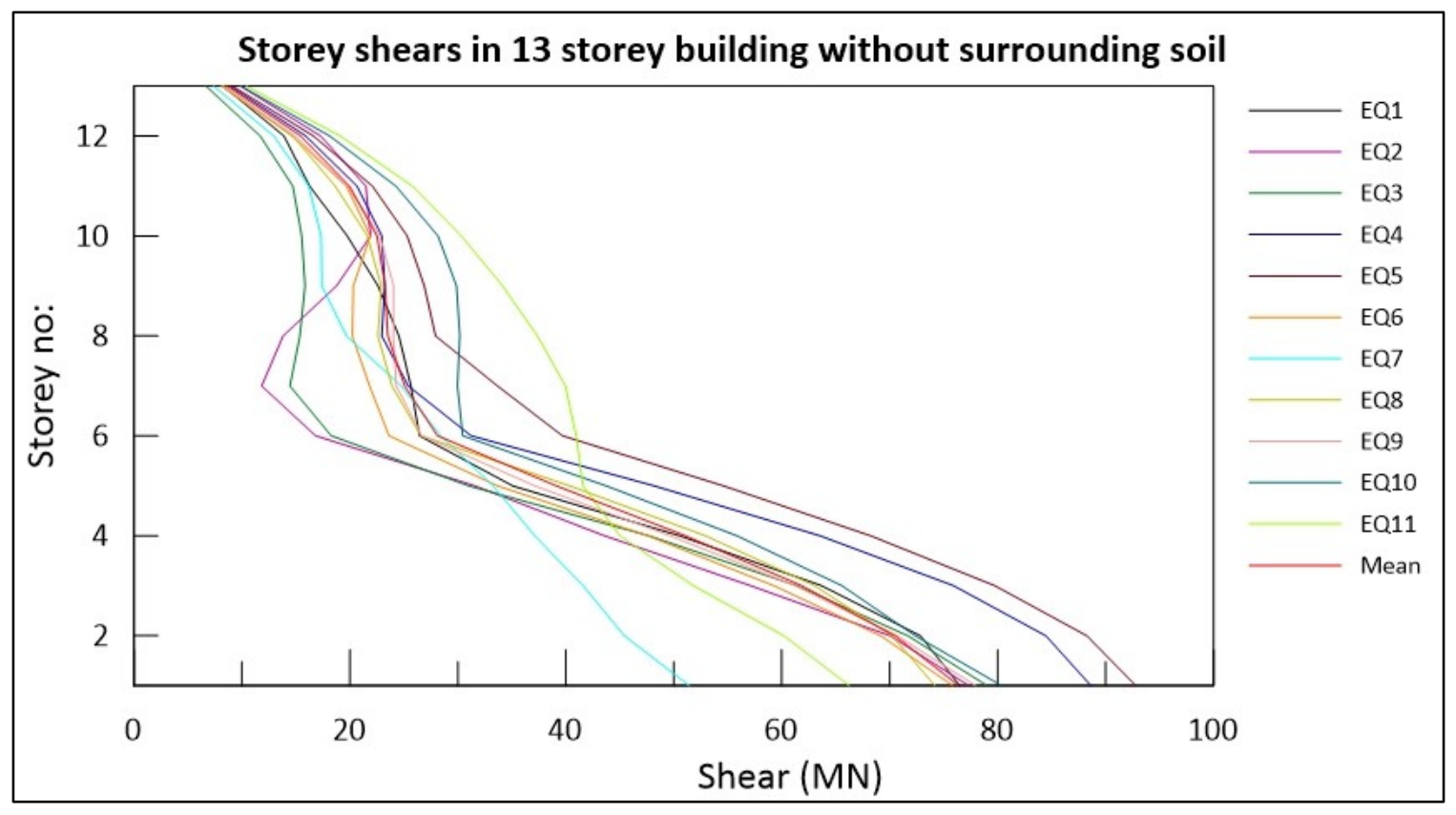

Figure B-46 Storey shears in 13storey building without any surrounding soil analyzed for 11 earthquake inputs compatible with Vancouver site B spectrum 


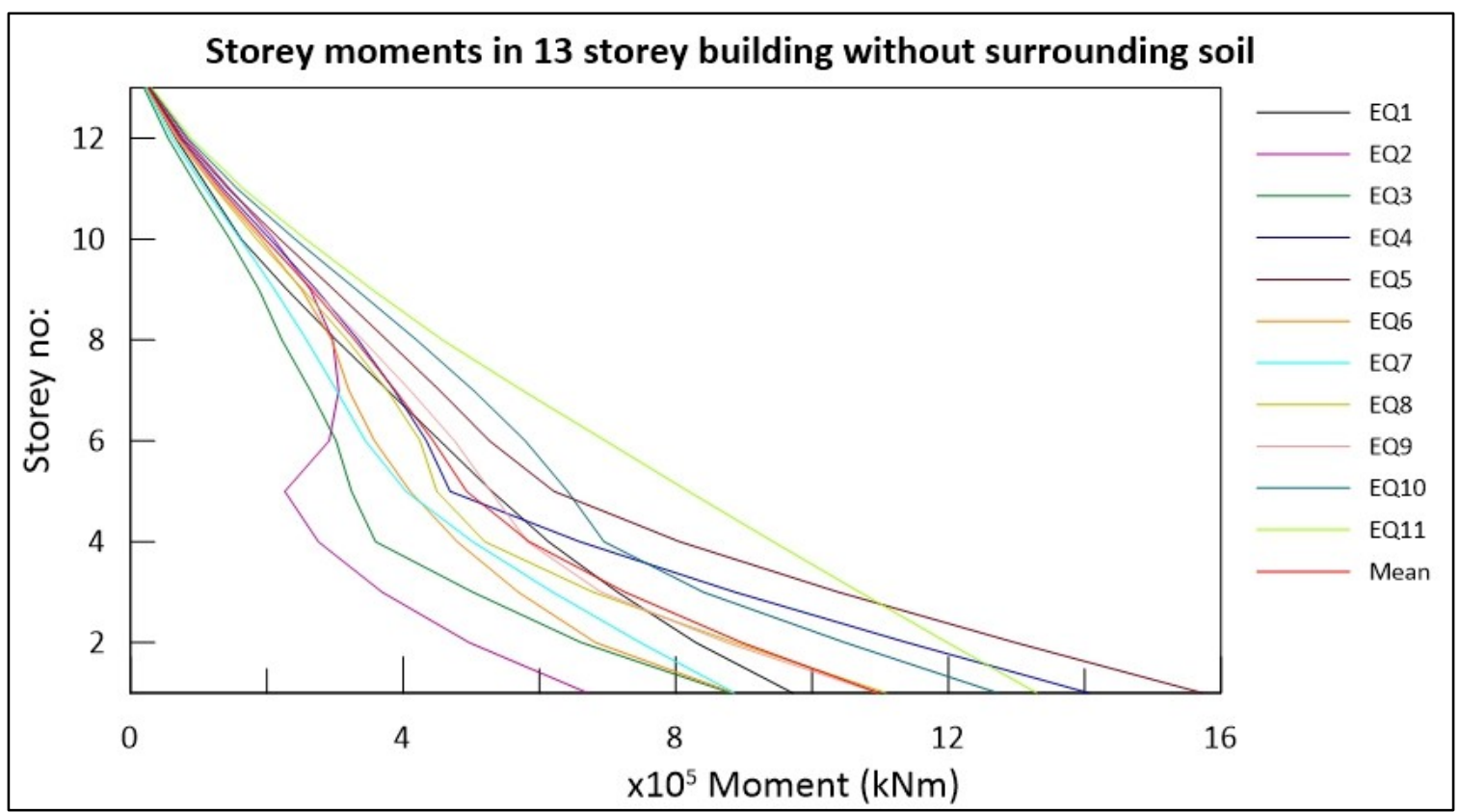

Figure B-47 Storey moments in 13storey building without any surrounding soil analyzed for 11 earthquake inputs compatible with Vancouver site B spectrum

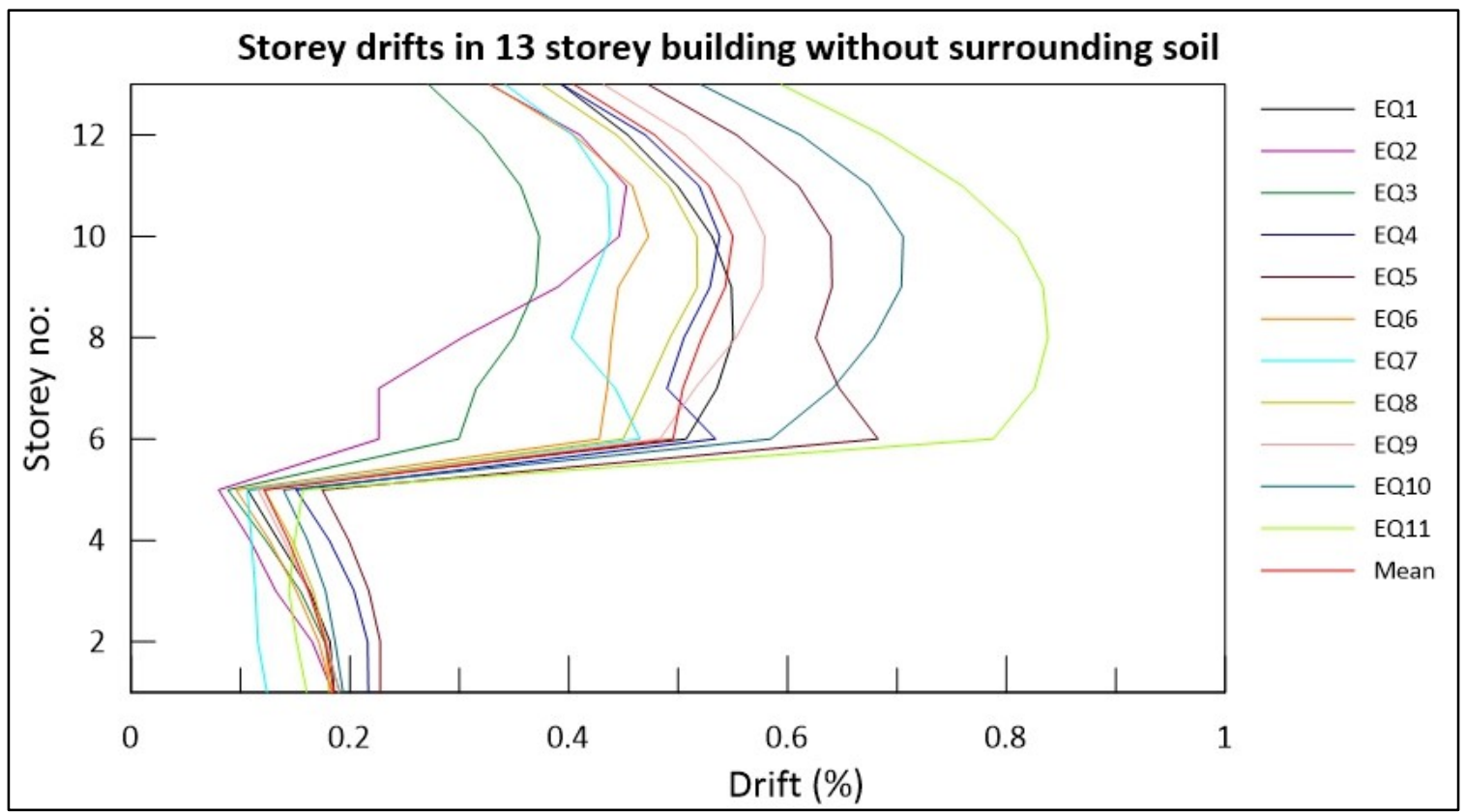

Figure B-48 Storey drifts in 13storey building without any surrounding soil analyzed for 11 earthquake inputs compatible with Vancouver site B spectrum 


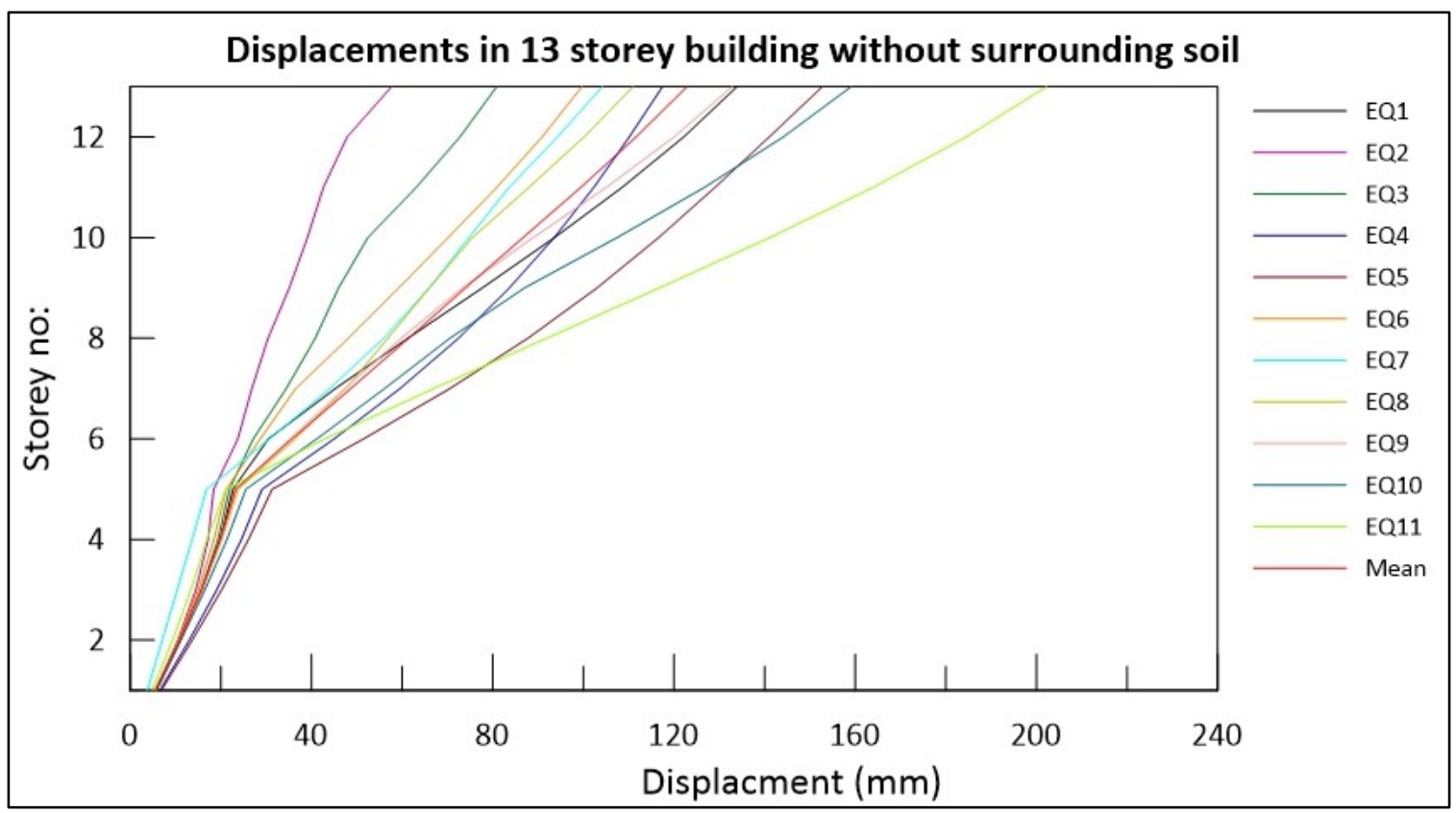

Figure B-49 Displacements in 13storey building without any surrounding soil analyzed for 11 earthquake inputs compatible with Vancouver site B spectrum

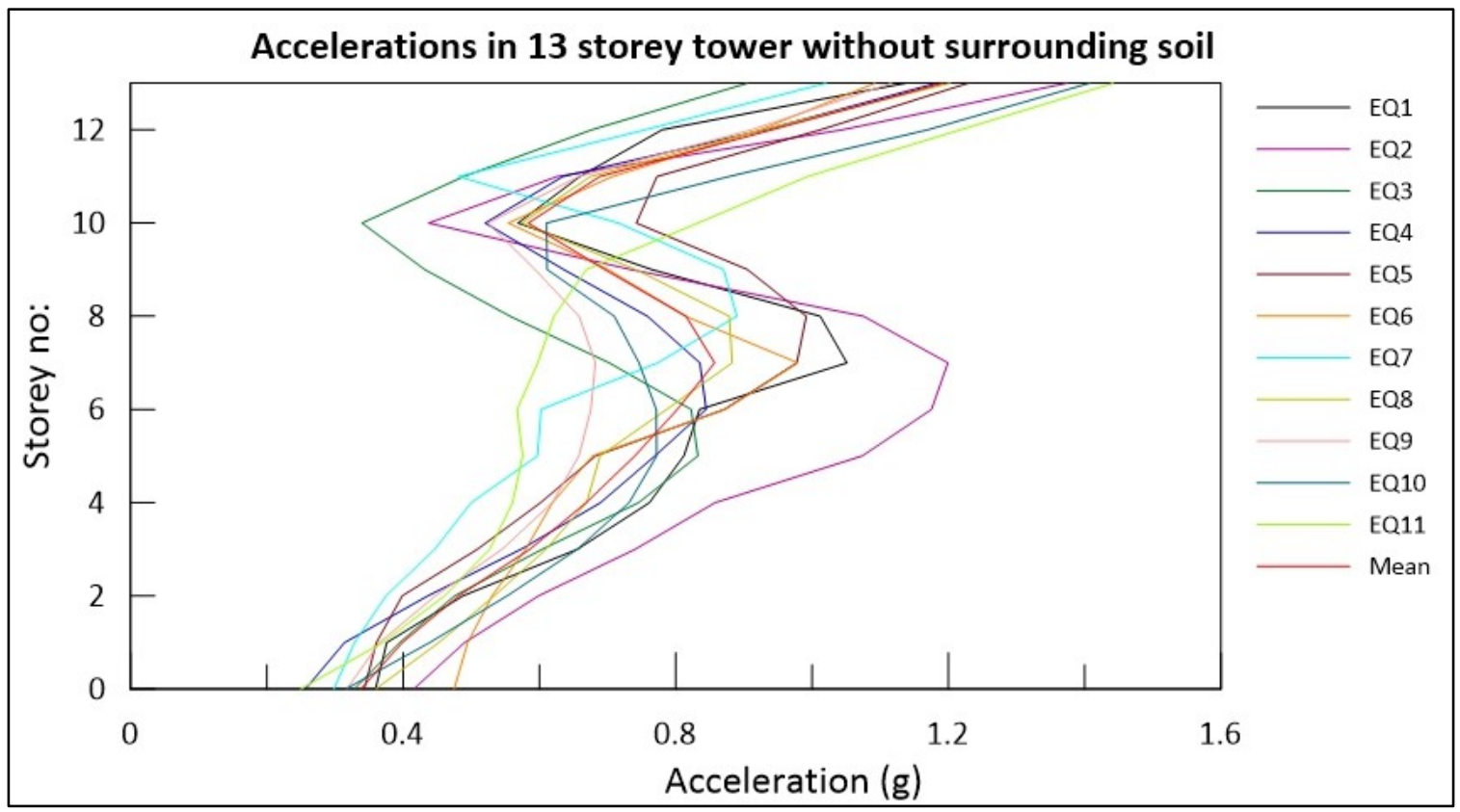

Figure B-50 Accelerations in 13storey building without any surrounding soil analyzed for 11 earthquake inputs compatible with Vancouver site B spectrum 


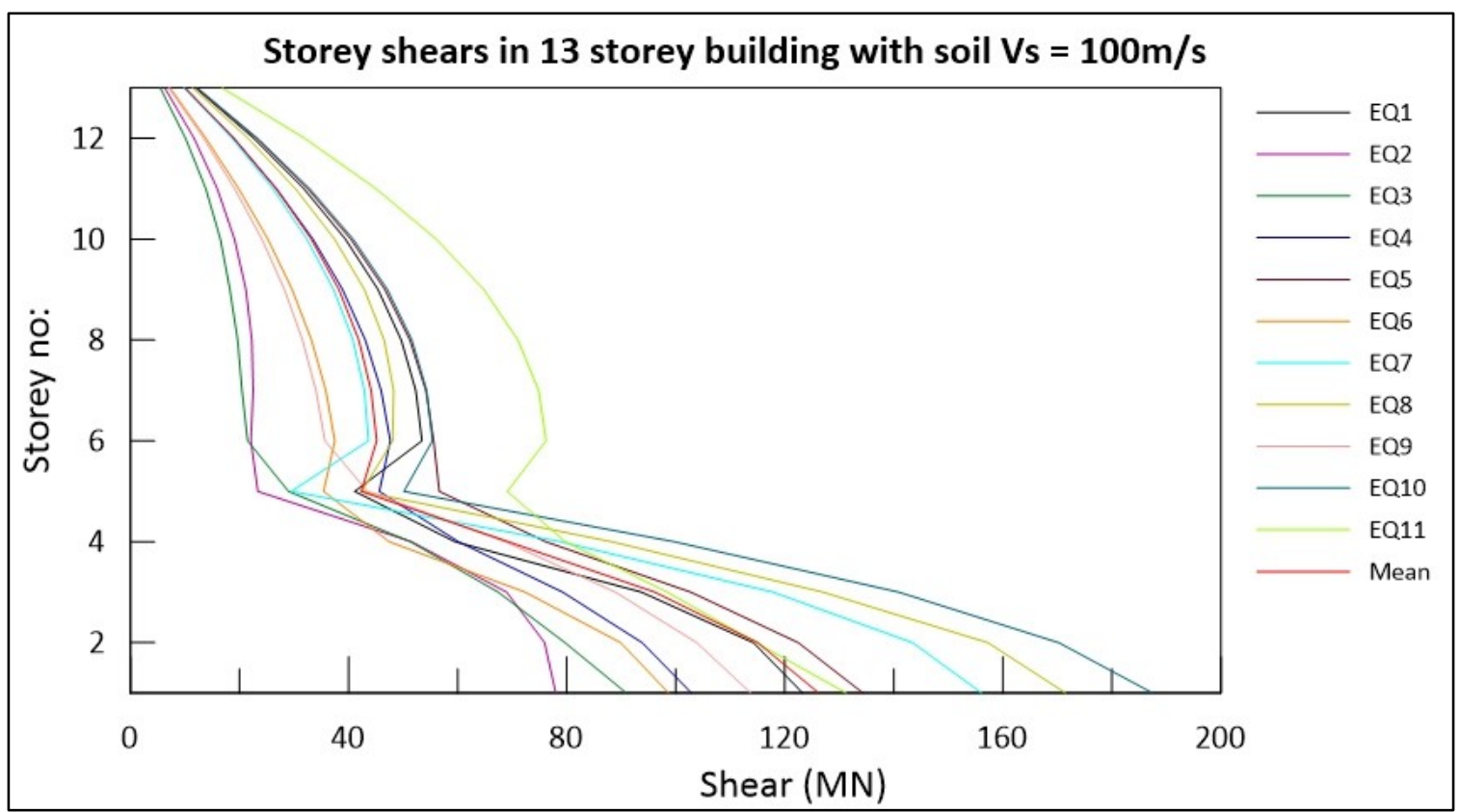

Figure B-51 Storey shears in 13storey building with soil shear wave velocity, Vs $=100 \mathrm{~m} / \mathrm{s}$ analyzed for 11 earthquake inputs compatible with Vancouver site B spectrum

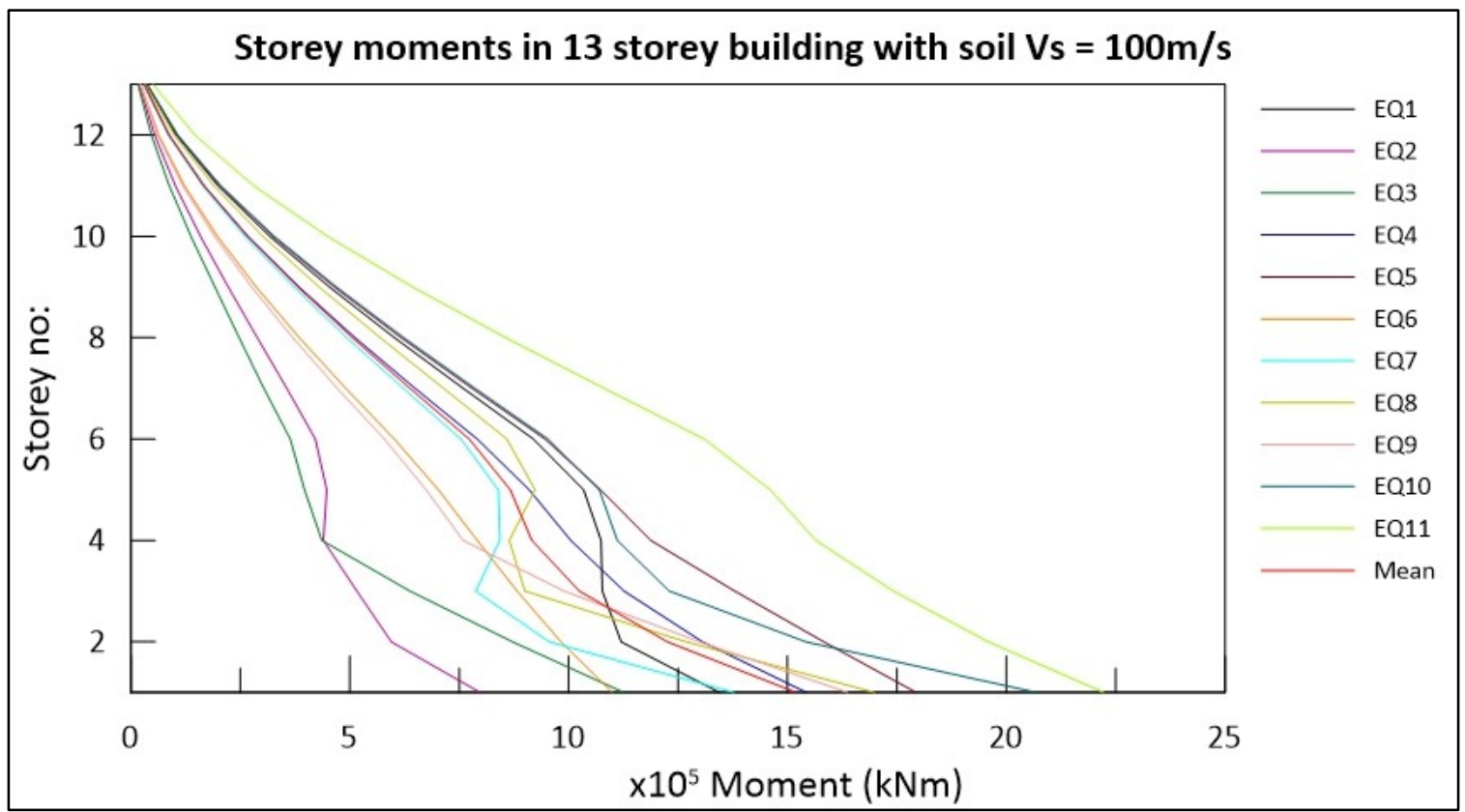

Figure B-52 Storey moments in 13storey building with soil shear wave velocity, Vs $=100 \mathrm{~m} / \mathrm{s}$ analyzed for 11 earthquake inputs compatible with Vancouver site B spectrum 


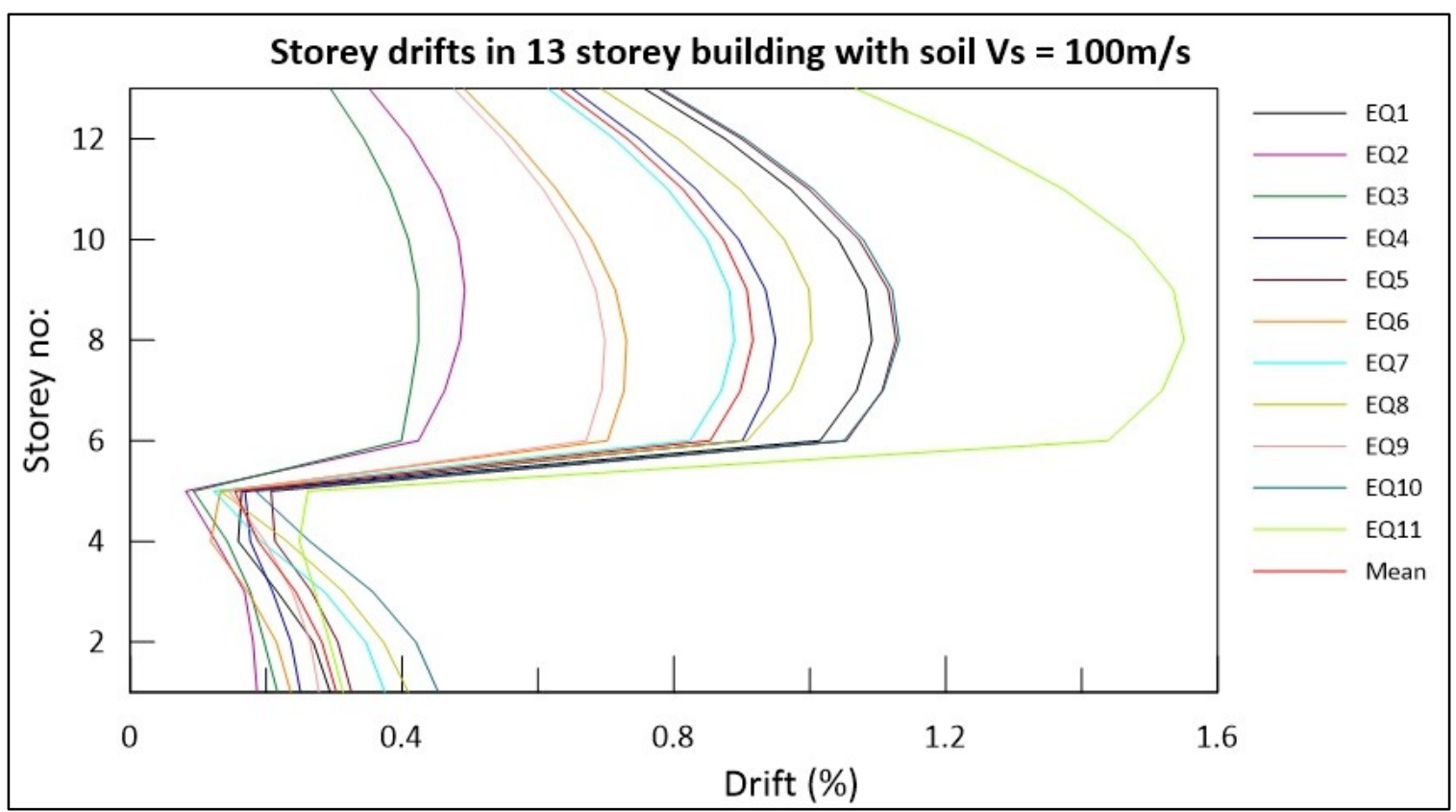

Figure B-53 Storey drifts in 13storey building with soil shear wave velocity, Vs $=100 \mathrm{~m} / \mathrm{s}$ analyzed for 11 earthquake inputs compatible with Vancouver site B spectrum

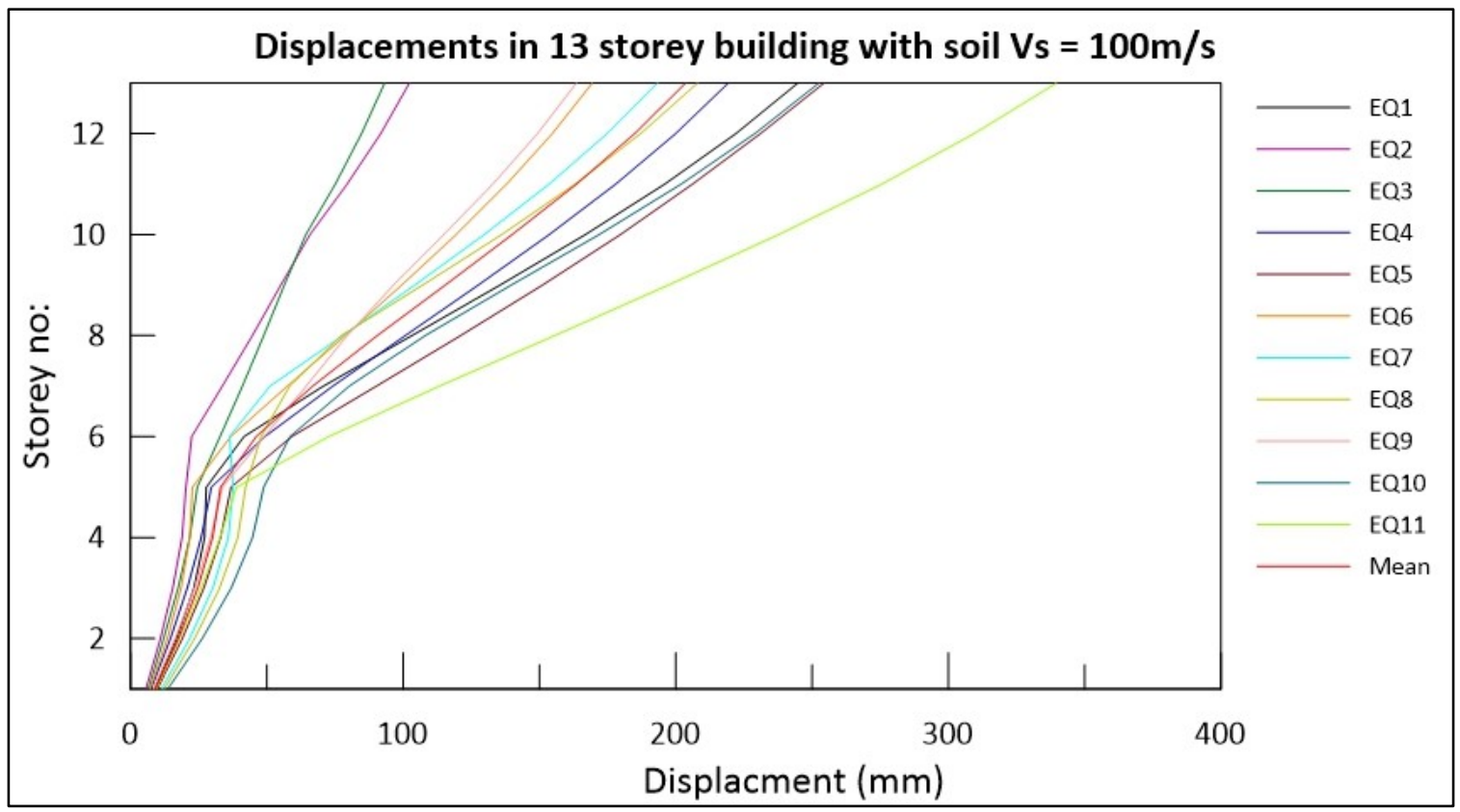

Figure B-54 Displacements in 13storey building with soil shear wave velocity, Vs $=100 \mathrm{~m} / \mathrm{s}$ analyzed for 11 earthquake inputs compatible with Vancouver site B spectrum 


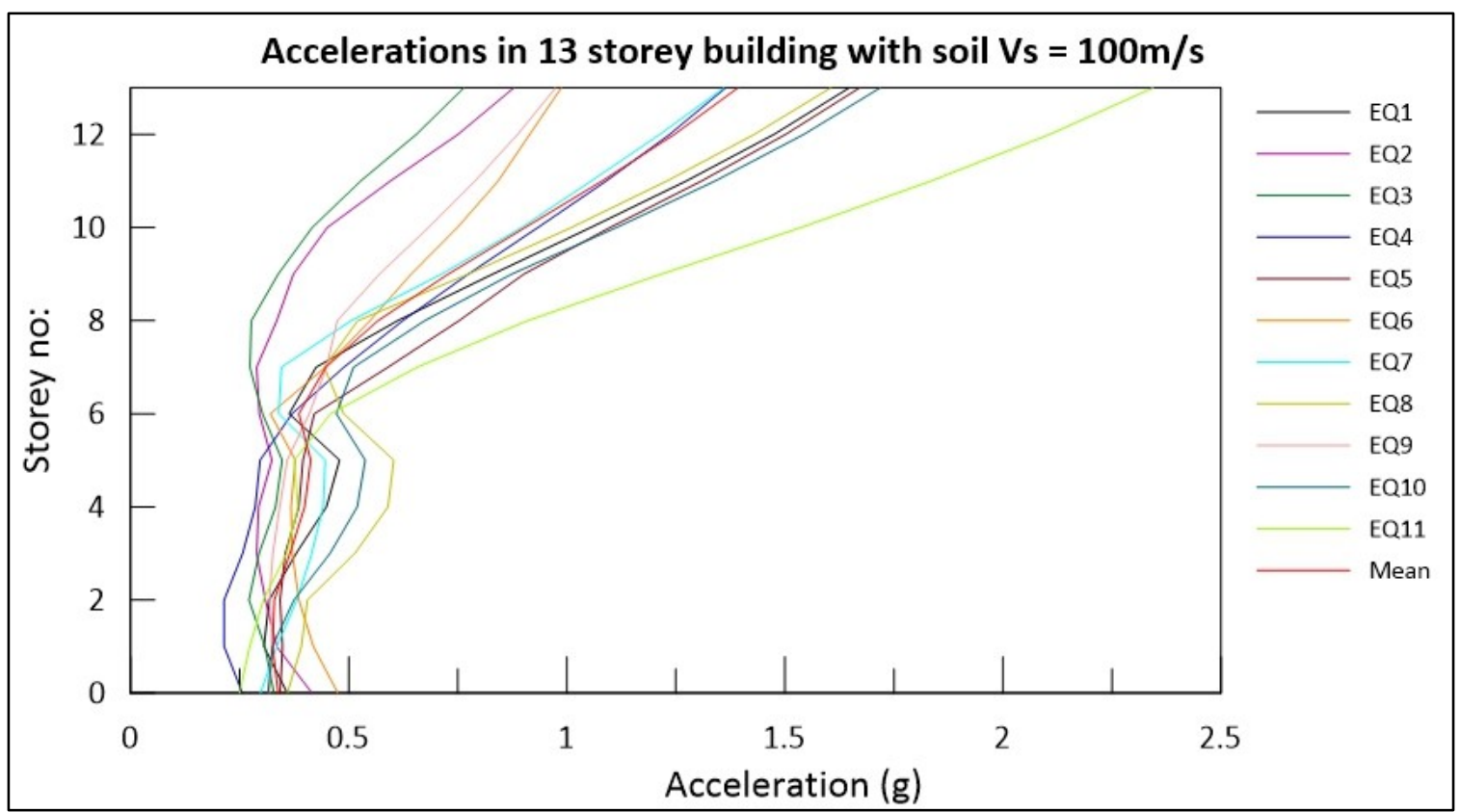

Figure B-55 Accelerations in 13storey building with soil shear wave velocity, Vs $=100 \mathrm{~m} / \mathrm{s}$ analyzed for 11 earthquake inputs compatible with Vancouver site B spectrum

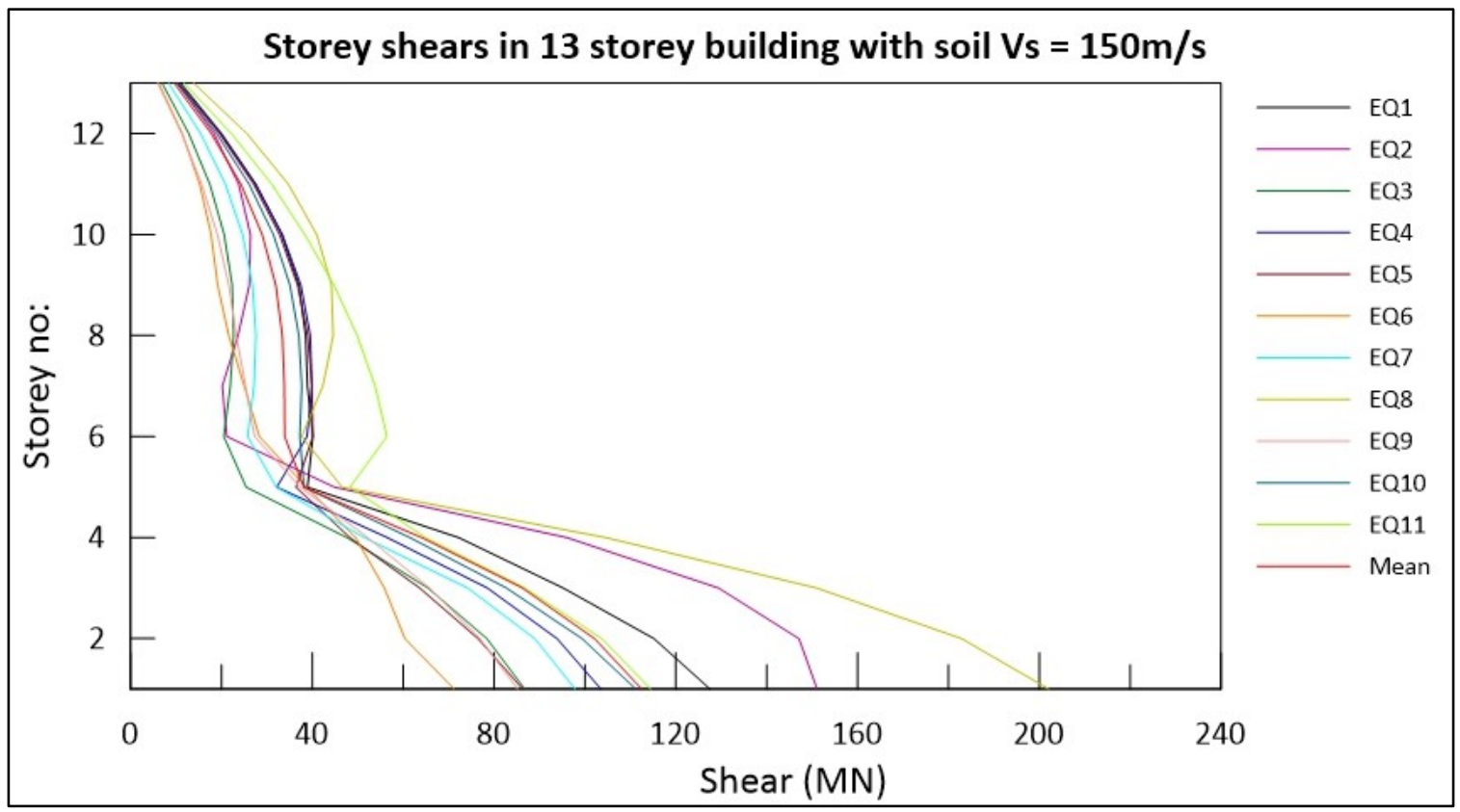

Figure B-56 Storey shears in 13storey building with soil shear wave velocity, Vs $=150 \mathrm{~m} / \mathrm{s}$ analyzed for 11 earthquake inputs compatible with Vancouver site B spectrum 


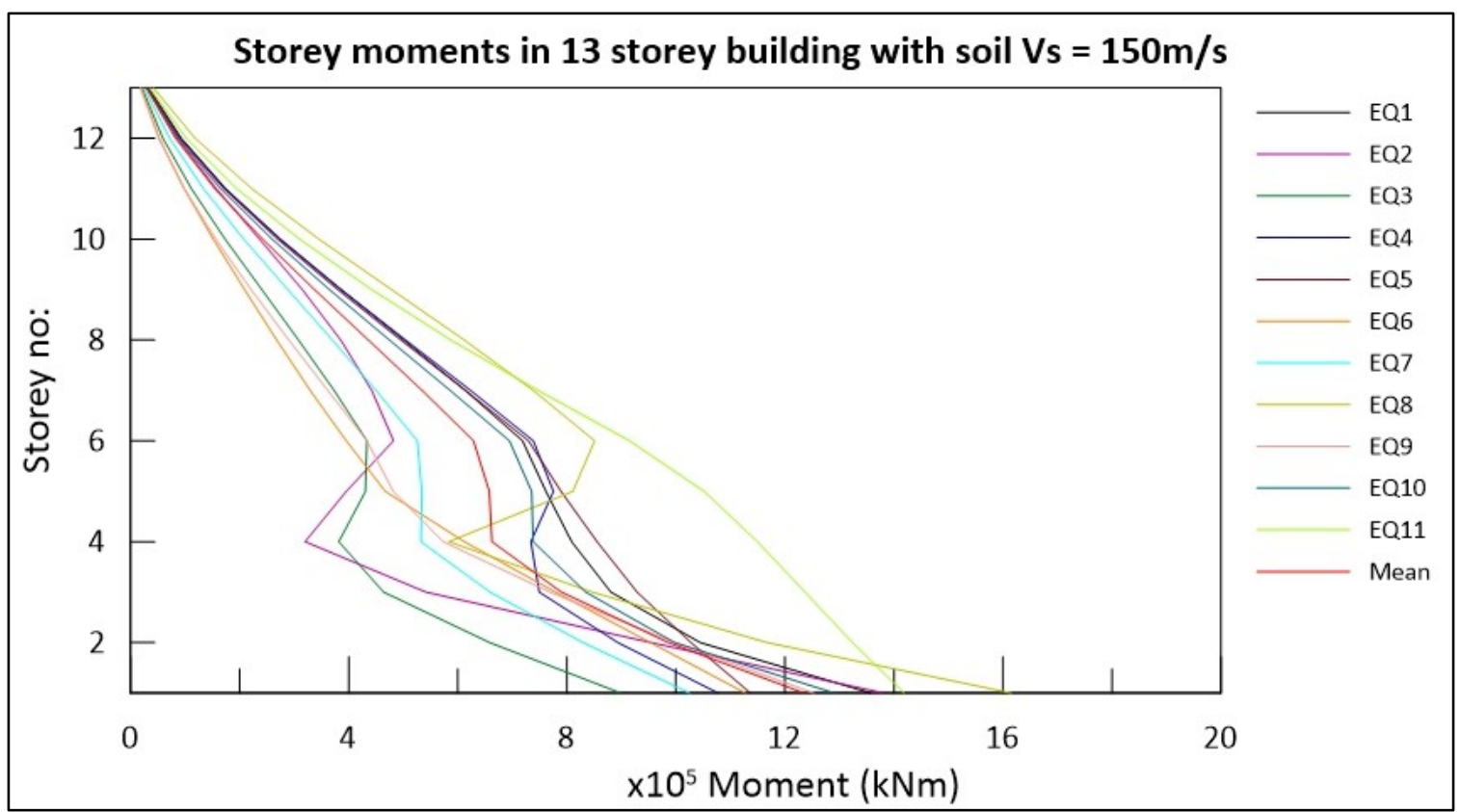

Figure B-57 Storey moments in 13storey building with soil shear wave velocity, Vs $=100 \mathrm{~m} / \mathrm{s}$ analyzed for 11 earthquake inputs compatible with Vancouver site B spectrum

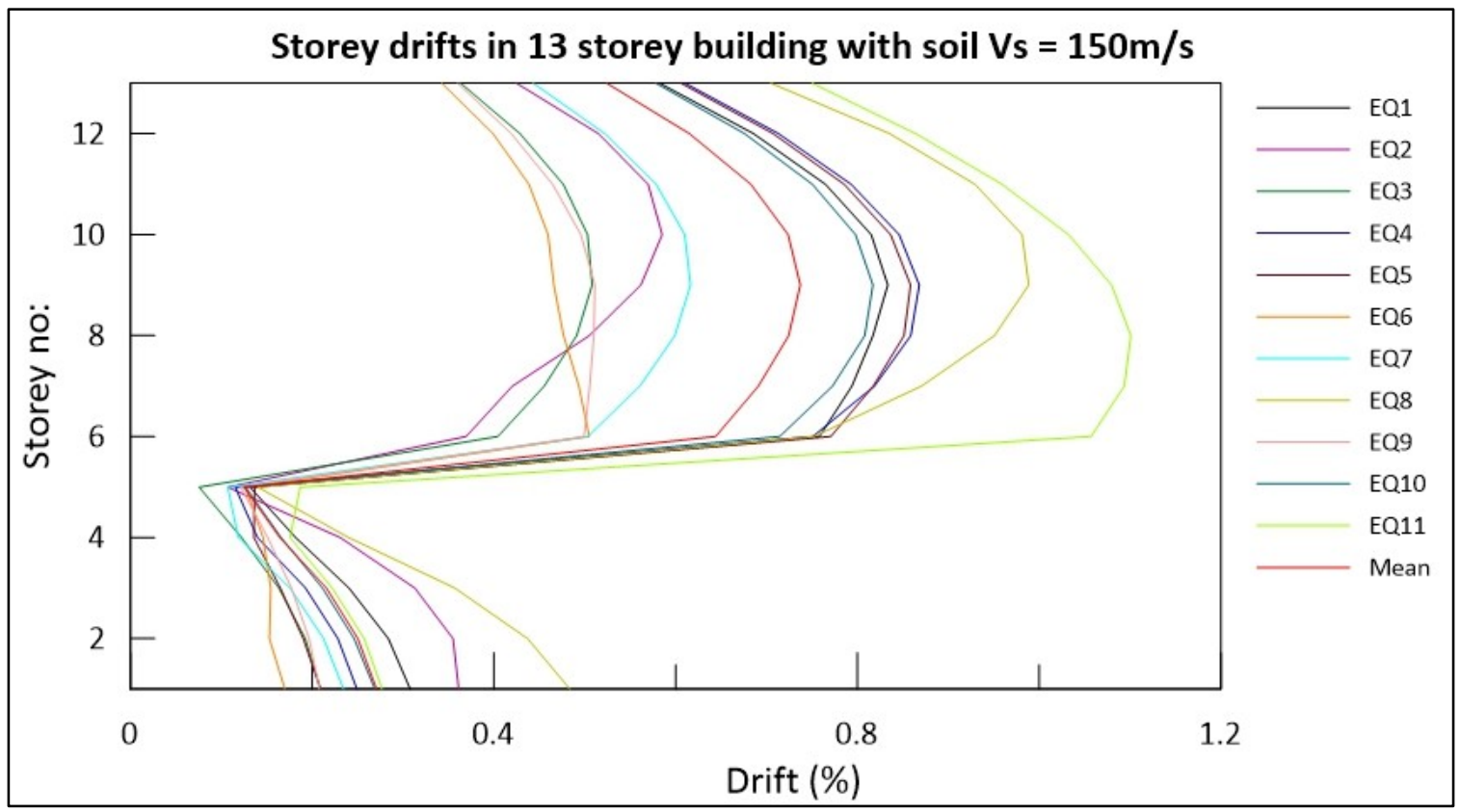

Figure B-58 Storey drifts in 13storey building with soil shear wave velocity, Vs $=150 \mathrm{~m} / \mathrm{s}$ analyzed for 11 earthquake inputs compatible with Vancouver site B spectrum 


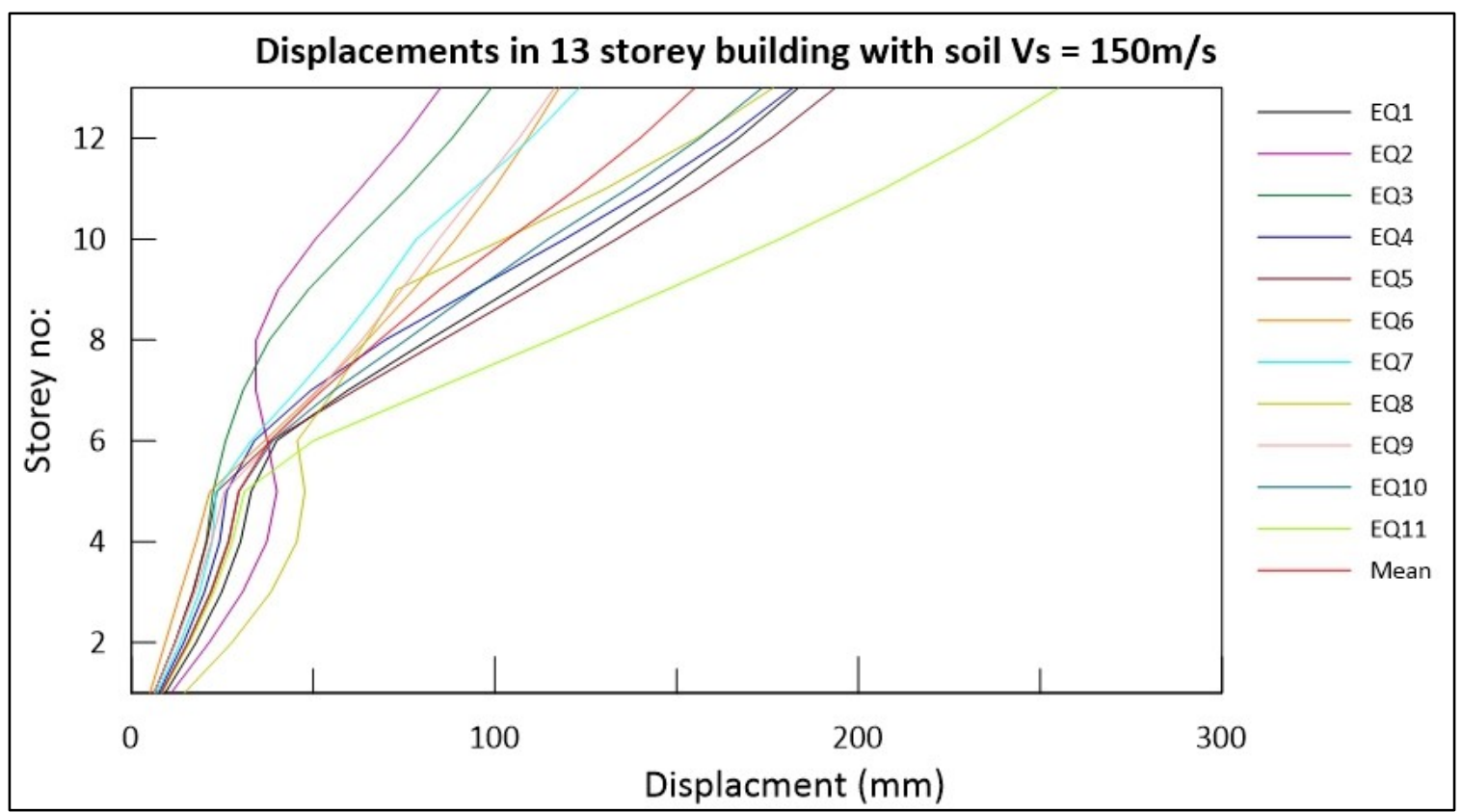

Figure B-59 Displacements in 13storey building with soil shear wave velocity, Vs $=150 \mathrm{~m} / \mathrm{s}$ analyzed for 11 earthquake inputs compatible with Vancouver site B spectrum

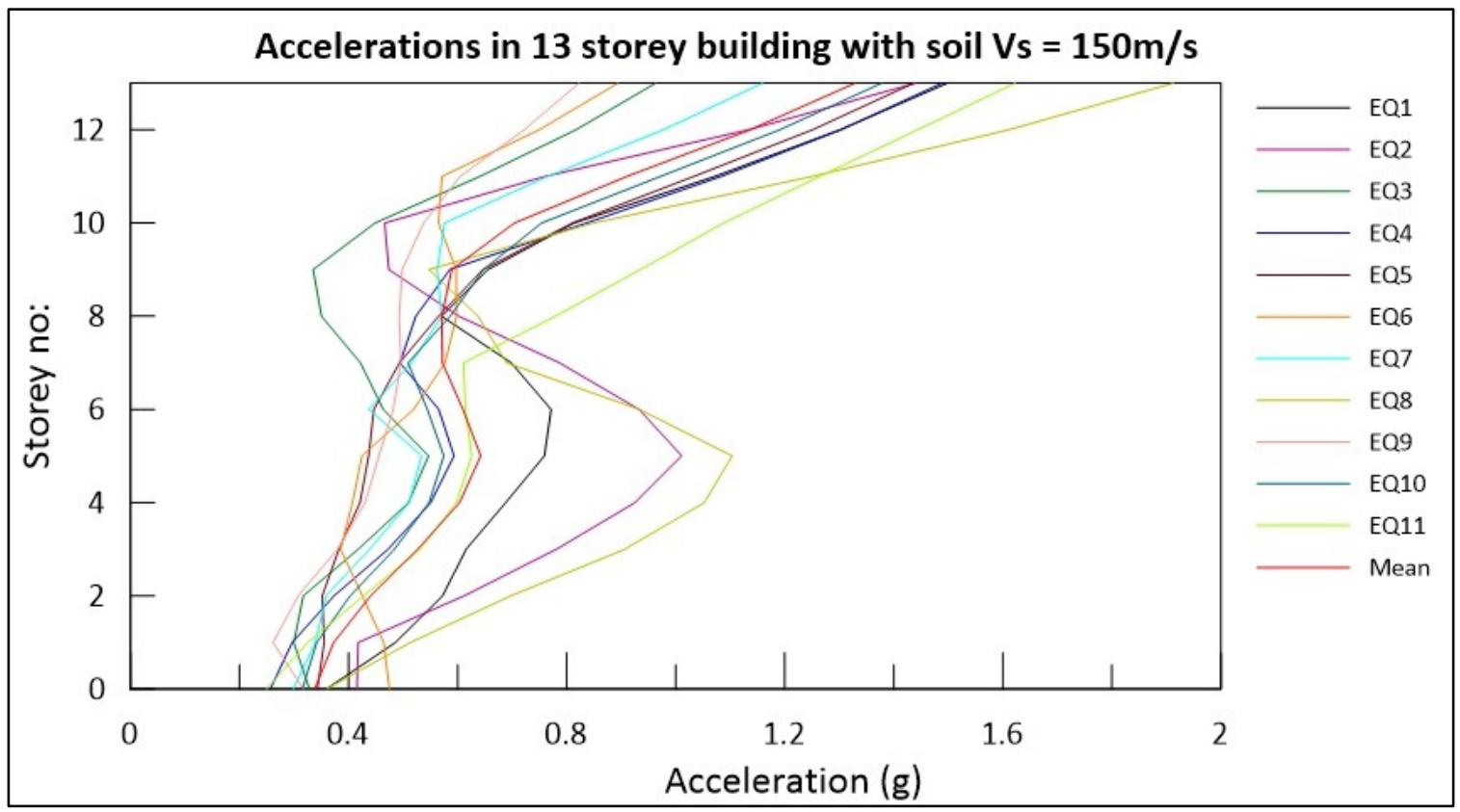

Figure B-60 Accelerations in 13storey building with soil shear wave velocity, Vs $=150 \mathrm{~m} / \mathrm{s}$ analyzed for 11 earthquake inputs compatible with Vancouver site B spectrum 


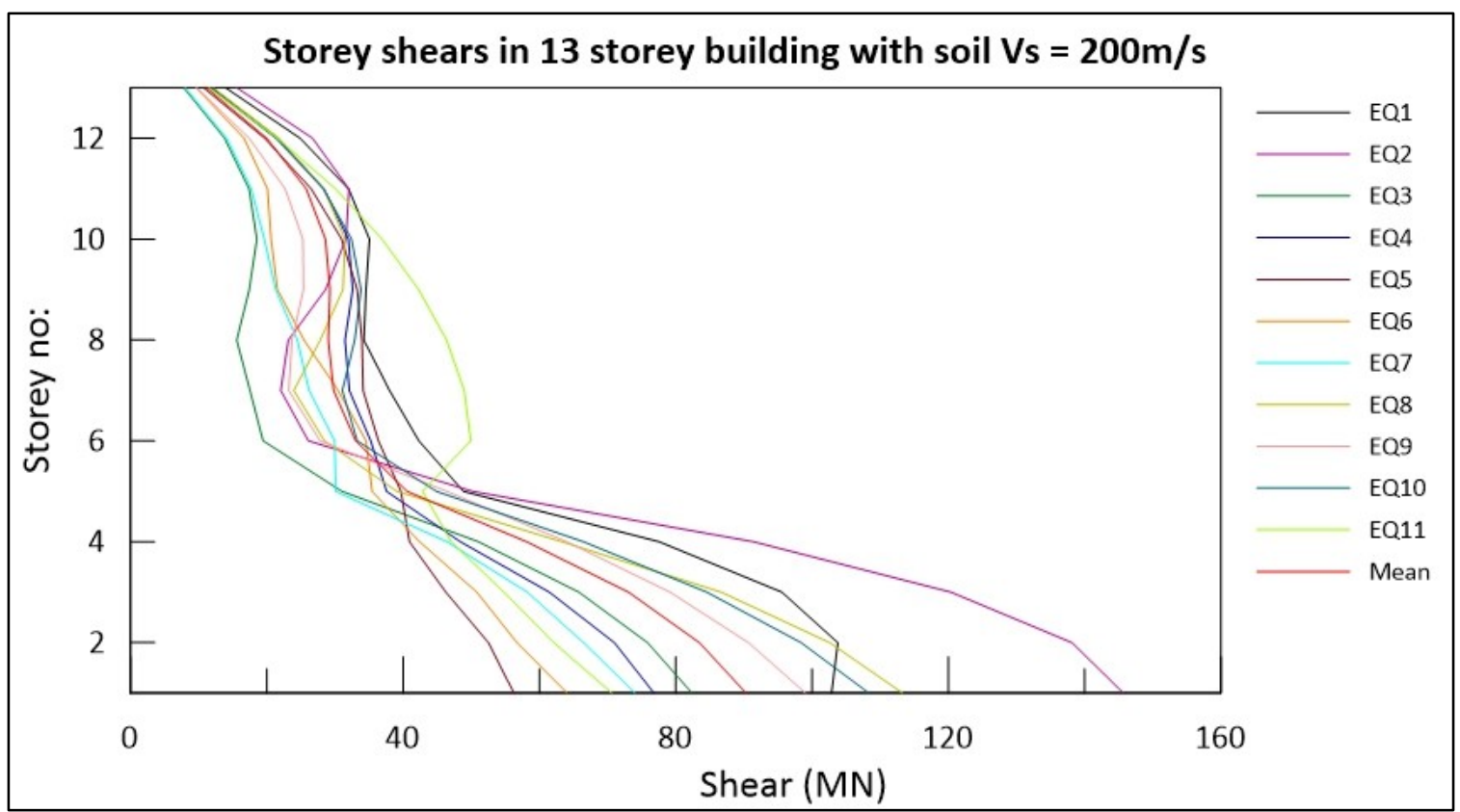

Figure B-61 Storey shears in 13storey building with soil shear wave velocity, Vs $=200 \mathrm{~m} / \mathrm{s}$ analyzed for 11 earthquake inputs compatible with Vancouver site B spectrum

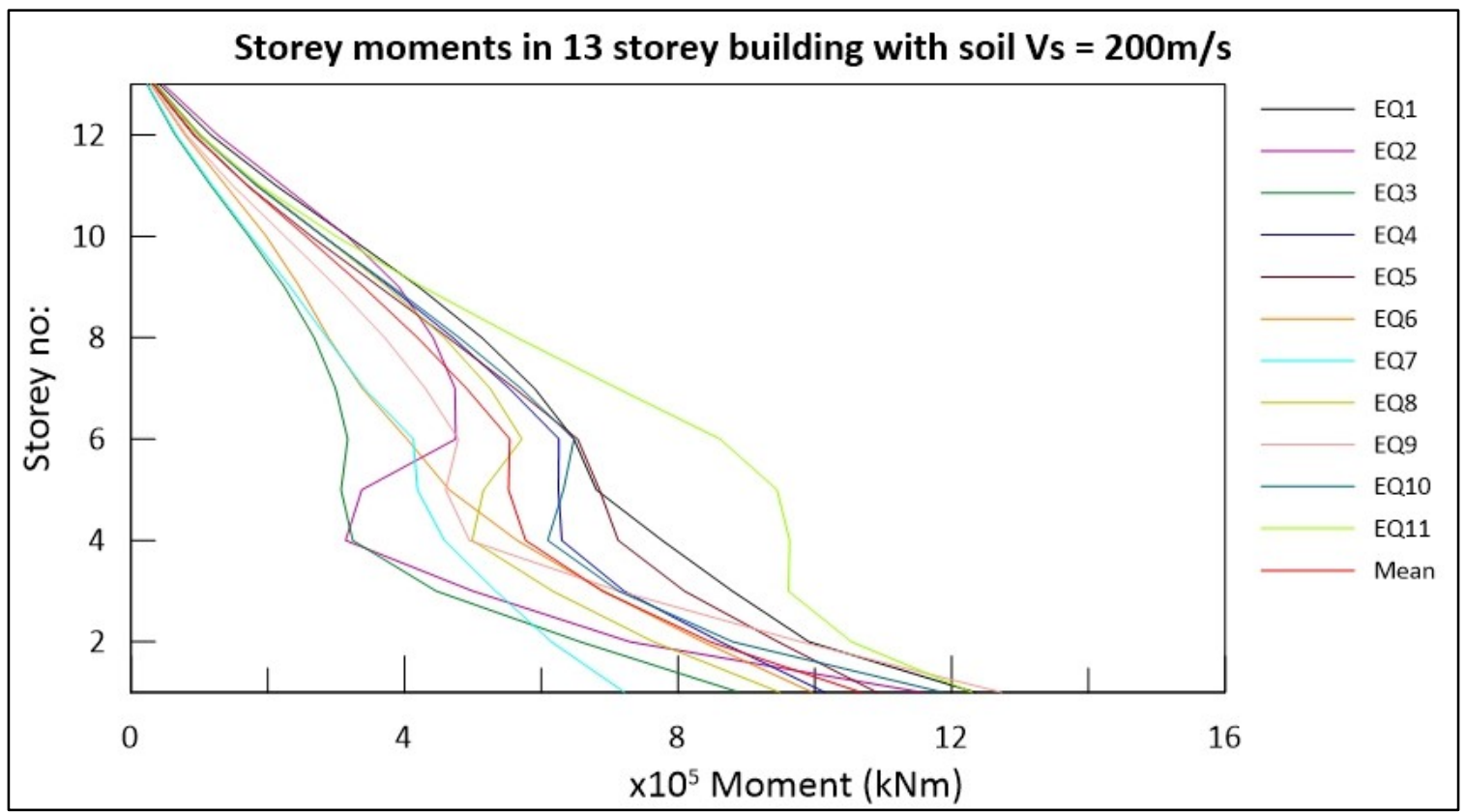

Figure B-62 Storey moments in 13storey building with soil shear wave velocity, Vs $=200 \mathrm{~m} / \mathrm{s}$ analyzed for 11 earthquake inputs compatible with Vancouver site B spectrum 


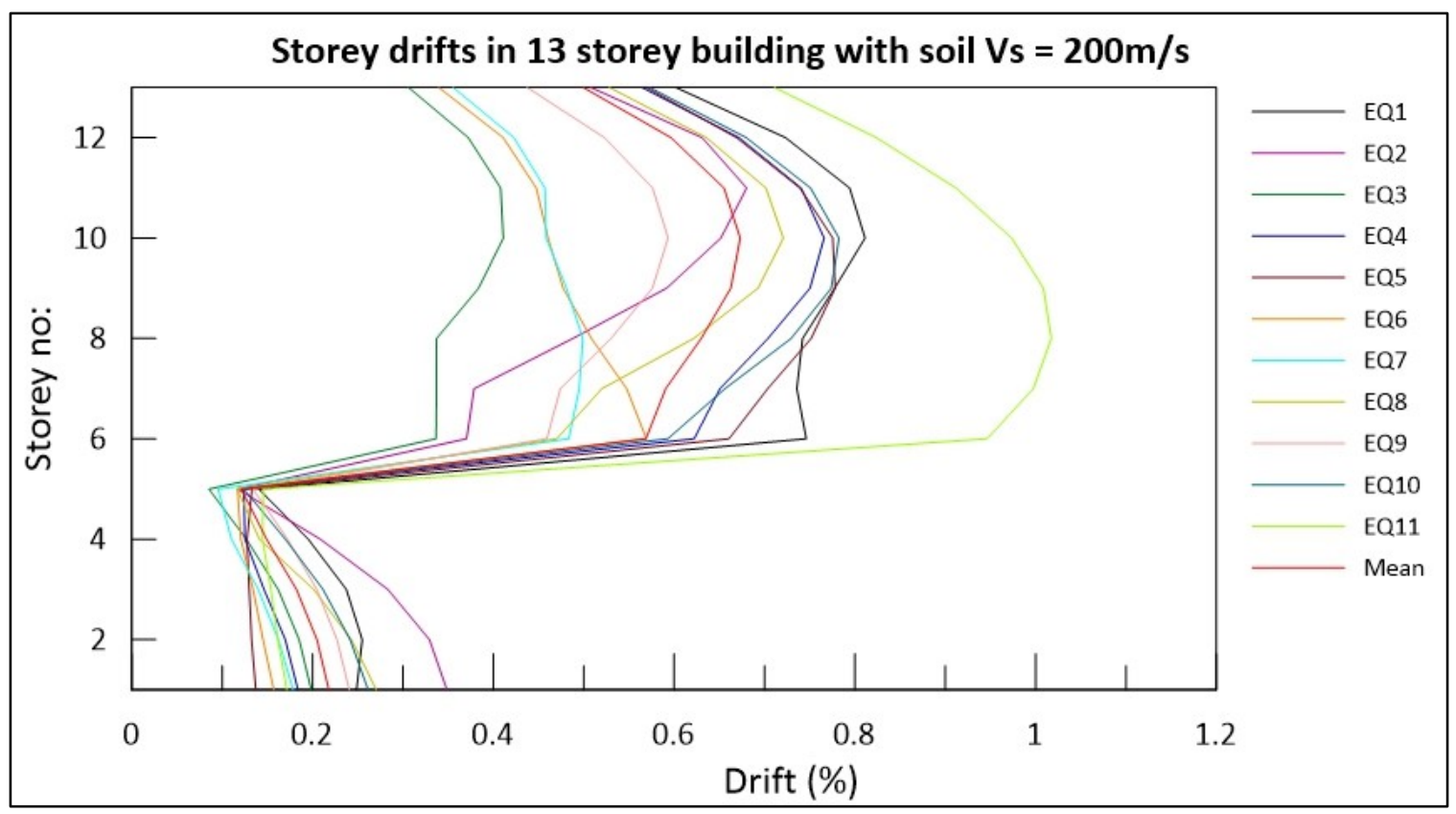

Figure B-63 Storey drifts in 13storey building with soil shear wave velocity, Vs $=200 \mathrm{~m} / \mathrm{s}$ analyzed for 11 earthquake inputs compatible with Vancouver site B spectrum

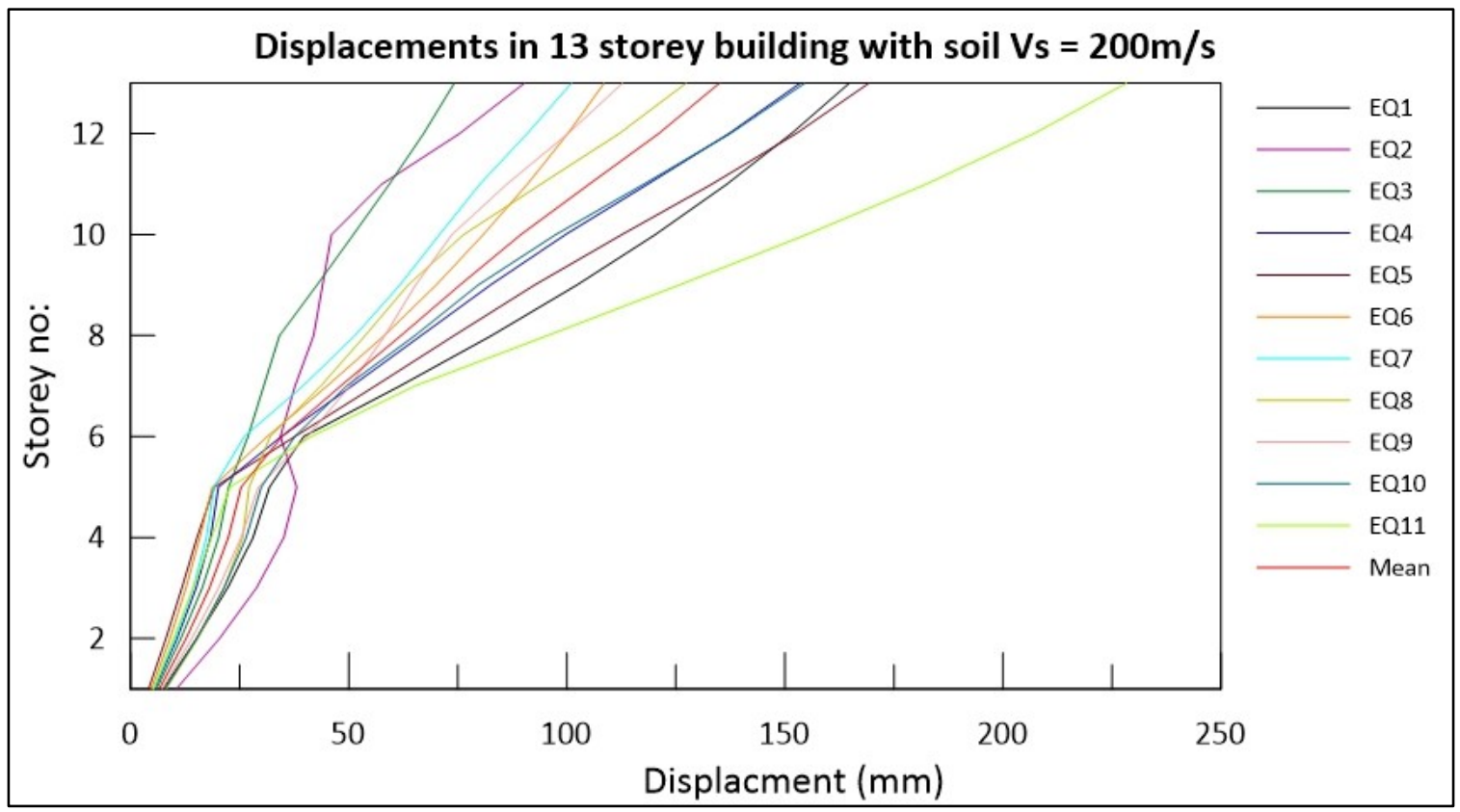

Figure B-64 Displacements in 13storey building with soil shear wave velocity, Vs = 200m/s analyzed for 11 earthquake inputs compatible with Vancouver site B spectrum 


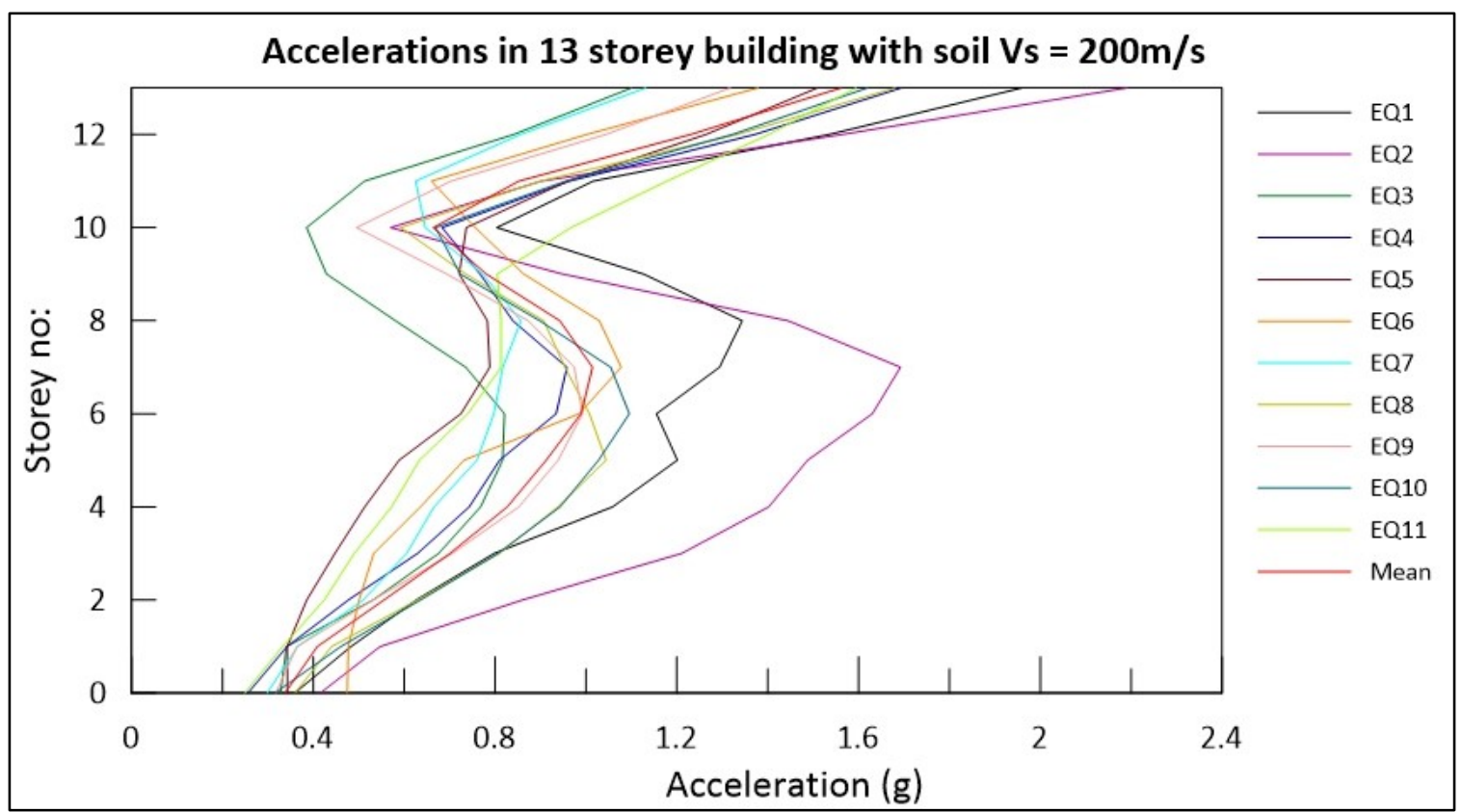

Figure B-65 Accelerations in 13storey building with soil shear wave velocity, Vs = 200m/s analyzed for 11 earthquake inputs compatible with Vancouver site B spectrum

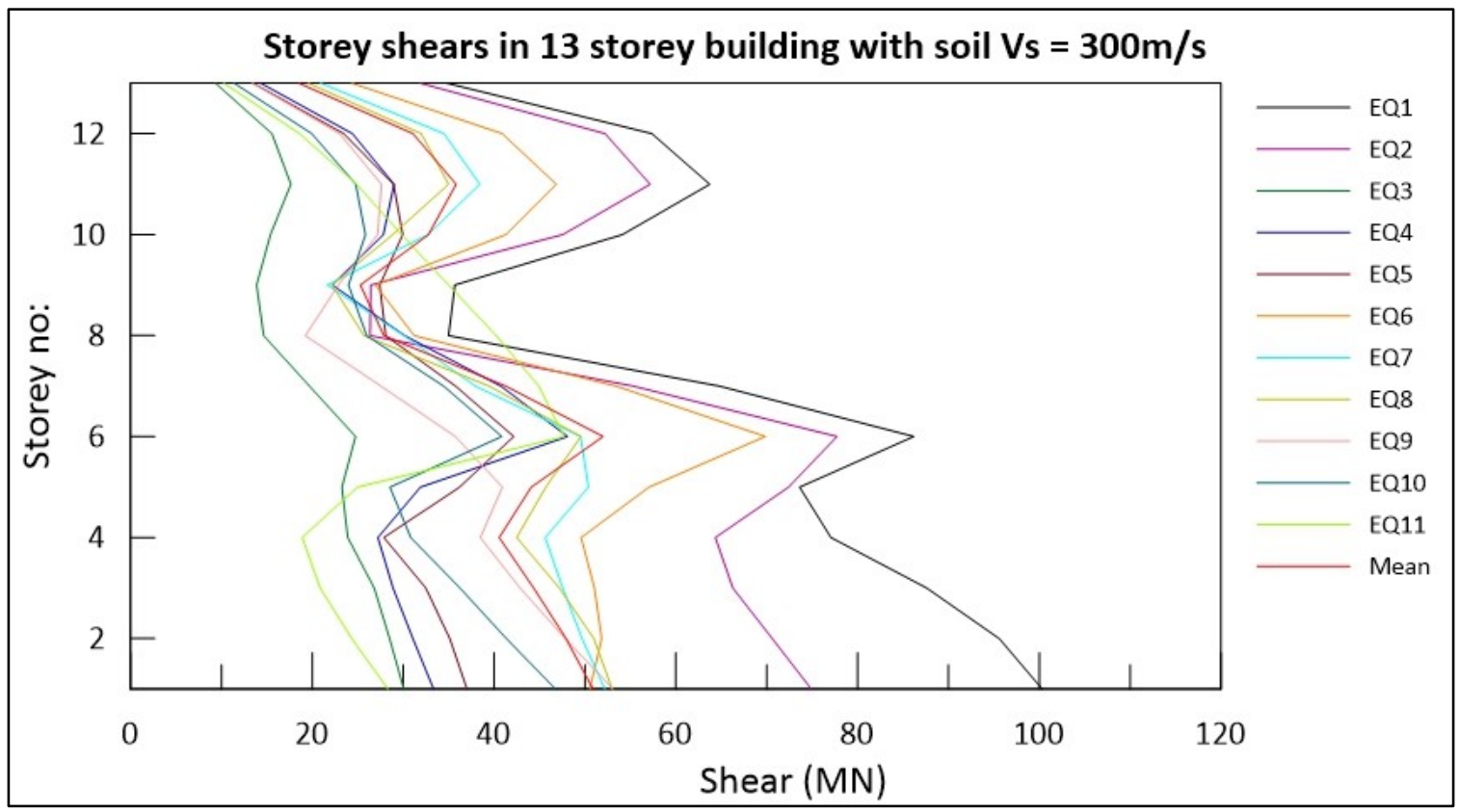

Figure B-66 Storey shears in 13storey building with soil shear wave velocity, Vs $=300 \mathrm{~m} / \mathrm{s}$ analyzed for 11 earthquake inputs compatible with Vancouver site B spectrum 


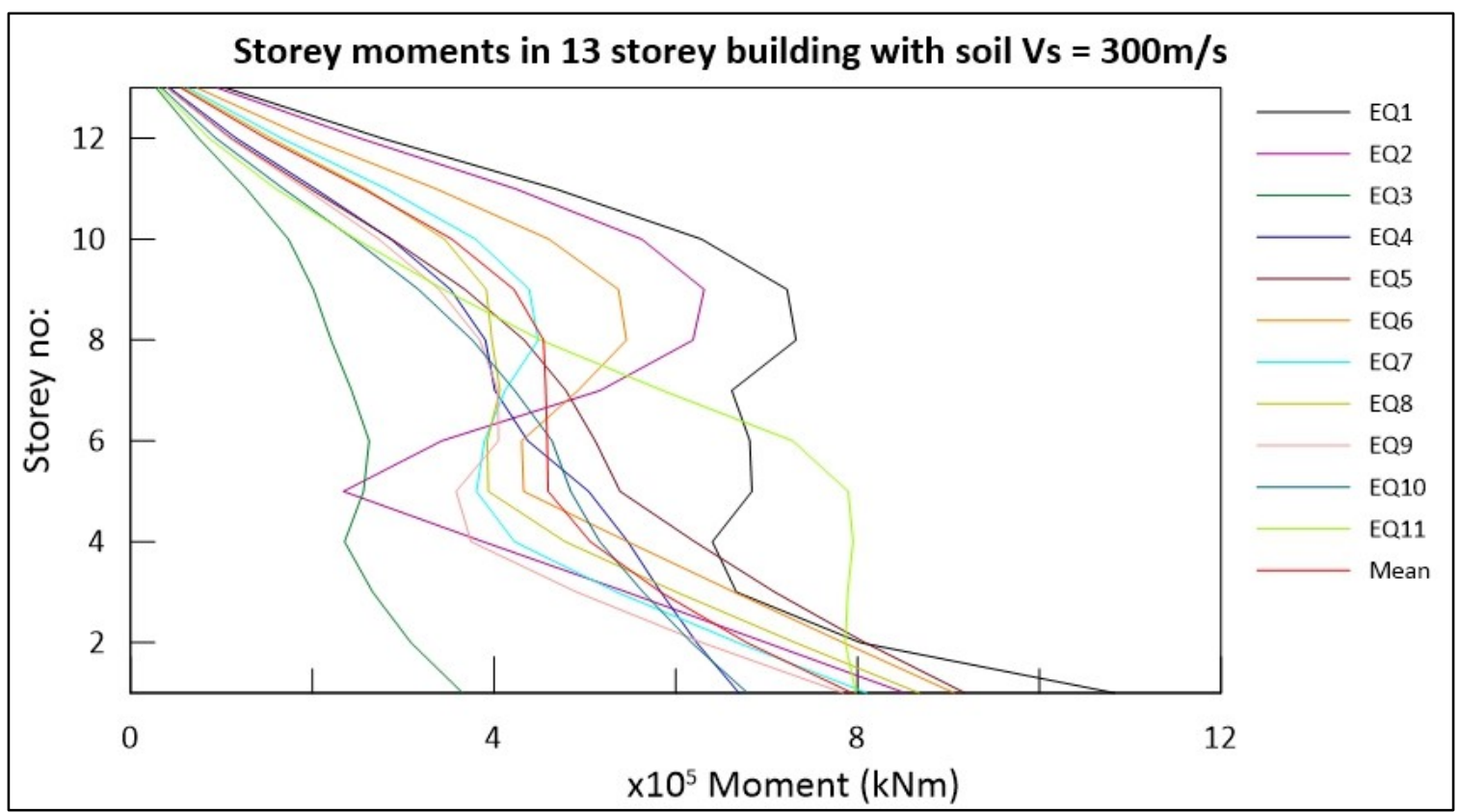

Figure B-67 Storey moments in 13storey building with soil shear wave velocity, Vs $=300 \mathrm{~m} / \mathrm{s}$ analyzed for 11 earthquake inputs compatible with Vancouver site B spectrum

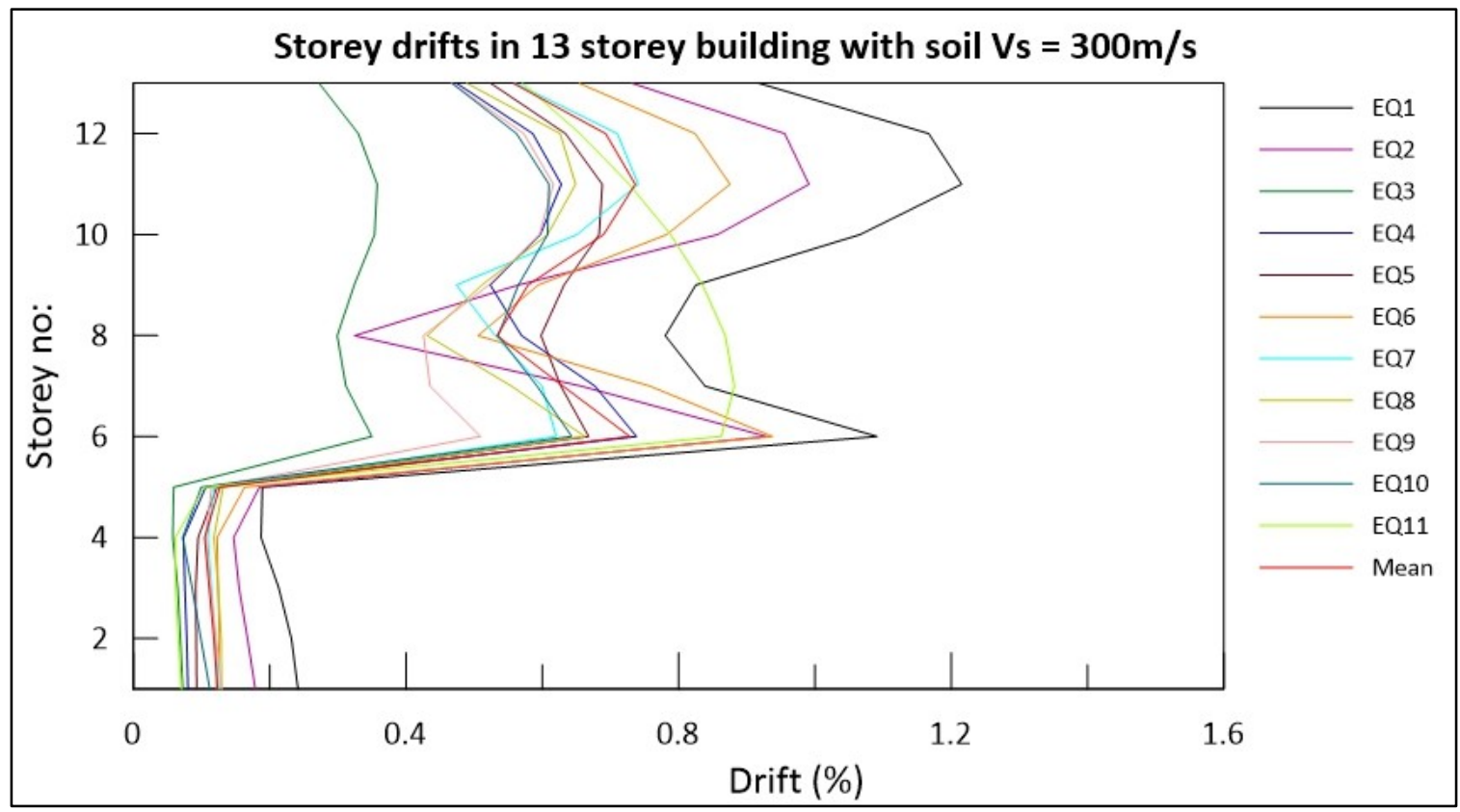

Figure B-68 Storey drifts in 13storey building with soil shear wave velocity, Vs $=300 \mathrm{~m} / \mathrm{s}$ analyzed for 11 earthquake inputs compatible with Vancouver site B spectrum 


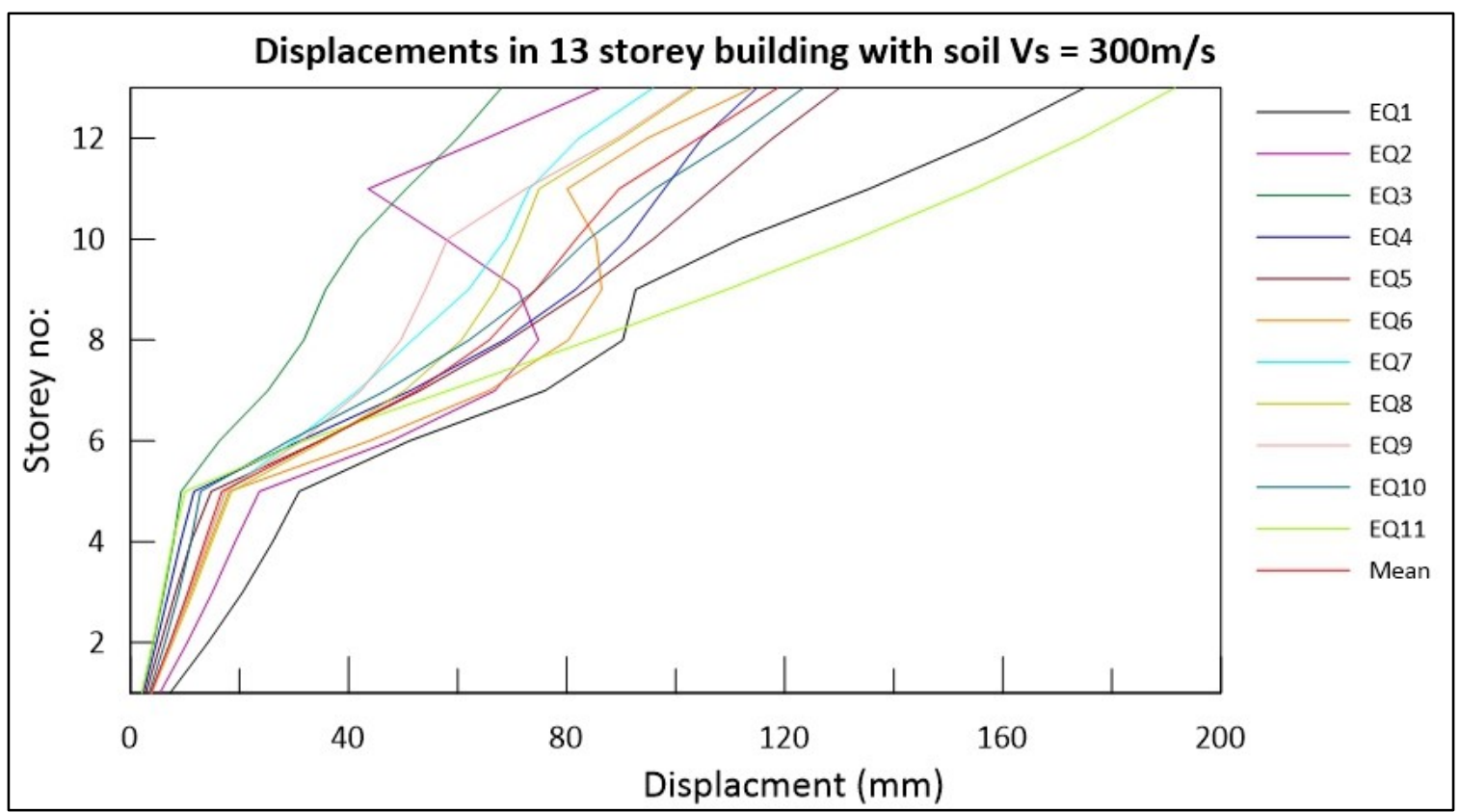

Figure B-69 Displacements in 13storey building with soil shear wave velocity, Vs $=300 \mathrm{~m} / \mathrm{s}$ analyzed for 11 earthquake inputs compatible with Vancouver site B spectrum

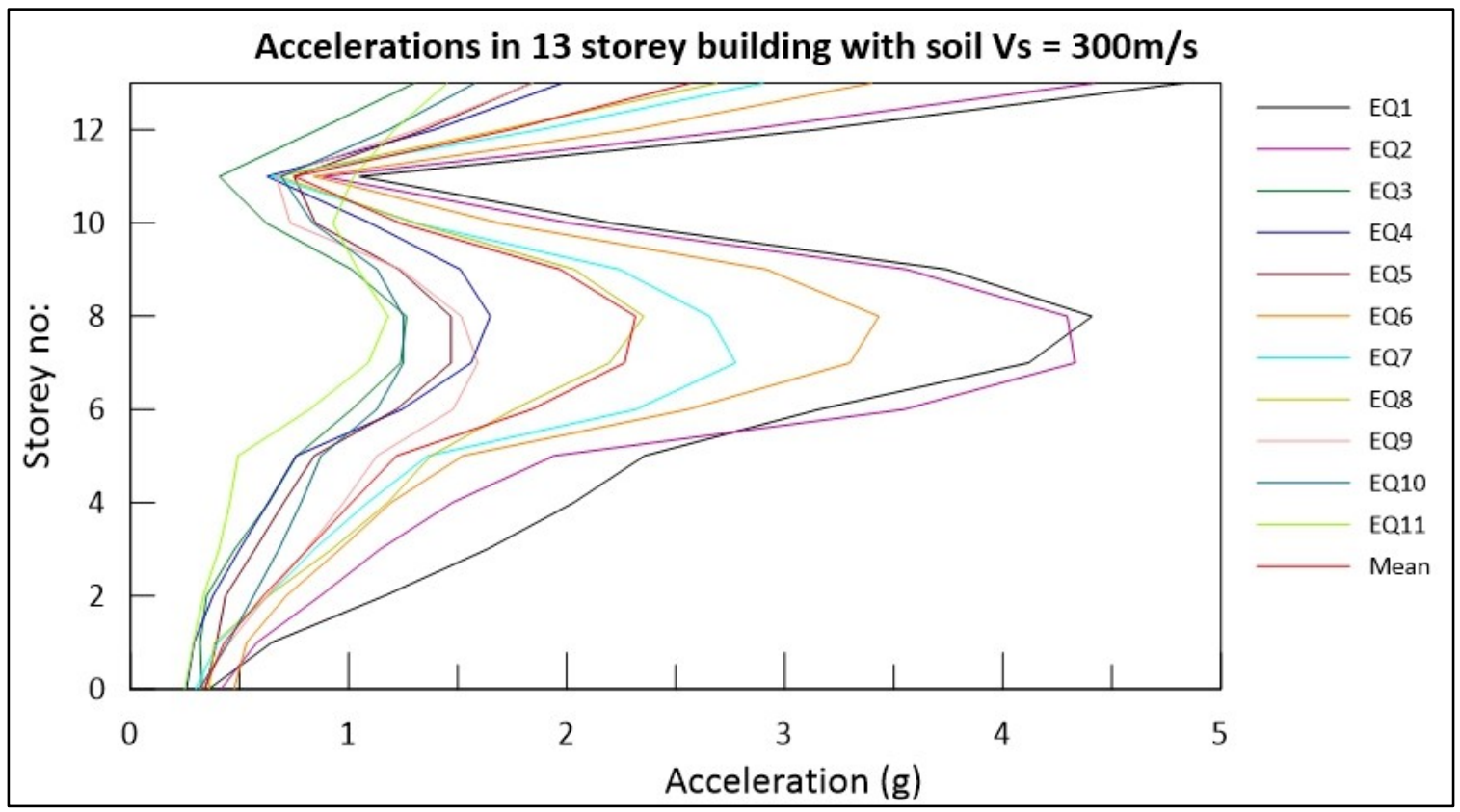

Figure B-70 Accelerations in 13storey building with soil shear wave velocity, Vs = 300m/s analyzed for 11 earthquake inputs compatible with Vancouver site B spectrum 


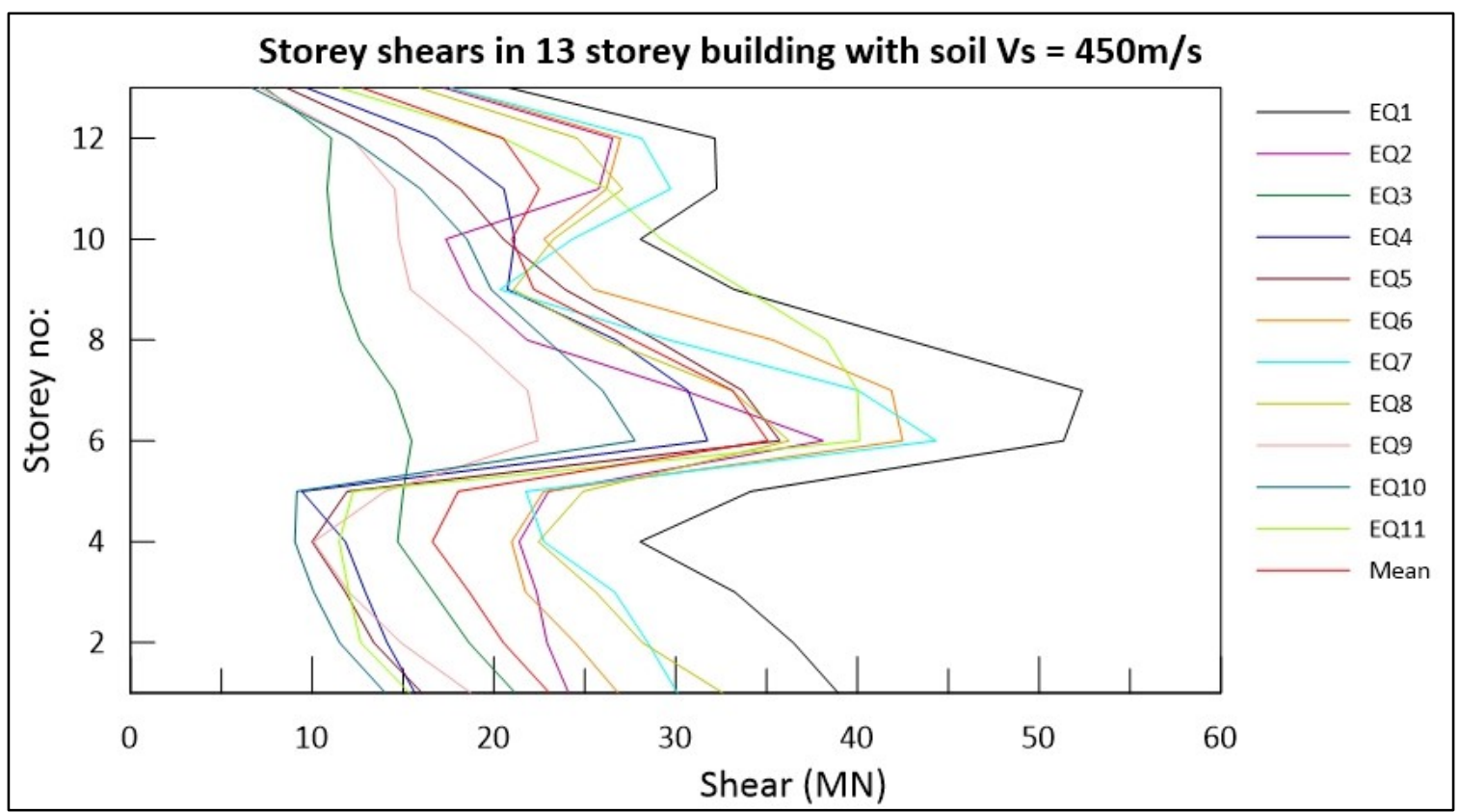

Figure B-71 Storey shears in 13storey building with soil shear wave velocity, Vs $=450 \mathrm{~m} / \mathrm{s}$ analyzed for 11 earthquake inputs compatible with Vancouver site B spectrum

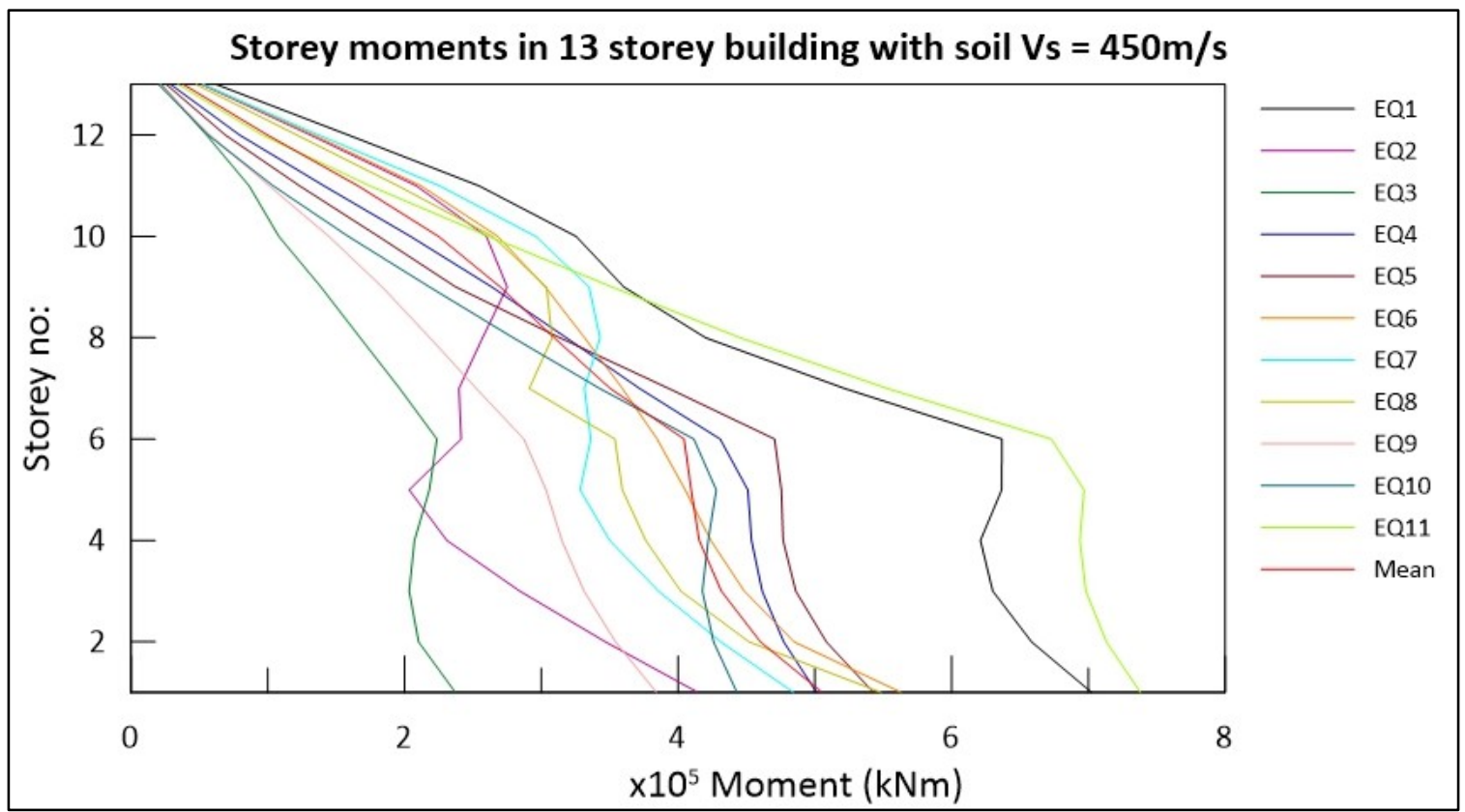

Figure B-72 Storey moments in 13storey building with soil shear wave velocity, Vs $=450 \mathrm{~m} / \mathrm{s}$ analyzed for 11 earthquake inputs compatible with Vancouver site B spectrum 


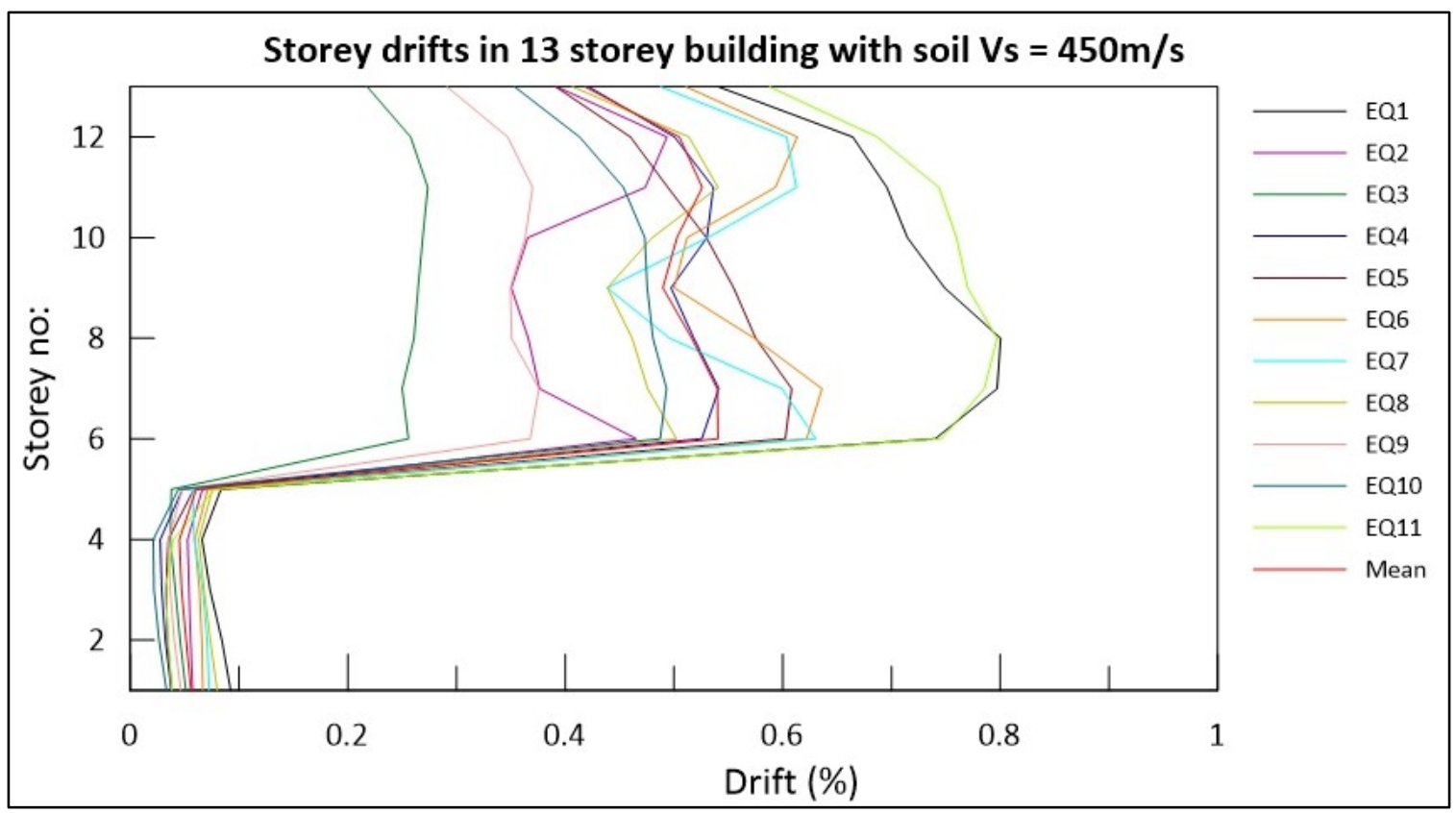

Figure B-73 Storey drifts in 13storey building with soil shear wave velocity, Vs $=450 \mathrm{~m} / \mathrm{s}$ analyzed for 11 earthquake inputs compatible with Vancouver site B spectrum

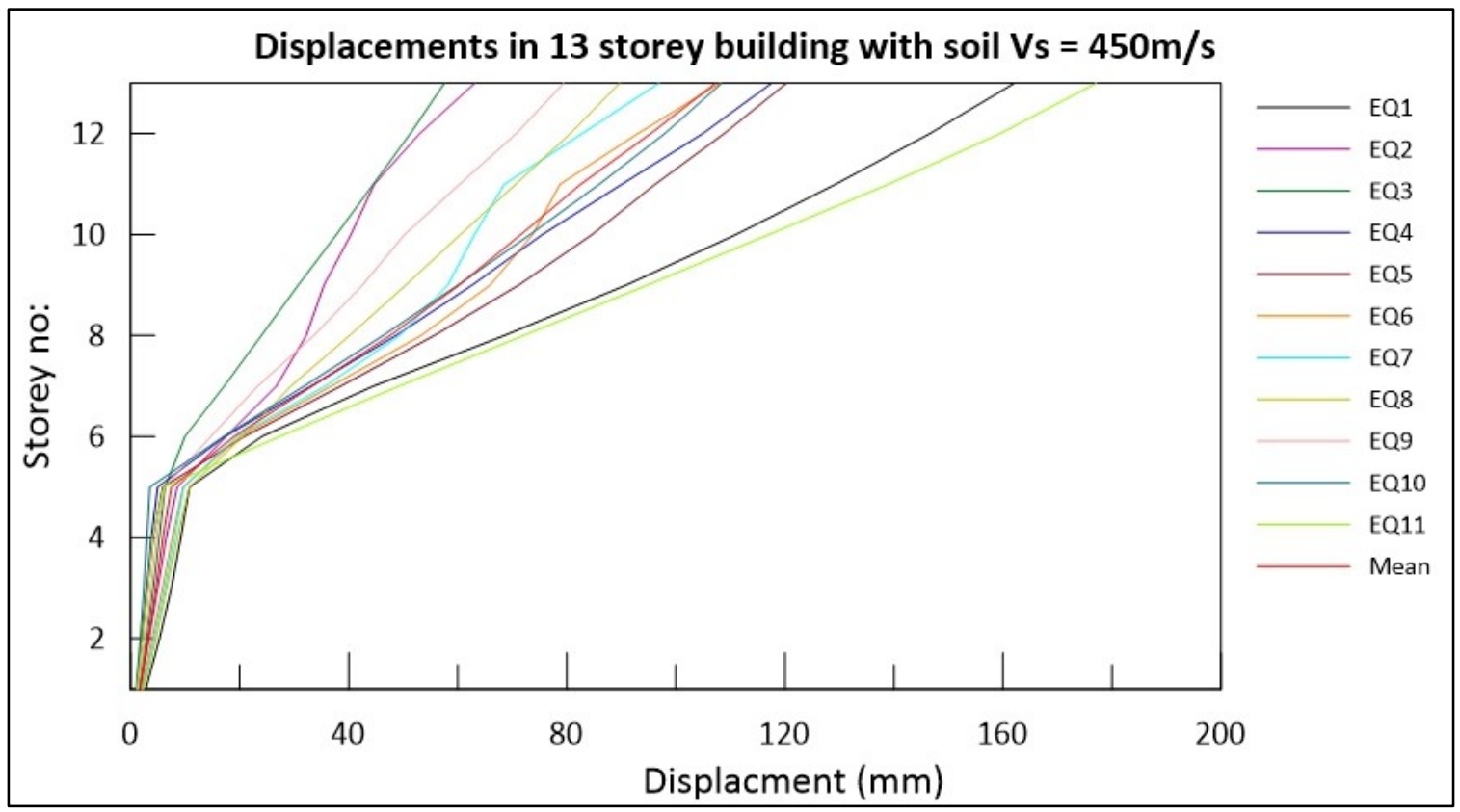

Figure B-74 Displacements in 13storey building with soil shear wave velocity, Vs $=450 \mathrm{~m} / \mathrm{s}$ analyzed for 11 earthquake inputs compatible with Vancouver site B spectrum 


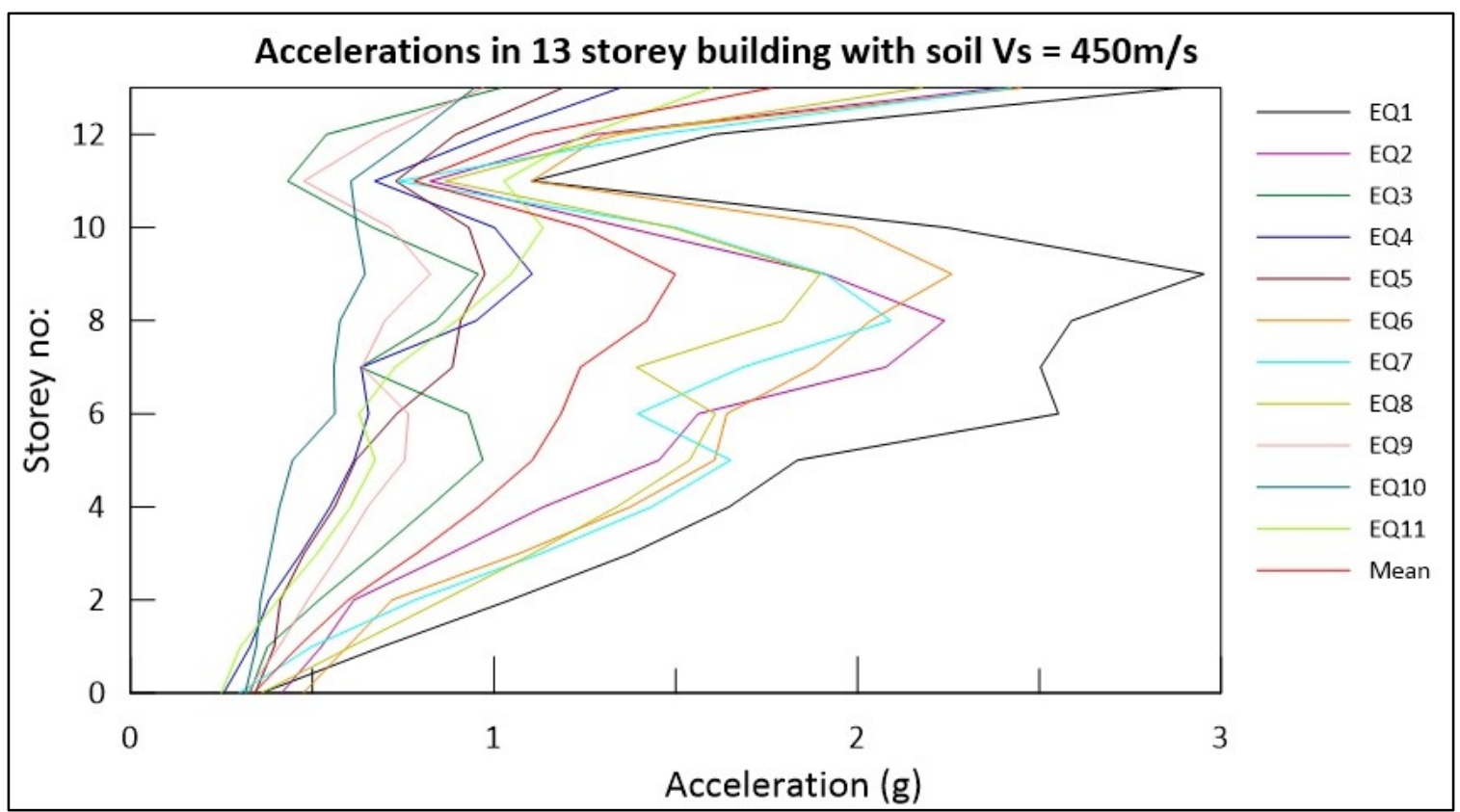

Figure B-75 Accelerations in 13storey building with soil shear wave velocity, $\mathrm{Vs}=450 \mathrm{~m} / \mathrm{s}$ analyzed for 11 earthquake inputs compatible with Vancouver site B spectrum

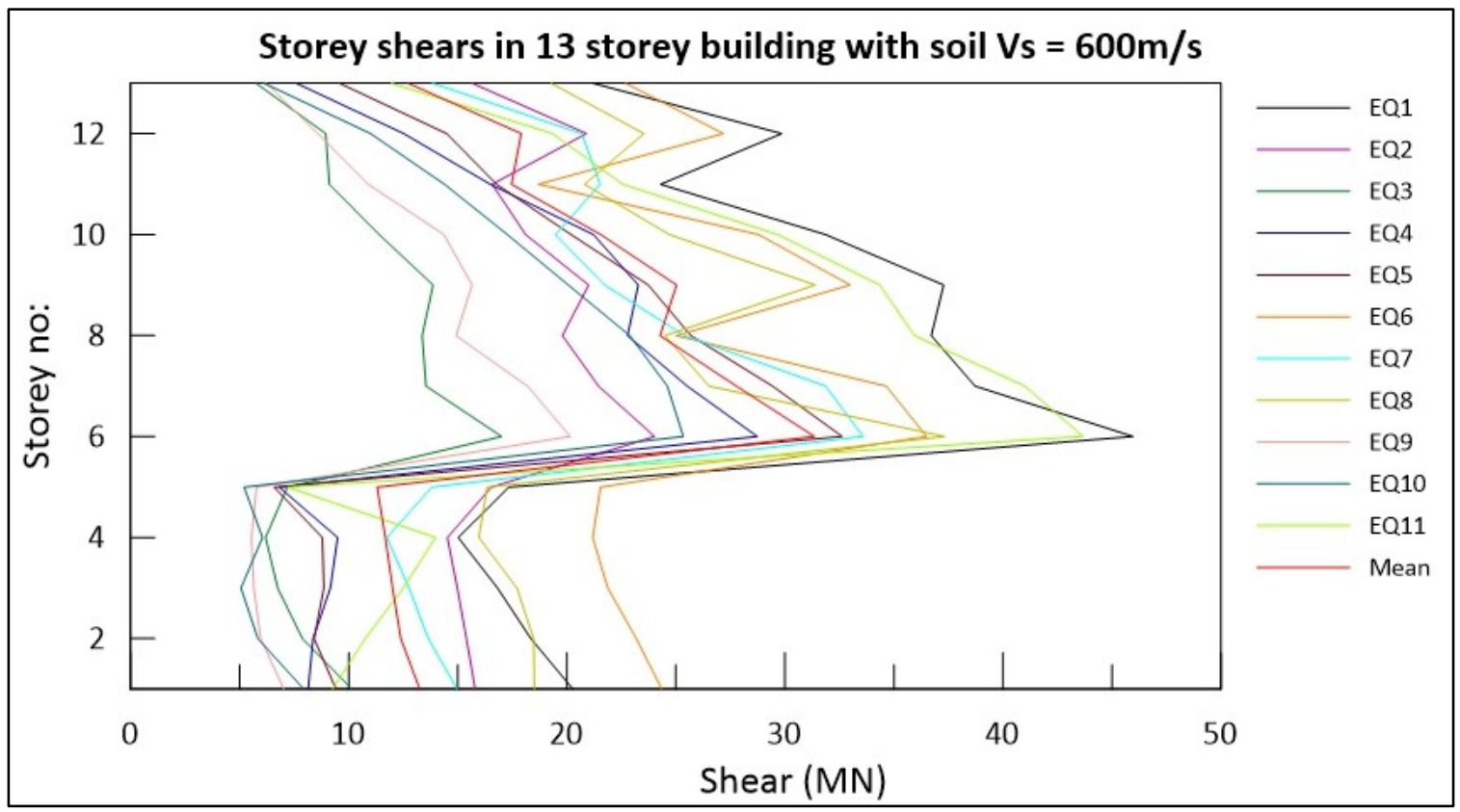

Figure B-76 Storey shears in 13storey building with soil shear wave velocity, Vs $=600 \mathrm{~m} / \mathrm{s}$ analyzed for 11 earthquake inputs compatible with Vancouver site B spectrum 


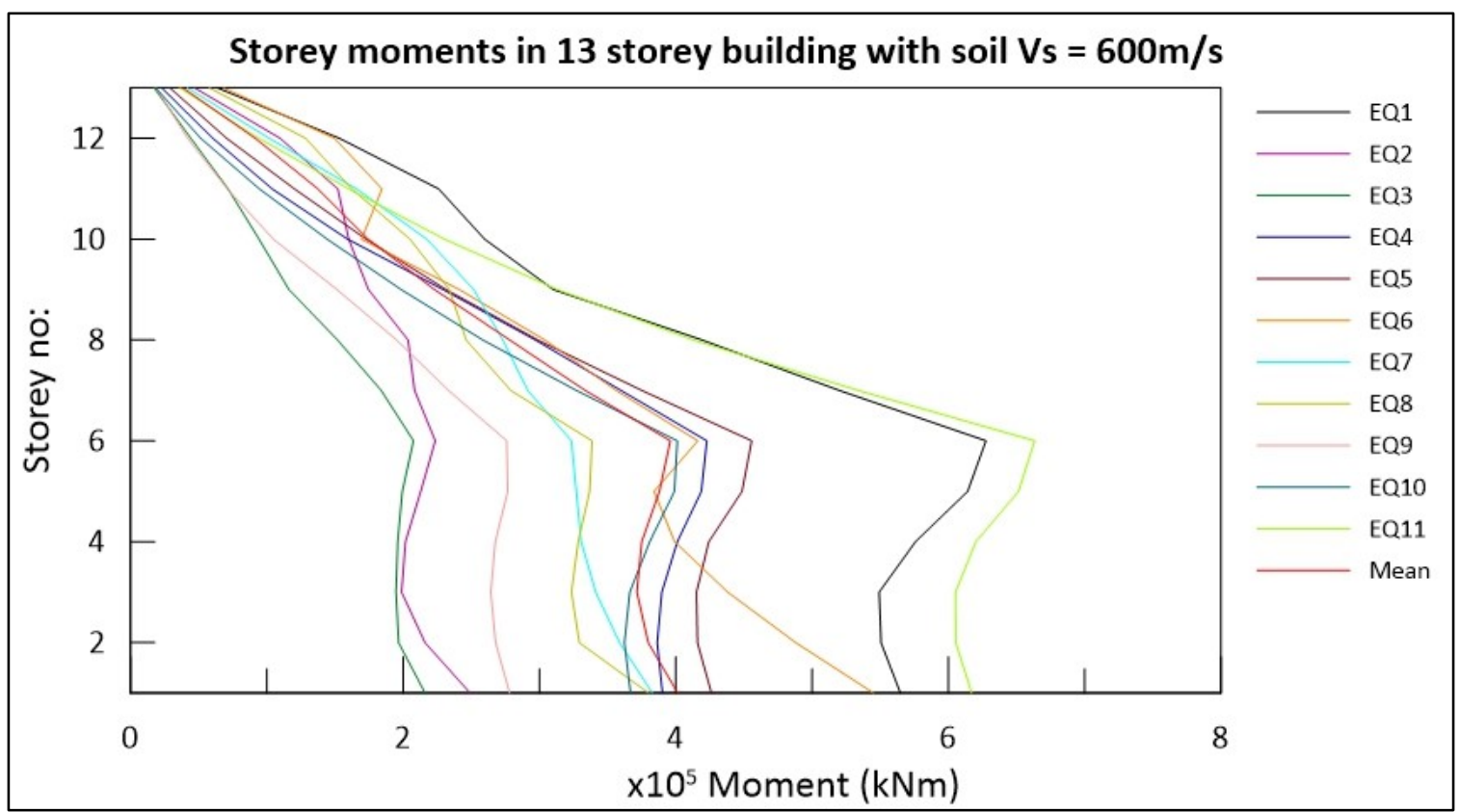

Figure B-77 Storey moments in 13storey building with soil shear wave velocity, Vs $=600 \mathrm{~m} / \mathrm{s}$ analyzed for 11 earthquake inputs compatible with Vancouver site B spectrum

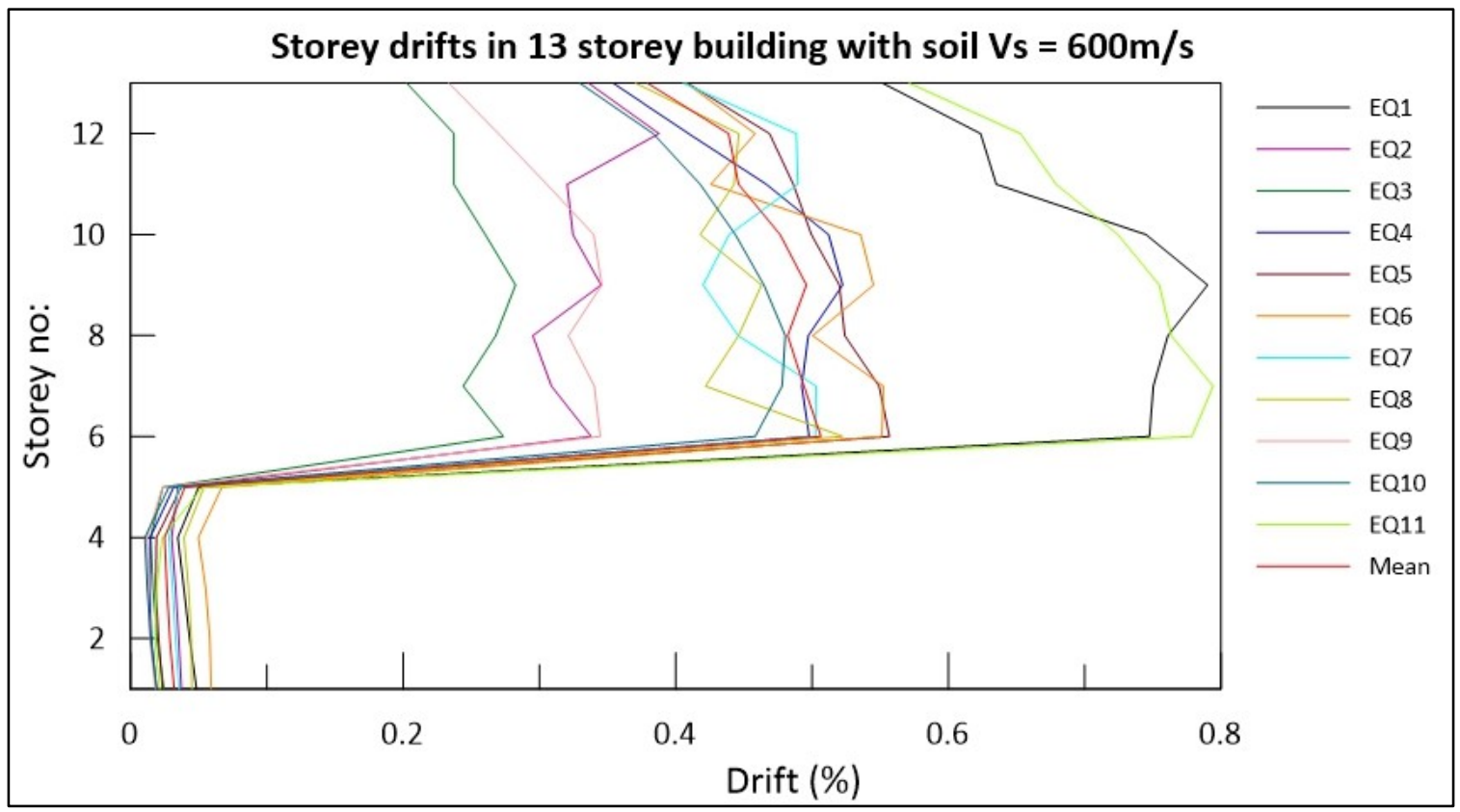

Figure B-78 Storey drifts in 13storey building with soil shear wave velocity, Vs $=600 \mathrm{~m} / \mathrm{s}$ analyzed for 11 earthquake inputs compatible with Vancouver site B spectrum 


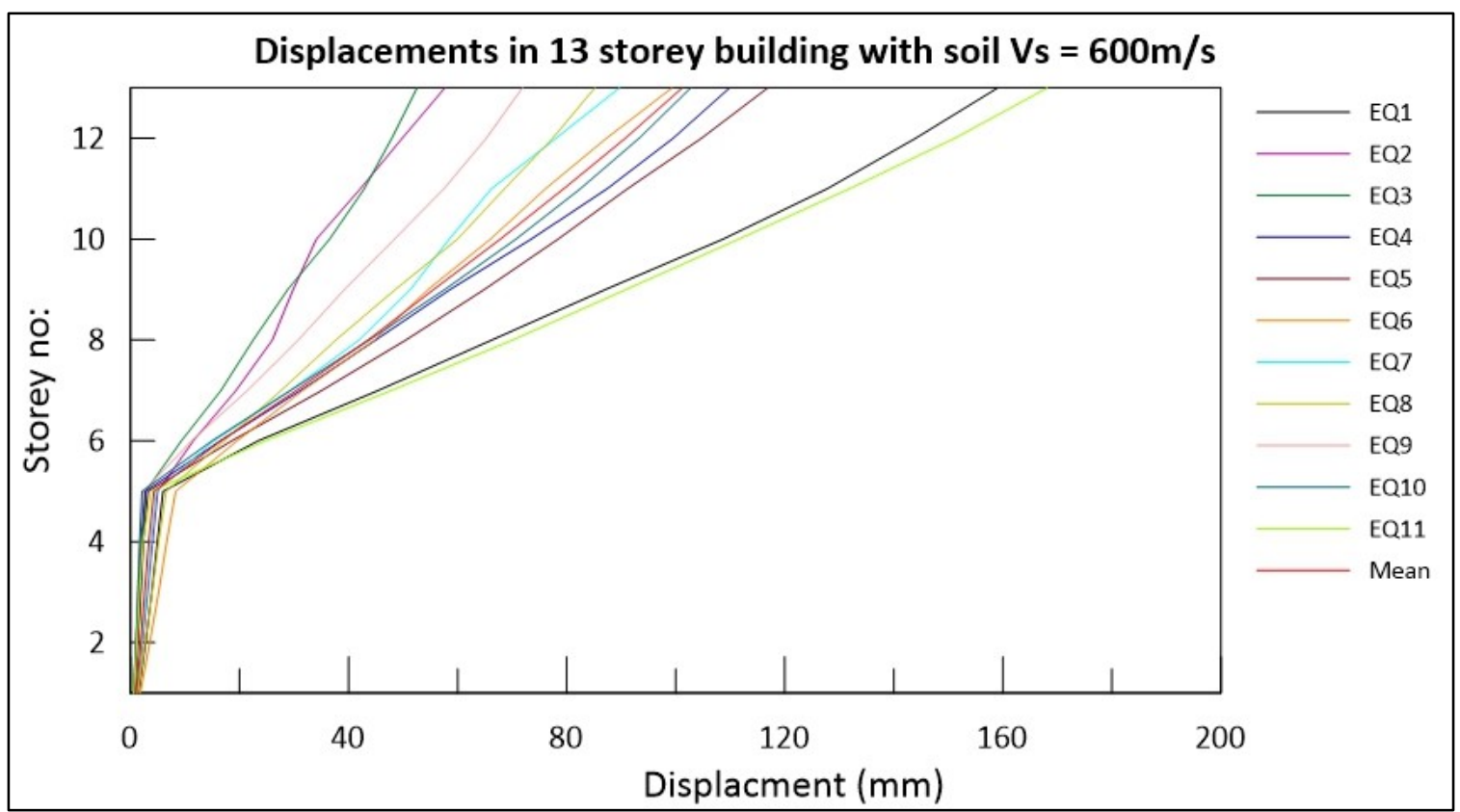

Figure B-79 Displacements in 13storey building with soil shear wave velocity, Vs $=600 \mathrm{~m} / \mathrm{s}$ analyzed for 11 earthquake inputs compatible with Vancouver site B spectrum

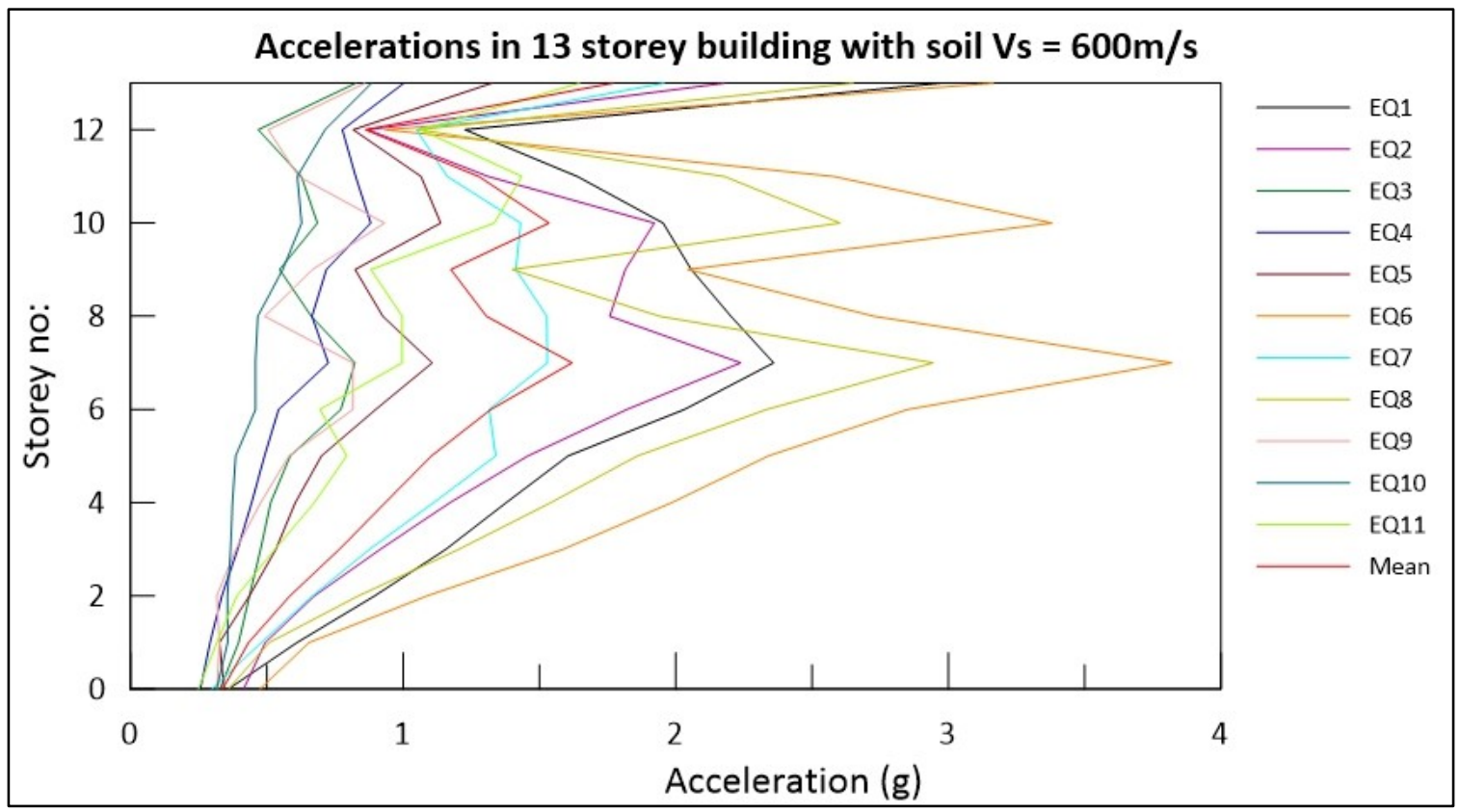

Figure B-80 Accelerations in 13storey building with soil shear wave velocity, Vs $=600 \mathrm{~m} / \mathrm{s}$ analyzed for 11 earthquake inputs compatible with Vancouver site B spectrum 


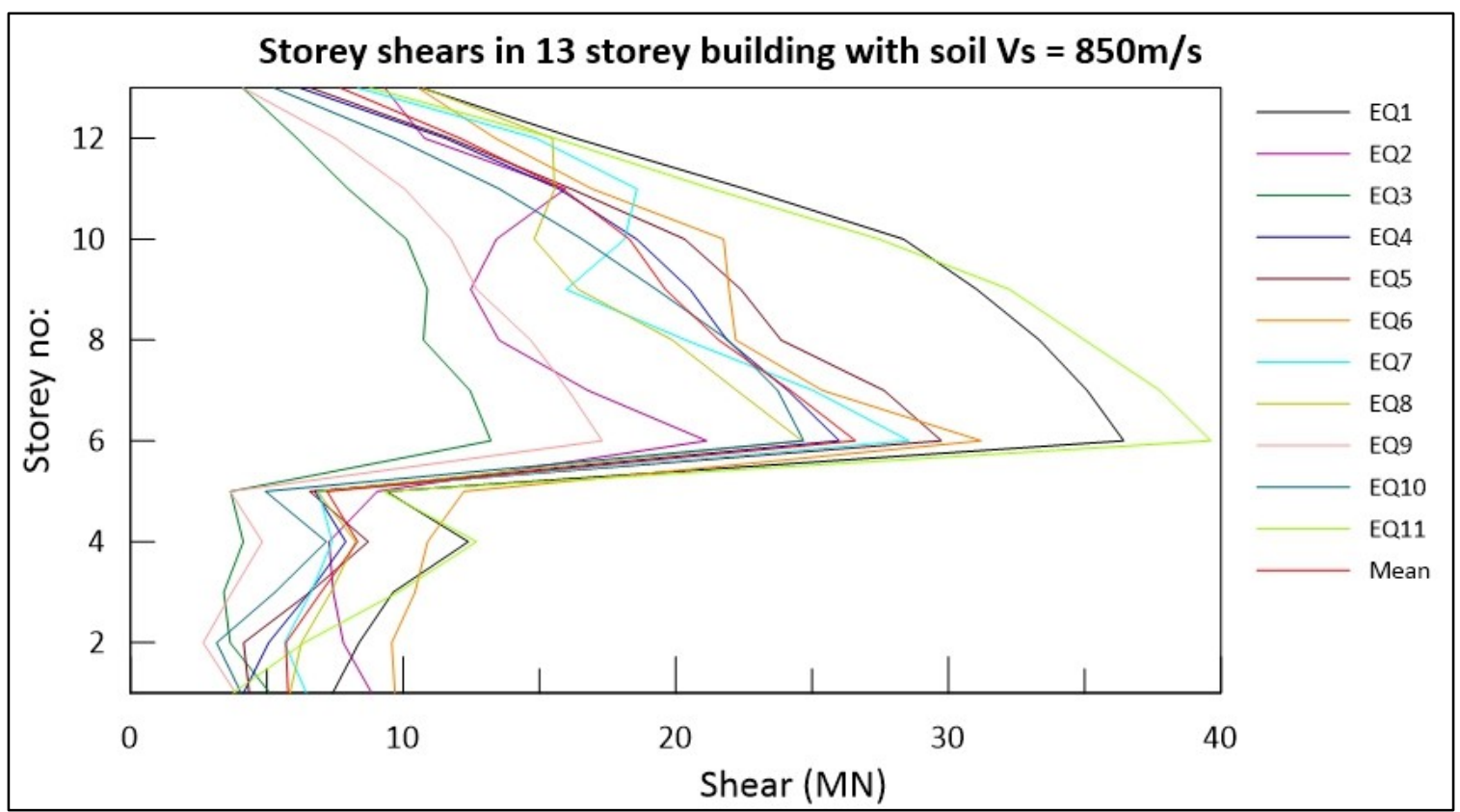

Figure B-81 Storey shears in 13storey building with soil shear wave velocity, Vs $=850 \mathrm{~m} / \mathrm{s}$ analyzed for 11 earthquake inputs compatible with Vancouver site B spectrum

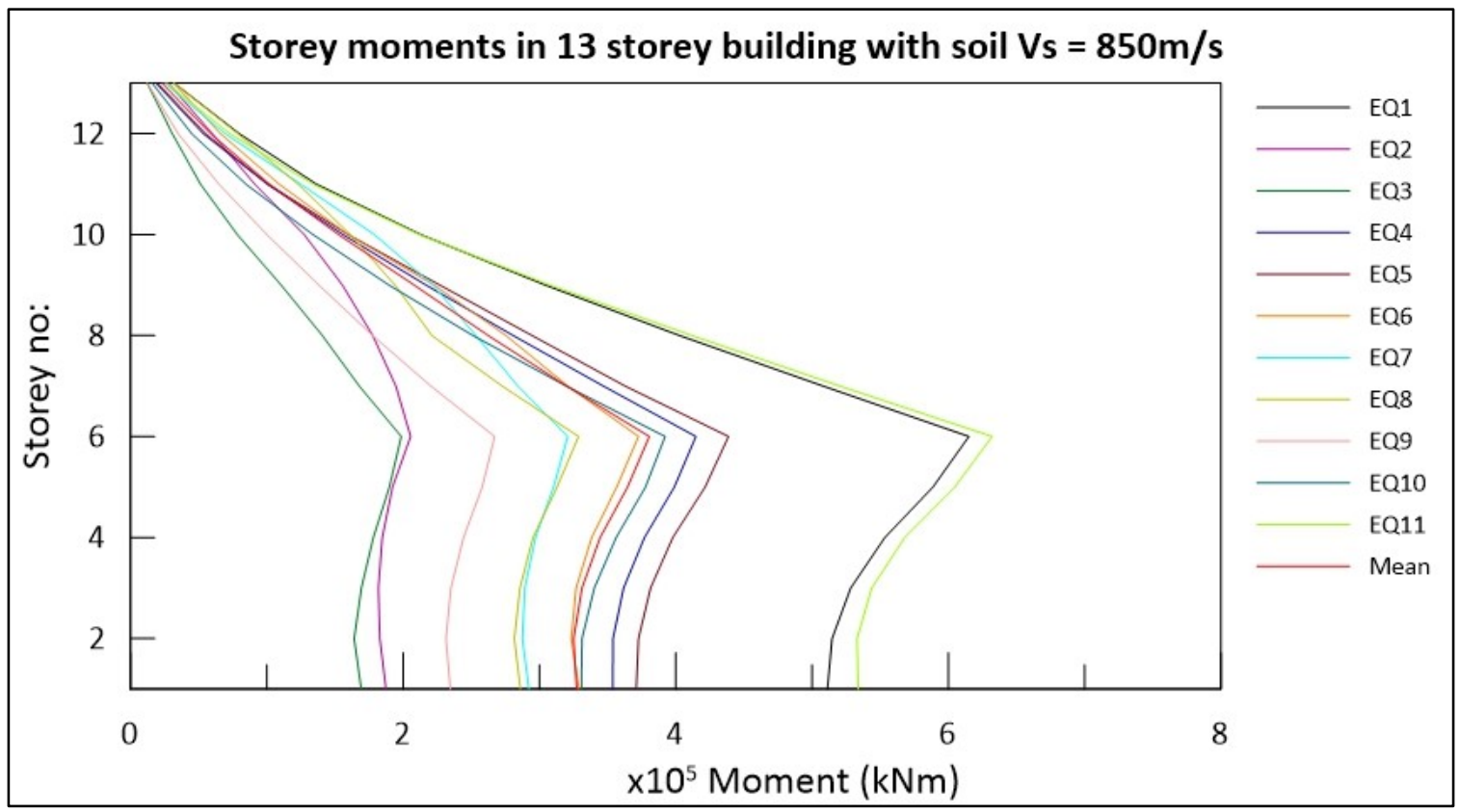

Figure B-82 Storey moments in 13storey building with soil shear wave velocity, Vs $=850 \mathrm{~m} / \mathrm{s}$ analyzed for 11 earthquake inputs compatible with Vancouver site B spectrum 


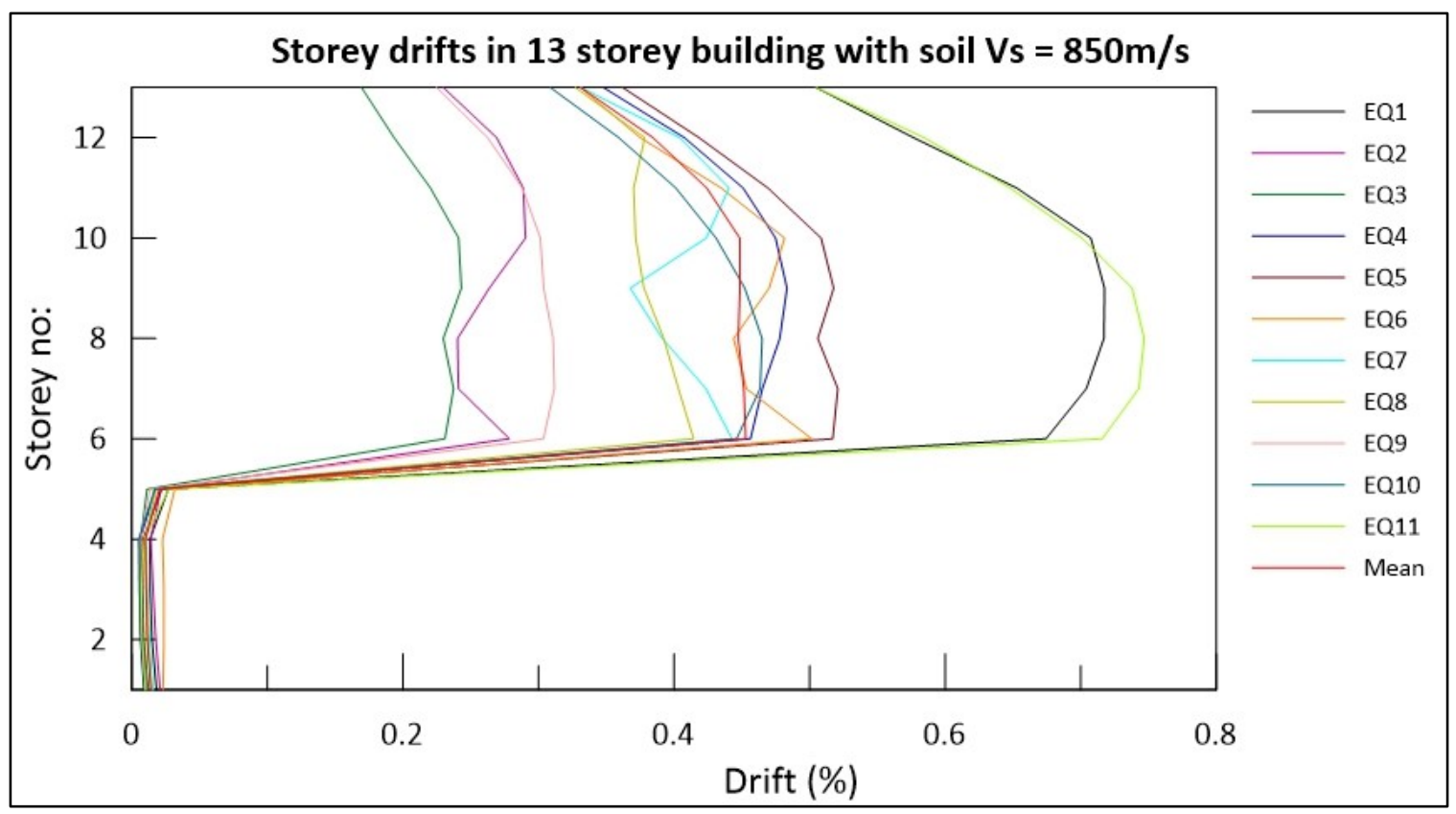

Figure B-83 Storey drifts in 13storey building with soil shear wave velocity, Vs $=850 \mathrm{~m} / \mathrm{s}$ analyzed for 11 earthquake inputs compatible with Vancouver site B spectrum

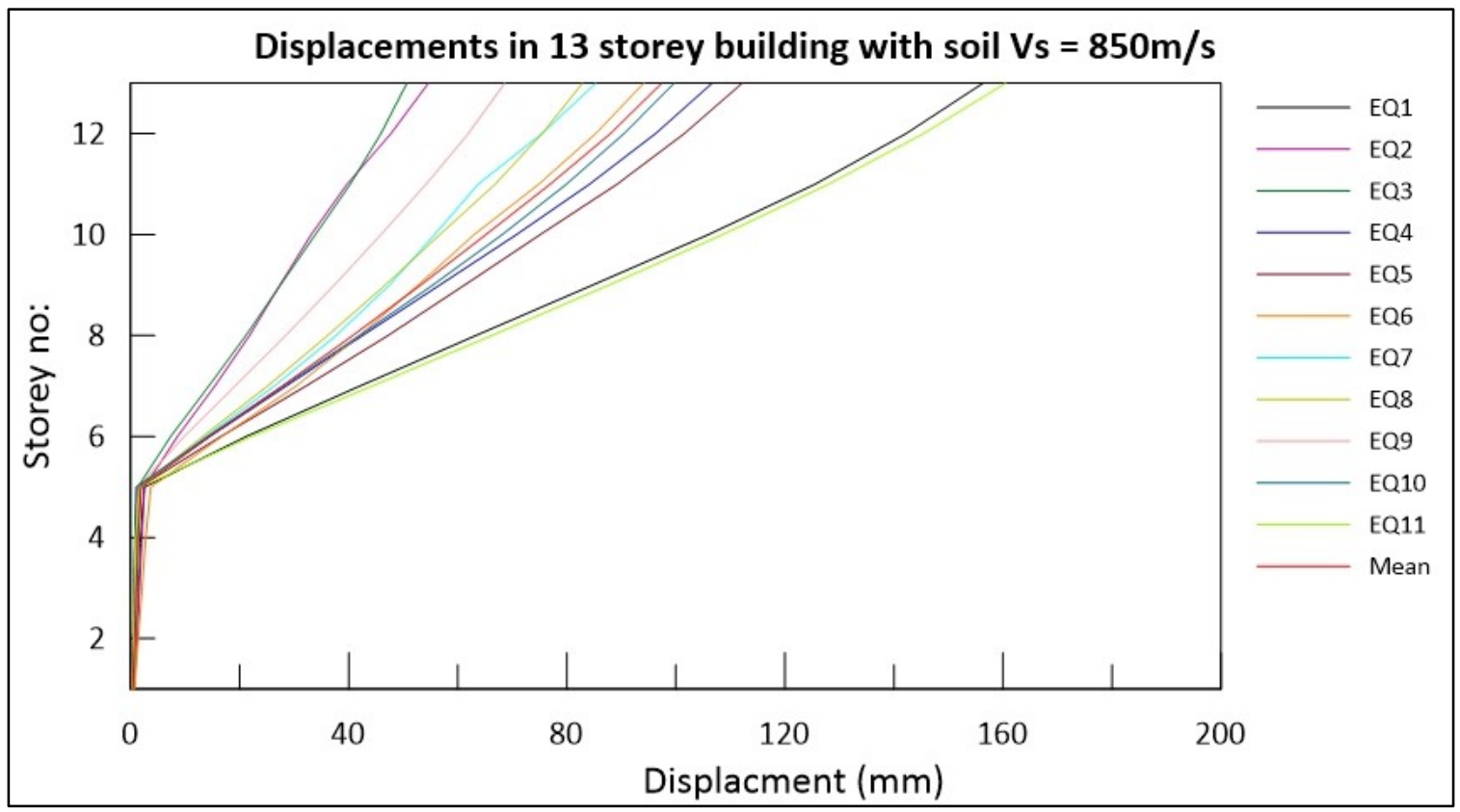

Figure B-84 Displacements in 13storey building with soil shear wave velocity, Vs $=850 \mathrm{~m} / \mathrm{s}$ analyzed for 11 earthquake inputs compatible with Vancouver site B spectrum 


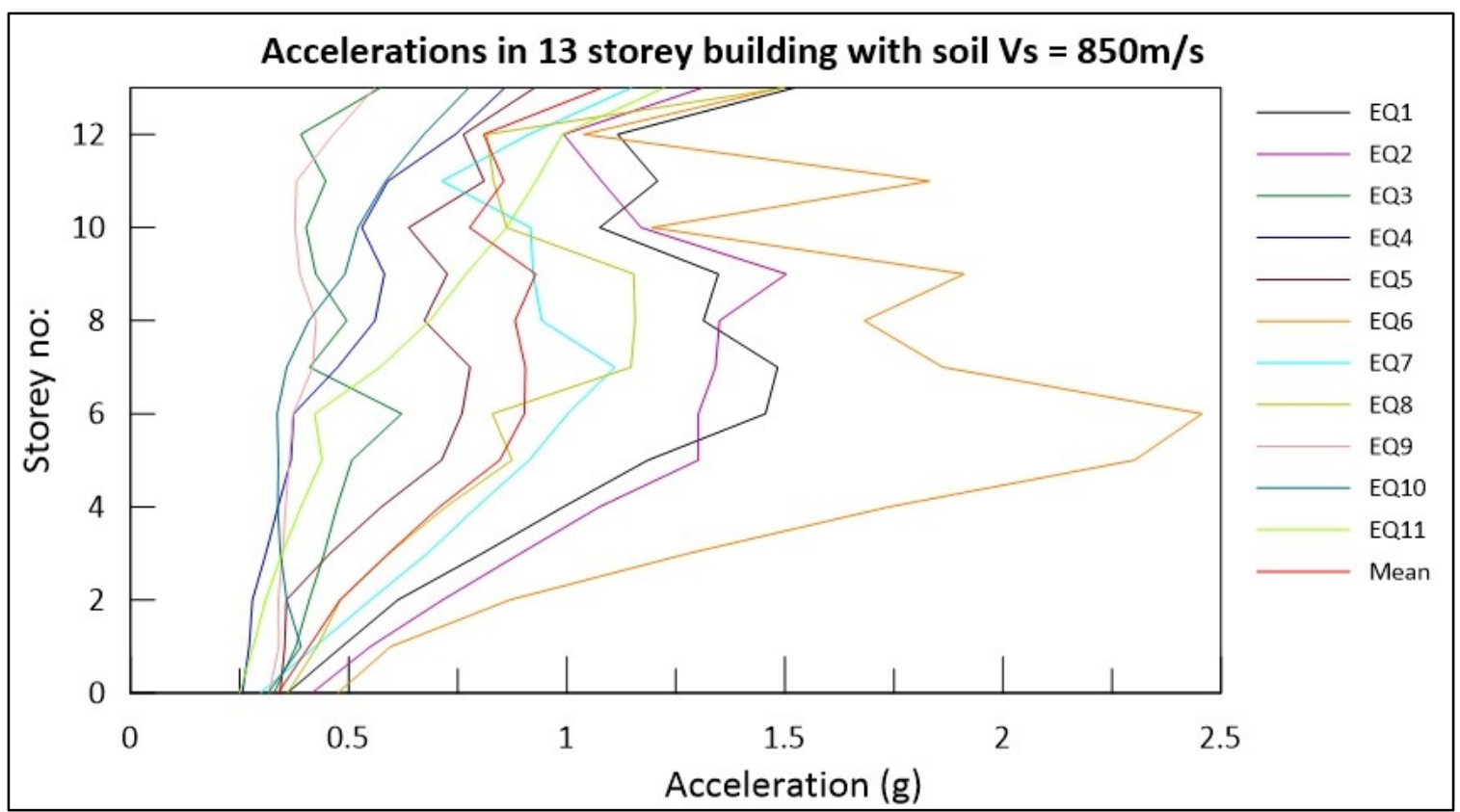

Figure B-85 Accelerations in 13storey building with soil shear wave velocity, $\mathrm{Vs}=850 \mathrm{~m} / \mathrm{s}$ analyzed for 11 earthquake inputs compatible with Vancouver site B spectrum

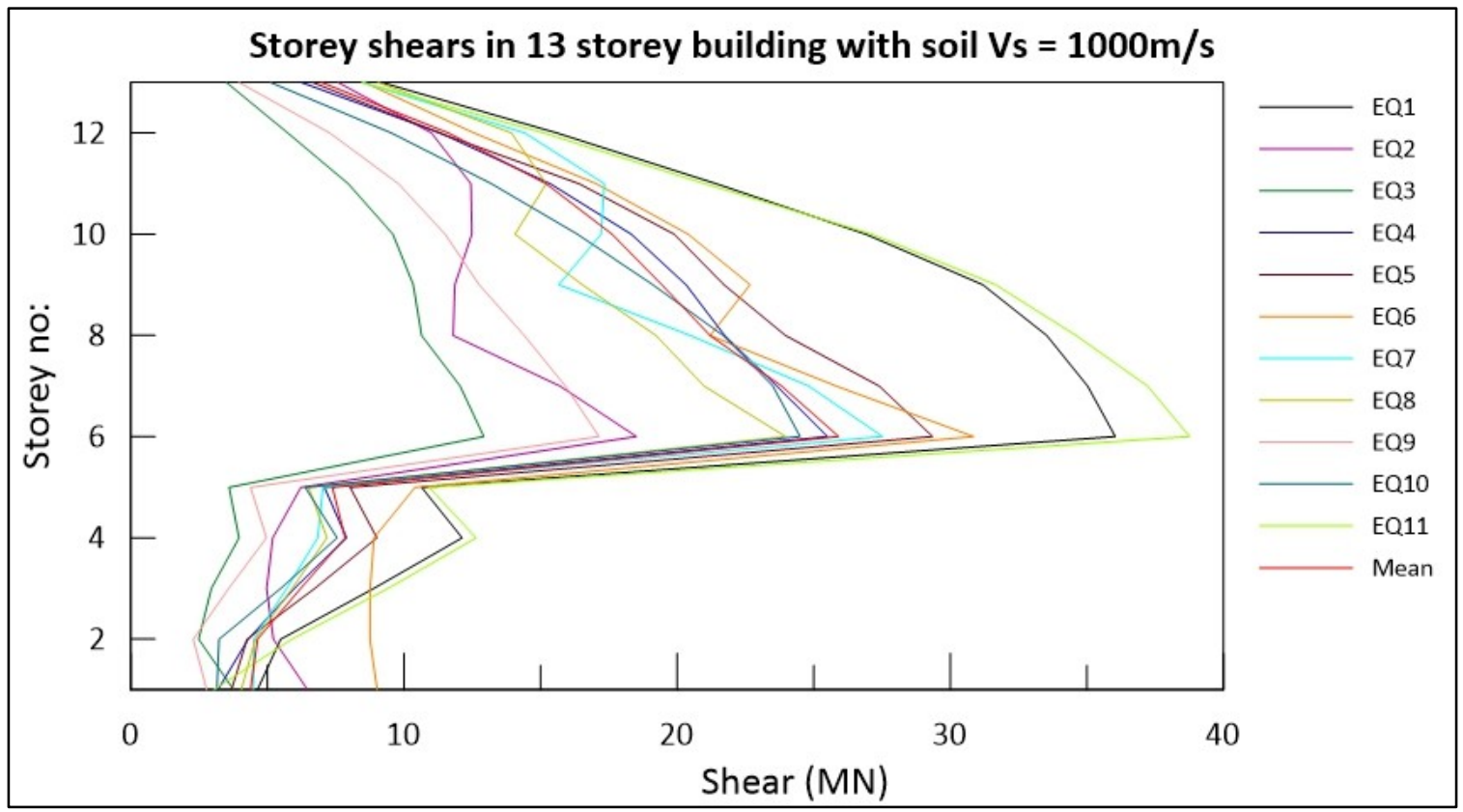

Figure B-86 Storey shears in 13storey building with soil shear wave velocity, Vs $=1000 \mathrm{~m} / \mathrm{s}$ analyzed for 11 earthquake inputs compatible with Vancouver site B spectrum 


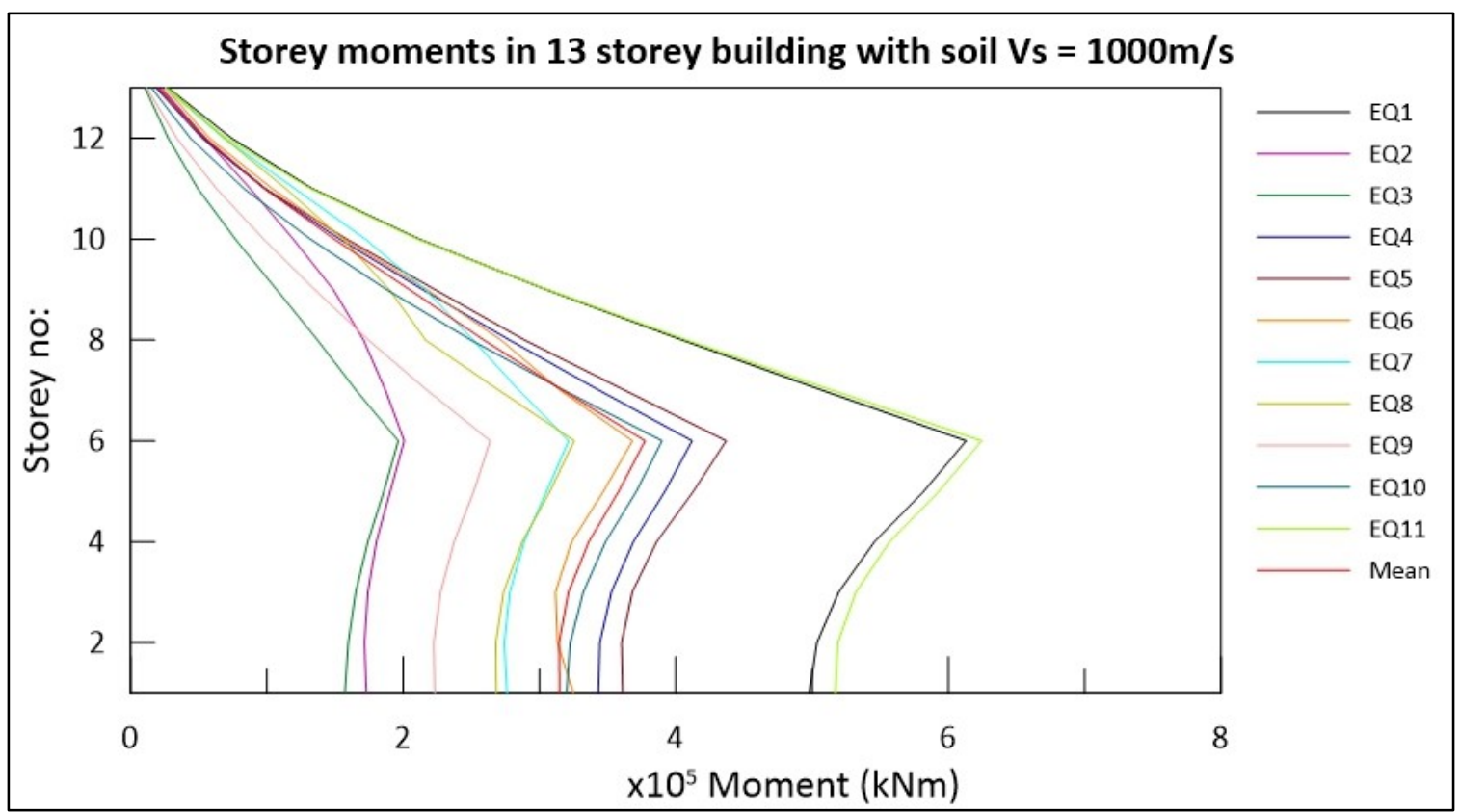

Figure B-87 Storey moments in 13storey building with soil shear wave velocity, Vs $=1000 \mathrm{~m} / \mathrm{s}$ analyzed for 11 earthquake inputs compatible with Vancouver site B spectrum

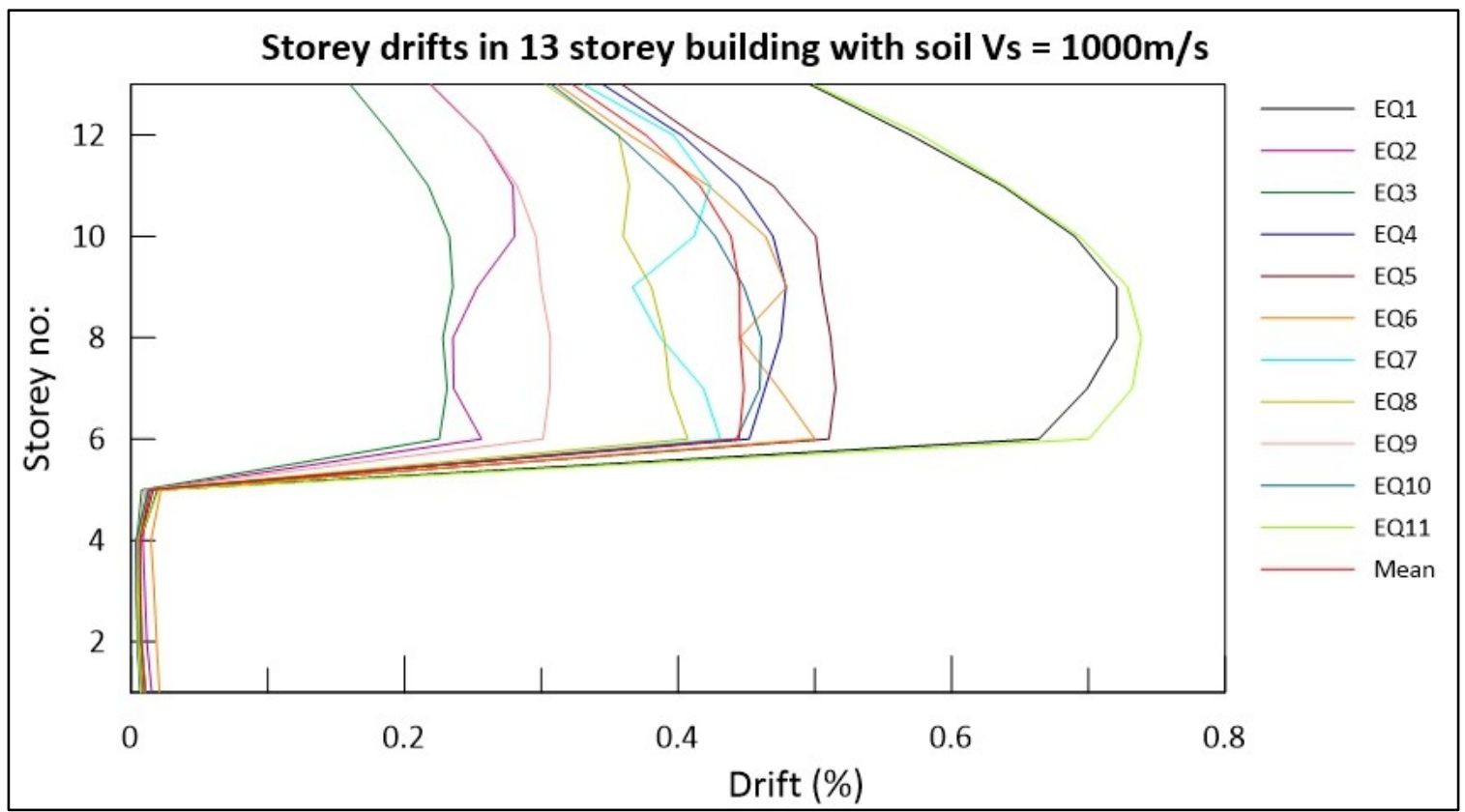

Figure B-88 Storey drifts in 13storey building with soil shear wave velocity, Vs $=1000 \mathrm{~m} / \mathrm{s}$ analyzed for 11 earthquake inputs compatible with Vancouver site B spectrum 


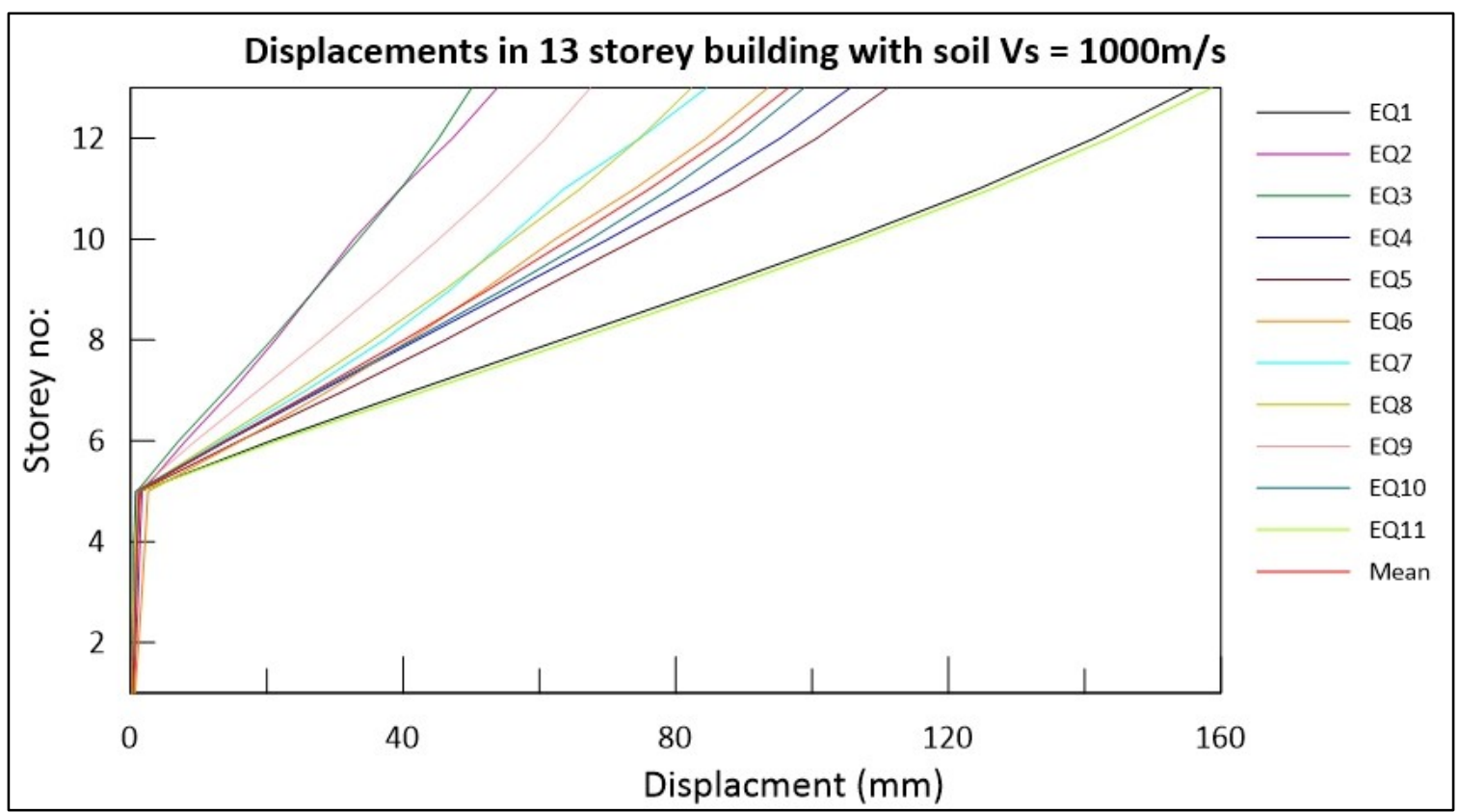

Figure B-89 Displacements in 13storey building with soil shear wave velocity, Vs $=1000 \mathrm{~m} / \mathrm{s}$ analyzed for 11 earthquake inputs compatible with Vancouver site B spectrum

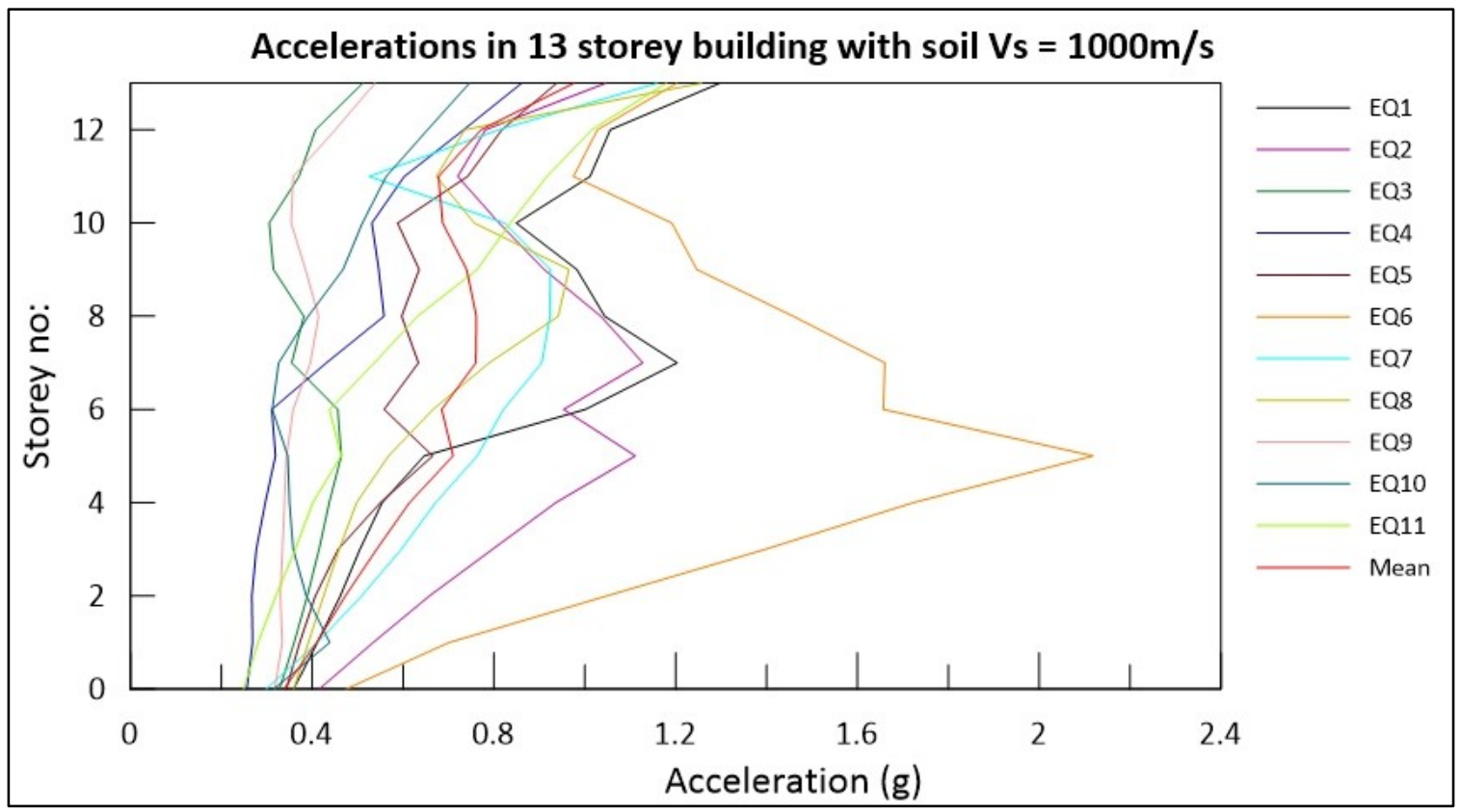

Figure B-90 Accelerations in 13storey building with soil shear wave velocity, Vs $=1000 \mathrm{~m} / \mathrm{s}$ analyzed for 11 earthquake inputs compatible with Vancouver site B spectrum 
17 Storey building:

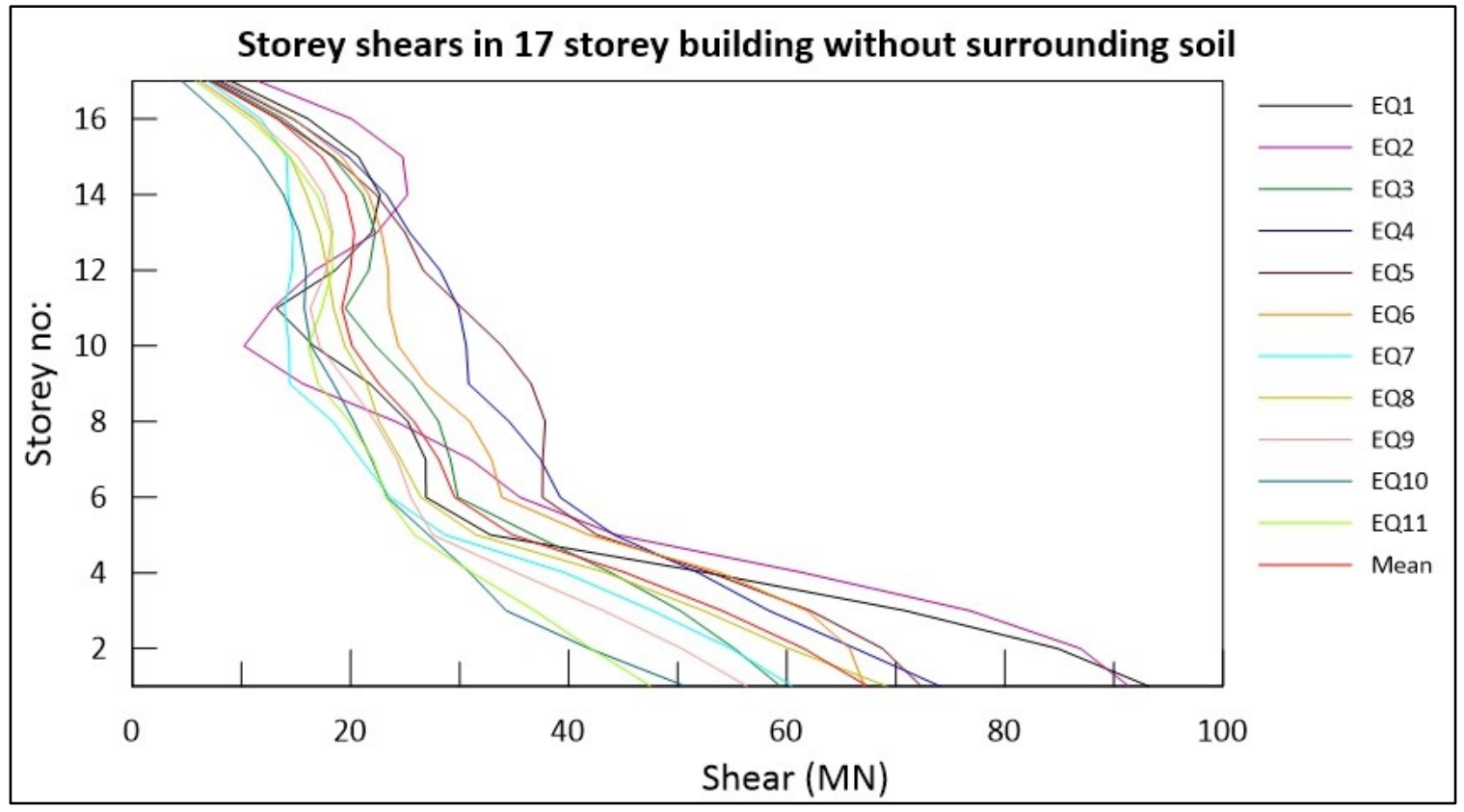

Figure B-91 Storey shears in 17storey building without any surrounding soil analyzed for 11 earthquake inputs compatible with Vancouver site B spectrum

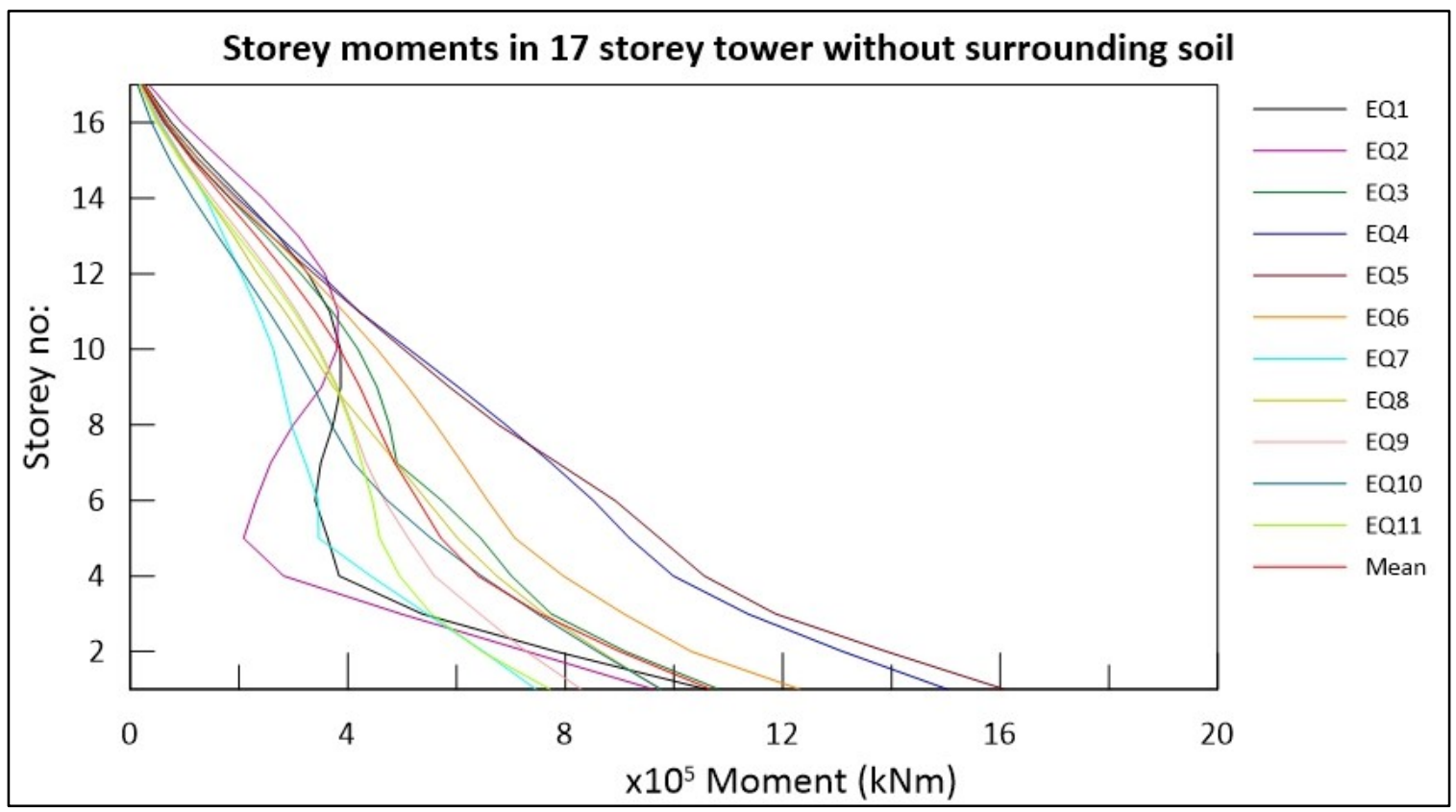

Figure B-92 Storey moments in 17storey building without any surrounding soil analyzed for 11 earthquake inputs compatible with Vancouver site B spectrum 


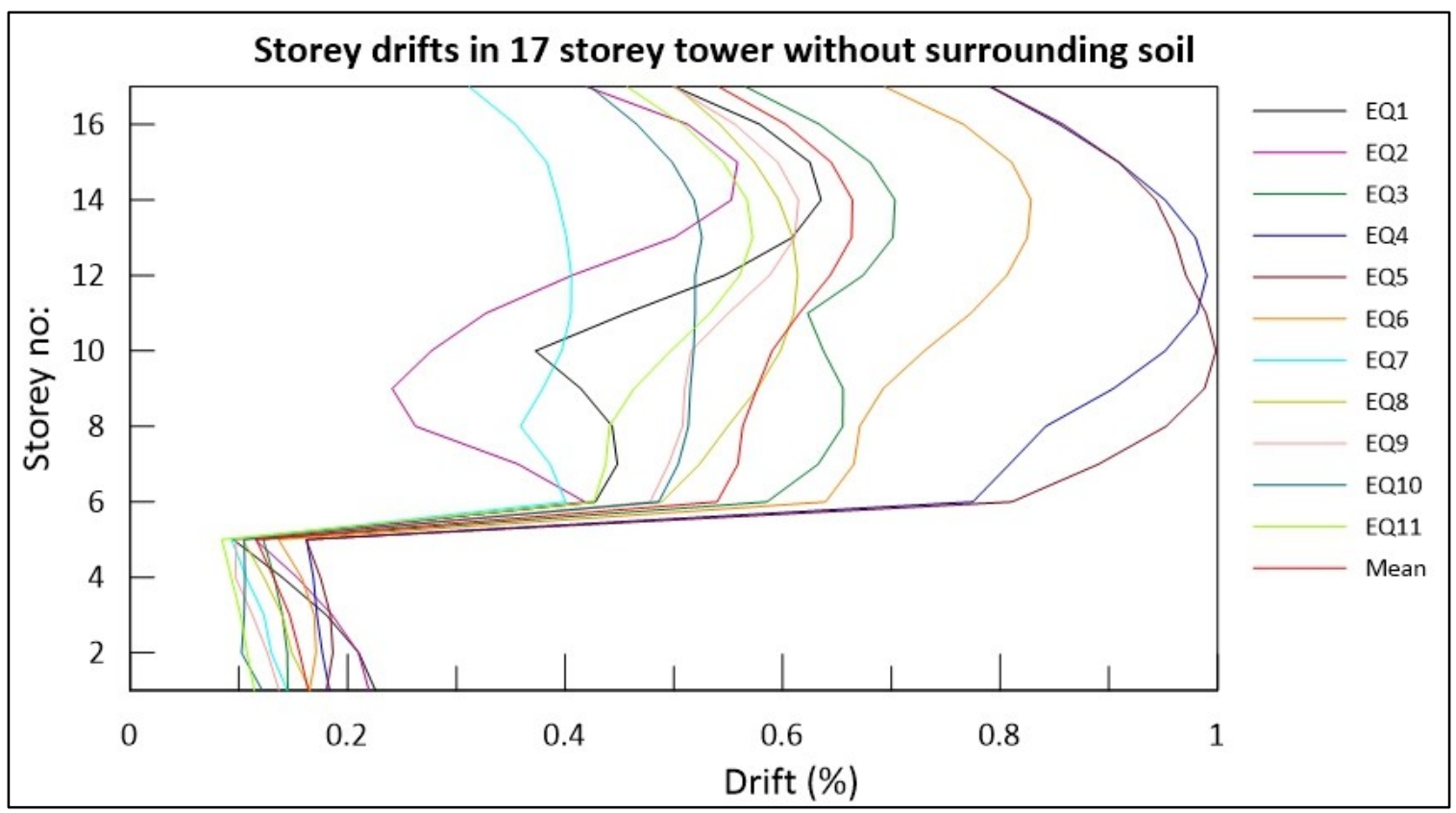

Figure B-93 Storey drifts in 17storey building without any surrounding soil analyzed for 11 earthquake inputs compatible with Vancouver site B spectrum

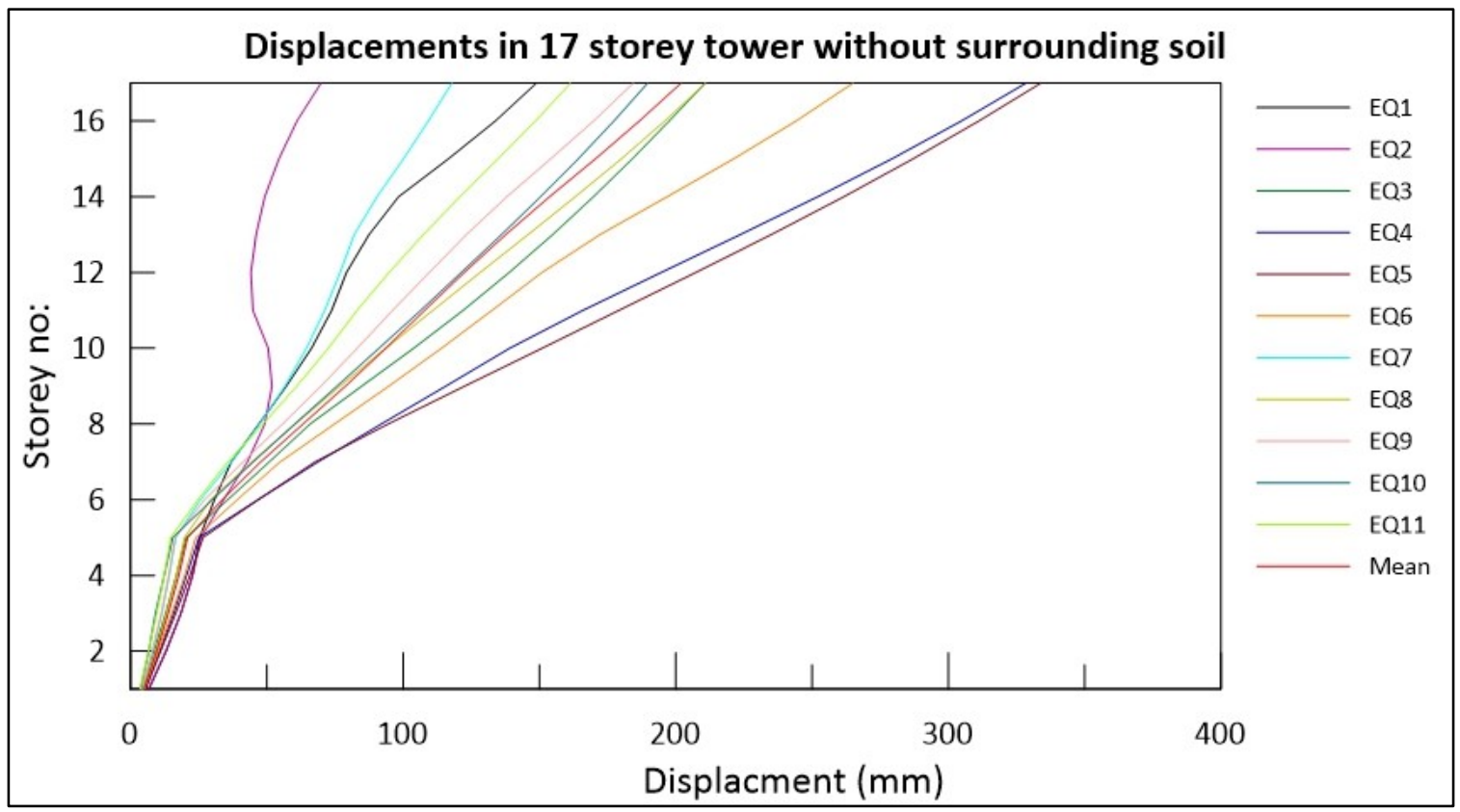

Figure B-94 Displacements in 17storey building without any surrounding soil analyzed for 11 earthquake inputs compatible with Vancouver site B spectrum 


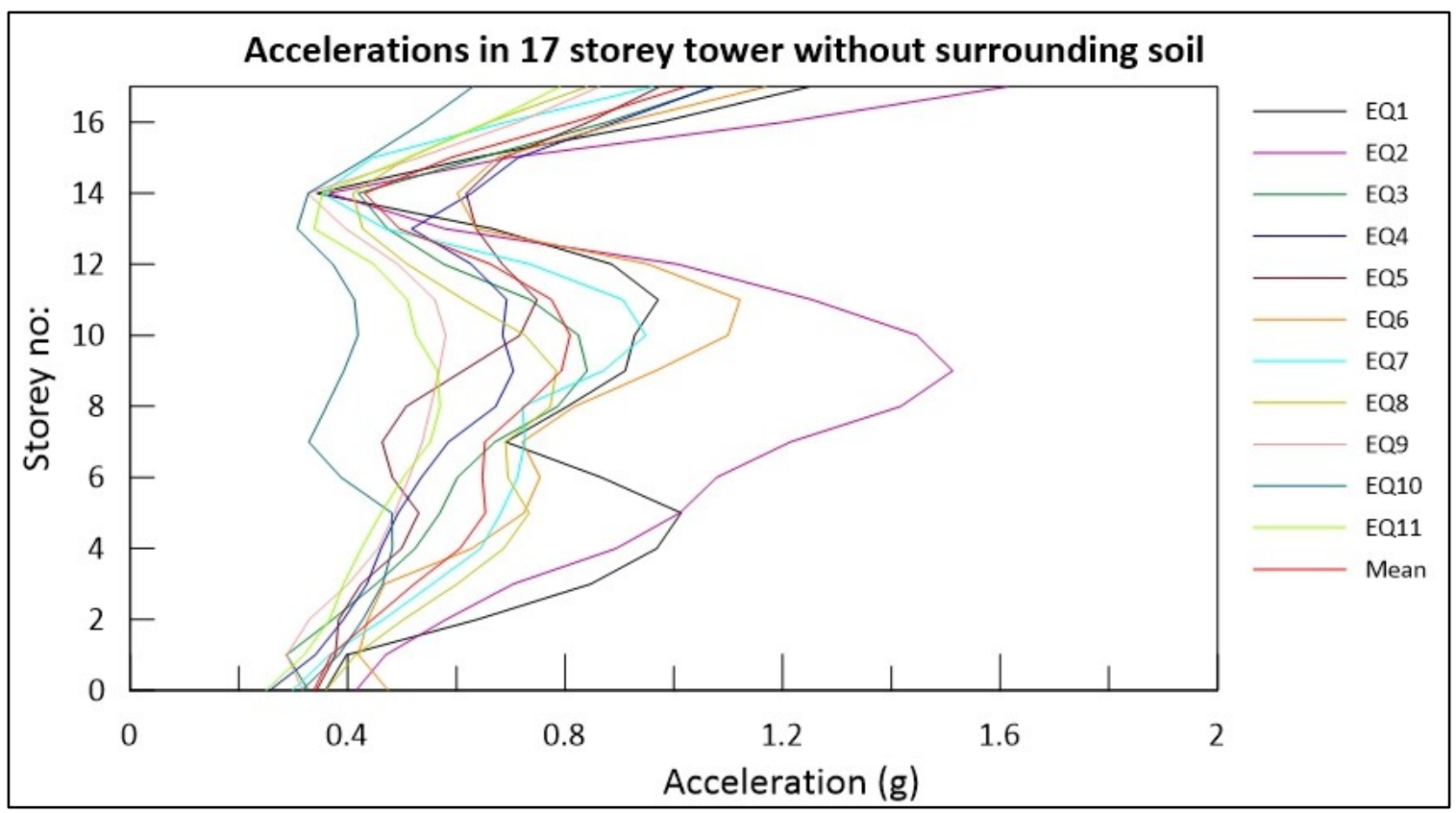

Figure B-95 Accelerations in 17storey building without any surrounding soil analyzed for 11 earthquake inputs compatible with Vancouver site B spectrum

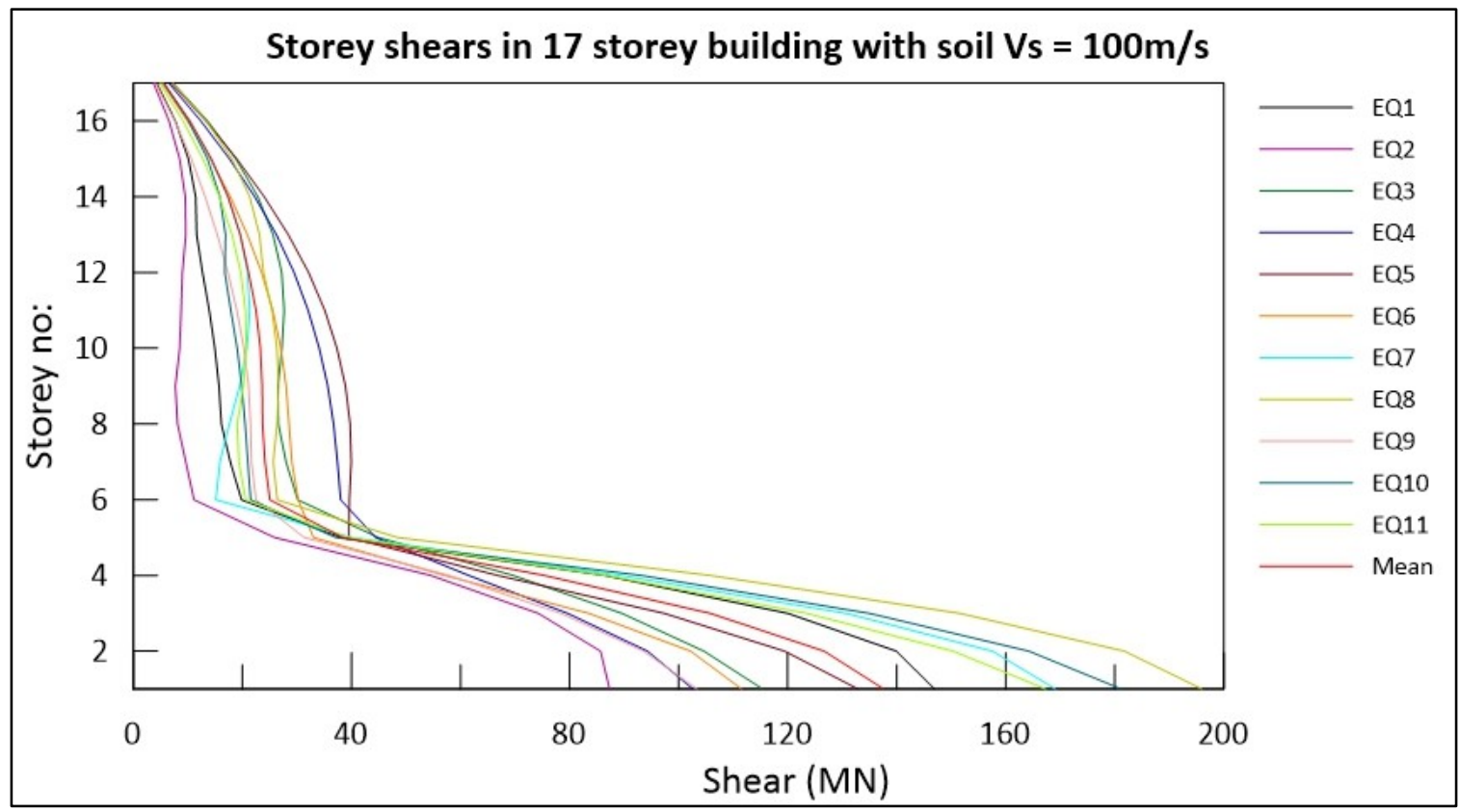

Figure B-96 Storey shears in 17storey building with soil shear wave velocity, Vs $=100 \mathrm{~m} / \mathrm{s}$ analyzed for 11 earthquake inputs compatible with Vancouver site B spectrum 


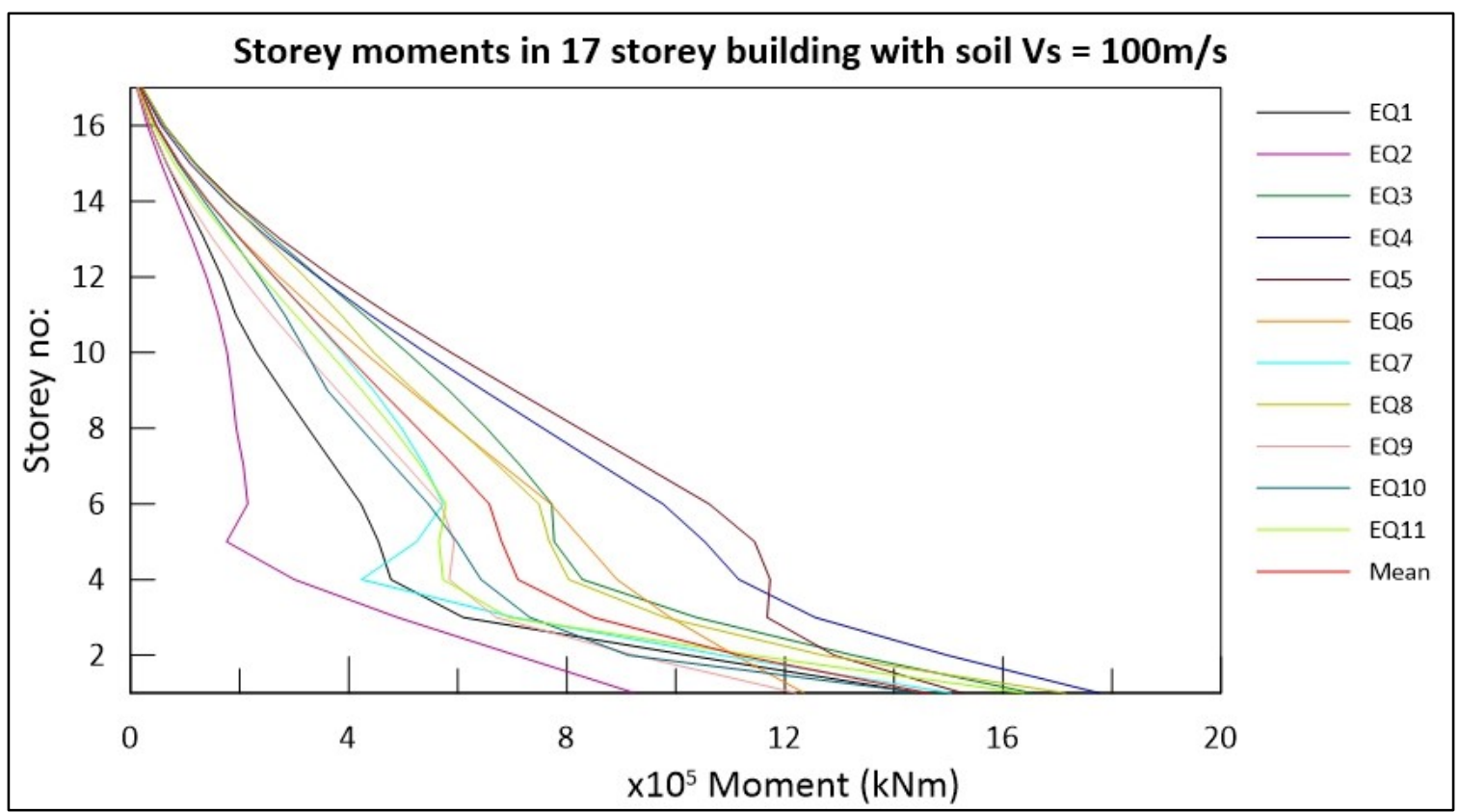

Figure B-97 Storey moments in 17storey building with soil shear wave velocity, Vs $=100 \mathrm{~m} / \mathrm{s}$ analyzed for 11 earthquake inputs compatible with Vancouver site B spectrum

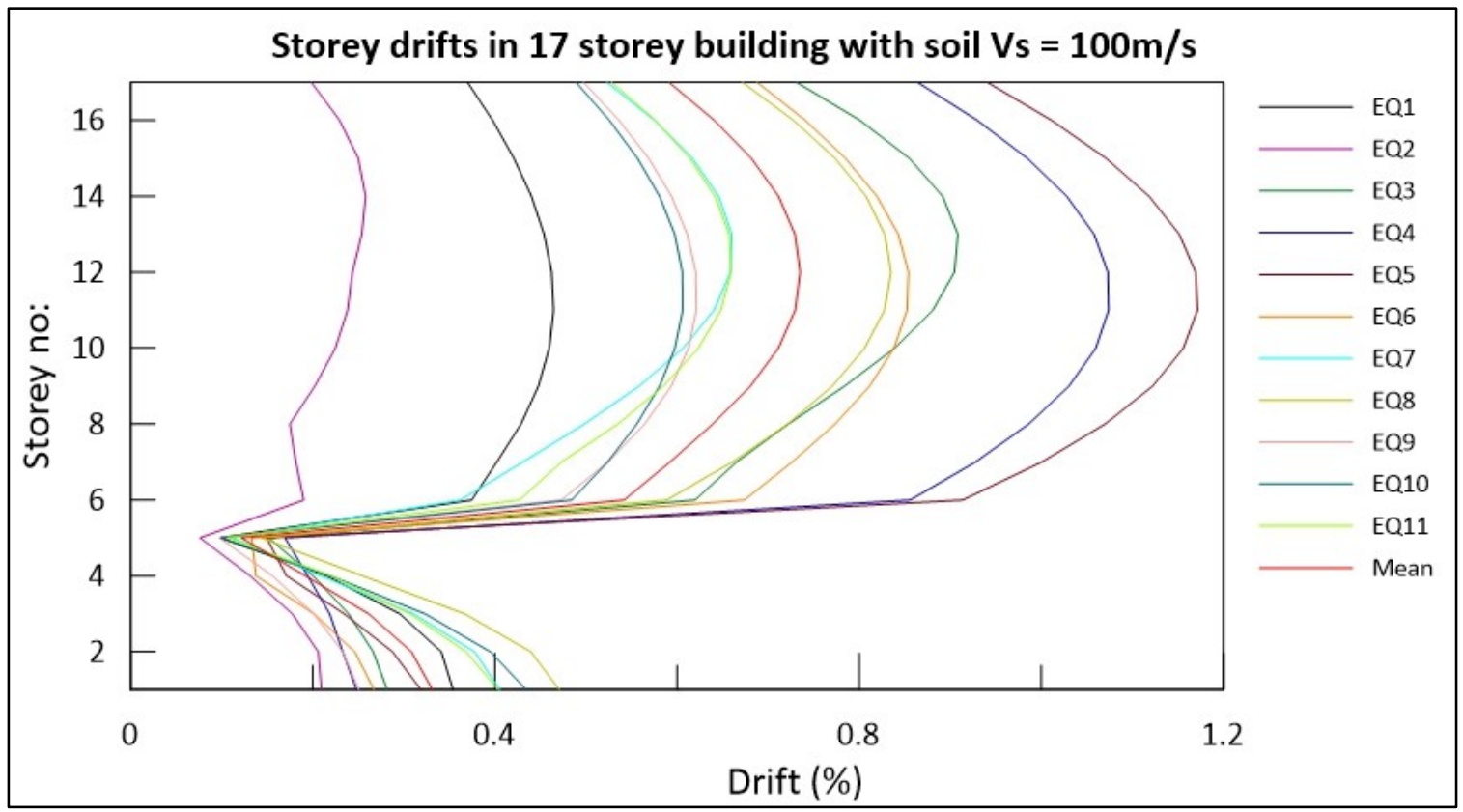

Figure B-98 Storey drifts in 17storey building with soil shear wave velocity, Vs $=100 \mathrm{~m} / \mathrm{s}$ analyzed for 11 earthquake inputs compatible with Vancouver site B spectrum 


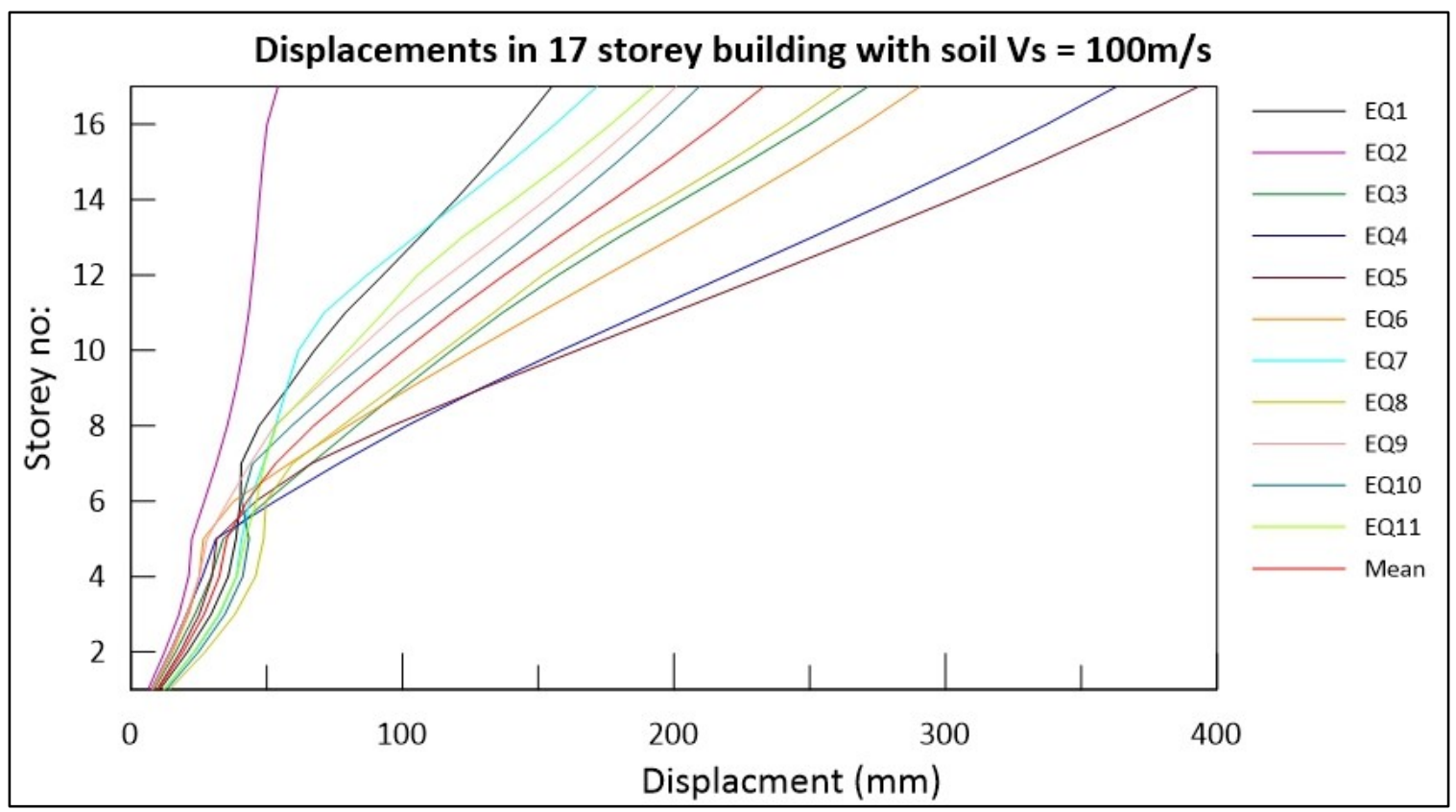

Figure B-99 Displacements in 17storey building with soil shear wave velocity, Vs $=100 \mathrm{~m} / \mathrm{s}$ analyzed for 11 earthquake inputs compatible with Vancouver site B spectrum

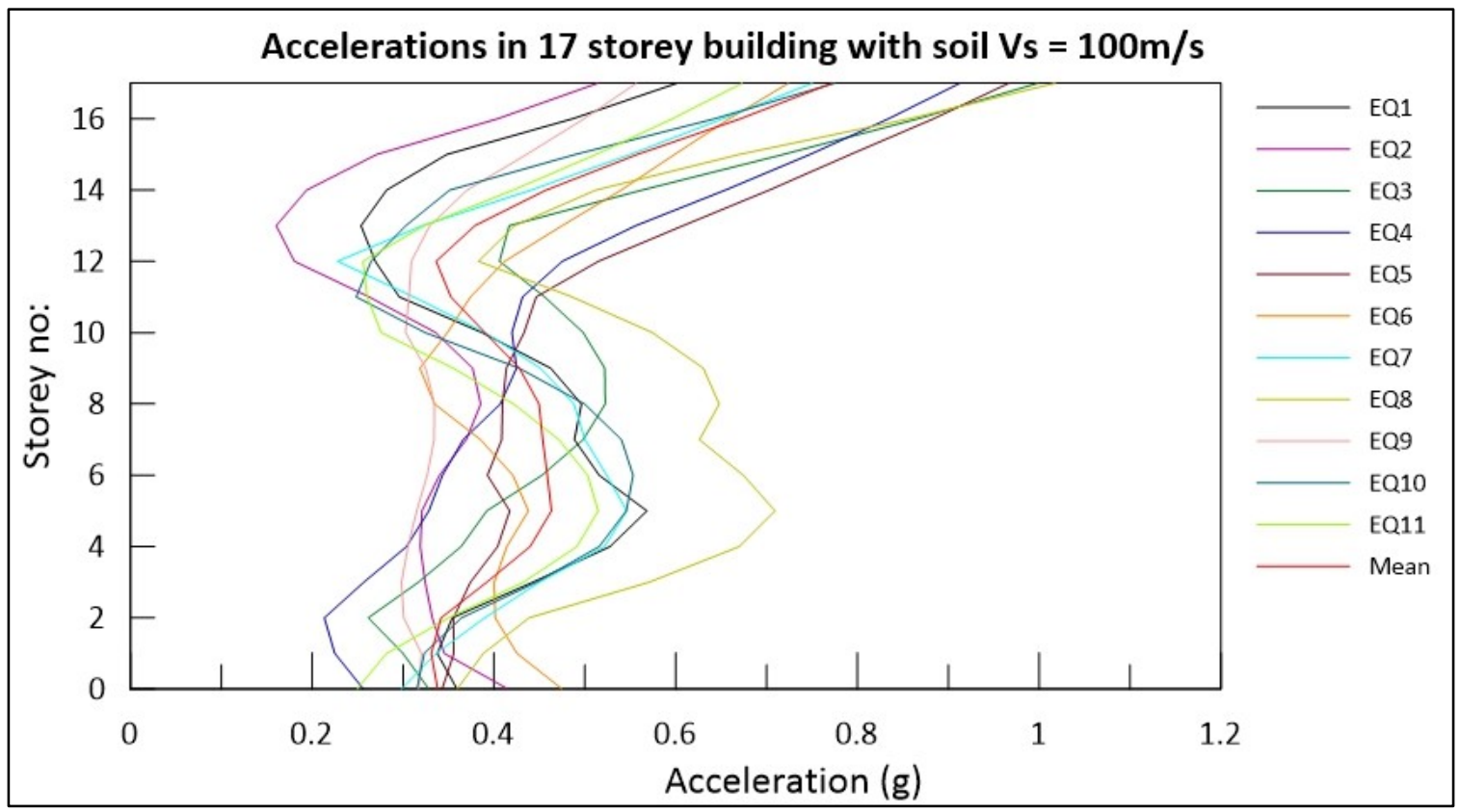

Figure B-100 Accelerations in 17storey building with soil shear wave velocity, Vs $=100 \mathrm{~m} / \mathrm{s}$ analyzed for 11 earthquake inputs compatible with Vancouver site B spectrum 


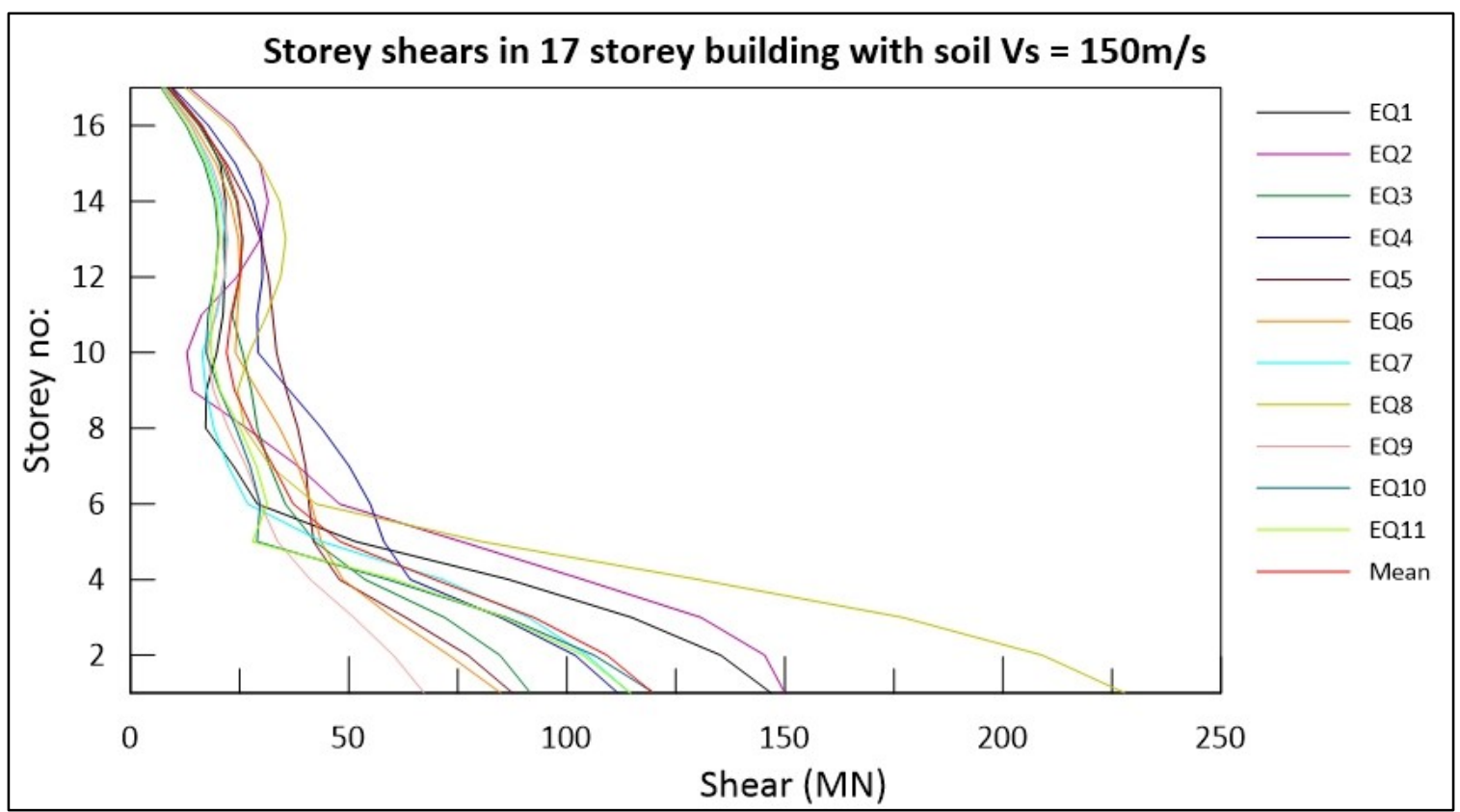

Figure B-101 Storey shears in 17storey building with soil shear wave velocity, Vs $=150 \mathrm{~m} / \mathrm{s}$ analyzed for 11 earthquake inputs compatible with Vancouver site B spectrum

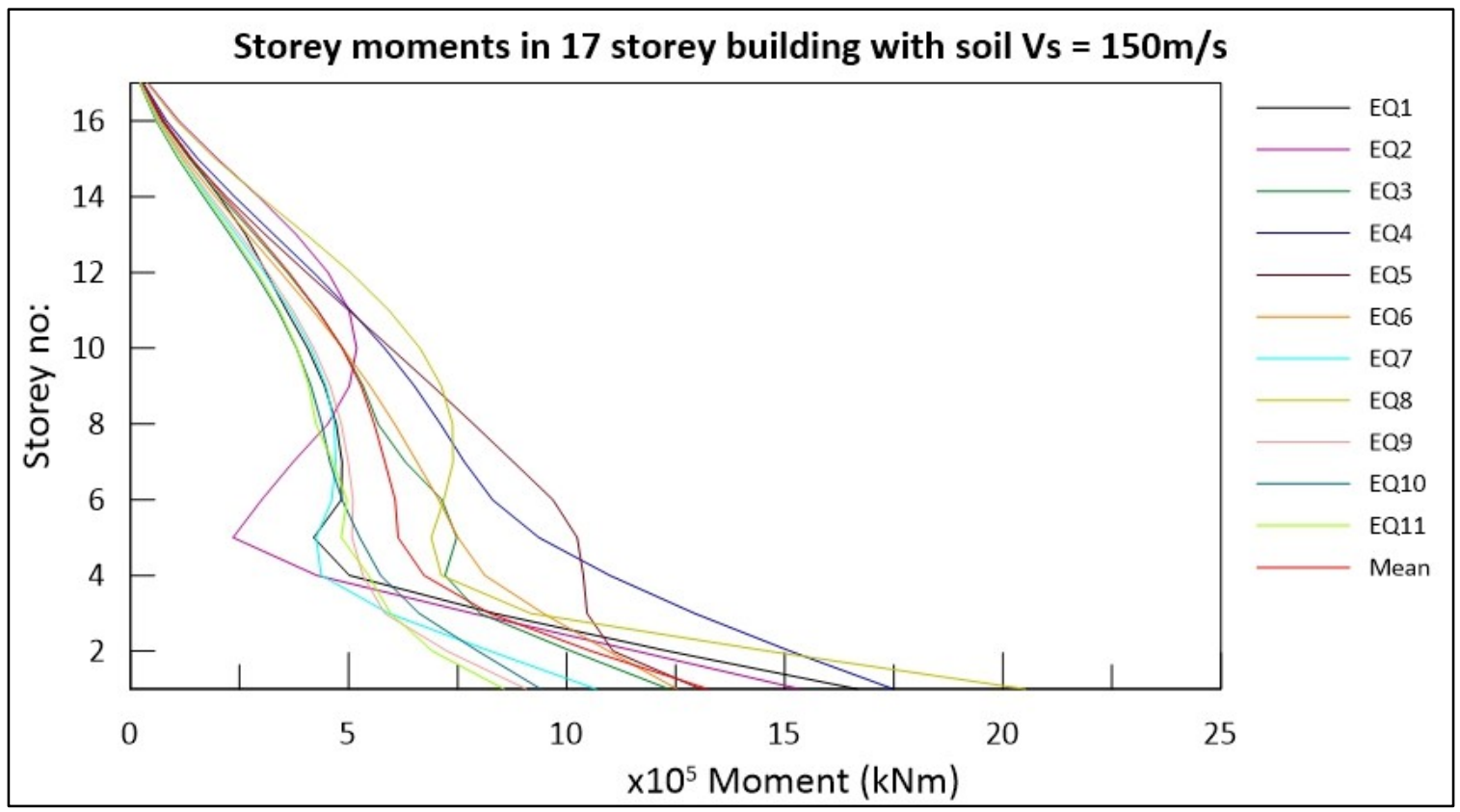

Figure B-102 Storey moments in 17storey building with soil shear wave velocity, Vs $=100 \mathrm{~m} / \mathrm{s}$ analyzed for 11 earthquake inputs compatible with Vancouver site B spectrum 


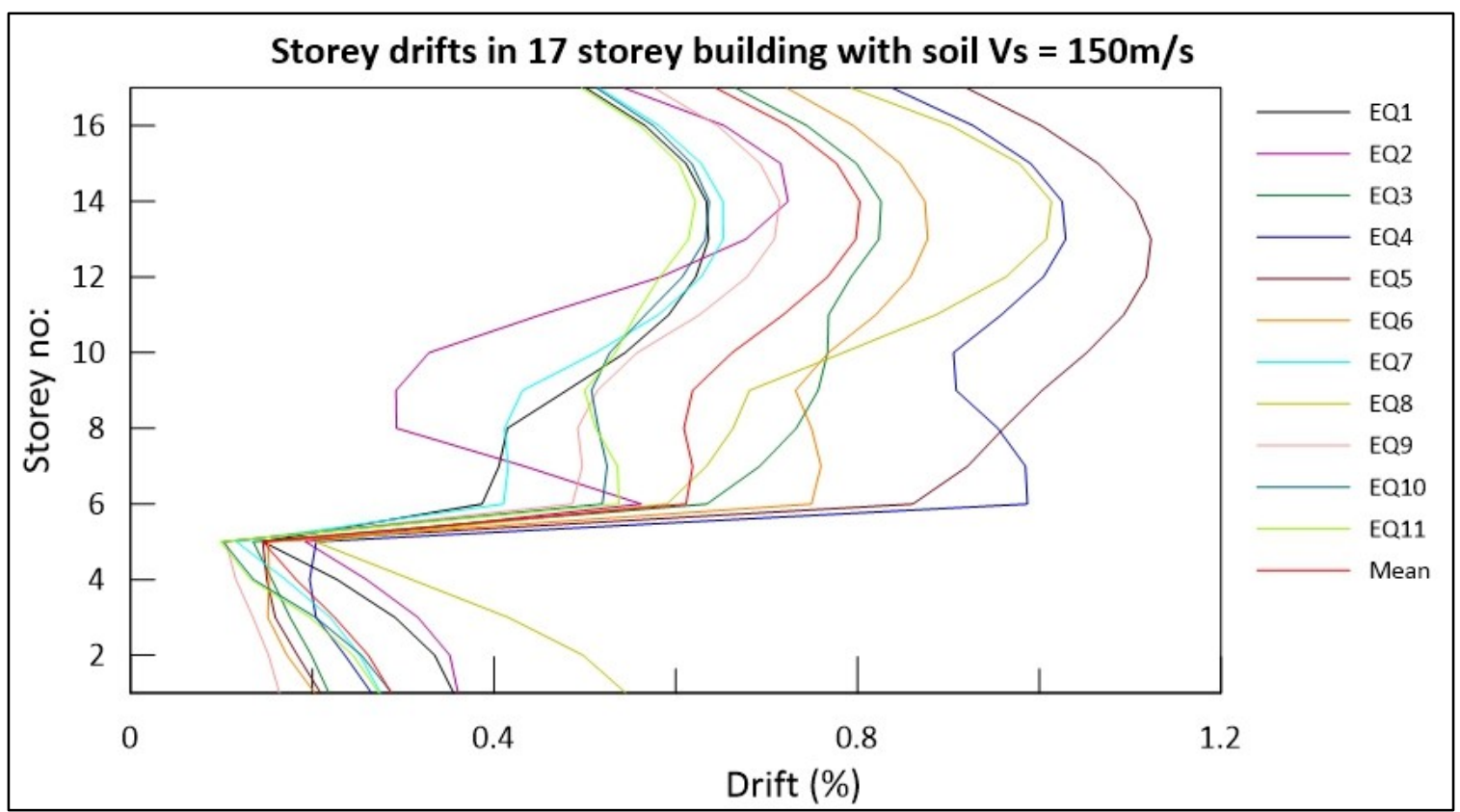

Figure B-103 Storey drifts in 17storey building with soil shear wave velocity, $\mathrm{Vs}=150 \mathrm{~m} / \mathrm{s}$ analyzed for 11 earthquake inputs compatible with Vancouver site B spectrum

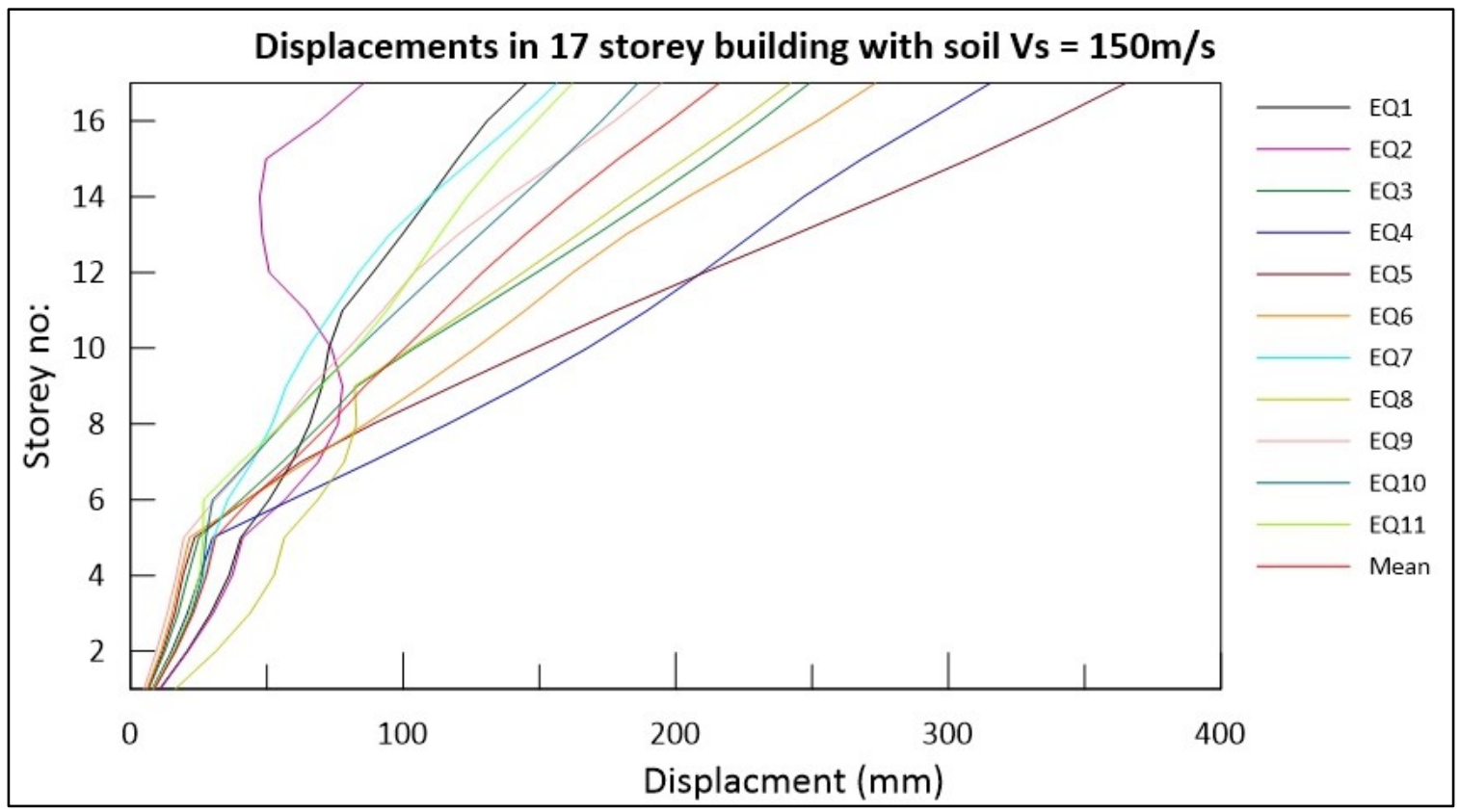

Figure B-104 Displacements in 17storey building with soil shear wave velocity, Vs $=150 \mathrm{~m} / \mathrm{s}$ analyzed for 11 earthquake inputs compatible with Vancouver site B spectrum 


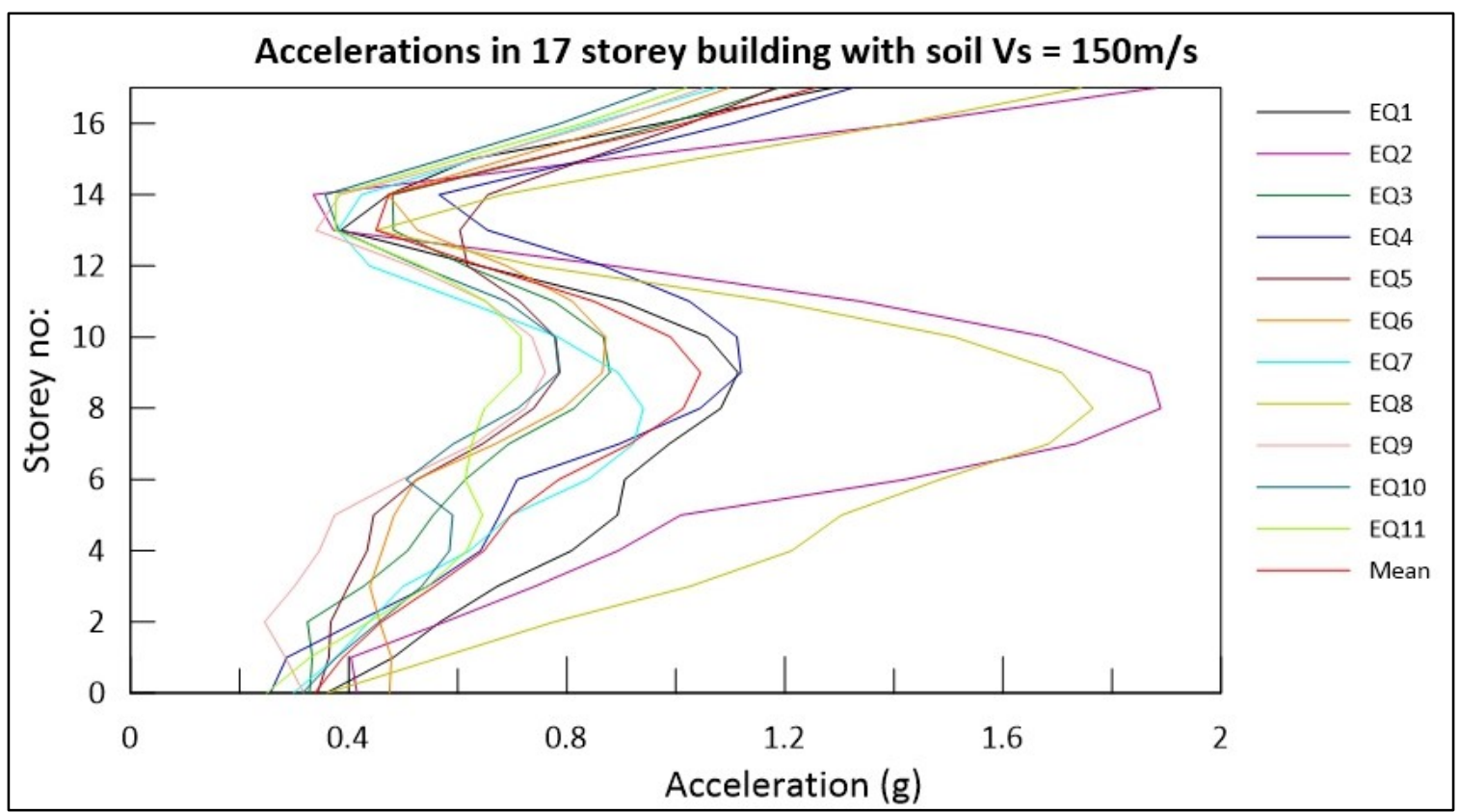

Figure B-105 Accelerations in 17 storey building with soil shear wave velocity, Vs $=150 \mathrm{~m} / \mathrm{s}$ analyzed for 11 earthquake inputs compatible with Vancouver site B spectrum

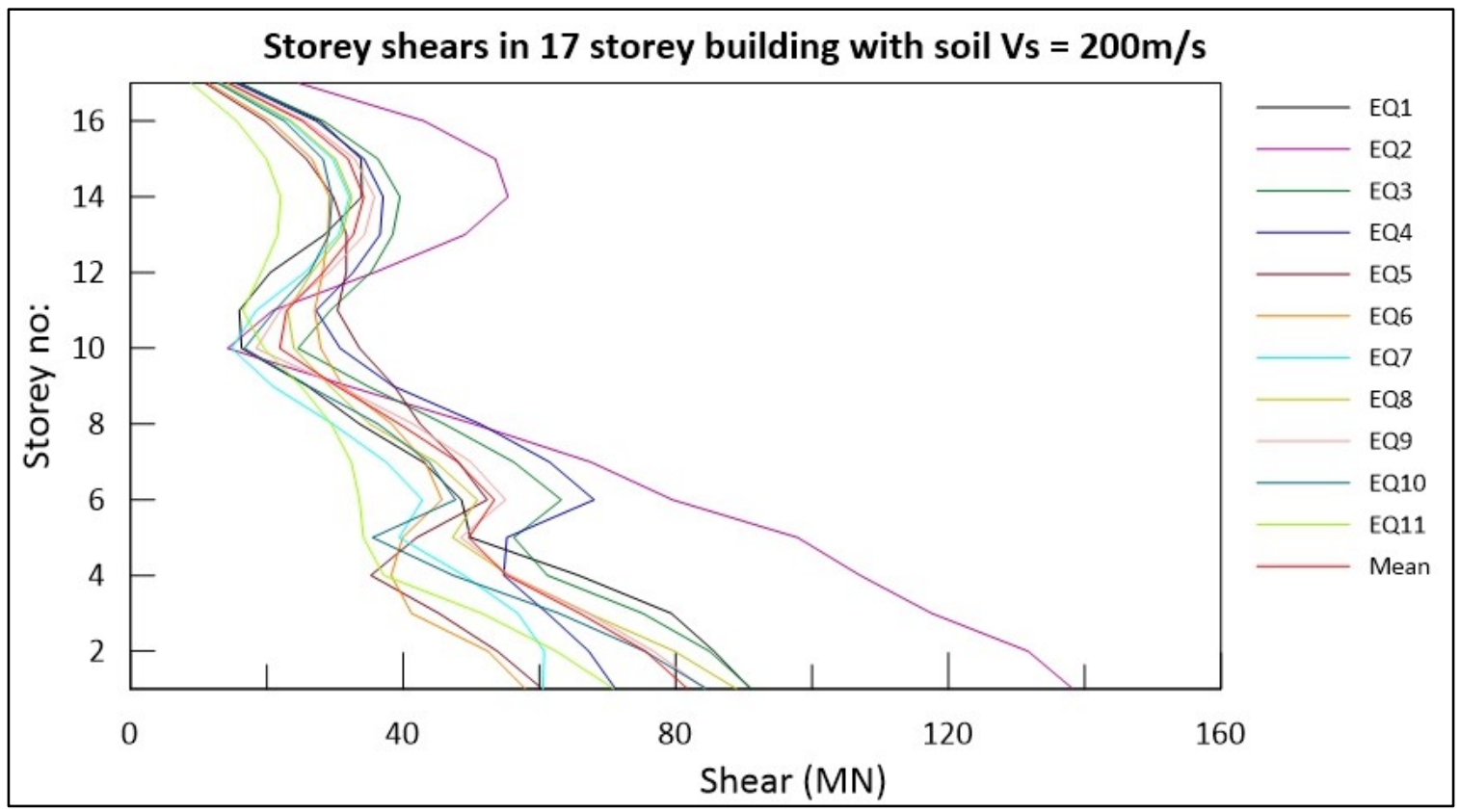

Figure B-106 Storey shears in 17storey building with soil shear wave velocity, Vs = 200m/s analyzed for 11 earthquake inputs compatible with Vancouver site B spectrum 


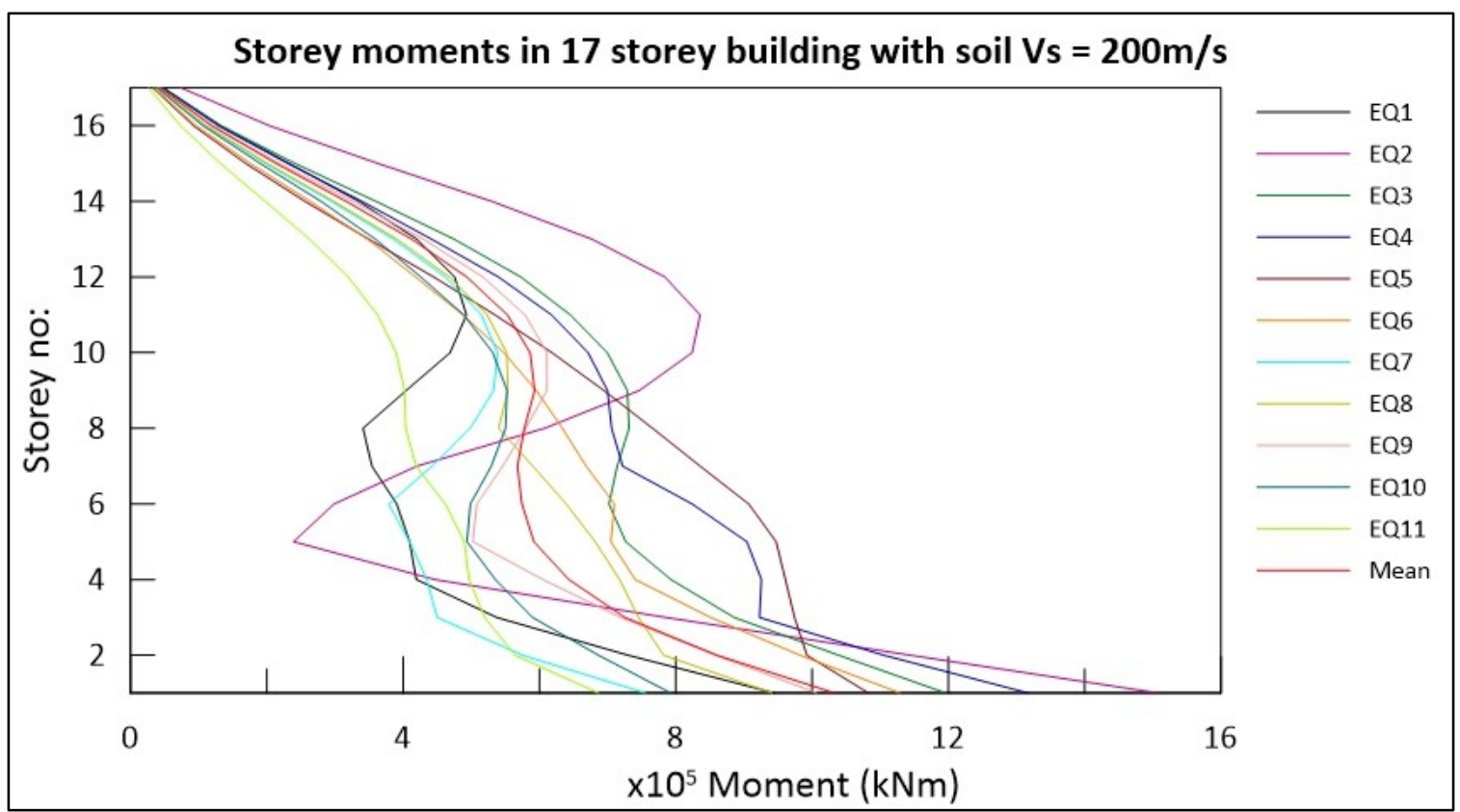

Figure B-107 Storey moments in 17storey building with soil shear wave velocity, Vs $=200 \mathrm{~m} / \mathrm{s}$ analyzed for 11 earthquake inputs compatible with Vancouver site B spectrum

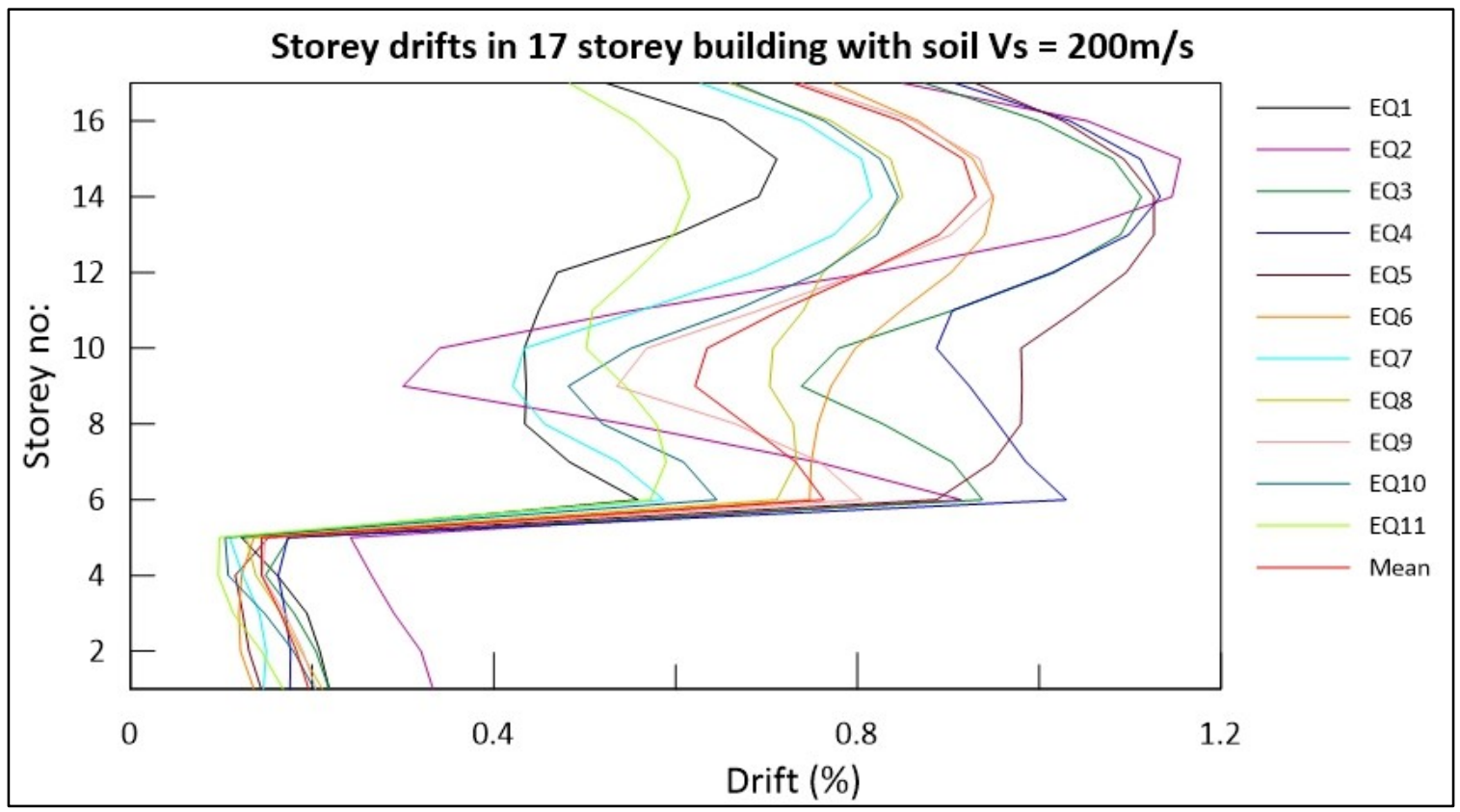

Figure B-108 Storey drifts in 17storey building with soil shear wave velocity, Vs =200m/s analyzed for 11 earthquake inputs compatible with Vancouver site B spectrum 


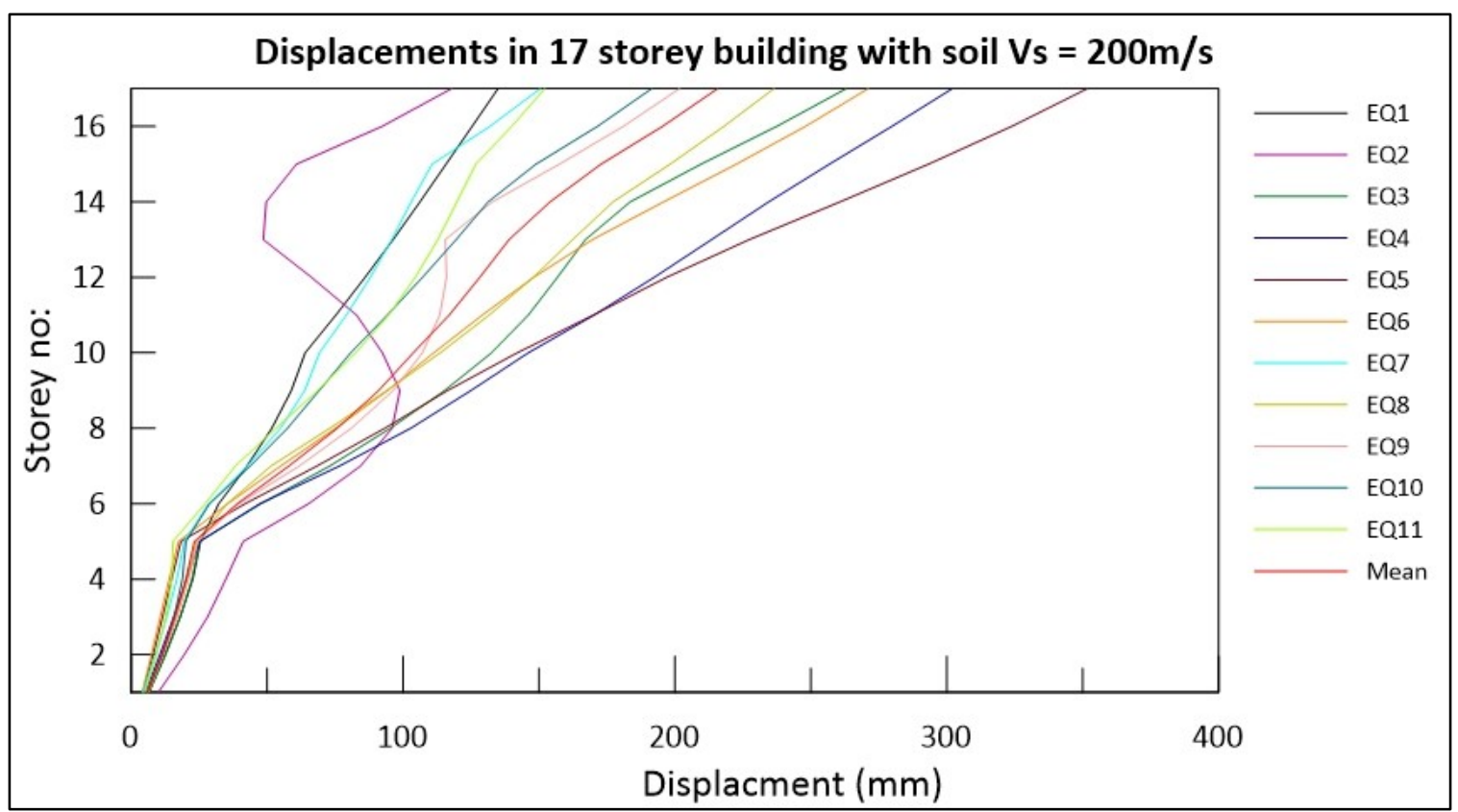

Figure B-109 Displacements in 17storey building with soil shear wave velocity, Vs $=200 \mathrm{~m} / \mathrm{s}$ analyzed for 11 earthquake inputs compatible with Vancouver site B spectrum

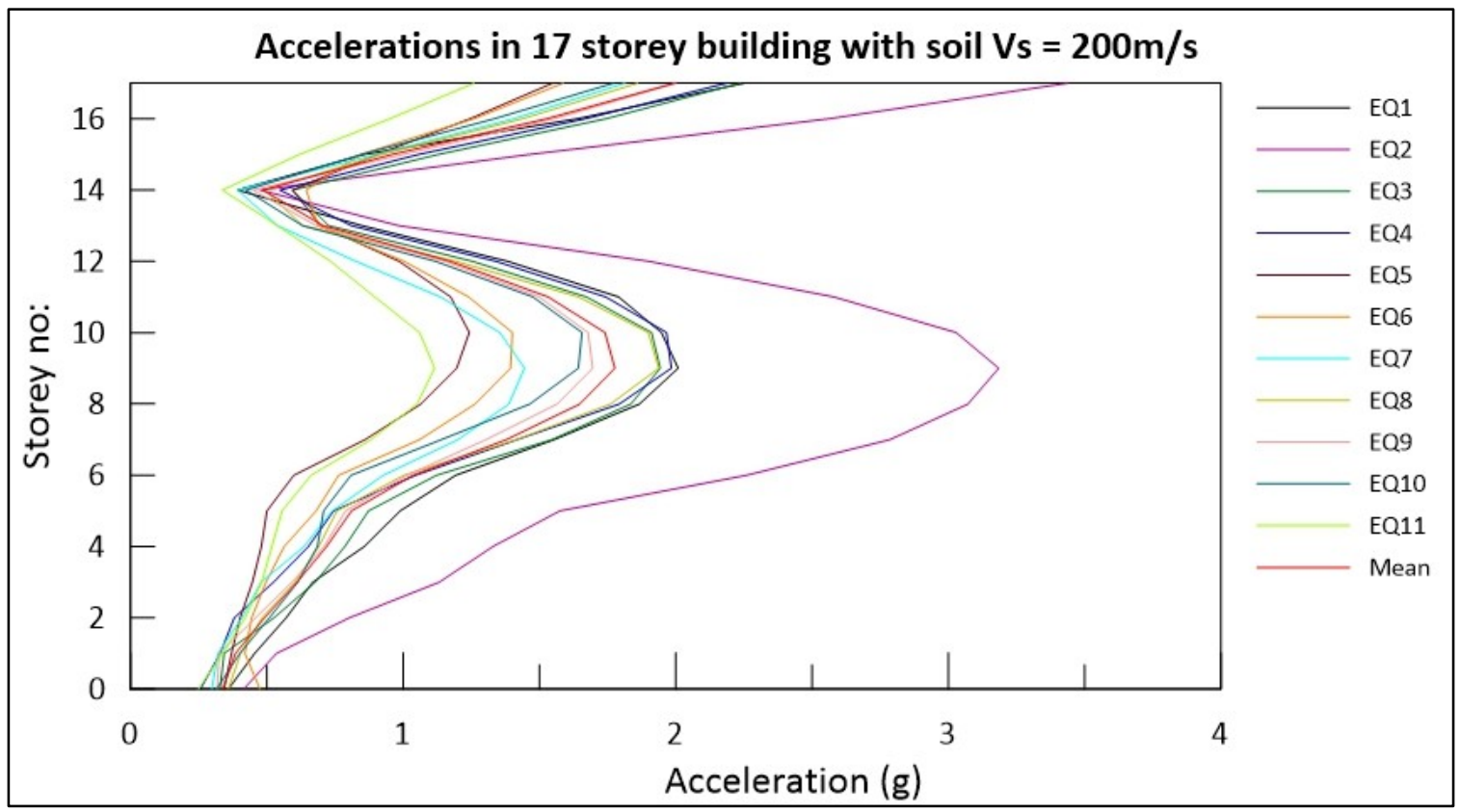

Figure B-110 Accelerations in 17storey building with soil shear wave velocity, Vs $=200 \mathrm{~m} / \mathrm{s}$ analyzed for 11 earthquake inputs compatible with Vancouver site B spectrum 


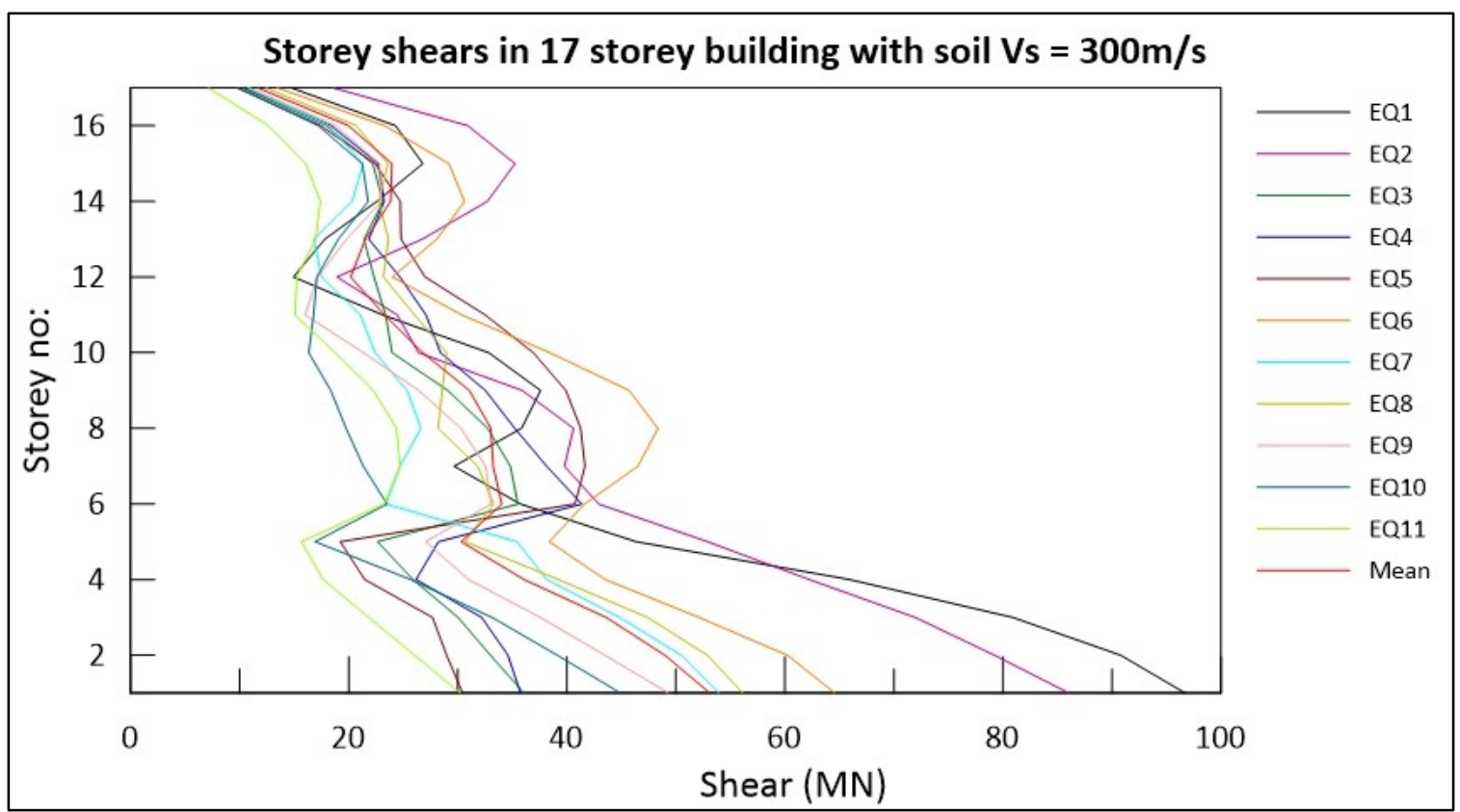

Figure B-111 Storey shears in 17storey building with soil shear wave velocity, Vs $=300 \mathrm{~m} / \mathrm{s}$ analyzed for 11 earthquake inputs compatible with Vancouver site B spectrum

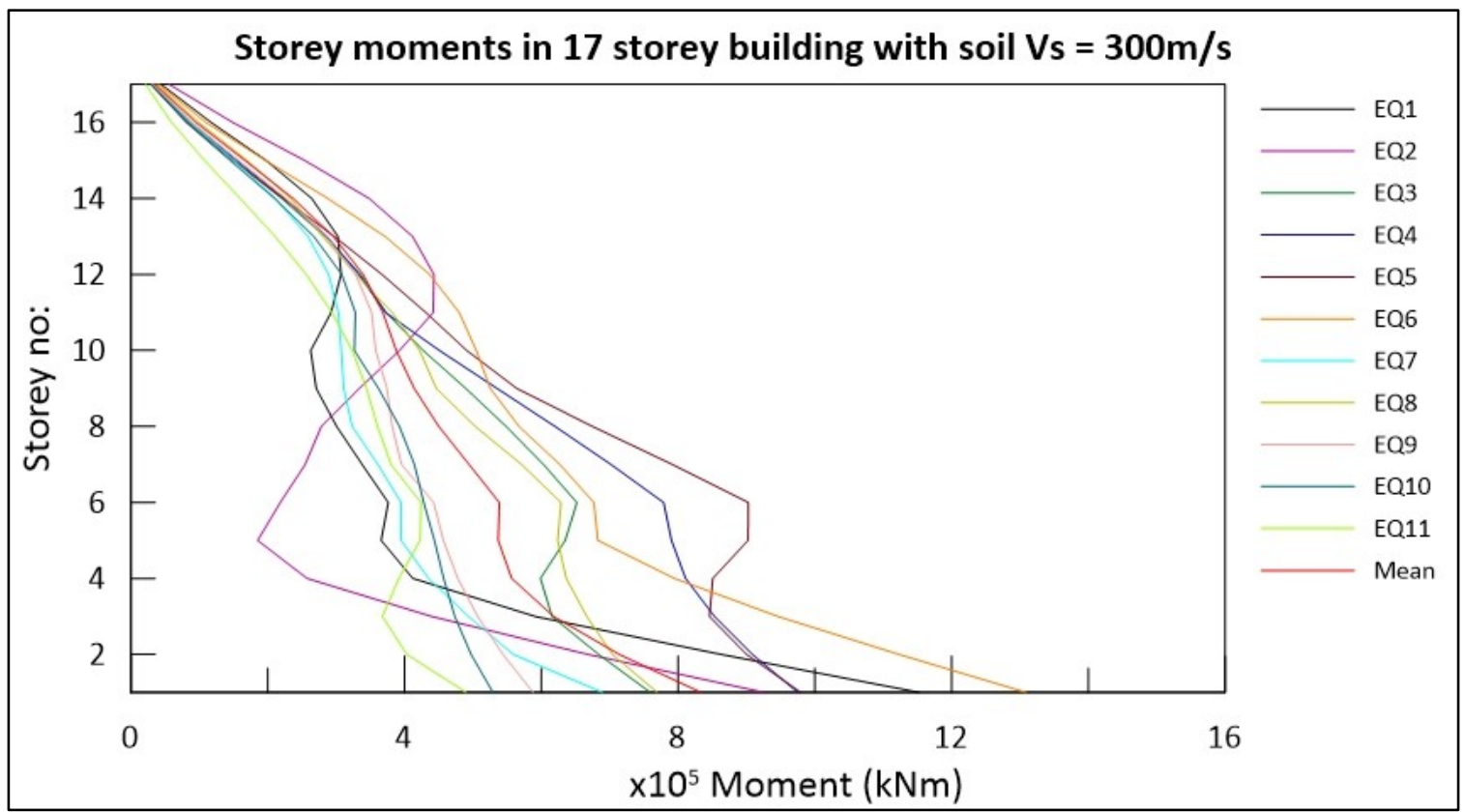

Figure B-112 Storey moments in 17 storey building with soil shear wave velocity, Vs $=300 \mathrm{~m} / \mathrm{s}$ analyzed for 11 earthquake inputs compatible with Vancouver site B spectrum 


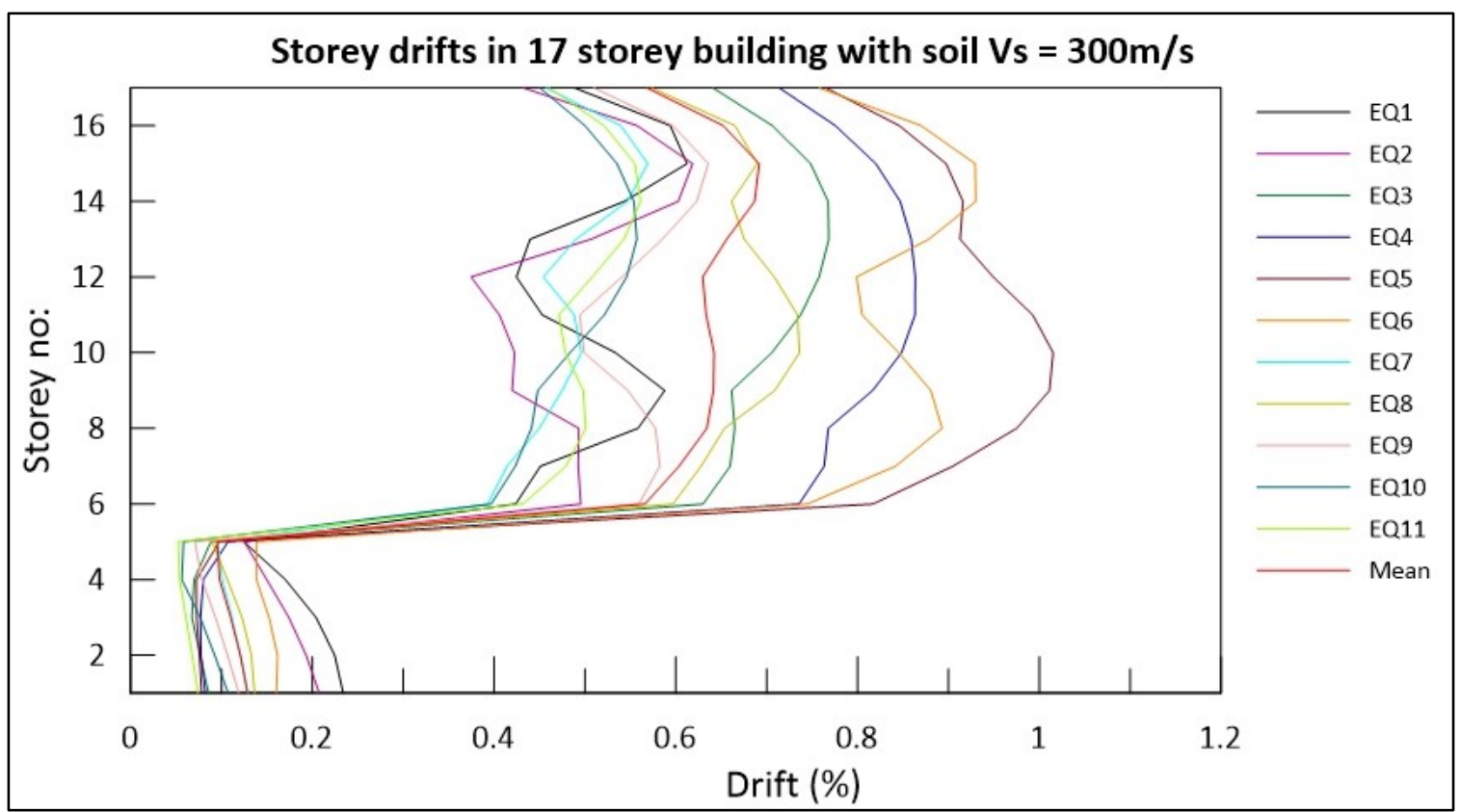

Figure B-113 Storey drifts in 17storey building with soil shear wave velocity, $\mathrm{Vs}=300 \mathrm{~m} / \mathrm{s}$ analyzed for 11 earthquake inputs compatible with Vancouver site B spectrum

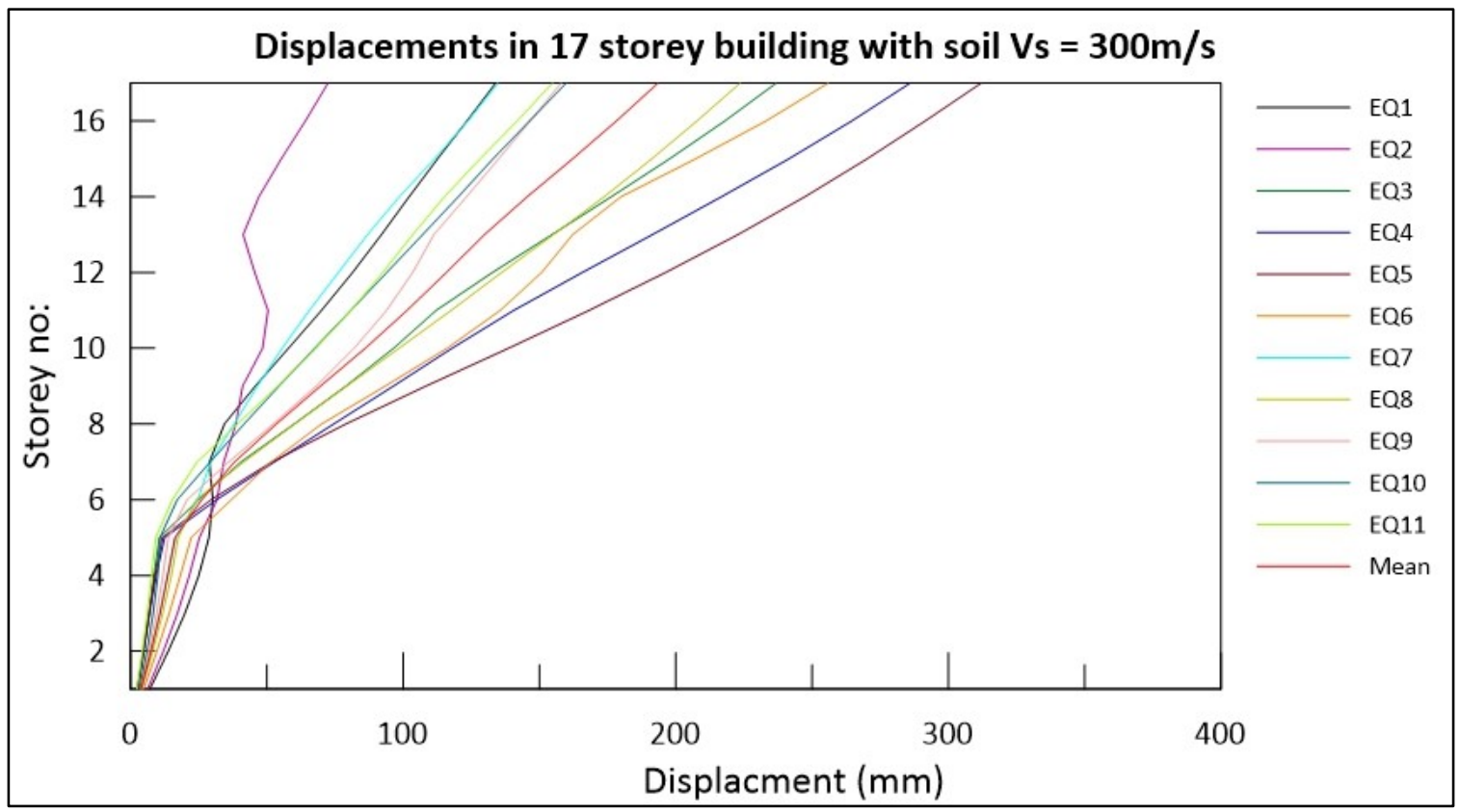

Figure B-114 Displacements in 17 storey building with soil shear wave velocity, Vs $=300 \mathrm{~m} / \mathrm{s}$ analyzed for 11 earthquake inputs compatible with Vancouver site B spectrum 


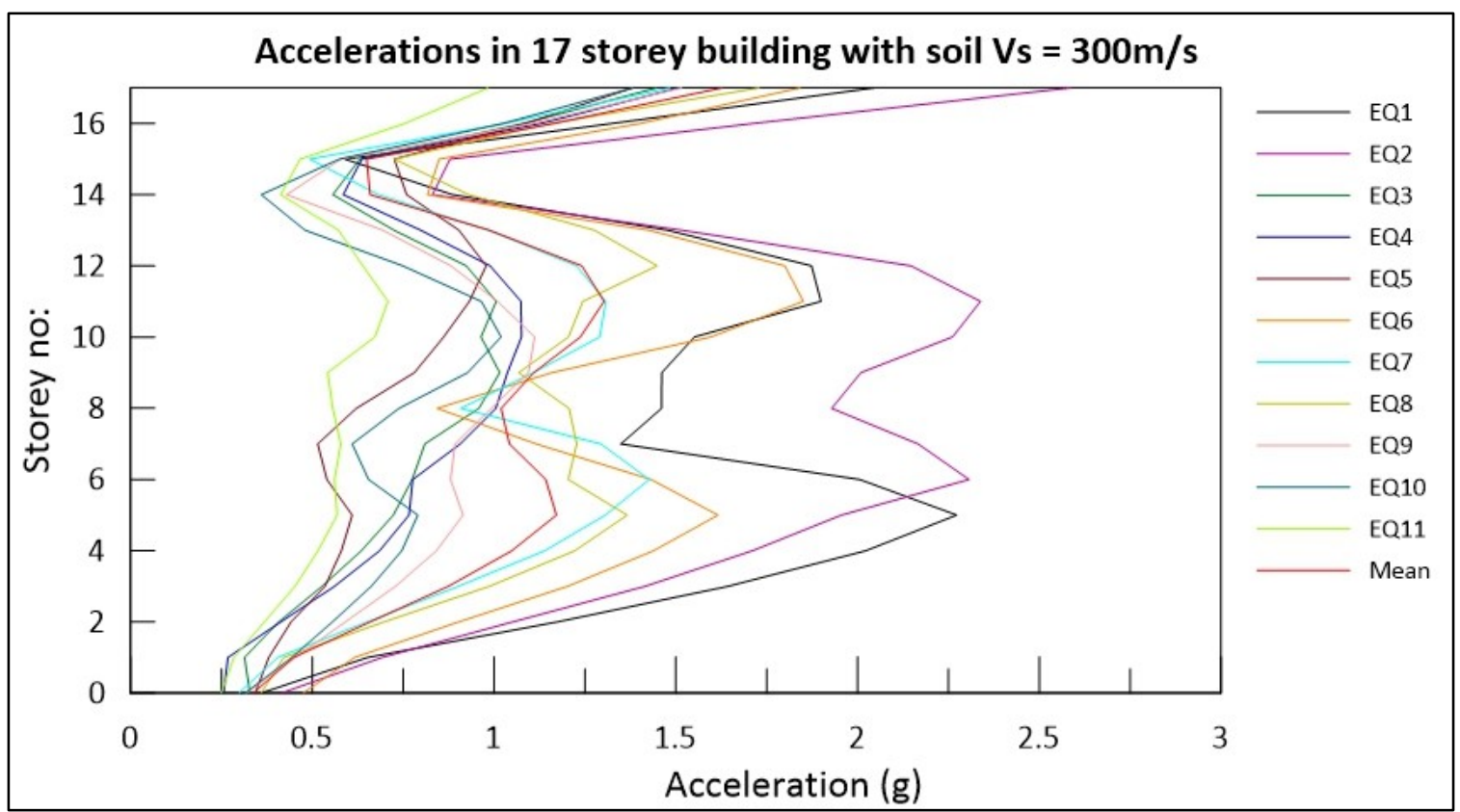

Figure B-115 Accelerations in 17 storey building with soil shear wave velocity, $\mathrm{Vs}=300 \mathrm{~m} / \mathrm{s}$ analyzed for 11 earthquake inputs compatible with Vancouver site B spectrum

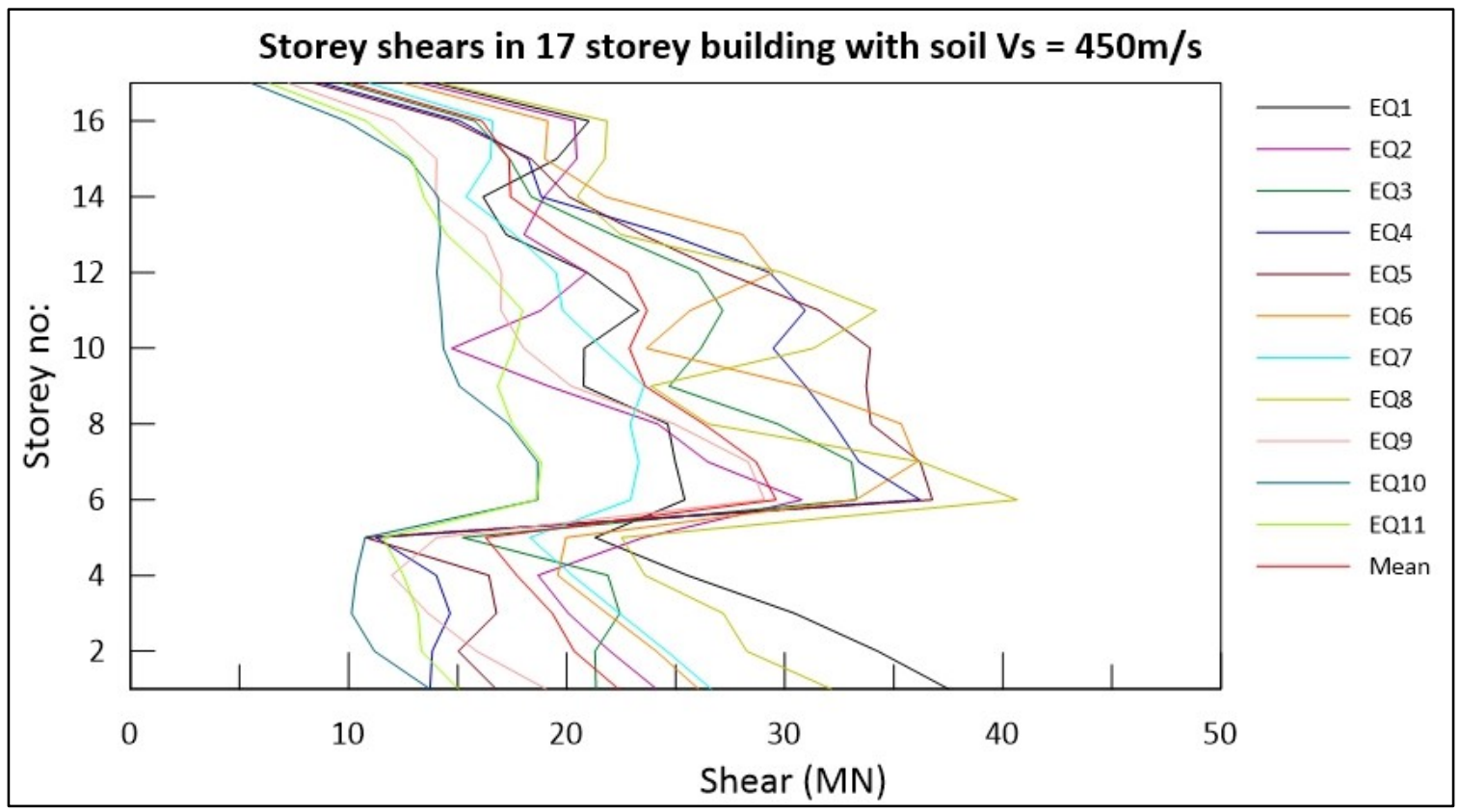

Figure B-116 Storey shears in 17storey building with soil shear wave velocity, Vs $=450 \mathrm{~m} / \mathrm{s}$ analyzed for 11 earthquake inputs compatible with Vancouver site B spectrum 


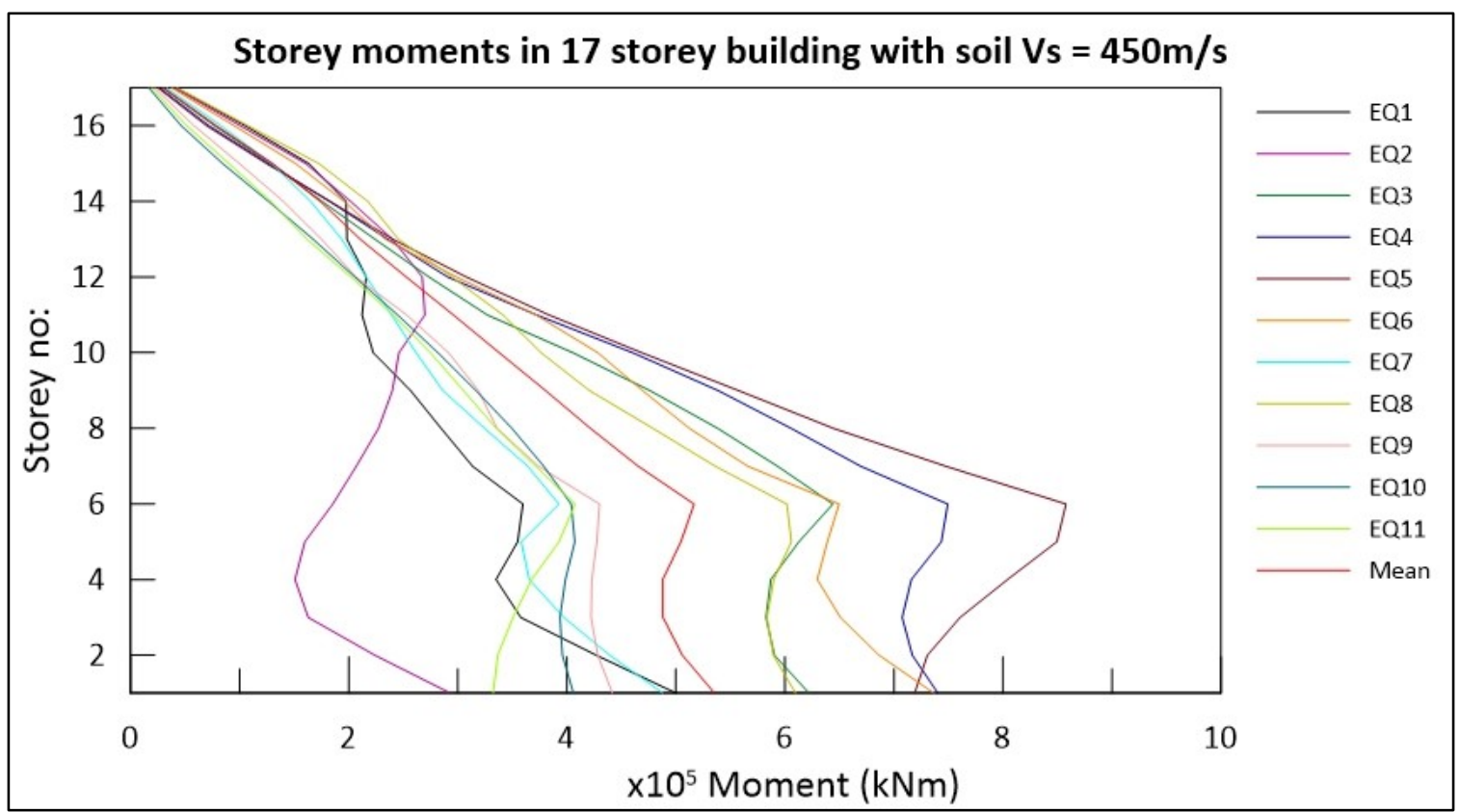

Figure B-117 Storey moments in 17 storey building with soil shear wave velocity, Vs $=450 \mathrm{~m} / \mathrm{s}$ analyzed for 11 earthquake inputs compatible with Vancouver site B spectrum

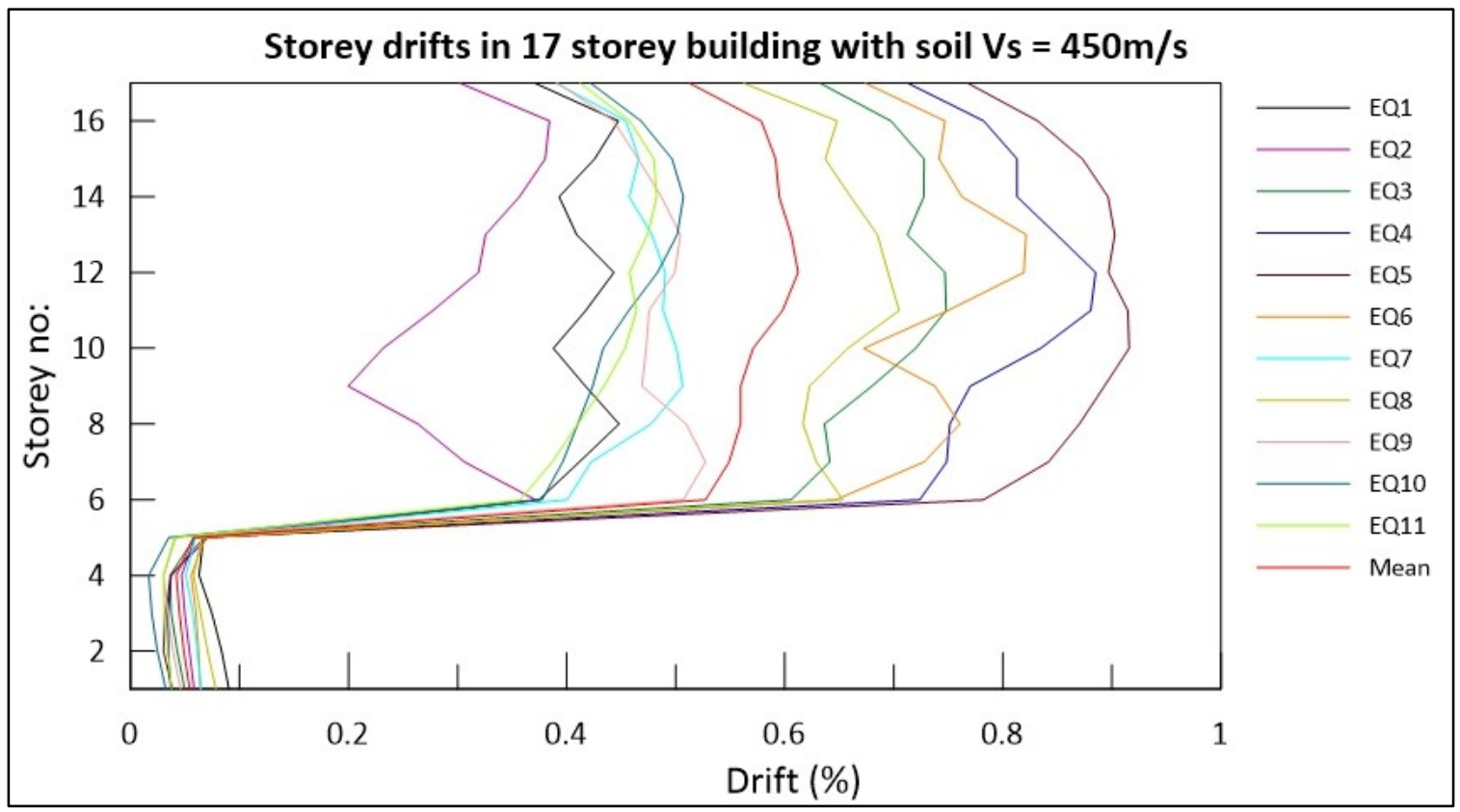

Figure B-118 Storey drifts in 17storey building with soil shear wave velocity, Vs $=450 \mathrm{~m} / \mathrm{s}$ analyzed for 11 earthquake inputs compatible with Vancouver site B spectrum 


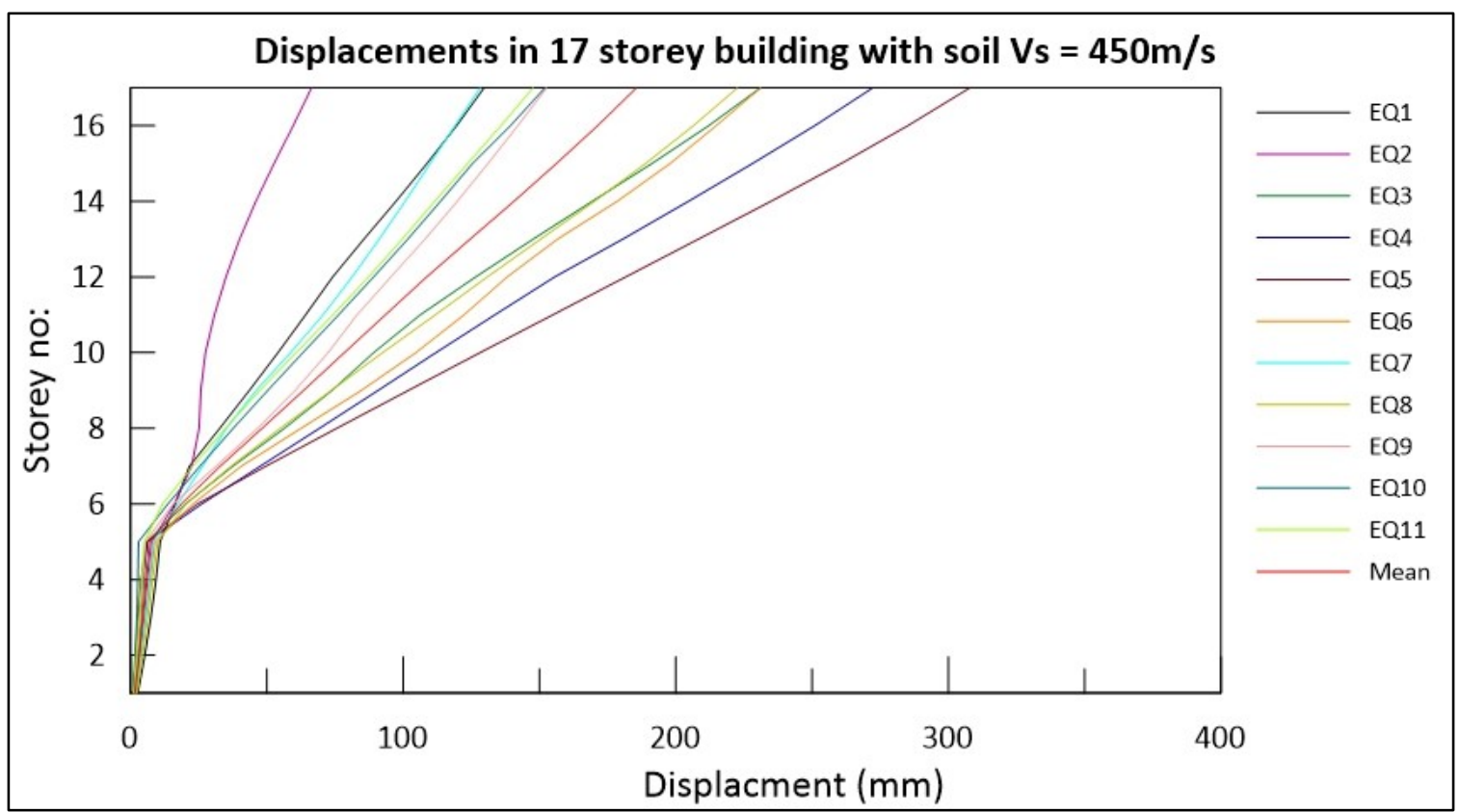

Figure B-119 Displacements in 17storey building with soil shear wave velocity, Vs $=450 \mathrm{~m} / \mathrm{s}$ analyzed for 11 earthquake inputs compatible with Vancouver site B spectrum

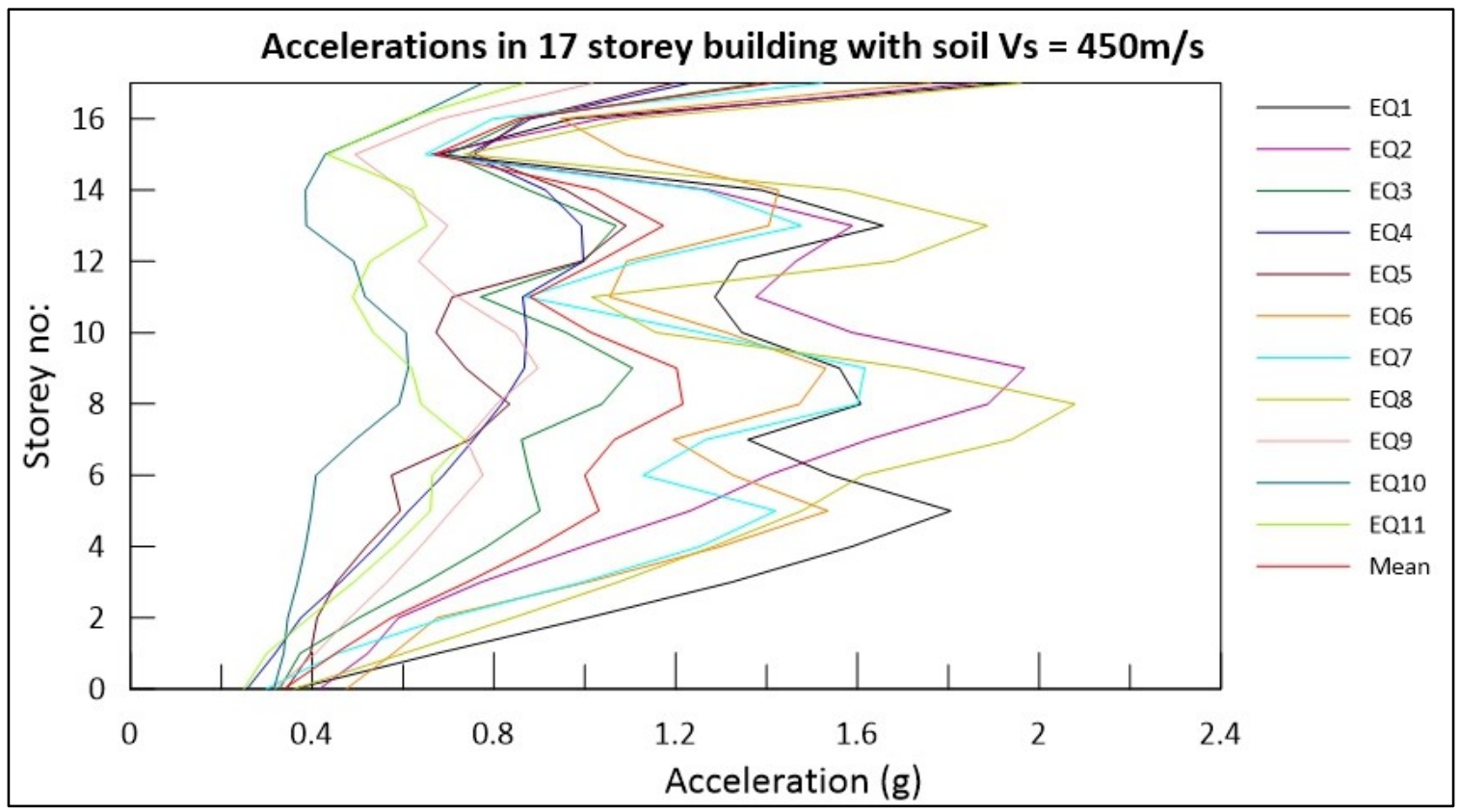

Figure B-120 Accelerations in 17storey building with soil shear wave velocity, Vs $=450 \mathrm{~m} / \mathrm{s}$ analyzed for 11 earthquake inputs compatible with Vancouver site B spectrum 


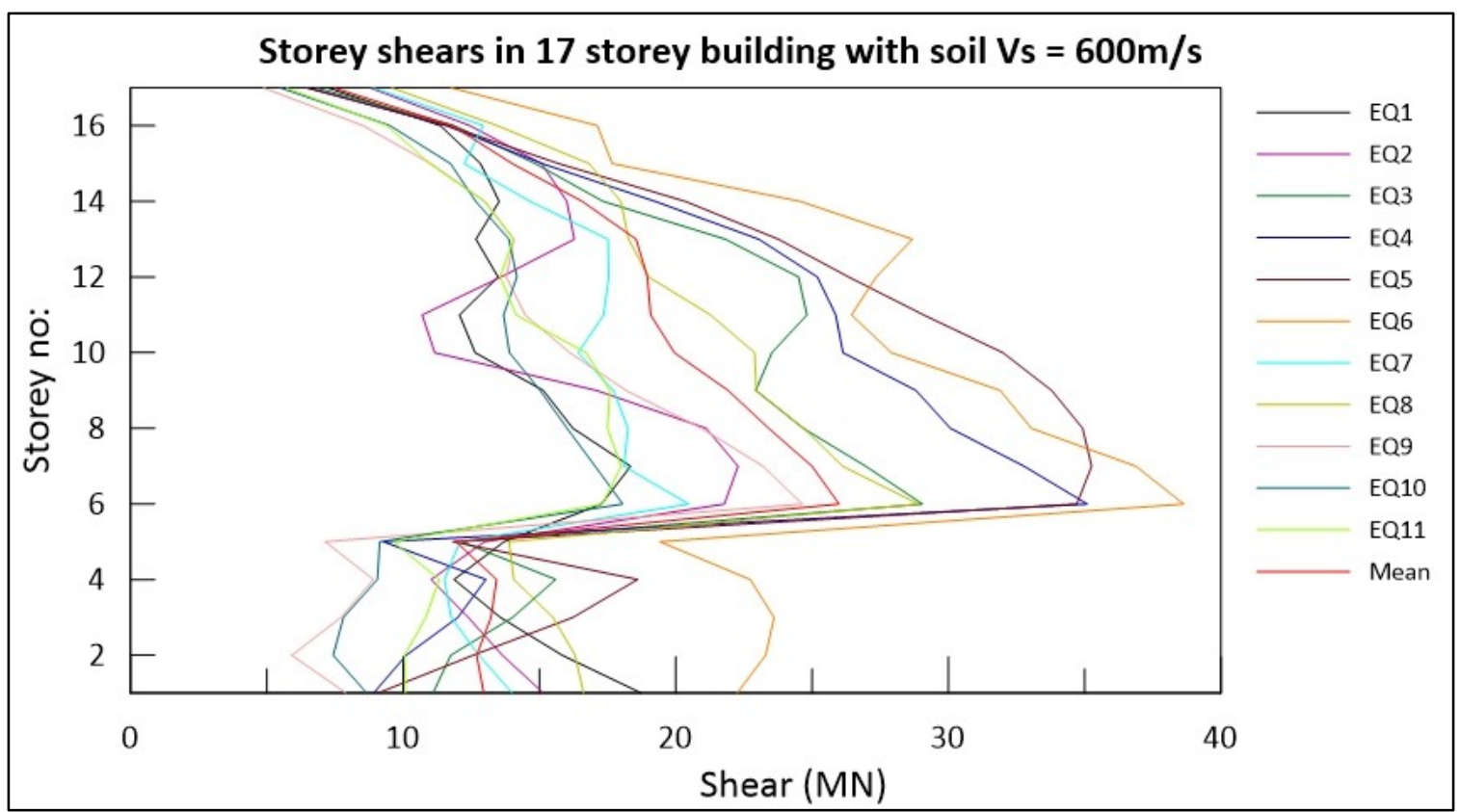

Figure B-121 Storey shears in 17storey building with soil shear wave velocity, Vs $=600 \mathrm{~m} / \mathrm{s}$ analyzed for 11 earthquake inputs compatible with Vancouver site B spectrum

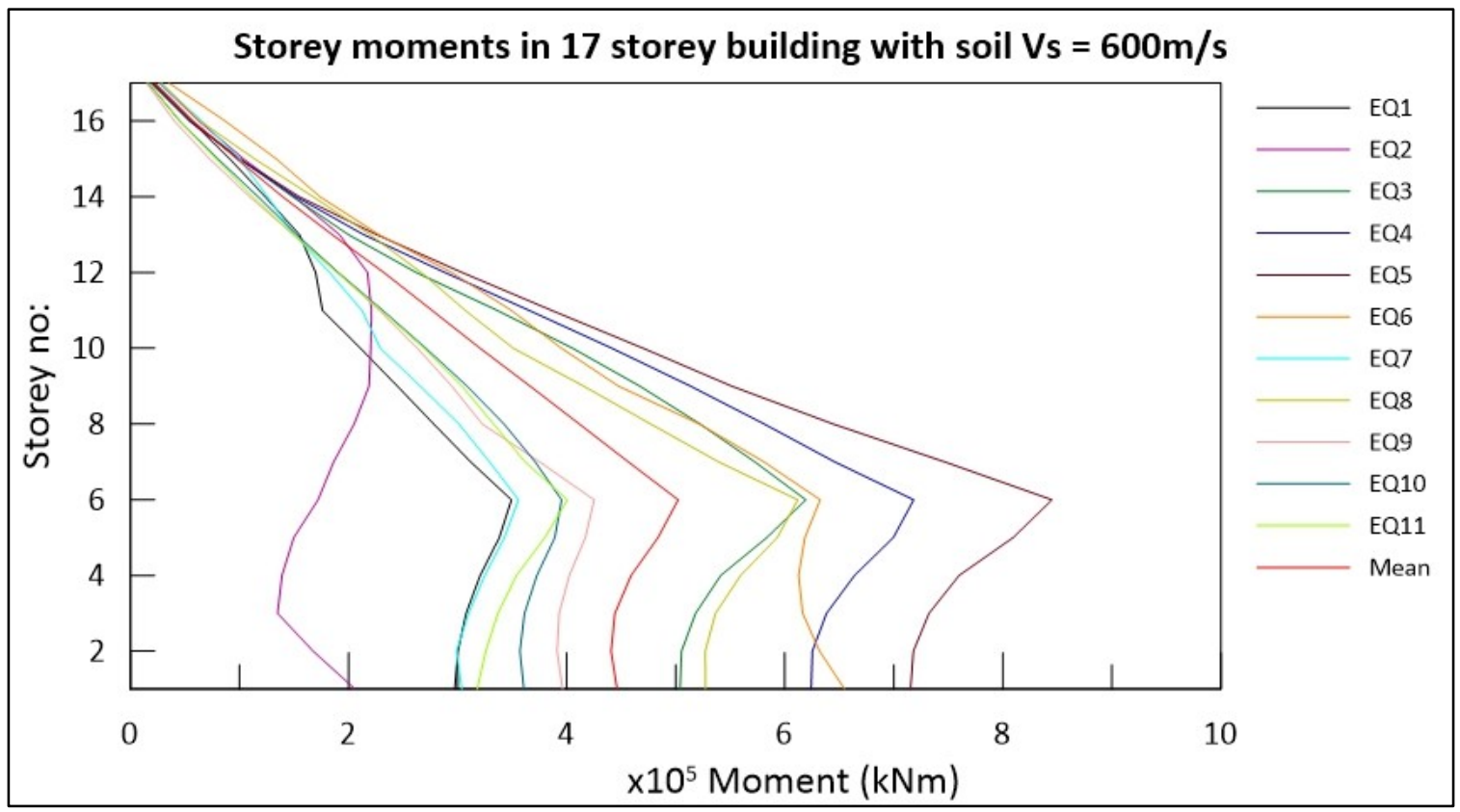

Figure B-122 Storey moments in 17storey building with soil shear wave velocity, Vs $=600 \mathrm{~m} / \mathrm{s}$ analyzed for 11 earthquake inputs compatible with Vancouver site B spectrum 


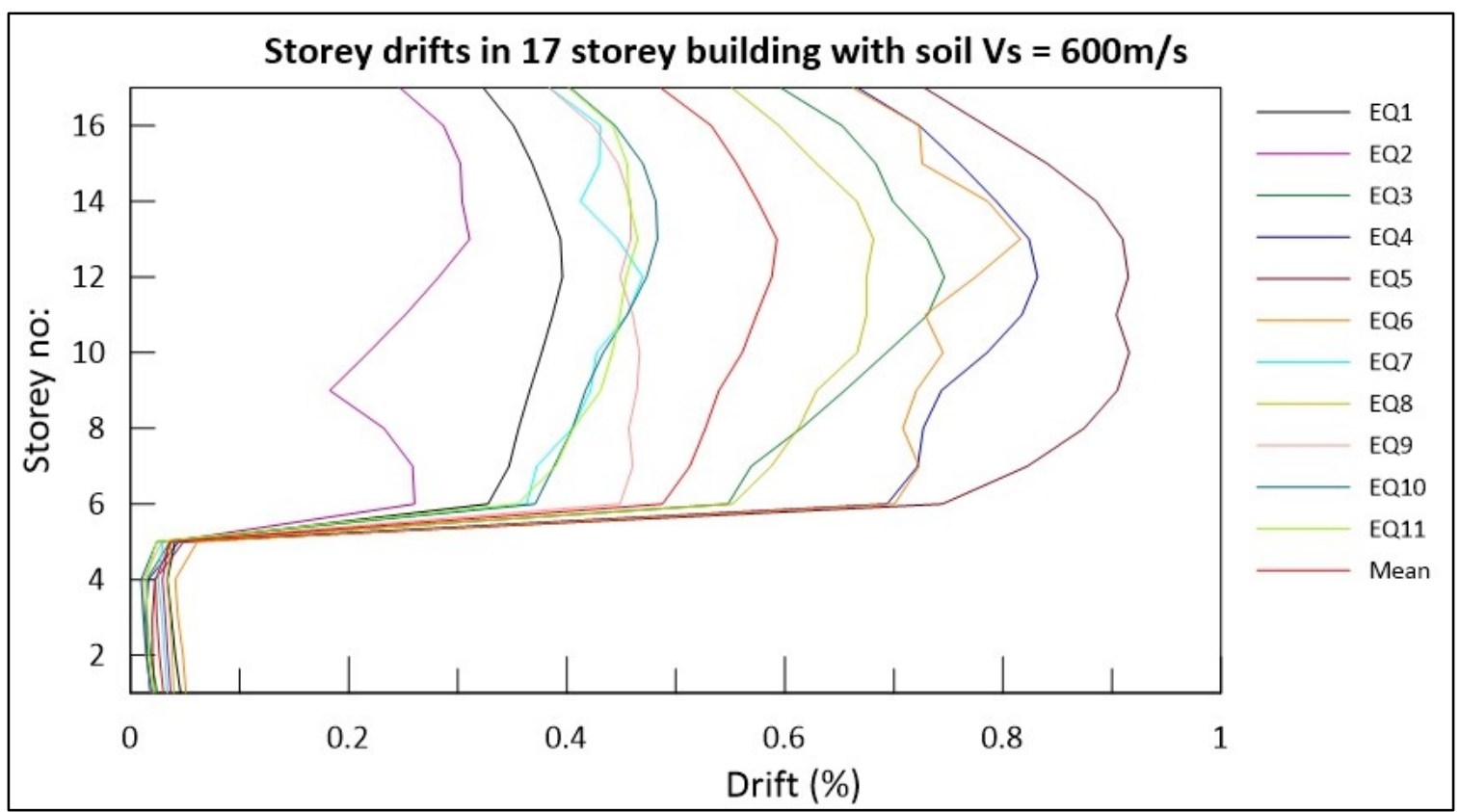

Figure B-123 Storey drifts in 17storey building with soil shear wave velocity, $\mathrm{Vs}=600 \mathrm{~m} / \mathrm{s}$ analyzed for 11 earthquake inputs compatible with Vancouver site B spectrum

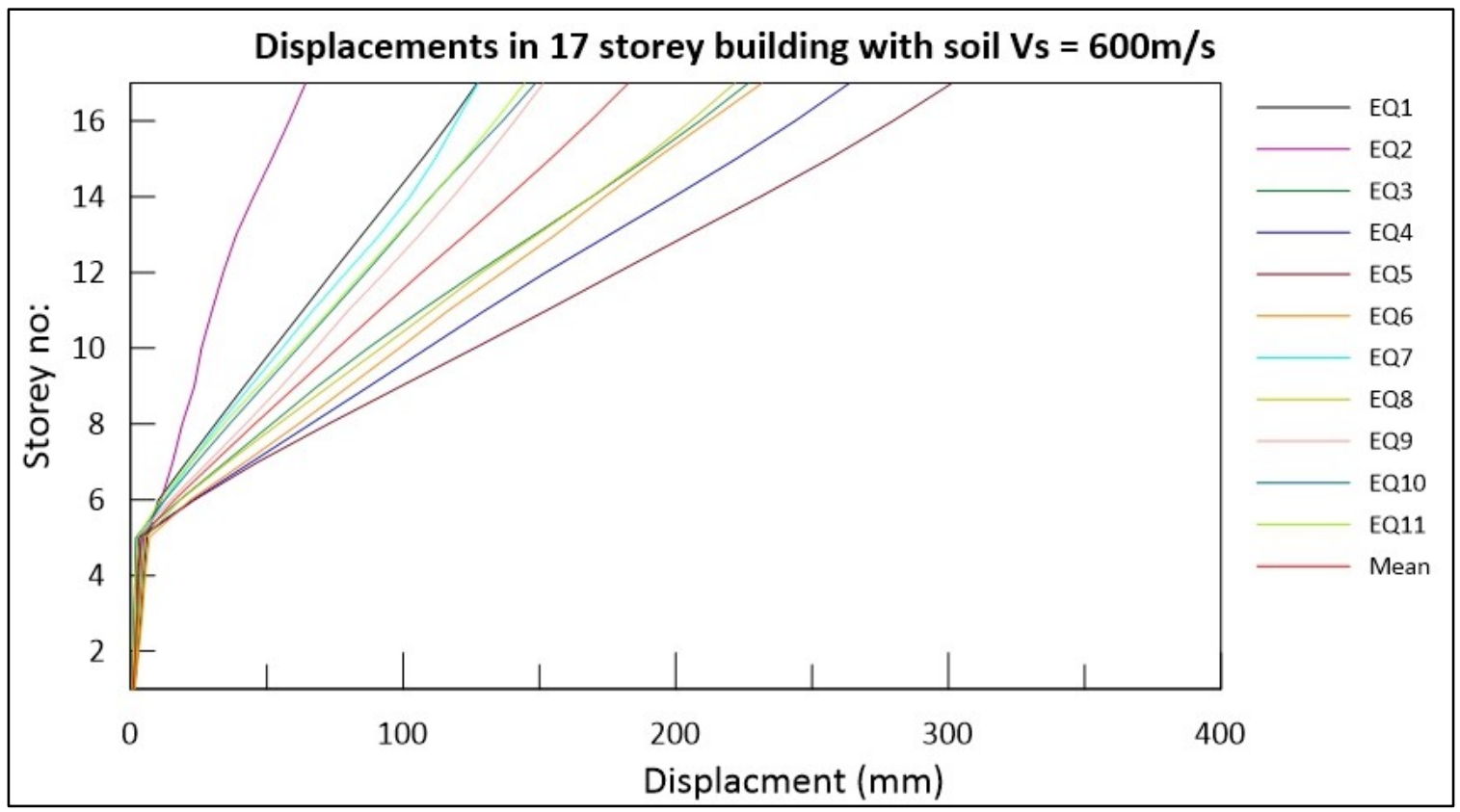

Figure B-124 Displacements in 17storey building with soil shear wave velocity, Vs $=600 \mathrm{~m} / \mathrm{s}$ analyzed for 11 earthquake inputs compatible with Vancouver site B spectrum 


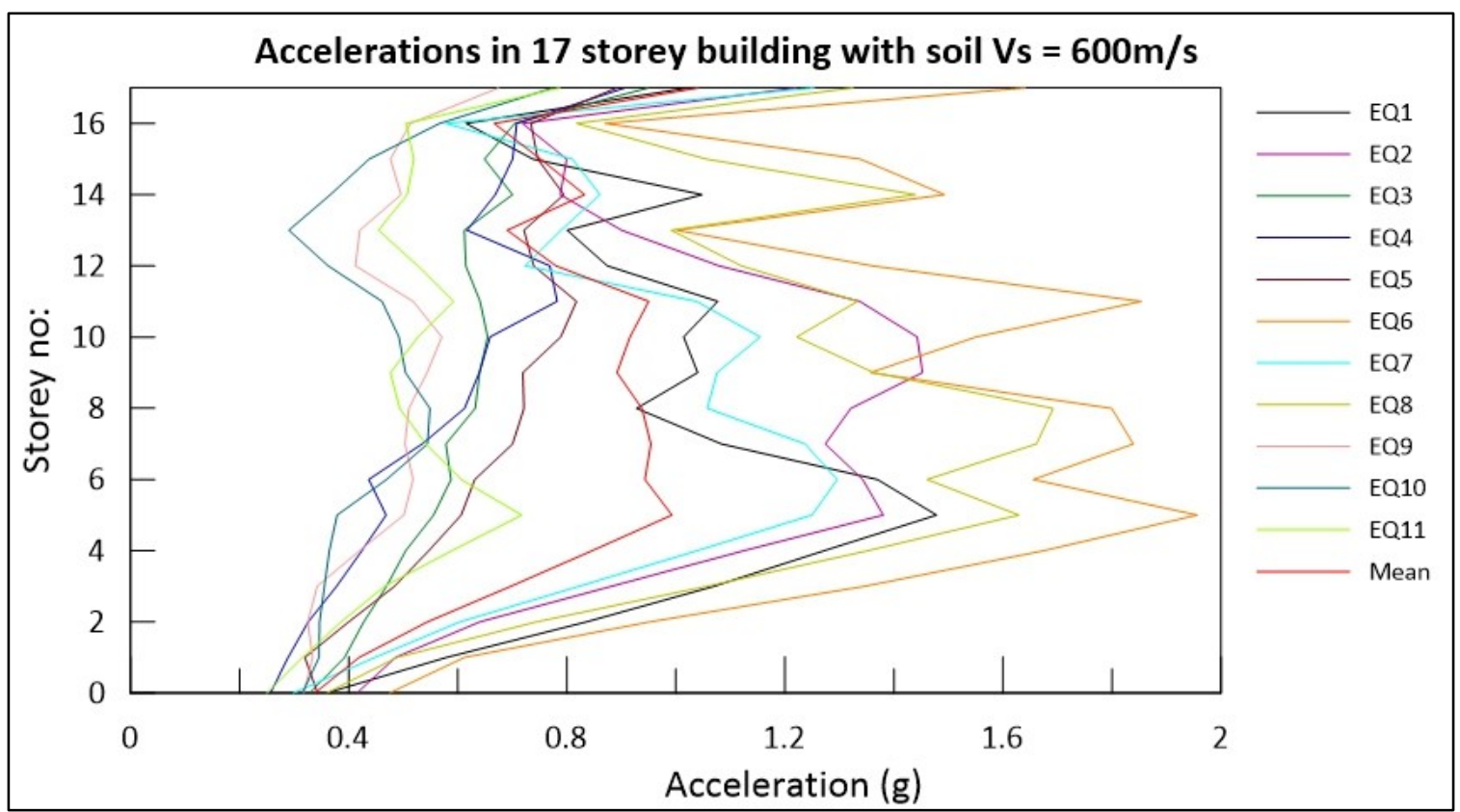

Figure B-125 Accelerations in 17 storey building with soil shear wave velocity, Vs $=600 \mathrm{~m} / \mathrm{s}$ analyzed for 11 earthquake inputs compatible with Vancouver site B spectrum

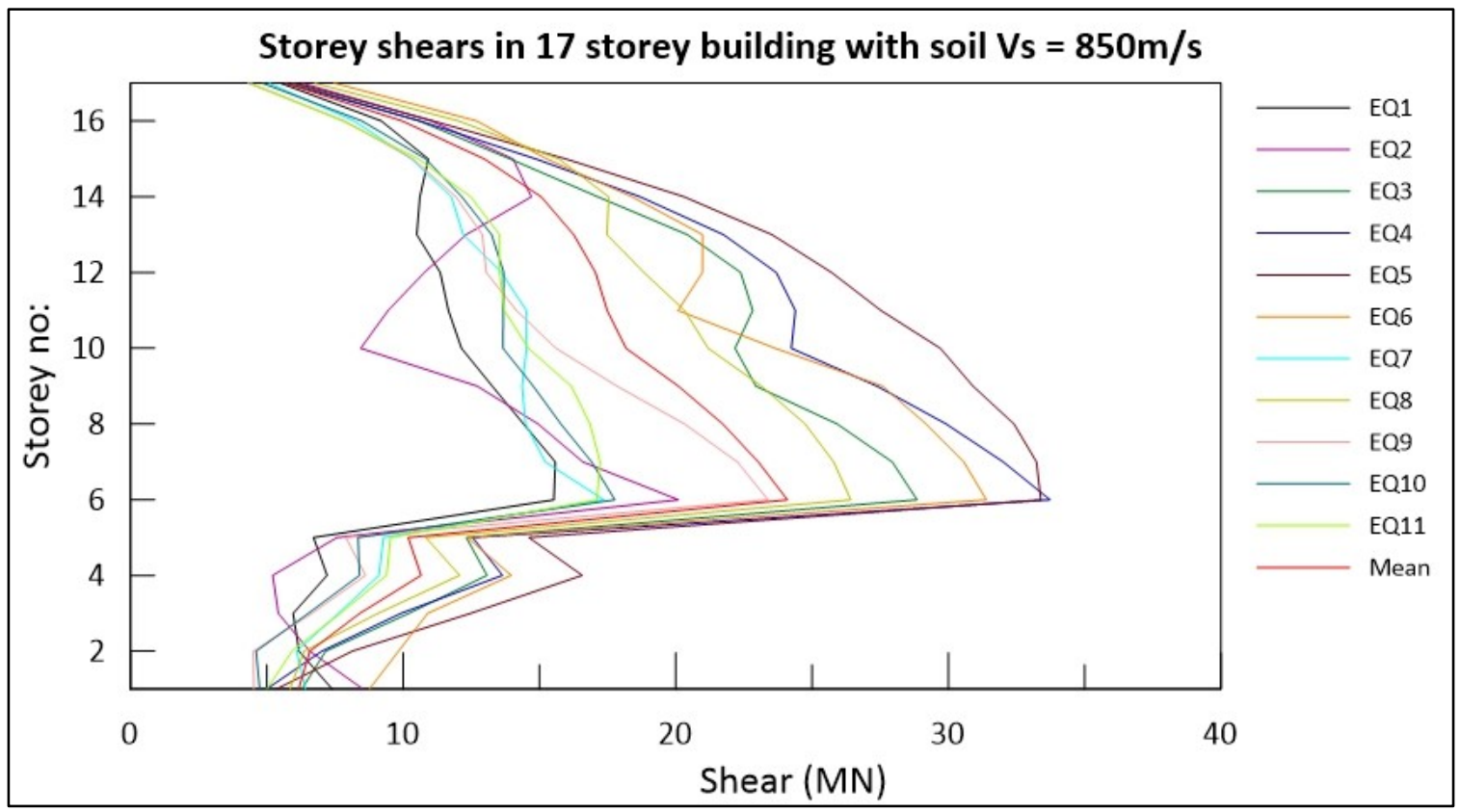

Figure B-126 Storey shears in 17storey building with soil shear wave velocity, Vs $=850 \mathrm{~m} / \mathrm{s}$ analyzed for 11 earthquake inputs compatible with Vancouver site B spectrum 


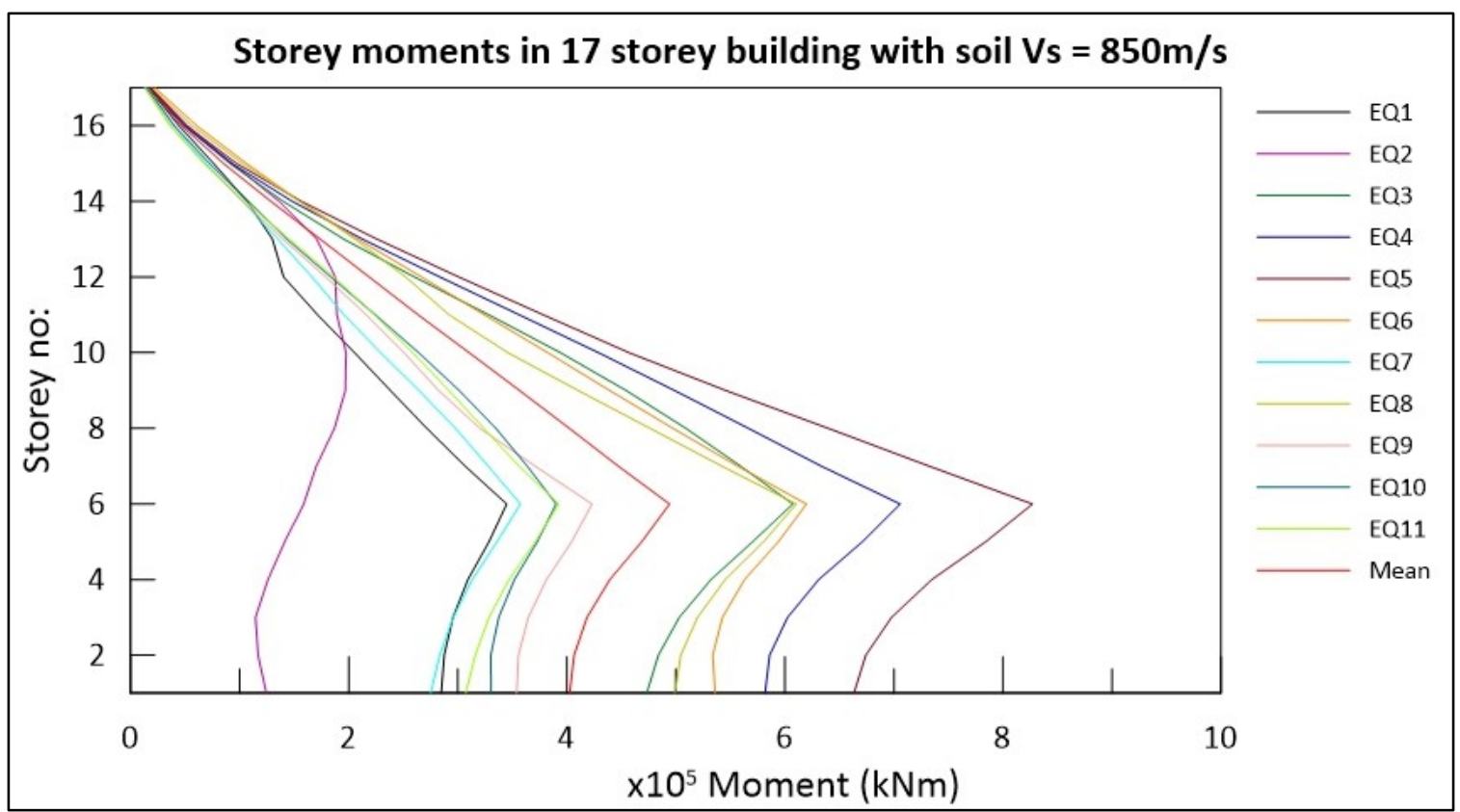

Figure B-127 Storey moments in 17storey building with soil shear wave velocity, Vs $=850 \mathrm{~m} / \mathrm{s}$ analyzed for 11 earthquake inputs compatible with Vancouver site B spectrum

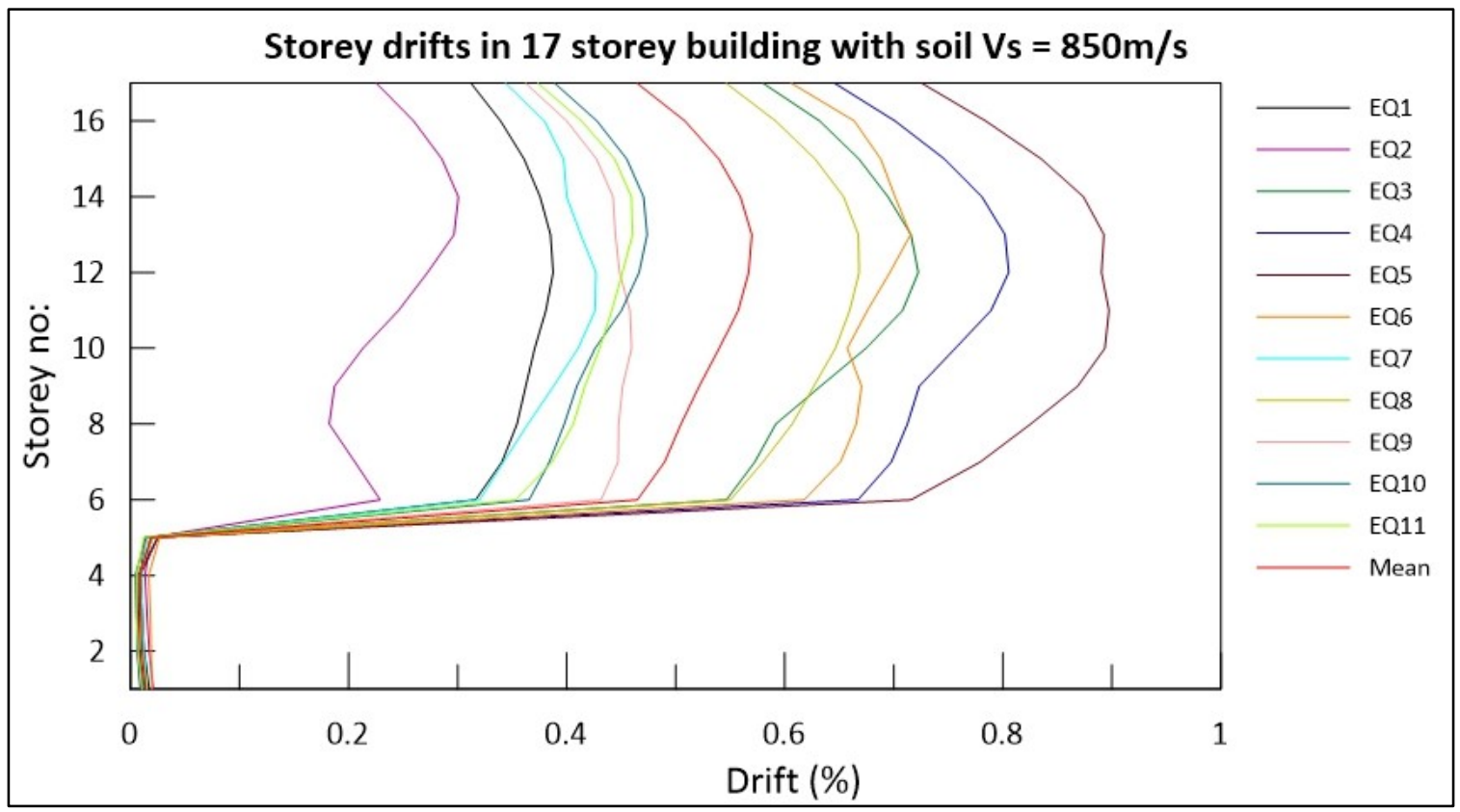

Figure B-128 Storey drifts in 17storey building with soil shear wave velocity, Vs $=850 \mathrm{~m} / \mathrm{s}$ analyzed for 11 earthquake inputs compatible with Vancouver site B spectrum 


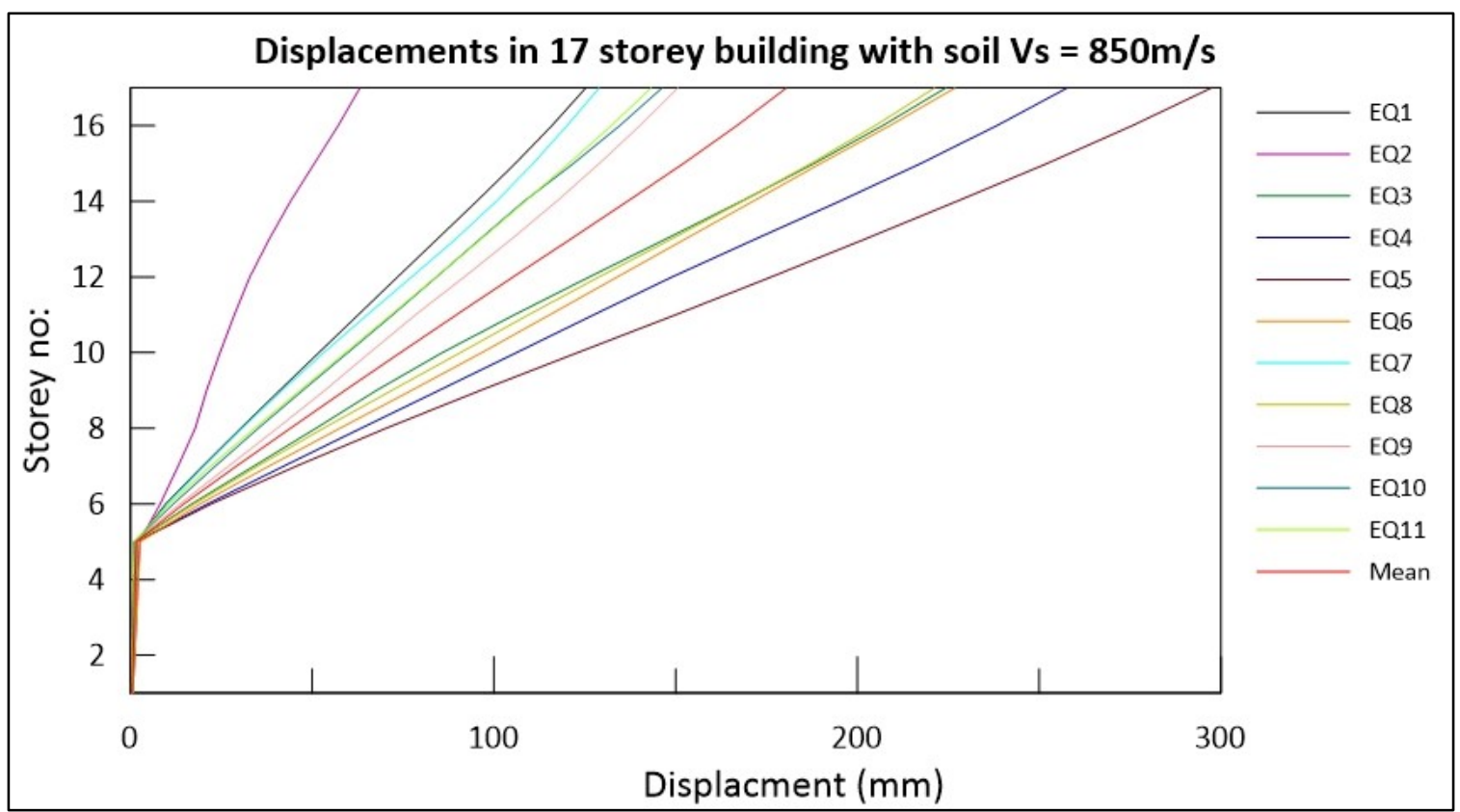

Figure B-129 Displacements in 17storey building with soil shear wave velocity, Vs $=850 \mathrm{~m} / \mathrm{s}$ analyzed for 11 earthquake inputs compatible with Vancouver site B spectrum

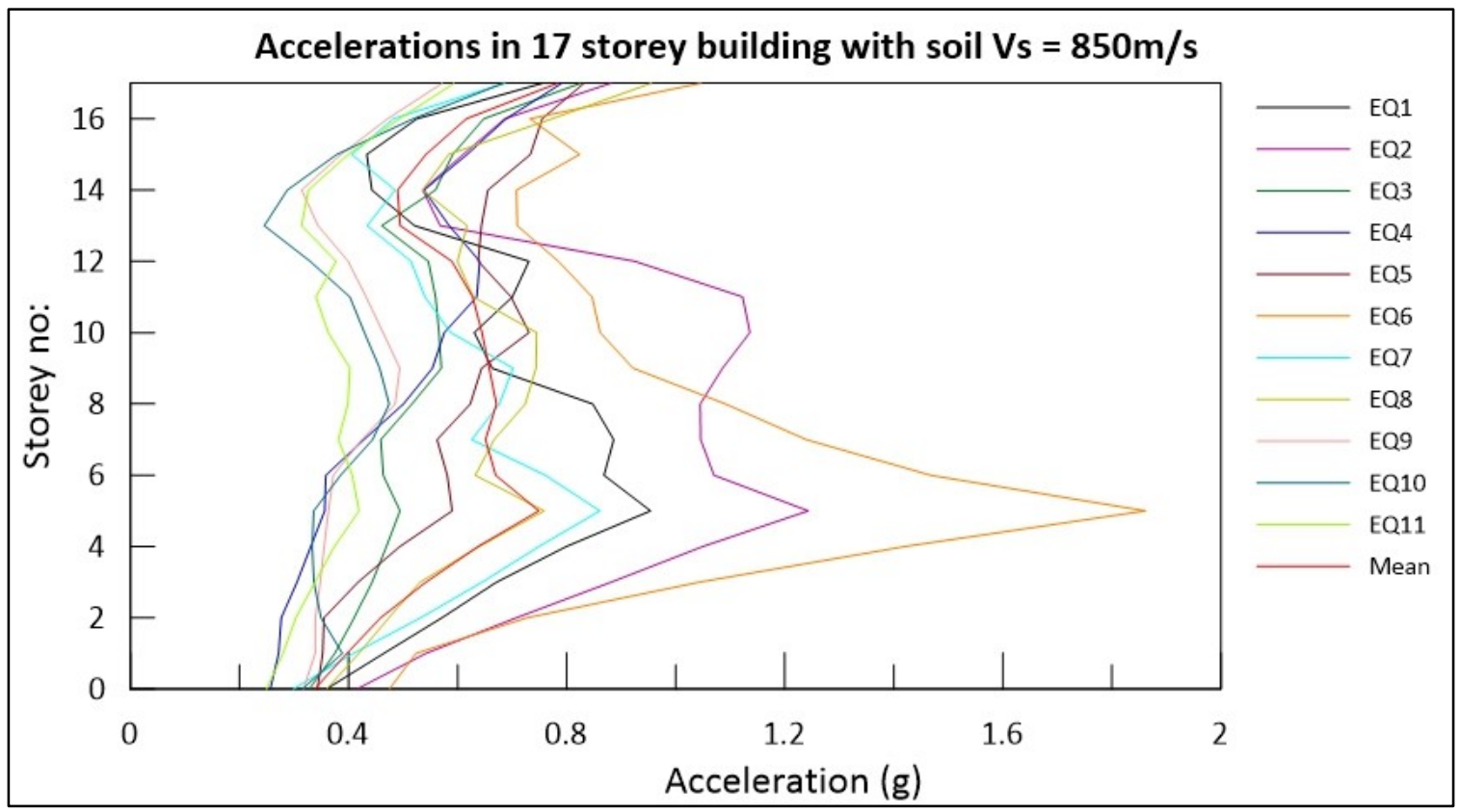

Figure B-130 Accelerations in 17storey building with soil shear wave velocity, Vs $=850 \mathrm{~m} / \mathrm{s}$ analyzed for 11 earthquake inputs compatible with Vancouver site B spectrum 


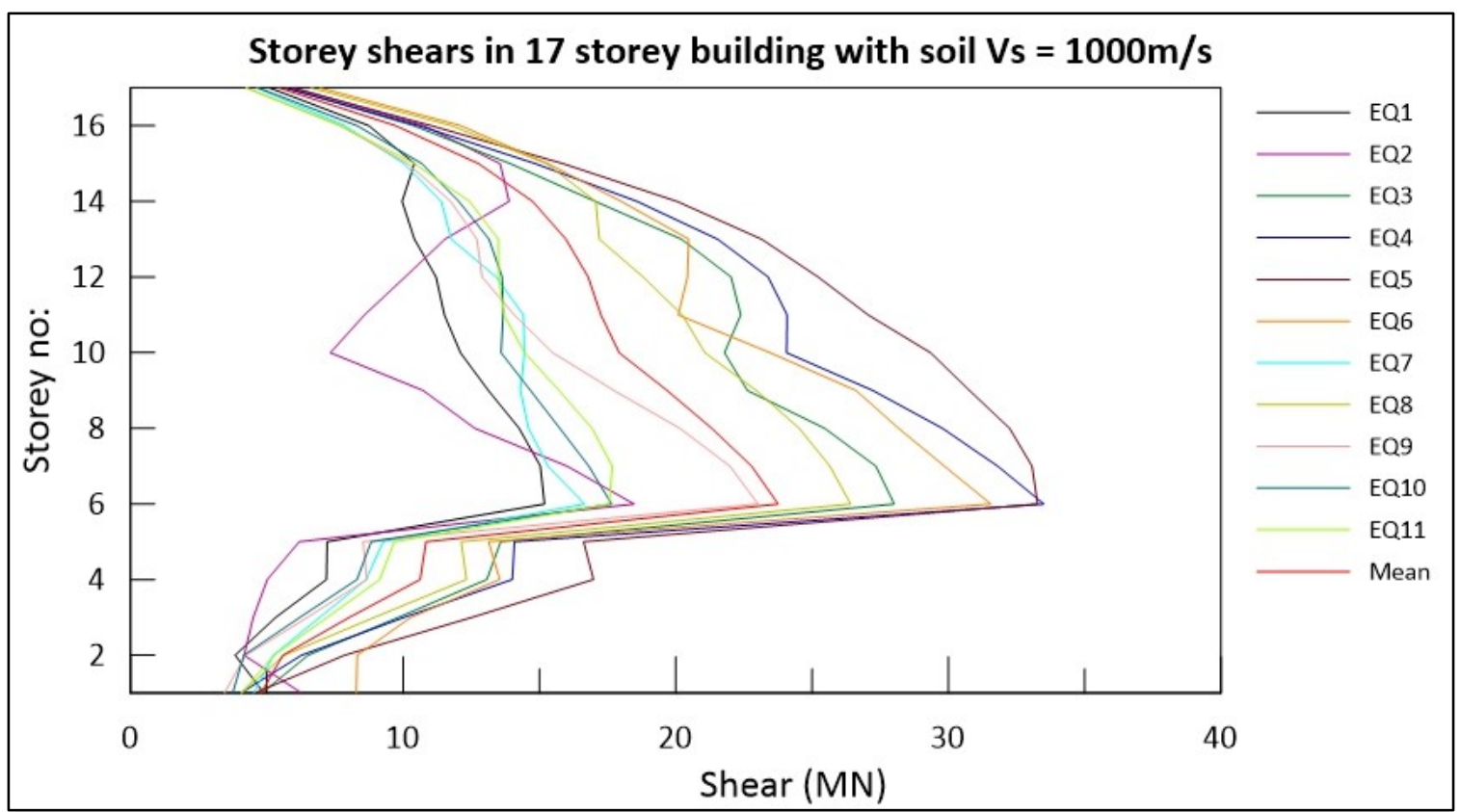

Figure B-131 Storey shears in 17storey building with soil shear wave velocity, Vs $=1000 \mathrm{~m} / \mathrm{s}$ analyzed for 11 earthquake inputs compatible with Vancouver site B spectrum

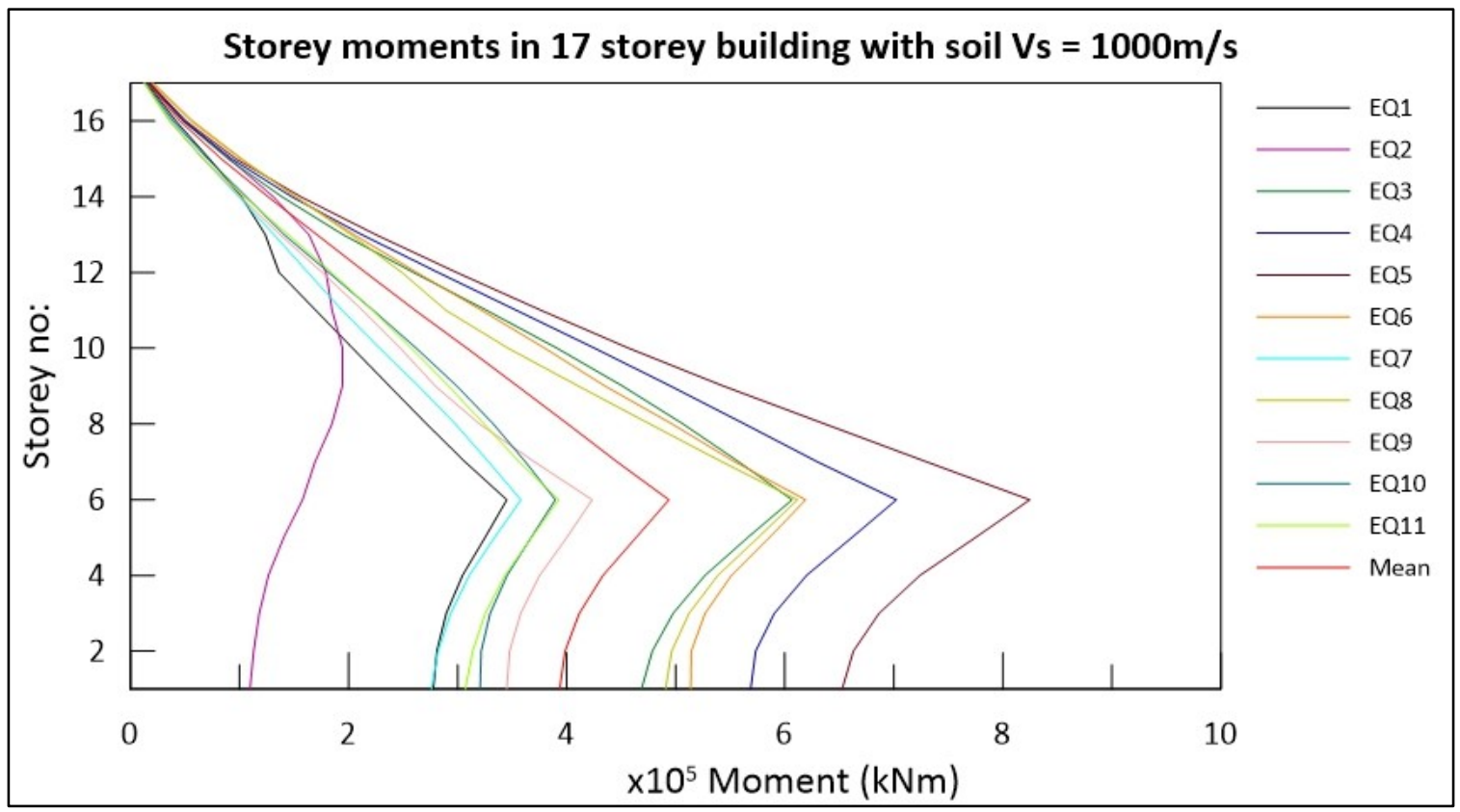

Figure B-132 Storey moments in 17storey building with soil shear wave velocity, Vs $=1000 \mathrm{~m} / \mathrm{s}$ analyzed for 11 earthquake inputs compatible with Vancouver site B spectrum 


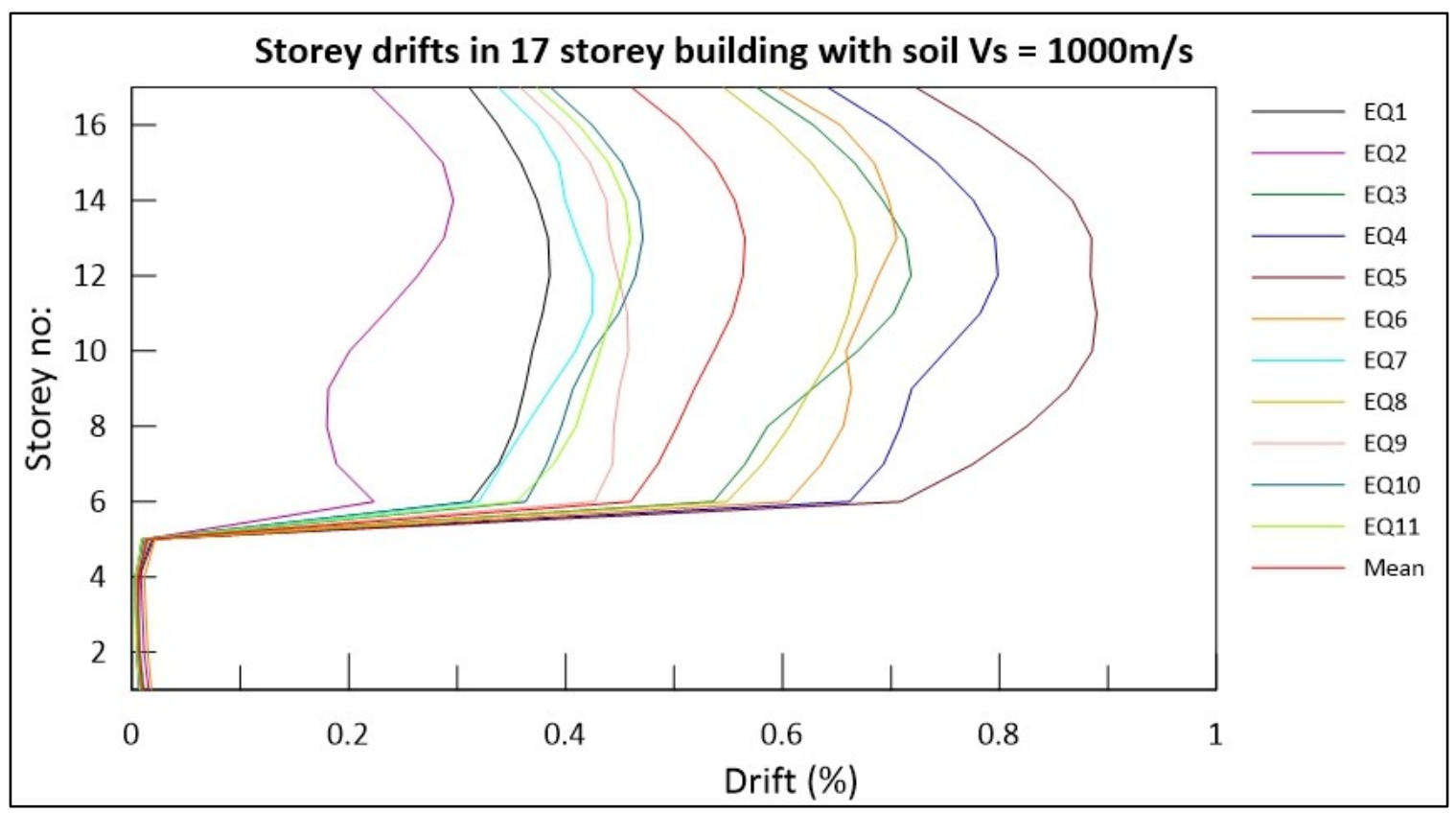

Figure B-133 Storey drifts in 17storey building with soil shear wave velocity, Vs $=1000 \mathrm{~m} / \mathrm{s}$ analyzed for 11 earthquake inputs compatible with Vancouver site B spectrum

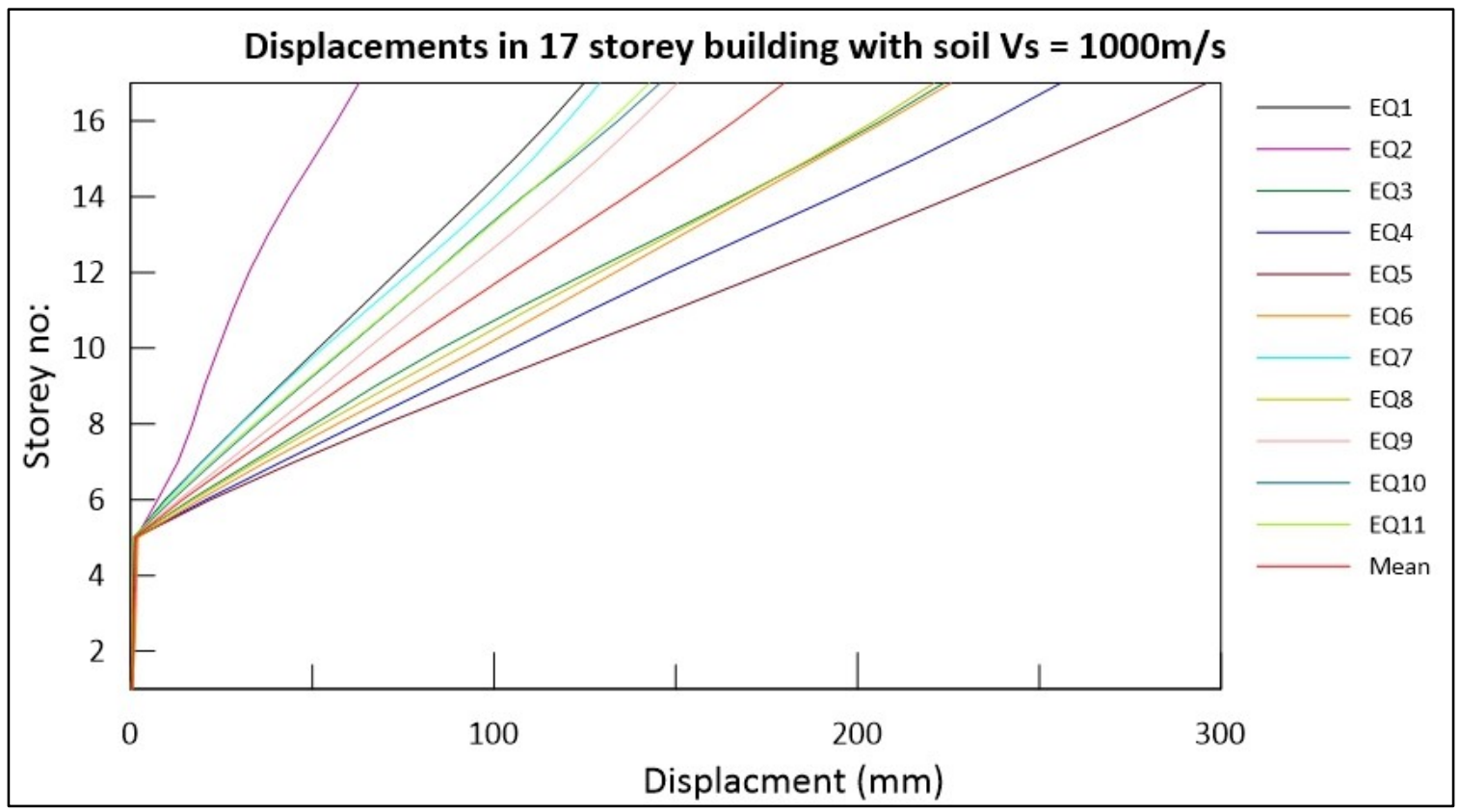

Figure B-134 Displacements in 17storey building with soil shear wave velocity, Vs $=1000 \mathrm{~m} / \mathrm{s}$ analyzed for 11 earthquake inputs compatible with Vancouver site B spectrum 


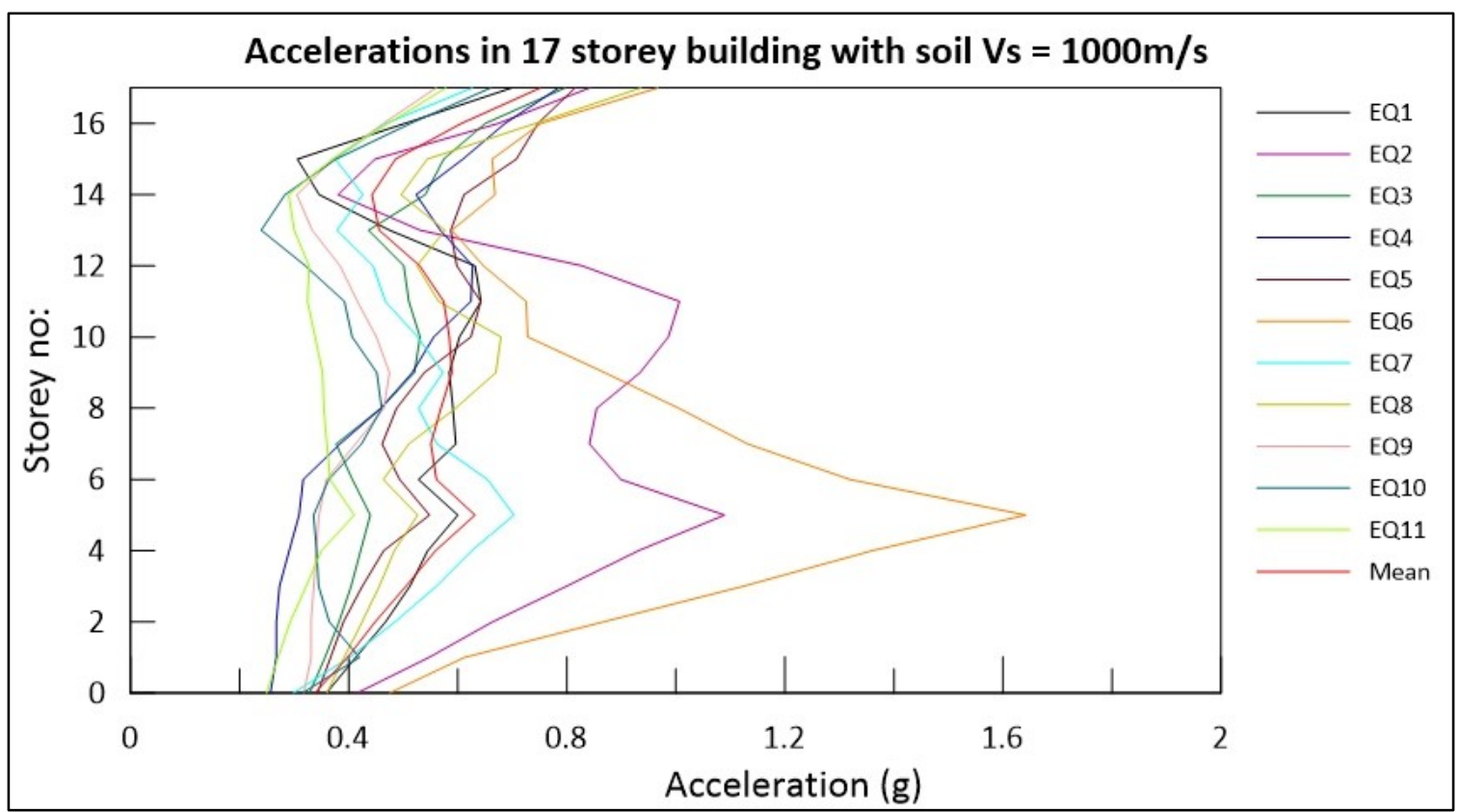

Figure B-135 Accelerations in 17 storey building with soil shear wave velocity, Vs $=1000 \mathrm{~m} / \mathrm{s}$ analyzed for 11 earthquake inputs compatible with Vancouver site B spectrum

\section{1 storey building}

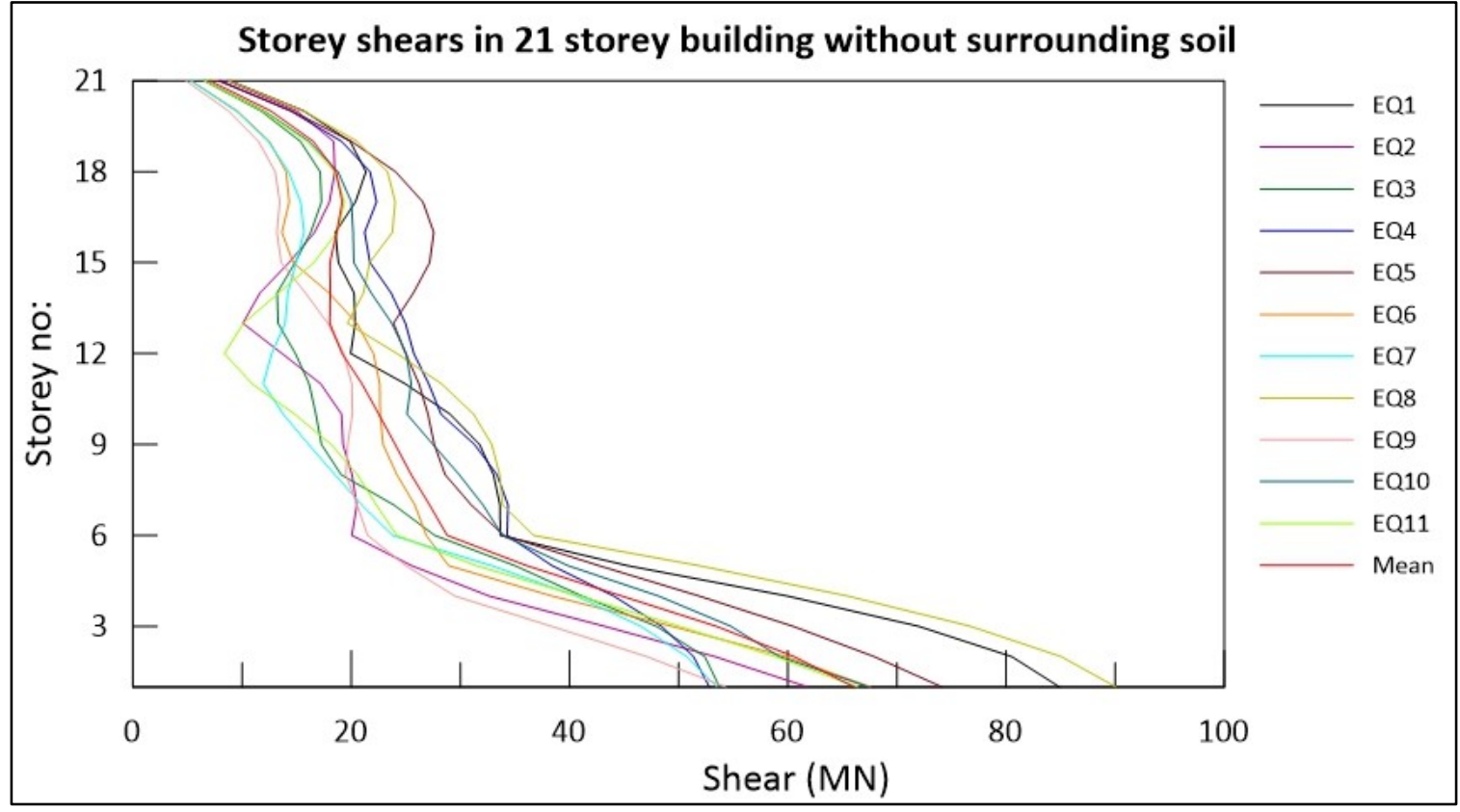

Figure B-136 Storey shears in 21storey building without any surrounding soil analyzed for 11 earthquake inputs compatible with Vancouver site B spectrum 


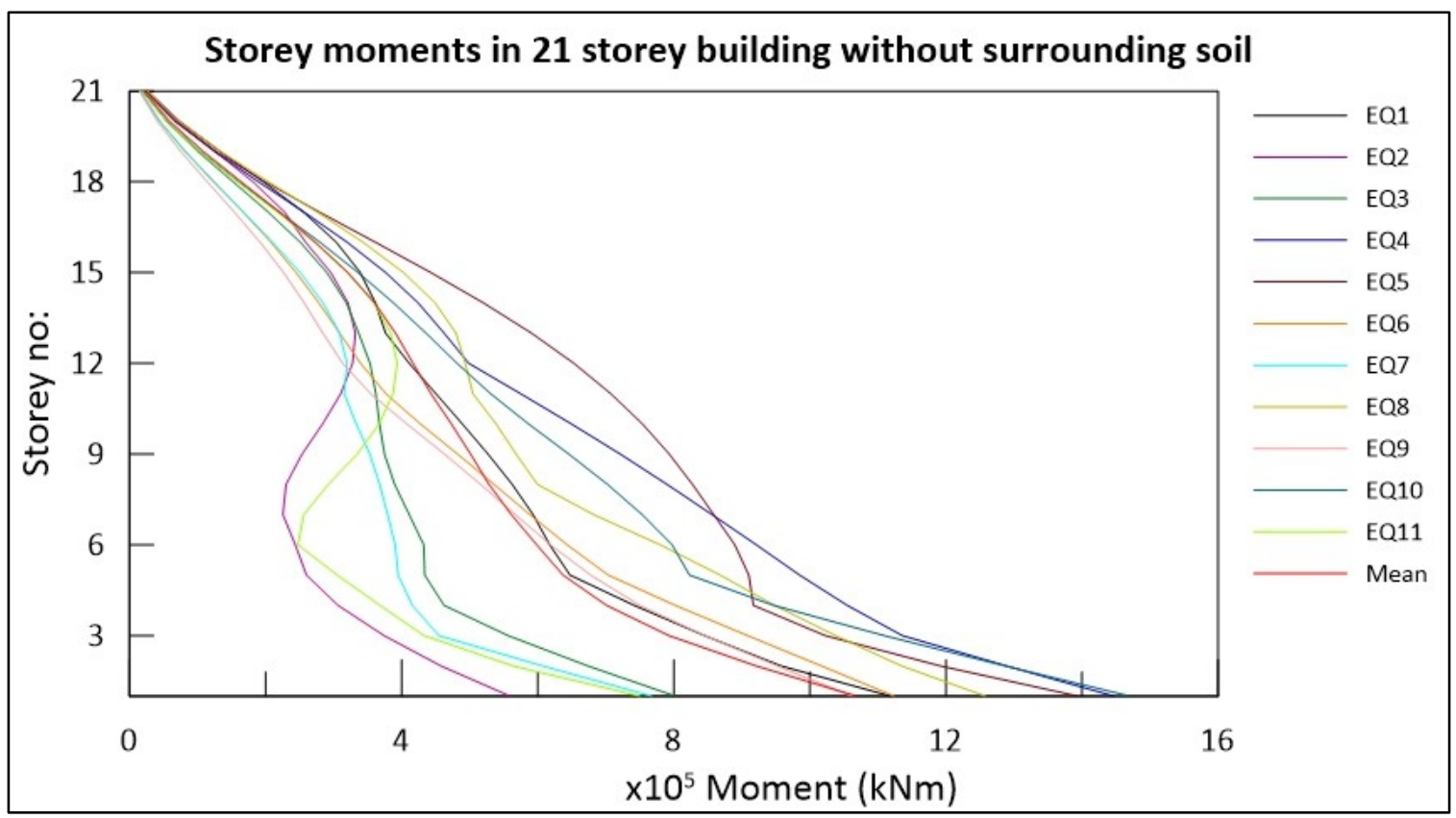

Figure B-137 Storey moments in 21storey building without any surrounding soil analyzed for 11 earthquake inputs compatible with Vancouver site B spectrum

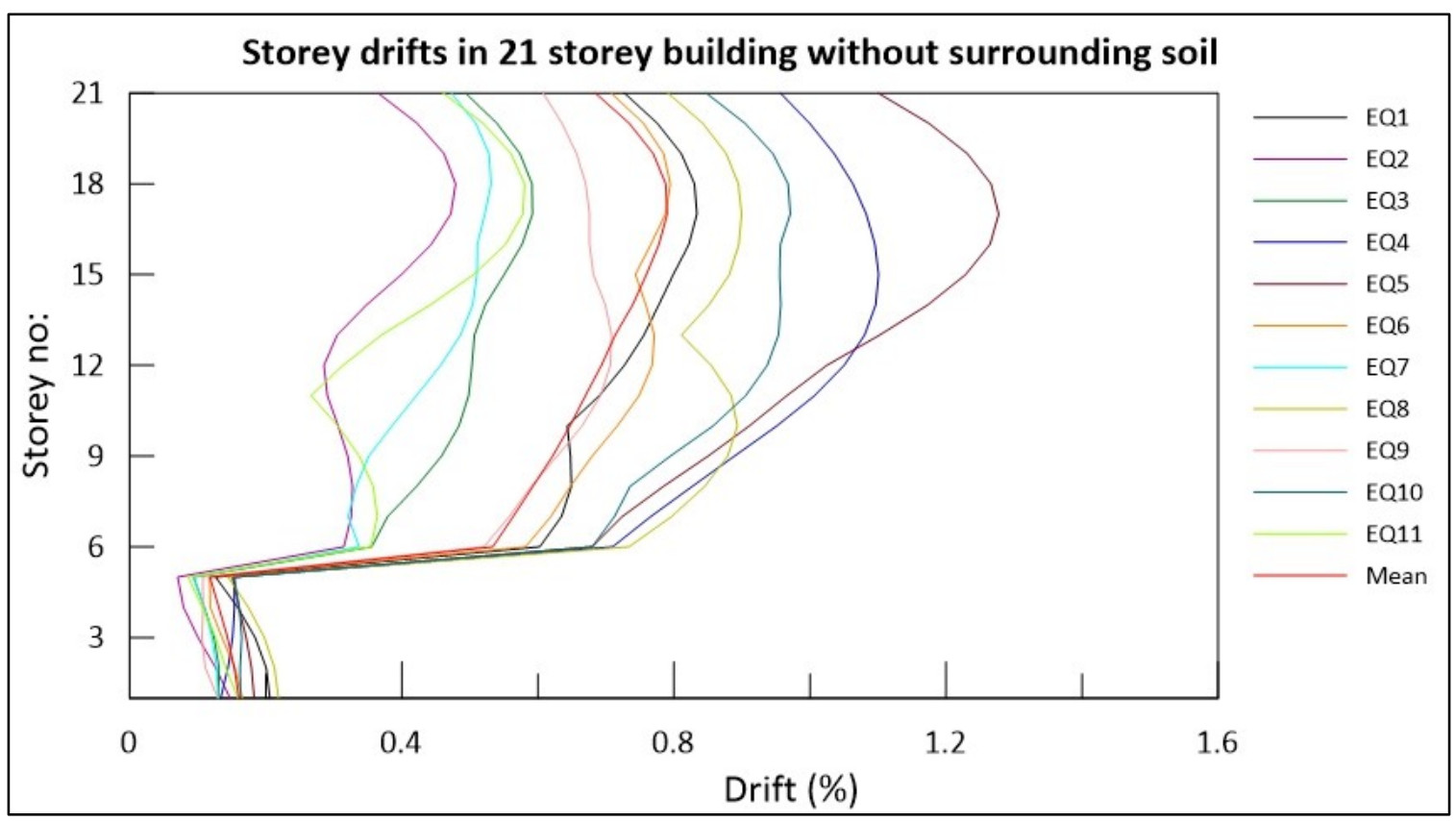

Figure B-138 Storey drifts in 21storey building without any surrounding soil analyzed for 11 earthquake inputs compatible with Vancouver site B spectrum 


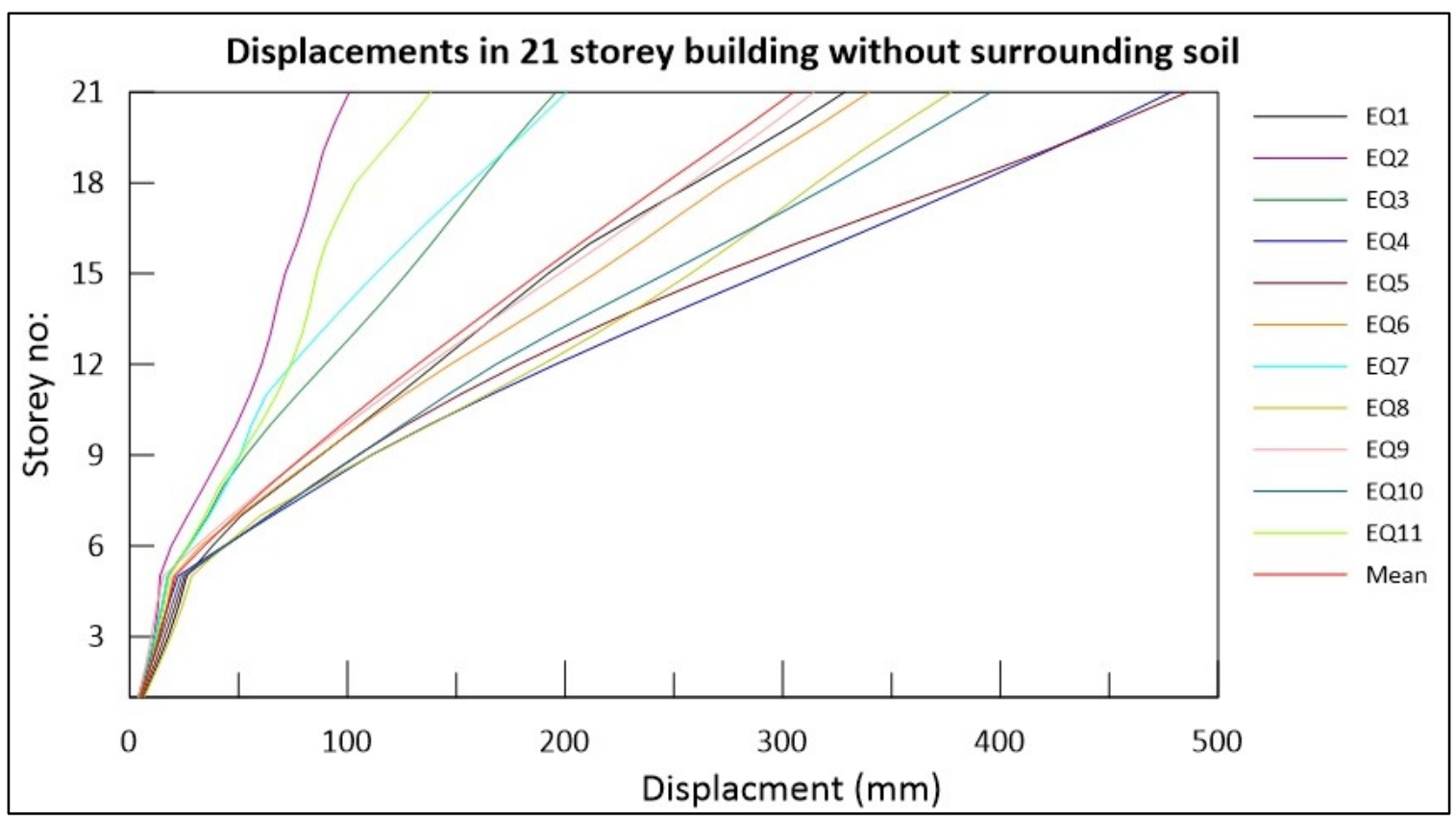

Figure B-139 Displacements in 21storey building without any surrounding soil analyzed for 11 earthquake inputs compatible with Vancouver site B spectrum

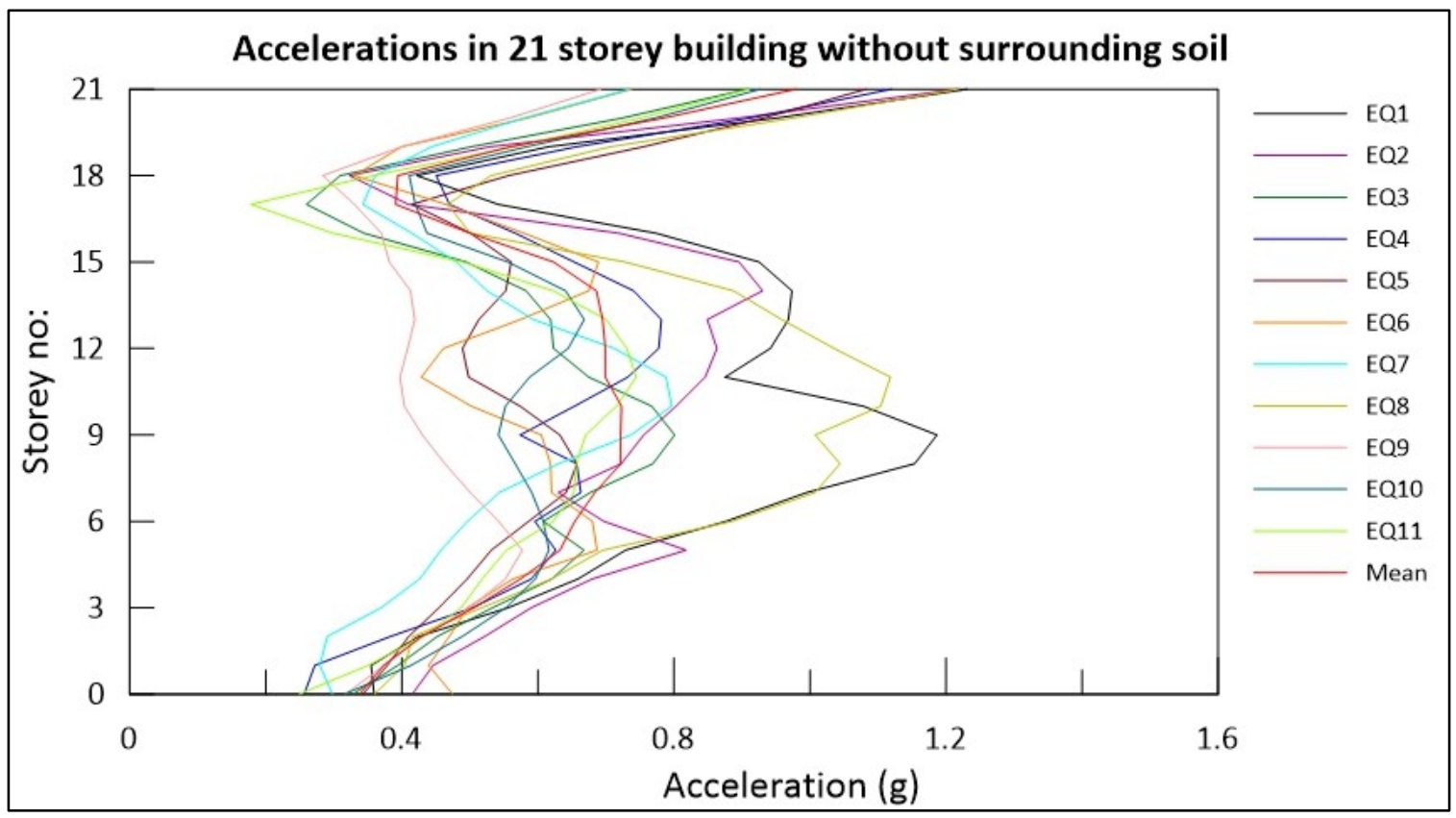

Figure B-140 Accelerations in 21storey building without any surrounding soil analyzed for 11 earthquake inputs compatible with Vancouver site B spectrum 


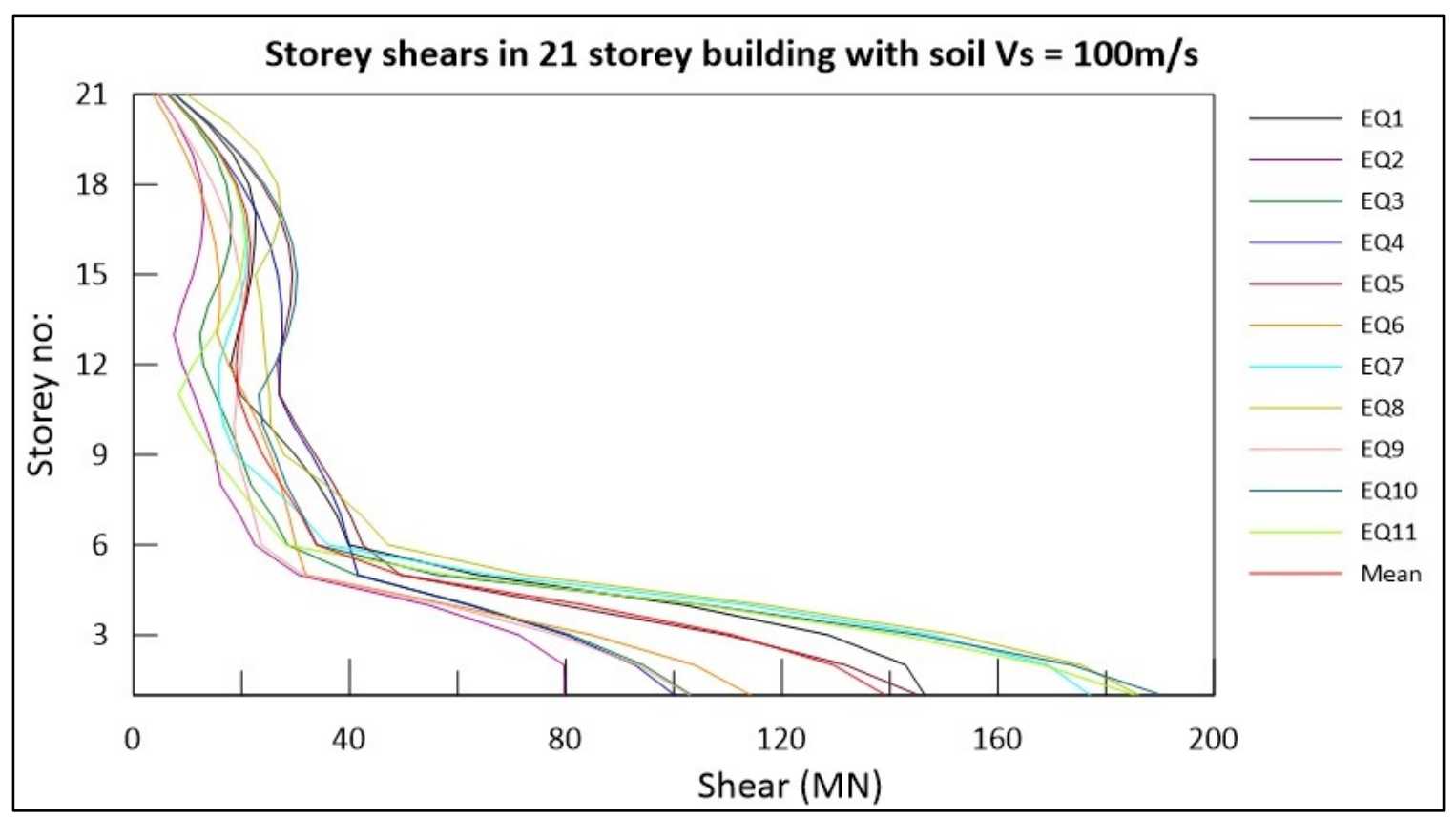

Figure B-141 Storey shears in 21storey building with soil shear wave velocity, Vs $=100 \mathrm{~m} / \mathrm{s}$ analyzed for 11 earthquake inputs compatible with Vancouver site B spectrum

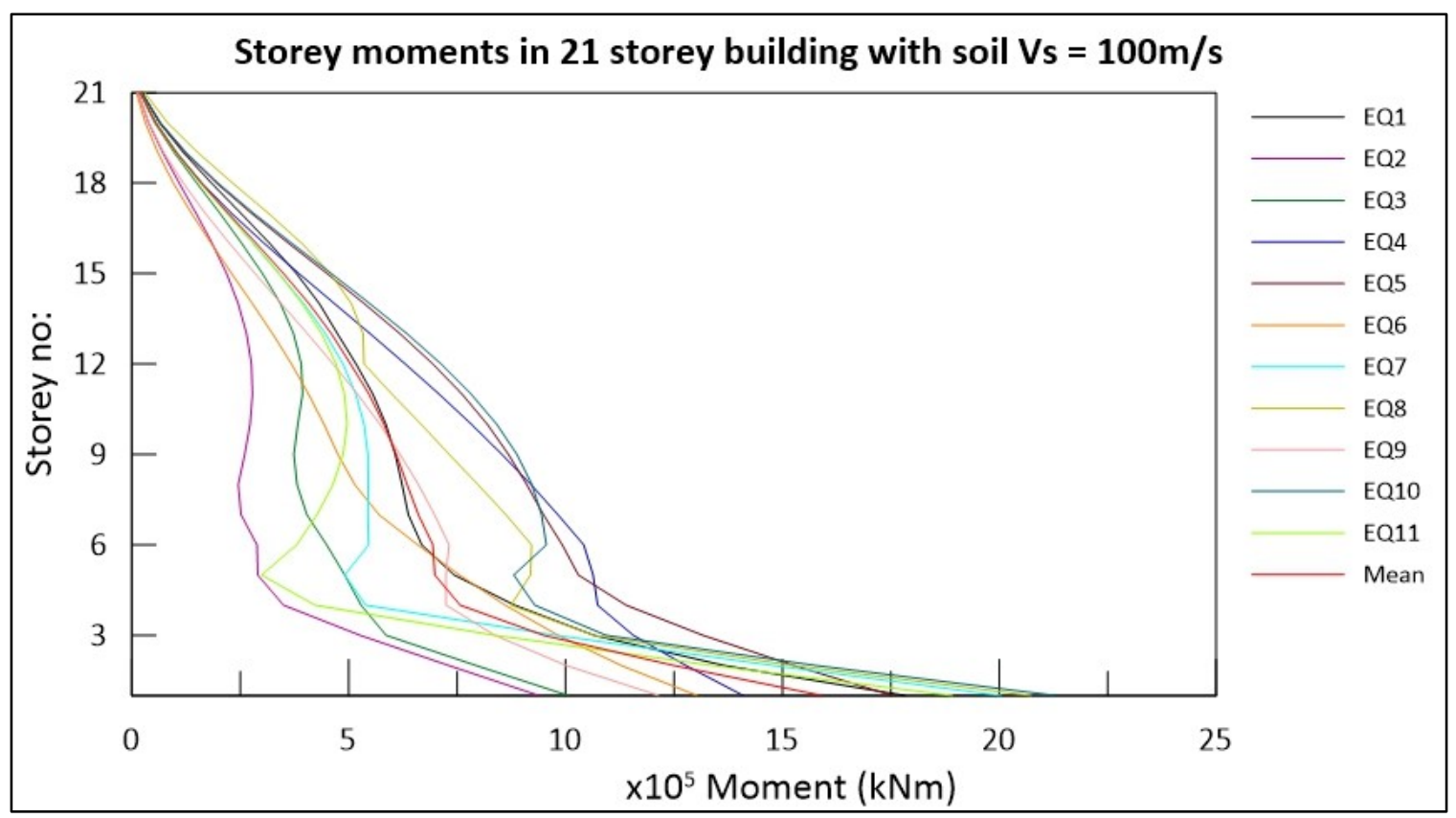

Figure B-142 Storey moments in 21storey building with soil shear wave velocity, Vs $=100 \mathrm{~m} / \mathrm{s}$ analyzed for 11 earthquake inputs compatible with Vancouver site B spectrum 


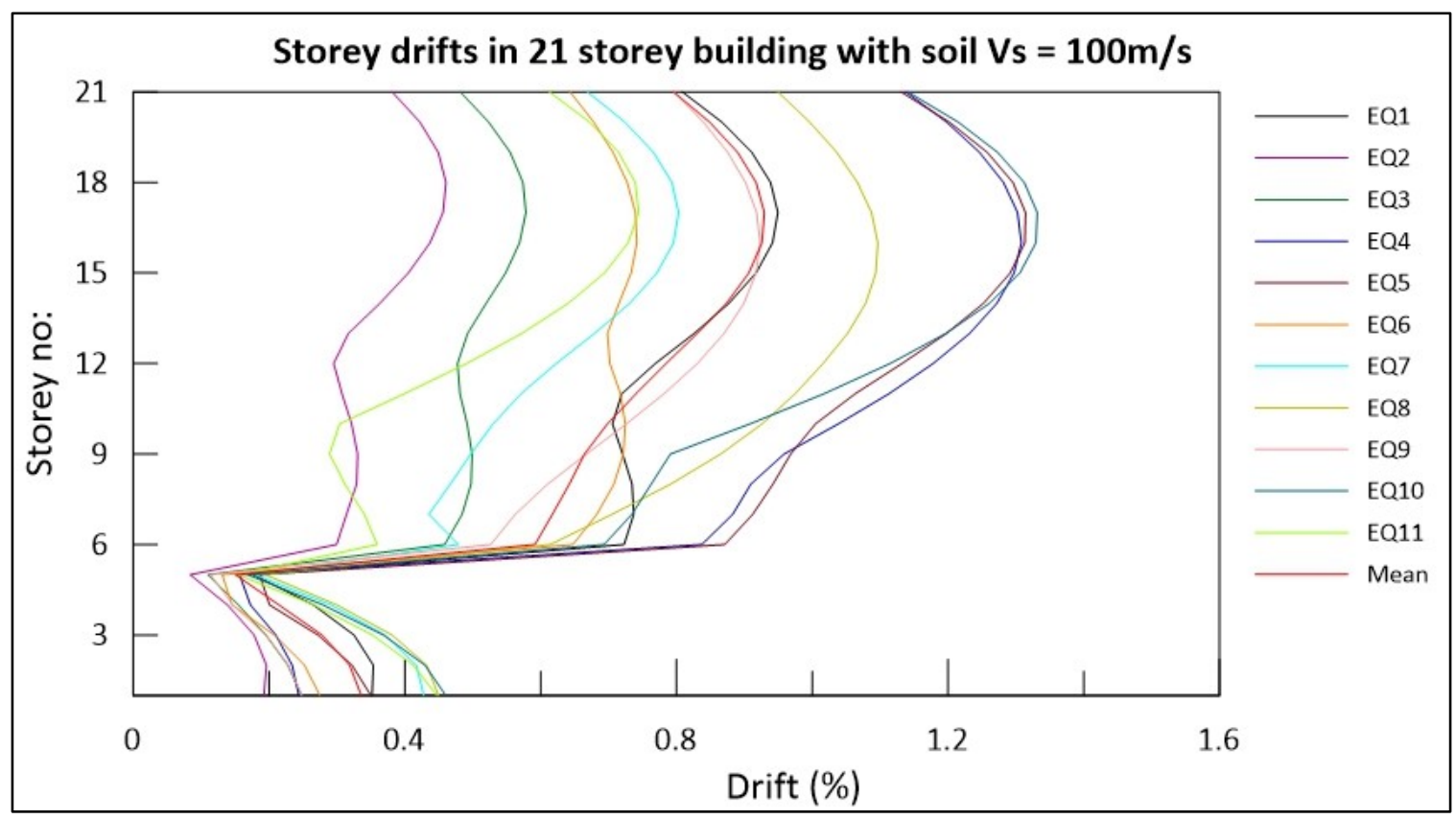

Figure B-143 Storey drifts in 21storey building with soil shear wave velocity, Vs $=100 \mathrm{~m} / \mathrm{s}$ analyzed for 11 earthquake inputs compatible with Vancouver site B spectrum

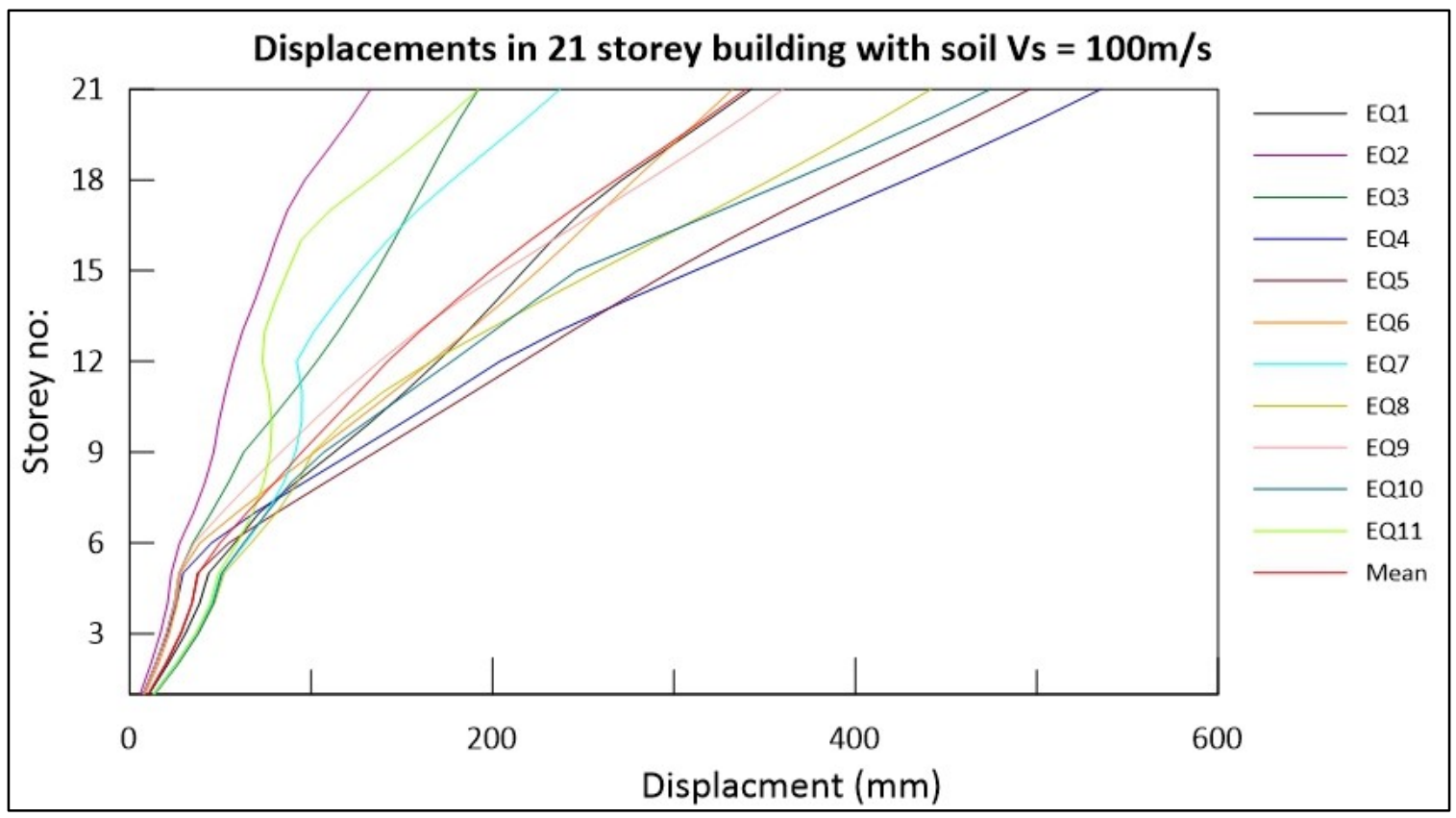

Figure B-144 Displacements in 21storey building with soil shear wave velocity, Vs $=100 \mathrm{~m} / \mathrm{s}$ analyzed for 11 earthquake inputs compatible with Vancouver site B spectrum 


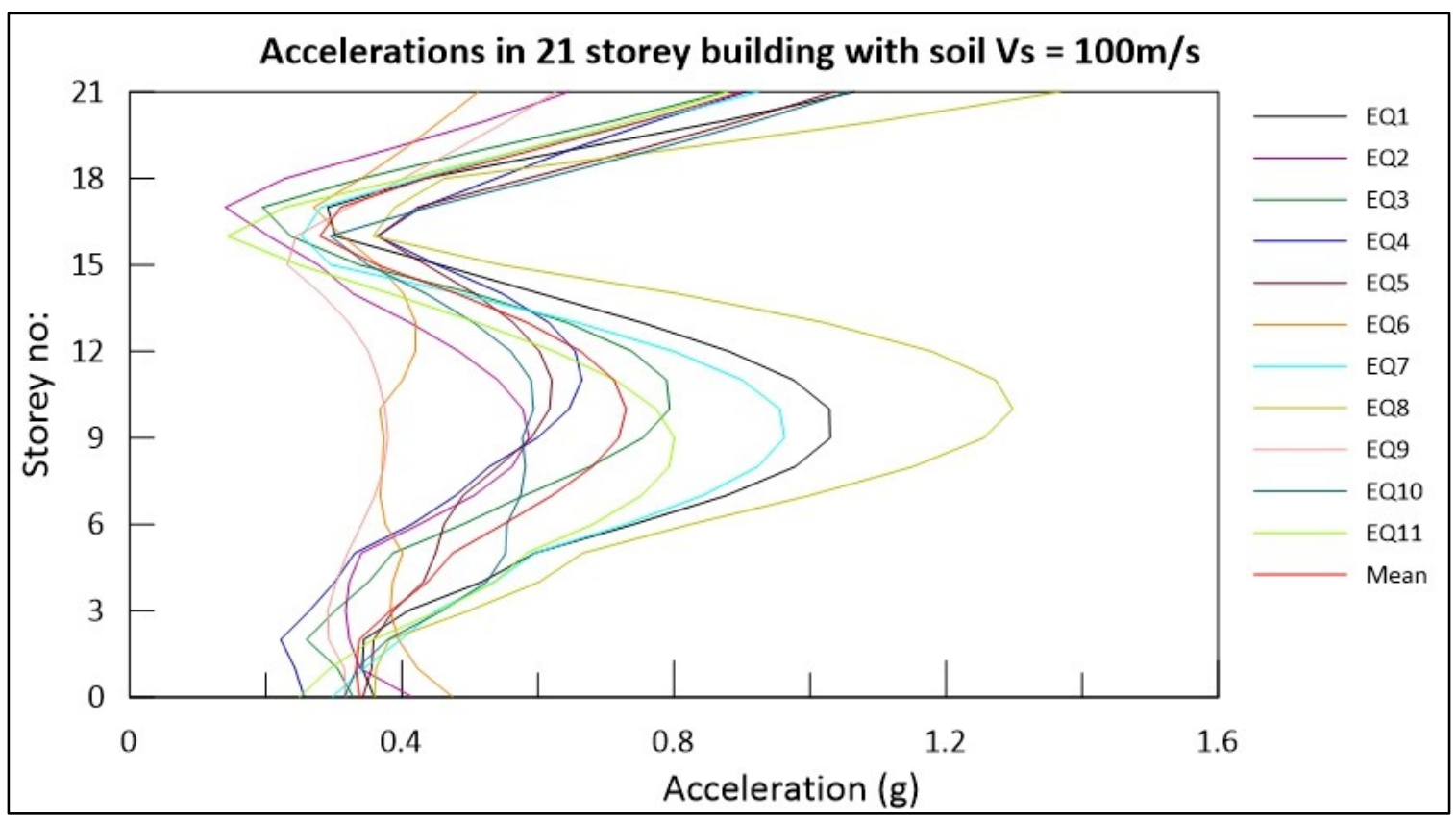

Figure B-145 Accelerations in 21storey building with soil shear wave velocity, Vs $=100 \mathrm{~m} / \mathrm{s}$ analyzed for 11 earthquake inputs compatible with Vancouver site B spectrum

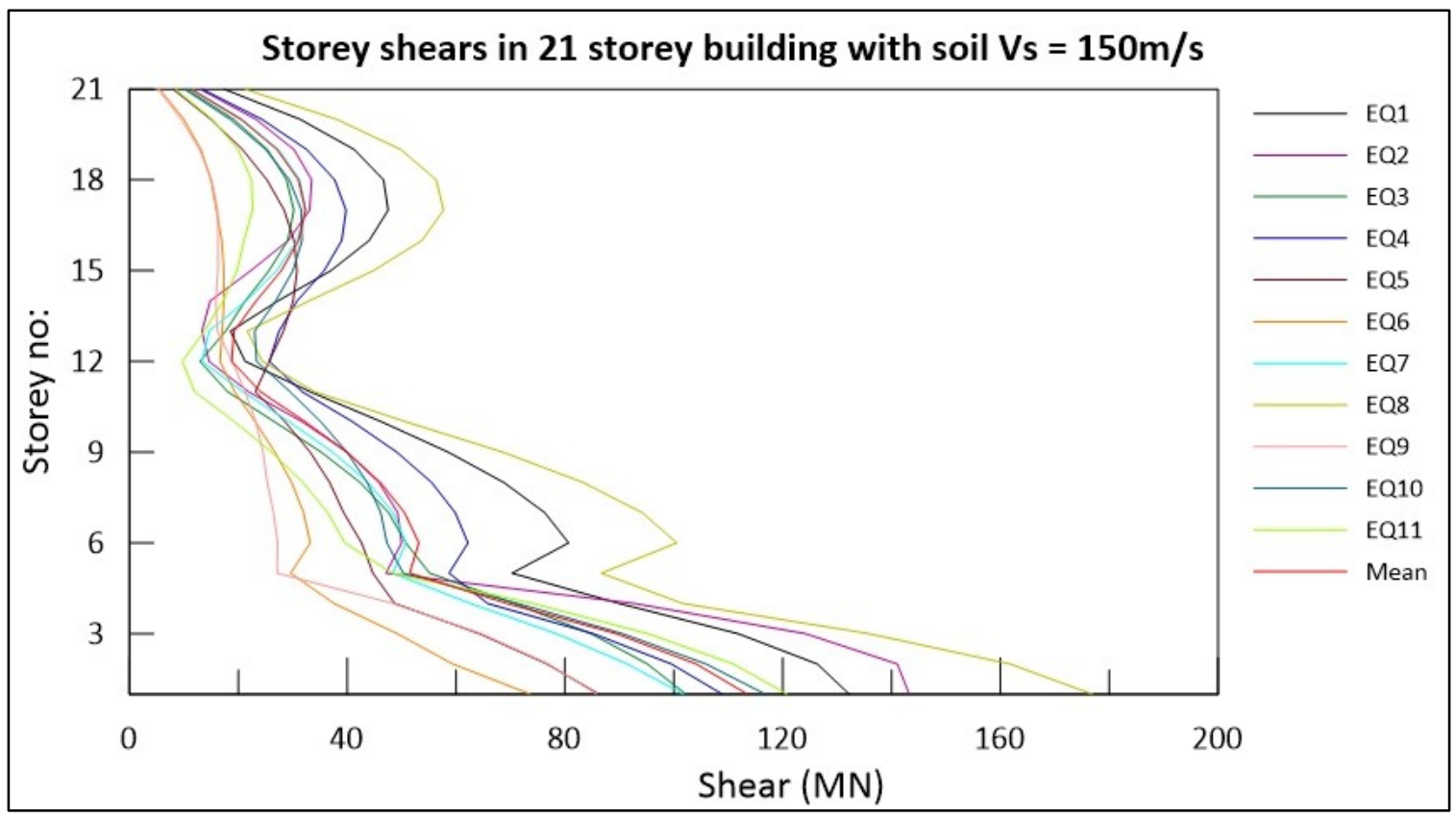

Figure B-146 Storey shears in 21storey building with soil shear wave velocity, Vs $=150 \mathrm{~m} / \mathrm{s}$ analyzed for 11 earthquake inputs compatible with Vancouver site B spectrum 


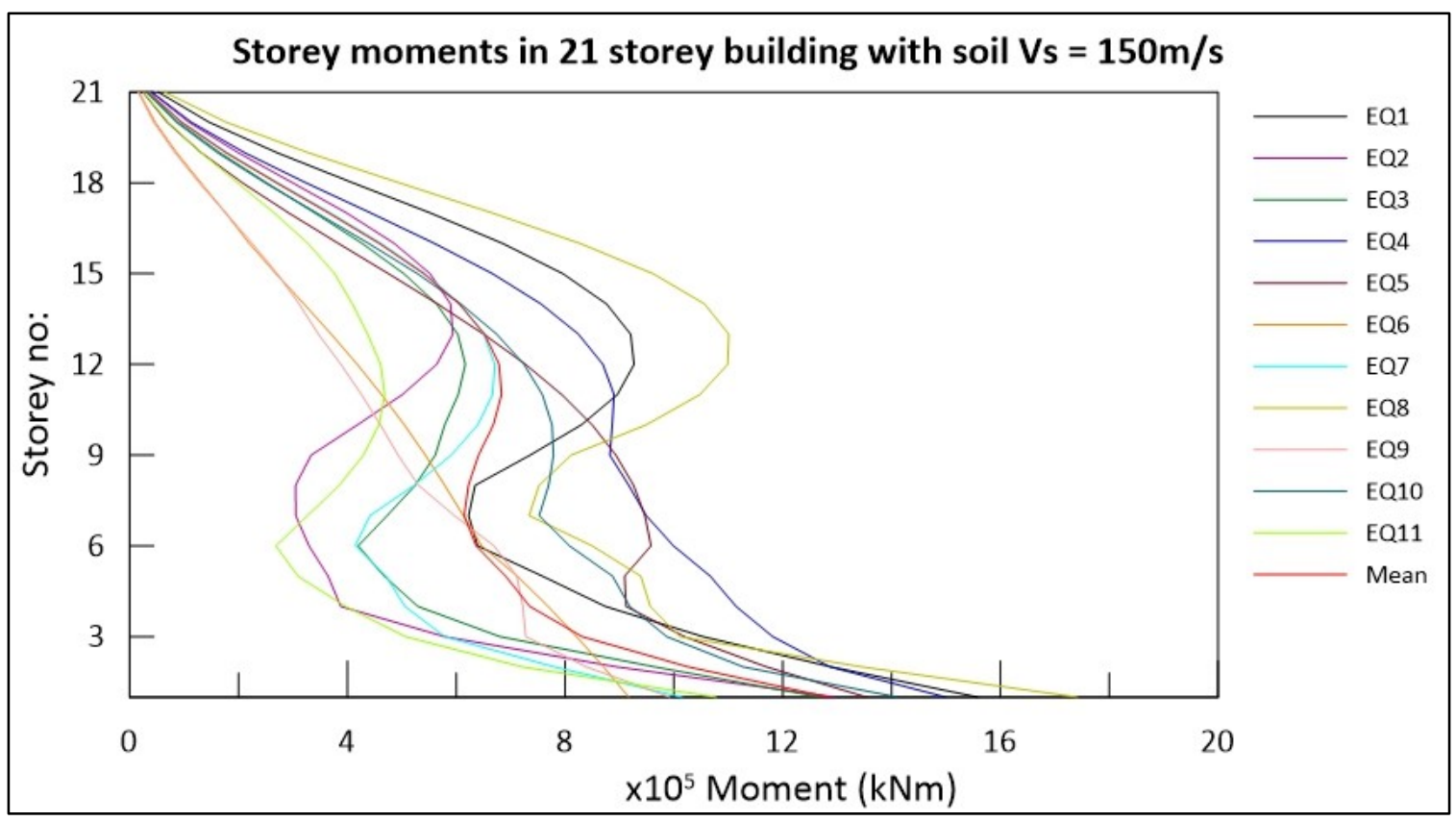

Figure B-147 Storey moments in 21storey building with soil shear wave velocity, Vs $=100 \mathrm{~m} / \mathrm{s}$ analyzed for 11 earthquake inputs compatible with Vancouver site B spectrum

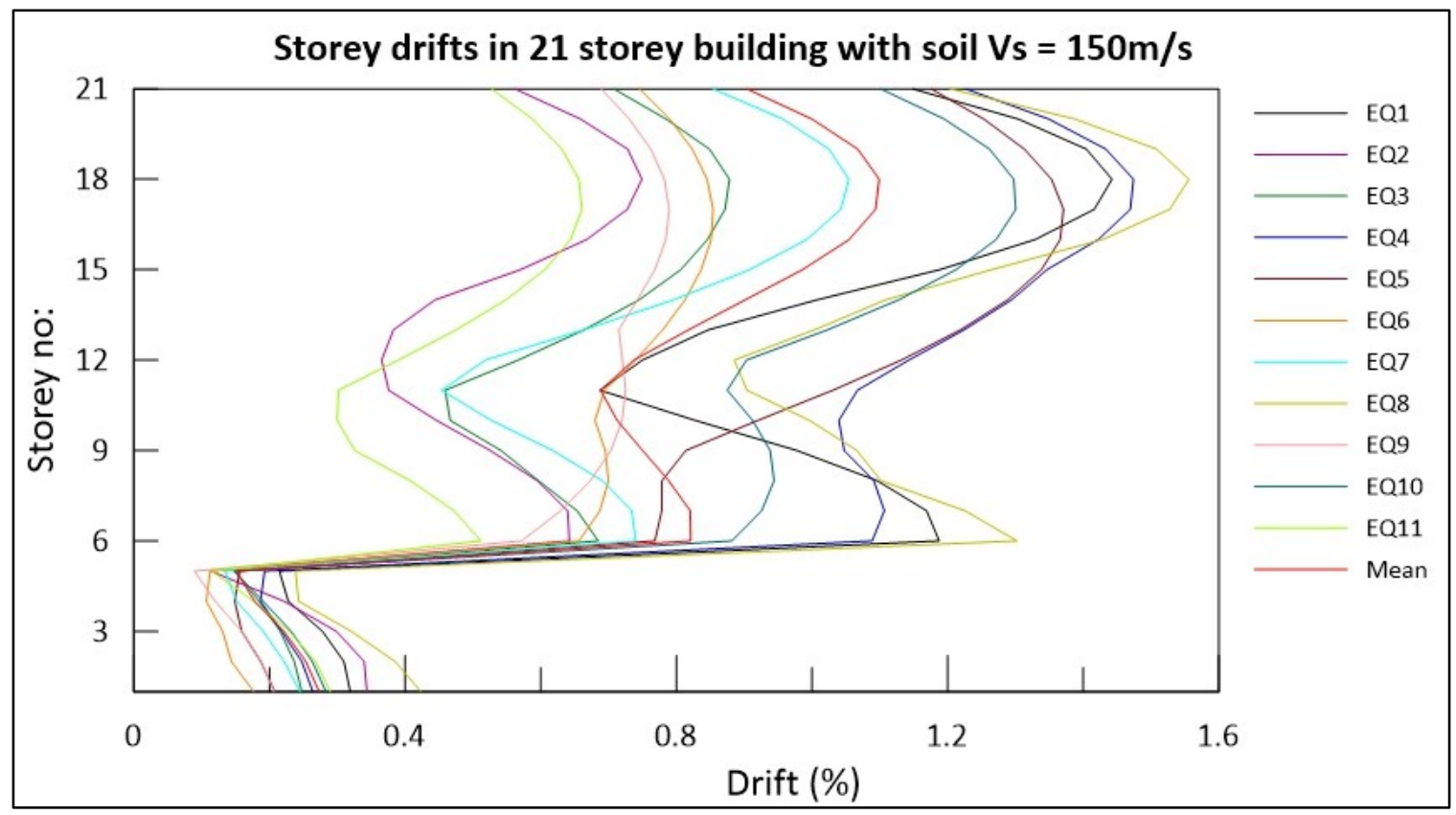

Figure B-148 Storey drifts in 21storey building with soil shear wave velocity, Vs $=150 \mathrm{~m} / \mathrm{s}$ analyzed for 11 earthquake inputs compatible with Vancouver site B spectrum 


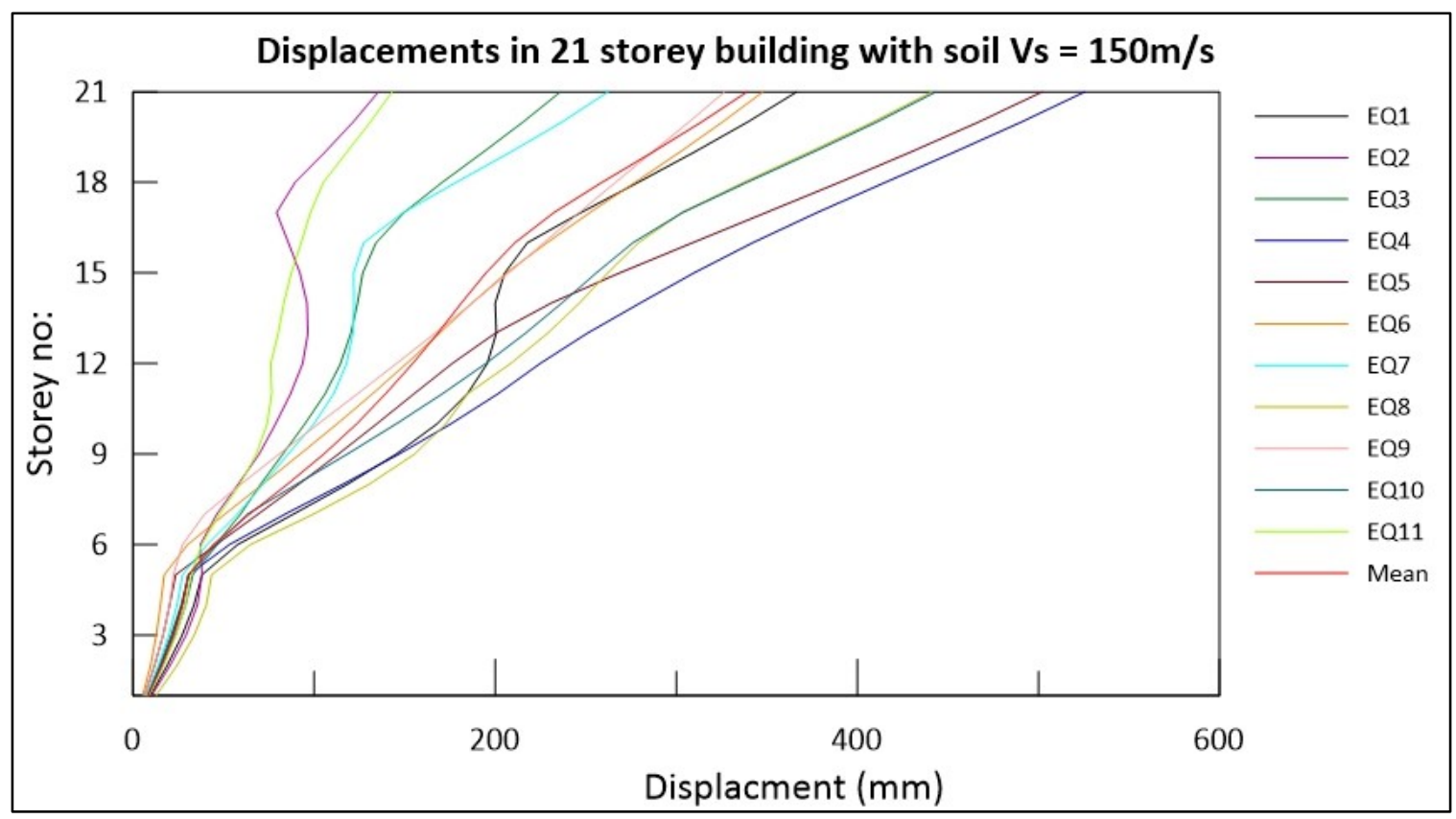

Figure B-149 Displacements in 21 storey building with soil shear wave velocity, Vs $=150 \mathrm{~m} / \mathrm{s}$ analyzed for 11 earthquake inputs compatible with Vancouver site B spectrum

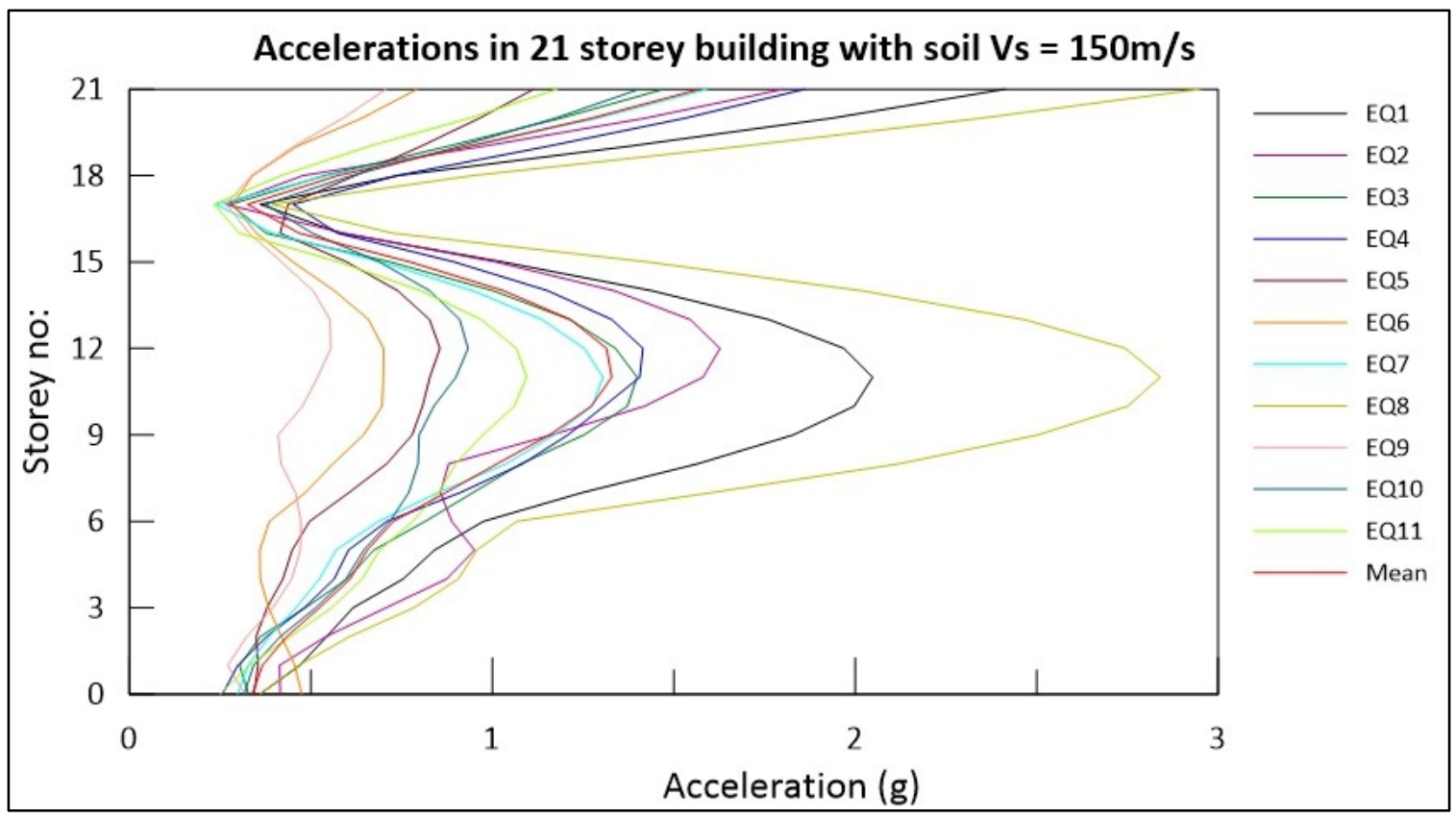

Figure B-150 Accelerations in 21storey building with soil shear wave velocity, Vs $=150 \mathrm{~m} / \mathrm{s}$ analyzed for 11 earthquake inputs compatible with Vancouver site B spectrum 


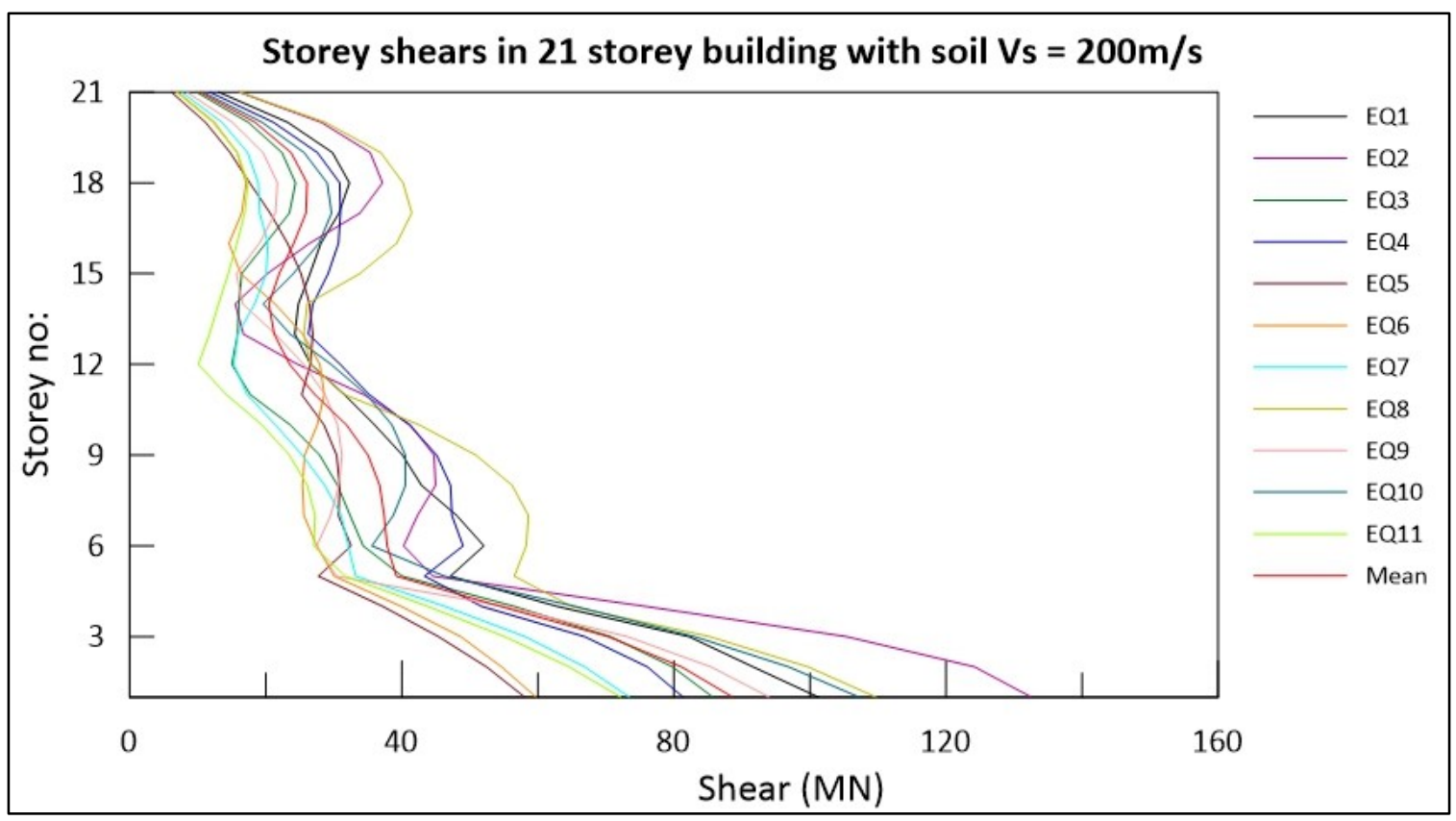

Figure B-151 Storey shears in 21storey building with soil shear wave velocity, Vs $=200 \mathrm{~m} / \mathrm{s}$ analyzed for 11 earthquake inputs compatible with Vancouver site B spectrum

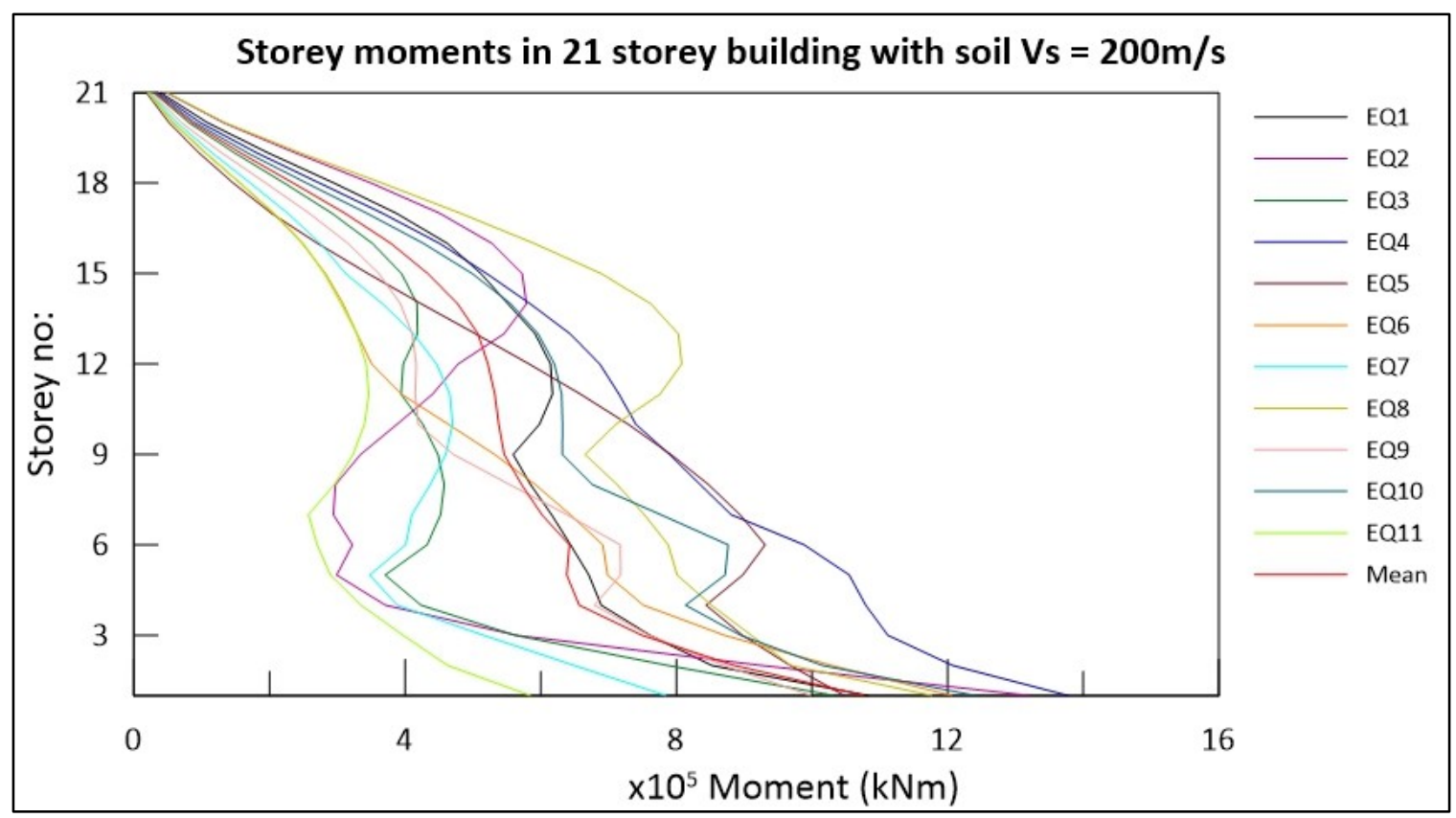

Figure B-152 Storey moments in 21storey building with soil shear wave velocity, Vs $=200 \mathrm{~m} / \mathrm{s}$ analyzed for 11 earthquake inputs compatible with Vancouver site B spectrum 


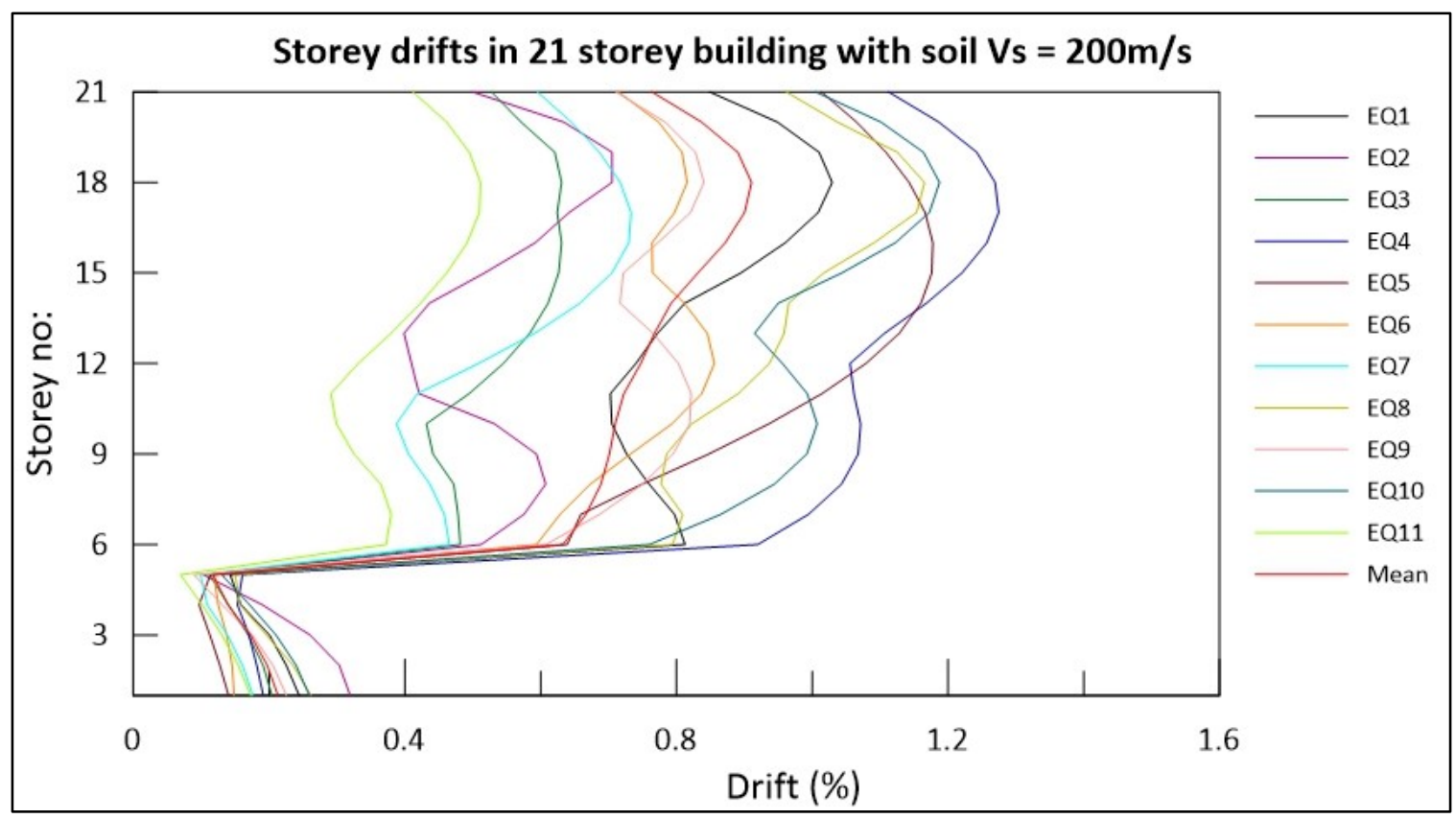

Figure B-153 Storey drifts in 21storey building with soil shear wave velocity, Vs $=200 \mathrm{~m} / \mathrm{s}$ analyzed for 11 earthquake inputs compatible with Vancouver site B spectrum

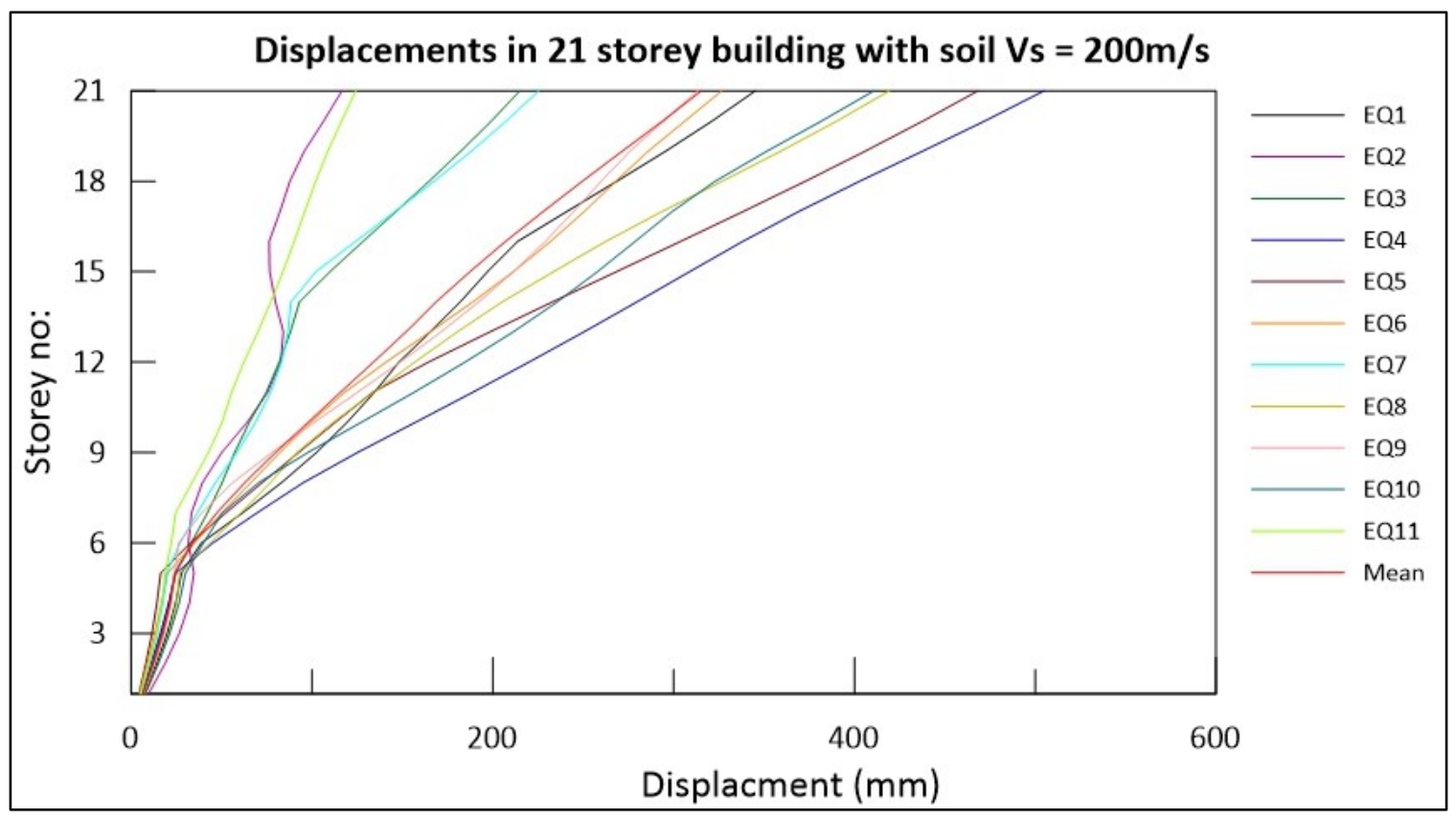

Figure B-154 Displacements in 21storey building with soil shear wave velocity, Vs $=200 \mathrm{~m} / \mathrm{s}$ analyzed for 11 earthquake inputs compatible with Vancouver site B spectrum 


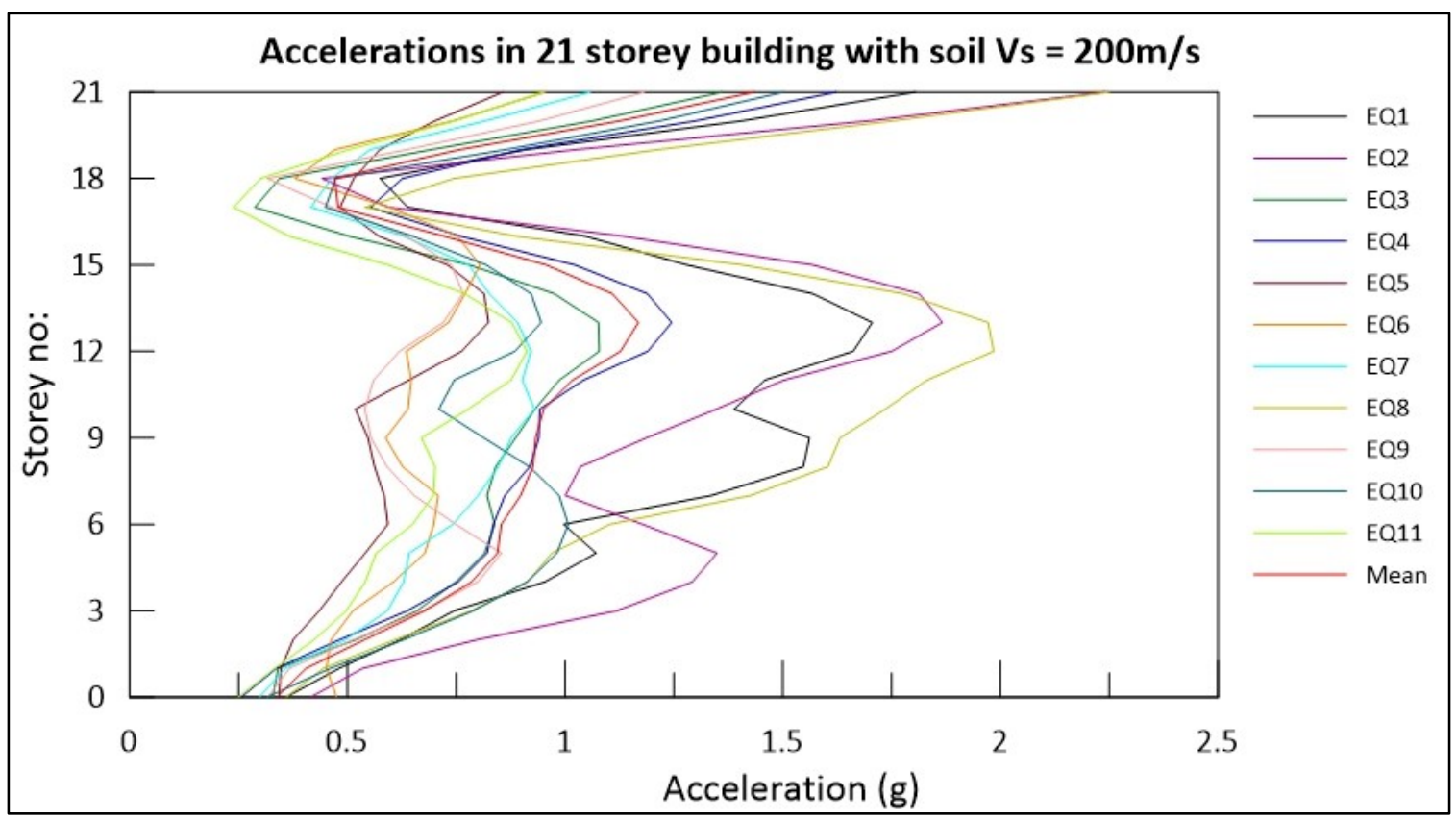

Figure B-155 Accelerations in 21storey building with soil shear wave velocity, Vs $=200 \mathrm{~m} / \mathrm{s}$ analyzed for 11 earthquake inputs compatible with Vancouver site B spectrum

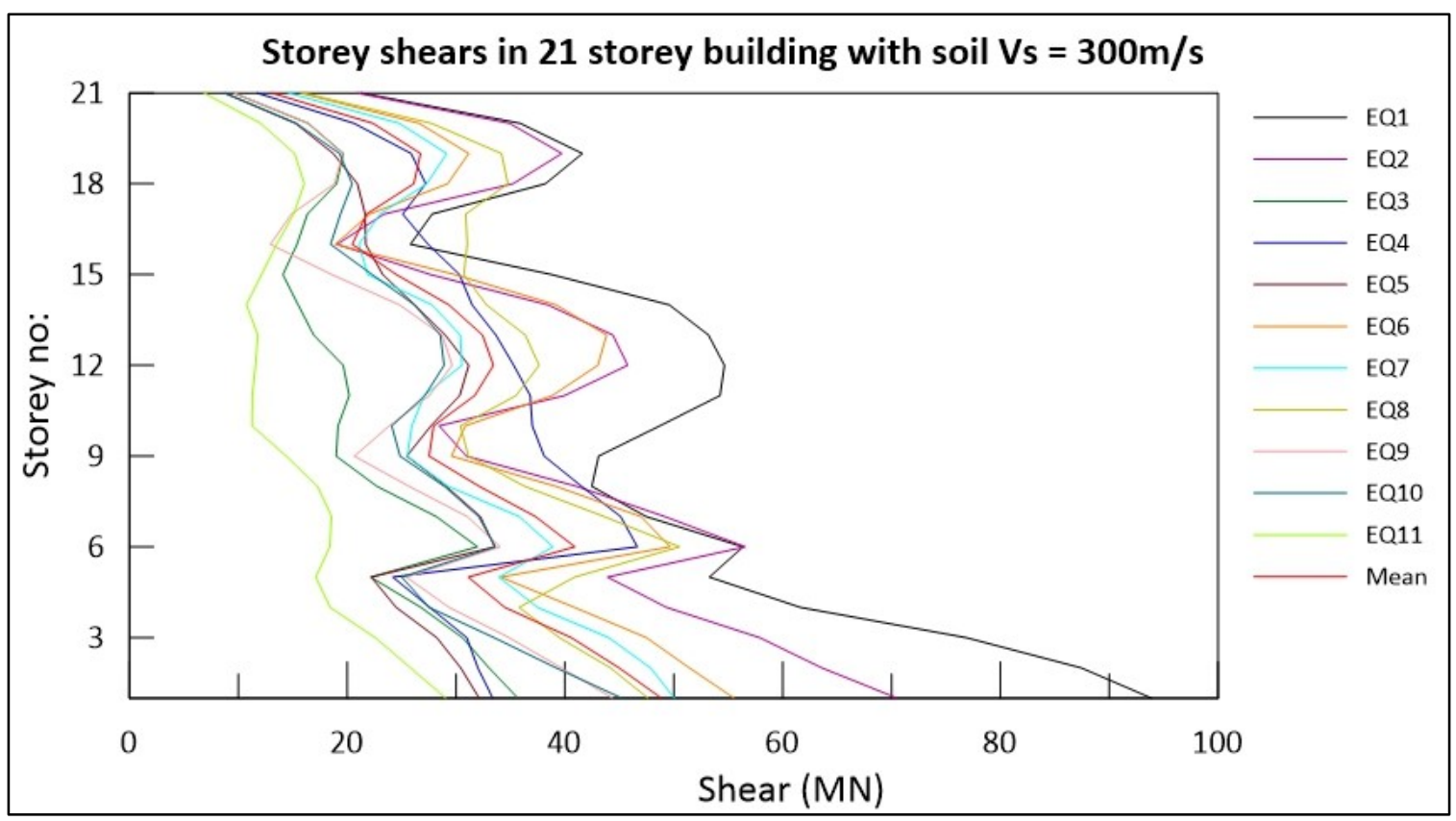

Figure B-156 Storey shears in 21storey building with soil shear wave velocity, Vs $=300 \mathrm{~m} / \mathrm{s}$ analyzed for 11 earthquake inputs compatible with Vancouver site B spectrum 


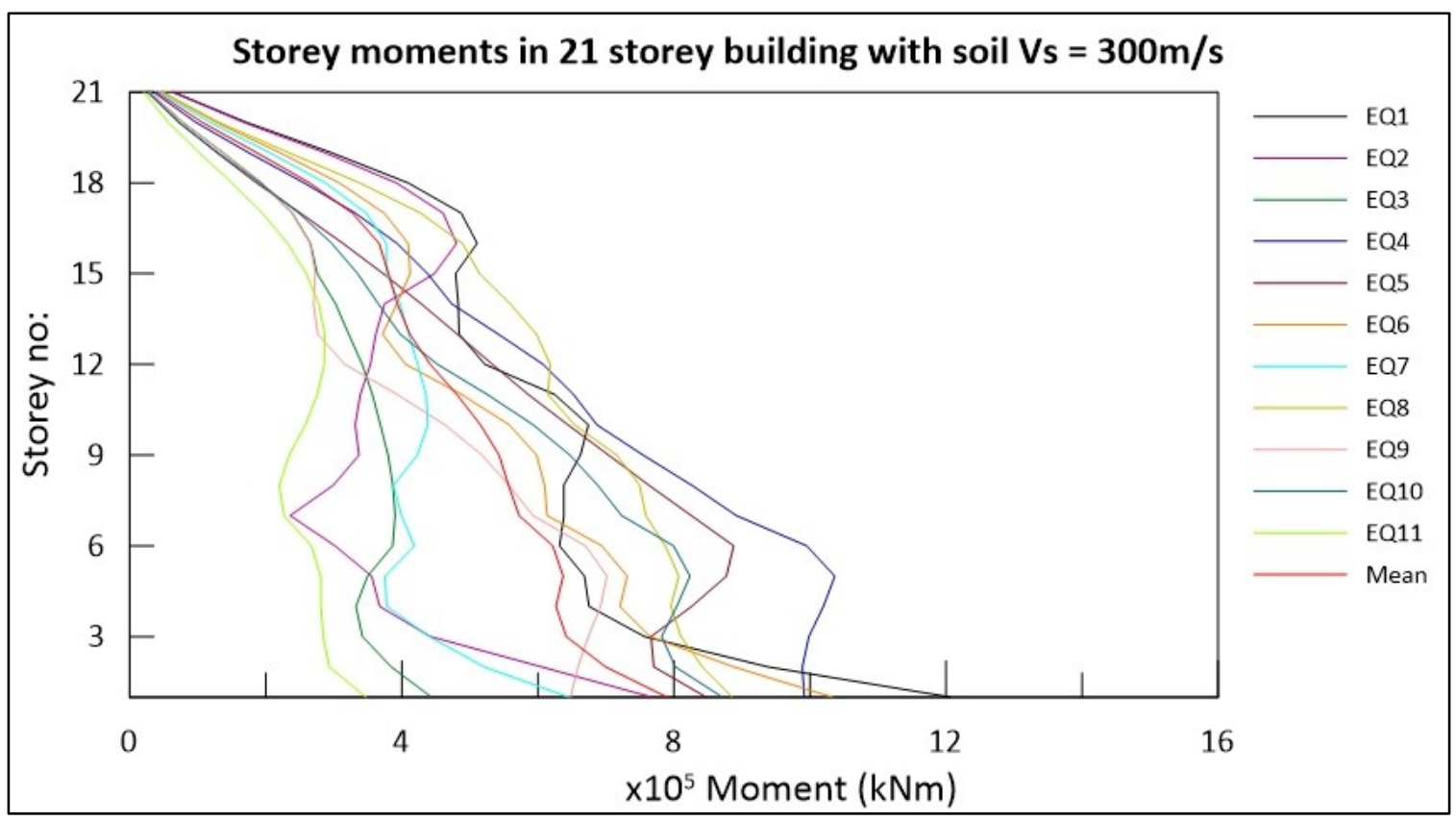

Figure B-157 Storey moments in 21storey building with soil shear wave velocity, Vs $=300 \mathrm{~m} / \mathrm{s}$ analyzed for 11 earthquake inputs compatible with Vancouver site B spectrum

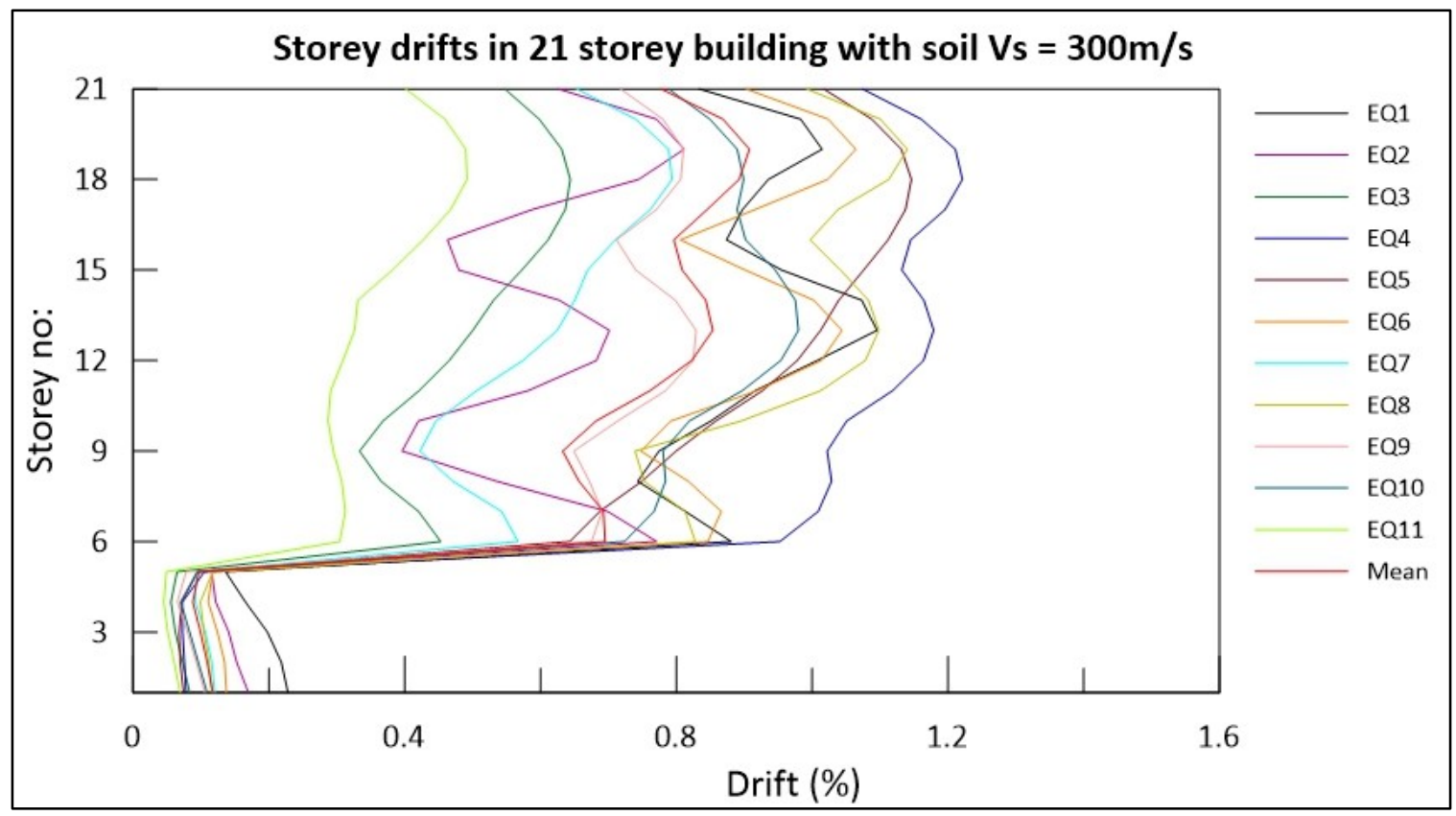

Figure B-158 Storey drifts in 21storey building with soil shear wave velocity, Vs $=300 \mathrm{~m} / \mathrm{s}$ analyzed for 11 earthquake inputs compatible with Vancouver site B spectrum 


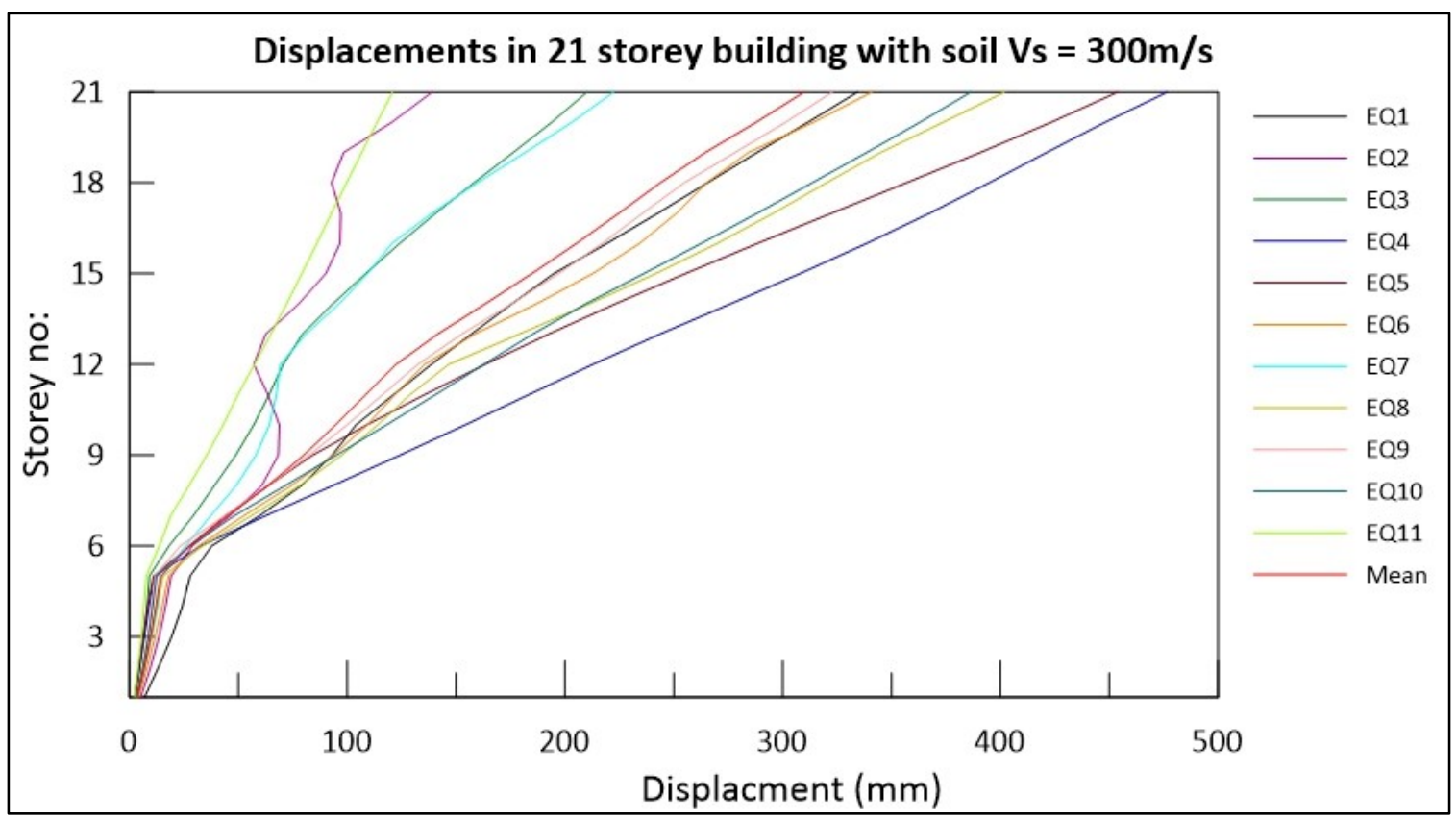

Figure B-159 Displacements in 21 storey building with soil shear wave velocity, Vs $=300 \mathrm{~m} / \mathrm{s}$ analyzed for 11 earthquake inputs compatible with Vancouver site B spectrum

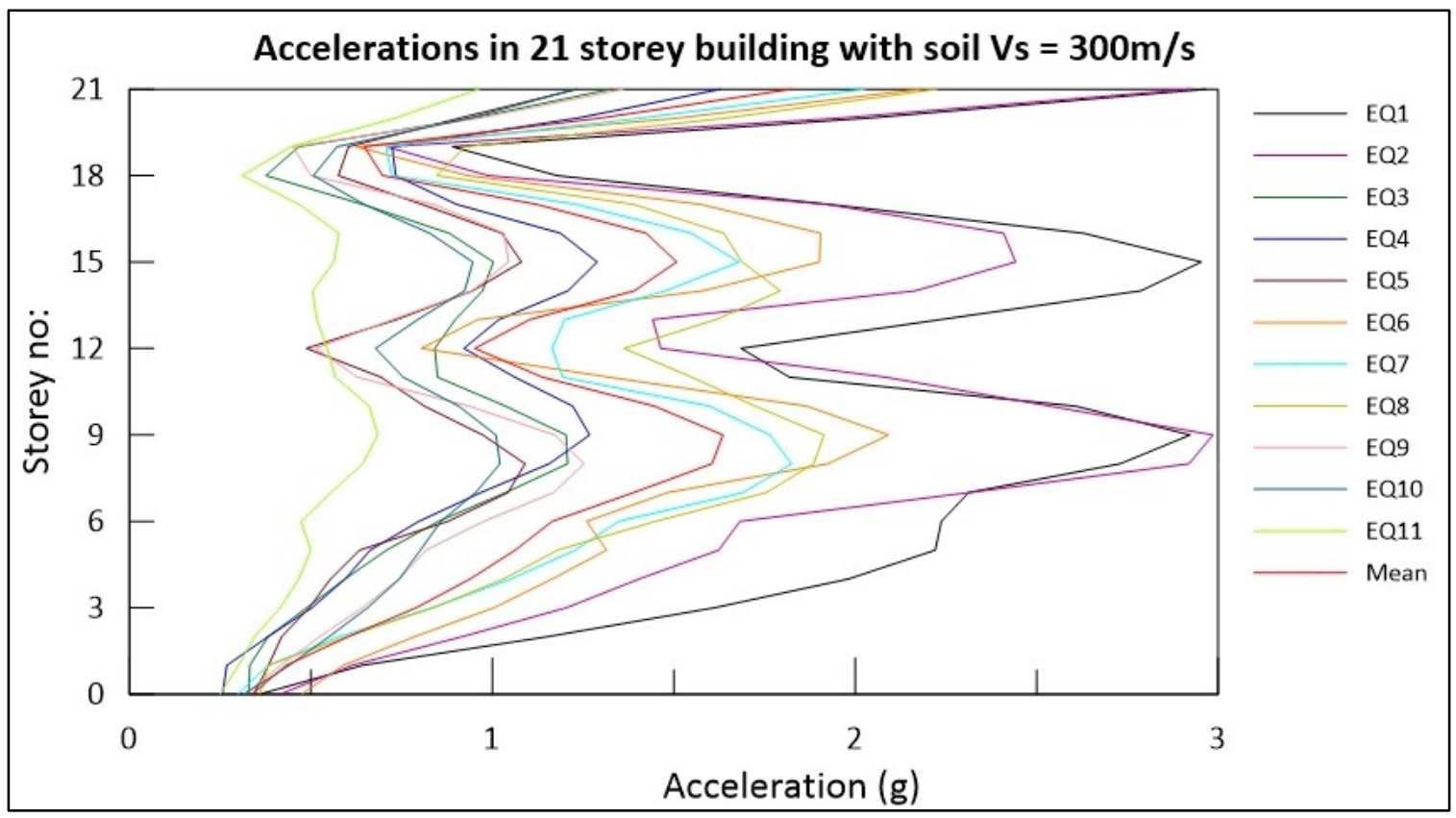

Figure B-160 Accelerations in 21storey building with soil shear wave velocity, Vs $=300 \mathrm{~m} / \mathrm{s}$ analyzed for 11 earthquake inputs compatible with Vancouver site B spectrum 


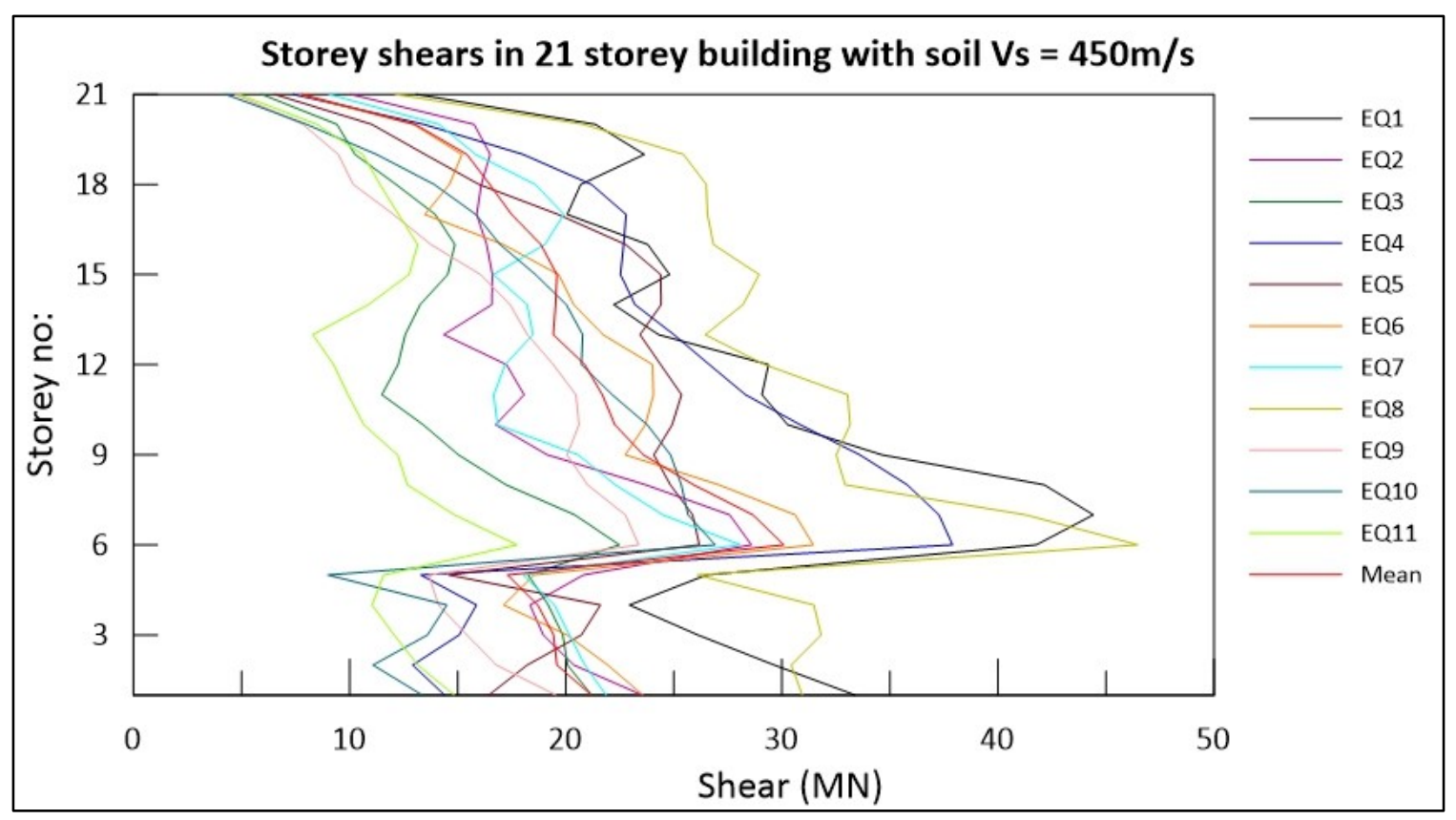

Figure B-161 Storey shears in 21storey building with soil shear wave velocity, Vs $=450 \mathrm{~m} / \mathrm{s}$ analyzed for 11 earthquake inputs compatible with Vancouver site B spectrum

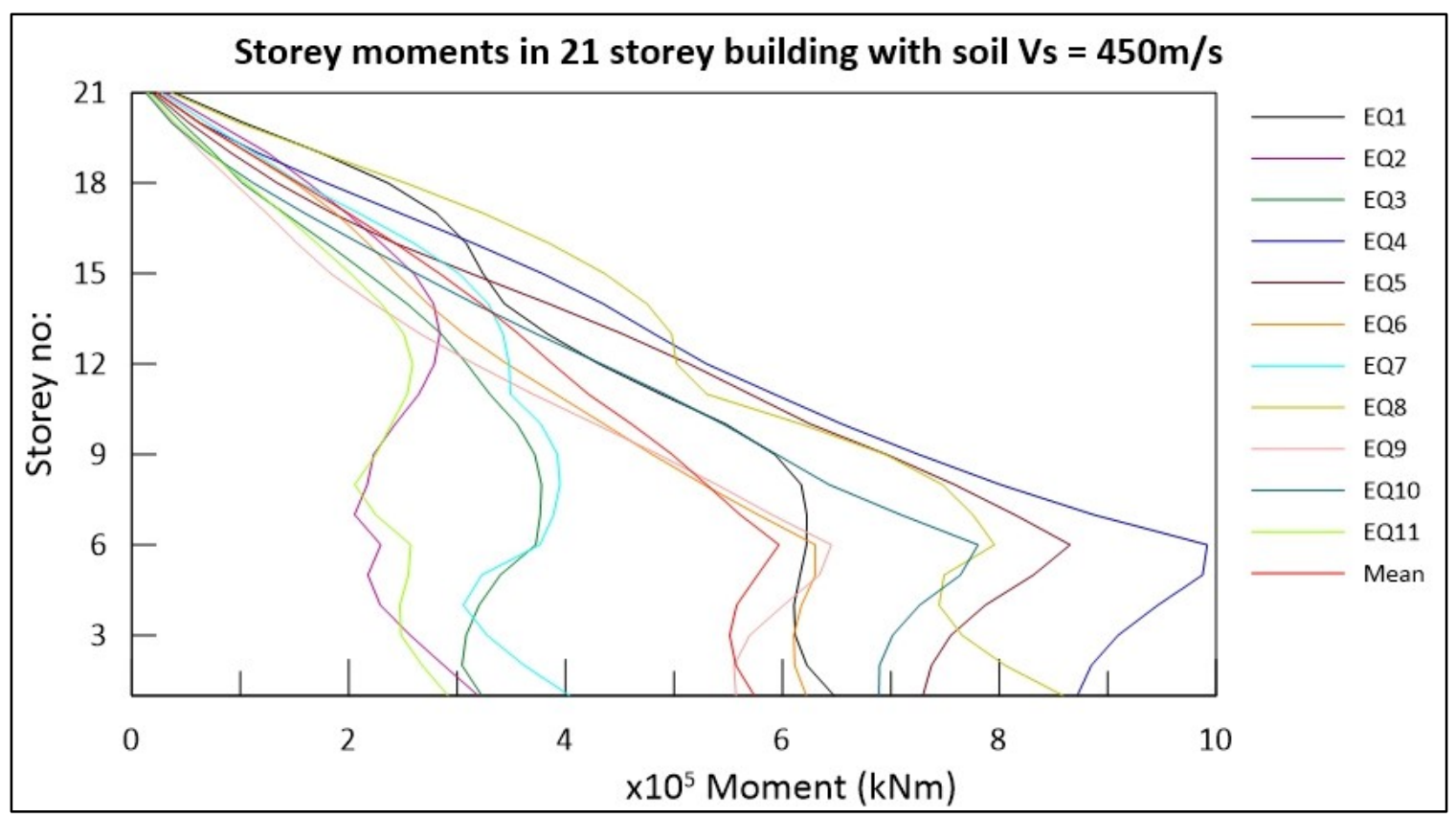

Figure B-162 Storey moments in 21storey building with soil shear wave velocity, Vs $=450 \mathrm{~m} / \mathrm{s}$ analyzed for 11 earthquake inputs compatible with Vancouver site B spectrum 


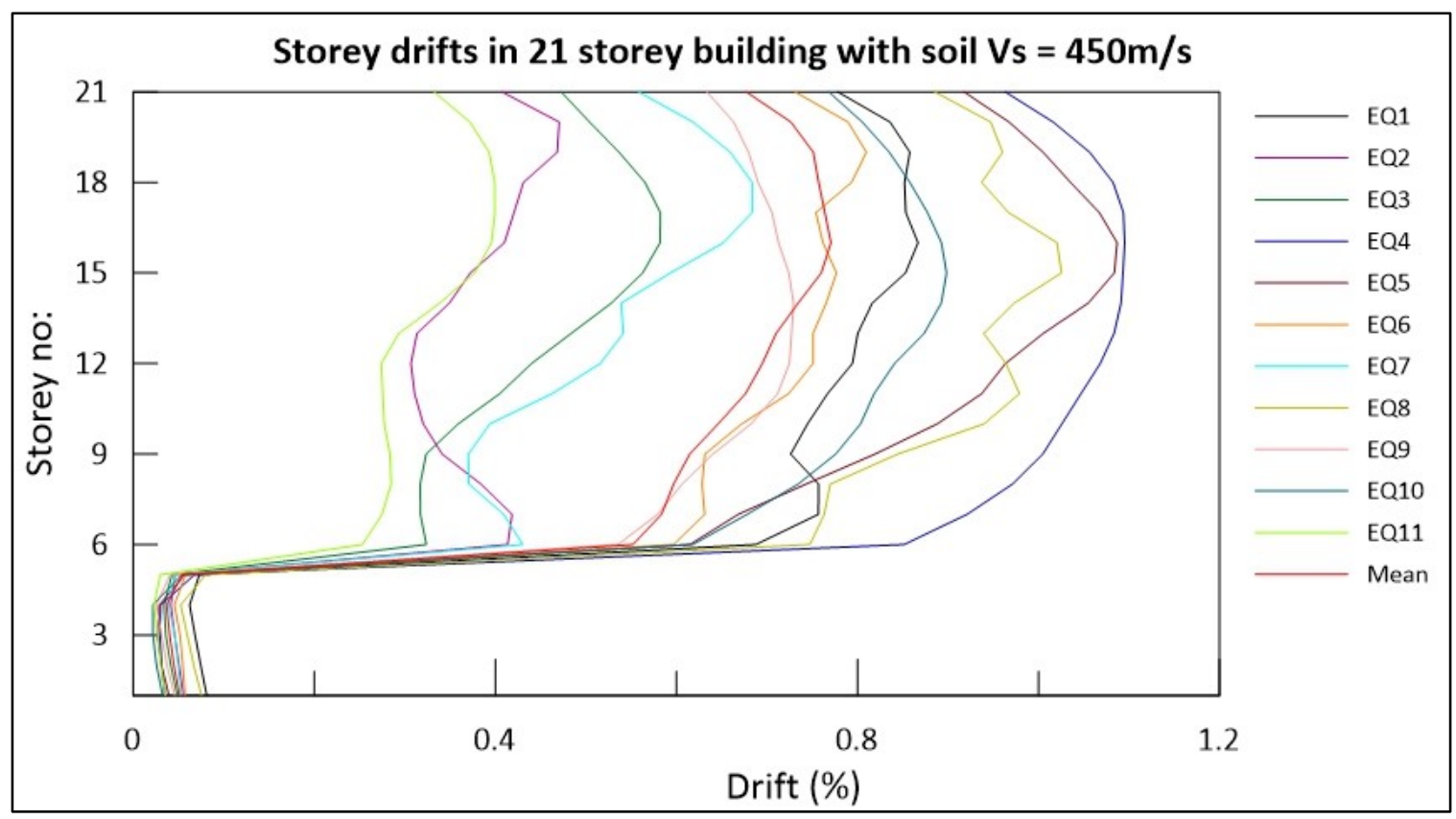

Figure B-163 Storey drifts in 21storey building with soil shear wave velocity, Vs $=450 \mathrm{~m} / \mathrm{s}$ analyzed for 11 earthquake inputs compatible with Vancouver site B spectrum

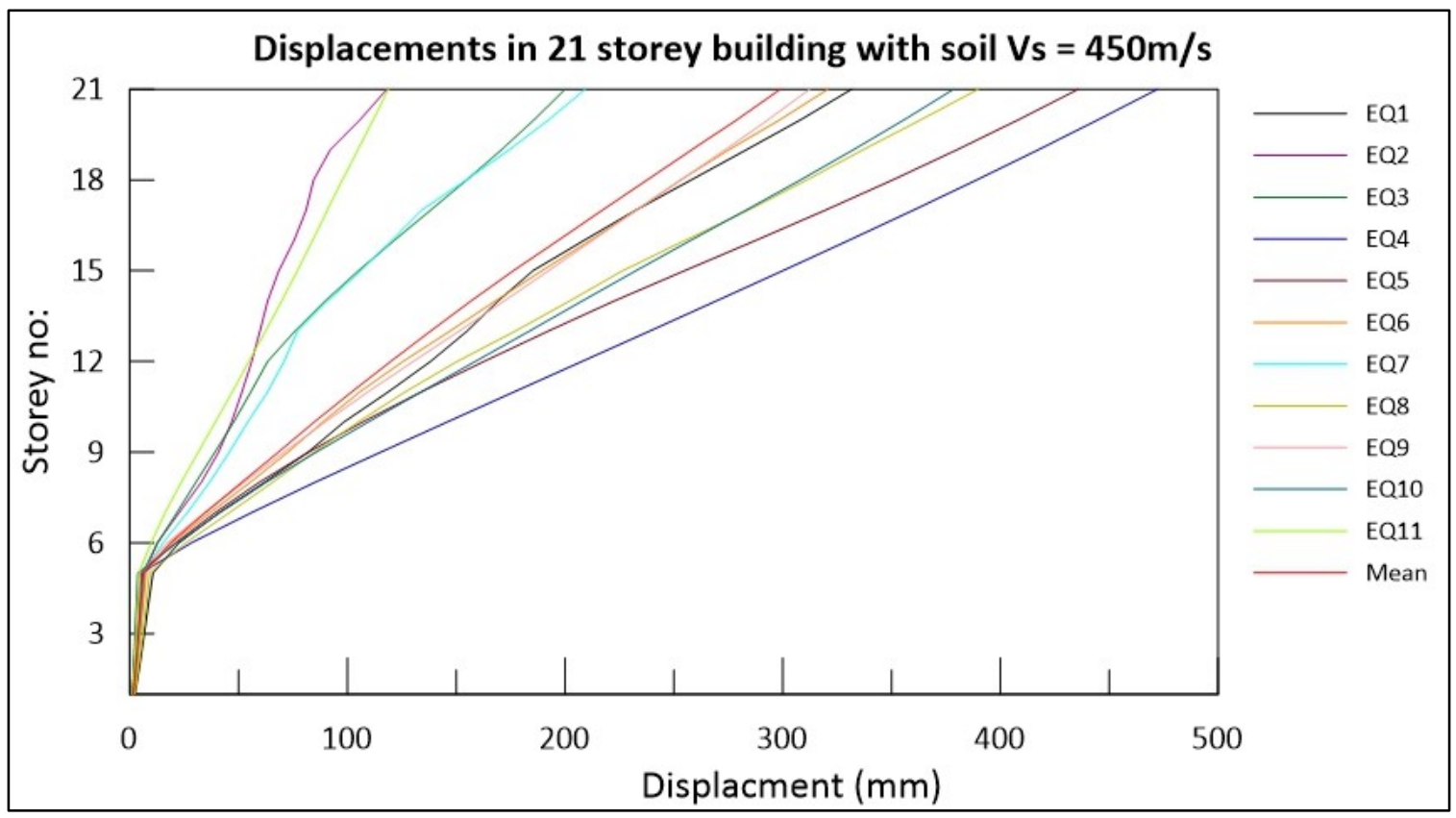

Figure B-164 Displacements in 21storey building with soil shear wave velocity, Vs $=450 \mathrm{~m} / \mathrm{s}$ analyzed for 11 earthquake inputs compatible with Vancouver site B spectrum 


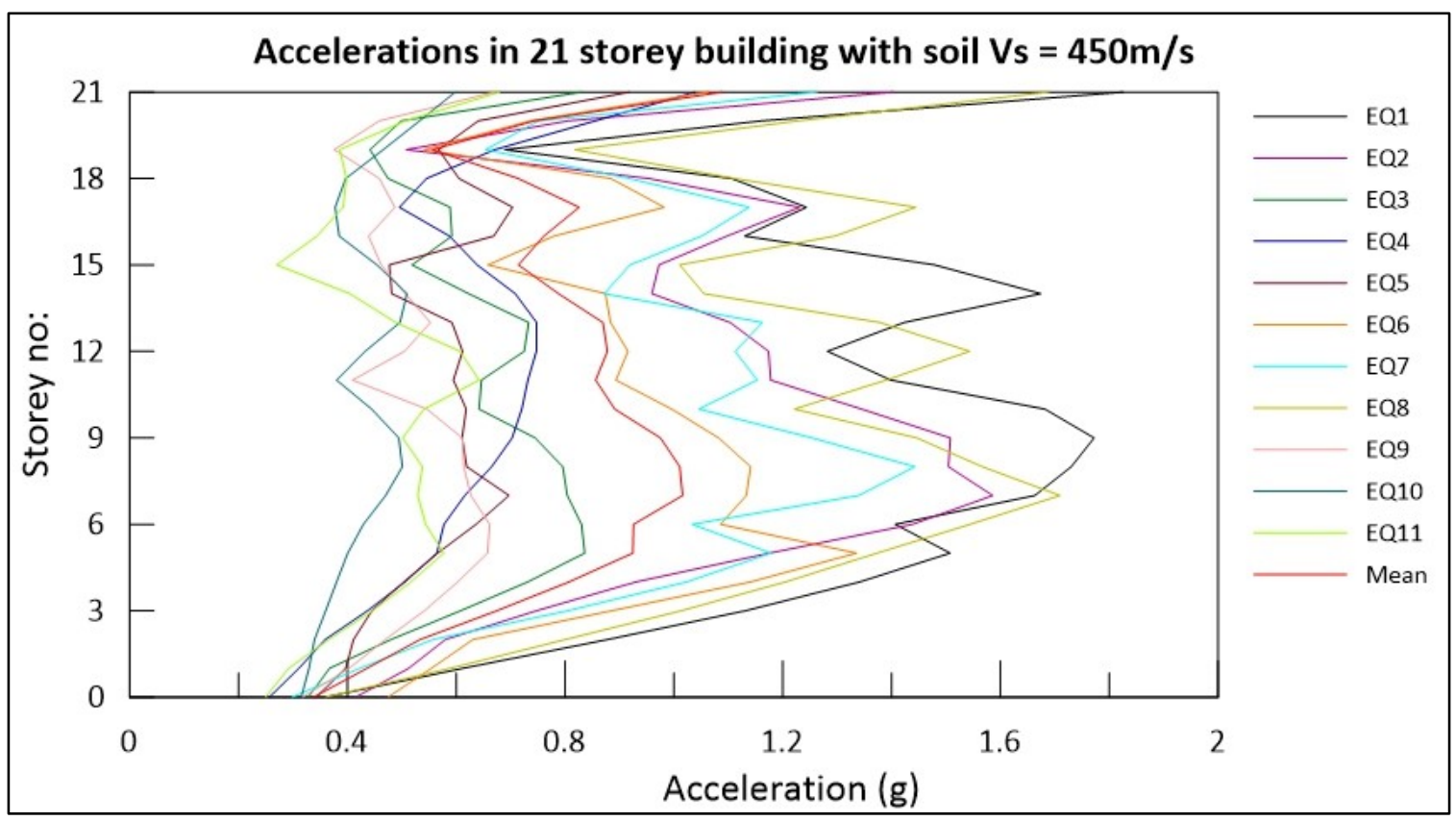

Figure B-165 Accelerations in 21storey building with soil shear wave velocity, Vs $=450 \mathrm{~m} / \mathrm{s}$ analyzed for 11 earthquake inputs compatible with Vancouver site B spectrum

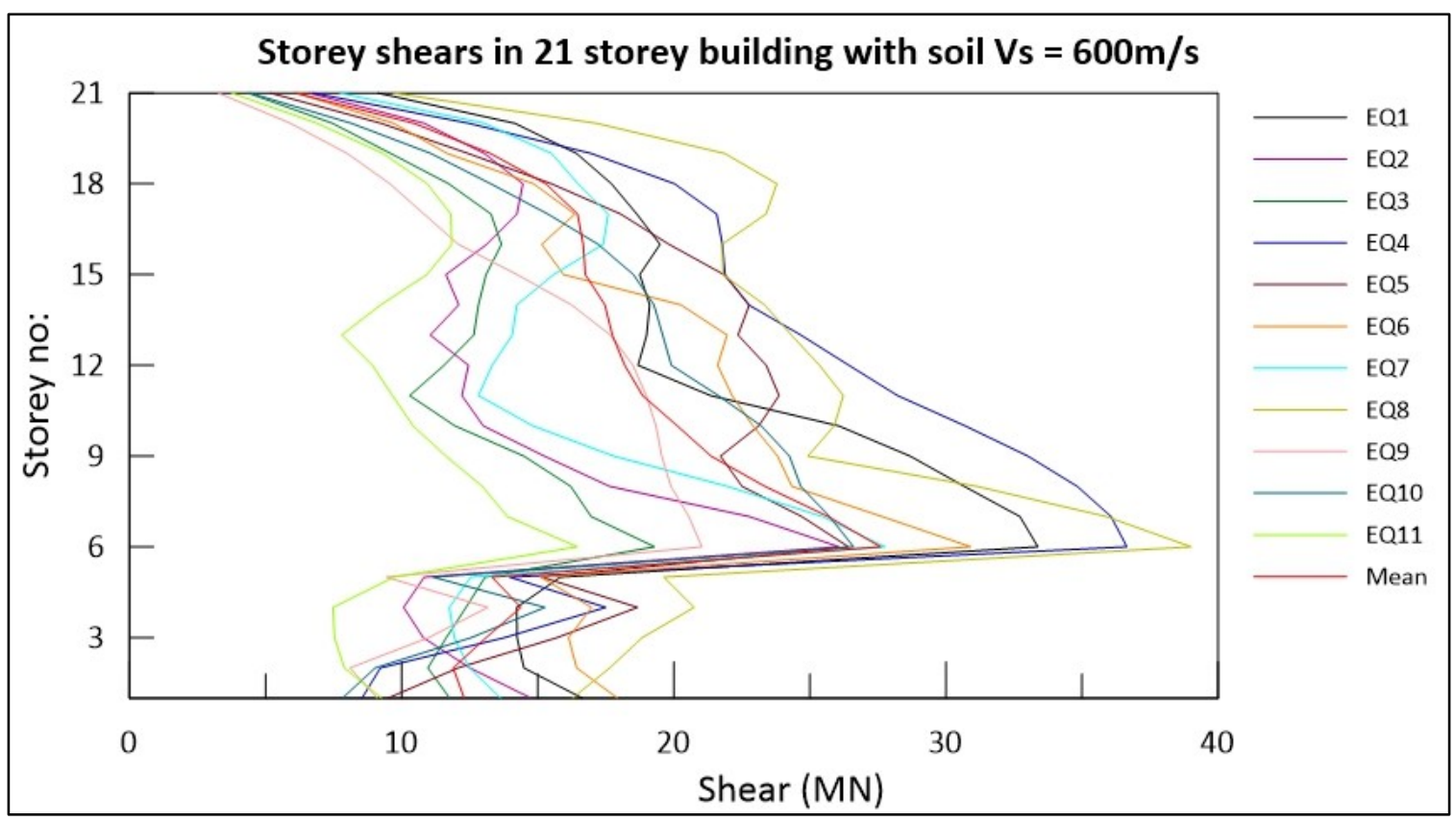

Figure B-166 Storey shears in 21storey building with soil shear wave velocity, Vs $=600 \mathrm{~m} / \mathrm{s}$ analyzed for 11 earthquake inputs compatible with Vancouver site B spectrum 


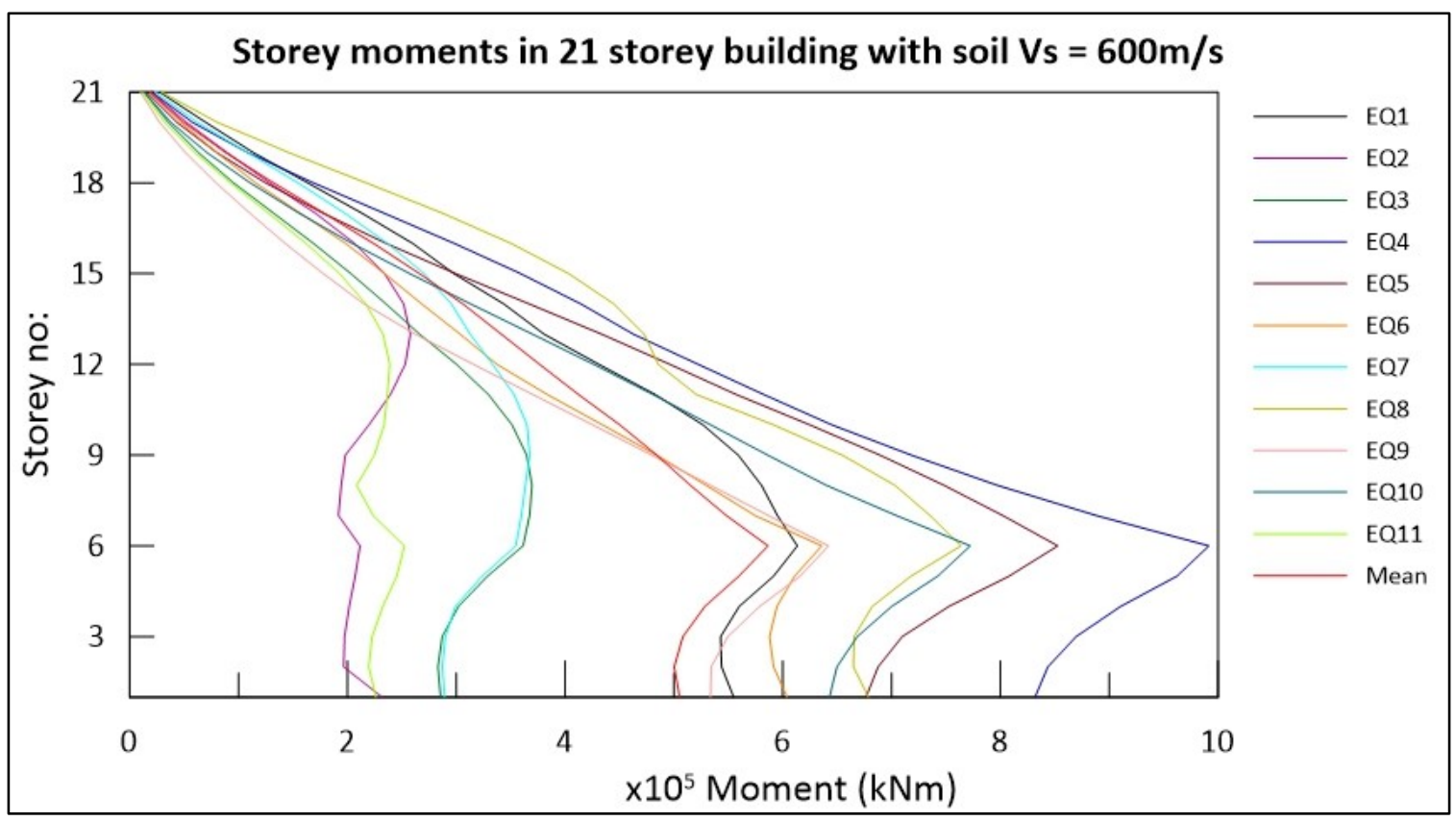

Figure B-167 Storey moments in 21storey building with soil shear wave velocity, Vs $=600 \mathrm{~m} / \mathrm{s}$ analyzed for 11 earthquake inputs compatible with Vancouver site B spectrum

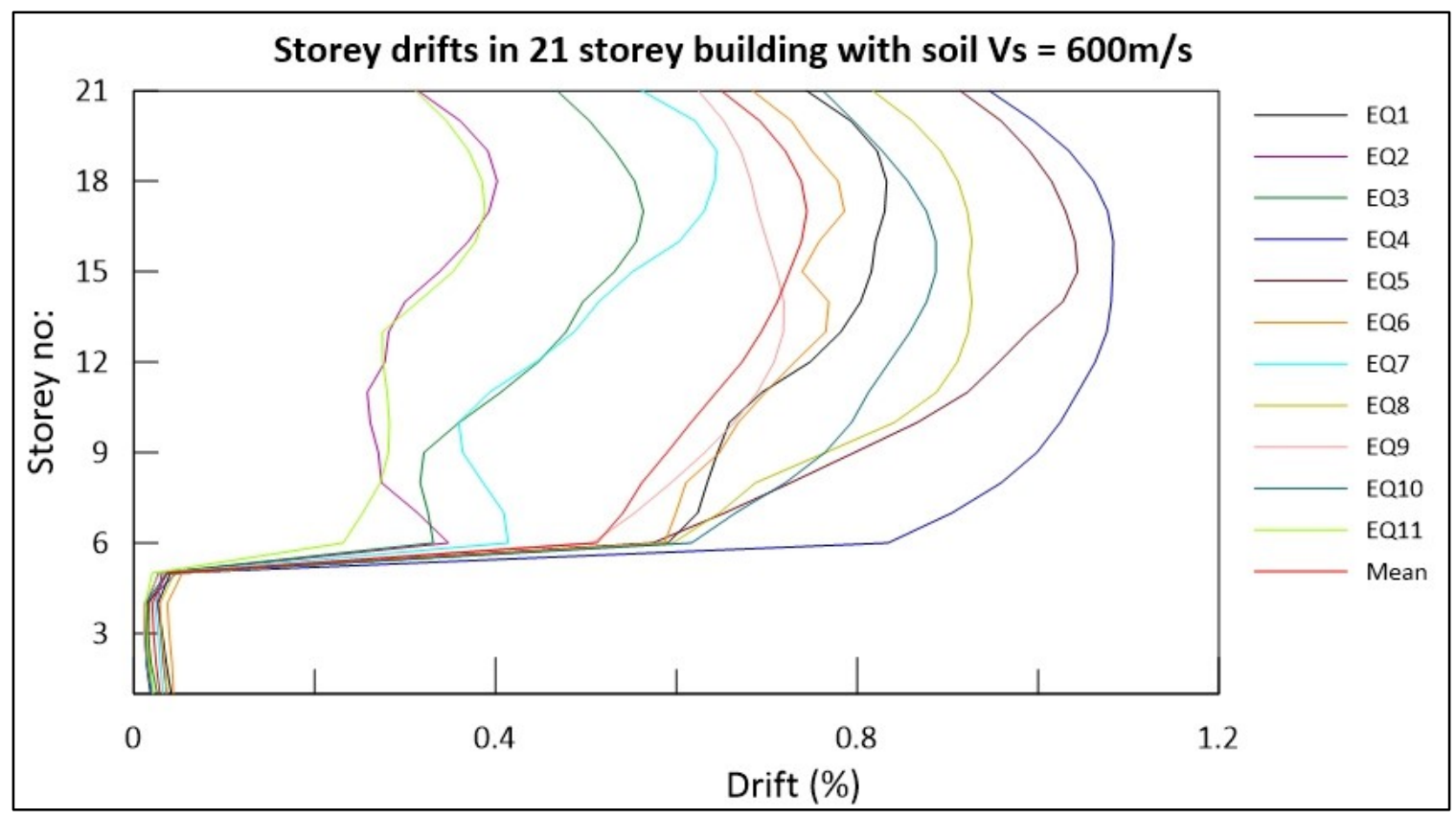

Figure B-168 Storey drifts in 21storey building with soil shear wave velocity, Vs $=600 \mathrm{~m} / \mathrm{s}$ analyzed for 11 earthquake inputs compatible with Vancouver site B spectrum 


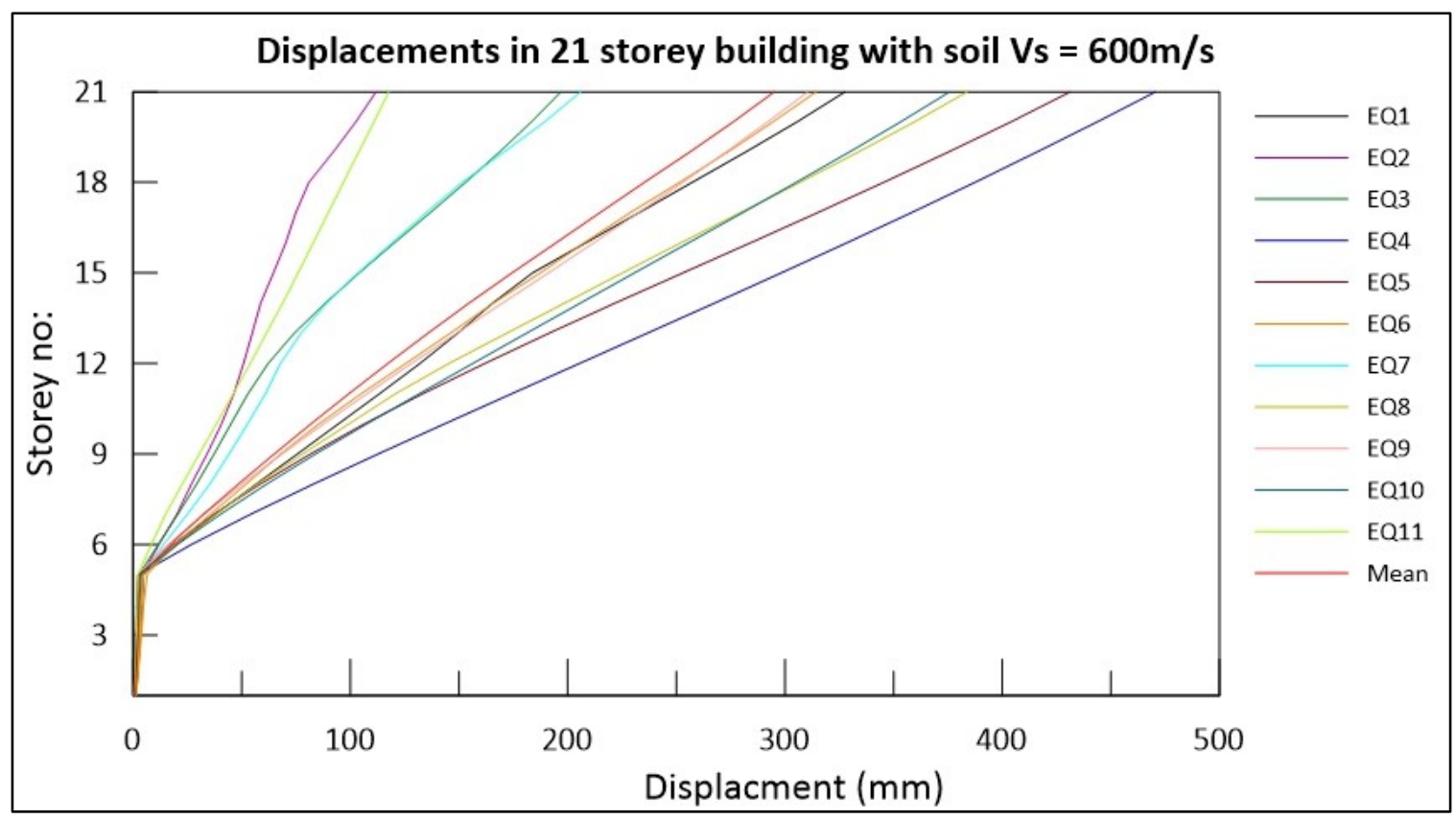

Figure B-169 Displacements in 21 storey building with soil shear wave velocity, Vs $=600 \mathrm{~m} / \mathrm{s}$ analyzed for 11 earthquake inputs compatible with Vancouver site B spectrum

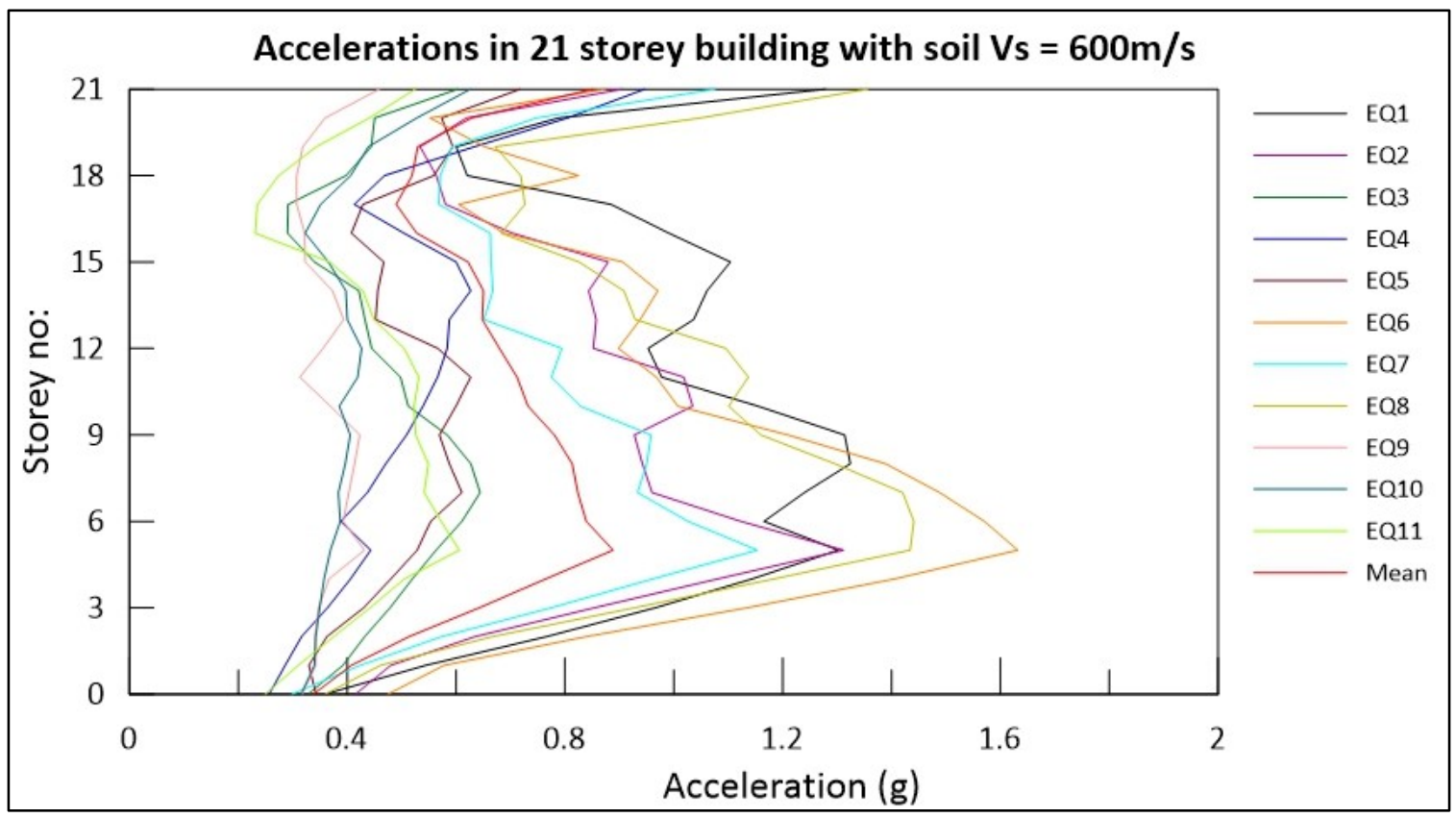

Figure B-170 Accelerations in 21storey building with soil shear wave velocity, Vs $=600 \mathrm{~m} / \mathrm{s}$ analyzed for 11 earthquake inputs compatible with Vancouver site B spectrum 


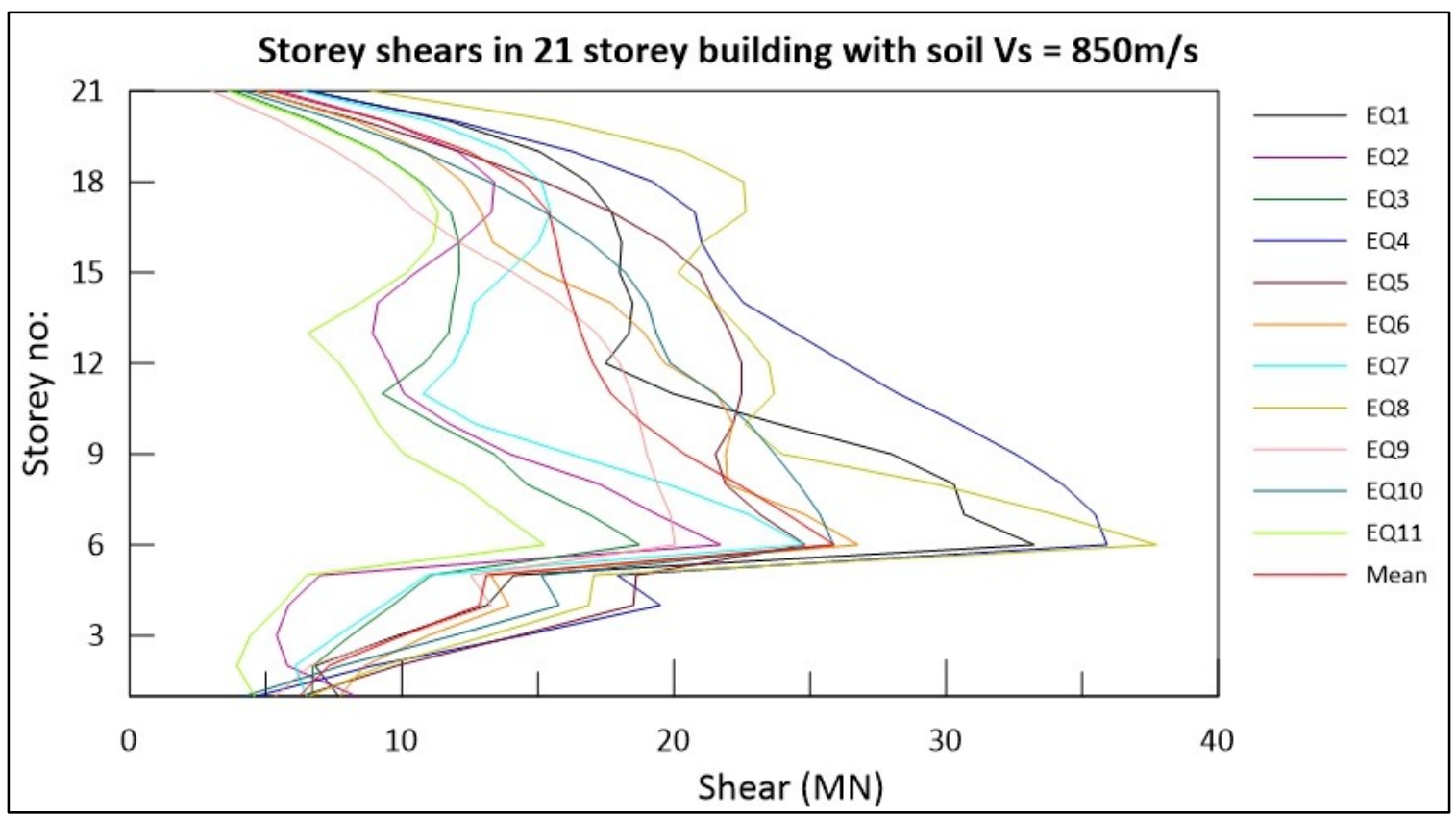

Figure B-171 Storey shears in 21storey building with soil shear wave velocity, Vs $=850 \mathrm{~m} / \mathrm{s}$ analyzed for 11 earthquake inputs compatible with Vancouver site B spectrum

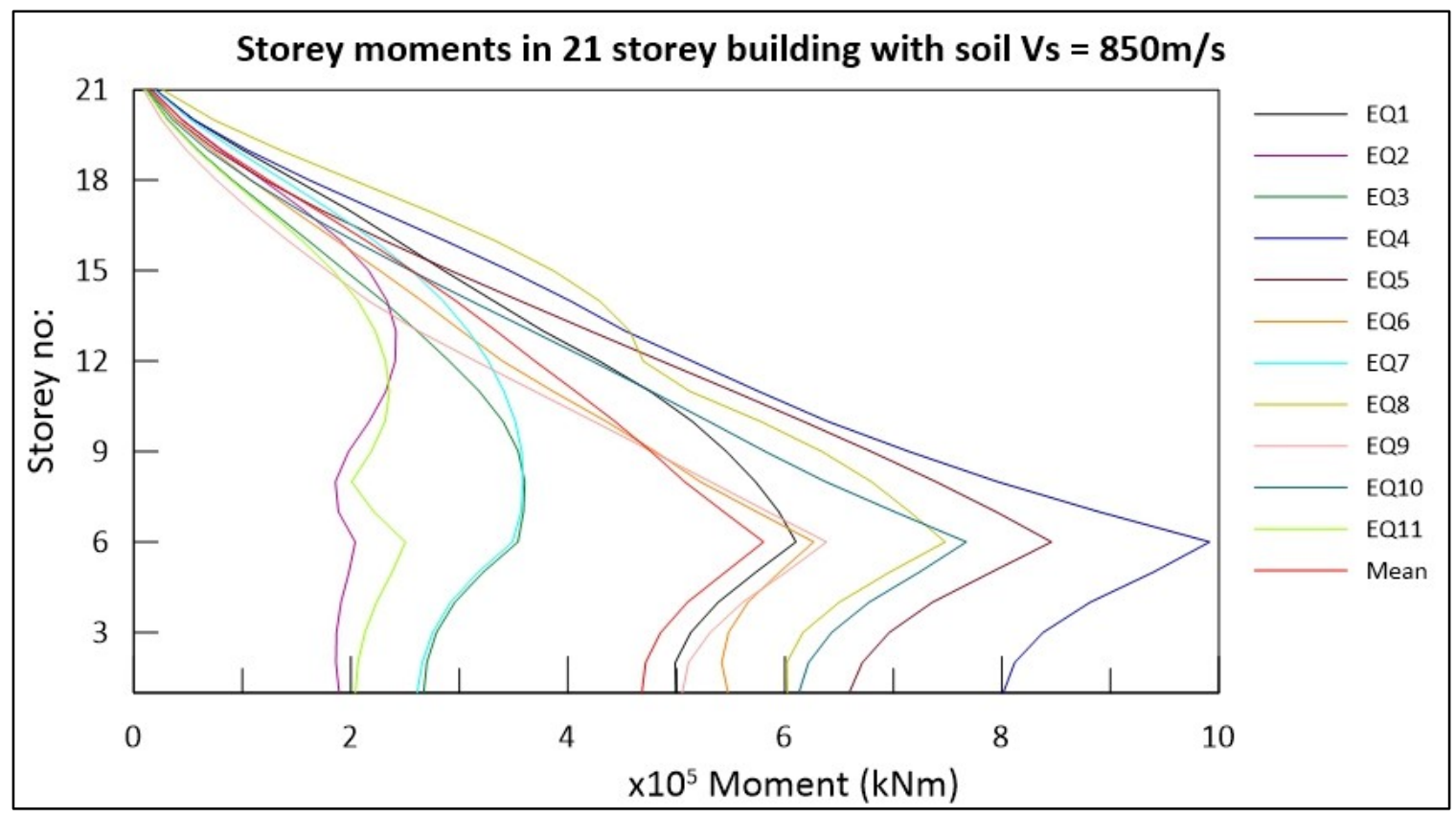

Figure B-172 Storey moments in 21storey building with soil shear wave velocity, Vs $=850 \mathrm{~m} / \mathrm{s}$ analyzed for 11 earthquake inputs compatible with Vancouver site B spectrum 


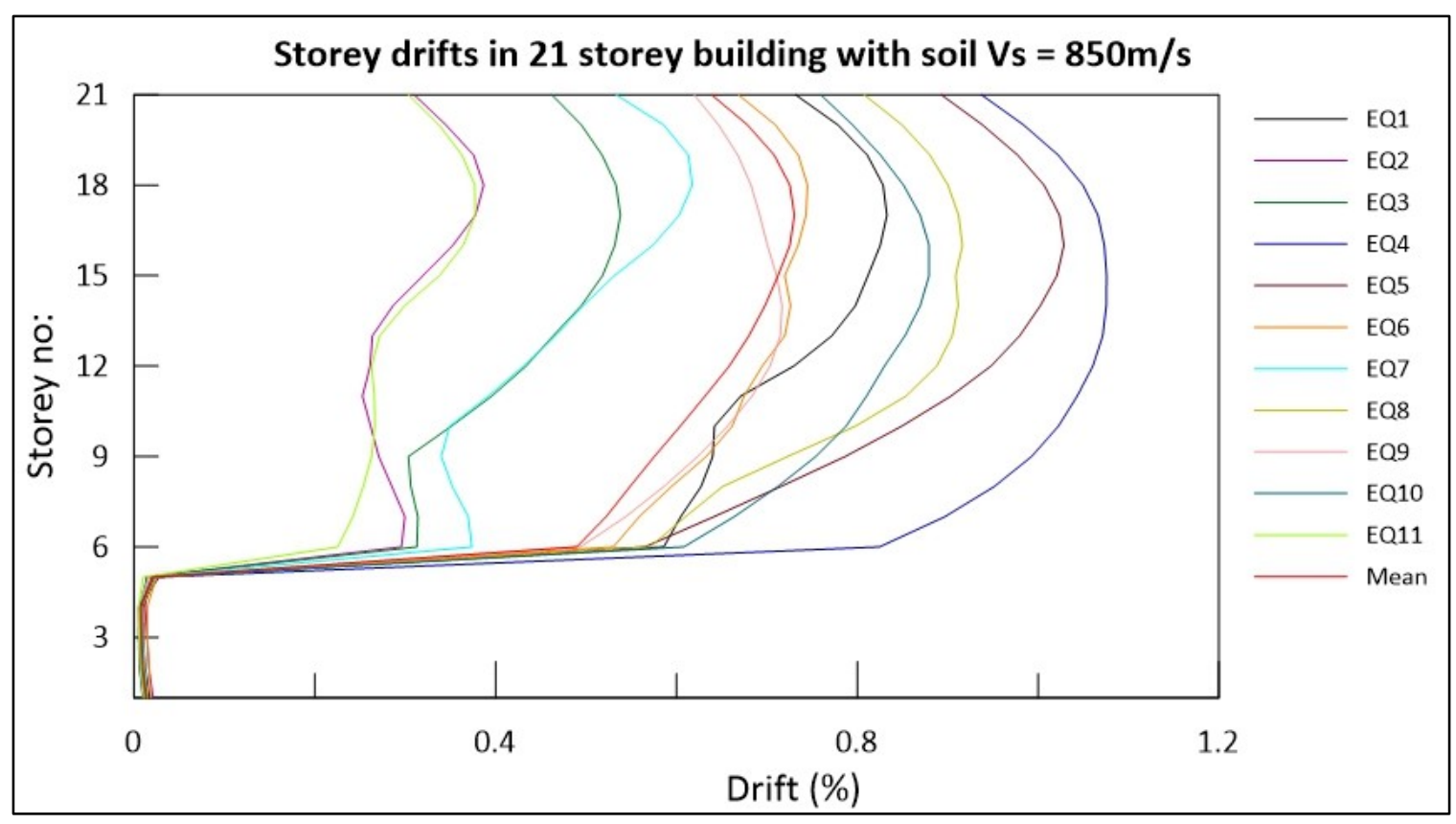

Figure B-173 Storey drifts in 21storey building with soil shear wave velocity, Vs $=850 \mathrm{~m} / \mathrm{s}$ analyzed for 11 earthquake inputs compatible with Vancouver site B spectrum

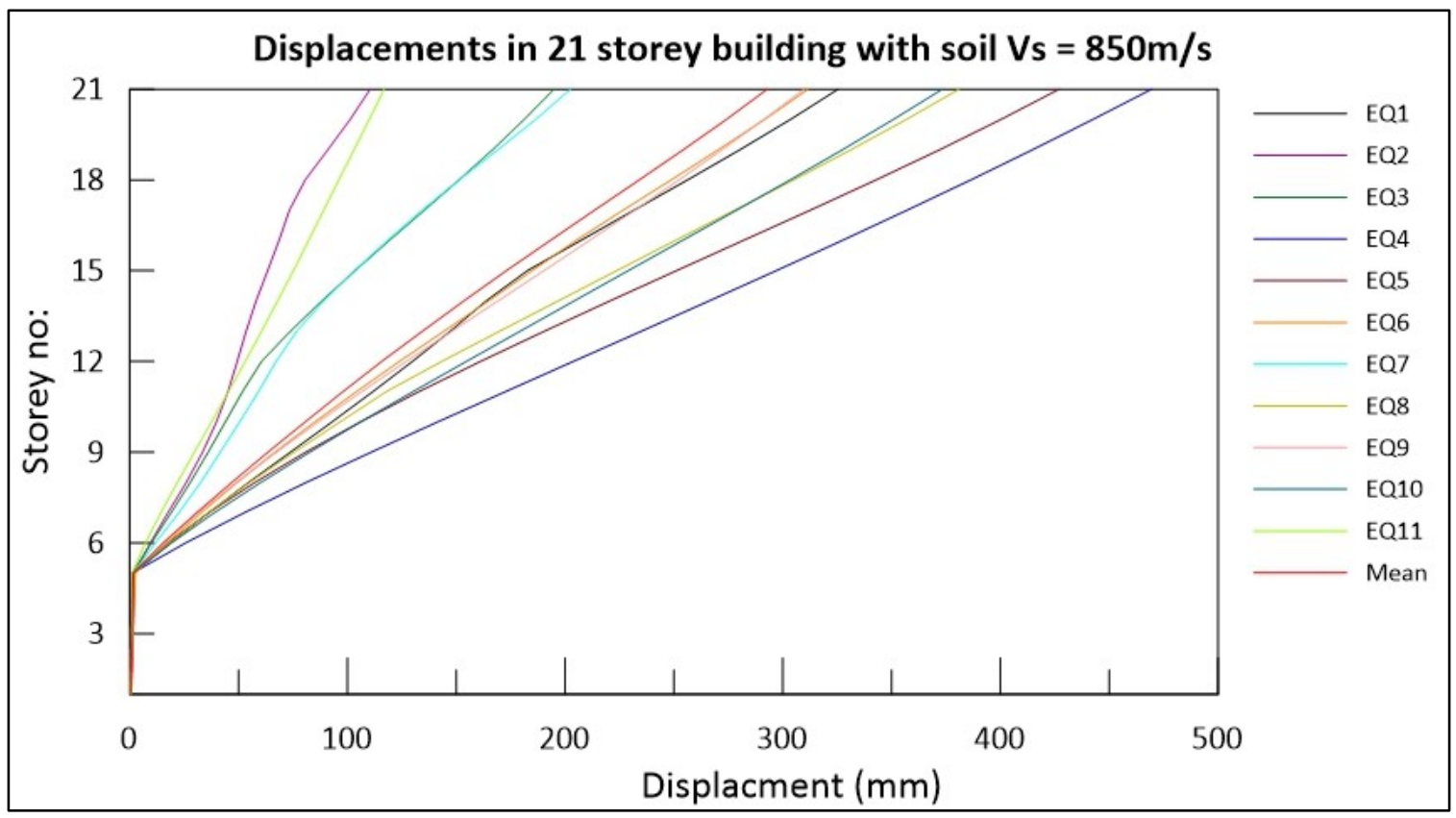

Figure B-174 Displacements in 21storey building with soil shear wave velocity, Vs $=850 \mathrm{~m} / \mathrm{s}$ analyzed for 11 earthquake inputs compatible with Vancouver site B spectrum 


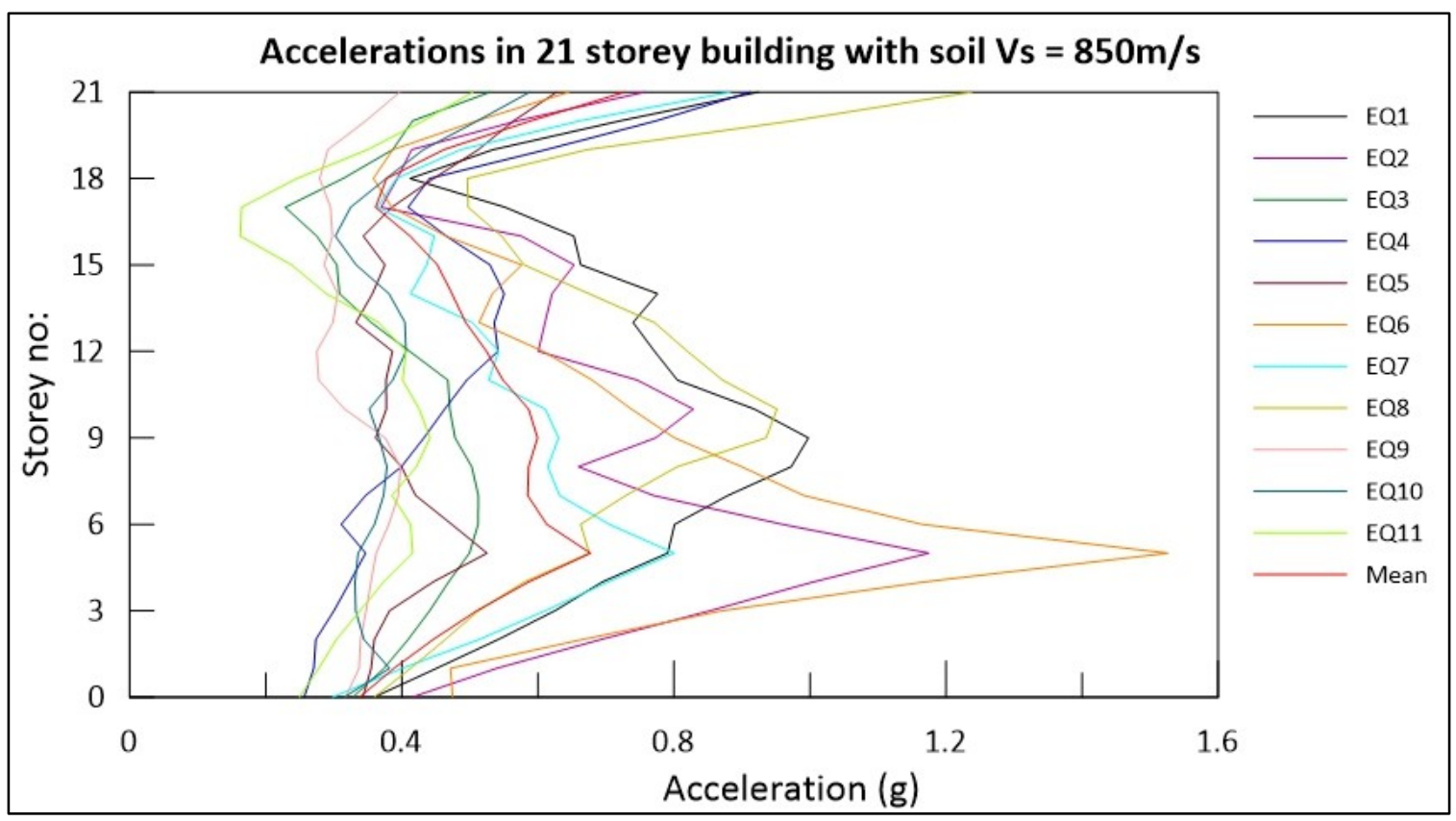

Figure B-175 Accelerations in 21storey building with soil shear wave velocity, Vs $=850 \mathrm{~m} / \mathrm{s}$ analyzed for 11 earthquake inputs compatible with Vancouver site B spectrum

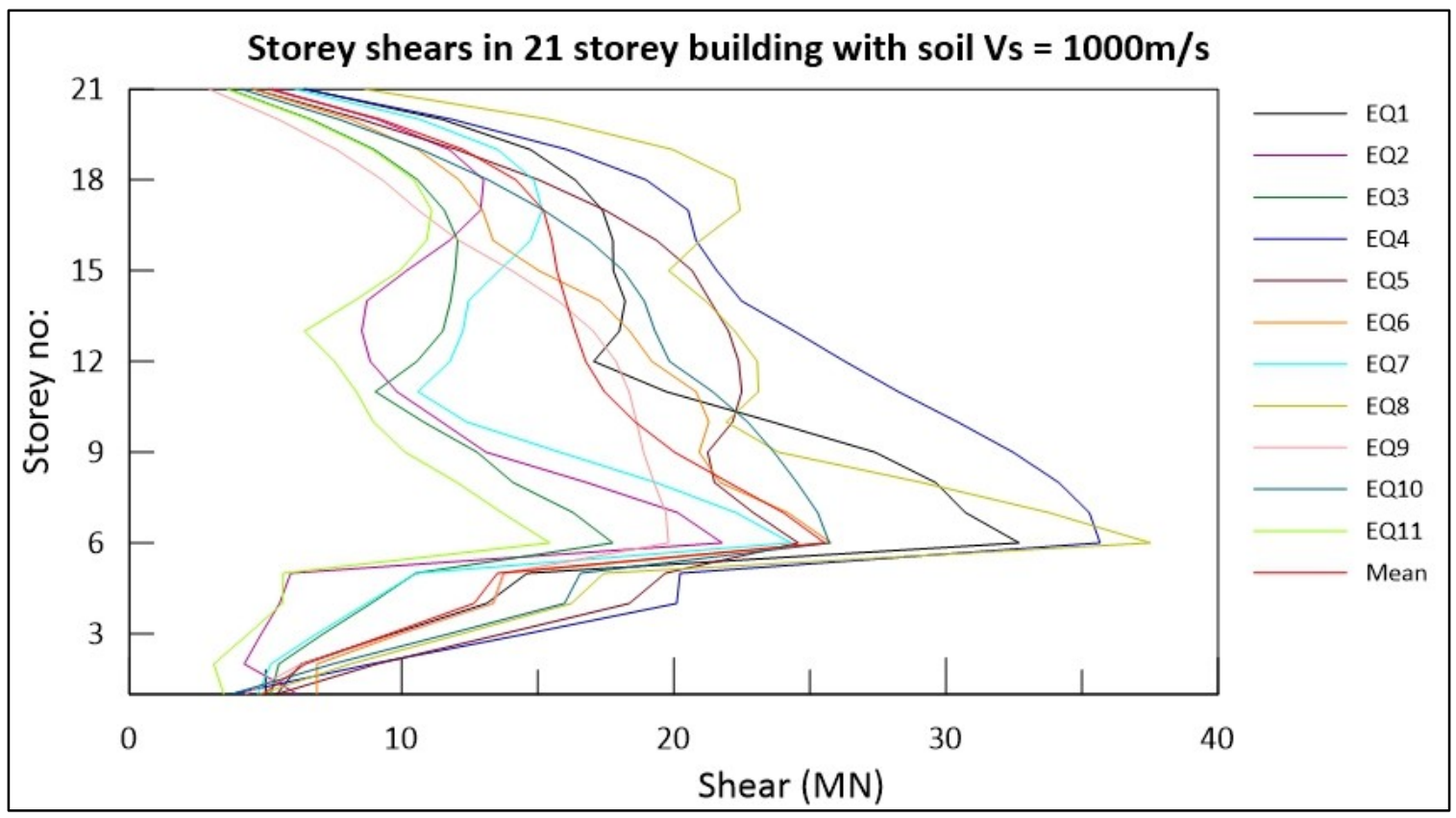

Figure B-176 Storey shears in 21storey building with soil shear wave velocity, Vs $=1000 \mathrm{~m} / \mathrm{s}$ analyzed for 11 earthquake inputs compatible with Vancouver site B spectrum 


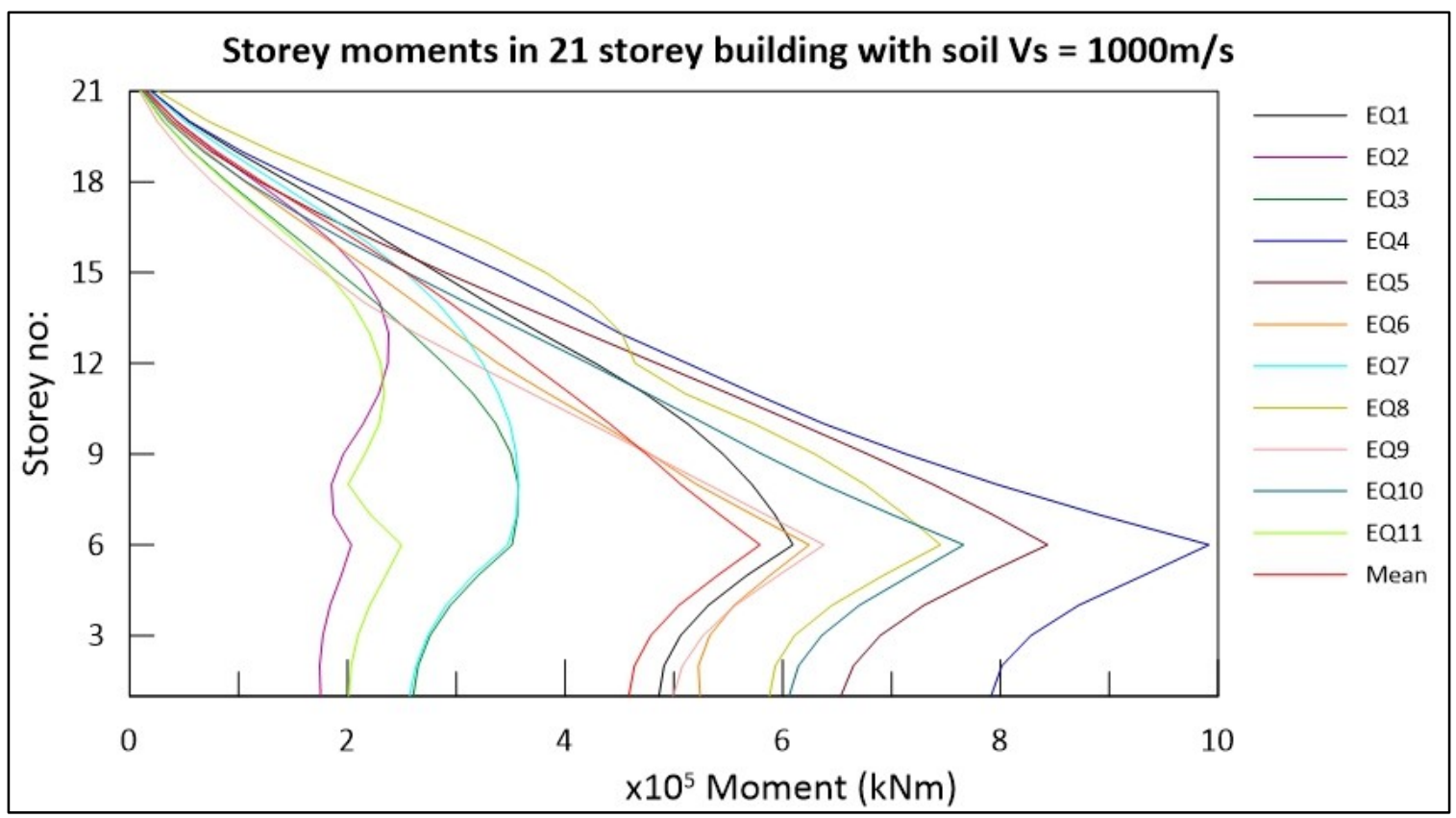

Figure B-177 Storey moments in 21storey building with soil shear wave velocity, Vs $=1000 \mathrm{~m} / \mathrm{s}$ analyzed for 11 earthquake inputs compatible with Vancouver site B spectrum

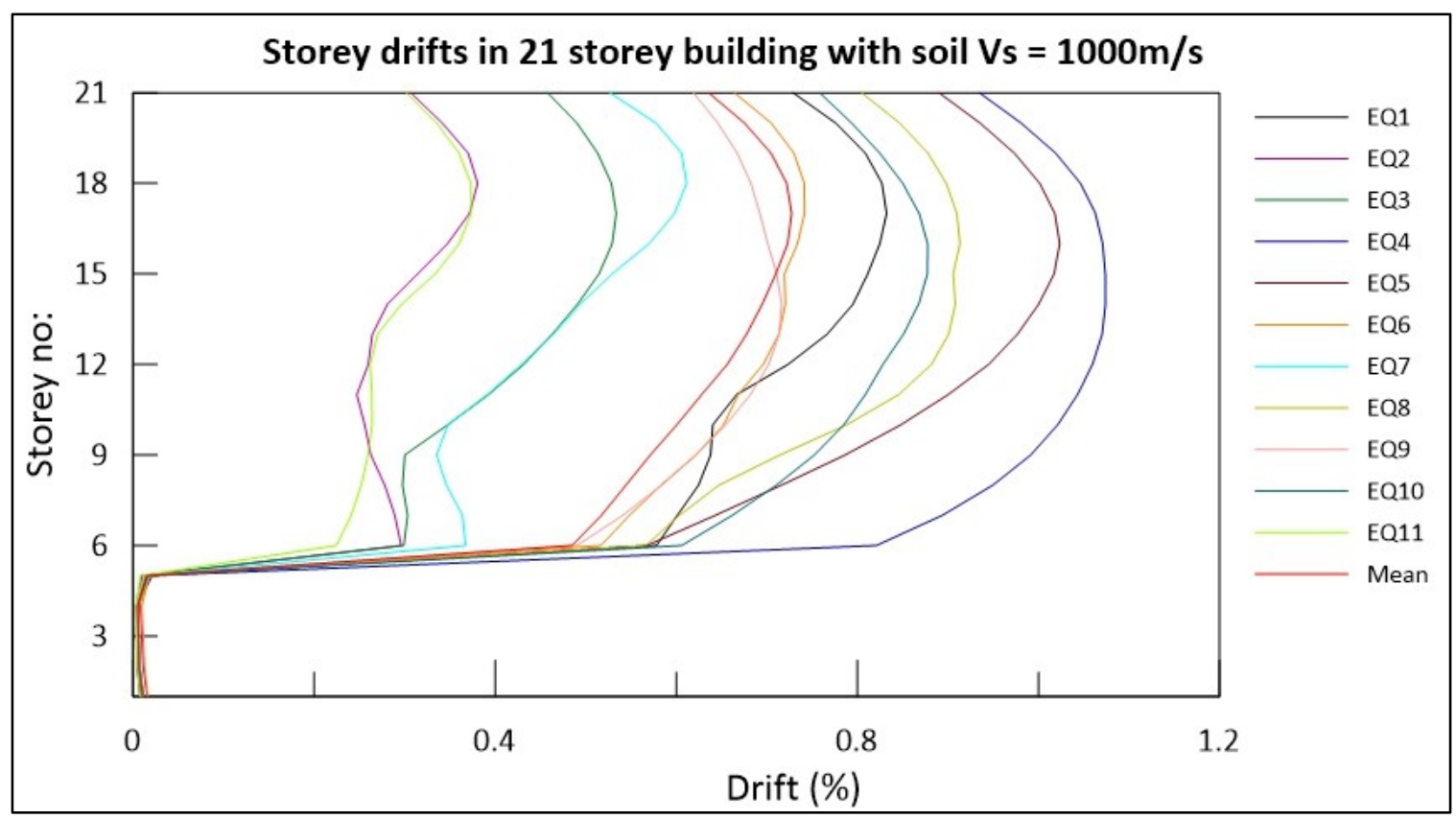

Figure B-178 Storey drifts in 21storey building with soil shear wave velocity, Vs $=1000 \mathrm{~m} / \mathrm{s}$ analyzed for 11 earthquake inputs compatible with Vancouver site B spectrum 


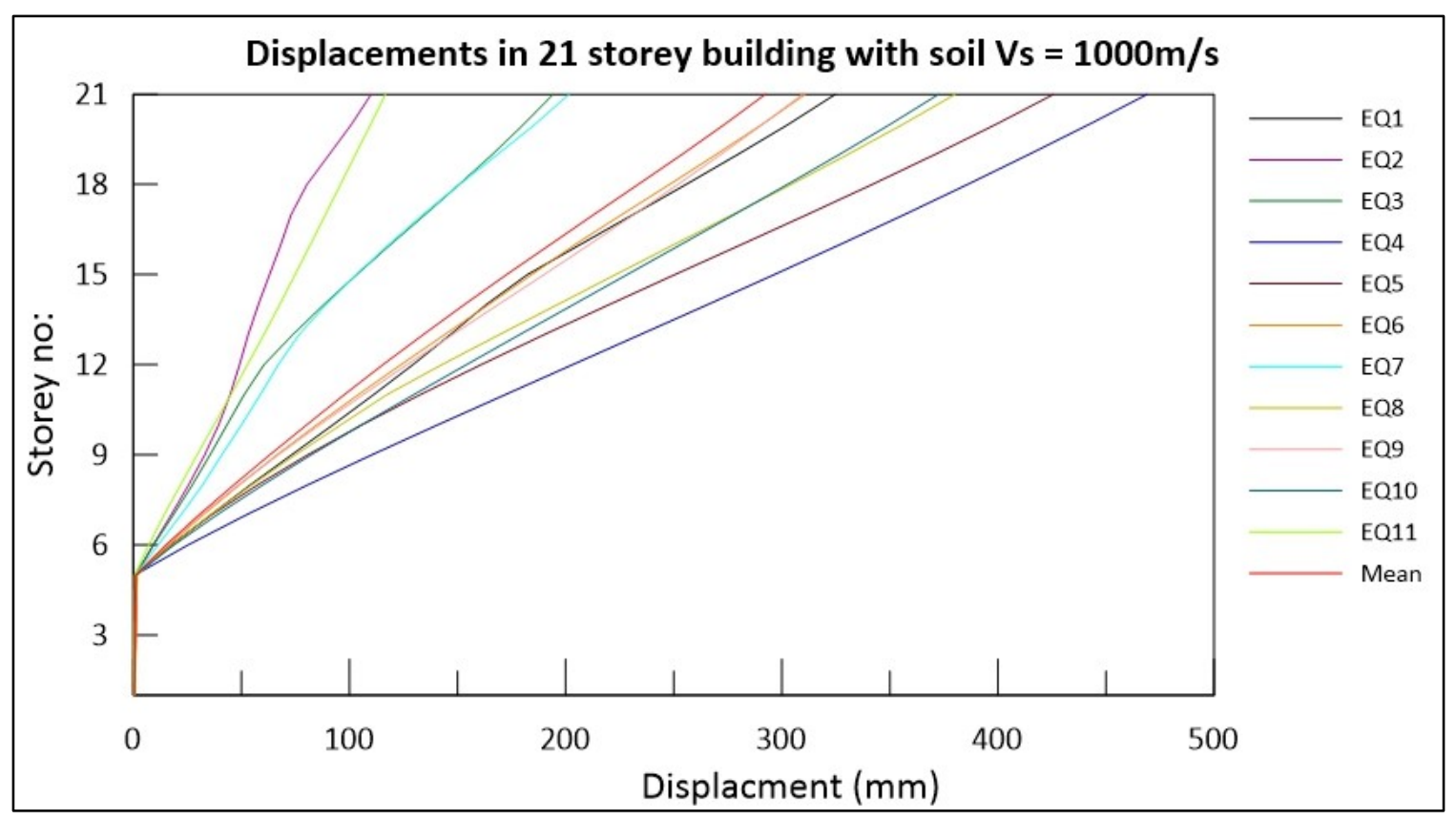

Figure B-179 Displacements in 21storey building with soil shear wave velocity, Vs $=1000 \mathrm{~m} / \mathrm{s}$ analyzed for 11 earthquake inputs compatible with Vancouver site B spectrum

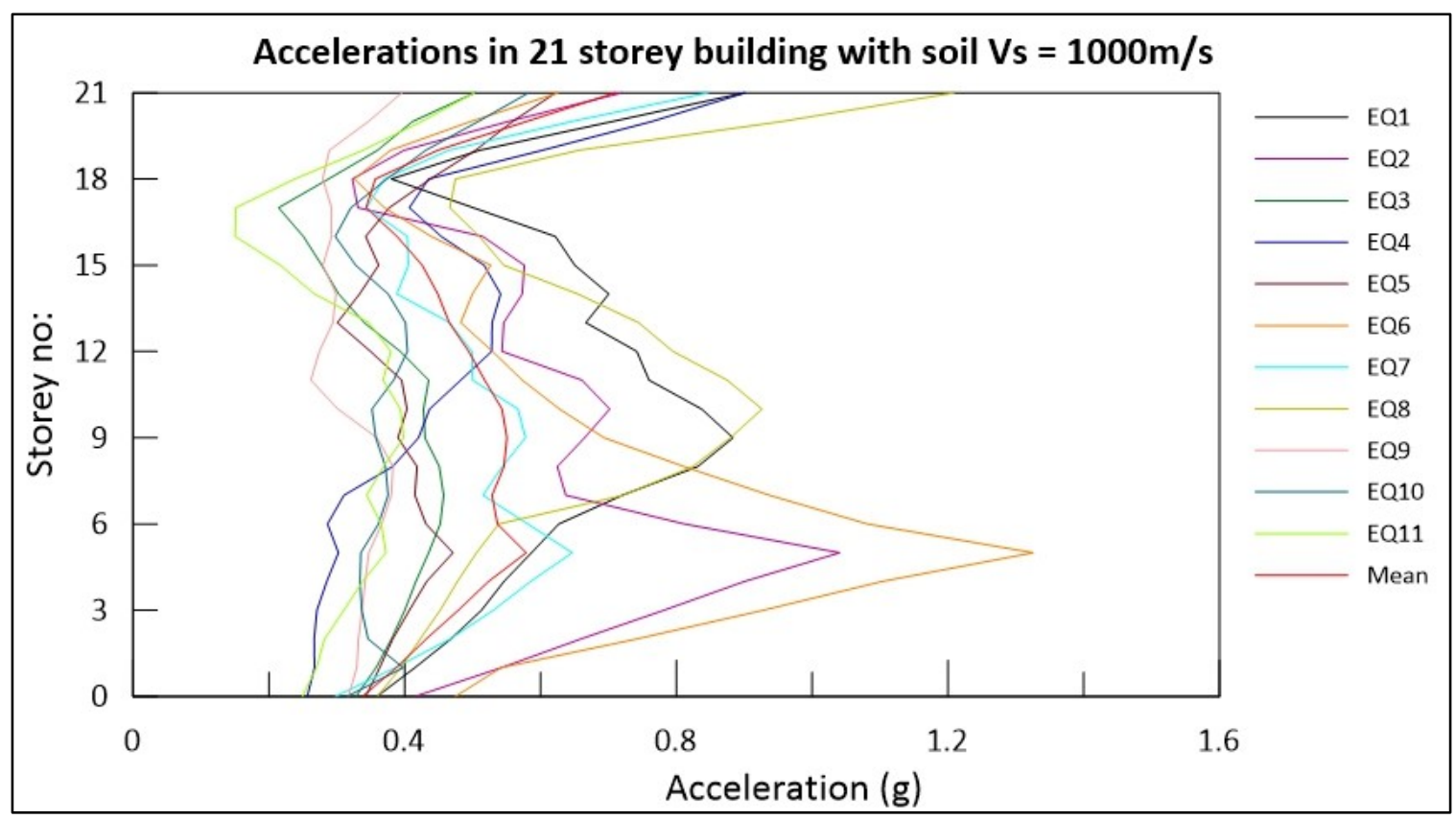

Figure B-180 Accelerations in 21storey building with soil shear wave velocity, Vs $=1000 \mathrm{~m} / \mathrm{s}$ analyzed for 11 earthquake inputs compatible with Vancouver site B spectrum 
25 storey building

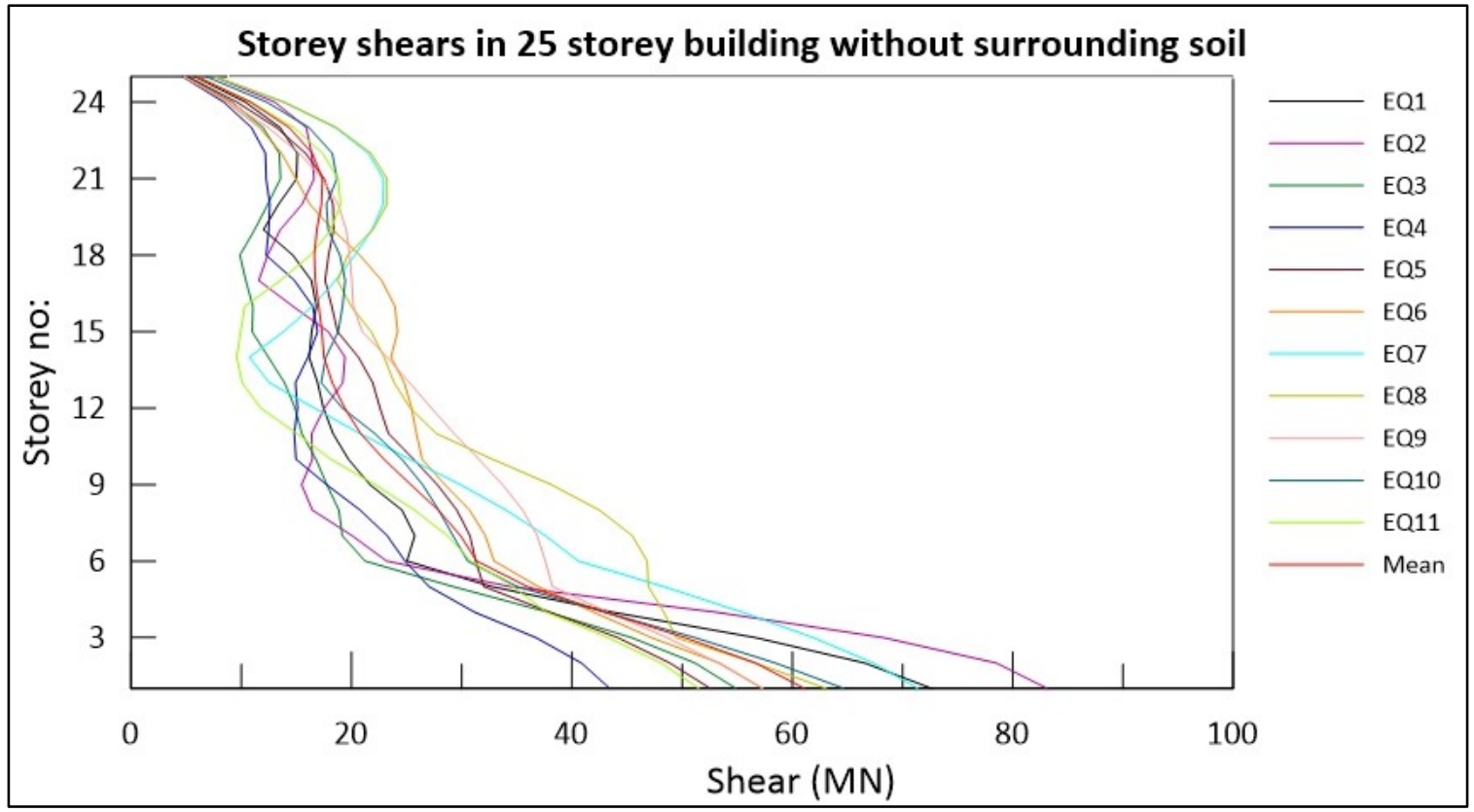

Figure B-181 Storey shears in 25storey building without any surrounding soil analyzed for 11 earthquake inputs compatible with Vancouver site B spectrum

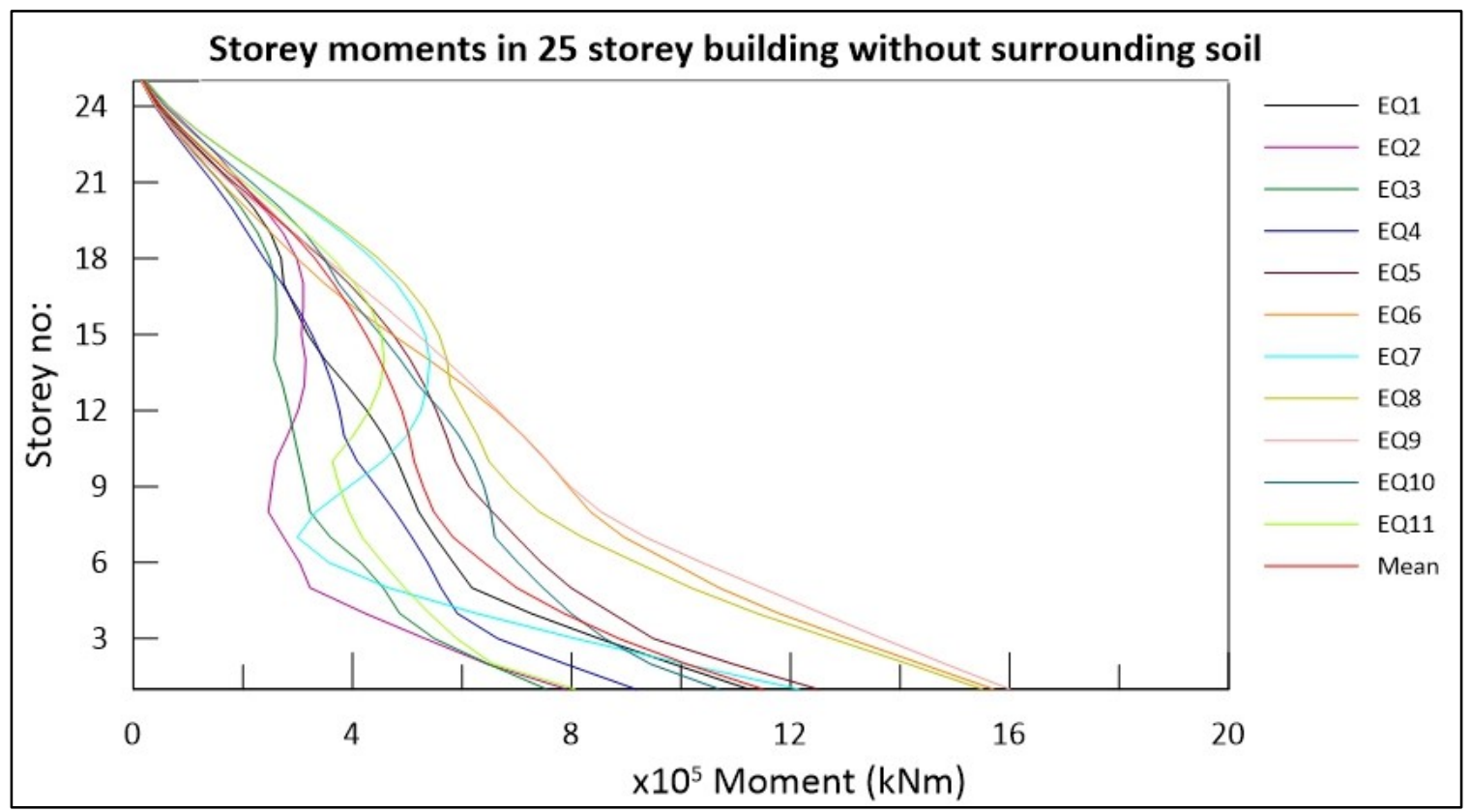

Figure B-182 Storey moments in 25storey building without any surrounding soil analyzed for 11 earthquake inputs compatible with Vancouver site B spectrum 


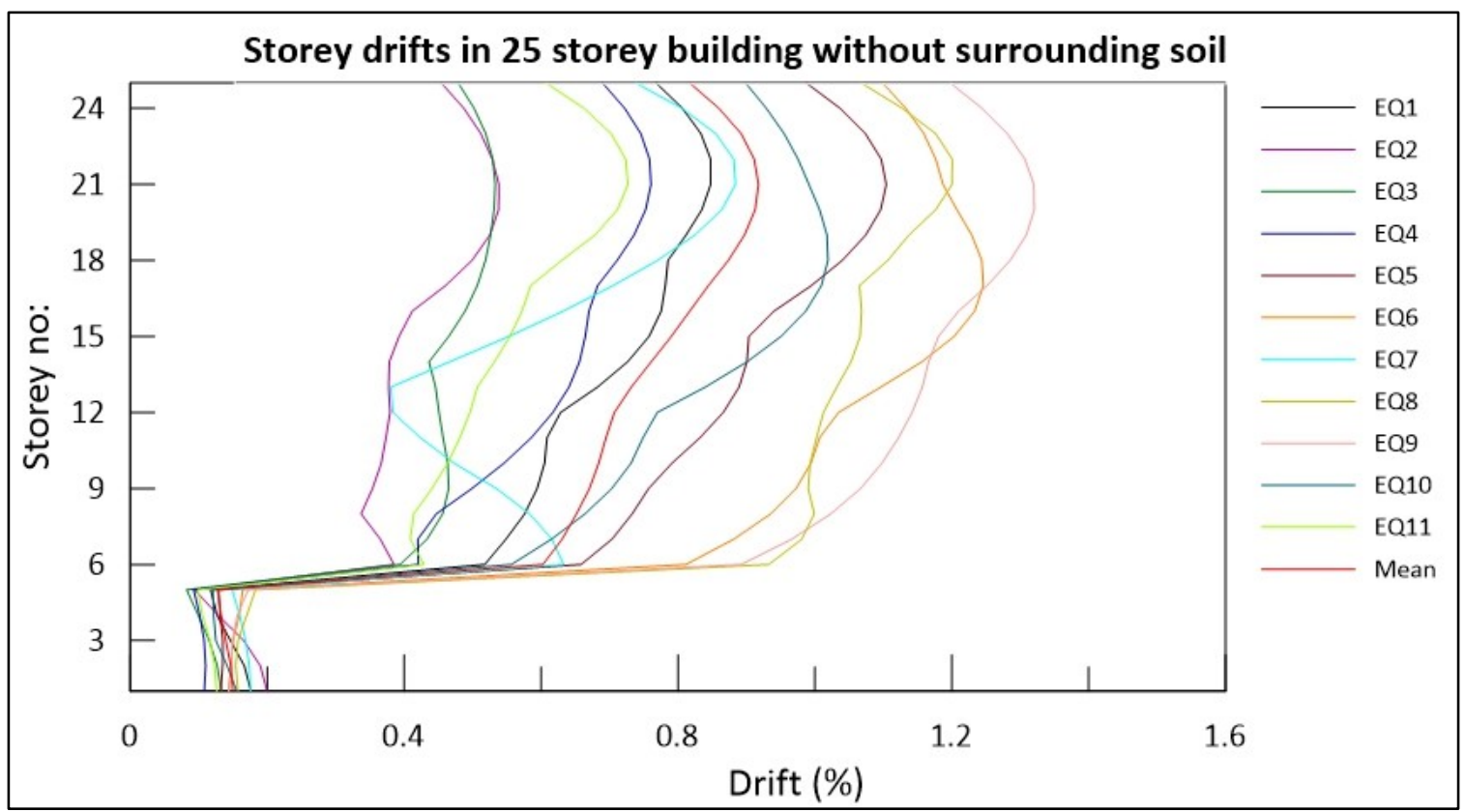

Figure B-183 Storey drifts in 25storey building without any surrounding soil analyzed for 11 earthquake inputs compatible with Vancouver site B spectrum

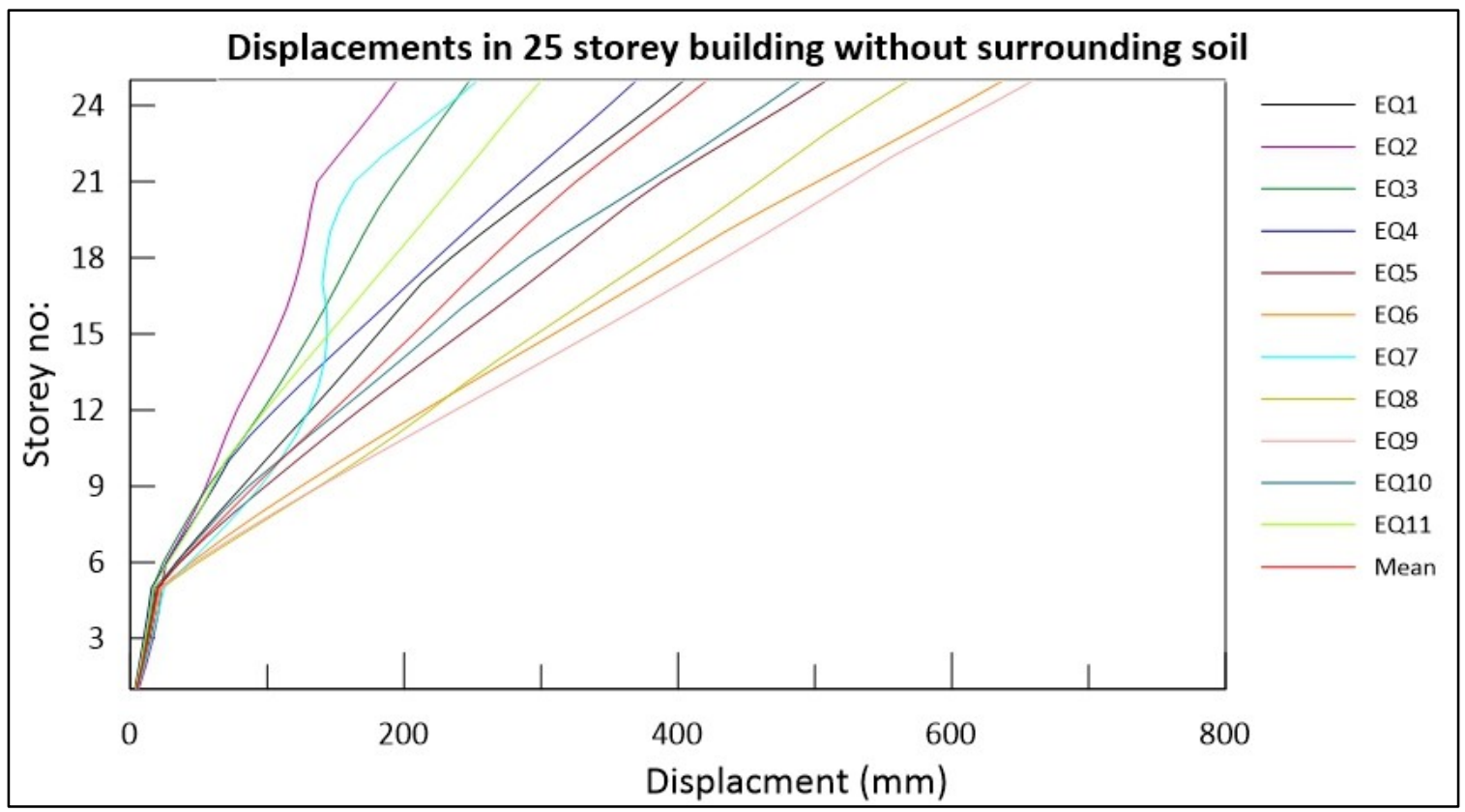

Figure B-184 Displacements in 25storey building without any surrounding soil analyzed for 11 earthquake inputs compatible with Vancouver site B spectrum 


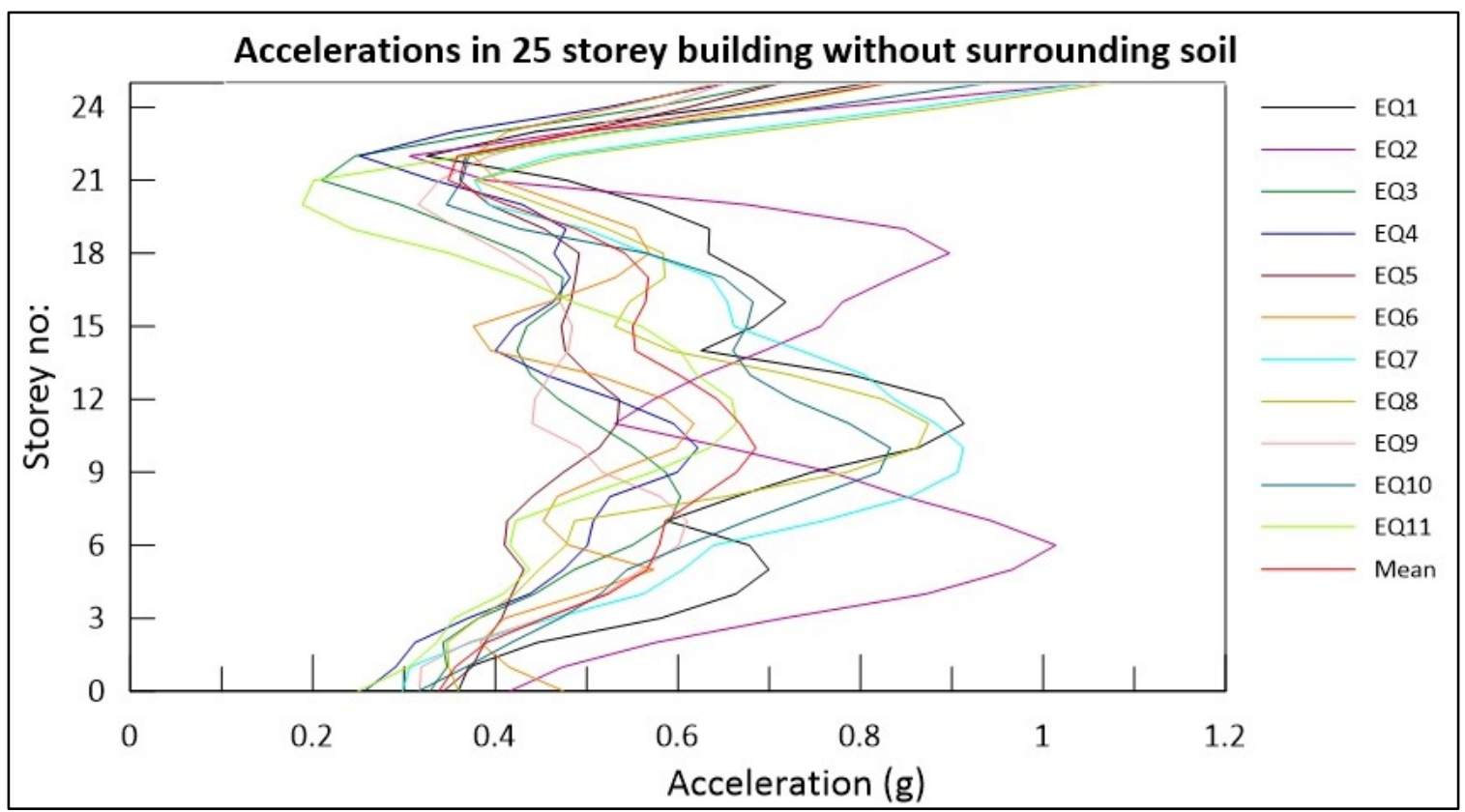

Figure B-185 Accelerations in 25storey building without any surrounding soil analyzed for 11 earthquake inputs compatible with Vancouver site B spectrum

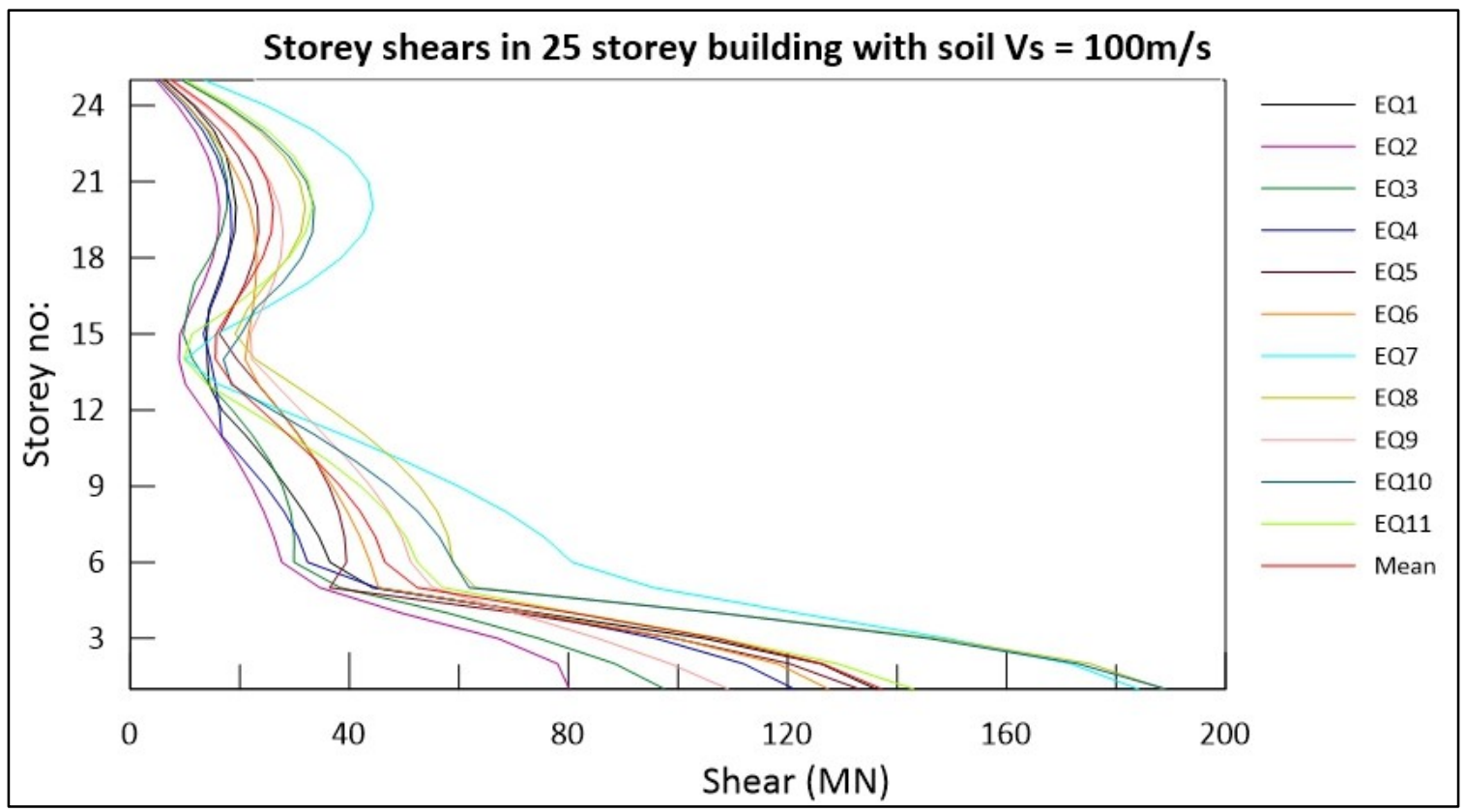

Figure B-186 Storey shears in 25storey building with soil shear wave velocity, Vs $=100 \mathrm{~m} / \mathrm{s}$ analyzed for 11 earthquake inputs compatible with Vancouver site B spectrum 


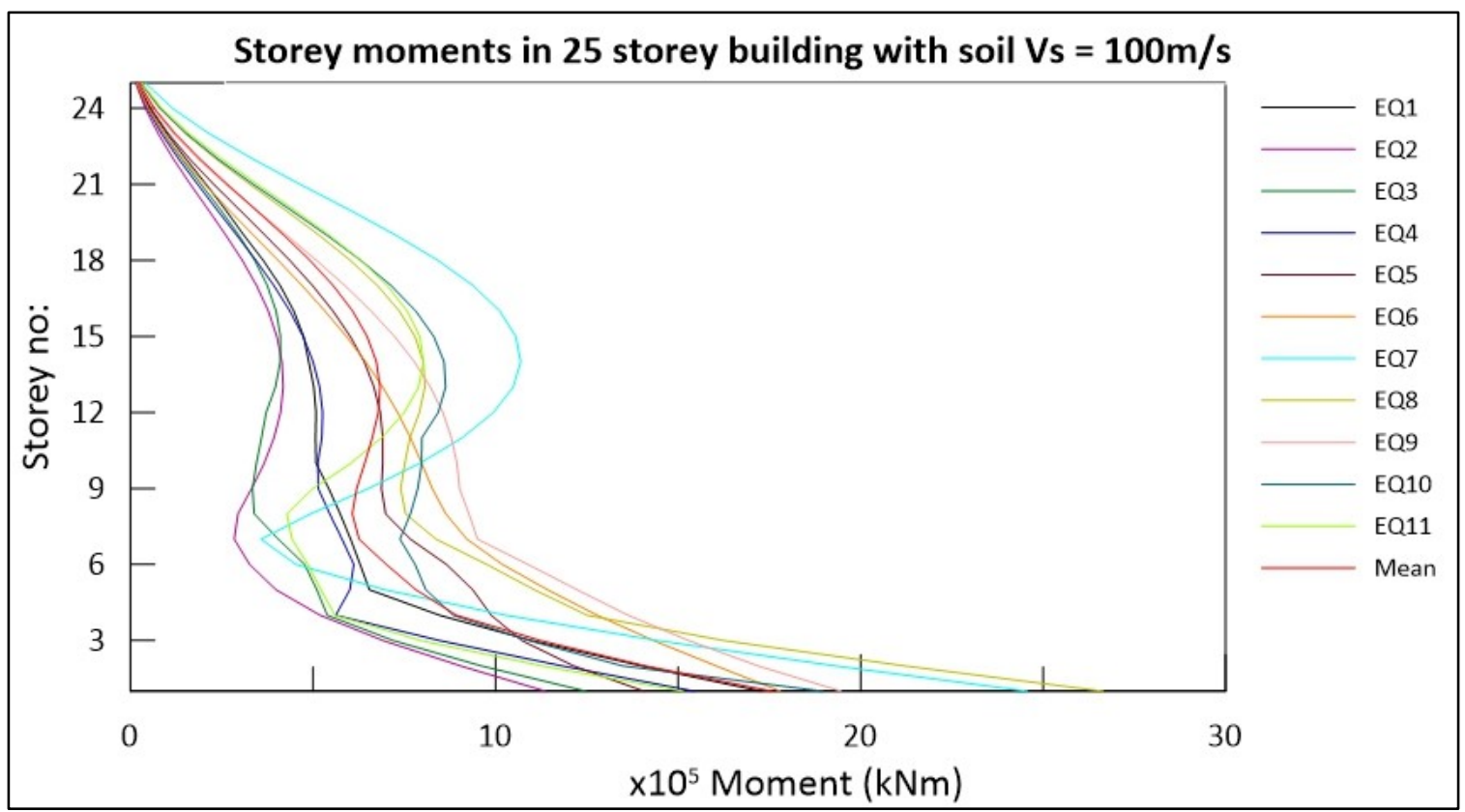

Figure B-187 Storey moments in 25storey building with soil shear wave velocity, Vs $=100 \mathrm{~m} / \mathrm{s}$ analyzed for 11 earthquake inputs compatible with Vancouver site B spectrum

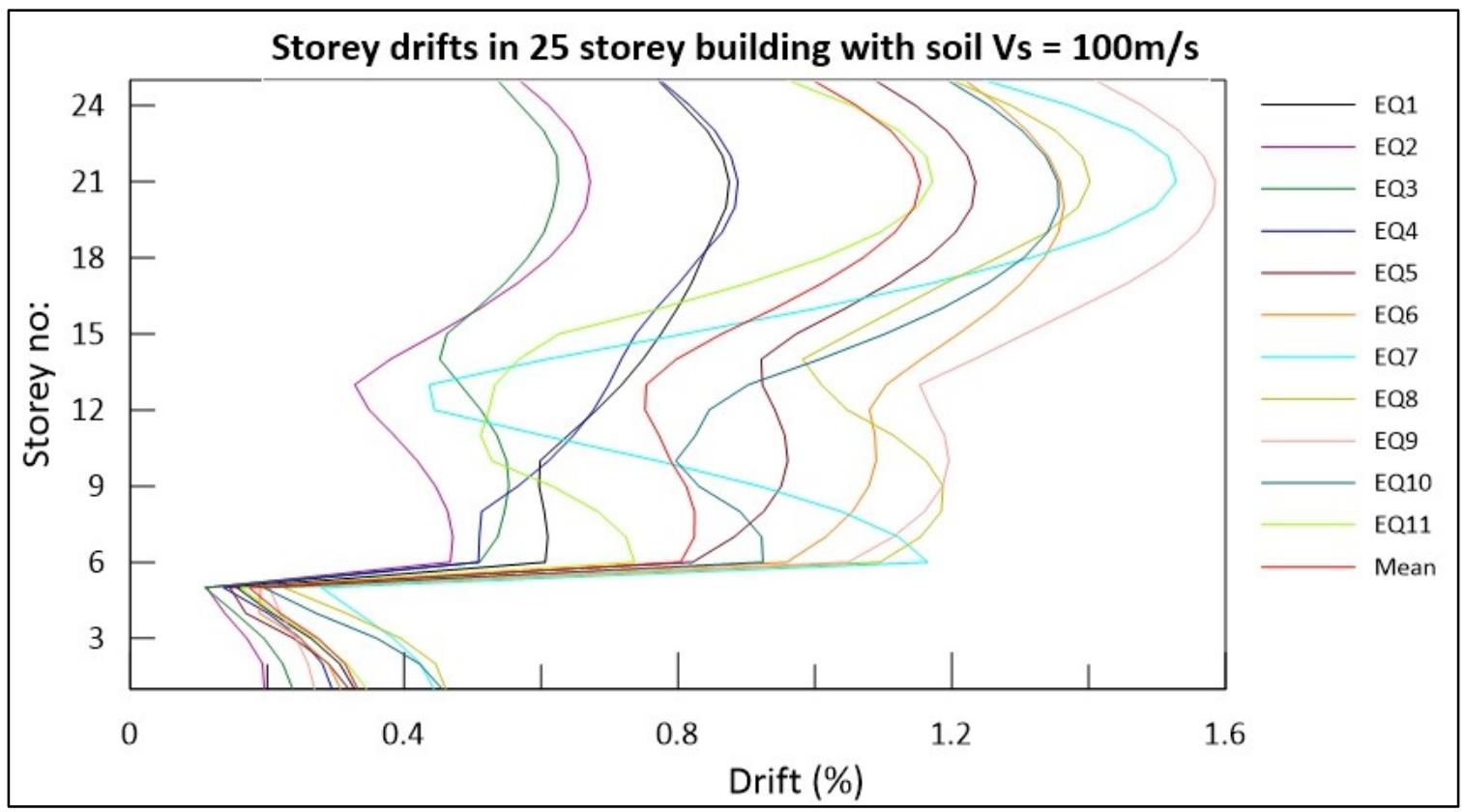

Figure B-188 Storey drifts in 25storey building with soil shear wave velocity, Vs $=100 \mathrm{~m} / \mathrm{s}$ analyzed for 11 earthquake inputs compatible with Vancouver site B spectrum 


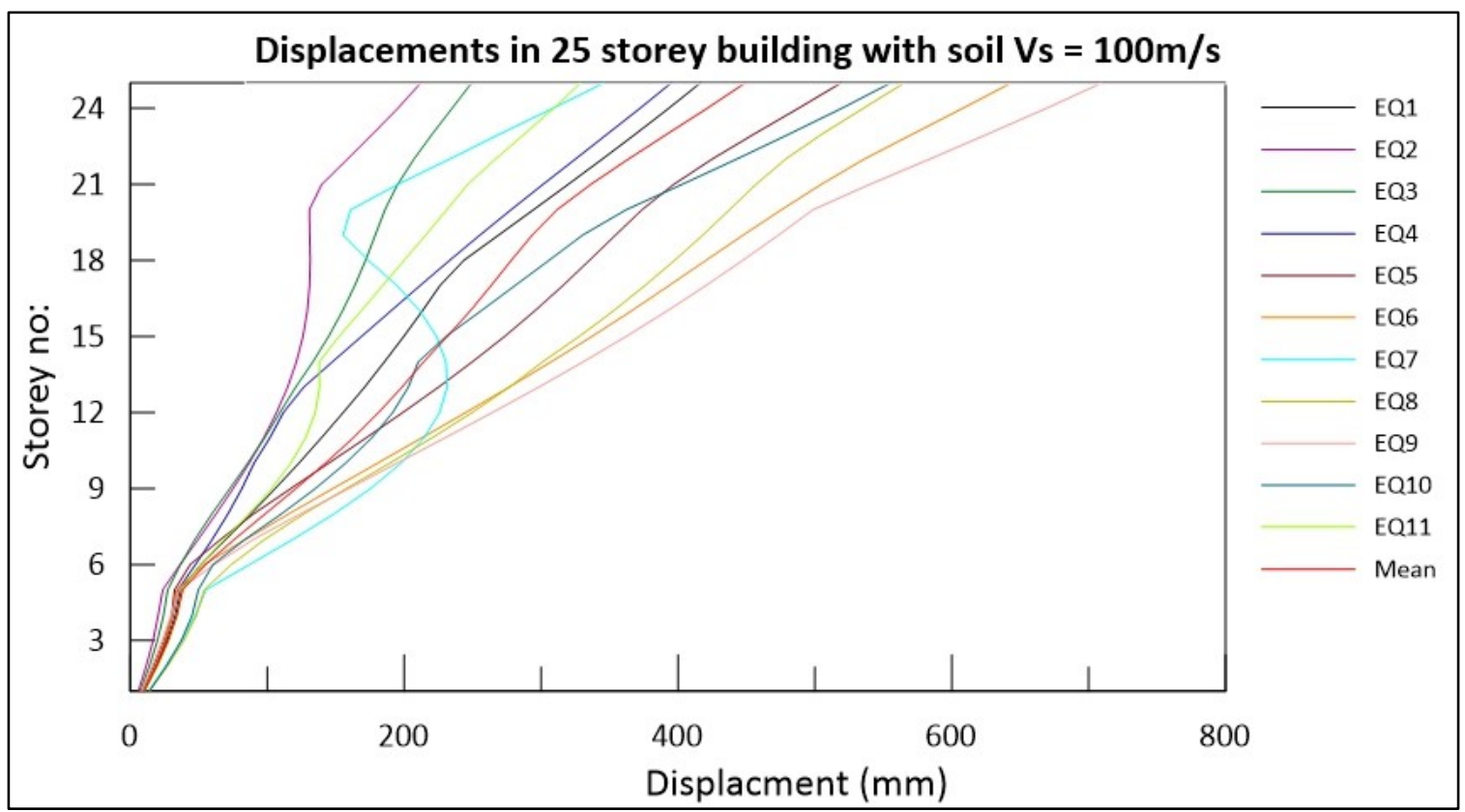

Figure B-189 Displacements in 25storey building with soil shear wave velocity, Vs $=100 \mathrm{~m} / \mathrm{s}$ analyzed for 11 earthquake inputs compatible with Vancouver site B spectrum

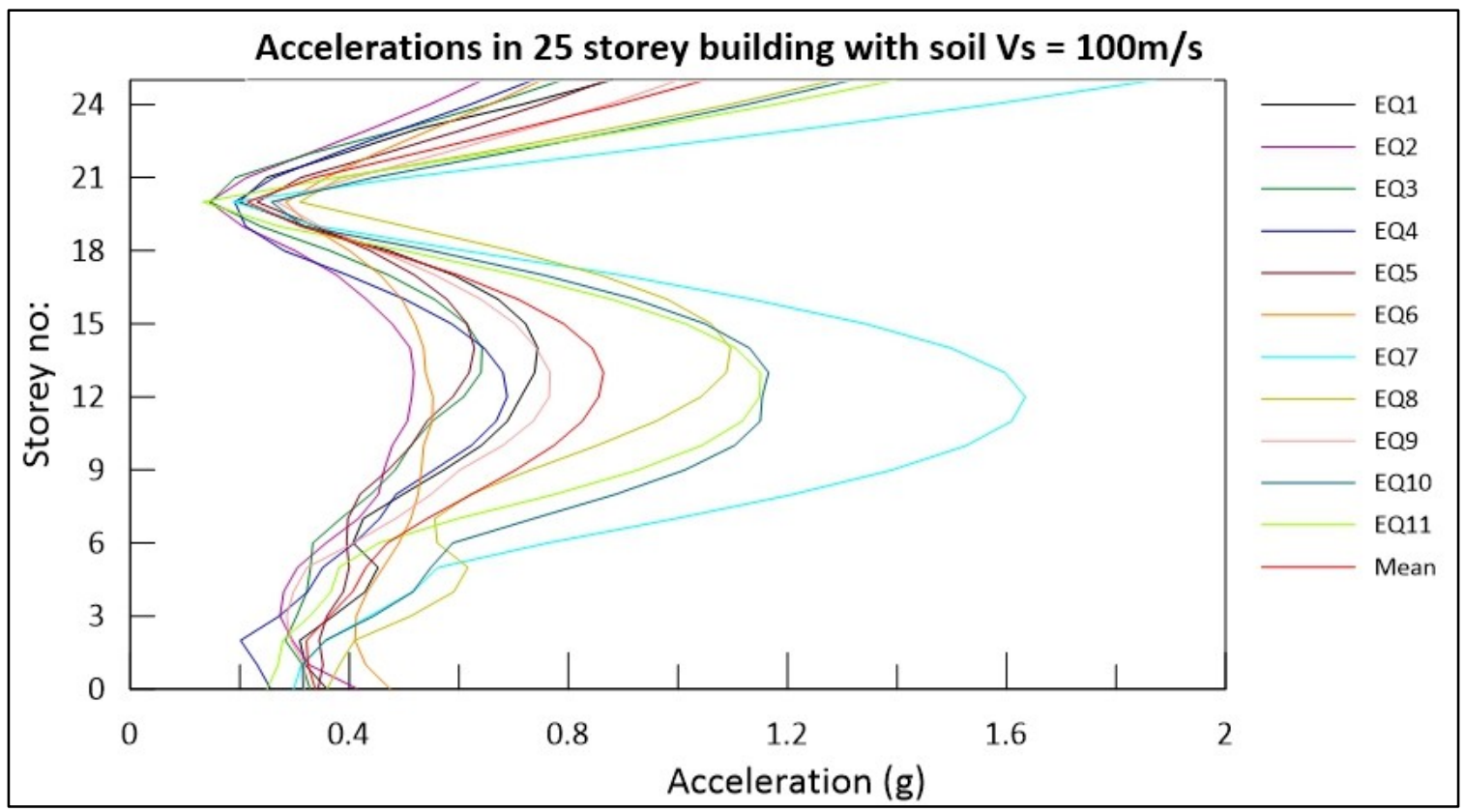

Figure B-190 Accelerations in 25storey building with soil shear wave velocity, Vs $=100 \mathrm{~m} / \mathrm{s}$ analyzed for 11 earthquake inputs compatible with Vancouver site B spectrum 


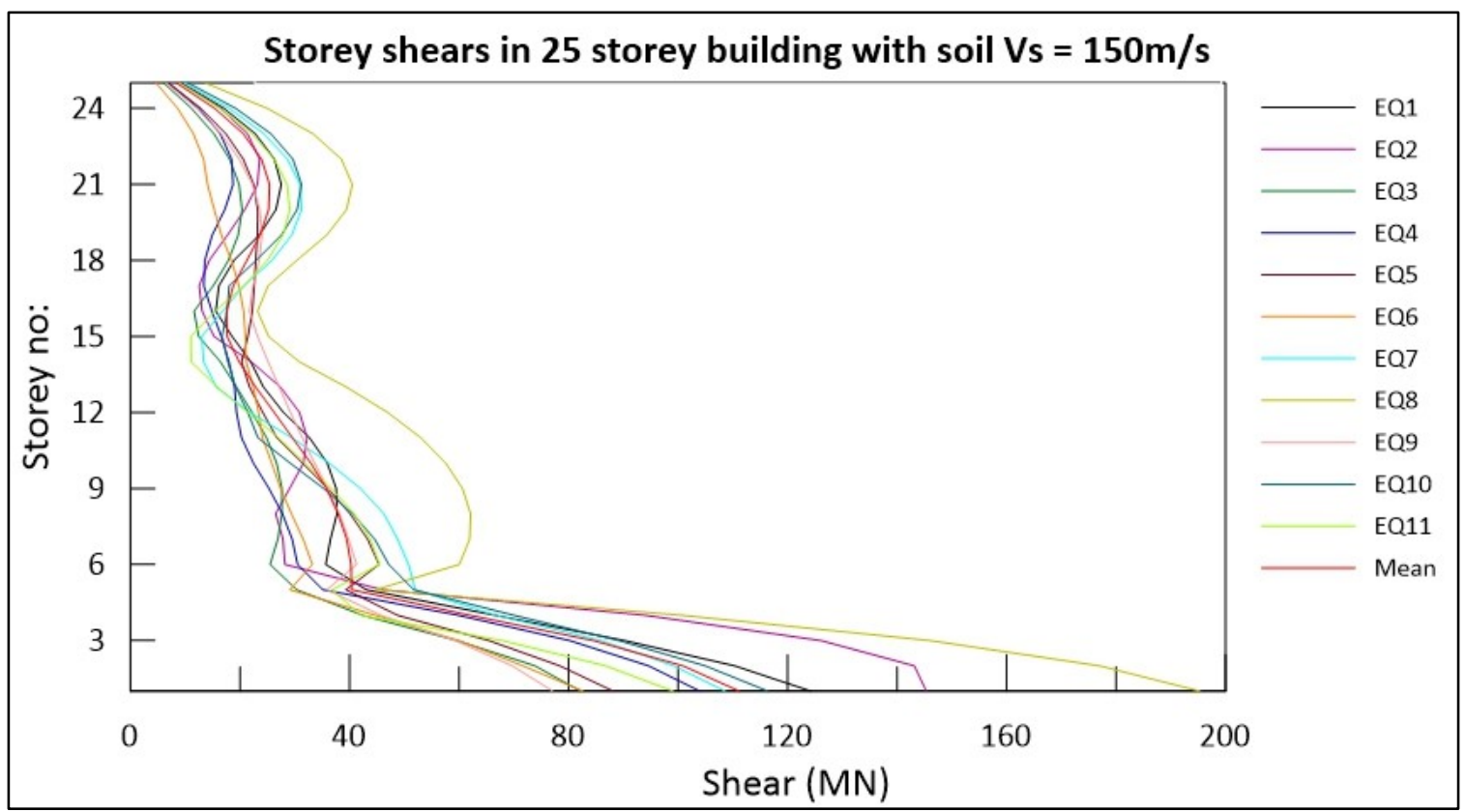

Figure B-191 Storey shears in 25storey building with soil shear wave velocity, Vs $=150 \mathrm{~m} / \mathrm{s}$ analyzed for 11 earthquake inputs compatible with Vancouver site B spectrum

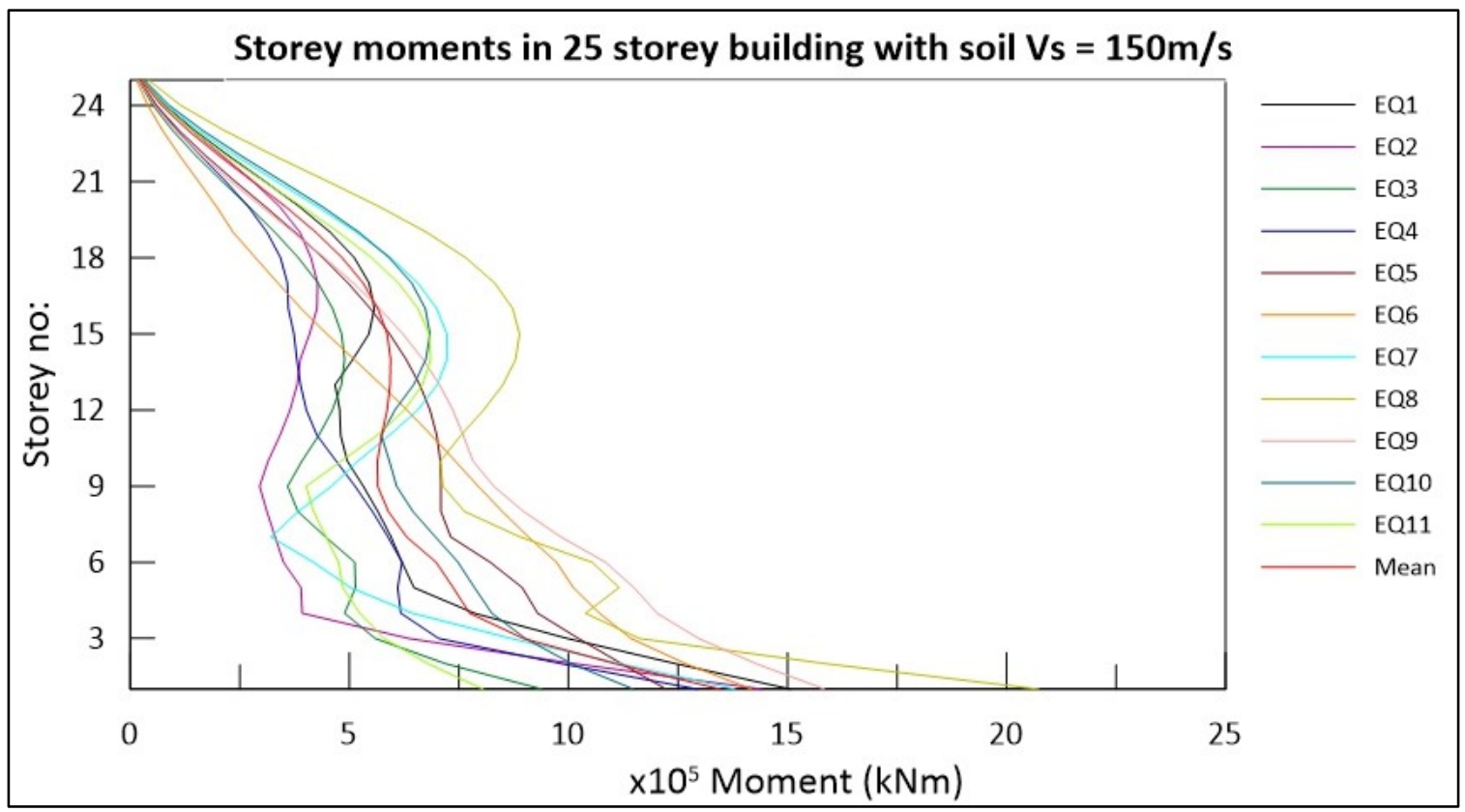

Figure B-192 Storey moments in 25storey building with soil shear wave velocity, Vs $=100 \mathrm{~m} / \mathrm{s}$ analyzed for 11 earthquake inputs compatible with Vancouver site B spectrum 


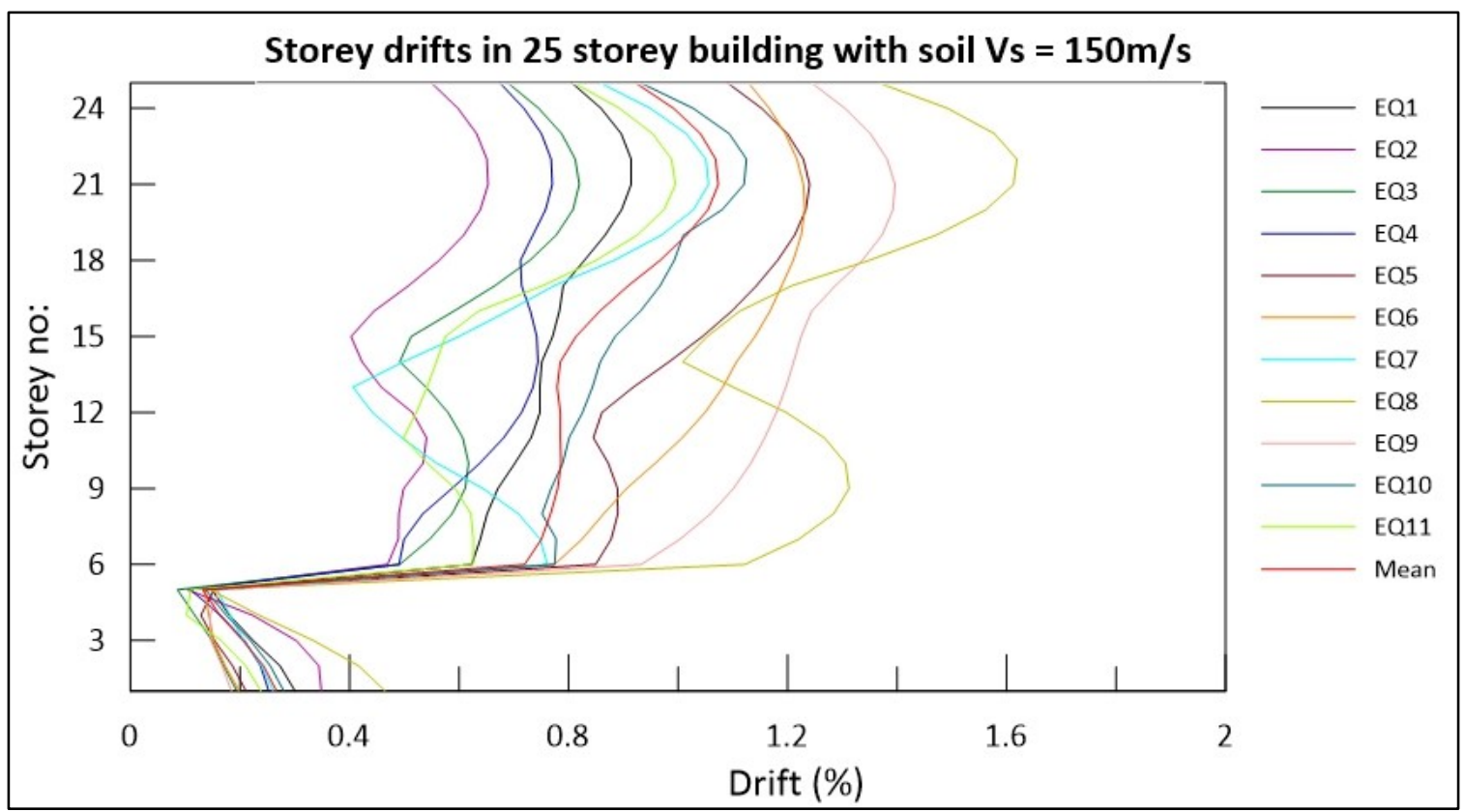

Figure B-193 Storey drifts in 25storey building with soil shear wave velocity, Vs $=150 \mathrm{~m} / \mathrm{s}$ analyzed for 11 earthquake inputs compatible with Vancouver site B spectrum

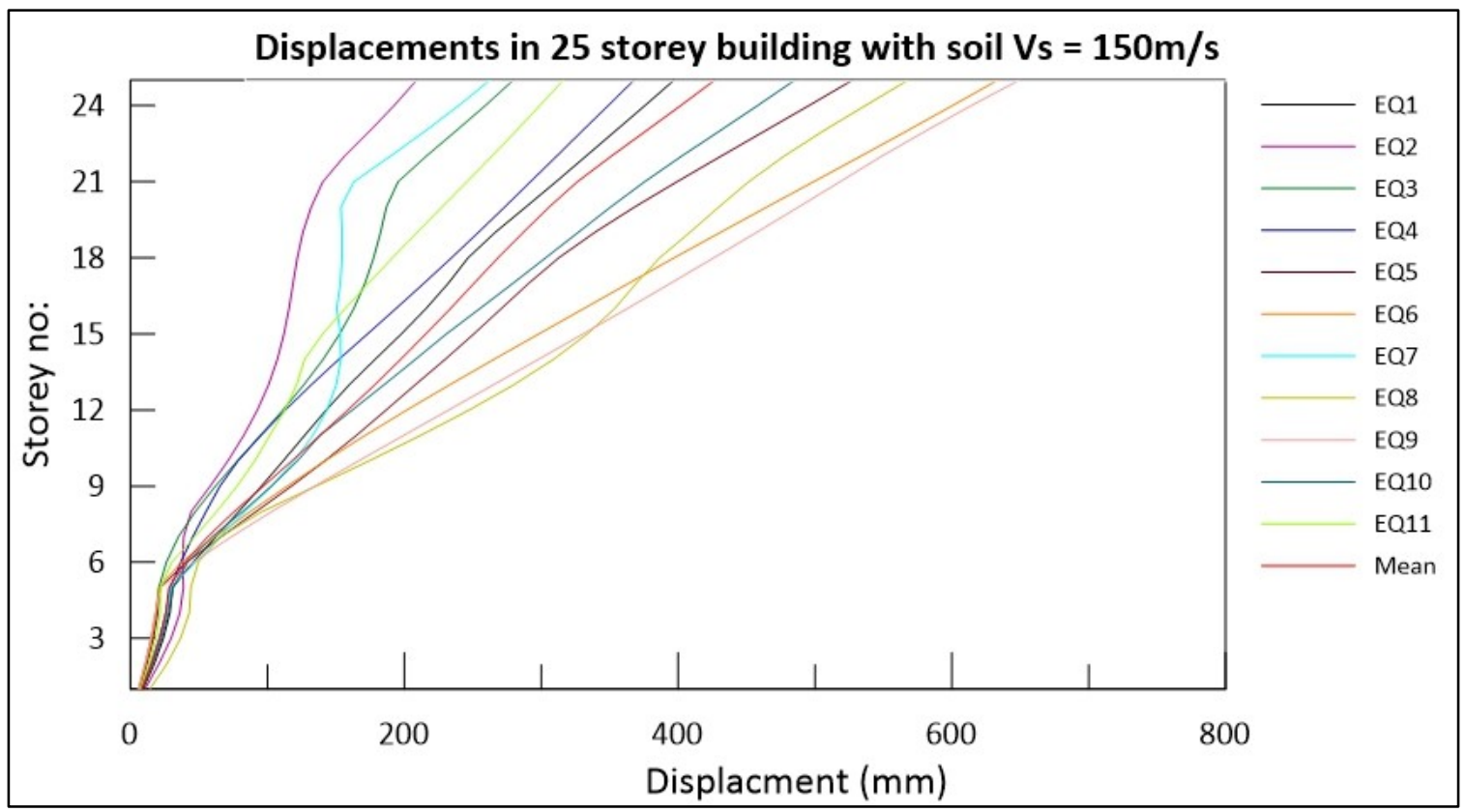

Figure B-194 Displacements in 25storey building with soil shear wave velocity, Vs $=150 \mathrm{~m} / \mathrm{s}$ analyzed for 11 earthquake inputs compatible with Vancouver site B spectrum 


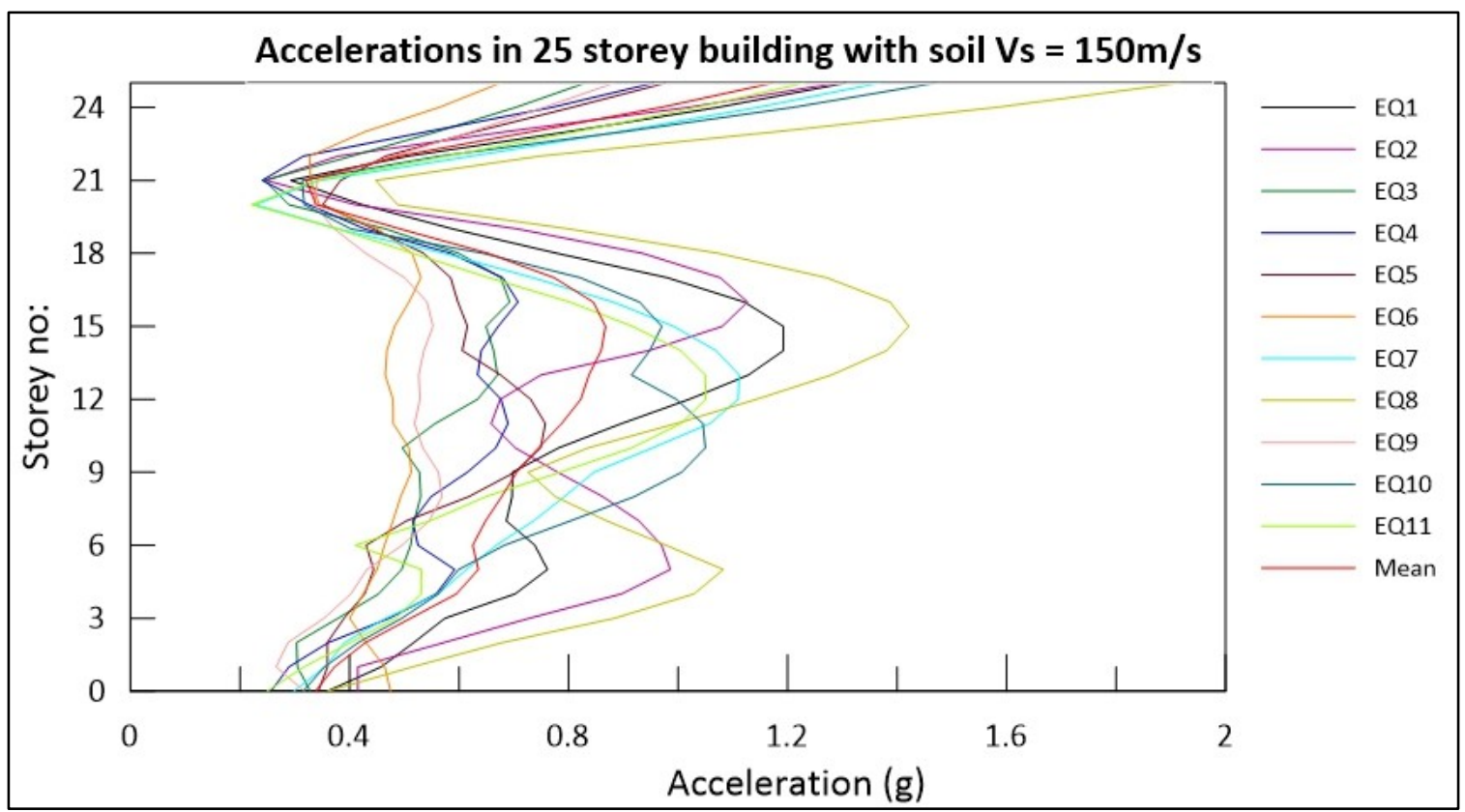

Figure B-195 Accelerations in 25storey building with soil shear wave velocity, Vs $=150 \mathrm{~m} / \mathrm{s}$ analyzed for 11 earthquake inputs compatible with Vancouver site B spectrum

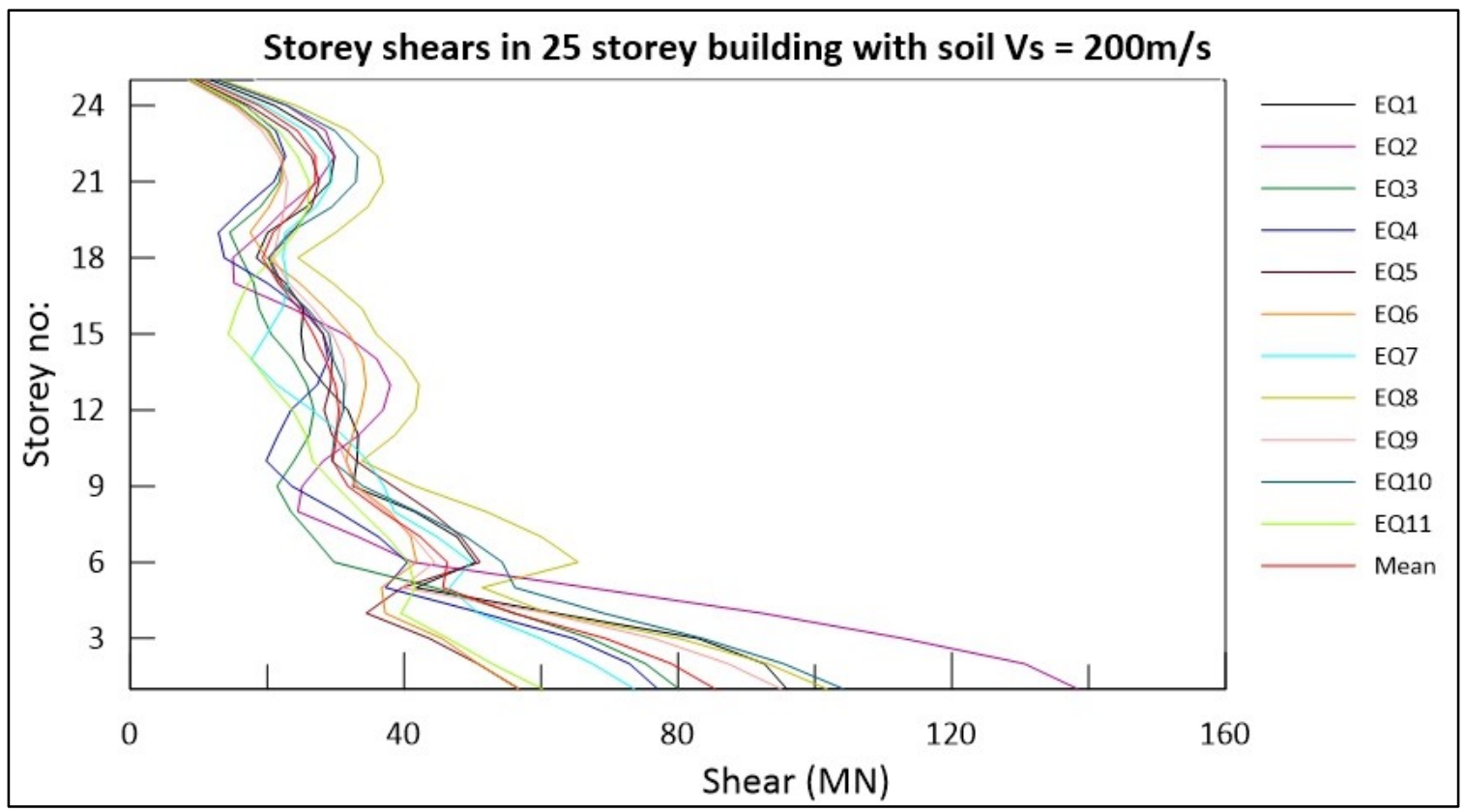

Figure B-196 Storey shears in 25storey building with soil shear wave velocity, Vs = 200m/s analyzed for 11 earthquake inputs compatible with Vancouver site B spectrum 


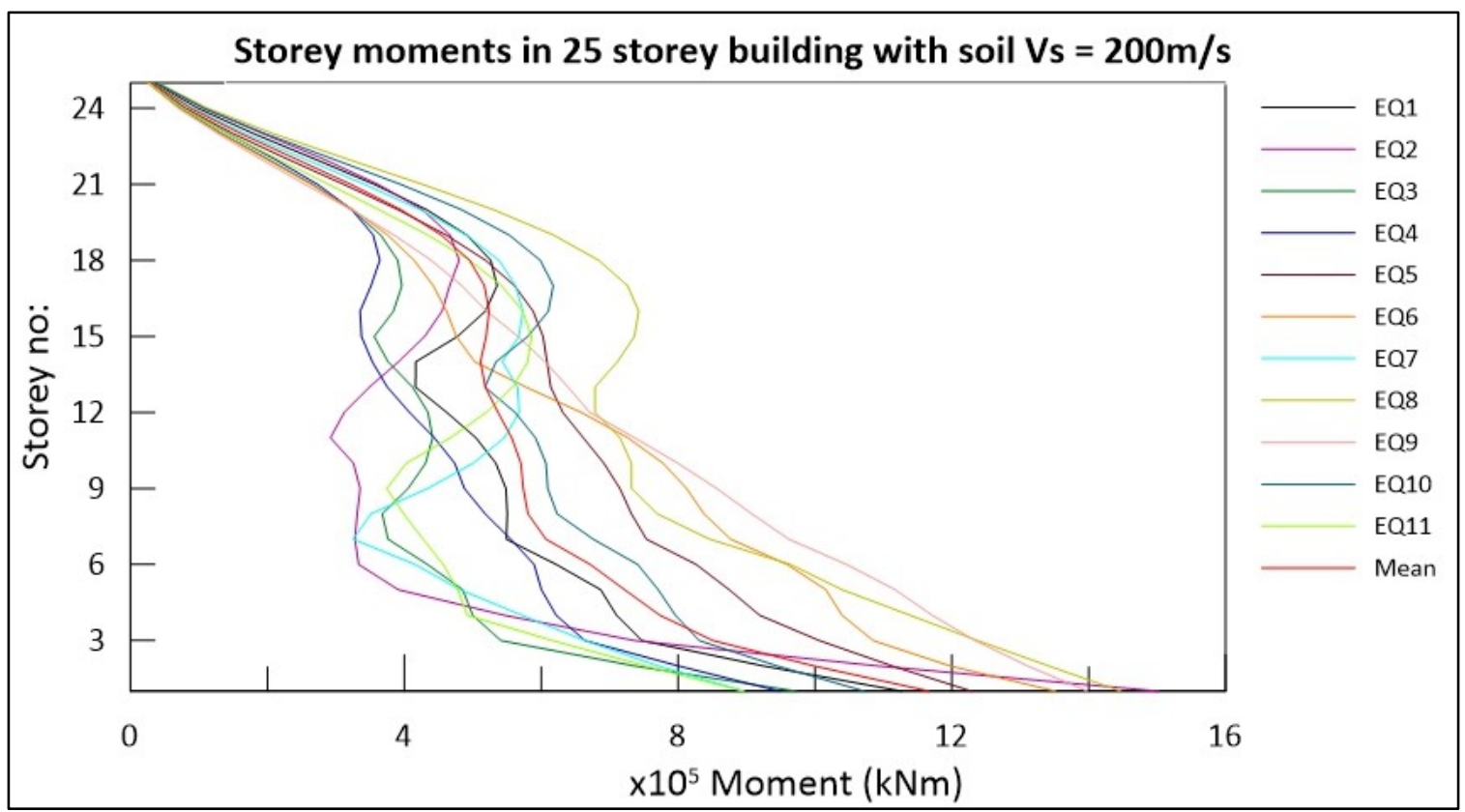

Figure B-197 Storey moments in 25storey building with soil shear wave velocity, Vs $=200 \mathrm{~m} / \mathrm{s}$ analyzed for 11 earthquake inputs compatible with Vancouver site B spectrum

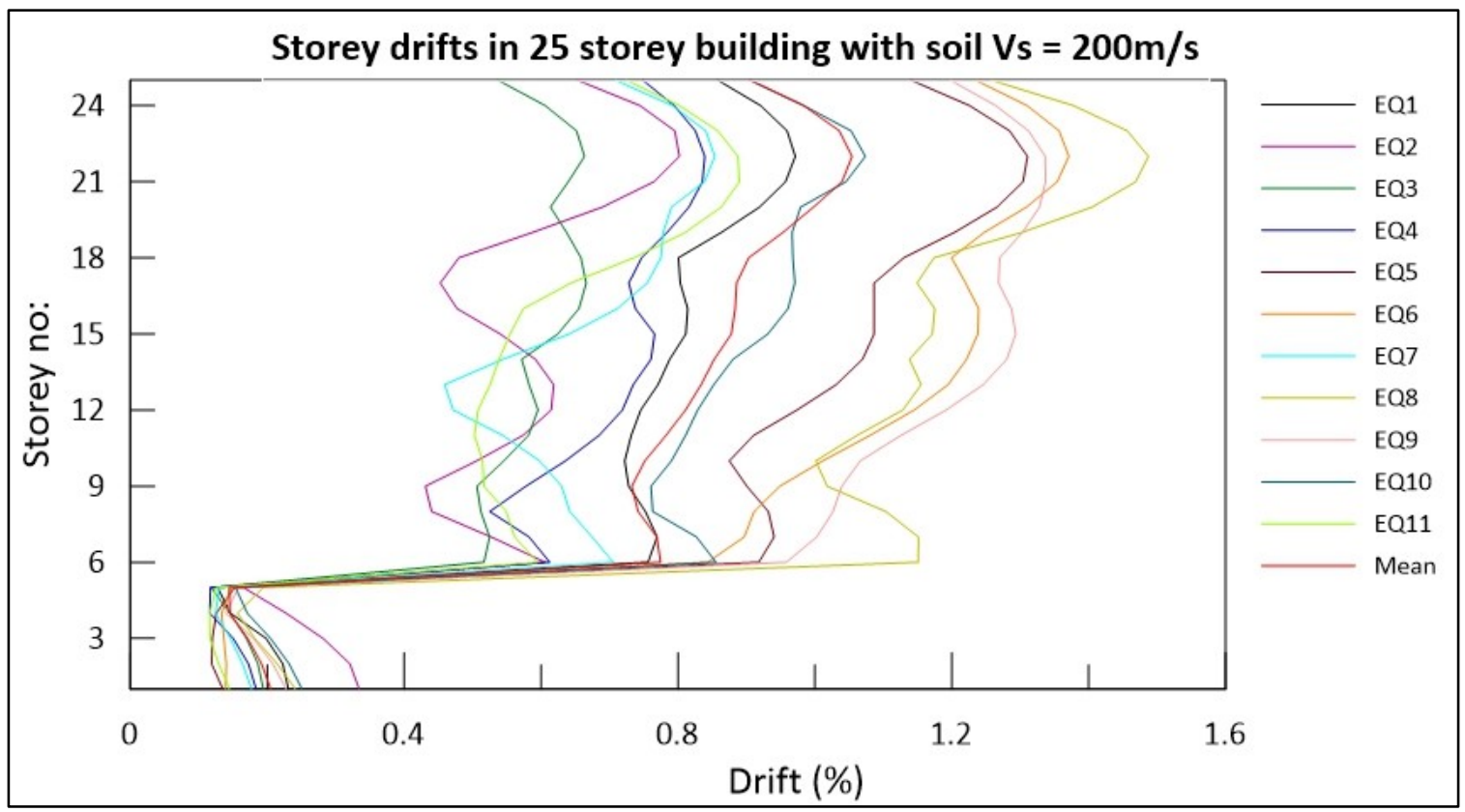

Figure B-198 Storey drifts in 25storey building with soil shear wave velocity, Vs =200m/s analyzed for 11 earthquake inputs compatible with Vancouver site B spectrum 


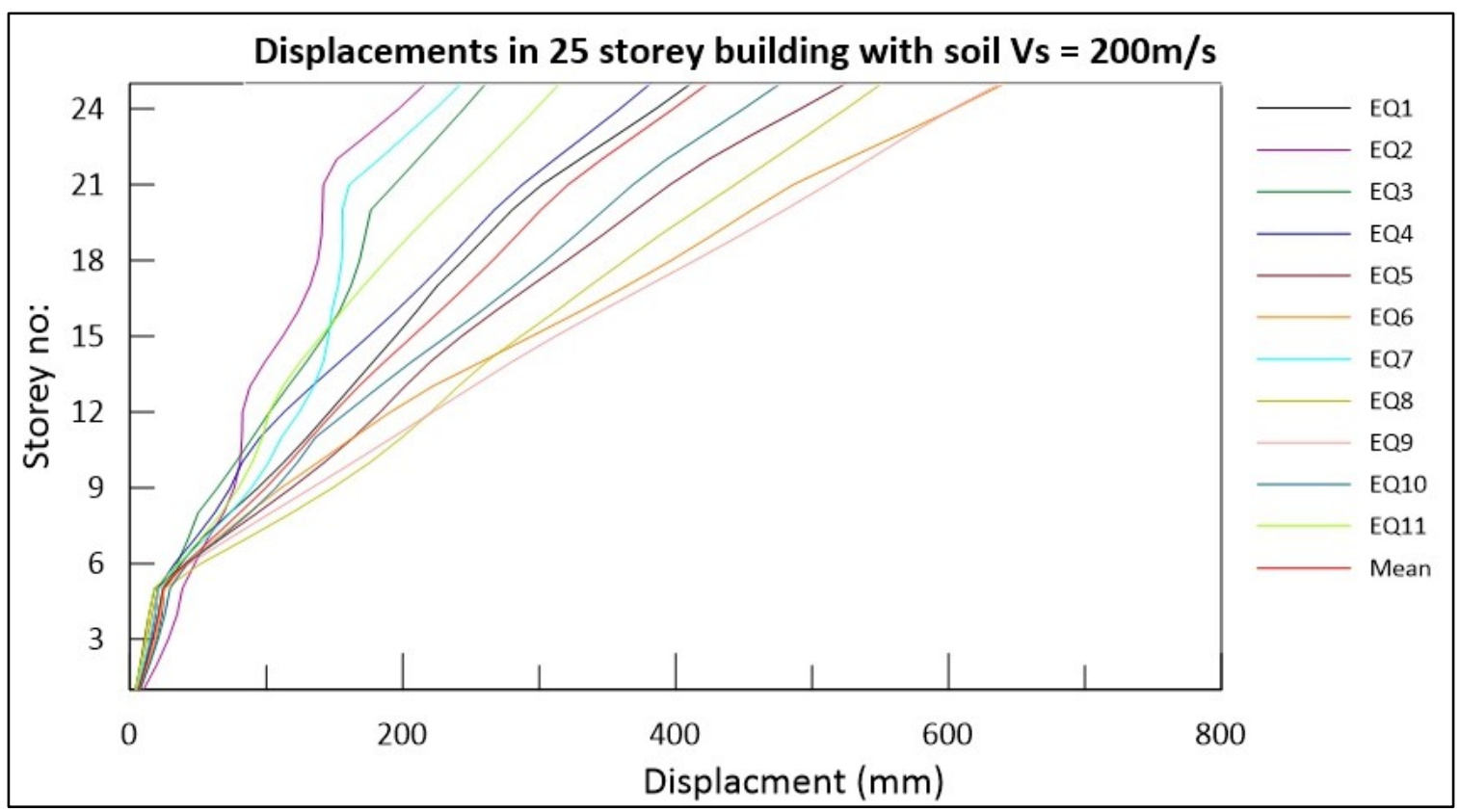

Figure B-199 Displacements in 25storey building with soil shear wave velocity, Vs $=200 \mathrm{~m} / \mathrm{s}$ analyzed for 11 earthquake inputs compatible with Vancouver site B spectrum

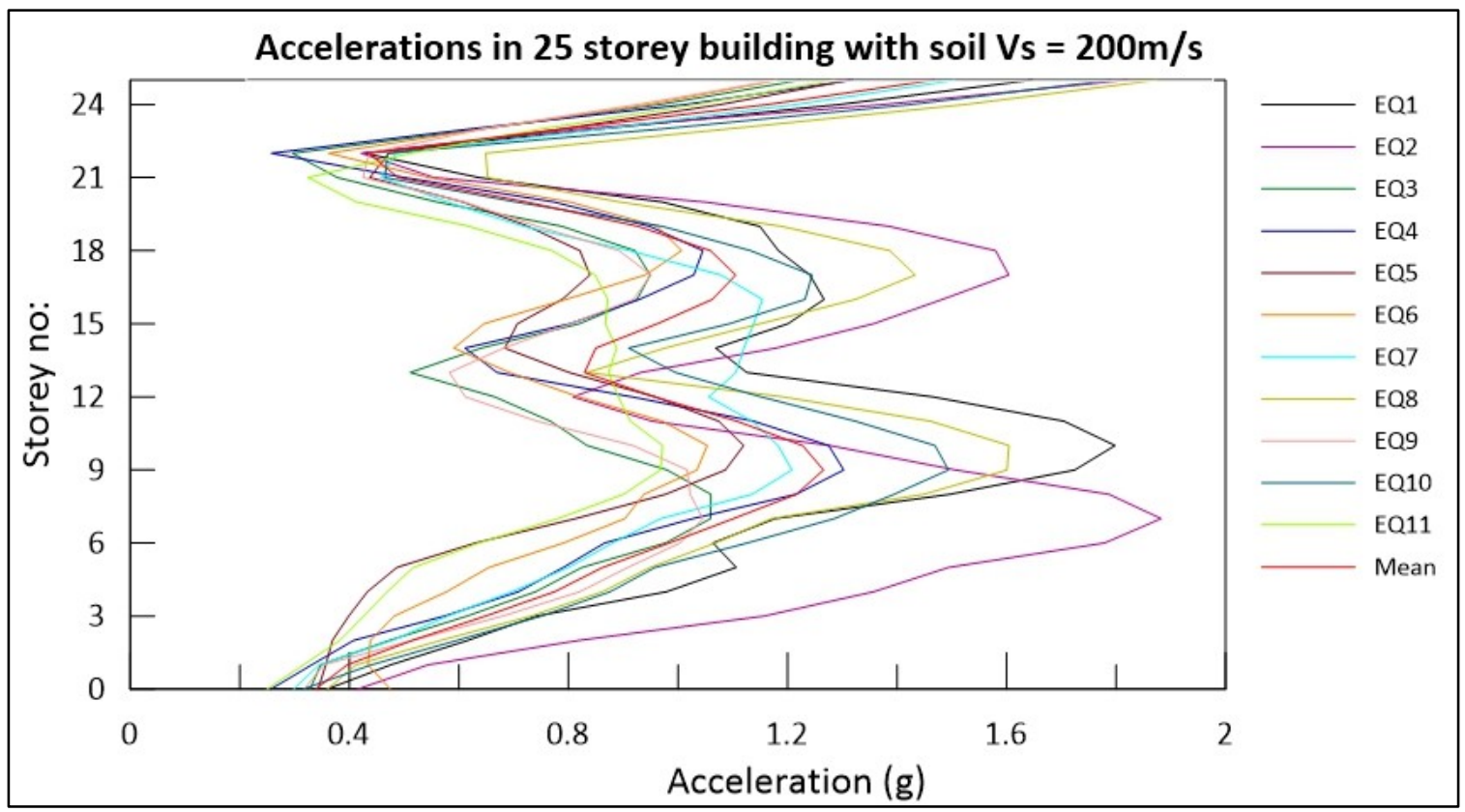

Figure B-200 Accelerations in 25storey building with soil shear wave velocity, Vs $=200 \mathrm{~m} / \mathrm{s}$ analyzed for 11 earthquake inputs compatible with Vancouver site B spectrum 


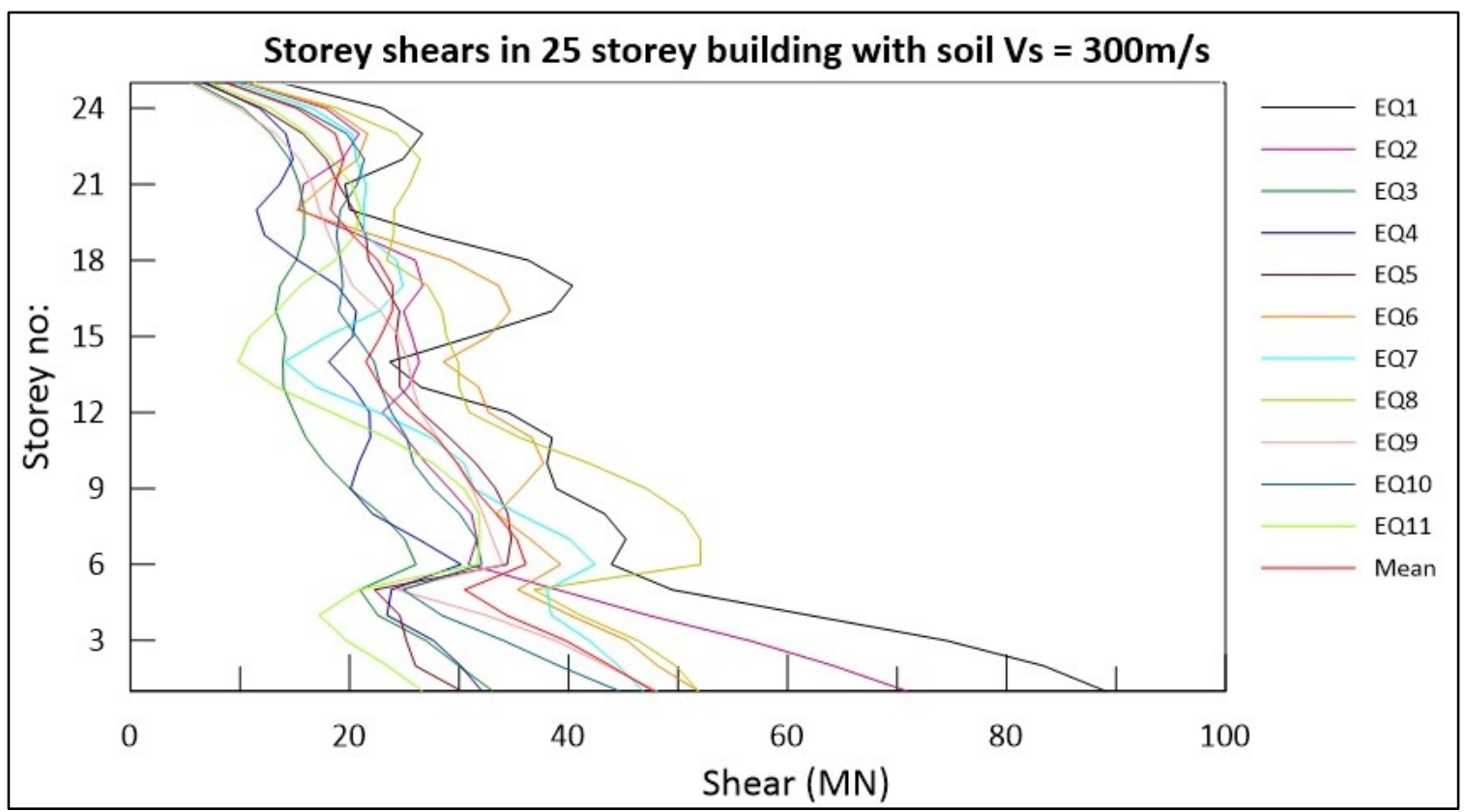

Figure B-201 Storey shears in 25storey building with soil shear wave velocity, Vs $=300 \mathrm{~m} / \mathrm{s}$ analyzed for 11 earthquake inputs compatible with Vancouver site B spectrum

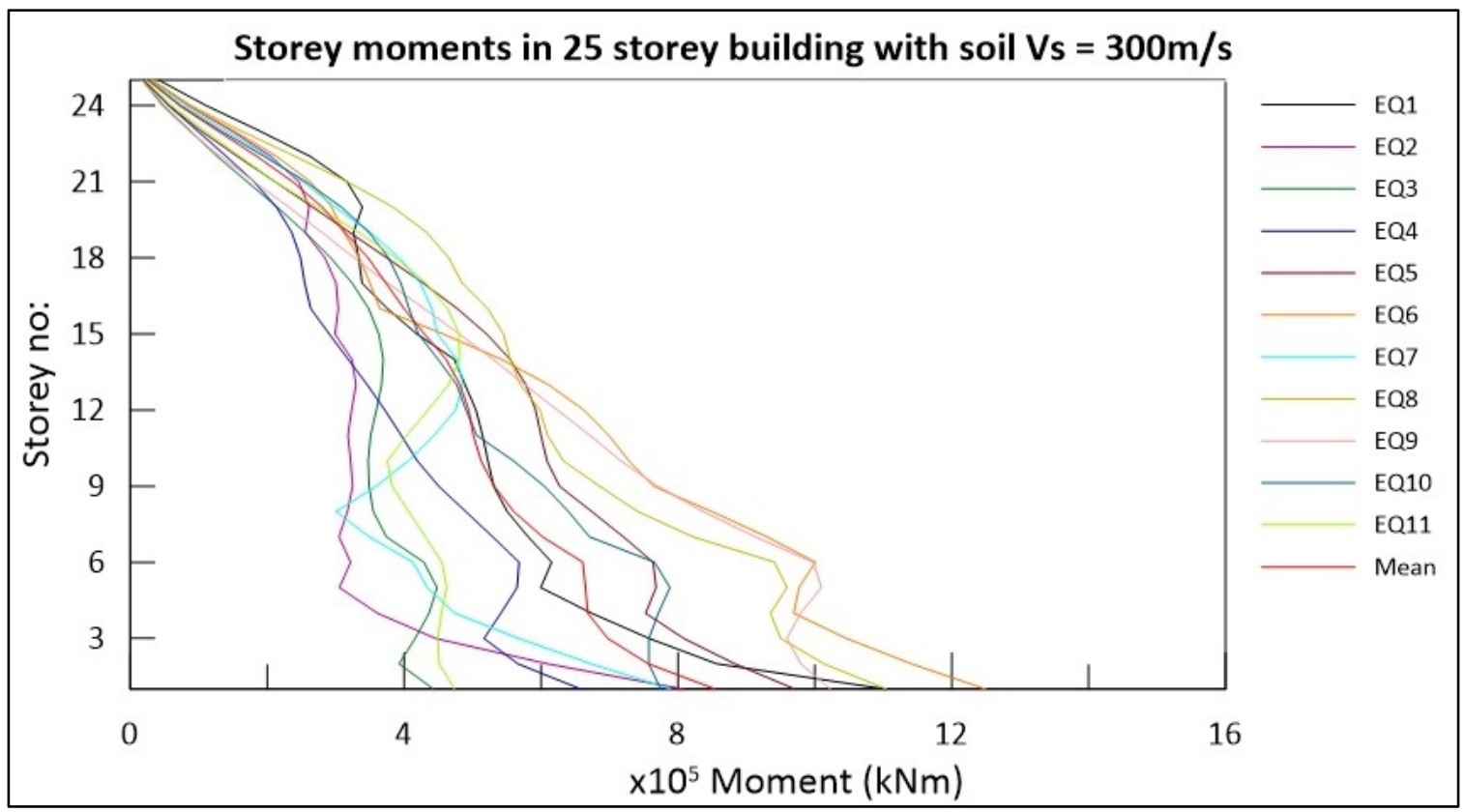

Figure B-202 Storey moments in 25storey building with soil shear wave velocity, Vs $=300 \mathrm{~m} / \mathrm{s}$ analyzed for 11 earthquake inputs compatible with Vancouver site B spectrum 


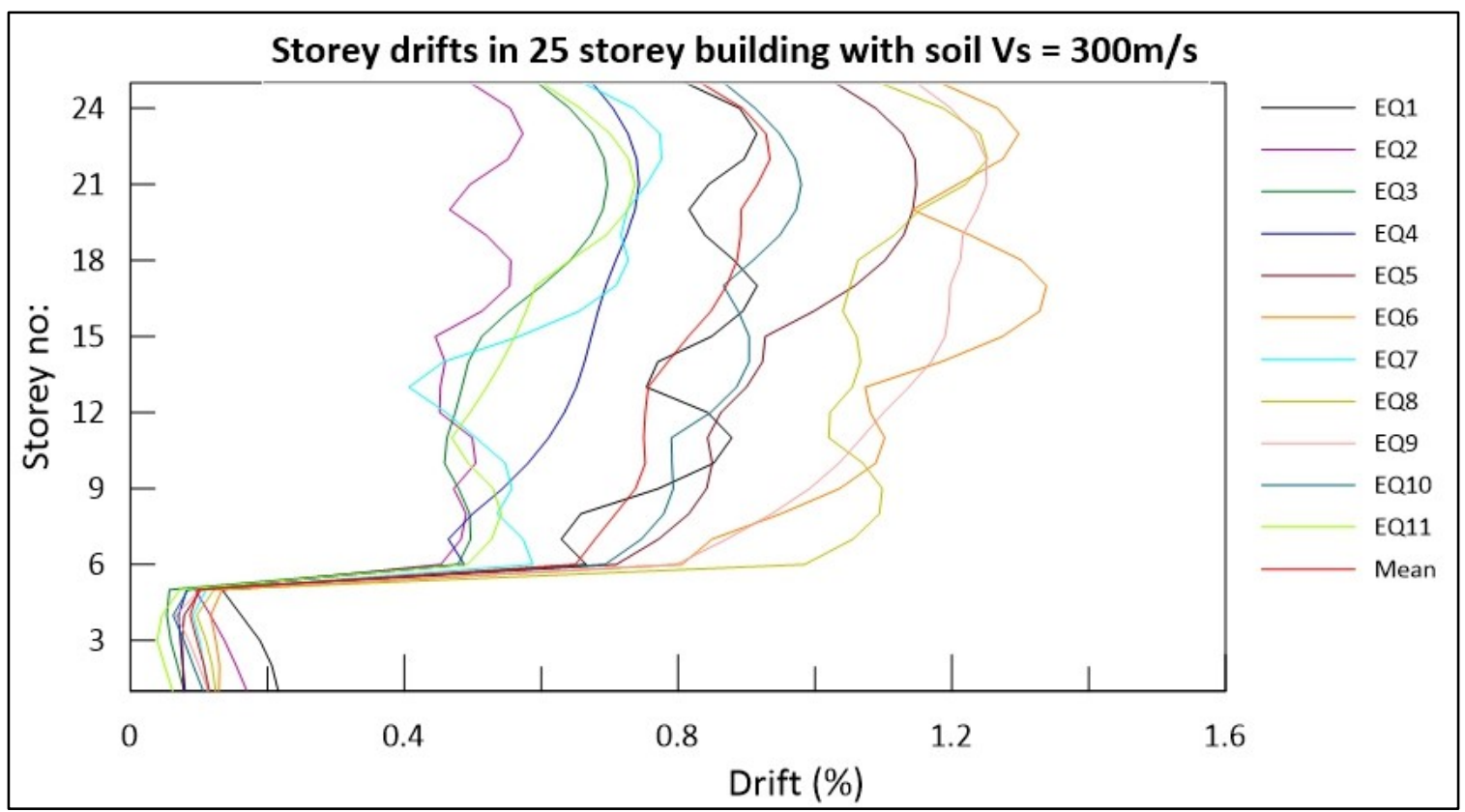

Figure B-203 Storey drifts in 25storey building with soil shear wave velocity, Vs $=300 \mathrm{~m} / \mathrm{s}$ analyzed for 11 earthquake inputs compatible with Vancouver site B spectrum

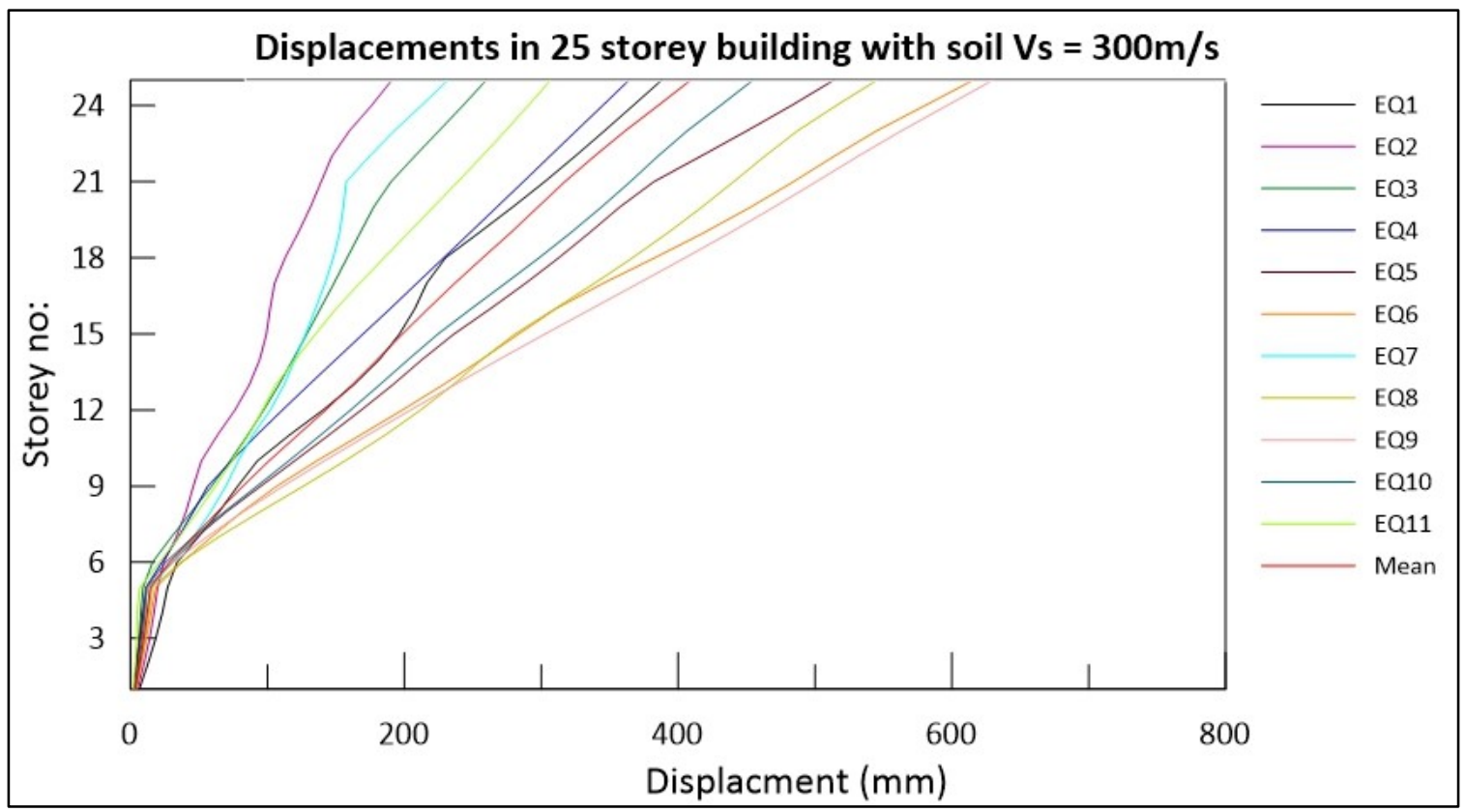

Figure B-204 Displacements in 25storey building with soil shear wave velocity, Vs $=300 \mathrm{~m} / \mathrm{s}$ analyzed for 11 earthquake inputs compatible with Vancouver site B spectrum 


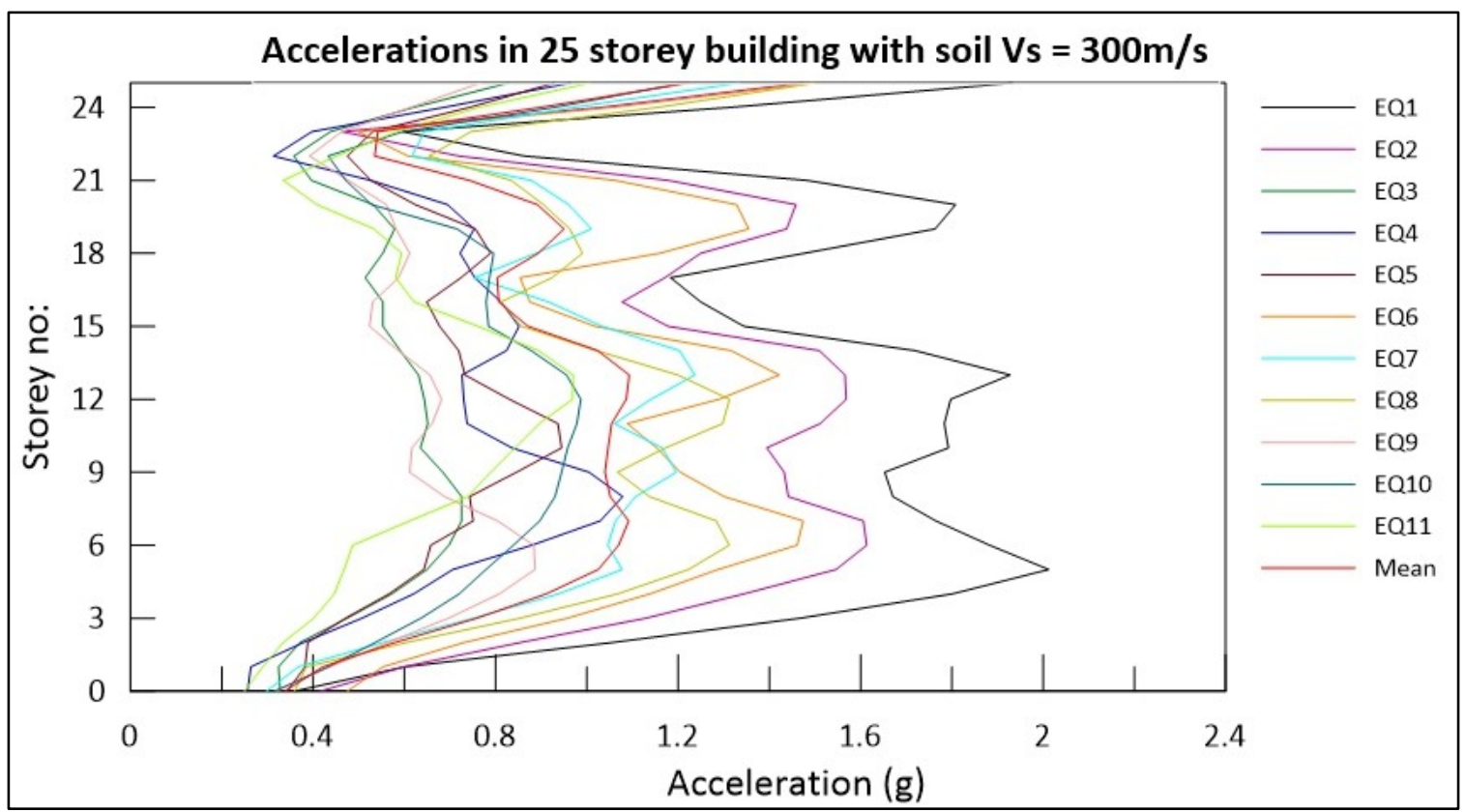

Figure B-205 Accelerations in 25storey building with soil shear wave velocity, Vs $=300 \mathrm{~m} / \mathrm{s}$ analyzed for 11 earthquake inputs compatible with Vancouver site B spectrum

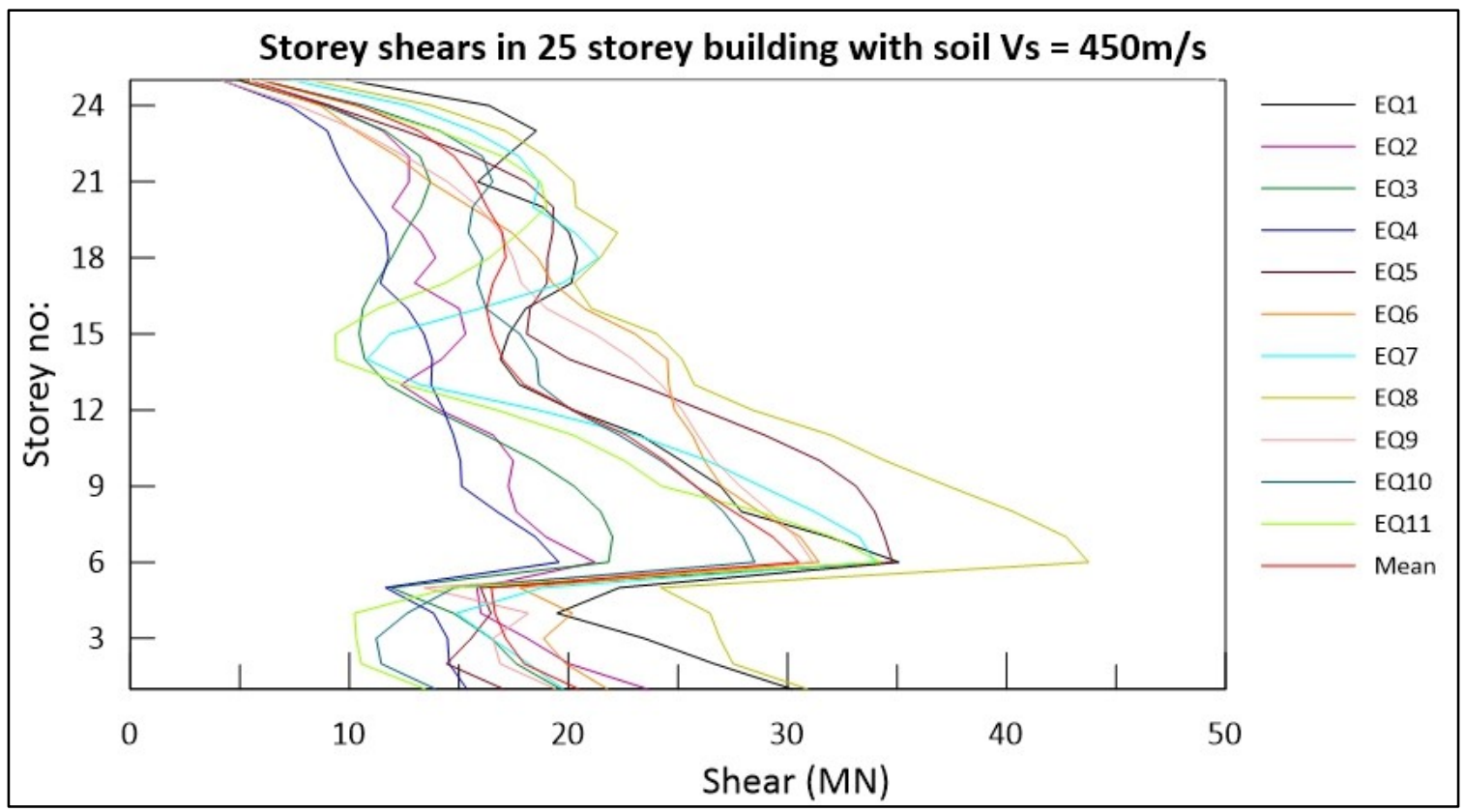

Figure B-206 Storey shears in 25storey building with soil shear wave velocity, Vs $=450 \mathrm{~m} / \mathrm{s}$ analyzed for 11 earthquake inputs compatible with Vancouver site B spectrum 


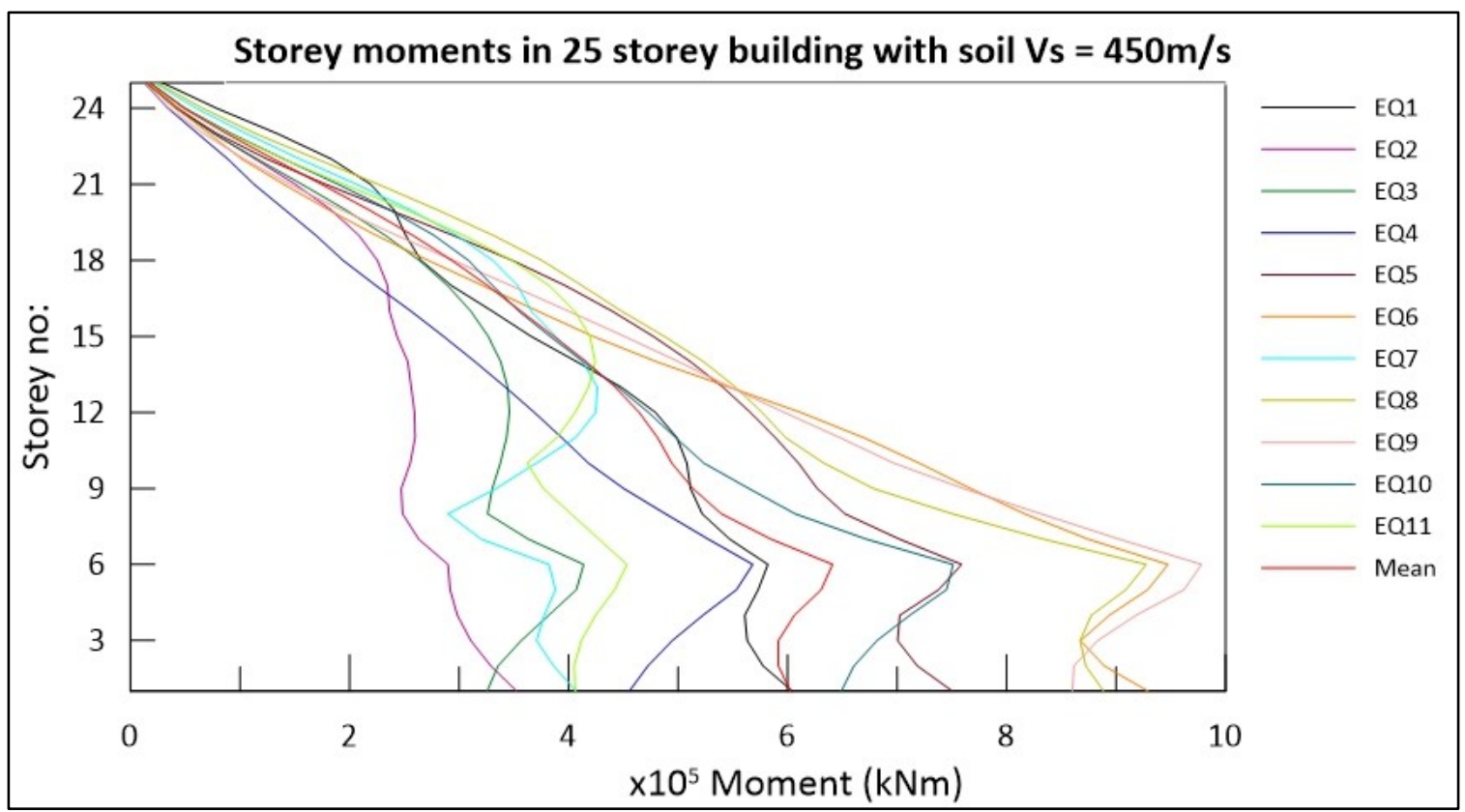

Figure B-207 Storey moments in 25storey building with soil shear wave velocity, Vs $=450 \mathrm{~m} / \mathrm{s}$ analyzed for 11 earthquake inputs compatible with Vancouver site B spectrum

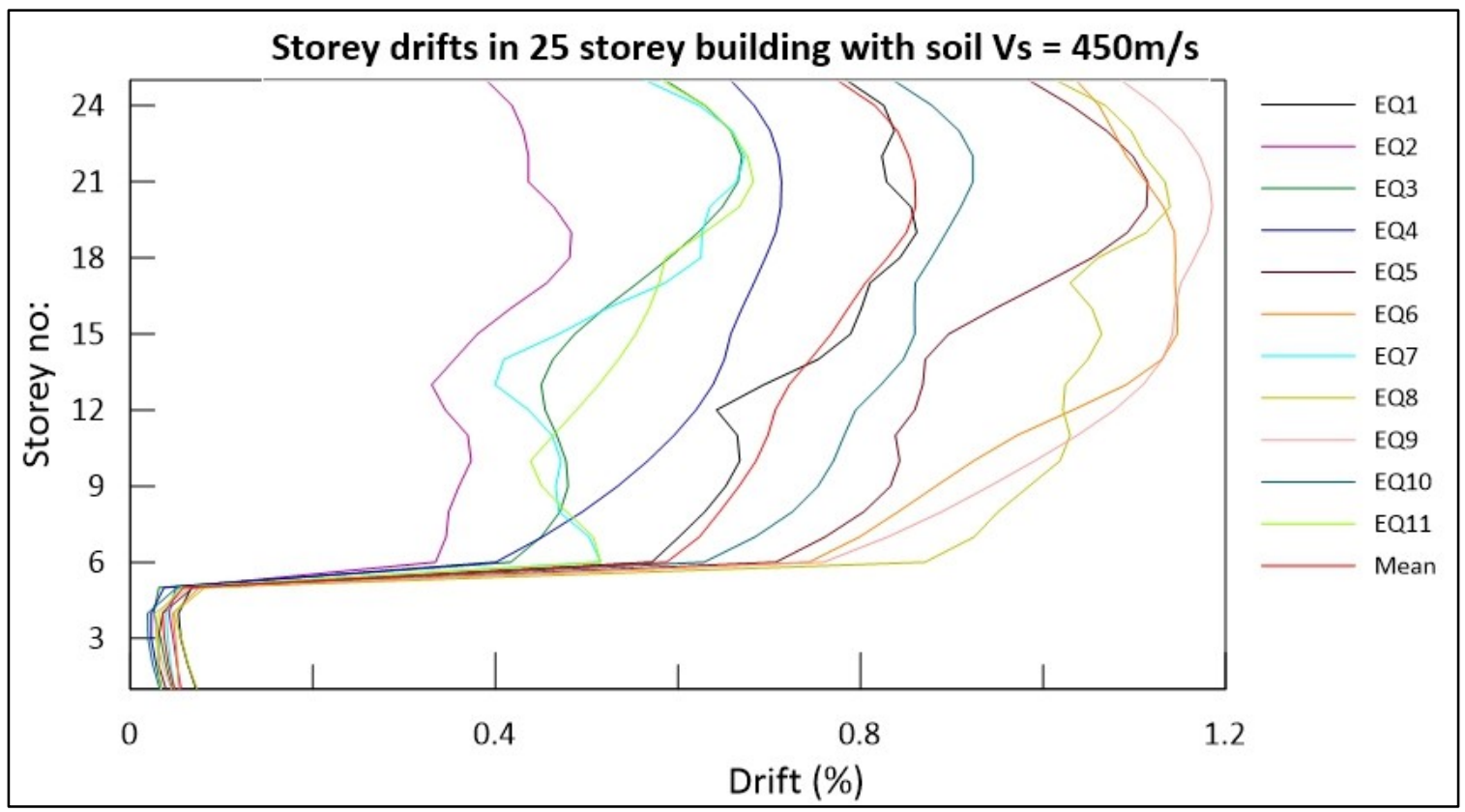

Figure B-208 Storey drifts in 25storey building with soil shear wave velocity, Vs $=450 \mathrm{~m} / \mathrm{s}$ analyzed for 11 earthquake inputs compatible with Vancouver site B spectrum 


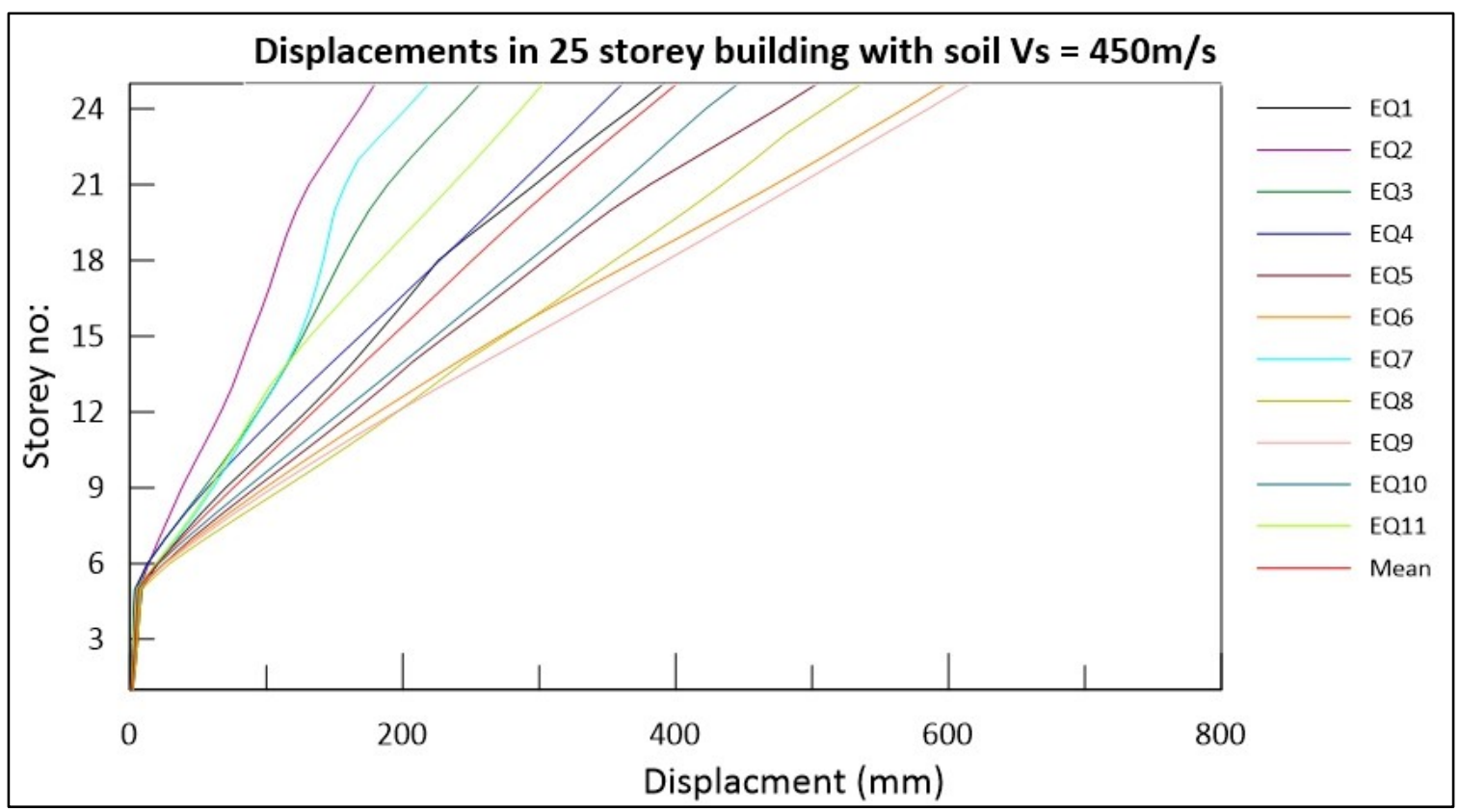

Figure B-209 Displacements in 25storey building with soil shear wave velocity, Vs $=450 \mathrm{~m} / \mathrm{s}$ analyzed for 11 earthquake inputs compatible with Vancouver site B spectrum

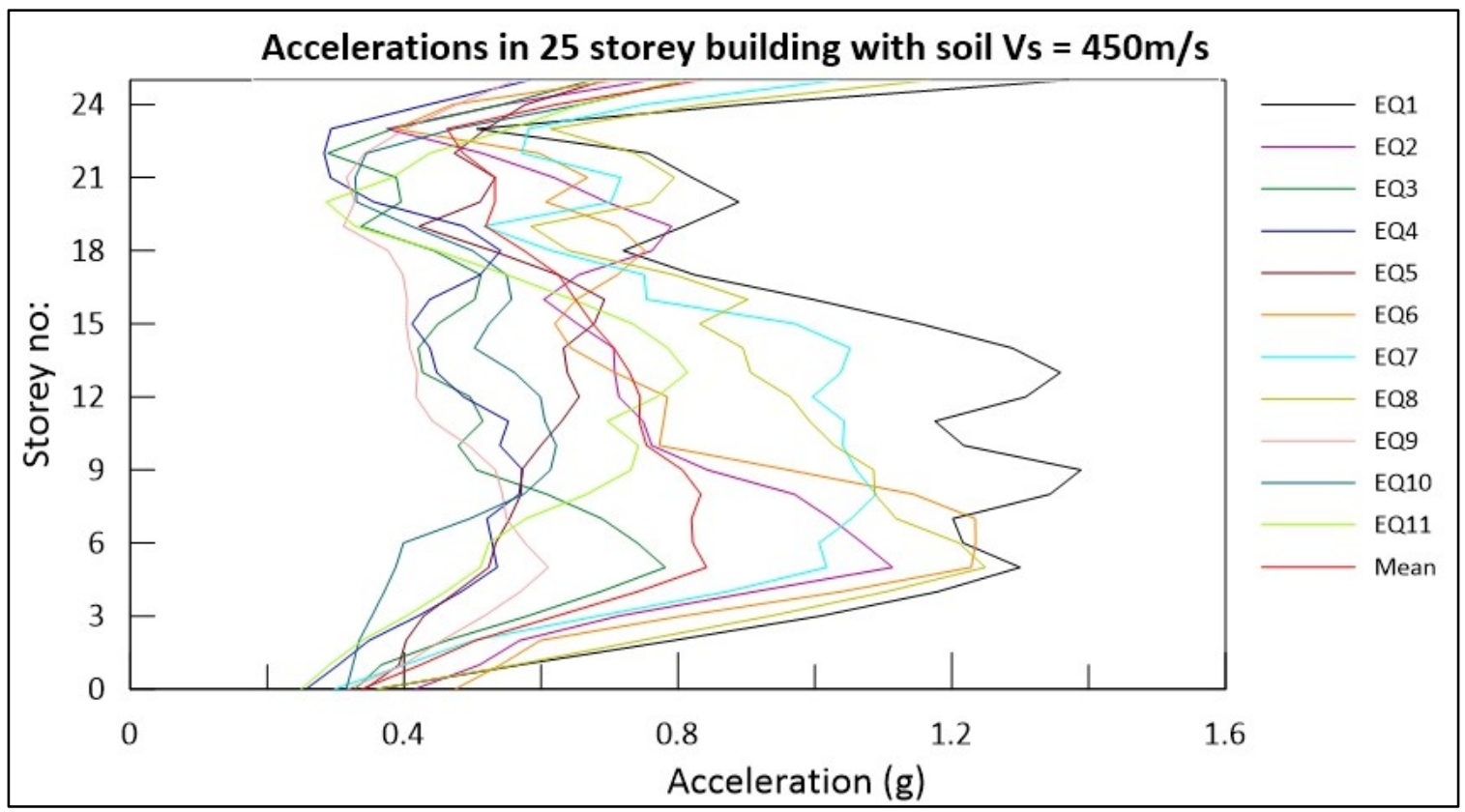

Figure B-210 Accelerations in 25storey building with soil shear wave velocity, Vs $=450 \mathrm{~m} / \mathrm{s}$ analyzed for 11 earthquake inputs compatible with Vancouver site B spectrum 


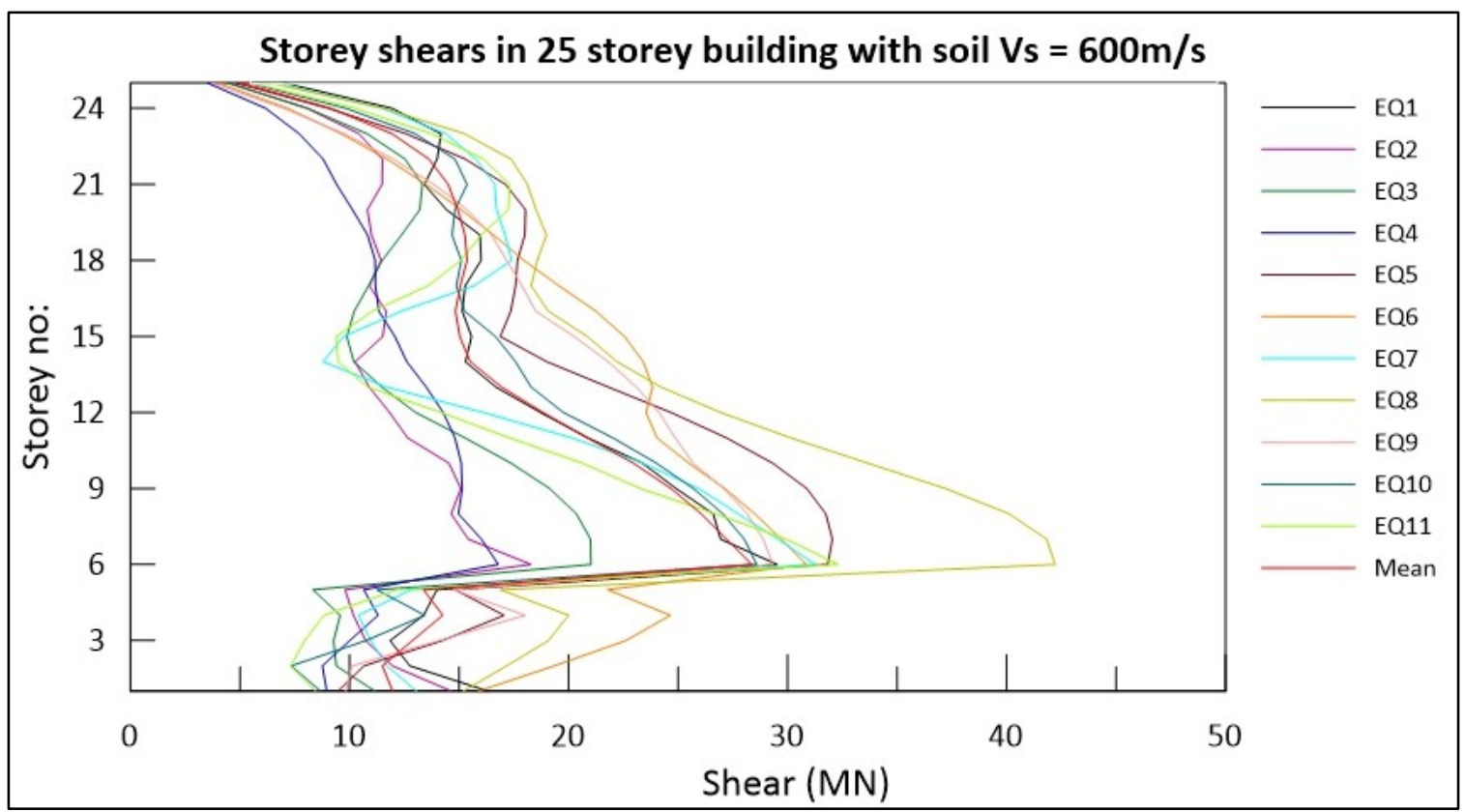

Figure B-211 Storey shears in 25storey building with soil shear wave velocity, Vs $=600 \mathrm{~m} / \mathrm{s}$ analyzed for 11 earthquake inputs compatible with Vancouver site B spectrum

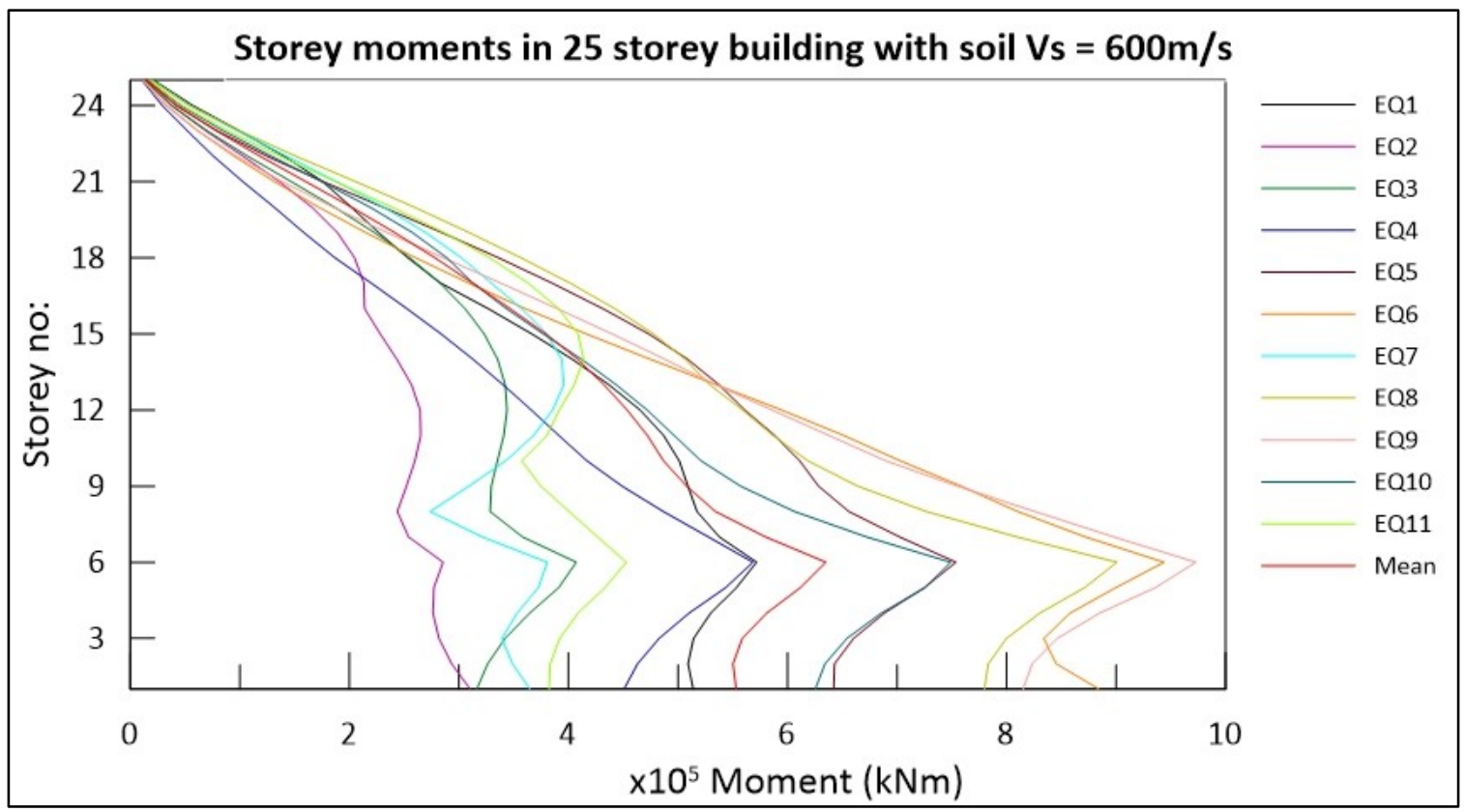

Figure B-212 Storey moments in 25storey building with soil shear wave velocity, Vs $=600 \mathrm{~m} / \mathrm{s}$ analyzed for 11 earthquake inputs compatible with Vancouver site B spectrum 


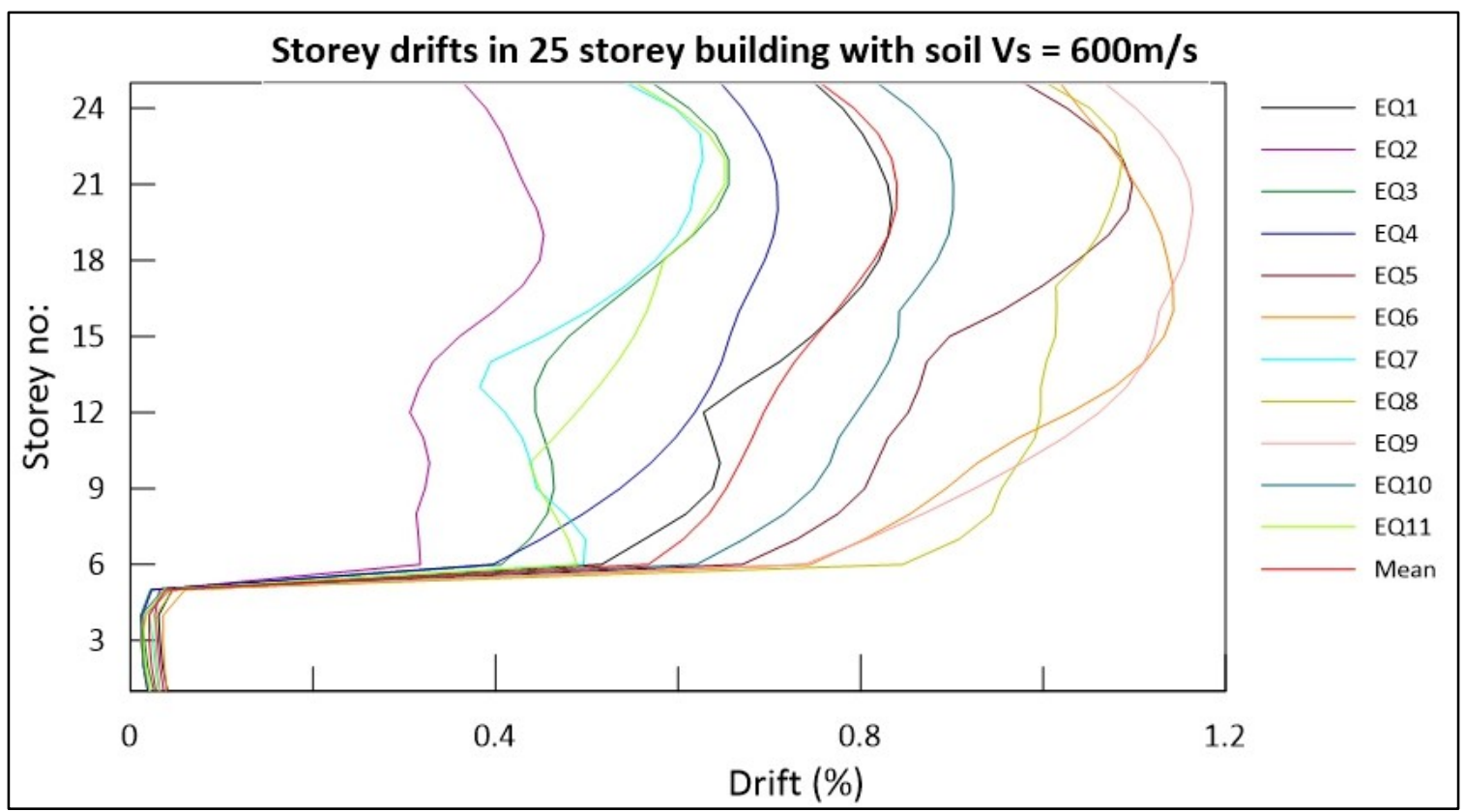

Figure B-213 Storey drifts in 25storey building with soil shear wave velocity, $\mathrm{Vs}=600 \mathrm{~m} / \mathrm{s}$ analyzed for 11 earthquake inputs compatible with Vancouver site B spectrum

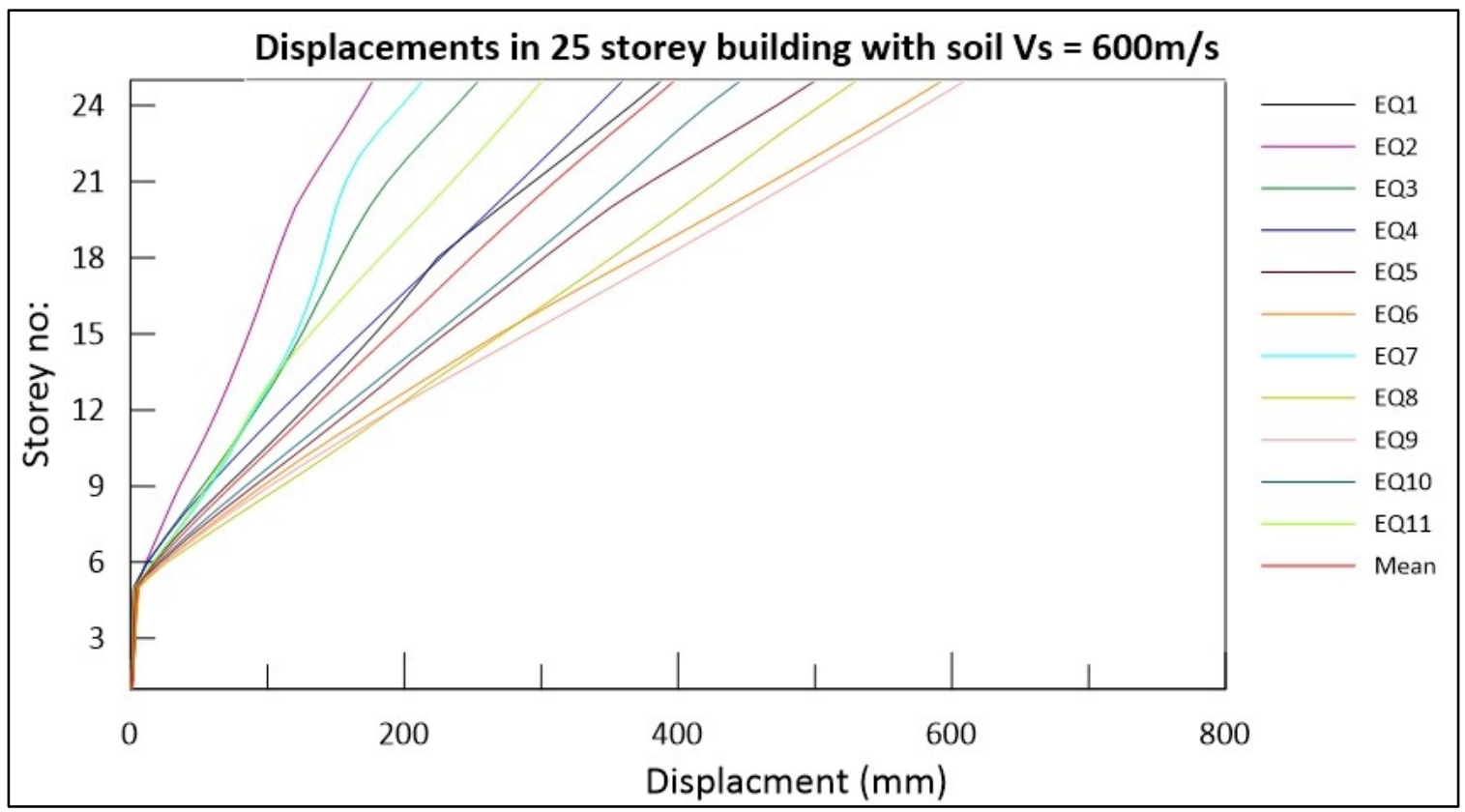

Figure B-214 Displacements in 25storey building with soil shear wave velocity, Vs $=600 \mathrm{~m} / \mathrm{s}$ analyzed for 11 earthquake inputs compatible with Vancouver site B spectrum 


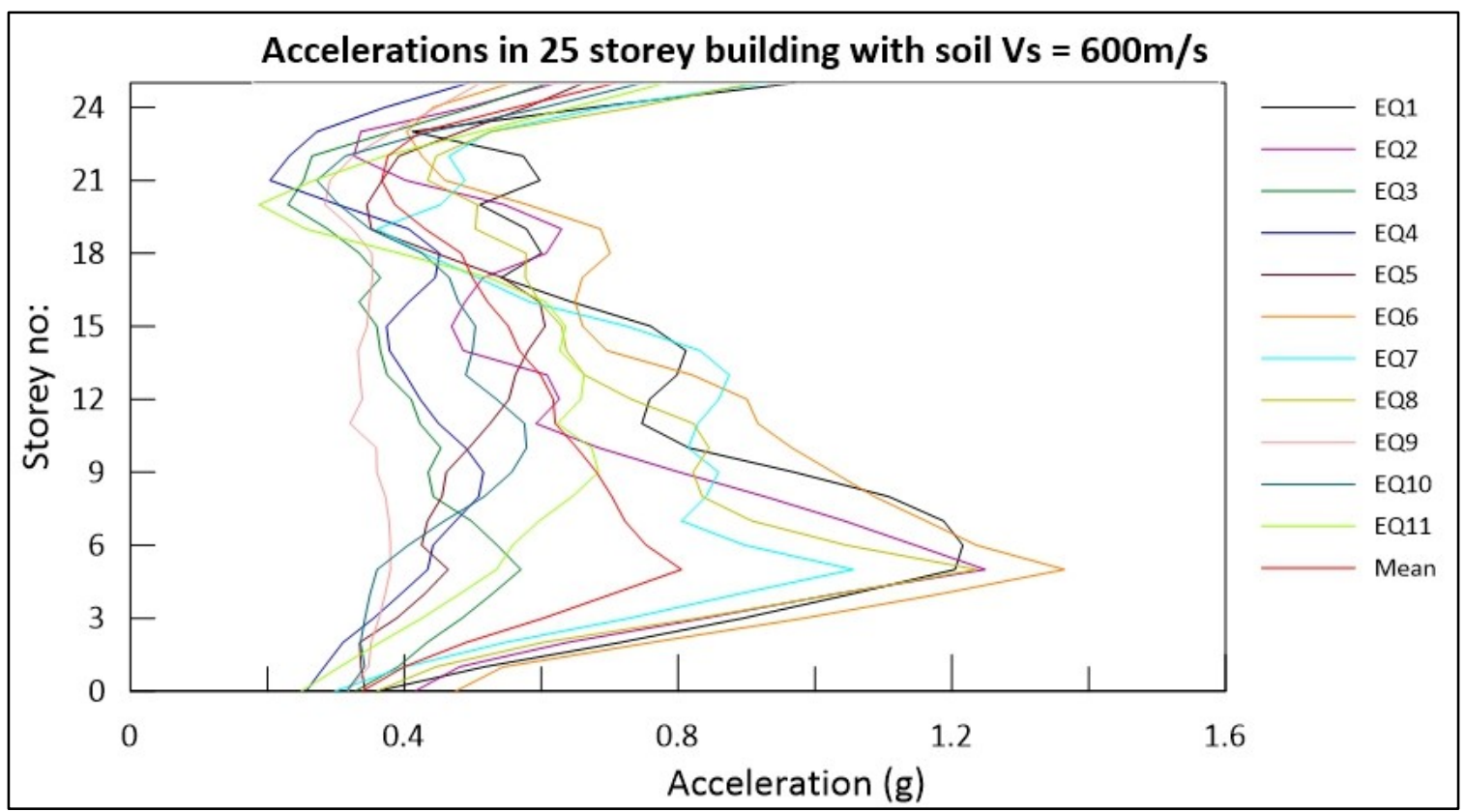

Figure B-215 Accelerations in 25storey building with soil shear wave velocity, $\mathrm{Vs}=600 \mathrm{~m} / \mathrm{s}$ analyzed for 11 earthquake inputs compatible with Vancouver site B spectrum

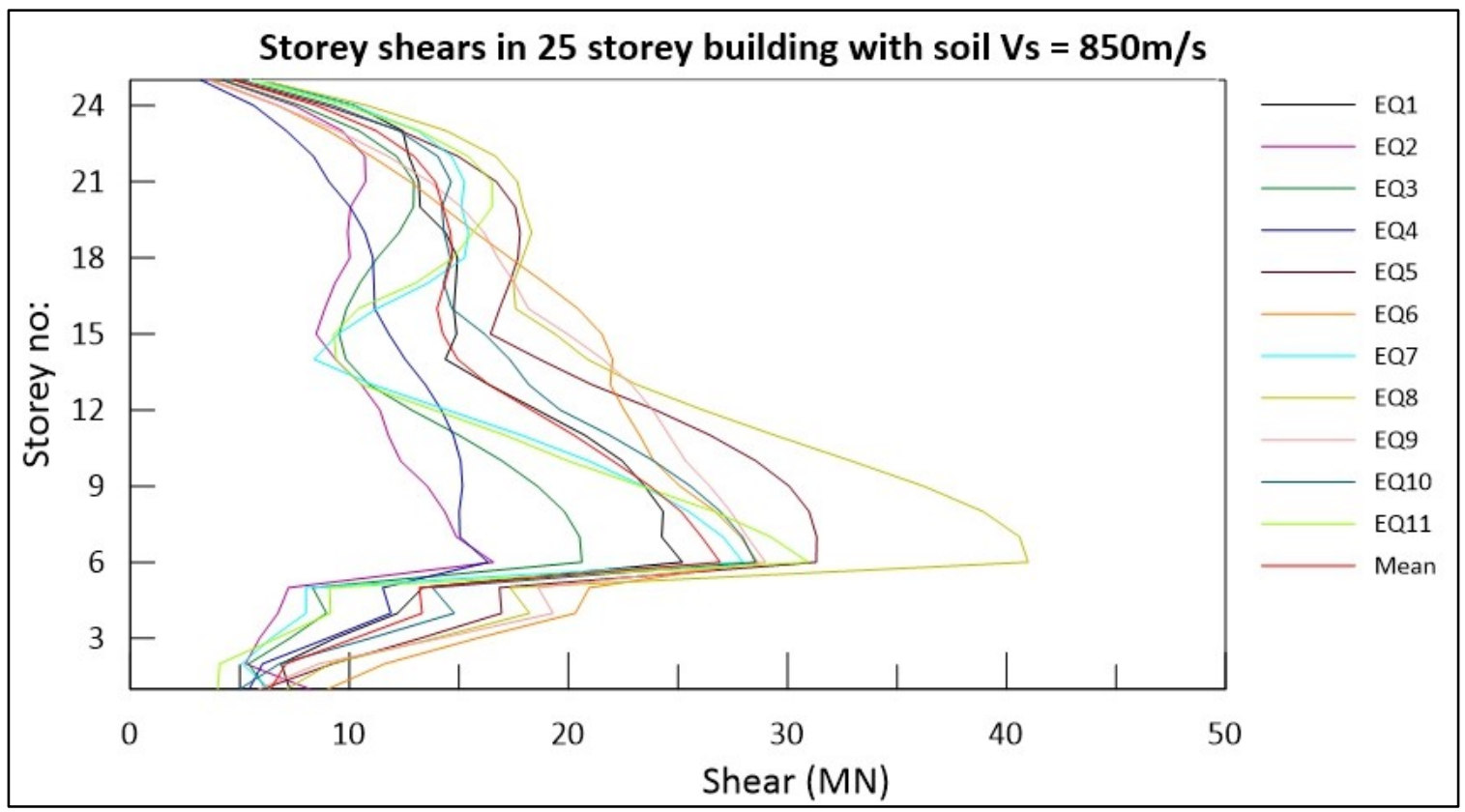

Figure B-216 Storey shears in 25storey building with soil shear wave velocity, Vs $=850 \mathrm{~m} / \mathrm{s}$ analyzed for 11 earthquake inputs compatible with Vancouver site B spectrum 


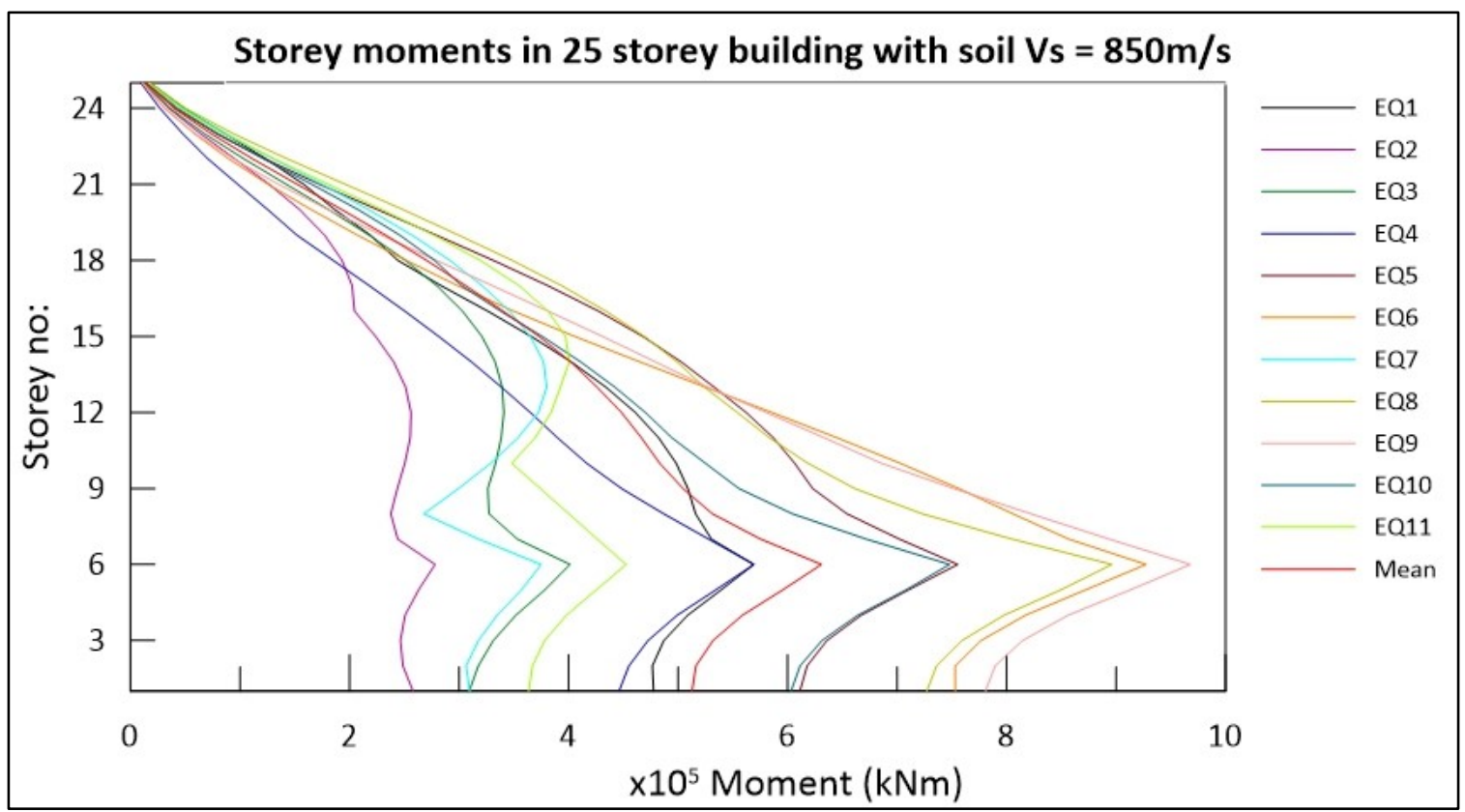

Figure B-217 Storey moments in 25storey building with soil shear wave velocity, Vs $=850 \mathrm{~m} / \mathrm{s}$ analyzed for 11 earthquake inputs compatible with Vancouver site B spectrum

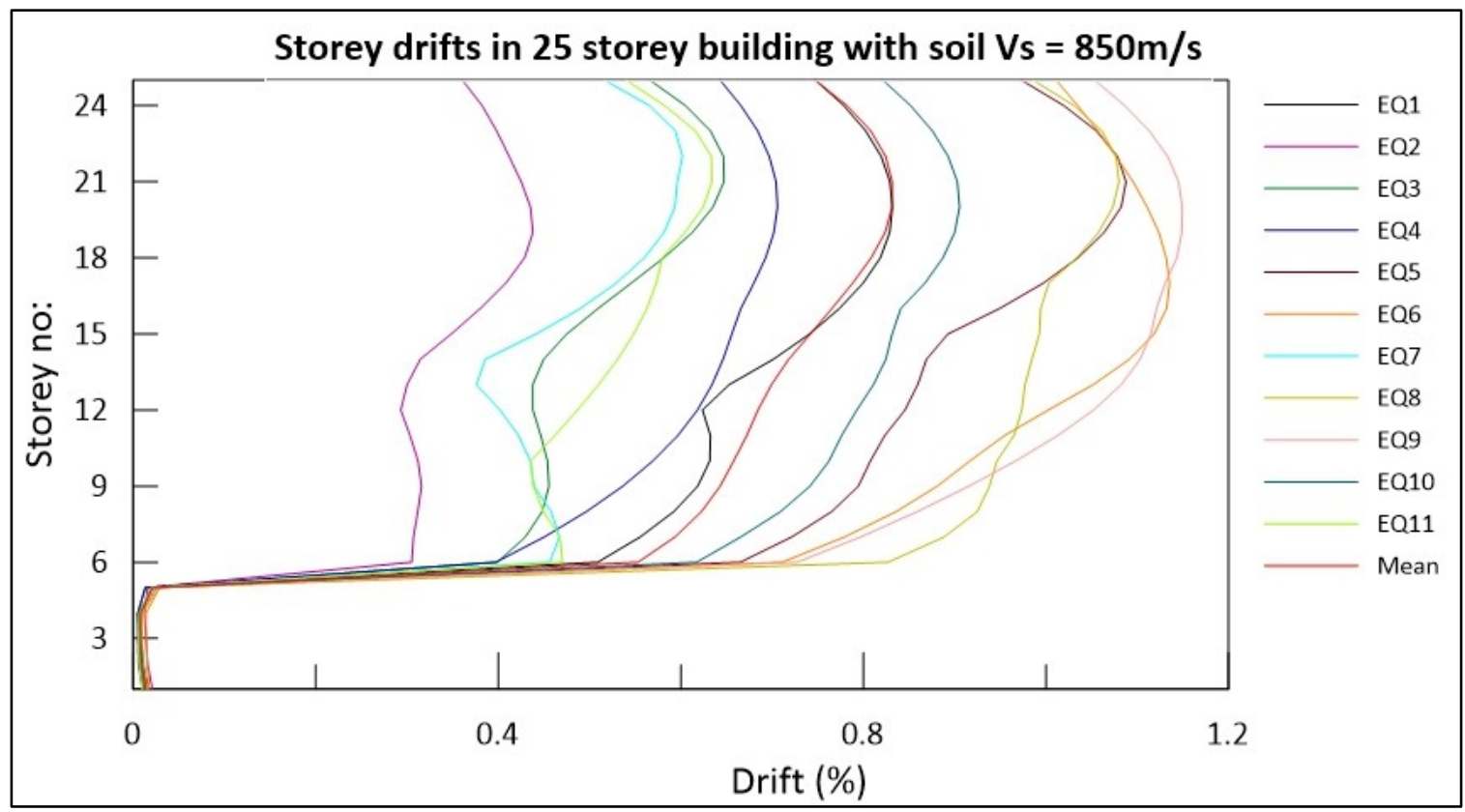

Figure B-218 Storey drifts in 25storey building with soil shear wave velocity, Vs $=850 \mathrm{~m} / \mathrm{s}$ analyzed for 11 earthquake inputs compatible with Vancouver site B spectrum 


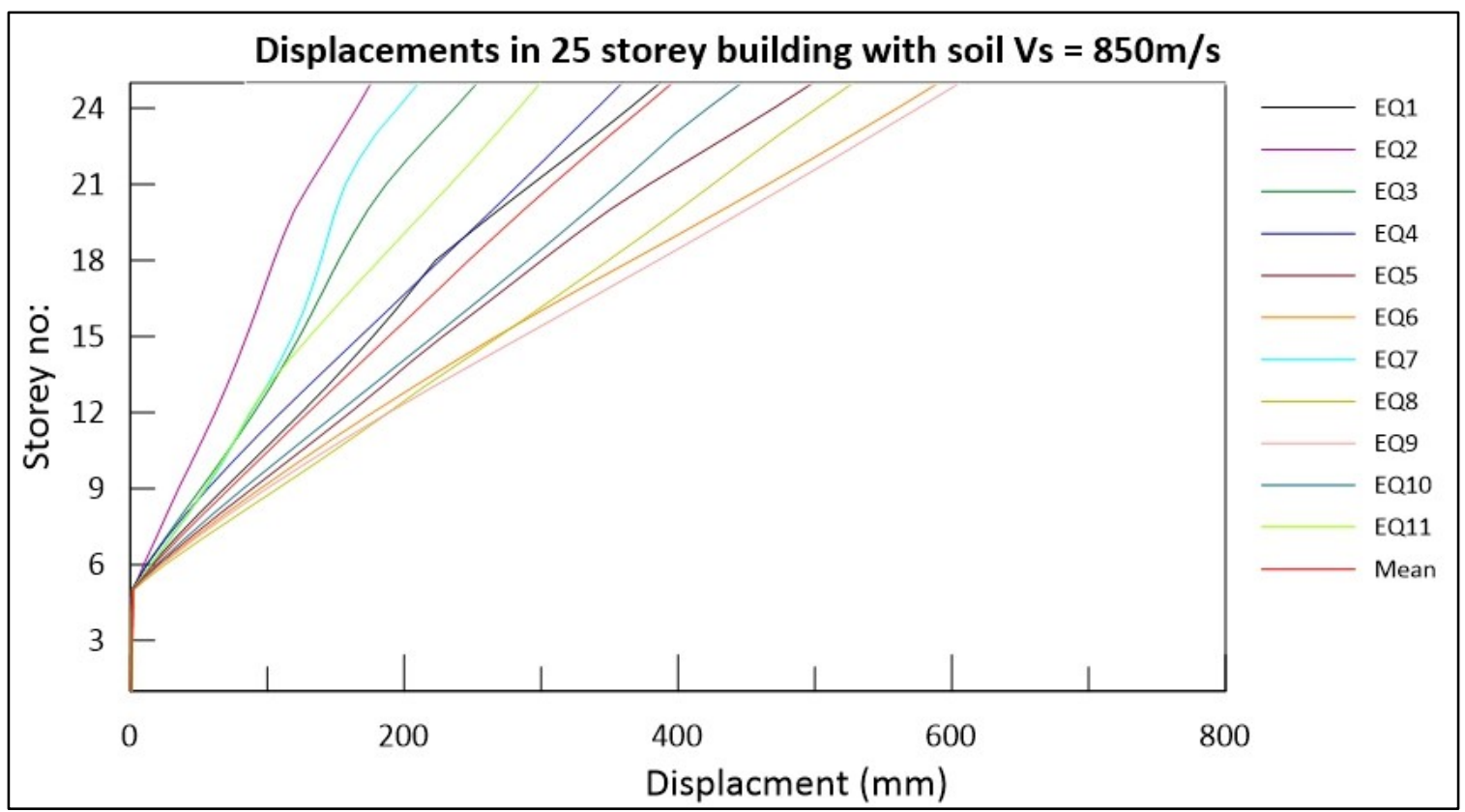

Figure B-219 Displacements in 25storey building with soil shear wave velocity, Vs $=850 \mathrm{~m} / \mathrm{s}$ analyzed for 11 earthquake inputs compatible with Vancouver site B spectrum

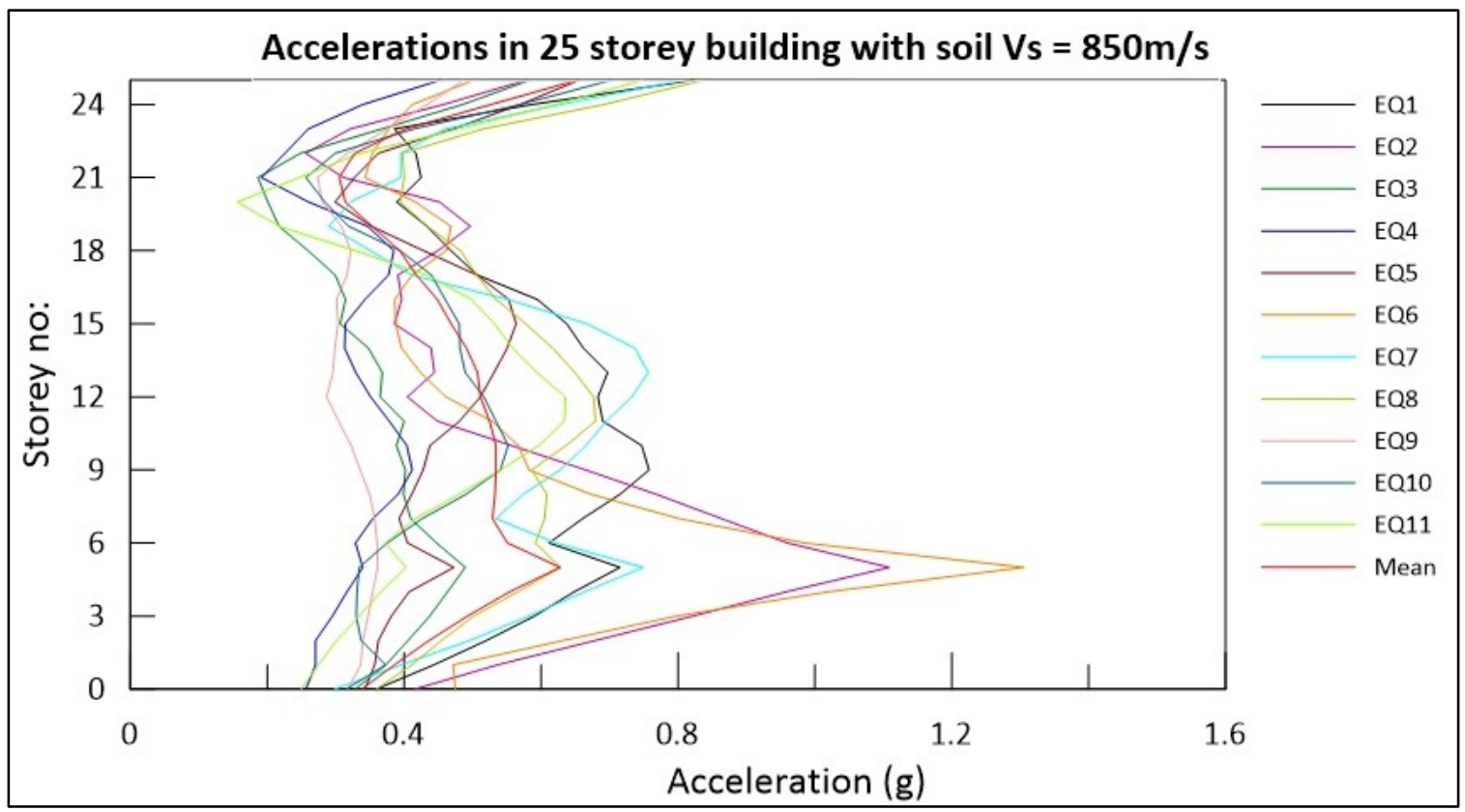

Figure B-220 Accelerations in 25storey building with soil shear wave velocity, Vs $=850 \mathrm{~m} / \mathrm{s}$ analyzed for 11 earthquake inputs compatible with Vancouver site B spectrum 


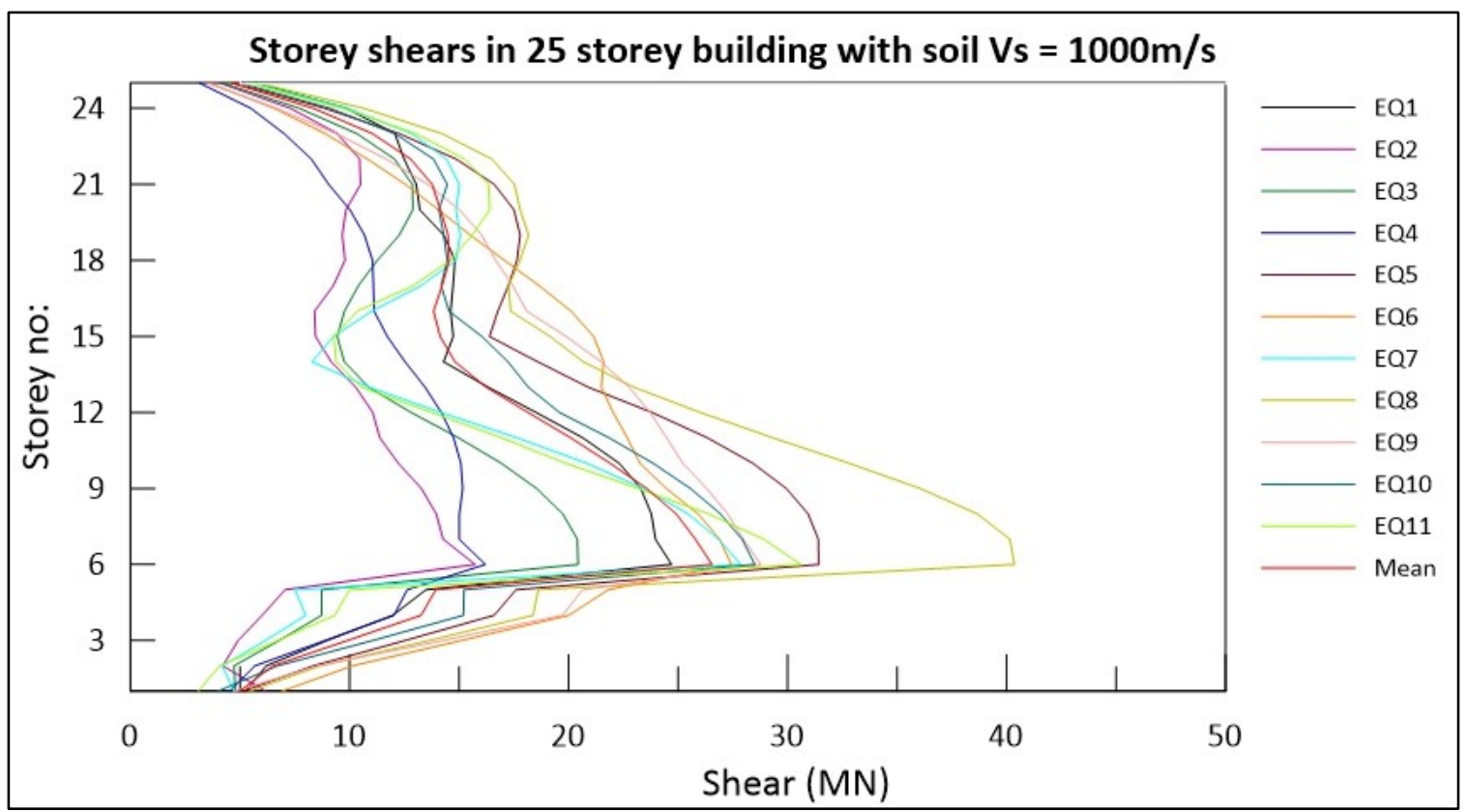

Figure B-221 Storey shears in 25storey building with soil shear wave velocity, Vs $=1000 \mathrm{~m} / \mathrm{s}$ analyzed for 11 earthquake inputs compatible with Vancouver site B spectrum

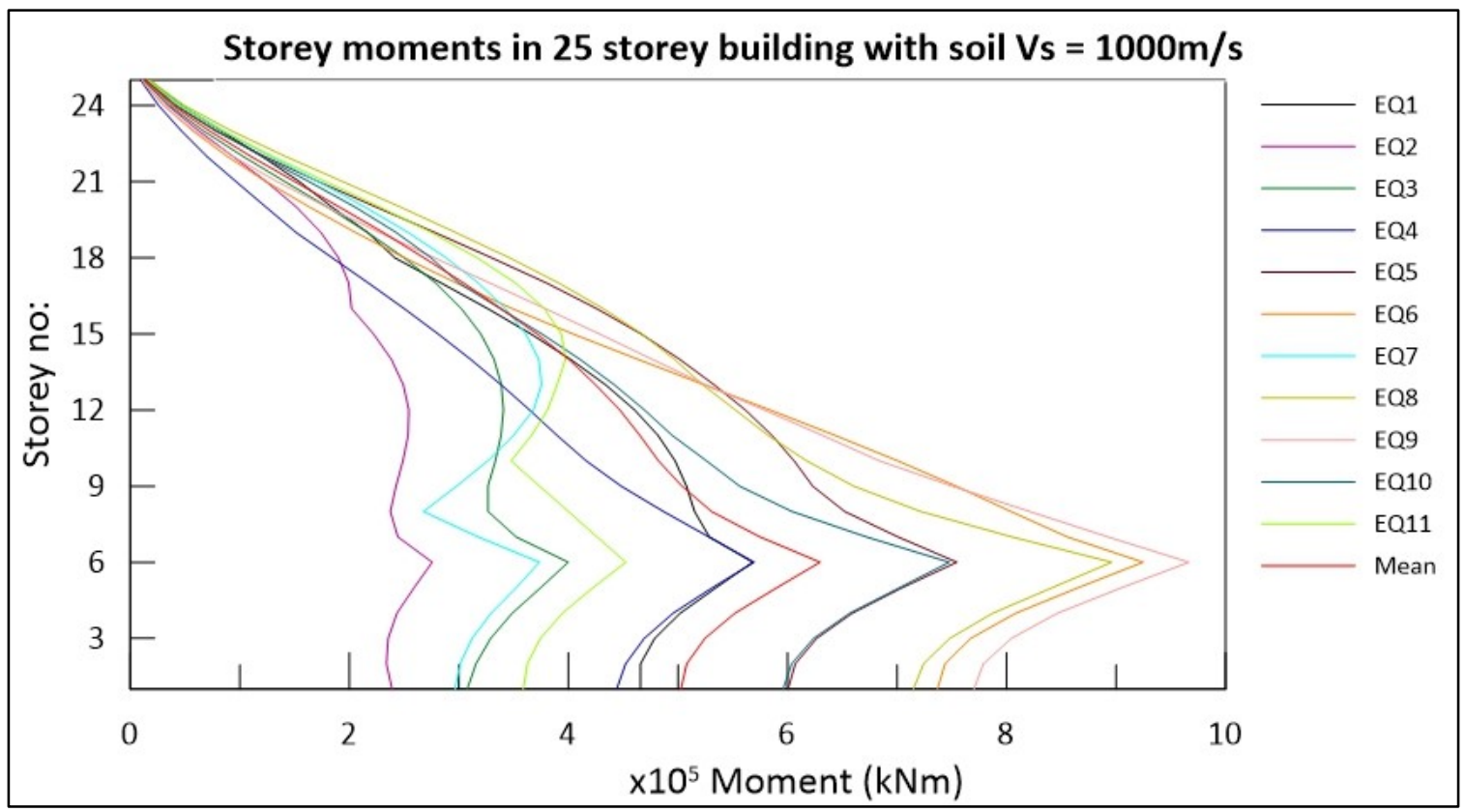

Figure B-222 Storey moments in 25storey building with soil shear wave velocity, Vs $=1000 \mathrm{~m} / \mathrm{s}$ analyzed for 11 earthquake inputs compatible with Vancouver site B spectrum 


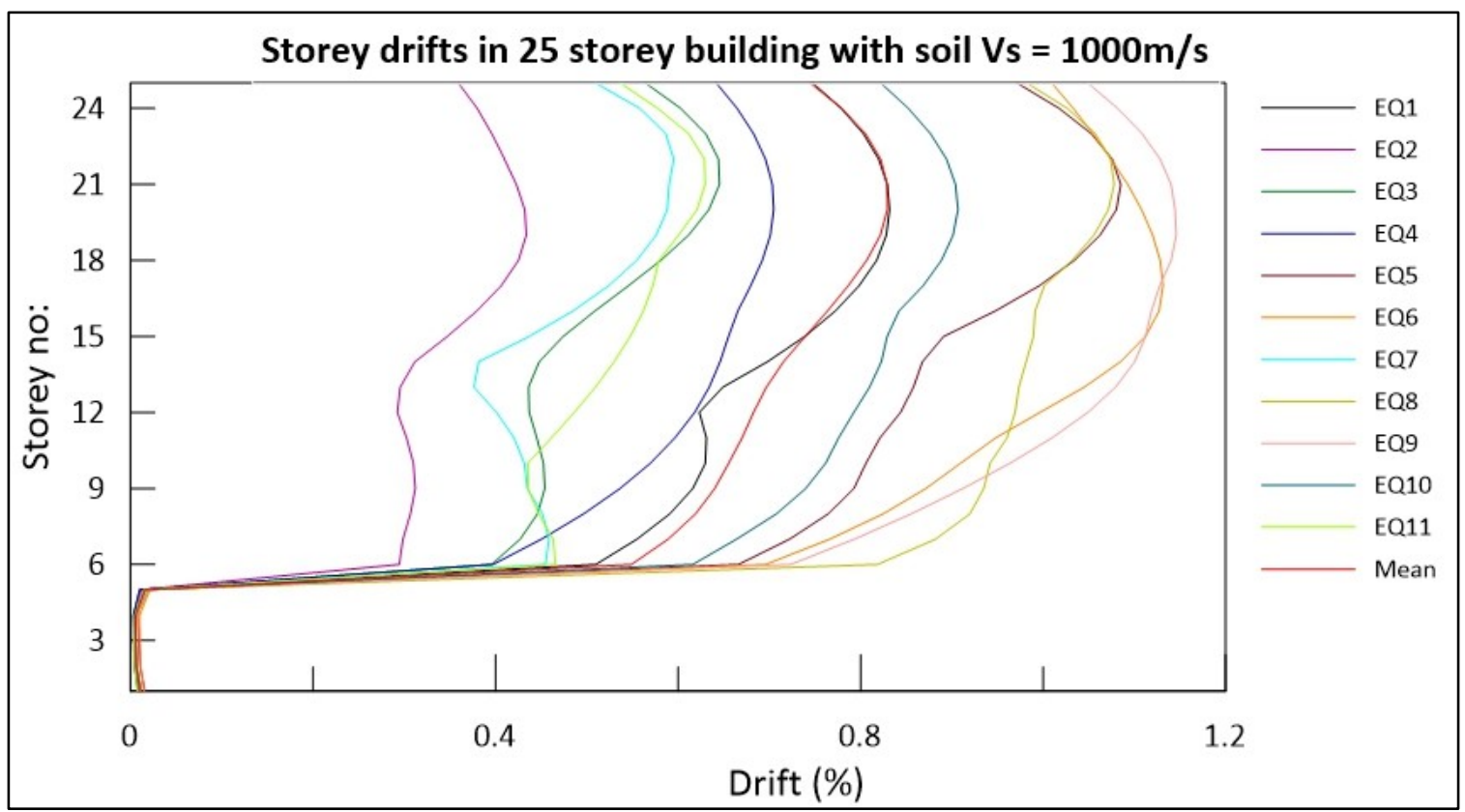

Figure B-223 Storey drifts in 25storey building with soil shear wave velocity, Vs $=1000 \mathrm{~m} / \mathrm{s}$ analyzed for 11 earthquake inputs compatible with Vancouver site B spectrum

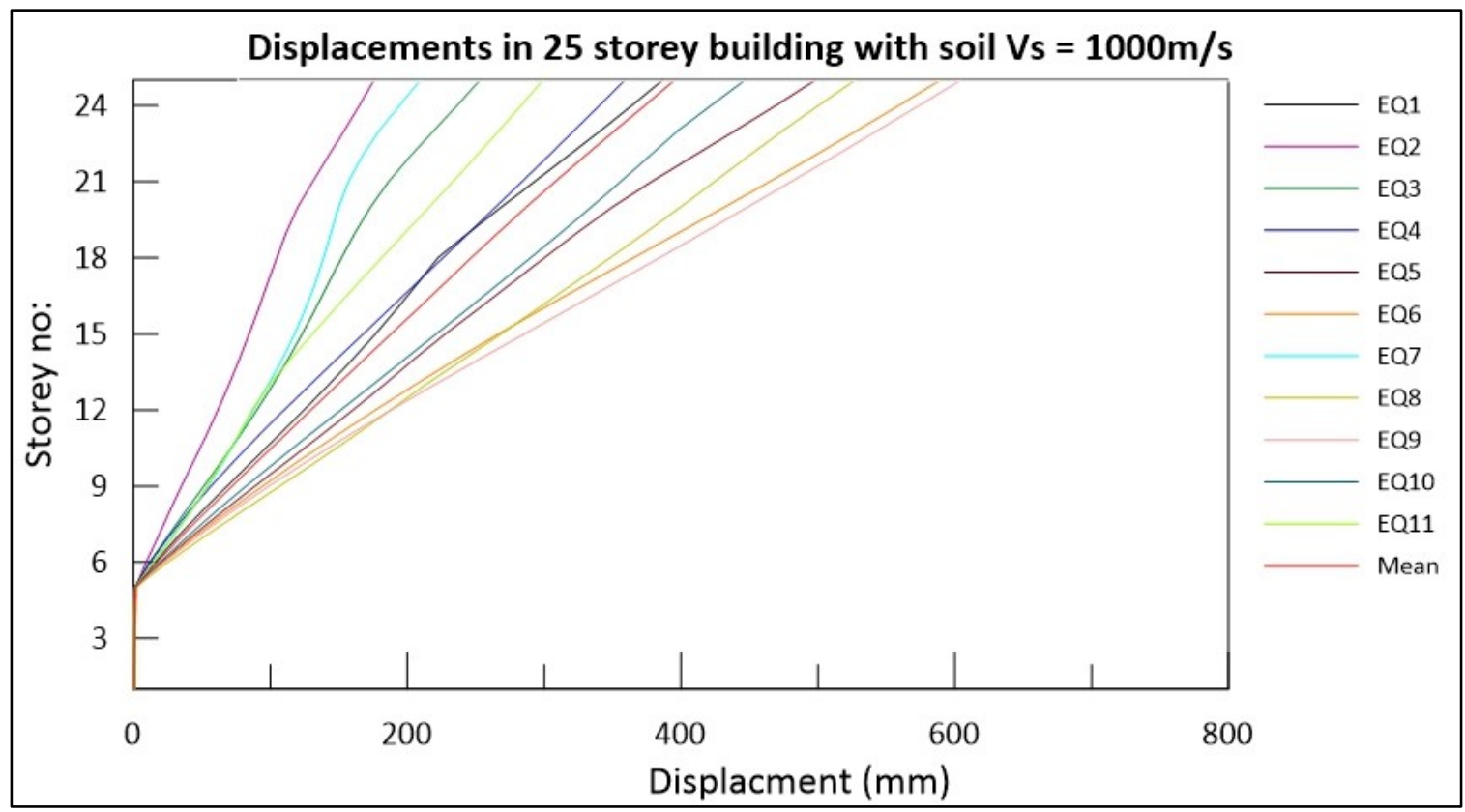

Figure B-224 Displacements in 25storey building with soil shear wave velocity, Vs $=1000 \mathrm{~m} / \mathrm{s}$ analyzed for 11 earthquake inputs compatible with Vancouver site B spectrum 


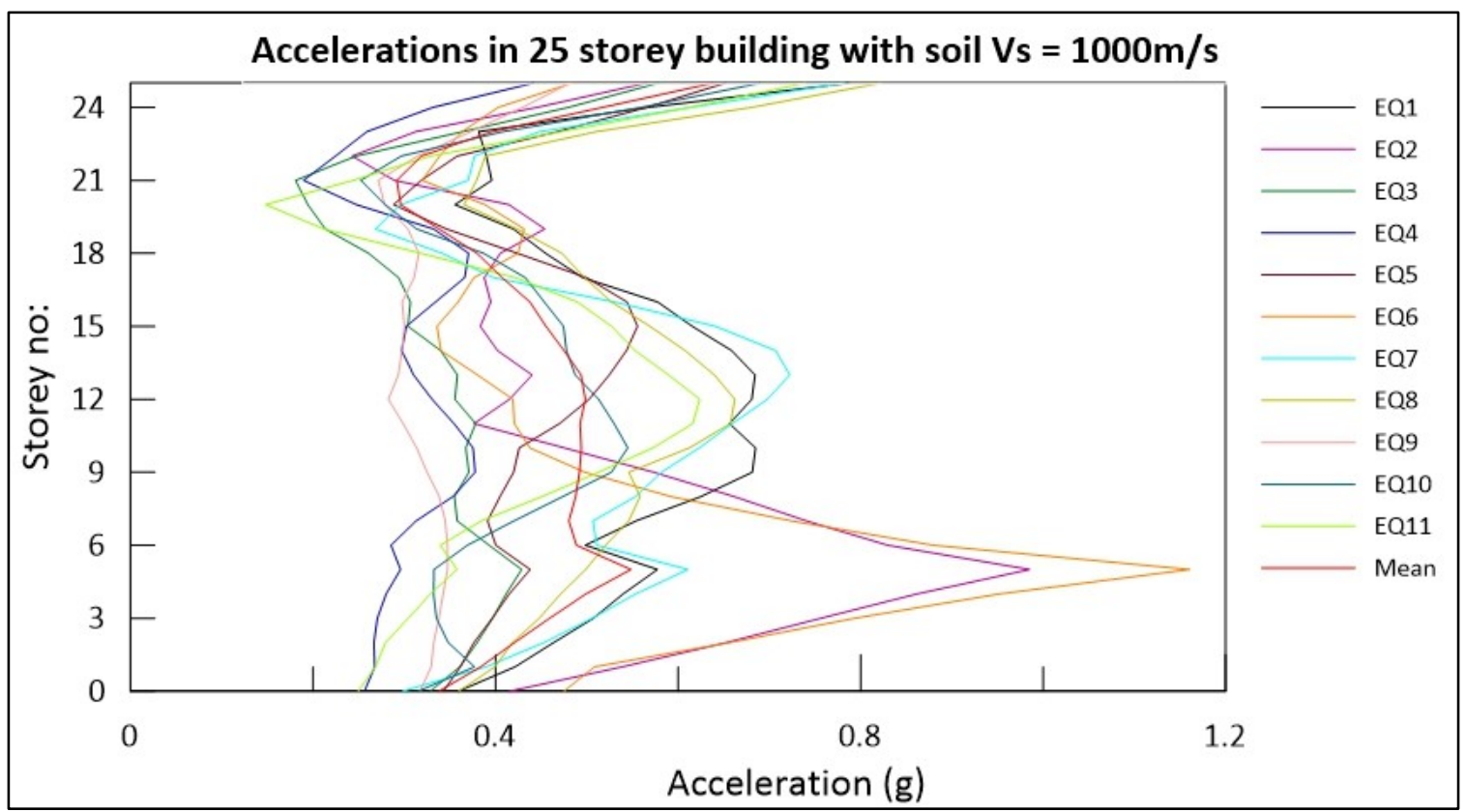

Figure B-225 Accelerations in 25storey building with soil shear wave velocity, Vs $=1000 \mathrm{~m} / \mathrm{s}$ analyzed for 11 earthquake inputs compatible with Vancouver site B spectrum 
Appendix C - Magnification factor values observed at the base of the tower for building on soil overlying rock

The magnification factor values observed for various building heights are listed in Table C-1 to Table C-5. 
Table C-1: Magnification factor values in the base storey of the tower for 9 storey building

\begin{tabular}{|l|l|l|l|l|l|}
\hline \multicolumn{5}{|c|}{ 9 storey building - Soil type middle of site class C, Vs $=450 \mathrm{~m} / \mathrm{s}$} \\
\hline Case no: & Acceleration & Drift & Displacement & Moment & Shear \\
\hline BOSR (200/450) & 1.25 & 1.19 & 1.32 & 1.19 & 1.05 \\
\hline BOSR (300/450) & 1.10 & 1.08 & 0.91 & 1.10 & 0.98 \\
\hline BOSR (450/450) & 0.89 & 0.91 & 0.70 & 0.93 & 0.83 \\
\hline BOR (200/450) & 2.02 & 2.52 & 1.80 & 2.58 & 2.34 \\
\hline BOR (300/450) & 1.84 & 1.73 & 1.22 & 1.76 & 1.68 \\
\hline BOR (450/450) & 1.70 & 1.08 & 0.82 & 1.13 & 1.02 \\
\hline 9 storey building & - Soil type borderline of site class B and site class C, Vs $=750 \mathrm{~m} / \mathrm{s}$ \\
\hline Case no: & Acceleration & Drift & Displacement & Moment & Shear \\
\hline BOSR (200/750) & 1.67 & 2.18 & 1.56 & 2.23 & 2.00 \\
\hline BOSR (300/750) & 1.03 & 1.26 & 0.62 & 1.32 & 1.20 \\
\hline BOSR (450/750) & 0.87 & 1.10 & 0.56 & 1.16 & 1.03 \\
\hline BOR (200/750) & 1.71 & 2.62 & 1.60 & 2.70 & 2.50 \\
\hline BOR (300/750) & 4.05 & 1.08 & 0.70 & 1.16 & 1.51 \\
\hline BOR (450/750) & 2.38 & 1.06 & 0.47 & 1.16 & 1.04 \\
\hline 9 storey building - Soil type middle of site class B, Vs $=1000$ m/s \\
\hline Case no: & Acceleration & Drift & Displacement & Moment & Shear \\
\hline BOSR (200/1000) & 1.32 & 2.26 & 1.52 & 2.34 & 2.36 \\
\hline BOSR (300/1000) & 0.78 & 1.03 & 0.51 & 1.10 & 1.11 \\
\hline BOSR (450/1000) & 0.70 & 0.96 & 0.48 & 1.02 & 1.01 \\
\hline BOR (200/1000) & 1.45 & 2.53 & 1.61 & 2.63 & 2.62 \\
\hline BOR (300/1000) & 4.33 & 1.50 & 0.67 & 1.91 & 0.97 \\
\hline BOR (450/1000) & 1.79 & 0.97 & 0.45 & 1.14 & 0.91 \\
\hline
\end{tabular}


Table C-2: Magnification factor values in the base storey of the tower for 13 storey building

\begin{tabular}{|l|l|l|l|l|l|}
\hline \multicolumn{5}{|c|}{13 storey building - Soil type middle of site class C, Vs $=450 \mathrm{~m} / \mathrm{s}$} \\
\hline Case no: & Acceleration & Drift & Displacement & Moment & Shear \\
\hline BOSR (200/450) & 0.34 & 1.08 & 0.45 & 0.74 & 0.93 \\
\hline BOSR (300/450) & 0.36 & 0.86 & 0.33 & 0.61 & 0.73 \\
\hline BOSR (450/450) & 0.32 & 0.71 & 0.23 & 0.51 & 0.61 \\
\hline BOR (200/450) & 1.25 & 1.17 & 1.10 & 1.04 & 1.23 \\
\hline BOR (300/450) & 2.59 & 2.68 & 1.16 & 3.25 & 0.95 \\
\hline BOR (450/450) & 0.89 & 1.19 & 0.31 & 1.17 & 0.62 \\
\hline 13 storey building & - Soil type borderline of site class B and site class C, Vs $=750 \mathrm{~m} / \mathrm{s}$ \\
\hline Case no: & Acceleration & Drift & Displacement & Moment & Shear \\
\hline BOSR (200/750) & 0.84 & 1.11 & 0.90 & 0.93 & 1.07 \\
\hline BOSR (300/750) & 0.62 & 0.80 & 0.31 & 0.81 & 0.73 \\
\hline BOSR (450/750) & 0.53 & 0.73 & 0.28 & 0.72 & 0.69 \\
\hline BOR (200/750) & 1.01 & 1.15 & 0.95 & 1.12 & 1.12 \\
\hline BOR (300/750) & 2.40 & 1.02 & 0.42 & 1.15 & 0.69 \\
\hline BOR (450/750) & 1.18 & 0.83 & 0.28 & 0.87 & 0.67 \\
\hline 13 storey building - Soil type middle of site class B, Vs = 1000 m/s \\
\hline Case no: & Acceleration & Drift & Displacement & Moment & Shear \\
\hline BOSR (200/1000) & 0.91 & 1.09 & 0.92 & 0.95 & 1.04 \\
\hline BOSR (300/1000) & 0.64 & 0.76 & 0.29 & 0.74 & 0.68 \\
\hline BOSR (450/1000) & 0.55 & 0.73 & 0.27 & 0.69 & 0.66 \\
\hline BOR (200/1000) & 1.05 & 1.11 & 0.94 & 1.04 & 1.08 \\
\hline BOR (300/1000) & 1.94 & 1.02 & 0.34 & 1.12 & 0.71 \\
\hline BOR (450/1000) & 0.77 & 0.80 & 0.26 & 0.78 & 0.64 \\
\hline
\end{tabular}


Table C-3: Magnification factor values in the base storey of the tower for 17 storey building

\begin{tabular}{|l|l|l|l|l|l|}
\hline \multicolumn{5}{|c|}{17 storey building - Soil type middle of site class C, Vs $=450 \mathrm{~m} / \mathrm{s}$} \\
\hline Case no: & Acceleration & Drift & Displacement & Moment & Shear \\
\hline BOSR (200/450) & 0.69 & 0.88 & 0.78 & 0.83 & 1.17 \\
\hline BOSR (300/450) & 0.69 & 0.92 & 0.61 & 0.84 & 1.11 \\
\hline BOSR (450/450) & 0.55 & 0.83 & 0.50 & 0.71 & 1.08 \\
\hline BOR (200/450) & 2.47 & 2.03 & 1.79 & 2.19 & 1.25 \\
\hline BOR (300/450) & 1.84 & 1.21 & 0.86 & 1.15 & 1.19 \\
\hline BOR (450/450) & 1.45 & 1.01 & 0.58 & 0.92 & 1.09 \\
\hline 17 storey building & - Soil type borderline of site class B and site class C, Vs $=750 \mathrm{~m} / \mathrm{s}$ \\
\hline Case no: & Acceleration & Drift & Displacement & Moment & Shear \\
\hline BOSR (200/750) & 1.60 & 1.45 & 1.30 & 1.91 & 1.13 \\
\hline BOSR (300/750) & 0.93 & 0.94 & 0.55 & 0.99 & 1.08 \\
\hline BOSR (450/750) & 0.78 & 0.90 & 0.52 & 0.95 & 1.06 \\
\hline BOR (200/750) & 2.02 & 1.61 & 1.48 & 2.13 & 1.23 \\
\hline BOR (300/750) & 3.04 & 1.02 & 0.64 & 1.16 & 1.15 \\
\hline BOR (450/750) & 1.49 & 0.89 & 0.51 & 0.93 & 1.08 \\
\hline 17 storey building - Soil type middle of site class B, Vs = 1000 m/s \\
\hline Case no: & Acceleration & Drift & Displacement & Moment & Shear \\
\hline BOSR (200/1000) & 1.13 & 1.63 & 1.34 & 2.17 & 1.16 \\
\hline BOSR (300/1000) & 0.92 & 0.95 & 0.52 & 1.01 & 1.07 \\
\hline BOSR (450/1000) & 0.80 & 0.93 & 0.50 & 0.98 & 1.06 \\
\hline BOR (200/1000) & 1.98 & 1.61 & 1.41 & 2.15 & 1.23 \\
\hline BOR (300/1000) & 2.13 & 0.98 & 0.54 & 1.08 & 1.008 \\
\hline BOR (450/1000) & 1.03 & 0.92 & 0.49 & 0.97 & 1.06 \\
\hline
\end{tabular}


Table C-4: Magnification factor values in the base storey of the tower for 21 storey building

\begin{tabular}{|l|l|l|l|l|l|}
\hline \multicolumn{5}{|c|}{ 21 storey building - Soil type middle of site class C, Vs $=450 \mathrm{~m} / \mathrm{s}$} \\
\hline Case no: & Acceleration & Drift & Displacement & Moment & Shear \\
\hline BOSR (200/450) & 0.59 & 1.17 & 0.77 & 1.08 & 0.80 \\
\hline BOSR (300/450) & 0.51 & 0.90 & 0.44 & 0.76 & 0.78 \\
\hline BOSR (450/450) & 0.43 & 0.75 & 0.38 & 0.59 & 0.75 \\
\hline BOR (200/450) & 1.20 & 1.43 & 1.25 & 1.39 & 1.00 \\
\hline BOR (300/450) & 2.29 & 2.16 & 1.24 & 2.11 & 0.81 \\
\hline BOR (450/450) & 1.18 & 1.08 & 0.45 & 1.00 & 0.74 \\
\hline 21 storey building & - Soil type borderline of site class B and site class C, Vs $=750 \mathrm{~m} / \mathrm{s}$ \\
\hline Case no: & Acceleration & Drift & Displacement & Moment & Shear \\
\hline BOSR (200/750) & 1.10 & 1.25 & 1.04 & 1.13 & 1.00 \\
\hline BOSR (300/750) & 0.70 & 0.78 & 0.41 & 0.63 & 0.83 \\
\hline BOSR (450/750) & 0.62 & 0.75 & 0.39 & 0.57 & 0.81 \\
\hline BOR (200/750) & 1.20 & 1.30 & 1.12 & 1.18 & 1.02 \\
\hline BOR (300/750) & 2.10 & 0.88 & 0.44 & 0.83 & 0.89 \\
\hline BOR (450/750) & 1.17 & 0.77 & 0.33 & 0.65 & 0.83 \\
\hline 21 storey building - Soil type middle of site class B, Vs = 1000 m/s \\
\hline Case no: & Acceleration & Drift & Displacement & Moment & Shear \\
\hline BOSR (200/1000) & 1.36 & 1.30 & 1.18 & 1.20 & 1.01 \\
\hline BOSR (300/1000) & 0.85 & 0.82 & 0.40 & 0.62 & 0.82 \\
\hline BOSR (450/1000) & 0.75 & 0.80 & 0.39 & 0.59 & 0.81 \\
\hline BOR (200/1000) & 1.35 & 1.36 & 1.24 & 1.24 & 1.01 \\
\hline BOR (300/1000) & 1.68 & 1.02 & 0.44 & 0.81 & 0.81 \\
\hline BOR (450/1000) & 0.93 & 0.88 & 0.37 & 0.67 & 0.81 \\
\hline
\end{tabular}


Table C-5: Magnification factor values in the base storey of the tower for 25 storey building

\begin{tabular}{|l|l|l|l|l|l|}
\hline \multicolumn{5}{|c|}{25 storey building - Soil type middle of site class C, Vs $=450 \mathrm{~m} / \mathrm{s}$} \\
\hline Case no: & Acceleration & Drift & Displacement & Moment & Shear \\
\hline BOSR (200/450) & 0.47 & 0.93 & 0.64 & 0.82 & 1.13 \\
\hline BOSR (300/450) & 0.49 & 0.87 & 0.45 & 0.77 & 1.03 \\
\hline BOSR (450/450) & 0.41 & 0.82 & 0.41 & 0.73 & 0.97 \\
\hline BOR (200/450) & 1.74 & 1.48 & 1.42 & 1.76 & 0.97 \\
\hline BOR (300/450) & 1.54 & 1.29 & 0.74 & 1.48 & 1.12 \\
\hline BOR (450/450) & 0.84 & 0.99 & 0.41 & 0.99 & 1.00 \\
\hline 25 storey building & - Soil type borderline of site class B and site class C, Vs $=750 \mathrm{~m} / \mathrm{s}$ \\
\hline Case no: & Acceleration & Drift & Displacement & Moment & Shear \\
\hline BOSR (200/750) & 1.16 & 1.10 & 1.21 & 1.19 & 1.12 \\
\hline BOSR (300/750) & 0.83 & 1.07 & 0.60 & 1.05 & 1.00 \\
\hline BOSR (450/750) & 0.70 & 1.03 & 0.59 & 1.00 & 0.99 \\
\hline BOR (200/750) & 1.61 & 1.36 & 1.52 & 1.47 & 1.03 \\
\hline BOR (300/750) & 2.00 & 1.03 & 0.49 & 1.08 & 0.97 \\
\hline BOR (450/750) & 1.22 & 0.98 & 0.46 & 0.95 & 0.97 \\
\hline 25 storey building - Soil type middle of site class B, Vs = 1000 m/s \\
\hline Case no: & Acceleration & Drift & Displacement & Moment & Shear \\
\hline BOSR (200/1000) & 1.34 & 1.22 & 1.29 & 1.27 & 1.08 \\
\hline BOSR (300/1000) & 0.87 & 1.02 & 0.57 & 0.98 & 0.98 \\
\hline BOSR (450/1000) & 0.75 & 1.01 & 0.57 & 0.96 & 0.97 \\
\hline BOR (200/1000) & 1.61 & 1.34 & 1.47 & 1.41 & 1.04 \\
\hline BOR (300/1000) & 1.49 & 1.00 & 0.48 & 1.01 & 0.97 \\
\hline BOR (450/1000) & 0.93 & 0.98 & 0.48 & 0.93 & 0.97 \\
\hline
\end{tabular}




\section{Appendix D - Spectra plots}

The spectra of acceleration recorded at the base of the structure for BOSR case when the soil under the building has shear wave velocities of $750 \mathrm{~m} / \mathrm{s}$ and $1000 \mathrm{~m} / \mathrm{s}$, free field spectra of the horizontal acceleration recorded by propagating site A motion through the soil block (having $750 \mathrm{~m} / \mathrm{s}$ and $1000 \mathrm{~m} / \mathrm{s}$ shear wave velocities) without the structure and the side soil, and the spectra of the site A earthquake input motion are plotted as shown in Figure D-1 toFigure D-10. 
$\underline{\text { Soil type borderline between site class B and site class C case }}$

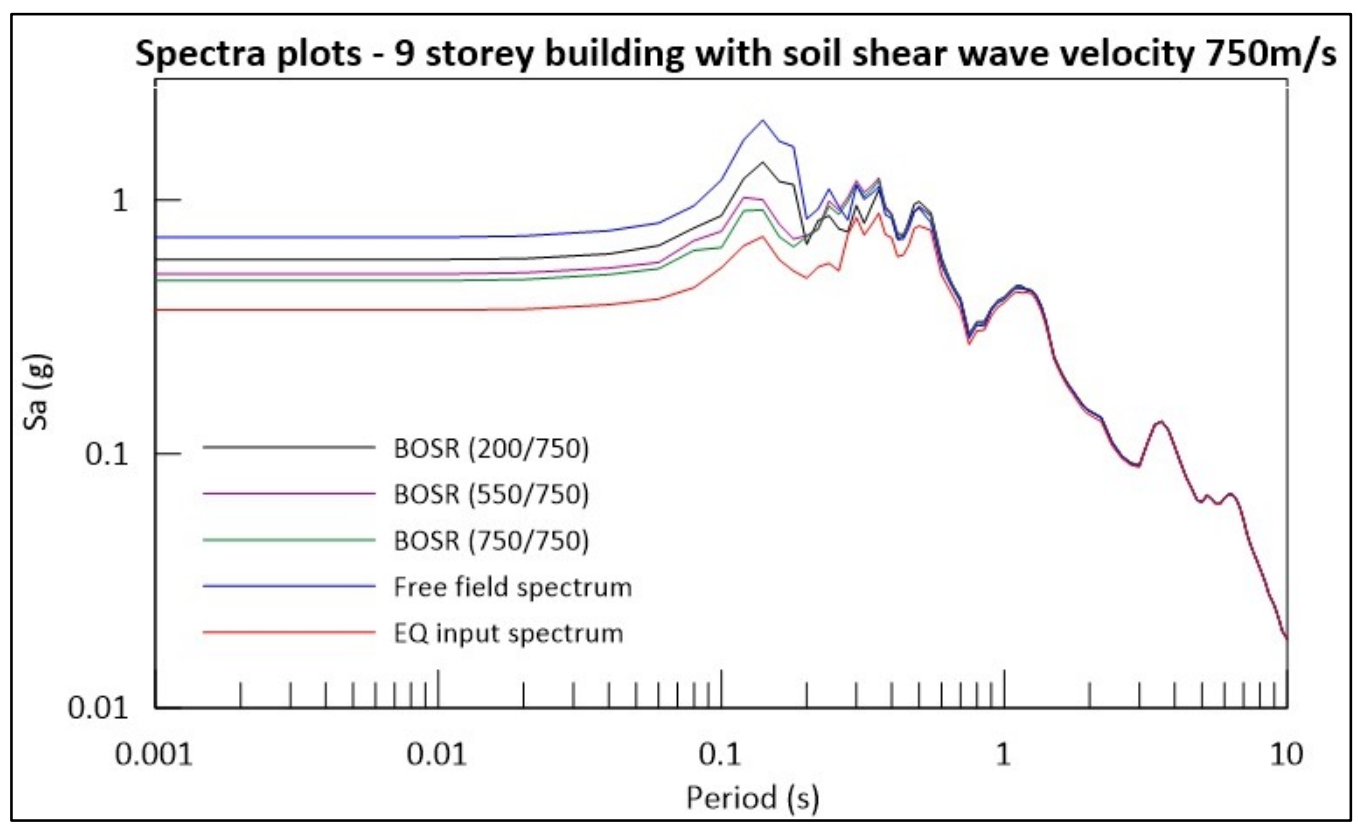

Figure D-1: Spectra plots for 9 storey building, soil type borderline between site class B and site class C $(750 \mathrm{~m} / \mathrm{s})$

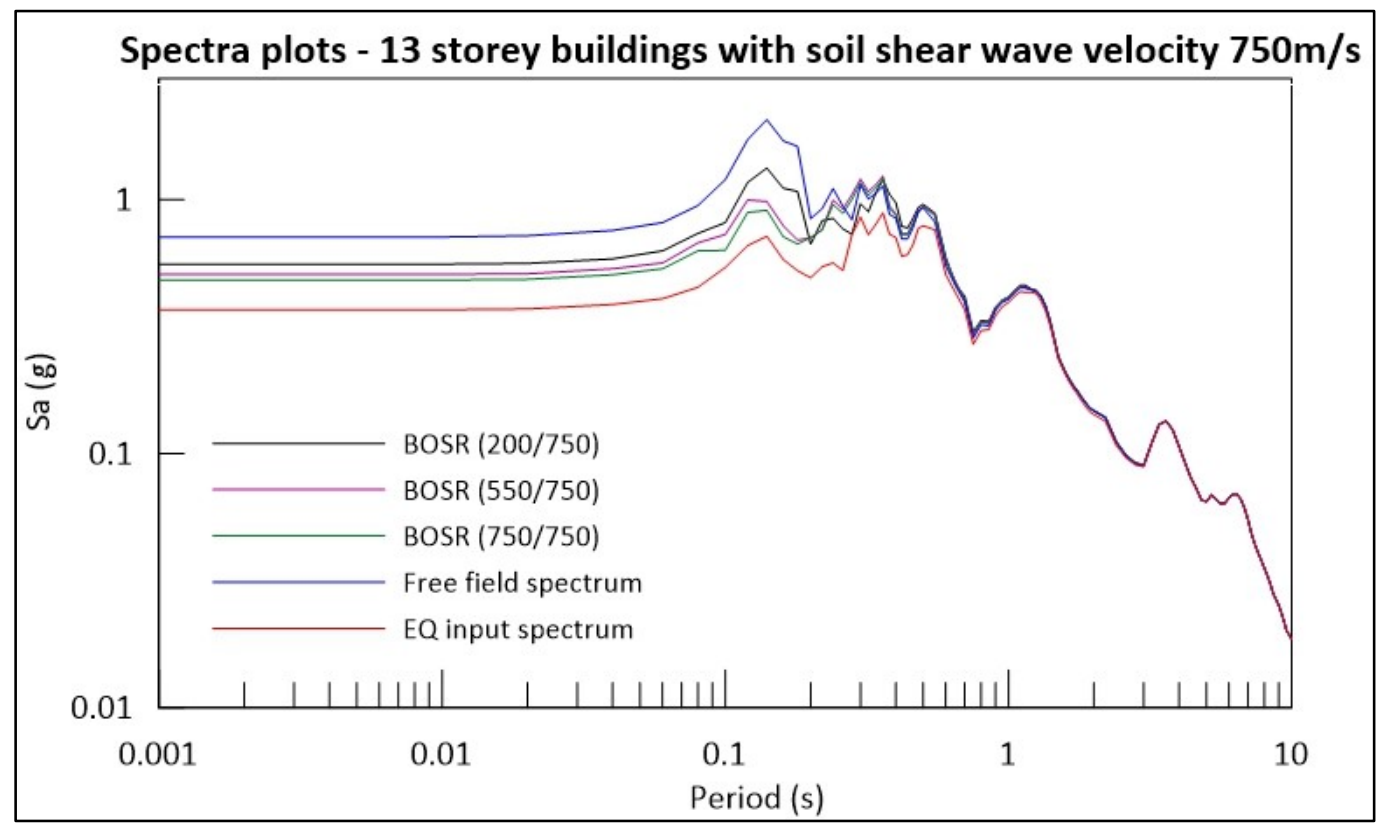

Figure D-2: Spectra plots for 13 storey building, soil type borderline between site class B and site class C $(750 \mathrm{~m} / \mathrm{s})$ 


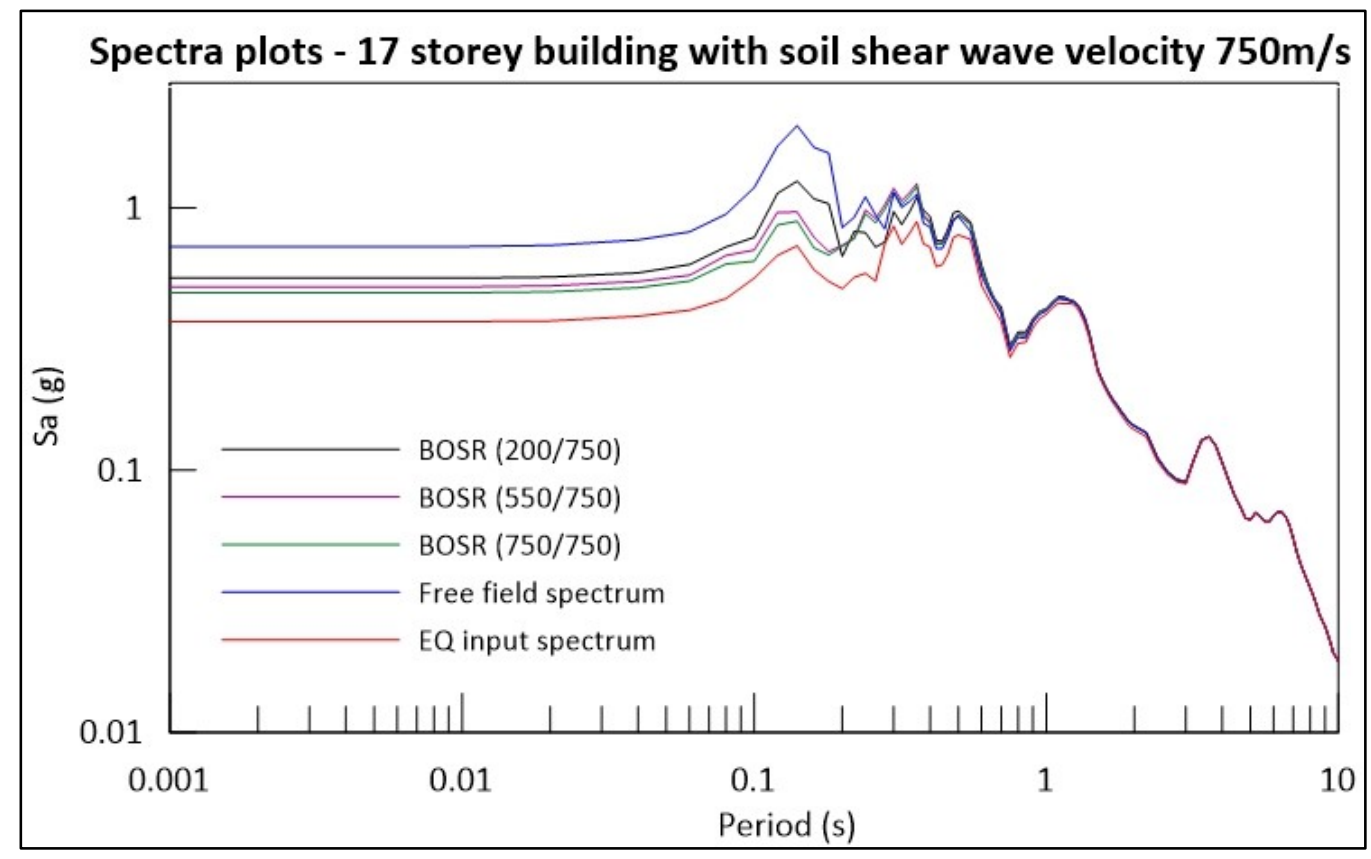

Figure D-3: Spectra plots for 17 storey building, soil type borderline between site class B and site class C $(750 \mathrm{~m} / \mathrm{s})$

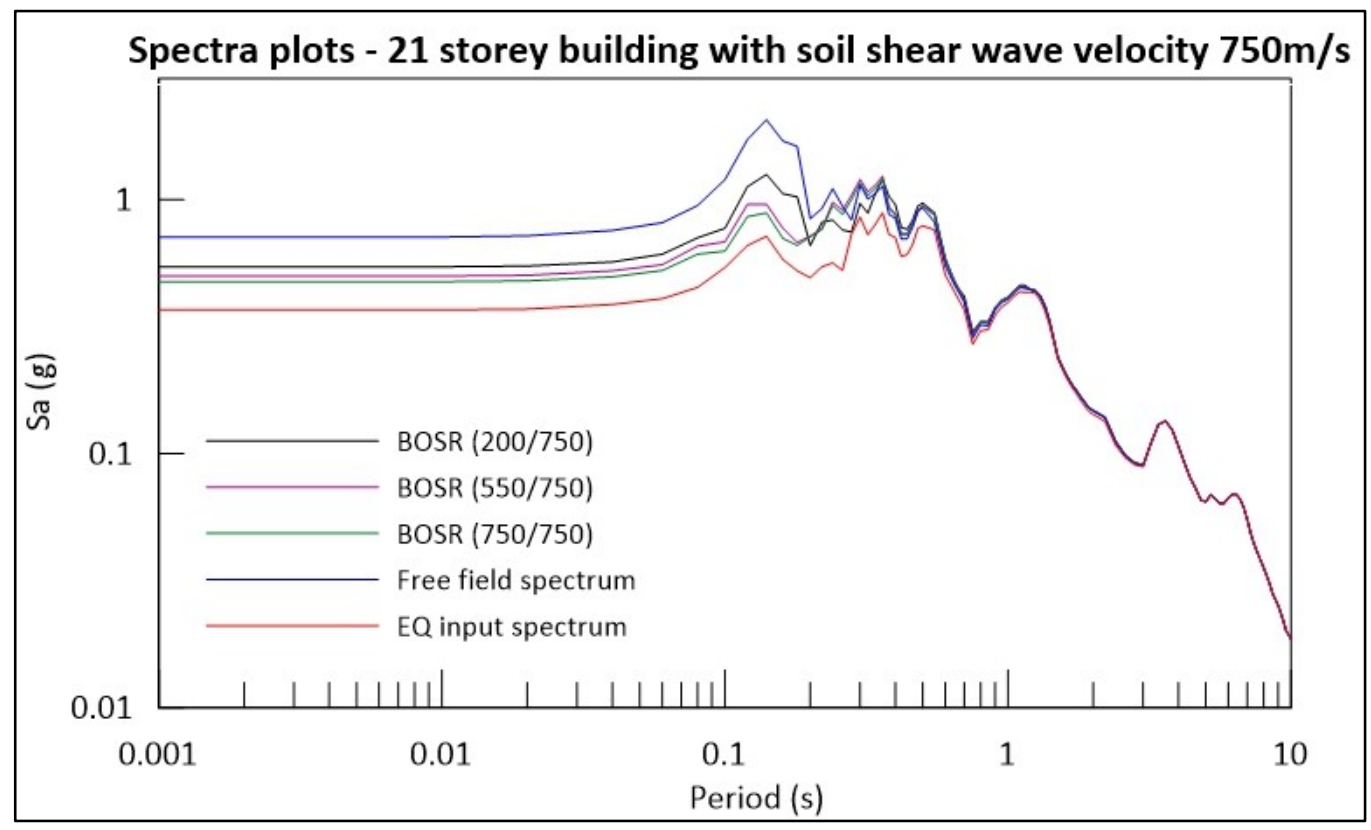

Figure D-4: Spectra plots for 21 storey building, soil type borderline between site class B and site class C $(750 \mathrm{~m} / \mathrm{s})$ 


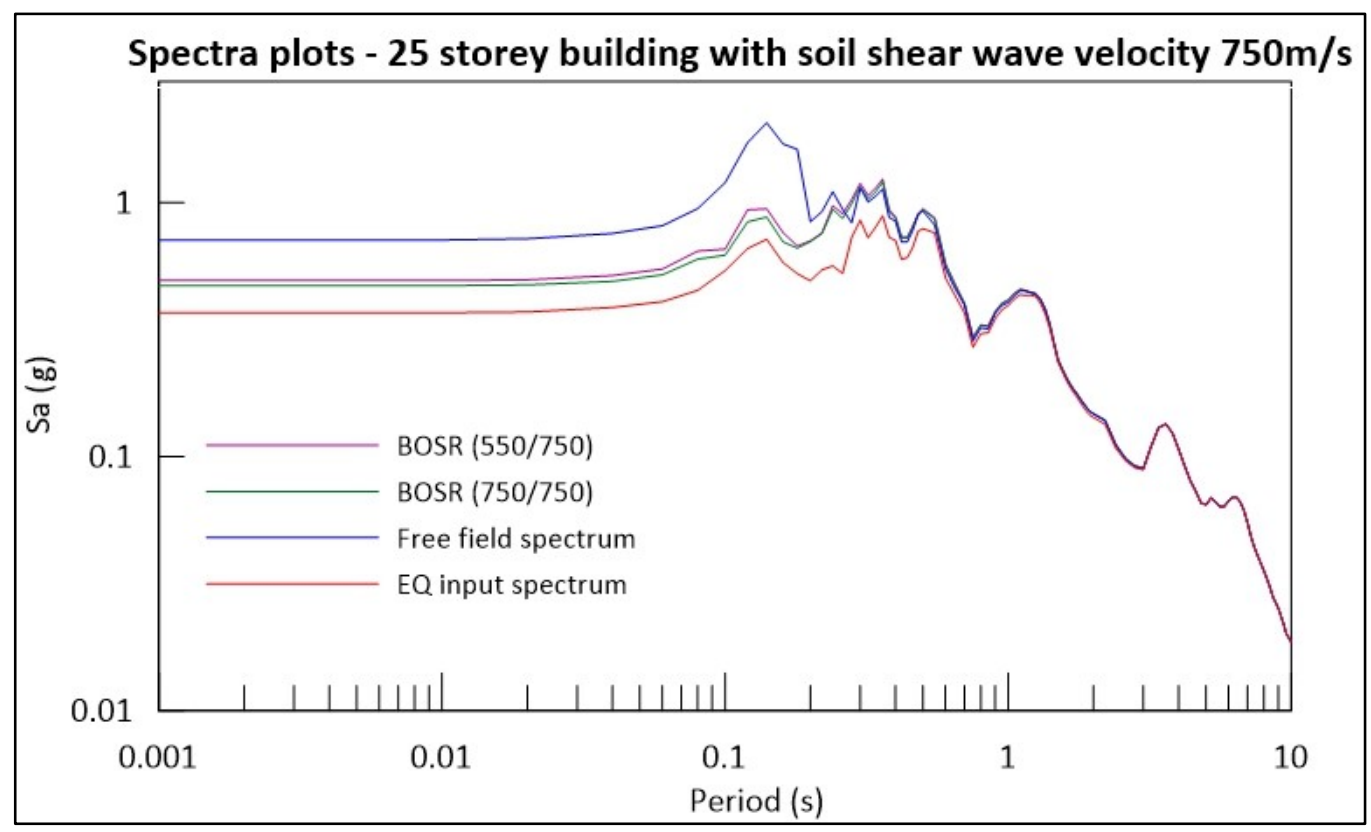

Figure D-5: Spectra plots for 25 storey building, soil type borderline between site class B and site class C $(750 \mathrm{~m} / \mathrm{s})$

$\underline{\text { Soil type middle of site class B case }}$

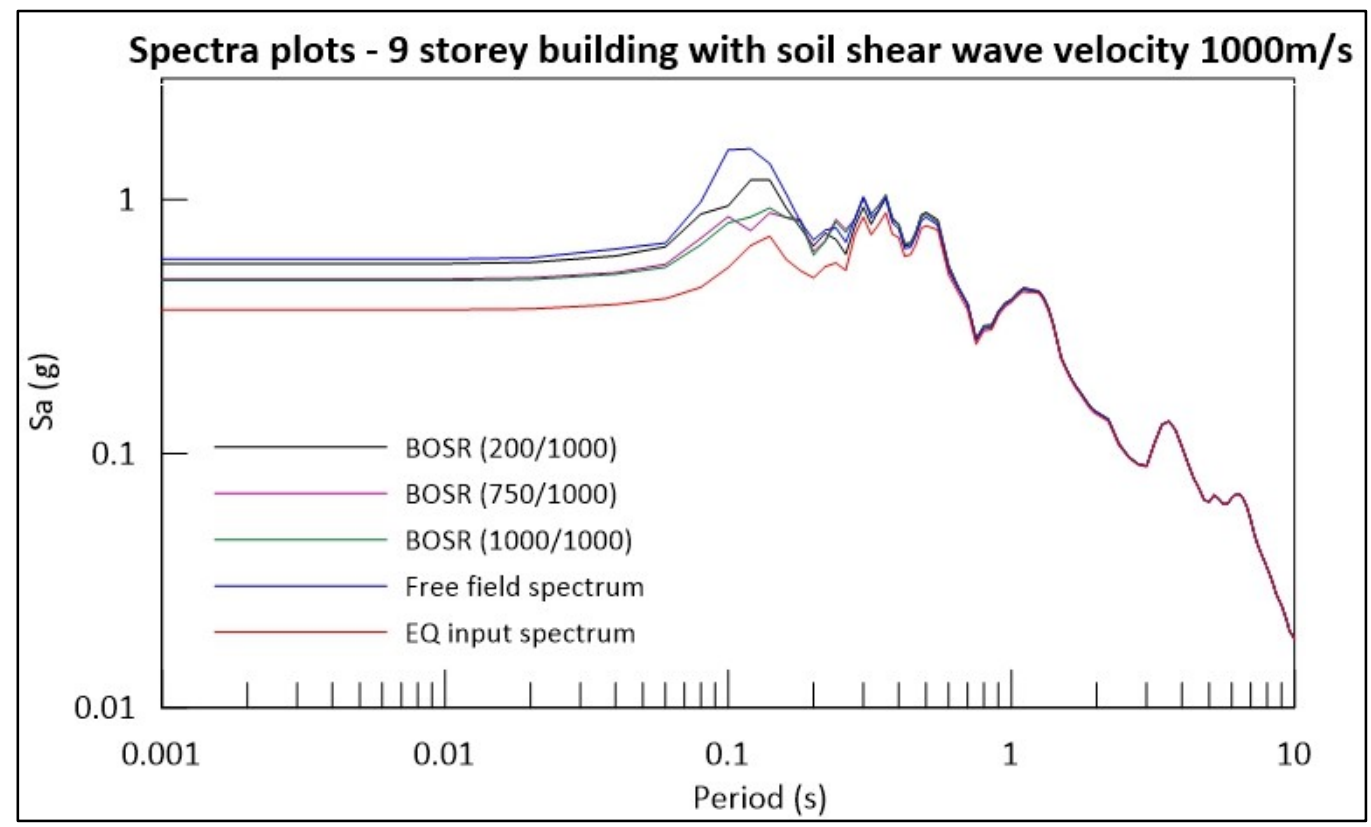

Figure D-6: Spectra plots for 9 storey building, soil type middle of site class B $(1000 \mathrm{~m} / \mathrm{s})$ 


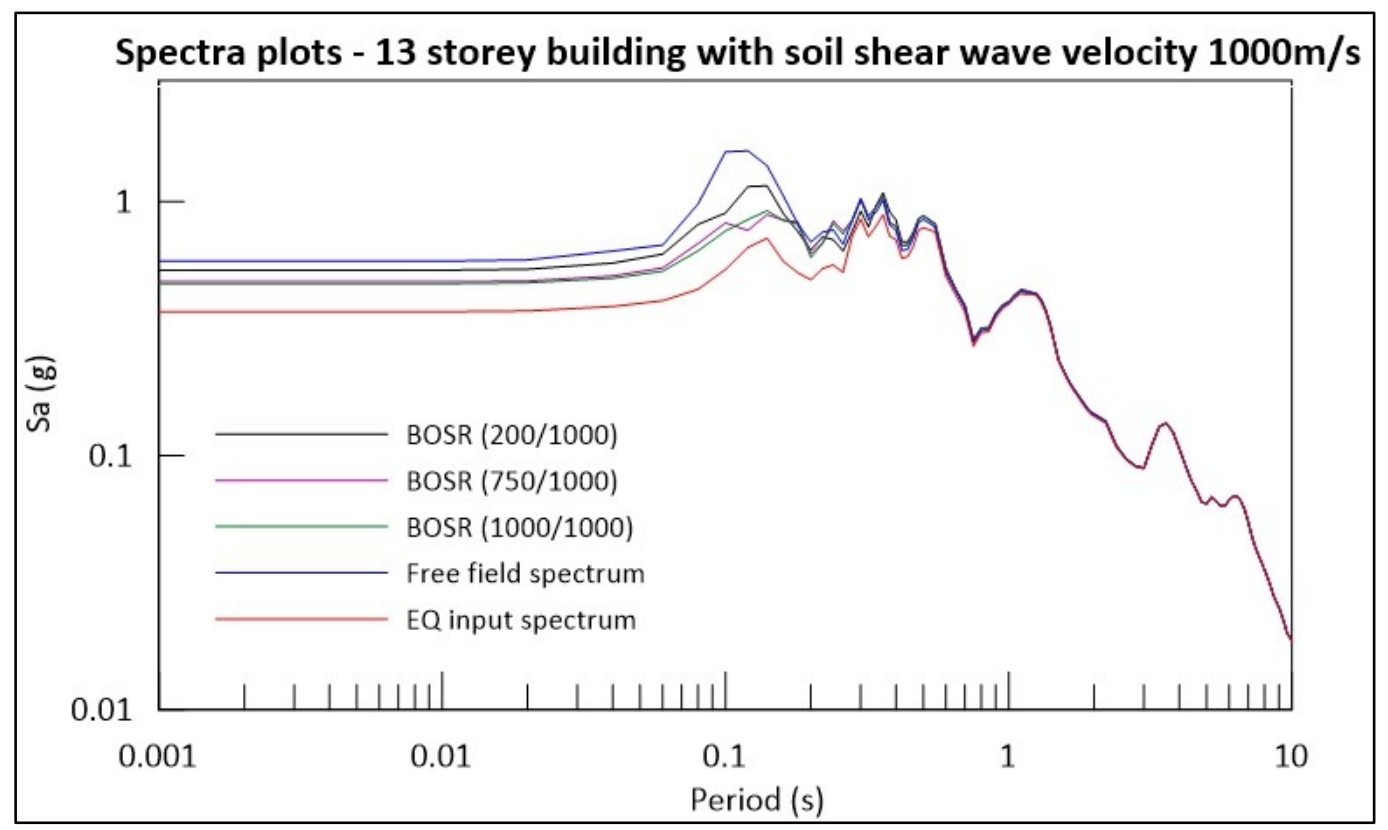

Figure D-7: Spectra plots for 13 storey building, soil type middle of site class B $(1000 \mathrm{~m} / \mathrm{s})$

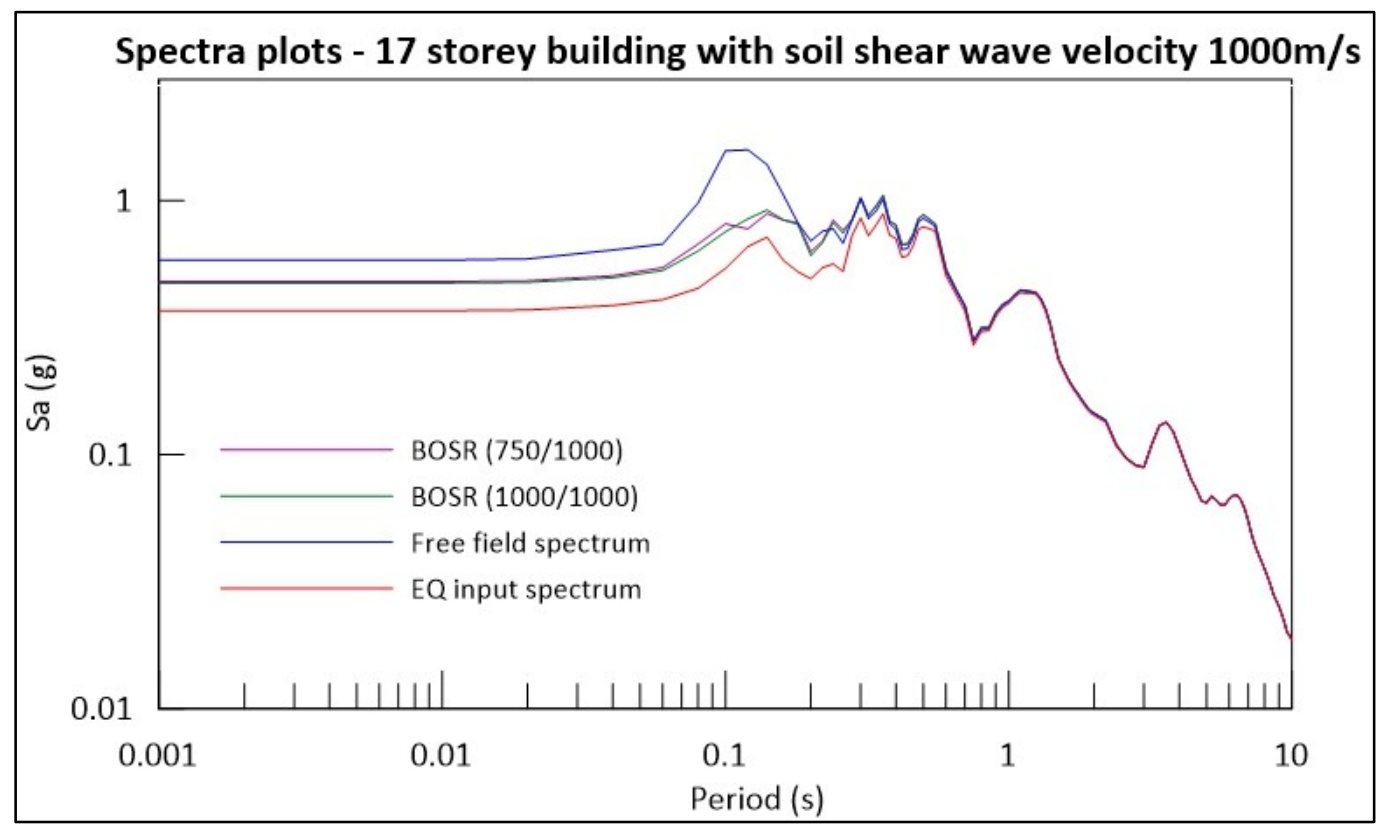

Figure D-8: Spectra plots for 17 storey building, soil type middle of site class B $(1000 \mathrm{~m} / \mathrm{s})$ 


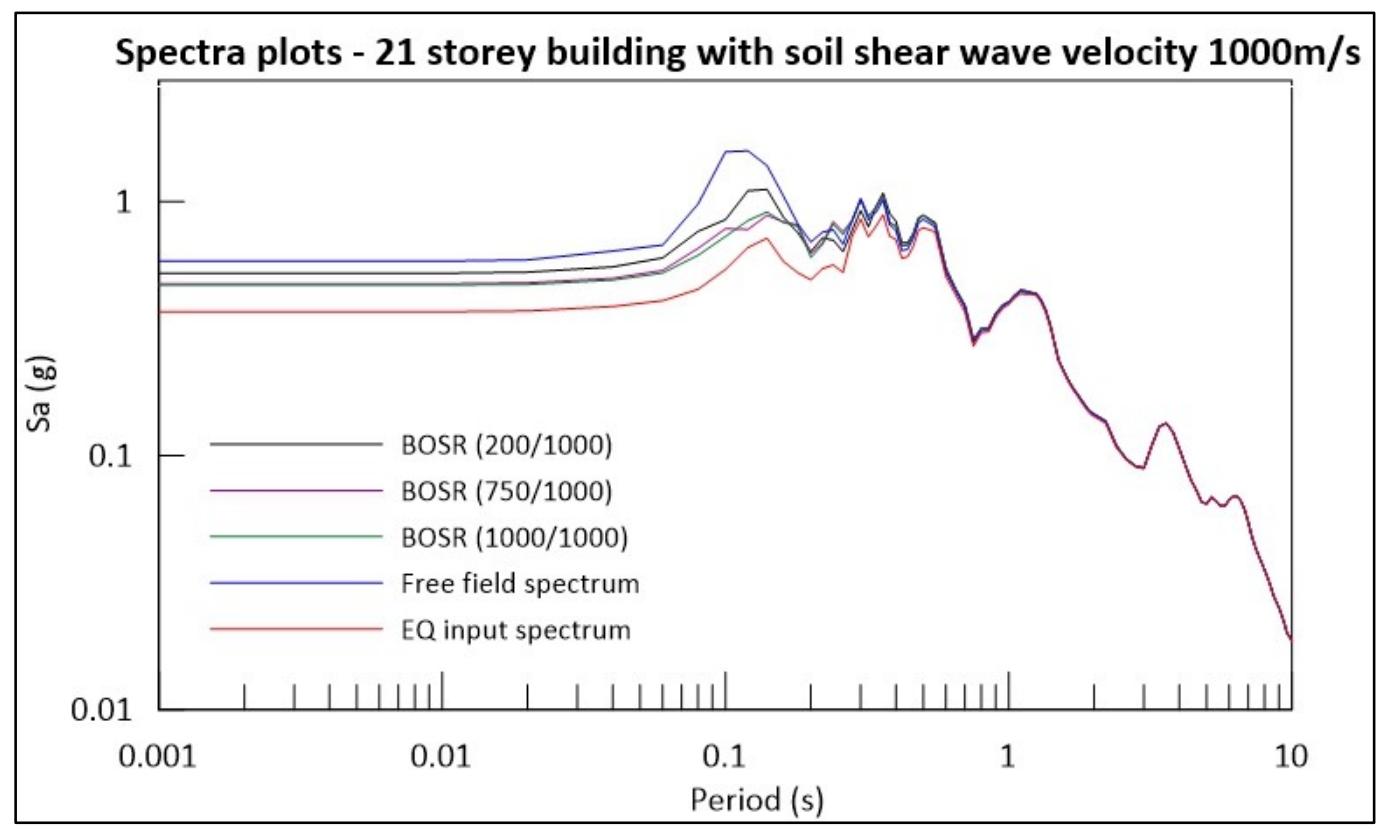

Figure D-9: Spectra plots for 21 storey building, soil type middle of site class B $(1000 \mathrm{~m} / \mathrm{s})$

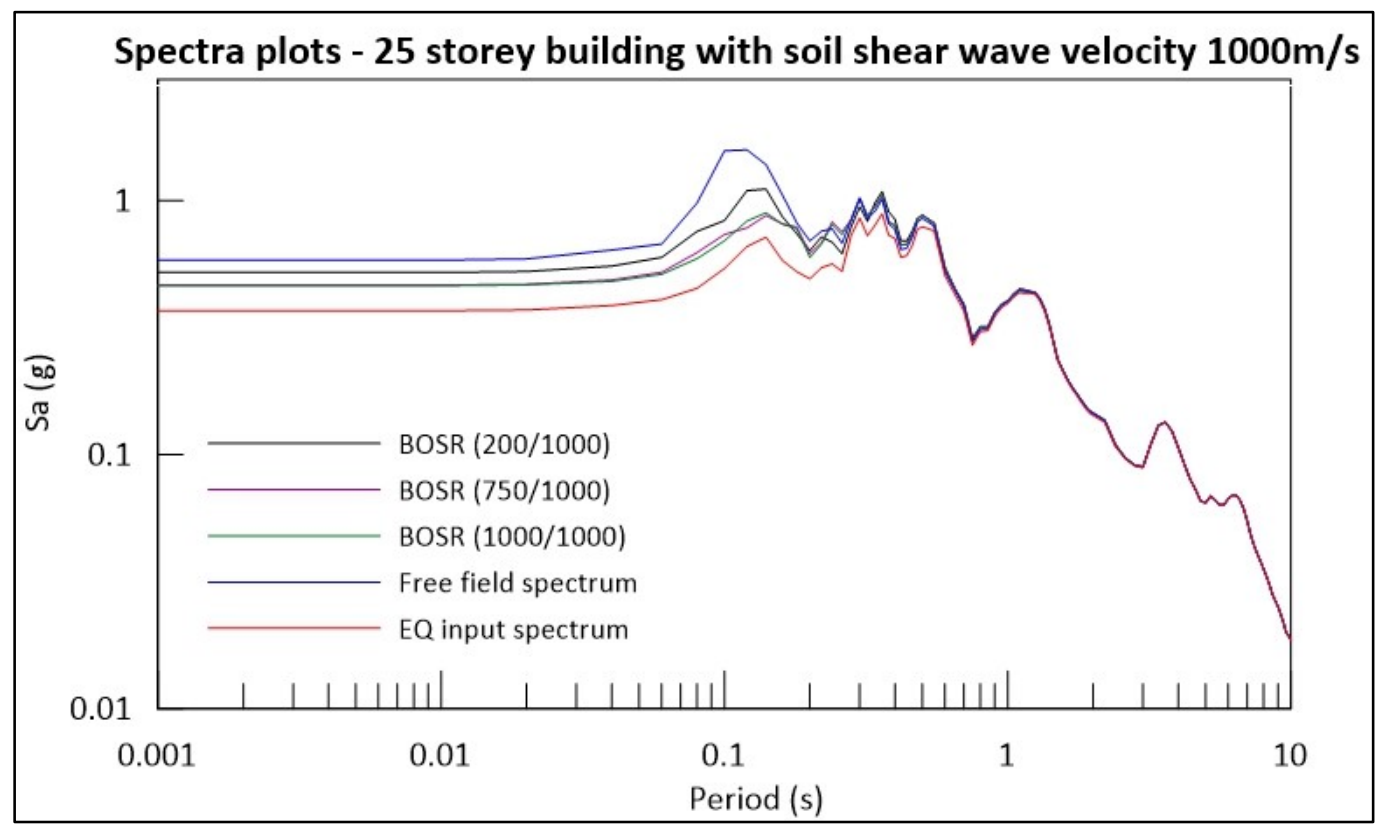

Figure D-10: Spectra plots for 25 storey building, soil type middle of site class B (1000m/s) 


\section{Appendix E - Plots for vertical displacement of the foundation slab}

The vertical displacement of the foundation slab recorded at its end points for varying building heights and different BOSR cases analyzed are as shown in Figure E-1 toFigure E-44. 


\section{$\underline{9 \text { storey building }}$}

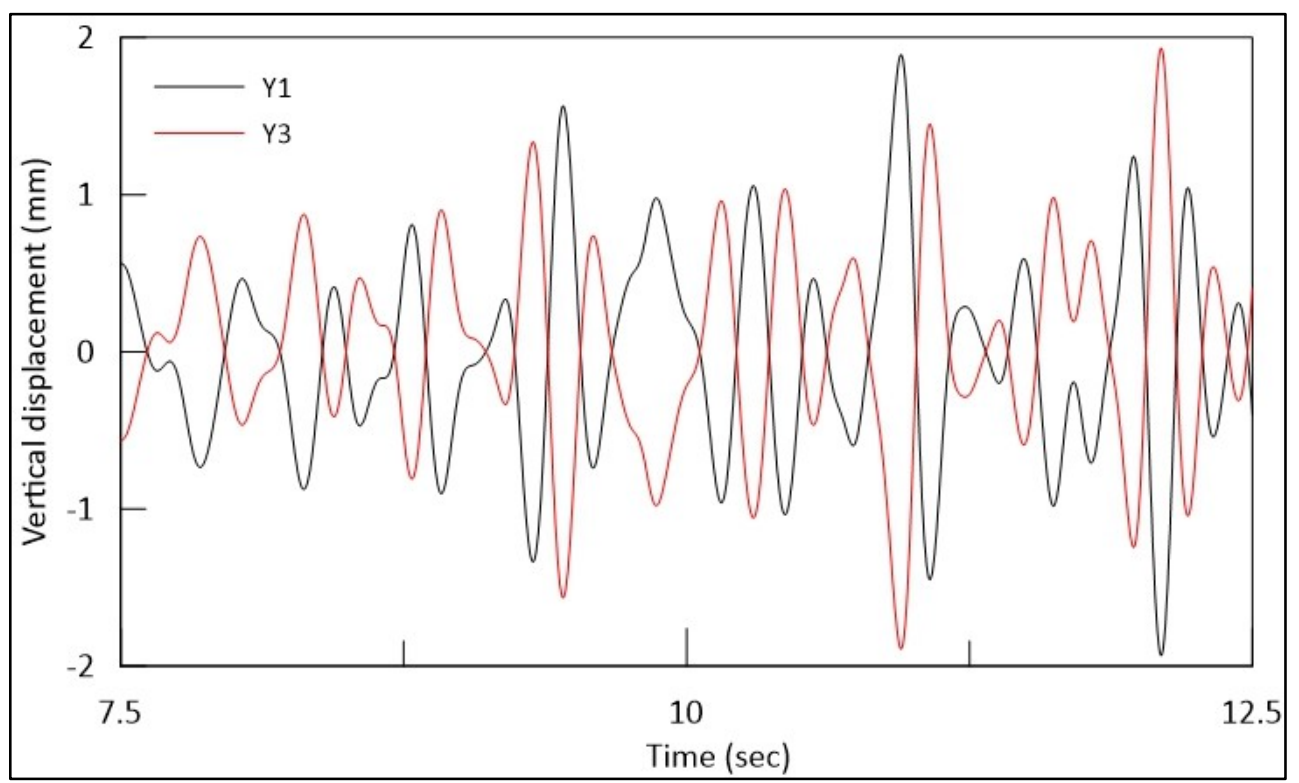

Figure E-1: Vertical displacement at the end points of the foundation for 9 storey building, soil type middle of site class C $(450 \mathrm{~m} / \mathrm{s})$ with side soil having shear wave velocity $300 \mathrm{~m} / \mathrm{s}$

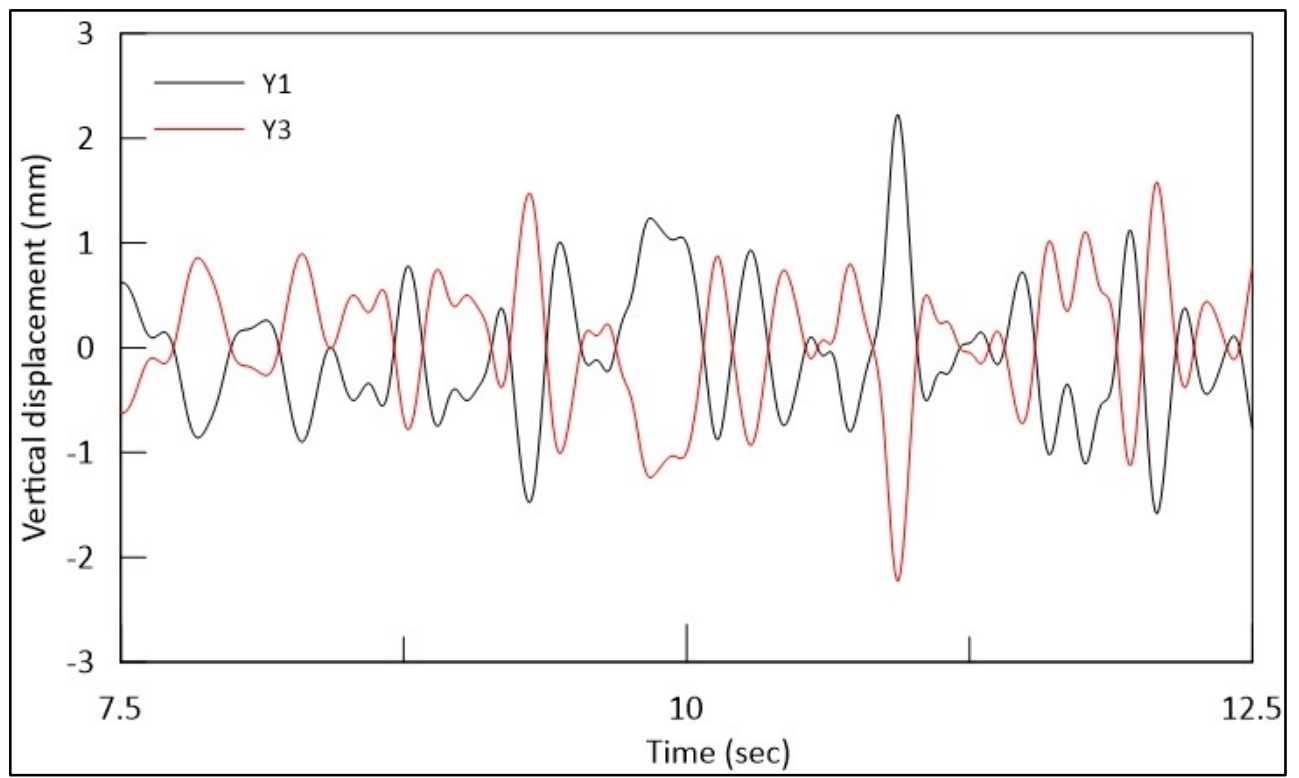

Figure E-2: Vertical displacement at the end points of the foundation for 9 storey building, soil type middle of site class C $(450 \mathrm{~m} / \mathrm{s})$ with side soil having shear wave velocity $450 \mathrm{~m} / \mathrm{s}$ 


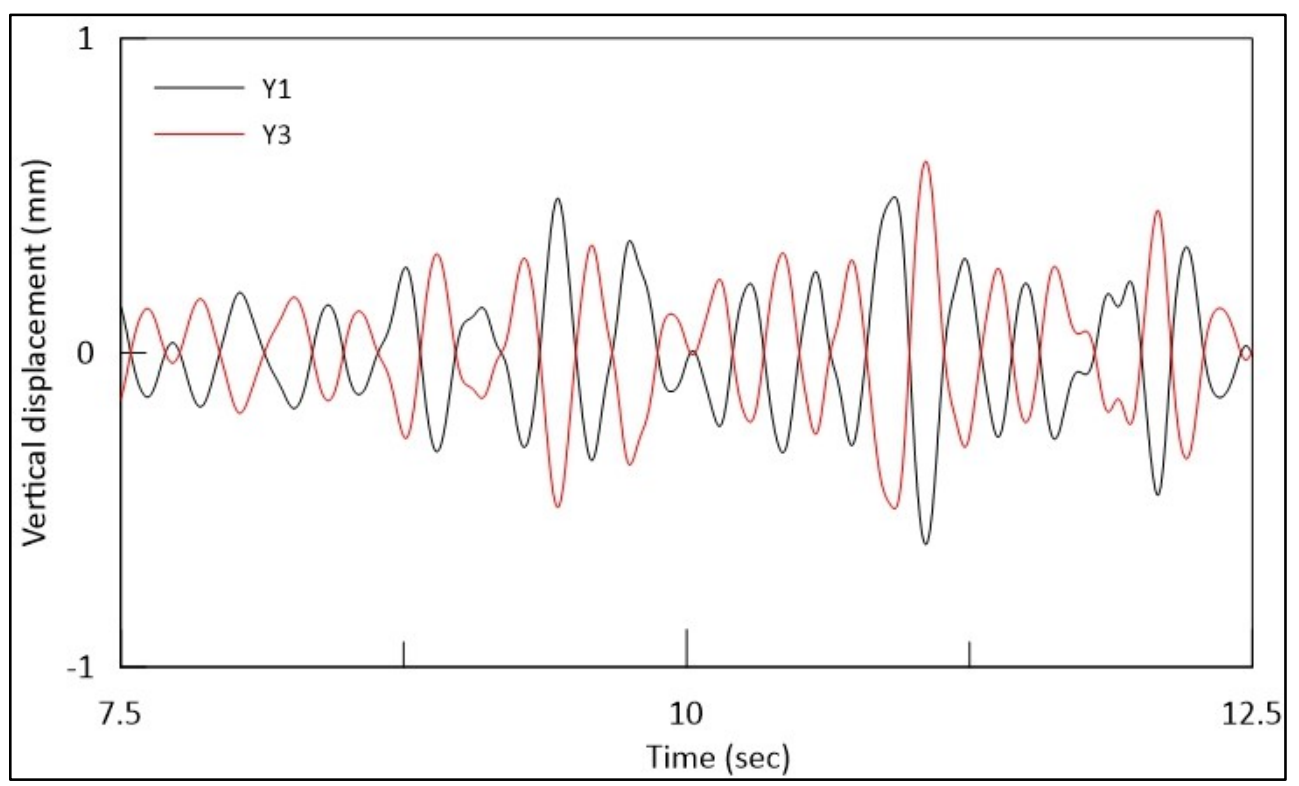

Figure E-3: Vertical displacement at the end points of the foundation for 9 storey building, soil type borderline of site class B and site class C $(750 \mathrm{~m} / \mathrm{s})$ with side soil having shear wave velocity $200 \mathrm{~m} / \mathrm{s}$

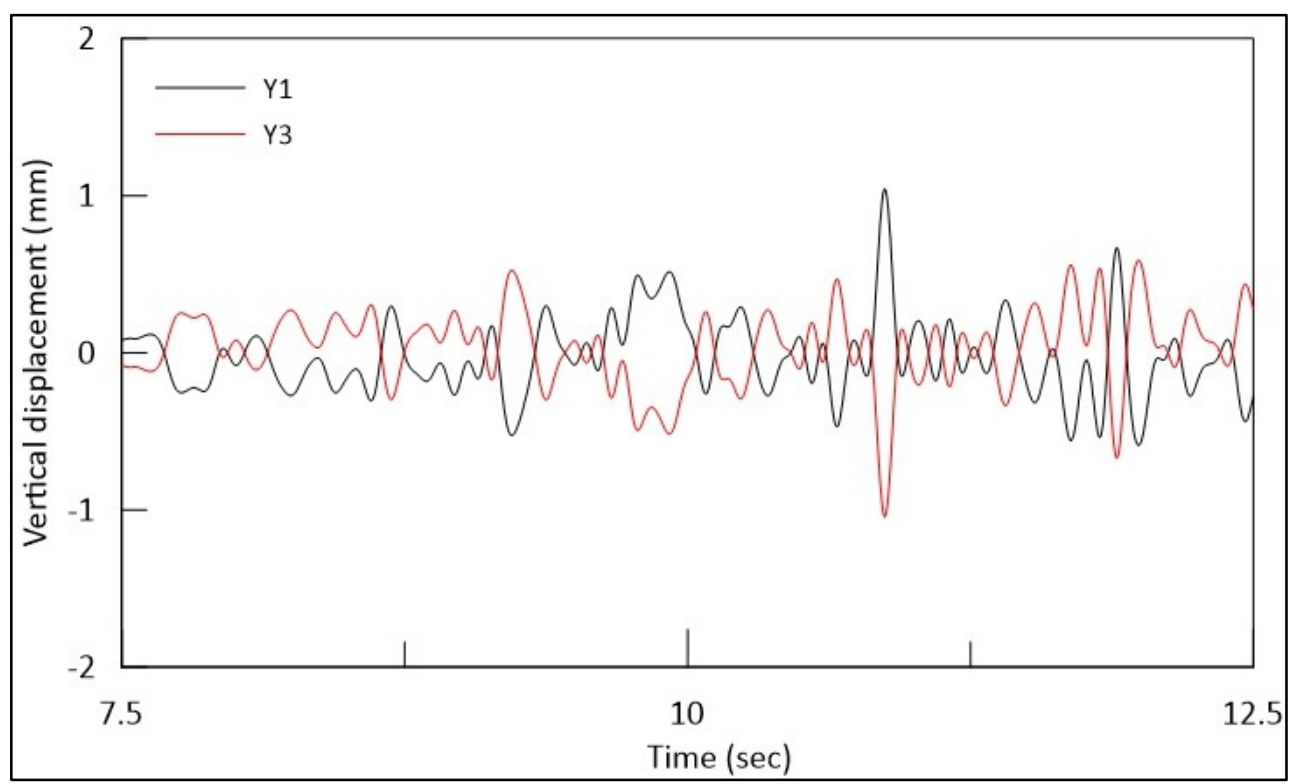

Figure E-4: Vertical displacement at the end points of the foundation for 9 storey building, soil type borderline of site class B and site class C $(750 \mathrm{~m} / \mathrm{s})$ with side soil having shear wave velocity $550 \mathrm{~m} / \mathrm{s}$ 


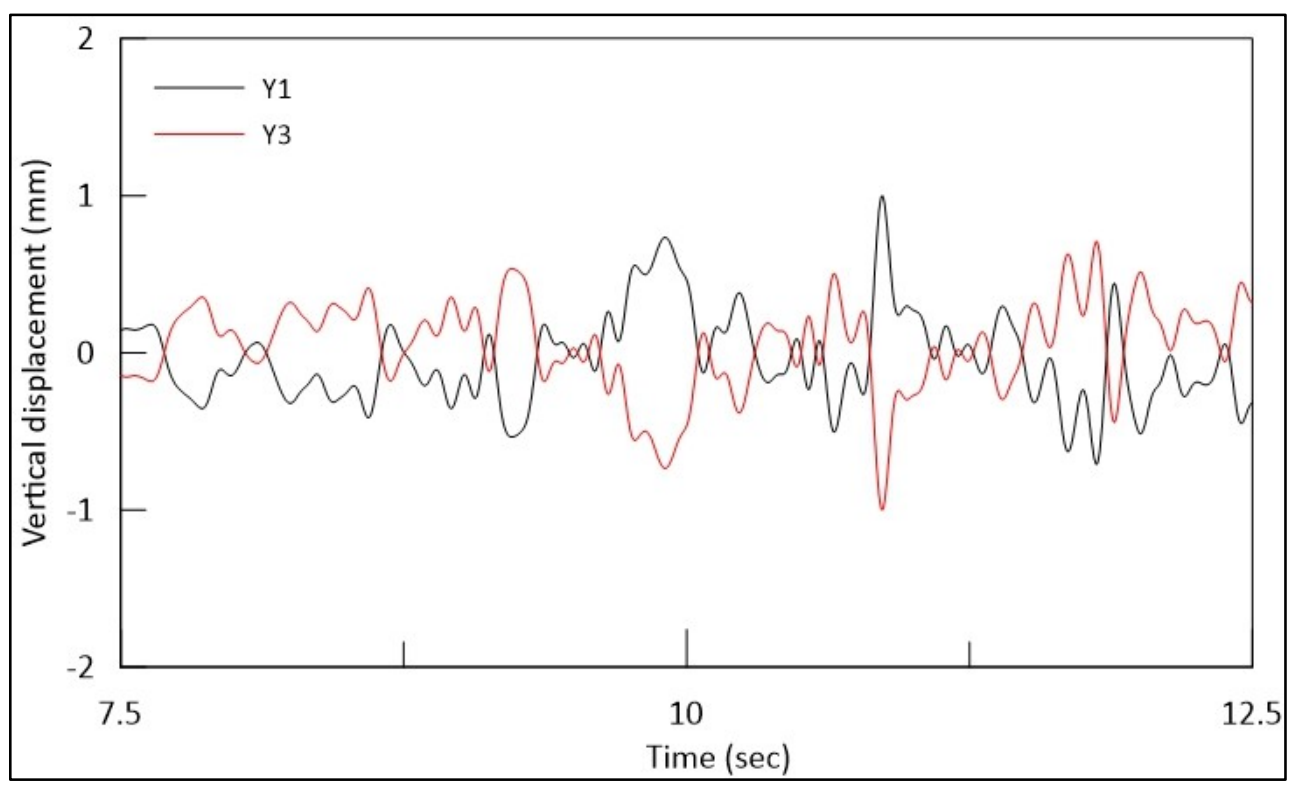

Figure E-5: Vertical displacement at the end points of the foundation for 9 storey building, soil type borderline of site class B and site class C $(750 \mathrm{~m} / \mathrm{s})$ case with side soil having shear wave velocity $750 \mathrm{~m} / \mathrm{s}$

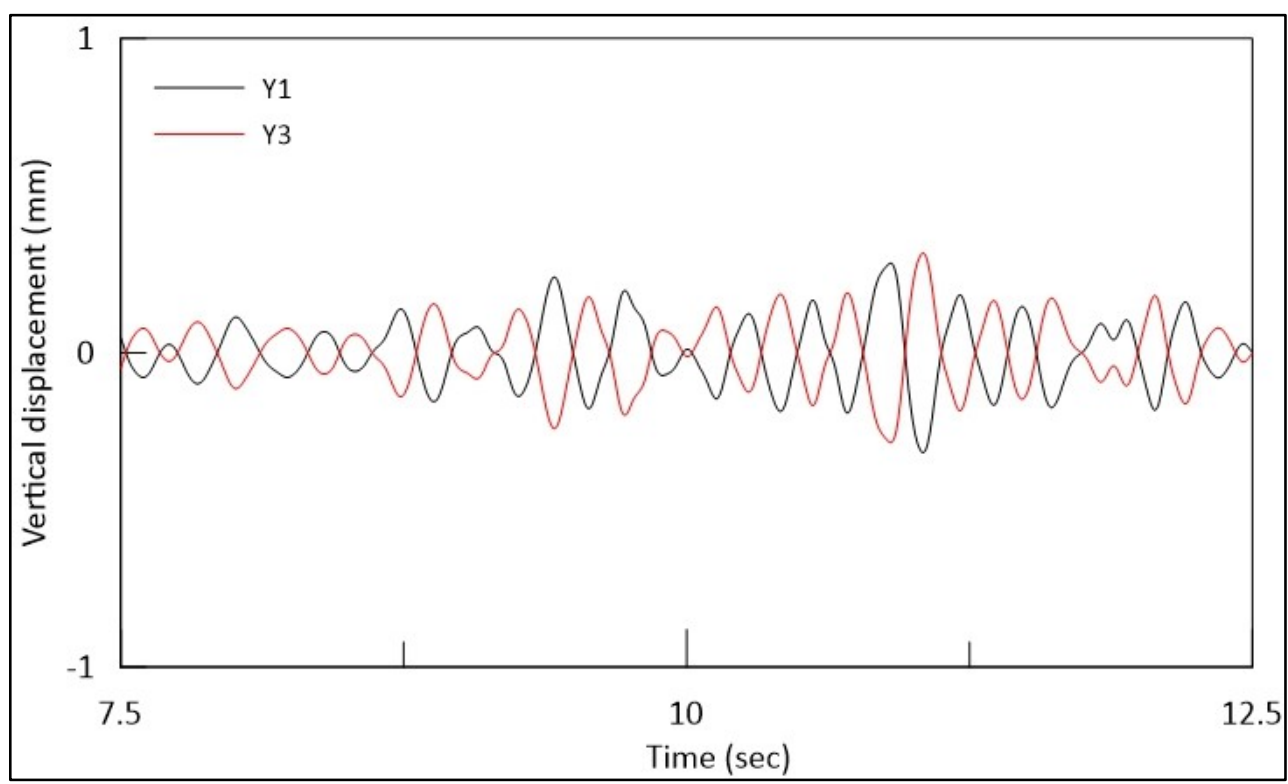

Figure E-6: Vertical displacement at the end points of the foundation for 9 storey building, soil type middle of site class B $(1000 \mathrm{~m} / \mathrm{s})$ with side soil having shear wave velocity $200 \mathrm{~m} / \mathrm{s}$ 


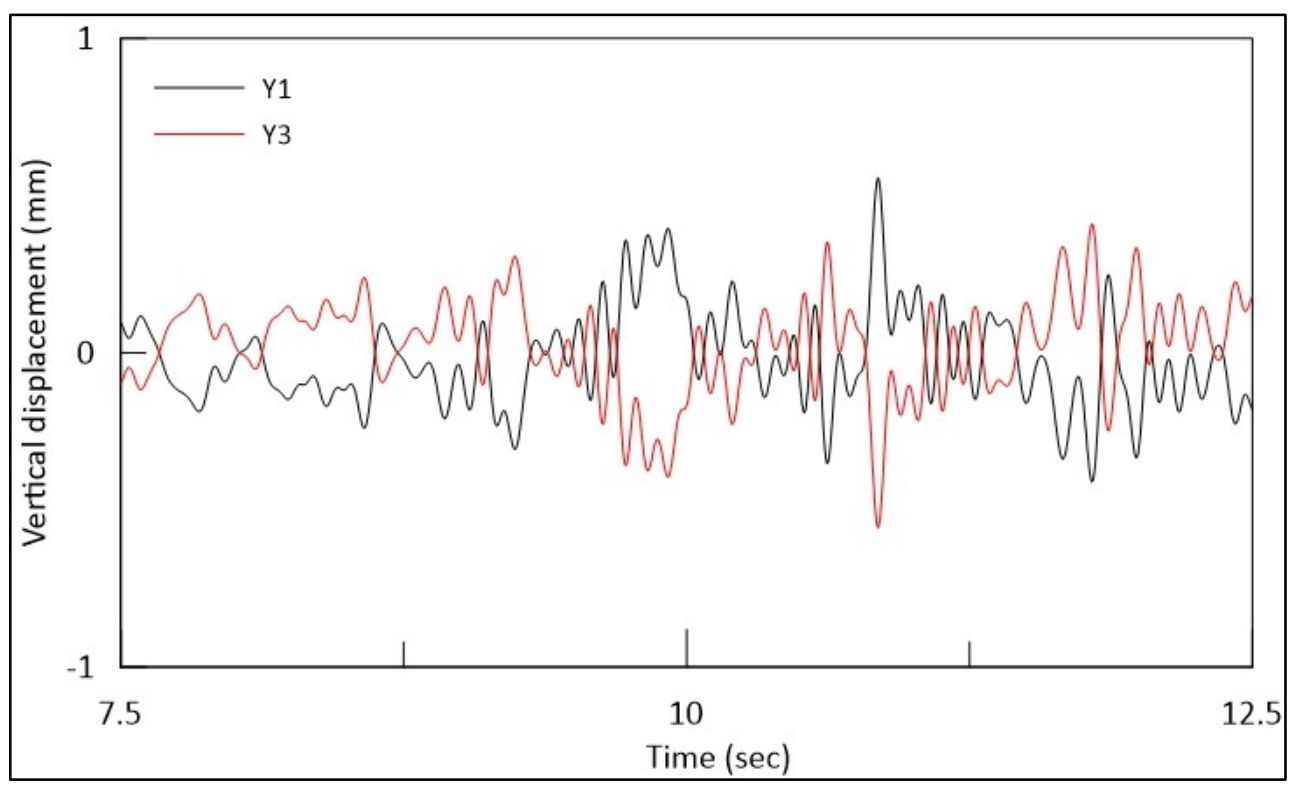

Figure E-7: Vertical displacement at the end points of the foundation for 9 storey building, soil type middle of site class B $(1000 \mathrm{~m} / \mathrm{s})$ with side soil having shear wave velocity $750 \mathrm{~m} / \mathrm{s}$

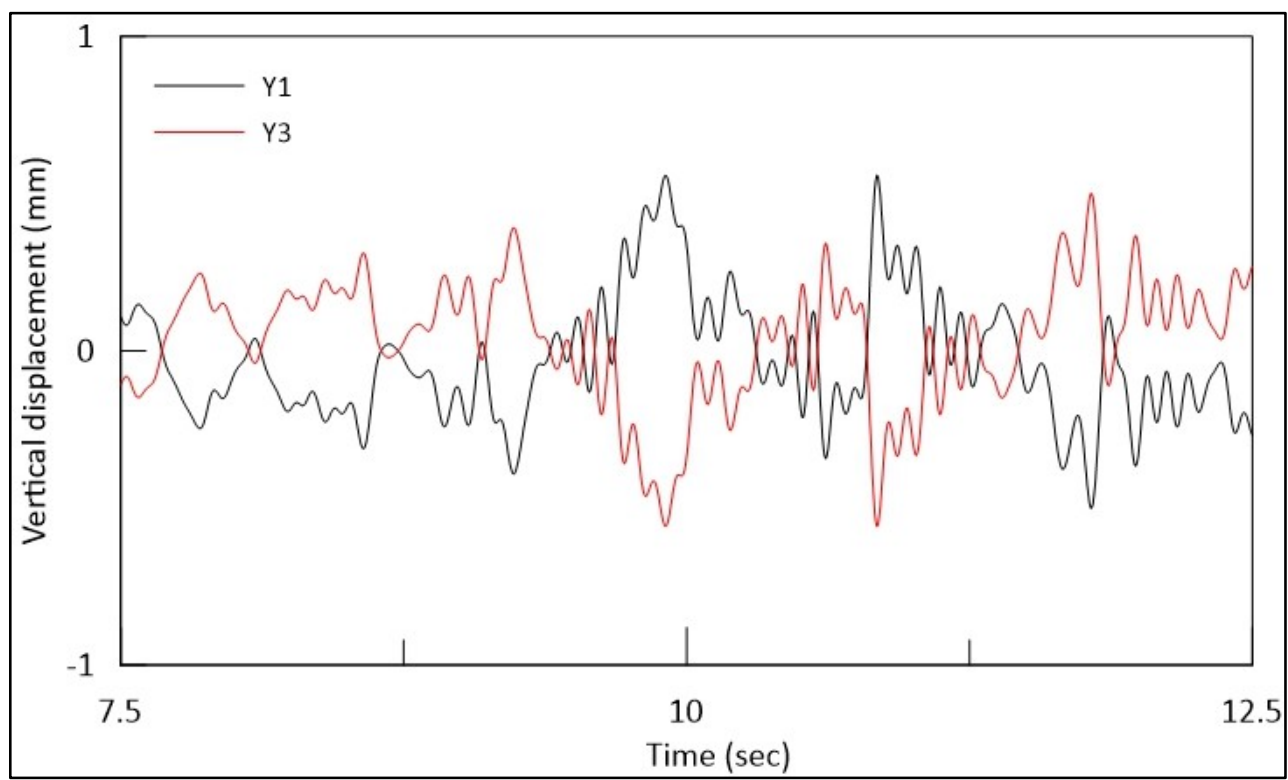

Figure E-8: Vertical displacement at the end points of the foundation for 9 storey building, soil type middle of site class B $(1000 \mathrm{~m} / \mathrm{s})$ with side soil having shear wave velocity $1000 \mathrm{~m} / \mathrm{s}$ 


\section{$\underline{13 \text { storey building results }}$}

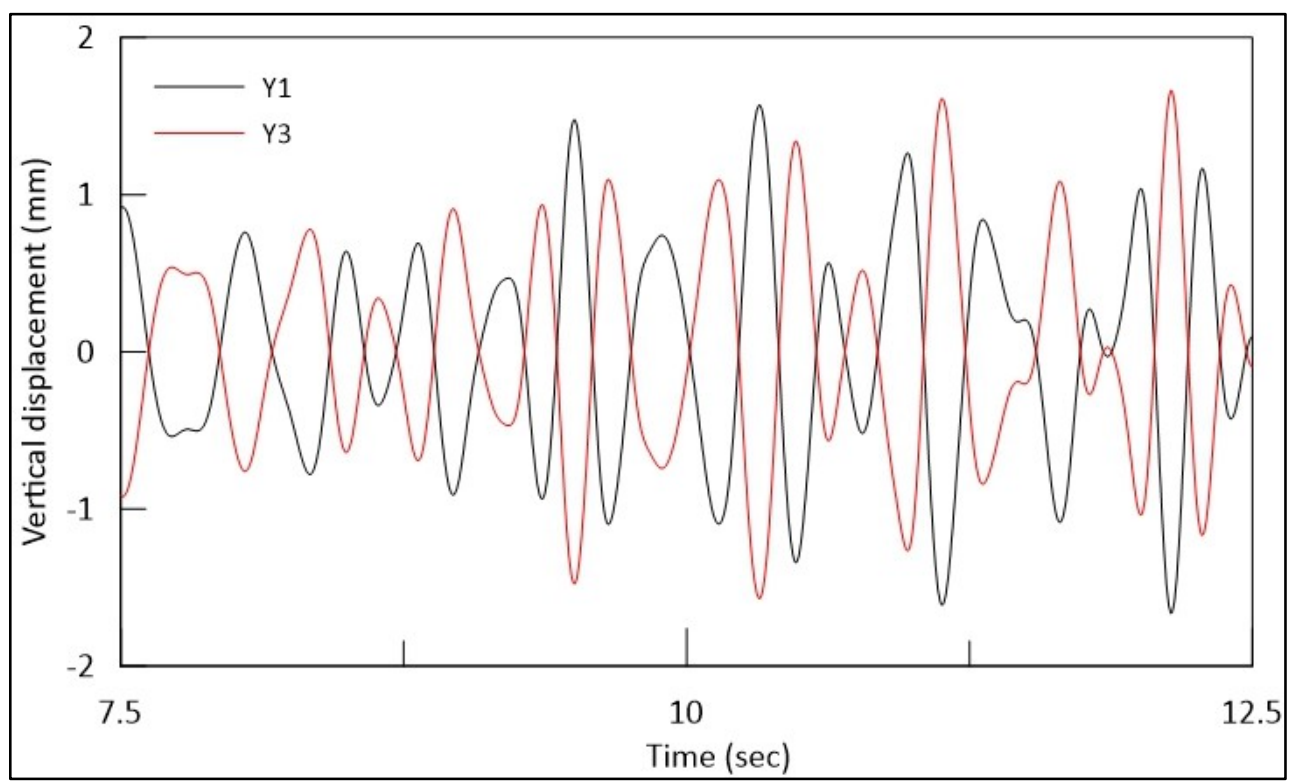

Figure E-9: Vertical displacement at the end points of the foundation for 13 storey building, soil type middle of site class C $(450 \mathrm{~m} / \mathrm{s})$ with side soil having shear wave velocity $200 \mathrm{~m} / \mathrm{s}$

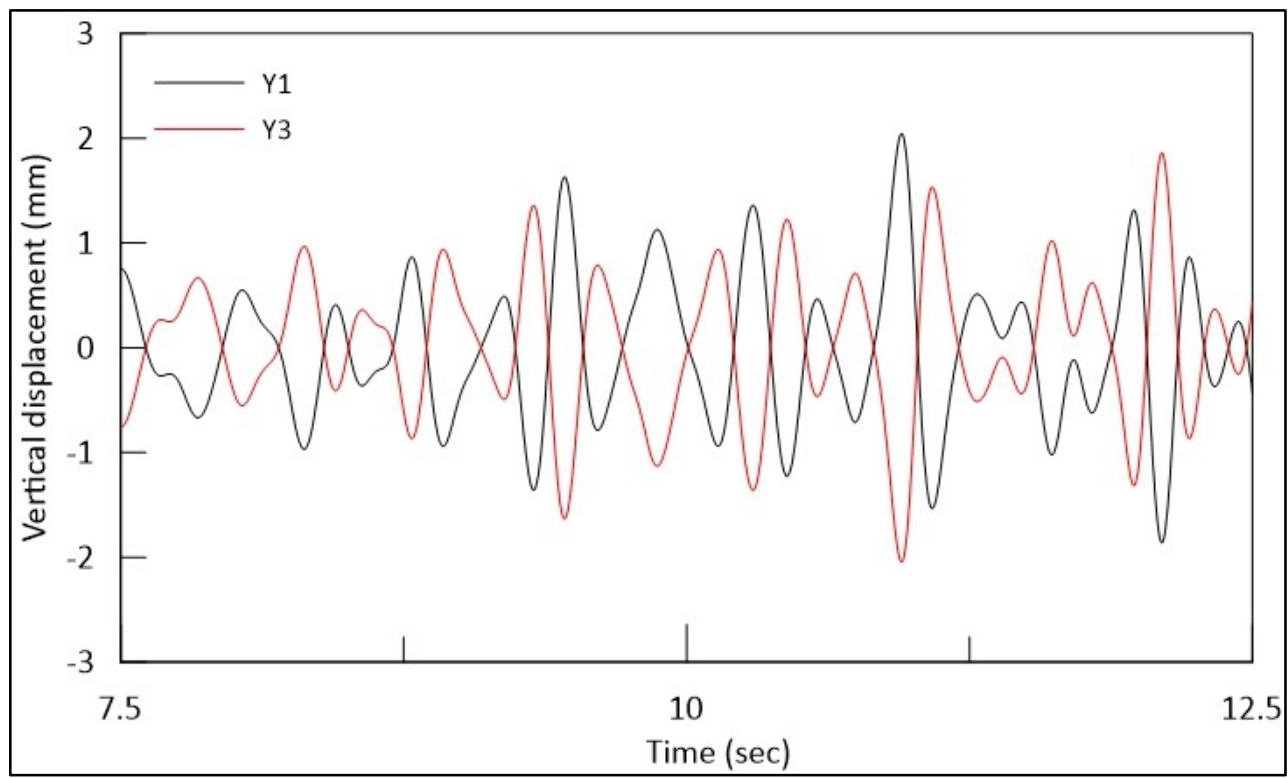

Figure E-10: Vertical displacement at the end points of the foundation for 13 storey building, soil type middle of site class C $(450 \mathrm{~m} / \mathrm{s})$ with side soil having shear wave velocity $300 \mathrm{~m} / \mathrm{s}$ 


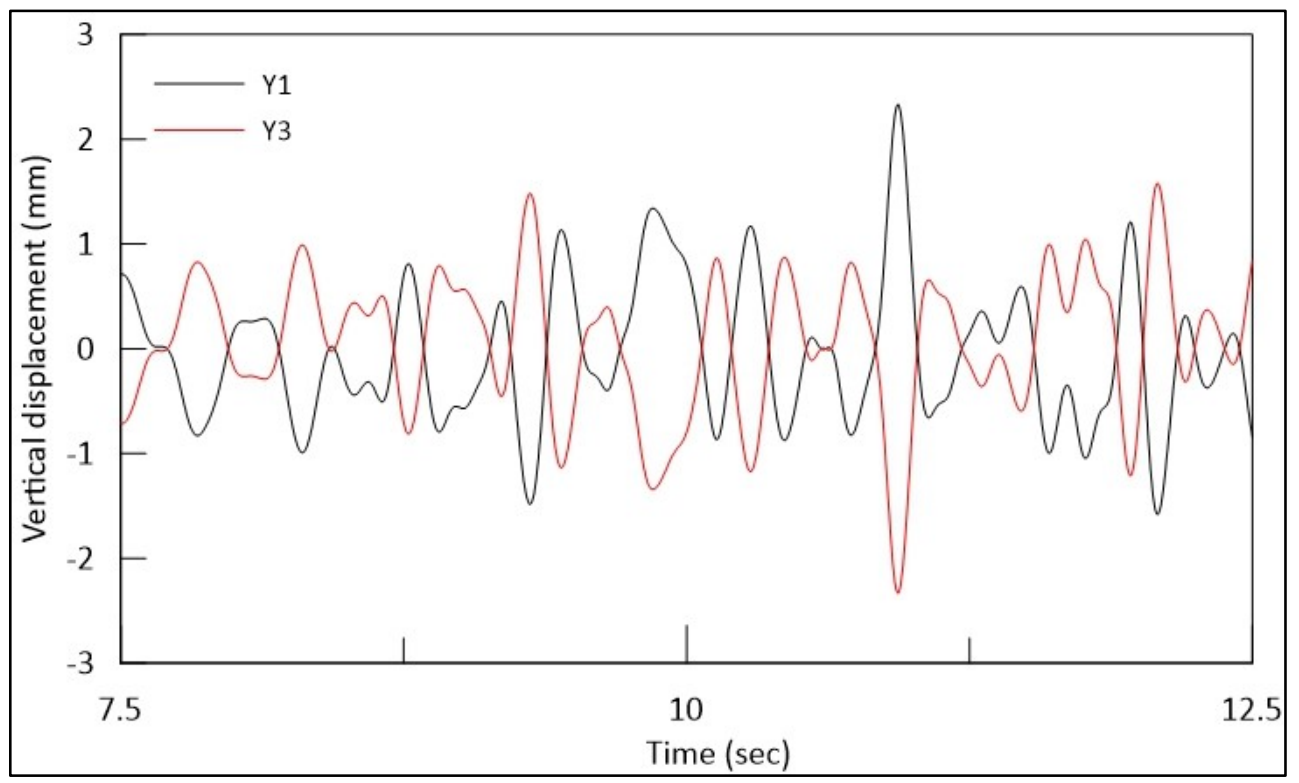

Figure E-11: Vertical displacement at the end points of the foundation for 13 storey building, soil type middle of site class C $(450 \mathrm{~m} / \mathrm{s})$ with side soil having shear wave velocity $450 \mathrm{~m} / \mathrm{s}$

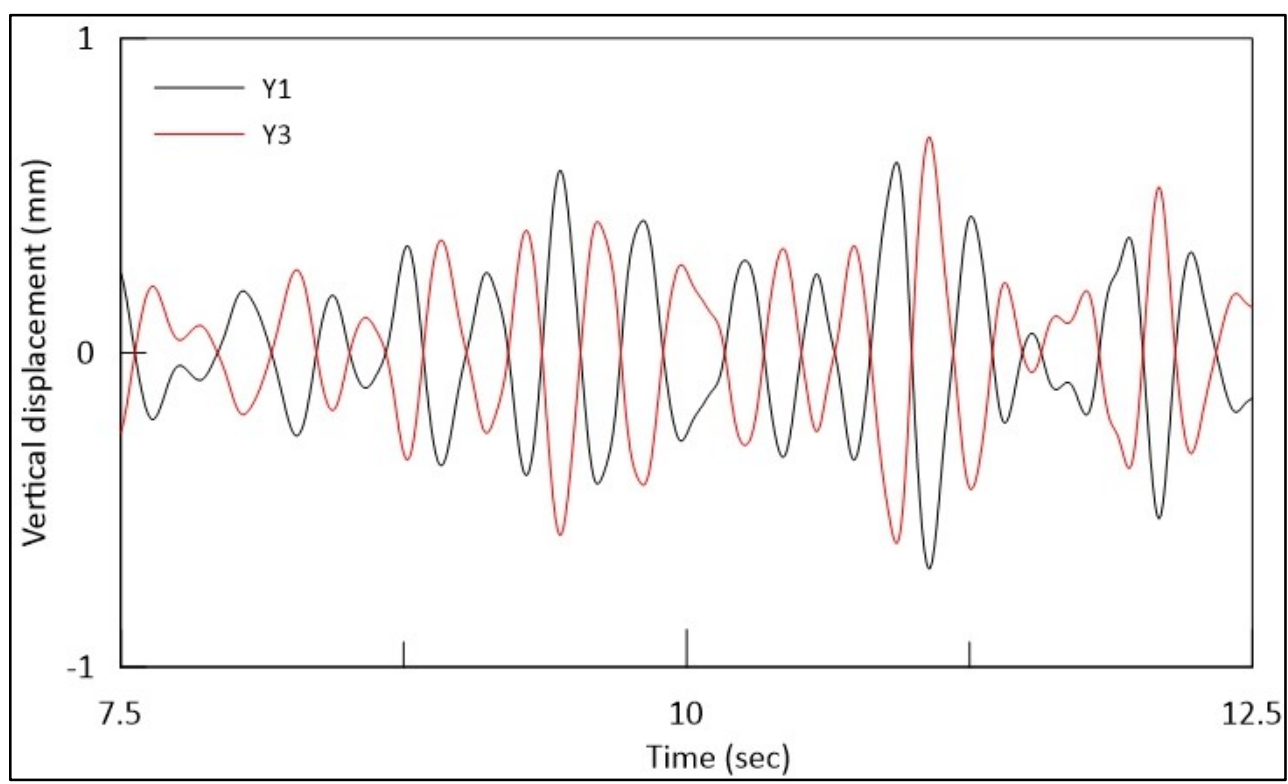

Figure E-12: Vertical displacement at the end points of the foundation for 13 storey building, soil type borderline of site class B and site class C $(750 \mathrm{~m} / \mathrm{s})$ with side soil having shear wave velocity $200 \mathrm{~m} / \mathrm{s}$ 


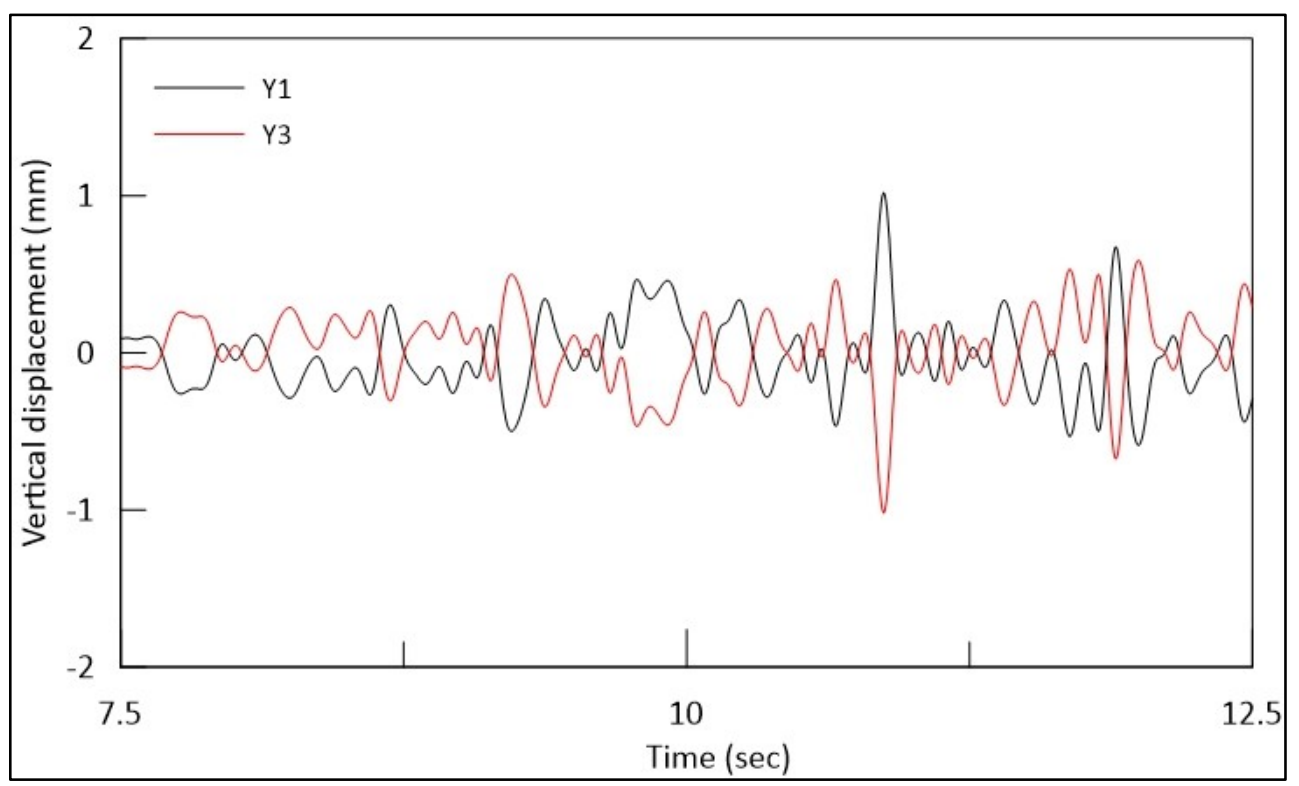

Figure E-13: Vertical displacement at the end points of the foundation for 13 storey building, soil type borderline of site class B and site class C $(750 \mathrm{~m} / \mathrm{s})$ with side soil having shear wave velocity $550 \mathrm{~m} / \mathrm{s}$

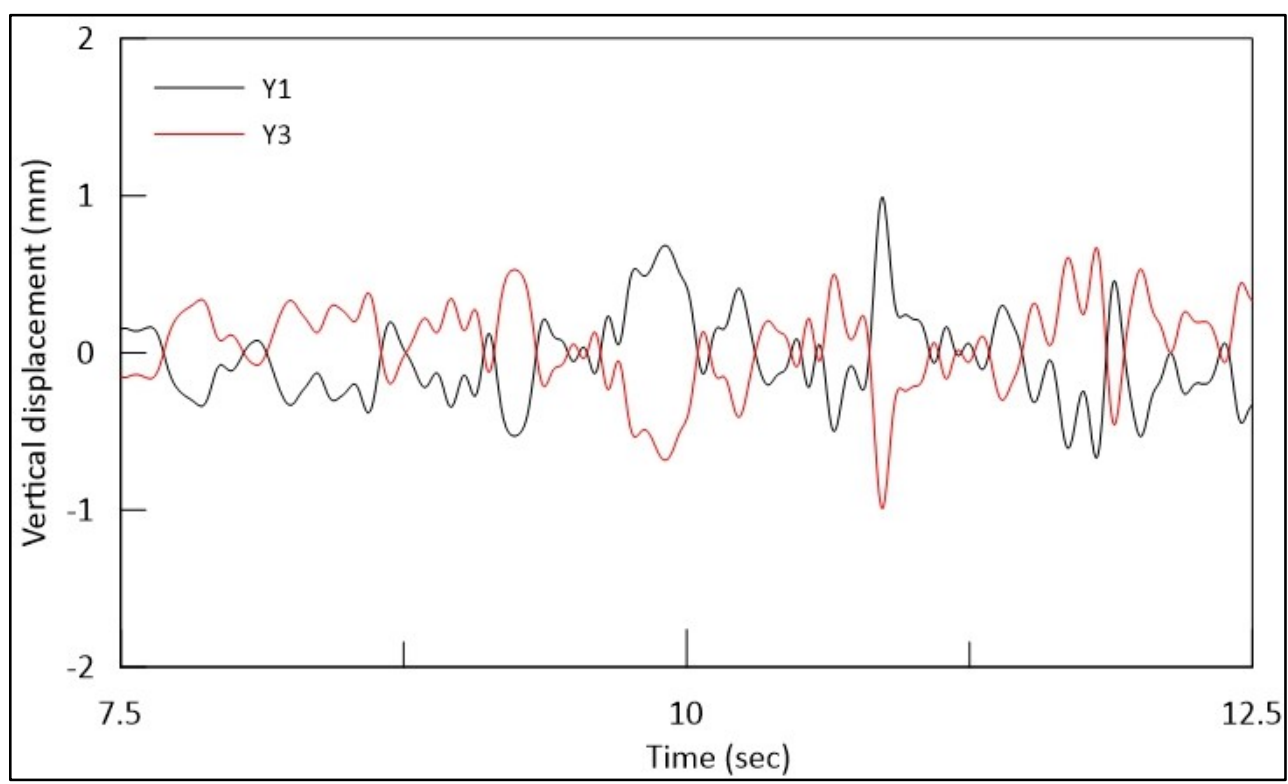

Figure E-14: Vertical displacement at the end points of the foundation for 13 storey building, soil type borderline of site class B and site class C $(750 \mathrm{~m} / \mathrm{s})$ with side soil having shear wave velocity $750 \mathrm{~m} / \mathrm{s}$ 


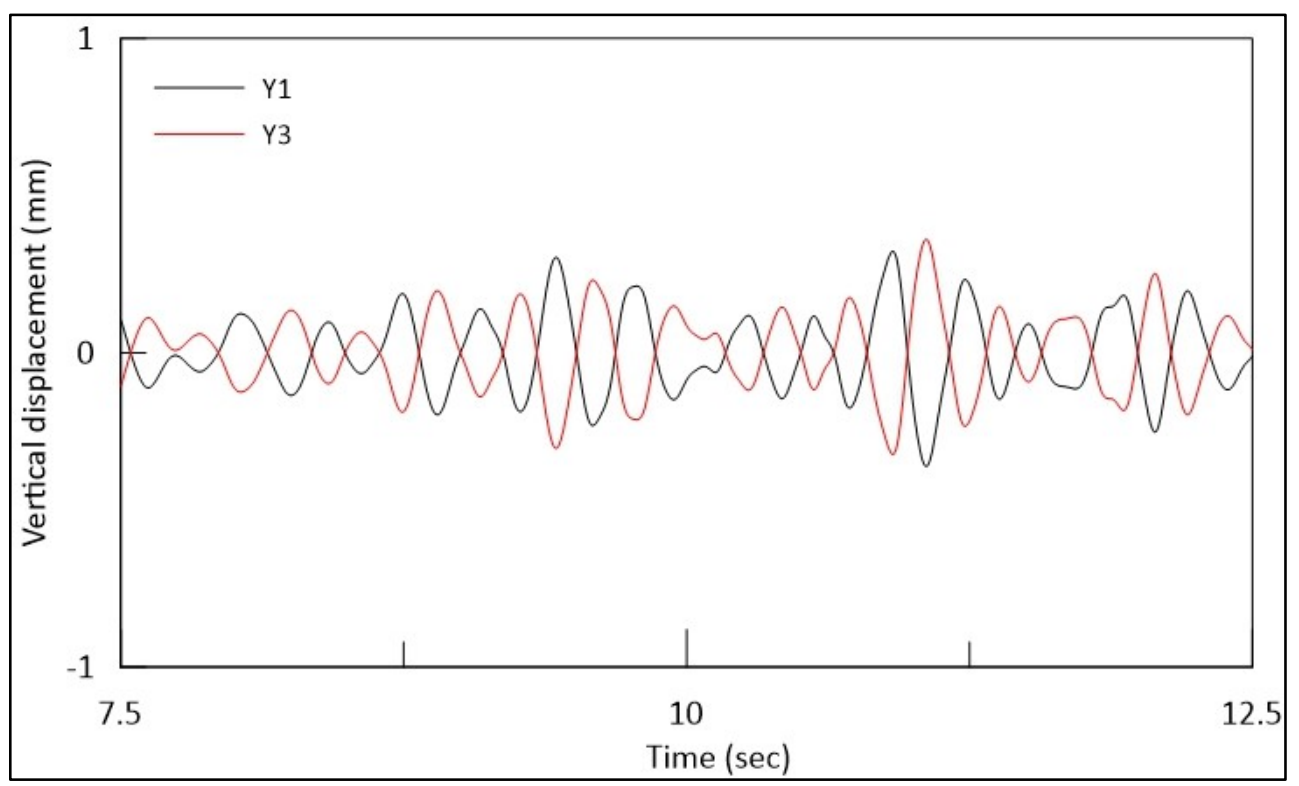

Figure E-15: Vertical displacement at the end points of the foundation for 13 storey building, soil type middle of site class B $(1000 \mathrm{~m} / \mathrm{s})$ with side soil having shear wave velocity $200 \mathrm{~m} / \mathrm{s}$

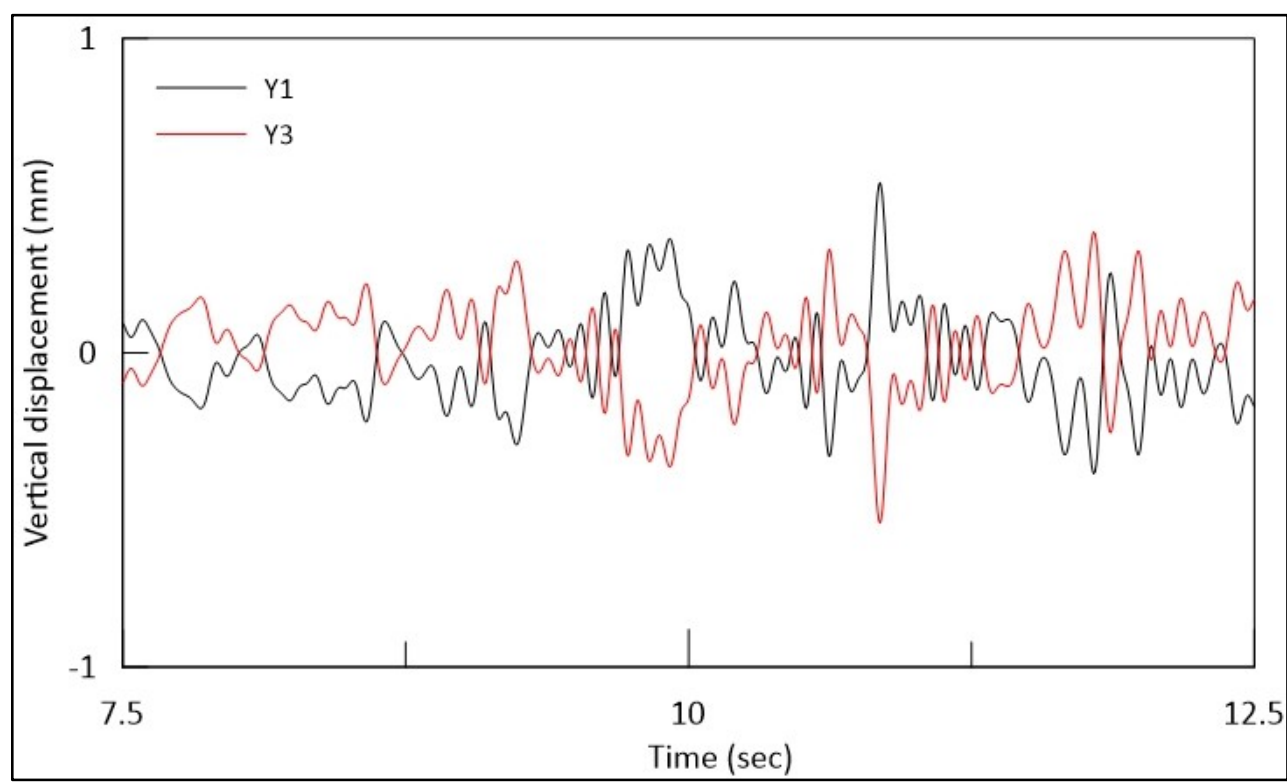

Figure E-16: Vertical displacement at the end points of the foundation for 13 storey building, soil type middle of site class B $(1000 \mathrm{~m} / \mathrm{s})$ with side soil having shear wave velocity $750 \mathrm{~m} / \mathrm{s}$ 


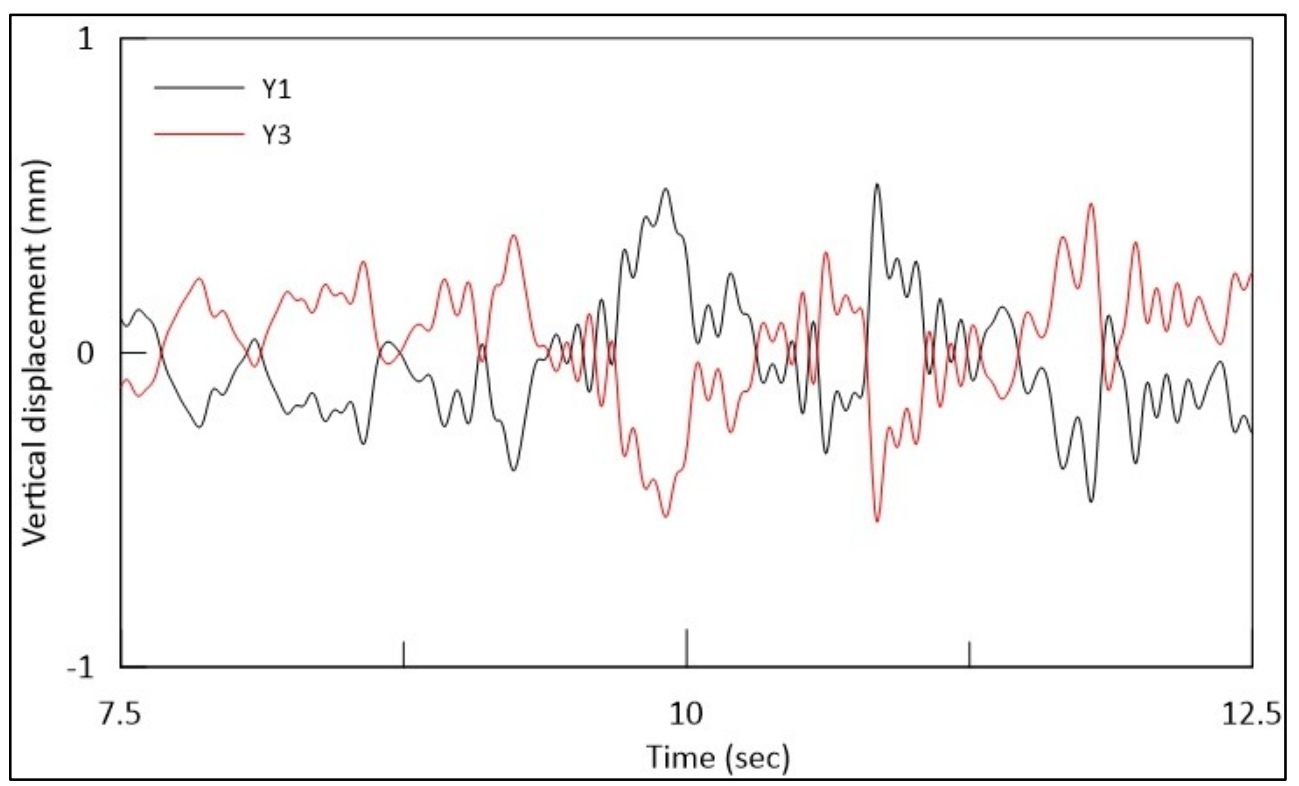

Figure E-17: Vertical displacement at the end points of the foundation for 13 storey building, soil type middle of site class B $(1000 \mathrm{~m} / \mathrm{s})$ with side soil having shear wave velocity $1000 \mathrm{~m} / \mathrm{s}$

\section{7 storey building}

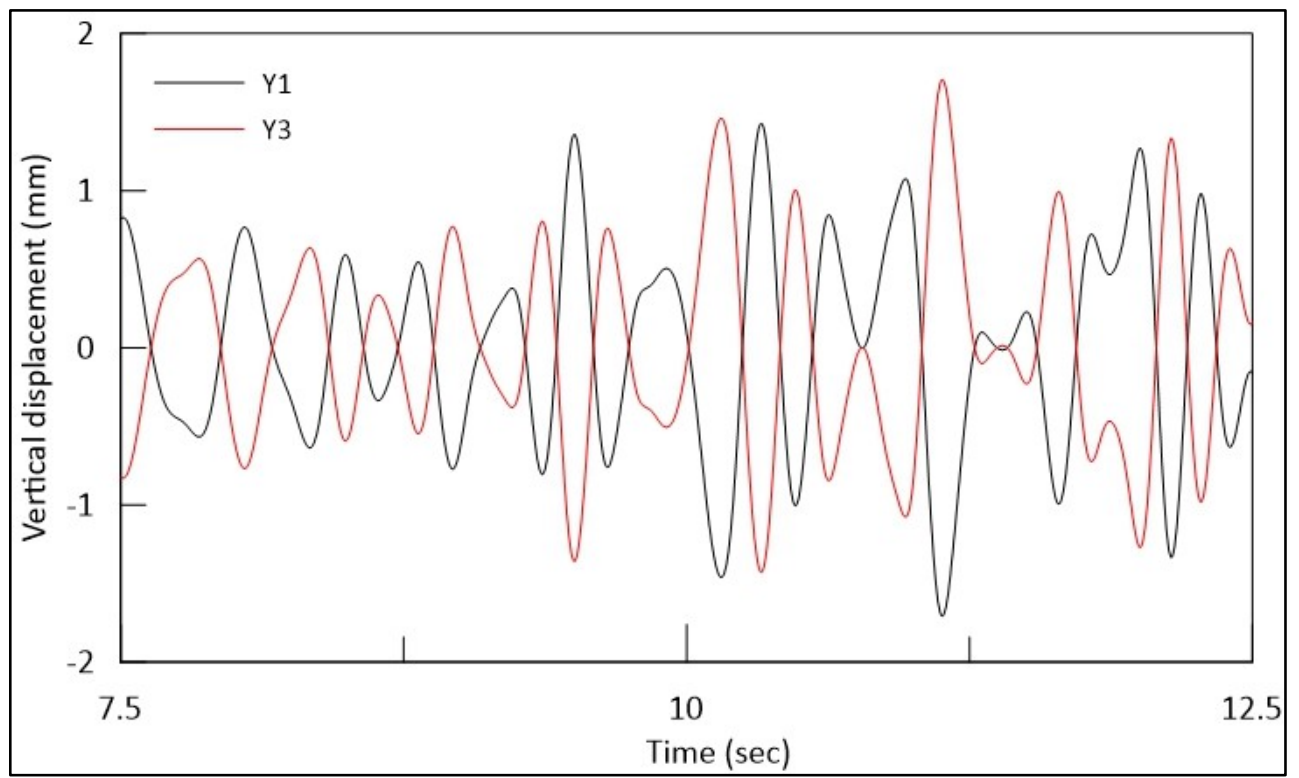

Figure E-18: Vertical displacement at the end points of the foundation for 17 storey building, soil type middle of site class C $(450 \mathrm{~m} / \mathrm{s})$ with side soil having shear wave velocity $200 \mathrm{~m} / \mathrm{s}$ 


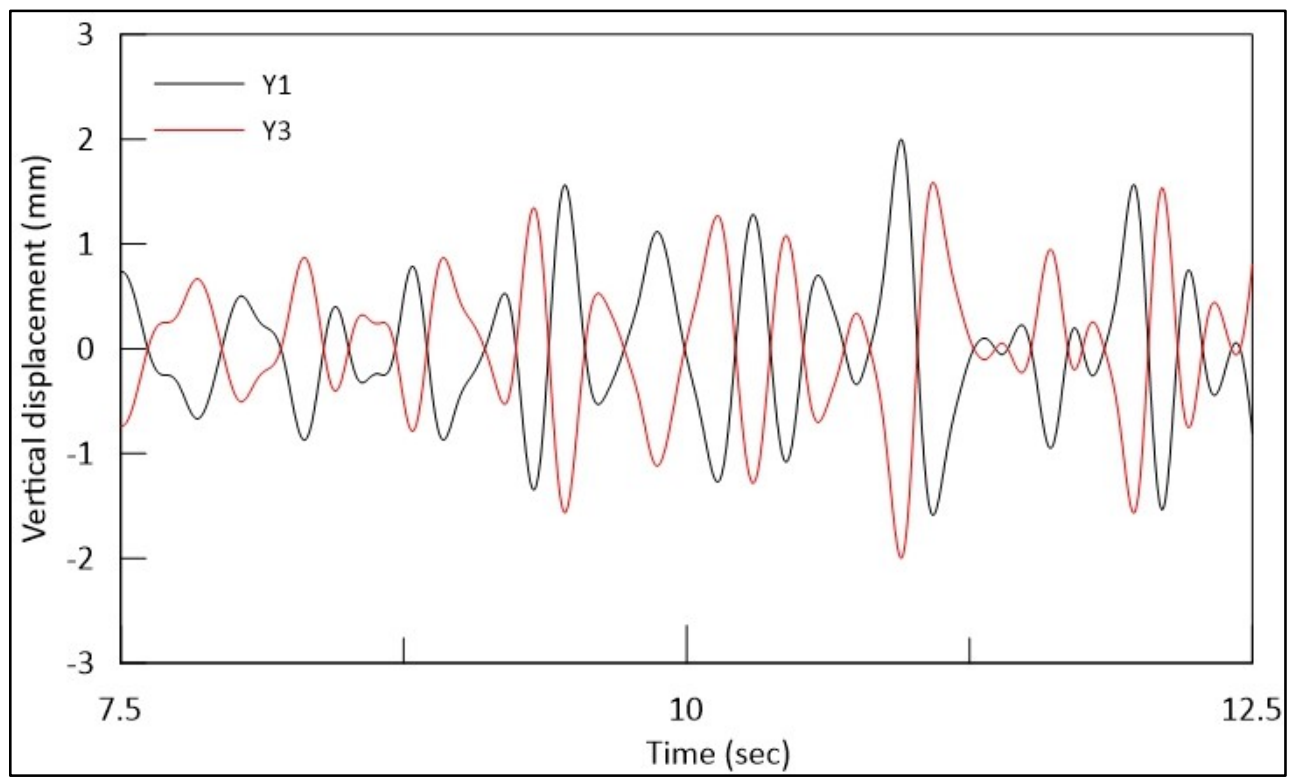

Figure E-19: Vertical displacement at the end points of the foundation for 17 storey building, soil type middle of site class C $(450 \mathrm{~m} / \mathrm{s})$ with side soil having shear wave velocity $300 \mathrm{~m} / \mathrm{s}$

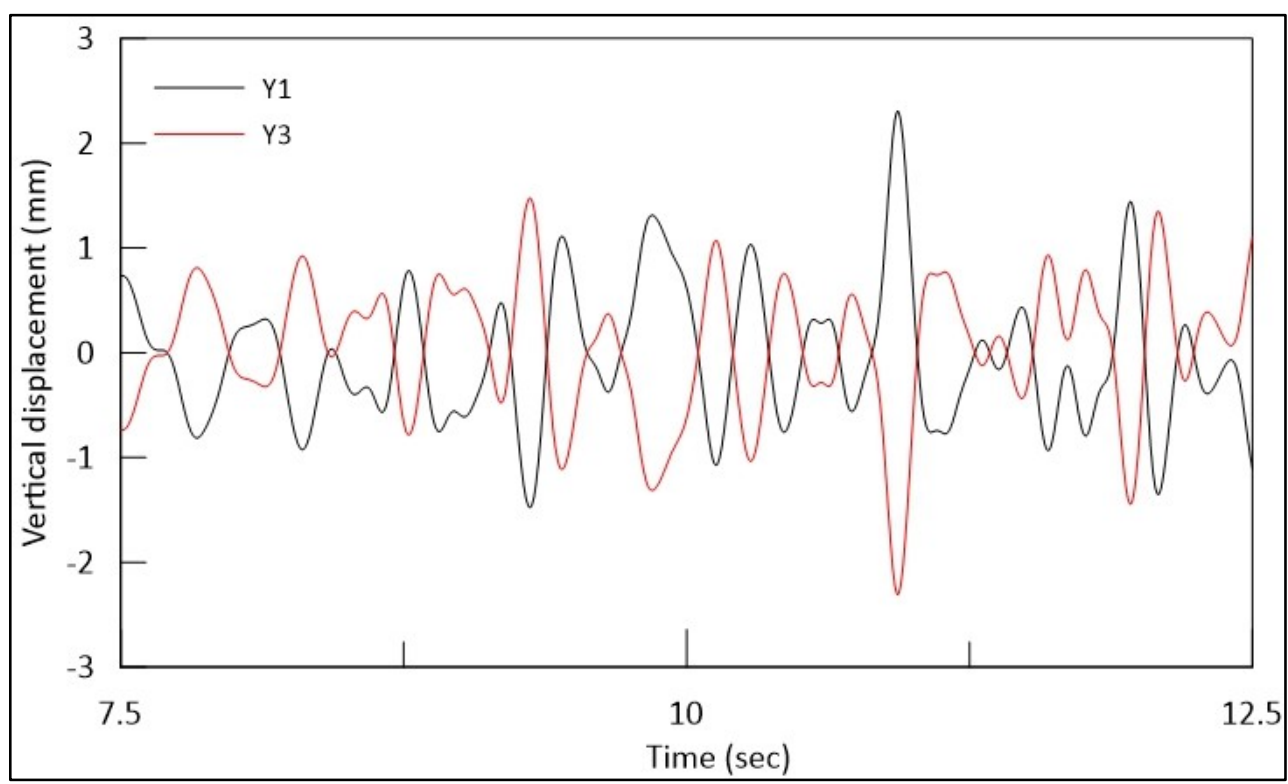

Figure E-20: Vertical displacement at the end points of the foundation for 17 storey building, soil type middle of site class C $(450 \mathrm{~m} / \mathrm{s})$ with side soil having shear wave velocity $450 \mathrm{~m} / \mathrm{s}$ 


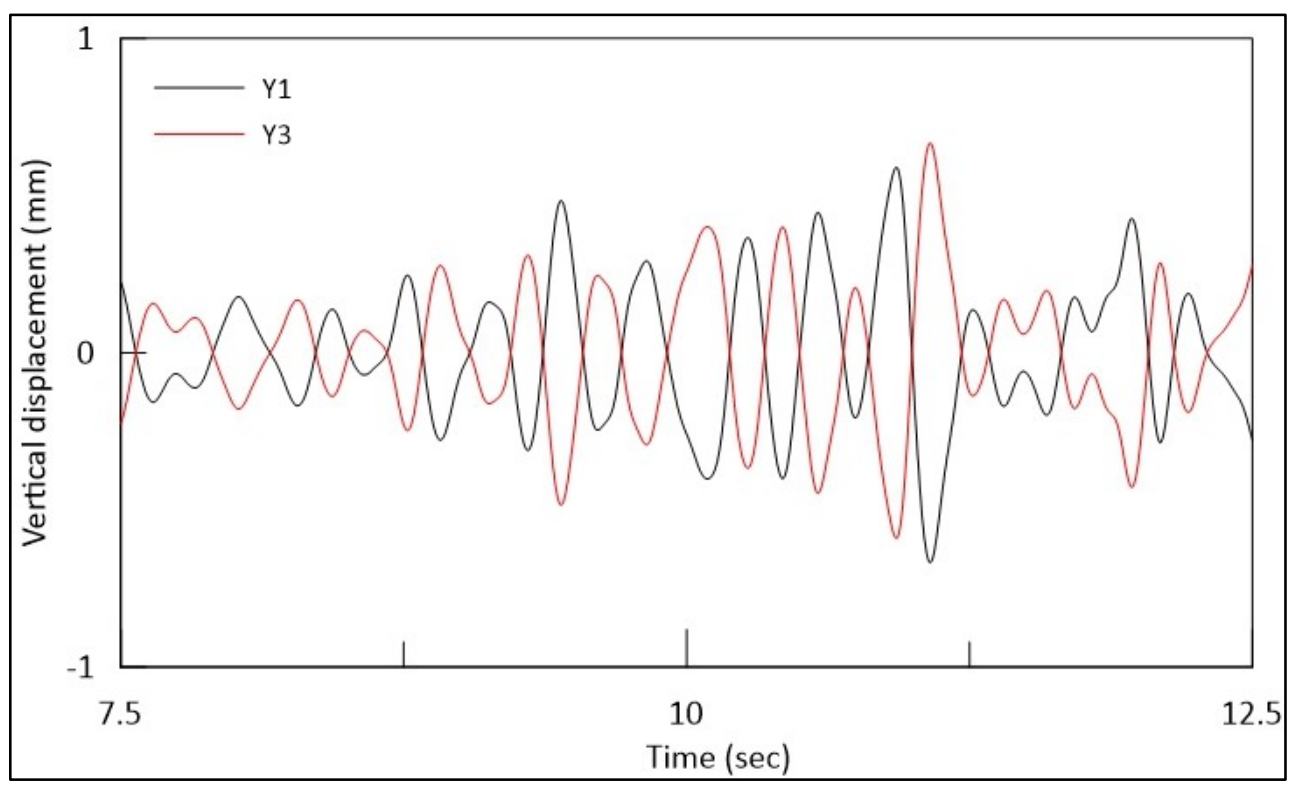

Figure E-21: Vertical displacement at the end points of the foundation for 17 storey building, soil type borderline of site class B and site class C $(750 \mathrm{~m} / \mathrm{s})$ with side soil having shear wave velocity $200 \mathrm{~m} / \mathrm{s}$

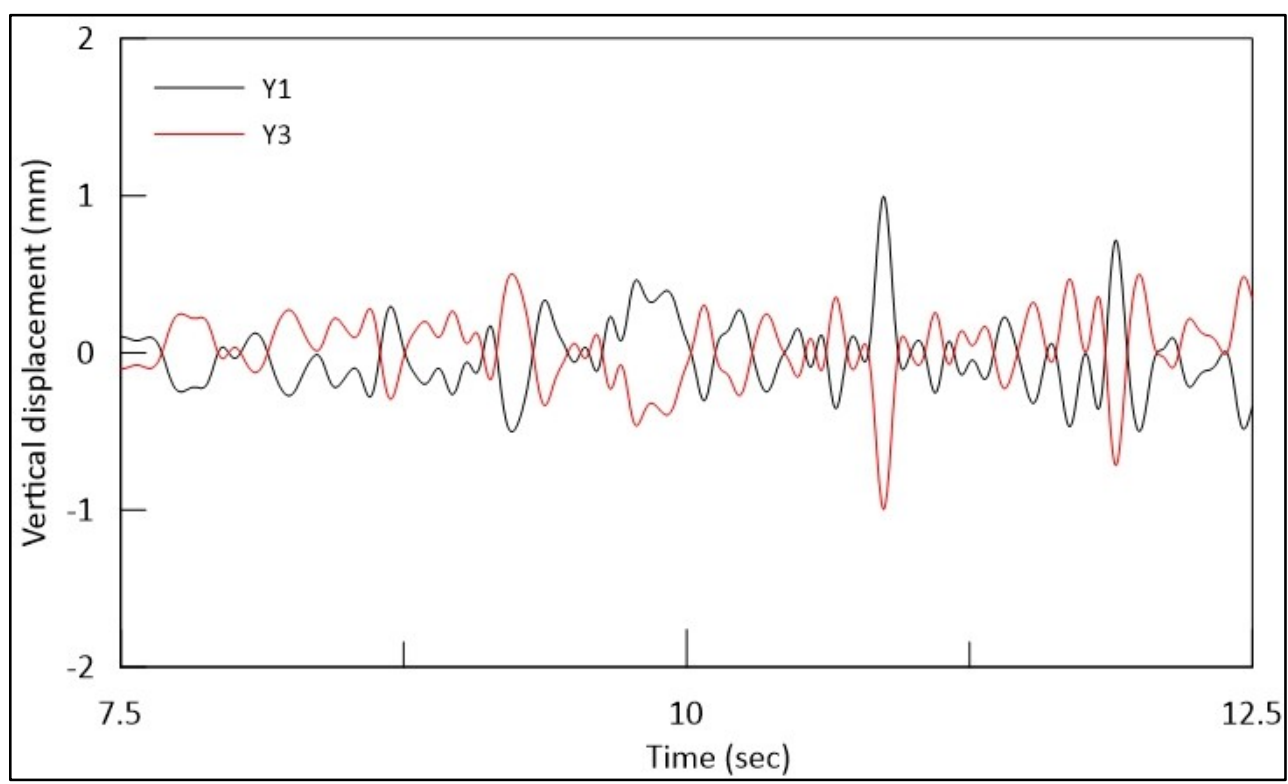

Figure E-22: Vertical displacement at the end points of the foundation for 17 storey building, soil type borderline of site class B and site class C $(750 \mathrm{~m} / \mathrm{s})$ with side soil having shear wave velocity $550 \mathrm{~m} / \mathrm{s}$ 


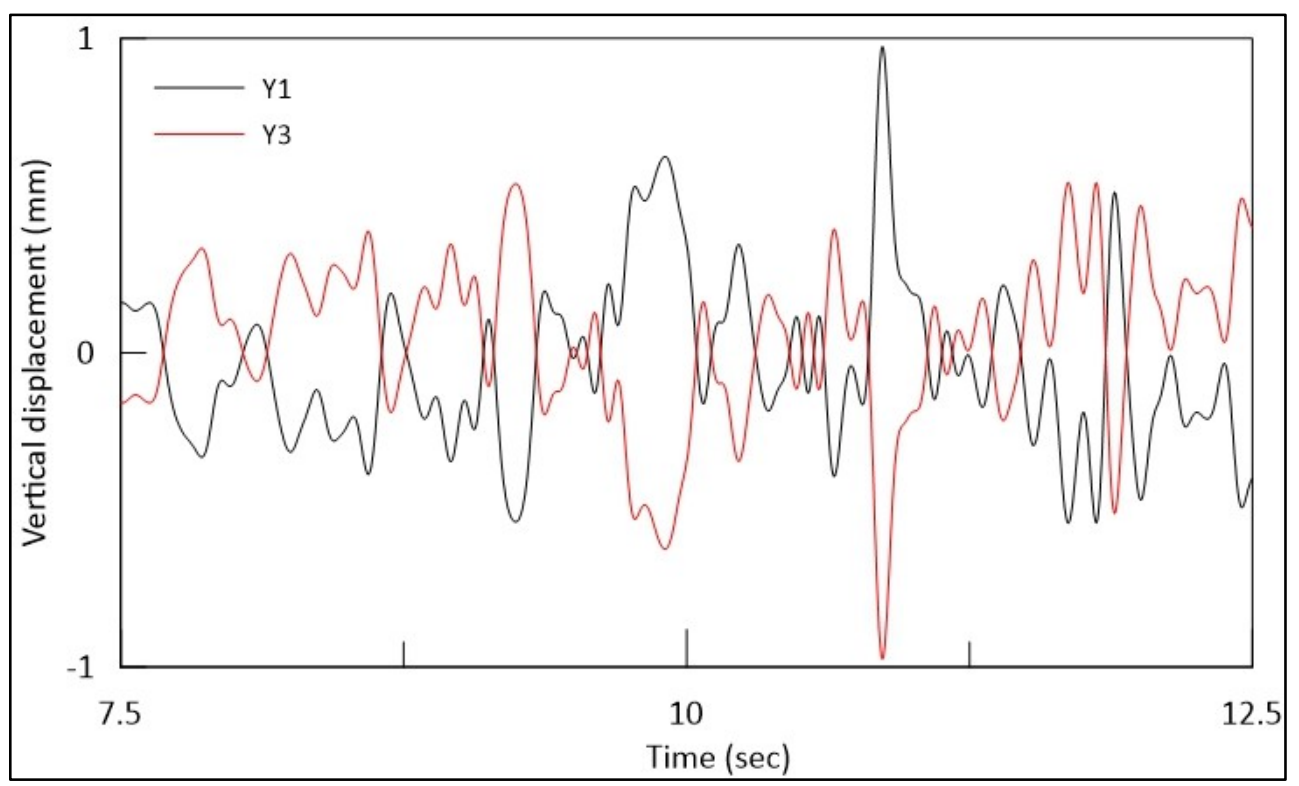

Figure E-23: Vertical displacement at the end points of the foundation for 17 storey building, soil type borderline of site class B and site class C $(750 \mathrm{~m} / \mathrm{s})$ with side soil having shear wave velocity $750 \mathrm{~m} / \mathrm{s}$

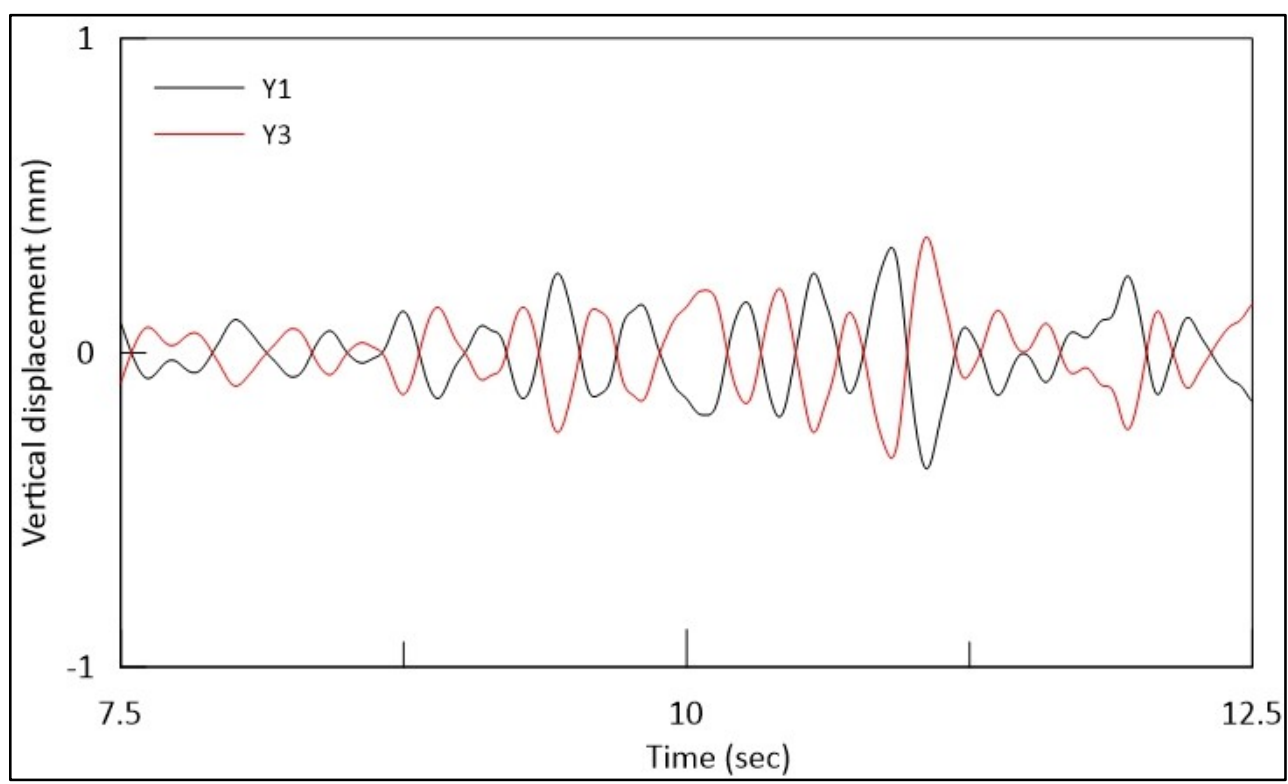

Figure E-24: Vertical displacement at the end points of the foundation for 17 storey building, soil type middle of site class B $(1000 \mathrm{~m} / \mathrm{s})$ with side soil having shear wave velocity $200 \mathrm{~m} / \mathrm{s}$ 


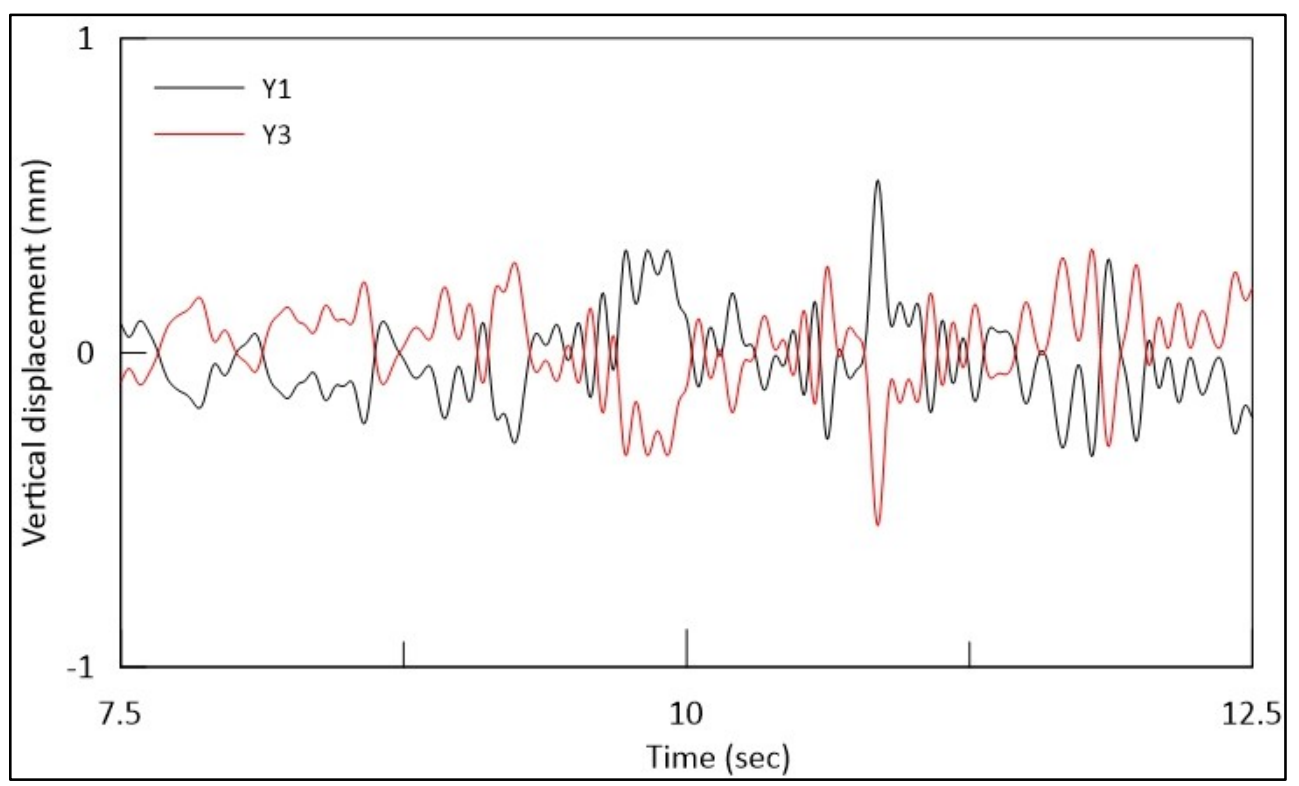

Figure E-25: Vertical displacement at the end points of the foundation for 17 storey building, soil type middle of site class B $(1000 \mathrm{~m} / \mathrm{s})$ with side soil having shear wave velocity $750 \mathrm{~m} / \mathrm{s}$

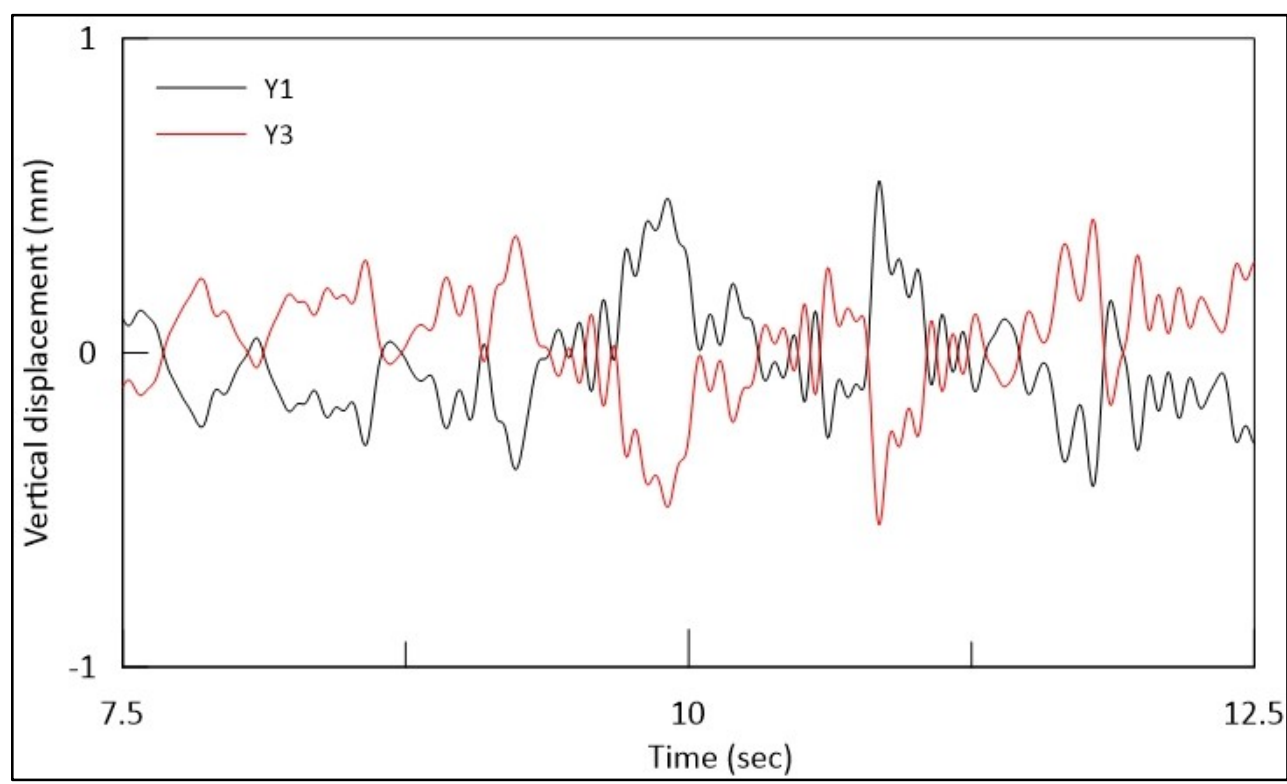

Figure E-26: Vertical displacement at the end points of the foundation for 17 storey building, soil type middle of site class B $(1000 \mathrm{~m} / \mathrm{s})$ with side soil having shear wave velocity $1000 \mathrm{~m} / \mathrm{s}$ 


\section{1 storey building}

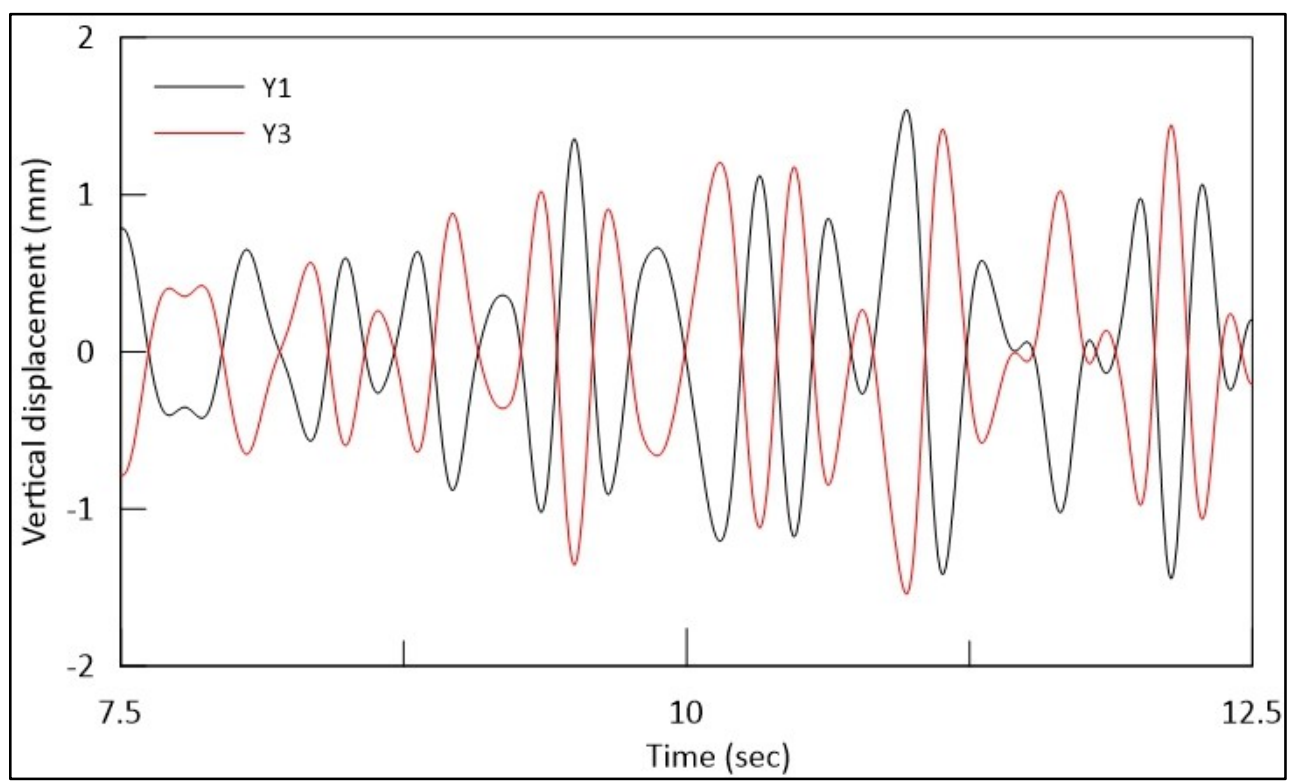

Figure E-27: Vertical displacement at the end points of the foundation for 21 storey building, soil type middle of site class C $(450 \mathrm{~m} / \mathrm{s})$ with side soil having shear wave velocity $200 \mathrm{~m} / \mathrm{s}$

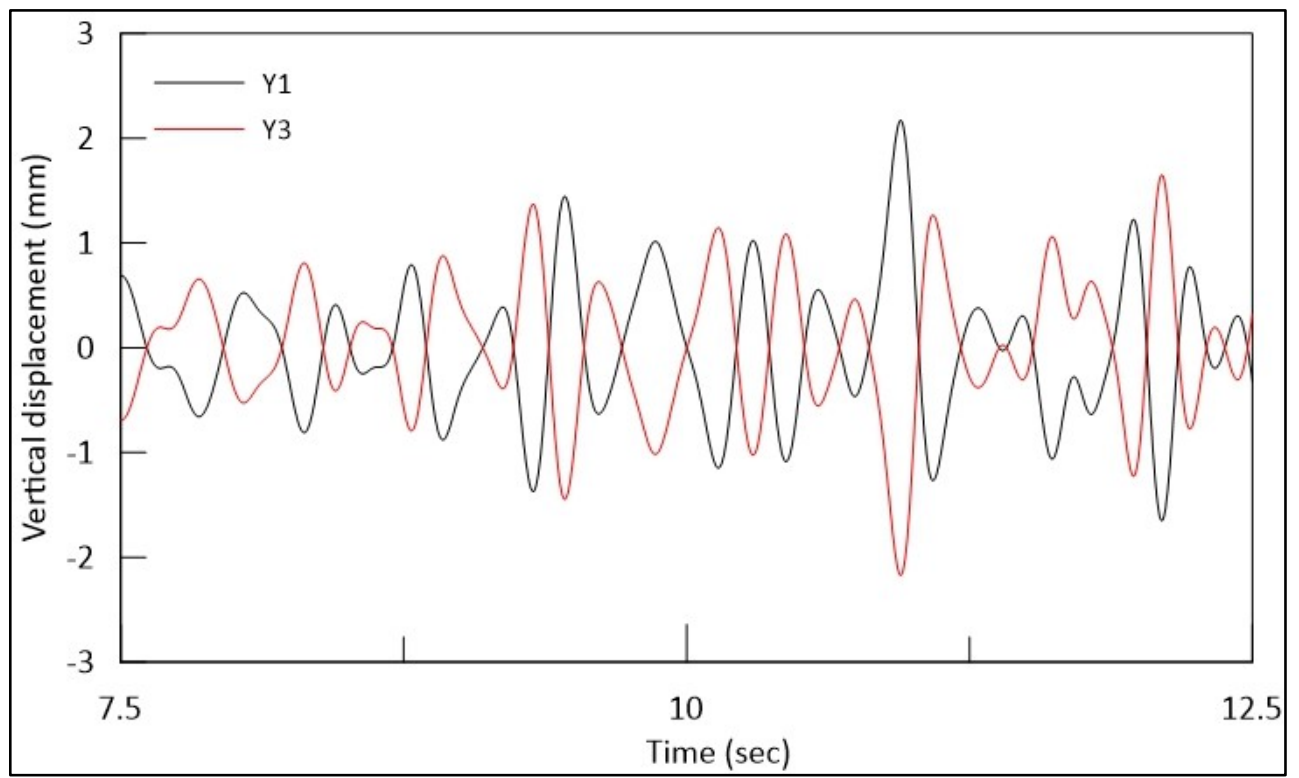

Figure E-28: Vertical displacement at the end points of the foundation for 21 storey building, soil type middle of site class C $(450 \mathrm{~m} / \mathrm{s})$ with side soil having shear wave velocity $300 \mathrm{~m} / \mathrm{s}$ 


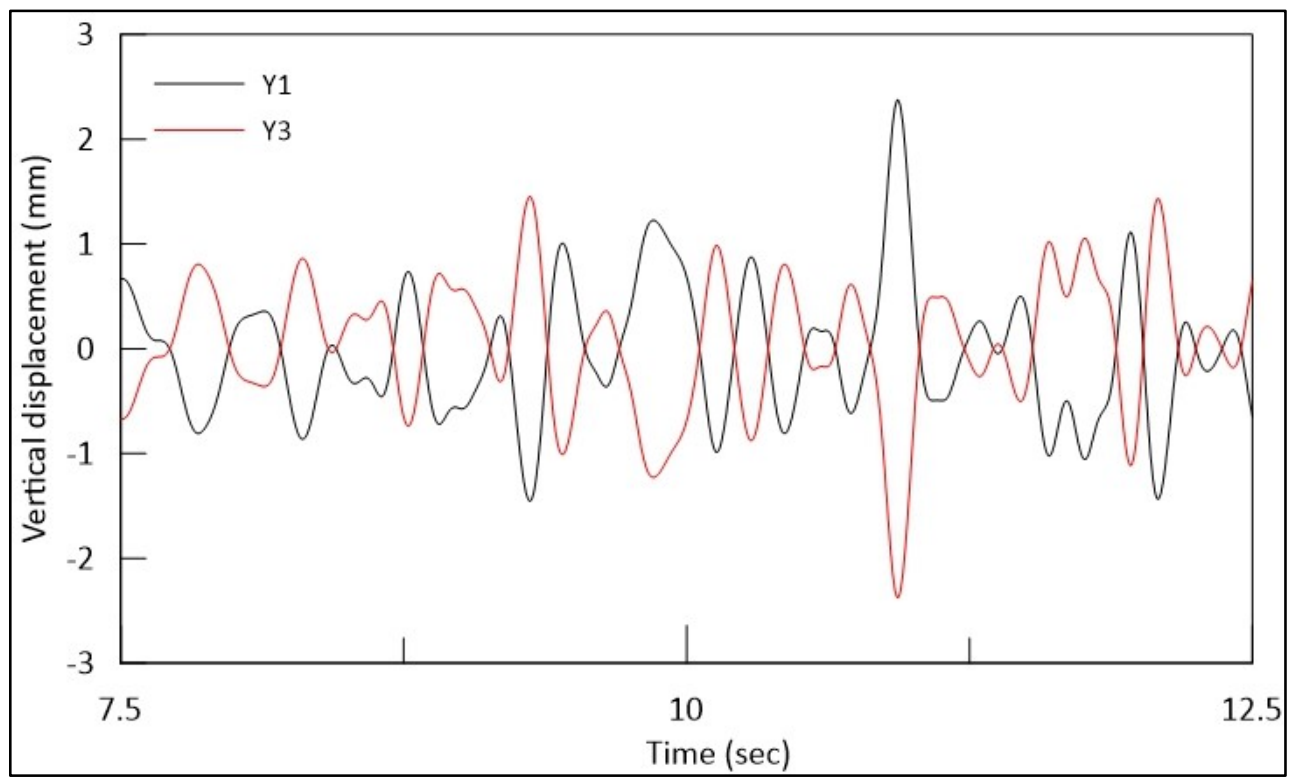

Figure E-29: Vertical displacement at the end points of the foundation for 21 storey building, soil type middle of site class C $(450 \mathrm{~m} / \mathrm{s})$ with side soil having shear wave velocity $450 \mathrm{~m} / \mathrm{s}$

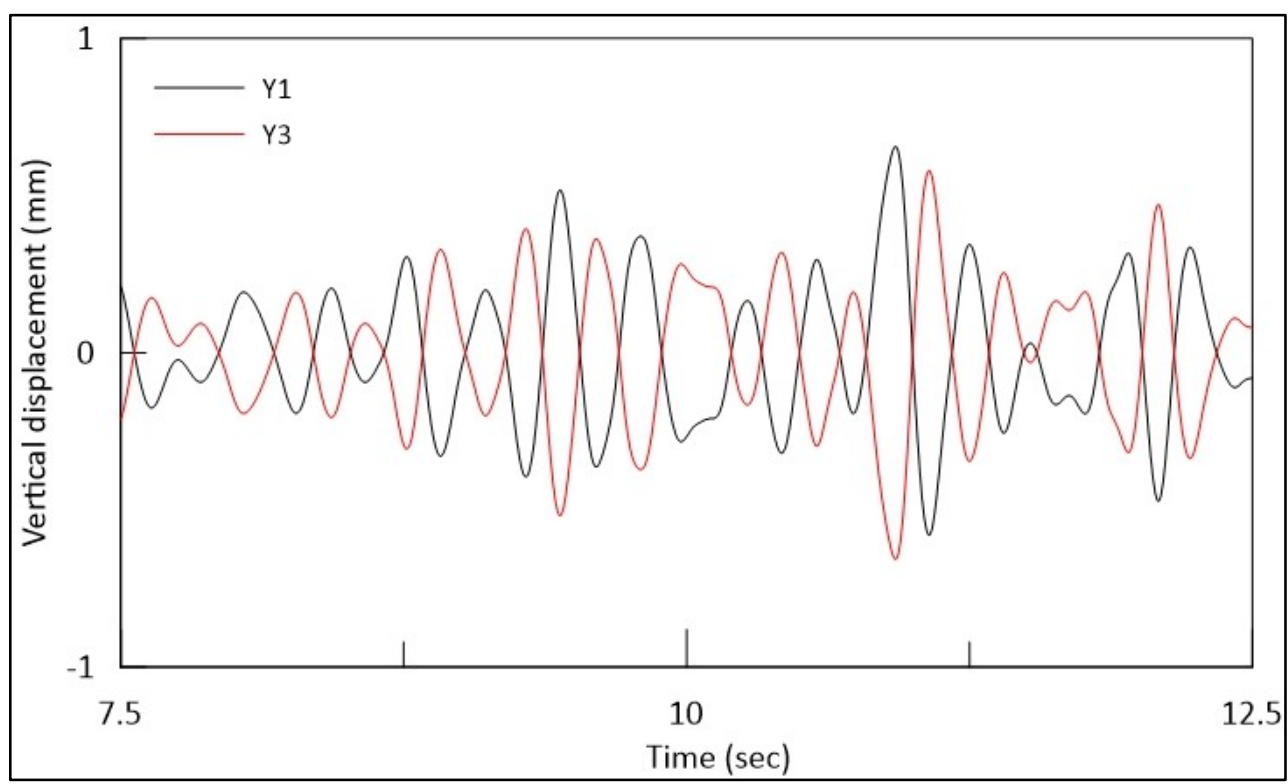

Figure E-30: Vertical displacement at the end points of the foundation for 21 storey building, soil type borderline of site class B and site class C $(750 \mathrm{~m} / \mathrm{s})$ with side soil having shear wave velocity $200 \mathrm{~m} / \mathrm{s}$ 


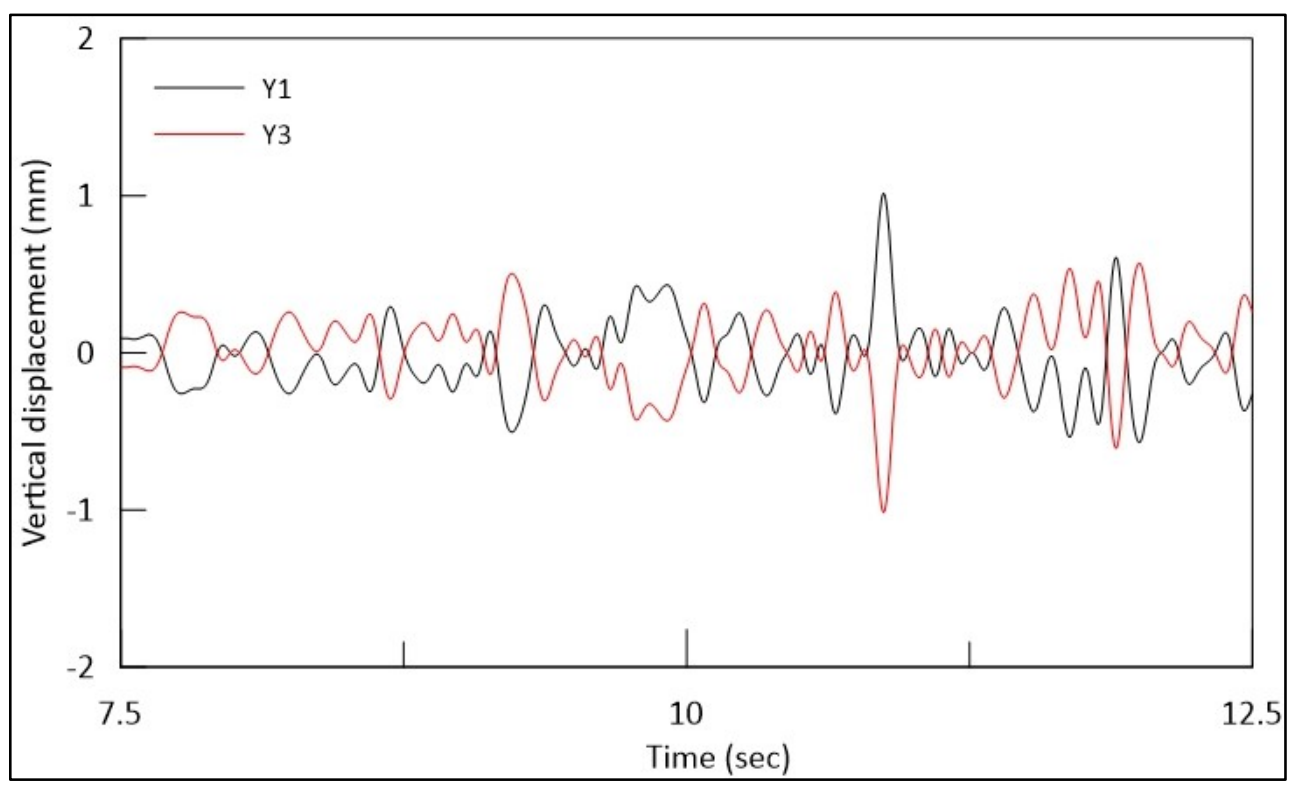

Figure E-31: Vertical displacement at the end points of the foundation for 21 storey building, soil type borderline of site class B and site class C $(750 \mathrm{~m} / \mathrm{s})$ with side soil having shear wave velocity $550 \mathrm{~m} / \mathrm{s}$

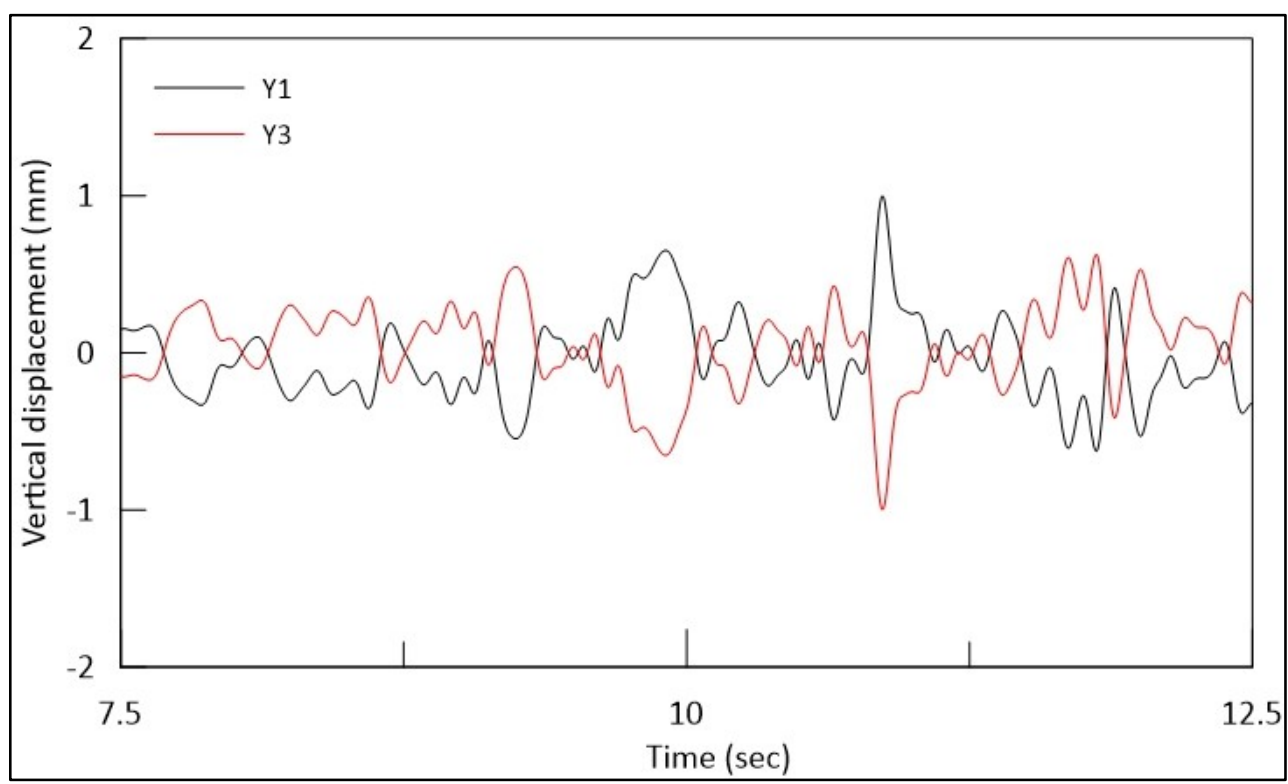

Figure E-32: Vertical displacement at the end points of the foundation for 21 storey building, soil type borderline of site class B and site class C $(750 \mathrm{~m} / \mathrm{s})$ with side soil having shear wave velocity $750 \mathrm{~m} / \mathrm{s}$ 


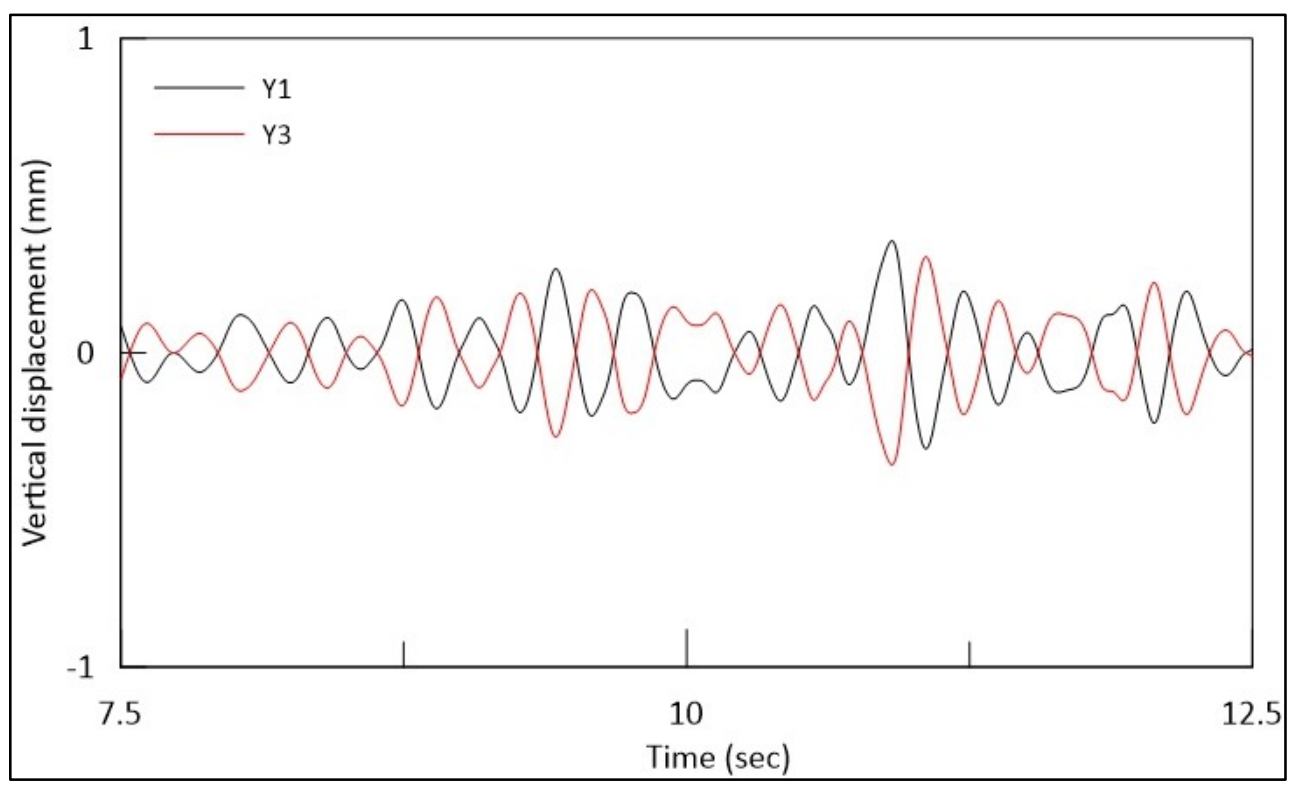

Figure E-33: Vertical displacement at the end points of the foundation for 21 storey building, soil type middle of site class B $(1000 \mathrm{~m} / \mathrm{s})$ with side soil having shear wave velocity $200 \mathrm{~m} / \mathrm{s}$

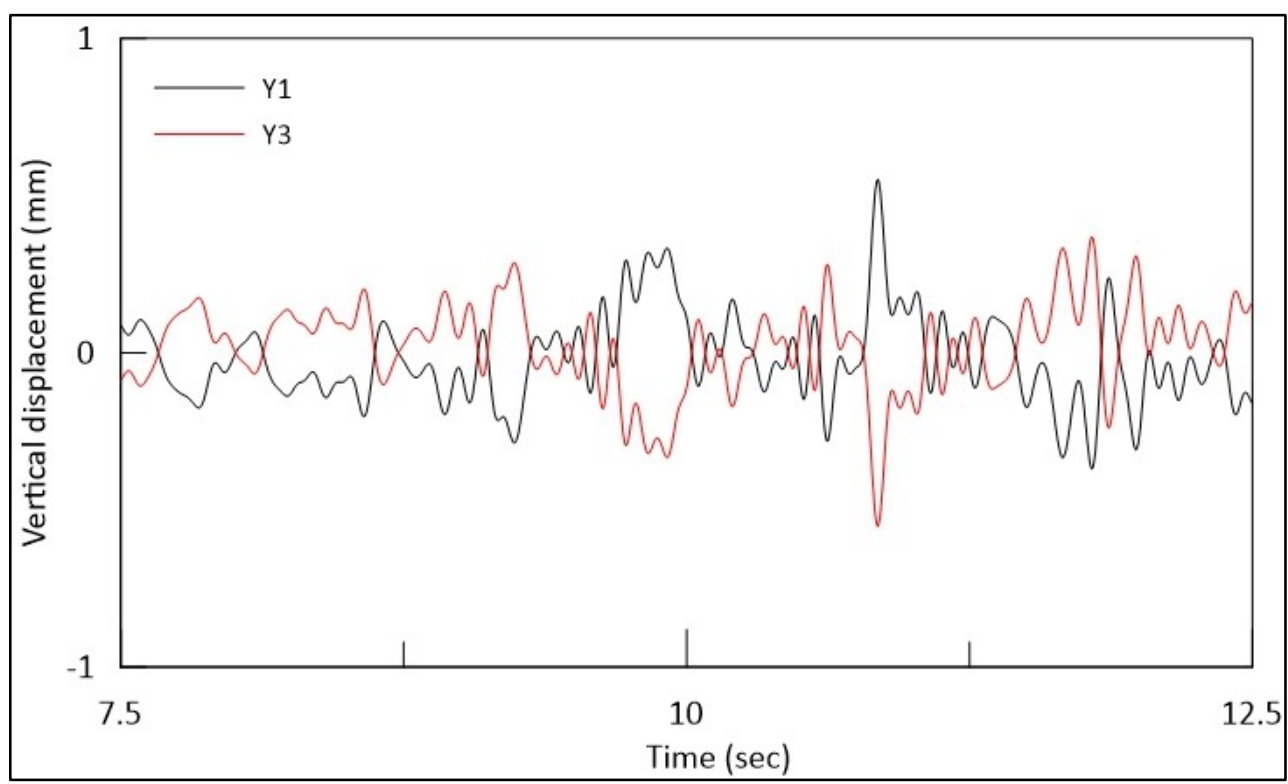

Figure E-34: Vertical displacement at the end points of the foundation for 21 storey building, soil type middle of site class B $(1000 \mathrm{~m} / \mathrm{s})$ with side soil having shear wave velocity $750 \mathrm{~m} / \mathrm{s}$ 


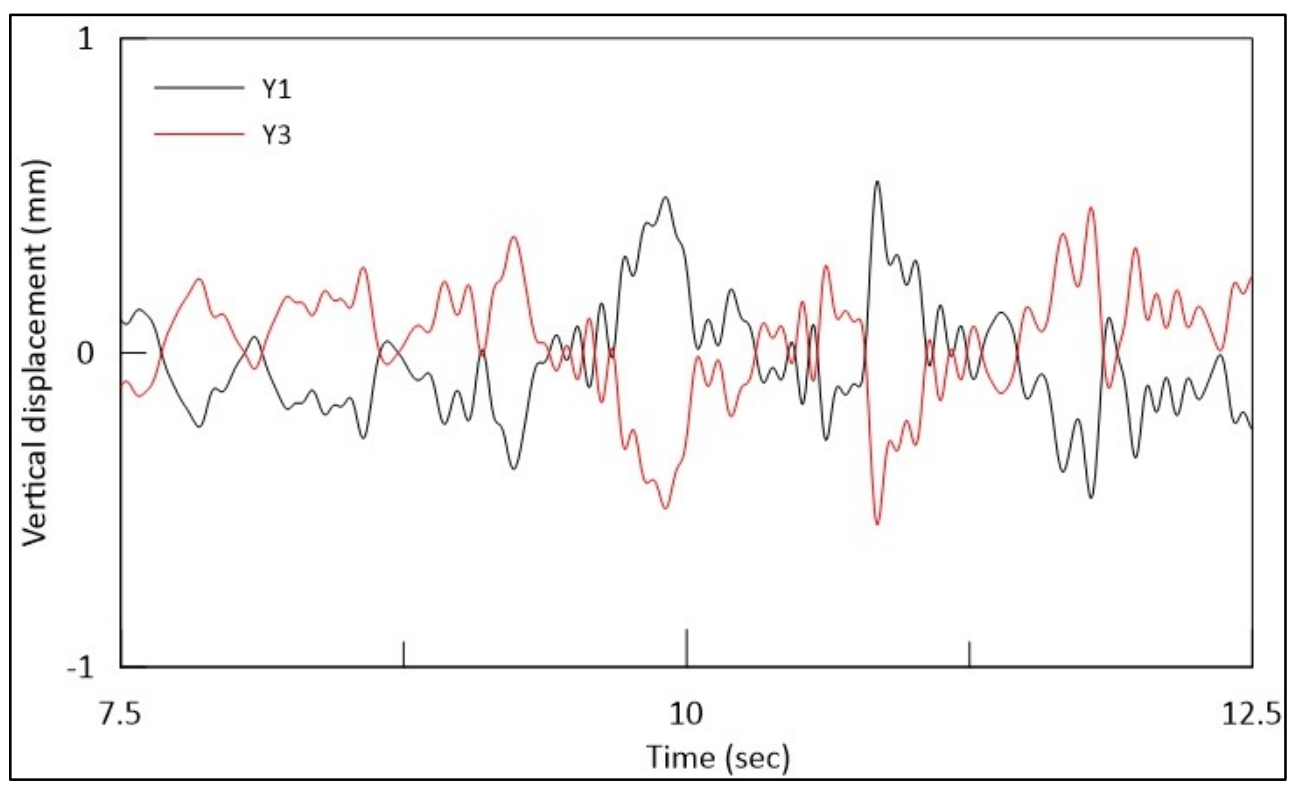

Figure E-35: Vertical displacement at the end points of the foundation for 21 storey building, soil type middle of site class B $(1000 \mathrm{~m} / \mathrm{s})$ with side soil having shear wave velocity $1000 \mathrm{~m} / \mathrm{s}$

\section{5 storey building}

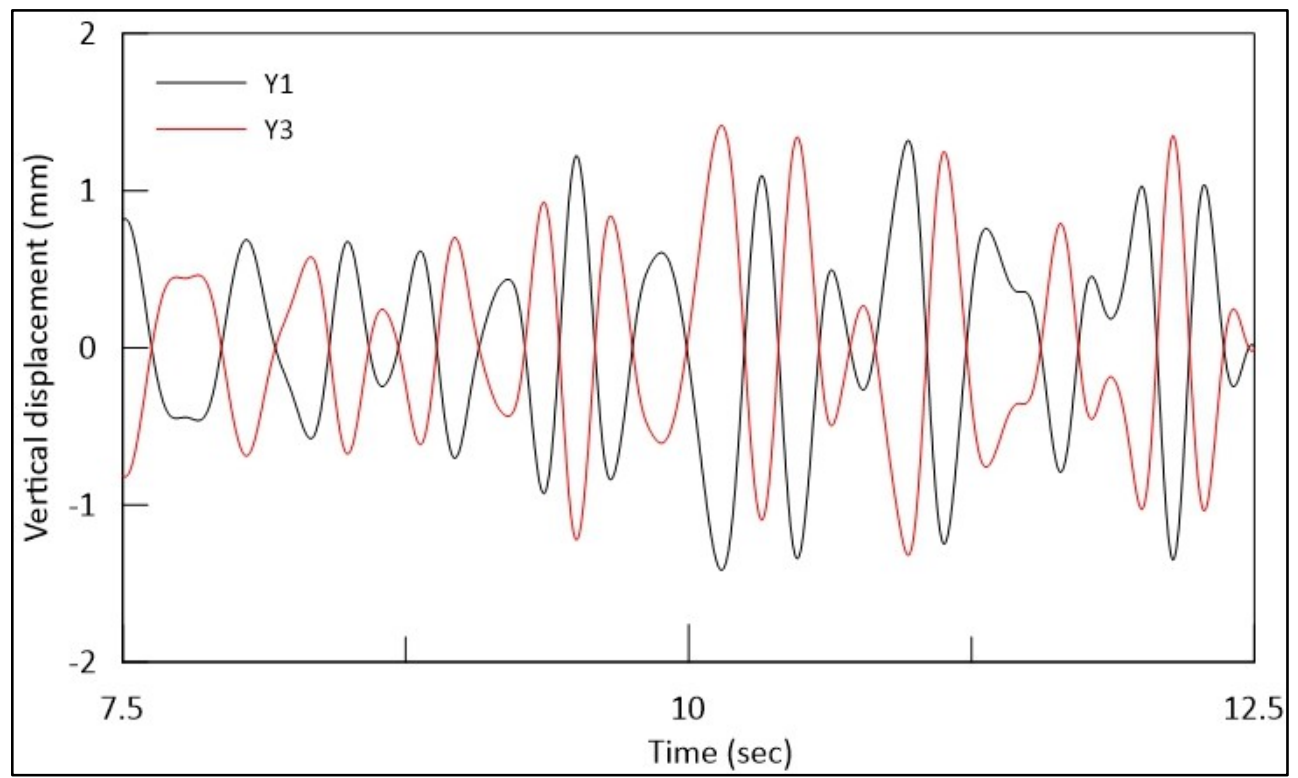

Figure E-36: Vertical displacement at the end points of the foundation for 25 storey building, soil type middle of site class C $(450 \mathrm{~m} / \mathrm{s})$ with side soil having shear wave velocity $200 \mathrm{~m} / \mathrm{s}$ 


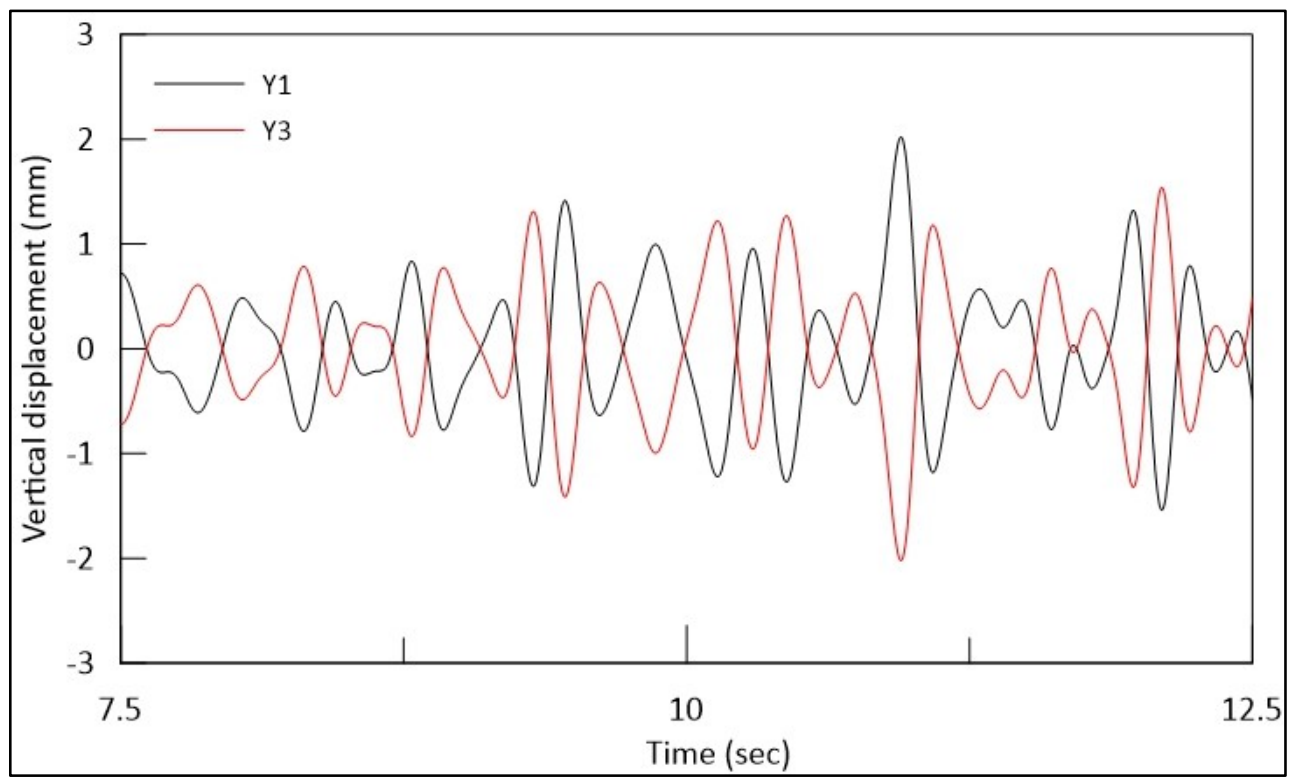

Figure E-37: Vertical displacement at the end points of the foundation for 25 storey building, soil type middle of site class C $(450 \mathrm{~m} / \mathrm{s}$ with side soil having shear wave velocity $300 \mathrm{~m} / \mathrm{s}$

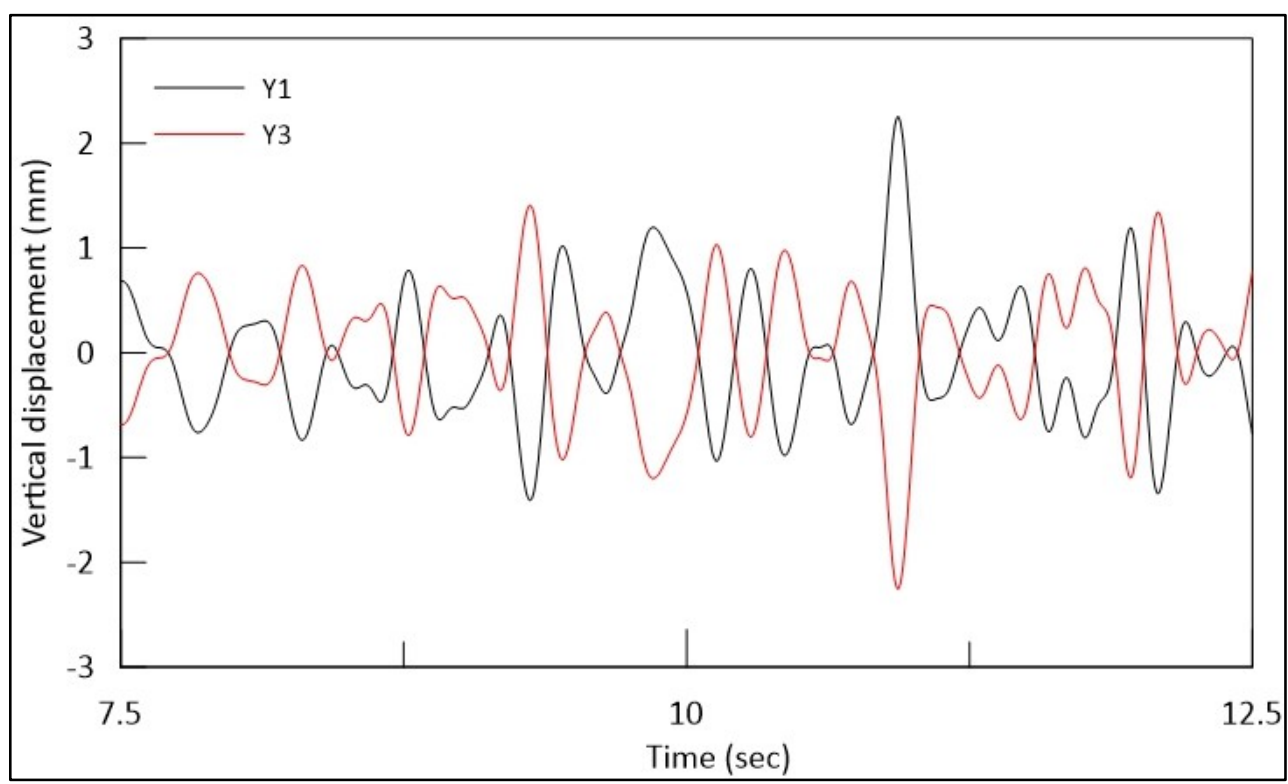

Figure E-38: Vertical displacement at the end points of the foundation for 25 storey building, soil type middle of site class C $(450 \mathrm{~m} / \mathrm{s})$ with side soil having shear wave velocity $450 \mathrm{~m} / \mathrm{s}$ 


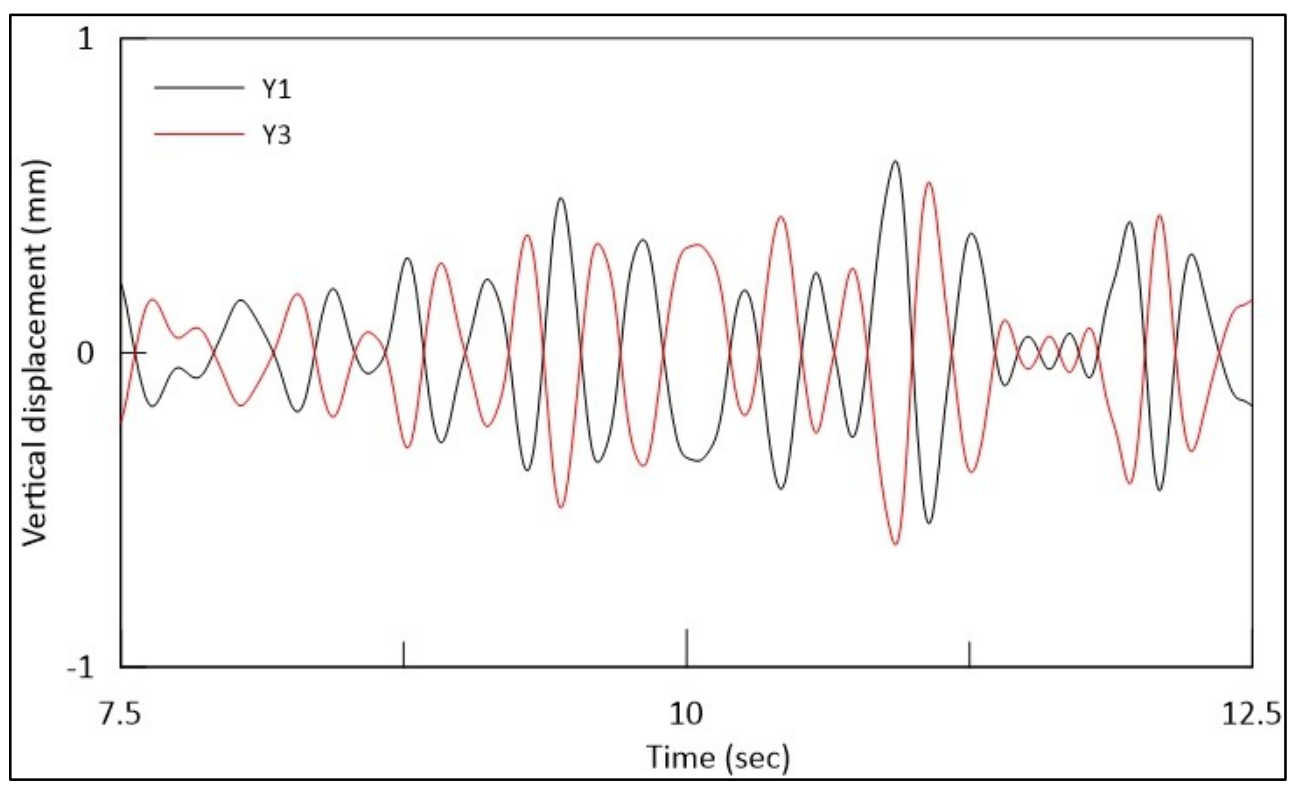

Figure E-39: Vertical displacement at the end points of the foundation for 25 storey building, soil type borderline of site class B and site class C $(750 \mathrm{~m} / \mathrm{s})$ with side soil having shear wave velocity $200 \mathrm{~m} / \mathrm{s}$

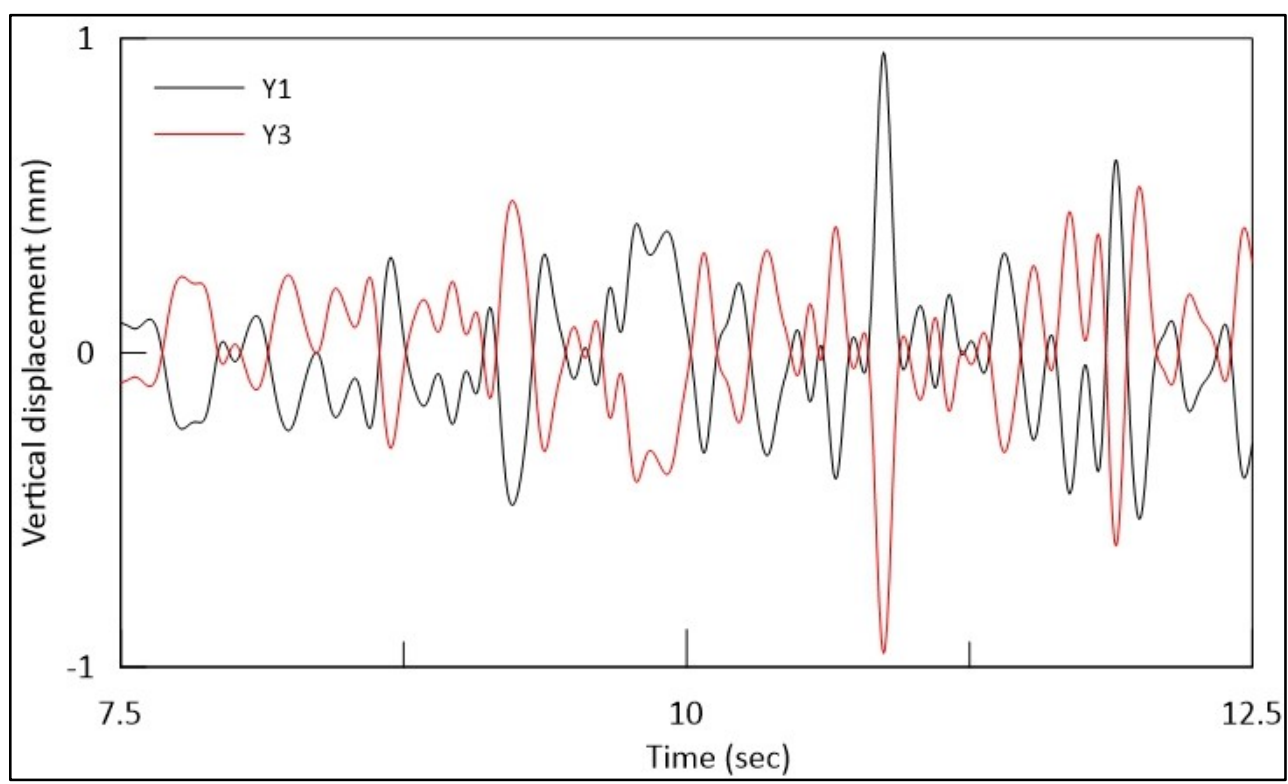

Figure E-40: Vertical displacement at the end points of the foundation for 25 storey building, soil type borderline of site class B and site class C $(750 \mathrm{~m} / \mathrm{s})$ with side soil having shear wave velocity $550 \mathrm{~m} / \mathrm{s}$ 


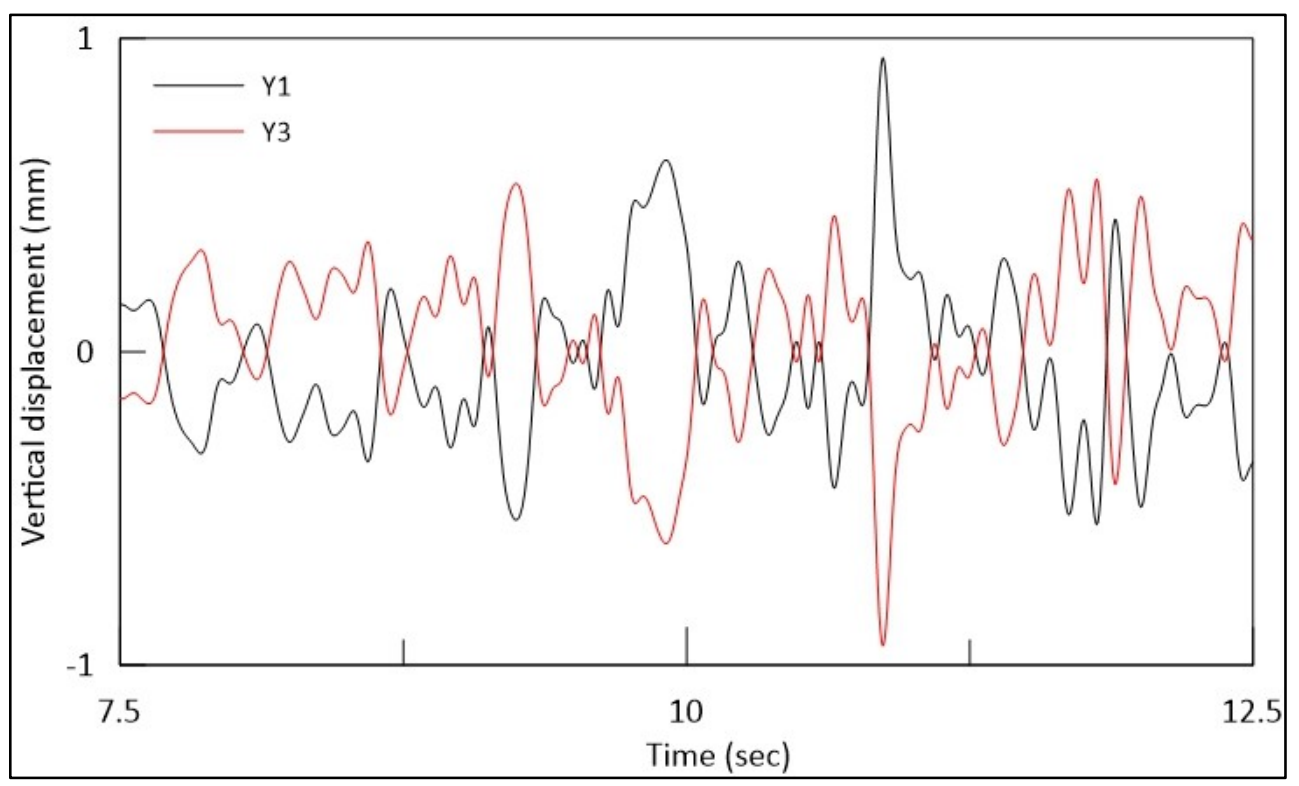

Figure E-41: Vertical displacement at the end points of the foundation for 25 storey building, soil type borderline of site class B and site class C $(750 \mathrm{~m} / \mathrm{s})$ with side soil having shear wave velocity $750 \mathrm{~m} / \mathrm{s}$

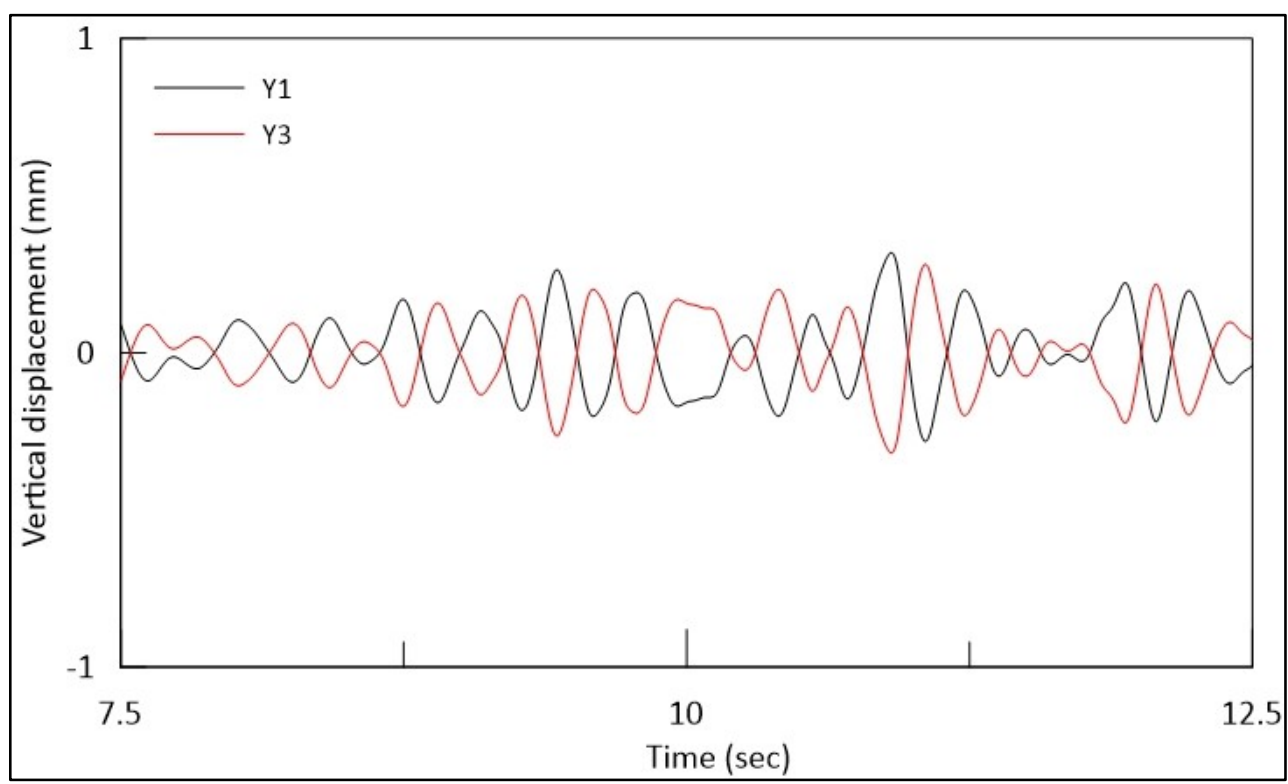

Figure E-42: Vertical displacement at the end points of the foundation for 25 storey building, soil type middle of site class B $(1000 \mathrm{~m} / \mathrm{s})$ with side soil having shear wave velocity $200 \mathrm{~m} / \mathrm{s}$ 


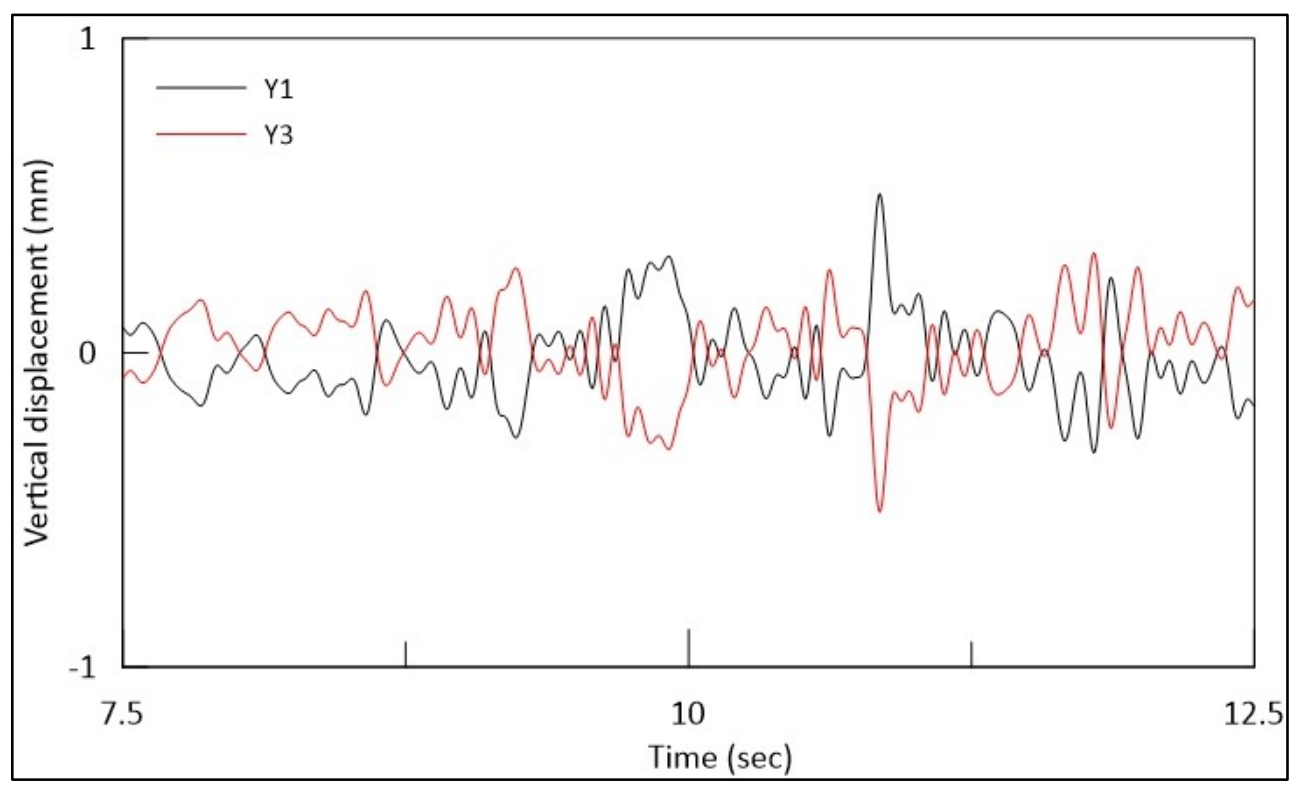

Figure E-43: Vertical displacement at the end points of the foundation for 25 storey building, soil type middle of site class B $(1000 \mathrm{~m} / \mathrm{s})$ with side soil having shear wave velocity $750 \mathrm{~m} / \mathrm{s}$

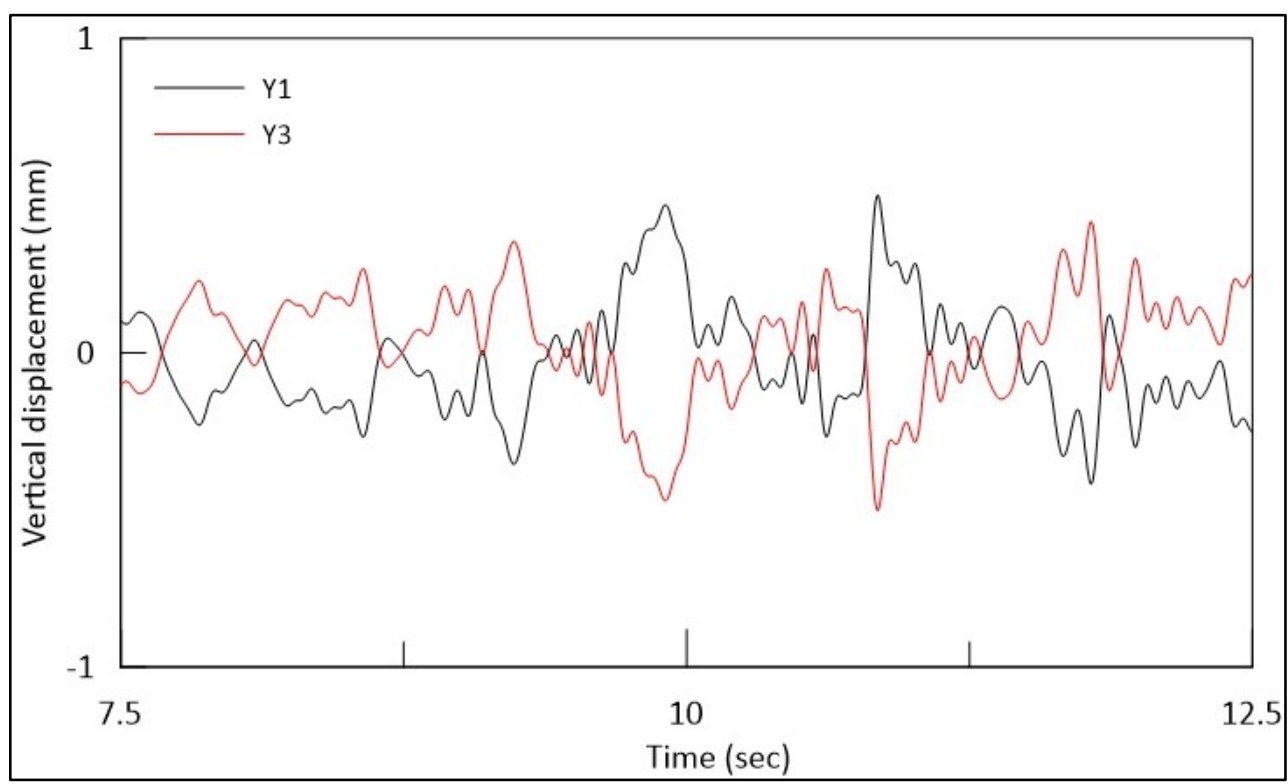

Figure E-44: Vertical displacement at the end points of the foundation for 25 storey building, soil type middle of site class B $(1000 \mathrm{~m} / \mathrm{s})$ with side soil having shear wave velocity $1000 \mathrm{~m} / \mathrm{s}$ 